

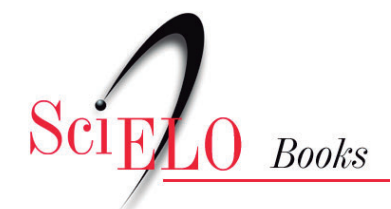

\title{
Agroclimatología del Ecuador
}

\author{
Fredi Portilla Farfán
}

PORTILLA FARFÁN, F. Agroclimatología del Ecuador [online]. Quito: Editorial Abya-Yala, 2018, 645 p. ISBN: 978-9978-10-492-7. https://doi.org/10.7476/9789978104927.

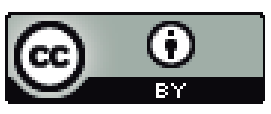

All the contents of this work, except where otherwise noted, is licensed under a Creative Commons Attribution 4.0 International license.

Todo o conteúdo deste trabalho, exceto quando houver ressalva, é publicado sob a licença Creative Commons Atribição $\underline{4.0}$.

Todo el contenido de esta obra, excepto donde se indique lo contrario, está bajo licencia de la licencia $\underline{\text { Creative }}$ Commons Reconocimento 4.0. 
$\underline{\text { Agroclimatología del Ecuador }}$ 

Fredi Portilla Farfán

\section{Agroclimatología del Ecuador}

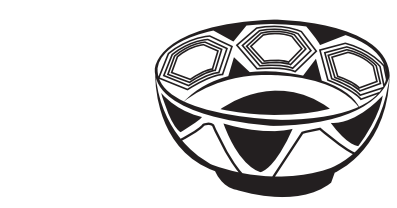

ABYA| UNIVERIDAD

2018 


\section{Agroclimatología del Ecuador}

o Fredi Portilla Farfán

1ra edición: Universidad Politécnica Salesiana

Av. Turuhuayco 3-69 y Calle Vieja

Cuenca-Ecuador

Casilla: 2074

P.B.X. $(+593$ 7) 2050000

Fax: $(+5937) 4088958$

e-mail:rpublicas@ups.edu.ec

www.ups.edu.ec

Área de Ciencias de la Vida

CARRERA DE INGENIERÍA AMBIENTAL

Grupo de Investigación

en Biotecnología y Ambiente (INBIAM)

Diagramación Editorial Universitaria Abya-Yala

y Edición: Quito-Ecuador

Derechos de Autor: 053802

ISBN UPS: $\quad$ 978-9978-10-310-4

Tiraje: $\quad 300$ ejemplares

Impresión: $\quad$ Editorial Universitaria Abya-Yala

Quito-Ecuador

Impreso en Quito-Ecuador, junio de 2018

Publicación arbitrada de la Universidad Politécnica Salesiana 
A quienes diariamente se esfuerzan por conocer más sobre el clima y buscan integrar soluciones para prevenir desastres antrópicos, así como afrontar la mitigación frente a los naturales.

A esos luchadores diarios que no se amilanan ante las circunstancias adversas y tienen su mirada puesta en mejores días para la humanidad. 



\section{Agradecimientos}

A quienes aportaron con su conocimiento $y$ destrezas para la elaboración de este estudio, y en particular a los técnicos y autoridades del INAMHI (Instituto Nacional Autónomo de Meteorología e Hidrología del Ecuador) quienes facilitaron los datos.

Al Dr. Antonio Saá Requejo, profesor de Climatología de la Universidad Politécnica de Madrid por su aporte científico, técnico y humano. Un agradecimiento muy especial a las autoridades de la Universidad Politécnica Salesiana del Ecuador, por su apoyo moral y económico. 
Capítulo I

Introducción ............................................................................. 17

Características generales del Ecuador ........................................... 18

Topografía y geología........................................................ 18

Hidrología ......................................................................... 21

Vegetación y cultivos............................................................ 25

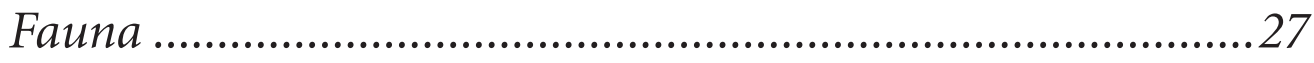

Aproximación a la climatología del Ecuador ................................. 28

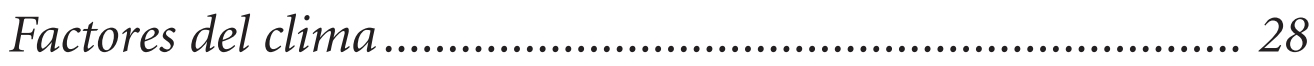

Elementos del clima........................................................ 34

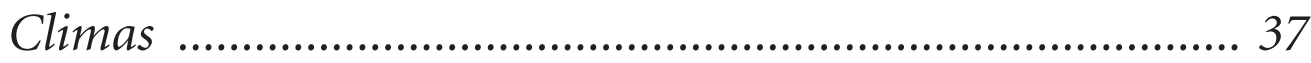

CApítulo II

Materiales $\quad$...................................................................................... 41

Base de datos del INAMHI...................................................... 41

Programas informáticos ........................................................... 45

Capítulo III

Métodos $\quad$..................................................................................................... 47

Métodos climáticos generales......................................................... 47

Método de relleno de datos......................................................... 51

Método cartográfico .................................................................. 53

Método de automatización ......................................................... 60 


\section{Capítulo IV}

Resultados y discusión

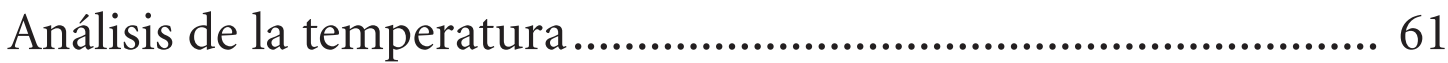

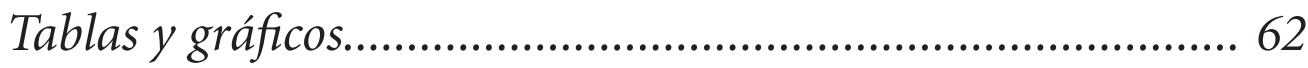

Cartografía ....................................................................... 64

Análisis de la precipitación........................................................... 79

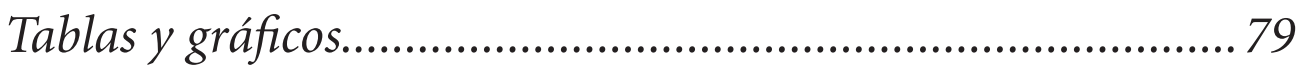

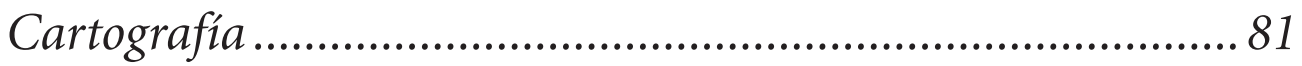

Análisis de la humedad relativa .................................................... 102

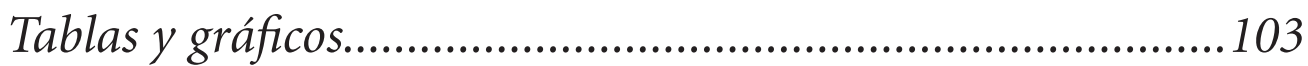

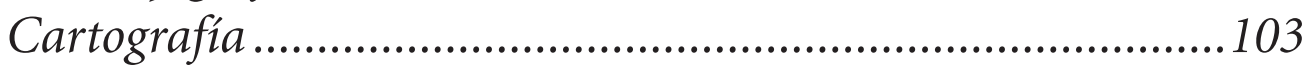

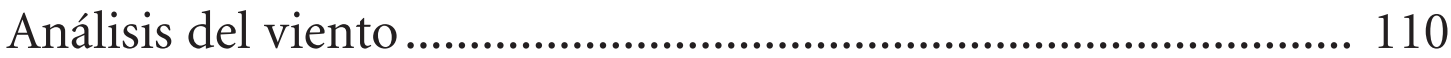

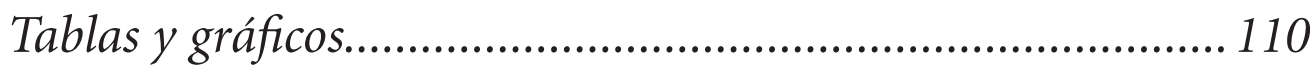

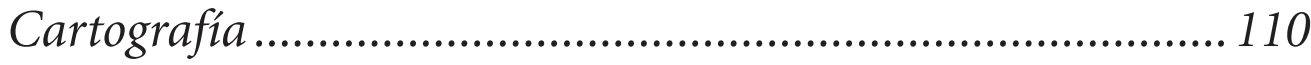

Análisis de la evapotranspiración ................................................. 121

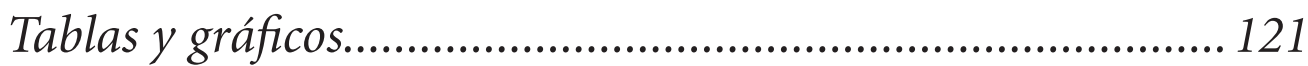

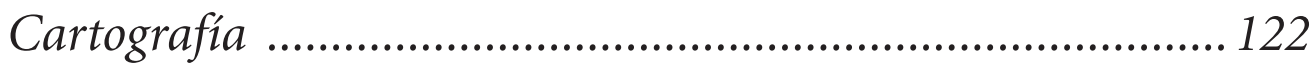

Análisis de balance hídrico......................................................... 126

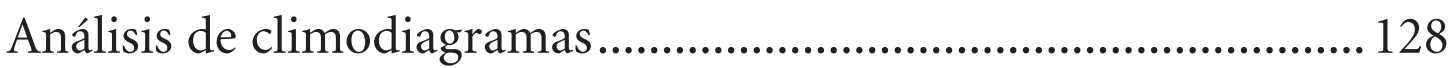

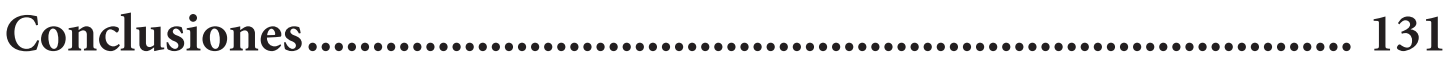

Referencias .......................................................................... 133

ANEXOS $\quad$.......................................................................... 135 


\section{Índice de Figuras}

Figura 1.1. Mapa del Ecuador ..................................................... 20

Figura 1.2. Mapa de montañas y ríos en Ecuador .......................... 24

Figura 1.3. Mapa vegetación del Ecuador....................................... 26

Figura 1.4. Mapa de la vegetación del Ecuador (2) ....................... 27

Figura 2.1. Ubicación de las estaciones en el mapa del Ecuador continental........................................................... 42

Figura 2.2. Ubicación de las estaciones en las Islas Galápagos ..... 44

Figura 3.1. Ejemplo de fichero de datos INAMHI, 2009 .............. 47

Figura 3.2. Ejemplo de libro Excel creado para almacenar datos . 48

Figura 3.3. Ejemplo de libro Excel cargado de valores ................. 49

Figura 3.4. Ejemplo de hoja modelo formato estándar para ubicar resumen de variables .................................................... 50

Figura 3.5. Ejemplo de archivo informativo generado

a partir del relleno de datos.......................................................... 52

Figura 3.6. Ejemplo de hoja estándar con resumen

de resultados de temperatura luego del rellenado de datos .......... 52

Figura 3.7. Mapa de máscara del Ecuador ..................................... 55

Figura 3.8. Mapa de máscara de Galápagos .................................. 56

Figura 3.9. Mapa de altitud del Ecuador ........................................ 56

Figura 3.10. Mapa de altitud de las Galápagos.............................. 57 
12

Figura 3.11. Mapa provincias del Ecuador ................................... 57

Figura 3.12. Mapa de identificación de las Islas Galápagos........... 58

Figura 3.13. Mapa de ubicación de las estaciones en el Ecuador.. 58

Figura 3.14. Mapa de ubicación de estaciones en Galápagos........ 59

Figura 3.15. Visualización de un mapa en Idrisi............................ 60

Figura 4.1. Temperatura media anual - Ecuador ........................... 64

Figura 4.2. Temperatura media de mínimas anual-Ecuador......... 66

Figura 4.3. Temperatura media mínima absoluta anual-Ecuador 67 Figura 4.4. Temperatura media de máximas anual - Ecuador ...... 68 Figura 4.5. Temperatura media máxima absoluta anual - Ecuador.................................................................. 69

Figura 4.6. Temperatura media de mayo - Ecuador ....................... 70

Figura 4.7. Temperatura media de agosto - Ecuador....................... 71

Figura 4.8. Temperatura media anual - Galápagos .......................... 73

Figura 4.9. Temperatura media de mínimas anual - Galápagos ... 74

Figura 4.10. Temperatura media mínima

absoluta anual - Galápagos........................................................... 75

Figura 4.11. Temperatura media de máximas anual - Galápagos. 76

Figura 4.12. Temperatura media máxima

absoluta anual - Galápagos......................................................... 77

Figura 4.13. Temperatura media de mayo - Galápagos ................. 78

Figura 4.15. Precipitación media anual - Ecuador ........................ 82

Figura 4.16. Precipitación mediana anual - Ecuador .................... 83

Figura 4.17. Precipitación media anual de mayo - Ecuador......... 84

Figura 4.18. Precipitación media anual de agosto - Ecuador........ 85

Figura 4.19. Precipitación anual percentil 80 - Ecuador ................ 86 
Figura 4.20. Precipitación anual percentil 20 - Ecuador............... 87

Figura 4.21. Precipitación media anual - Galápagos..................... 88

Figura 4.22. Precipitación mediana anual - Galápagos................. 88

Figura 4.23. Precipitación media anual de mayo - Galápagos...... 89

Figura 4.25. Precipitación anual percentil 20 - Galápagos ............ 90

Figura 4.26. Precipitación anual percentil 80 - Galápagos ........... 91

Figura 4.27. Precipitación máxima en 24 horas

media anual - Ecuador ............................................................... 92

Figura 4.28. Precipitación máxima en 24 horas

máxima absoluta - Ecuador ......................................................... 93

Figura 4.29. Precipitación máxima en 24 horas

mínima absoluta - Ecuador .......................................................... 94

Figura 4.30. Precipitación máxima en 24 horas T10 - Ecuador.... 95

Figura 4.31. Precipitación máxima en 24 horas T100 - Ecuador. 97

Figura 4.32. Precipitación máxima en 24 horas

media anual - Galápagos......................................................... 98

Figura 4.33. Precipitación máxima en 24 horas

máxima absoluta - Galápagos..................................................... 99

Figura 4.34. Precipitación máxima en 24 horas

mínima absoluta - Galápagos ......................................................... 100

Figura 4.35. Precipitación máxima

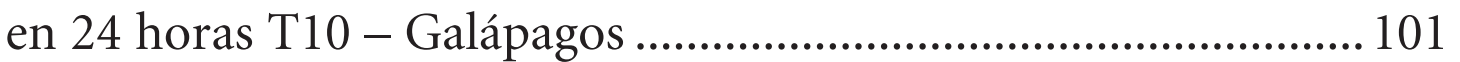

Figura 4.36. Precipitación máxima

en 24 horas T100 - Galápagos ......................................................... 102

Figura 4.37. Humedad relativa media anual - Ecuador ............... 104

Figura 4.38. Humedad relativa de mayo - Ecuador .................... 105

Figura 4.39. Humedad relativa de agosto - Ecuador ................... 106

Figura 4.40. Humedad relativa media anual - Galápagos........... 107 
14

Figura 4.41. Humedad relativa mayo - Galápagos ....................... 108

Figura 4.42. Humedad relativa agosto - Galápagos..................... 109

Figura 4.43. Viento velocidad media mayo (m/s) - Ecuador...... 111

Figura 4.44. Viento velocidad media agosto (m/s) - Ecuador .... 112

Figura 4.45. Viento frecuencia norte $(\mathrm{m} / \mathrm{s})$ - Ecuador................ 113

Figura 4.46. Viento frecuencia norte este $(\mathrm{m} / \mathrm{s})$ - Ecuador......... 114

Figura 4.47. Viento frecuencia este (m/s)- Ecuador ...................... 115

Figura 4.48. Viento frecuencia sur (m/s) - Ecuador...................... 116

Figura 4.49. Viento frecuencia sur este (m/s) - Ecuador .............. 116

Figura 4.50. Viento frecuencia sur oeste (m/s) - Ecuador ............ 117

Figura 4.51. Viento frecuencia Oeste (m/s) - Ecuador................. 118

Figura 4.52. Viento frecuencia norte-oeste (m/s) - Ecuador ....... 119

Figura 4.53. Viento velocidad media agosto (m/s) - Galápagos.. 120

Figura 4.54. Viento frecuencia sur este (m/s) - Galápagos ........... 120

Figura 4.55. Evapotranspiración

según Thornthwaite - Ecuador

Figura 4.56. Evapotranspiración

según Heargreaves - Ecuador

Figura 4.57. Evapotranspiración

según Thornthwaite - Galápagos............................................... 125

Figura 4.58. Evapotranspiración

según Heargreaves - Galápagos 


\section{Índice de Gráficos}

Gráfico 4.1. Relación entre la altitud (m)

y la temperatura media anual $\left({ }^{\circ} \mathrm{C}\right)$

Gráfico 4.2. Relación entre la altitud

y la precipitación media anual

Gráfico 4.3. Relación altitud geográfica $(\mathrm{m})$ versus ubicación de estaciones $(\mathrm{m})$ en las Islas Galápagos

Gráfico 4.4. Relación entre la altitud $(\mathrm{m})$ y la humedad relativa anual $(\%)$

Gráfico 4.5. Relación entre la altitud (m)

y la Evapotranspiración según Thornthwaite

Gráfico 4.6. Relación entre la altitud (m)

y la evapotranspiración ( $\mathrm{mm}$ ) según Hargreaves 



\section{Capítulo I \\ Introducción}

La climatología indudablemente es una ciencia aplicable a todas las áreas del conocimiento y en este caso de enorme trascendencia para el área de la Ingeniería Agronómica, Ambiental y afines. El presente trabajo constituye una aproximación a la climatología del Ecuador continental e insular en base de datos oficiales que propende servir a futuro para estudios de aplicación en el área de ciencias de la vida.

Los estudios relativos al clima del Ecuador regularmente han estado enfocados al sector turístico, área importante de desarrollo; sin embargo es menester estructurar una climatología que tenga aplicación en el área agropecuaria y ambiental, fuente de autoconsumo y de generación de divisas.

No se encuentra, sin embargo, una climatología estadística sistemática del Ecuador que permita situarse con una cierta amplitud en el contexto de un estudio climático del conjunto del país.

A partir de datos oficiales proporcionados por el INAMHI (Instituto Nacional de Meteorología e Hidrología del Ecuador), el presente trabajo tuvo como objetivo formular una climatología estadística básica que nos permita afrontar trabajos más específicos posteriormente. 


\section{Características generales del Ecuador}

El Ecuador, país sudamericano, toma su nombre de la línea imaginaria ecuatorial que divide el planeta en hemisferio norte y hemisferio sur. Un evento importante en la historia de la geografía mundial fue la expedición geodésica de 1736 dirigida por el geógrafo francés Carlos María de La Condamine, cuando la Real Audiencia de Quito (hoy Ecuador) formaba parte del Imperio Español. La Condamine y sus colegas midieron los arcos de la curvatura de la tierra en la línea ecuatorial cerca de Quito y de Pedernales en la costa del Pacífico; estas medidas proporcionaron la primera evidencia exacta del tamaño de la tierra y condujeron al establecimiento del sistema métrico internacional. Cuando el país logró su independencia en 1830, el nombre República del Ecuador fue adoptado, evidentemente debido a la fama que la expedición geodésica francesa dio a la región (Neill, 1995).

A continuación la recopilación de las características para situarse en el contexto natural. La climatología del Ecuador está supeditada a diferentes factores:

\section{Topografía y geología}

El Ecuador continental está situado al Noroeste de América del Sur, entre los $01^{\circ} 28^{\prime}$ de Latitud Norte y $05^{\circ} 01$ de Latitud Sur y desde los $75^{\circ} 11$ en la planicie Amazónica hasta los $81^{\circ} 01$ de longitud Oeste. Limita al norte con Colombia, al sur y al este con Perú y al oeste con el océano Pacífico. El territorio del Ecuador continental está dividido en tres regiones naturales claramente diferenciadas entre sí, ya sea por su topografía, clima, vegetación y población. Las tres regiones son: Costa o Litoral, Sierra o Región Andina, y el Oriente o Amazonía. A $1120 \mathrm{~km}$ de la costa ecuatoriana en dirección Oeste se encuentra el Archipiélago de Colón o Islas Galápagos que como su nombre lo indica está integrado por varias islas. Se considera la cuarta región natural del Ecuador (CIDEIBER, 1999). 
19

a) Costa o Litoral

Territorio conformado por llanuras fértiles, colinas, cuencas sedimentarias y elevaciones de poca altitud. La componen siete provincias: Esmeraldas, Manabí, Guayas, Los Ríos, Santa Elena, El Oro y Santo Domingo. El suelo de la región Litoral es generalmente bajo, con pequeñas elevaciones que no sobrepasan los $800 \mathrm{~m}$ de altura sobre el nivel del mar. El principal sistema montañoso de la región lo constituye la cordillera Costera o de Chongón o Colonche que divide a la región en dos subregiones denominadas Costa Externa y Costa Interna. Es una planicie aluvial baja y cuenta con varios sistemas fluviales importantes que constituyen excelentes vías como transporte naturales.

\section{b) Sierra}

La cordillera de los Andes atraviesa el Ecuador de norte a sur formando dos cadenas montañosas, la occidental y la oriental. Entre las dos cordilleras se encuentra una meseta que llega hasta los tres mil metros de altura, conformada por quince diferentes hoyas donde se extienden valles o mesetas interandinas con una altura media de 2 500 metros sobre el nivel del mar y con una anchura que no excede de 60 o 70 kilómetros. De entre todas las cumbres destacan múltiples picos coronados por nieves perpetuas, muchos de ellos volcanes, entre los 2500 y los 6000 metros de altura. El Chimborazo, con sus 6310 metros y situado en el centro del país, es la montaña más alta de los Andes ecuatorianos; además, destacan también el Cotopaxi (5 897 metros), el Cayambe (5 790 metros), el Antisana (5 705 metros), el Altar (5 320 metros), los Illinizas (5 266 metros), el Sangay (5 230 metros), el Tungurahua (5 016 metros). La Sierra está conformada por diez provincias: Carchi, Imbabura, Pichincha, Bolívar, Cotopaxi, Chimborazo, Cañar, Tungurahua, Azuay y Loja.

c) Amazonía

El relieve de la Amazonía o región oriental está conformado por colinas que se originan en la parte oriental de los Andes y descienden 
hasta las llanuras del Amazonas, a cuya cuenca pertenecen importantes ríos como el Putumayo, el Napo y el Pastaza. Hay dos subregiones geográficas: Alta Amazonía y llanura Amazónica. En la primera se encuentran las cordilleras de Napo Galeras, Cutucú y Cóndor. Los relieves más sobresalientes de la región se encuentran en la parte norte, cerca del volcán Sumaco, y los más bajos hacia el lado este. En la Amazonía se encuentran seis de las provincias del país: Napo, Sucumbíos, Orellana, Pastaza, Morona Santiago y Zamora Chinchipe. En esta región existen importantes yacimientos petrolíferos que en la actualidad constituyen la base de la economía ecuatoriana.

Figura 1.1

\section{Mapa del Ecuador}

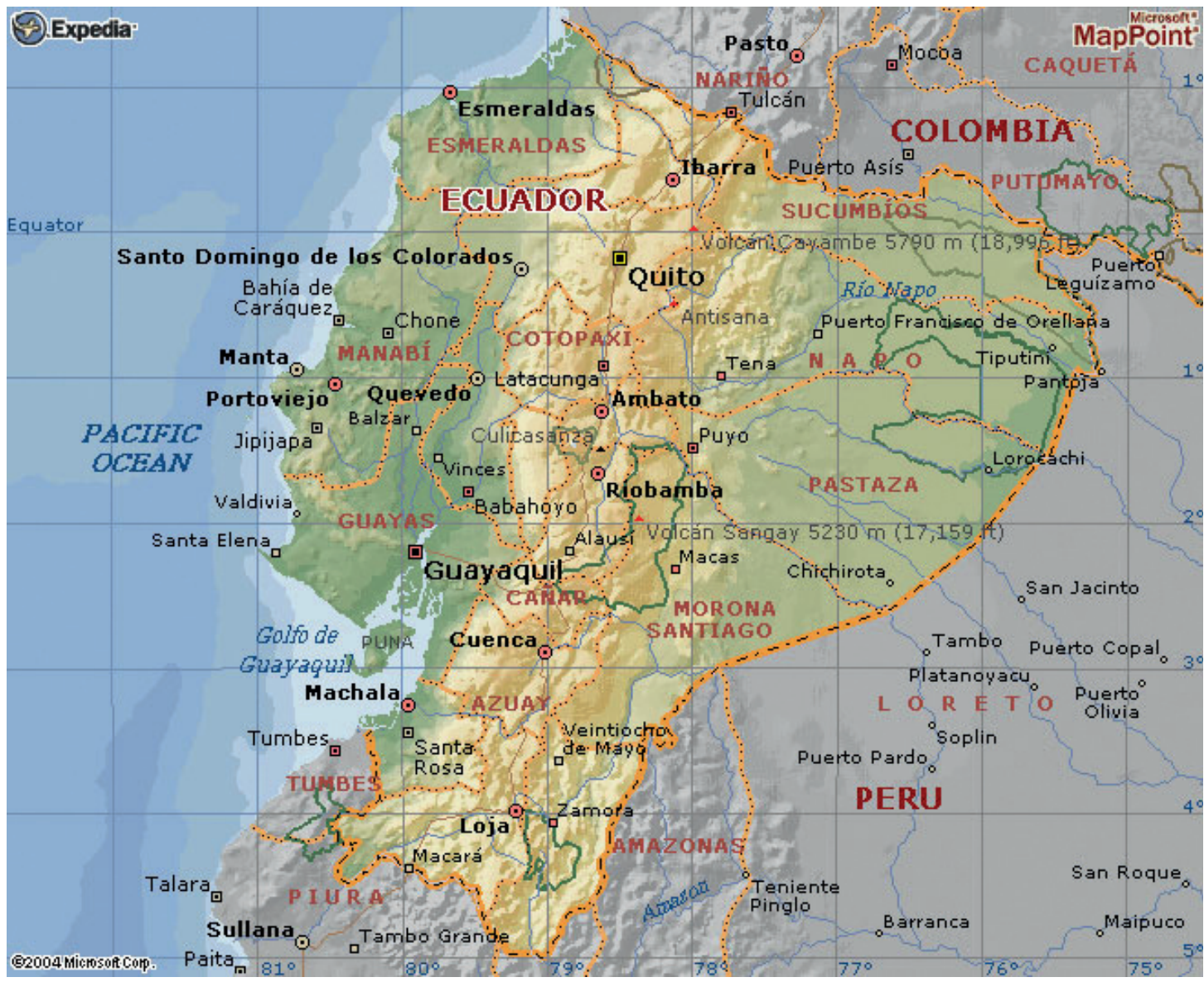

Fuente: Microsoft Corporation 2004 
d) Galápagos o Región Insular

La región insular, archipiélago de Colón o islas Galápagos, se encuentra en el océano Pacífico a 1120 kilómetros de la costa nacional y está constituido por 13 islas mayores, 6 menores y 42 islotes de origen volcánico que suman una extensión superficial de 8010 kilómetros cuadrados. La mayor elevación de estas islas es el volcán Wolf, con 1707 metros sobre el nivel del mar. La fundación de carácter científico que rige el archipiélago y que lleva el nombre de Charles Darwin (en homenaje al sabio inglés que arribó a las Galápagos en 1835, donde perfeccionó su teoría sobre la evolución de las especies que impulsó el desarrollo de las ciencias y amplió el horizonte del conocimiento humano) tiene como misión esencial la de realizar investigaciones con el objetivo de lograr la conservación de los ecosistemas que sobreviven en el archipiélago. Estas islas constituyen el último reducto de diversas especies únicas de fauna y flora, lo que constituye un patrimonio natural imprescindible para la ciencia.

\section{Hidrología}

El Ecuador dispone de una rica red hidrográfica, salvo en las zonas occidentales y meridionales áridas de la Costa. La mayoría de ríos se originan en los Andes y las corrientes se dirigen unas hacia la llanura amazónica y otras hacia el océano Pacífico. Estas últimas, debido a la proximidad de las montañas respecto a la línea costera, tienen por lo general un curso breve pero caudaloso y son navegables en algunos tramos (Ecuaworld, 2009).

a) Cuencas hidrográficas de la vertiente del Pacífico:

Chota: este río nace en el monte Olivo, entre las provincias de Imbabura y Carchi y desemboca en el océano Pacífico colombiano con el nombre de Mira.

Esmeraldas: este río baña la provincia del mismo nombre, formado por la unión de los ríos Canande, Guayllabamba (recorre parte de la provincia de Pichincha) y Quinindé. 
Guayas: este río desemboca en el golfo de Guayaquil y recibe las aguas de los ríos Daule y Babahoyo. El río Daule, con sus afluentes, baña las provincias de Manabí, Los Ríos y Guayas. El río Babahoyo, formado especialmente por el río Yaguachi - y este por la unión de los ríos chimboracenses Chimbo y Chanchán-, recorre las provincias de Chimborazo, Los Ríos y Guayas. La cuenca del Guayas es la más importante de todas, posee una superficie de $40000 \mathrm{~km} 2$.

Cañar: este río se origina en la laguna de Culebrillas con el nombre de San Antonio y desemboca en el golfo de Guayaquil. Recorre las provincias de Cañar y Guayas.

Jubones: este río está formado por las aguas de los ríos León, Girón, Rircay y San Francisco, que nacen en las estribaciones del nudo de Portete-Tinajillas. Recorre las provincias de Azuay y El Oro, y desemboca en el Pacífico.

Macará: este río nace con el nombre de Espíndola, en el nudo de Sabanilla. En su recorrido por Loja toma el nombre de Calvas y, finalmente, de Macará. Se une al río Catamayo y llega al océano Pacífico peruano con el nombre de río Chira.

b) Cuencas hidrográficas de la vertiente del Amazonas:

Esta vertiente hidrográfica está formada por la afluencia de numerosos ríos que nacen en la cordillera Oriental de los Andes y en la cordillera Amazónica. Principalmente se caracterizan por ser ríos caudalosos y navegables en casi todo su curso. Se destacan en dicha vertiente los ríos:

Putumayo: este río en su mayor parte pertenece al territorio colombiano, pero recibe las aguas del río ecuatoriano San Miguel. Desemboca en el Amazonas.

Napo: este río se forma por la unión de algunos ríos procedentes principalmente de las provincias de Tungurahua y Cotopaxi, en 
su recorrido recibe las aguas de los ríos Coca, Aguarico y Curaray; al unirse con el río Marañón forma el gran río Amazonas.

Tigre: este río surge de la confluencia de los ríos Conambo y Pituyacu, en la provincia de Pastaza. Desemboca en el río Marañón.

Pastaza: este río nace en la provincia de Tungurahua con el nombre de río Cutuchi y Patate, recibe las aguas del Palora y Guasago. Desagua en el río Marañón.

Santiago: este río resulta de la unión de los ríos Namangoza y Zamora. El primero recibe las aguas de los ríos Paute y Upano. El segundo se forma en la provincia de Loja y recibe a los ríos Nangaritza y Yacuambi. Deposita sus aguas en el río Marañón.

c) Cuencas lacustres:

A lo largo de la Sierra ecuatoriana y en parte de la Región Amazónica, se localizan áreas lacustres que tienen características y atractivos especiales: son la fuente de formación de muchos ríos y han servido para la construcción de proyectos, especialmente deportivos o turísticos, como es el caso del autódromo construido a orillas de Yaguarcocha o el incremento de la pesca en las diferentes lagunas del territorio nacional. Estas cuencas lacustres están compuestas por algunos lagos y por muchas lagunas de diversa forma y tamaño. La provincia de Imbabura cuenta con un notable número de lagos; por ejemplo, el lago San Pablo, conocido por los aborígenes como Chicapán, el Culcocha y el Yaguarcocha, célebre por haber sido el escenario del combate librado entre caranquis e Incas. En la Amazonía se encuentran también algunos lagos de importancia, como el Limoncocha, Taracoa, Zancudococha, Jatuncocha, Cuyabeno y Lago Agrio.

En las demás provincias serranas se destacan complejos naturales de lagunas y lagunillas. Únicamente se consideran a las más importantes en:

Pichincha: Muertepungu, Dormida y Secas. 
Cotopaxi: Yambo y Quilotoa.

Chimborazo: Coito y Osogoche o Cubillín.

Cañar: Culebrillas y Aucacocha.

Azuay: Osohuayco, Luspa, Angas, Toreadora y más de 150 lagunas situadas en la cordillera del Cajas y Chanchán.

Figura 1.2

Mapa de montañas y ríos en Ecuador

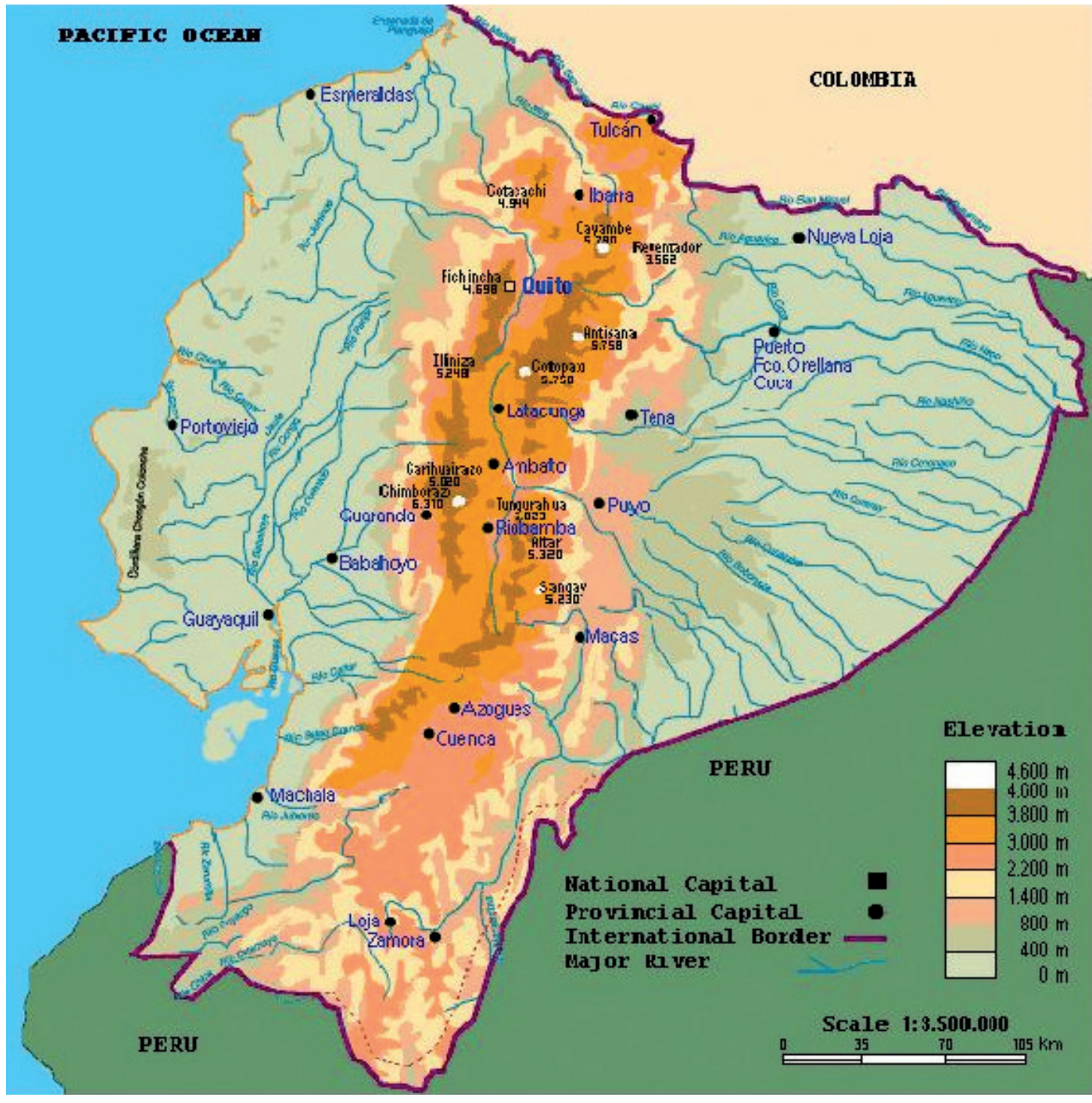

Fuente: Fundación Simbiosis, 2007 


\section{5}

\section{Vegetación y cultivos}

Neill (1995), en su investigación sobre la vegetación del Ecuador, dice que ésta fue iniciada casi hace 200 años. Se podría afirmar que Alexander von Humboldt (1807) fundó las disciplinas científicas de la ecología vegetal y la fitogeografía luego de sus viajes al Ecuador y a otras regiones de América tropical con Aimé Bonpland durante 1799-1804. Sus descripciones de los cambios en la vegetación observados al ascender una montaña tropical y sus comparaciones con otros cambios similares de vegetación observados al viajar de la línea ecuatorial a los polos, fueron conceptos fundamentales en la historia de la biogeografía.

En los múltiples ámbitos climáticos, la vegetación varía notablemente y se observan asociaciones que van desde las sabanas xerófilas hasta la selva pluvial. A este panorama general, que corresponde a las variaciones ya observadas desde algunos parajes semidesérticos de la Costa hasta el ambiente ecuatorial húmedo del oriente, se deben añadir los contrastes derivados de las diversas alturas del terreno, sobre todo en la Sierra, hasta llegar a los pajonales de los páramos y a la ausencia de vegetación en las cimas (Ecuaworld, 2009).

La flora ecuatoriana es distinta en cada región ecuatoriana, aunque muchos productos vegetales de la Costa crecen también en la región oriental. Así por ejemplo es el caso del cacao, el arroz, el tabaco, el algodón, la tagua, la paja toquilla, la caña de azúcar, la mandioca, el caucho y gran variedad de frutas, el naranjo, el ananá, y el coco. La Costa constituye la región más fértil del país, sus llanuras están dedicadas a la agricultura tropical y de exportación como el banano, el café, el cacao, el mango y fibras. En esta zona se ubican también los criaderos de camarón para la exportación.

Los productos vegetales de la Sierra varían desde las formas de las tierras bajas hasta las de las zonas templadas y frías, así en las altas montañas son lugares de pastizales como la Stipa eriostachia, bajo los 3500 metros sobre el nivel del mar se cultivan trigo, cebada, maíz, patatas, fréjol, arvejas, cucúrbitas; y bajo los $2500 \mathrm{msnm}$ se culti- 
van frutales de hoja caduca, y bajo los 1000 msnm cítricos, caña de azúcar, café y otros (CIDEIBER, 1999). Actualmente se cultivan de forma intensiva flores para la exportación, constituyéndose en una fuente de trabajo permanente y de ingreso de divisas para el Estado.

Al Oriente le caracterizan los principales productos que son el café, la palma africana, los cítricos, el plátano, la yuca y variadas frutas tropicales. La amazonia es una región principalmente ganadera debido a la abundancia y calidad de sus pastos tropicales.

La región insular o Galápagos, dadas sus características cuyas islas pequeñas y las partes bajas de las de mayor tamaño son zonas secas y desérticas, no así las islas mayores en sus partes altas, que presentan áreas húmedas y muy densa vegetación tropical. No es una zona productiva en sí, aunque tiene algunos pequeños cultivos tropicales para el autoconsumo de sus pobladores, sino por el contrario es una zona natural dedicada a la investigación científica y al turismo.

Figura 1.3

Mapa vegetación del Ecuador

\section{Vegetation}
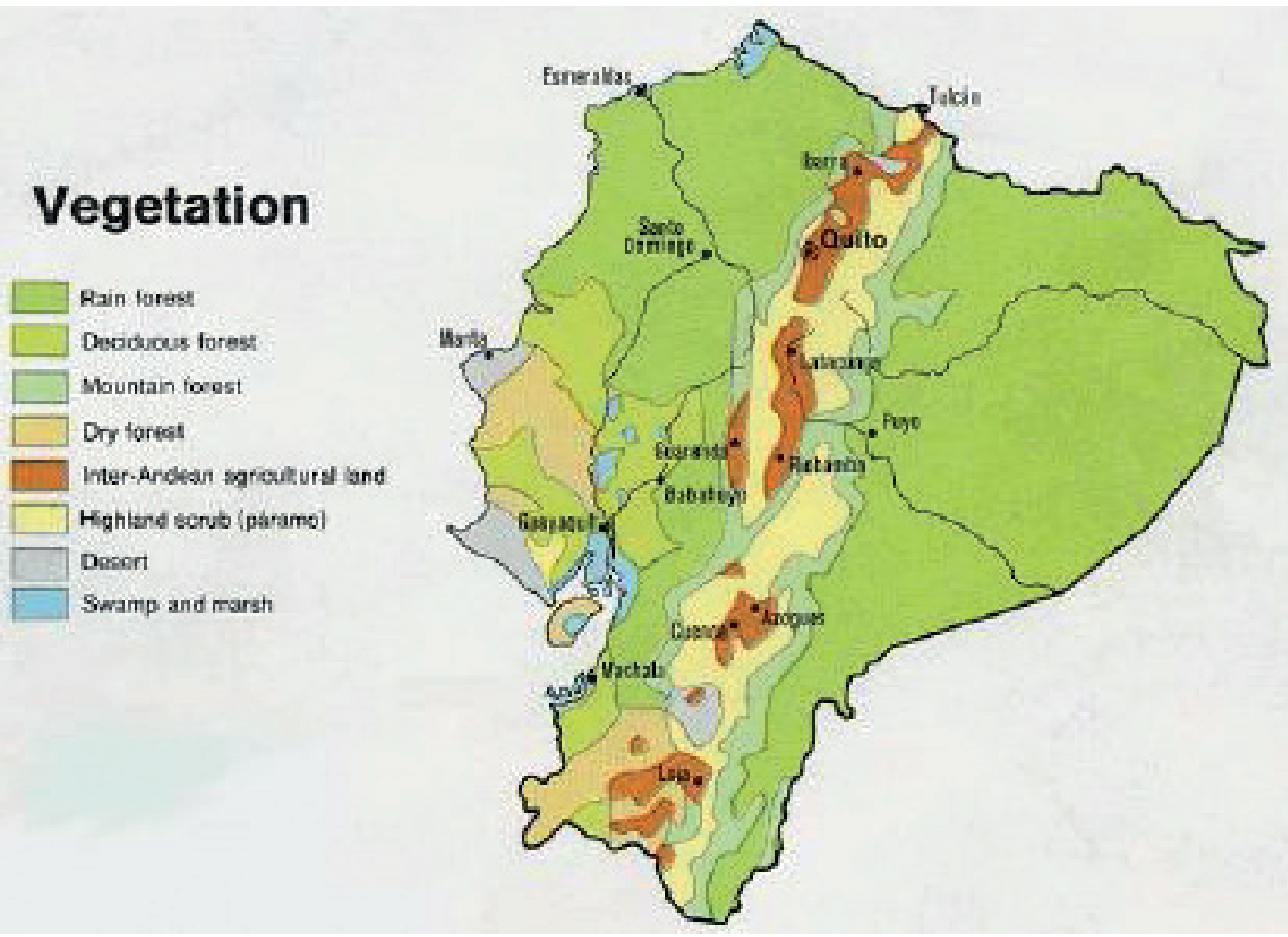

Fuente: Central Intelligence Agency (CIA), zonu ecuador, 1973. 
Figura 1.4

Mapa de la vegetación del Ecuador (2)

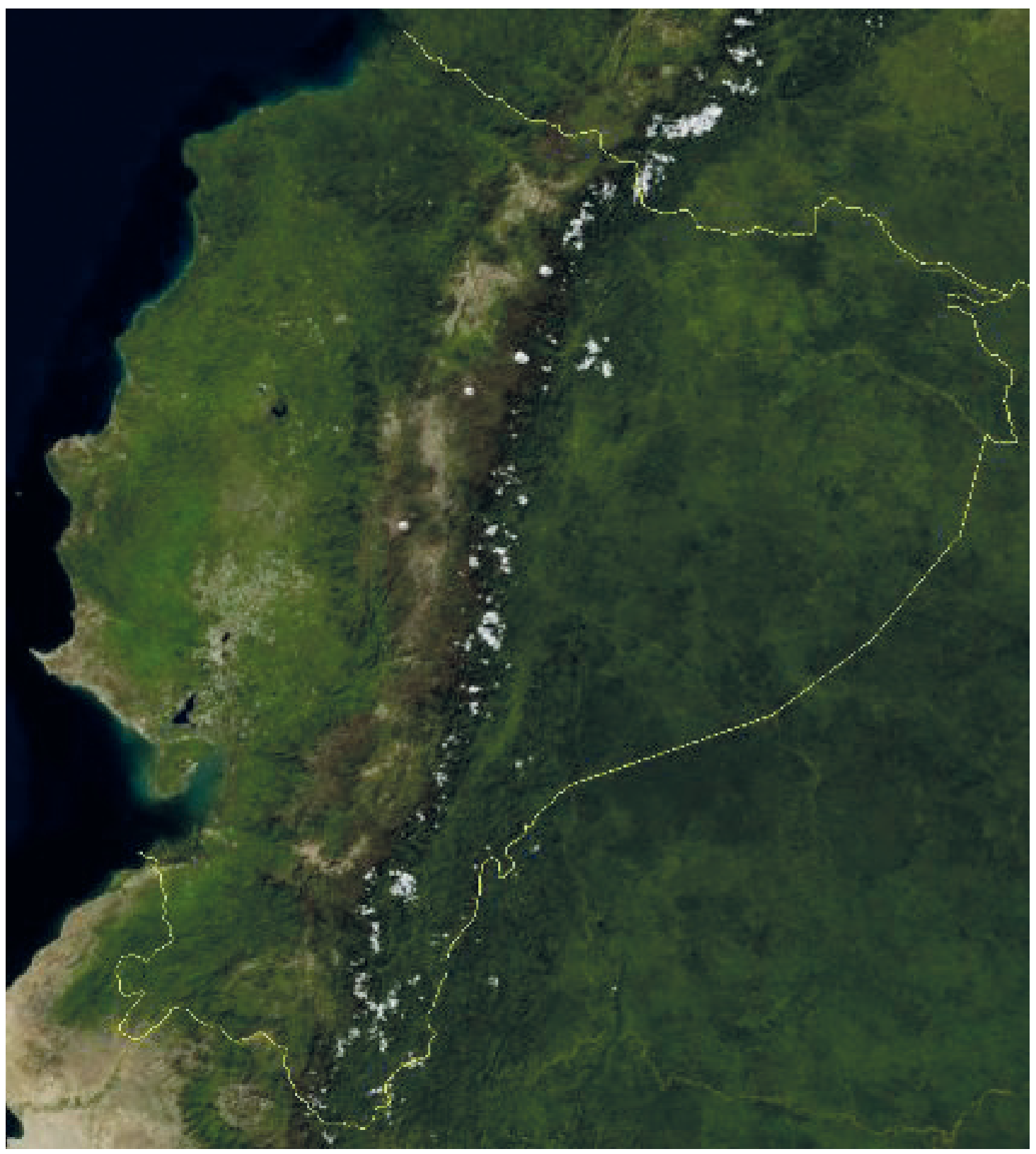

Fuente: Central Intelligence Agency (CIA), zonu.com, 1973

\section{Fauna}

Siguiendo el informe de CIDEIBER (1999) podemos decir que la fauna ecuatoriana varía de región a región. En la Costa se encuentran monos, pumas, jaguares, osos hormigueros, tapires, zorros, el cocodrilo en los ríos, las serpientes en la selva y multitud de aves. 
En la Sierra, coexisten gran variedad de aves, lobos, raposas, conejos y el ganado doméstico de las zonas templadas. En el piso frío interandino hay aves de vuelo sostenido y extenso como el cóndor, el curiquenque, la perdiz, el veranero; en la zona templada interandina viven los gallinazos, las tórtolas, los colibríes, los gavilanes, las lechuzas y los guirachuros.

La fauna de la región Oriental es mucho más variada y comprende numerosos cuadrúmanos, felinos, plantígrados, reptiles, ofidios, aves e insectos. Entre los ofidios cabe mencionar a la estrella palo, la boa, la anaconda o panguly las culebras equis, la coral, la rabihueso, la motolo, la critomachacuy, la pumapalo, la sichapalo, la palanda y la jahuaraizín. En los ríos y las lagunas viven el bagre, la lisa, la dama, el barbudo, la bocachica, los bufeos y los manatíes o vacas marinas. Entre los mamíferos, monos de largas colas, vampiros, venados y puercoespines; entre los carniceros, una variedad del oso negro, el tigre marino y una especie de gato negro de gran tamaño, el amichi.

En las islas Galápagos, son numerosas las tortugas (con especies gigantes) y las tortuguillas, las iguanas y los lagartos. Una variedad de aves como el piquero de patas azules, el cormorán, y otras cuyas características sirvieron para la redacción de la obra de Charles Darwin, evolución de las especies, luego de su estancia en las islas.

\section{Aproximación a la climatología del Ecuador}

Para aproximarse a la climatología de un lugar, región o país, es necesario considerar los factores que modifican el clima y los elementos del clima.

\section{Factores del clima}

Las características climatológicas del Ecuador (INAMHI, 2009), responden a una diversidad de factores que modifican su condición natural, tales como: latitud geográfica, altitud del suelo, dirección de las cadenas montañosas, distancia al océano, los vientos y las corrientes marinas. 
a) Latitud. El Ecuador por su situación astronómica (entre los $01^{\circ} 28^{\prime}$ de Latitud Norte y $05^{\circ} 01$ de Latitud Sur y desde los $75^{\circ} 11$ en la planicie Amazónica hasta los $81^{\circ} 01$ de longitud Oeste), en el centro de la Zona Tórrida debería tener un clima completamente cálido de manera general, sin embargo la realidad es diferente debido a la influencia de otros factores que modifican el clima.

b) Altitud. Es el factor que más contribuye a modificar el clima. Si se considera que partiendo del nivel del mar la temperatura desciende un grado por cada 200 metros de altura, el clima tiene una fluctuación de aproximadamente 31 grados, ya que el nivel de sus tierras va desde 0 metros al nivel del mar hasta 6310 metros que es su máxima altura en las cumbres del Chimborazo. De esta manera, el país goza del privilegio de poseer todos los tipos de clima, desde el cálido del Litoral hasta el glacial de las alturas andinas.

La altura y la dirección norte sur de las cordilleras Occidental y Oriental del sistema montañoso de los Andes impide la penetración de los vientos cálidos y húmedos del Occidente y del Oriente al interior de las hoyas o valles andinos, que quedan caracterizadas específicamente por este factor.

c) Distancia al océano. La Región Litoral o Costa por estar cerca del Océano Pacífico recibe una acción térmica modificadora del clima, no así la sierra y la región andina que se encuentran detrás de cordillera occidental de los Andes. La región insular está completamente influenciada por los fenómenos meteorológicos originados en el océano Pacífico.

d) Vientos. Los vientos que soplan desde los Andes disminuyen la temperatura de las zonas bajas de la Costa y Oriente. Además, al chocar con los vientos calientes y húmedos de estas regiones producen las precipitaciones. Las tres regiones continentales que distingue el territorio ecuatoriano, Costa, Sierra y Oriente se diferencian entre sí y son el lugar de origen de grandes masas de aire que toman de ellas sus características, produciéndose con su desplazamiento ciertas 
modificaciones causadas por las variaciones que sufre al pasar por regiones con diferentes cualidades (INAMHI, 2009). Las masas de aire generadas son:

- Masas Tropicales Marítimas. Estas masas se originan en las extensiones oceánicas y se distinguen por su alta temperatura y gran contenido de humedad.

- Masas Tropicales Continentales. Estas masas se caracterizan por bajas temperaturas y un contenido menor de humedad, su lugar de origen son las planicies del Litoral y del Oriente, distinguiéndose estas últimas por un mayor contenido de humedad.

- Masas Templadas. Estas masas se caracterizan por bajas temperaturas y un contenido muy irregular de humedad, se sitúan en los valles interandinos.

- Masas de Aire Frías. Estas masas se asientan en las mesetas andinas y en las cimas altas de las montañas (más de $3000 \mathrm{~m}$ de altura); las temperaturas son menores o iguales a $0^{\circ} \mathrm{C}$ y la humedad depende de la influencia de las masas de aire que recibe.

Los vientos predominantes en el Ecuador son los alisios del Nordeste en el Hemisferio Norte y los del Sudeste en el Hemisferio Sur, alterándose esta prevalencia por el comportamiento de las masas de aire y los desplazamientos del cinturón ecuatorial. Por lo expuesto, en el Ecuador se forman masas de aire estáticas y móviles con características propias (INAMHI, 2009). El papel de estas masas de aire puede resumirse de la siguiente forma:

1) La región costanera central (Península de Santa Elena y Sur de Manabí) está bajo la influencia de la corriente fría de Humboldt la mayor parte del tiempo. En Salinas la temperatura de la superficie marítima disminuye entre los meses de Junio y Septiembre que corresponden al invierno austral. Masas de aire marítimo relativamente frío invaden la faja costera dando lugar a neblinas y lloviznas con valores de precipitaciones muy débiles, determinando un clima seco. Sin embargo, la corriente fría de Humboldt tiene una influencia importante 
en las partes altas de los relieves (cordillera costera de Chongón) donde son responsables de zonas notablemente más húmedas. Característica especial tiene la provincia norteña de Esmeraldas, llamada la provincia verde debido a su lozana vegetación. Esta provincia concentra los valores más altos de humedad relativa a lo largo del año. La cuenca del Guayas (provincias del Guayas y Los Ríos), es la zona que mayor precipitación recibe en invierno y es un área de alto riesgo de inundación.

2) La región de la Sierra, se encuentra bajo la influencia alterna de Masas de Aire Tropical Marítimo (MATM) y Masas de Aire Tropical Continental (MATC). Desde inicios de Septiembre, la ZCIT (que se encuentra a esa época del año sobre el Hemisferio Norte y en proceso de alcanzar el Ecuador), después de rechazar los alisios del Sudeste, moviliza hacia el continente las MATM. Estos al sumarse los alisios del nordeste dan inicio a la estación lluviosa. A fines de Diciembre, la ZCIT que aún se encuentra en el Hemisferio Norte, detiene el movimiento anterior, y sin que haya mayor ingreso de aire marítimo húmedo, provoca una ligera recesión de la pluviometría que corresponde al llamado veranillo del Niño de fines de Diciembre-Enero. Mientras tanto, debido a las fuertes temperaturas, las MATC de la llanura amazónica siguen reforzándose y al verse empujadas hacia la cordillera, ingresan en parte al callejón interandino y dan lugar a un segundo pico lluvioso a partir de Marzo. En las hoyas interandinas, sigue válido el régimen anteriormente expuesto de una estación lluviosa con dos picos separados por una corta estación seca. Sin embargo, por estar mejor abrigadas, por recibir aire marítimo o continental casi totalmente descargado de humedad y porque ahí reinan Masas de Aire Templado Continental, el total de las precipitaciones es menor y el clima más estable y seco.

3) La región amazónica se encuentra principalmente bajo la influencia de las MATC, las mismas que se originan en la Amazonía Central y que gran parte del año actúan como perturbaciones tropicales; sin embargo y aunque sea en forma limitada, también se observa una ligera recesión de las precipitaciones a fines de Diciembre y en Enero. 
Como ejemplo del comportamiento del viento, citamos las conclusiones realizadas por el INAMHI (2006) en la región fronteriza colombo ecuatoriana:

- La velocidad del viento con la altura se incrementa, especialmente entre la superficie del suelo y el nivel de $850 \mathrm{hPa}$ (aproximadamente $1500 \mathrm{~m}$ ).

- El comportamiento del viento a nivel de superficie en las estaciones localizadas en la zona fronteriza Ecuador-Colombia, está directamente ligado a la altura del terreno, relieve, vegetación y época del año.

- En la estación meteorológica Nuevo Rocafuerte, en diciembre y enero la dirección predominante del viento es noreste.

- Desde febrero hasta el mes de octubre, la máxima frecuencia del viento se registra en la dirección noroeste, seguida de la dirección noreste.

- En Nueva Loja, de enero a marzo la mayor frecuencia del viento corresponde a la dirección oeste; entre abril y agosto se observan vientos del sur; mientras que de septiembre a diciembre prevalecen los vientos del este.

- En Tulcán durante todo el año prevalecen vientos de dirección del este dirigiéndose hacia el oeste.

- El comportamiento del viento en la zona Norte de la Región Interandina y Oriental del Ecuador, en el nivel de $850 \mathrm{hPa}$, evaluado a través de la información del modelo numérico GFS, tiene componente noreste dirigiéndose al suroeste.

e) Corrientes marinas. Las llanuras del sur y centro de la región Litoral reciben la influencia de la Corriente Fría de Humboldt, la misma que disminuye la temperatura hasta la altura del Cabo Pasado, así como no permite el paso de los vientos cálidos y húmedos del Pacífico, haciendo que en estas zonas las precipitaciones sean escasas, convirtiendo en muy secos a los suelos de la Península de Santa Elena. La corriente cálida de El Niño, en cambio, influye en el clima de la región Litoral desde el norte hasta el Cabo Pasado, haciéndola más abrigada y 
aumentando de forma importante el régimen de lluvias en este sector. Este fenómeno es conocido como El Niño, ya que las precipitaciones anuales empiezan a mediados o fines de diciembre, alrededor de la Navidad. La temperatura cambia de una isla a otra en las Galápagos y primariamente esto se debe a la influencia de los cambios de temperatura en el océano Pacífico (Schwerdtfeger, 1976).

Debido a que la corriente caliente ecuatorial incursiona anualmente hacia el sur, gran parte de la costa del Ecuador, así como las Islas Galápagos, tienen un patrón unimodal, con una estación lluviosa que se extiende de diciembre a abril o mayo y una estación seca larga que se extiende de mayo a diciembre. La longitud y la intensidad de la estación seca varían en la región de la costa. Salinas, por ejemplo, en la punta occidental de la península de Santa Elena, es la más afectada por la corriente de Humboldt que pasa muy cerca a la costa y recibe solo cerca de $125 \mathrm{~mm}$ de lluvia al año, principalmente en febrero y marzo. Guayaquil, que se encuentra ubicado en la desembocadura del Río Guayas y más alejado de la influencia de la corriente de Humboldt, recibe casi $1000 \mathrm{~mm}$ de lluvia, con una estación seca de siete meses. Pichilingue, en el interior del valle Guayas y hacia el norte, recibe más de $2400 \mathrm{~mm}$, pero experimenta una estación seca significativa de cuatro meses de agosto a noviembre. San Lorenzo, ubicado en el noroeste del país, tiene un clima influenciado por la corriente cálida ecuatorial y tiene solo una estación seca corta alrededor de noviembre. Las áreas del interior en la planicie costera, cerca de la frontera norte con Colombia, probablemente reciben más de 5 000 mm de lluvia al año, pero no hay suficiente registros meteorológicos que lo comprueben (Neill y Jorgensen, 2009).

Un estudio particular realizado por Villacís, Galárraga y Francou (2000) sobre la influencia de El Niño en la precipitación en los Andes centrales del Ecuador, en base a datos del periodo 1965-1998 y pertenecientes a 16 estaciones, tiene como resultado que en el área de estudio predomina el régimen de precipitaciones ecuatorial, que es determinado principalmente por el paso de la Zona de Convergencia 
Inter Tropical. En este régimen la estación lluviosa comienza en septiembre y termina en mayo, observándose dos picos de precipitación, uno principal entre marzo y abril y un segundo de menor intensidad entre octubre y noviembre. Durante los meses de diciembre y enero disminuye la precipitación. La principal estación seca se presenta de junio a agosto. Concluye el estudio manifestando que los resultados obtenidos hasta el momento, deben ser validados, mediante el análisis de otras variables climáticas.

\section{Elementos del clima}

Entre las variables o elementos principales del clima están: la temperatura, la precipitación, la humedad relativa, y la heliofanía.

Temperatura. En la Región Interandina la temperatura está vinculada estrechamente con la altura. Entre los 1500 y 3000 metros los valores medios varían entre los $10{ }^{\circ} \mathrm{C}$ y $16^{\circ} \mathrm{C}$ con máximas que pueden superar los $25^{\circ} \mathrm{C}$ y mínimas que se aproximan al cero, en verano (especialmente en el mes de agosto). En la región Oriental, zona Litoral e Islas Galápagos, la media anual se establece entre los 24 ${ }^{\circ} \mathrm{C}$ y $26^{\circ} \mathrm{C}$, con extremos que raramente sobrepasan los $36^{\circ} \mathrm{C}$ o bajan a menos de los $14^{\circ} \mathrm{C}$. Por ejemplo Guayaquil es una ciudad caliente y húmeda con temperaturas que sobrepasan los $30^{\circ} \mathrm{C}$ de diciembre a mayo, coincidiendo con el invierno (Schwerdtfeger, 1976).

Hablando de la temperatura, el estudio realizado por Cáceres, Mejía y Ontaneda (1995), sobre evidencias del cambio climático en el Ecuador, reporta los siguientes resultados y recomendaciones:

- El problema de la atribución de los cambios encontrados a un determinado efecto, es por el momento difícil de definir tanto a nivel global y con mucha más razón a nivel regional y local.

- La temperatura media presenta un valor de cambio de $0.5^{\circ} \mathrm{C}$ $1.6^{\circ} \mathrm{C}$ en la Zona Urbana de Altura (ciudades de la Sierra) y de $1.5^{\circ} \mathrm{C}$ en la Zona Rural de Altura es de $1.5^{\circ} \mathrm{C}$. Estos indicadores son superiores a los detectados a nivel global. Este aspecto debe 


\section{5}

ser analizado con mayor profundidad, considerando adicionalmente otros aspectos que pueden generar ruido en las series.

- La zona urbana marina (ciudades portuarias) indica un cambio permanente en el tiempo de la temperatura y oscila entre $0,5^{\circ} \mathrm{C}$ y $1,0{ }^{\circ} \mathrm{C}$, valores que se acercan mucho más a las estimaciones a nivel mundial.

- La zona rural marina es la única que no presenta una señal fuerte de un cambio positivo de la temperatura. Se considera que se deberá investigar lo que sucede en otras localidades no consideradas y que tienen similares características.

- Las temperaturas mínimas y máximas absolutas tienden a ser cada vez más altas, lo que evidencia un posible cambio. La tendencia positiva en los valores de la temperatura mínima absoluta es más evidente en la región interandina que en la región costanera.

- Los incrementos más significativos, tanto de temperatura mínima absoluta como de temperatura máxima absoluta se producen en la estación de Ambato.

- Los cambios en la temperatura máxima absoluta por lo general son de mayor intensidad en la región interandina que en la región Litoral.

- Los mayores incrementos en la región Litoral, tanto en temperatura máxima absoluta como mínima absoluta, se registran en la estación de Guayaquil.

- Los resultados se inscriben íntegramente dentro del ámbito del cambio climático.

- Las incertidumbres encontradas en la investigación no impiden reconocer la existencia de un cambio, sea cual fuere su causa.

- Es necesario continuar con estudios e investigaciones relativas a la detección del cambio climático.

Precipitación. La Región Amazónica, al igual que el noreste de la provincia de Esmeraldas (región Litoral), son las zonas más lluviosas con totales anuales que fluctúan entre los 3000 y $4000 \mathrm{~mm}$. En la Región Costa, los valores más bajos se registran en el sector comprendido entre Manta y la Península de Santa Elena cuyos re- 
gistros alcanzan los $250 \mathrm{~mm}$, mientras que precipitaciones anuales superiores a los $3000 \mathrm{~mm}$ pueden observarse hacia el interior de la región hasta una altura aproximada de los $1500 \mathrm{~m}$.

En la Región Interandina, se observan dos estaciones lluviosas, de Febrero a Mayo (muy intensa y copiosa) y de Octubre a Noviembre (más liviana y menos abundante); con una primera estación seca muy marcada entre Junio y Septiembre, y con una segunda menos acentuada en Diciembre-Enero. Los totales pluviométricos fluctúan entre los 700 y $1500 \mathrm{~mm}$, generalmente. En las hoyas interandinas los valores anuales se ubican en el orden de los $500 \mathrm{~mm}$. Por otra parte, en las regiones situadas sobre los $3500 \mathrm{~m}$ de altura, se observan frecuentes neblinas y las lluvias son generalmente de larga duración y débil intensidad. Los patrones anuales de precipitación en la región andina del Ecuador están profundamente influenciados por las oscilaciones de la Zona de Convergencia Intertropical (ZCIT), la baja presión en medio de enormes corrientes de masas de aire continental al norte y al sur de la línea ecuatorial, que está asociada con la nubosidad y fuertes lluvias. La ZCIT cambia de posición de $10^{\circ} \mathrm{N}$ de latitud en el solsticio de junio, a $5^{\circ} \mathrm{S}$ de latitud en el solsticio de diciembre. Por lo tanto, la ZCIT pasa sobre el Ecuador dos veces al año durante sus oscilaciones hacia el norte y sur. Los cambios en la ZCIT producen una distribución bimodal de las lluvias en las localidades andinas del Ecuador, con dos períodos lluviosos y dos períodos secos durante el año (Neill y Jorgensen, 2009).

Un estudio de riesgo climático en la cuenca del Guayas (provincia de Los Ríos y Guayas) realizado por Martínez, Nieto, Briones, Romero y Hernández (2005), establecieron niveles de amenaza de precipitación en base de la media de precipitación para la estación seca y la estación húmeda. Se consideró como estación húmeda a enero, febrero, marzo y abril, mayo y diciembre como meses de transición, junio, julio, agosto, septiembre, octubre y noviembre como estación seca. Se calculó la media y la desviación estándar de precipitación para ambas estaciones. Con estos niveles se establecieron para la estación húmeda categorías de amenaza de inundación por precipitación o sequía por déficit de precipitación: 
- Amenaza extrema por exceso (precipitación $>750 \mathrm{~mm}$ )

- Amenaza alta por exceso $(500 \mathrm{~mm}<$ precipitación $<=750 \mathrm{~mm})$

- Sin amenaza por precipitación $(250 \mathrm{~mm}<$ precipitación $<=$ $500 \mathrm{~mm}$

- Amenaza alta por déficit $(100 \mathrm{~mm}<$ precipitación $<=250 \mathrm{~mm})$

- Amenaza extrema por déficit (precipitación $<100 \mathrm{~mm}$ )

Humedad relativa (HR). Los porcentajes cercanos al 100\% de humedad están ubicados en la amazonia durante todo el año y en la costa en periodo invernal. En la región andina tiende a situarse en un $80 \%$ en periodo invernal y abajar a hasta $10 \%$ en el verano.

Heliofanía. En toda la llanura litoral hasta una altura de $500 \mathrm{~m}$ en la ladera de la cordillera Occidental, el promedio anual de horas de brillo solar fluctúa entre las 600 y 1700 horas, siendo las más favorables de este número las zonas más secas. En la región interandina, la insolación fluctúa entre las 1200 y 2000 horas anuales con ciertas excepciones de lugares muy lluviosos. Pese a la poca información de datos existentes en la región amazónica se ha determinado que la insolación se ubica entre las 1000 y 1400 horas anuales. En el Archipiélago de Colón, el promedio anual de insolación se ubica alrededor de las 2000 horas anuales.

La duración del día cambia muy poco durante el año, cada día tiene 12 horas de luz solar, con una variación de no más de 30 minutos en cualquier punto del país. En la línea ecuatorial, la cantidad total de radiación solar alcanza el máximo en los equinoccios; esto es sólo un $13 \%$ más alto que la cantidad mínima de radiación interceptada en los solsticios. Una consecuencia de esta relativa constancia anual de radiación solar, es la variación estacional baja en la temperatura promedio del aire en las latitudes ecuatoriales (Neill y Jorgensen, 2009).

\section{Climas}

El principal obstáculo que se encuentra al estudiar el clima en el Ecuador es la escasez de registros a largo plazo y, particularmente, la falta completa de registros de áreas remotas, escasamente pobladas 
donde los extremos climáticos como altos niveles de lluvias se cree que ocurren pero no han sido medidos. Sólo algunos lugares del país tienen registros meteorológicos de 50 años o más, principalmente la mayoría de las ciudades grandes como Quito, Guayaquil y Cuenca (Neill y Jorgensen, 2009). La convergencia de los factores con los elementos del clima, generan diversos climas en el Ecuador:

\section{Clima de la Costa}

Esta región posee un clima tropical o ecuatorial, cuya temperatura media anual varía entre 22 y $26^{\circ} \mathrm{C}$. Se caracteriza por las constantes precipitaciones en forma desigual en los distintos lugares y durante todo el año; los principales meses de lluvia se sitúan entre diciembre y mediados de mayo, período considerado como de invierno. Esta desigualdad en la precipitación pluvial obedece al efecto de las corrientes marinas de Humboldt y El Niño. Principalmente se consideran dos grandes zonas climáticas de la Costa ecuatoriana: cálida-fresca-seca y cálida-ardiente-húmeda (Neill y Jorgensen, 2009).

La primera se extiende desde el puerto de Manta hasta la Isla Puná y desde el perfil costanero hasta la cordillera Costanera. Sus tierras son secas y áridas. Su temperatura ambiental oscila entre 23 ${ }^{\circ} \mathrm{C}$ y $26{ }^{\circ} \mathrm{C}$, con continuas corrientes de aire procedentes del mar.

La segunda comprende los territorios de la costa interna hasta los declives de la cordillera Occidental; por estar alejada del mar, su clima es extremadamente caluroso con una temperatura de $26^{\circ} \mathrm{C}$ y con constantes lluvias por el incremento de la altitud.

\section{Clima de la Sierra}

El clima de la Sierra es muy variado, debido a la presencia de la cordillera de los Andes y a los vientos que soplan por los valles y llanuras. En esta región se localizan los siguientes climas, conocidos como pisos o escalones climáticos: tropical andino, subtropical andino, templado, frío y glacial (Neill y Jorgensen, 2009). 
En el tropical andino la temperatura varía entre las 20 y 25 ${ }^{\circ} \mathrm{C}$. Las lluvias son escasas y la atmósfera seca. Comprende todas las tierras bajas de la Sierra hasta una altura de $1500 \mathrm{~m}$. A este piso climático pertenecen los valles del Catamayo, Macará, Puyango, Chota, Guayllabamba y Yunguilla.

El subtropical andino va desde los 1500 hasta los $2500 \mathrm{~m}$, con una temperatura de $20{ }^{\circ} \mathrm{C}$. A este piso corresponden los valles de Ibarra, Los Chillos, Paute y Loja. Lluvias abundantes en invierno y poco frecuentes en verano caracterizan a este piso.

El templado, con una temperatura de $17^{\circ} \mathrm{C}$, se sitúa en los lugares que van desde los 2500 hasta los $3500 \mathrm{~m}$. Se caracteriza este eslabón climático por tener lluvias abundantes, granizadas frecuentes, ambiente nublado y por ser el más poblado. Aquí se asientan algunas ciudades, como Tulcán, Latacunga, Riobamba y otras.

El piso frío comprende todos aquellos lugares que van desde los 3500 hasta las $5650 \mathrm{~m}$. Su temperatura varía entre $1{ }^{\circ} \mathrm{C}$ y $10^{\circ} \mathrm{C}$. Se dan torrenciales aguaceros, neblinas espesas y lloviznas casi constantes. Este clima se destaca especialmente en los nudos y páramos, como en El Ángel, Mojanda-Cajas, Chasqui, Llanganatis y Buerán.

El glacial forma el último piso climático de la Sierra ecuatoriana. Se sitúa por encima de los 5650 hasta los $6310 \mathrm{~m}$, en la cumbre del Chimborazo. Se caracteriza por registrar temperaturas Inferiores a los $0{ }^{\circ} \mathrm{C}$ y poseer nieve perpetua, truenos, neblinas y aguaceros constantes.

Excepto algunos valles especialmente abrigados, la meseta andina a causa del relieve, goza de temperaturas primaverales durante todos los meses del año (Quito $13,50^{\circ} \mathrm{C}$ de temperatura media anual; Ibarra, más al norte, $15{ }^{\circ} \mathrm{C}$; Riobamba en la zona central $13,5^{\circ} \mathrm{C}$; Cuenca, en el sur, $14,2^{\circ} \mathrm{C}$ ), pero las lluvias varían mucho de una hoya a otra. Así, en la regada por el río Guayllabamba, que corresponde al sector de Quito, las precipitaciones medias son de $1041 \mathrm{~mm}$ al año; en la del Chota (Ibarra) bajan drásticamente a $480 \mathrm{~mm}$; en la de 
Chimbo (Riobamba) descienden a $420 \mathrm{~mm}$ y en la de Paute (Cuenca) la cifra se eleva en cambio a $738 \mathrm{~mm}$. En ciertos valles, las lluvias suelen escasear (Chota $347 \mathrm{~mm}$, Puéllaro $354 \mathrm{~mm}$ ) y más arriba, sobre los páramos estériles, las temperaturas son decididamente frías y pueden situarse incluso a valores bajo cero. En Rato de Antisana, a poca distancia de la línea equinoccial pero a $4095 \mathrm{~m}$ de altura, el mes más cálido registra una temperatura media de $6{ }^{\circ} \mathrm{C}$ y el más frío de $3,3{ }^{\circ} \mathrm{C}$; las precipitaciones, de 1000 a $2000 \mathrm{~mm}$, caen en forma de nieve o granizo. En las cimas de la cordillera, por encima de los 4700 $\mathrm{m}$, se encuentran formaciones glaciares (Neill, y Jorgensen, 2009).

\section{Clima de la Región Amazónica}

Es igual al de la costa interna, es decir, cálido-ardiente-húmedo. La temperatura varía entre $22{ }^{\circ} \mathrm{C}$ y $26{ }^{\circ} \mathrm{C}$; es la región más húmeda del país. Es un área sujeta a abundante precipitación (más de $3000 \mathrm{~mm}$ anuales). Los flancos de los Andes forman una zona densamente nublada, debido a que allí se condensan grandes masas de vapor proveniente del Atlántico y de la selva amazónica.

\section{Clima de la Región Insular}

Las Galápagos, al igual que la Sierra, (Neill y Jorgensen, 2009), posee pisos climáticos, conocidos como:

Desértico, caracterizado por una sequía extrema y una temperatura de $21^{\circ} \mathrm{C}$. Corresponde a las franjas que se extienden al nivel del mar.

Tropical, parecido al anterior, se extiende de $0 \mathrm{~m}$ a $250 \mathrm{~m}$ de altitud.

Templado, va de los $250 \mathrm{~m}$ a los $450 \mathrm{~m}$ y tiene una temperatura de $17^{\circ} \mathrm{C}$.

Frío, con temperaturas interiores a los $14^{\circ} \mathrm{C}$, se extiende sobre los $450 \mathrm{~m}$. 


\section{Capítulo II Materiales}

Los materiales utilizados para este trabajo de investigación se refieren a la base de datos meteorológicos del INAMHI y programas informáticos.

\section{Base de datos del INAMHI}

Para el presente trabajo fue menester recurrir a la cooperación interinstitucional del Instituto Nacional de Meteorología e Hidrología del Ecuador INAMHI. Se realizaron las gestiones pertinentes, especificando el destino académico científico de la información, solicitando el envío de datos, que fue realizado a través de internet y en formato Word, estación por estación. Se receptaron datos de 41 estaciones referidas a las variables siguientes: temperatura mínima, temperatura media, temperatura máxima, temperatura media de mínimas, temperatura media de máximas, precipitación media, precipitación máxima en 24 horas, humedad relativa, velocidad y dirección de viento (en ésta ha habido dos estaciones carentes datos la número 250 y la 192, lo cual fue confirmado oportunamente).

La lista de las estaciones recibidas se recoge en la tabla 2.1. y se representa en los mapas del Ecuador continental (Figura 2.1.) e insular o Islas Galápagos (Figura 2.2.). Se puede apreciar que existen zonas territoriales extensas que no disponen de estaciones meteorológicas como la región amazónica y las Islas Galápagos. Esto de alguna manera dificulta conocer con exactitud los valores de los elementos del 
clima en esas regiones. También se pondrá de manifiesto más adelante, cuando se analicen los mapas correspondientes, cuya interpolación tuvo que realizarse alrededor de veinte estaciones a la redonda en el caso continental y en el insular con las tres únicas estaciones existentes.

\section{Figura 2.1}

Ubicación de las estaciones en el mapa del Ecuador continental.

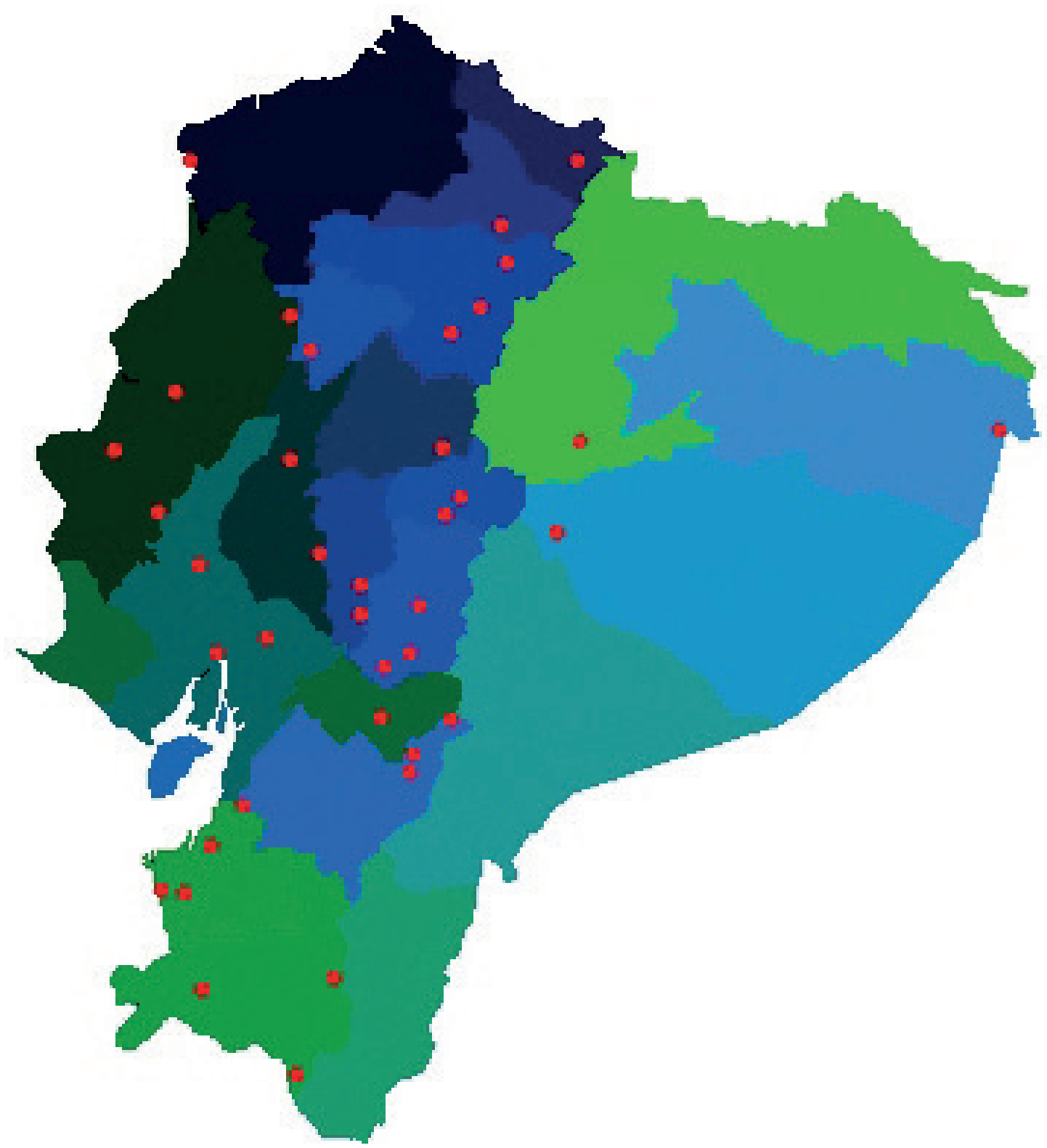

Elaboración: Autor, 2009 
Tabla 2.1

Listado de estaciones meteorológicas INAMHI - Ecuador, 2009

\begin{tabular}{|c|c|c|c|c|}
\hline Código & Nombre & Latitud & Longitud & Altitud \\
\hline M002 & La Tola & $-0,23$ & $-78,37$ & 2480 \\
\hline M003 & Izobamba & $-0,37$ & $-78,55$ & 3058 \\
\hline M004 & Rumipamba-Salcedo & $-1,02$ & $-78,59$ & 2628 \\
\hline M005 & Portoviejo-Utm & $-1,04$ & $-80,47$ & 60 \\
\hline M006 & Pichilingue & $-1,10$ & $-79,46$ & 120 \\
\hline M007 & Nuevo Rocafuerte & $-0,92$ & $-75,42$ & 205 \\
\hline M008 & Puyo & $-1,51$ & $-77,94$ & 960 \\
\hline M026 & Puerto Ila & $-0,48$ & $-79,34$ & 260 \\
\hline M031 & Cañar & $-2,55$ & $-78,94$ & 3083 \\
\hline M033 & La Argelia-Loja & $-4,04$ & $-79,20$ & 2160 \\
\hline M037 & Milagro (Ingenio Valdez) & $-2,12$ & $-79,60$ & 13 \\
\hline M050 & Arenales-Cola De San Pablo & $-2,58$ & $-78,55$ & 2200 \\
\hline M070 & Tena & $-0,98$ & $-77,81$ & 665 \\
\hline M103 & San Gabriel & 0,60 & $-77,82$ & 2860 \\
\hline M105 & Otavalo & 0,24 & $-78,26$ & 2556 \\
\hline M126 & Patate & $-1,30$ & $-78,50$ & 2360 \\
\hline M129 & Caluma & $-1,62$ & $-79,29$ & 350 \\
\hline M130 & Chillanes & $-1,98$ & $-79,06$ & 2330 \\
\hline M131 & San Pablo De Atenas & $-1,82$ & $-79,07$ & 2750 \\
\hline M134 & Guamote & $-1,93$ & $-78,72$ & 3020 \\
\hline M135 & Pachamama-Tixan & $-2,20$ & $-78,78$ & 3690 \\
\hline M136 & Chunchi & $-2,28$ & $-78,92$ & 2245 \\
\hline M138 & Paute & $-2,78$ & $-78,76$ & 2289 \\
\hline M139 & Gualaceo & $-2,88$ & $-78,78$ & 2360 \\
\hline M148 & Celica & $-4,10$ & $-79,95$ & 1984 \\
\hline M150 & Amaluza Inamhi & $-4,58$ & $-79,43$ & 1672 \\
\hline M153 & Muisne & 0,62 & $-80,02$ & 6 \\
\hline M160 & El Carmen & $-0,28$ & $-79,46$ & 250 \\
\hline
\end{tabular}


44

\begin{tabular}{|l|l|r|r|r|}
\hline M162 & Chone & $-0,71$ & $-80,11$ & 20 \\
\hline M166 & Olmedo-Manabí & $-1,40$ & $-80,21$ & 50 \\
\hline M179 & Arenillas & $-3,56$ & $-80,06$ & 60 \\
\hline M185 & Machala-Utm & $-3,05$ & $-79,73$ & 13 \\
\hline M191 & Charles Darwin Inamhi & $-0,73$ & $-90,30$ & 6 \\
\hline M192 & Bellavista-Isla S. Cruz & $-0,70$ & $-90,37$ & 194 \\
\hline M221 & San Cristóbal-Galápagos & $-0,90$ & $-89,60$ & 6 \\
\hline M250 & La Capilla Cedege & $-1,70$ & $-79,98$ & 0 \\
\hline M258 & Querochaca (Uta) & $-1,40$ & $-78,58$ & 2940 \\
\hline M292 & Granja Sta. Inés (Utm) & $-3,29$ & $-79,90$ & 5 \\
\hline M482 & Chacras & $-3,54$ & $-80,20$ & 60 \\
\hline MA2T & Tomalón-Tabacundo & 0,03 & $-78,23$ & 2790 \\
\hline MA2V & Guayaquil-Radio Sonda & $-2,20$ & $-79,88$ & 6 \\
\hline
\end{tabular}

Fuente: INAMHI, 2009. Elaboración: Autor, 2009

Figura 2.2

Ubicación de las estaciones en las Islas Galápagos

○
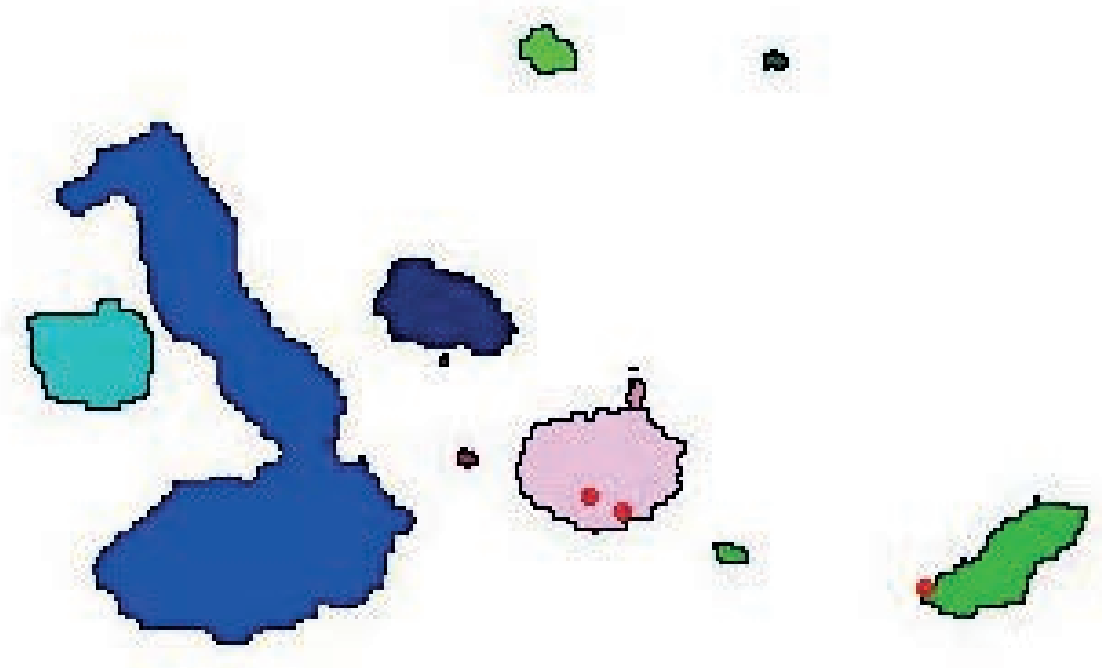

Elaboración: Autor, 2009 


\section{5}

\section{Programas informáticos}

Los programas informáticos utilizados fueron:

- Cartalinx 1997. Clark labs. University Graduate School of Geography. Worcester, MA, USA.

- $\quad$ Excel 2007. Microsoft Corporation. Redmond, WA-USA

- VBA visual basic for aplications: para automatizar procedimientos y realizar cálculos. Este lenguaje de programar está implementado bajo los programas del paquete office de Microsoft y usado en Excel.

- Idrisi for Windows 1997. Versión 2.00.000 Clark labs, the Idrisi Project. Clark University Graduate School of Geography. Worcester, MA, USA.

- Microsoft Paint versión 5.1 Copyright 2007 Microsoft Corporation.

- Corel Photo Paint тм 1998-1997. Versión 7.373. Corel Corporation. Eastman Kodak Company, Brooklyn, NY, USA.

Cabe anotar que las marcas citadas no sugieren ningún apoyo o recomendación por parte del autor, simplemente se refieren como los utilizan. 



\section{Capítulo III Métodos}

En el desarrollo del presente trabajo se utilizaron los siguientes métodos:

\section{Métodos climáticos generales}

Los ficheros de datos suministrados por el INAMHI (ver Figura 3.1.), aunque incluían la terminación "doc" eran solo de texto, por lo que se cambió la extensión a "txt”.

Figura 3.1

Ejemplo de fichero de datos INAMHI, 2009

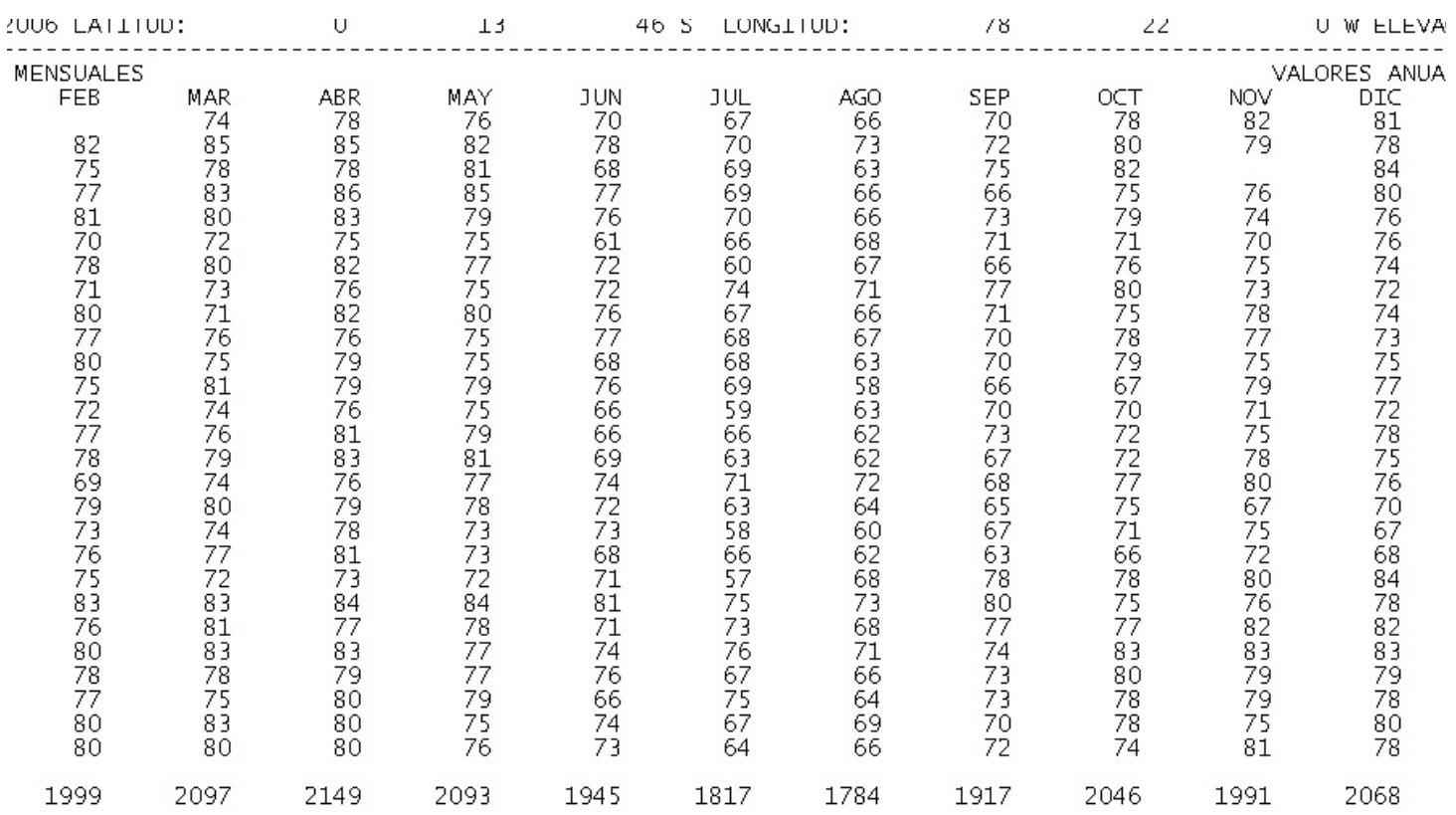

Elaboración: Autor, 2009 


\section{Figura 3.2}

Ejemplo de libro Excel creado para almacenar datos

\begin{tabular}{|l|r|r|r|r|r|r|}
\hline Nombre & Latitud & Longitud & Altitud & \\
\hline LA TOLA & -0.22944444 & -78.3666667 & 2480 & \\
\hline IZOBAMBA & -0.36666667 & -78.55 & 3058 & \\
\hline RUMIPAMBA & -1.01805556 & -78.5922222 & 2628 & \\
\hline PORTOVIEJC & -1.04055556 & -80.465 & 60 & \\
\hline PICHILINGUE & -1.1 & -79.4616667 & 120 & \\
\hline NUEVO ROC & -0.91666667 & -75.4166667 & 205 & \\
\hline PUYO & -1.5075 & -77.9438889 & 960 & \\
\hline PUERTO ILA & -0.47611111 & -79.3388889 & 260 & \\
\hline CANAR & -2.55138889 & -78.9375 & 3083 & \\
\hline LA ARGELIA & -4.03638889 & -79.2011111 & 2160 & \\
\hline MILAGRO(INI & -2.11555556 & -79.5991667 & 13 & \\
\hline ARENALES- & -2.57694444 & -78.55 & 2200 & \\
\hline TENA & -0.98472222 & -77.8138889 & 665 & \\
\hline SAN GABRIE & 0.60416667 & -77.8194444 & 2860 & \\
\hline OTAVALO & 0.23777778 & -78.2597222 & 2556 & \\
\hline PATATE & -1.30027778 & -78.5 & 2360 & \\
\hline CALUMA & -1.62 & -79.2930556 & 350 & \\
\hline CHILLANES & -1.97555556 & -79.0633333 & 2330 & \\
\hline SAN PABLO & -1.81527778 & -79.0652778 & 2750 & \\
\hline GUAMOTE & -1.93333333 & -78.7166667 & 3020 & \\
\hline PACHAMAM & -2.195 & -78.7816667 & 3690 & \\
\hline CHUNCHI & -2.27527778 & -78.9236111 & 2245 & \\
\hline PAUTE & -2.7775 & -78.7588889 & 2289 & \\
\hline GUALACEO & -2.88194444 & -78.7763889 & 2360 & \\
\hline CELICA & -4.10472222 & -79.9513889 & 1984 & \\
\hline AMALUZA IN & -4.58472222 & -79.4305556 & 1672 & \\
\hline MUISNE & 0.615 & -80.0244444 & 6 & \\
\hline EL CARMEN & -0.28083333 & -79.455 & 250 & \\
\hline CHONE & -0.705 & -80.1086111 & 20 & \\
\hline II MENOM & -139555556 & -80.2108333 & 50 & \\
\hline
\end{tabular}

Elaboración: Autor, 2009

Se programó en VBA para cargar los ficheros de datos de manera automática y se estableció el archivo librería.xls como hoja de cálculo de almacenamiento de la programación. Se cargaron datos de 41 estaciones meteorológicas con las siguientes variables y sus respectivas abreviaciones:

- Temperatura mínima:

tmin

- Temperatura media:

tmed

- Temperatura máxima:

tmax

- Temperatura media de mínimas:

tmmin 
- Temperatura media de máximas:

tmmax

- Precipitación:

$\mathrm{RR}$

- Precipitación máxima en 24 horas:

$\operatorname{rrmax}$

- Humedad relativa:

HR

- Viento:

VV

Se generó un libro Excel (ver Figura 3.2.) con la información de cada variable y hojas que correspondían a cada estación, así las listas de las estaciones procesadas: Lista TM (temperatura), Lista RR (precipitación), Lista VV (viento), Lista HR (humedad relativa) y Lista ETP (evapotranspiración). Se programó una función VBA para cargar los valores de mes y año de cada una de las estaciones (ver Figura 3.3.). Este libro sirvió de base para la construcción de posteriores libros Excel para procesar datos, recoger y representar resultados.

Figura 3.3

Ejemplo de libro Excel cargado de valores

\begin{tabular}{|c|c|c|c|c|c|}
\hline Año & Mes & Valor & Año & Mes & Valor \\
\hline 1992 & 1 & & 1993 & 4 & 80 \\
\hline 1992 & 2 & 86 & 1993 & 5 & 79 \\
\hline 1992 & 3 & 88 & 1993 & 6 & 76 \\
\hline 1992 & 4 & 86 & 1993 & 7 & 75 \\
\hline 1992 & 5 & 84 & 1993 & 8 & 72 \\
\hline 1992 & 6 & 79 & 1993 & 9 & 71 \\
\hline 1992 & 7 & 76 & 1993 & 10 & 71 \\
\hline 1992 & 8 & 77 & 1993 & 11 & 71 \\
\hline 1992 & 9 & 75 & 1993 & 12 & 70 \\
\hline 1992 & 10 & 73 & 1994 & 1 & 80 \\
\hline 1992 & 11 & 72 & 1994 & 2 & 82 \\
\hline 1992 & 12 & 66 & 1994 & 3 & 77 \\
\hline 1993 & 1 & 75 & 1994 & 4 & 81 \\
\hline 1993 & 2 & 85 & 1994 & 5 & 77 \\
\hline 1993 & 3 & 81 & 1994 & 6 & 74 \\
\hline
\end{tabular}

Elaboración: Autor, 2009 


\section{0}

Los libros Excel abiertos son:

- Datos ClimaE listas.xls

- Datos ClimaE tmed.xls

- Datos ClimaE tmin.xls

- Datos ClimaE tmax.xls

- Datos ClimaE Tmedia maximas.xls

- Datos ClimaE Tmedia minimas.xls

- Datos ClimaE lluvia.xls

- Datos ClimaE lluvia max.xls

- Datos ClimaE HR.xls

- Datos ClimaE viento.xls

- Datos ClimaE vientoD.xls

Se programó una serie de funciones para obtener medias, mínimas y máximas mensuales. Finalmente los resúmenes se ubicaron en hojas modelos sobre formatos estándar de climatología como se puede ver en el ejemplo de la Figura 3.4. de la estación MA2V (Guayaquil-radio Sonda) correspondiente a la variable temperatura.

Figura 3.4

Ejemplo de hoja modelo formato estándar para ubicar resumen de variables

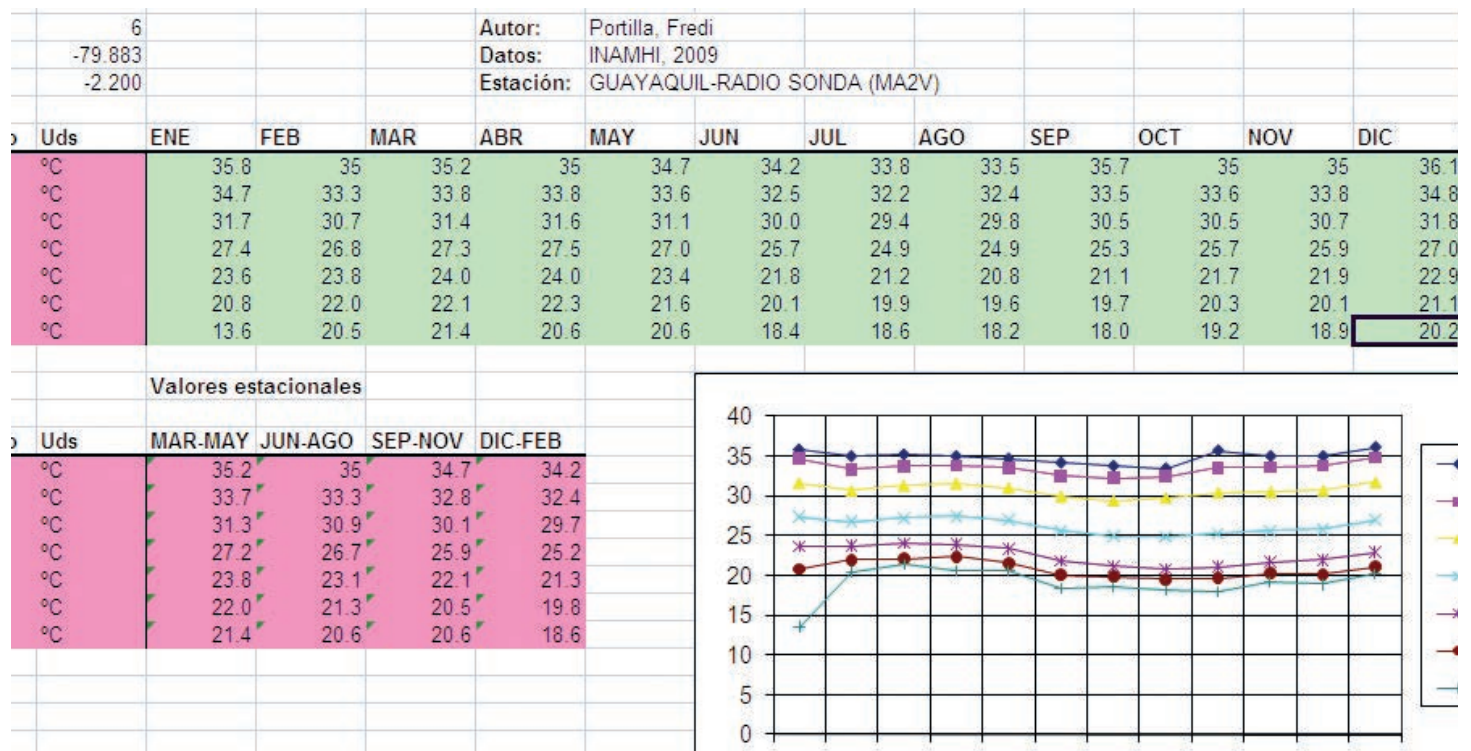

Elaboración: Autor, 2009 
51

Las diferentes hojas contienen tablas y gráficos que corresponden a cada estación y tipos de variables estudiadas. En el caso de las variables de temperatura van en una sola hoja. Todos los resúmenes de resultados se pueden consultar en el listado de Anexos Agroclimatología (1-15) ubicados al final del presente documento.

\section{Método de relleno de datos}

Analizados los resúmenes de resultados de cada una de las variables estudiadas, se encontró la dificultad de que la mayoría de estaciones tenían ausencia de datos ya sea en varios años completos o en algunos meses, por lo que fue menester programar para el relleno de datos correspondiente. Se usó una rutina que tomaba los datos de los libros base originales y generaba nuevos libros Excel con los datos rellenos. El proceso buscaba las estaciones más cercanas a la estación objetivo, calculaba los coeficientes de correlación de los datos de la estación objetivo con los de todas las demás y calculaba los datos faltantes por regresión lineal empezando por la estación de mayor coeficiente de correlación con información significativa. Los coeficientes de correlación eran considerados si se cumplían los siguientes condiciones:

- Los datos comunes eran más de cinco.

- El resultado de la correlación aporta más información que el uso de la media, evaluado por la expresión R2 > 1/n-2.

- Había datos faltantes en la estación objetivo que tenían datos en la estación considerada.

Por cada estación rellenada el programa generaba un archivo de texto informativo (ver Figura 3.5.) que reportaba el número de datos faltantes, las correlaciones de los datos con la de otras estaciones seleccionadas y el relleno correspondiente. Primero se probó rellenar o interpolar con datos de cinco estaciones cercanas, no siendo suficiente por cuanto arrojaban todavía datos faltantes; fue entonces necesario hacer con diez estaciones a la redonda, logrando así que todas las estaciones estén completamente llenas. 


\section{Figura 3.5}

\section{Ejemplo de archivo informativo generado a partir del relleno de datos}

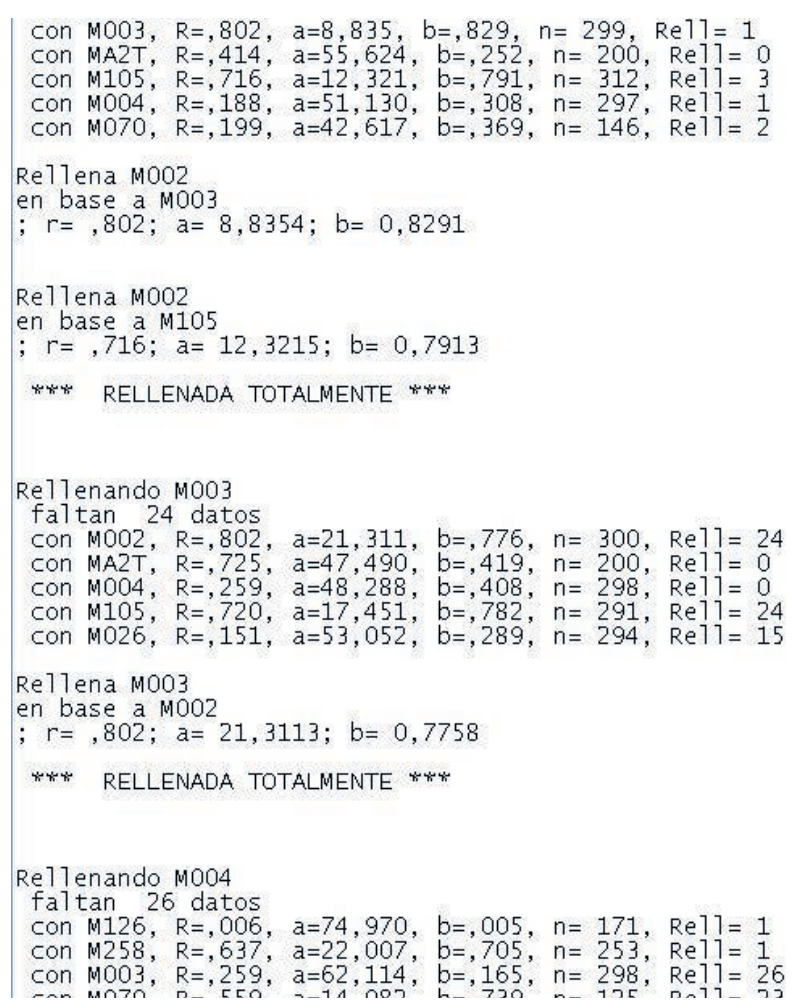

Elaboración: Autor, 2009

Figura 3.6

Ejemplo de hoja estándar con resumen de resultados de temperatura luego del rellenado de datos

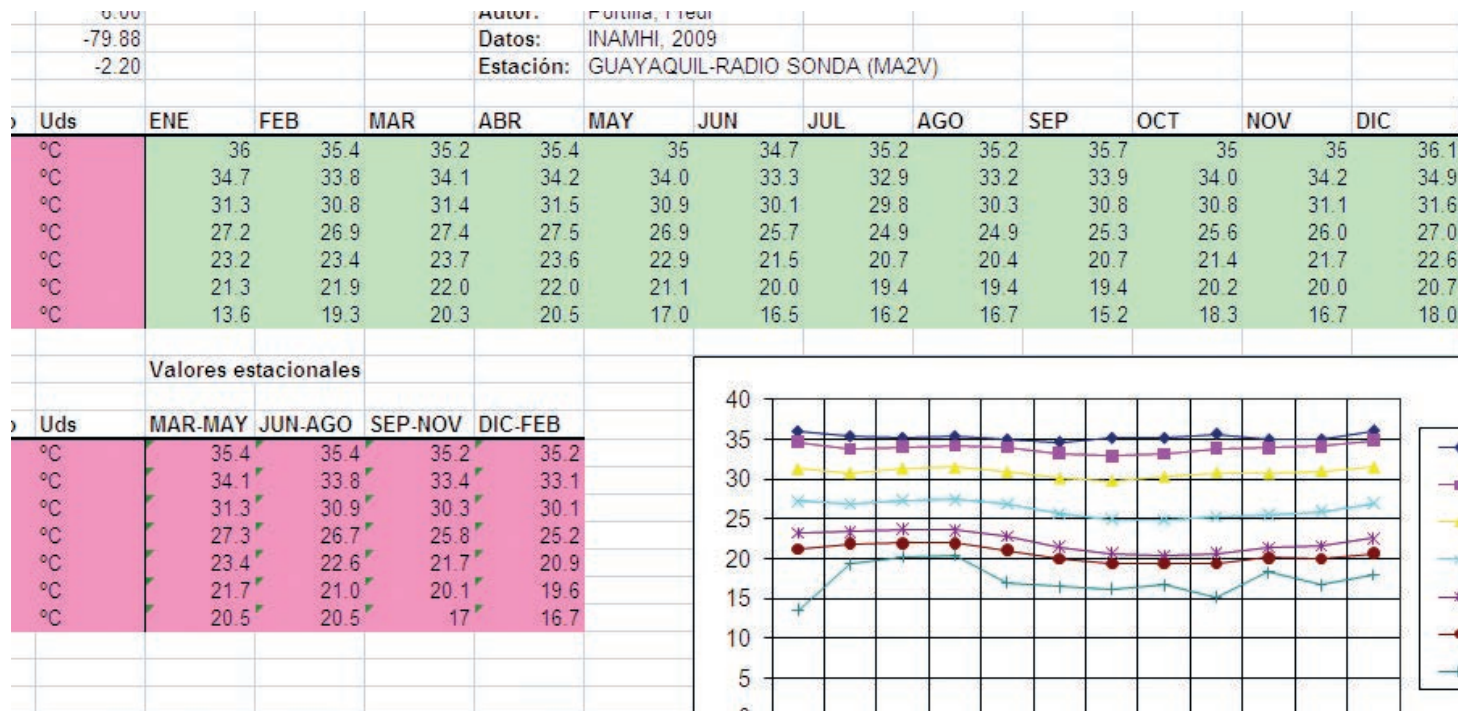

Elaboración: Autor, 2009 
Realizado el relleno de datos, nuevamente se procedió a construir los resúmenes de resultados, repitiendo los pasos ya señalados anteriormente. La Figura 3.6. corresponde a la estación MA2V (Guayaquil-Radio Sonda), del resumen de temperatura con datos rellenados.

\section{Método cartográfico}

Obtenidos los resúmenes y resultados de cada una de las variables en estudio, se procedió a programar para la generación de los mapas correspondientes. En primer lugar se generó código para recopilar automáticamente la información relativa a cada estación para los distintos parámetros que darían lugar a mapas en ficheros utilizables por el GIS de referencia, Idrisi. Después se utilizó una función Interpolación específica, y se trabajó por separado entre las estaciones de Ecuador continental que para efectos de nombrar archivos se utiliza el prefijo (e) y del Ecuador insular o Islas Galápagos con el prefijo (g). La interpolación para e fue de 20 estaciones a la redonda y para g de todas existentes que son 3.

Los parámetros de la interpolación fueron la altitud, la latitud, la longitud, las distancias, medias, mínimas y máximas de X i Y. Utilizando el programa Idrisi, se diseñaron los mapas bases: EcuMas que es la máscara, EcuaAlt mapa de altitud, Ecupro mapa de las provincias,Eculim mapa de los límites, eetphar mapa de la ubicación de las estaciones. Para el mapa de altitud se utilizó el "Clark Labs volumen tres. 1 km Global Elevation Model”. Se digitalizó con Cartalink a partir de los mapas (ver figuras 3.7, 3.8, 3.9 y 3.10).

Para interpolar el programa parte de una máscara con los límites del Ecuador, una para el continente (ver Figura 3.7.) y otra para la región insular o Islas Galápagos (ver Figura 3.8.), con el objetivo de perder tiempo en cálculos de fuera del permitido objeto de este trabajo. Estas máscaras fueron digitalizadas para esta función junto con los de las altitudes (Figura 3.9. para el Ecuador continental y Figura 3.10 para las Galápagos) y límites de las provincias (Figura 3.11. para zona continental y Figura 3.12. para las islas) con Cartalinx. 


\section{4}

Los mapas digitales de la zona continental comprendían la zona de latitud $278^{\circ} 48^{\prime}$ sur a $285^{\circ}$ norte (se usaron latitudes a partir del polo sur para evitar valores negativos) y de longitud $85^{\circ}$ oeste a $95^{\circ} 30^{\prime}$ oeste. El mapa se dividió en una rejilla de 780 filas y 744 columnas para generar las celdas o pixels del mapa. Los mapas de la zona insular comprendían la zona de latitud $267^{\circ} 30^{\prime}$ sur a $271^{\circ}$ sur y de longitud $88^{\circ} 30^{\prime}$ oeste a $92^{\circ}$ oeste.

Si existía datos en alguno de los pixeles del mapa se tomaba la media de los valores existentes y no se procedía a la interpolación. Si no existía datos de un pixel se procedía a interpolar su valor. Para ello se buscaban las 20 estaciones más cercanas (en Galápagos las tres existentes) en distancia sobre eje xy (proyección horizontal). Previamente se hicieron pruebas con cinco, diez y quince estaciones, pero la interpolación generaba un reporte de falta de datos y los mapas mostraban distorsión en la distribución de los colores. Esto se debe a que hay zonas como la región amazónica que tienen pocas estaciones y muy distantes entre ellas.

Una vez encontradas las estaciones cercanas se procedía a la interpolación de sus valores considerando como factor ponderado la inversa de la distancia al cuadrado. Aquí como distancia y para tener en cuenta el factor altitud, se consideraba la distancia en el espacio $x-y-z$ en proporción de $1 \mathrm{~km}$ en el plano xy equivalente a $100 \mathrm{~m}$ en altitud, justificado en trabajos previos realizados por el Director de este trabajo.

El mapa de altitud utilizado fue extraído de la publicación digita Clark Labs volumen 3. 1 km Global Elevation Model. Los mapas correspondientes a Galápagos tenían un problema al no contar con estaciones representativas de las zonas altas, por lo que se procedió a establecer la altitud como covariable en el proceso de interpolación; lo que supone que los valores a interpolar en cada punto se trasladaban a cero metros de altitud, se interpolan según lo visto anteriormente y se restituyen a la altitud del pixel. Para estas traslaciones y restituciones se utilizaba la correlación de la variable con la altitud para todos los puntos disponibles con datos. 
Figura 3.7

Mapa de máscara del Ecuador

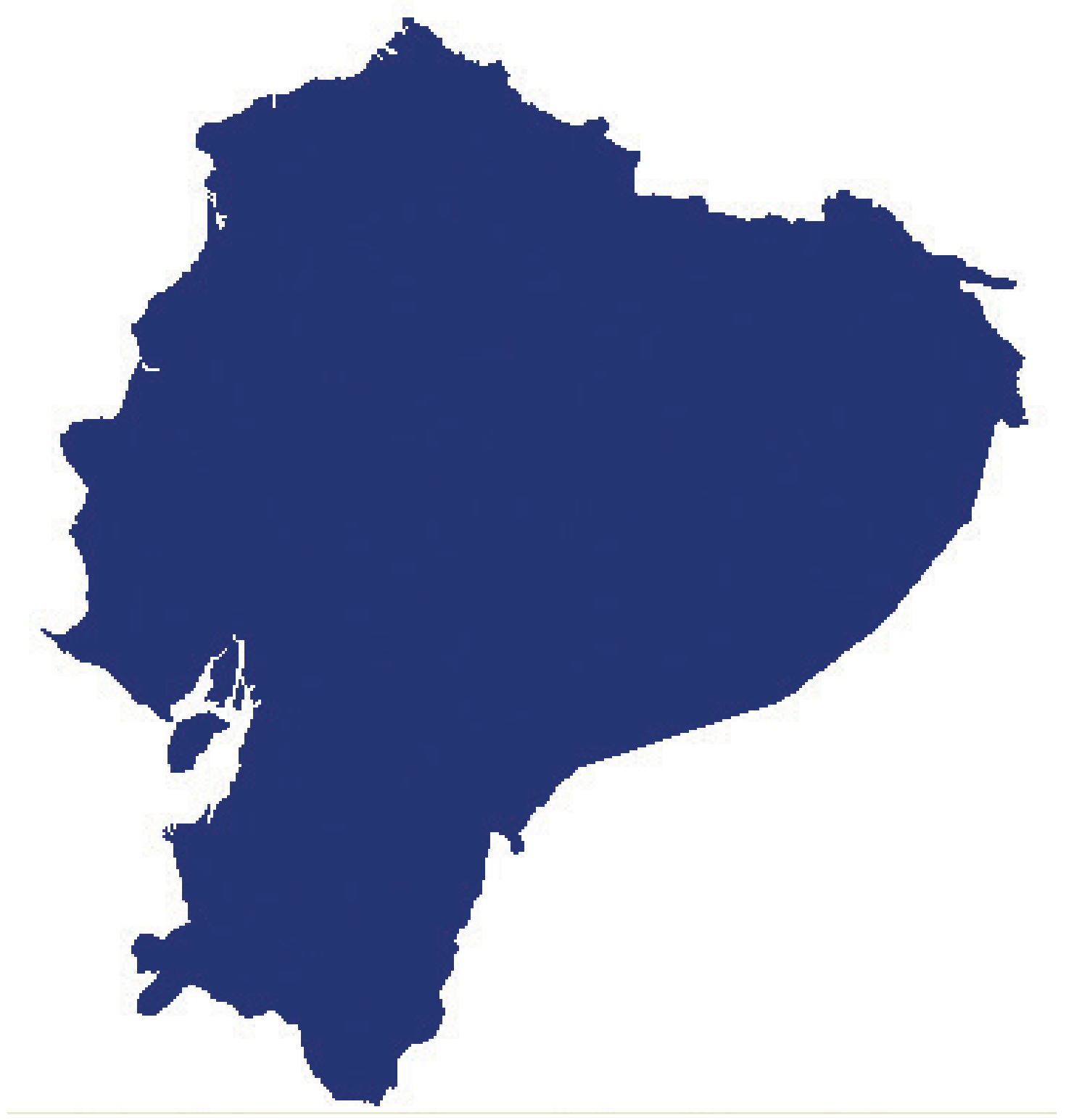

Elaboración: Autor, 2009 


\section{6}

Figura 3.8

Mapa de máscara de Galápagos

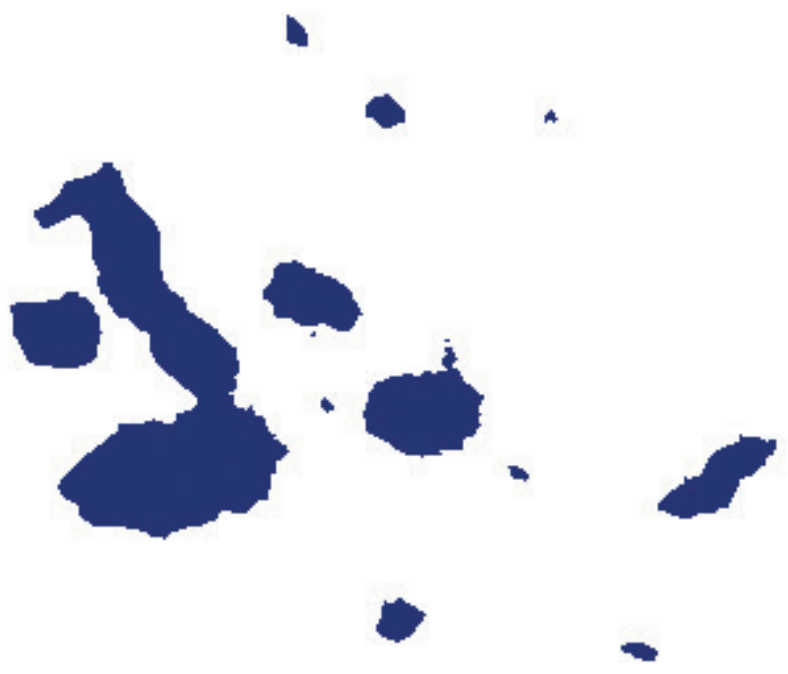

Elaboración: Autor, 2009

Figura 3.9

Mapa de altitud del Ecuador

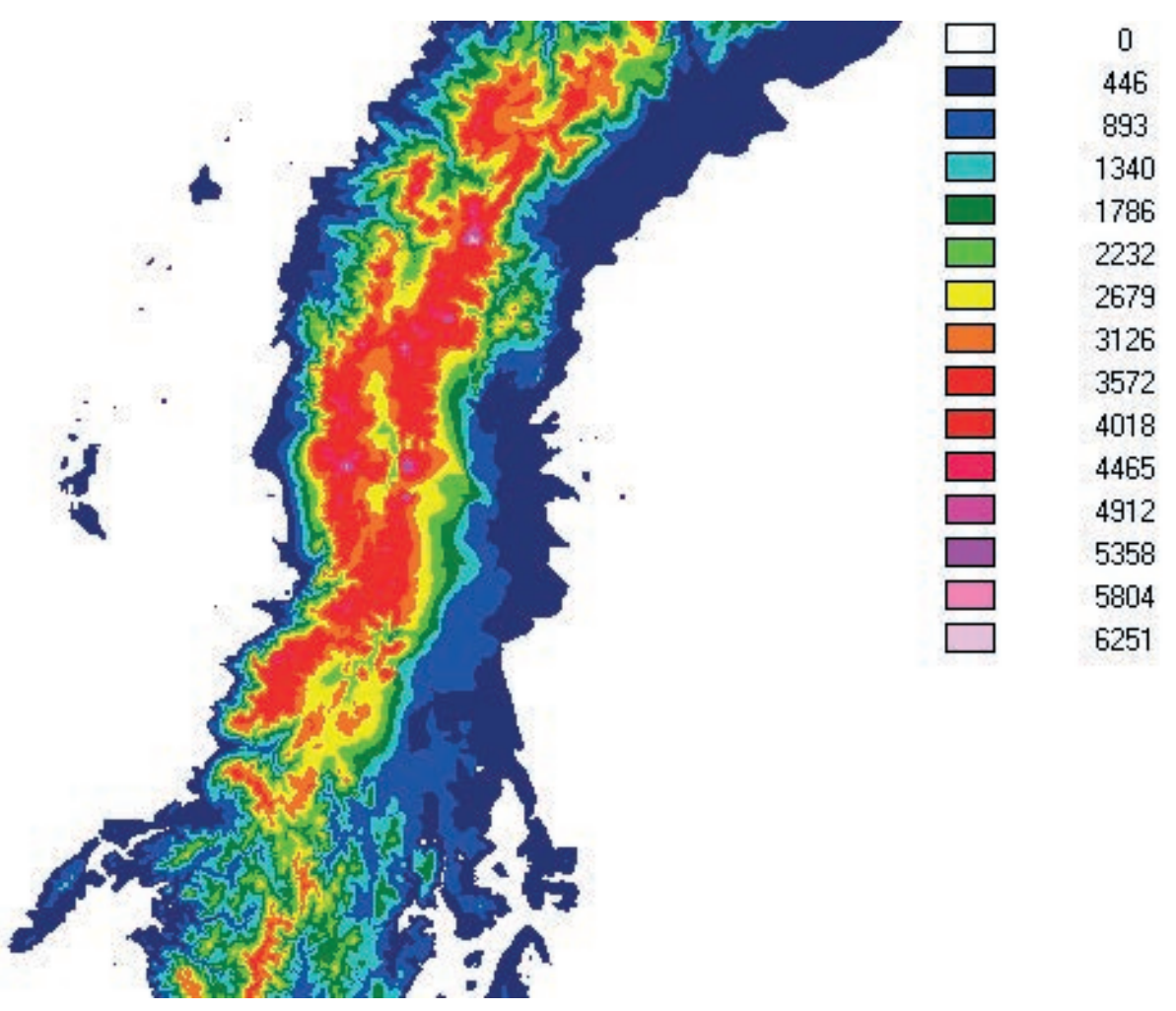

Elaboración: Autor, 2009 


\section{7}

Figura 3.10

Mapa de altitud de las Galápagos

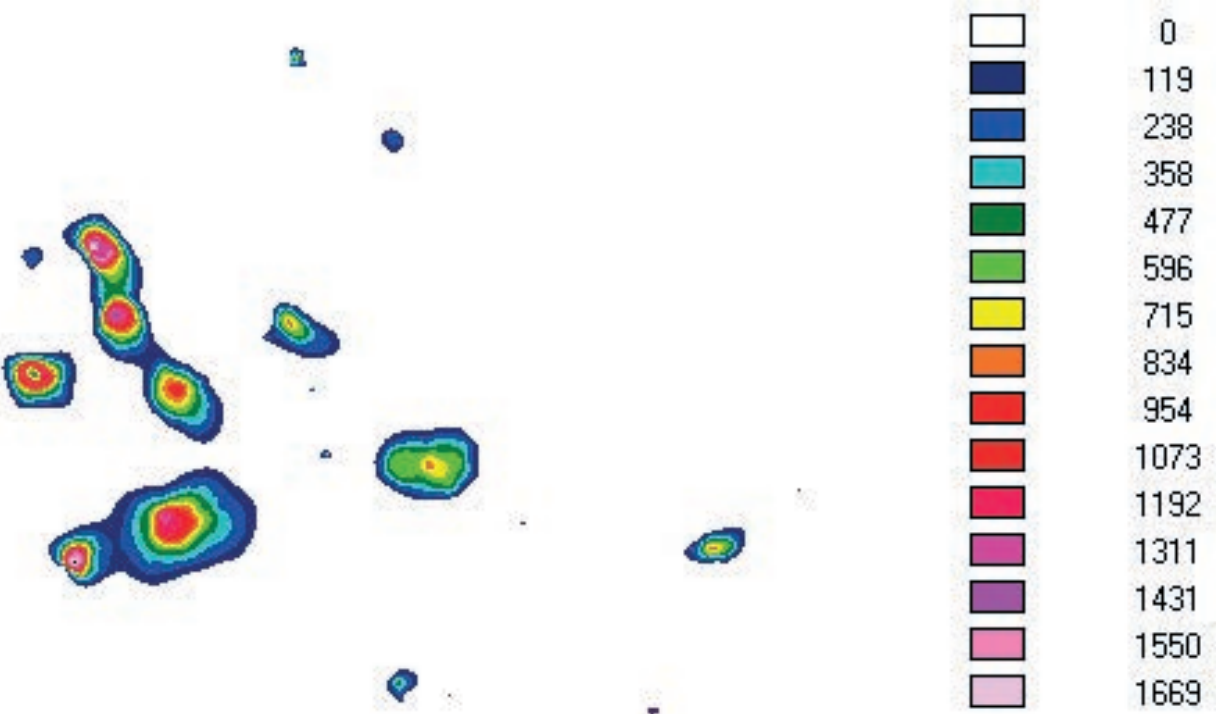

Elaboración: Autor, 2009

Figura 3.11

Mapa provincias del Ecuador

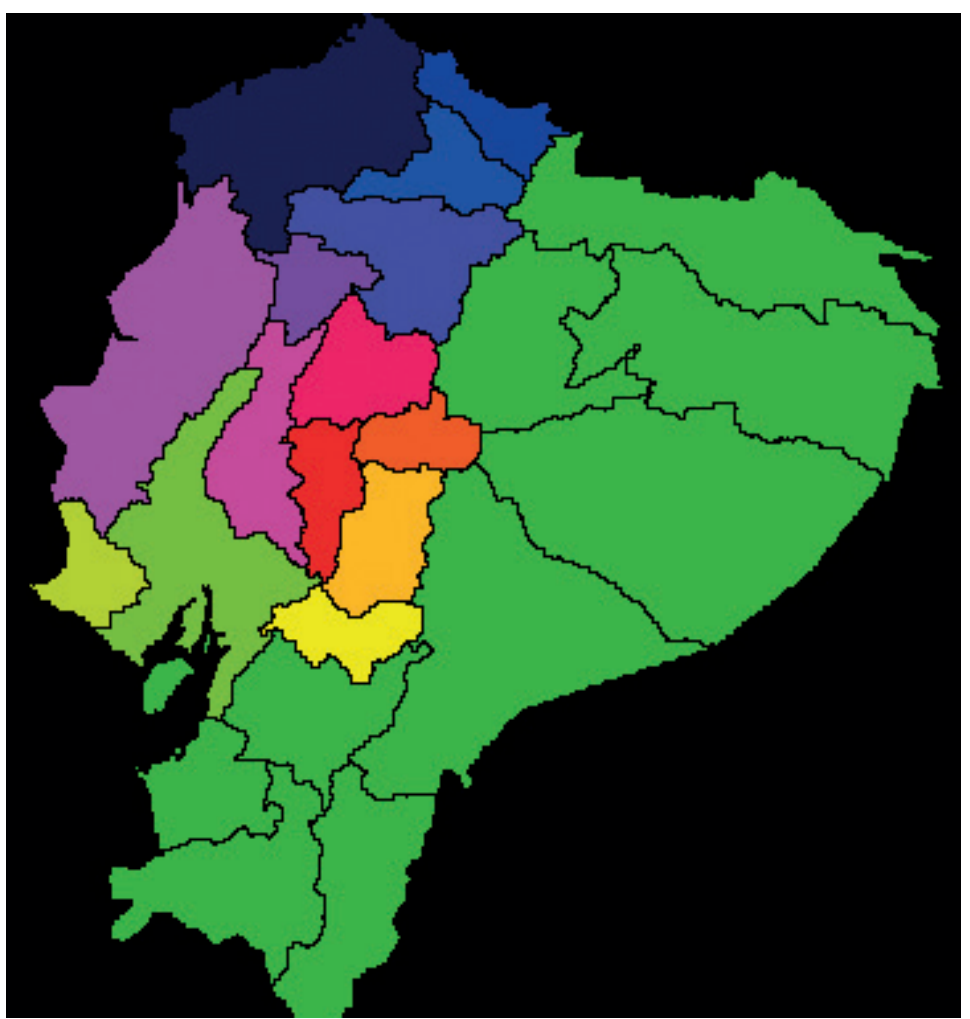

Elaboración: Autor, 2009 
Figura 3.12

Mapa de identificación de las Islas Galápagos
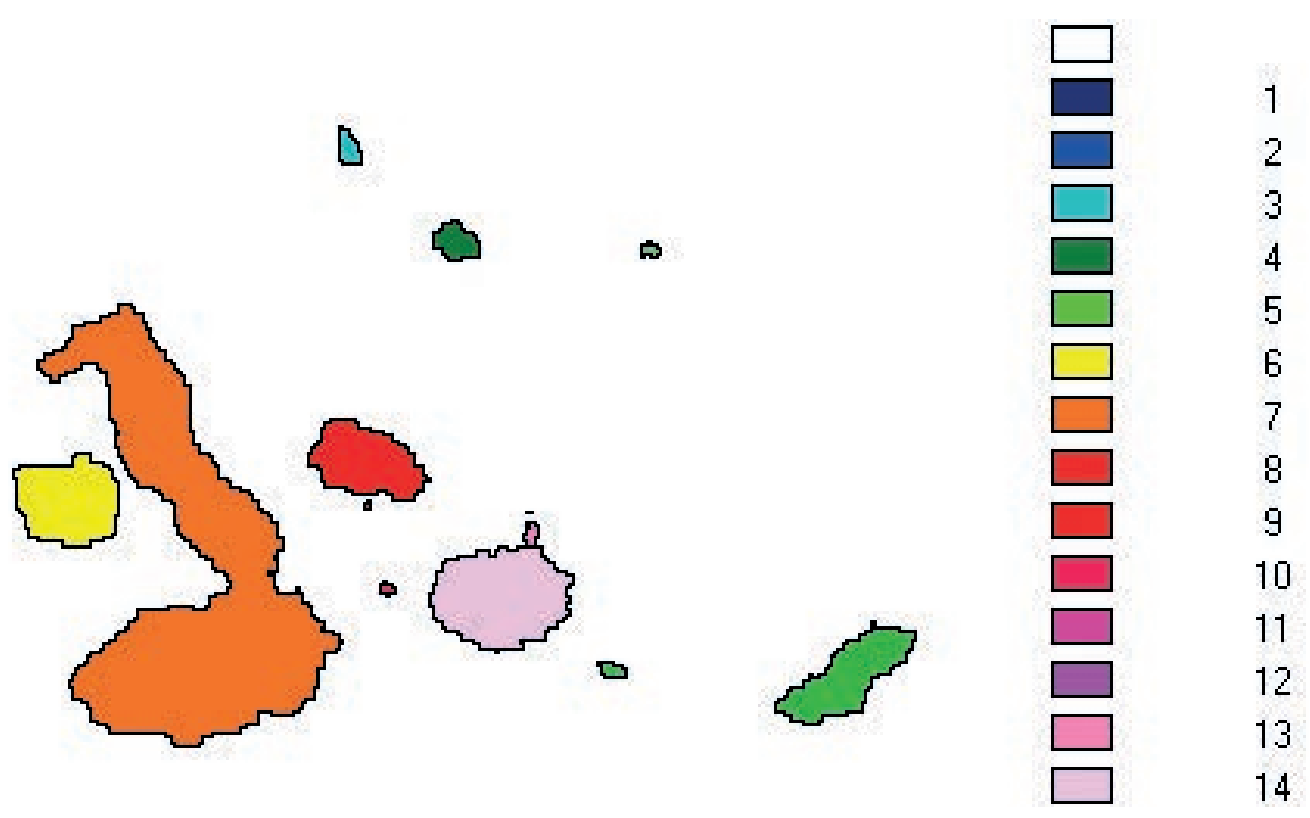

Elaboración: Autor, 2009

Figura 3.13

Mapa de ubicación de las estaciones en el Ecuador

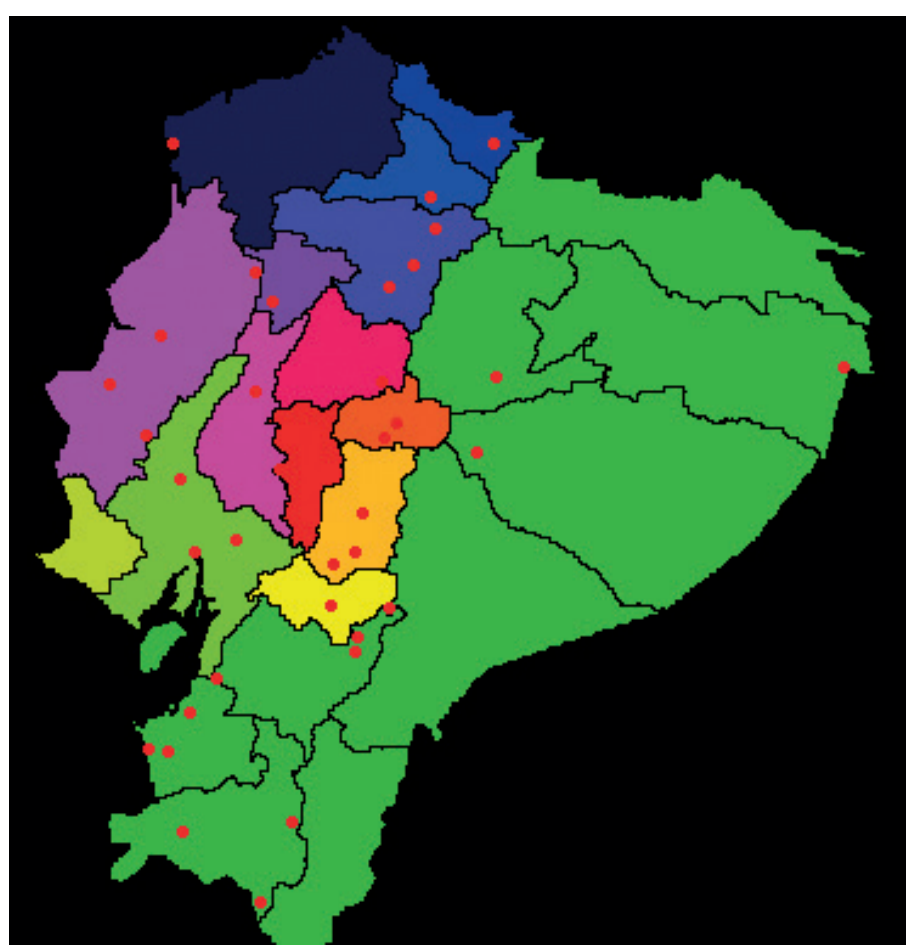

Elaboración: Autor, 2009 


\section{9}

Figura 3.14

Mapa de ubicación de estaciones en Galápagos

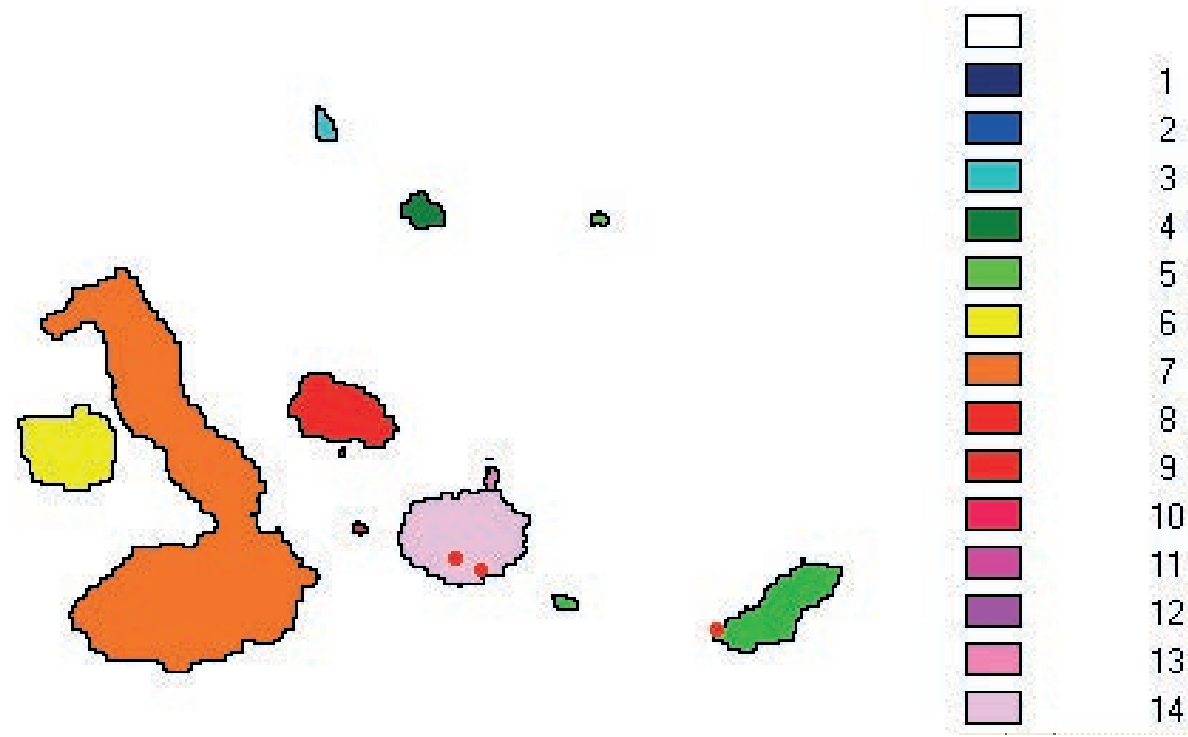

Elaboración: Autor, 2009

La generación de mapas reclasificados, en los cuales se pasa de valores reales a clases de rangos de esos valores, también se realizó con programas propios que automatizaba el proceso y en cierto modo mejoraban el disponible en Idrisi. Para hacer posible la reclasificación de forma automática se definieron las clases con los límites del valor mínimo, el valor máximo y los percentiles 10, 20, 30, 50, 70, 80, 90 y 100. Como se aprecia se ha seccionado la población de datos en bloques del 10\% excepto en la zona central de datos donde no hace falta tanta diferenciación y se han establecido saltos del 20\%. Se tienen por tanto, ocho clases sistemáticas en cada mapa más el fondo del mapa (valor 0 ) que genera un corte si hay valores positivos y negativos en el mismo mapa. Además se redondean los valores lo máximo posible a condición de que todos los valores de corte sean diferentes. El proceso realiza todos los cálculos y genera los mapas reclasificados, su fichero de documentación y leyenda, y la indicación de la paleta a usar. La paleta de colores básica utilizada va del rojo amarillo-verde-azul, o inversa según valoración subjetiva de la variable. Por ejemplo la precipitación va del rojo (menor precipitación) al azul (mayor) mientras las temperaturas van del azul (frío) a rojo (calor). 
Finalmente la visualización se realizó con el programa Idrisi (ver Figura 3.15), desde donde se pasó una copia al programa de proceso de imágenes Photo Paint para guardar en JPG y pegarlos en esta memoria

Figura 3.15

Visualización de un mapa en Idrisi

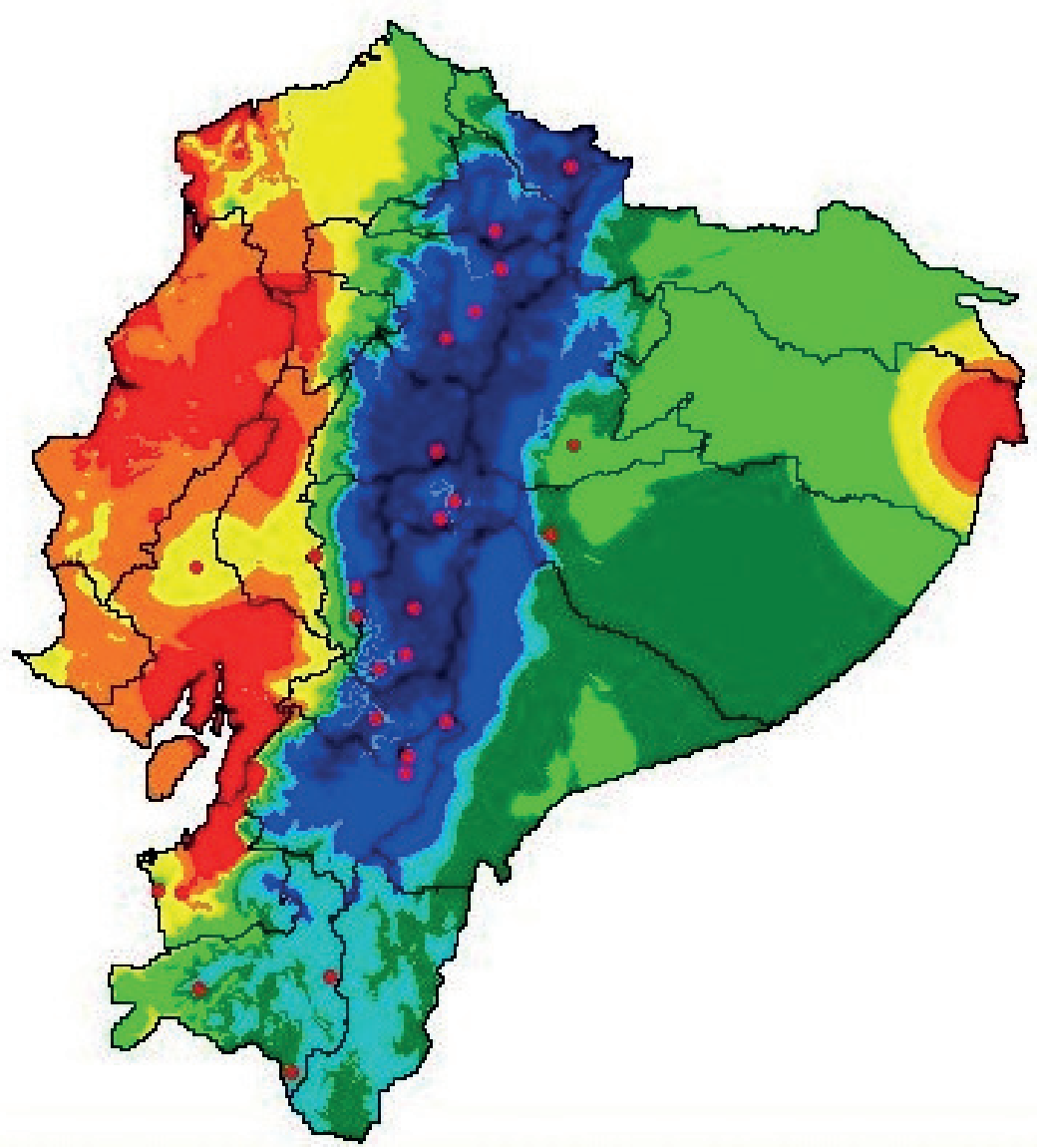

Elaboración: Autor, 2009

\section{Método de automatización}

Todos los procesos realizados fueron automatizados con VBA para poder procesar la cantidad de información y los múltiples procedimientos que incluye este trabajo. Esto implica un control de Excel, sus libros, sus hojas de datos y el contenido de todas las celdas. Sin estas automatizaciones hubiera sido imposible avanzar en un tiempo razonable por lo que destacamos en este apartado. 


\section{Capítulo IV \\ Resultados y discusión}

Las variables estudiadas en este trabajo fueron:

La temperatura en grados centígrados $\left({ }^{\circ} \mathrm{C}\right)$ : mínima absoluta, media de mínimas, media, máxima absoluta y media de máximas anuales. Igualmente por su relevancia para considerar algunas cuestiones estacionales se estudia la temperatura media anual de mayo y de agosto.

La precipitación o lluvia en mm: la media anual, la mediana, la media anual de mayo y agosto, los percentiles 20 y 80, la lluvia máxima en un periodo de 24 horas (media anual, mediana, media de mayo, media de agosto, percentil 20 y percentil 80, periodos de retorno en 10 y 100 años).

La humedad relativa en \%: media anual, media de mayo y de agosto.

La velocidad y dirección del viento: media de mayo, media de agosto; frecuencias norte, norte-este, este, sur, sur-este, sur-oeste, oeste y norte-oeste.

La evapotranspiración: calculadas de acuerdo a las fórmulas de Thornthwaite y Hargreaves.

\section{Análisis de la temperatura}

La temperatura como uno de los ejes centrales en la determinación del clima, no es una excepción en el caso de la geografía ecuatoriana, cuyo relieve accidentado de la parte central o andina con 
elevadas montañas de nieves permanentes domina las llanuras de la verde amazonia y del litoral. Como se desprenderá del análisis comparativo de los registros sistematizados del INAMHI, la temperatura en el Ecuador es diferente de acuerdo a la geografía, así las temperaturas altas propias de un clima tropical están en la costa y amazonia, y las temperaturas templadas y frías en la sierra o región andina.

Capítulo aparte es el estudio de la temperatura de la región insular, cuyo origen volcánico presenta un relieve accidentado que sumado al encuentro de las corrientes submarinas de Humboldt (fría) y del Niño (caliente), modifican la temperatura de las Galápagos, que como se analizará más adelante presenta un clima propio de ésta región del planeta.

\section{Tablas y gráficos}

Los datos INAMHI, fueron procesados de acuerdo a lo ya especificado en el apartado de la metodología. Los resultados se pueden apreciar en los anexos respectivos (Anexo 1: Resumen de la temperatura con relleno de datos: tablas y gráficos). Cada una de las estaciones muestran tablas donde están los datos de Ta temperatura máxima absoluta, T'a (tmmax) temperatura media de máximas, $\mathrm{T}$ (tmax) temperatura máxima, tm (tmed) temperatura media, $\mathrm{t}(\mathrm{tmin})$ temperatura mínima, $\mathrm{t}^{\prime} \mathrm{a}(\mathrm{tmmin})$ temperatura media de mínimas y ta temperatura mínima absoluta. Cada tabla muestra la realidad década zona donde está ubicada la estación, así las temperaturas más altas se encuentran en las regiones del litoral y amazonía, mientras que las más bajas están en la región andina o sierra.

Una segunda tabla para cada estación meteorológica, muestra una caracterización para una subdivisión de cuatro periodos en el año, unos valores estacionales para: marzo-mayo (periodo invernal intenso), junio-agosto (verano intenso), septiembre-noviembre (invierno leve) y diciembre-febrero (veranillo del niño). Igualmente la realidad que muestra cada estación es el reflejo de la zona de su influencia, pues la región amazónica muestra una uniformidad en temperaturas dentro de su invierno regular a lo largo del año, la región costa una dife- 


\section{3}

rencia marcada en los meses del invierno con temperaturas elevadas y de verano con temperaturas bajas; la sierra con valores distantes entre el invierno y el verano pero con un registro de temperaturas absolutas tanto mínimas como máximas registradas en los meses de junio a agosto, que es el verano. La región insular mantiene una casi uniformidad en temperatura durante todo el año.

Los gráficos de cada una de las estaciones, muestran con claridad la variación de las temperaturas, y la equidistancia entre los valores calculados de la temperatura media de máximas y media de mínimas con la temperatura media, así como su distanciamiento o alejamiento de las temperaturas máximas y mínimas. Las líneas que marcan las temperaturas máximas absolutas y las mínimas absolutas, muestran los cambios bruscos de temperatura que existe en el Ecuador.

El Gráfico 4.1 muestra la relación entre la temperatura y la altitud, así a mayor altura menor temperatura y viceversa, concordando con lo manifestado en apartado 1.3.1 de los factores del clima. Este gráfico muestra la ubicación de la zona costera, amazonia e insular a nivel del mar con temperaturas entre $24^{\circ} \mathrm{C}$ y $27^{\circ} \mathrm{C}$, mientras que zonas de la región andina entre los $2000 \mathrm{~m}$ y $3000 \mathrm{~m}$ tienen un rango de temperaturas entre los $11^{\circ} \mathrm{C}$ y $17^{\circ} \mathrm{C}$.

\section{Gráfico 4.1}

Relación entre la altitud $(\mathrm{m})$ y la temperatura media anual $\left({ }^{\circ} \mathrm{C}\right)$

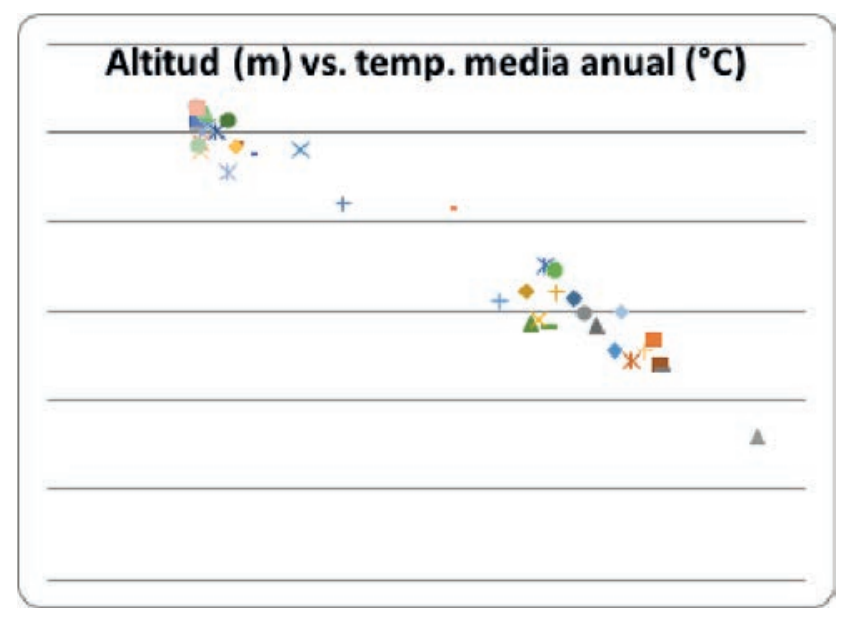

Elaboración: Autor, 2009 
64

\section{Cartografía}

Se debe recordar, que la base de datos utilizado en los mapas corresponde al periodo 1980-2006. Así mismo, los colores utilizados van desde el azul intenso indicativo de la temperatura más baja hasta el rojo para las temperaturas más altas, correspondiendo los puntos de corte a los percentiles $0,10,20,30,50,70,80,90$ y 100 .

Figura 4.1

Temperatura media anual - Ecuador

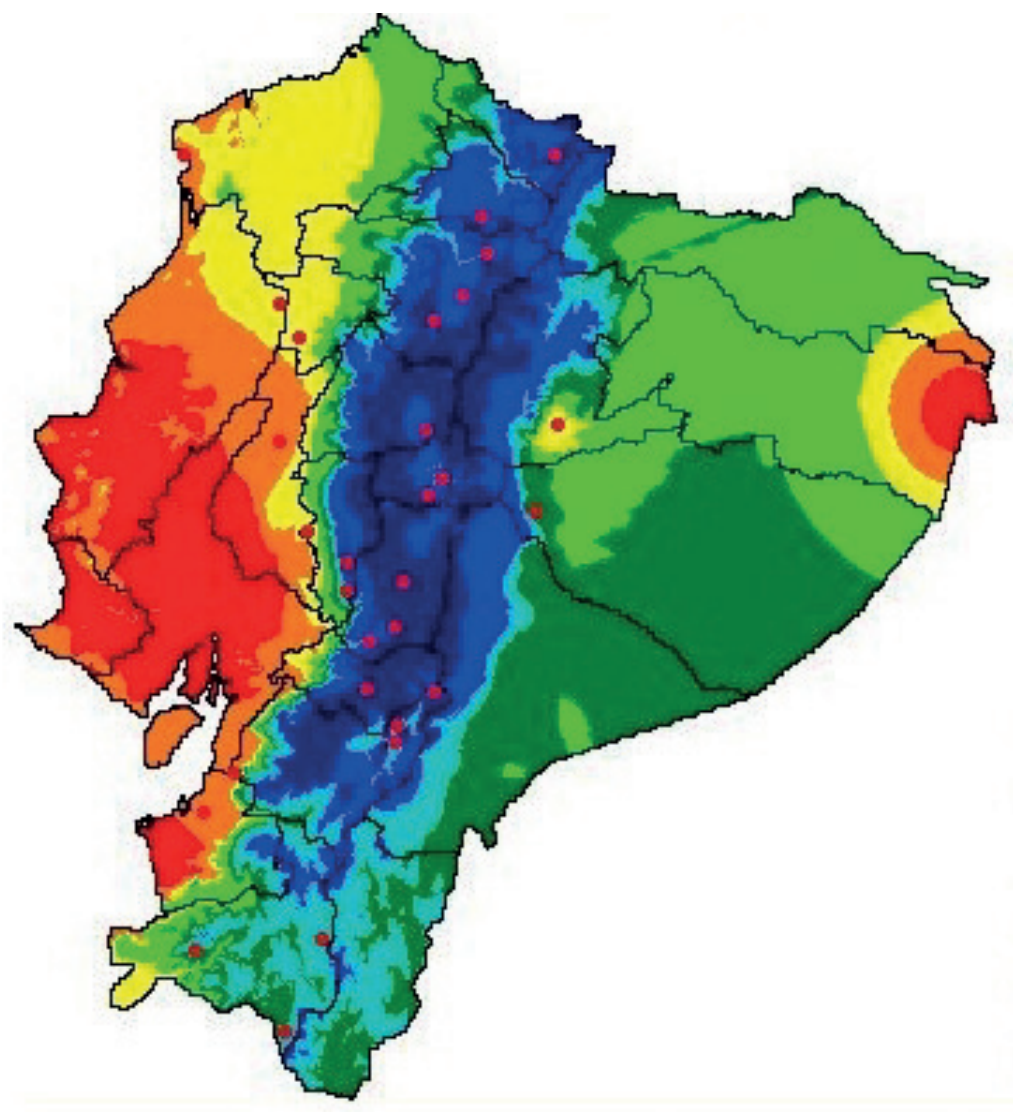

Elaboración: Autor, 2009

\section{TEMPERATURA DEL ECUADOR CONTINENTAL}

Para el análisis de la temperatura en el Ecuador continental (periodo 1980-2006), se debe recordar que la altitud tiene su relevancia en las tres regiones naturales. La temperatura media anual en la Sierra (15 ${ }^{\circ} \mathrm{C}$ ) está muy distante de la media anual presentes en la Costa y Orien- 
te $\left(25^{\circ} \mathrm{C}\right)$ y esto se debe a la influencia de la cordilleras Occidental y Oriental de Los Andes (ver gráficos de Anexo 1). En el mismo orden y a mayor distancia comparativa se ubican las máximas y mínimas absolutas, así en la Sierra se aproximan al cero absoluto o menos como el caso de la estación 135 (Pachamama-Tixán), mientras que en la Costa y Oriente descienden por debajo de $10{ }^{\circ} \mathrm{C}$ como el ejemplo de la estación 008 (Puyo); igual el caso de las máximas absolutas que en la Sierra alcanzan los $30^{\circ} \mathrm{C}$ (estación 03-Cañar) y en la Costa sobrepasan los $38^{\circ} \mathrm{C}$ (estación 005-Portoviejo). Las temperaturas media de máximas y media de mínimas mantienen su equidistancia de la media anual, como lo demuestran los gráficos del anexo 1.

En cuanto a la temperatura media anual (Figura 4.1) la influencia de la altitud de la cordillera de los Andes, cuyos picos nevados permanentes modifican el clima ecuatorial, se muestra en el mapa ocupando la franja central de norte a sur y en un rango de temperatura media anual entre $7.8^{\circ} \mathrm{C}$ y $13.7^{\circ} \mathrm{C}$ (percentil 0-10). Esta temperatura modifica el clima de la parte central andina ecuatoriana. La siguiente clase o categoría que comprende de 13.7 a $15.7^{\circ} \mathrm{C}$ (percentil 10-20), corresponde a un clima frío-templado, propio de las ciudades y campos de las hoyas interandinas, y de las estribaciones de las cordilleras oriental y occidental. El clima templado, predomina en el austro ecuatoriano y las bases de las cordilleras, cuya categoría o clase comprende de 15.7 a $18.7^{\circ} \mathrm{C}$ (percentil 20-30). La categoría $18.7-21.5^{\circ} \mathrm{C}$ (percentil $30-50$ ), indica la zona subtropical propia de la amazonia sur ecuatoriana, mientras que la categoría 21.5-23. $7^{\circ} \mathrm{C}$ (percentil 50-70) denota la zona tropical del norte de la amazonia, así como de la franja costera tropical húmeda de la base de la cordillera occidental de norte a sur (provincias de Esmeraldas, Manabí, Los Ríos, Santo Domingo, Bolívar, Loja y El Oro). La categoría comprendida entre 23.7 y $24.5^{\circ} \mathrm{C}$ (percentil $70-80$ ), denota la zona tropical de la zona norte oeste (provincia de Manabí, Esmeraldas, Santo Domingo y Los Ríos), así también muestra una franja en la zona norte oriental de la amazonia (provincias de Orellana y Sucumbíos), y un nicho en la amazonia central (provincia del Napo). 


\section{6}

Los percentiles 90 (80-90) y 100 (90-100), abarcan las zonas tropicales del Ecuador, que comprenden la costa centro occidental (provincias de Manabí, Santa Elena, Guayas y parte de El Oro), así como una franja de la zona del extremo oriental de la amazonia (provincias de Sucumbíos y Orellana).

Figura 4.2

Temperatura media de mínimas anual-Ecuador

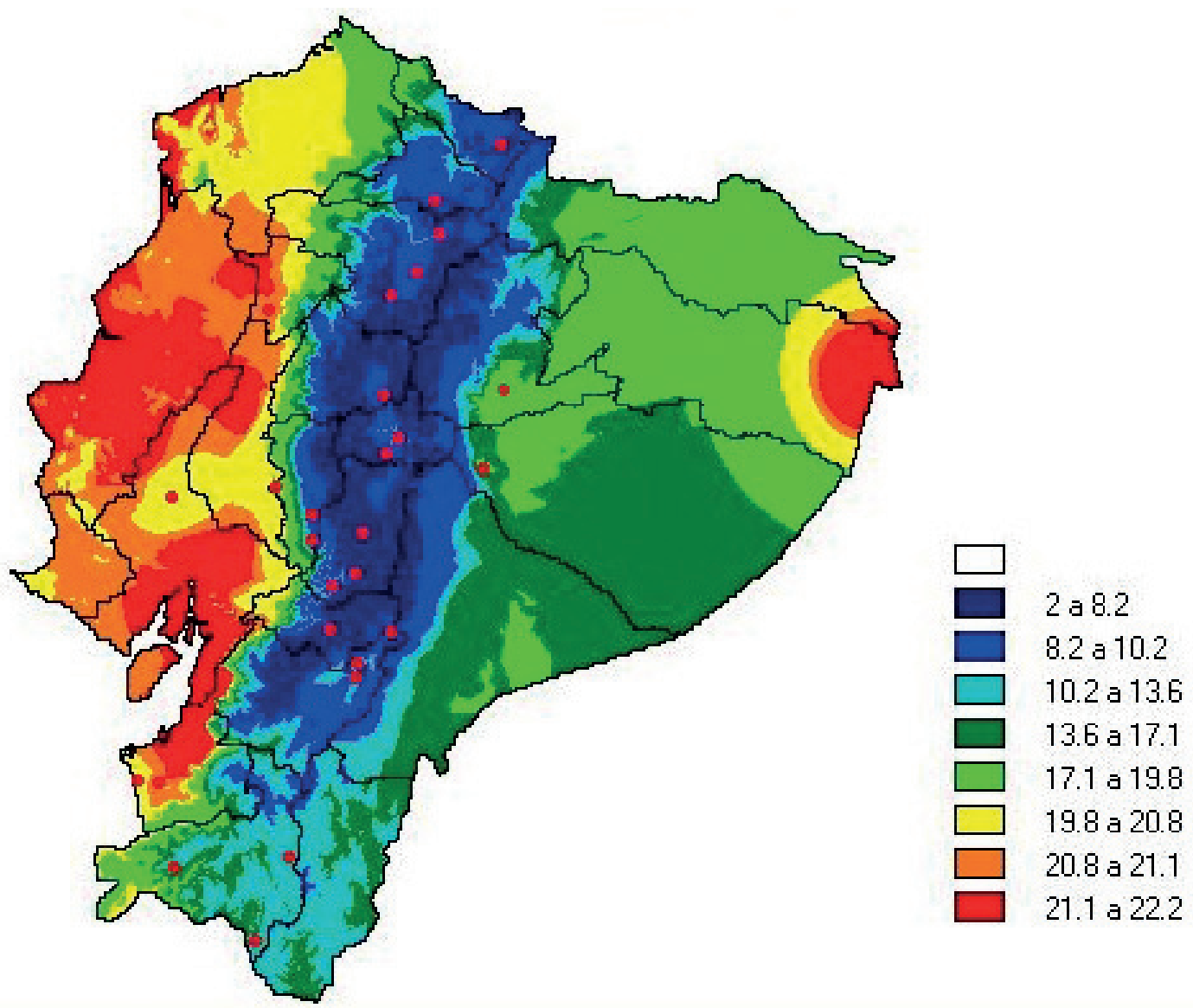

Elaboración: Autor, 2009

La temperatura media de mínimas anual (ver Figura 4.2), cuyas categorías o clases sufren un descenso en sus valores de hasta $5{ }^{\circ} \mathrm{C}$ con respecto a la temperatura media anual. La ubicación de las categorías es muy similar entre los dos mapas, destacándose que el percentil 7080 , se ubica en la zona central costera interior (cuenca del río Guayas) con mayor intensidad en los meses de julio y agosto, meses fríos para la región Litoral. Por ejemplo la estación MA2V Guayaquil- Radio Son- 
67

da ubicada a $6 \mathrm{~m}$ sobre el nivel del mar, presenta una temperatura de media de mínimas de $19.4^{\circ} \mathrm{C}$ en julio y agosto; y en la región sierra, la estación M139 Gualaceo ubicada a 2360 m reporta una media de mínimas para agosto de $5.2{ }^{\circ} \mathrm{C}$, considerado mes caluroso durante el día y frío durante la noche (ver tablas y gráficos del Anexo 1).

\section{Figura 4.3}

Temperatura media mínima absoluta anual-Ecuador
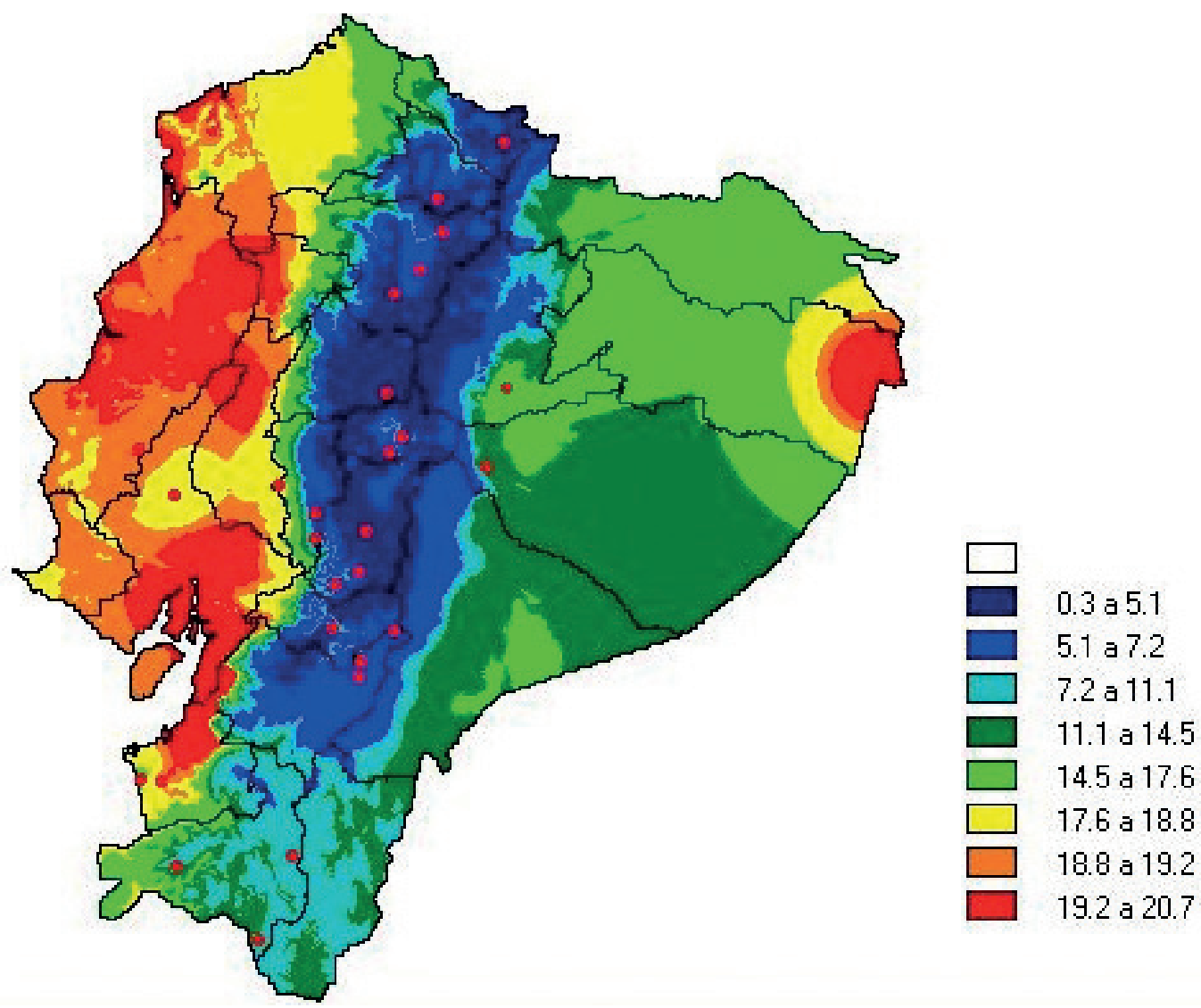

Elaboración: Autor, 2009

El mapa de la figura 4.3 denota la ubicación de las temperaturas media de mínimas absolutas registradas en el Ecuador. Nuevamente coincidiendo con el mapa anterior (Figura 4.2.), pero con un descenso de temperatura de unos $2{ }^{\circ} \mathrm{C}$, la distribución se mantiene en todo el territorio continental. Igualmente se mantiene el efecto de descenso en la zona central costera interior (cuenca del río Guayas). Las temperaturas mínimas absolutas registradas entre los años 1980 
y 2006, muestran que en la zona andina se registraron temperaturas bajo ${ }^{\circ} \mathrm{C}$, como es el caso de la estación M131 San Pablo de Atenas ubicada a $2750 \mathrm{~m}$ que en los meses desde mayo hasta septiembre reportó temperaturas mínimas absolutas de $-4.5^{\circ} \mathrm{C},-3.5^{\circ} \mathrm{C},-2.5^{\circ} \mathrm{C}$, $-3.5^{\circ} \mathrm{C}$ y $-3.5^{\circ} \mathrm{C}$, respectivamente (ver Anexo 1). Estas temperaturas se distancian de los valores de la temperatura media, sin embargo la distribución geográfica es bastante similar a la temperatura media anual (ver Figura 4.1).

\section{Figura 4.4}

Temperatura media de máximas anual - Ecuador

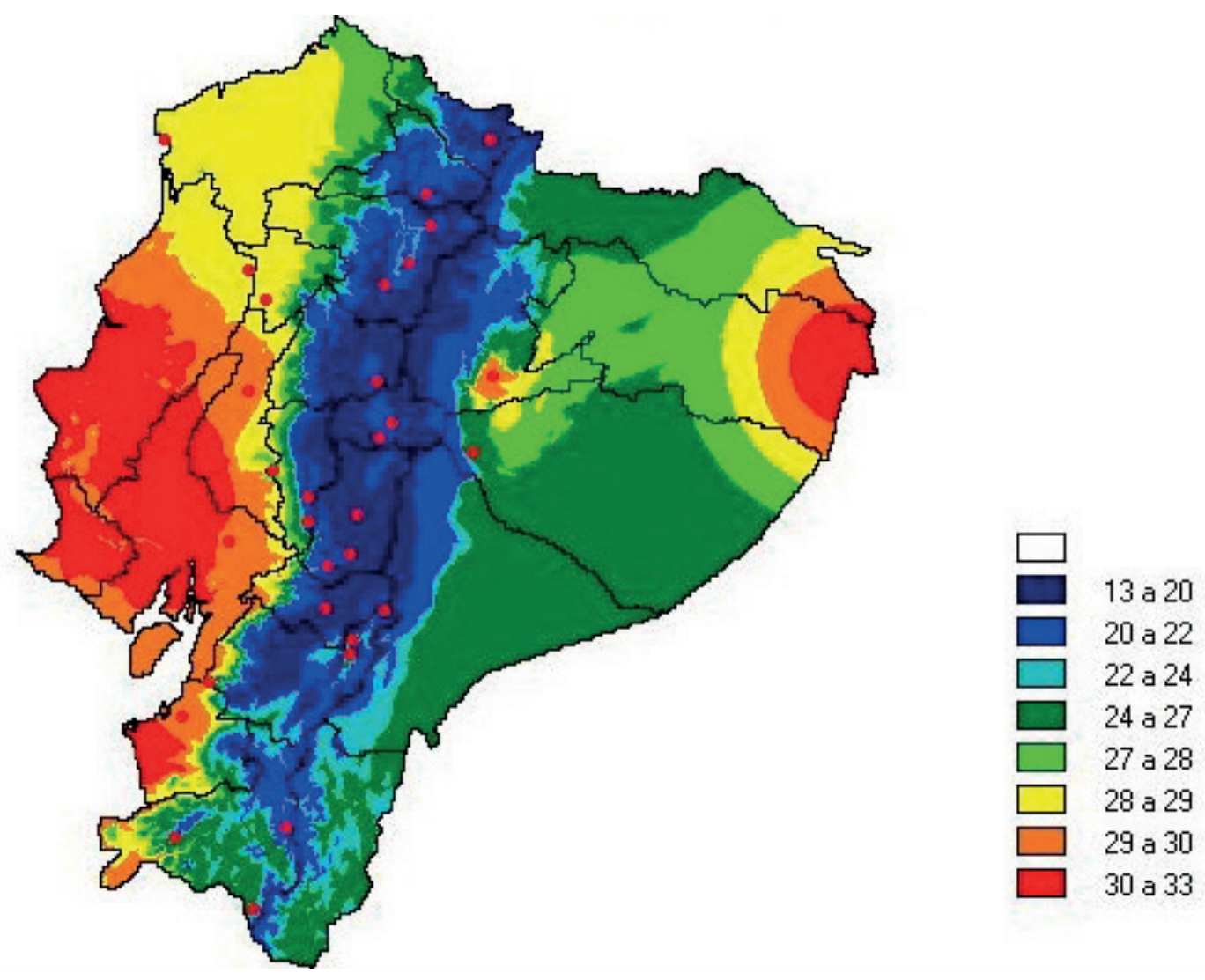

Elaboración: Autor, 2009

Las categorías o clases en cuanto a valores son unos $5{ }^{\circ} \mathrm{C}$ más altos que las clases de la Figura 4.1. (temperatura media anual) y la distribución geográfica es bastante similar, destacando que las temperaturas más altas de $30^{\circ} \mathrm{C}$ a $33^{\circ} \mathrm{C}$ (percentil 90-100) se ubican en 
la zona costera centro sur y en el extremo oriental de la Amazonía. Así por ejemplo la estación M292 Granja Santa Inés (UTM) ubicada a $5 \mathrm{~m}$ sobre el nivel del mar, registra para el mes de abril la temperatura media de máximas de $33.2^{\circ} \mathrm{C}$, mientras que la estación M136 Chunchi ubicada a $2245 \mathrm{~m}$ y para el mismo mes, reporta $21.4{ }^{\circ} \mathrm{C}$ (ver anexo 1).

\section{Figura 4.5}

Temperatura media máxima absoluta anual - Ecuador

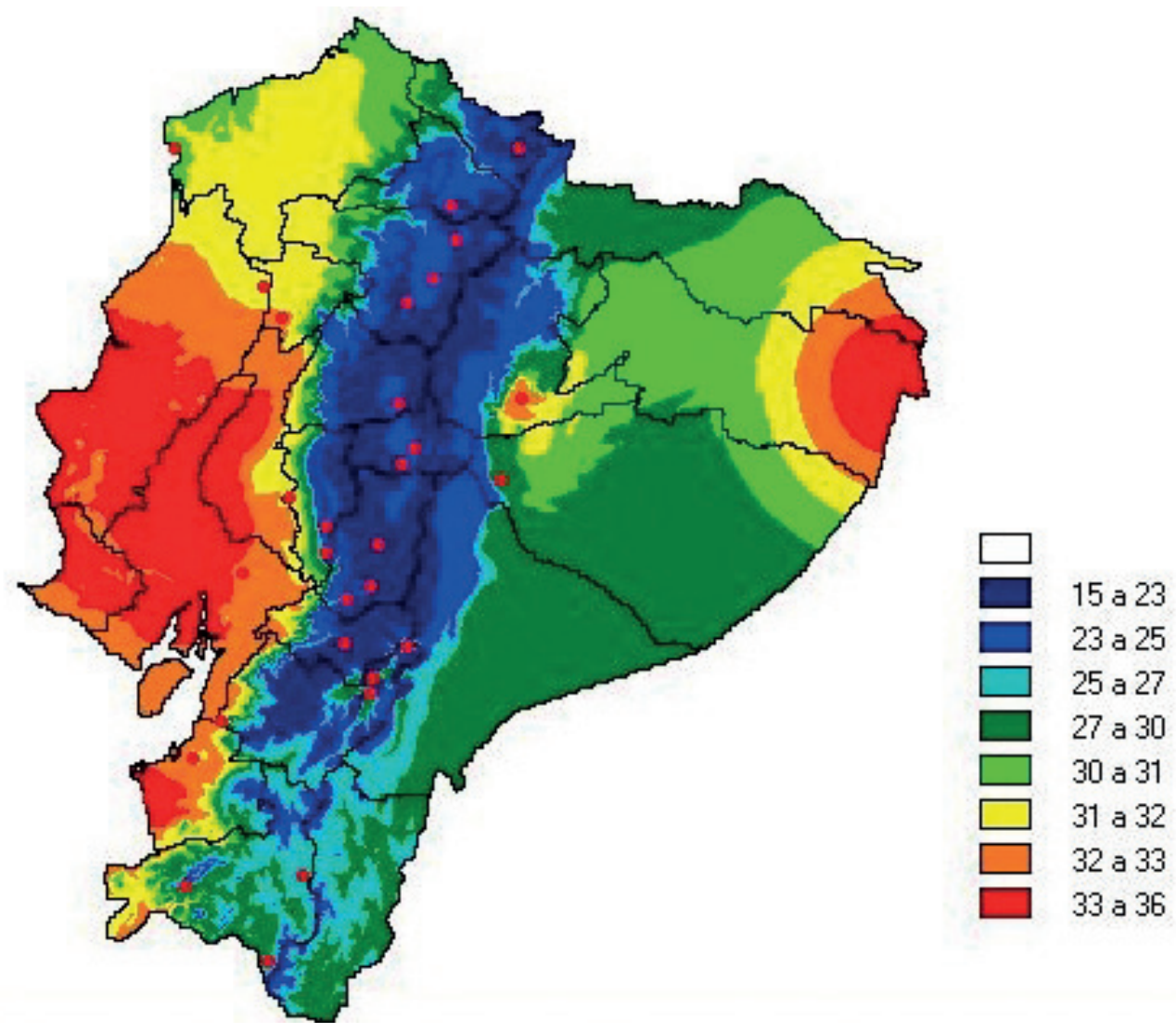

Elaboración: Autor, 2009

La temperaturas medias de máximas absolutas (Figura 4.5) presentan $3{ }^{\circ} \mathrm{C}$ más altos que la temperatura media de máximas (Figura 4.4.) y $8{ }^{\circ} \mathrm{C}$ respecto a la temperatura media anual (Figura 4.1), sin embargo la distribución geográfica se mantiene, salvo el caso de la zona costera extremo norte occidental (provincia de Esmeraldas), donde reporta un enfriamiento con valores entre los $30{ }^{\circ} \mathrm{C}$ a $31{ }^{\circ} \mathrm{C}$ 
(percentil 50-70). Por ejemplo la estación MA2V Guayaquil ubicada a 6 metros sobre el nivel del mar reporta un promedio anual de máximas absolutas de $36,1^{\circ} \mathrm{C}$, mientras que la estación M103 San Gabriel ubicada a $2860 \mathrm{~m}$ reporta un promedio anual de temperaturas máximas absolutas de $26.2^{\circ} \mathrm{C}$ (ver Anexo 1).

Pasamos a fijarnos ahora en los valores estacionales que se pueden consultar en su totalidad en el Anexo 1. Aquí nos centraremos fundamentalmente y dada la continuidad relativa a lo largo del año de la temperatura, en la cartografía de los meses de mayo y agosto.

Figura 4.6

Temperatura media de mayo - Ecuador
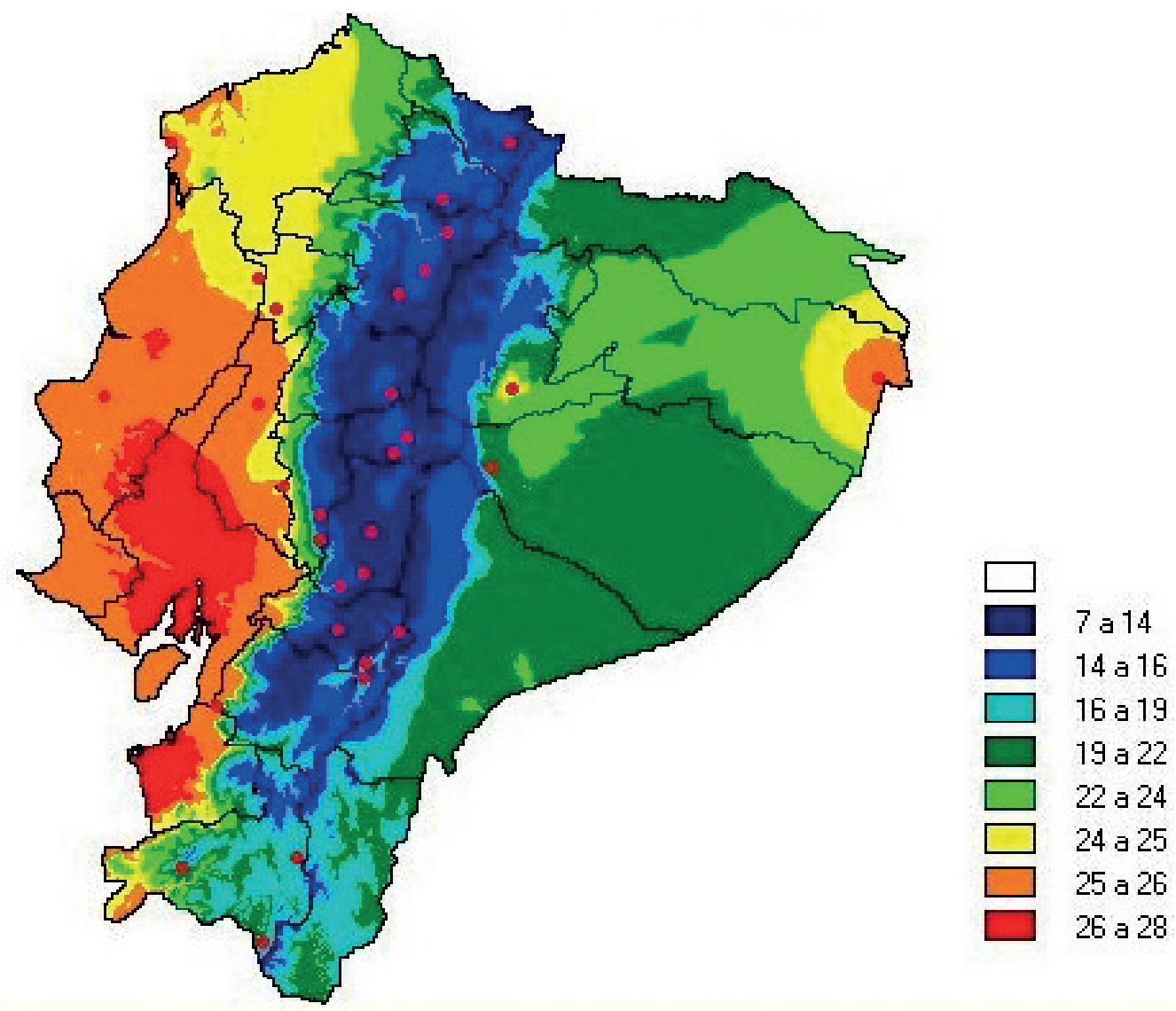

Elaboración: Autor, 2009

Mayo es el mes del invierno dominante en todo el Ecuador, así en la sierra la temperatura más baja es de $7^{\circ} \mathrm{C}$ (percentil 0-10), en el oriente es de $19^{\circ} \mathrm{C}$ (percentil 30-50) y en la costa de $26^{\circ} \mathrm{C}$ (percentil 
90-100). Existe entre $0.5^{\circ} \mathrm{C}$ y $1^{\circ} \mathrm{C}$ diferencia entre la temperatura media de mayo (Figura 4.6) y la temperatura media anual (Figura 4.1); siendo esta diferencia menor en los percentiles bajos $(0-10)$ con $7^{\circ} \mathrm{C} \mathrm{a}$ $14{ }^{\circ} \mathrm{C}$, y una diferencia mayor en los percentiles (90-100) que reporta temperaturas entre $26^{\circ} \mathrm{C}$ y $28^{\circ} \mathrm{C}$. La distribución cartográfica es muy similar en los dos mapas (Figuras 4.1 y 4.6). Como ejemplo de la diferencia citaremos a la estación M037 Milagro ubicada a 13 metros sobre el nivel del mar, reporta una temperatura media de $26.2^{\circ} \mathrm{C}$ en mayo y de $25.5^{\circ} \mathrm{C}$ de temperatura media anual (ver anexo 1 ).

Figura 4.7

Temperatura media de agosto - Ecuador

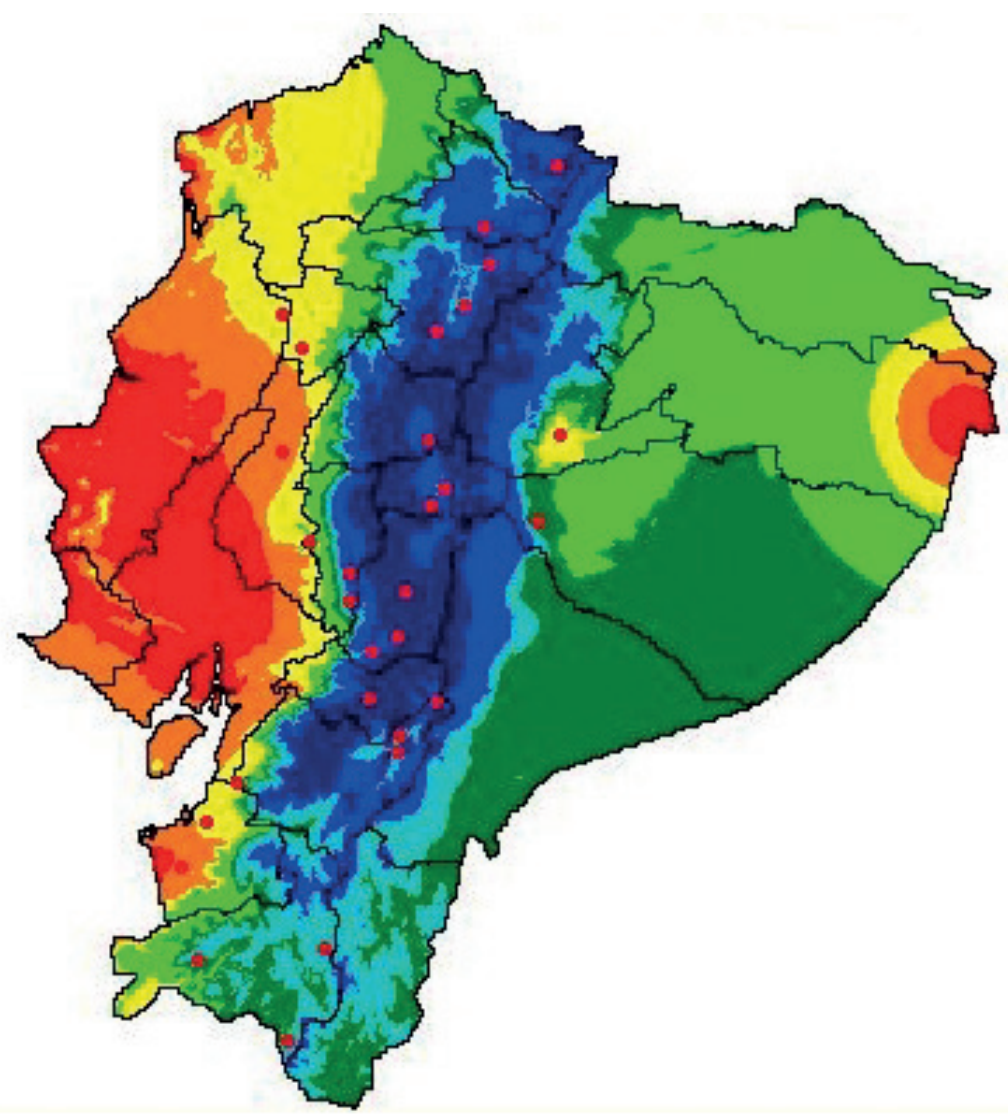

7.7 a 13.1

13.1 a 15

15 a 18.2

18.2 a 20.6

20.6 a 22.8

22.8 a 23.5

23.5 a 24.1

24.1 a 25.4

Elaboración: Autor, 2009

Agosto es el mes referente del verano en el Ecuador (Figura 4.7), cuyas temperaturas medias son más bajas que la temperatura media anual (Figura 4.1 ) en $0.5^{\circ} \mathrm{C}$ a $1{ }^{\circ} \mathrm{C}$; y, $2^{\circ} \mathrm{C}$ más bajo los per- 
centiles $90-100$ y $1{ }^{\circ} \mathrm{C}$ más bajo los percentiles $0-10$,que los de la temperatura media de mayo (Figura 4.6). La distribución geográfica es muy similar entre los tres mapas (figuras) ya citados.

Cabe indicar que la región amazónica aunque es la más extensa en territorio es la que menos estaciones meteorológicas dispone, y las que existen al momento no satisface para el análisis de datos. Esto se refleja en la interpolación de estaciones más cercanas realizada y cuyos resultados graficados y dibujados en los respectivos mapas del Ecuador continental presentan distribución de la temperatura un tanto atípica para esta región. Por ejemplo la distribución de la temperatura media anual en la zona norte oriental (ver Figura 4.1).

En síntesis los resultados de temperatura del Ecuador continental de una manera general concuerdan con lo expuesto por el investigador Schwerdtfeger (1976) quien destaca la variación de temperatura una zona geográfica pequeña donde la altitud es un factor determinante. La diferenciación de climas expuesta por Neill y Jorgensen (2009) de las tres regiones naturales reafirma lo dicho que la altitud es un factor regulador del elemento temperatura, así mientras más alta es la meseta andina, mayor cantidad de frío existe y viceversa. Así las ciudades ubicadas en la meseta andina, propenden a mantener una temperatura primaveral durante todo el año, mientras que las ciudades de la costa y oriente mantienen temperaturas propias del trópico (ver Gráfico 4.1).

\section{Temperatura del Ecuador insular o GaláPagos}

El Ecuador insular o Islas Galápagos, presenta un cuadro diferente al Ecuador continental, aunque un tanto parecido al de la región Litoral en cuanto a temperaturas. Esta cuarta región natural del Ecuador, no posee elevaciones tan altas como la meseta andina, sin embargo no dejan de tener influencia las montañas y volcanes existentes como reguladores del clima. Sin embargo, son las corrientes marinas fría de Humboldt y la cálida del Niño, las que regulan la temperatura de las islas, concordando así con lo expuesto por el 
INAMHI (ver 1.3.1 factores del clima). En la discusión de nuestros resultados ha de tenerse en cuenta que las estaciones disponibles son solo tres y todas ellas por debajo de los $194 \mathrm{~m}$ de altitud y que en la generación de los mapas se ha forzado una correlación con la altitud. Del análisis de las tablas y cuadros del anexo 1 (Resumen de temperaturas), las tres estaciones existentes en las islas, presentan una temperatura uniforme a lo largo de todo el año $\left(24^{\circ} \mathrm{C}\right)$, siendo las máximas cercanas a los $30^{\circ} \mathrm{C}$ (estación 221- San Cristóbal), y las mínimas no bajan de los $16^{\circ} \mathrm{C}$ (estación 192- Bellavista). En forma general se concuerda con lo expuesto por Neill (2009) que aunque los valores son diferentes pero no distantes, esto conlleva a la clasificación climática de zona tropical seca (ver 1.3.3. climas).

\section{Figura 4.8}

Temperatura media anual - Galápagos

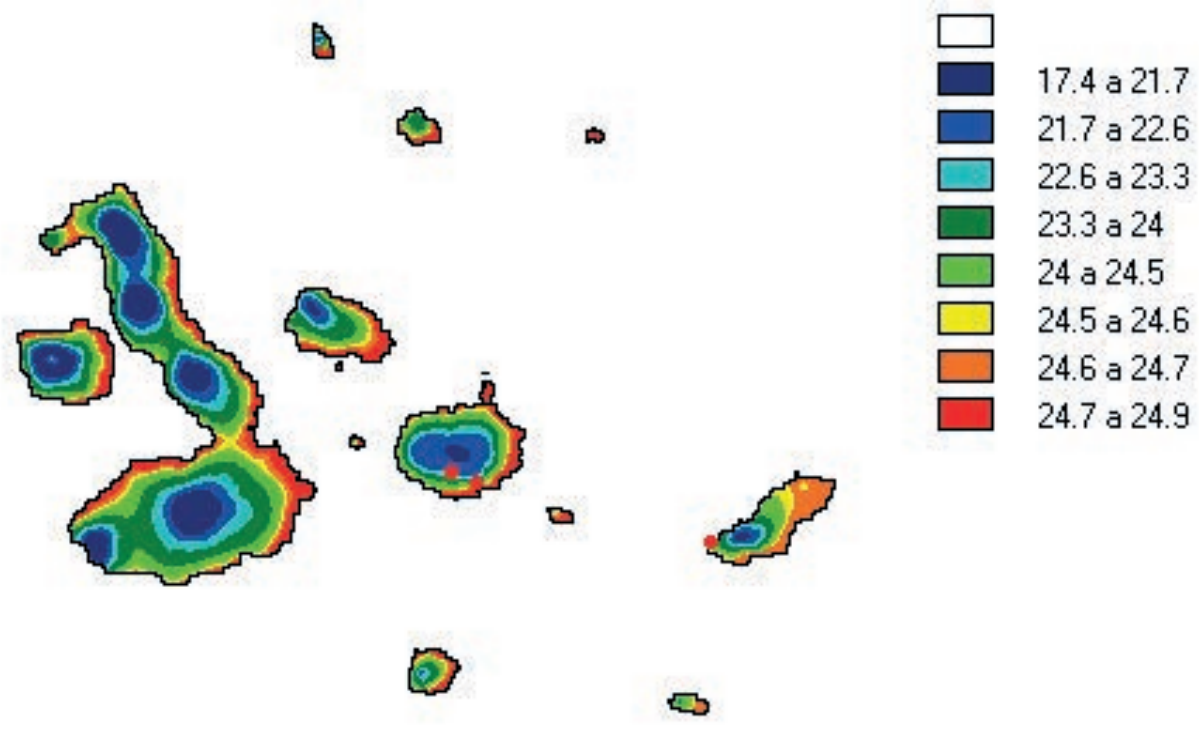

Elaboración: Autor, 2009

La temperatura media anual de las islas Galápagos (Figura 4.8.) es diferente a lo largo del año aunque no distantes como es el caso de la estación M191 Charles Darwin ubicada a $6 \mathrm{~m}$ de altitud cuyas medias mensuales de diciembre a mayo alcanzan los $26^{\circ} \mathrm{C}$ y de junio a noviembre los $23^{\circ} \mathrm{C}$, es decir $3{ }^{\circ} \mathrm{C}$ de diferencia. Igualmente tiene rango de 7 grados entre el percentil $0-10\left(17^{\circ} \mathrm{C}\right)$ de la zona de 
los volcanes y el percentil $90-100\left(24^{\circ} \mathrm{C}\right)$ de la zona costera, denotando de esta manera que la temperatura es templada-cálida. En igual forma se reporta la temperatura de las dos estaciones M192 y M221 (ver Anexo 1).

Comparando con la temperatura media de la región continental (Figura 4.1), se tiene que la temperatura media de Galápagos es inferior en $1{ }^{\circ} \mathrm{C}$ al percentil más alto $90-100\left(25.2^{\circ} \mathrm{C}-26.5^{\circ} \mathrm{C}\right)$ que se ubica en la zona costera central y sur, y superior con $10^{\circ} \mathrm{C}$ al percentil más bajo $0-10\left(7.8^{\circ} \mathrm{C}-13.7^{\circ} \mathrm{C}\right)$ que se ubica en la zona andina central y norte. $\mathrm{Al}$ igual sucede en el territorio continental, el percentil más bajo (0-10) cubre las cúspides de las montañas isleñas, y conforme se desciende, los otros percentiles en orden sucesivo van cubriendo el territorio insular hasta llegar al percentil mayor (90100) que cubre las playas costeras de las islas Galápagos (Figura 4.8).

Figura 4.9

Temperatura media de mínimas anual - Galápagos

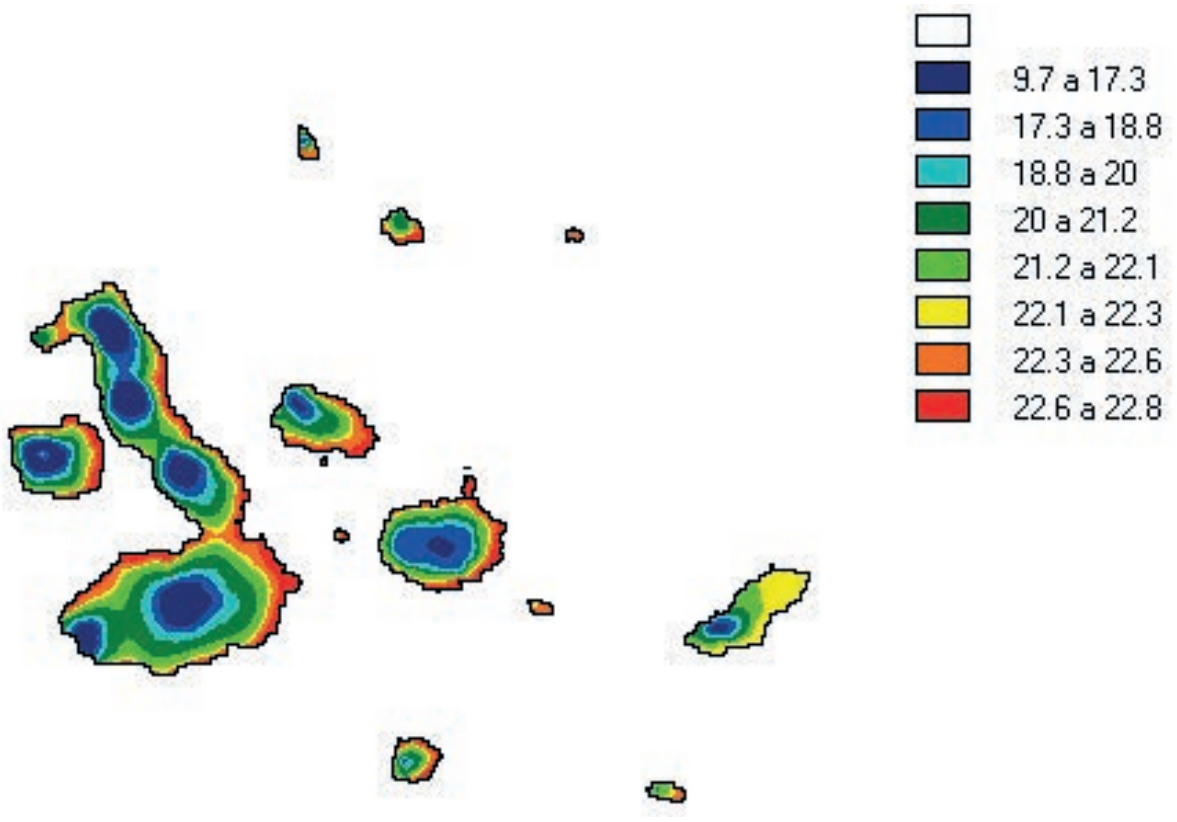

Elaboración: Autor, 2009

La distribución en el mapa de la temperatura media de mínimas anual (Figura 4.9), no difiere mayormente de la temperatura 


\section{5}

media anual (Figura 4.8.); así la temperatura media mínima anual más baja $9.7^{\circ} \mathrm{C}-17.3^{\circ} \mathrm{C}$ (percentil 0-10) se registra en los picos volcánicos de las islas y se ubica en $22,6^{\circ} \mathrm{C}$ (percentil 90-100) a nivel de las playas o franja costera de las islas. Existe un descenso de temperaturas de $7{ }^{\circ} \mathrm{C}$ a nivel de los volcanes (percentil 0-10) y de $2{ }^{\circ} \mathrm{C}$ en las áreas de playas y zonas costeras adyacentes. Los percentiles intermedios (30-70) muestran un descenso de $3^{\circ} \mathrm{C}$.

Figura 4.10

Temperatura media mínima absoluta anual - Galápagos

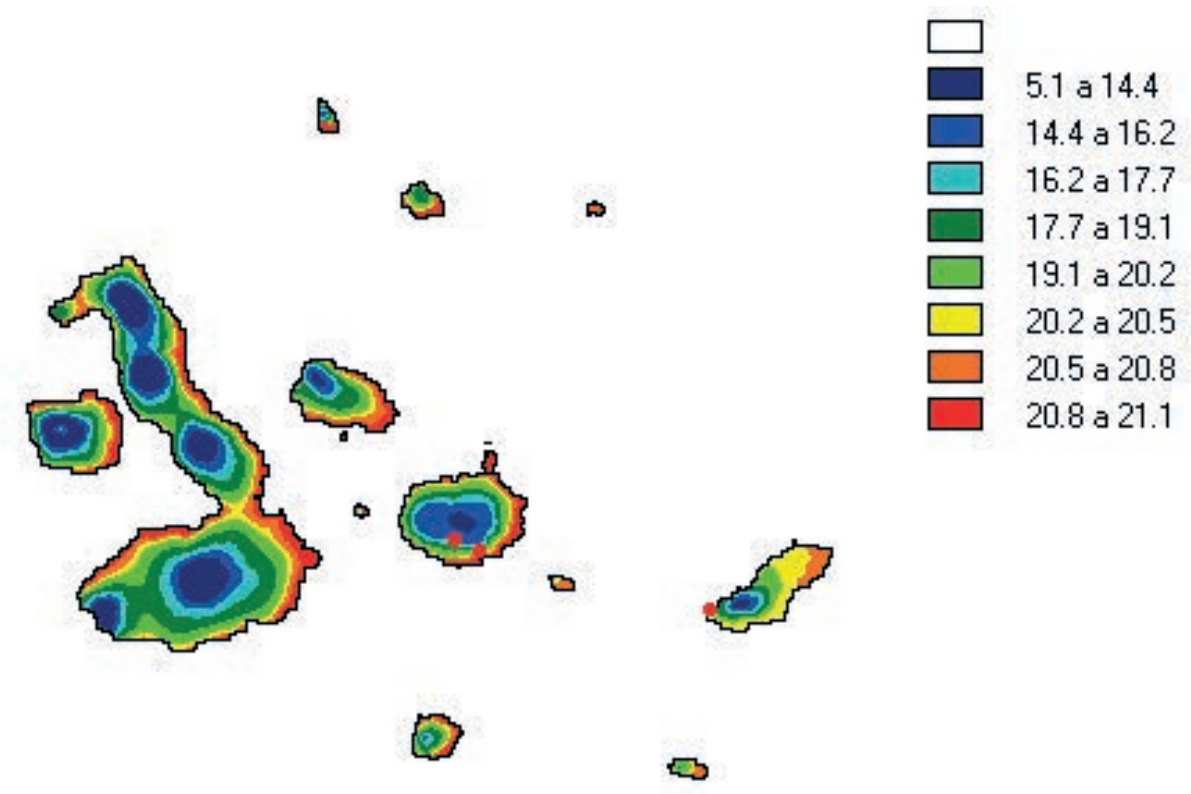

Elaboración: Autor, 2009

La temperatura media de mínimas absoluta (Figura 4.10) muestra una distribución similar a la temperatura media de mínimas (Figura 4.8). Se diferencia en cuanto a valores, pues registra un descenso de $12{ }^{\circ} \mathrm{C}$ (percentil 0-10) y de $4{ }^{\circ} \mathrm{C}$ (percentil 90-100) con respecto a los valores de la temperatura media anual (Figura 4.8), es decir $5{ }^{\circ} \mathrm{C}$ menos a nivel de montañas y $2{ }^{\circ} \mathrm{C}$ menos a nivel de playas que la temperatura media de mínimas (Figura 4.9). 


\section{6}

\section{Figura 4.11}

Temperatura media de máximas anual - Galápagos

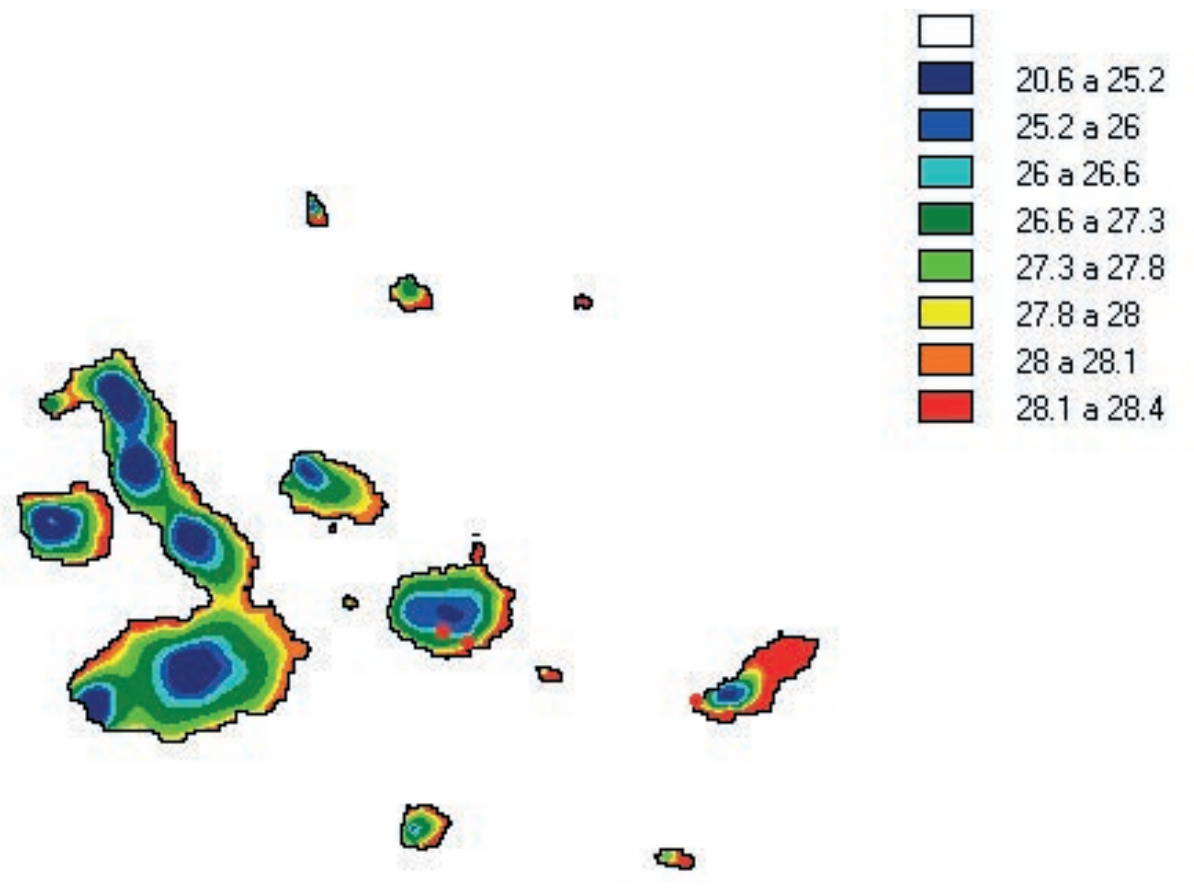

Elaboración: Autor, 2009

$\mathrm{Al}$ analizar la temperatura media máxima anual (Figura 4.11) se puede notar la diferencia con la temperatura media anual (Figura 4.8), ya que existen un ascenso de $4^{\circ}$, así en los picos volcánicos de 20.6 a $25.2^{\circ} \mathrm{C}$ (percentil $0-10$ ) y en la zona costera de $28.1^{\circ} \mathrm{C}$ a 28.4 ${ }^{\circ} \mathrm{C}$ (percentil 90-100). La media de máximas altas se ubica de enero a mayo principalmente como se puede apreciar en el Anexo 1 en lo que corresponde a la estación M221 San Cristóbal.

En cuanto a las temperaturas máximas absolutas anuales (Figura 4.12), en los picos volcánicos registra $26.4{ }^{\circ} \mathrm{C}$ (percentil 0-10) y en la zona costera $29.3^{\circ} \mathrm{C}$ (percentil 90-100). Es de notar que el rango entre la primera clase y la última, no son más que $3{ }^{\circ} \mathrm{C}$ grados, así que la distribución de las máximas absolutas tiende a ser uniforme en todas las islas. Se diferencia en al menos $9^{\circ} \mathrm{C}$ de ascenso térmico a nivel de las montañas (percentil 0-10) y de $5^{\circ} \mathrm{C}$ de ascenso térmico a nivel de la zona costera de las islas con respecto a los valores de la temperatura media anual (Figura 4.8). La estación M192 Bellavista 
de la Isla Santa Cruz reporta la temperatura media de máximas absoluta más alta registrada en el periodo $1980-2006$ con $39.8^{\circ} \mathrm{C}$ en el mes de marzo (ver Anexo 1).

\section{Figura 4.12}

Temperatura media máxima absoluta anual - Galápagos

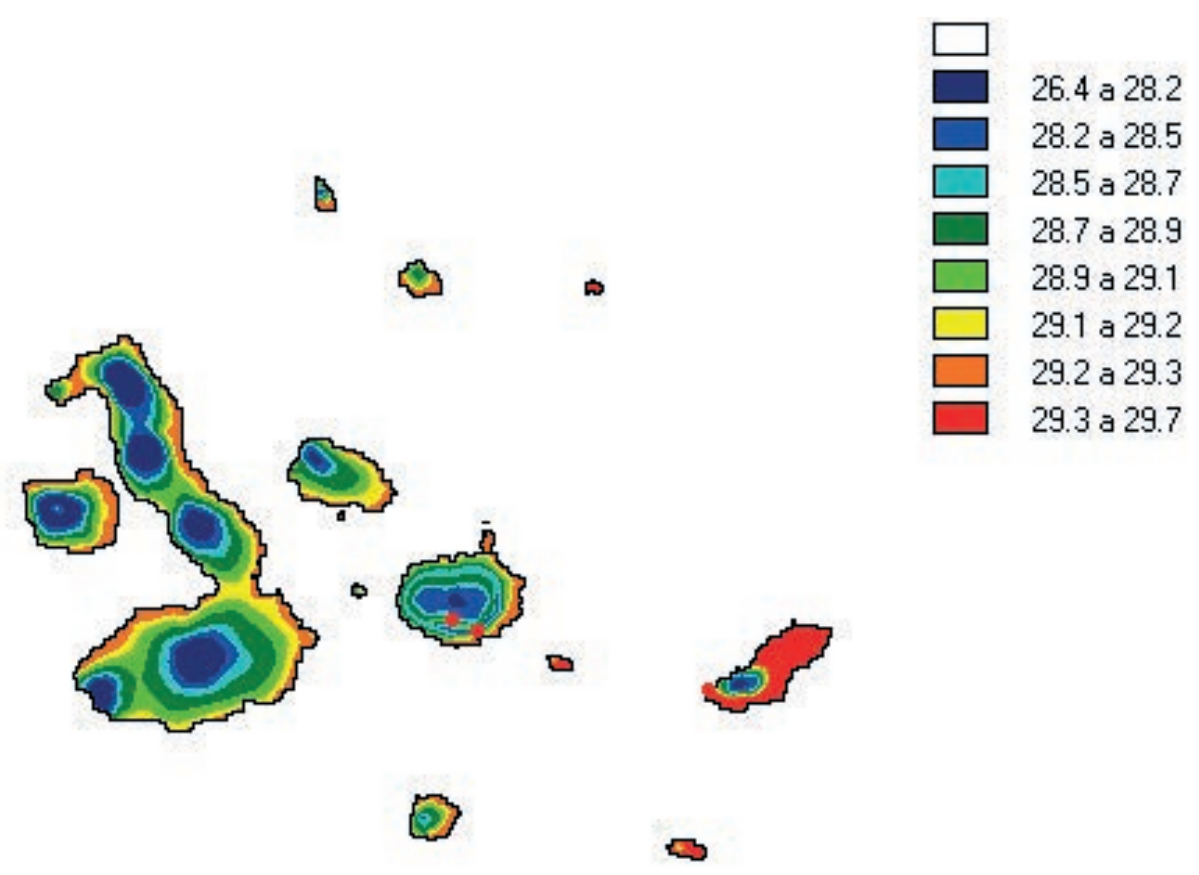

Elaboración: Autor, 2009

Al igual con lo hecho con el Ecuador continental, ahora nos centraremos en los datos estacionales de Mayo y Agosto que se pueden consultar en su totalidad en el Anexo 1.

La temperatura media de mayo (Figura 4.13) denota una distribución parecida a la temperatura media anual (Figura 4.8), pero con valores superiores, así hay un ascenso de $2{ }^{\circ} \mathrm{C}$ a nivel de las cúspides montañosas (percentil $0-10$ ) y de $1{ }^{\circ} \mathrm{C}$ a nivel de las zonas costeras (percentil 90-100). Este mes presenta un rango de $7^{\circ} \mathrm{C}$ de diferencia entre el percentil más bajo (0-10) y el más alto (90-100). 


\section{8}

Figura 4.13

Temperatura media de mayo - Galápagos

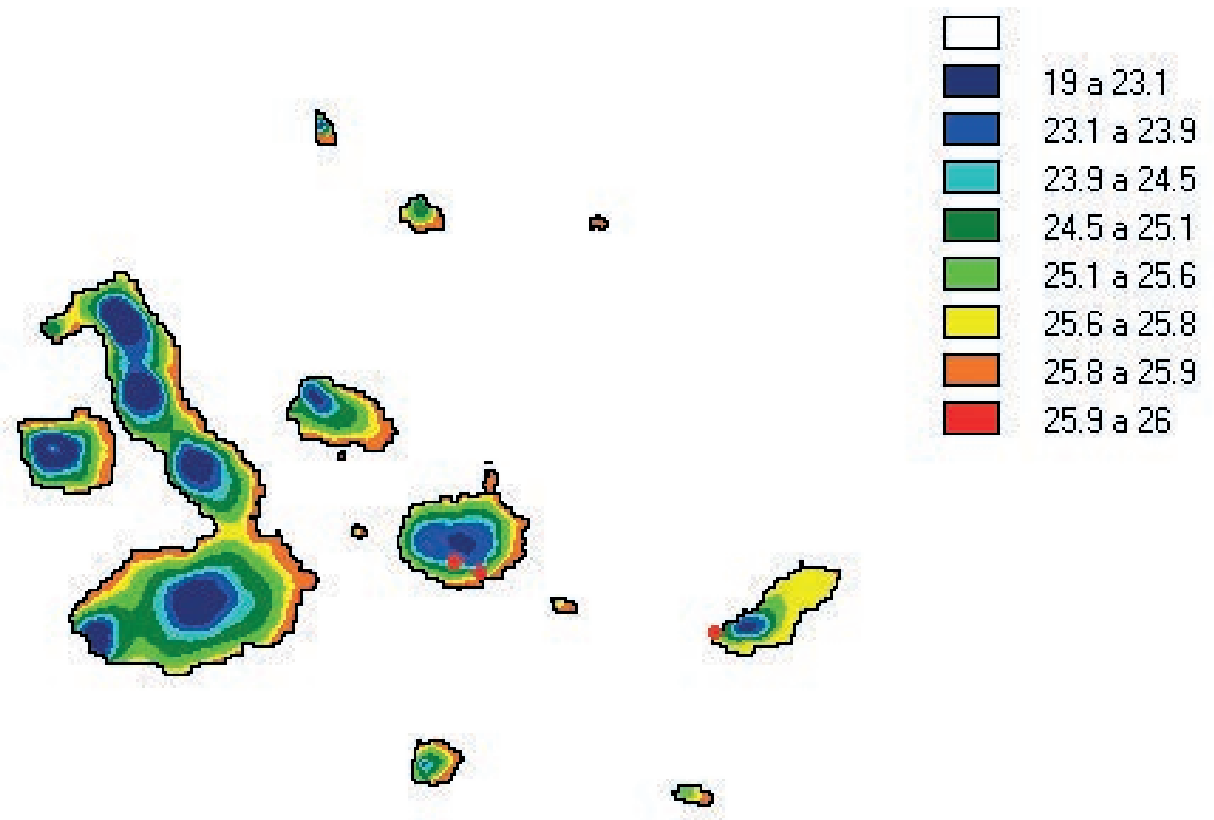

Elaboración: Autor, 2009

Figura 4.14

Temperatura media de agosto - Galápagos

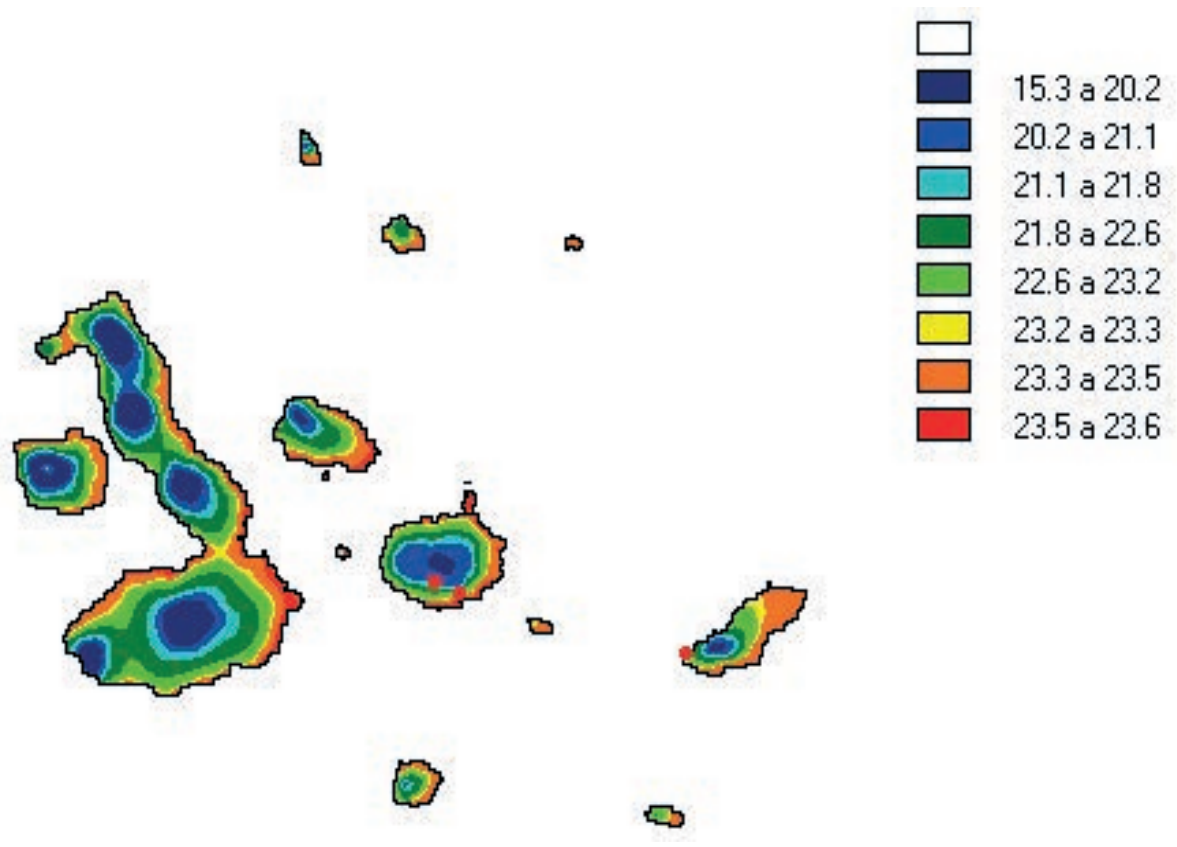

Elaboración: Autor, 2009 
La temperatura media de agosto (Figura 4.14) muestra una distribución similar a la de la temperatura media anual (Figura 4.8), con valores de descenso en $2{ }^{\circ} \mathrm{C}$ para el percentil más bajo (0-10) y de 1 ${ }^{\circ} \mathrm{C}$ para el percentil más alto (90-100); y de $4{ }^{\circ} \mathrm{C}$ a $2{ }^{\circ} \mathrm{C}$ de descenso en los mismos percentiles en comparación con la temperatura media de mayo (Figura 4.13). Así por ejemplo la estación M192 Bellavista de la Isla Santa Cruz ubicada a $194 \mathrm{~m}$ de altitud reporta una temperatura media de $24.1^{\circ} \mathrm{C}$ para mayo y $20.4^{\circ} \mathrm{C}$ para agosto (ver Anexo 1).

\section{Análisis de la precipitación}

La precipitación o lluvia en el Ecuador, corresponde a dos estaciones climáticas definidas que son el invierno y el verano, pero tiene una distribución especial en los meses del año; así, un invierno intenso en los meses de febrero a mayo y un invierno leve durante los meses de octubre a noviembre, mientras que un verano muy seco durante los meses de junio a agosto y un verano leve conocido como el veranillo del Niño durante los meses de diciembre a enero. Esto se desprende del análisis de los datos de precipitación correspondiente al periodo 19802006 proporcionados por el INAMHI (ver tablas y gráficos de los anexos 2 y 3). Al igual que la temperatura, el análisis de la precipitación, se hará por separado del Ecuador continental y de las Islas Galápagos.

\section{Tablas y gráficos}

Para el análisis de la precipitación se generaron dos anexos de resultados $(2$ y 3 ) con tablas y gráficos que muestran la tendencia, intensidad y frecuencia de la lluvia en el Ecuador continental como en el insular. Las diferentes estaciones llevan en la hoja de cálculo, las iniciales RR al inicio, para diferenciarse de los otros elementos del clima. Del periodo en estudio 1980-2006, la intensidad lluviosa más fuerte se ubica en los meses de febrero-marzo en la costa, abril-mayo en la sierra, mayo-junio en el oriente, mientras que el verano coincide en los meses de julio-agosto y el veranillo del niño ( menos intenso) en diciembre-enero. Existe un invierno leve, con menos cantidad de lluvia que regularmente es conocido por los agricultores como las lluvias para la siembra, que ocurre de octubre a noviembre. 
Las treinta y ocho estaciones meteorológicas continentales, distribuidas en las tres regiones naturales: Costa, Sierra y Oriente, arrojan resultados diversos en cuanto intensidad lluviosa se refiere. Así se puede apreciar en las tablas del anexo 2, que la precipitación media anual en la zona costanera y sierra central-norte, tuvieron un intenso invierno durante los años 1983-1984, 1997-1998 mientras que el oriente y la sierra austral mantenían cantidades de precipitación parecidas con los otros años. Gráficamente se puede apreciar la distribución de la lluvia a lo largo del año en el anexo 3, donde las estaciones ubicadas en la costa ecuatoriana señalan que los meses de intensidad lluviosa son de febrero a mayo, pero esencialmente febrero y marzo donde alcanzan las máximas; mientras que, en la sierra teniendo un periodo invernal parecido en fechas, sin embargo las máximas de precipitación las alcanzan en abril y mayo. La región oriental, si bien muestra un cuadro similar al de las otras regiones teniendo sus máximas precipitaciones en los meses de abril y mayo, su frecuencia lluviosa es casi invariable a lo largo de todo el año. Un cuadro parecido, sucede con el segundo invierno ecuatorial o invierno leve, en el cual las lluvias no son tan abundantes como en periodo de febrero a mayo, pero si son importantes para la agricultura, por cuanto son épocas de siembra en todo el país. Este invierno leve se pude apreciar en el mismo anexo 3, que va desde finales de septiembre a noviembre e inclusive primeros días de diciembre, luego de lo cual le sigue el denominado veranillo del niño que es muy corto, por cuanto la intensidad lluviosa se inicia a mediados o finales de enero de cada año.

La falta de agua en el país se siente principalmente en los meses de julio y agosto, y así lo demuestran las tablas del anexo 2, existiendo algunos años considerados problemáticos para la agricultura y la generación de energía hidroeléctrica como lo fueron los años 1990 y 2001, por ejemplo, cuando el verano se extendió y las cantidades de lluvia dejados por el invierno no fueron las normales.

En el Gráfico 4.2. se puede apreciar la relación entre la altitud y la precipitación media anual, donde la cantidad mayor de lluvia ha 
81

caído desde los $1000 \mathrm{~m}$ hacia abajo, esto corresponde a las regiones costera y amazónica, mientras que en la región andina la precipitación media anual no supera los $1500 \mathrm{~mm}$ de lluvia a $3000 \mathrm{~m}$ de altitud. Un ejemplo es la estación M003 Izobamba ubicada a 3058 m de altitud reporta $1431.3 \mathrm{~mm}$ de lluvia media anual, y por el contrario la estación M008 INAMHI Puyo (región oriental) ubicada a 960 m de altitud reporta $4579 \mathrm{~mm}$ de lluvia media anual.

Gráfico 4.2

Relación entre la altitud y la precipitación media anual

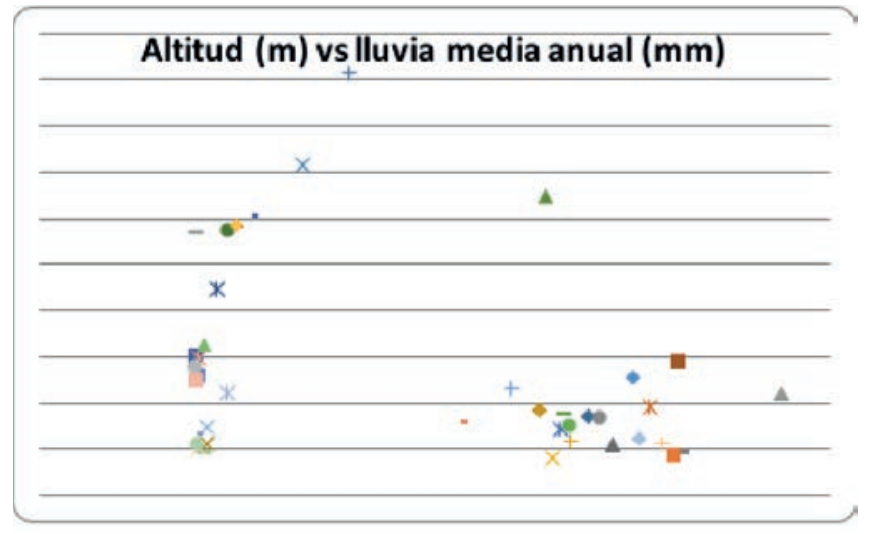

Elaboración: Autor, 2009

\section{Cartografía}

Los resultados de precipitación expresados en imagen cartográfica corresponden a la precipitación media anual, la mediana, los percentiles 20 y 80, y los meses de mayo y agosto. La paleta de colores utilizada, indica que al color rojo ladrillo le corresponde las cantidades (percentiles) más bajas de mm de lluvia, mientras que al color azul intenso le corresponde los valores (percentiles) más altos de precipitación en $\mathrm{mm}$. Los percentiles están organizados en categorías que van: 0-10, 10-20, 20-30, 30-50, 50-70, 70-80, 80-90, y 90-100.

\section{Precipitación en el Ecuador Continental}

Como muestra la Figura 4.15, la precipitación media anual se concentra en la amazonía y en el norte de la costa ecuatoriana 
(provincia de Esmeraldas, Los Ríos y norte de Manabí: percentiles del 70 al 100) con valores que llegan hasta $4700 \mathrm{~mm}$. Las zonas de la costa central y sur, y las estribaciones de la cordillera occidental y oriental (percentil 30-50) marcan valores de 1100 a $1900 \mathrm{~mm}$. Por el contrario la región centro norte andina, así como la parte centro occidental de la costa (provincia de Manabí) y extremo sur costanero (provincia de El Oro), son las zonas que menos lluvia anual reciben (percentil 0-10) con valores de 300-900 $\mathrm{mm}$. La zona sur andina tiene valores que van de 1000 a $1100 \mathrm{~mm}$ de lluvia (percentil 20-30). Por ejemplo la estación M134 Guamote (zona central andino) ubicada a $3020 \mathrm{~m}$ de altitud reporta $422.4 \mathrm{~mm}$ de lluvia media anual, frente a la estación M153 Muisne (costa norte) ubicada a $6 \mathrm{~m}$ de altitud reporta $2826.8 \mathrm{~mm}$ de lluvia media anual (ver Anexo 2 y 3 ).

Figura 4.15

Precipitación media anual - Ecuador

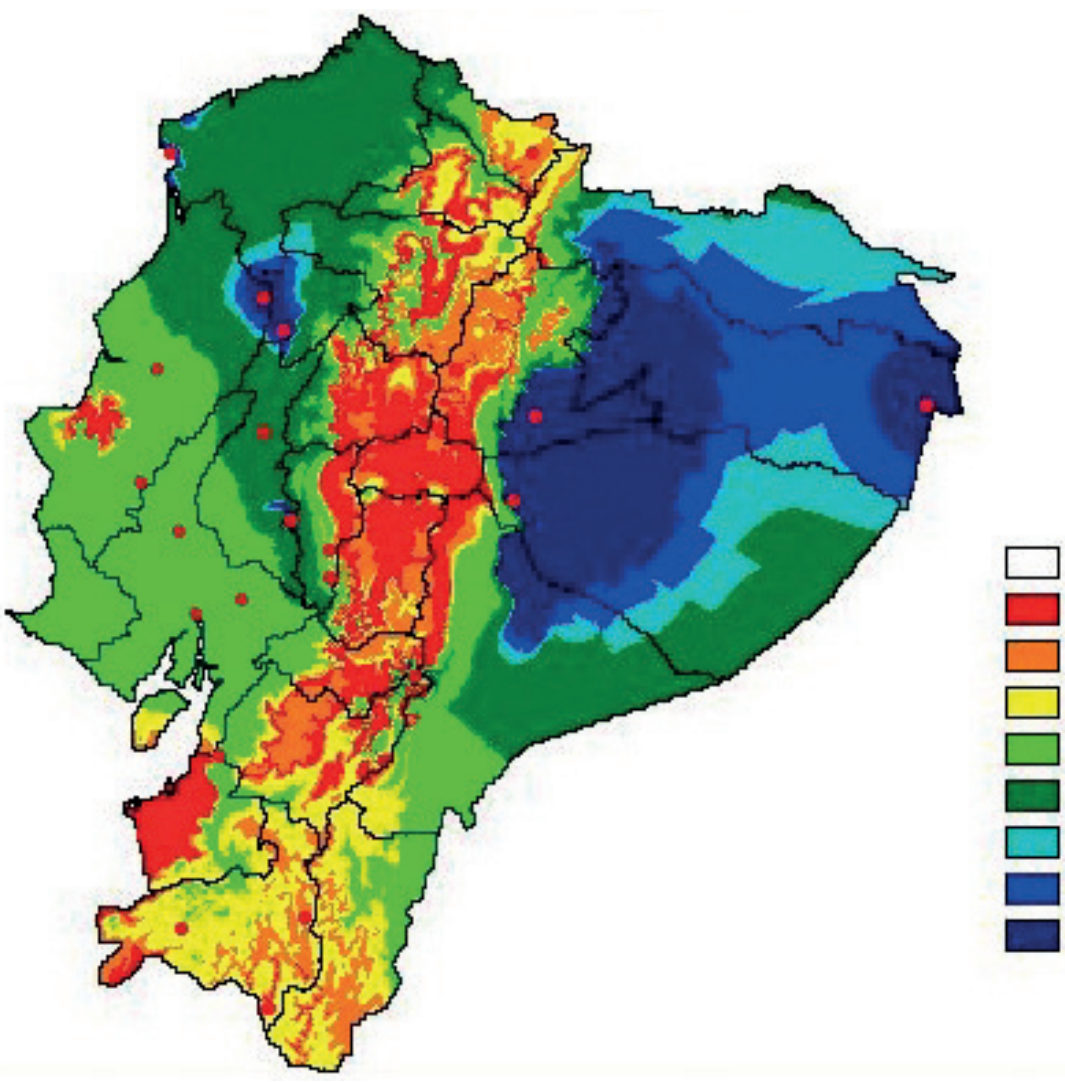




\section{3}

La precipitación mediana anual (Figura 4.16), no difiere sustancialmente en cuanto a la distribución de la lluvia en el territorio continental, aunque si se debe destacar que muestra un valor más bajo en el percentil 0-10 cuyo valor va de $200 \mathrm{~mm}-800 \mathrm{~mm}$. Y su ubicación en el mapa se concentra más en la sierra central, sur de la costa ecuatoriana y parte central de la provincia de Manabí.

Figura 4.16

Precipitación mediana anual - Ecuador

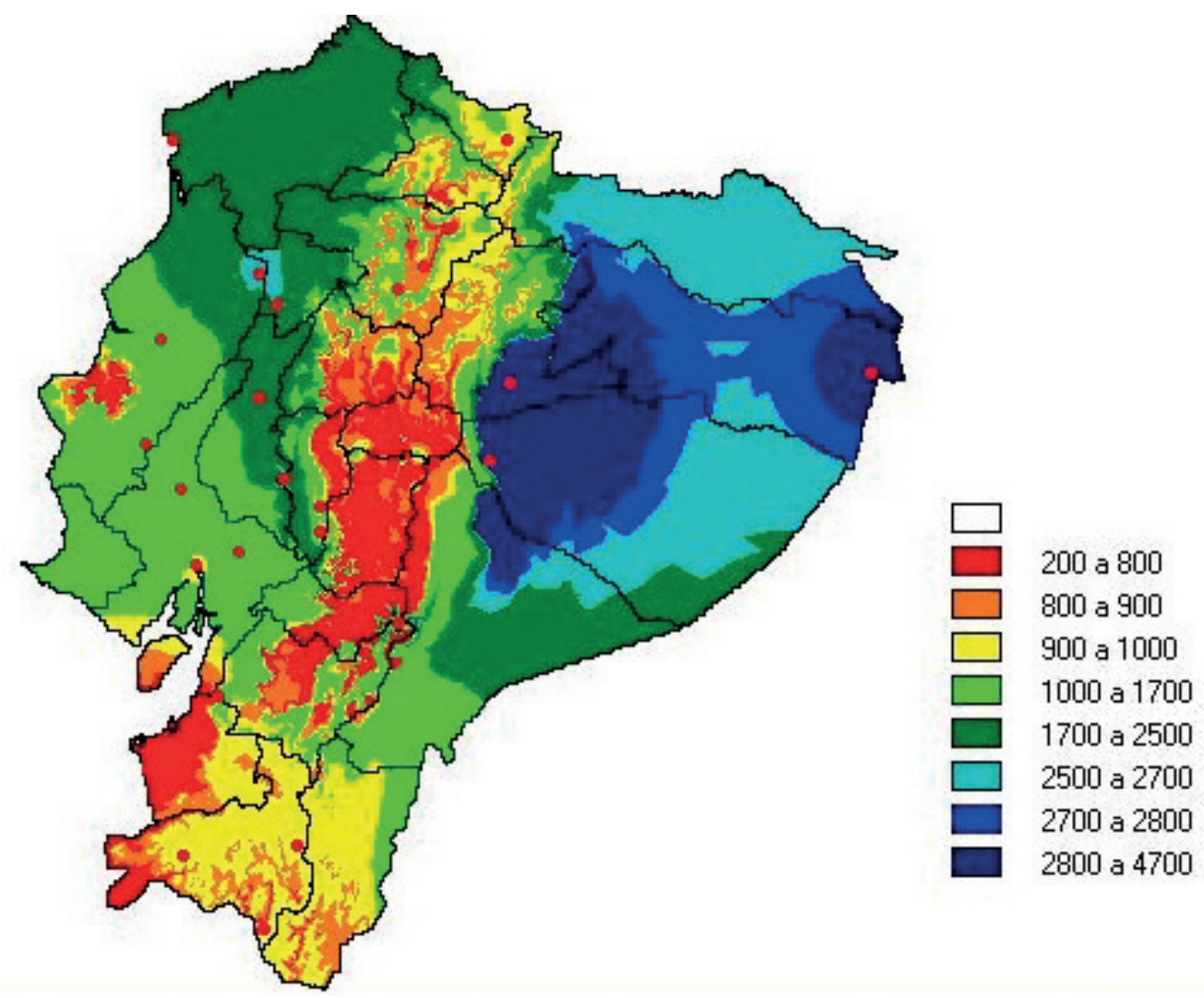

Elaboración: Autor, 2009

En cuanto se refiere a la distribución de la lluvia del mes de mayo (ver Figura 4.17) difiere de la precipitación media anual (Figura 4.15), ya que se puede ver que el percentil 0-10 con valores de 10 a $70 \mathrm{~mm}$ se ubica en la costa sur (El Oro) centro occidente (Manabí), extremo sur Loja) y central de la zona andina, mientras que los percentiles 90-100 con valores de 300 a $480 \mathrm{~mm}$ de lluvia cubren la zona centro-norte del Oriente; y, el percentil 50-70 con valores de 150 a 
$250 \mathrm{~mm}$ cubren la zona norte de la costa ecuatoriana (provincia de Esmeraldas), así por ejemplo, la estación M160 El Carmen ubicada a $250 \mathrm{~m}$ de altitud reporta $263 \mathrm{~mm}$ de lluvia media, mientras que la estación M136 Chunchi ubicada a 2245 m de altitud reporta 35.8 mm de lluvia media en mayo (ver Anexo 3).

Figura 4.17

Precipitación media anual de mayo - Ecuador

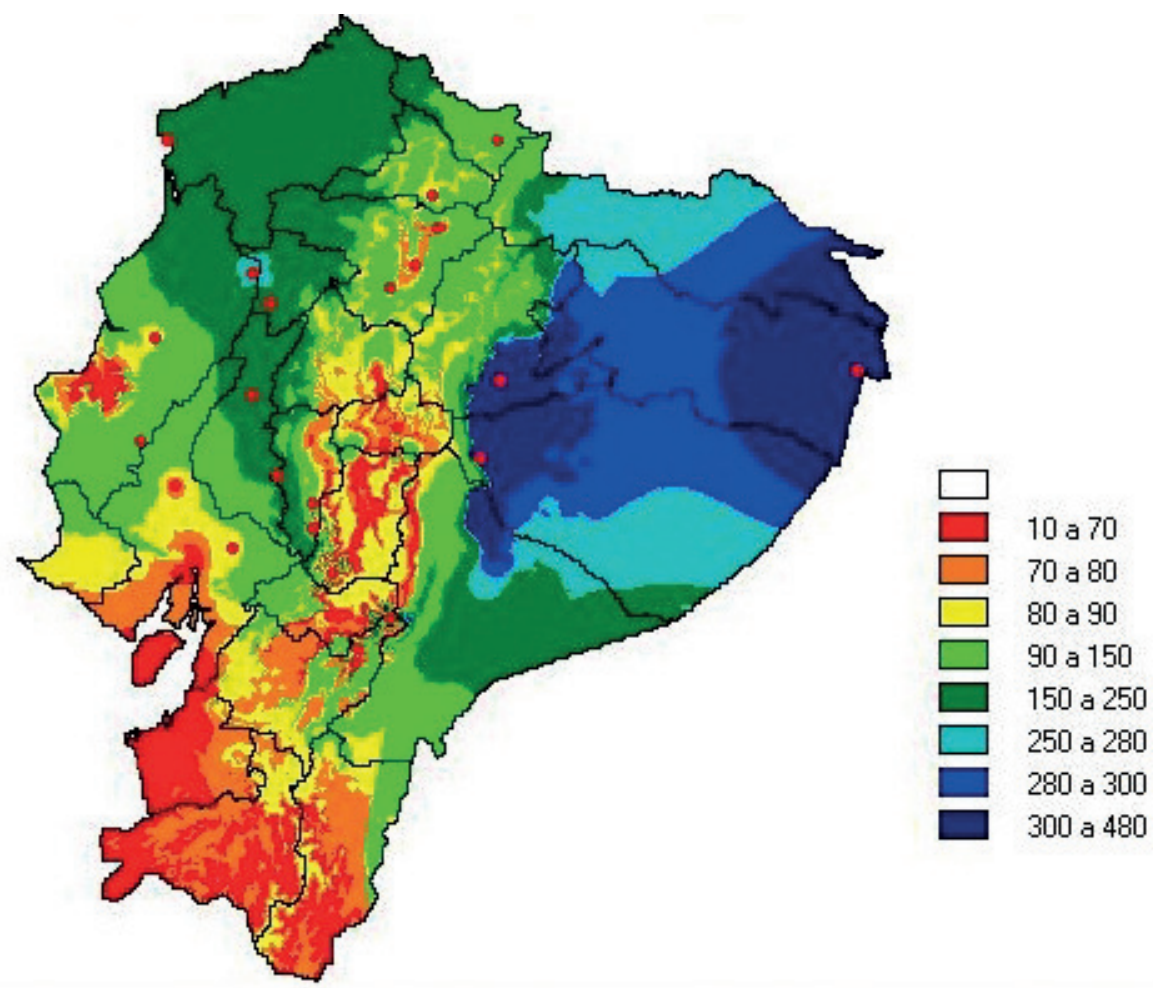

Elaboración: Autor, 2009

La distribución de la precipitación en Agosto (Figura 4.18), comparada con la precipitación media anual (Figura 4.15), muestra la zona de la costa central y sur como la más afectada en la con valores de 0-13 mm (percentil 0-10) y de 13-22 mm (percentil 10-20) en las provincias de Loja y hoyas interandinas. La región oriental mantiene los valores más altos de precipitación (percentil 90-100) alcanzando hasta $312 \mathrm{~mm}$ de lluvia en el verano, lo cual le convierte en una región que no sufre falta de agua en ningún periodo del año. Igual fenómeno sucede con la provincia de Esmeraldas, al norte de 


\section{5}

la costa ecuatoriana (percentil 50-70). Comparado agosto con mayo, los percentiles caen a valores inferiores, así para los percentiles menores (0-10) disminuye entre 10 a $70 \mathrm{~mm}$ y para los percentiles altos (90-100) disminuye entre 120 a $150 \mathrm{~mm}$. Para las mismas estaciones enunciadas en mayo, veamos lo que sucede en agosto: estación M160 El Carmen ubicada a $250 \mathrm{~m}$ de altitud reporta $43 \mathrm{~mm}$ de lluvia media, mientras que la estación M136 Chunchi ubicada a 245 m de altitud reporta $2.9 \mathrm{~mm}$ de lluvia ( ver Anexo 3).

\section{Figura 4.18}

Precipitación media anual de agosto - Ecuador

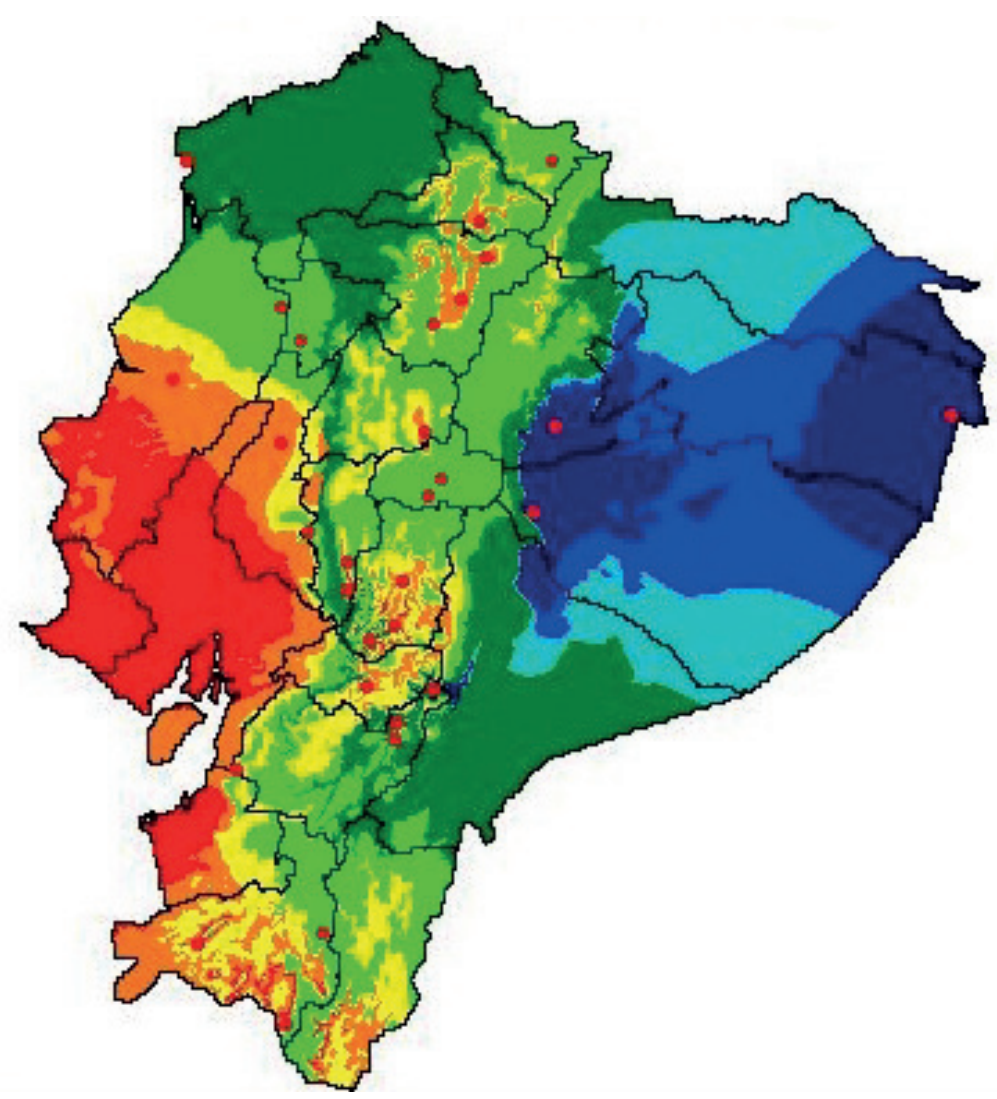

Elaboración: Autor, 2009

Al comparar la precipitación de los percentiles 80 y 20 (Figuras 4.19 y 4.20 , respectivamente), se confirma la similitud en la distribución de la precipitación vista en la figura 4.15, salvo la característica que presenta la figura 4.19, que ubica un nicho de alta precipitación en la costa norte central y occidental (límites de las provincias de 
Esmeraldas, Santo Domingo, Pichincha y Manabí, y zona costera del sur de Esmeraldas) con valores que están entre los 3100 y 5000 mm de lluvia (percentil 90-100), algo semejante a lo que ocurre en el centro y norte del Oriente ecuatoriano. Comparando los valores con la precipitación media anual (Figura 4.15), el percentil 80 (Figura 4.19) tiene un ascenso de 200 a $300 \mathrm{~mm}$, mientras que el percentil 20 tiene un descenso de 20 a 130 mm. Por ejemplo la estación M002 La Tola ubicada a $2480 \mathrm{~m}$ de altitud reporta los siguientes valores de lluvia media anual: percentil 20 con $714.1 \mathrm{~mm}$, media anual con $857.8 \mathrm{~mm}$ y percentil 80 con $1008.3 \mathrm{~mm}$ (ver anexo 3).

Figura 4.19

Precipitación anual percentil 80 - Ecuador

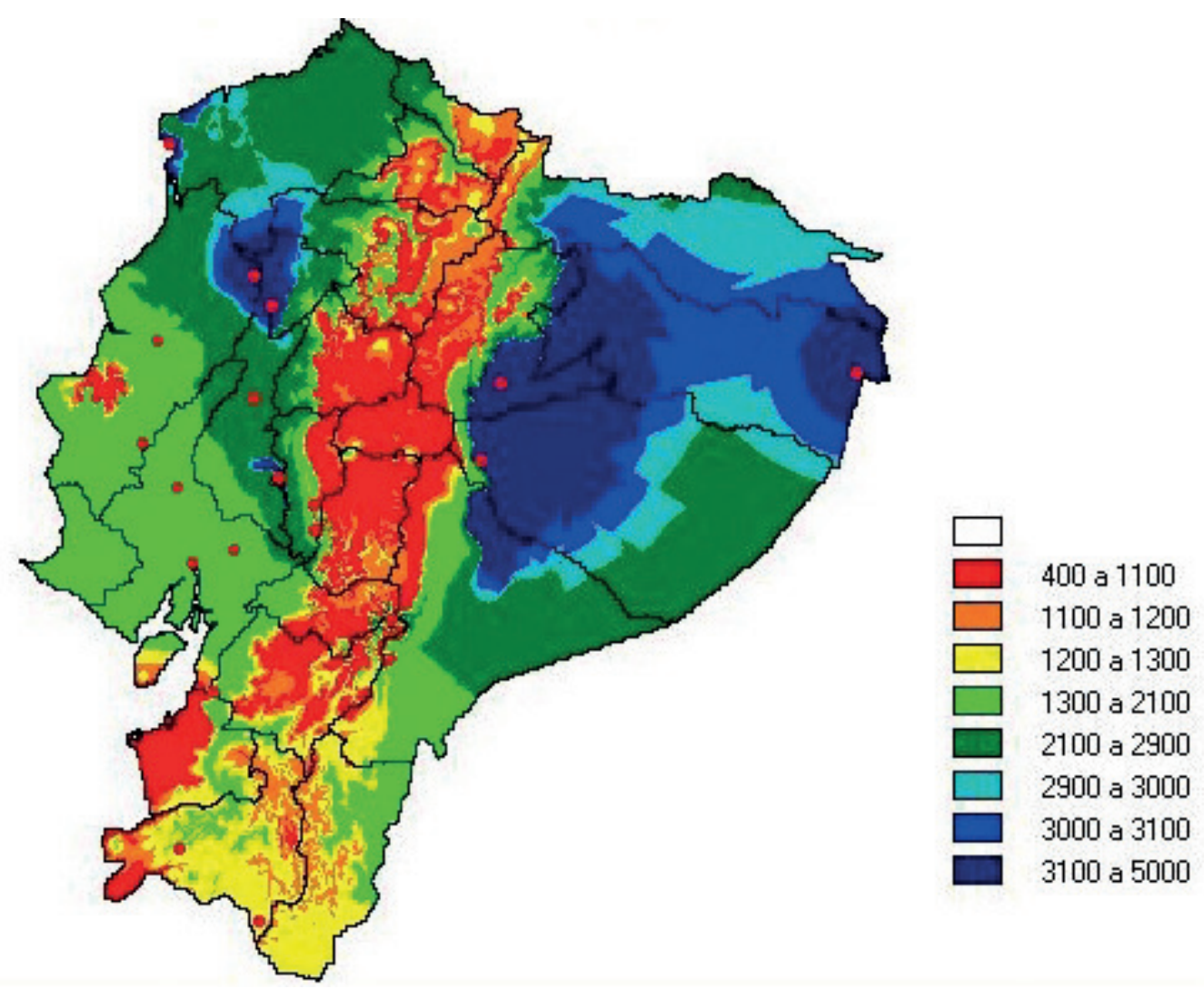

Elaboración: Autor, 2009 


\section{7}

\section{Figura 4.20}

Precipitación anual percentil 20 - Ecuador
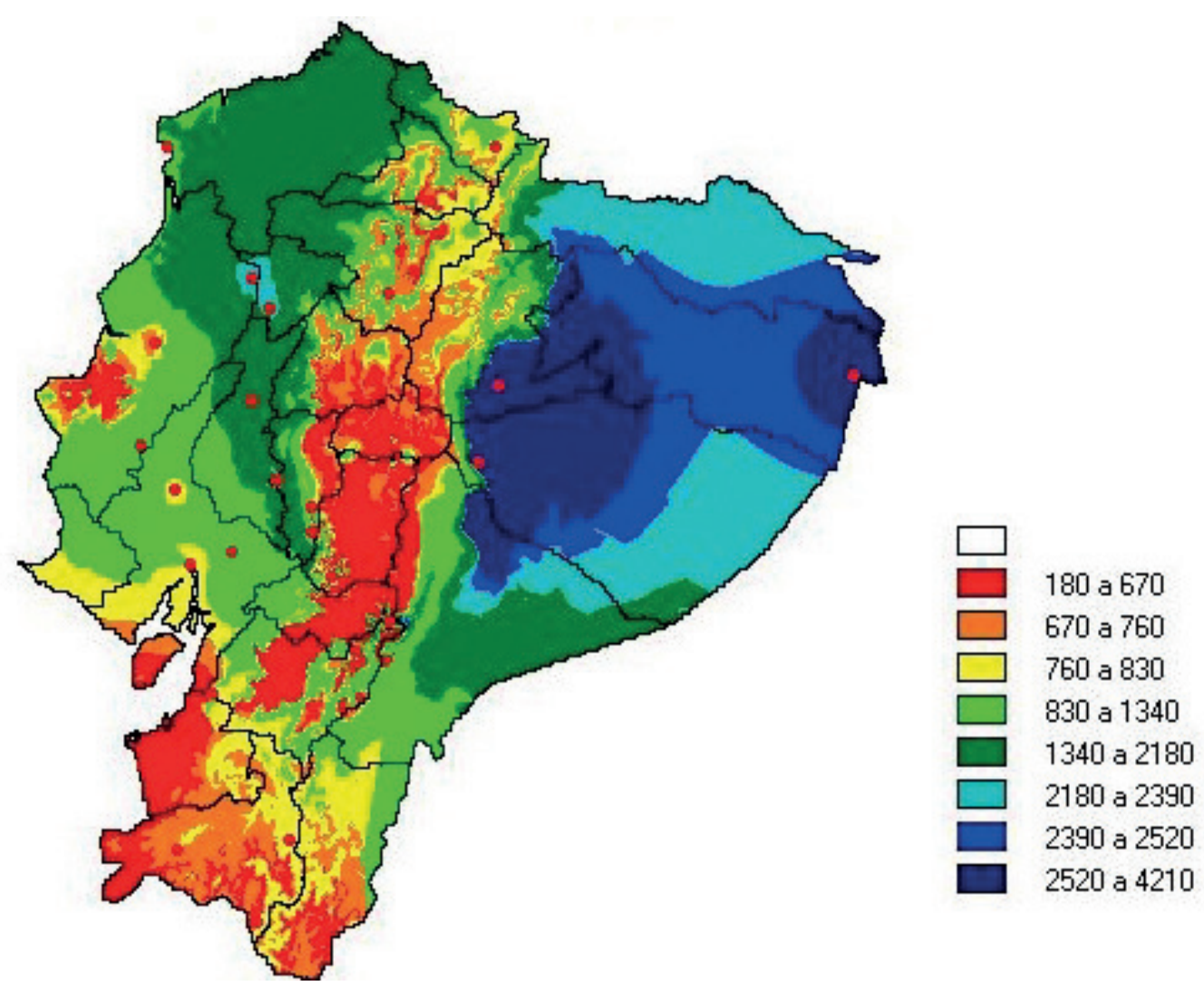

Elaboración: Autor, 2009

\section{Precipitación en el Ecuador Insular o Galápagos}

Las tres estaciones meteorológicas de la Islas Galápagos, muestran que las precipitaciones de hasta $3160 \mathrm{~mm}$, (percentil 90-100) se ubican en las cumbres de las bajas montañas y volcanes existentes, y los valores más bajos se encuentran en las playas (zonas costeras) con cantidades que van desde los $250 \mathrm{~mm}$ a los $300 \mathrm{~mm}$ (percentil 0-10). Así lo demuestra la figura 4.21 correspondiente a la precipitación media anual.

Muy parecida a la figura 4.21, se muestra la de la precipitación mediana (ver Figura 2.22), salvo que sus percentiles muestran valores más bajos, como es el caso del percentil 0-10 con valores de 50 a 100 $\mathrm{mm}$. Esto concuerda con lo expresado en que Galápagos es usualmente seca y casi desértica en las zonas costeras. Neill, y Jorgensen, (2009). 
Figura 4.21

Precipitación media anual - Galápagos

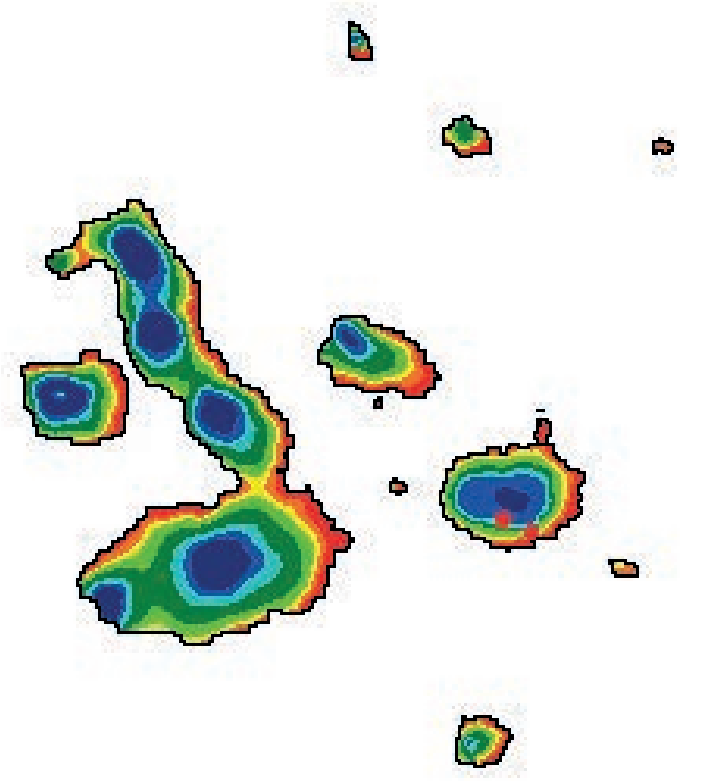

250 a 300

300 a 350

350 a 410

410 a 590

590 a 880

880 a 1160

1160 a 1470

1470 a 3160

Elaboración: Autor, 2009

\section{Figura 4.22}

Precipitación mediana anual - Galápagos
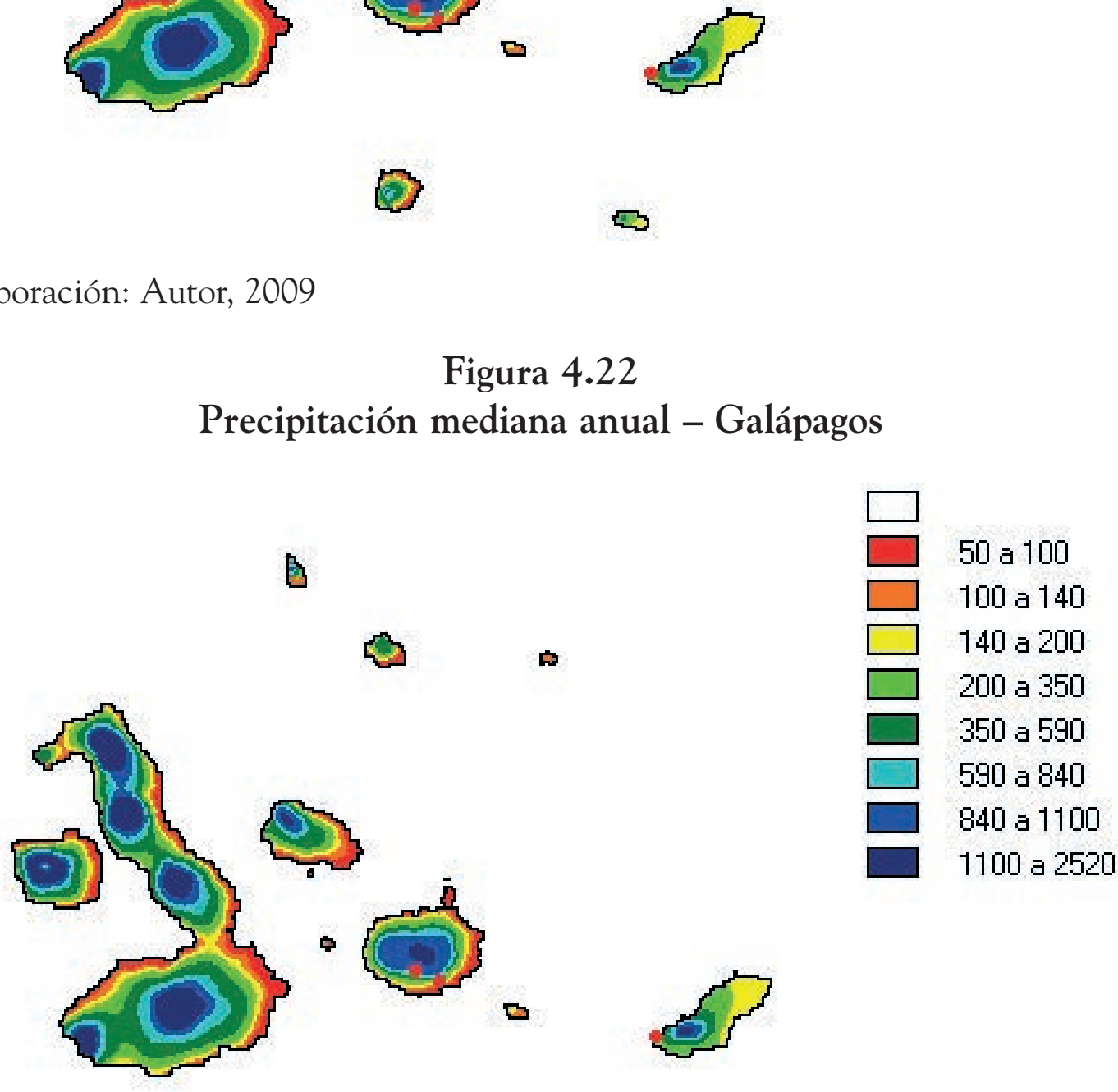

5

\section{밈}

Elaboración: Autor, 2009 
$\mathrm{Al}$ analizar el mapa de mayo (figura 4.23) y de agosto (Figura 4.24), la distribución de la lluvia se mantiene como en los mapas anteriores (4.22 y 4.21), sin embargo las cantidades de lluvia caídas distan mucho de las que ocurren en el continente, así agosto presenta valores negativos, que quiere decir simplemente que hay ausencia absoluta de lluvias. (Estos valores negativos son producto de la interpolación de datos entre las tres estaciones existentes). Igual fenómeno ocurre con los mapas del percentil 20 y de la media de agosto (figuras 4.25 y 4.24 , respectivamente).

Figura 4.23

Precipitación media anual de mayo - Galápagos
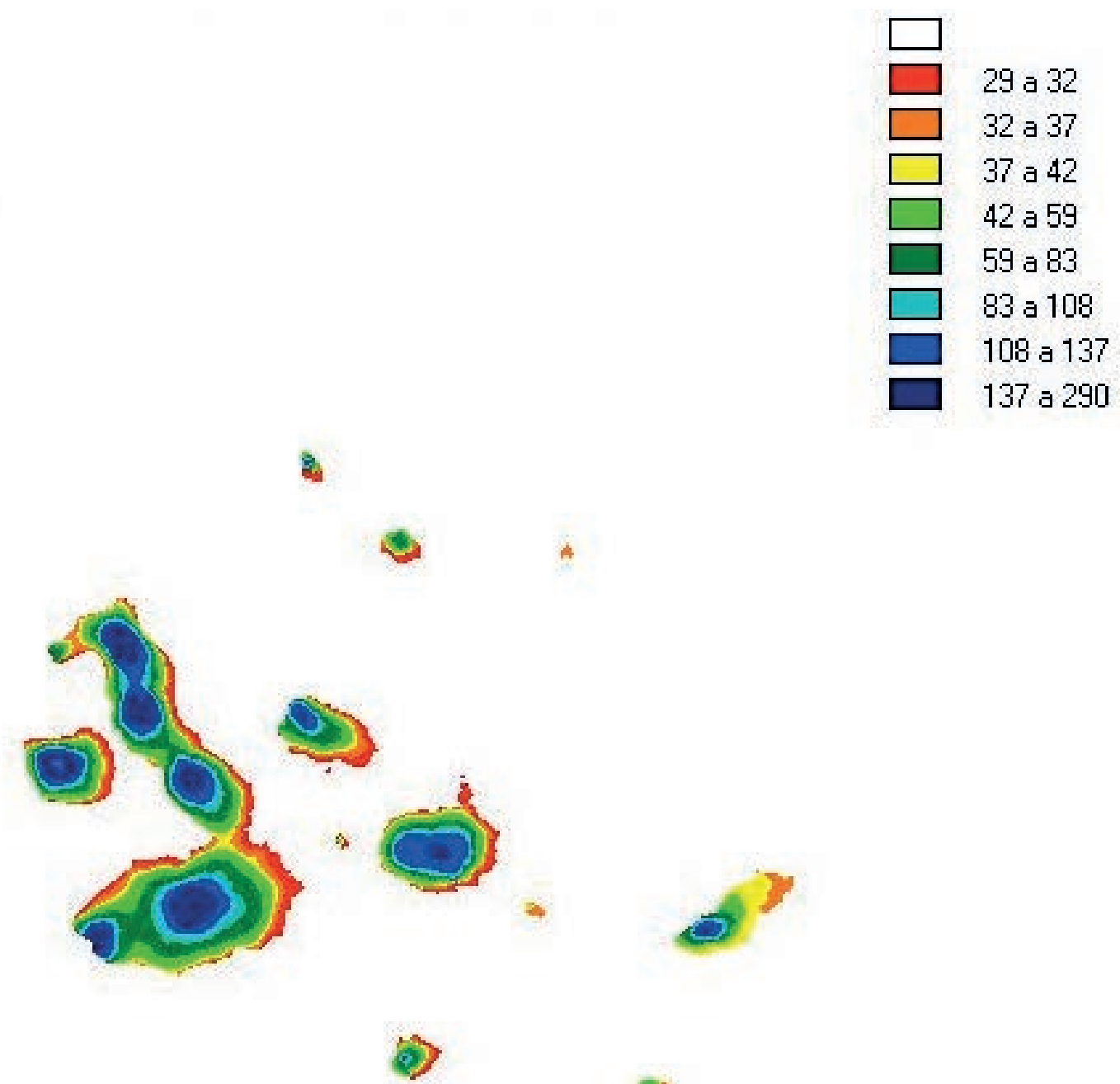

Elaboración: Autor, 2009 


\section{0}

Figura 4.24

Precipitación media anual de agosto - Galápagos

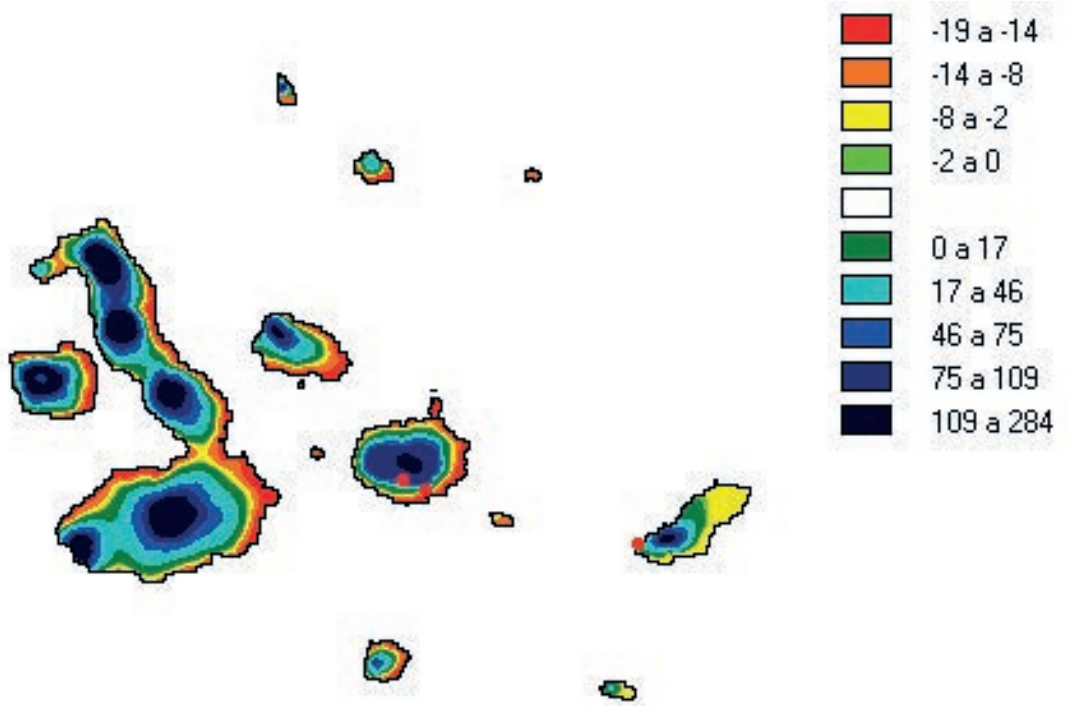

Elaboración: Autor, 2009

Figura 4.25

Precipitación anual percentil 20 - Galápagos

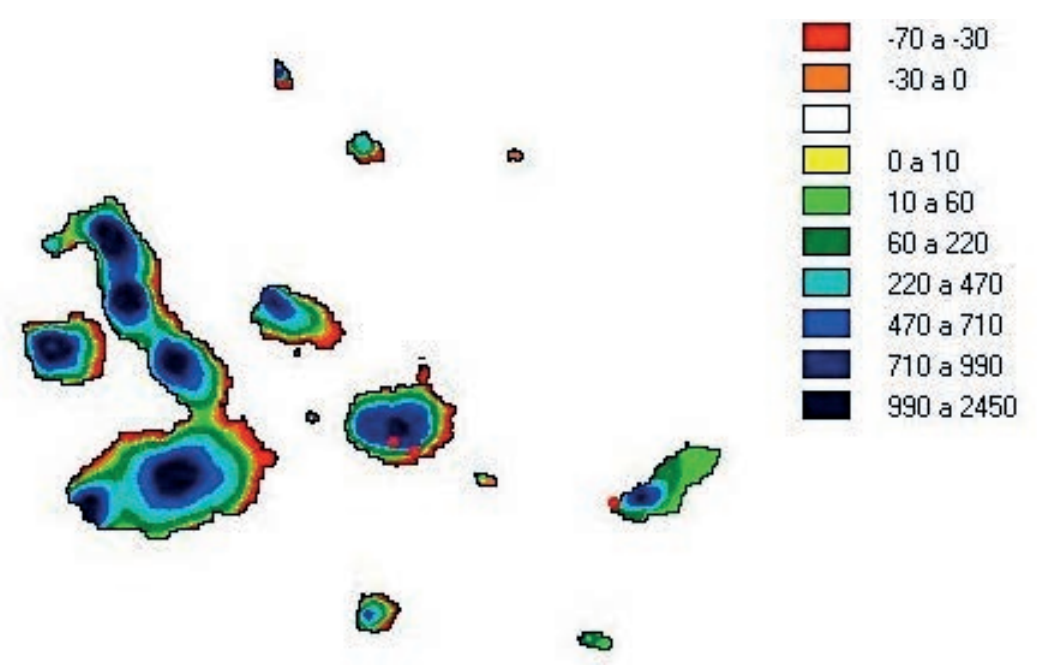

Elaboración: Autor, 2009

$\mathrm{Al}$ analizar la precipitación anual percentil 20 (Figura 4.25), aparecen valores negativos, y esto es debido a la regresión matemática de las tres estaciones existentes, no significando que existan lluvias negativas sino más bien ausencia de las mismas en las zonas que abarcan esos percentiles coloreados en el mapa de color rojo y anaranjado que corresponde a zonas costeras de las islas. Coincide de alguna manera 
con lo expuesto en la Figura 4.24 de la precipitación media de agosto, donde también denota la ausencia de lluvias en las mismas zonas.

Figura 4.26

Precipitación anual percentil 80 - Galápagos

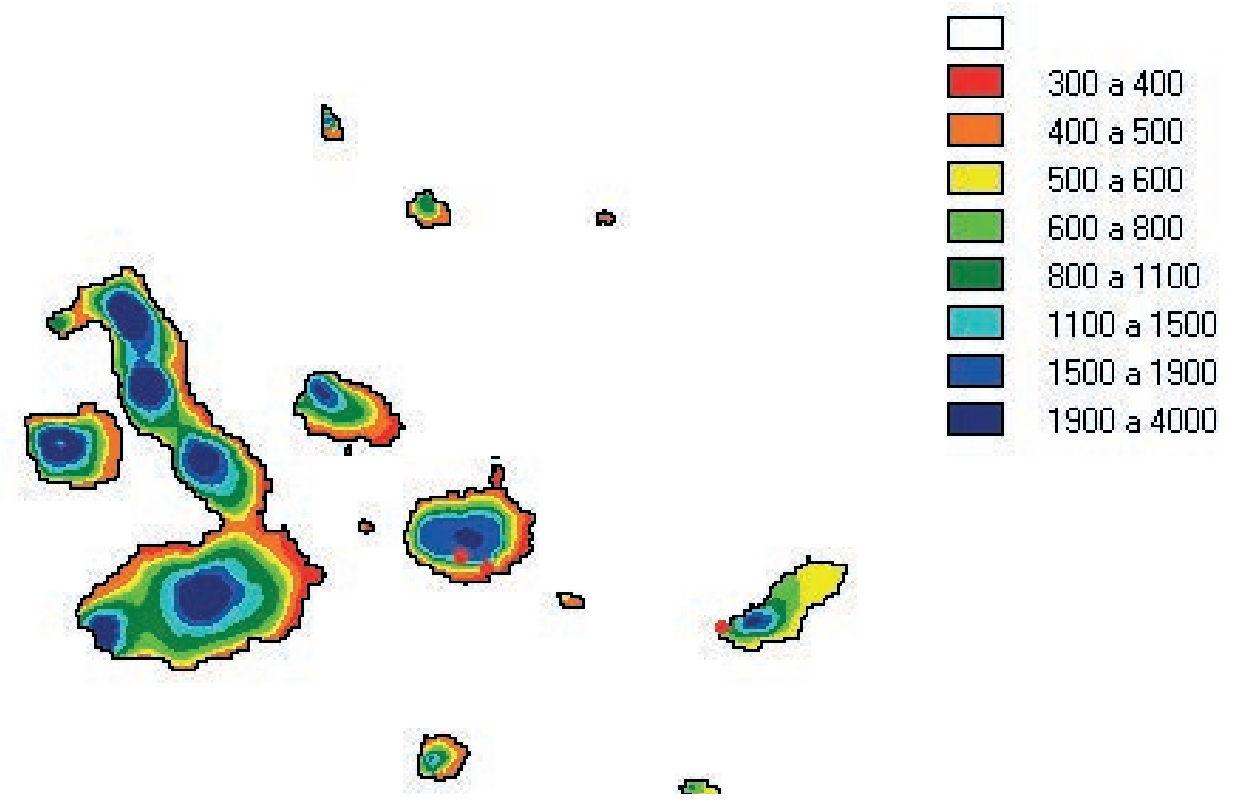

Elaboración: Autor, 2009

En el caso de la precipitación percentil 80 (Figura 4.26), la distribución de la lluvia está marcada porque las cantidades mayores se ubican en las cúspides, montañas y las estribaciones de las islas (percentiles de 70 a 100) y las menores en las playas o zonas costeras (percentil 0-10). La distribución en el mapa coincide con la expuesta para la precipitación media anual (ver Figura 4.21). Comparando los valores con la precipitación media anual (Figura 4.21), el percentil 80 (Figura 4.26) tiene un ascenso de 50 a $100 \mathrm{~mm}$, mientras que el percentil 20 (Figura 4.25) tiene un descenso de 300 a $330 \mathrm{~mm}$. Por ejemplo la estación M191 Charles Darwin ubicada a 6 m de altitud reporta 184.7 mm de lluvia para el percentil 20, un valor de $536.5 \mathrm{~mm}$ de lluvia media anual y $653.7 \mathrm{~mm}$ de lluvia para el percentil 80 (ver Anexo 3).

Precipitación máxima (en 24 horas) en el Ecuador continental

Para el análisis de la precipitación máxima en 24 horas se ha generado tres anexos para el periodo en estudio (1980 -2006): Anexo 
4, que corresponde a una tabla general de cálculo de medias, desviación típica, máximas y mínimas. Anexo 5, que corresponde a tablas y gráficos de las medias, desviación típica, máximas y mínimas. Anexo 6, que corresponde a la tabla Gumbel, de donde se someterá a cartografía los valores correspondientes a T10 tiempo de retorno para diez años y T100 tiempo de retorno para 100 años.

Figura 4.27

Precipitación máxima en 24 horas media anual - Ecuador
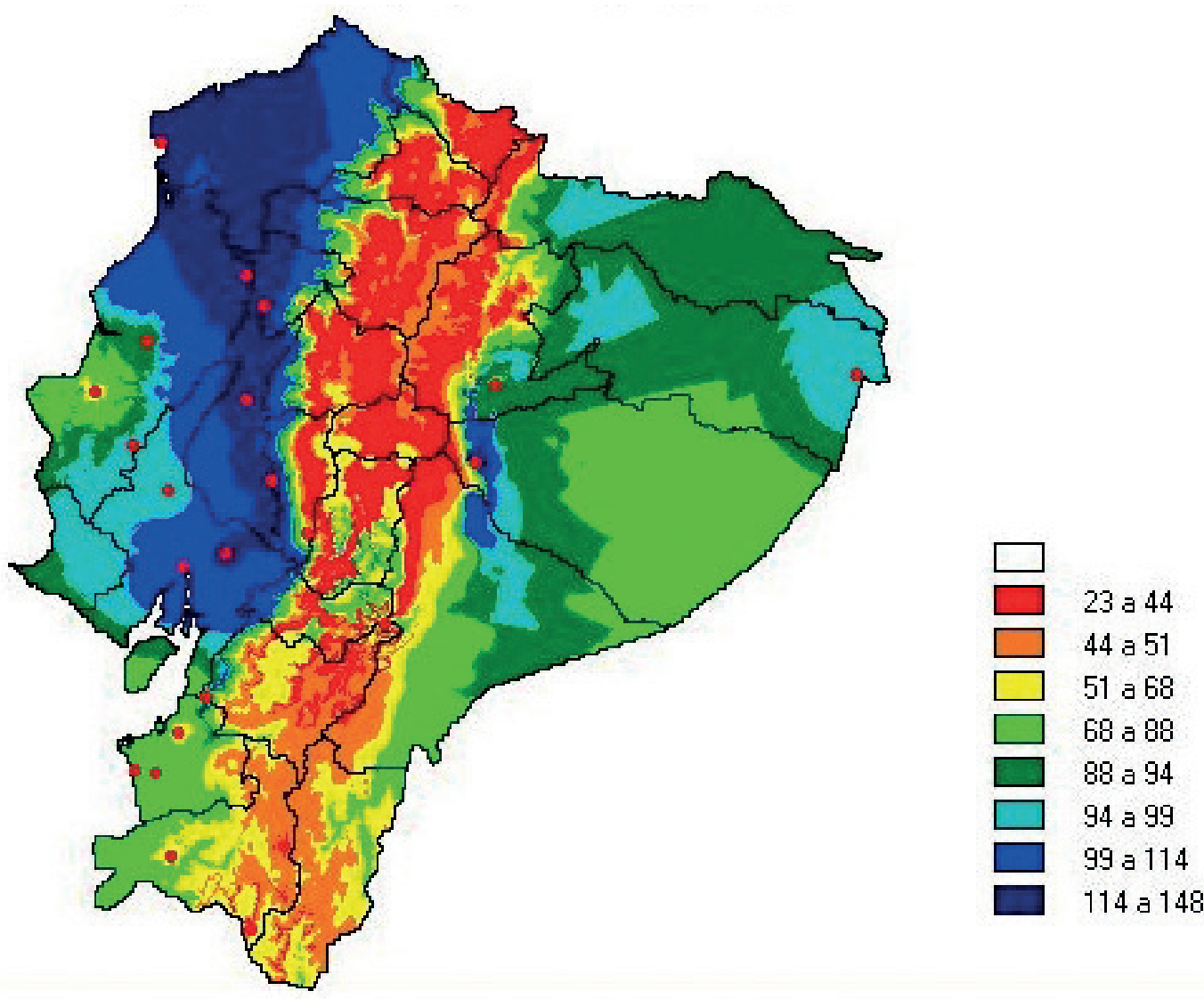

Elaboración: Autor, 2009

La precipitación máxima en 24 horas media anual (ver Figura 4.27), cuyos percentiles más altos ( 80 -90 y 90-100) con valores que van de $99 \mathrm{~mm}$ a $114 \mathrm{~mm}$ y de $114 \mathrm{~mm}$ a $148 \mathrm{~mm}$, respectivamente, cubren la zona litoral (norte y central), así como una pequeña zona central de la estribación de la cordillera oriental y parte del norte amazónico. La zona Oriental o Amazonia mantiene los valores comprendidos entre 


\section{3}

los percentiles 30 a 80 . Por su parte la región andina es cubierta con los percentiles más bajos (percentil 0-10) con valores de $23 \mathrm{~mm}$ a $44 \mathrm{~mm}$. La zona austral presenta valores de $44 \mathrm{~mm}$ a $51 \mathrm{~mm}$ (percentil 10-20), coincidiendo con el criterio expuesto para la zona andina en general. Hay un rango de $90 \mathrm{~mm}$ de lluvia máxima caída en 24 horas entre los percentiles 0-10 y el 90-100, y según la distribución en el mapa d la figura 4.27, los territorios que reciben mayor impacto están ubicados en el litoral ecuatoriano y par de la Amazonía. Como ejemplo citaremos a la estación M153 Muisne (zona costa norte) ubicada a 6 m de altitud reporta una media anual de precipitación máxima en 24 horas de $146.67 \mathrm{~mm}$, frente a la estación M148 Celica (zona sur andina) ubicada a $1984 \mathrm{~m}$ de altitud que reporta $71.1 \mathrm{~mm}$ de lluvia máxima. Este ejemplo denota un rango de $75 \mathrm{~mm}$ de diferencia entre las dos estaciones (ver Anexo 6).

Figura 4.28

Precipitación máxima en 24 horas máxima absoluta - Ecuador

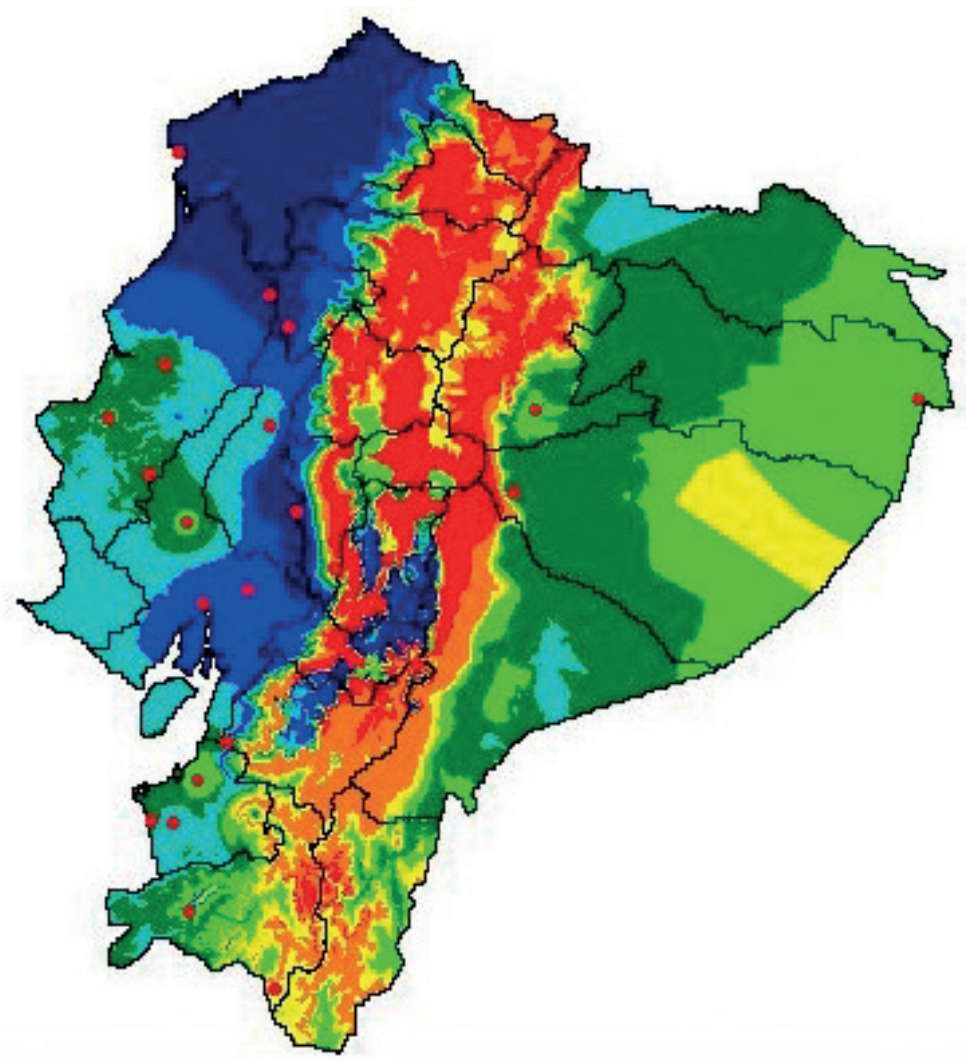




\section{4}

Los valores máximos absolutos de la precipitación máxima en 24 horas (Figura 4.28), con valores de hasta $470 \mathrm{~mm}$ de lluvia caída en 24 horas, zona geográfica que por lo general está alerta en el periodo invernal (fenómeno de la corriente del Niño). El mapa también muestra un área andina central, la costa sur (provincia de El Oro) y extremos norte y sur de la amazonía (Sucumbíos y Morona Santiago), sujeta a lluvias máximas absolutas en 24 horas, y es lo que le diferencia en la distribución del mapa anterior de la precipitación máxima en 24 horas media anual (Figura 4.27); y en valores hay un ascenso de $7 \mathrm{~mm}$ a $46 \mathrm{~mm}$ para el percentil $0-10,70 \mathrm{~mm}$ a $80 \mathrm{~mm}$ para el percentil $50-70$ y de $116 \mathrm{~mm}$ a $320 \mathrm{~mm}$ para el percentil 90-100, todo esto con respecto a la precipitación media máxima en 24 horas. Siguiendo con el ejemplo de las estaciones anteriores, estación M153 Muisne (zona costa norte) ubicada a $6 \mathrm{~m}$ de altitud reporta una media anual de precipitación máxima en 24 horas máxima absoluta de $464 \mathrm{~mm}$, frente a la estación M148 Celica (zona sur andina) ubicada a $1984 \mathrm{~m}$ de altitud que reporta $211 \mathrm{~mm}$ de lluvia máxima, lo que genera un rango de 250 $\mathrm{mm}$ de diferencia entre las dos estaciones (ver Anexo 6).

Figura 4.29

Precipitación máxima en 24 horas mínima absoluta - Ecuador

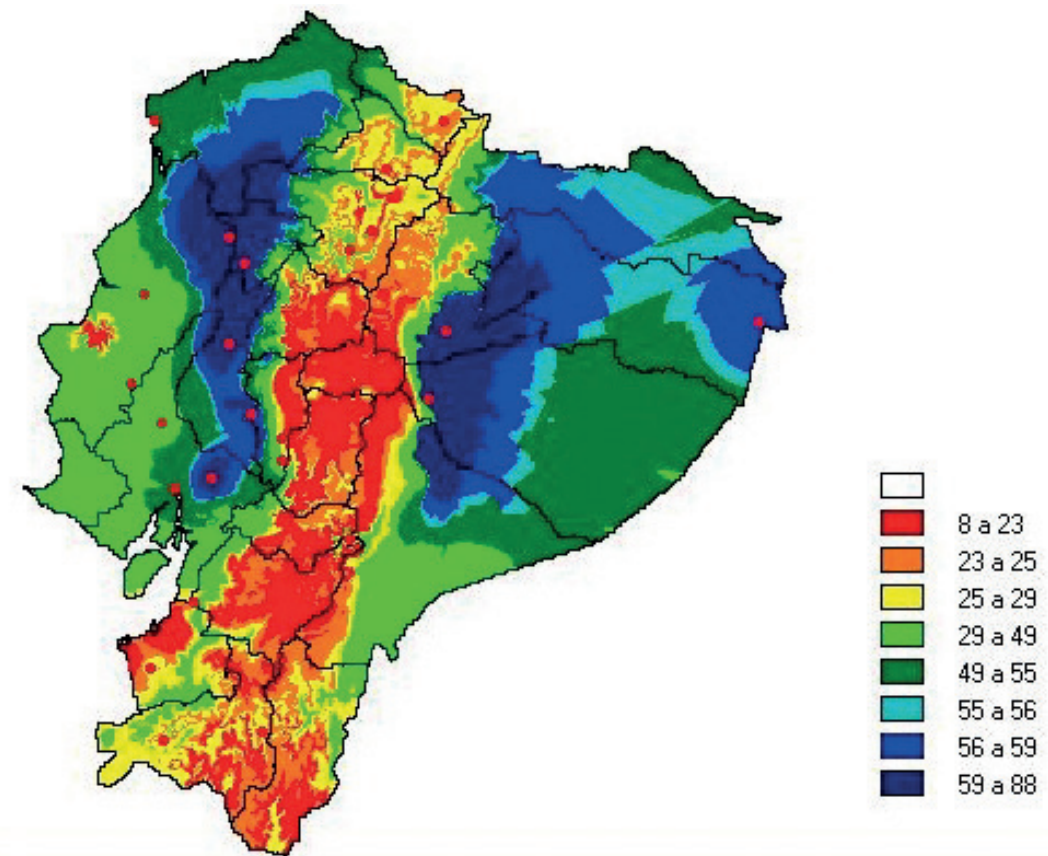

Elaboración: Autor, 2009 


\section{5}

Comparando con la precipitación máxima en 24 horas media anual (Figura 4.27), la distribución de la precipitación máxima en 24 horas mínima absoluta, difiere por cuanto, la región de influencia se ubica en la zona costa norte central y zona amazónica central norte para el percentil $90-100$ con valores de $59 \mathrm{~mm}$ a $88 \mathrm{~mm}$, mientras que la zona andina central sur recibe la influencia del percentil 0-10 con valores de $8 \mathrm{~mm}$ a $23 \mathrm{~mm}$. Respecto a los valores y siguiendo con las estaciones antes citadas, la estación M153 Muisne (zona costa norte) ubicada a $6 \mathrm{~m}$ de altitud reporta una media anual de precipitación máxima en 24 horas mínima absoluta de $52 \mathrm{~mm}$, frente a la estación M148 Celica (zona sur andina) ubicada a $1984 \mathrm{~m}$ de altitud que reporta $30.8 \mathrm{~mm}$ de lluvia, lo que genera un rango de $22 \mathrm{~mm}$ de diferencia entre las dos estaciones (ver Anexo 6).

La precipitación máxima en 24 horas mínima absoluta (Figura 4.29) sufre un descenso de $15 \mathrm{~mm}$ (percentil 0-10) y de $60 \mathrm{~mm}$ para el (percentil 90-100) comparado con la precipitación máxima en 24 horas media anual (Figura 4.27).

Figura 4.30

Precipitación máxima en 24 horas T10 - Ecuador

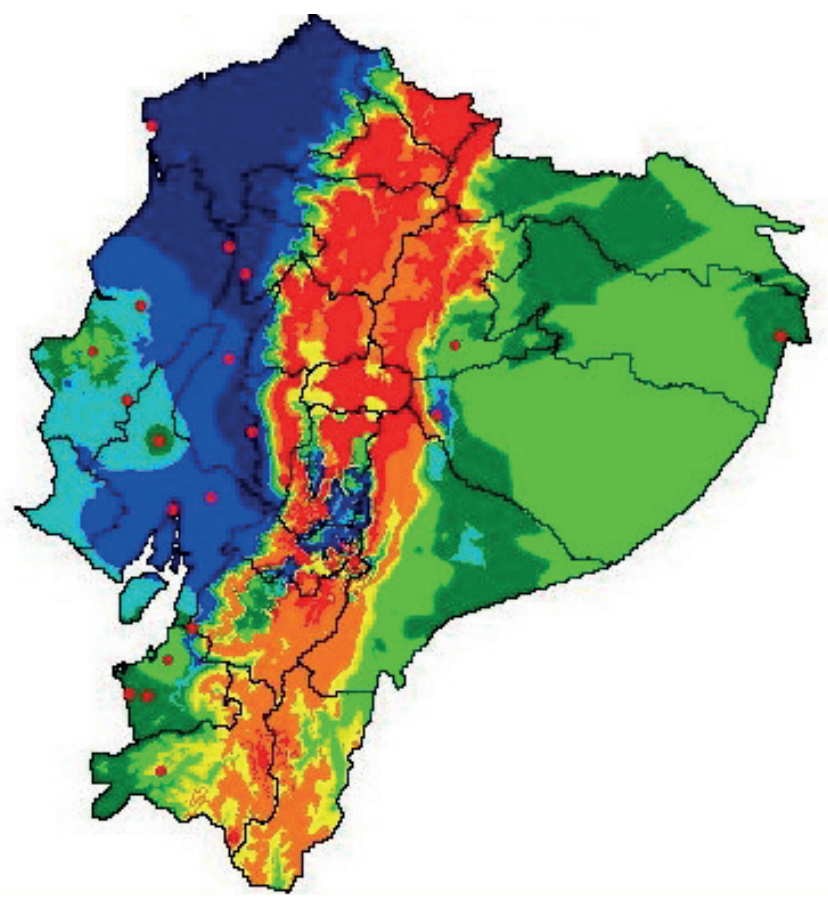


Comparada la distribución Gumbel de T10 tiempo de retorno en diez años (Figura 4.30) con la distribución de la precipitación máxima media anual (Figura 4.47) vemos que cubren las mismas áreas geográficas: zona litoral (norte y central), así como una pequeña zona central de la estribación de la cordillera oriental y parte del norte amazónico con altas precipitaciones máximas (percentil 90-100), pero también aparece un zona central andina con el mismo percentil con valores de 170 a 310 mm de lluvia. Lo último coincide con el área de distribución de la Figura 4.28 de la precipitación máxima en 24 horas máxima absoluta. Por su parte la región andina registra los valores más bajos de precipitación máxima en un periodo de retorno de 10 años (percentil 0-10) con valores 20-70 mm de lluvia. Existe un rango de 150 a $240 \mathrm{~mm}$ de lluvia entre el percentil más bajo y el más alto, lo que indica que cada diez años las zonas antes señaladas en la costa y sierra son sujetas de altas precipitaciones máximas en un periodo de 24 horas. Esto se puede apreciar claramente en el Anexo 4, así por ejemplo la estación M153 Muisne (costa norte) ubicada a $6 \mathrm{~m}$ de altitud reporta los siguientes valores: $121.6 \mathrm{~mm}$ en el año1982, 400 mm en el año 1992 y 93.3 mm en el año 2002; mientras que en la sierra la región andina la estación MA2T Tomalón- Tabacundo ubicada a $2790 \mathrm{~m}$ de altitud reporta los siguientes valores: 26.1 mm en el año 1982, 25.9 mm en el año 1992 y $34.2 \mathrm{~mm}$ en el año 2002. En el caso de la región oriental la estación M008 Puyo ubicada a 960 m de altitud reporta los siguientes valores: $108 \mathrm{~mm}$ en el año 1982, 163.5 mm en el año 1992 y 87.2 mm en el año 2002.

En lo que respecta a los valores de los percentiles comparados con los de la precipitación máxima media anual (Figura 4.27), existe un ascenso entre $20 \mathrm{~mm}$ a $30 \mathrm{~mm}$ para el percentil $0-10$, y entre 60 $\mathrm{mm}$ a $150 \mathrm{~mm}$ para el percentil 90-100.

La predicción realizada para la precipitación máxima en 24 horas para un periodo de retorno de 100 años- T100 (Figura 4.31), muestra una coincidencia general de la distribución con el mapa del periodo de retorno de 10 años (Figura 4.30), sin embargo aparece una mancha amarilla (percentil 20-30) con valores de $130 \mathrm{~mm}$ a $160 \mathrm{~mm}$ 
de lluvia máxima en la zona centro oriental de la Amazonía, aunque por la forma que tiene pude deberse a la interpolación de los datos debido a las pocas y distantes estaciones meteorológicas existentes en la zona. Otro detalle es que los valores de percentiles proyectados con respecto a la precipitación máxima en 24 horas para un T10 (Figura 4.30) son ascendentes entre $20 \mathrm{~mm}$ a $40 \mathrm{~mm}$ para el percentil $0-10, \mathrm{y}$ entre $90 \mathrm{~mm}$ a $200 \mathrm{~mm}$ para el percentil 90-100; y comparado con los valores de la precipitación máxima en 24 horas media anual (Figura 4.27) tiene un ascenso entre $20 \mathrm{~mm}$ a $70 \mathrm{~mm}$ para el percentil $0-10, \mathrm{y}$ entre $140 \mathrm{~mm}$ a $360 \mathrm{~mm}$ para el percentil 90-100.

Figura 4.31

Precipitación máxima en 24 horas T100 - Ecuador

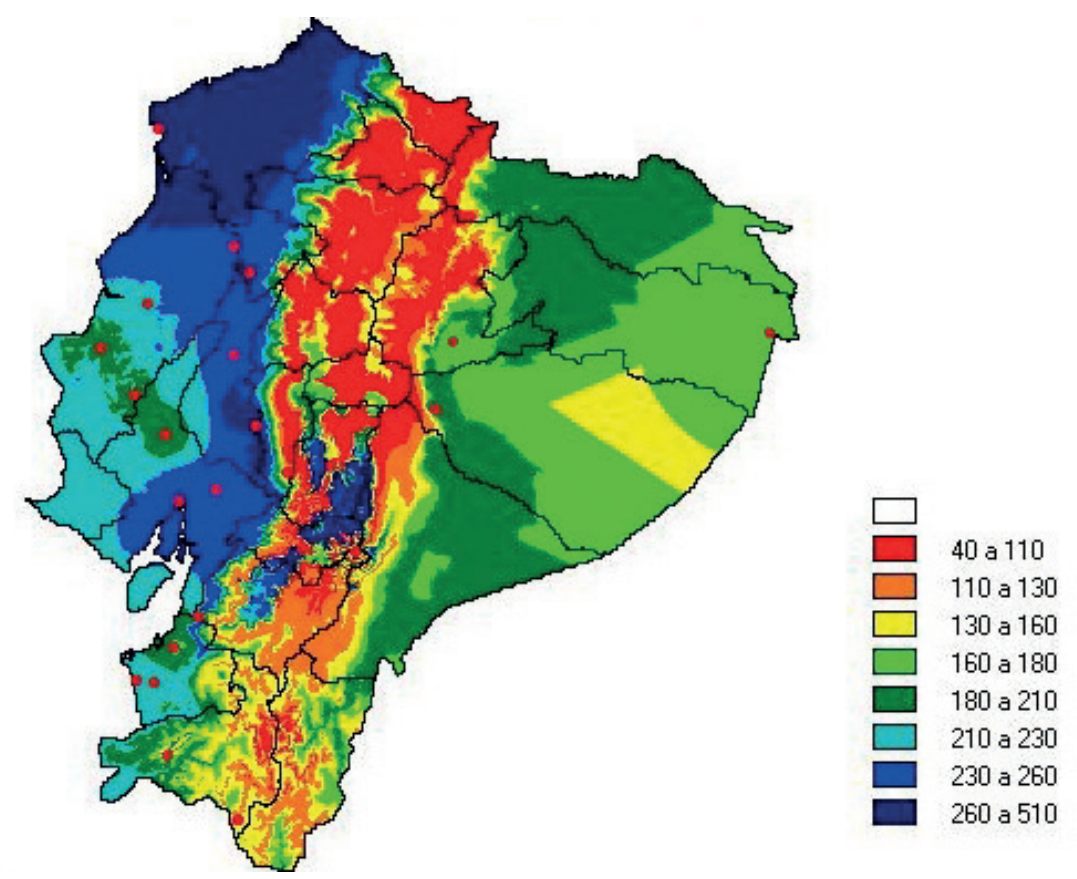

Elaboración: Autor, 2009

Tanto los resultados de precipitación como los de precipitación máxima en 24 horas, coinciden con la apreciación sobre el clima de las regiones del Ecuador (apartado 1.3.3) y favorecen la configuración de la red hidrográfica del Ecuador (apartado 1.1.2 hidrología, Ecuaworld, 2009). 


\section{Precipitación máxima (en 24 horas) en el Ecuador INSULAR O GALÁPAGOS}

Coincidiendo con el periodo invernal del Ecuador continental, la precipitación máxima en 24 horas llega a sus máximos valores durante los meses de febrero a junio. Así por ejemplo la estación M221 San Cristóbal ubicada a $6 \mathrm{~m}$ de altitud reporta una media de $34.9 \mathrm{~mm}$ y en marzo $32 \mathrm{~mm}$ de lluvia (ver tablas y gráficos de anexo 5).

El rango entre los percentiles no es mayor a 8 puntos, lo cual significa que la precipitación máxima en 24 horas tiende a ser uniforme en las islas, sin embargo la Figura 4.32 muestra que el percentil 90-100 se ubica en las cumbres de los volcanes.

Figura 4.32

Precipitación máxima en 24 horas media anual - Galápagos

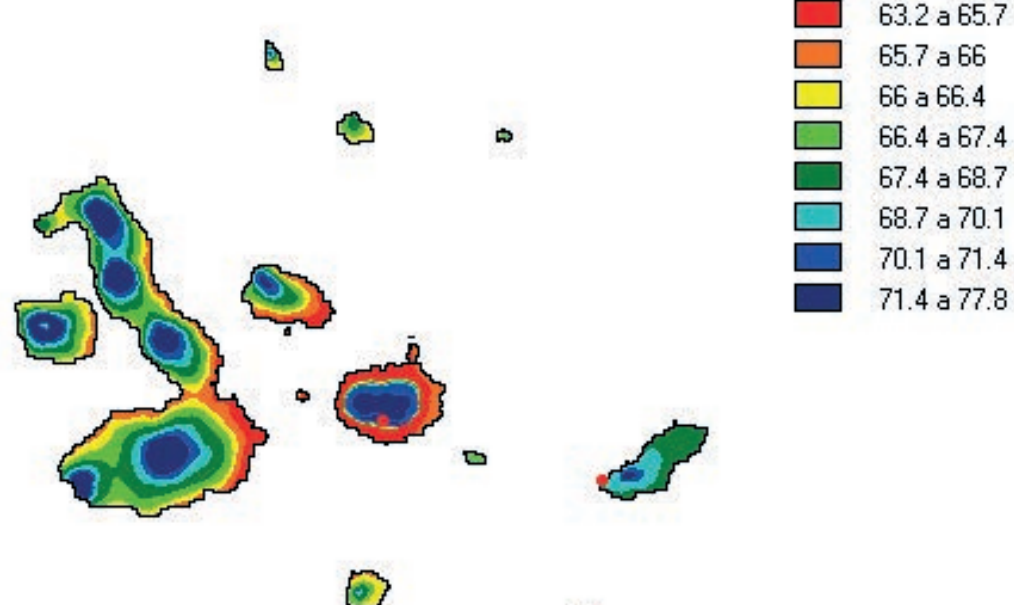

Elaboración: Autor, 2009

La ubicación de los percentiles en el mapa (Figura 4.32) dista de la realidad, pues los percentiles mayores deberían colorear las zonas costeras de las islas. Esta incongruencia sucede porque al existir datos de tres estaciones solamente, dos ubicadas a $6 \mathrm{~m}$ de altitud y una a $194 \mathrm{~m}$ de altitud, frente a la altitud de los volcanes promedio de $1500 \mathrm{~m}$, la correlación de datos se vuelve inaplicable, generando resultados como el indicado en la Figura 4.32 y que se volverá a repetir 


\section{9}

en las figuras 4.34 (precipitación máxima en 24h mínima absoluta) y 4.58 (evapotranspiración según Hargreaves). Es indispensable entonces, tener información de más estaciones y que estén ubicadas a mayor altura, si las hubiera o de lo contrario para futuros trabajos considerar la implantación de las mismas.

Gráfico 4.3

Relación altitud geográfica $(\mathrm{m})$ versus ubicación de estaciones (m) en las Islas Galápagos

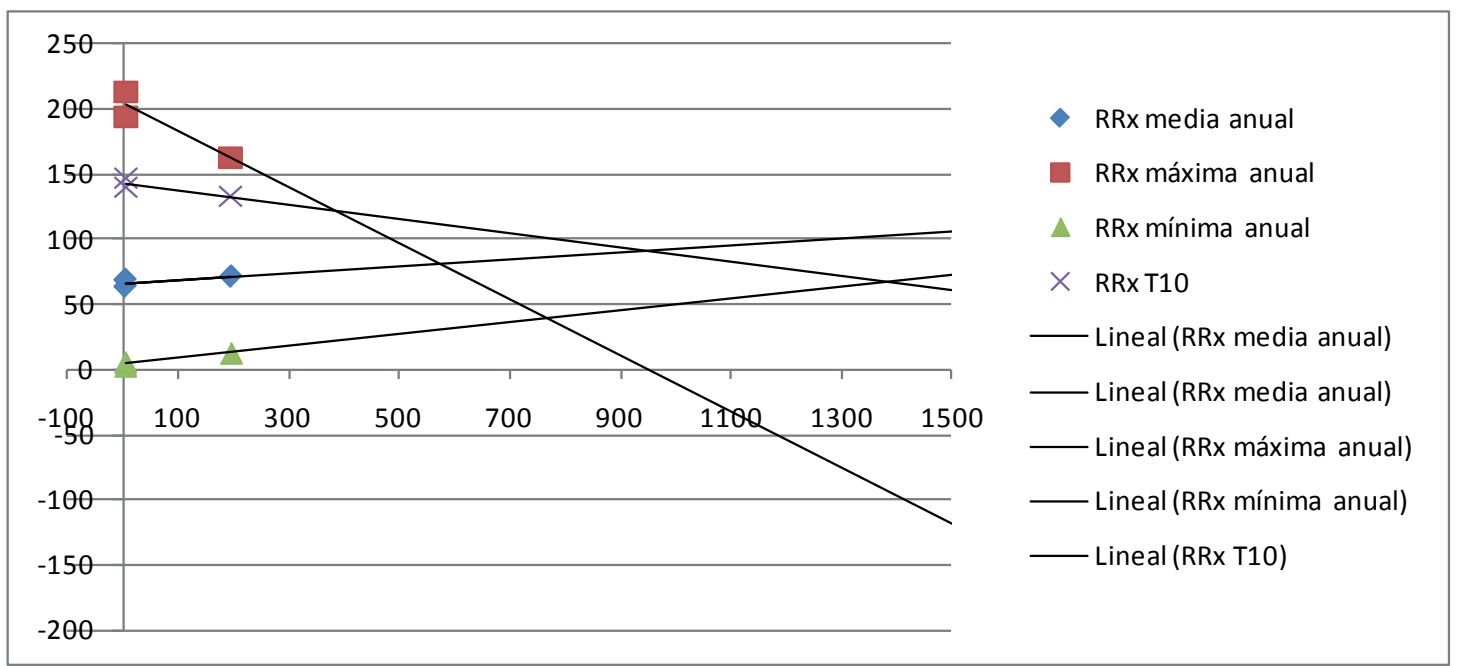

Elaboración: Autor, 2009

Figura 4.33

Precipitación máxima en 24 horas máxima absoluta - Galápagos

(a)

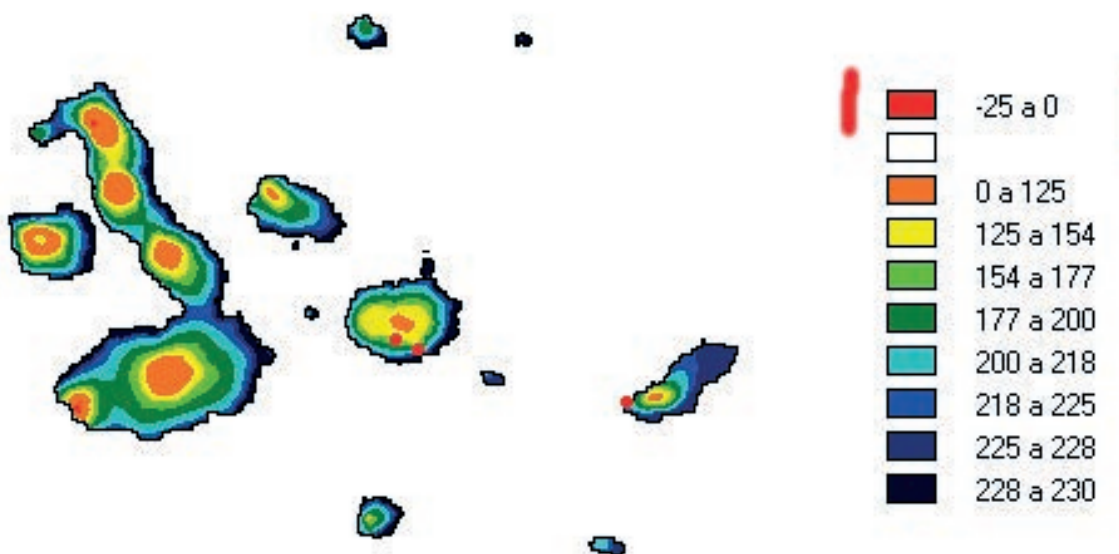

Elaboración: Autor, 2009 
100

Los valores del percentil $-25 \mathrm{~mm}$ a $0 \mathrm{~mm}$ (Figura 4.33) son valores hipotéticos fruto de la regresión, y en realidad no existe una precipitación negativa, simplemente quiere decir que no hubo precipitación en las zonas geográficas marcadas con ese percentil. Los valores máximos de precipitación máxima en 24 horas se han producido a nivel de las zonas costeras (playas) de las islas Galápagos, coincidiendo con lo que ocurre en el Ecuador continental donde la mayor cantidad de la precipitación máxima en 24 horas está a nivel del mar (Costa y Oriente), ver y comparar con figura 4.28. Comparada con la precipitación máxima en 24 horas media anual (Figura 4.32), existe un ascenso de unos $150 \mathrm{~mm}$ de lluvia. Los meses de mayor descarga de la precipitación máxima en 24 horas máxima absoluta están entre febrero y junio, así la estación M221 San Cristóbal reporta 213.5 mm en Abril y 207 mm en Mayo (ver Anexo 5).

Figura 4.34

Precipitación máxima en 24 horas mínima absoluta - Galápagos

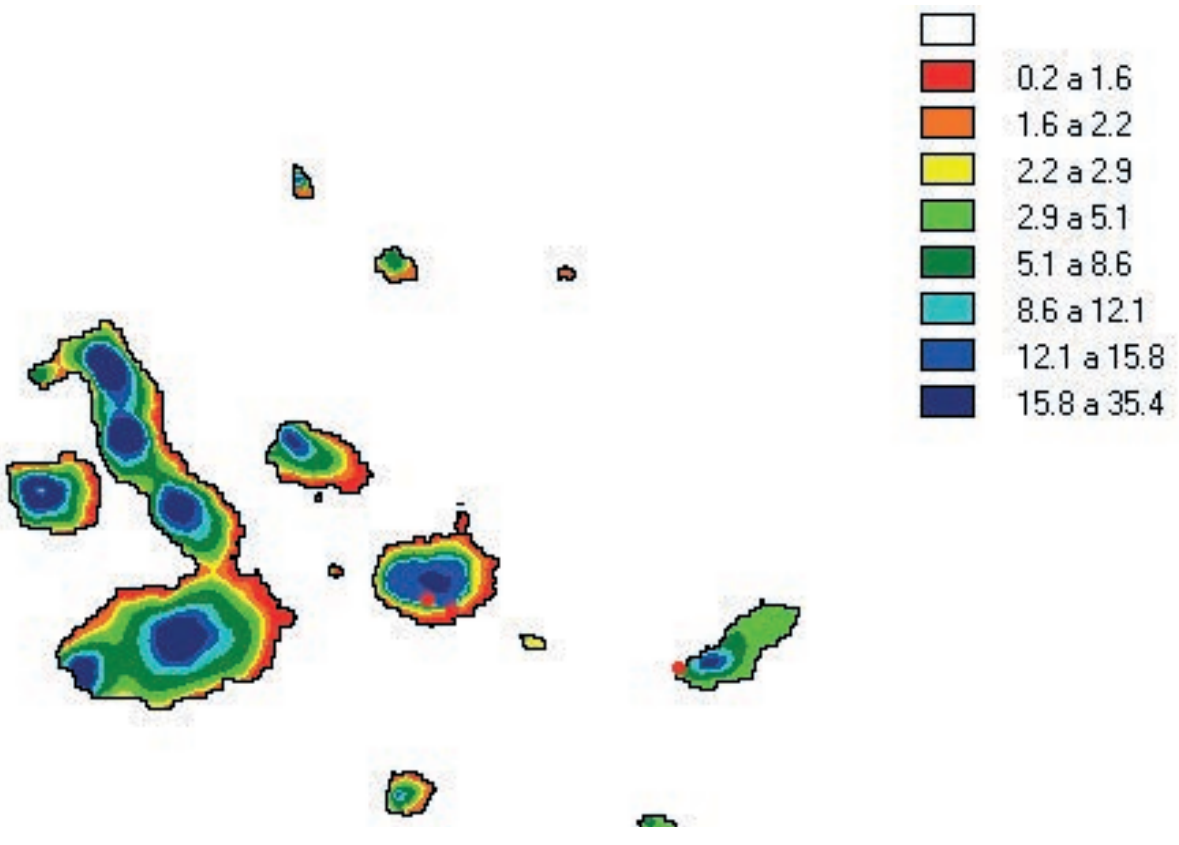

Elaboración: Autor, 2009

La Figura 4.34 indica que los valores de la precipitación máxima en 24 horas mínima absoluta son retenidos en sus percentiles 


\section{1}

mayores en las zonas altas de las islas. Tiene un rango de 15 puntos entre el percentil 0-10 y el 90-100, que no es muy amplio, lo que significa una cierta uniformidad en la distribución de la precipitación en el territorio insular en cuanto a mínimas absolutas. Comparado con la precipitación máxima en 24 horas media anual sufre un descenso entre $55 \mathrm{~mm}$ a $70 \mathrm{~mm}$ de lluvia máxima.

Figura 4.35

Precipitación máxima en 24 horas T10 - Galápagos

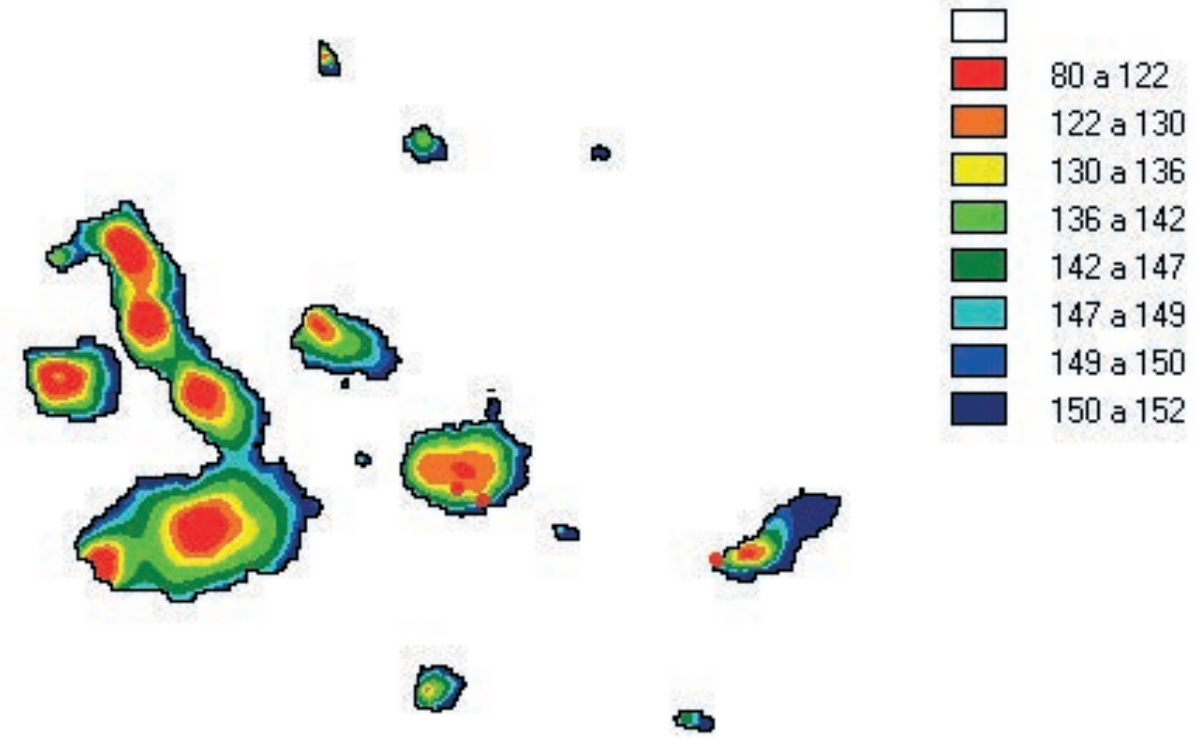

Elaboración: Autor, 2009

Comparada la precipitación máxima en 24 horas para un periodo de retorno de diez años T10 (Figura 4.35) con los valores de la precipitación máxima en 24 horas media anual (Figura 4.32), vemos que hay ascenso de $20 \mathrm{~mm}$ a $60 \mathrm{~mm}$ para el percentil $0-10$ y de 70 $\mathrm{mm}$ a $80 \mathrm{~mm}$ para el percentil 90 -100. Como ejemplo del tiempo de retorno de 10 años presentamos los valores de la estación M221 San Cristóbal ubicada a $6 \mathrm{~m}$ de altitud: $80.8 \mathrm{~mm}$ para el año 1982, $70.8 \mathrm{~mm}$ para el año 1992 y 80.3 para el año 2002. (ver Anexo 4). El rango no es muy distante, y se puede decir que el periodo de retorno de diez años ha sido muy parecido. 
102

Comparando la Figura 4.35 (tiempo de retorno en 10 años) con la Figura 4.36 (tiempo de retorno en cien años), la distribución de la lluvia máxima en 24 horas, es uniforme en las islas y en cada isla, situándose los percentiles de alta pluviosidad (90-100) en las playas o zona costera; pero, también es de notar que las cantidades de T100 casi duplican a las T10, especialmente en los percentiles altos 90-100 (268 $\mathrm{mm}$ contra $152 \mathrm{~mm}$, respectivamente. No así con el percentil más bajo $0-10$, que prácticamente se mantiene el mismo valor de $80 \mathrm{~mm}-120$ $\mathrm{mm}$. Esto indica que cada cien años, repite un fenómeno de mayor precipitación máxima en 24 horas cuya pluviosidad se distribuye en las partes geográficas bajas de las islas en una especie de inundación. Esto concuerda con la distribución pluvial especificado en las Figura 4.33 (Precipitación máxima en 24 horas máxima absoluta - Galápagos).

Figura 4.36

Precipitación máxima en 24 horas T100 - Galápagos
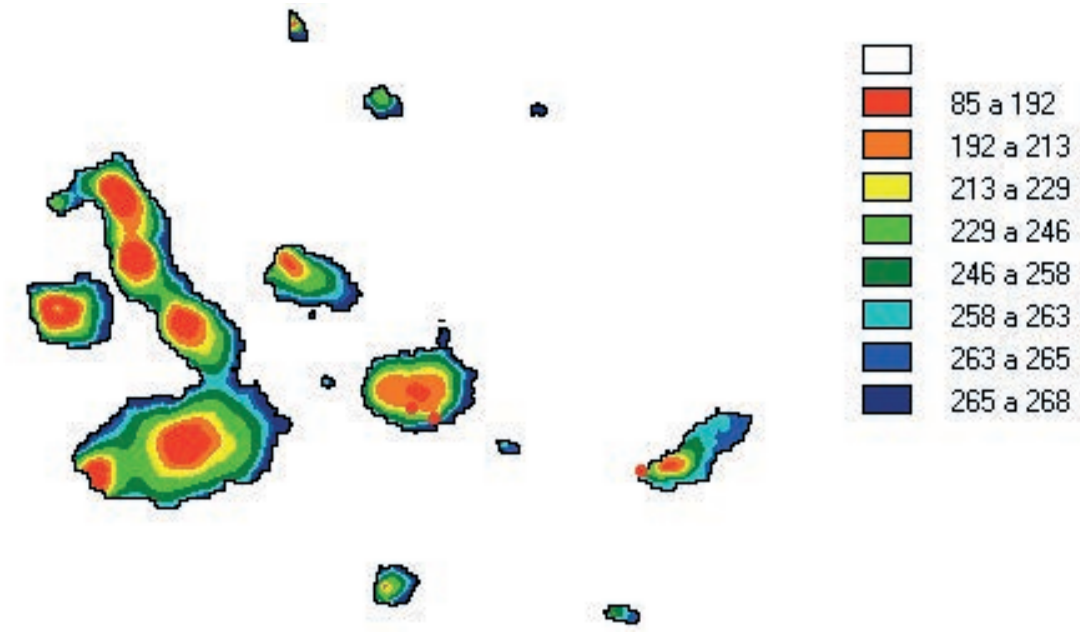

Elaboración: Autor, 2009

\section{Análisis de la humedad relativa}

Para el análisis de la humedad relativa del periodo en estudio 1980 -2006, igual que para el caso de los elementos del clima anteriores, se separa el Ecuador continental del insular. El análisis se basa en tablas, gráficos y mapas generados a partir de los datos INAMHI 2009. 
103

\section{Tablas y gráficos}

Los anexos generados son: Anexo 7, tablas de cálculo de medias y desviación típica, y el anexo 8 que corresponde a tablas gráficos de medias y desviación típica. Los resultados indican que la humedad relativa está relacionada íntimamente con la precipitación o cantidad de lluvia caída y la temperatura, así los valores altos de humedad relativa corresponde a los meses invernales y los más bajos a los de sequía o verano. Caso particular es el del Oriente donde la humedad relativa tiene valores altos y continuos como por ejemplo la estación M008 Puyo ubicada a $920 \mathrm{~m}$ de altitud reporta $90.74 \%$ para junio (valor más alto) y $87.11 \%$ en agosto (valor más bajo) ver en Anexo 7. En todo caso y en todo el territorio nacional, la humedad relativa se conserva sobre el 70\% como promedio deducidos del periodo sujeto de esta investigación. Los promedios más bajos, pero siempre por sobre el 70\%, son las estaciones de la región andina, como por ejemplo la estación M139 Gualaceo ubicada a $2360 \mathrm{~m}$ de altitud reporta $79.37 \%$ en abril y 74.97 en noviembre (ver anexo 7). El siguiente gráfico (4.3), resume lo expuesto de la relación altitud versus humedad relativa anual y confirma que en el Ecuador continental e insular no baja del 70\% durante todo el año.

\section{Gráfico 4.4}

Relación entre la altitud (m) y la humedad relativa anual (\%)

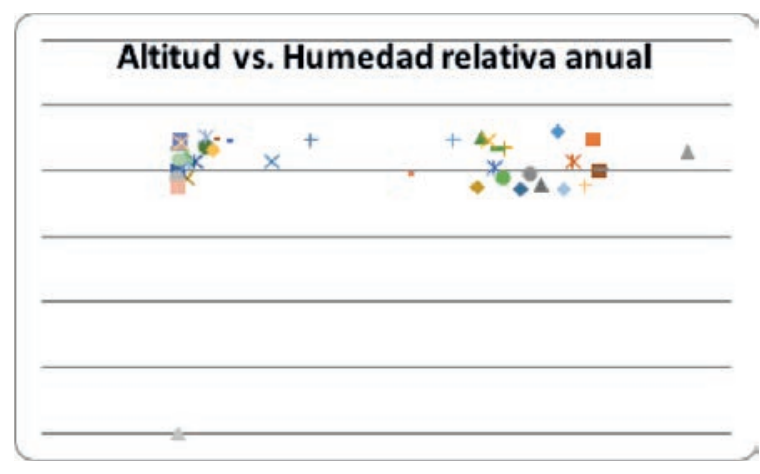

Elaboración: Autor, 2009

\section{Cartografía}

La generación de mapas se basa en los percentiles 0-10, 10-20, 20-30, 30-50, 50-70, 70-80, 80-90 y 90-100, correspondiendo los colores rojo ladrillo al percentil más bajo y el azul intenso al percentil más alto. 
104

\section{Humedad RElativa en el ECUADor CONTINENTAL}

La distribución de la humedad relativa en los mapas del Ecuador continental, son muy aproximados a los que muestran la distribución de la precipitación (Figuras 4.15, 4.16, 4.17 y 4.18). Lógicamente el porcentaje de humedad relativa presente obedece a la cantidad de lluvia caída, sin embargo como se puede ver en el anexo 8 , las estaciones de la región andina reportan humedades que pasan el $70 \%$ pero no superiores a $85 \%$, y esto se debe a la presencia de otros elementos y factores climáticos que afectan al porcentaje de humedad presente que se estudiarán más adelante.

Figura 4.37

Humedad relativa media anual - Ecuador

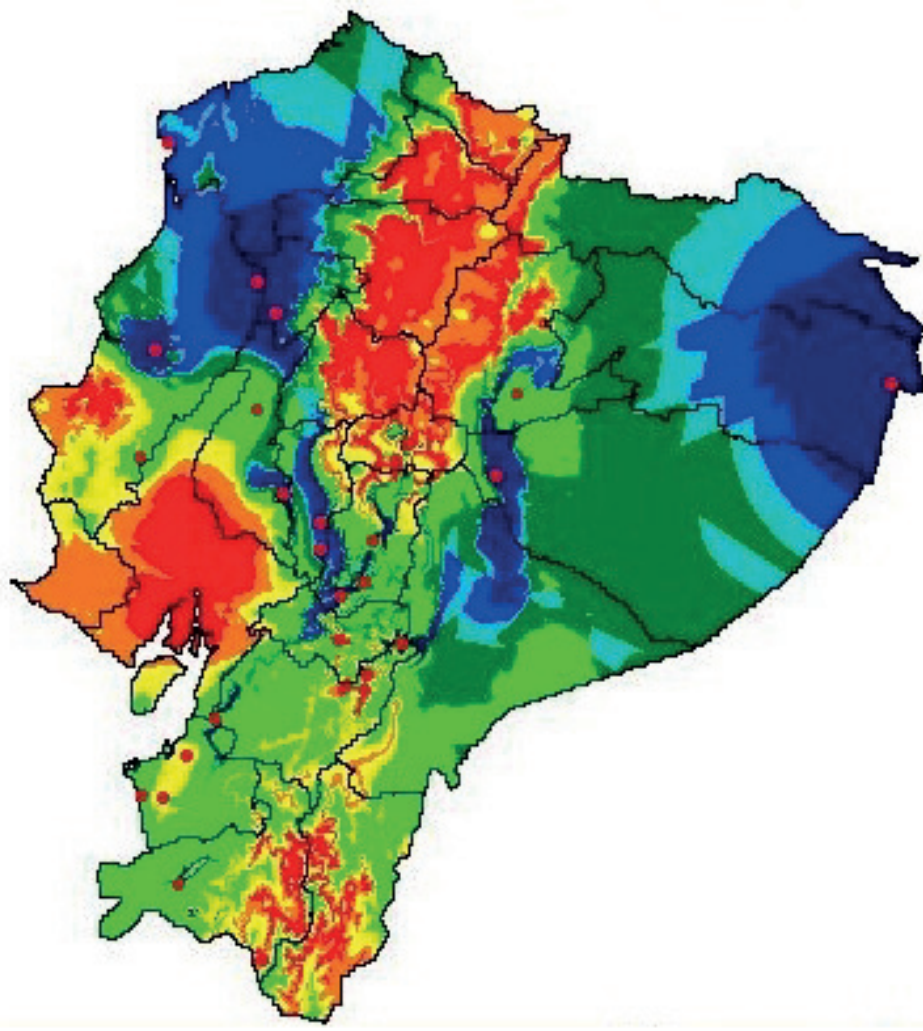

74.3 a 80.2

80.2 a 81.6

81.6 a 82.9

82.9 a 84.6

84.6 a 85.3

85.3 a 85.6

85.6 a 86.1

86.1 a 91.9

Elaboración: Autor, 2009

La Humedad relativa media anual (Figura 4.37) muestra una distribución típica del porcentaje de humedad relativa en el área continental. Los percentiles bajos (0-10) se ubican en la zona andina norte 


\section{5}

y sur, y el sur de la costa ecuatoriana (Guayas, Santa Elena, Sur de Manabí). La zona central andina (Chimborazo, Cañar y Azuay) presentan porcentajes sobre el $80 \%$ promedio anual (percentil 30-50). Igual caso sucede con la zona sur y central del Oriente. Por el contrario los valores más altos de humedad ( $86 \%-92 \%)$, están en la zona norte oriental y central occidental de la Amazonía y la costa norte. Un punto a resaltar es la presencia de humedad sobre el $80 \%$ (percentil 30-50) en la provincia sur del Ecuador (provincias de El Oro y Loja), cuyas precipitaciones son escasas menores a $1000 \mathrm{~mm}$ promedio anual (ver Figura 4.15, percentil 20-30); así por ejemplo la estación M179 Arenillas ubicada en el sur a 60 $\mathrm{m}$ de altitud reporta $82.5 \%$ de humedad relativa anual (ver Anexo 8).

Existe un rango de 12 puntos entre el percentil 0-10 y el 90100 , lo que significa que no hay mayor distancia entre zonas en cuanto a porcentaje de humedad relativa se refiere.

\section{Figura 4.38}

Humedad relativa de mayo - Ecuador

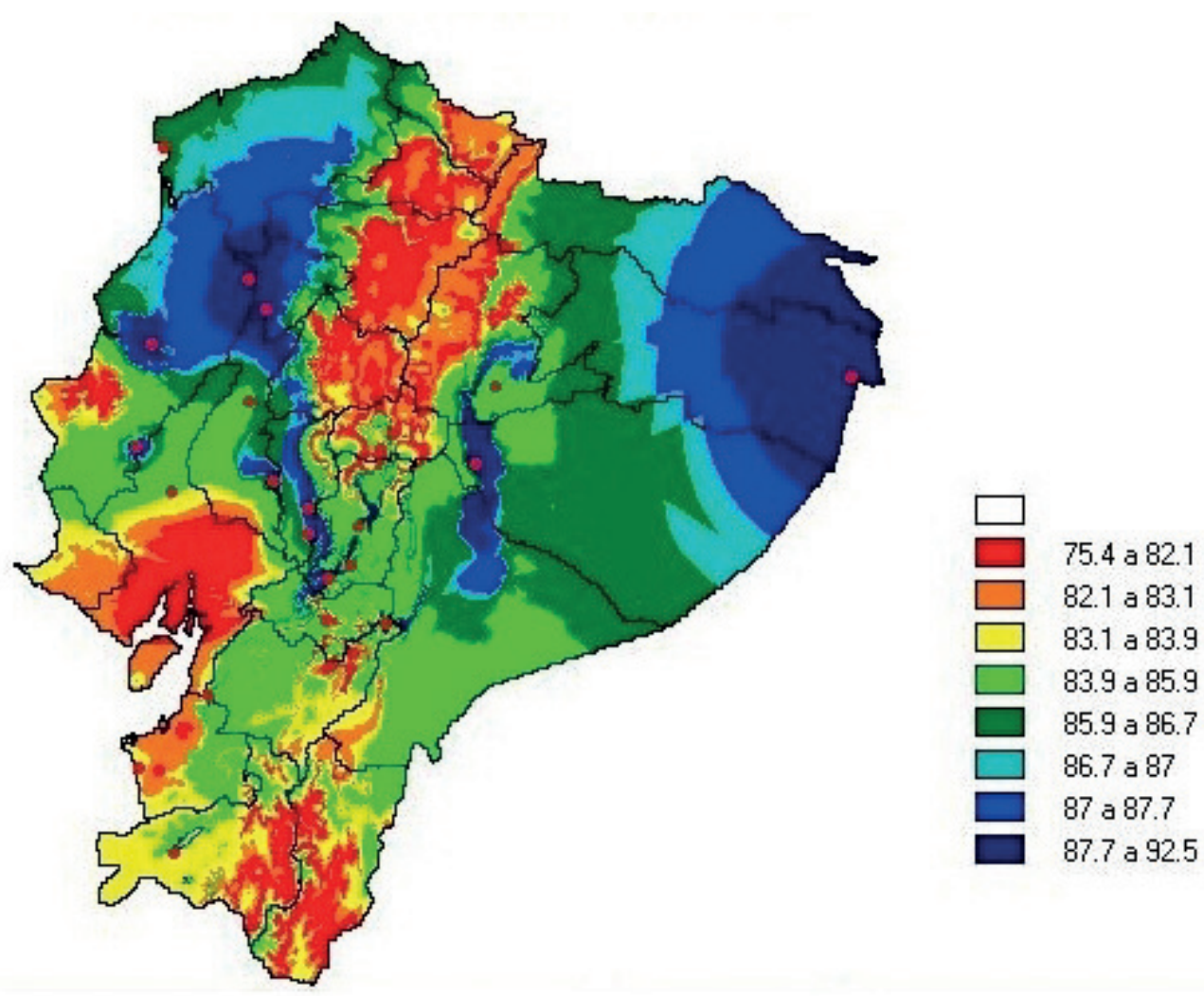

Elaboración: Autor, 2009 
106

Los datos promedios de humedad relativa de mayo (Figura 4.38) coincide en su distribución coincide con los de la precipitación media mayo (Figura 4.17) y la temperatura media mayo (Figura 4.6), pues al ser un mes de invierno intenso y de altas temperaturas, se produce más evapotranspiración y en consecuencia mayor humedad presente en la atmósfera. Sin embargo el menor porcentaje de humedad de 75\% (percentil 0-10) se encuentra en la zona andina norte y en la zona de la costa central y sur (provincias del Guayas, Santa Elena, El Oro), y el extremo sur de la sierra (provincias de Zamora Chinchipe y Loja). La estación M182 Chone ubicada en la costa central norte a $20 \mathrm{~m}$ de altitud reporta $89.8 \%$ de humedad relativa en mayo, mientras que la estación M033 Argelia-Loja ubicada en el sur a 2160 m de altitud reporta 75.9\% de humedad relativa media anual (ver Anexo 8).

Figura 4.39

Humedad relativa de agosto - Ecuador

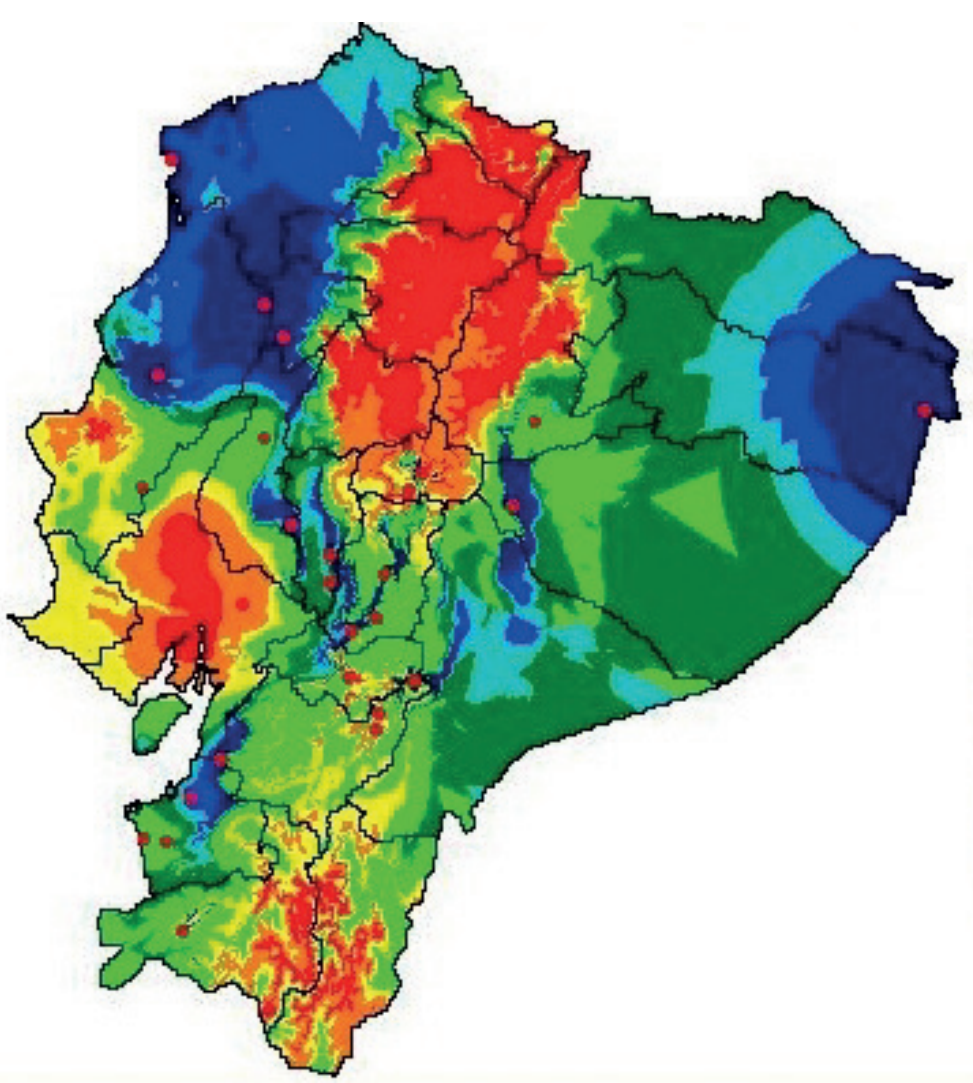


107

Comparando con los valores de la humedad relativa media anual (Figura 4.37), la humedad relativa media de mayo sube 1 punto, es decir no marca diferencia significativa.

Igual coincidencia distributiva de áreas geográficas de la humedad relativa (Figura 4.39), con las de la precipitación media en agosto (Figura 4.18) y la temperatura media de agosto (Figura 4.8). El porcentaje de humedad baja ostensiblemente en la región andina y la zona de costa central sur (cuenca del río Guayas) hasta valores del 64\% (percentil 0-10), y en la región oriental y norte de la costa a 85\% (percentil 90-100). Se nota un desplazamiento de alta humedad a la zona central del sur de la costa (norte de la provincia de El Oro y sur del Guayas), así como en la costa norte (norte de Manabí y Esmeraldas).

Comparando los valores con la humedad relativa media anual (Figura 4.37), la humedad relativa de agosto presenta un descenso de 10 puntos en el percentil 0-10 y de 1 punto en el percentil 90-100. El mayor descenso se produce a nivel de la zona andina norte (Figura 4.39).

\section{Humedad Relativa en el Ecuador insular o GaláPagos}

Figura 4.40

Humedad relativa media anual - Galápagos

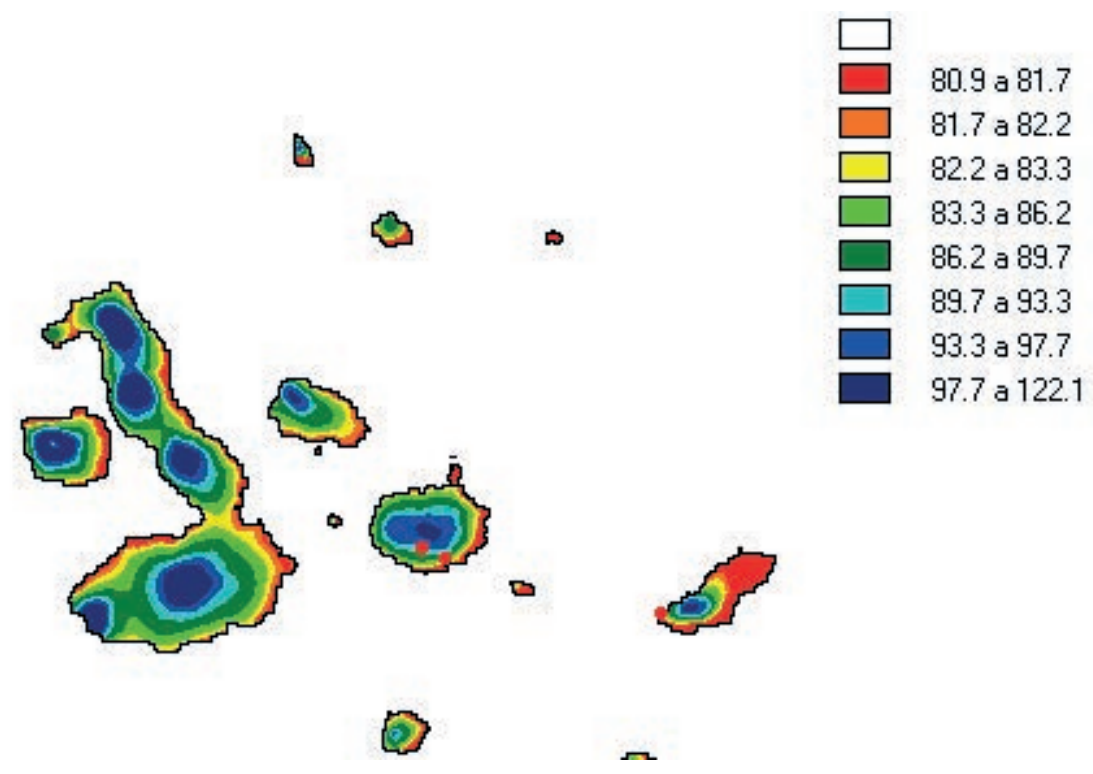

Elaboración: Autor, 2009 
108

La Figura 4.40 muestra la distribución de la humedad relativa media anual en las islas que es bastante uniforme, constituyendo las cumbres de los volcanes y sus estribaciones los que guardan la mayor cantidad de humedad, mientras que la zona costera tiene la clase de 81\%-82\% ( percentil 0-10). Esto concuerda con la distribución de la precipitación anual (Figura 4.21) y la temperatura media anual (Figura 4.12), y una similitud con la distribución de la humedad relativa anual en el Ecuador continental (Figura 4.37). Existe un rango de 17 puntos de diferencia entre el percentil 0-10 y el percentil 90-100, significando que hay una alta variación de la humedad relativa entre las zonas de playa hacia las cumbres de los volcanes.

Figura 4.41

Humedad relativa mayo - Galápagos

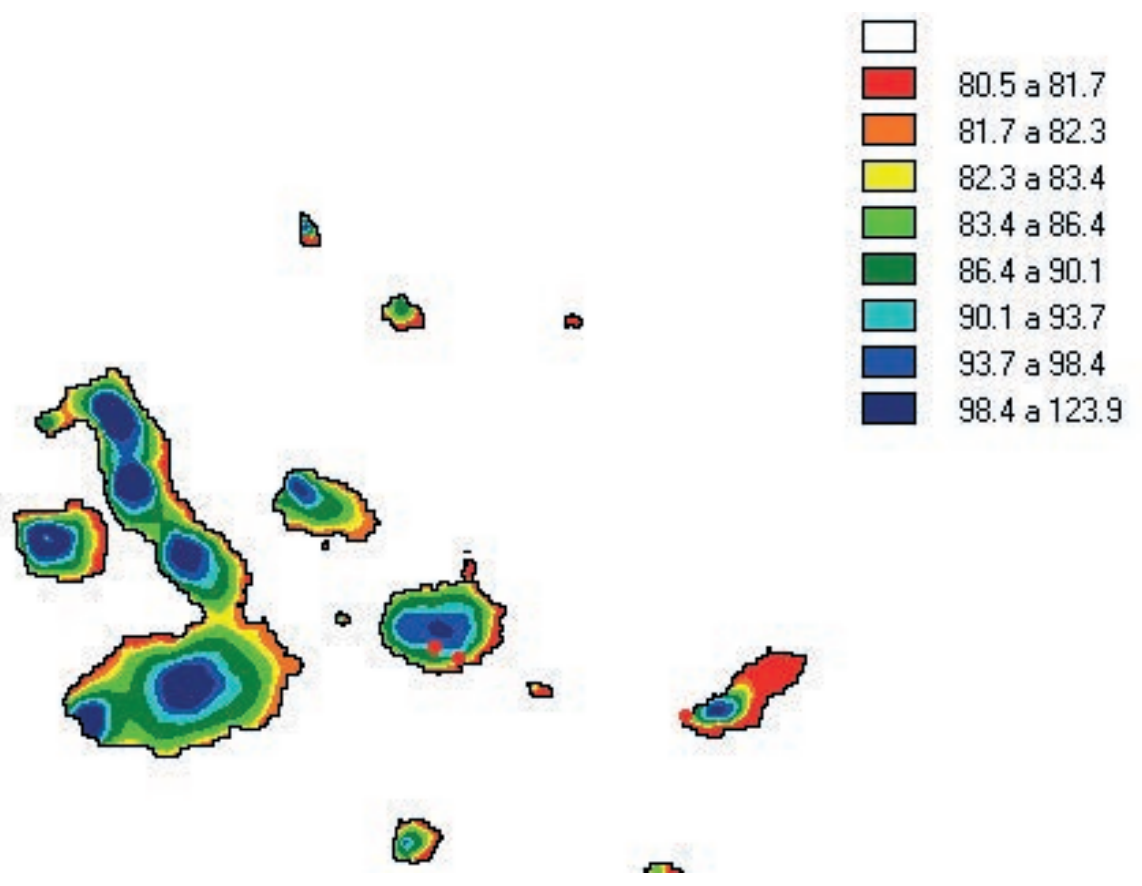

Elaboración: Autor, 2009

Los valores de la humedad relativa de mayo (Figura 4.41) prácticamente se mantienen iguales que los de la humedad relativa media anual (Figura 4.40), salvo en el percentil 90-100 donde se incrementa $0.7 \%$, e igualmente el rango de 18 puntos entre el percentil 0-10 y el 90-100, muestran que hay una alta variación de la humedad 


\section{9}

relativa entre las zonas de playa hacia las cumbres de los volcanes. Por ejemplo la estación M192 Bella Vista -Santa Cruz ubicada a 194 $\mathrm{m}$ de altitud reporta en mayo 91\% frente a 90.9\% de humedad relativa media anual (ver Anexo 8).

Figura 4.42

Humedad relativa agosto - Galápagos

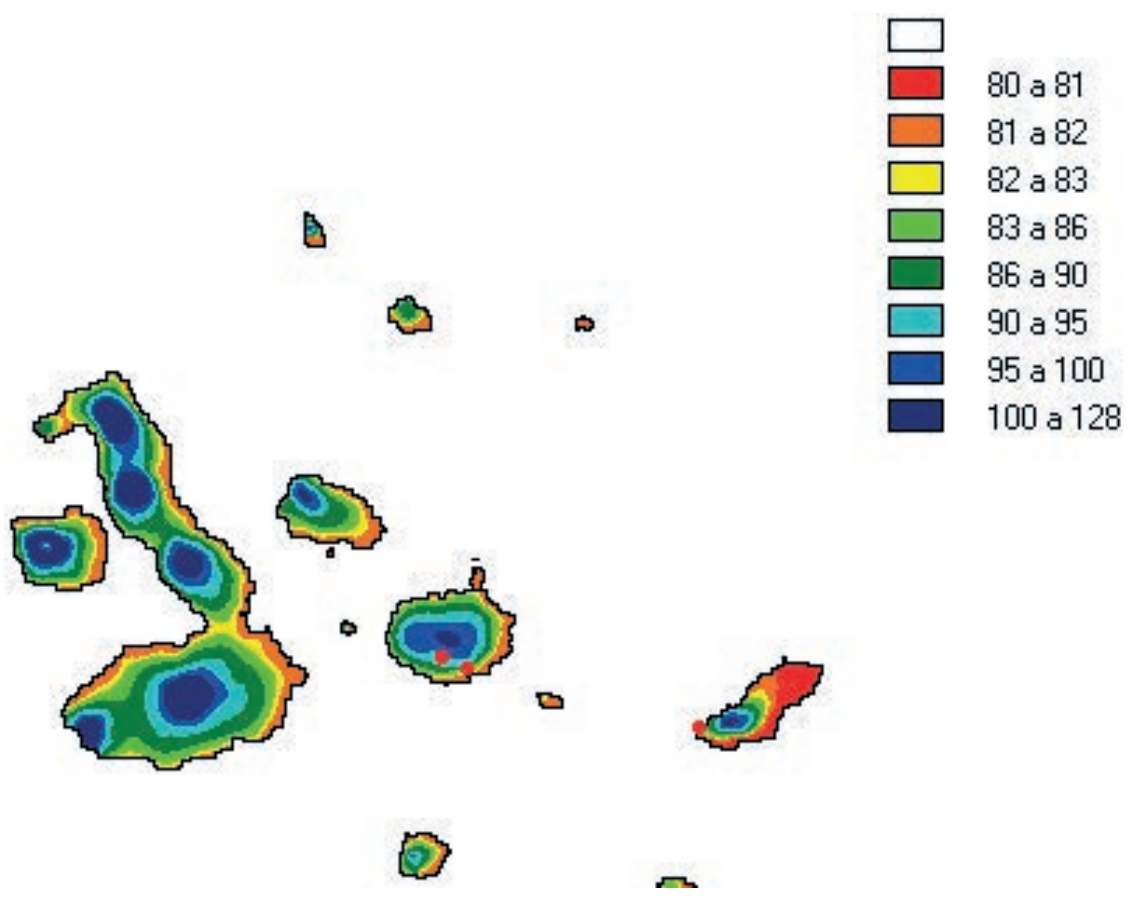

Elaboración: Autor, 2009

Los valores de la humedad relativa de agosto en Galápagos (Figura 4.42) se mantiene en valores parecidos a los de la humedad relativa media anual (Figura 4.40), salvo el percentil 90-100 que incrementa en 4 puntos.

Los porcentajes de humedad en los meses de mayo (Figura 4.41) y agosto (Figura 4.42), son parecidos, al igual que la distribución geográfica en las islas. Sin embargo los percentiles bajos de humedad relativa, son los que dominan en la extensa zona costera lo que le da la categoría de zona seca a lo largo de todo el año (ver apartado correspondiente al clima). 
110

\section{Análisis del viento}

El elemento viento como regulador del clima ecuatoriano, de acuerdo a los resultados obtenidos a partir de los datos INAMHI para el periodo 1980-2006, muestra velocidades y direcciones variadas que determinan una distribución geográfica propia, por lo que fue menester al igual que para los otros elementos del clima, separar el análisis para el Ecuador continental y el insular.

\section{Tablas y gráficos}

Los anexos 9 y 10 contienen las tablas de dirección dominante y velocidad del viento. Se confirmó la ausencia de datos de las estaciones 192 (Bellavista-Isla San Cristóbal) y 250 (CEDEGE), por lo que las estaciones consideradas en total son 39, de las cuales dos están en las islas Galápagos. Los datos enviados por el INAMHI están en $\mathrm{m} / \mathrm{s}$, en base de los cuales se ha calculado la media y la desviación estándar. En general los gráficos muestran que la zona de vientos fuertes está en la región Sierra y con dirección norte, por ejemplo la estación M033 La Argelia -Loja ubicada en el sur andino a $2160 \mathrm{~m}$ de altitud reporta que 11 de los doce meses del año tiene dirección dominante norte a una velocidad media de $9.4 \mathrm{~m} / \mathrm{s}$ y por el contrario la estación M Milagro-Valdez ubicada en la zona costa centro norte oriental a $13 \mathrm{~m}$ de latitud reporta que los doce meses del año tiene dirección sur oeste a una velocidad de $4.5 \mathrm{~m} / \mathrm{s}$ (ver anexos 9 y 10).

\section{Cartografía}

Los mapas generados muestran la dirección dominante y velocidad del viento tanto en la zona continental como en la insular, en base de los percentiles 0-10, 0-20, 20-30, 30-50, 50-70, 70-80, 80-90, 90-100. En este caso el color azul intenso indica la zona geográfica de mayor velocidad del viento y el color rojo las de menos intensidad. 
111

\section{VIENTO EN EL ECUADOR CONTINENTAL}

Para facilitar una comprensión didáctica se han tomado dos meses del año, mayo y agosto, para analizar la media de la velocidad y dirección dominante.

Figura 4.43

Viento velocidad media mayo $(\mathrm{m} / \mathrm{s})$ - Ecuador

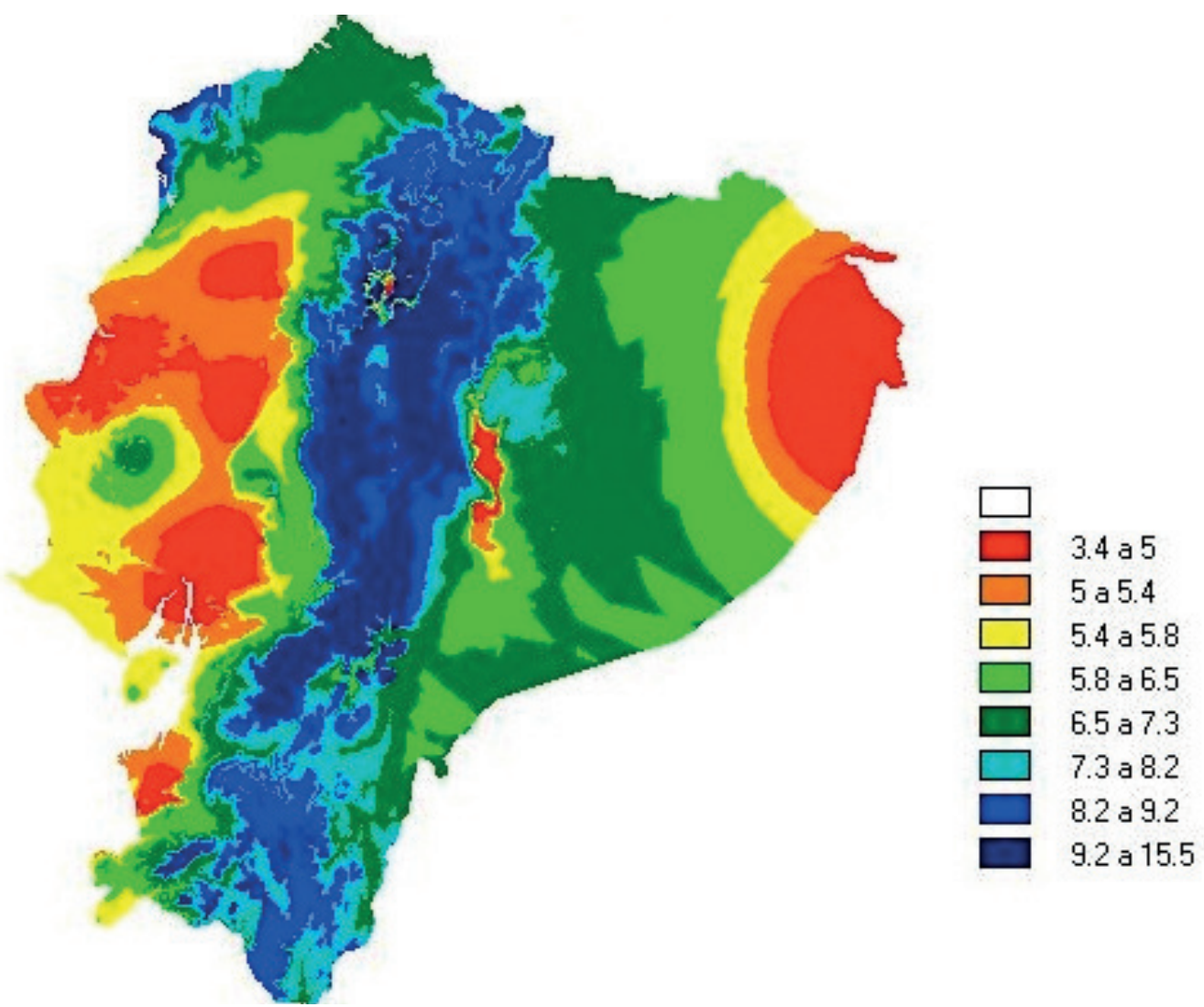

Elaboración: Autor, 2009

Comparando las figuras 4.43 (mayo) con la figura 4.44 (agosto), la distribución de la velocidad media en bastante similar en el territorio continental, salvo zonas de intensidad ventosa que aparecen en el mapa de mayo y que desaparecen en agosto como son el sur occidente de la provincia de Esmeraldas (costa norte occidental). La zona andina es la que concentra la velocidad del viento con los percentiles más altos 90-100 (11.8-19.3 m/s). El norte del litoral y el sur del Oriente concentran valores intermedios con los percentiles 50-70 $(7.2-8.7 \mathrm{~m} / \mathrm{s})$ y 
los valores más bajos (percentiles 0-10) están en la Costa centro - sur occidental y en la Amazonía norte-este. Conociendo que la ubicación de las altas temperaturas (ver Figura 4.1 temperatura media anual) están en esta última zona, se puede entender que el clima tropical sea sofocante por la poca movilidad e intensidad del viento.

Los valores del viento velocidad media de mayo (Figura 4.43) son muy parecidos a los de agosto (Figura 4.44), salvo que en los percentiles más altos 50 a 100, hay un incremento a favor del mes de agosto en unos 2 puntos. Esto regula la humedad relativa en el mes de agosto en la zona andina especialmente, cuando hay un decrecimiento del \% de HR (ver Figura 4.39).

\section{Figura 4.44}

Viento velocidad media agosto $(\mathrm{m} / \mathrm{s})$ - Ecuador

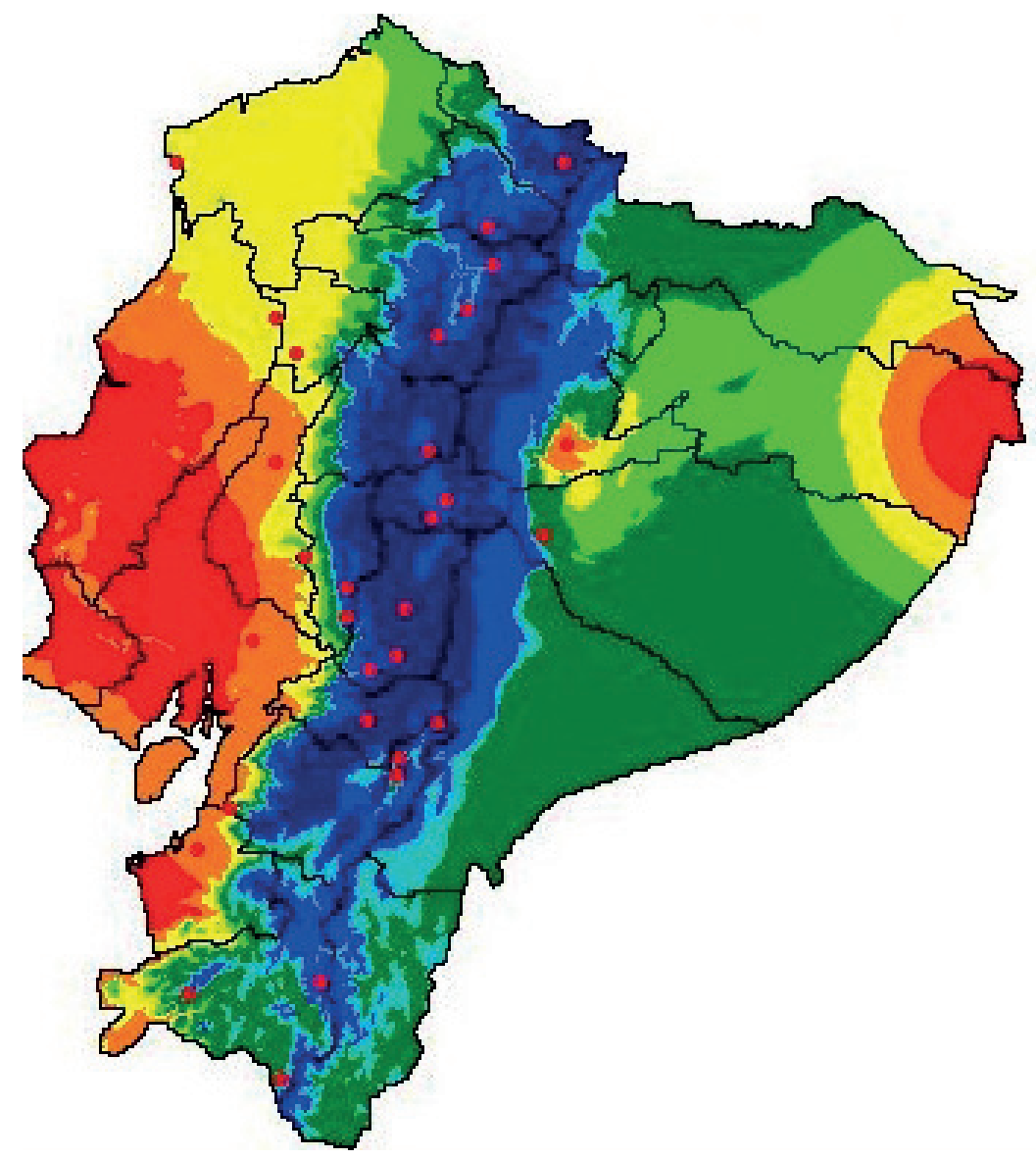


En lo que a frecuencia y dirección dominante del viento se refiere, la Figura 4.45 (velocidad frecuencia norte) muestra que los vientos son más intensos en zona sur del país cuyas masas tienen dirección norte. Ejemplo la estación M482 ubicada en el sur del país a $60 \mathrm{~m}$ de altitud reporta que los doce meses del año tiene dirección norte a una velocidad media de $6 \mathrm{~m} / \mathrm{s}$ (ver Anexo 10).

Figura 4.45

Viento frecuencia norte $(\mathrm{m} / \mathrm{s})$ - Ecuador

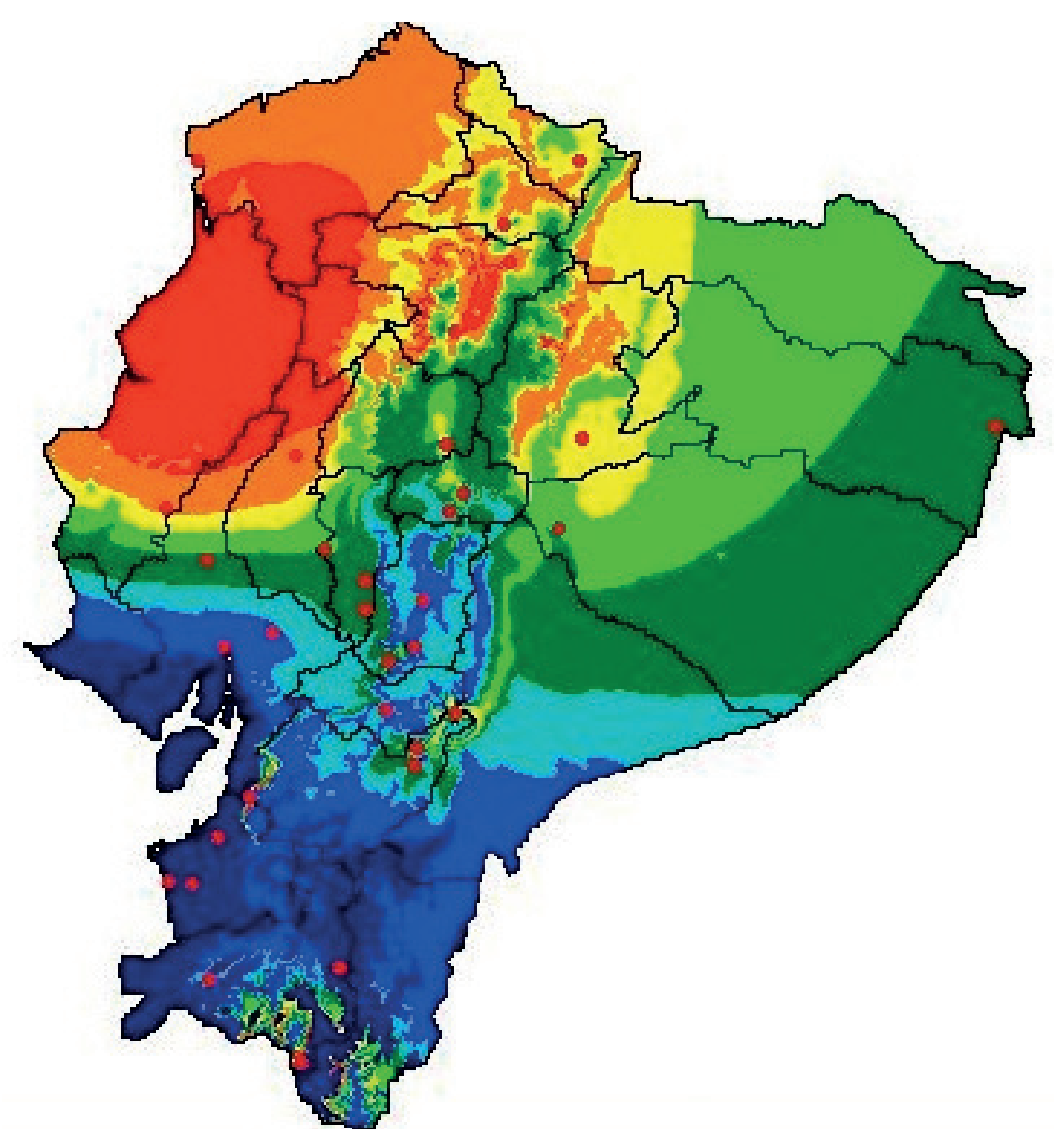

Elaboración: Autor, 2009

El viento con dirección dominante norte-este (Figura 4.46), se ubica intensamente en la zona central oriental de la Amazonía y en la Sierra norte. Por ejemplo la estación M105 Otavalo ubicada en zona andina norte a $2556 \mathrm{~m}$ de altitud reporta que 9 meses del año, el viento tiene dirección dominante norte-este con una velocidad de $7.5 \mathrm{~m} / \mathrm{s}$ y que 3 meses al año toma dirección norte a una velocidad de $6.4 \mathrm{~m} / \mathrm{s}$ (ver Anexo 10). 
114

Figura 4.46

Viento frecuencia norte este $(\mathrm{m} / \mathrm{s})$ - Ecuador

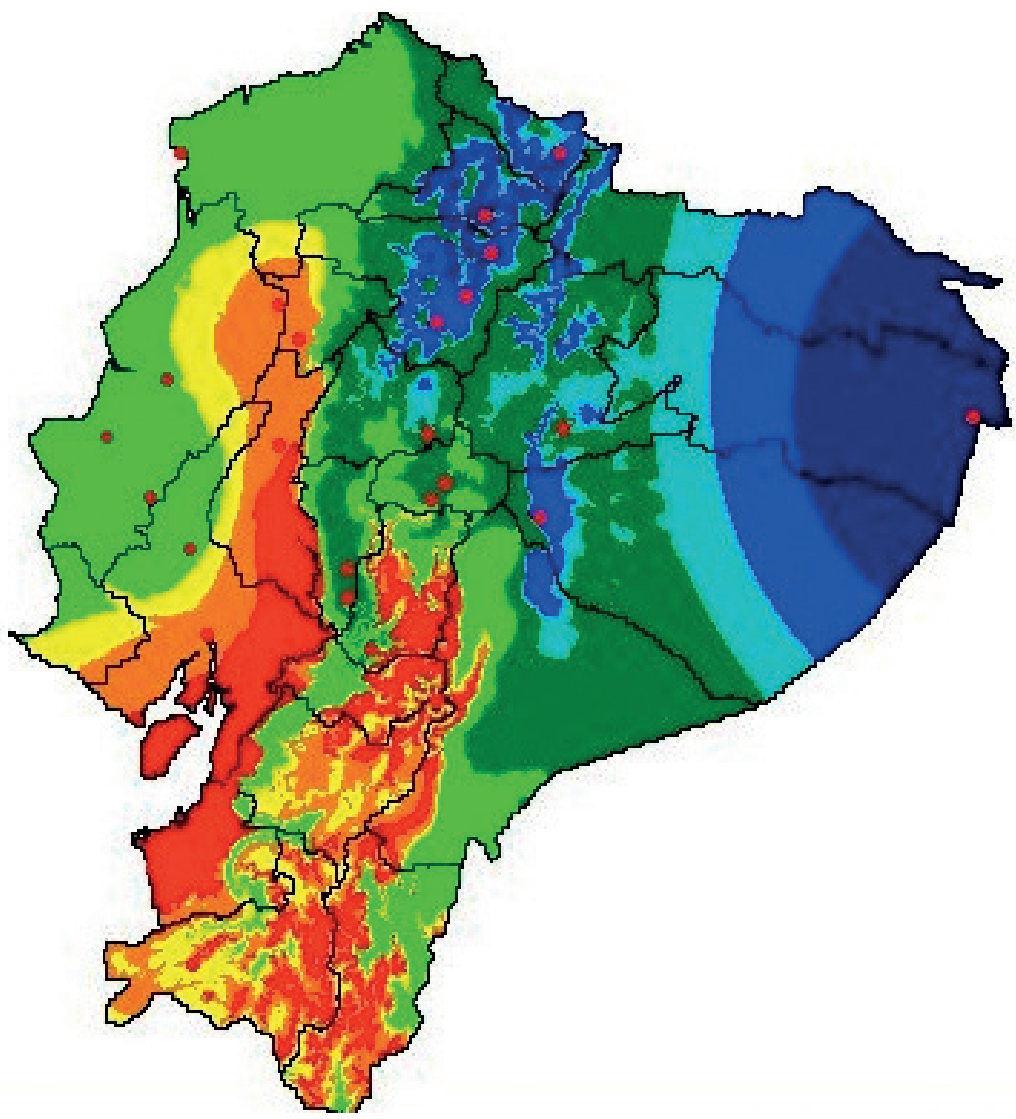

Elaboración: Autor, 2009

El viento con dirección dominante este (Figura 4.47), se ubica intensamente en la zona central y sur de la Sierra y sur de la Amazonía. Así la estación M126 Patate ubicada en el centro andino a 2360 $\mathrm{m}$ de altitud reporta que los 12 meses del año toma dirección dominante este a una velocidad media de $13 \mathrm{~m} / \mathrm{s}$ (ver Anexo 10).

El viento con dirección dominante sur (Figura 4.48) se concentra con mayor intensidad en el norte andino y el centro norte costero, así la estación M160 El Carmen ubicada en el centro norte de la costa a $250 \mathrm{~m}$ de altitud reporta que 10 meses al año tiene dirección dominante sur con una velocidad media de $4.2 \mathrm{~m} / \mathrm{s}$, en enero toma dirección norte a una velocidad media de $4.3 \mathrm{~m} / \mathrm{s}$ y en abril toma dirección norte-oeste a una velocidad media de $4.1 \mathrm{~m} / \mathrm{s}$. (ver Anexo 10). 
115

\section{Figura 4.47}

Viento frecuencia este $(\mathrm{m} / \mathrm{s})$ - Ecuador

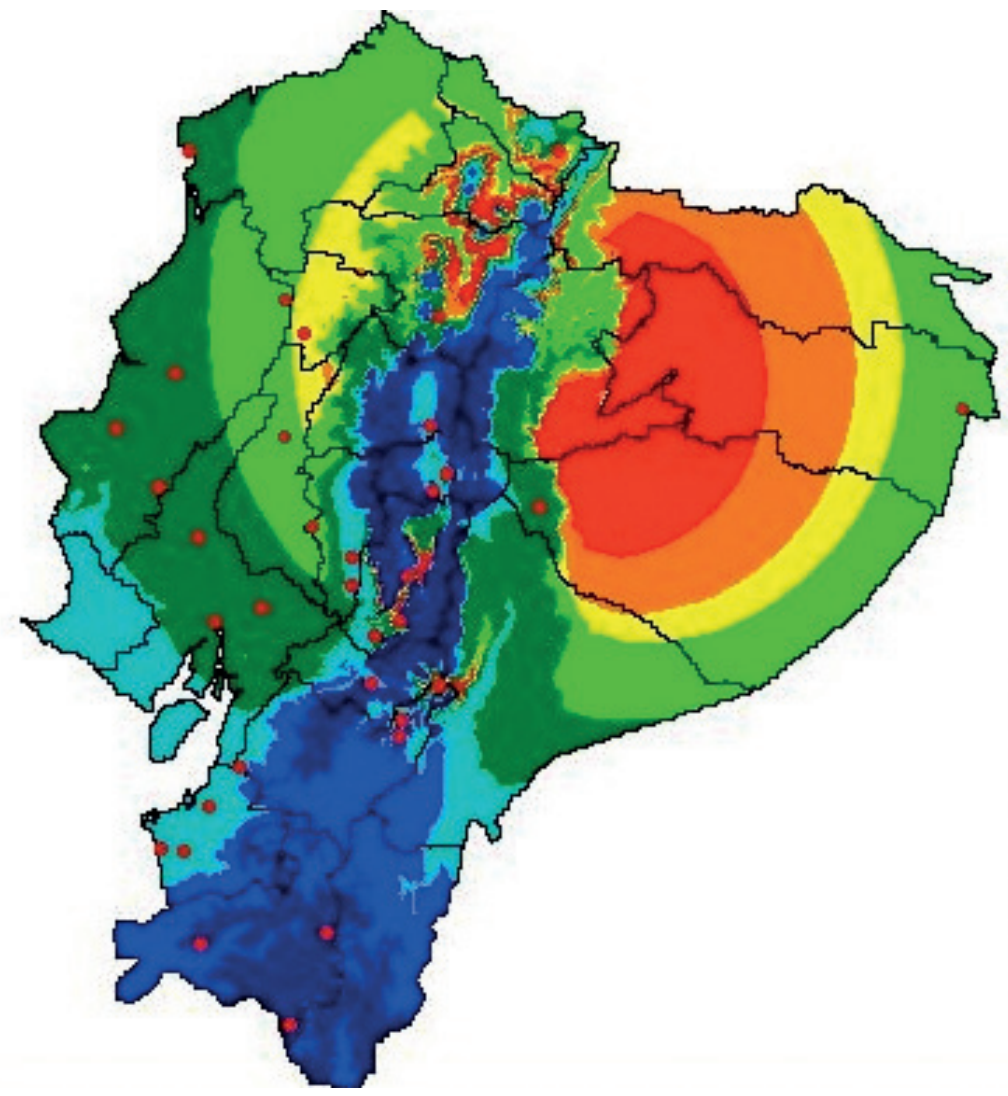

0.9 a 3.4

3.4 a 3.9

3.9 a 4.1

4.1 a 4.5

4.5 a 5.2

5.2 a 6.1

6.1 a 7.2

$7.2 \mathrm{a} 12.1$

Elaboración: Autor, 2009

El viento con frecuencia sur-este (Figura 4.49), denota que con mayor intensidad se concentra en la zona norte de la sierra y la costa central, así como en el centro sur andino (provincias de Azuay y Cañar); así la estación M166 Olmedo- Manabí ubicada en la costa central a $50 \mathrm{~m}$ de altitud reporta que 9 meses del año toma dirección dominante sur-este a una velocidad media de $7.3 \mathrm{~m} / \mathrm{s}$ y los tres meses restantes (abril, junio y septiembre) toma dirección norte-este a una velocidad media de $7.1 \mathrm{~m} / \mathrm{s}$. (ver Anexo 8).

El viento con frecuencia sur-oeste (Figura 4.50) muestra su intensidad en toda la costa externa o zona costera occidental, excepto el extremo sur (provincia de El Oro). Por ejemplo la estación M137 Milagro (Ingenio Valdez) ubicada en la costa central a $13 \mathrm{~m}$ de latitud, reporta que 12 meses al año tiene dirección sur-oeste con una velocidad media de $4.5 \mathrm{~m} / \mathrm{s}$ (ver Anexo 10). 
Figura 4.48

Viento frecuencia sur $(\mathrm{m} / \mathrm{s})$ - Ecuador

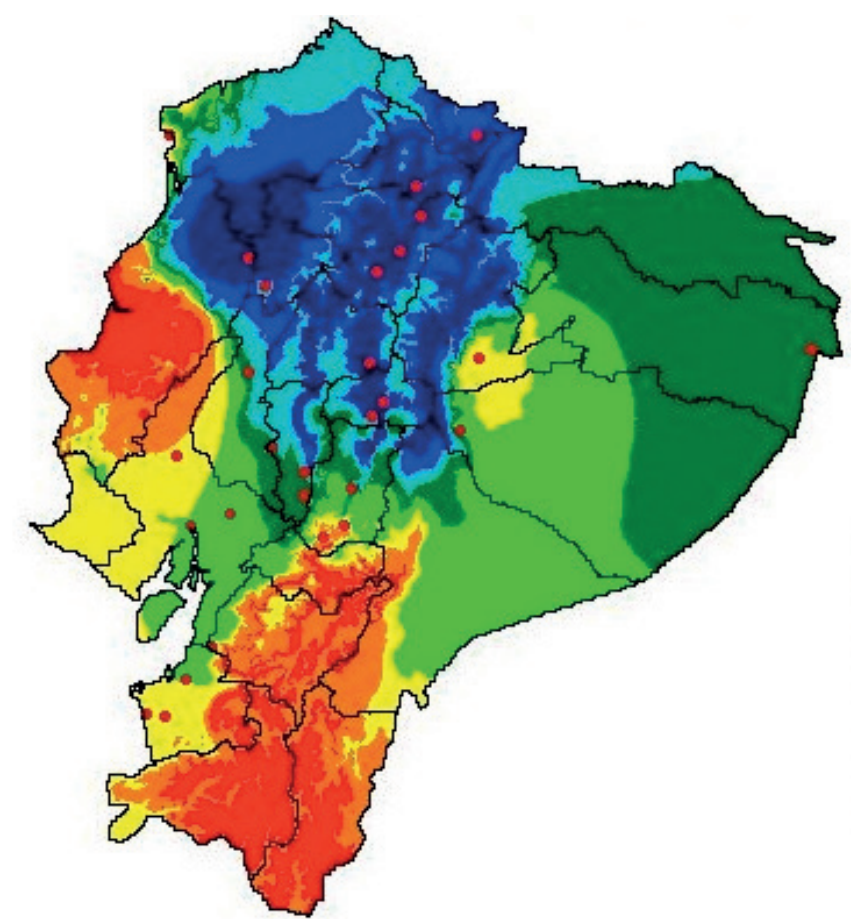

Elaboración: Autor, 2009

Figura 4.49

Viento frecuencia sur este $(\mathrm{m} / \mathrm{s})$ - Ecuador

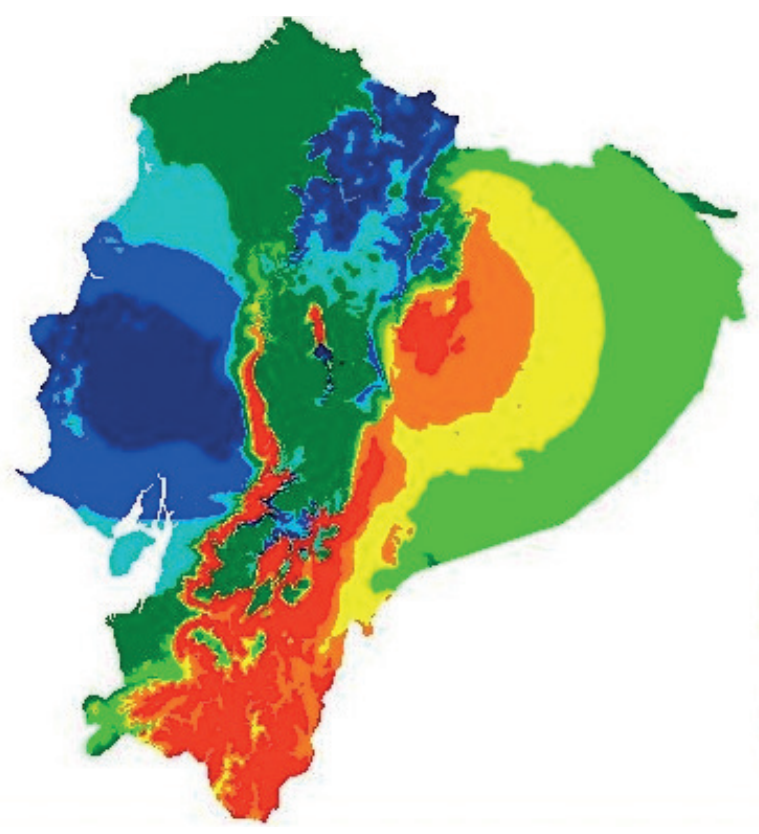




\title{
117
}

\author{
Figura 4.50
}

Viento frecuencia sur oeste $(\mathrm{m} / \mathrm{s})$ - Ecuador

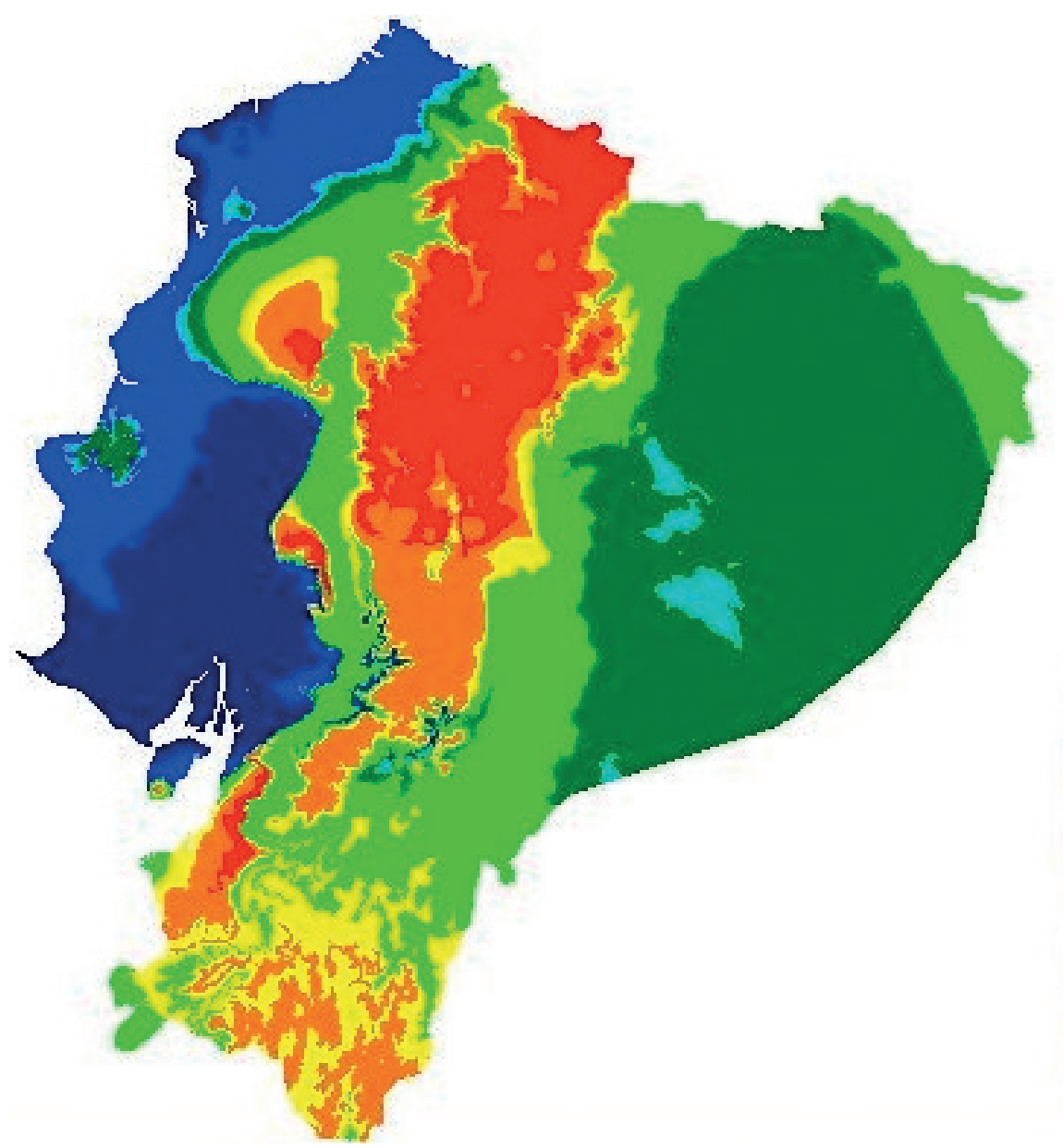

Elaboración: Autor, 2009

El viento frecuencia oeste (Figura 4.51) denota que la intensidad se ubica geográficamente en el norte andino, estribaciones oriental y occidental de Los Andes (excepto el sur), en la costa norte-occidental (Manabí y Esmeraldas) y en el centro sur de la Amazonía (provincia de Morona Santiago). Así por ejemplo la estación M130 Chillanes ubicada a $2330 \mathrm{~m}$ de altitud reporta que 11 meses del año tiene dirección dominante oeste con una velocidad media de $6.4 \mathrm{~m} / \mathrm{s}$ y el mes de marzo toma dirección sur-este a una velocidad media de $5.1 \mathrm{~m} / \mathrm{s}$ ( ver Anexo 10). 
118

Figura 4.51

Viento frecuencia Oeste $(\mathrm{m} / \mathrm{s})$ - Ecuador

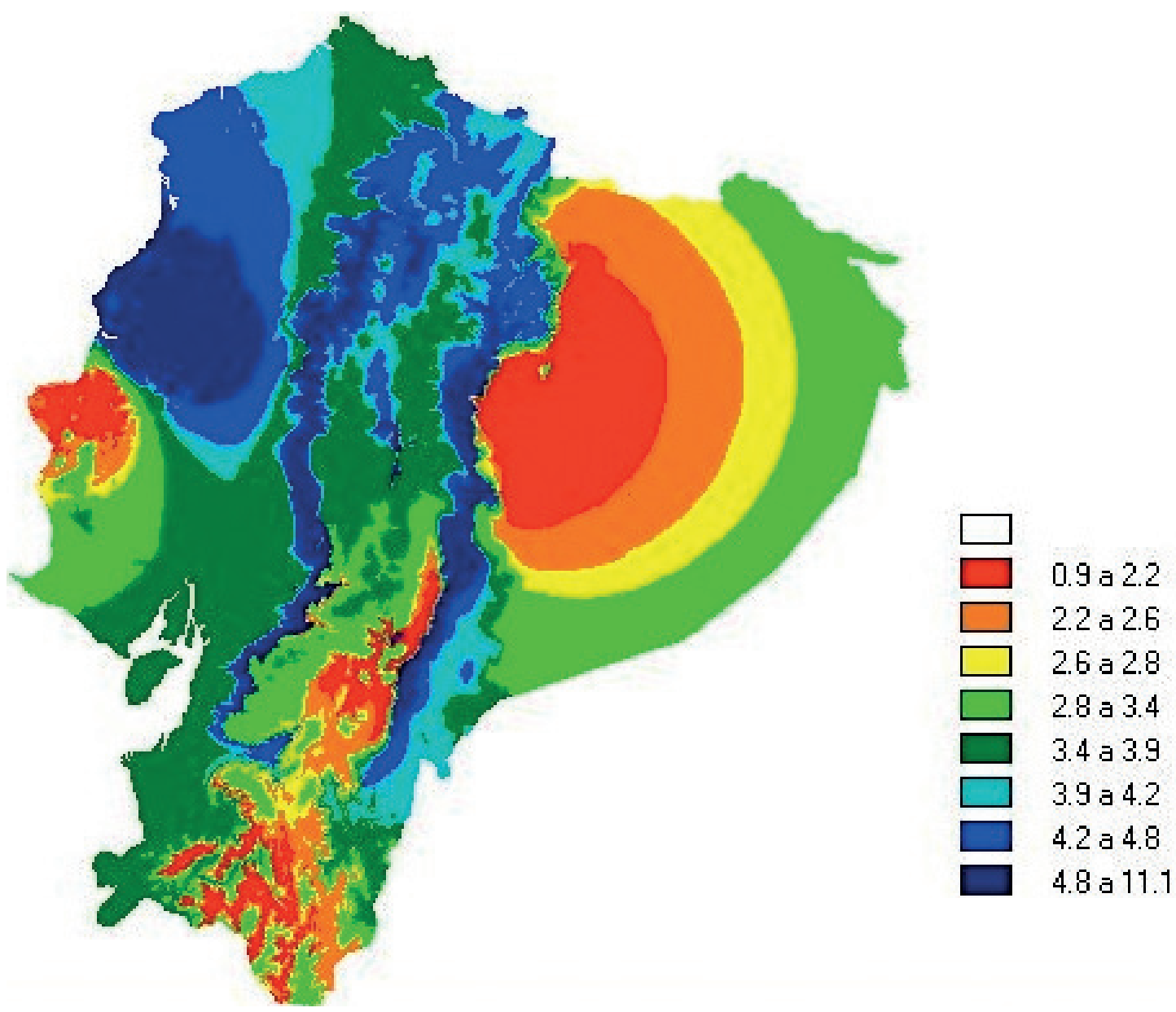

Elaboración: Autor, 2009

El viento frecuencia norte-oeste (Figura 4.52) muestra que la intensidad se ubica en las zonas centro occidental y sur del Litoral, sur andino y centro-sur amazónico. La estación M185 Machala (UTM) ubicada en la costa sur a $13 \mathrm{~m}$ de altitud reporta que 9 meses de año tiene dirección dominante norte-oeste con una velocidad media de $7.6 \mathrm{~m} / \mathrm{s}$; el mes de febrero toma dirección norte-este a 7.5 $\mathrm{m} /$, el mes de noviembre toma dirección norte a $5.3 \mathrm{~m} / \mathrm{s}$ y en diciembre toma dirección sur-oeste a $8.6 \mathrm{~m} / \mathrm{s}$. 
Figura 4.52

Viento frecuencia norte-oeste $(\mathrm{m} / \mathrm{s})-$ Ecuador

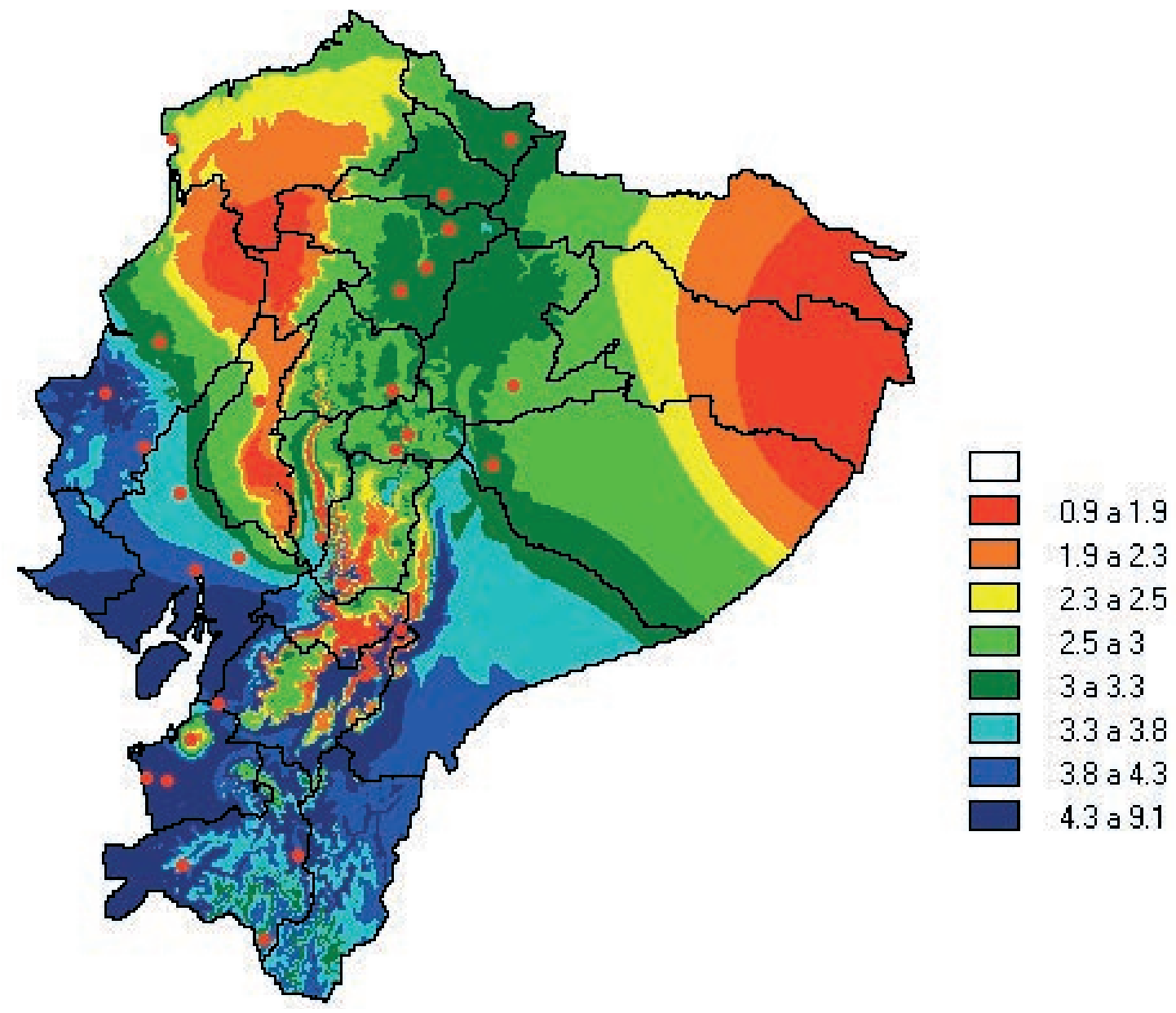

Elaboración: Autor, 2009

\section{Viento en el Ecuador insular o GaláPagos}

La interpolación de datos para las islas Galápagos, muestran solamente la media de agosto (Figura 4.53) y la frecuencia sur-este (Figura 4.54). La desventaja de tener tan solamente tres estaciones, dificultan tener una información completa.

La viento velocidad frecuencia sur-este (Figura 4.54), denota su intensidad ubicada en las zonas costeras sur y este; así lo indica la estación M221 San Cristóbal ubicado a $6 \mathrm{~m}$ de altitud reporta que los 12 meses del año tiene dirección dominante sur-este a una velocidad media de $8.8 \mathrm{~m} / \mathrm{s}$ (ver Anexo 10). 
Figura 4.53

Viento velocidad media agosto $(\mathrm{m} / \mathrm{s})$ - Galápagos

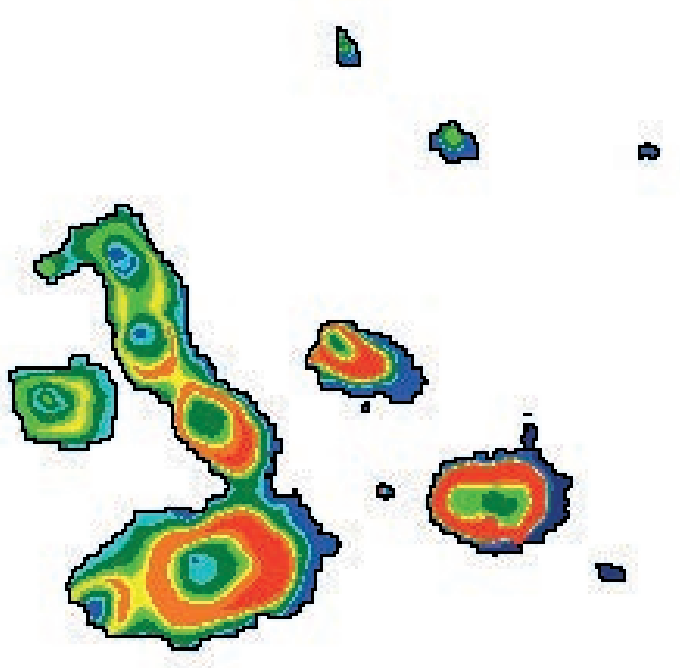

6.6 a 7.4

7.4 a 7.6

7.6 a 7.7

7.7 a 7.9

7.9 a 8.2

8.2 a 8.3

8.3 a 9

9 a 10.7

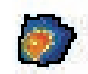

Elaboración: Autor, 2009

Figura 4.54

Viento frecuencia sur este $(\mathrm{m} / \mathrm{s})$ - Galápagos

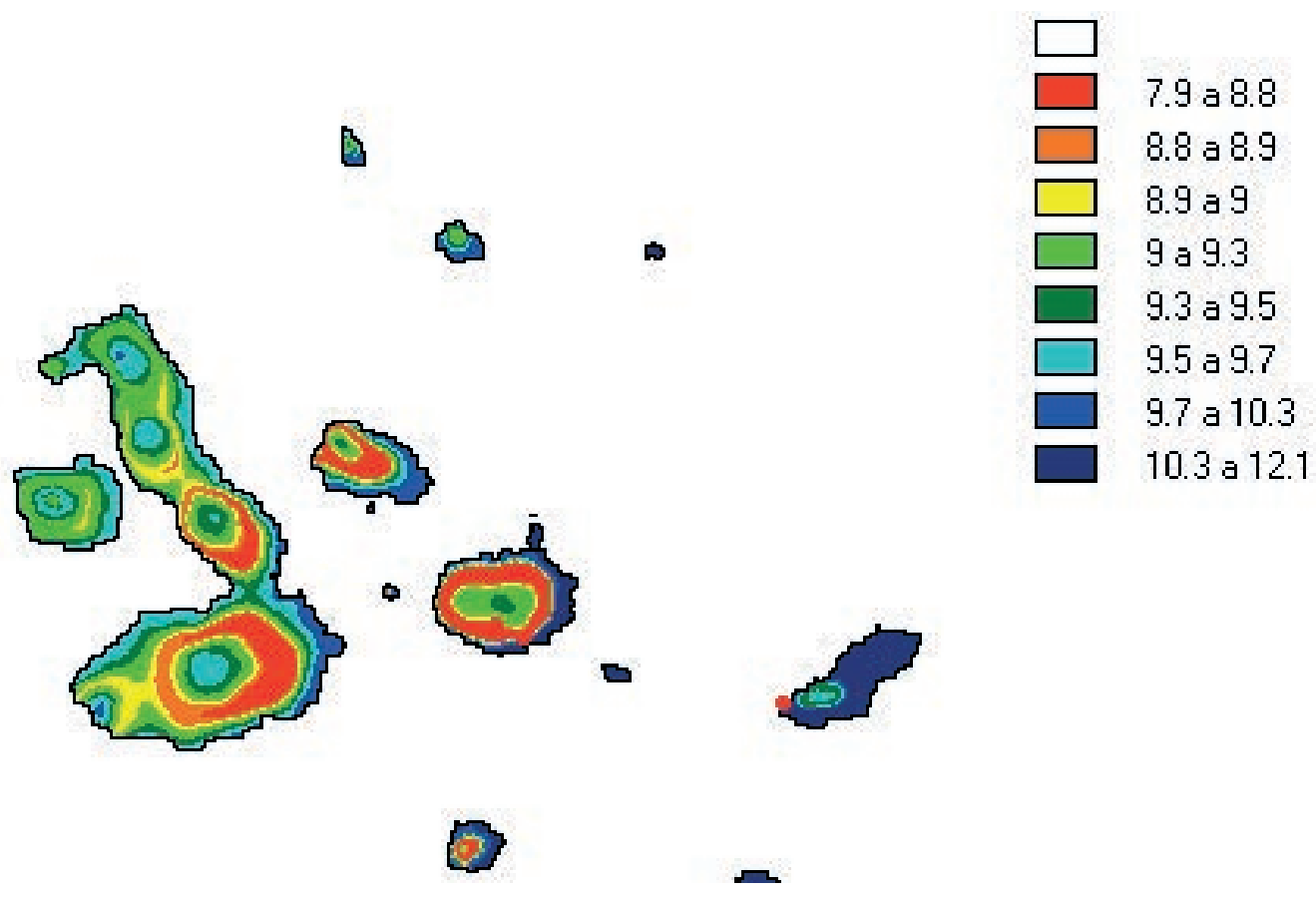

Elaboración: Autor, 2009 


\section{Análisis de la evapotranspiración}

La evapotranspiración ETP fue calculada utilizando los métodos de: Thornthwaite (en función de la temperatura media) y la de Hargreaves (en función de parámetros térmicos — temperaturas máxima, media y mínima - y la radiación solar). Se utilizaron los percentiles 0-10, 10-20, 20-30, 30-50, 50-70, 70-80, 80-90, 90-100. Igualmente para los resultados y análisis correspondiente se separa el Ecuador continental del insular o Galápagos.

\section{Tablas y gráficos}

El Anexo 11, contiene las tablas de cálculo de la ETP para cada estación. Cada tabla presenta las medias anuales de temperaturas y las medias mensuales y anuales de las ETPs según Thorthwaite y Hargreaves. Los valores de evapotranspiración más altos se ubican en la zona costera y oriental en comparación con la sierra donde están los valores más bajos.

Como resumen de la relación entre la altitud y la evapotranspiración se presentan los gráficos 4.4. y 4.5. En el caso de Thornwaite indica (Gráfico 4.4) que a mayor altitud menor transpiración; mientras que Hargreaves (Gráfico 4.5.) indica niveles parecidos de transpiración en las diferentes altitudes.

\section{Gráfico 4.5}

Relación entre la altitud (m) y la Evapotranspiración según Thornthwaite

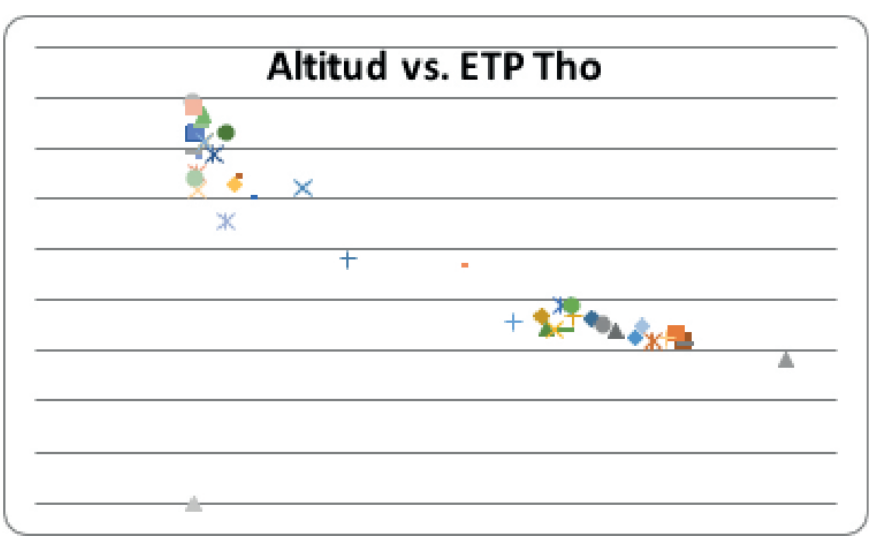

Elaboración: Autor, 2009 
122

\section{Gráfico 4.6}

Relación entre la altitud (m)

y la evapotranspiración $(\mathrm{mm})$ según Hargreaves

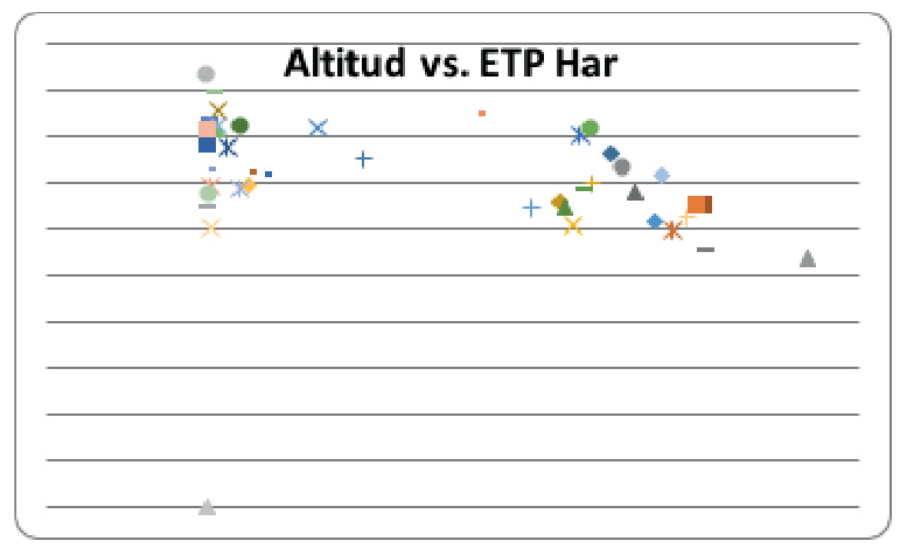

Elaboración: Autor, 2009

\section{Cartografía}

Los mapas generados para mostrar la evapotranspiración según Thornthwaite y Hargreaves, coinciden en los puntos principales de la distribución, aunque por los valores diferentes que cada método presenta, las imágenes no son exactamente iguales, como se verá a continuación.

\section{EVAPOTRANSPIRACIÓN EN EL ECUADOR CONTINENTAL}

La evapotranspiración según Thornthwaite (ver Figura 4.55) muestra que la evapotranspiración mayor está en la Costa, le sigue la región amazónica y en tercer lugar la región Andina. Localmente, hay intensa transpiración a nivel de la costa central y sur (Guayas, Santa Elena, Los Ríos, El Oro y Manabí), así como el extremo oriental norte de la región Amazónica (percentil 90-100) con valores se aproximan a los $1590 \mathrm{~mm}$. La costa norte y el resto de la superficie del oriente siguen con los percentiles que van de 50 a 90, e indican zonas de evapotranspiración menos intensas que la anterior pero mucho más fuertes que la Sierra donde reporta valores mínimos de $550 \mathrm{~mm}$. Las zonas descritas como de mayor evapotranspiración son aquellas donde la temperatura media anual es la más alta (Figura 
123

4.1), de alta precipitación (Figura 4.15) y alta humedad relativa (Figura 4.37), aunque esta última es baja en la costa central (cuenca del Guayas). Por ejemplo la estación M166 Olmedo-Manabí ubicada a $50 \mathrm{~m}$ de altitud reporta un valor de $1534 \mathrm{~mm}$ de ETP (evapotranspiración), mientras que la estación M138 Paute ubicada a 2289 m de altitud reporta $787 \mathrm{~mm}$ de ETP ( ver Anexo 11).

\section{Figura 4.55}

Evapotranspiración según Thornthwaite - Ecuador

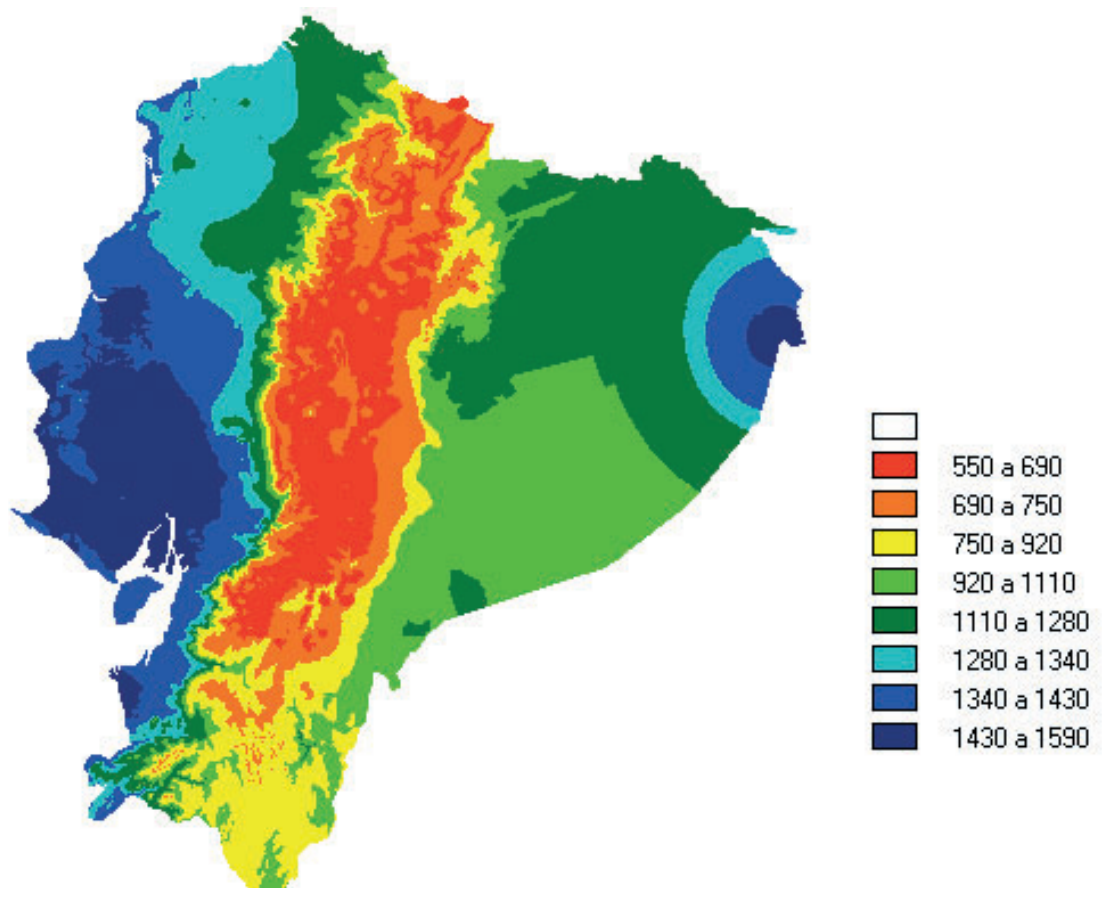

Elaboración: Autor, 2009

El mapa de ETP según el método de Hargreaves (Figura 4.56), reafirma lo expresado del mapa anterior (Figura 4.55) en cuanto a distribución geográfica se refiere, aunque la zona norte costera (provincia de Esmeraldas) mantiene una evapotranspiración alta pero con valores más bajos (1 $440 \mathrm{~mm}-1490 \mathrm{~mm}$ ) que se ubican en el percentil 50-70 y aparece una zona pequeña al sur de la provincia de Esmeraldas donde la evapotranspiración se aproxima a los valores mínimos del percentil 0-10 (1 $060 \mathrm{~mm}-1310 \mathrm{~mm}$ ). Otra diferencia de este mapa (Figura 4.56) con el Thornthwaite, es que ubica una zona de alta evapotranspiración (percentil 90-100) en el centro este de la Amazonía (provincias de Orellana y Napo). 
124

Figura 4.56

Evapotranspiración según Heargreaves - Ecuador

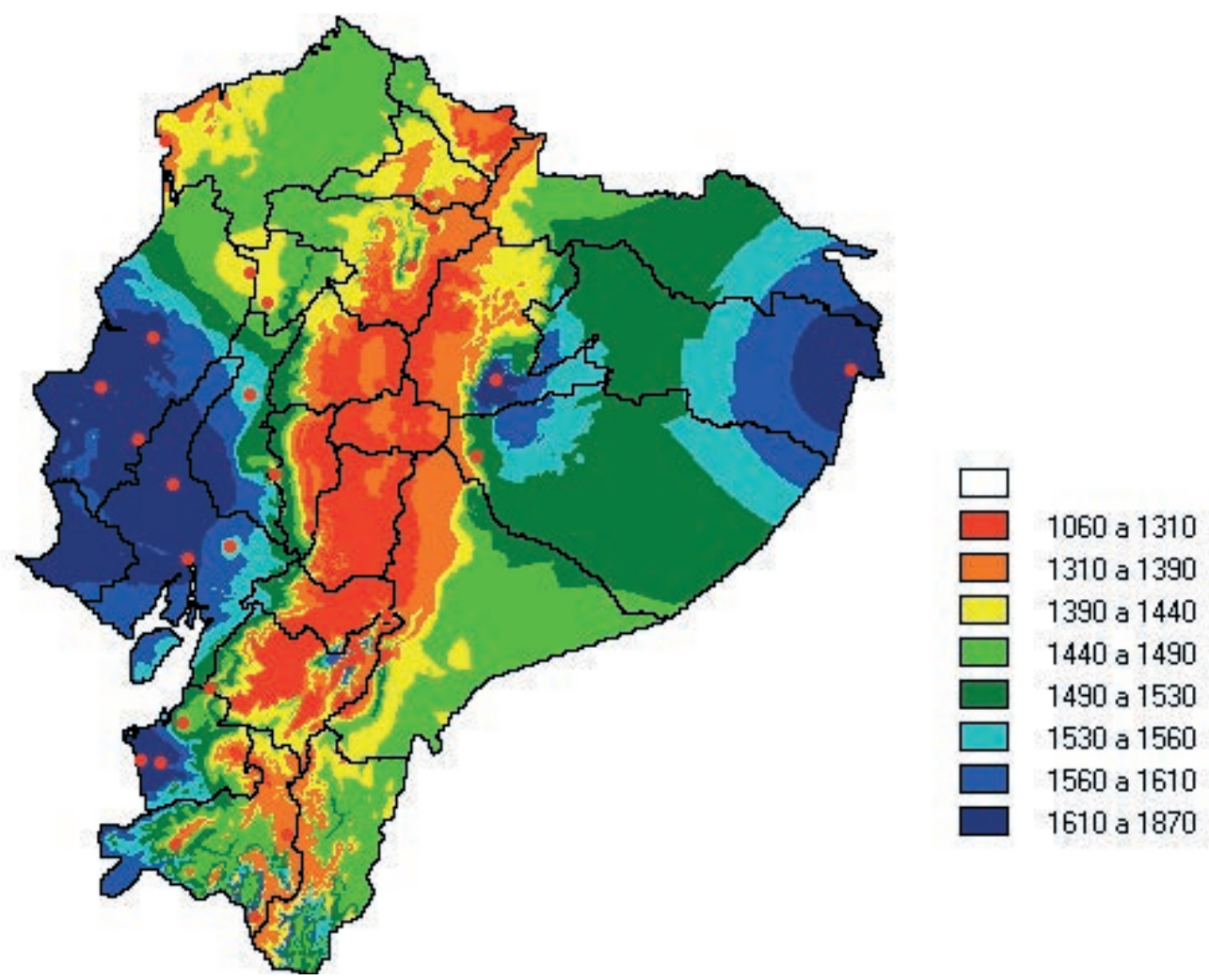

Elaboración: Autor, 2009

En cuanto a valores, Hargreaves (Figura 4.56) duplica al de Thornthwaite (Figura 4.55) en el percentil 0-10; y le lleva al menos 200 a $300 \mathrm{~mm}$ de diferencia en ascenso en el percentil 90-100.

\section{Evapotranspiración en el ECUAdor Insular o GaLÁPAgos}

En las Islas Galápagos, la distribución de la evapotranspiración es algo parecido al Ecuador continental, ubicándose los valores mínimos a nivel de las cimas volcánicas y sus estribaciones, y los valores altos (percentiles 90-100) en la zona costera o de playas. Lo dicho en cuanto a semejanzas y diferencias entre los métodos Thornthwaite y Hargreaves, se ratifica una vez más en las figuras 4.57 y 4.58 donde la temperatura y humedad relativa son directamente proporcionales a al evapotranspiración. 


\section{Figura 4.57}

Evapotranspiración según Thornthwaite - Galápagos

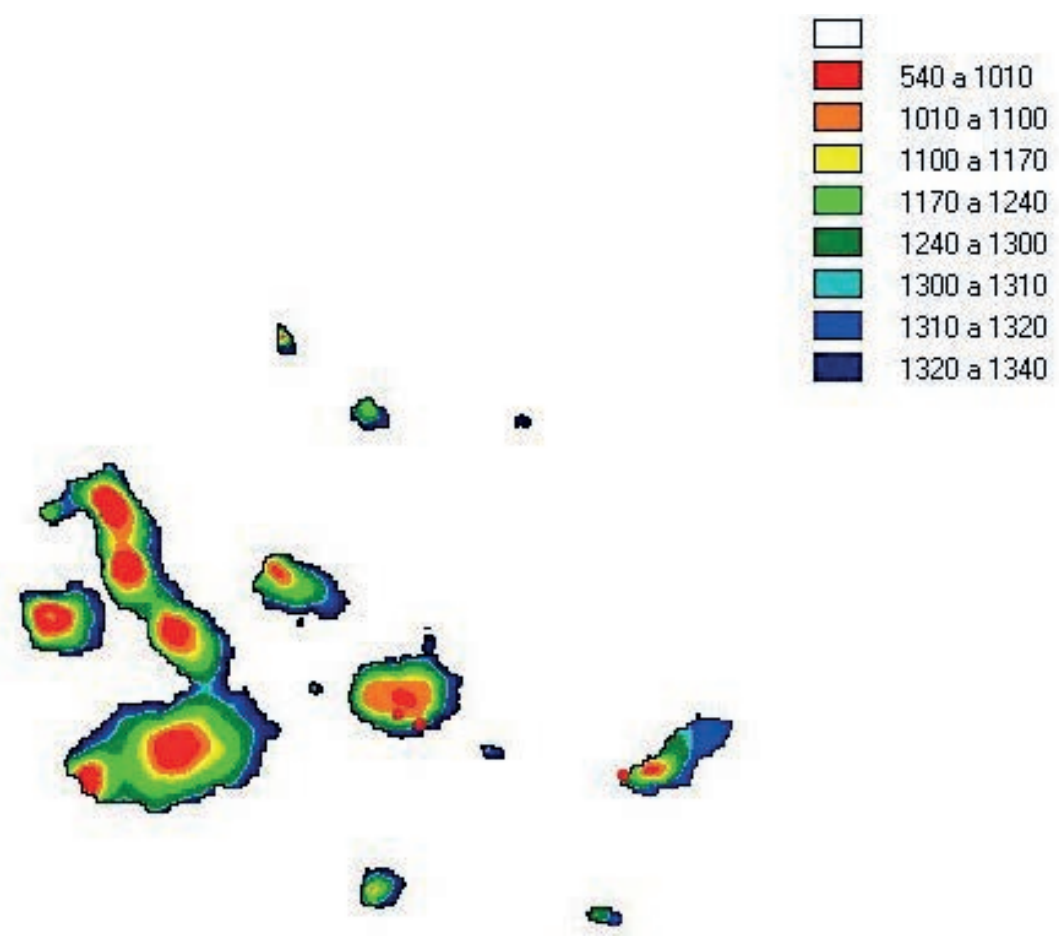

Elaboración: Autor, 2009

Figura 4.58

Evapotranspiración según Heargreaves - Galápagos

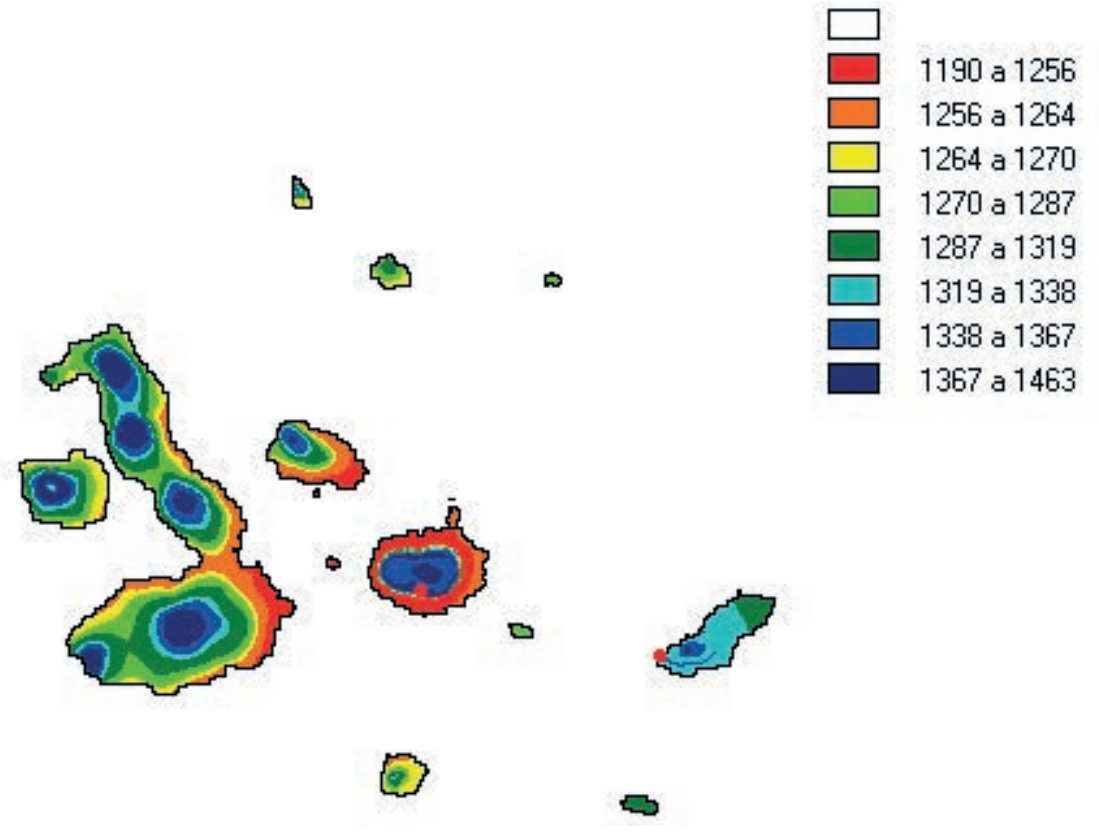

Elaboración: Autor, 2009 
En cuanto a valores, Hargreaves (Figura 4.58) duplica a Thorn-thwaite (Figura 4.57) en los percentiles 0-10, y reporta entre 20 a $120 \mathrm{~mm}$ de diferencia ascendente para el percentil 90-100.

\section{Análisis de balance hídrico}

A partir de los valores de las precipitaciones medias mensuales y de la evapotranspiración mensual según Thornthwaite, se elaboraron cuadros para estudiar el balance hídrico a lo largo del año. Las tablas muestran los valores calculados de diferencia entre la precipi-tación y la evapotranspiración (P-ET), reserva hídrica (R), variación de reserva (VR), ETR (evapotranspiración real), falta de agua (F), Exceso (Ex) y drenaje (D).

El Anexo 12 recoge las tablas del cálculo del balance hídrico por el método directo utilizando los parámetros antes descritos, mientras que el Anexo 13 presenta las tablas de cálculo mediante el método exponencial, en el cual se calculan todos los datos de la misma forma que en el método directo, pero considerando que en el periodo de sequía la reserva disminuye exponencialmente, para lo cual es menester introducir el concepto de PPA que es la pérdida potencial acumulada.

Los resultados obtenidos varían en cada estación, pero integrando por zonas de influencia, se puede ver que el balance hídrico responde indudablemente a la acción directa de los elementos del clima y esencialmente la temperatura y la precipitación. Las estaciones ubicadas en la zona oriental, reportan que el balance hídrico es favorable durante todo el año, existiendo un exceso durante los meses invernales intensos, pero que sin embargo son fácilmente drenados a través de la red fluvial de la Amazonía. Como ejemplo mirar los datos de la estación M007 Nuevo Rocafuerte ubicada a 205 m de la-titud, donde el valor máximo de drenaje ha sido en mayo de 199 $\mathrm{mm}$ y el menor en enero de $37 \mathrm{~mm}$ (ver Anexo 13). Este balance hídrico de la zona oriental favorece la densa vegetación tropical que cubre la Amazonía como ya fue manifestado anteriormente por el investi- 
gador Neill (1995). Se pudo apreciar en las figuras: 4.1 (temperatura media anual), 4.15 (precipitación media anual) y 4.35 (humedad relativa), que los percentiles altos 80 a 100 están ubicados en ésta región, lo cual le ponen en la categoría de una zona tropical húmeda.

Las estaciones ubicadas en la zona Andina o Sierra, muestran un balance hídrico favorable durante los meses invernales, y en algunas exceso durante los meses de abril y mayo, mientras que hay un balance hídrico desfavorable durante los meses de verano, especialmente notándose la falta de agua en agosto. Así por ejemplo ver la estación m002-La Tola ubicada a $2480 \mathrm{~m}$ de altitud, donde el valor F (falta) es de $26 \mathrm{~mm}$ mientras en abril hay un exceso de $60 \mathrm{~mm}$. Este es el reflejo casi uniforme de la zona andina, donde la sequía intensa de julio y agosto, deja estragos en la agricultura estacional. Es de notar que la red hidrográfica se origina en los Andes, y cuando la sequía se hace presente, los ríos tienden a secarse afectando con ello a las poblaciones de las estribaciones y regiones por donde cruza la red, e igual impacto sucede cuando las lluvias son intensas originando deslaves e inundaciones. Es de recordar que la sierra por su altitud tiene diferentes y múltiples áreas geográficas que conservan valores hídricos variados como en los humedales o los valles andinos de tierras profundas, esto favorece a que se tenga una agricultura variada que sortea las dificultades de los valores extremos de temperatura de invierno y verano.

Al hablar de balance hídrico en la costa, necesariamente se debe considerar dos zonas: la costa central oriental-norte, y la costa occidental y sur:

a) La primera que abarca las provincias de Esmeraldas, Norte de Manabí, Los Ríos, Santo Domingo y centro norte del Guayas, muestra un balance hídrico de excedentes en invierno y de falta en verano, así por ejemplo la estación MA2V Guayaquil ubicada a $6 \mathrm{~m}$ de altitud, muestra un exceso de agua en marzo de $142 \mathrm{~mm}$ y una falta de agua en septiembre de valor $109 \mathrm{~mm}$. Esta zona agrícola por excelencia, sufre inundaciones muy frecuentes año tras año, por el desbordamiento de los ríos que bajan de la sierra Es considerada zona tropical húmeda. 
b) La segunda zona de la costa que abarca las provincias de El Oro, sur de Manabí, Santa Elena y centro sur del Guayas, está marcada por mantener un balance hídrico muy desfavorable comparado con la primera zona, así por ejemplo la estación M292 Granja Sta. Inés (UTM) ubicada a $5 \mathrm{~m}$ de altitud reporta falta de agua durante todo el año, excepto el mes de febrero (inicio del invierno). Es la característica común de esta zona costera que ni durante el invierno logra cubrir sus necesidades hídricas, añadiéndose a esto las altas temperaturas imperantes en la zona, por lo que es considerada zona tropical seca.

Las Islas Galápagos o cuarta región del Ecuador, presenta un balance hídrico desfavorable, pues la falta de agua es durante todo el año, así por ejemplo la estación M191 Charles Darwin ubicada a $6 \mathrm{~m}$ de altitud reporta valores negativos de la diferencia entre precipitación y evapotranspiración, cero reservas de agua y una falta permanente a lo largo del año que llega a los $668 \mathrm{~mm}$ media anual. La influencia de las corrientes marinas de Humboldt (fría) y la del Niño (cálida), regulan el clima de las islas, manteniendo la temperatura media anual por debajo los $25^{\circ} \mathrm{C}$ y su humedad relativa del $80 \%$ en las playas y cercana al $100 \%$ en las alturas de sus volcanes (ver figuras 4.8 y 4.40 respectivamente). Dadas estas condiciones el suelo no se presta para cultivos, sin embargo mantiene vegetación propia de las islas, y en general es considerada esta región como tropical seca, como lo dicho anteriormente.

\section{Análisis de climodiagramas}

Para poner en evidencia gráfica y de una manera más rápida, las diferencias y similitudes entre las estaciones meteorológicas y sus zonas de influencia, se elaboraron climodiagramas. En el anexo 14 se puede observar para cada estación una tabla que calcula la precipitación media anual y la temperatura media anual, y dos gráficos:

El primer gráfico corresponde al Diagrama Ombrotérmico de Gaussen que permite identificar el periodo seco en el cual la precipitación es inferior a dos veces la temperatura media. Constan los doce 
meses del año en el eje de las X, y dos ejes Y paralelos donde están por un lado la temperatura media en ${ }^{\circ} \mathrm{C}$ y por otro la precipitación en $\mathrm{mm}$.

El segundo gráfico corresponde al diagrama de termohietas o climograma que permite comparar la temperatura media mensual con las precipitaciones medias, utilizando un sistema de coordenadas cartesianas que combina mes a mes los valores antes indicados.

En general se puede apreciar que cuando descienden las precipitaciones durante los meses de junio a septiembre, la temperatura marca el periodo de verano. Se debe recalcar la diferencia en la región Amazónica, donde prácticamente es invierno todo el año. 



\section{Conclusiones}

- El presente trabajo confirma lo mencionado por los diferentes autores en la introducción, que la altitud modifica la temperatura en el Ecuador continental, pues a mayor altitud menor temperatura.

- La precipitación es distinta en las regiones del país, así en el Oriente es continua e intensa durante todo el año, mientras que en la Costa, Sierra y región insular, el periodo invernal fuerte se ubica en los meses de febrero a mayo, un periodo de invierno leve en septiembre a noviembre. Por el contrario, los meses de secano son julio y agosto, y el veranillo del niño de diciembre a enero.

- La Costa central y sur ecuatoriana tiende a ser una zona de inundaciones por la cantidad e intensidad lluviosa en periodo invernal. Las provincias de Los Ríos, sur de Manabí, norte este del Guayas y El Oro, muestran exceso de agua durante el invierno y por el contrario falta de agua en verano.

- El viento es intenso en la zona andina, y especialmente en la parte central norte, lo que induce a bajar la temperatura en las montañas y disminuir la humedad relativa que es trasladada hacia la costa, modificando la temperatura del lugar y provocando que las masas de aire caliente suban a las estribaciones andinas. Se conforman así sub-zonas de bosques nublados.

- La humedad relativa superior al $90 \%$ se ubica en la zona oriental, con altas temperaturas media anual, altas y permanentes precipitaciones durante el año, alta evapotranspiración y vientos leves, conforman una zona tropical húmeda, 
con un sistema hídrico abundante y continuo, de exuberancia vegetal y diversidad en la fauna.

- La península de Santa Elena, sur de Manabí y oeste de la provincia del Guayas, conforma un área geográfica con baja humedad relativa, menor precipitación anual, alta temperatura y alta evapotranspiración, lo que le convierte en un zona tropical seca.

- Las Islas Galápagos reciben menor cantidad de precipitación anual en comparación con la zona continental, su humedad relativa media anual no baja del $80 \%$ en las zonas costeras y llega $100 \%$ en los volcanes, recibe la influencia de las corrientes marinas de Humboldt y El Niño y es una zona de poca intensidad de viento y su temperatura media anual es menor a $25^{\circ} \mathrm{C}$, le convierten en un nicho ecológico con características propias de un territorio tropical.

- El balance hídrico es totalmente favorable para la región oriental, mientras que para las regiones Costa, Sierra y Galápagos, existe un desbalance, pues mientras en invierno hay exceso en verano hay carencias o falta. Galápagos demuestra una falta de agua durante todo el año.

- La evapotranspiración es directamente proporcional a la temperatura y a la humedad, así la zona oriental y la costa ecuatoriana son lugares de alta evapotranspiración, mientras que la sierra tiene los valores menores. 


\section{Referencias}

Cáceres, L., Mejía, R., y Ontadeda, G. (1995). Evidencias del cambio climático en el Ecuador. Quito, Ecuador: INAMHI. (https://goo.gl/7UnXQr) (10/06/2009).

CIDEIBER (1999). Centro de Información y Documentación Empresarial sobre Iberoamérica. (https://goo.gl/eCgTcU) (18/05/2009).

CODESU Corporación para el Desarrollo Sostenible. (s/f). Mapas + planos del Ecuador. Mapas del Ecuador. (https://goo.gl/uPiM5w) (10/06/2009).

Ecuador and Galápagos Islands (1997-2009). MaQuiNet ${ }^{\circledR}$ (https:/goo. gl/18srBW) (18/05/2009).

ECUAWORLD (s/f). Mapa de Ecuador. (https://goo.gl/uTh4KH) (12/06/2009).

Ecuador Vegetation Map (1973). From: Central Intelligence Agency (CIA). (https://goo.gl/6ztbFj) (18/05/2009).

Fundación Simbiosis (2007). Mapa de montañas y ríos en Ecuador. (https:// goo.gl/CCrFBu) (10/06/2009).

INAMHI Instituto Nacional de Meteorología e Hidrología del Ecuador (s/f). (https://goo.gl/g7UwbF) (18/05/2009).

Martínez, R., Nieto, J., Briones, K., Romero, A., y Hernández, F. (2005). Índice de Riesgo Climático-Agrícola: Proyecto piloto para cultivo de arroz en las provincias de Guayas y Los Ríos, Ecuador. Instituto Oceanográfico de la Armada de Ecuador. (https://goo.gl/T3Dnm9) (10-06-2009). 
134

Neill, D. (1995-2009). Catálogo de las plantas vasculares del Ecuador. Research Projects: vegetation Missouri Botanical Garden (https:// goo.gl/5PhnBW) (18/05/2009).

Neill, D. y Jorgensen, P. (s.f). Catálogo de Plantas vasculares del Ecuador. Research Projets: Climates 1995 -2009. (https://goo.gl/Bd5nad) (18/05/2009).

Schwerdtfeger, W. (1976). Climates of Central and South America. World Survey of Climatology (178-189).Volume 12. Amsterdam: Elsevier Scientific Publishing Company.

Villacís, M., Galárraga, R., y Francou, B. (2000). Influencia de El Niño-oscilación del sur (enos) sobre la precipitación en los Andes centrales del Ecuador https://goo.gl/qaJcaC (10-06-2009). 
ANEXOS 



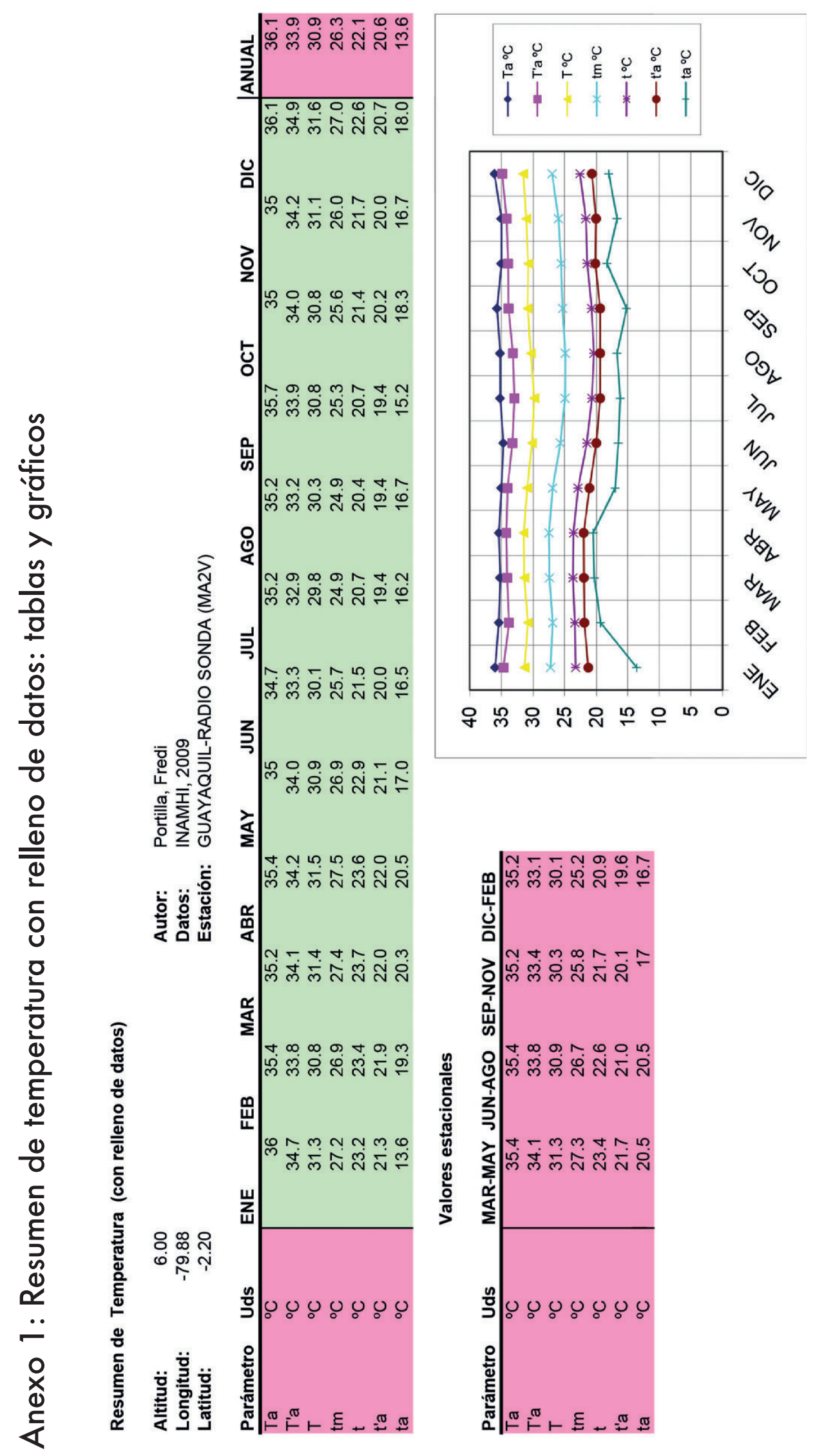




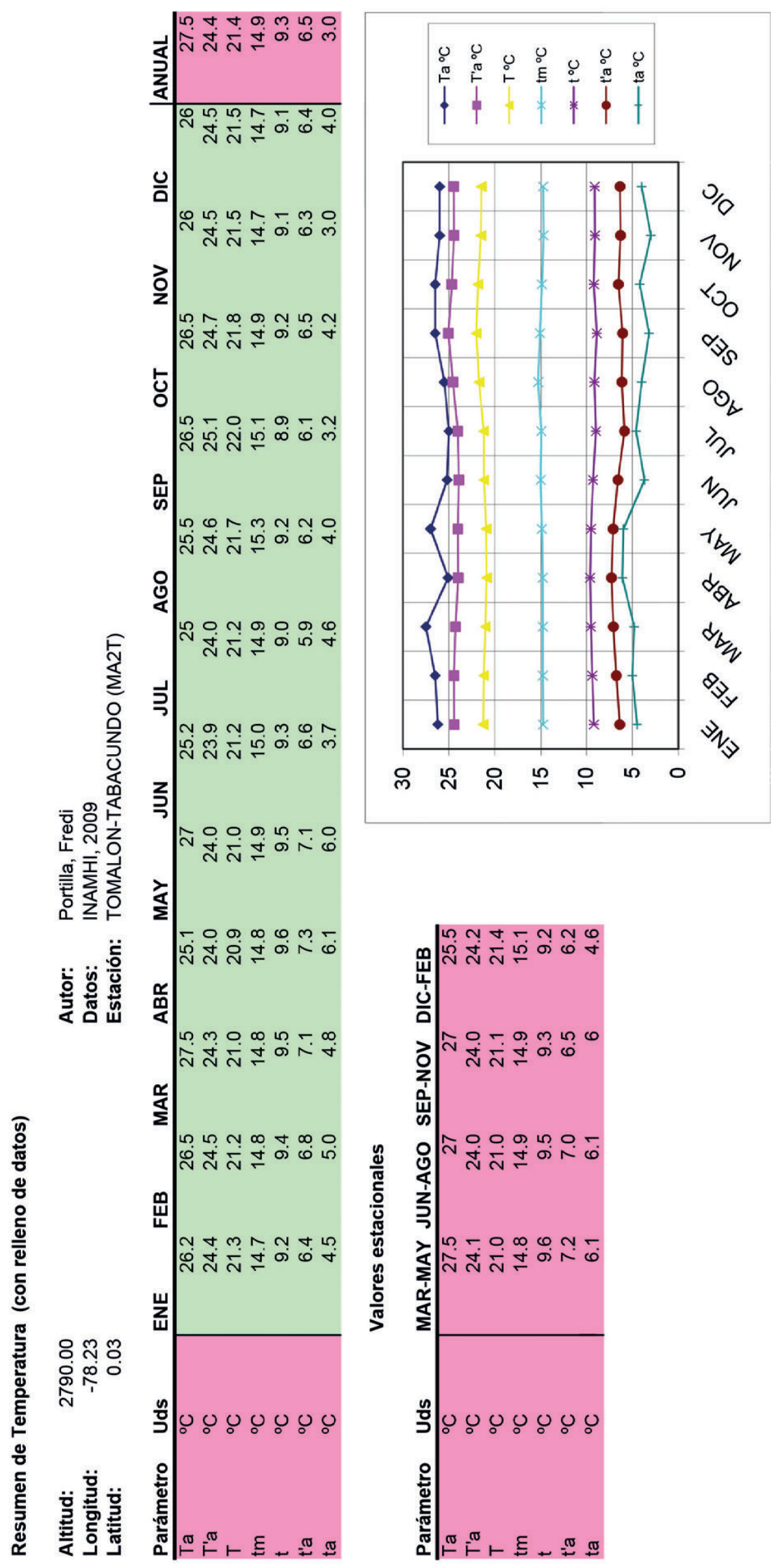




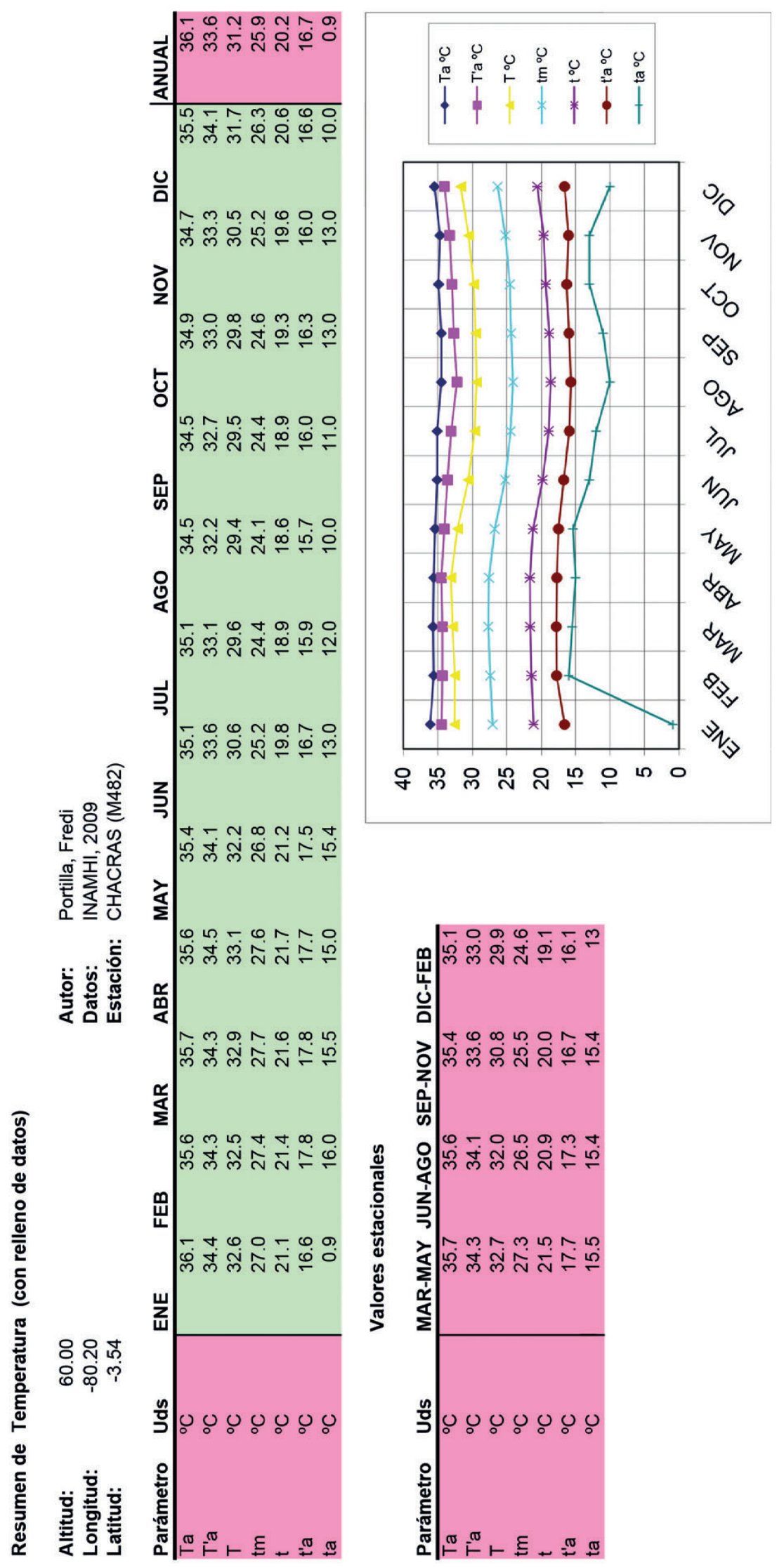


140

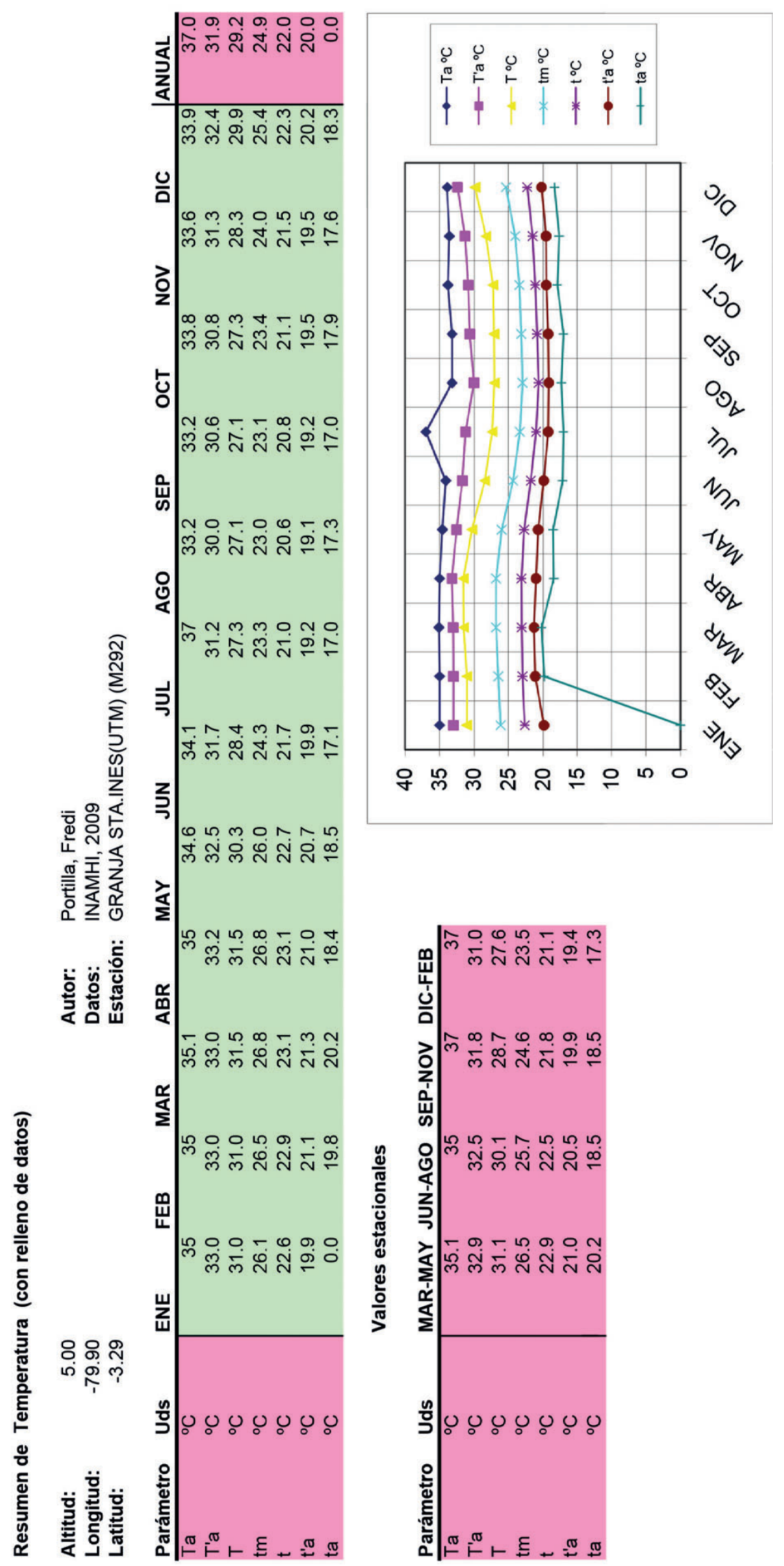


141

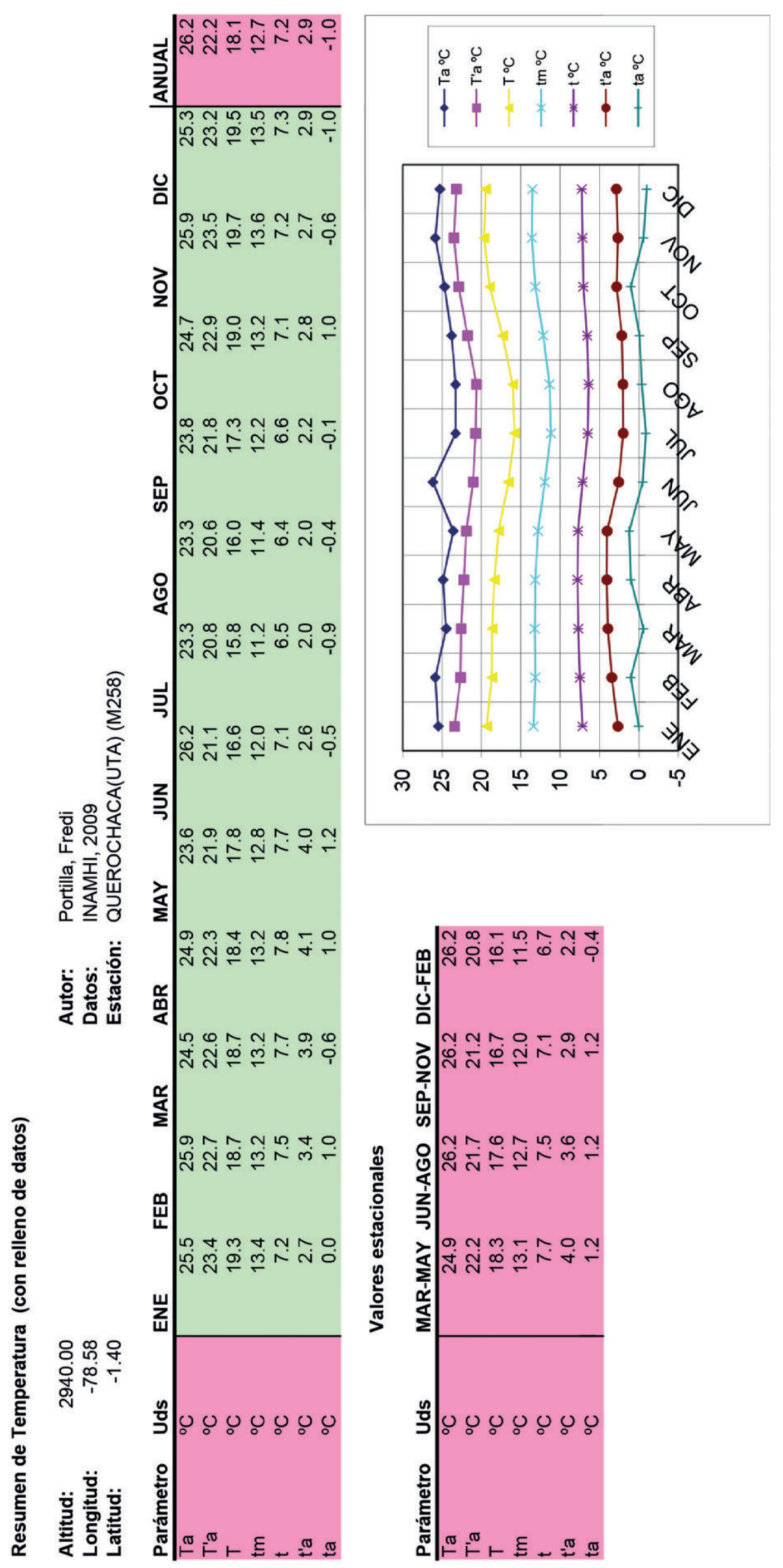


142

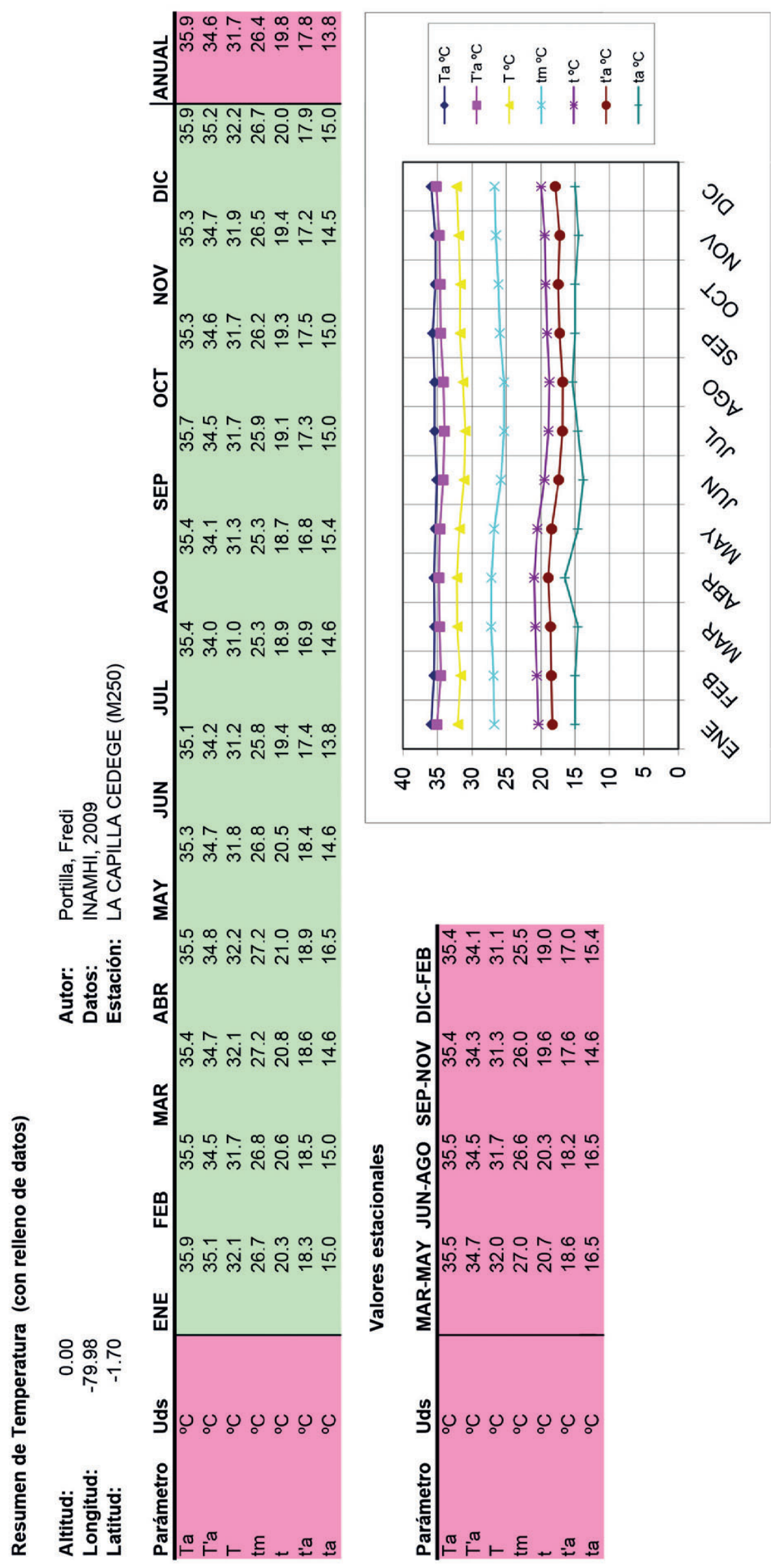


143

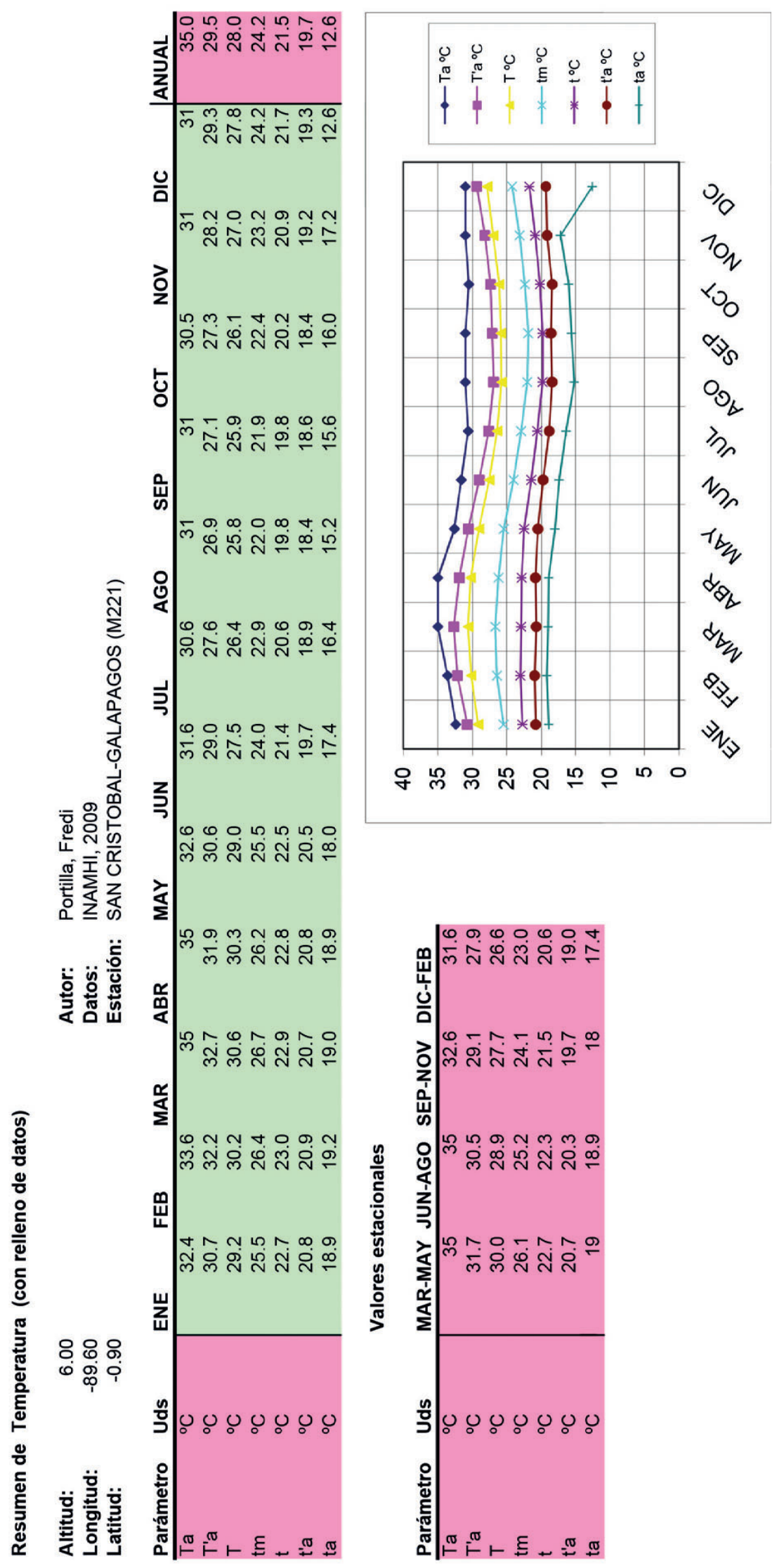


144

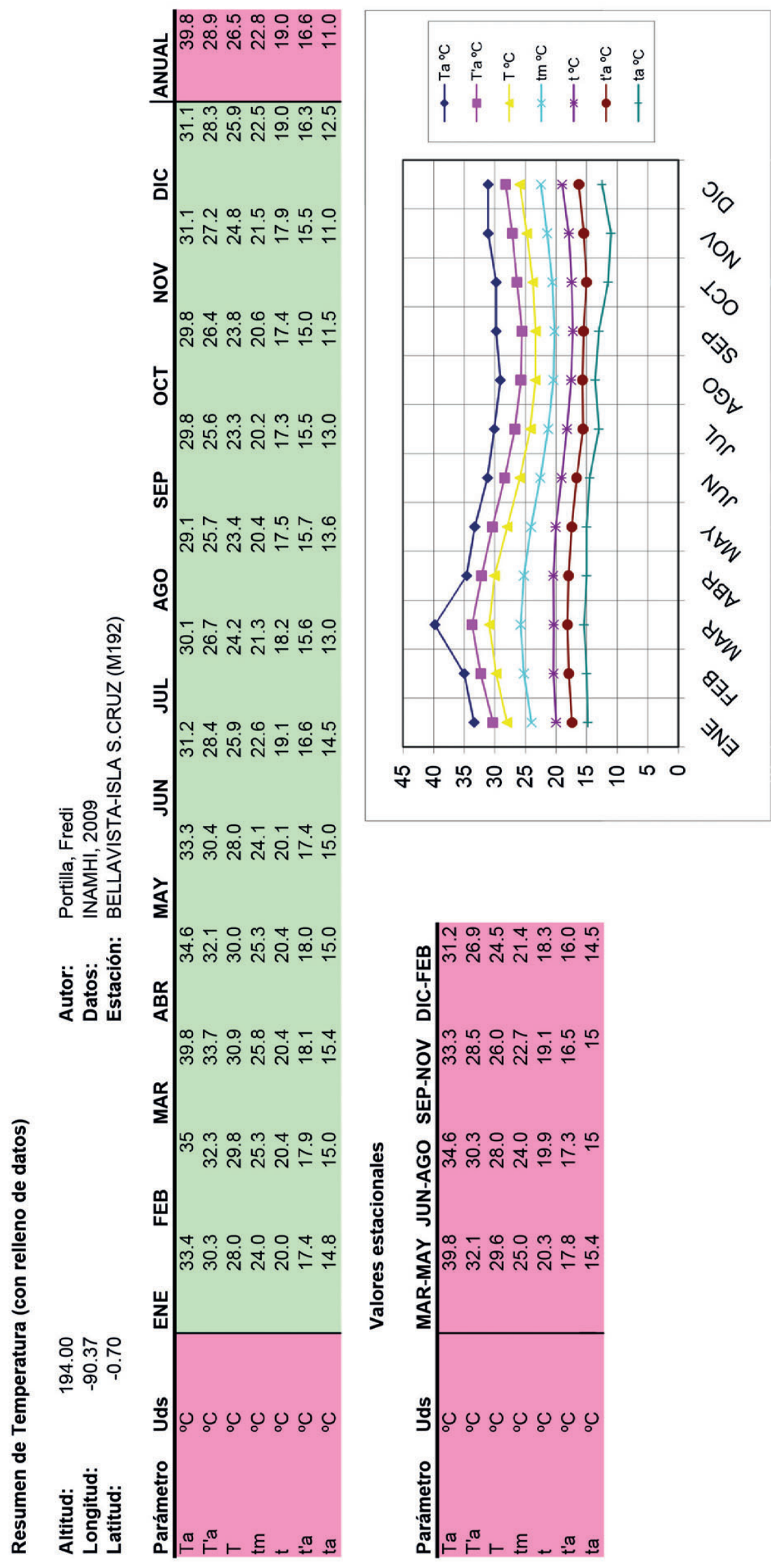


145

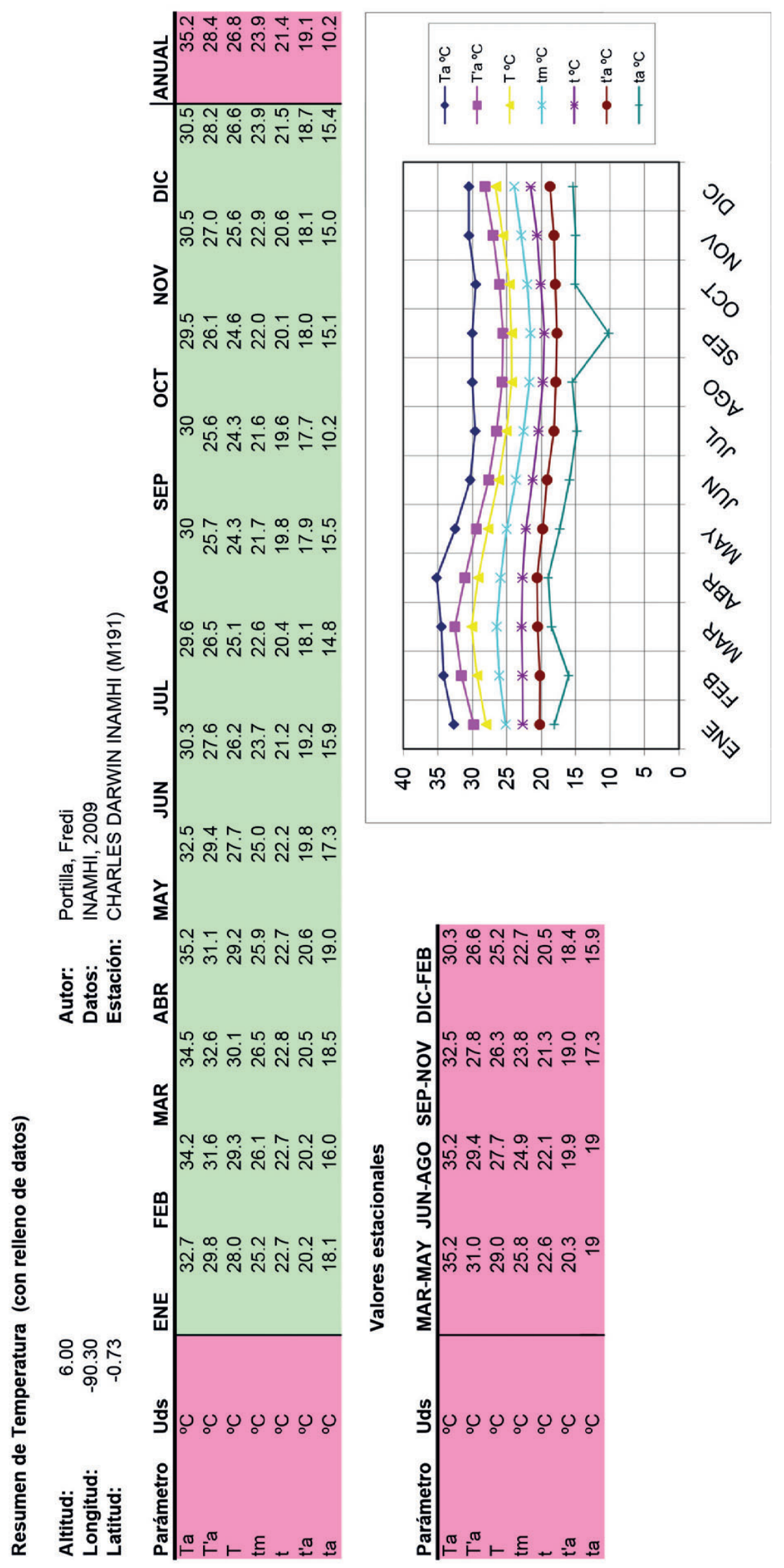




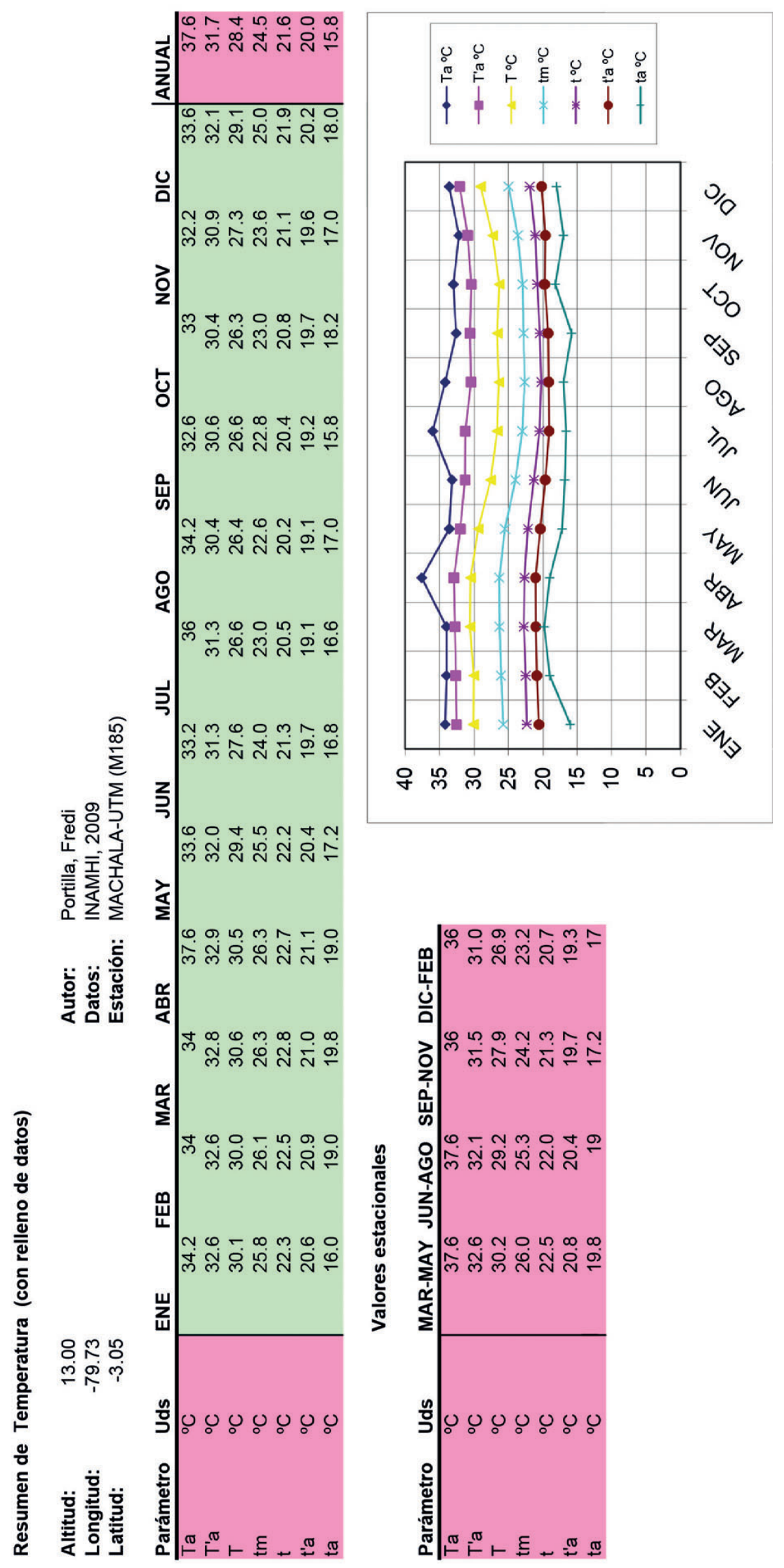




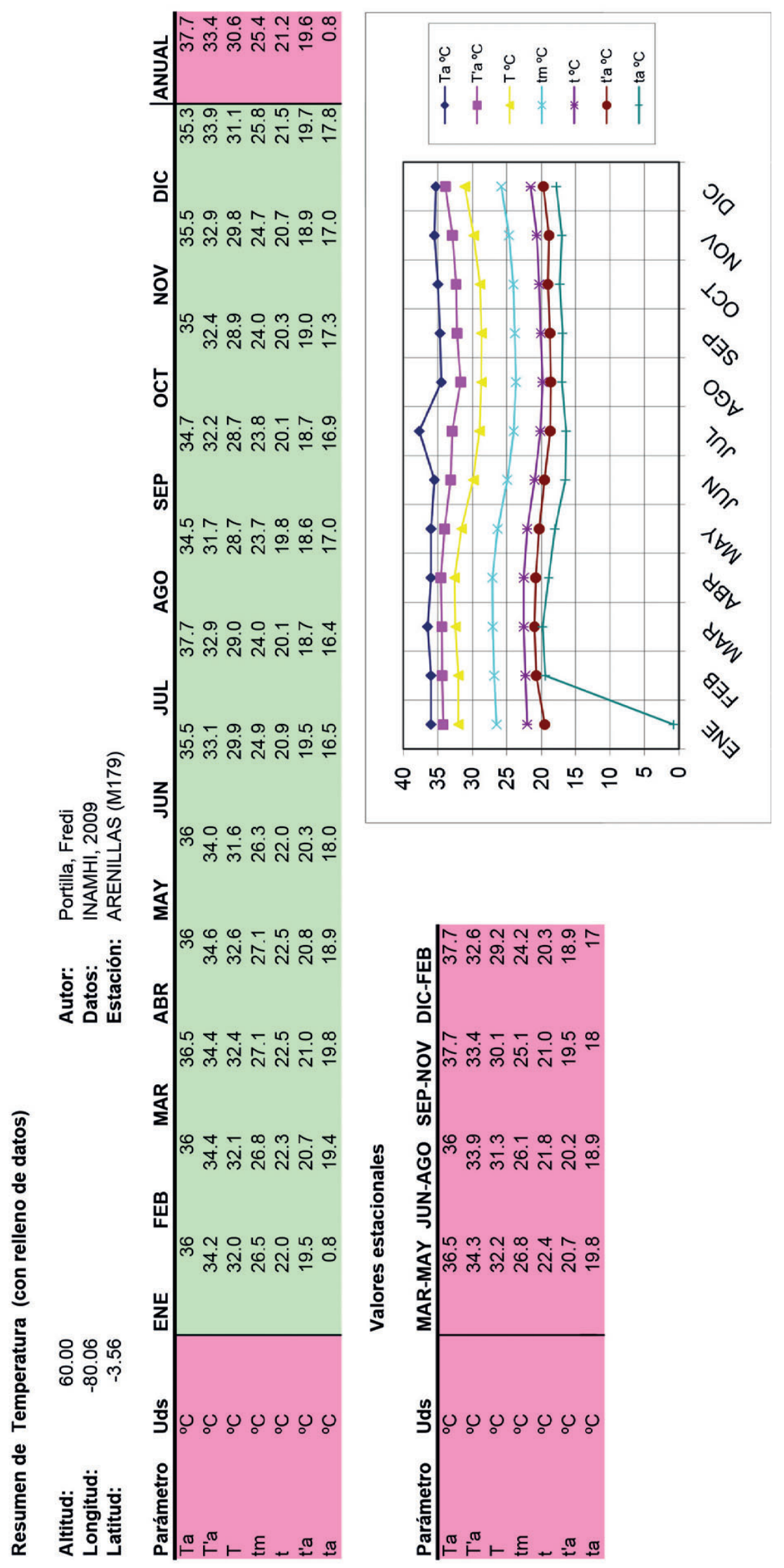




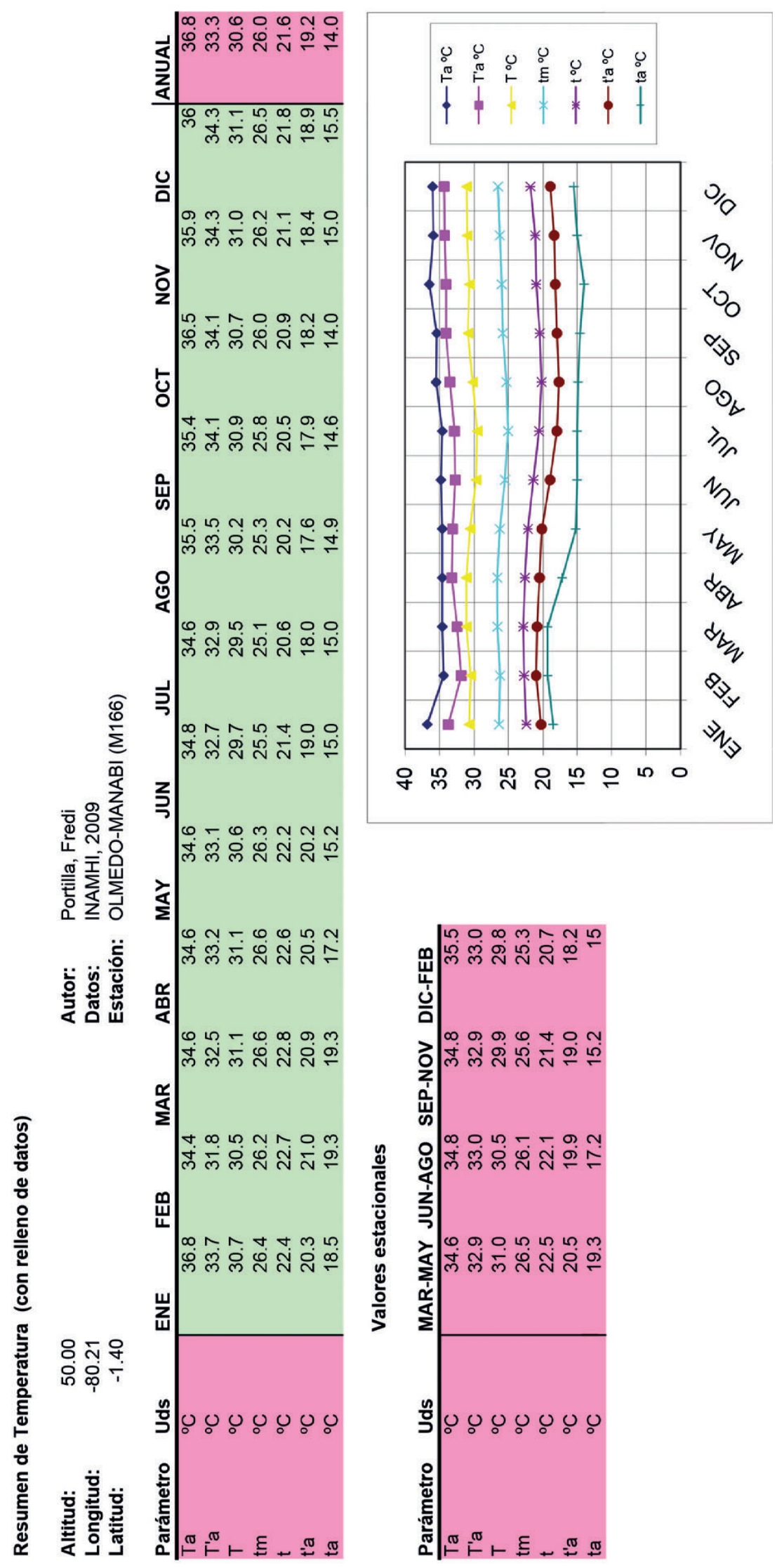




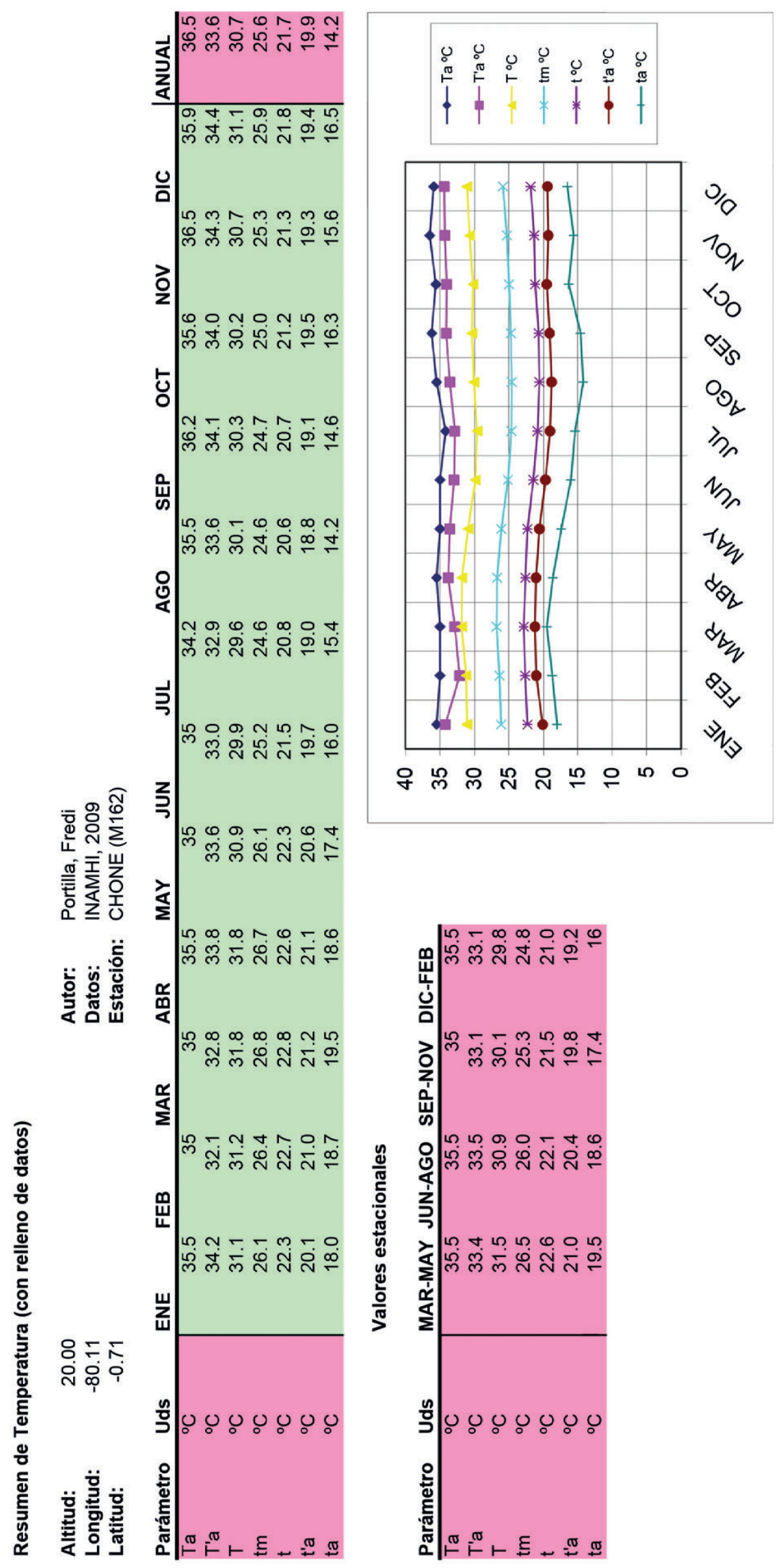


150

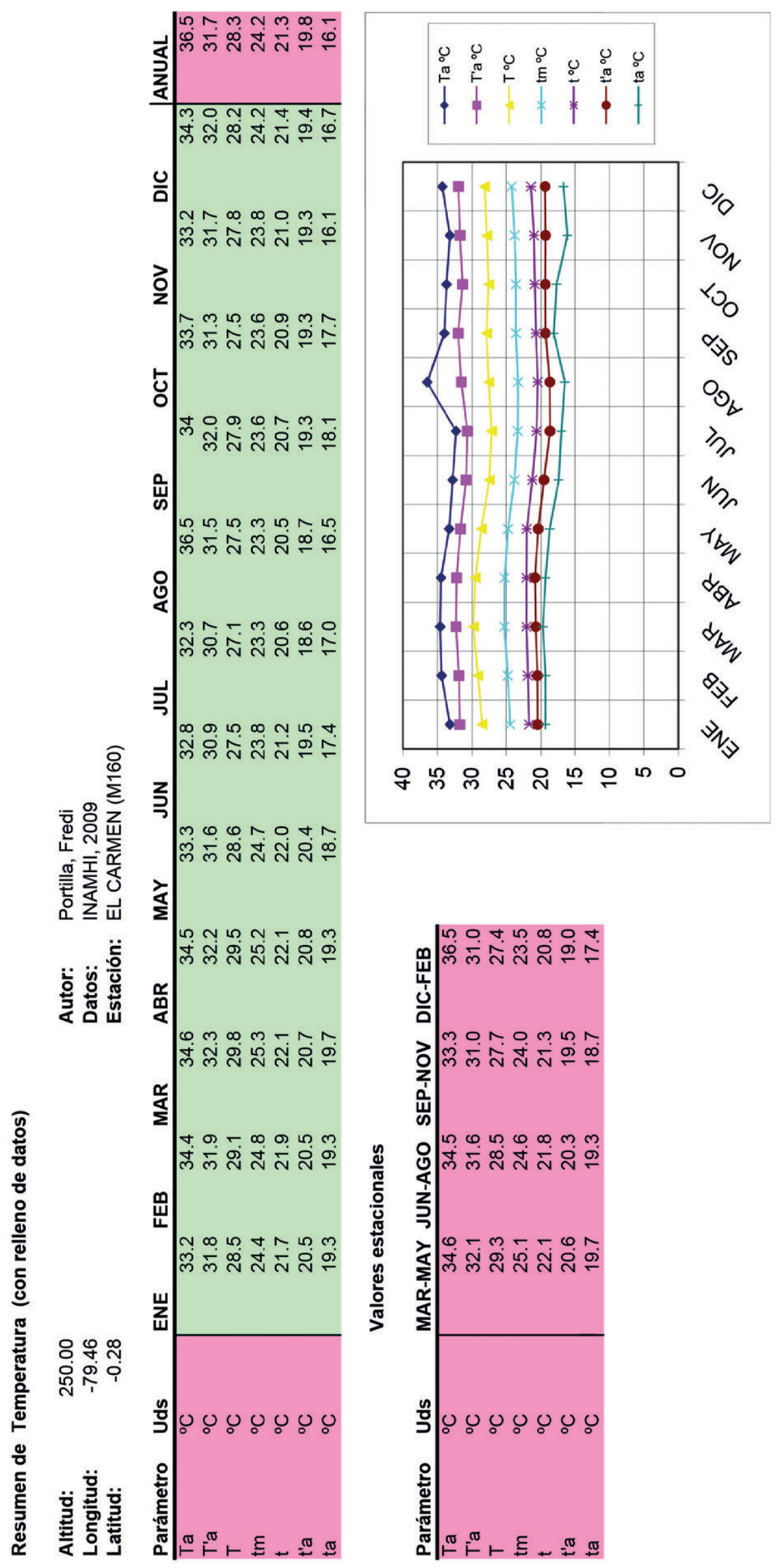


151

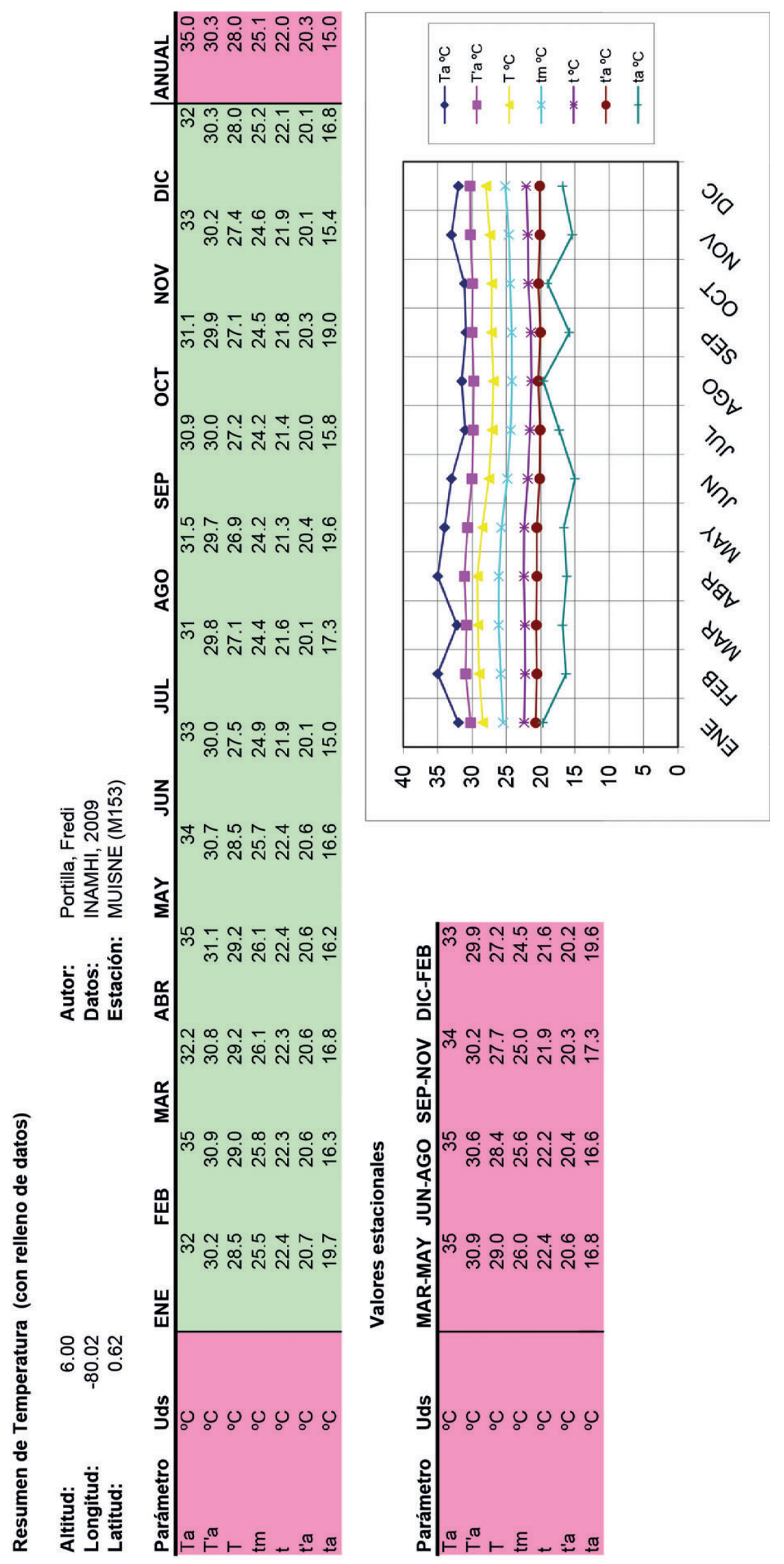


152

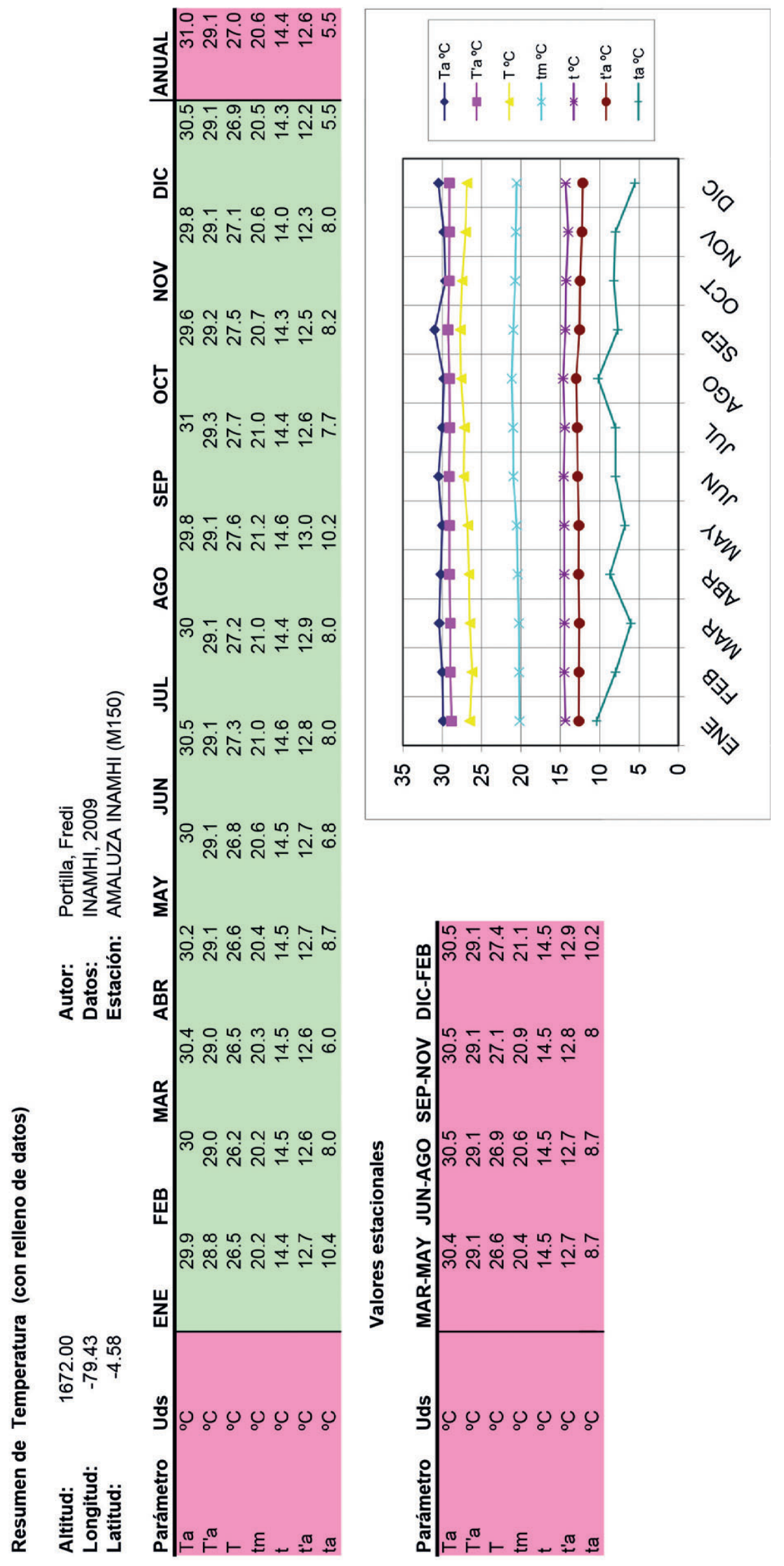


153

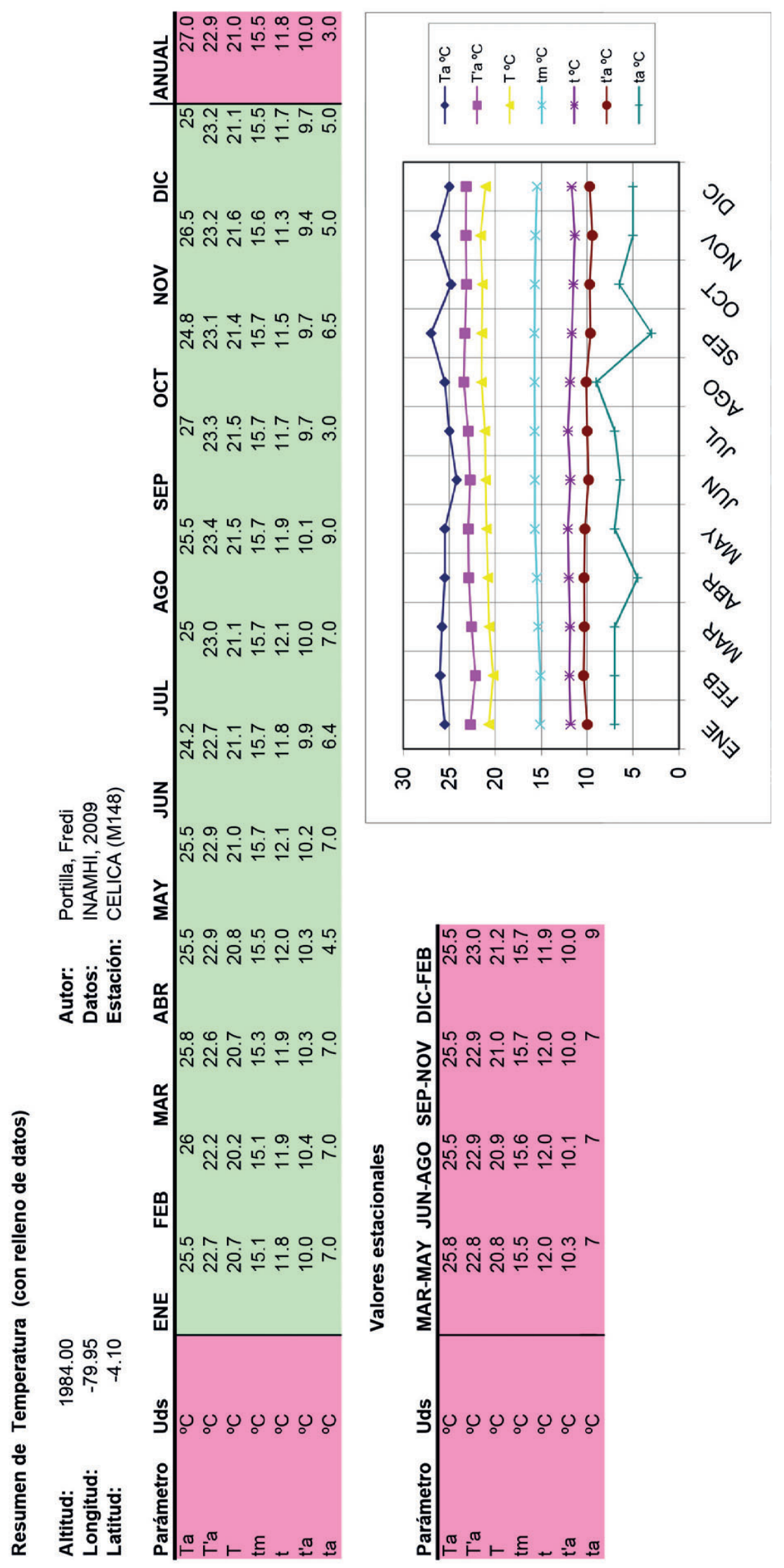


154

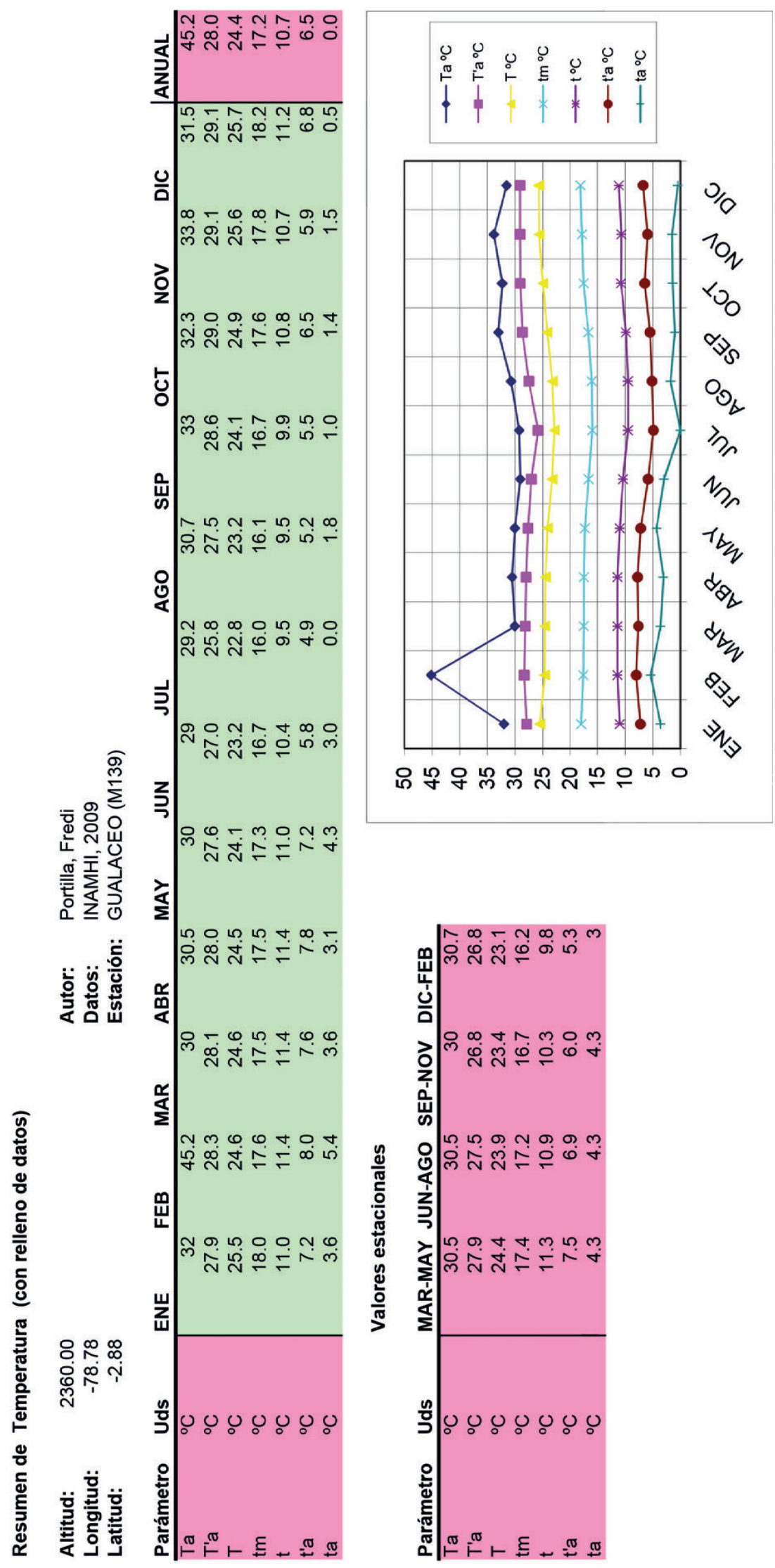


155

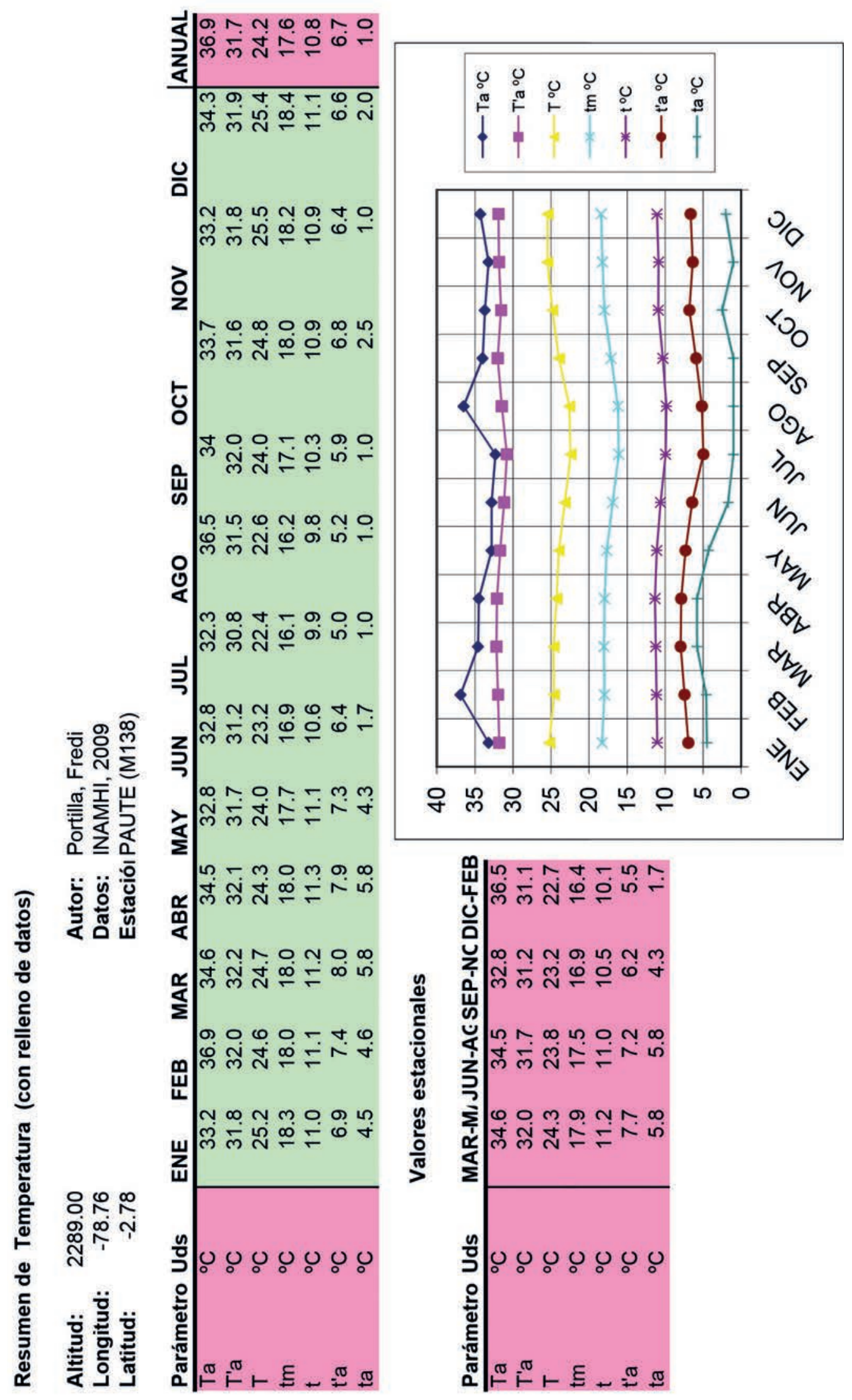


156

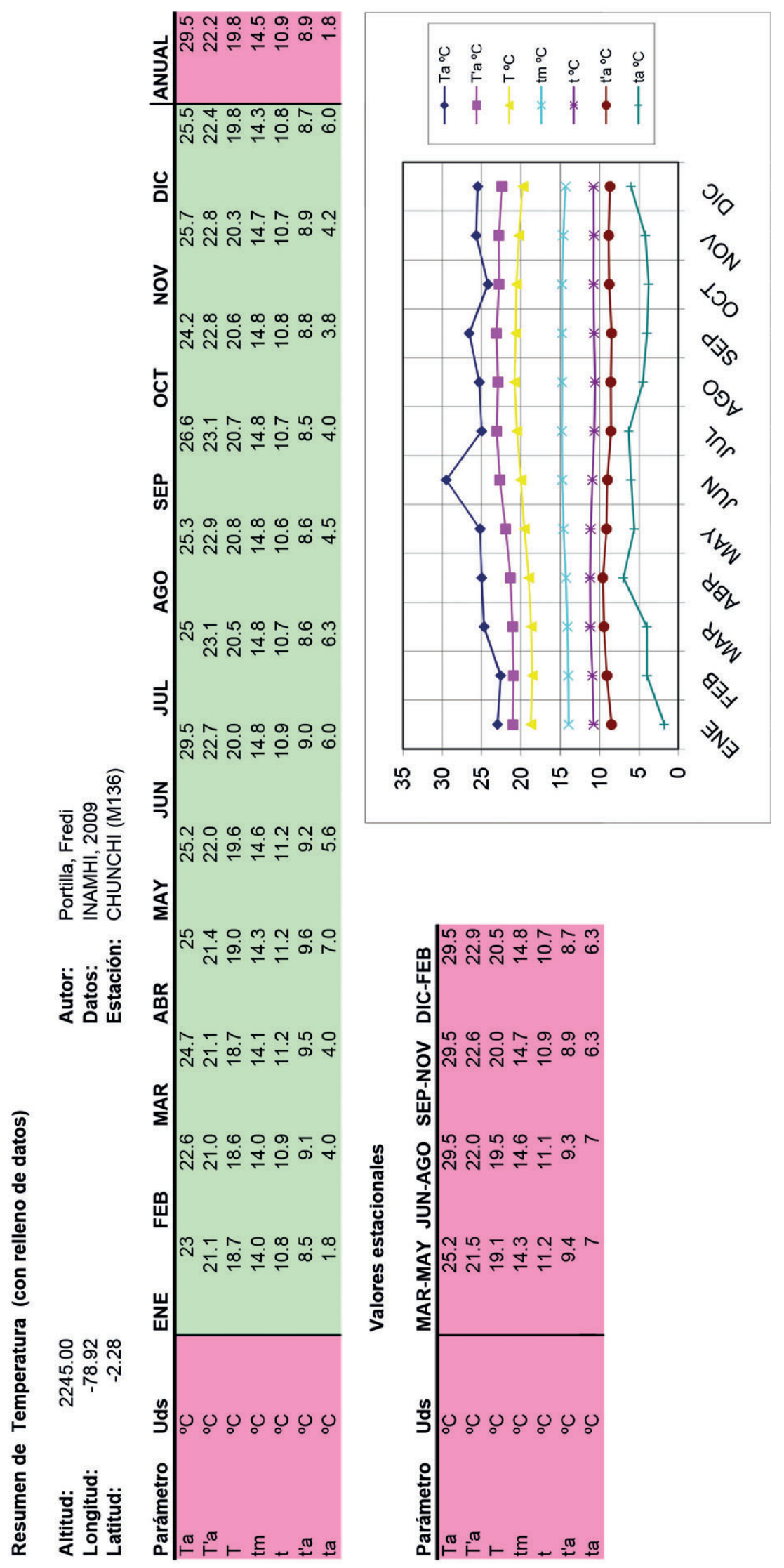


157

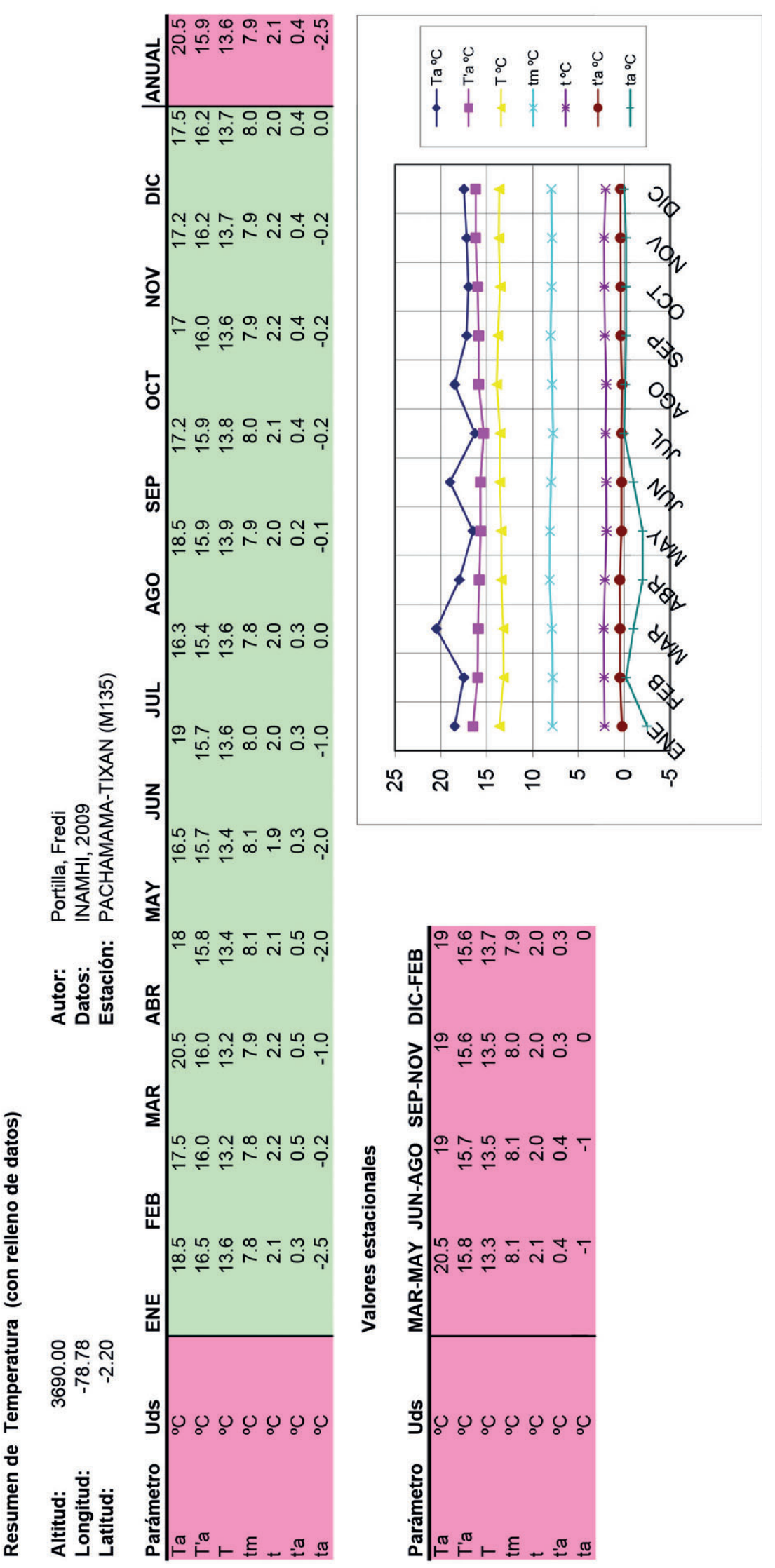


158

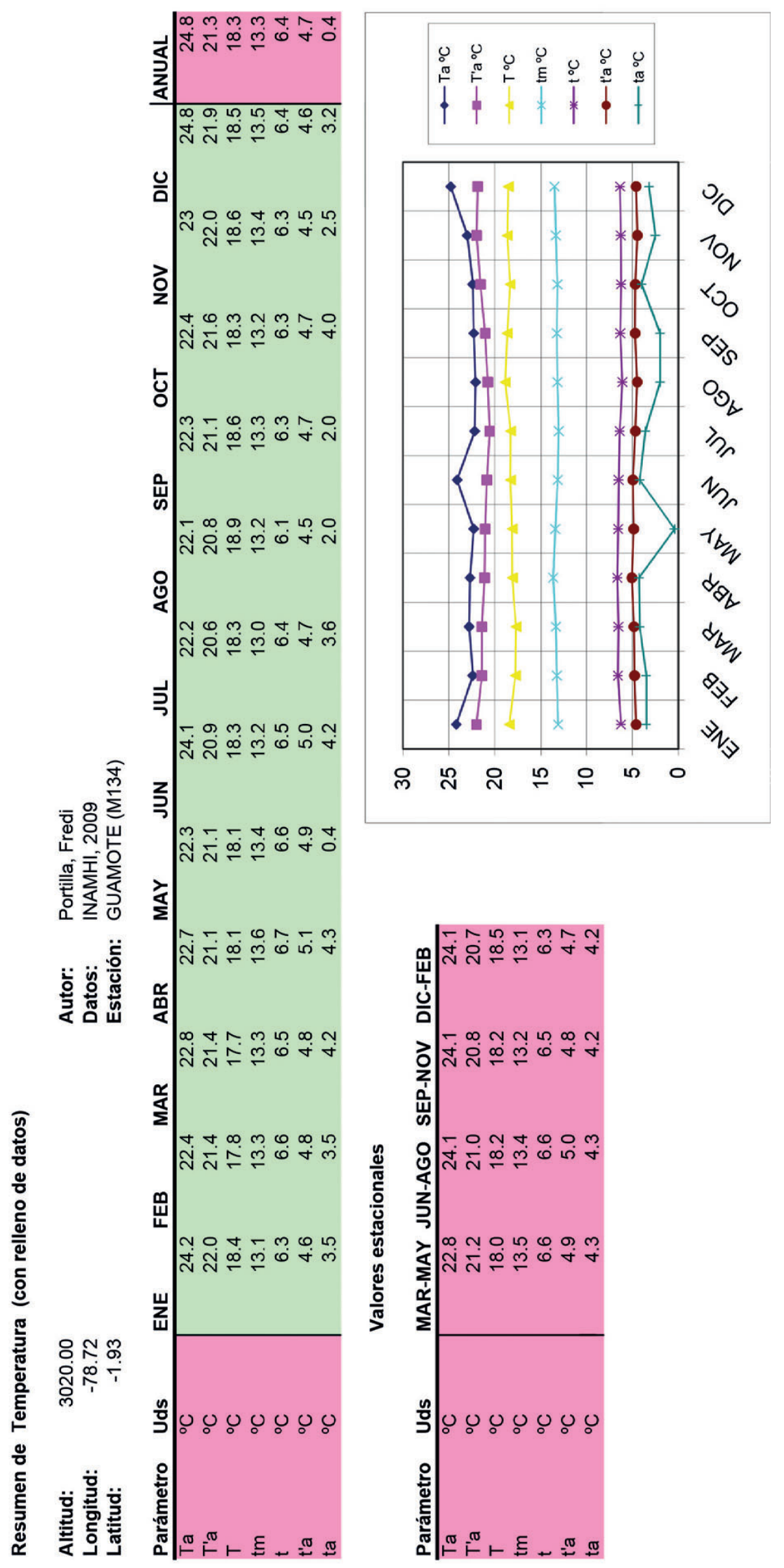


159

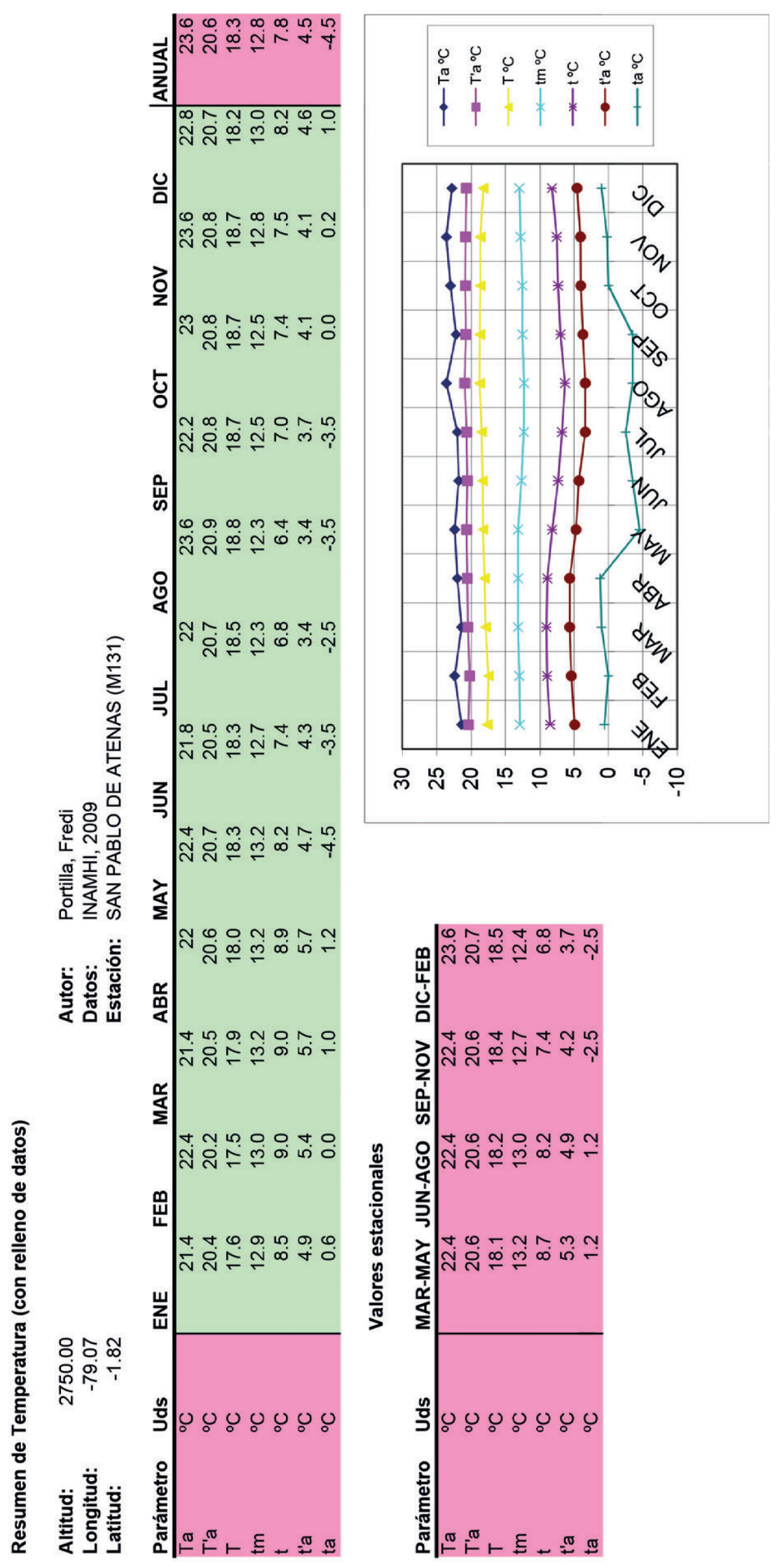


160

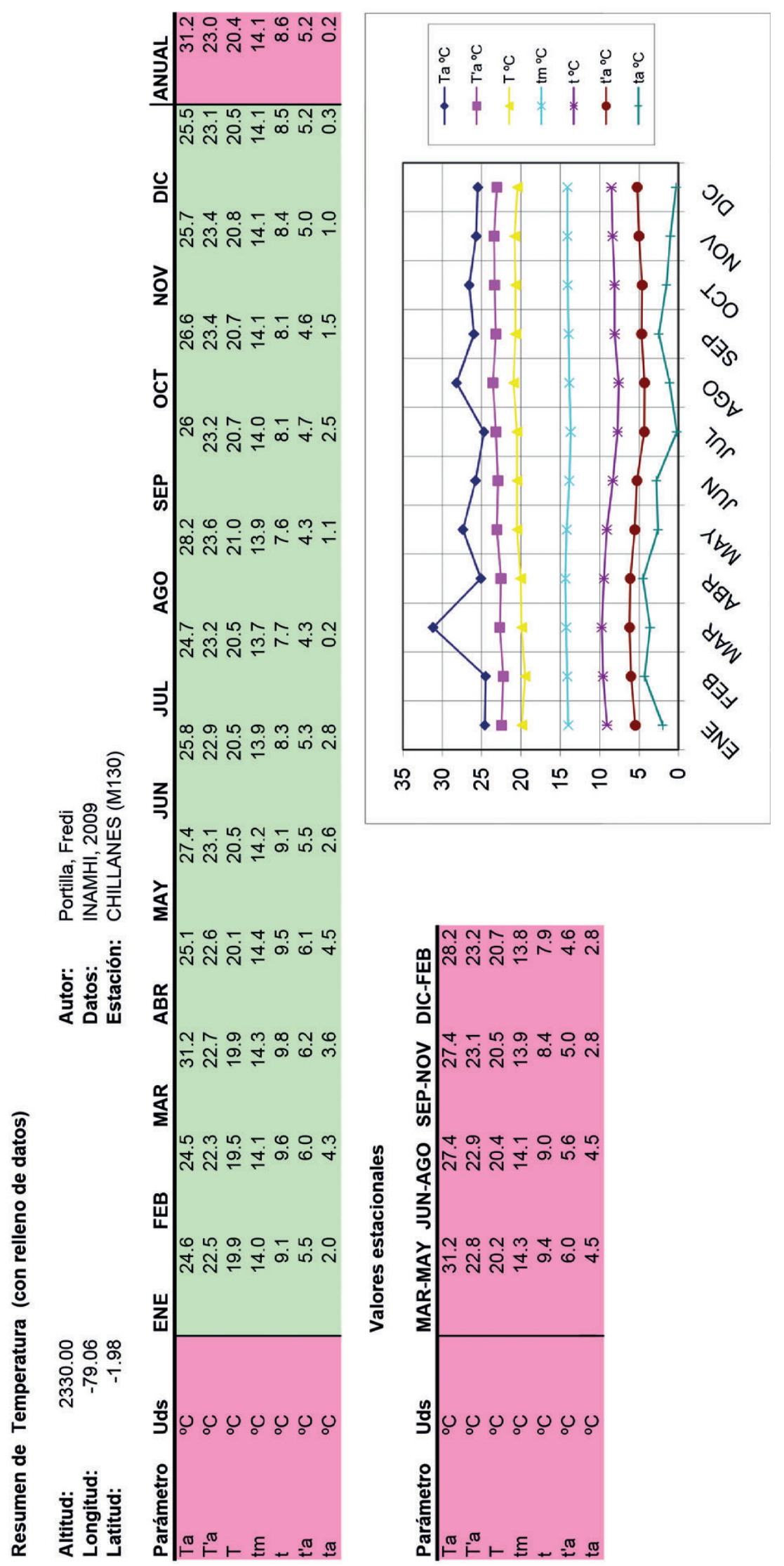


161

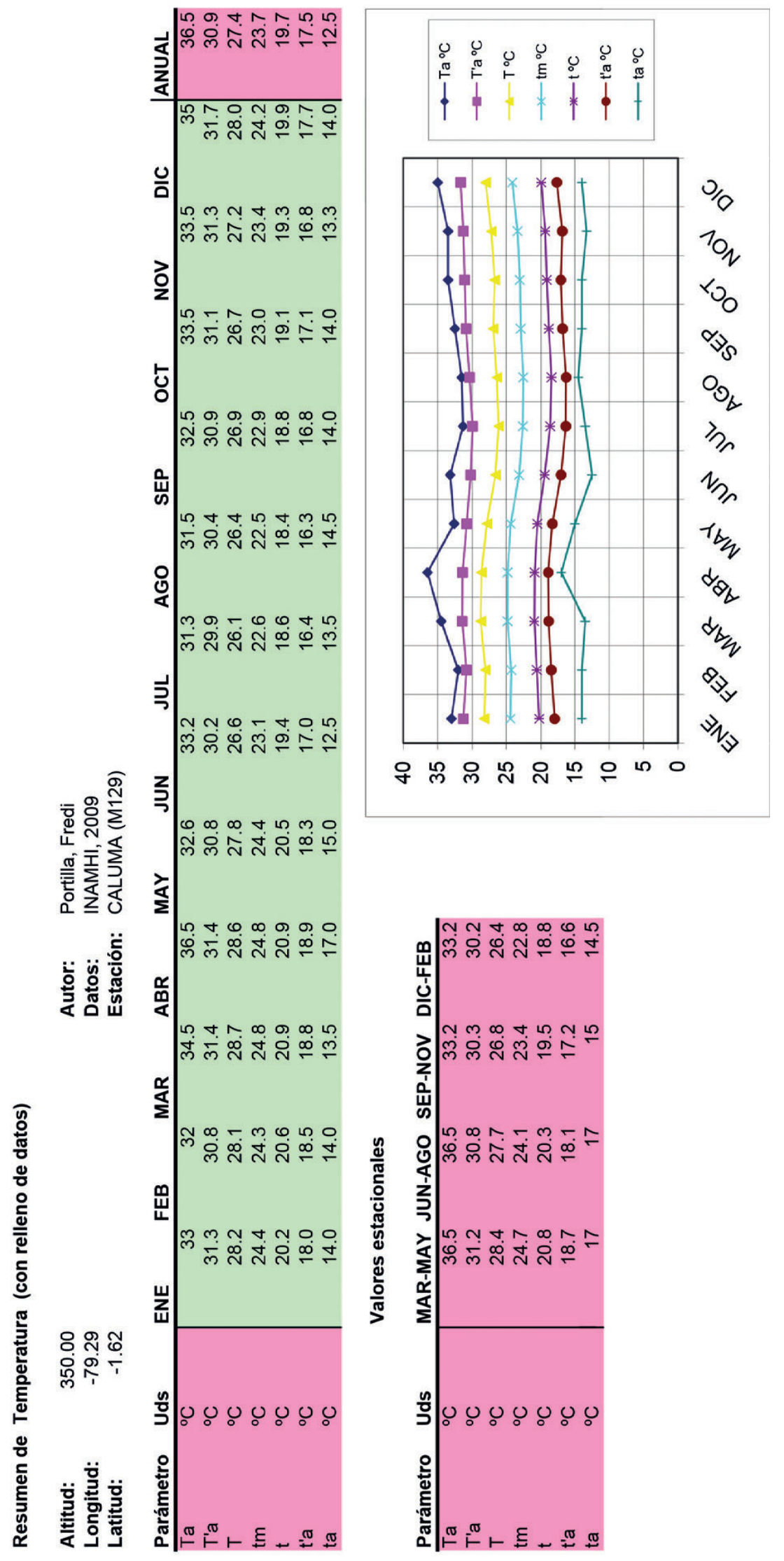


162

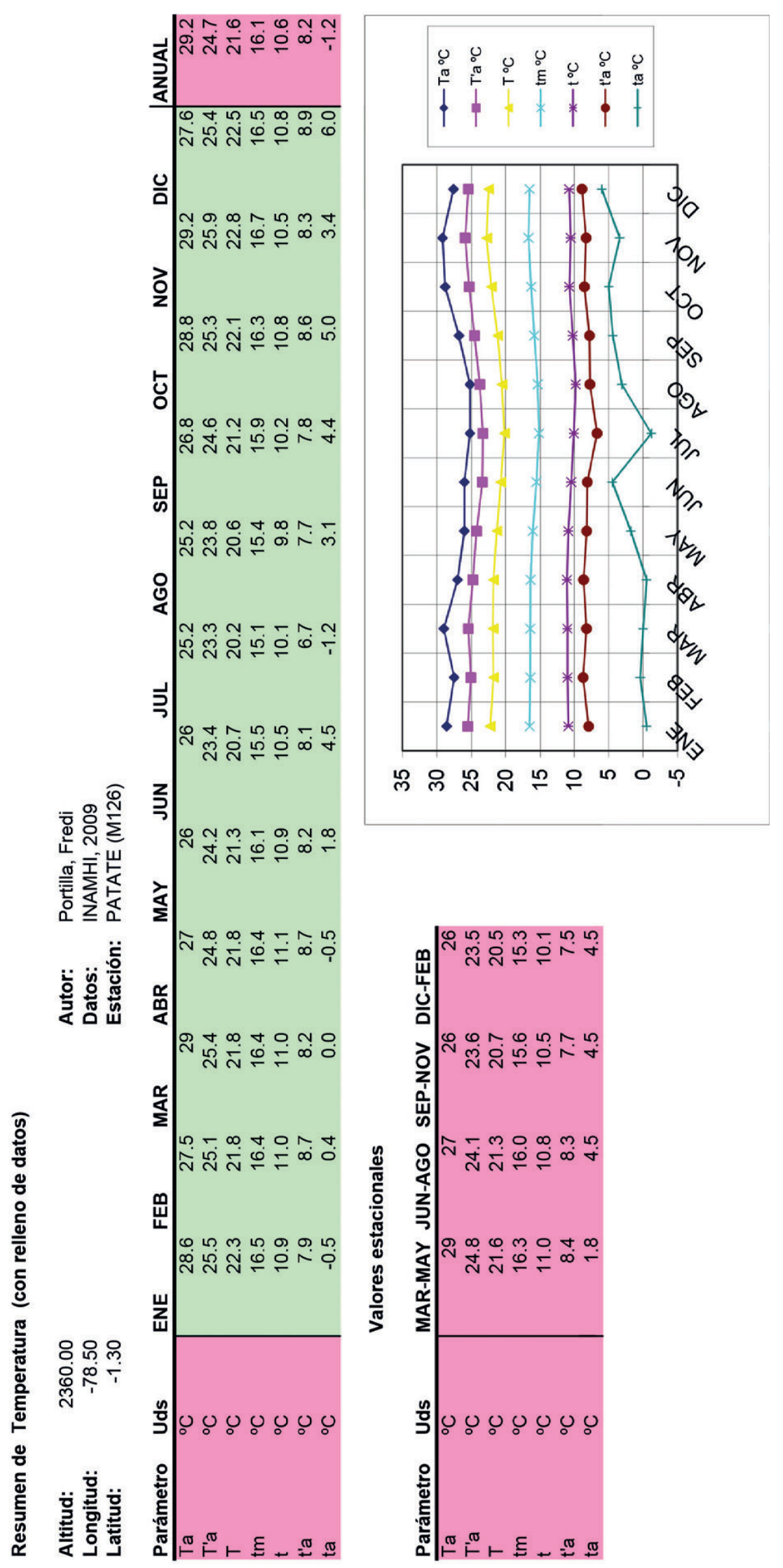


163

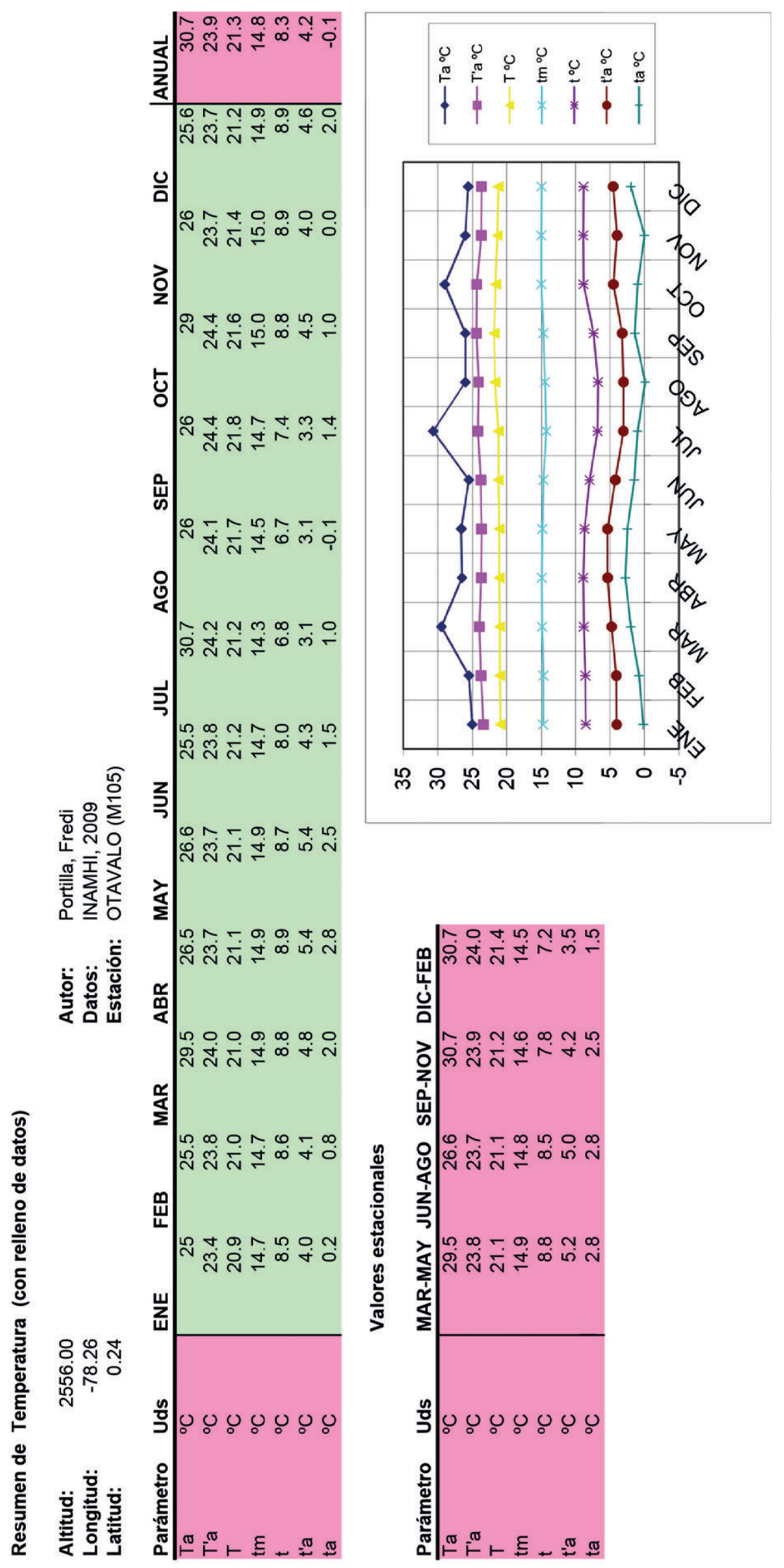




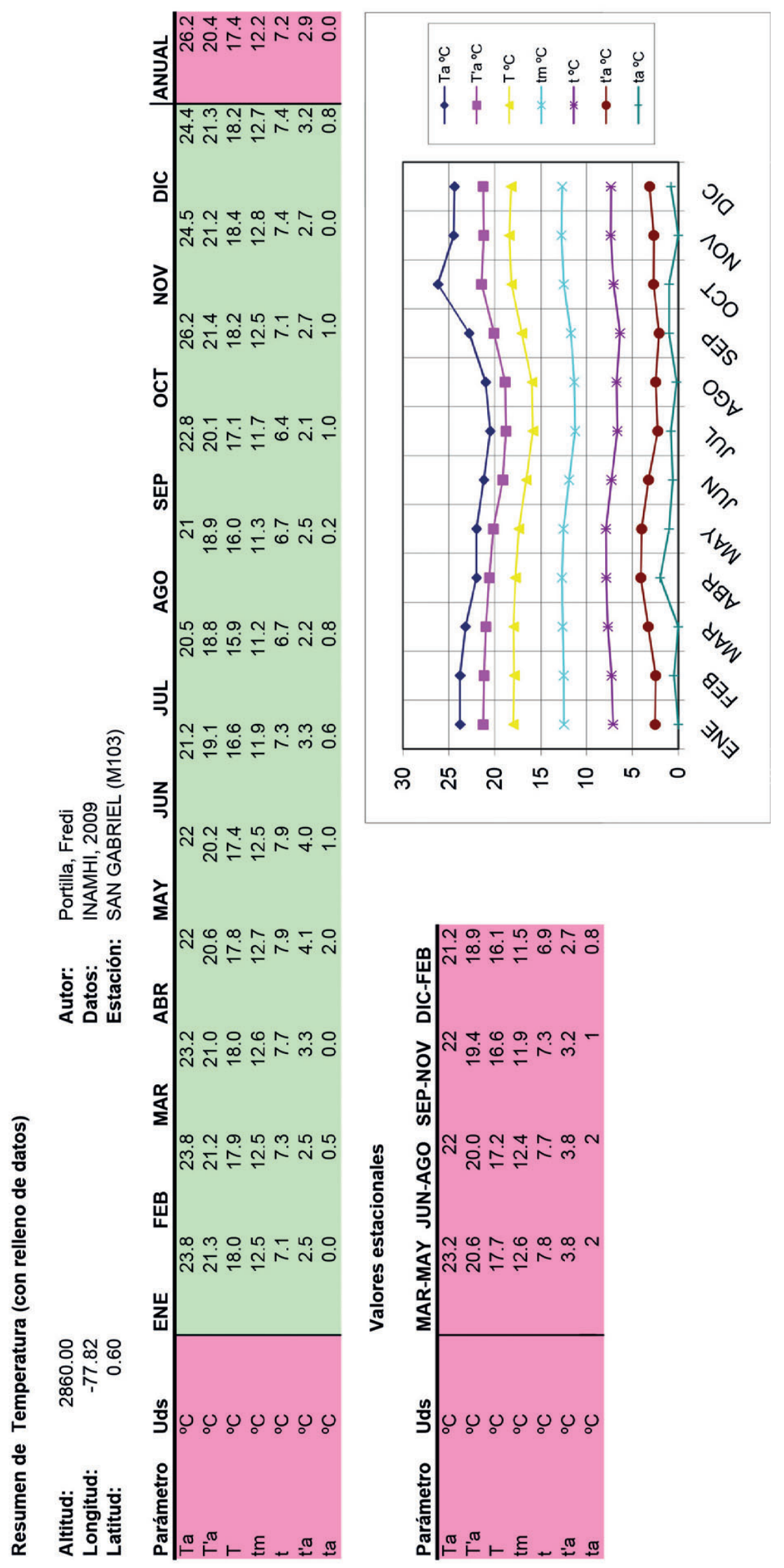


165

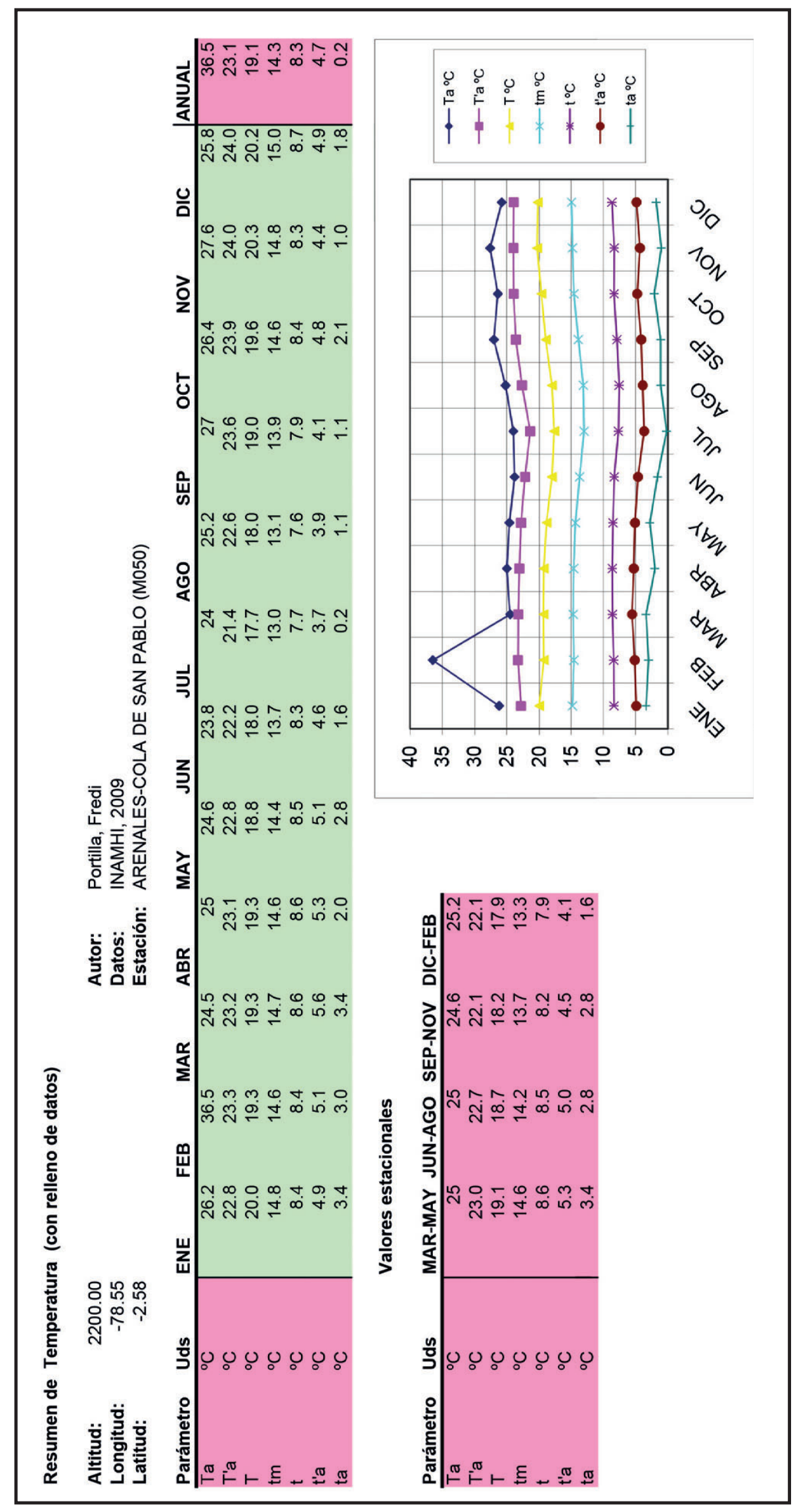


166

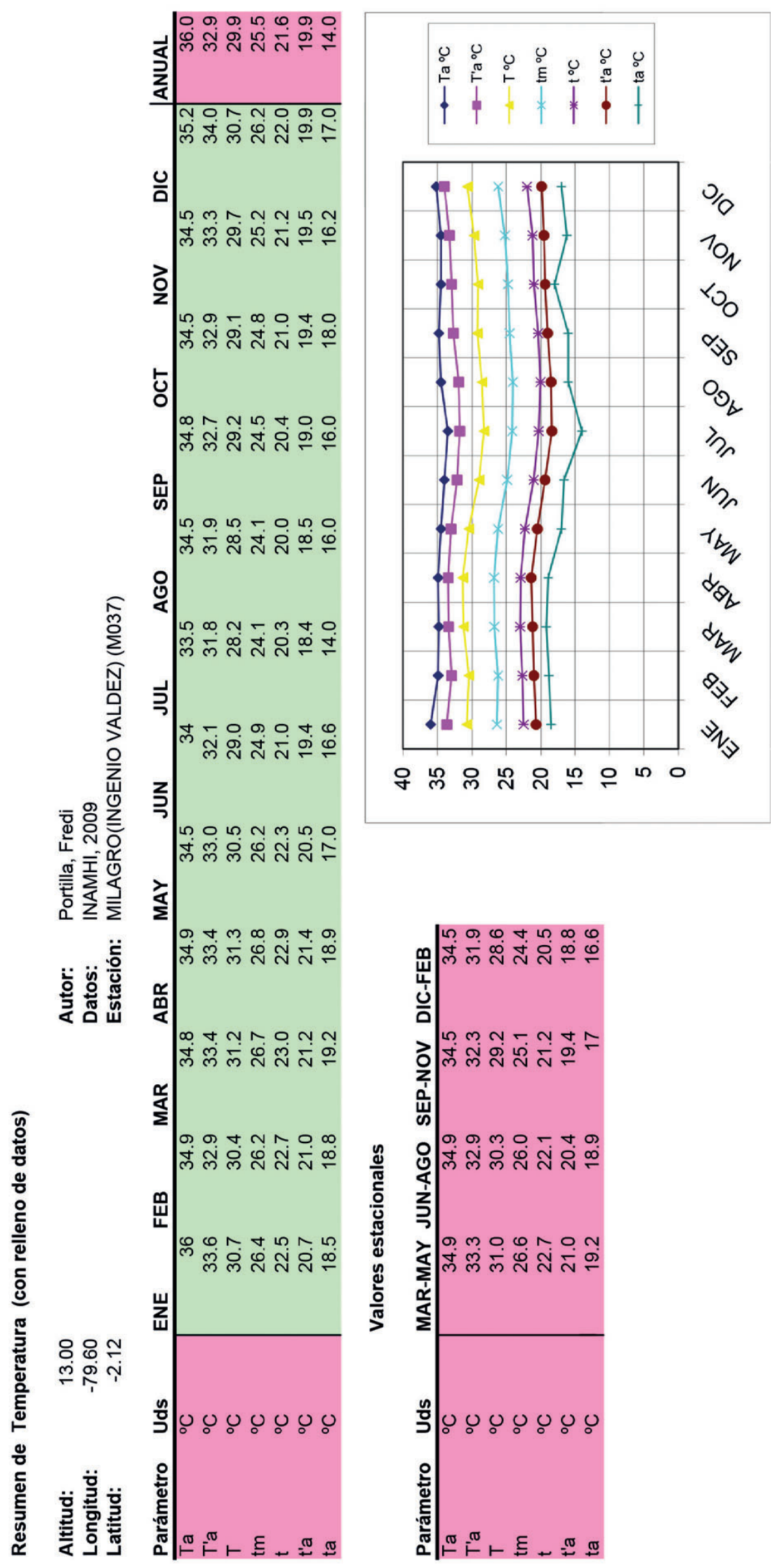




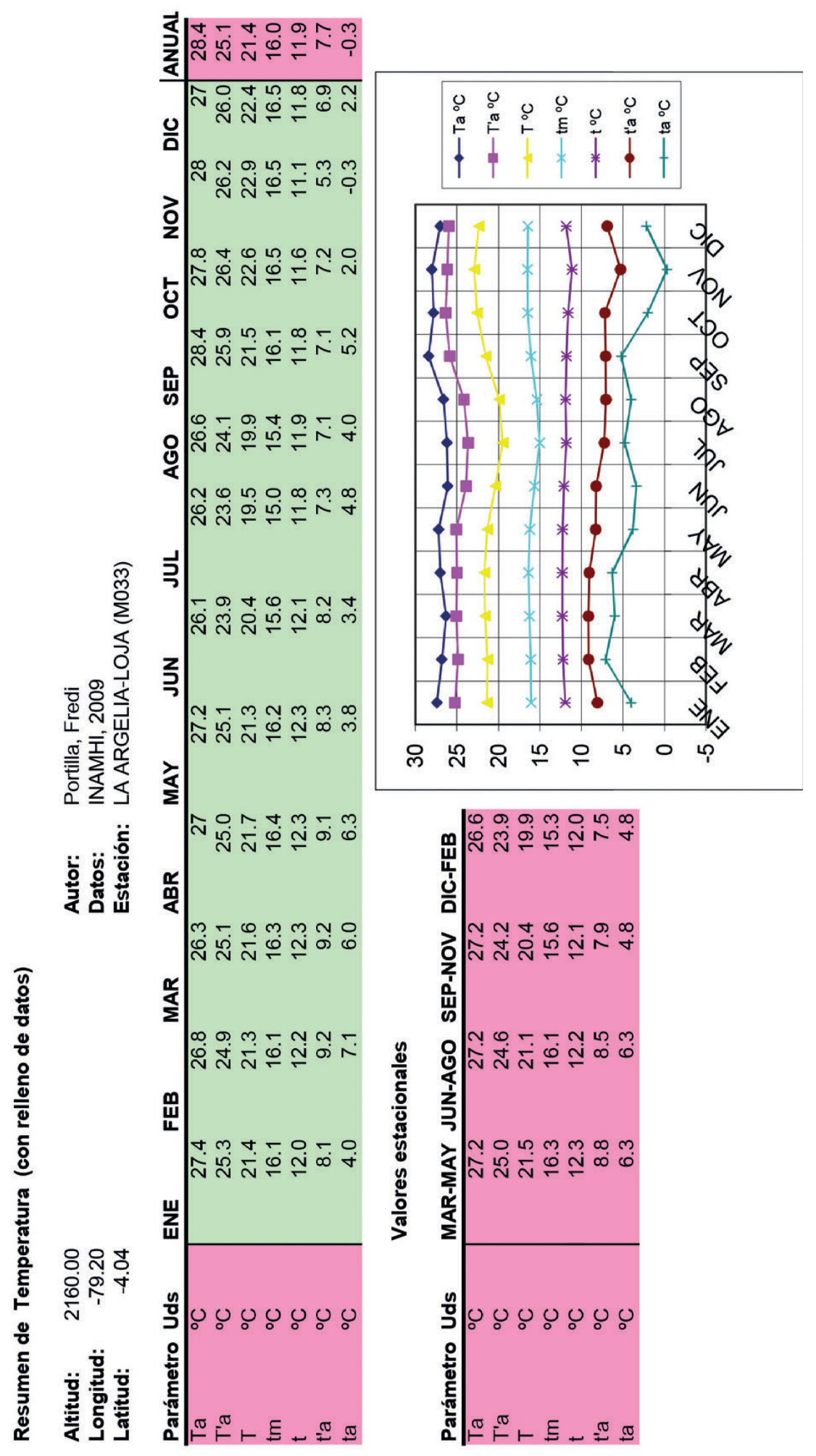


168

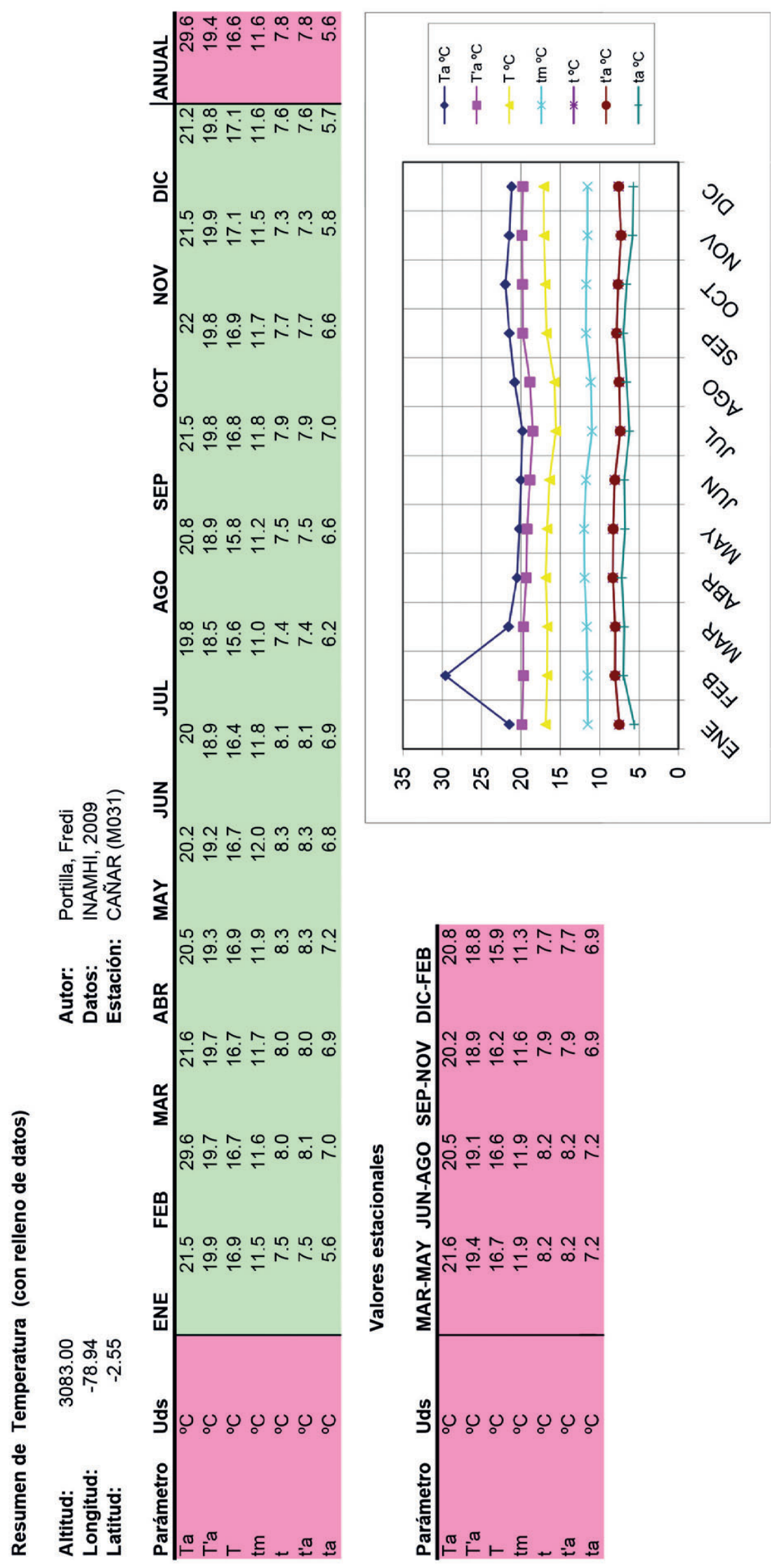




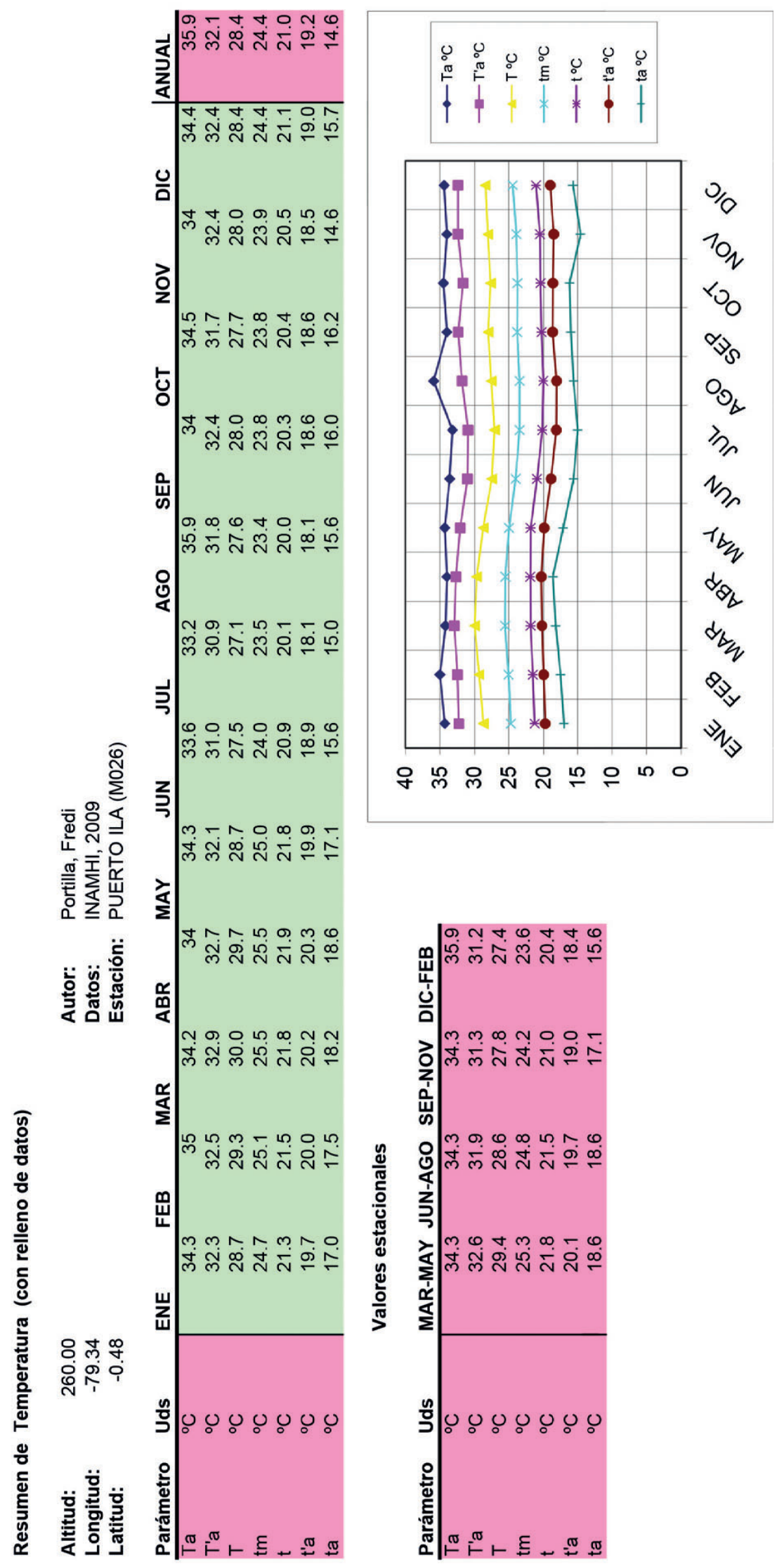


170

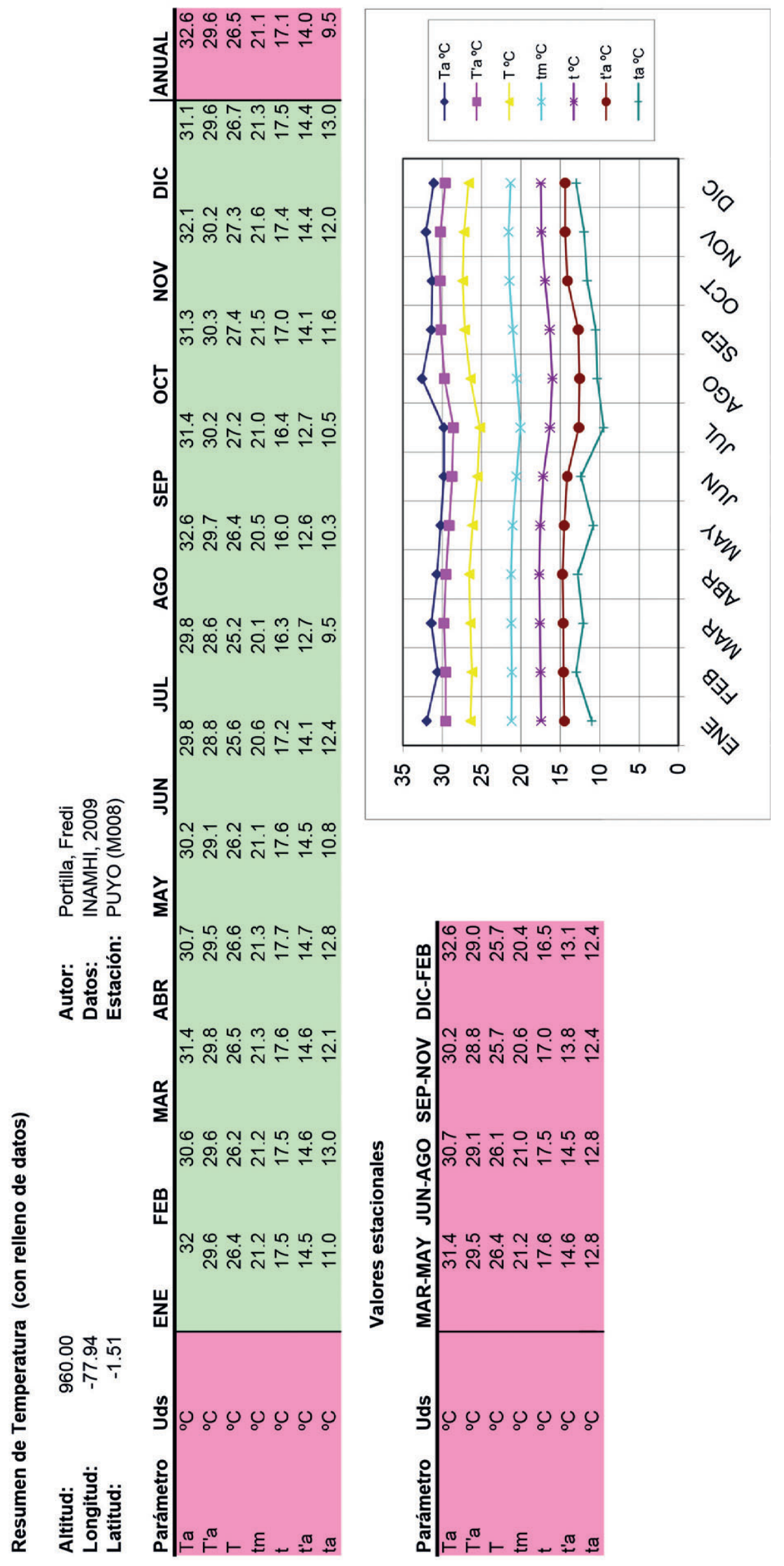


171

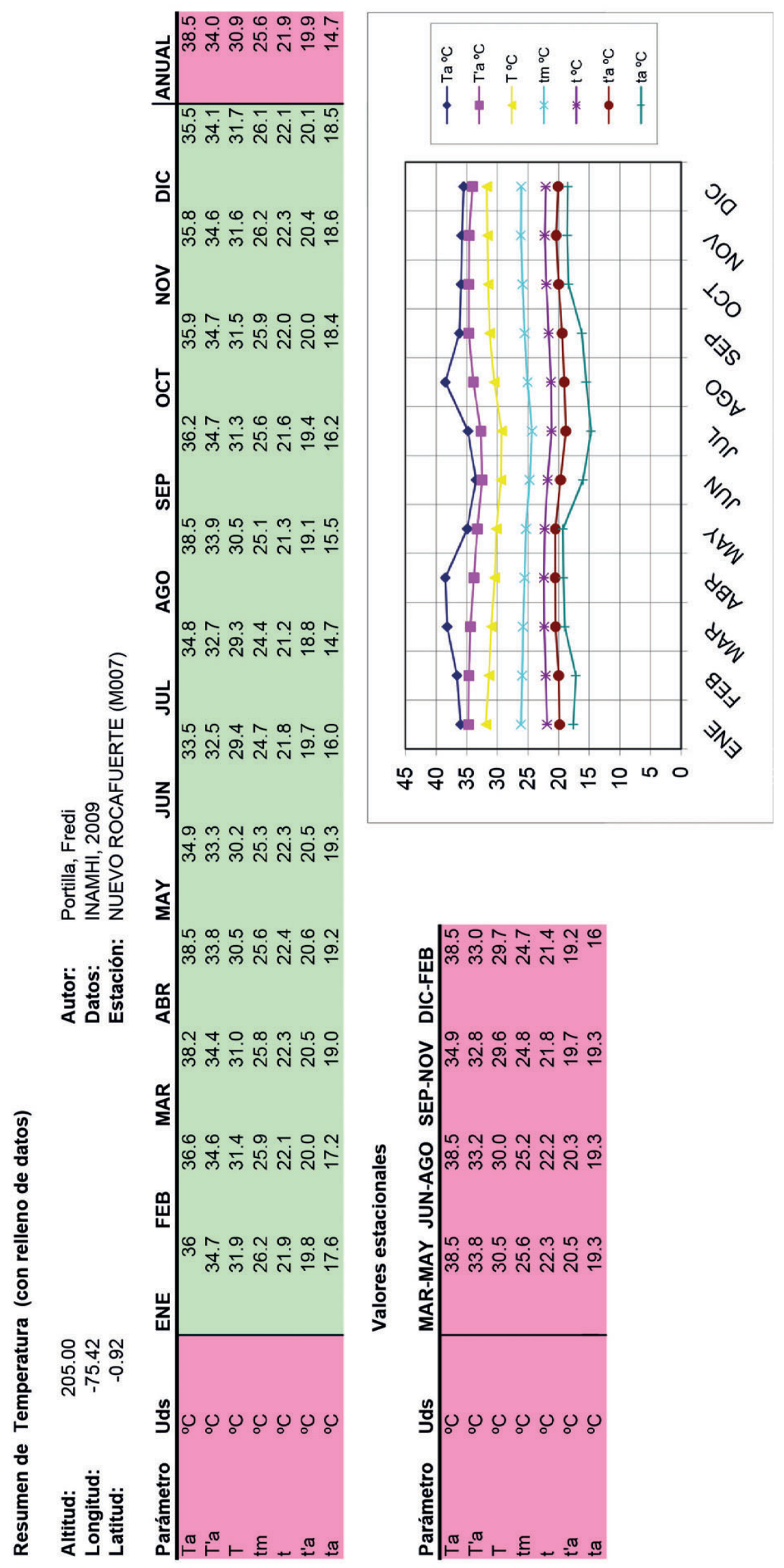


172

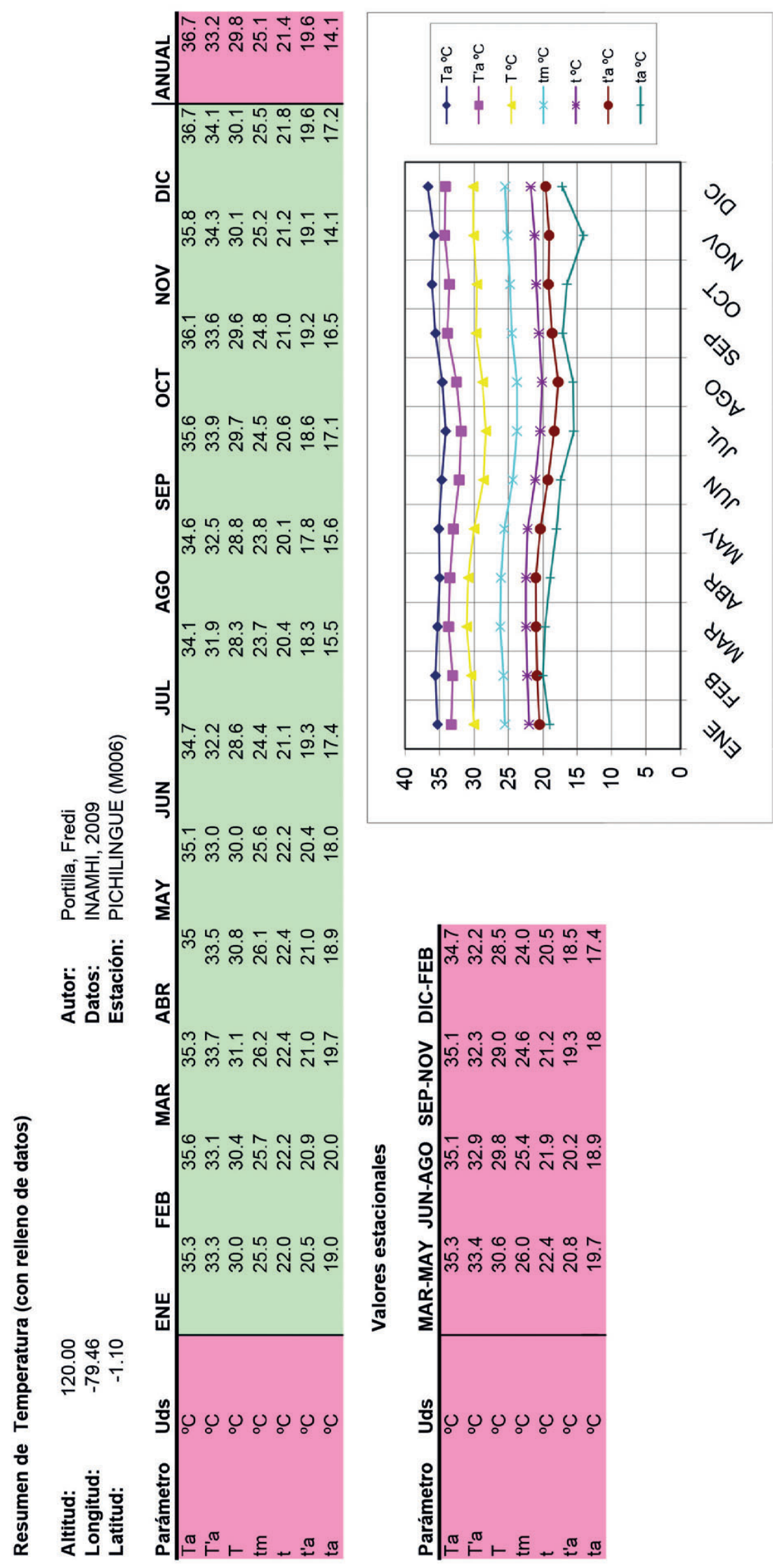


173

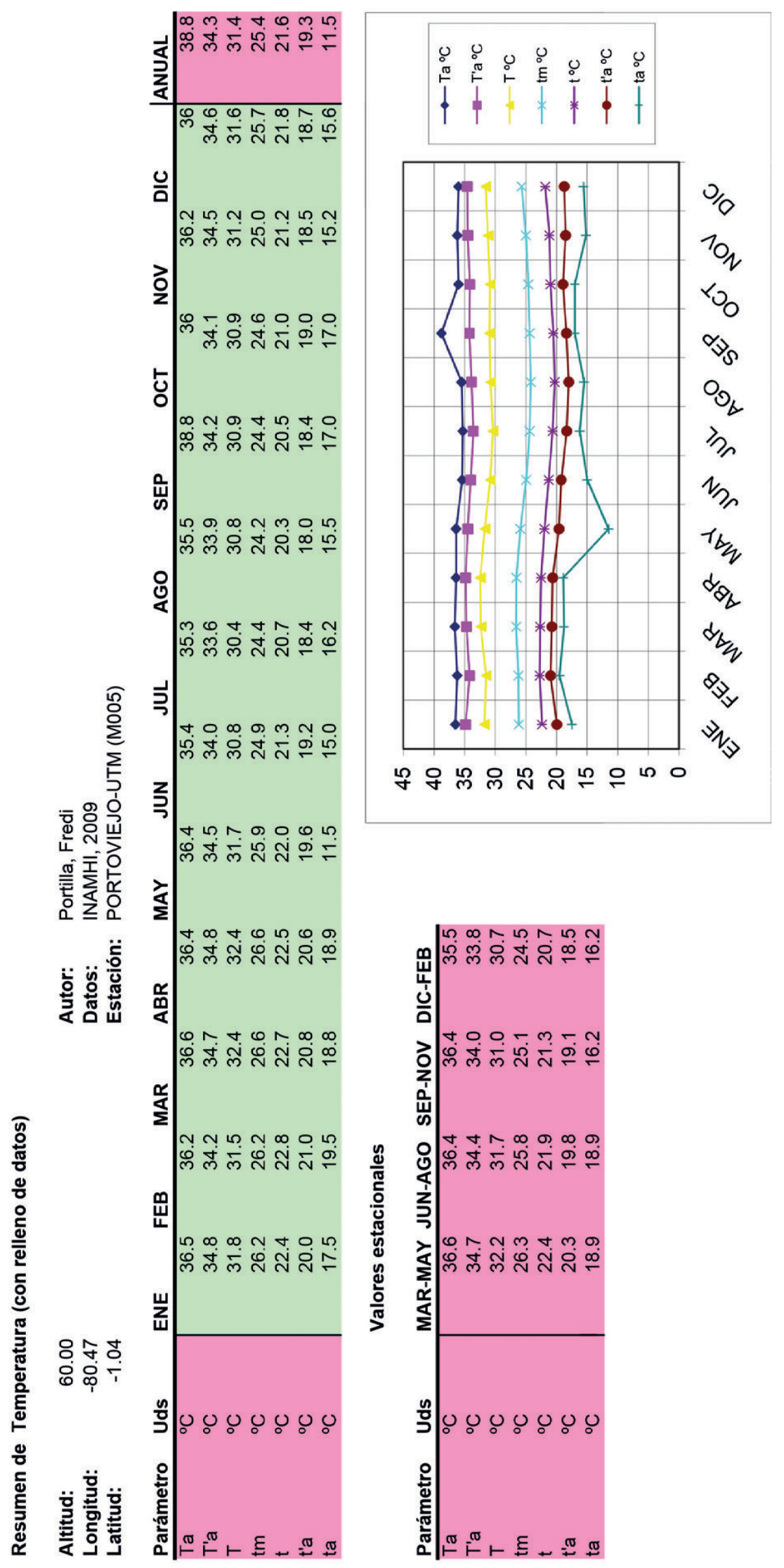


174

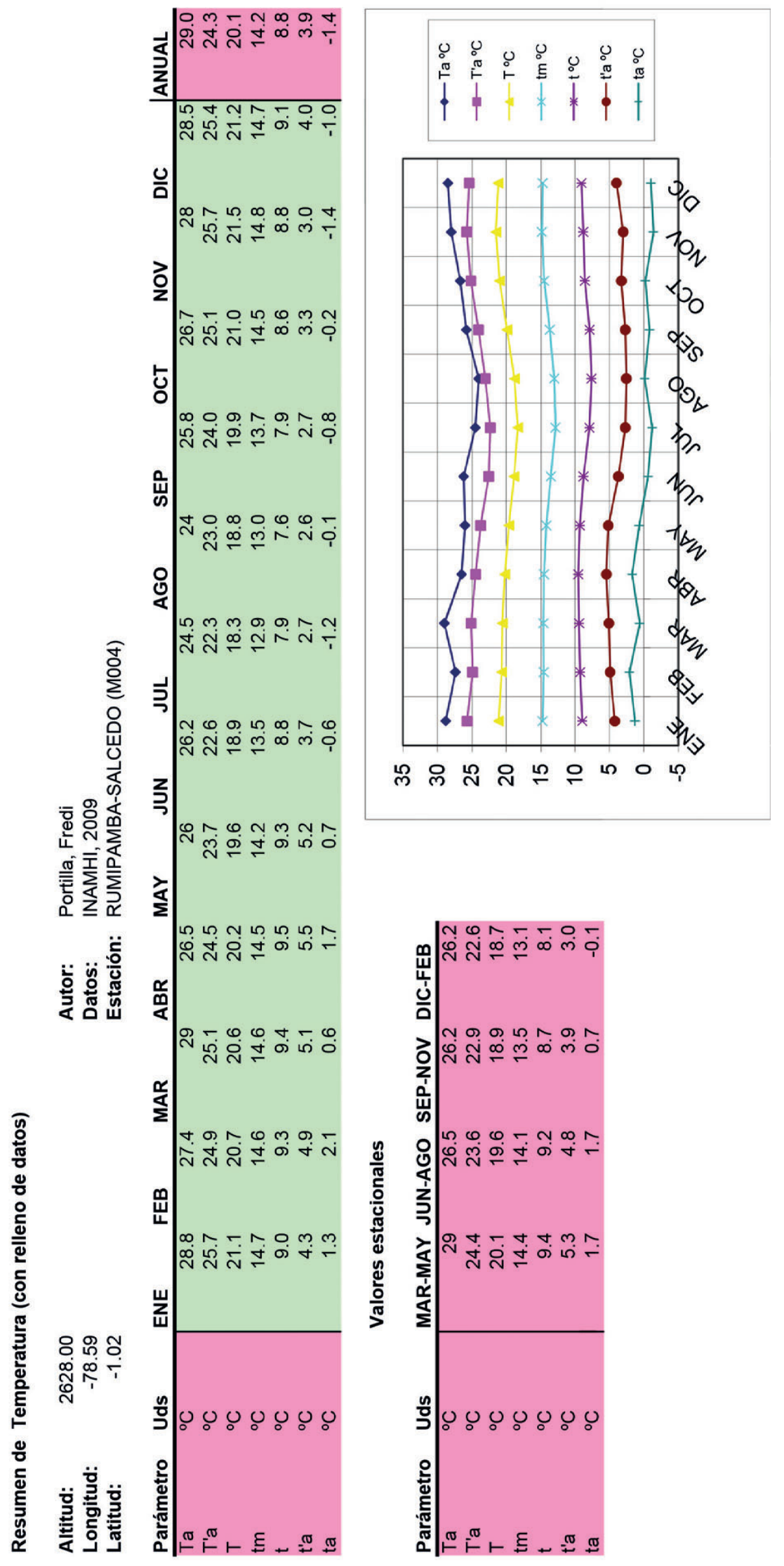


175

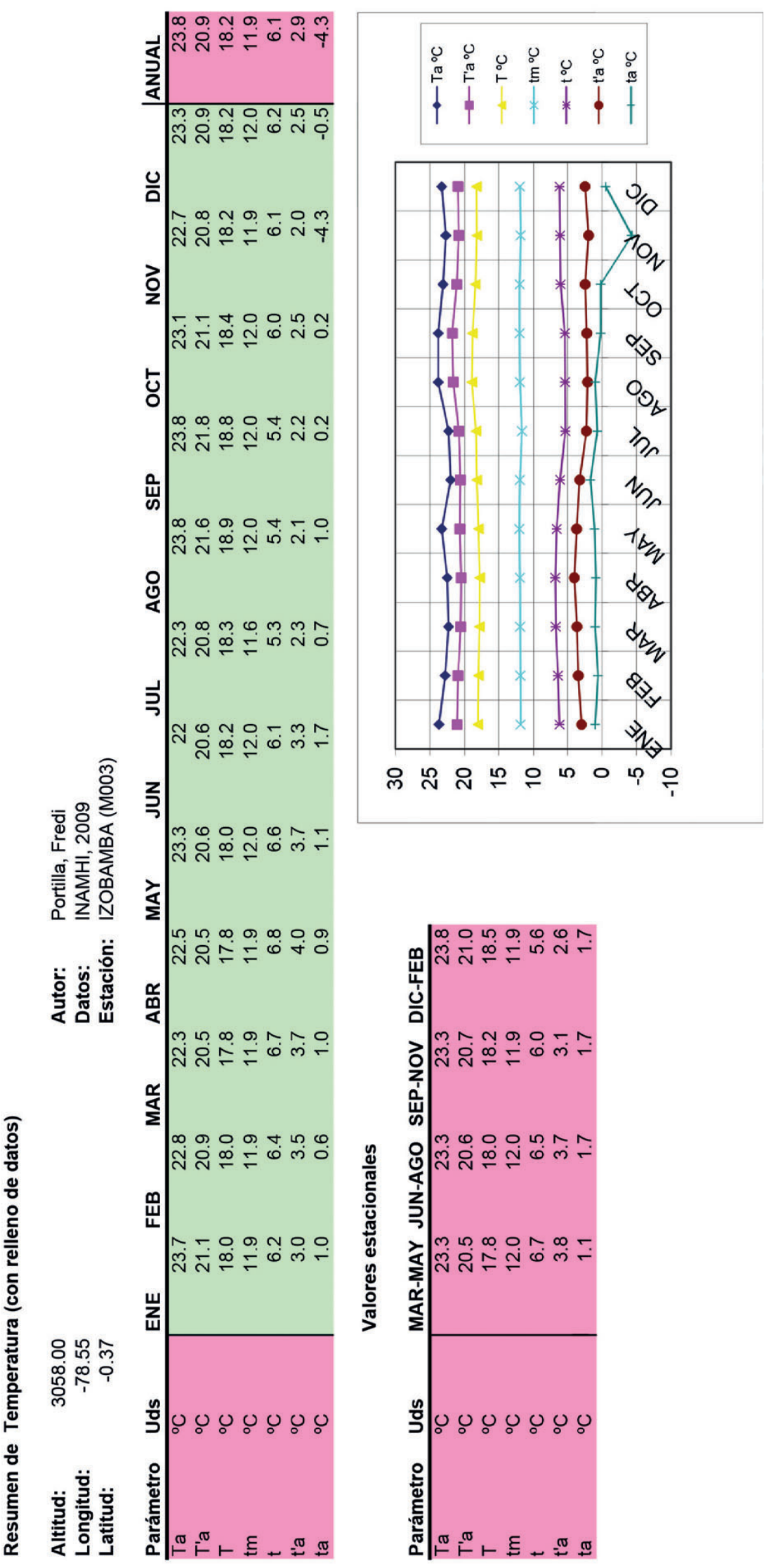


176

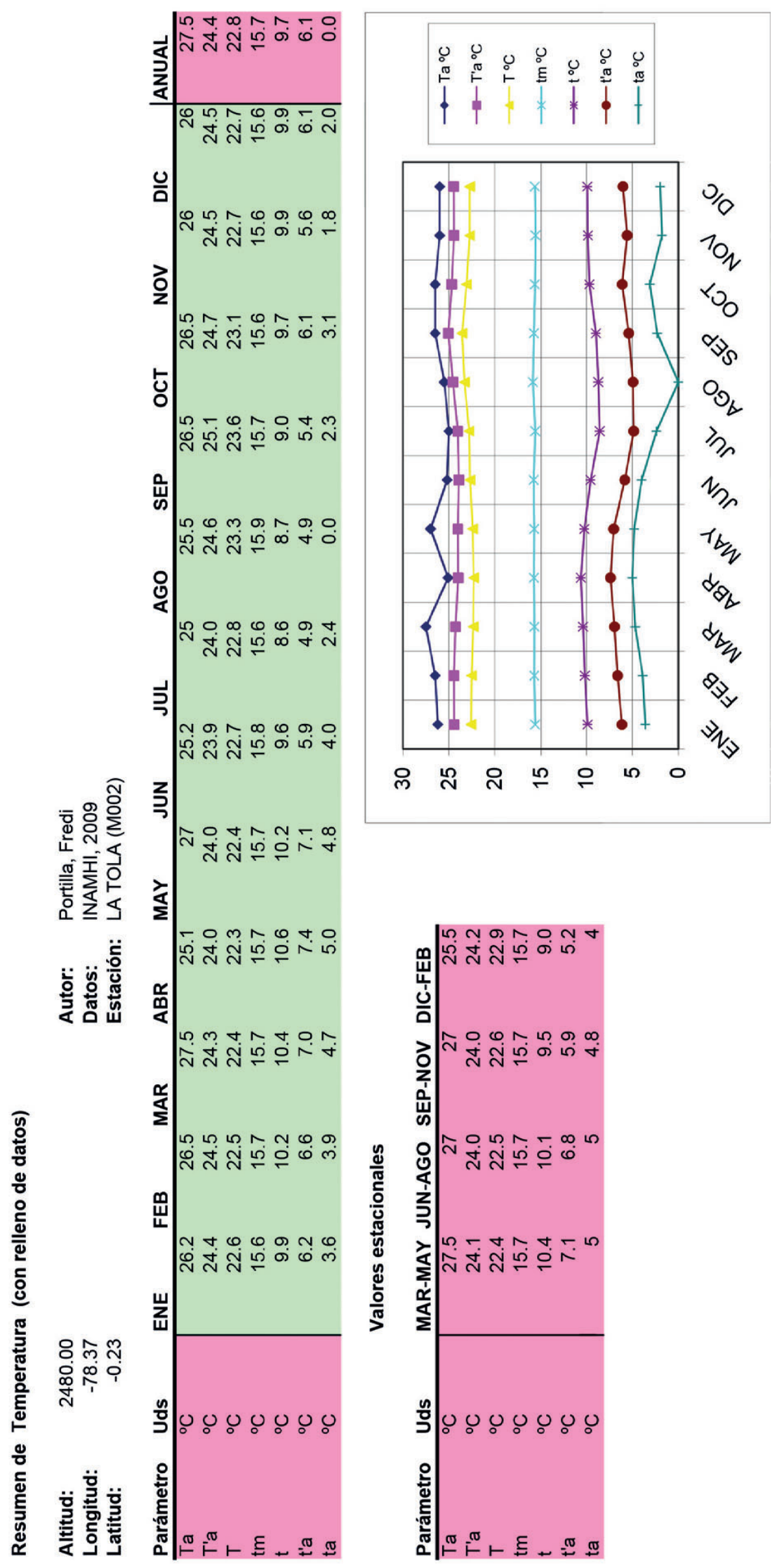




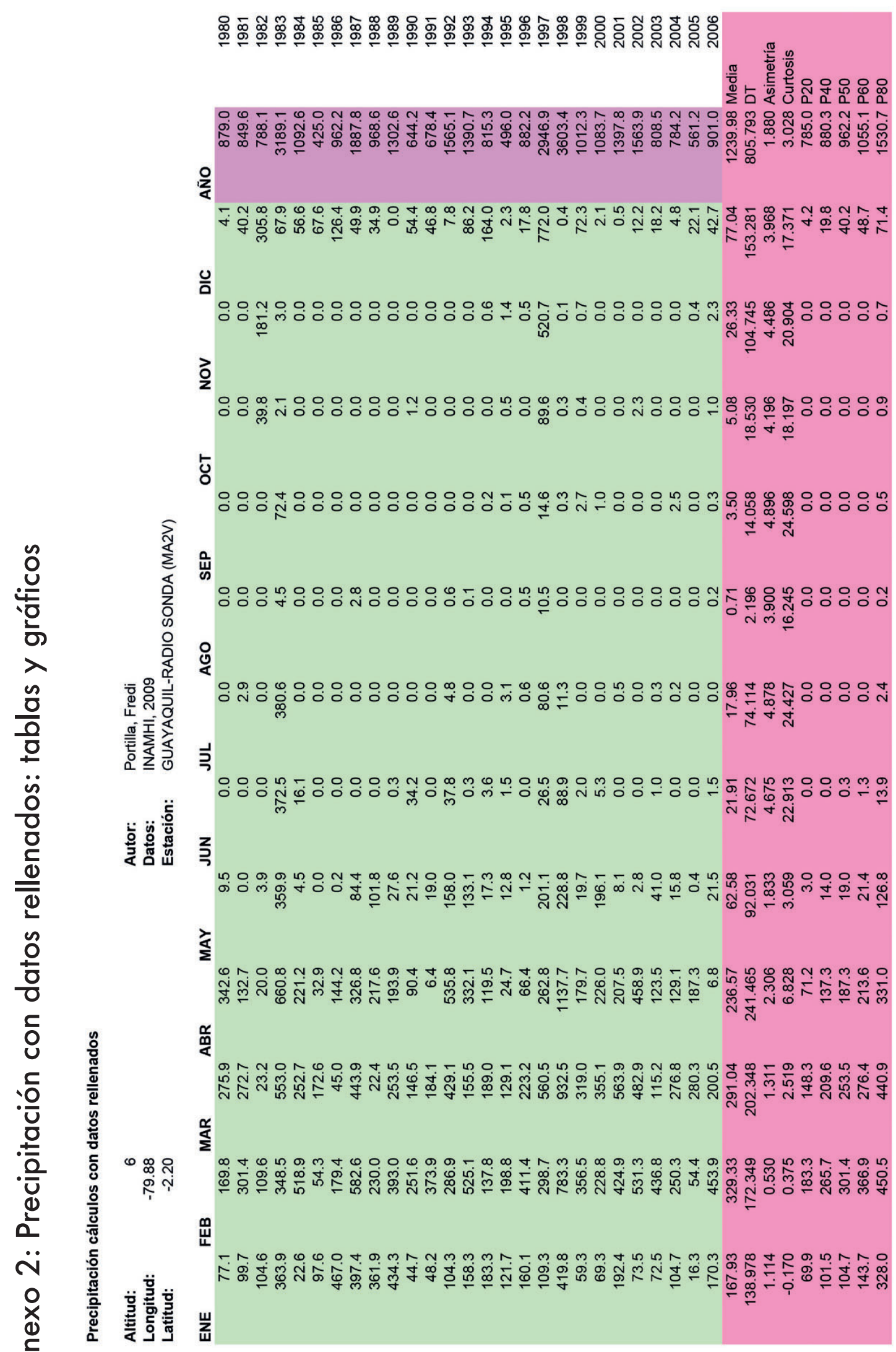


178

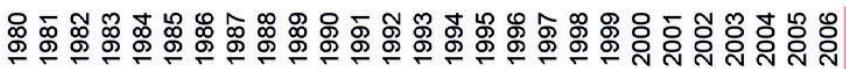

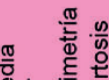

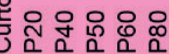

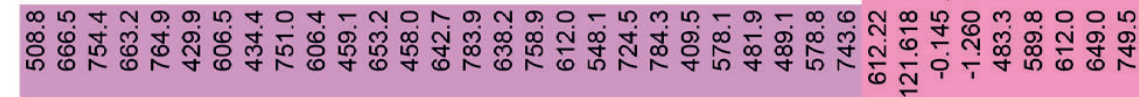

学

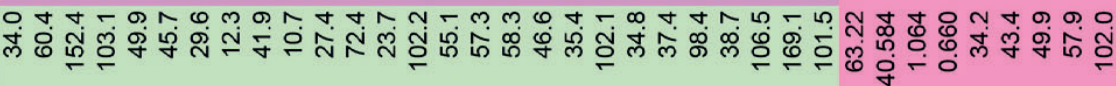

음

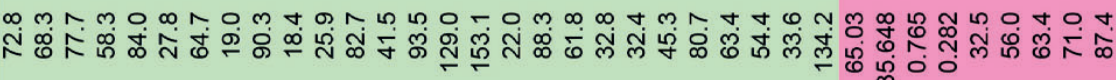

o

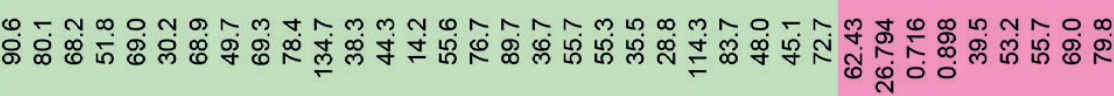

t. N้

䓀

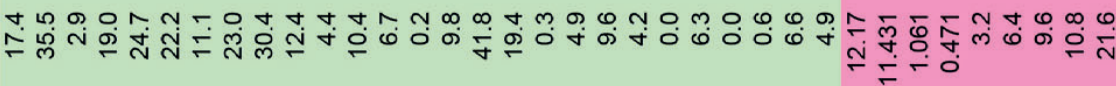

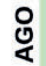

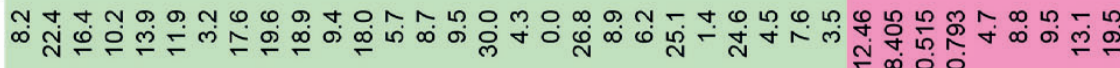

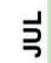

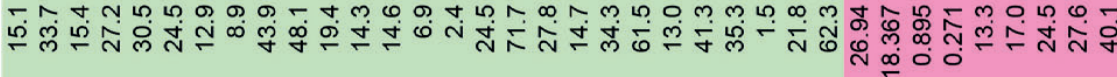

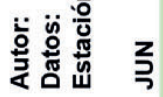

ம

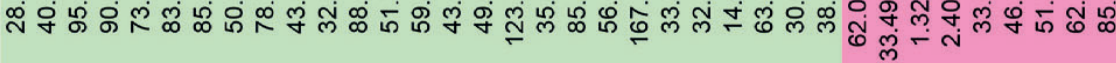

š

Q

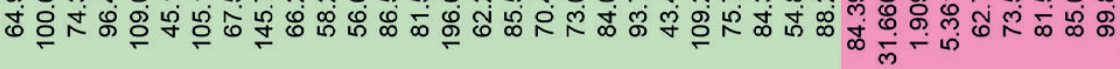

爱

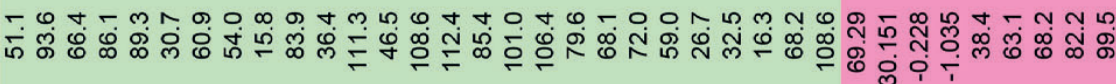

$\frac{\alpha}{\Sigma}$

공

จ

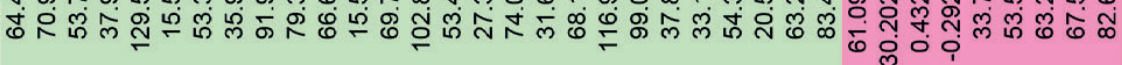

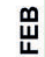

п

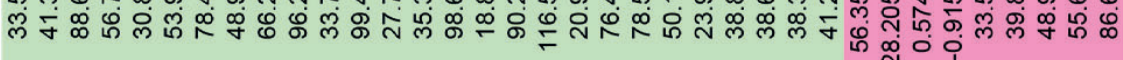




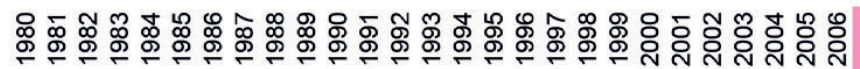

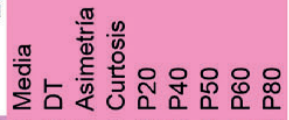

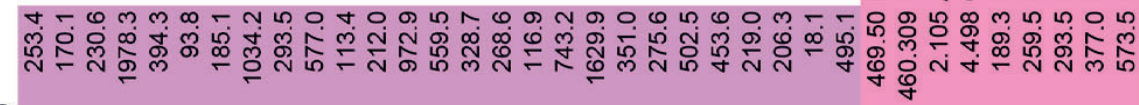

安 웅 先

$\underline{0}$

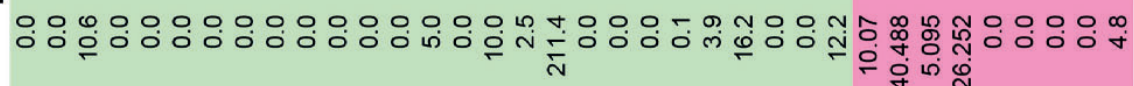
ว

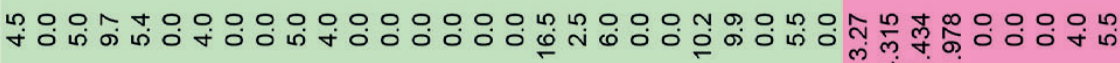

๖ั

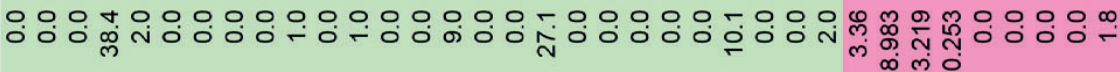
㟧

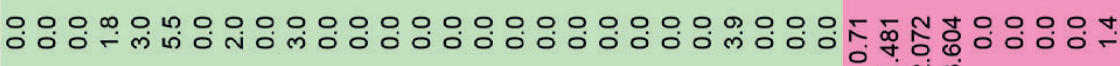

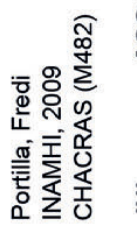
운

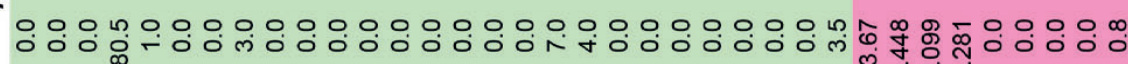
3 范产产惫

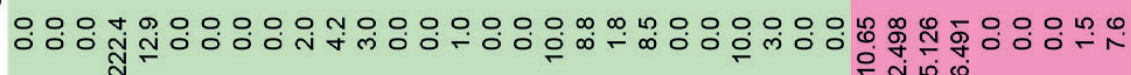

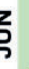

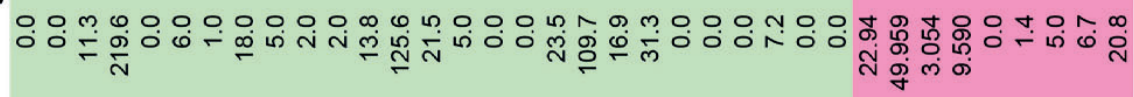

¿

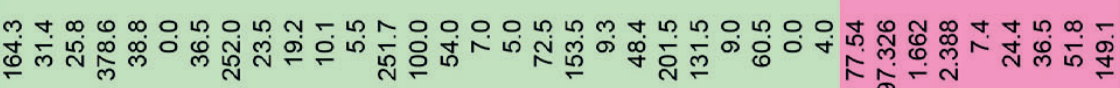

㩊 m mo-

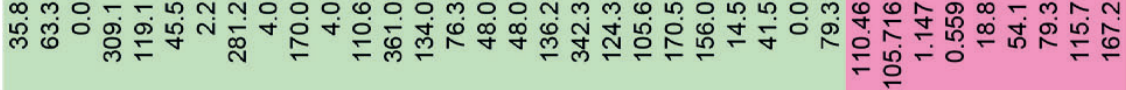

$\stackrel{\alpha}{\Sigma}$

윤ํำ 은

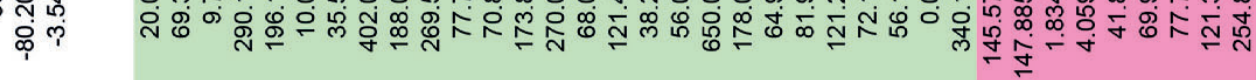
妥

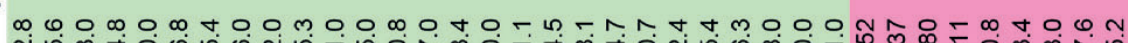

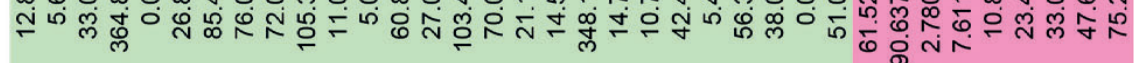
岂 
180

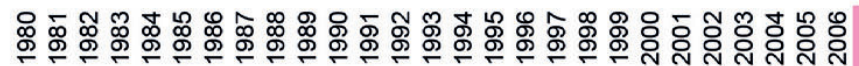

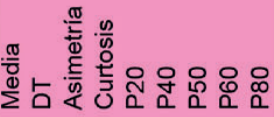

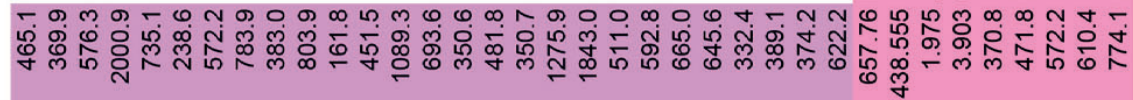

ì চ

믄

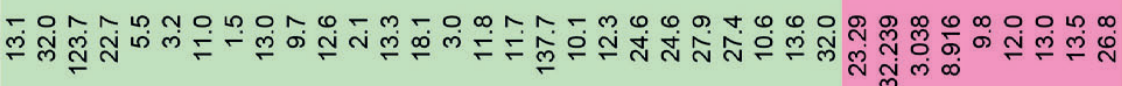
을

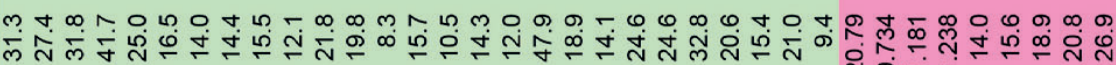
Ł

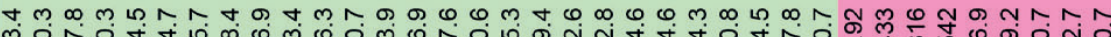

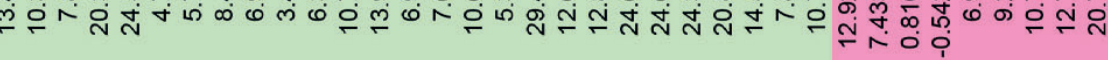
岃

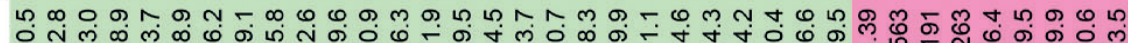

언

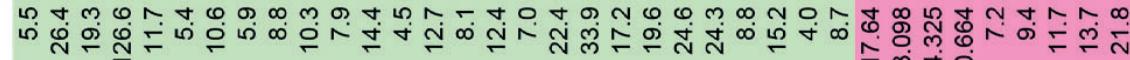

5

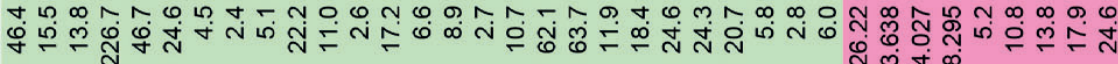

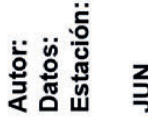

\section{3}

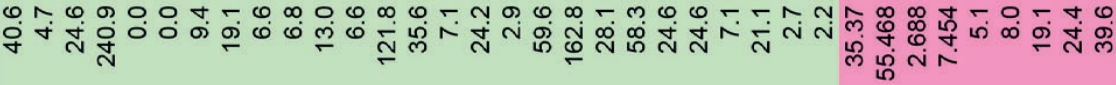

¿ 前家

㩊 ○ी

\section{$\stackrel{\frac{\infty}{\Sigma}}{\Sigma}$}

๓ ৪ ণ m

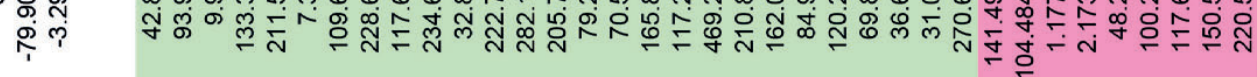
貼 - 0 个 n 0 n

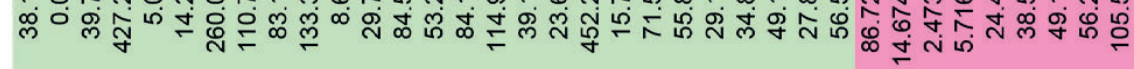


181

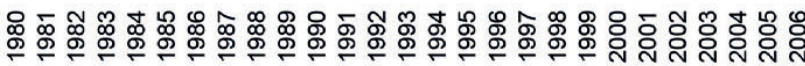

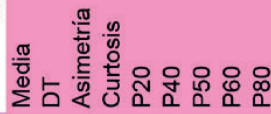

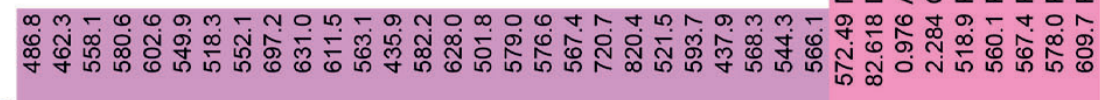

学

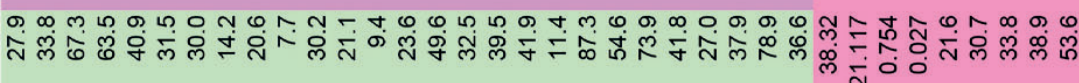

음

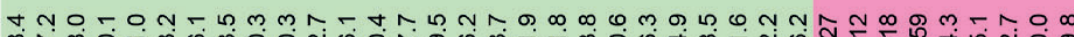

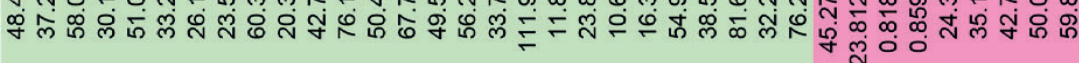

оे

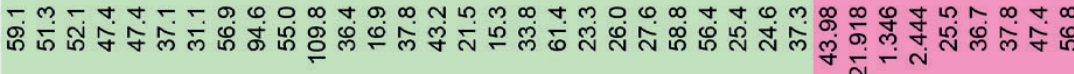
Łั

n ヘ 㟧

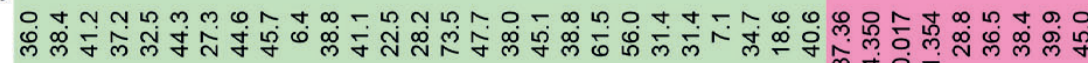
¿ํ - の

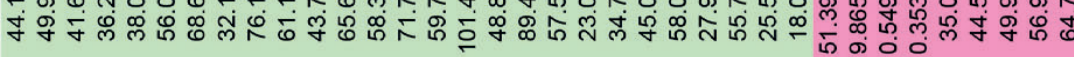
马 范范范

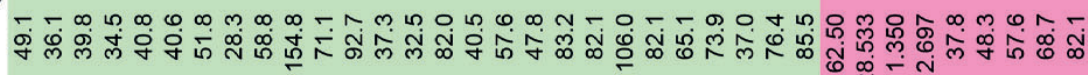
z

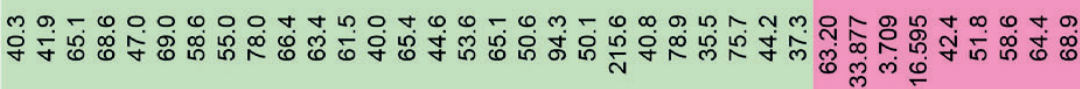
¿

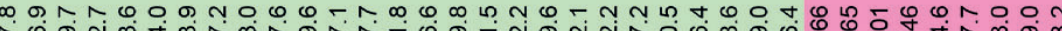

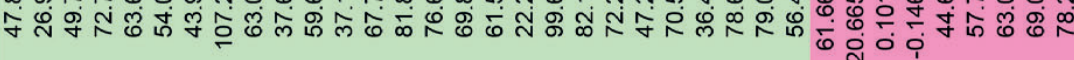

繙

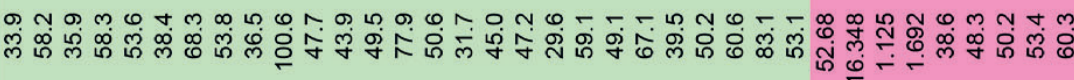

\section{$\frac{\alpha}{<}$}

m

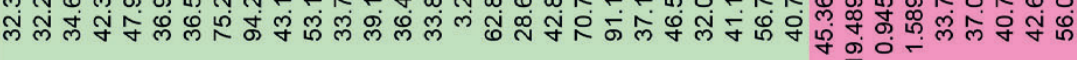

思 
182

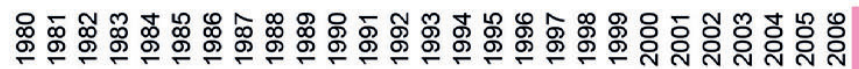

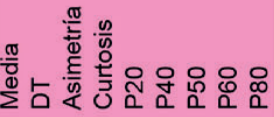

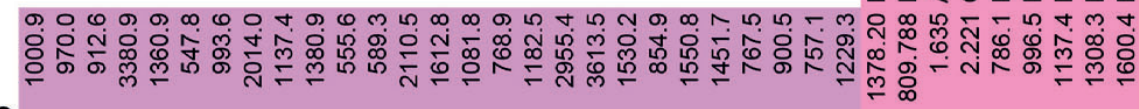

安

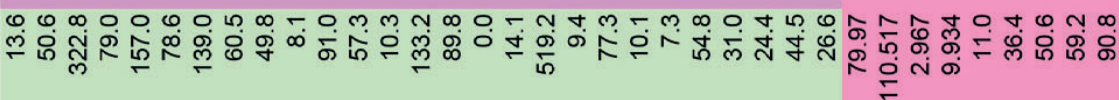

0

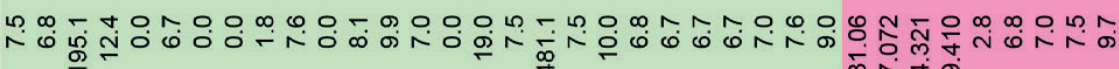

ว

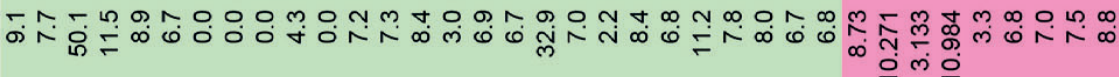

เ

숳

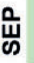

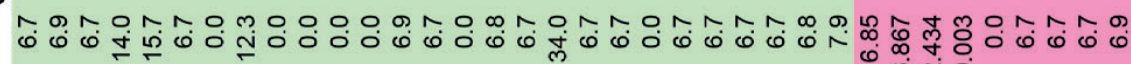

원

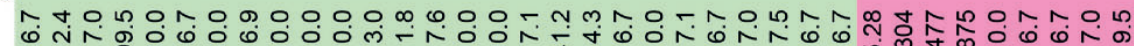

5

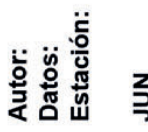

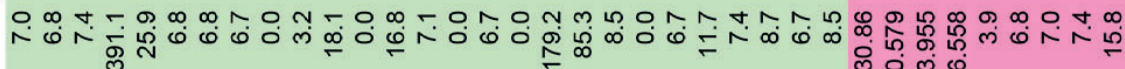

\section{年}

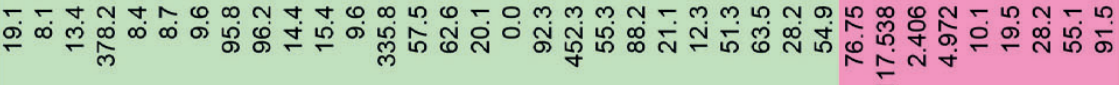

$\frac{2}{2}$

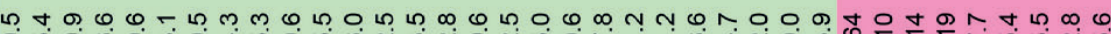

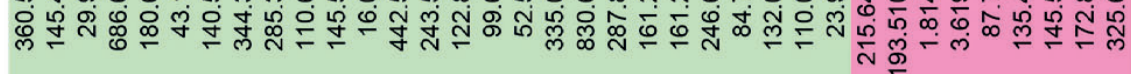
黄

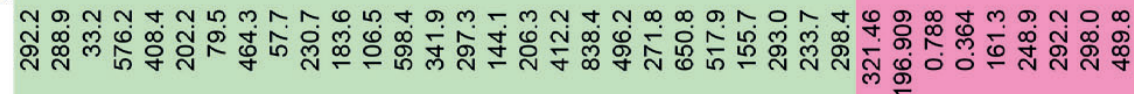
$\frac{\alpha}{\mathbf{L}}$

요웅 thn

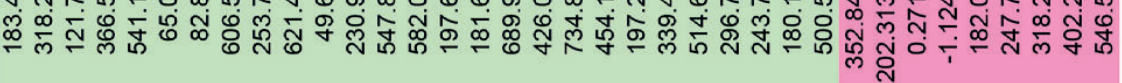
災

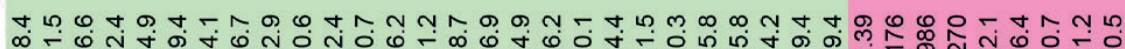

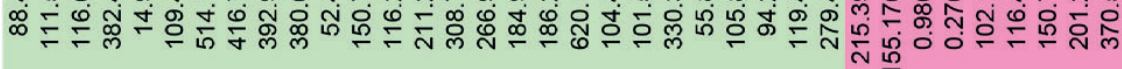
岂 


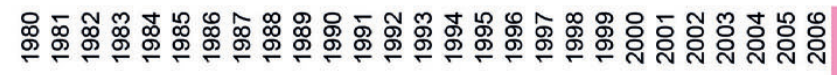

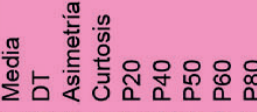

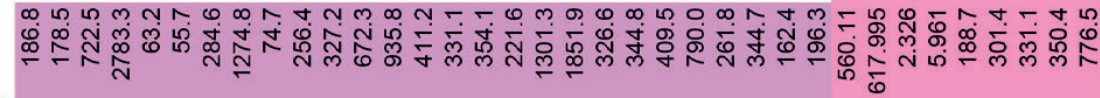

这

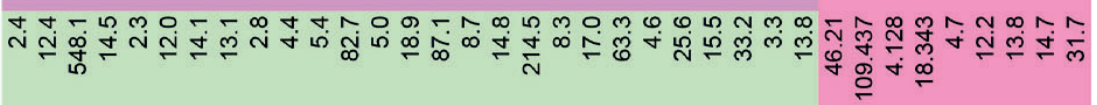

$\stackrel{0}{\square}$ 产

zo

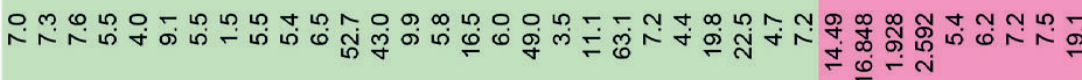

¿ั

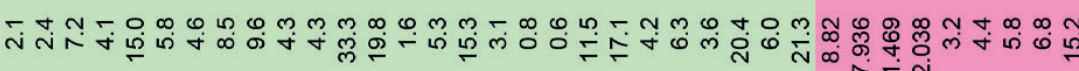

岗

ஸூ

¿ 央

S

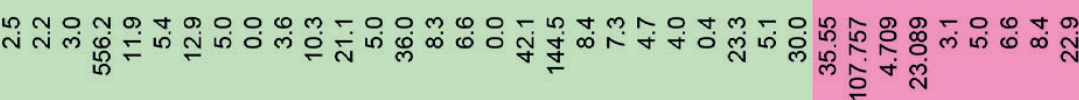

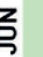

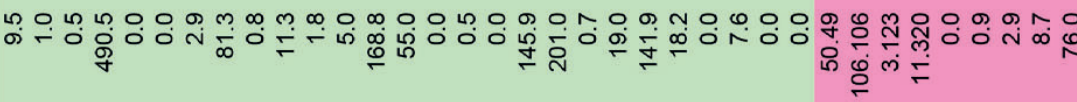

$\frac{\grave{2}}{2}$

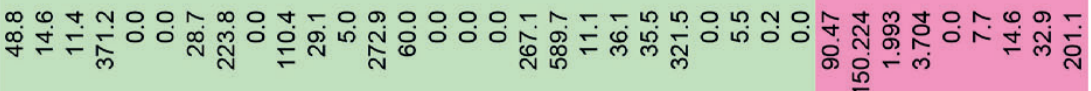

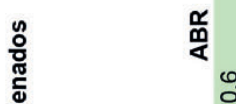

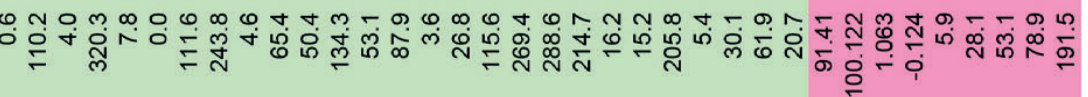
$\frac{d}{\frac{\alpha}{\alpha}}$

$\circ: 8$

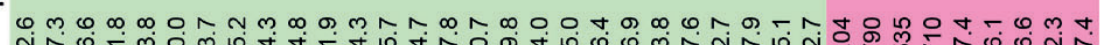

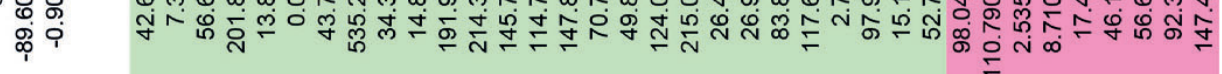
色

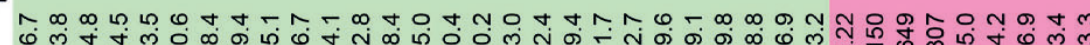

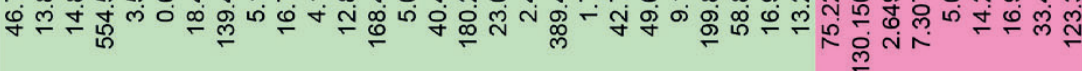
$\stackrel{w}{\Psi}$ 
184

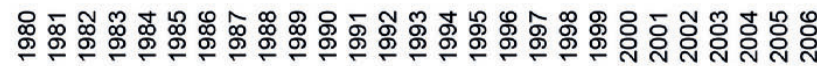

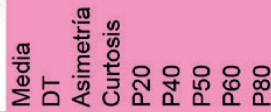

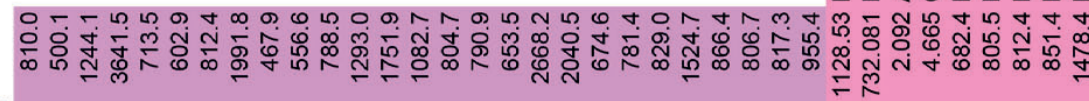

高

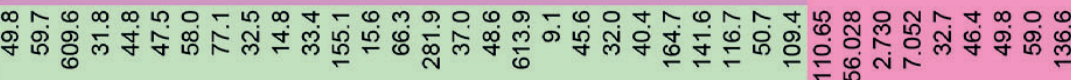

음

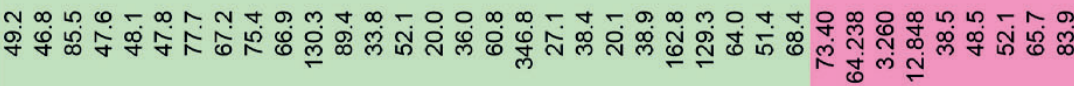

วิ

4⿻一力八

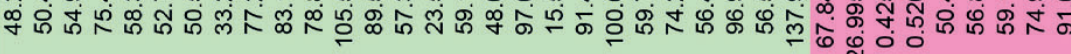

๖ั

n m mo $00 \pi$ o

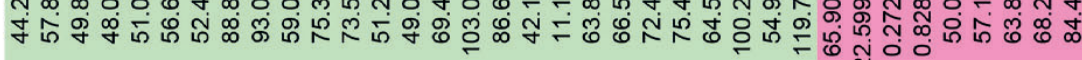

๙ิ

㟧

$0 \varphi \omega m+0 N-\infty N O-\infty m$ N

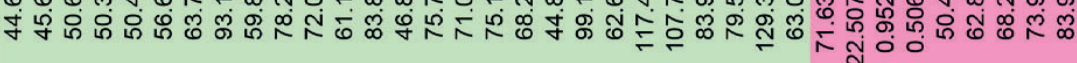

융

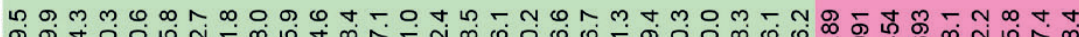

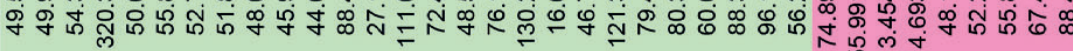

马

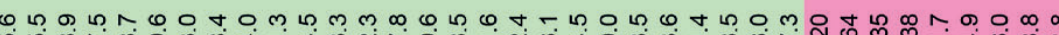

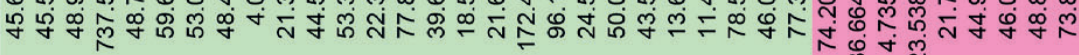

ב

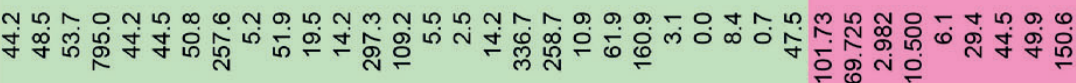

¿

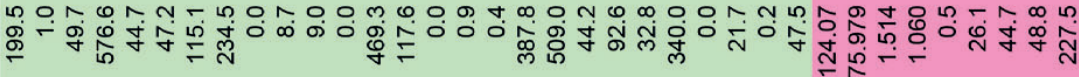

$\stackrel{\frac{\alpha}{m}}{\frac{m}{4}}$

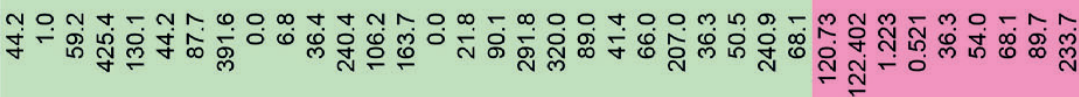

$\stackrel{\alpha}{\Sigma}$

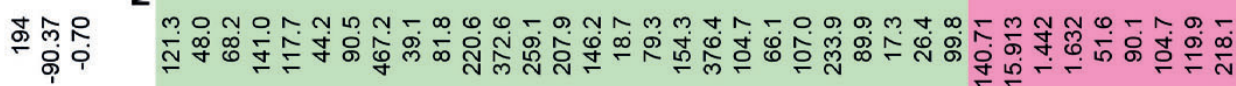

妥

ก $の$ ก

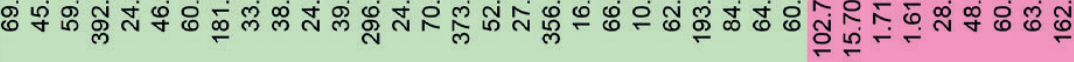




\section{5}

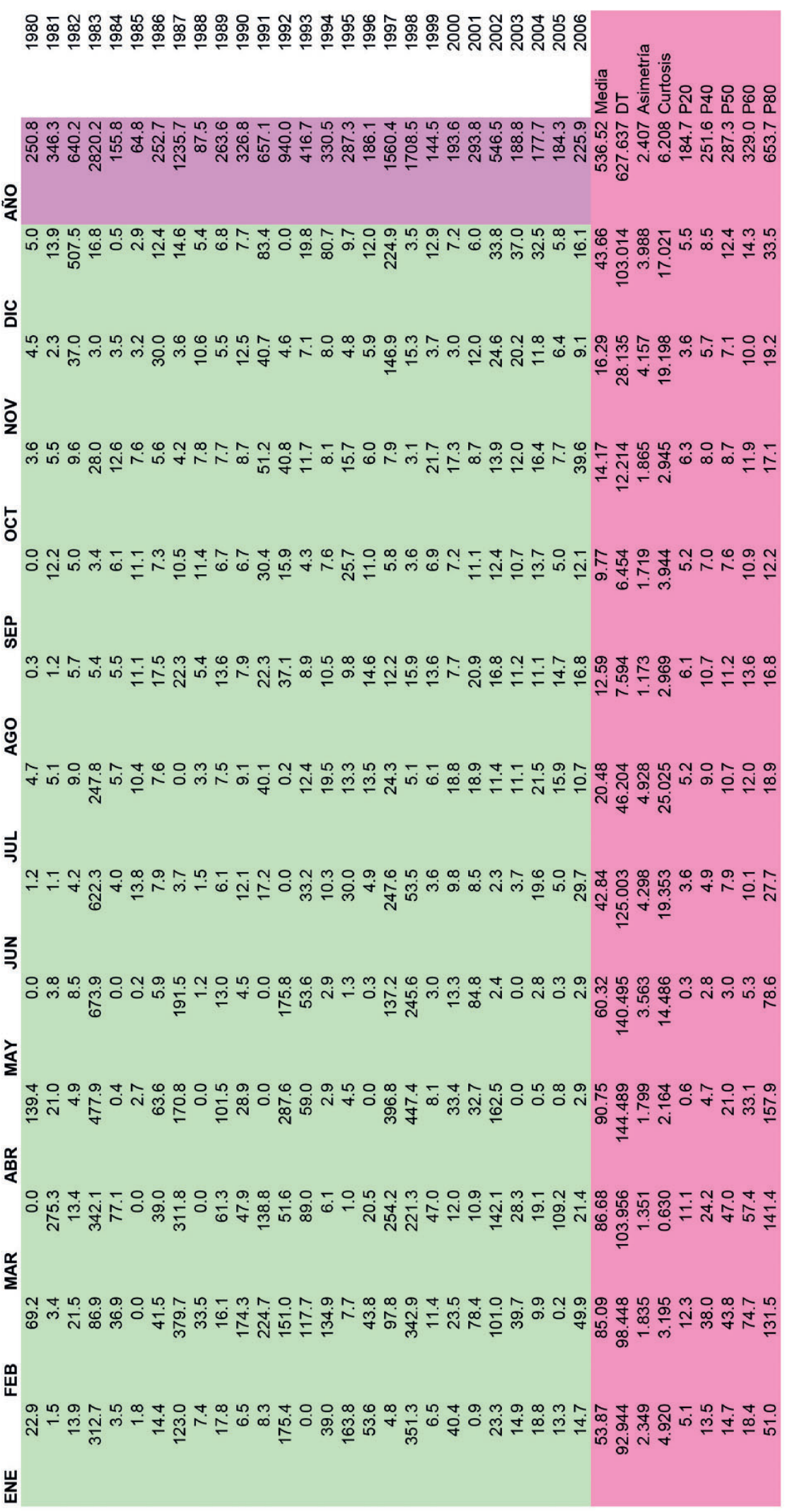


186

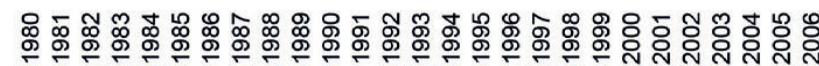

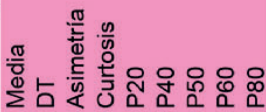

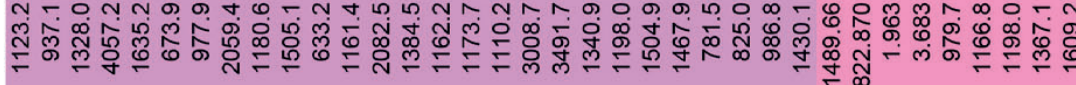

殏

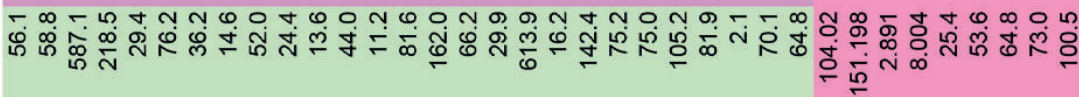
늠

on 0 O ON

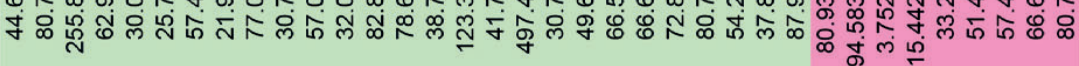

ว

m

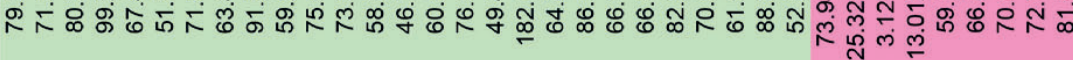

¿

ก กุ น

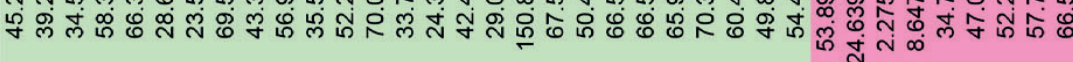

岗

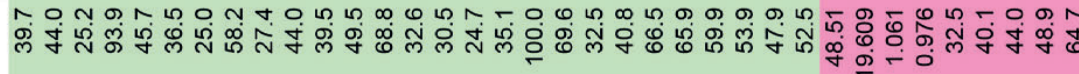

언

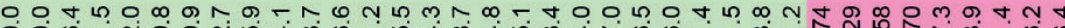

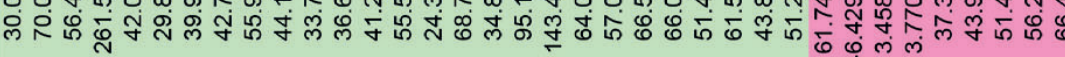

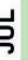

บ

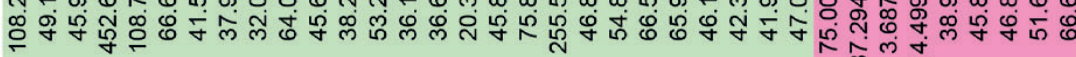

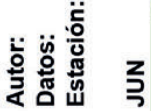

z 万人 ¿

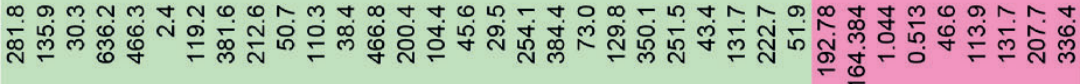
啚 ம

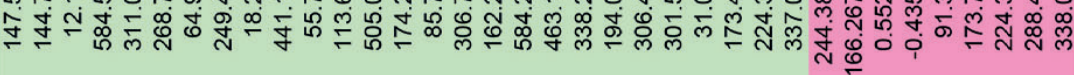
$\stackrel{\frac{\alpha}{L}}{\Sigma}$

m 页的

點 オ

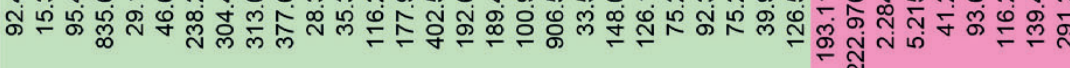




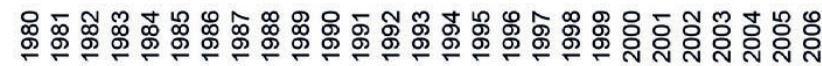

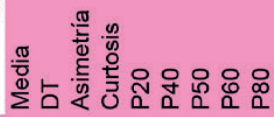

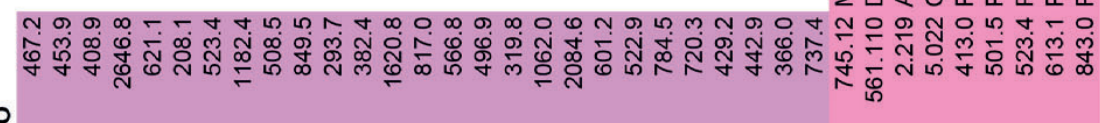

安

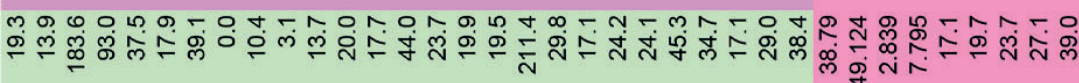

음 记

ว

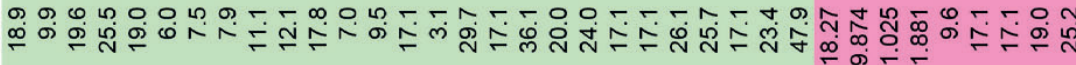

เั

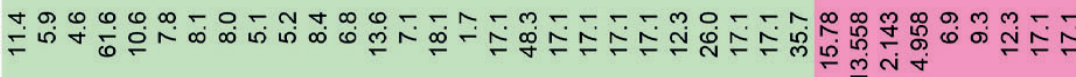

悹

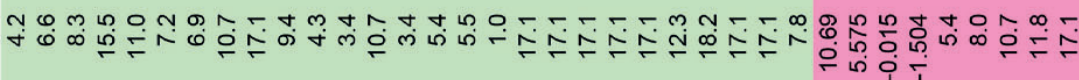
$-0$

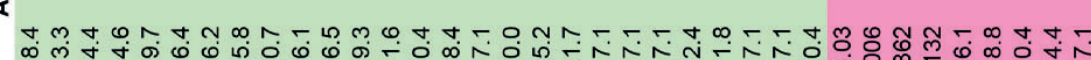

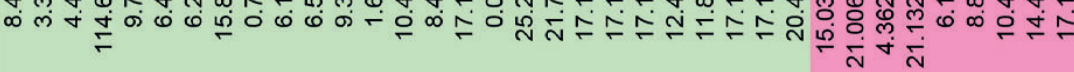

כ

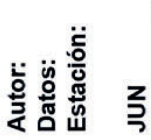
O듀

ב

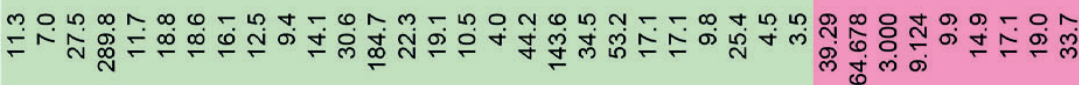

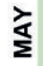

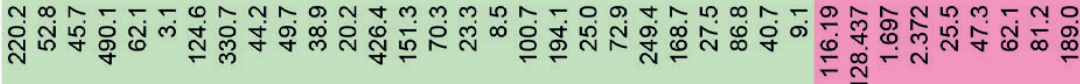

o mo m m m n t n

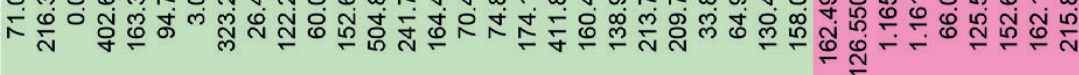

\section{$\stackrel{\alpha}{\underline{\alpha}}$}

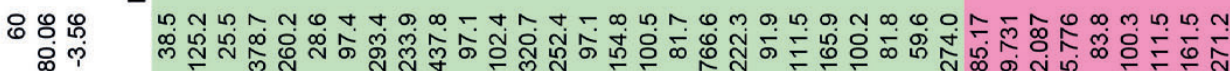

思 
188

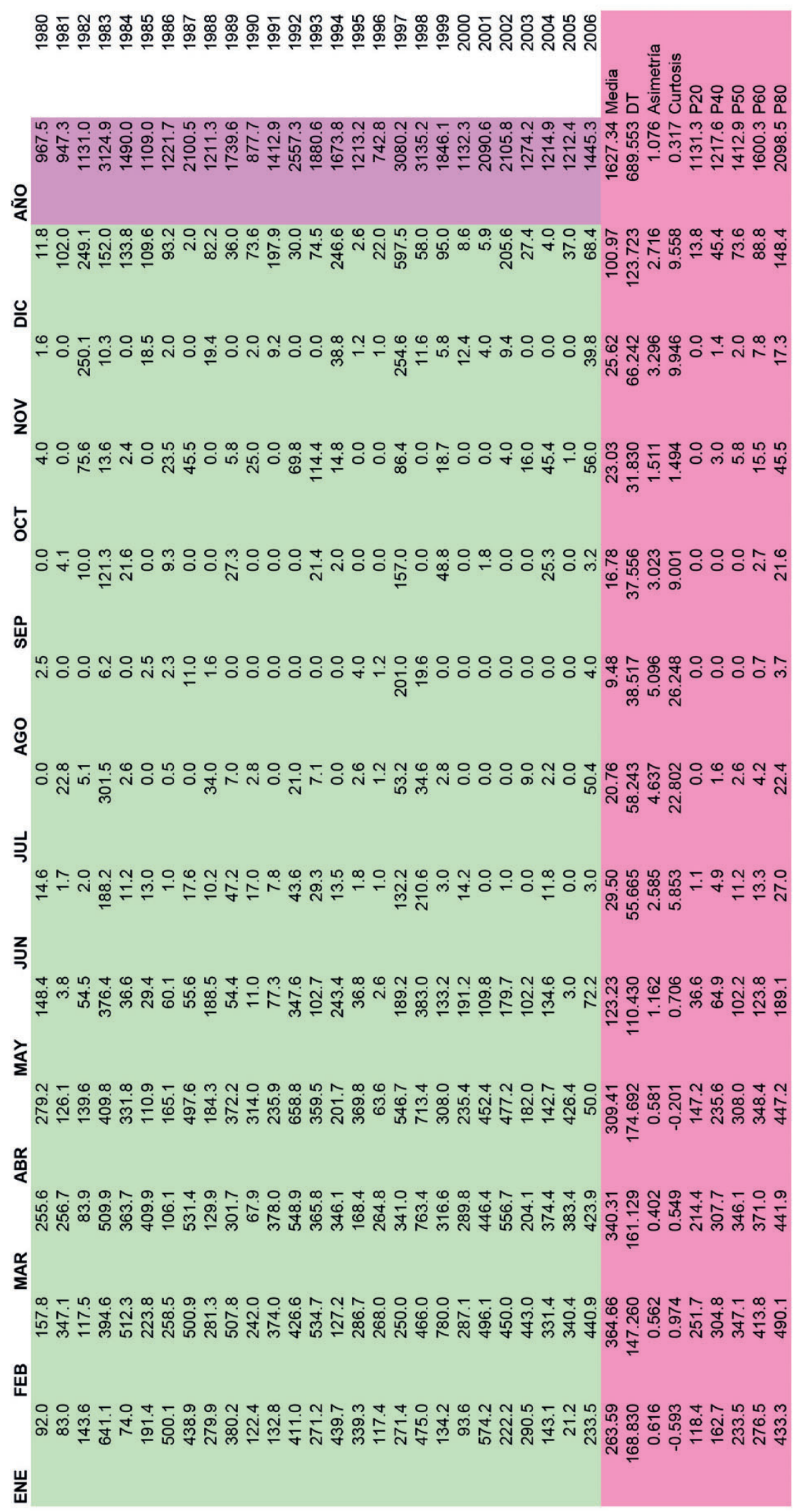




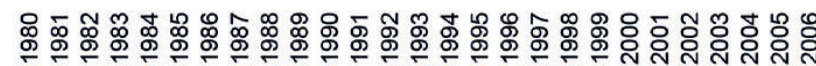

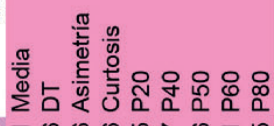

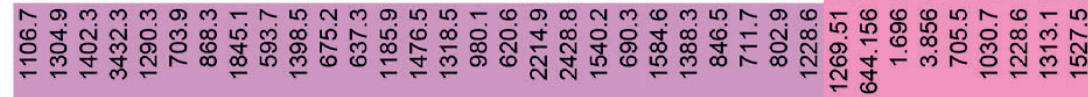

学

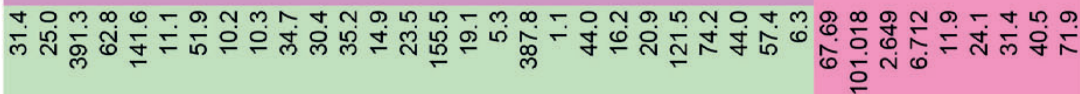

문

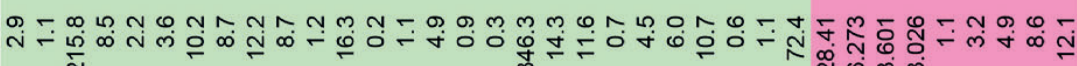

ว

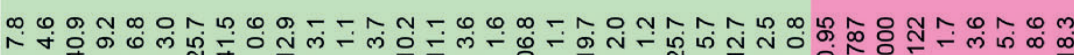
於

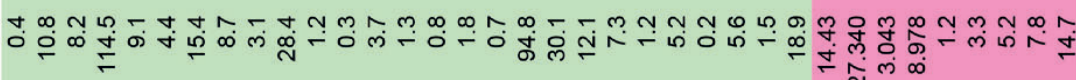

苀

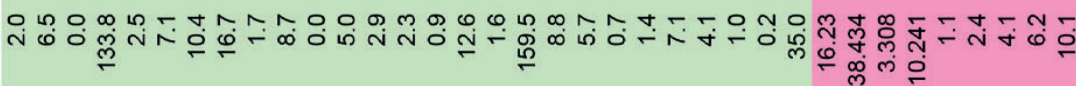
웅

क्ष

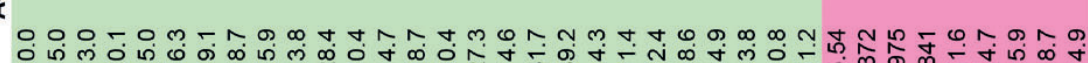

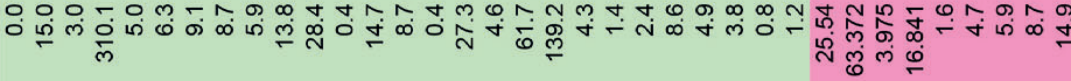

弓

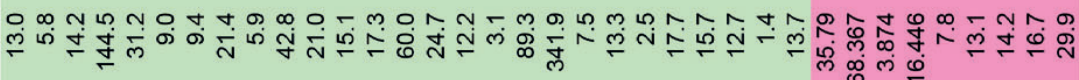

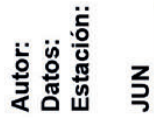

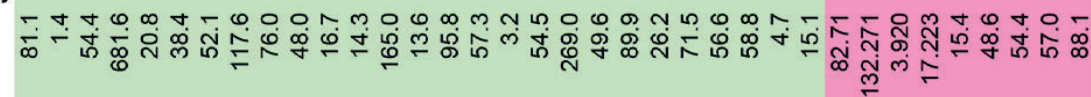
¿

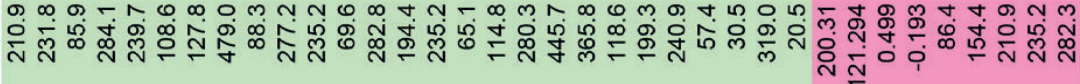
啚 ம 几

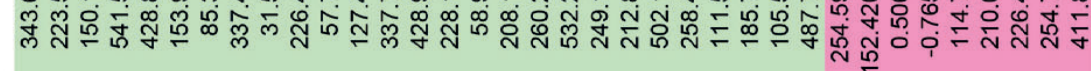
$\stackrel{\alpha}{\Sigma}$

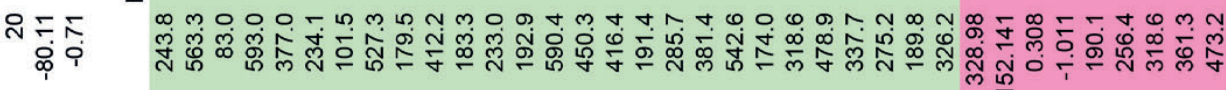
思

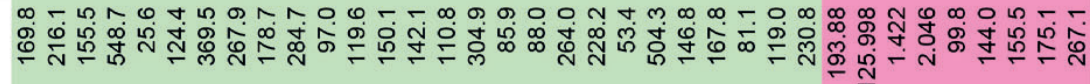
崫 
190

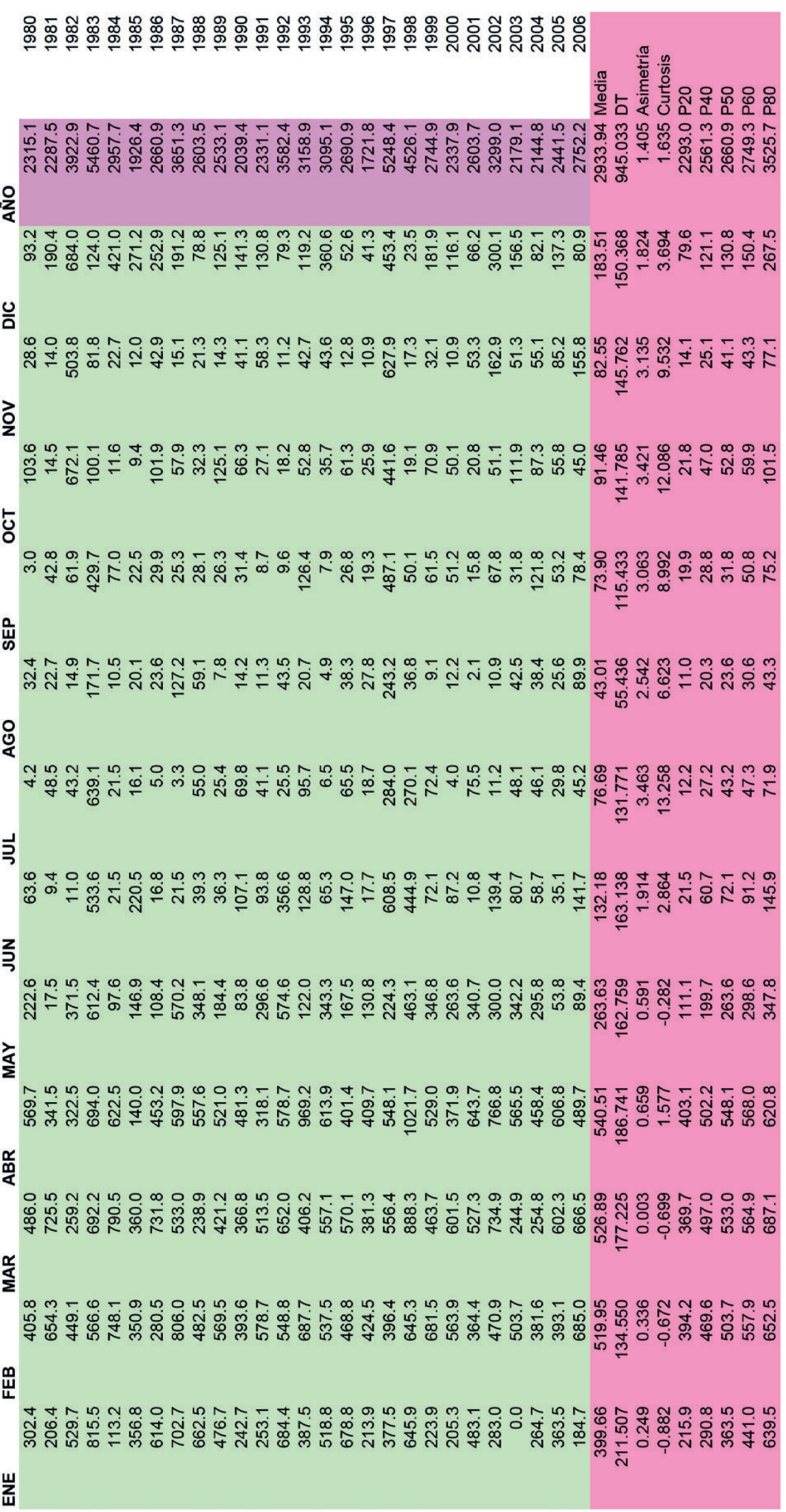


191

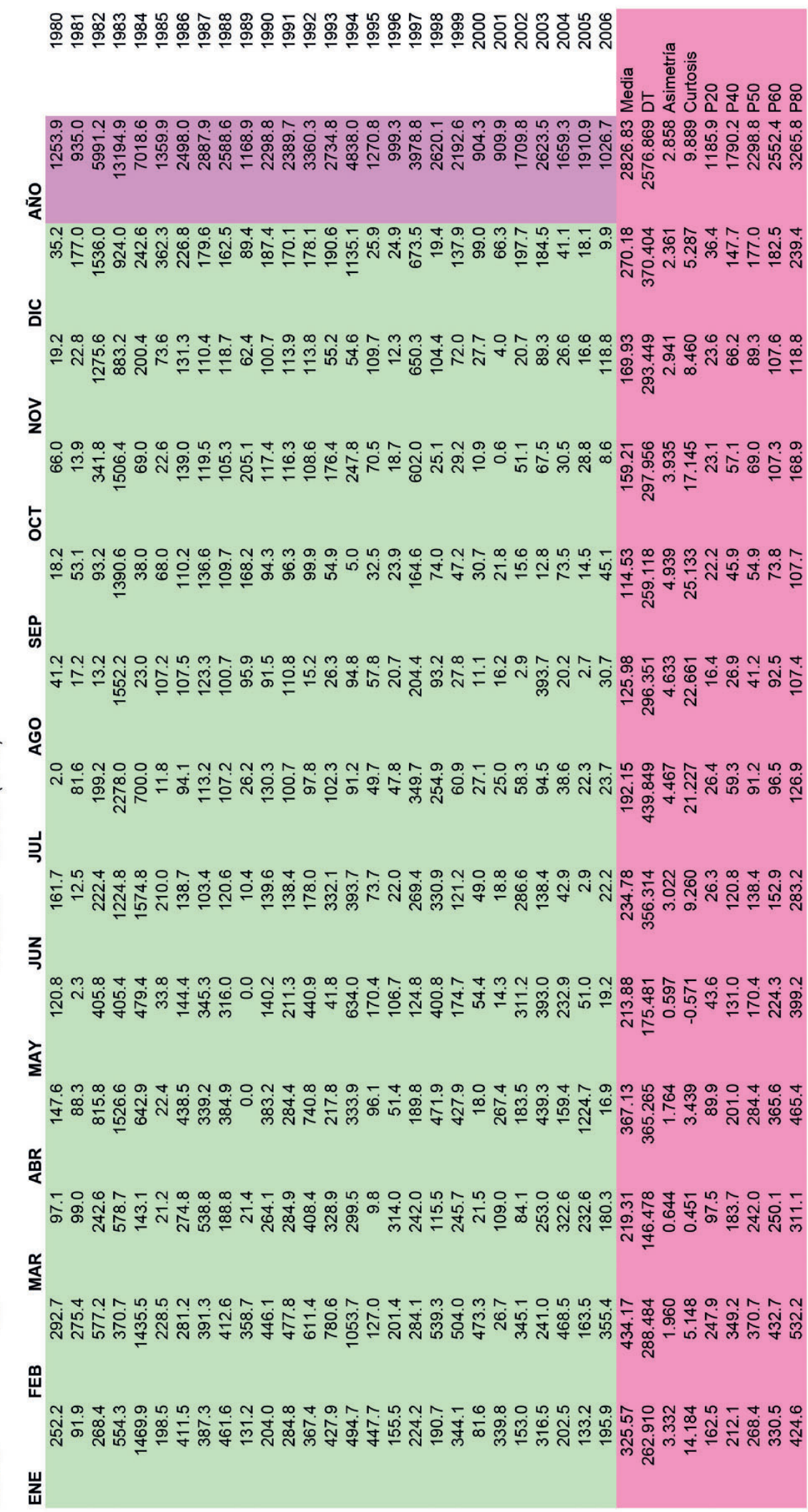


192

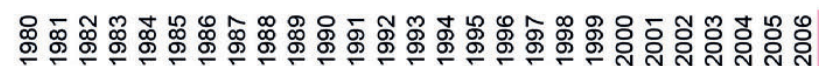

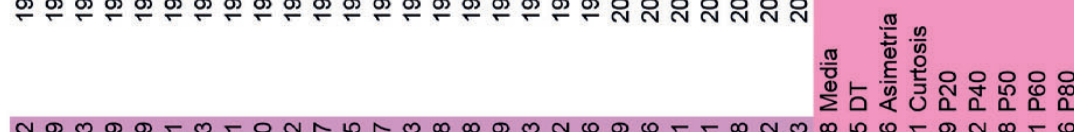

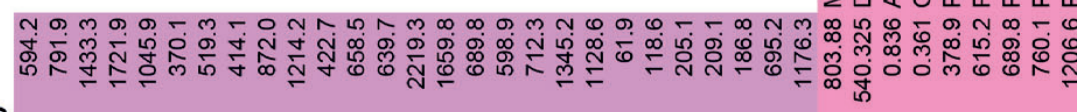

家

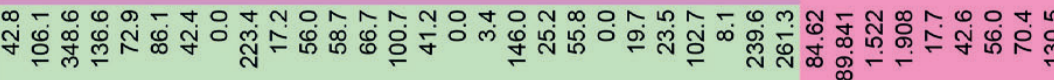

음

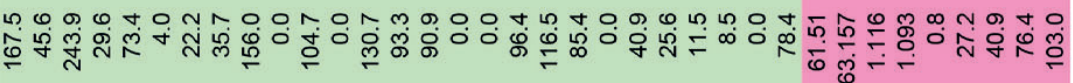

o

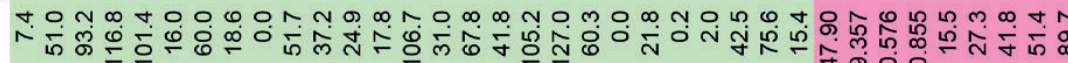

เ

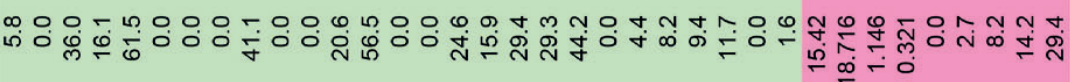

巡

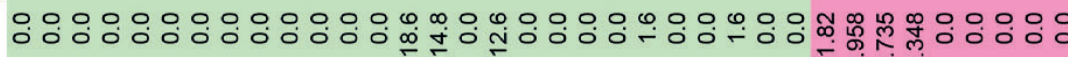

¿

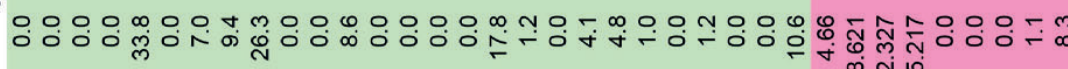

s

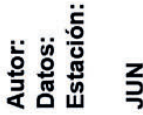

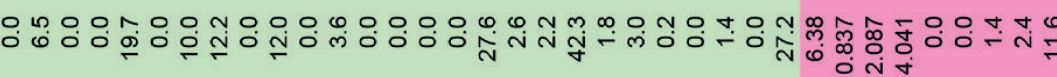

s

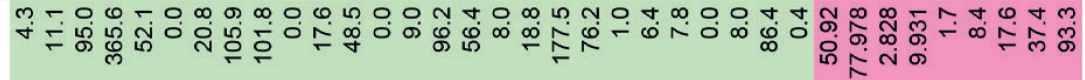

文

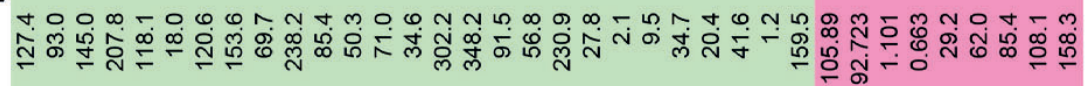
爱

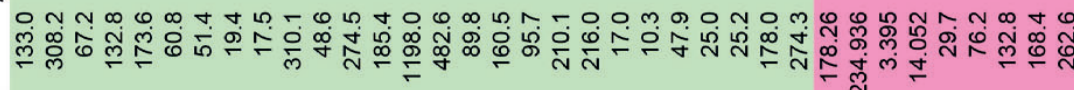

$\frac{\alpha}{\Sigma}$

0m. هัN 延

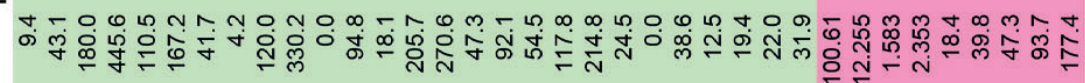
崖 
193

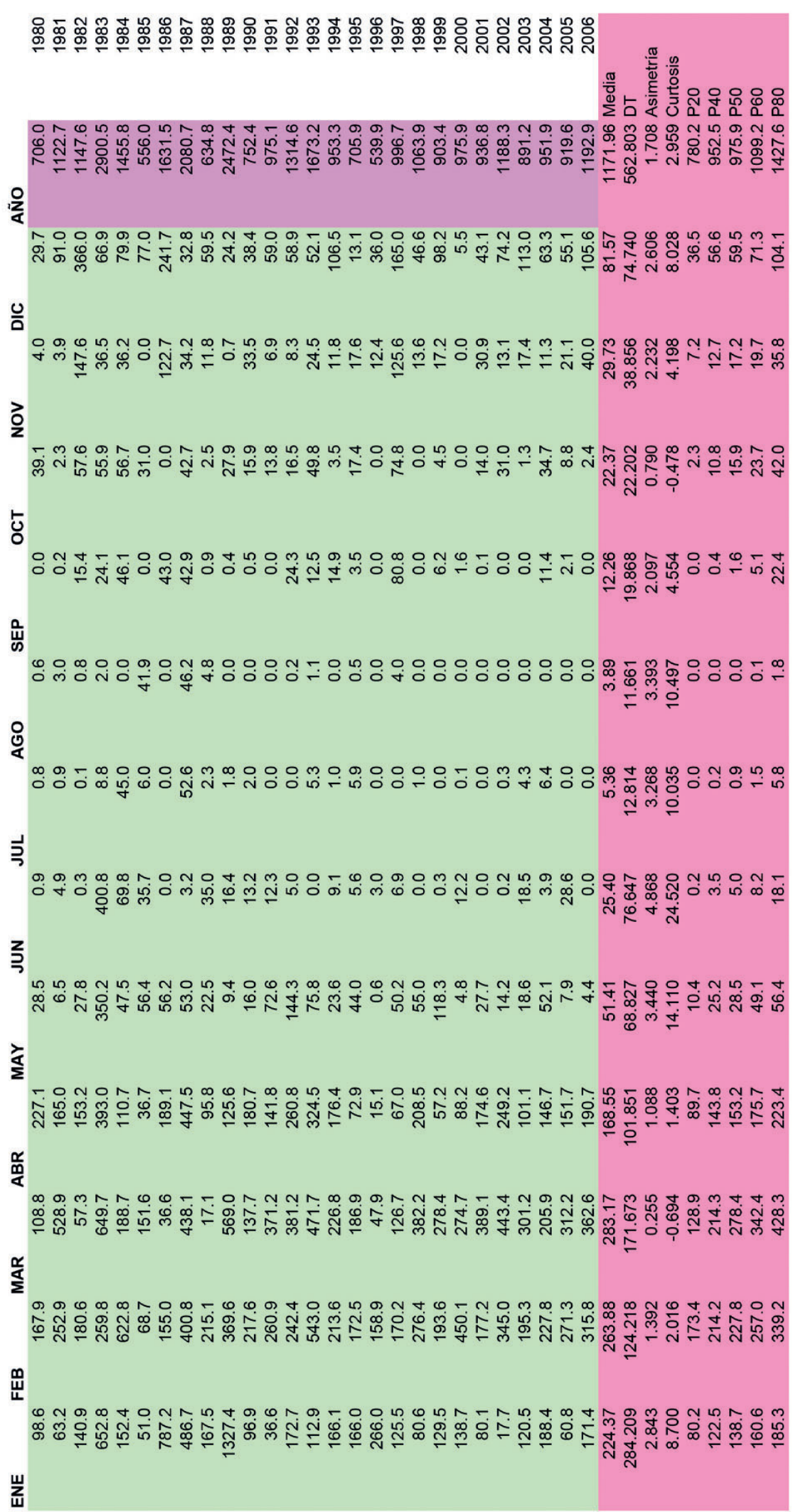


194

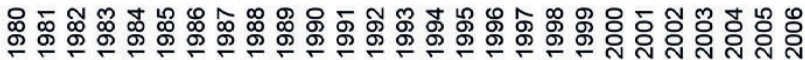

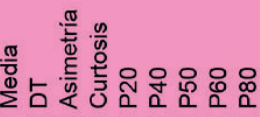

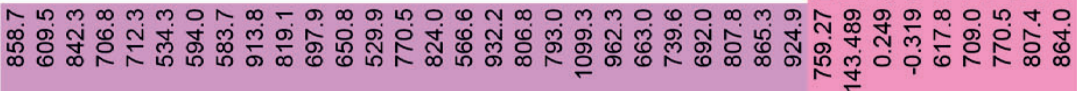

造

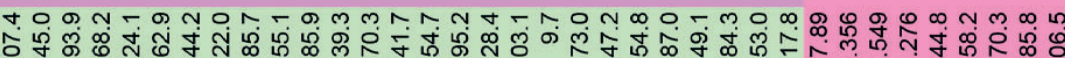

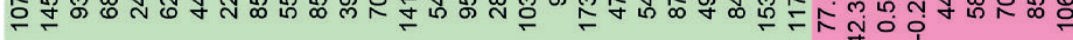

믐

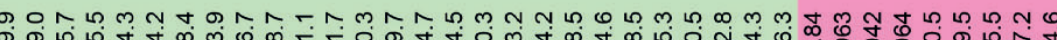

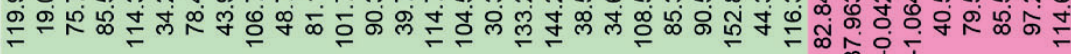

ว

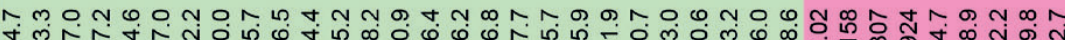

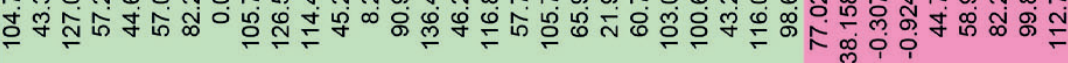

Ł

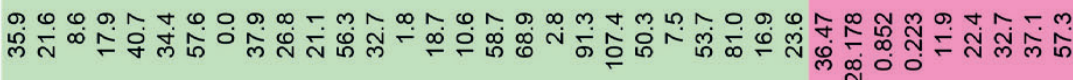

岗

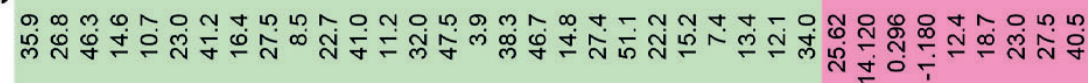

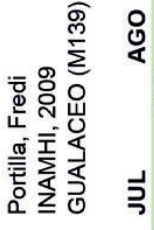

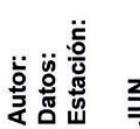

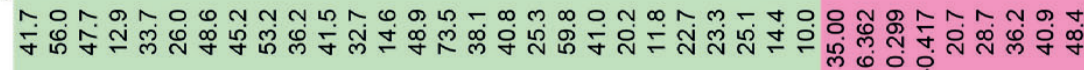

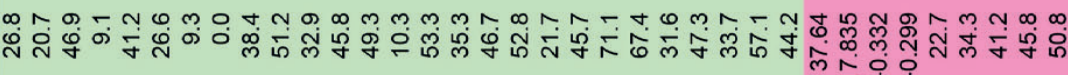
3

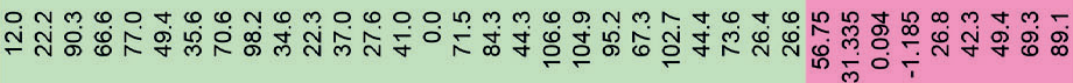

¿্র

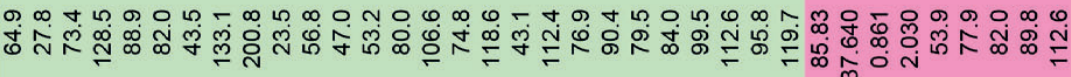

㩊 ด

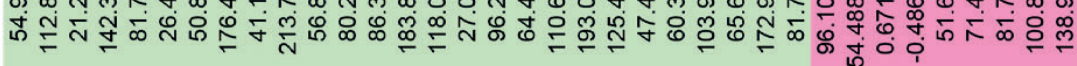

$\stackrel{\frac{\alpha}{L}}{\Sigma}$

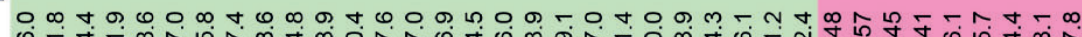

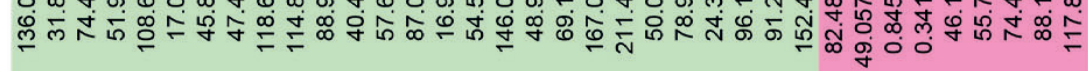

恚

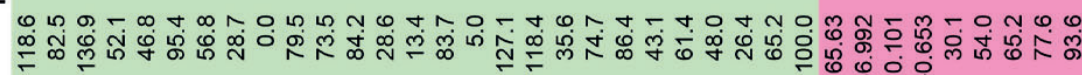
崫 
195

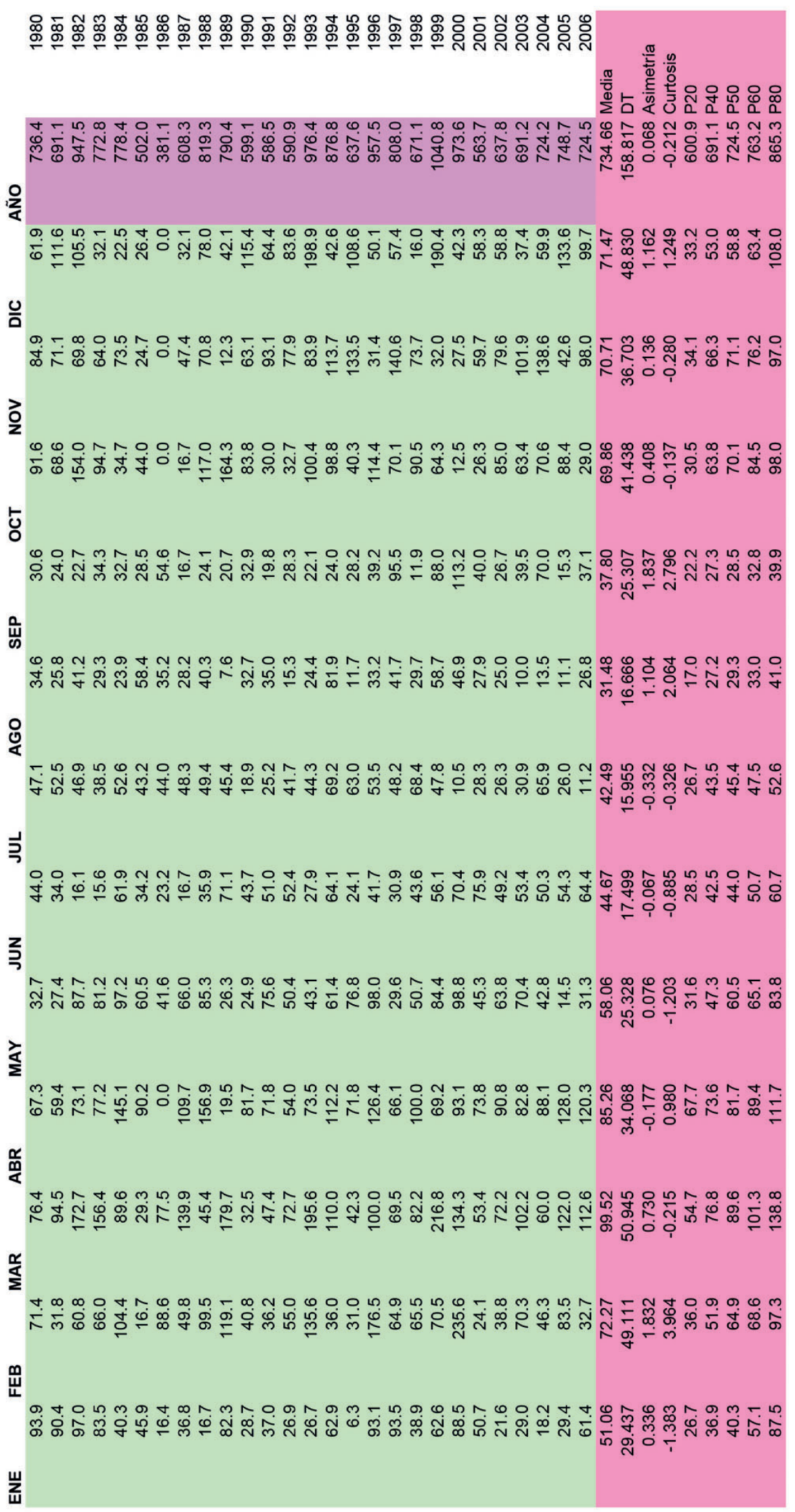


196

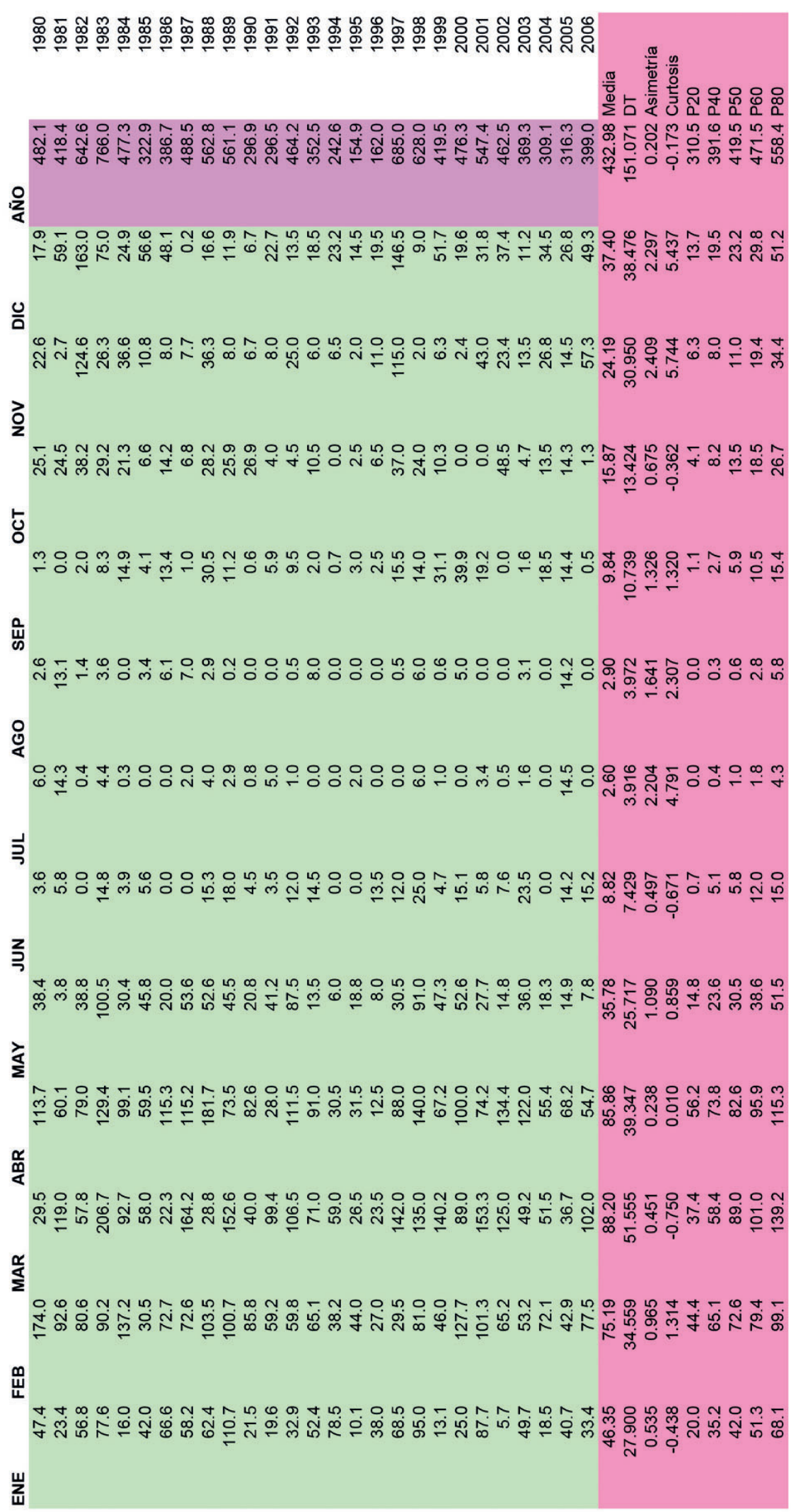


197

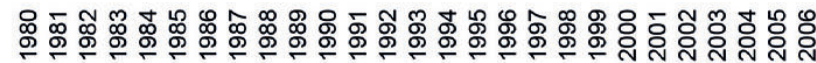

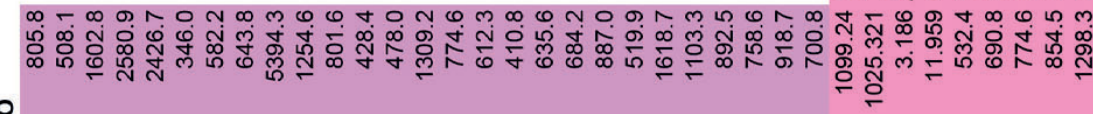

学

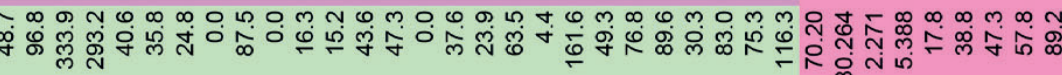

음

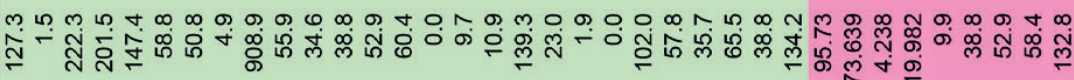

울

$\varphi \omega$ ข

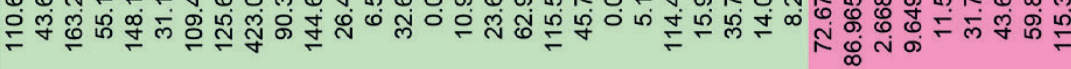

¿

吕웅

品

䟲

\&

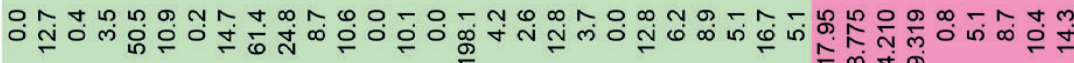

$\overrightarrow{3}$

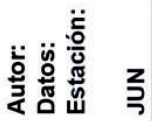

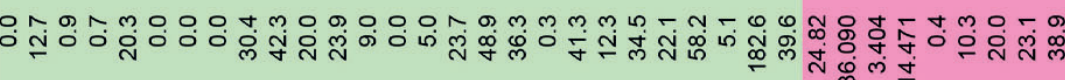

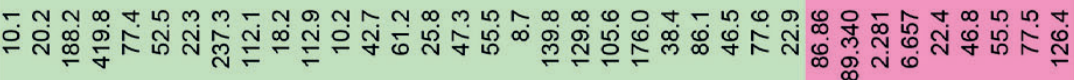

章 思-

爱

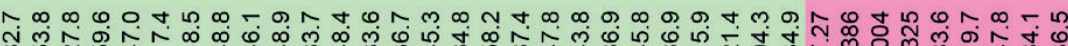

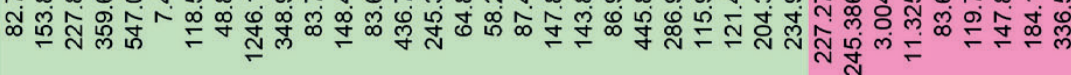

$\frac{\alpha}{2}$

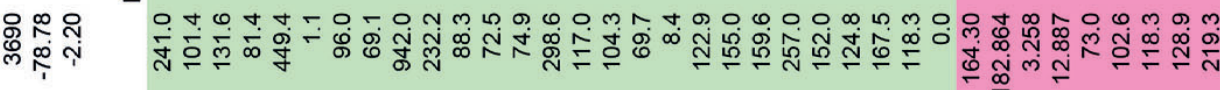

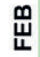

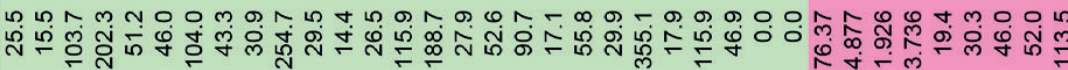

峞 
198

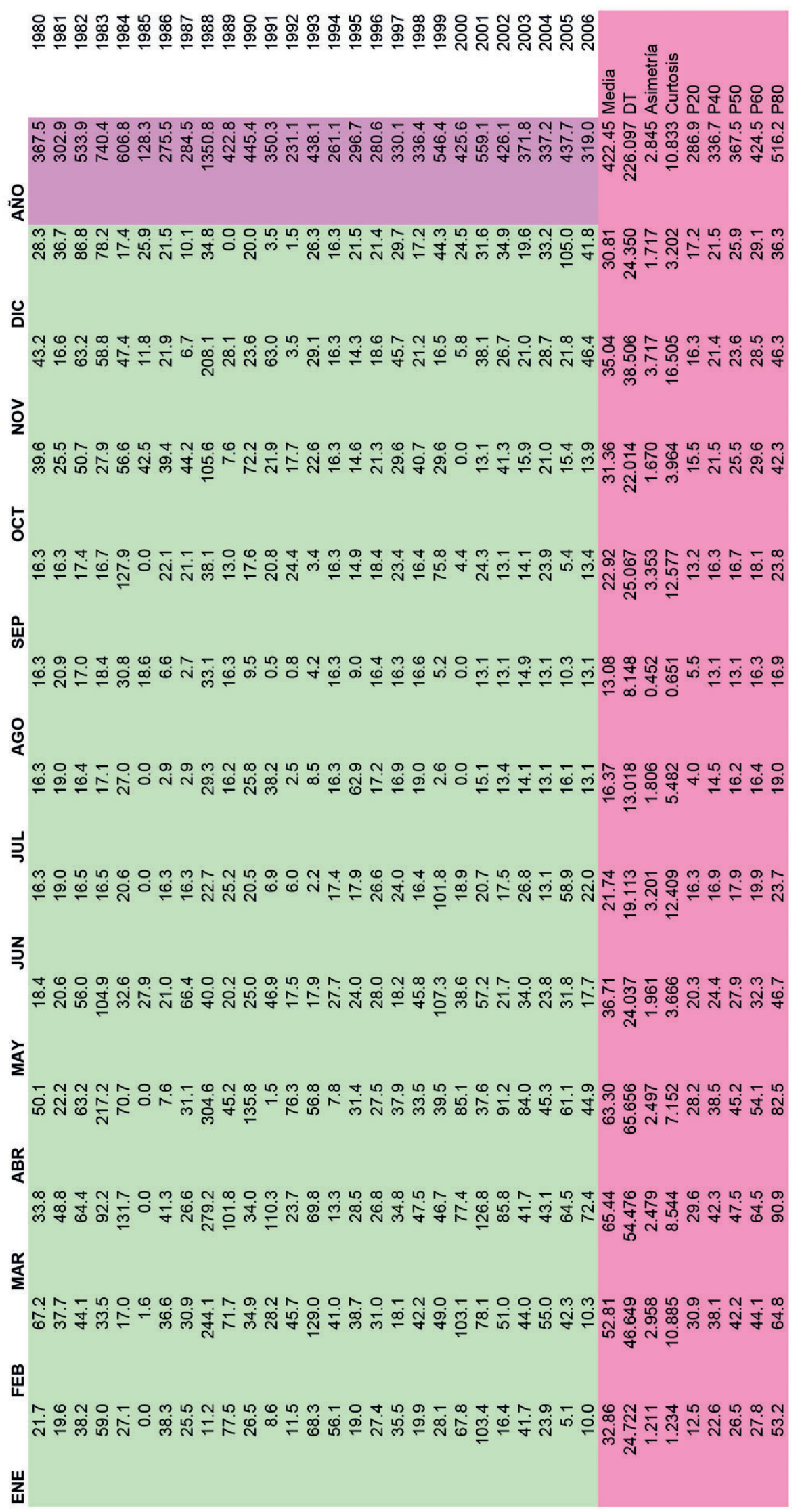




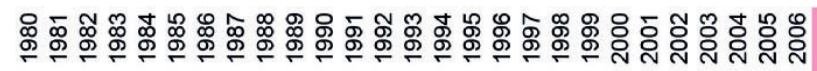

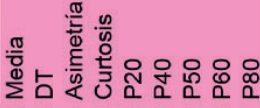

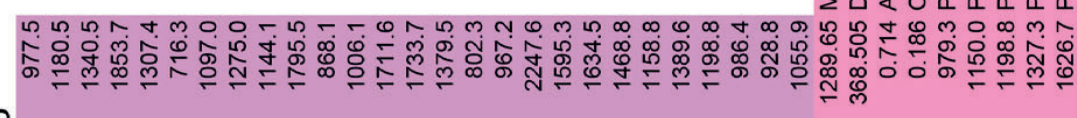
突

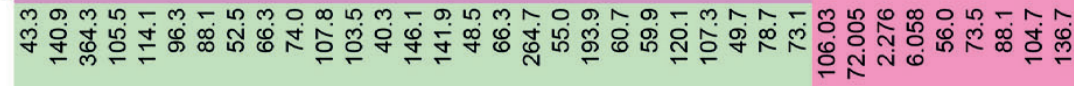
음

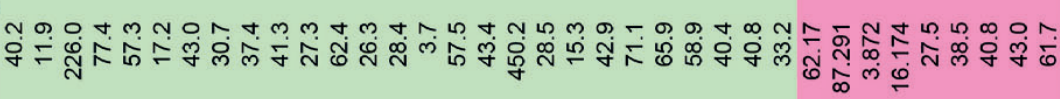
o

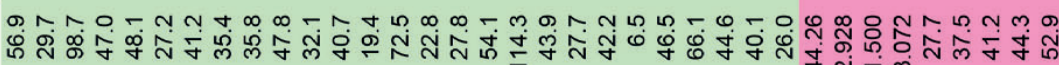
to

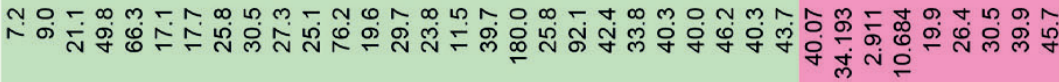

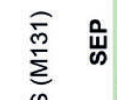

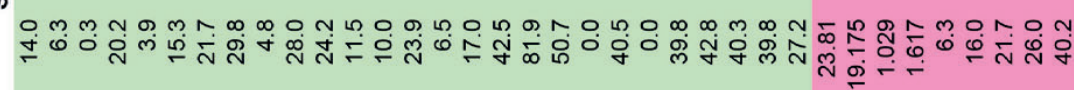
¿

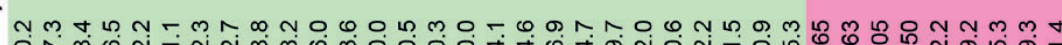

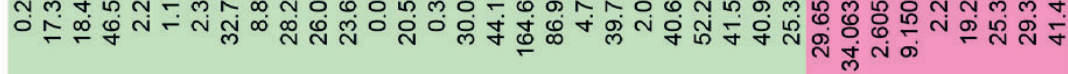
క

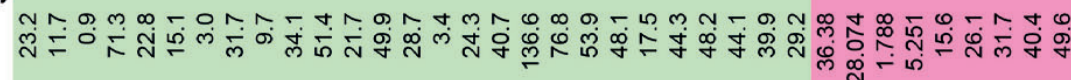

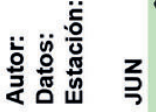

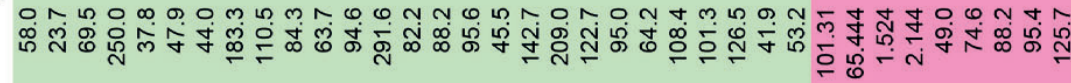

$\grave{\frac{x}{2}}$

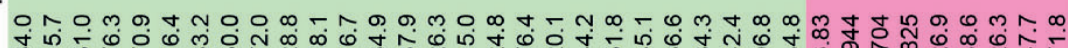

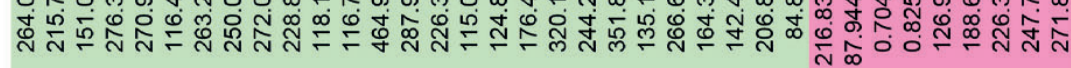

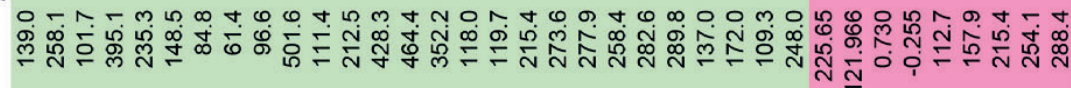

ㅇํㅇํำ

$\frac{\alpha}{\Sigma}$

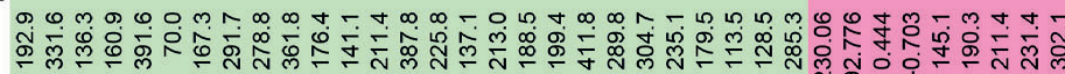
离

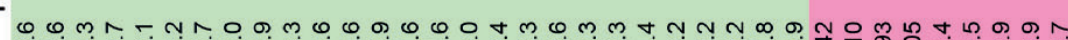

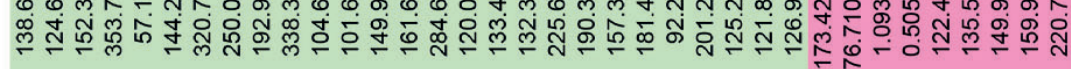
岂 
200

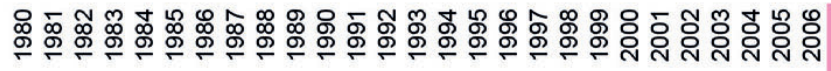

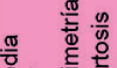

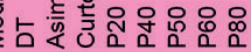

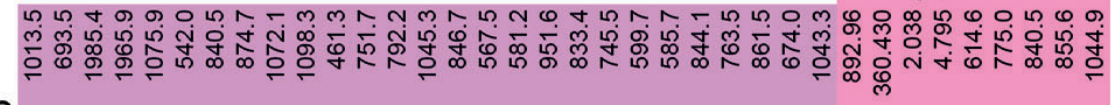

这

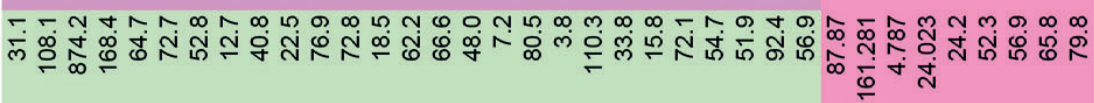

늠

Mํ.

zे

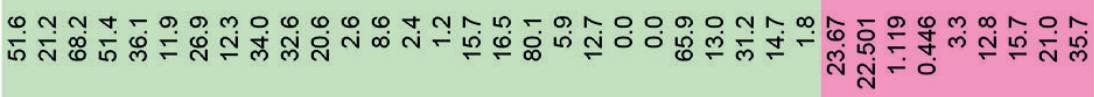

๖ั

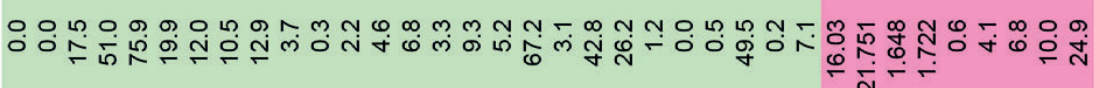

ติ

创

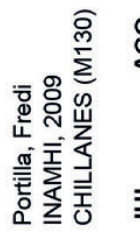

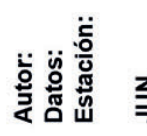

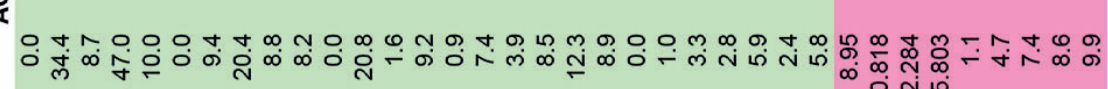

马

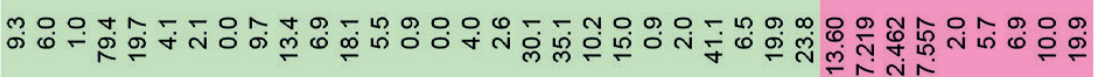

z

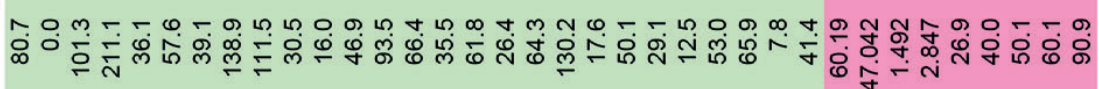

¿

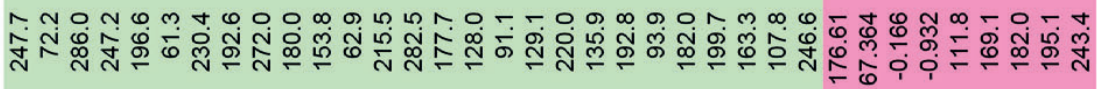

品

の น 几

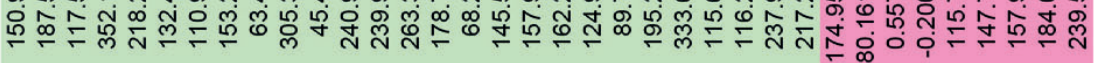

$\frac{\alpha}{\Sigma}$

மூ-

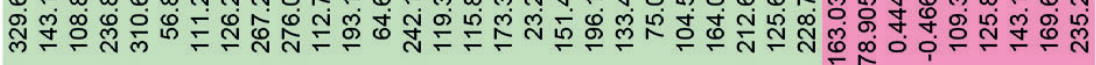

畧

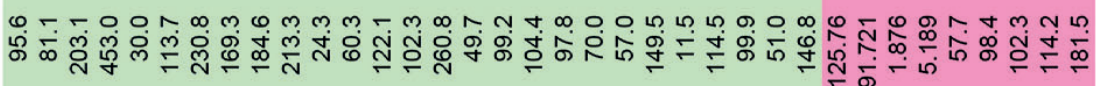


201

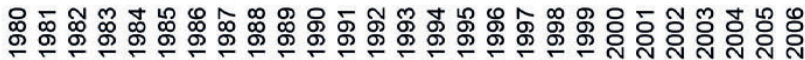

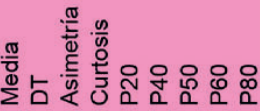

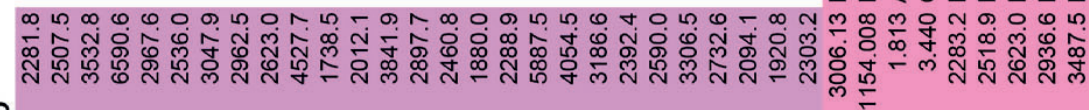

安

m

음

우으.

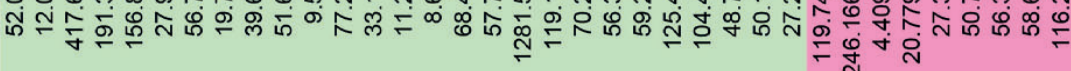

o ก t

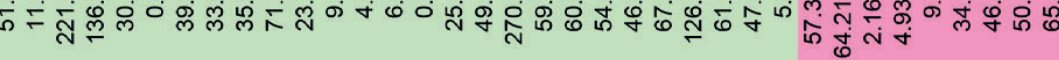

Ł

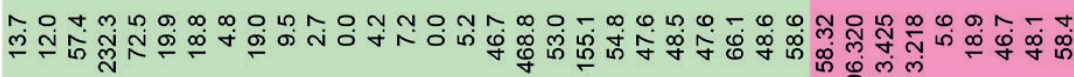

嵌

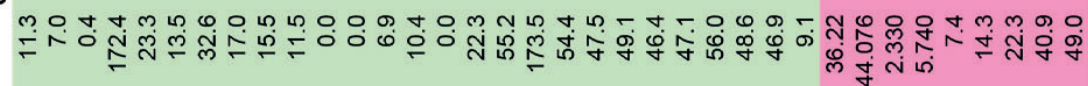
운

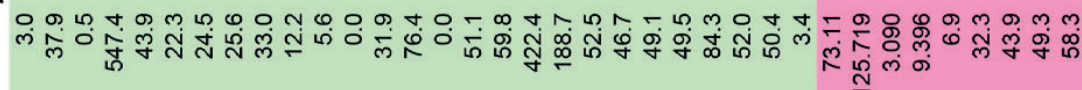
弓

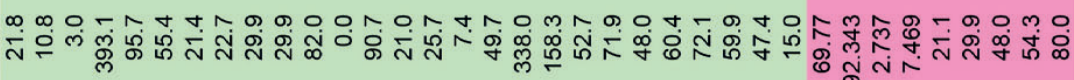

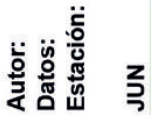

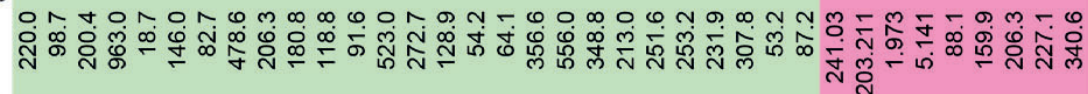

文

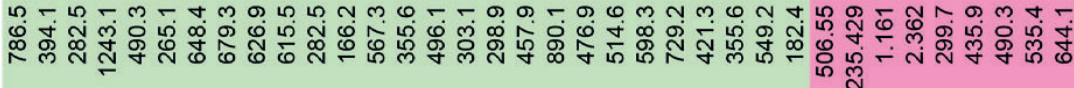
誉

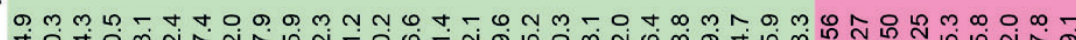

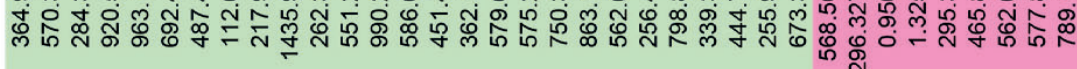

$\frac{\alpha}{\Sigma}$

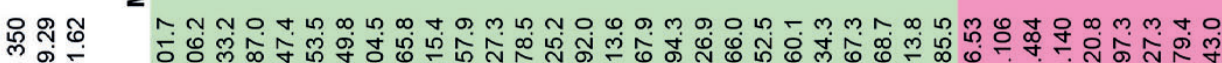

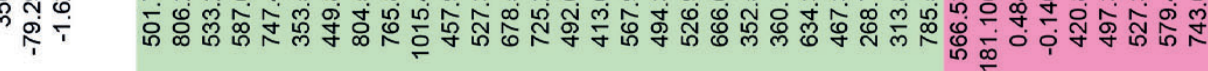
畠

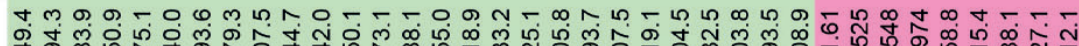

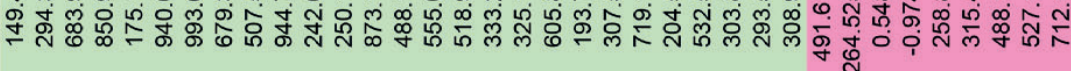
崖 


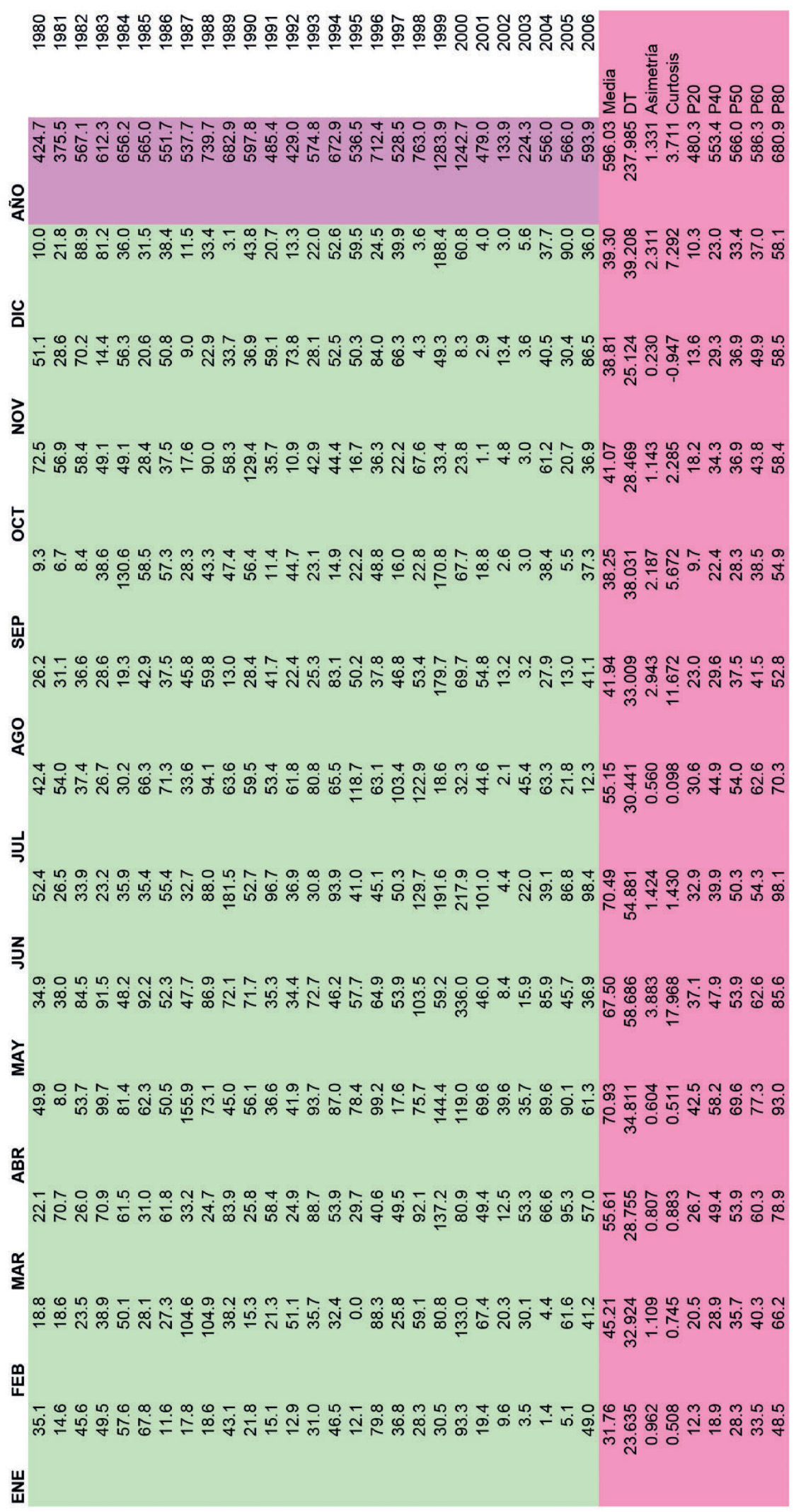


203

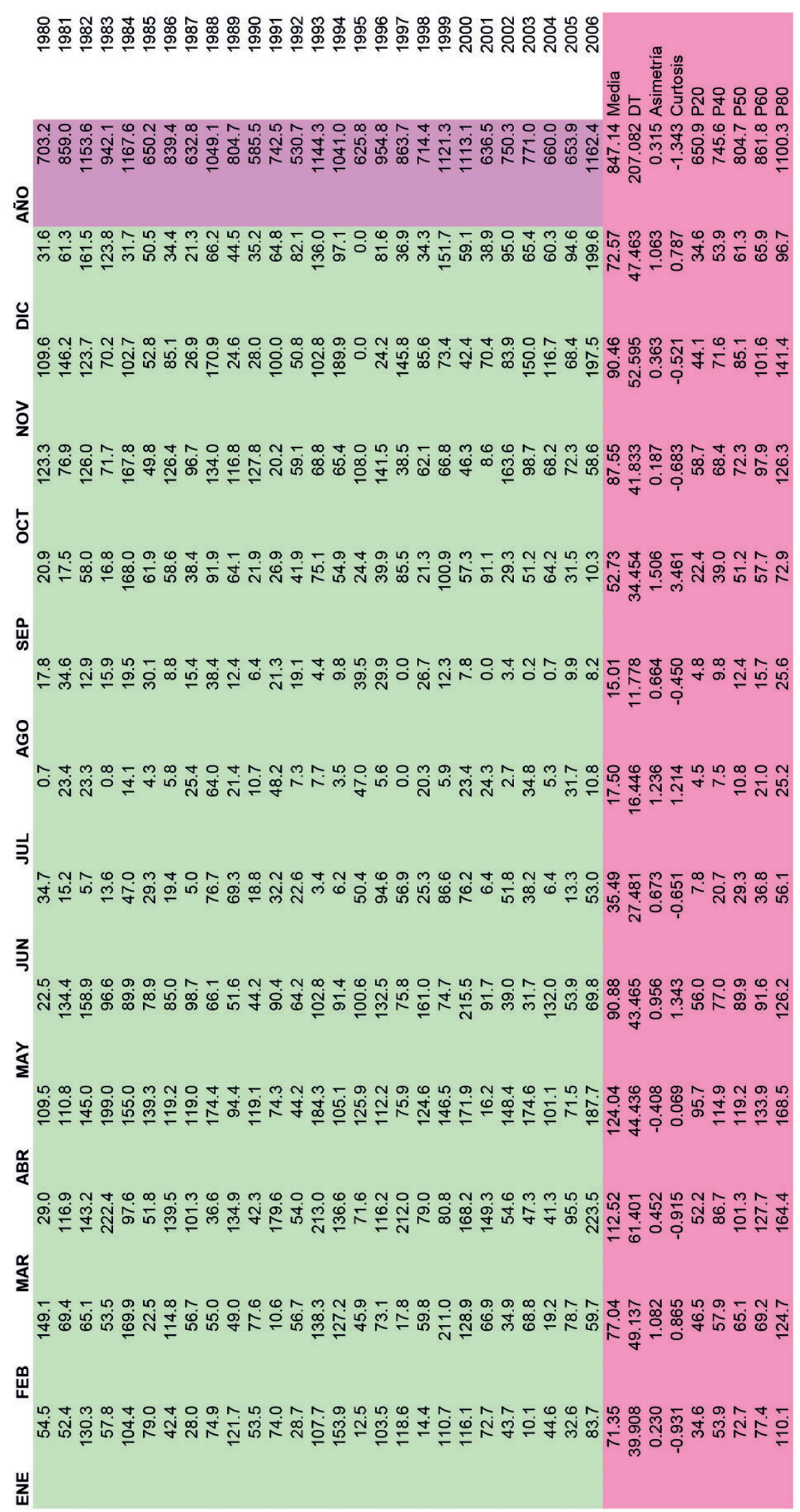




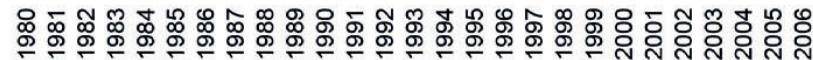

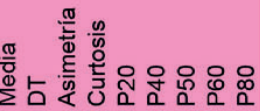

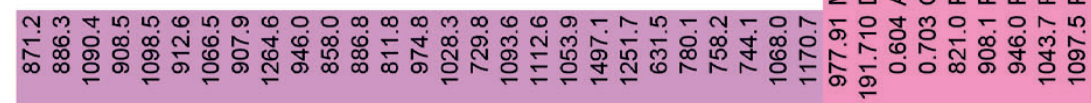

这 †

음

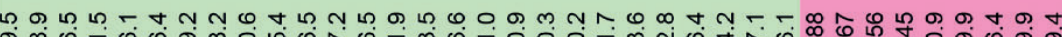

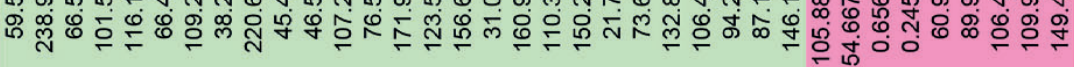

을

क ־

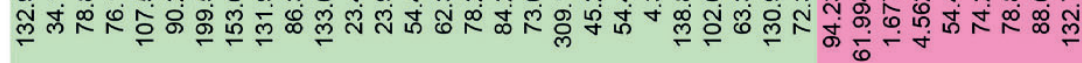

Ł

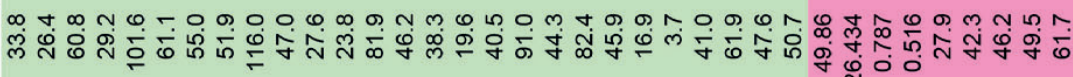

苍

+ ส่

운

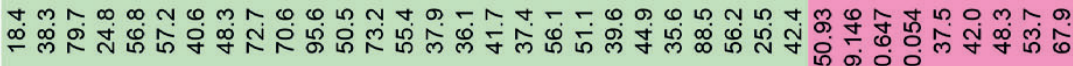
5 舟吕 $\mathbf{z}$

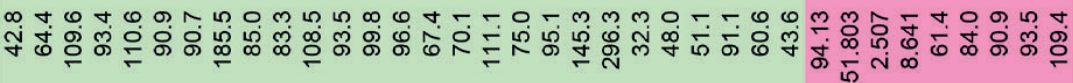

そ)

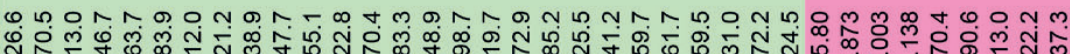

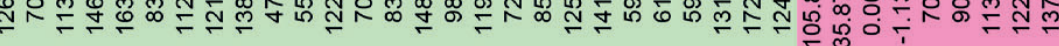

爵

オ人一

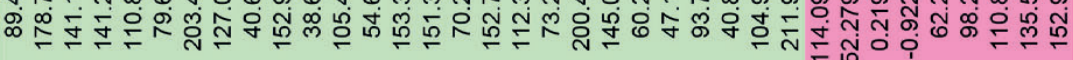

$\stackrel{\alpha}{\Sigma}$

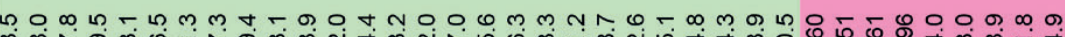
Љூ

思

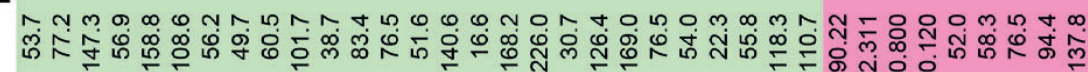
崫 
205

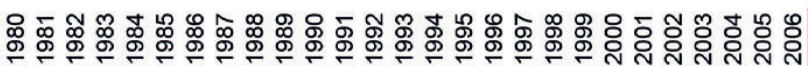

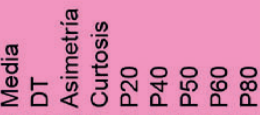

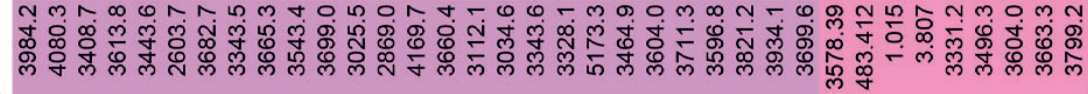

㲾

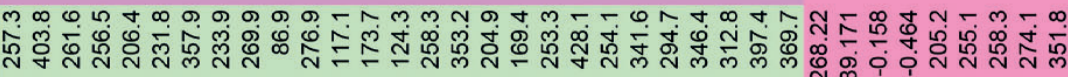

음

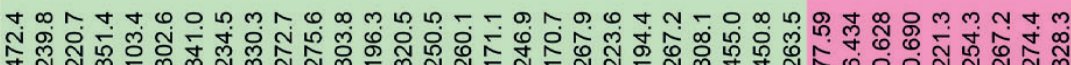

을

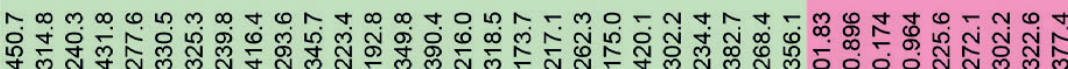

Ł

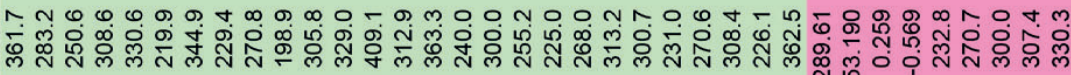

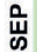

於

우

m

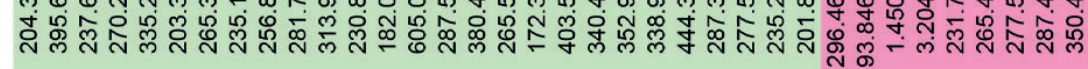

క

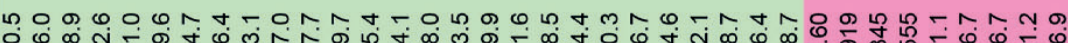

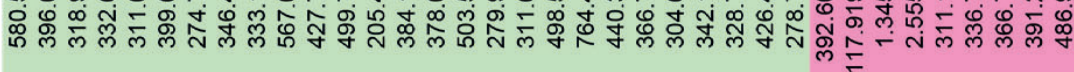

z

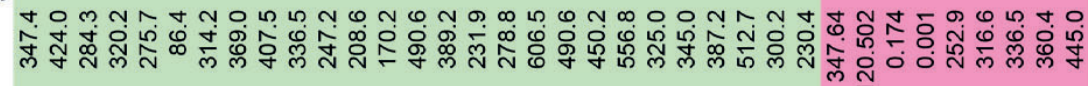

๖े

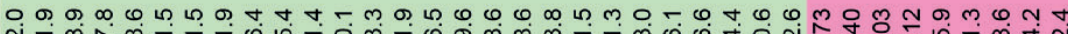

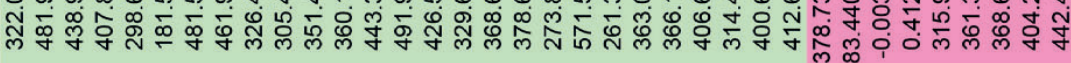

㩊

กૅ m N

$\frac{\alpha}{\Sigma}$

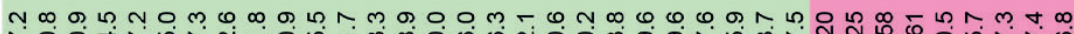

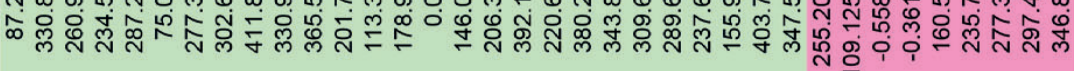

䎹

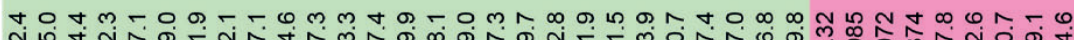

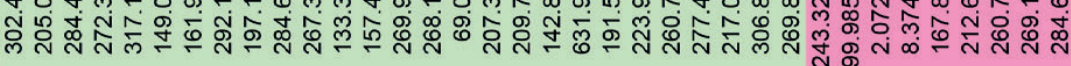
宸 


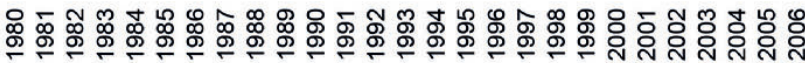

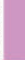
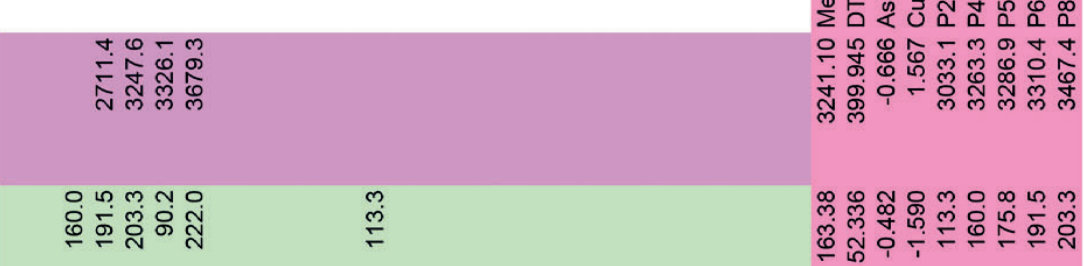

음

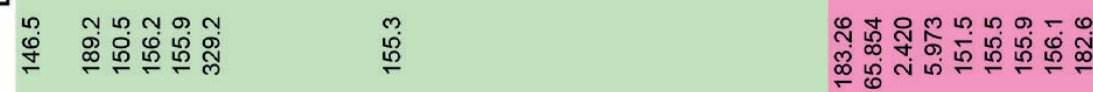

家

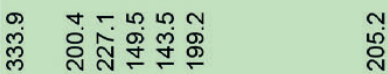

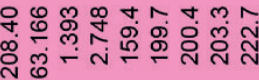

¿

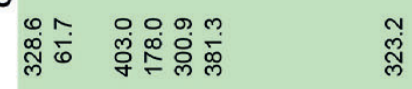

趝

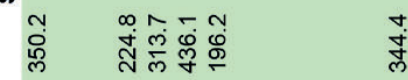

$\because$

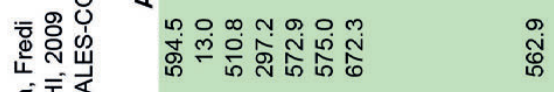

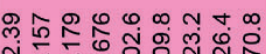

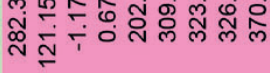

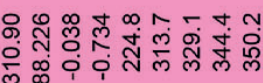

5

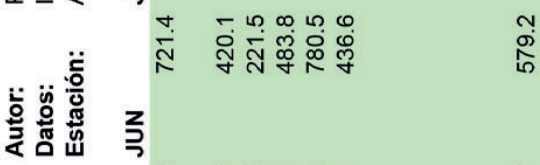

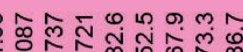

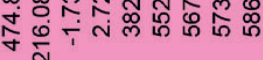

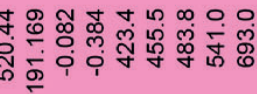

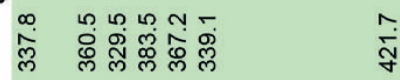

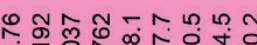

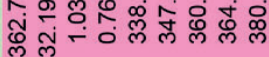

空

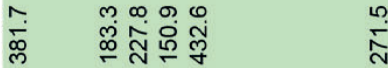

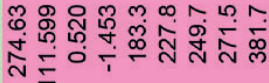

尊

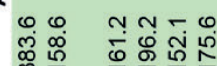

我

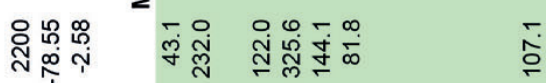

䍃

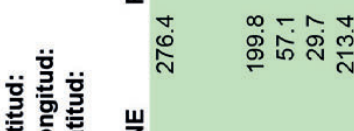

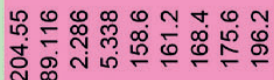

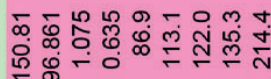

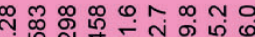

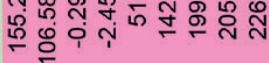




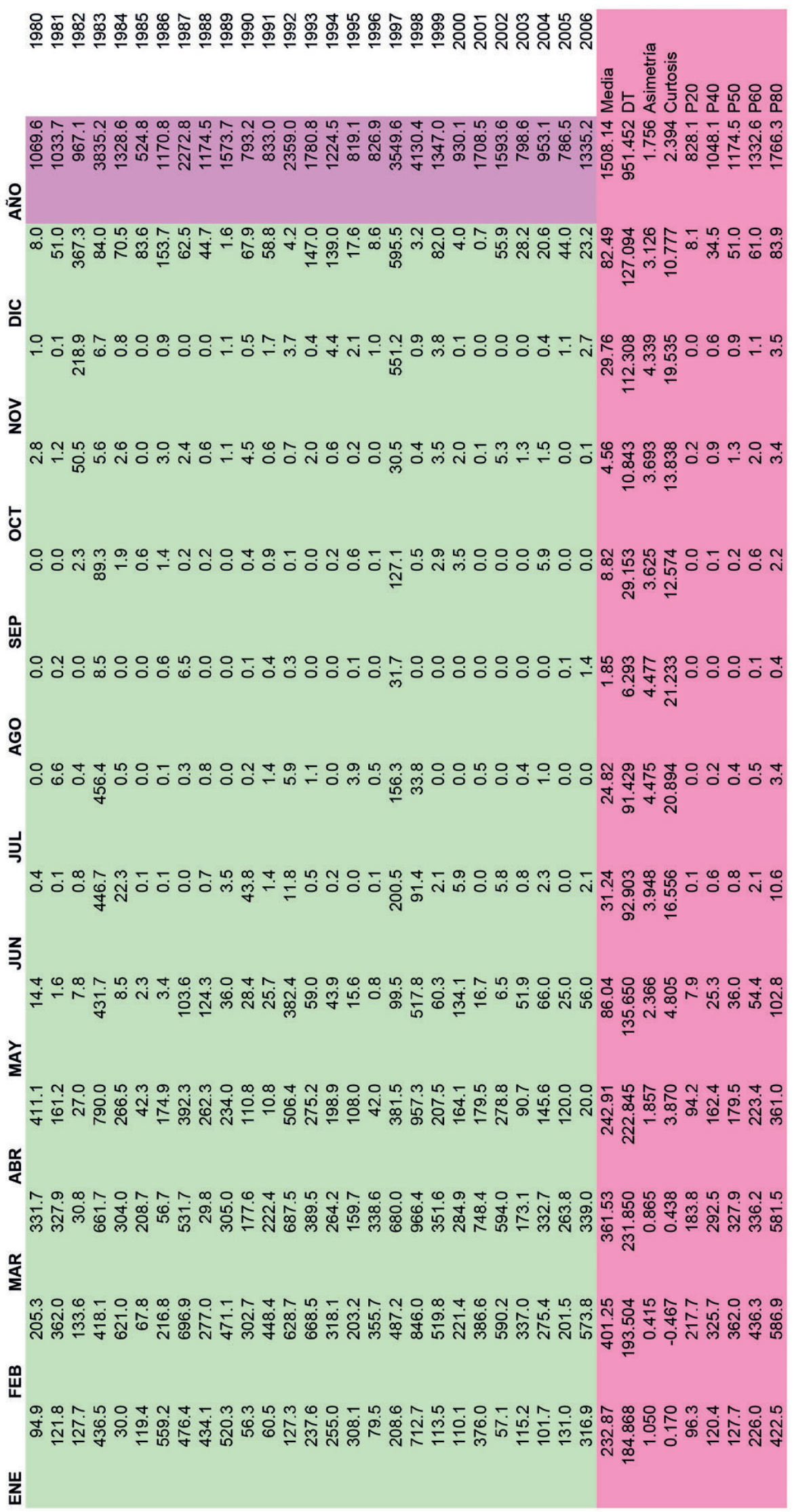


208

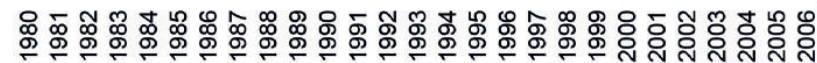

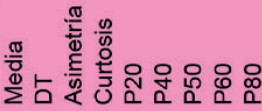

$\infty$
$\infty$
$\infty$
$\infty$
$\infty$
$\infty$

安

め。

$\stackrel{0}{0}$

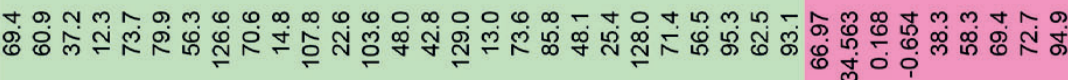

วั)

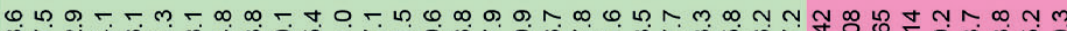

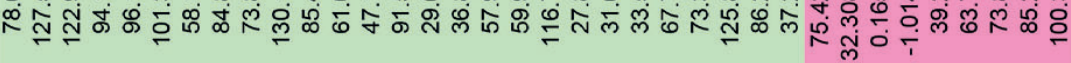

๖

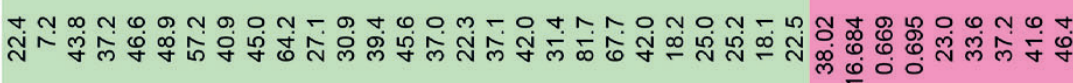

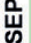

a)

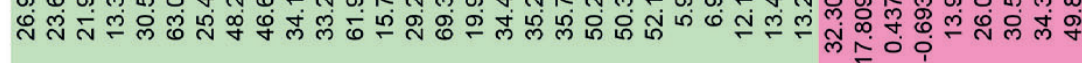

¿ำ

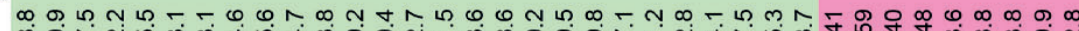
ळ

马

ค

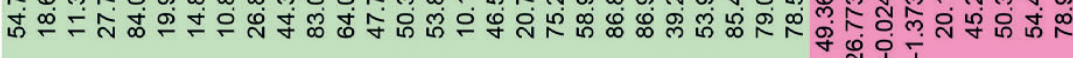

$\mathbf{z}$

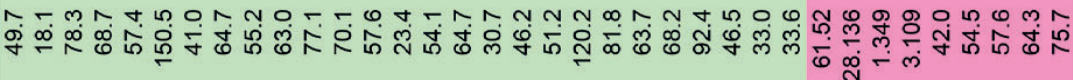

¿

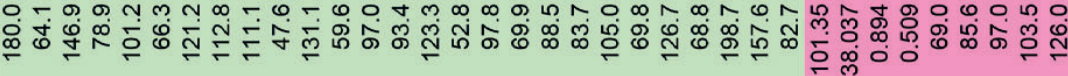

㩊

กา

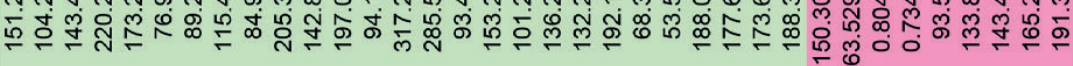

$\stackrel{\frac{\alpha}{\Sigma}}{\Sigma}$

^

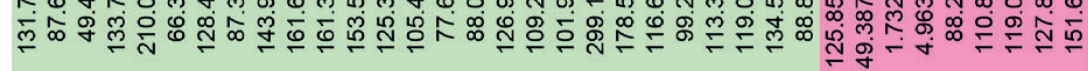

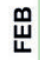

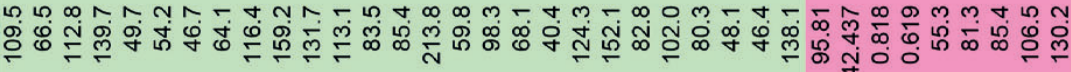
崫 


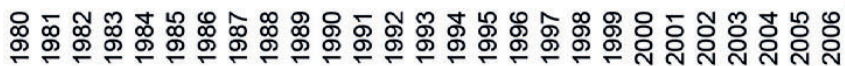

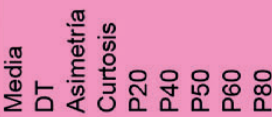

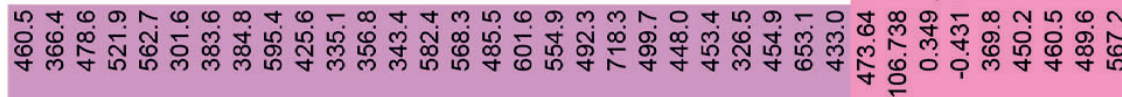

운

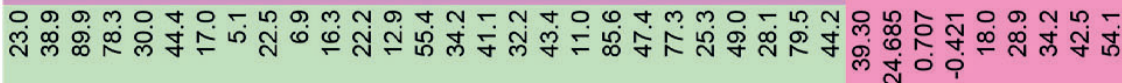

음

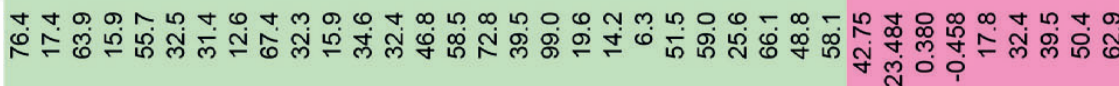

๖

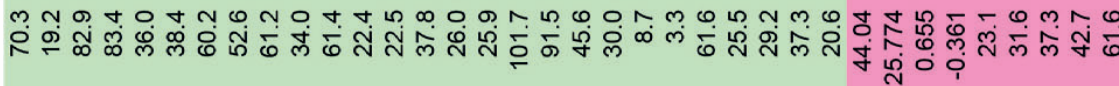

๖

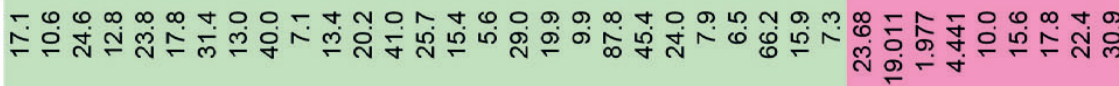

岀

ஸ̆

웅

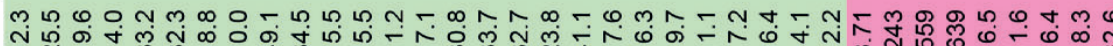

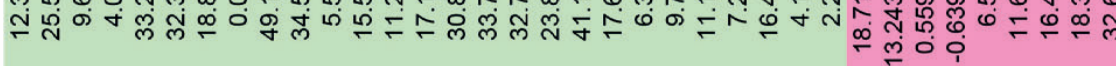

$\stackrel{5}{\zeta}$

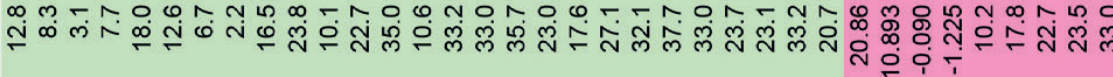

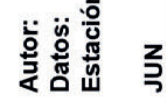

กุ

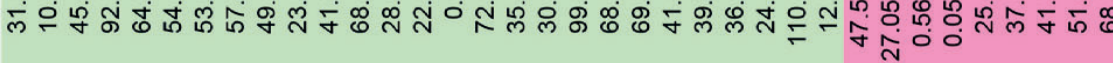

¿

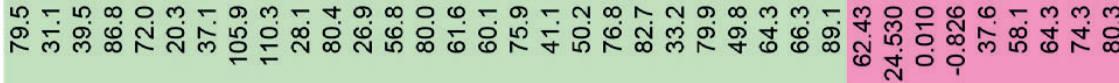

$\frac{\frac{\alpha}{m}}{\frac{m}{\alpha}}$

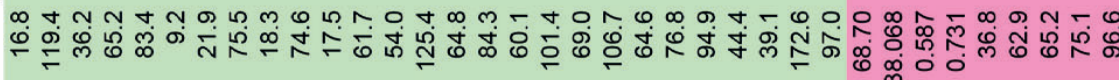

$\frac{\alpha}{\Sigma}$

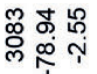

n

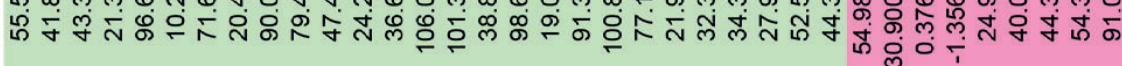

妥

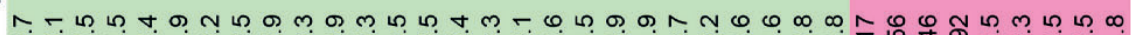

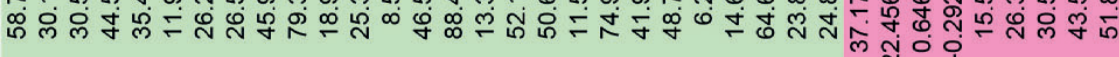




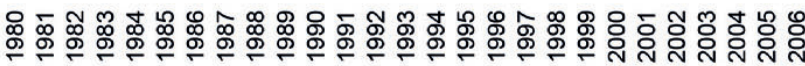

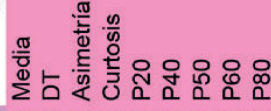

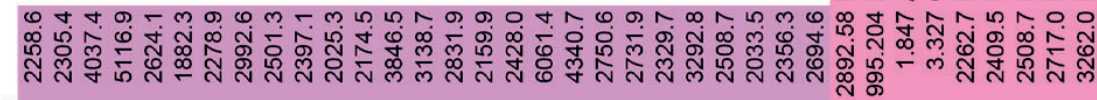

운 ळ 늠

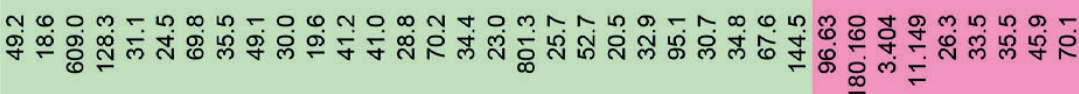
ว

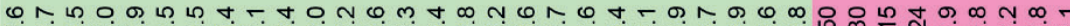

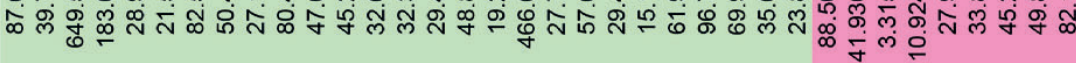
๖ั

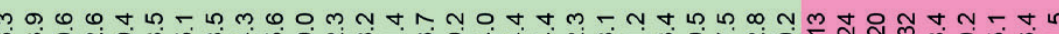

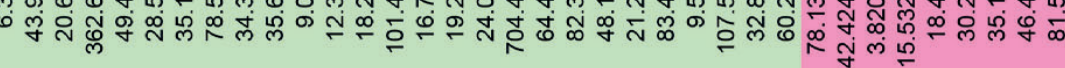

岗

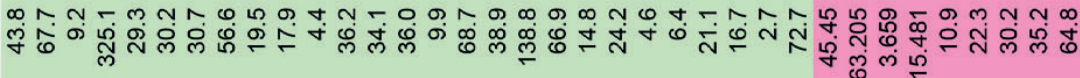

엉 N

马

п下

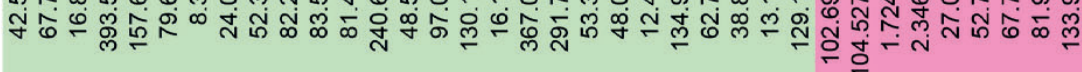

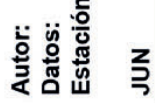

⿰纟)

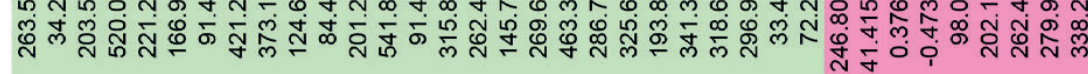

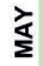

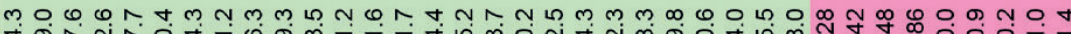

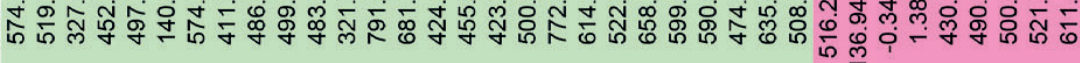

愛

ก m

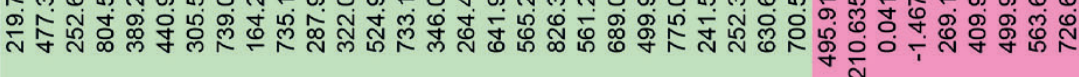
$\stackrel{\alpha}{\underline{\alpha}}$

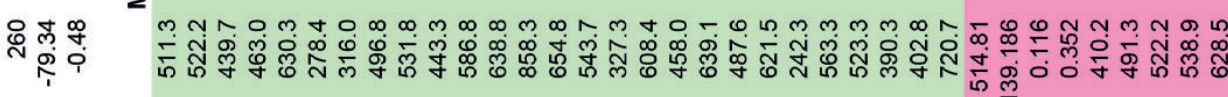
思

N

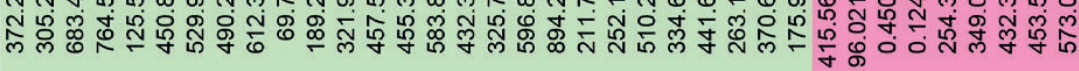
岂 


\section{1}

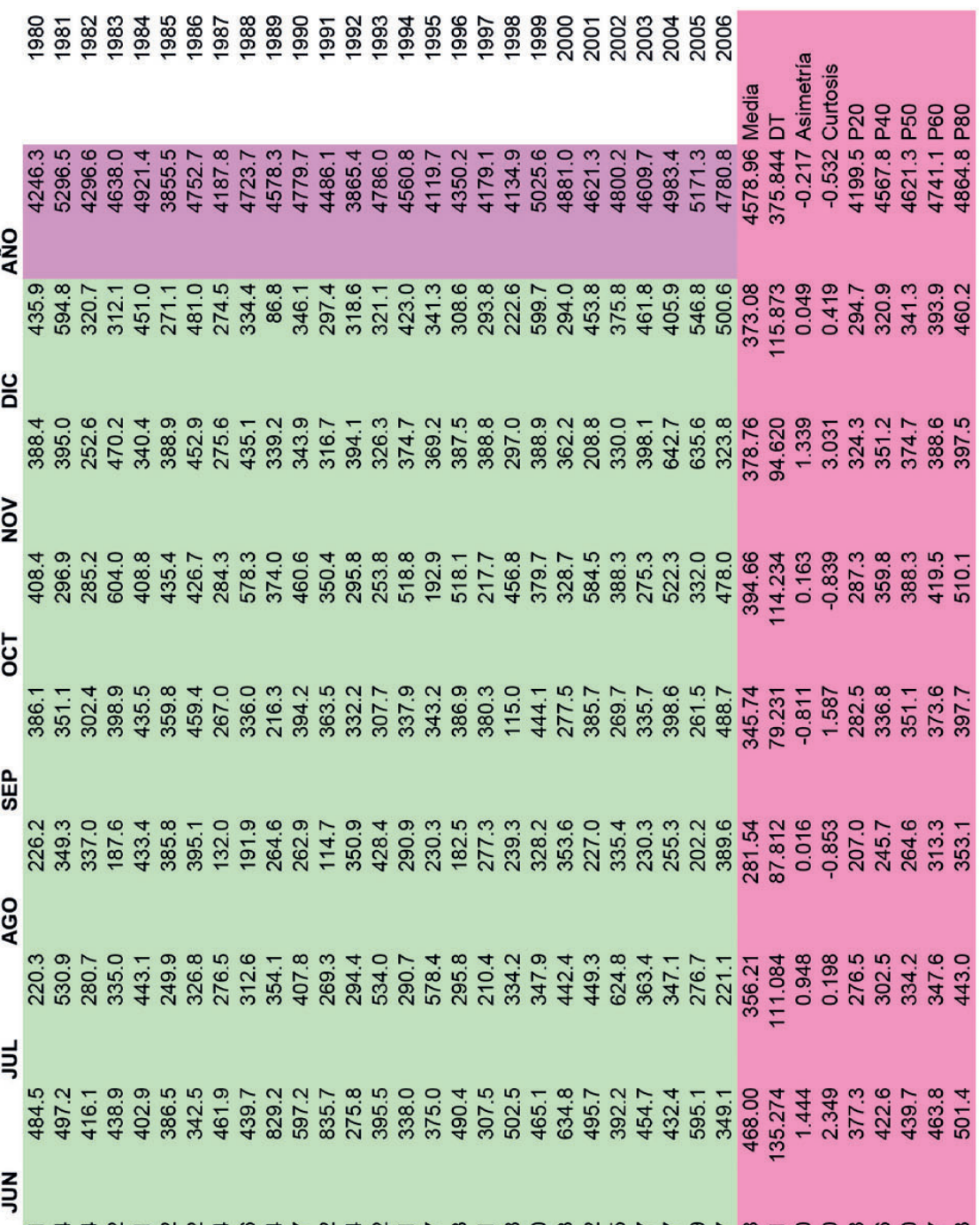

mano- 0 n $0-\infty m+0$ t

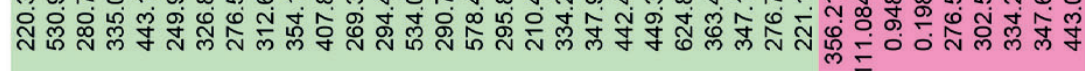

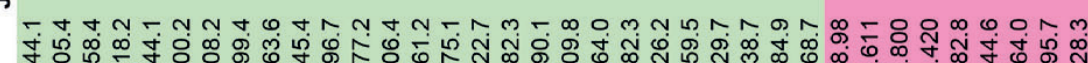

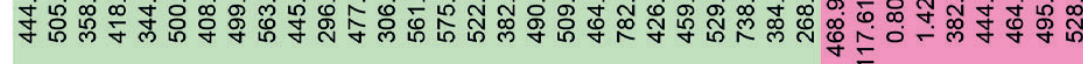

¿

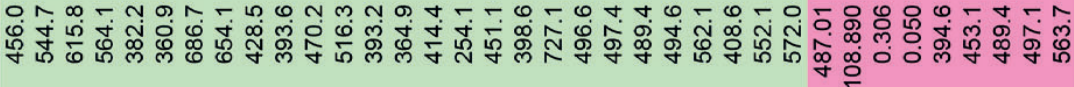

爱

๒

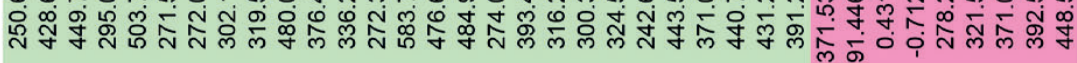

$\stackrel{\frac{\alpha}{L}}{\Sigma}$

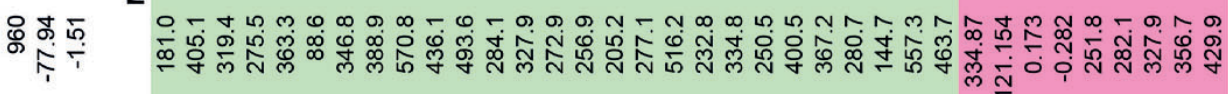

畠

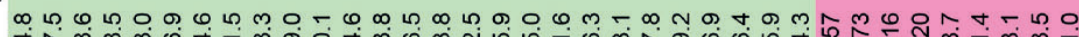

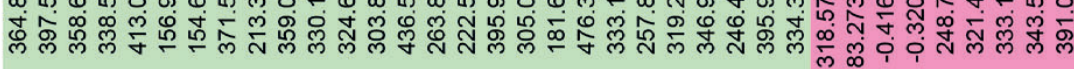
崖 


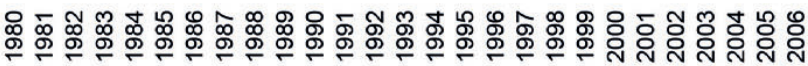

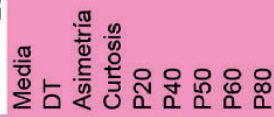

学

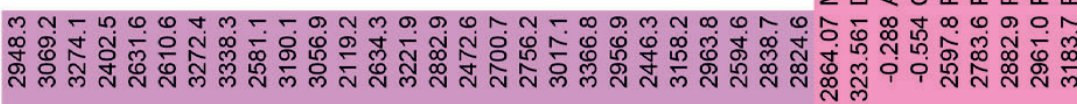
œ

늠

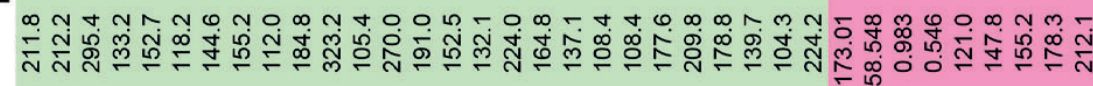

을

の우의

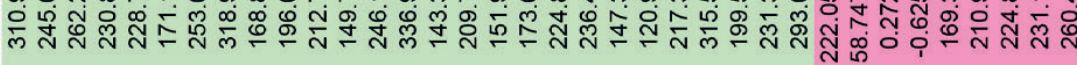
๖ั

ก 0 m

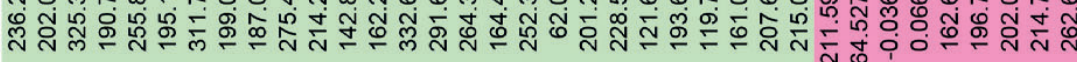

岃

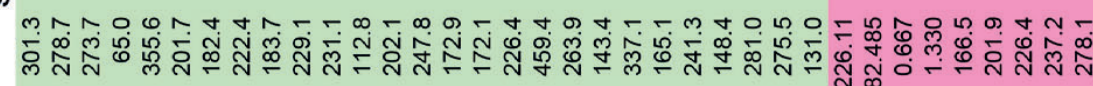

운

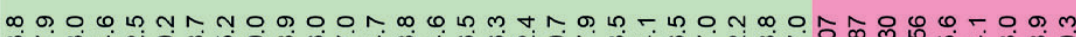

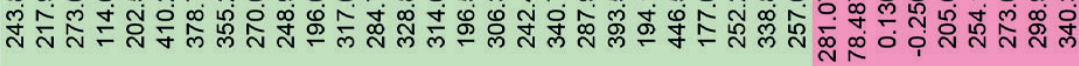

马

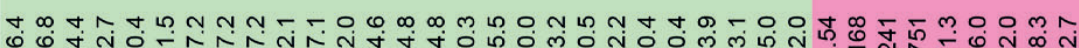

语范

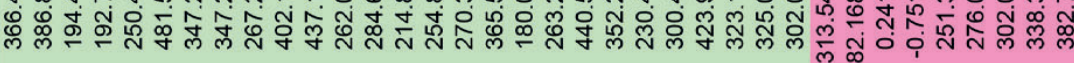

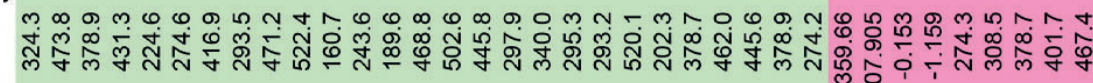
¿্ঠ

$\infty \sigma \infty \infty$ ए

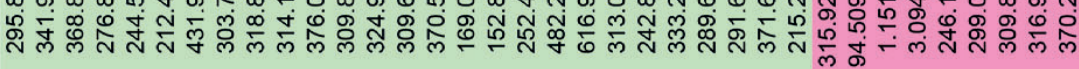

愛

^ น น

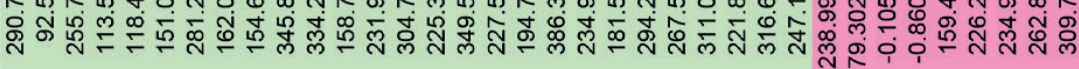

$\frac{\alpha}{\Sigma}$

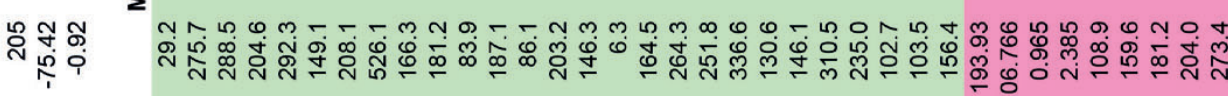
稒

ᄂ

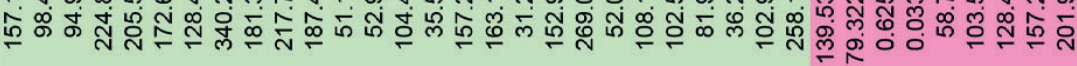
㟟 


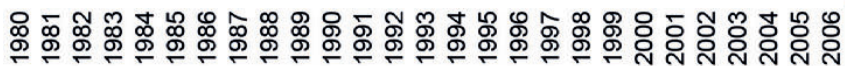

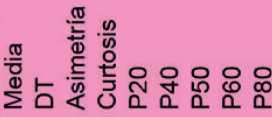

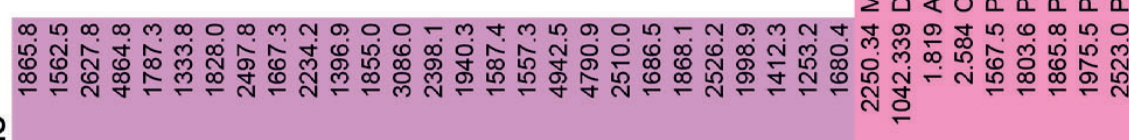

家

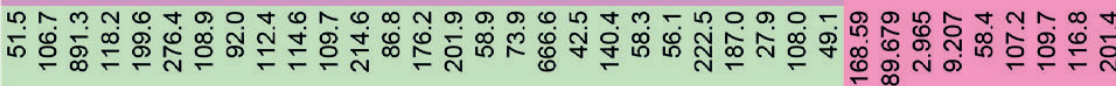

음

ஸ் 때

ว

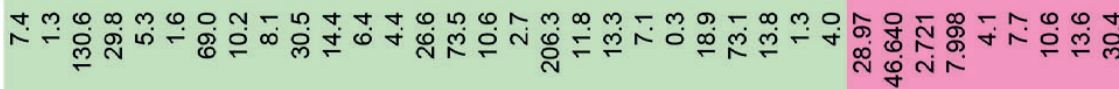

๖

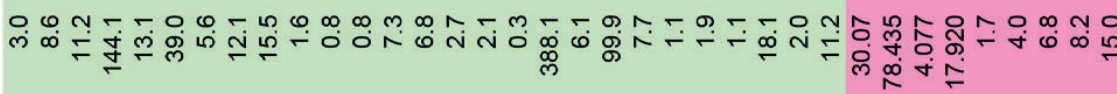

岀

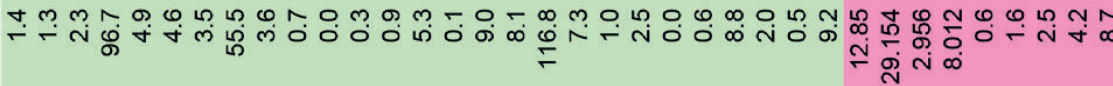

¿ำ

우의

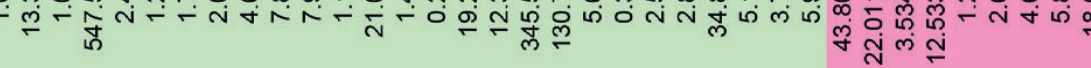

ร

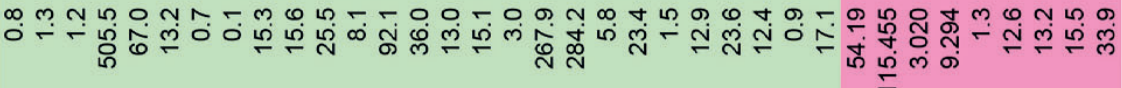

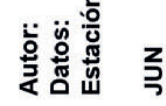

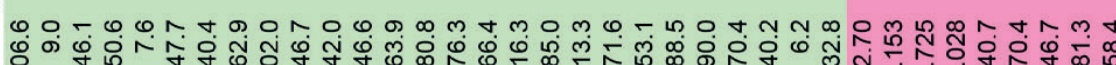

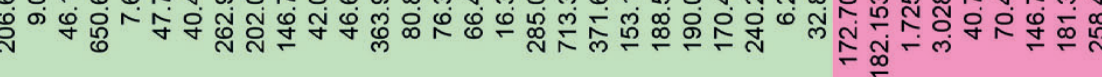

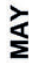

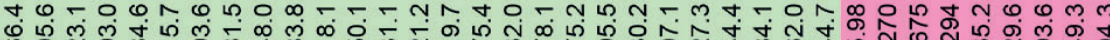

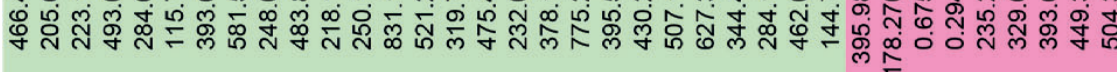

㩊

m m

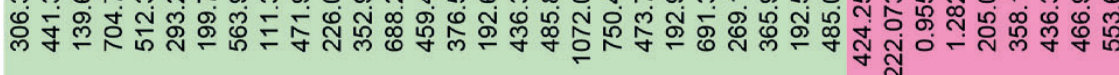
$\frac{\alpha}{\Sigma}$

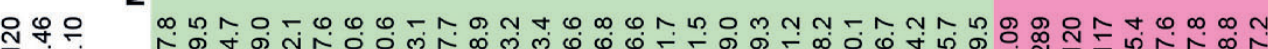

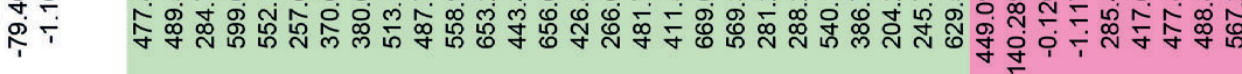

㠀

n t

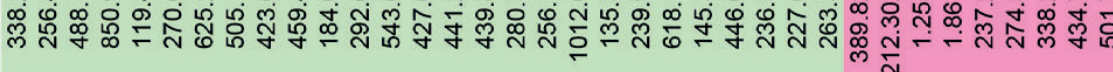




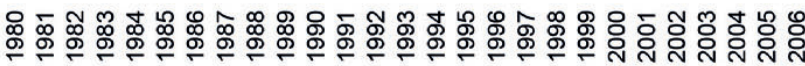

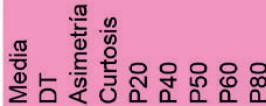

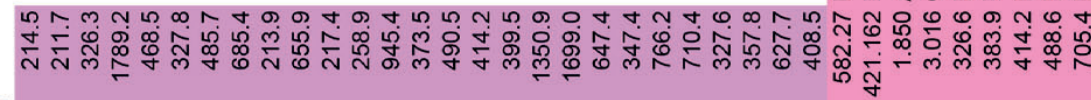

㲾

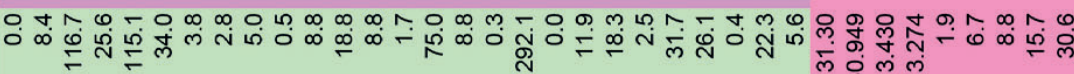

음

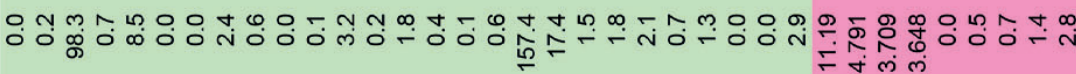

ò

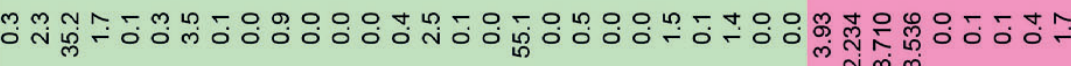

๖

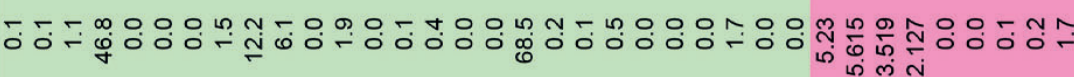

㟧

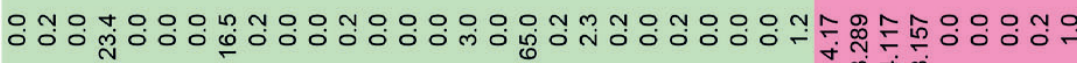

\&

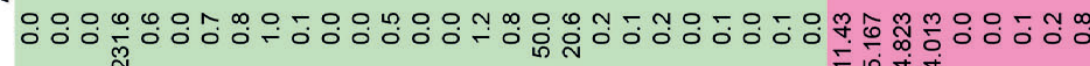

马 N

ב

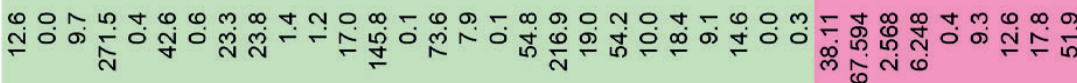

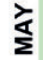

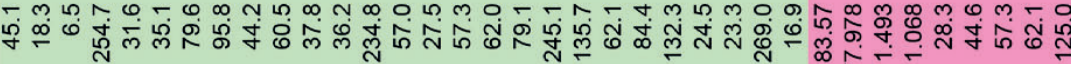

$\stackrel{\text { 䍃 }}{\leftarrow}$

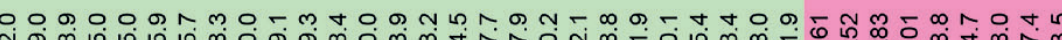

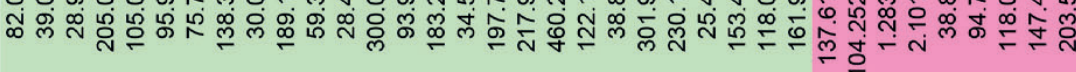

$\stackrel{\alpha}{\Sigma}$

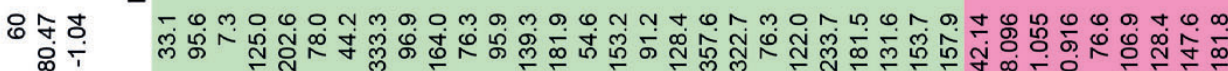

思 


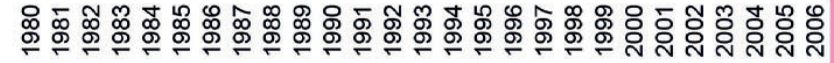

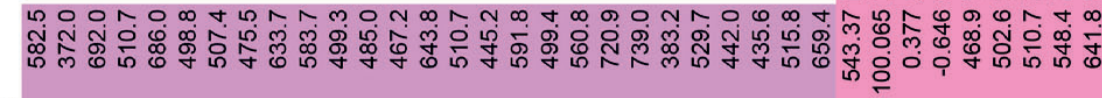

学 ฟै m

음

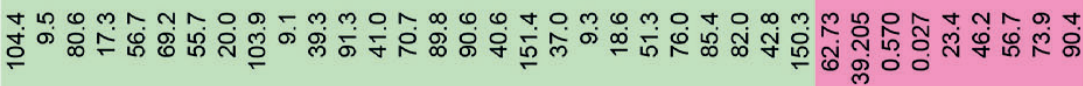

은

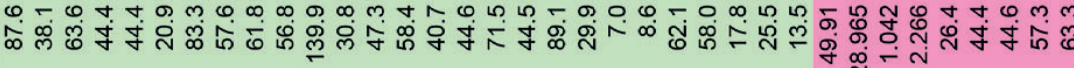
'气 花 ठัे फ़ लं

引 임

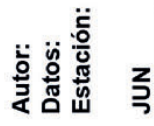

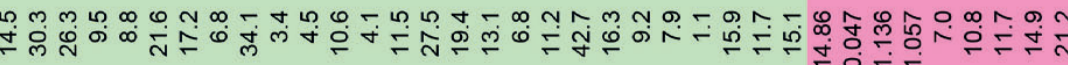

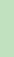

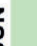

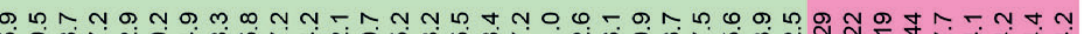

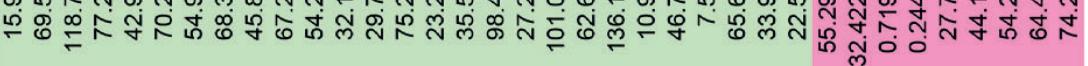

¿

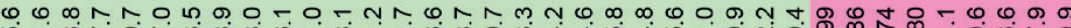

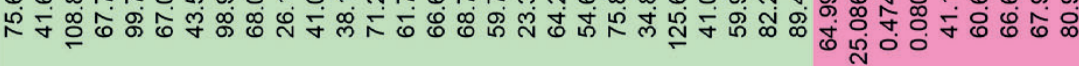

$\stackrel{\frac{N}{\mathscr{M}}}{\ll}$

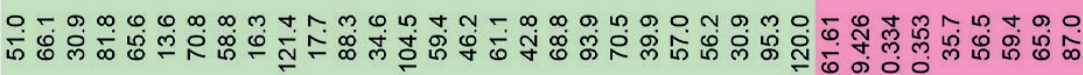

$\stackrel{\alpha}{\Sigma}$

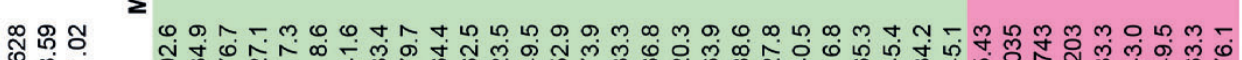

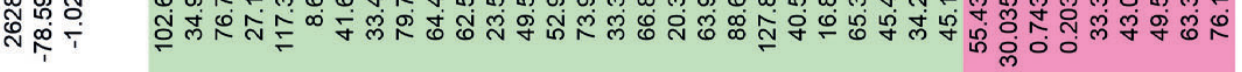
虫 


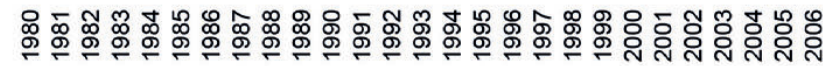

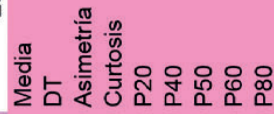

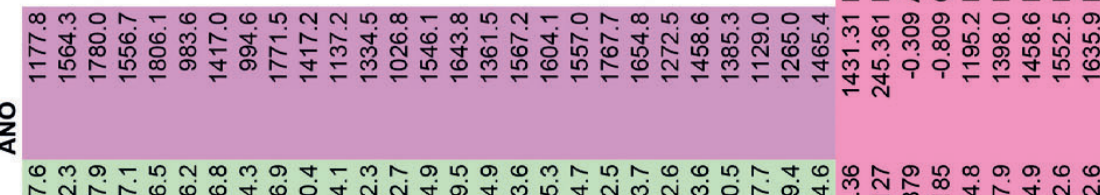

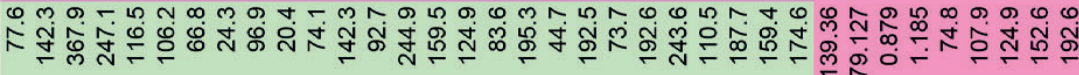

늠

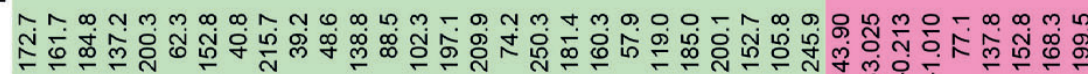

을

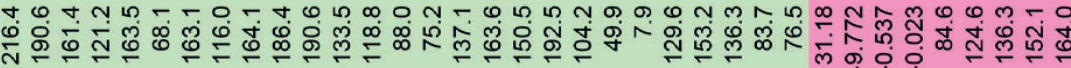
๖

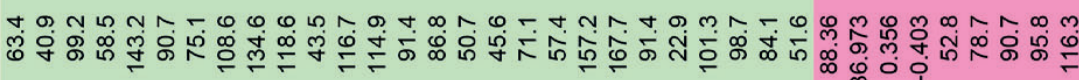

岀

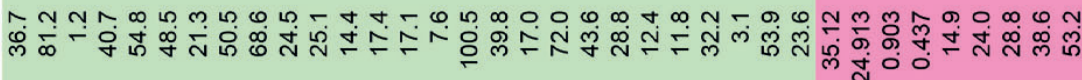
$-8 \stackrel{\circ}{\leq}$ 엉

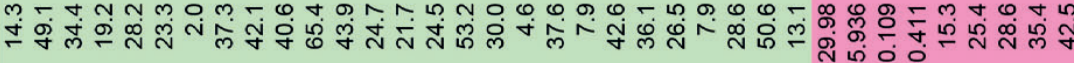

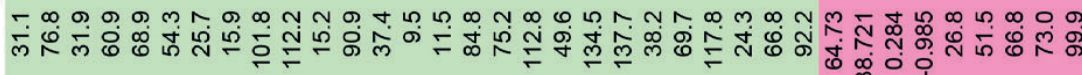
$\underline{z}$

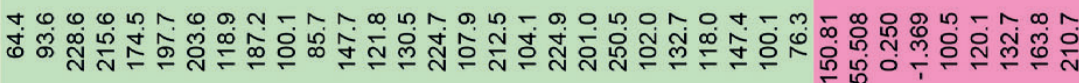
¿ t勿 m

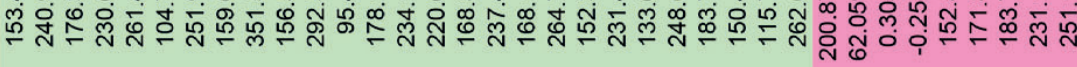
啚

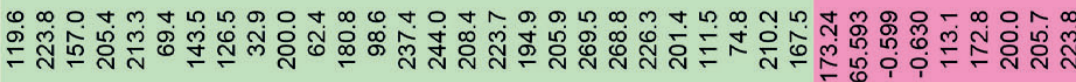
$\frac{\infty}{2}$

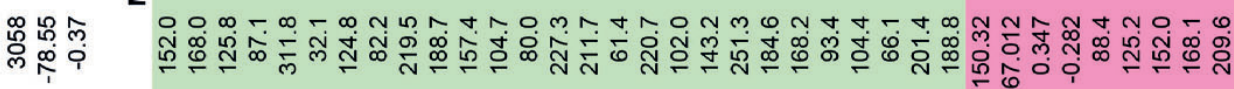
罖

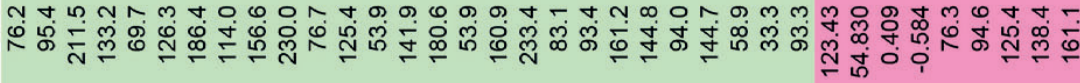




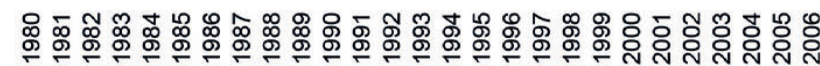

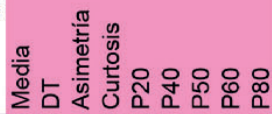

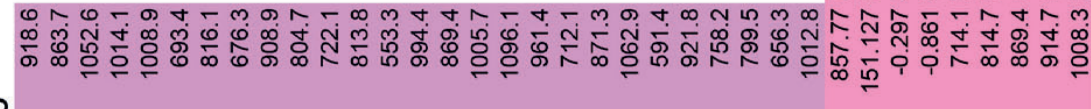

家

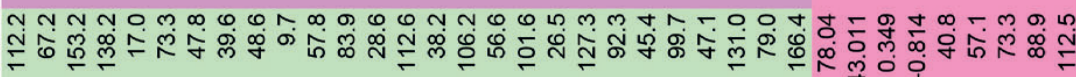
늠

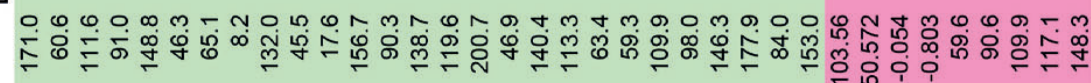

วิ n-

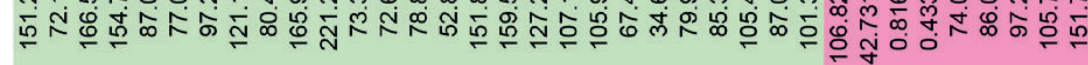
过

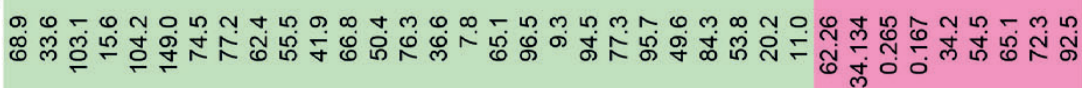

岗

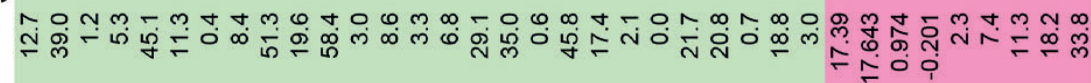

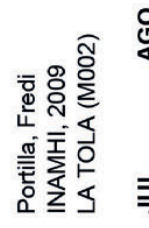

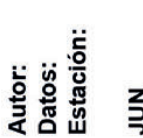

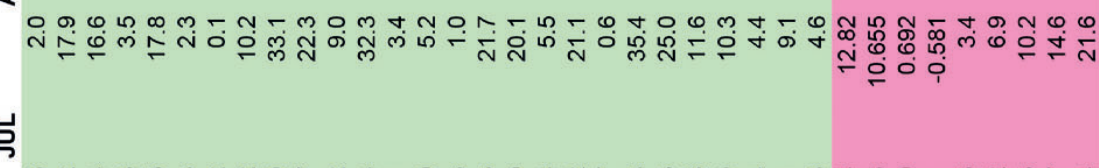

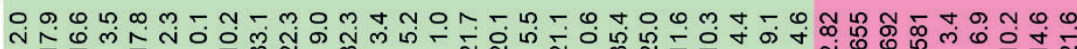

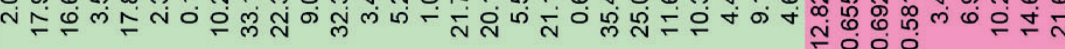
3

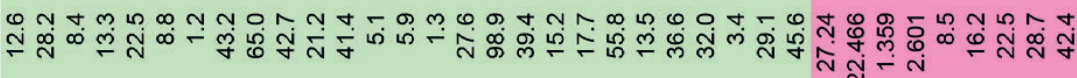

క ભ ભ

¿ 0 Gn

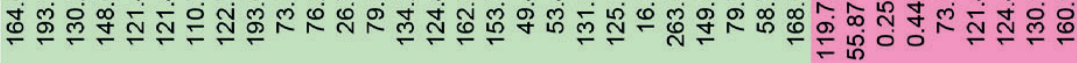

黄 Ф

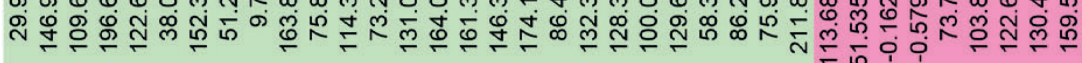

$\stackrel{\alpha}{\Sigma}$

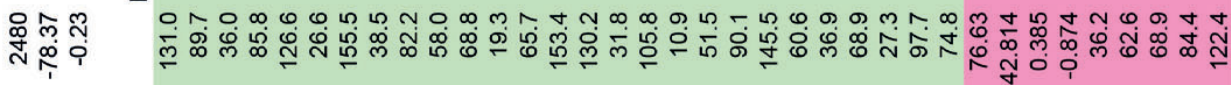

舀

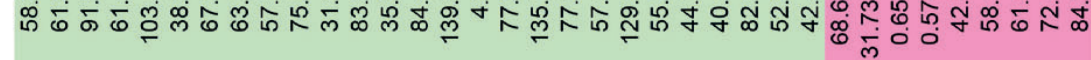
崫 

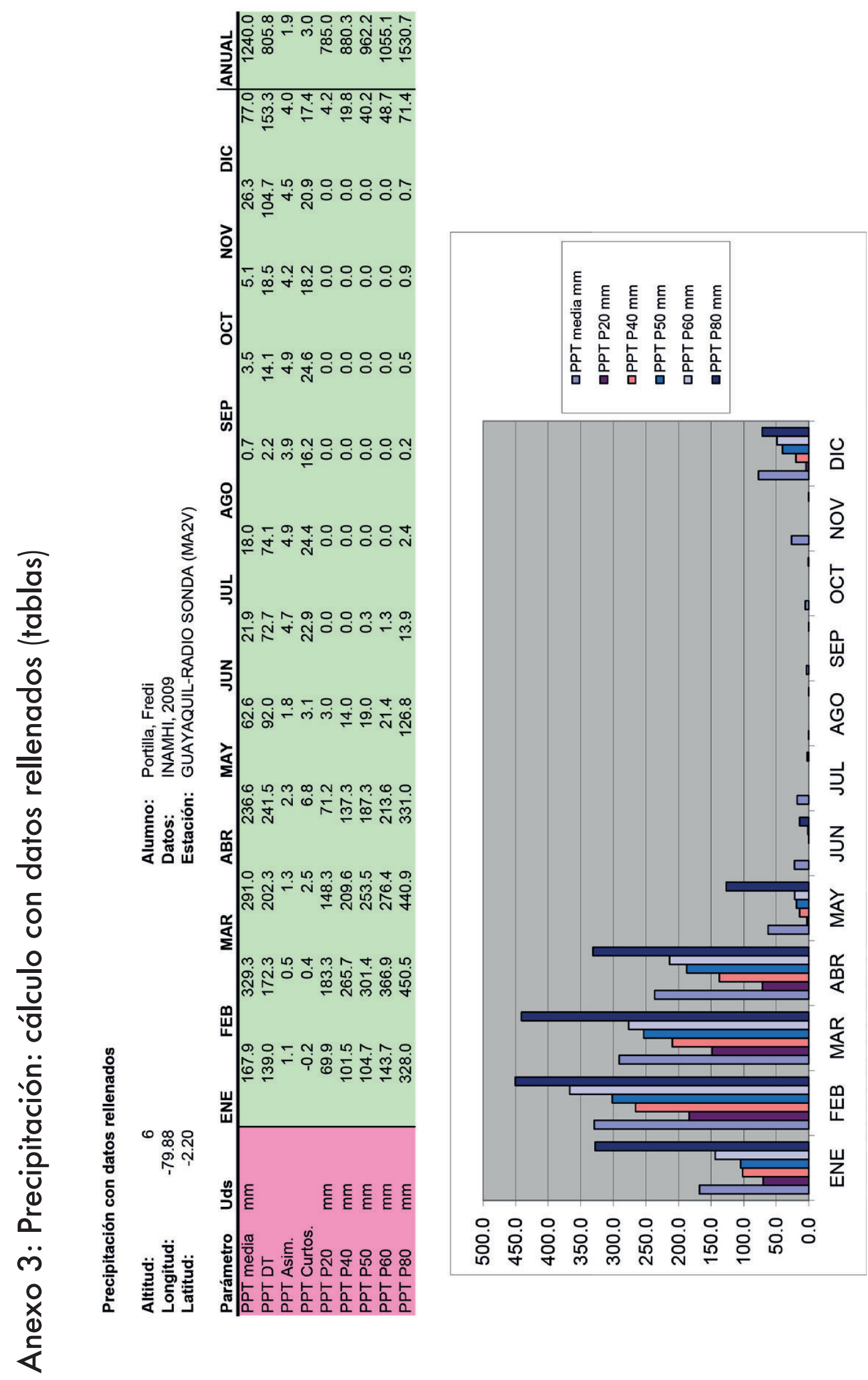


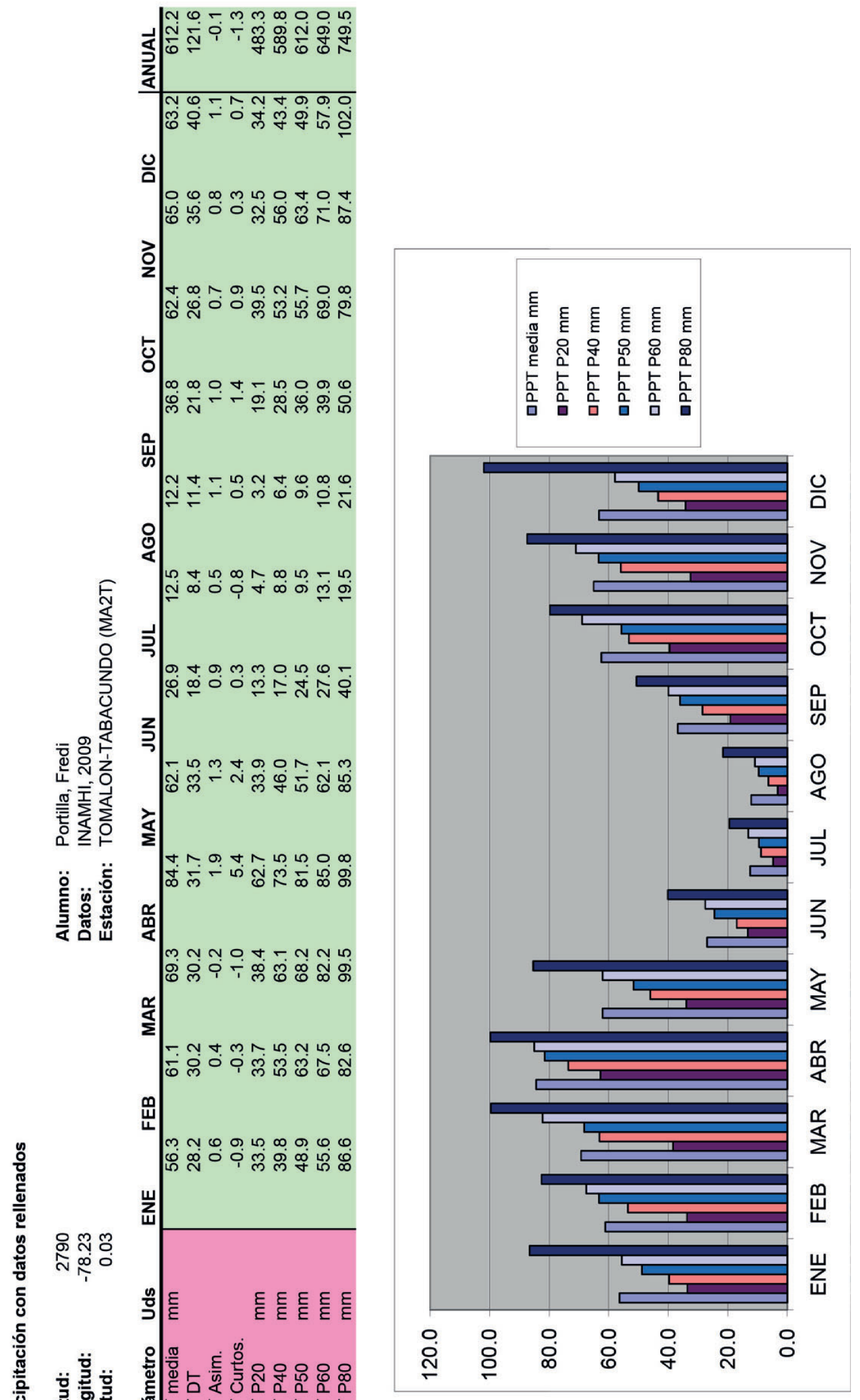




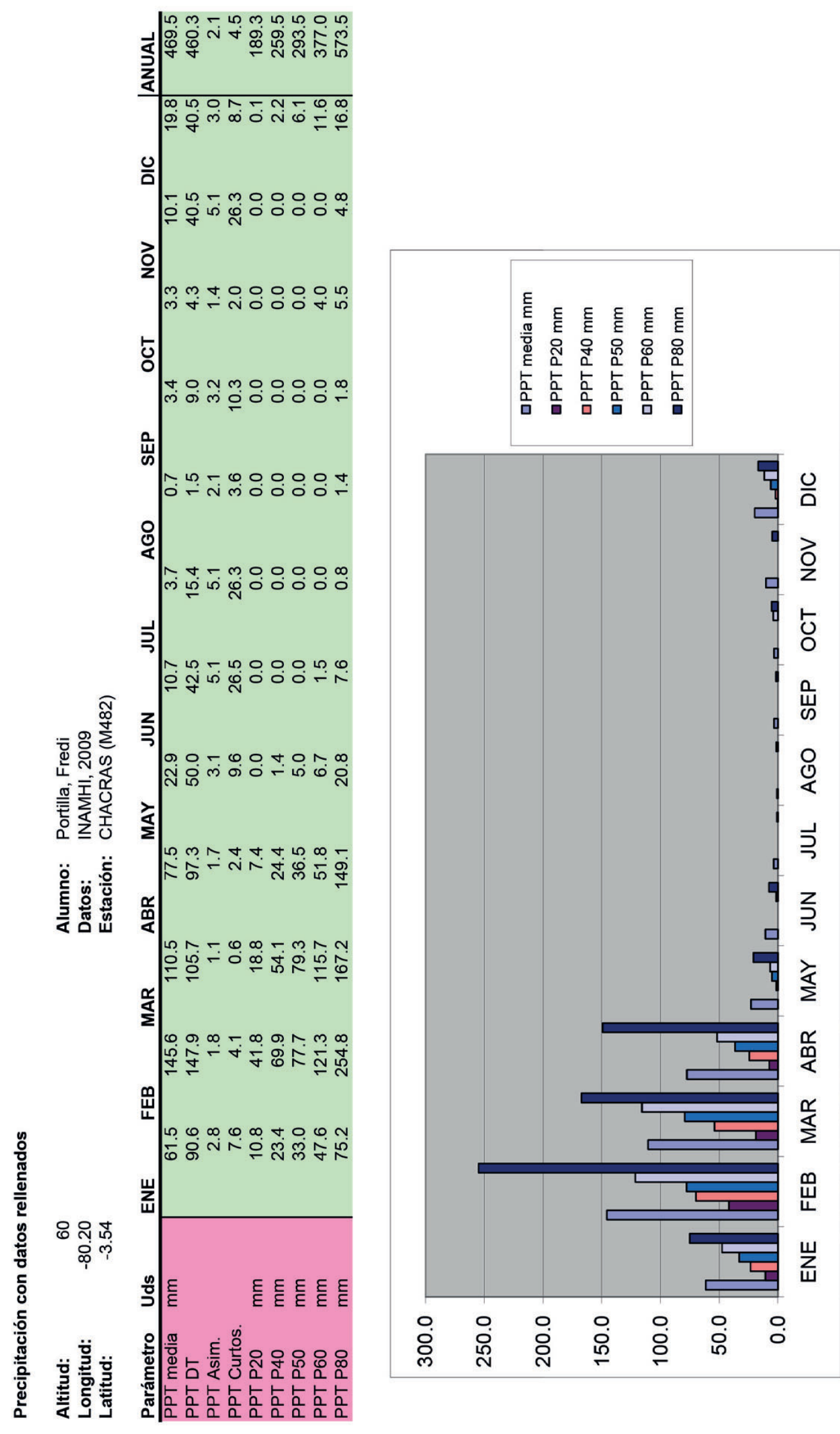



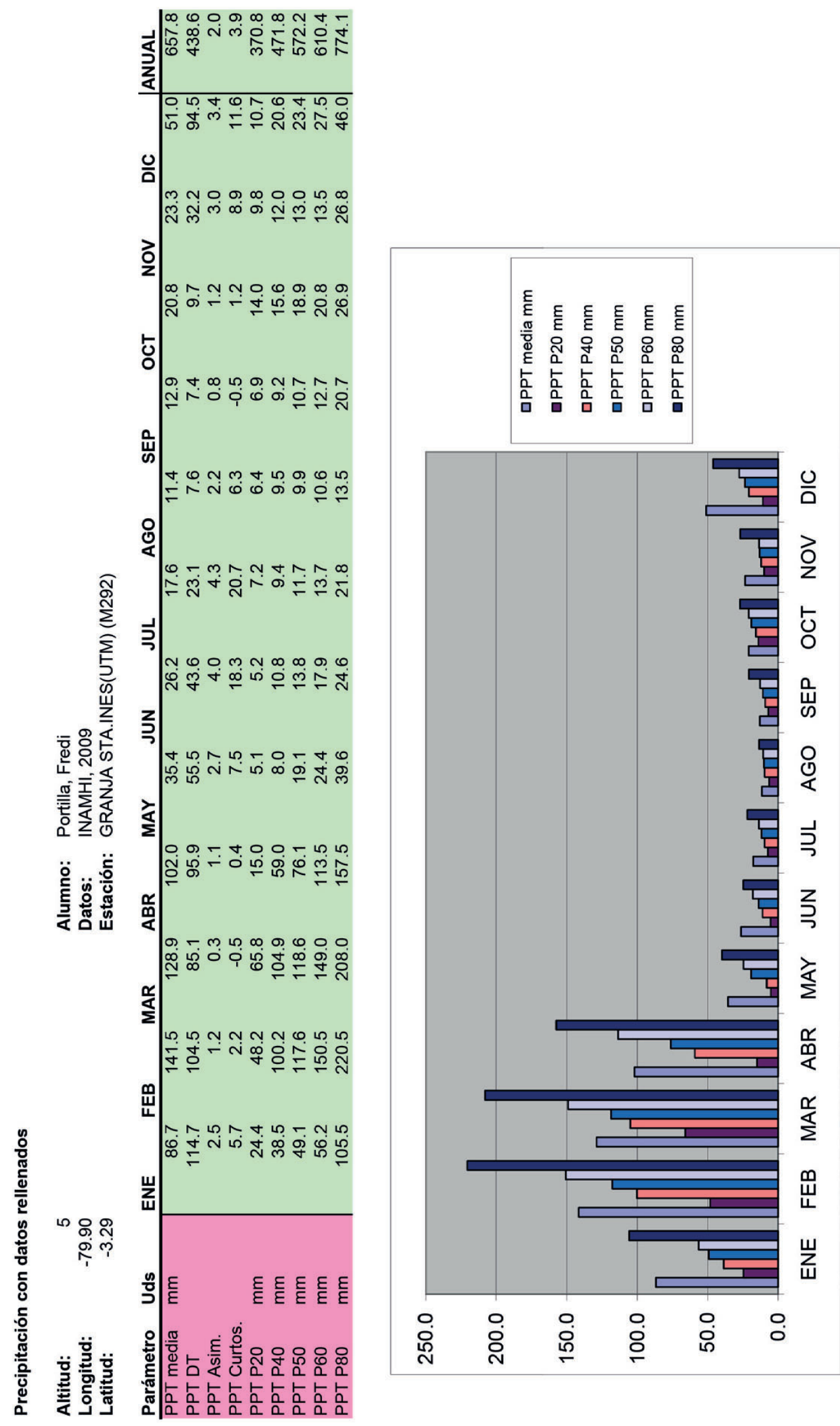

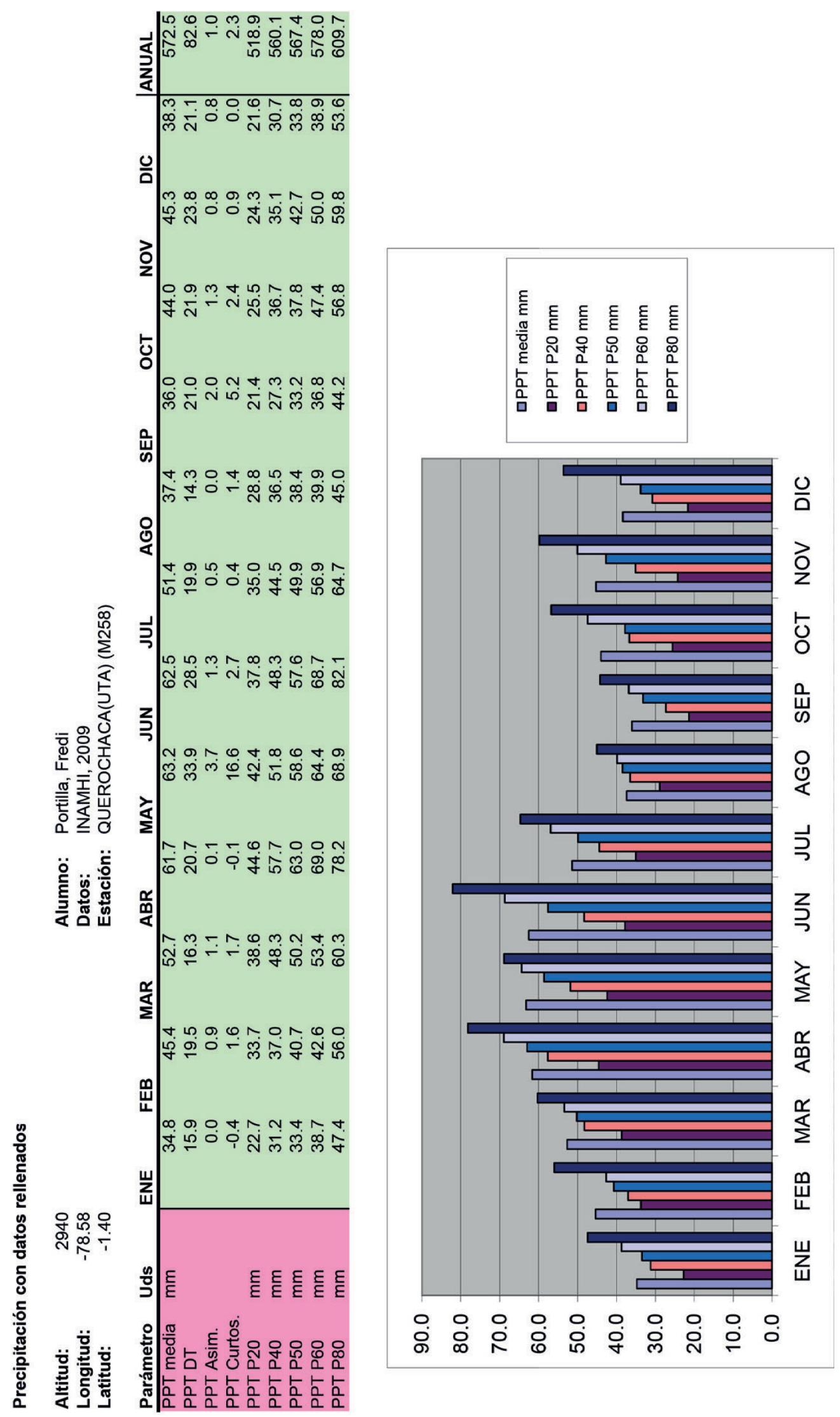


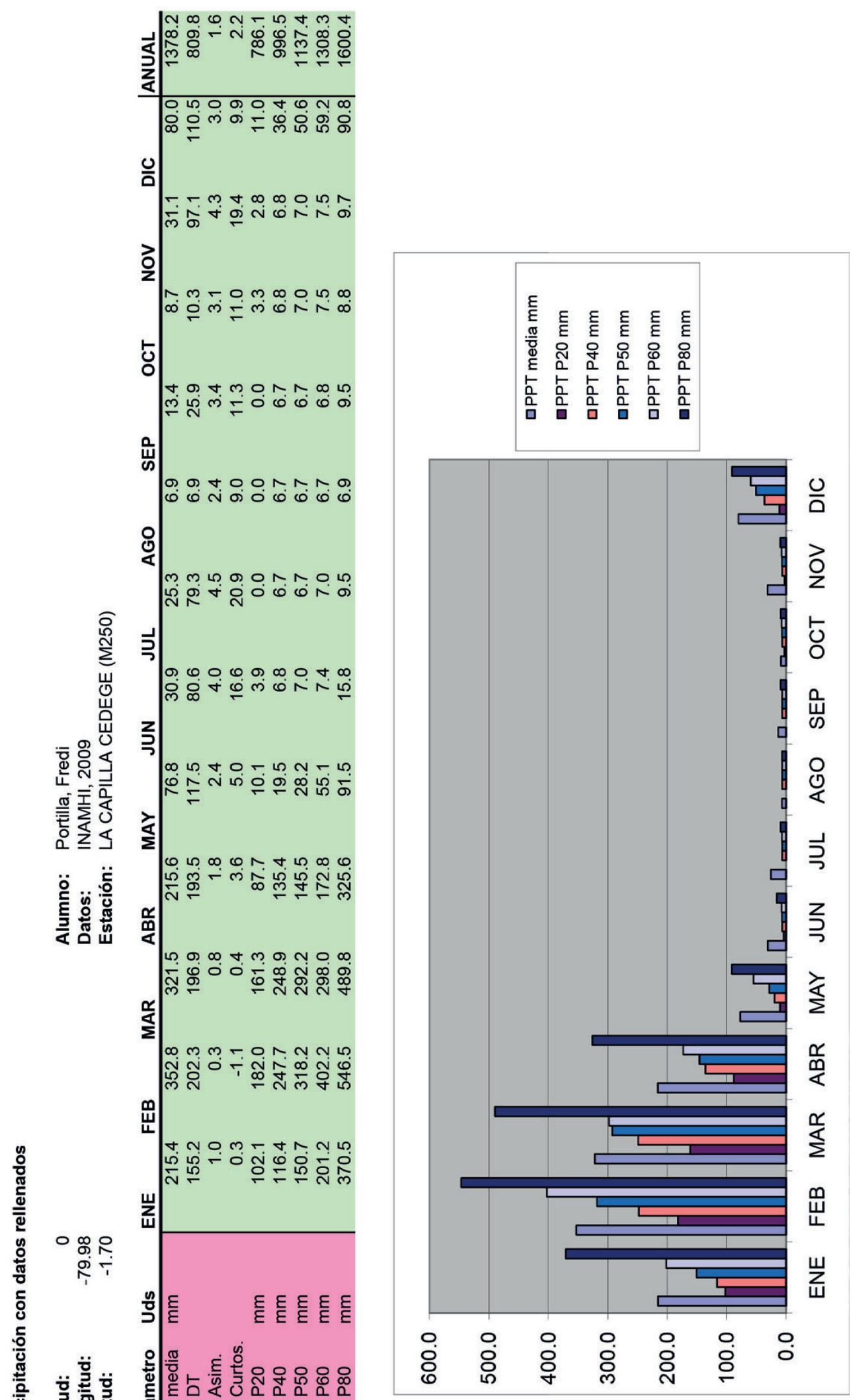




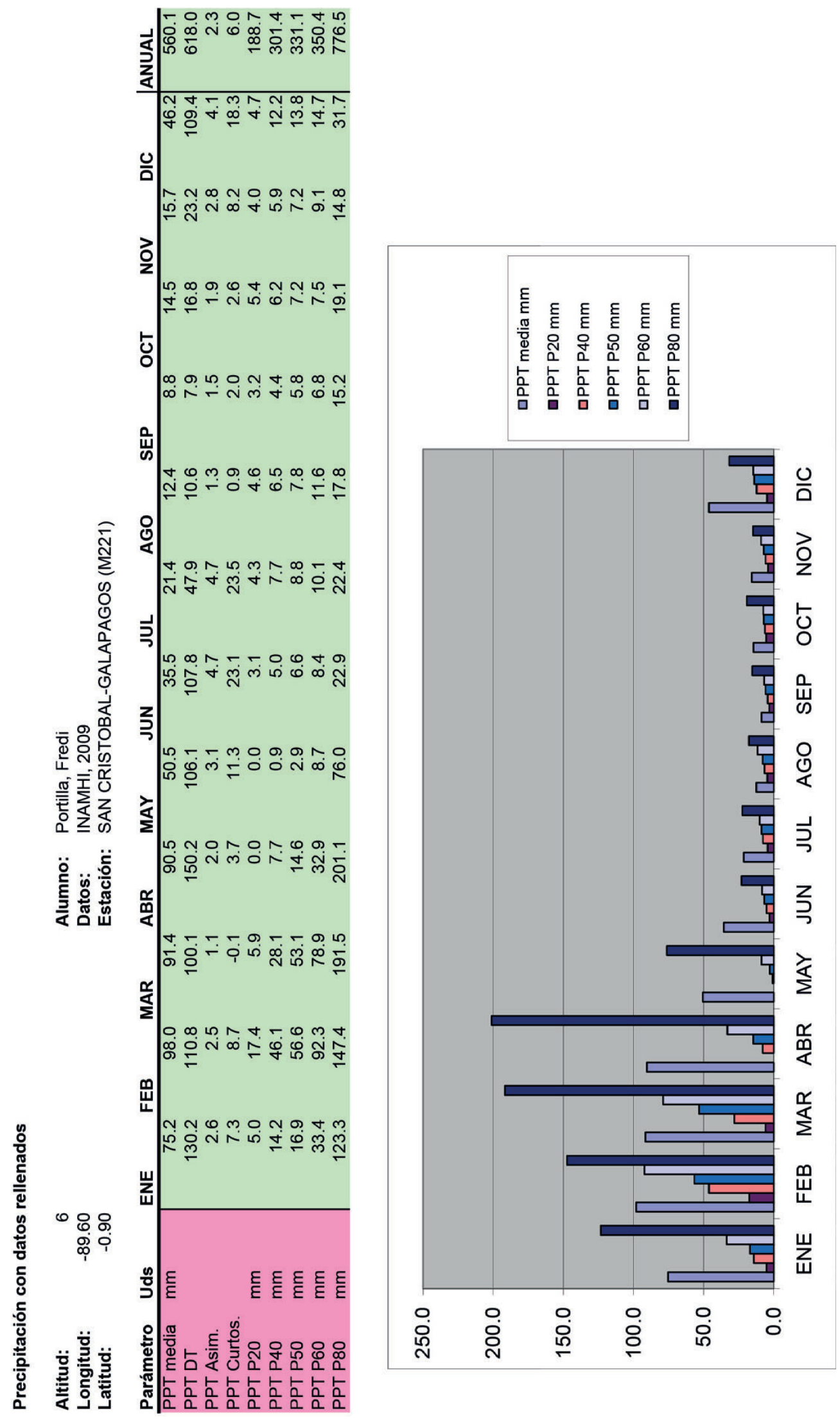



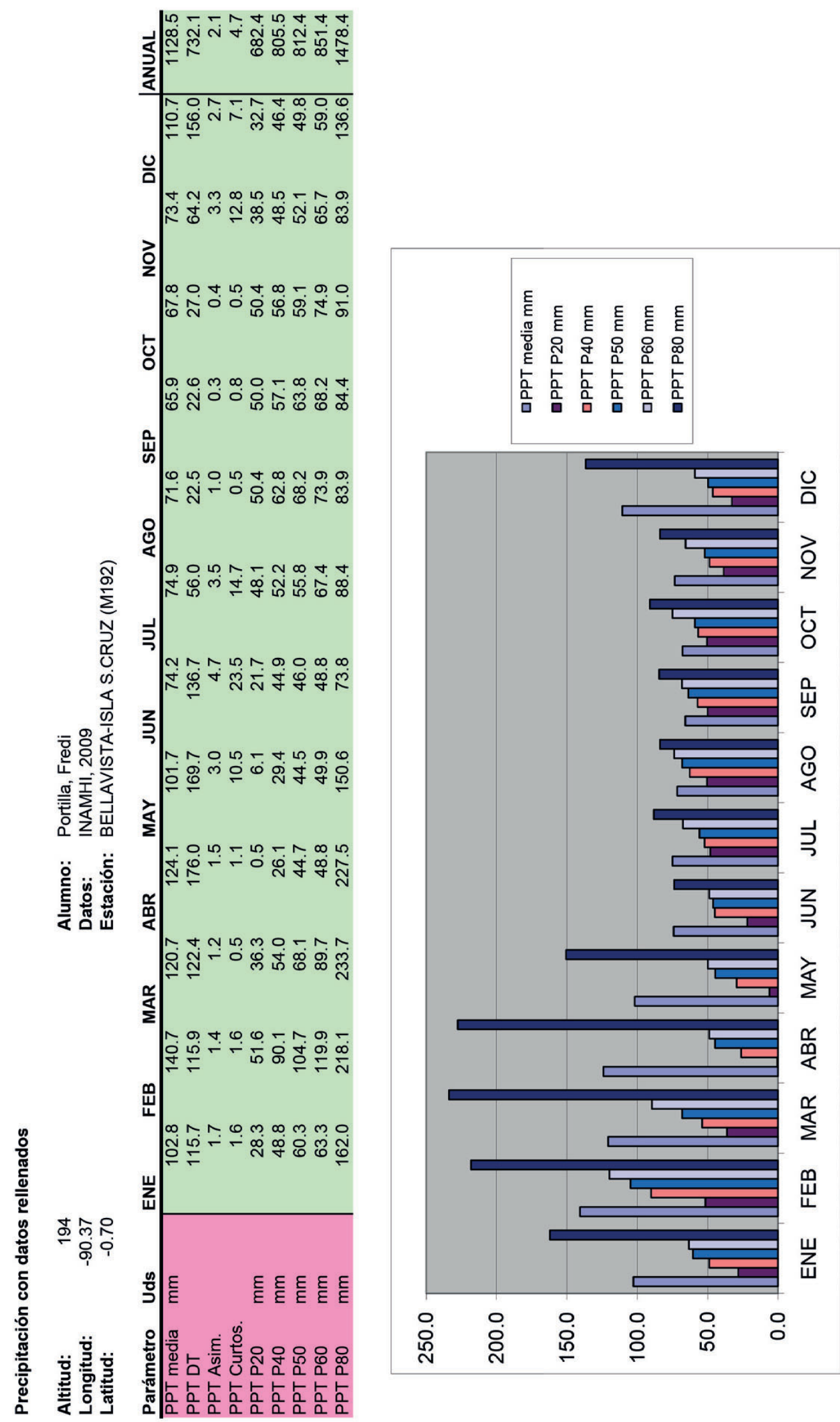

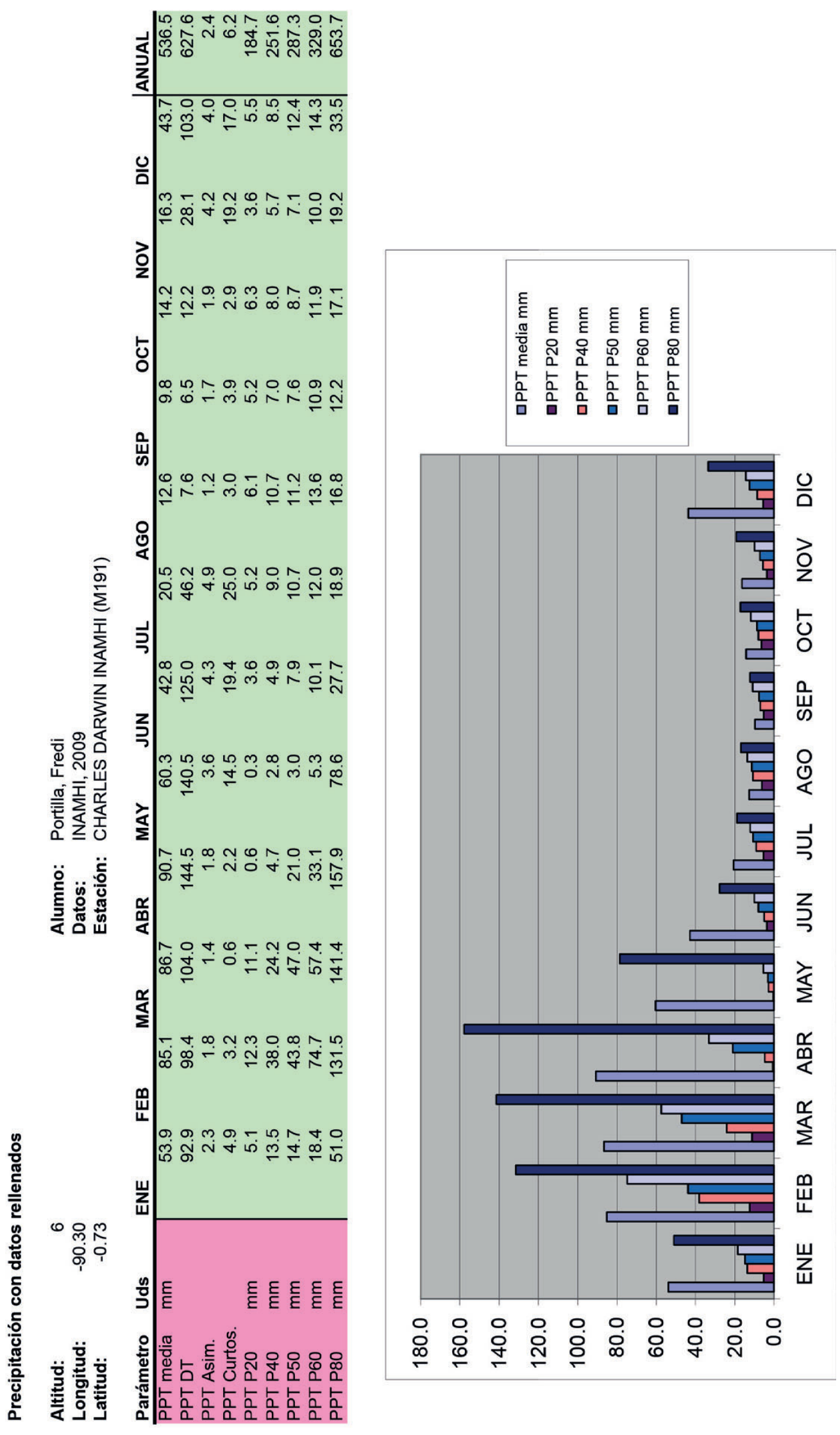

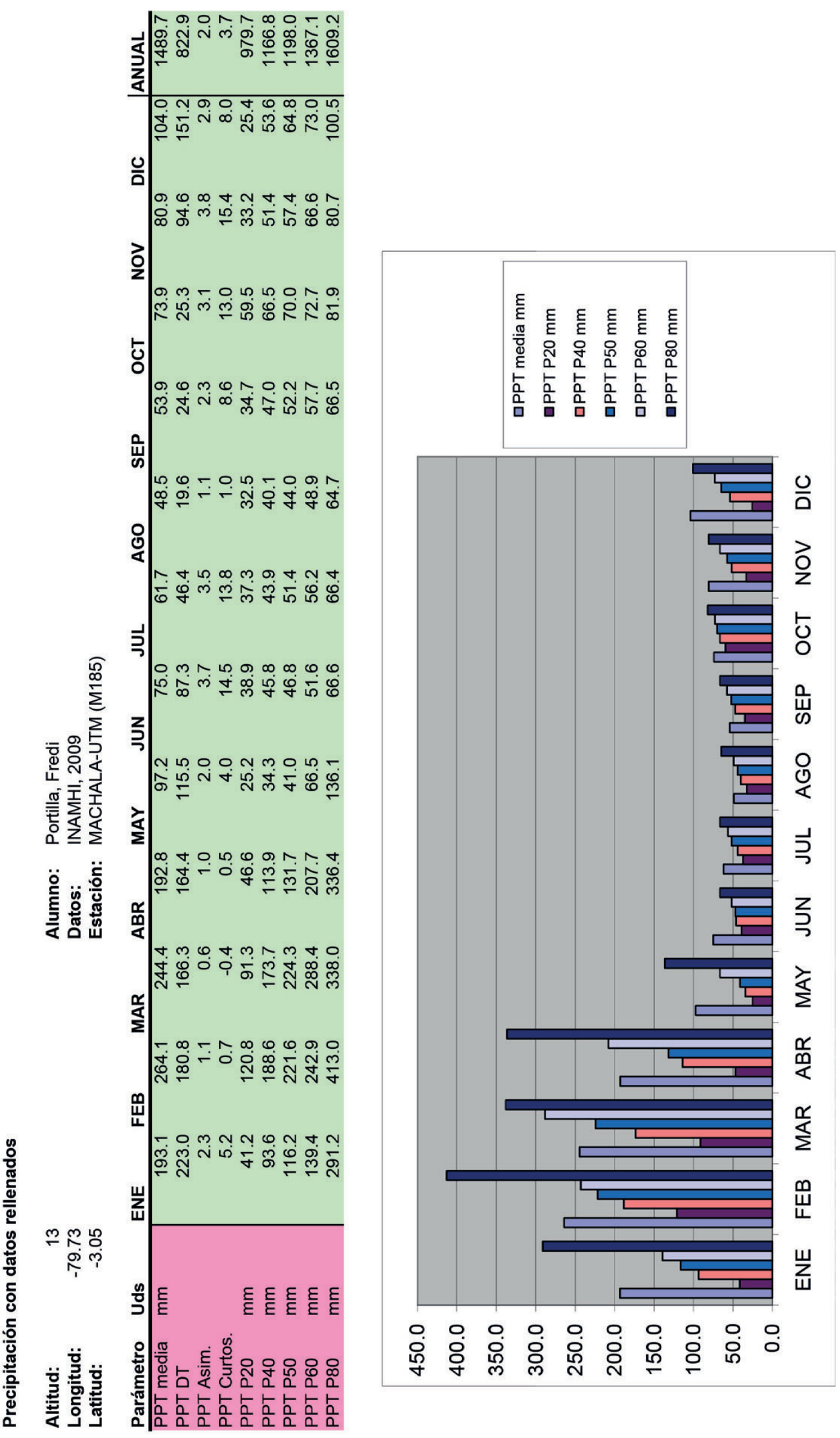


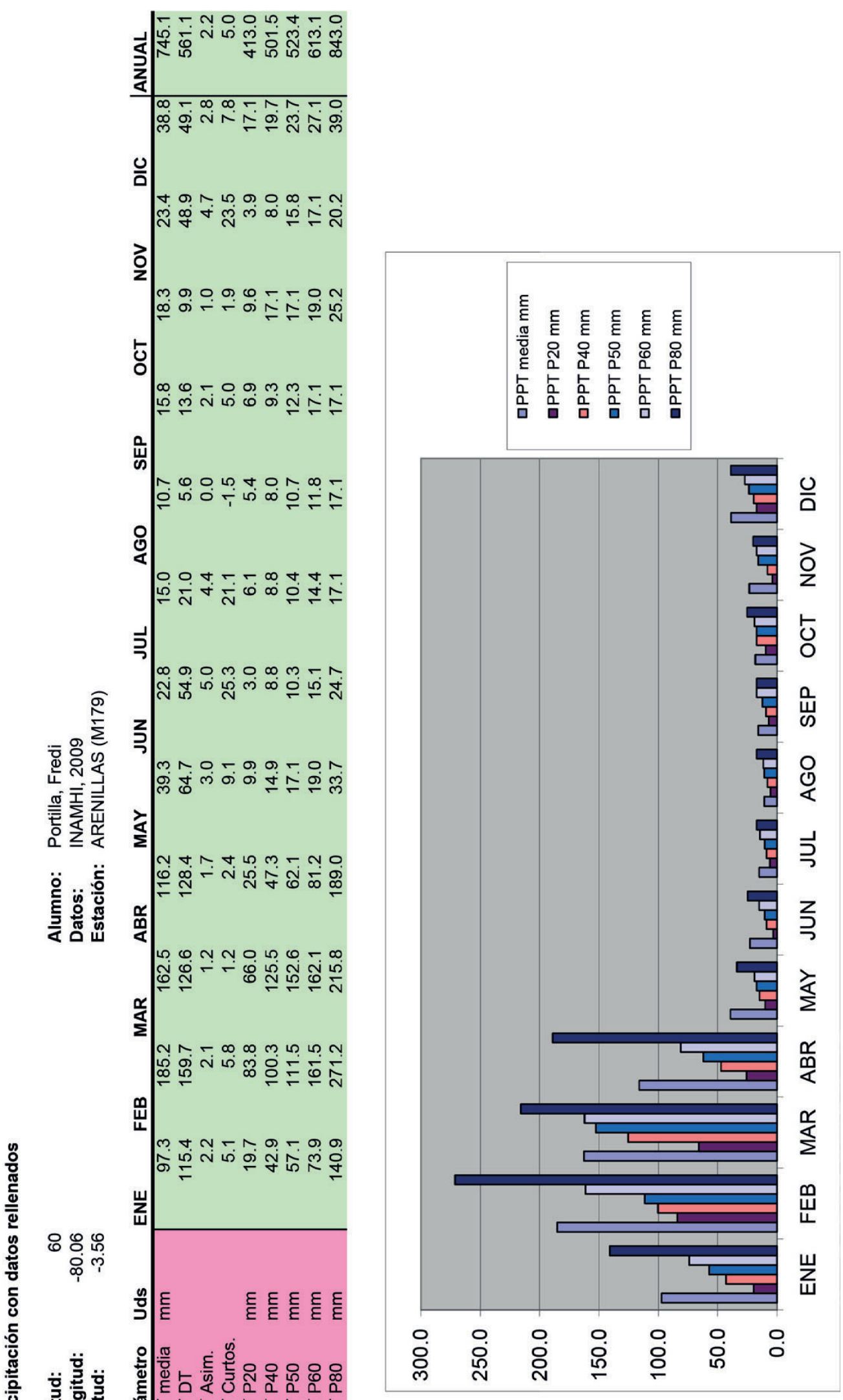




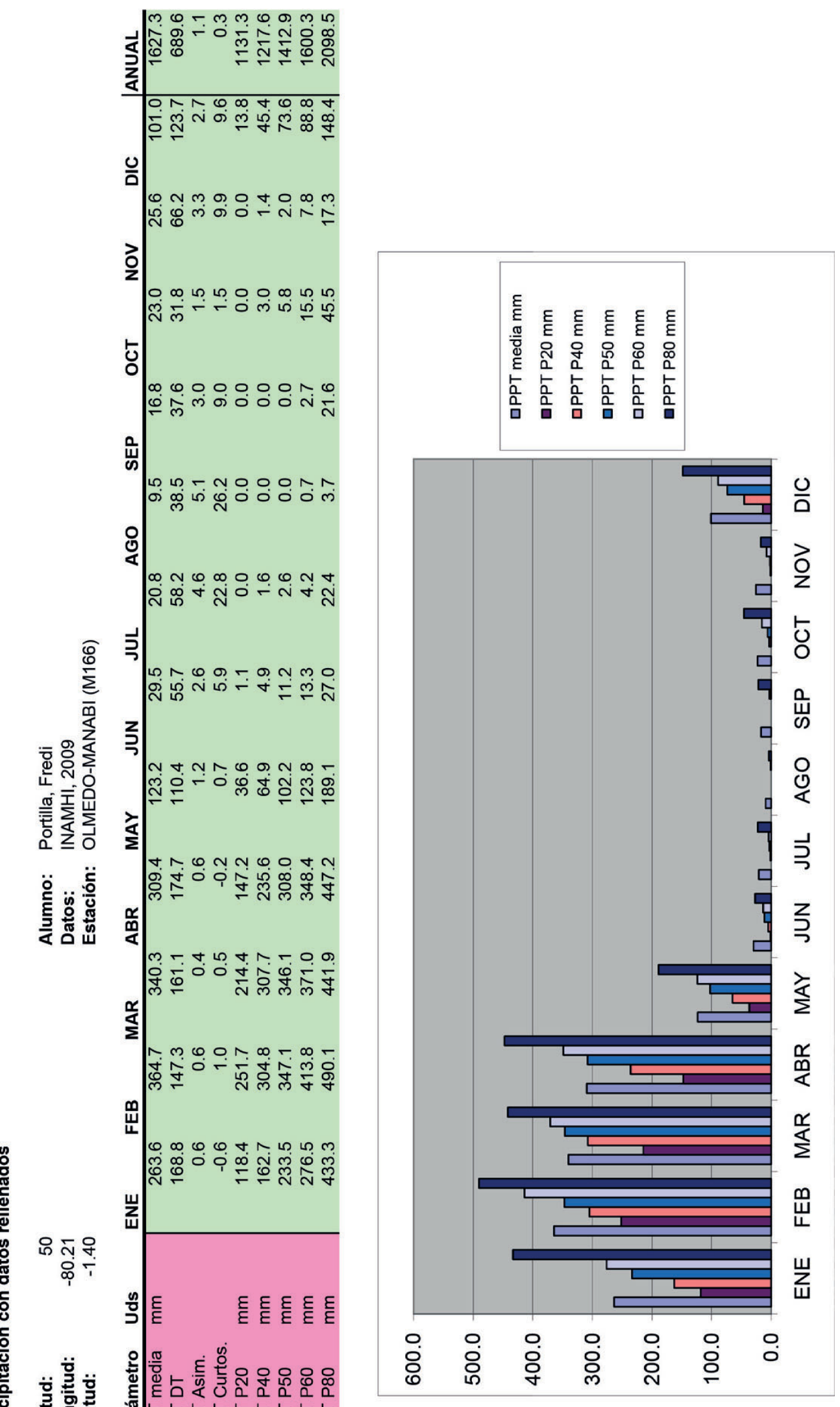



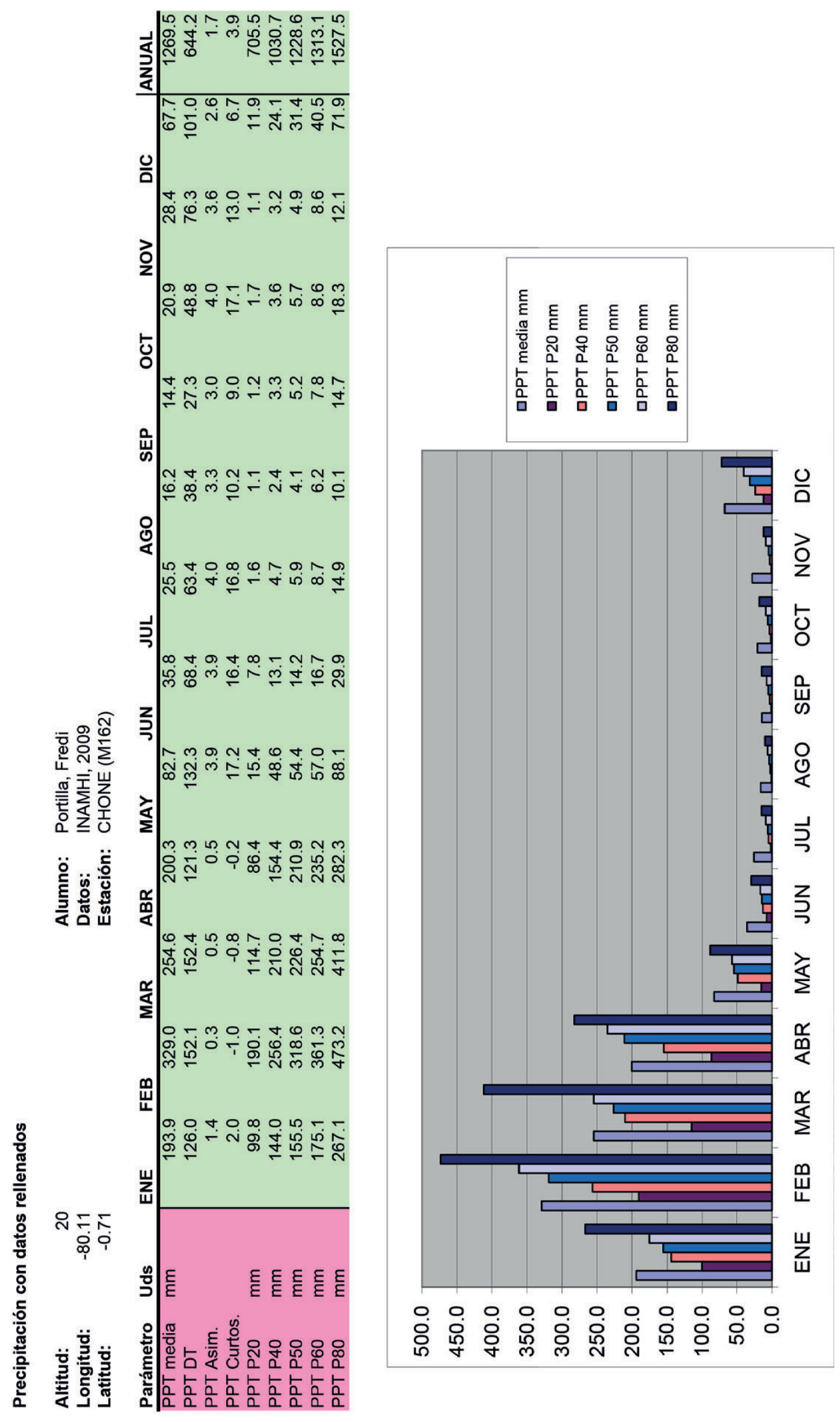


\section{1}
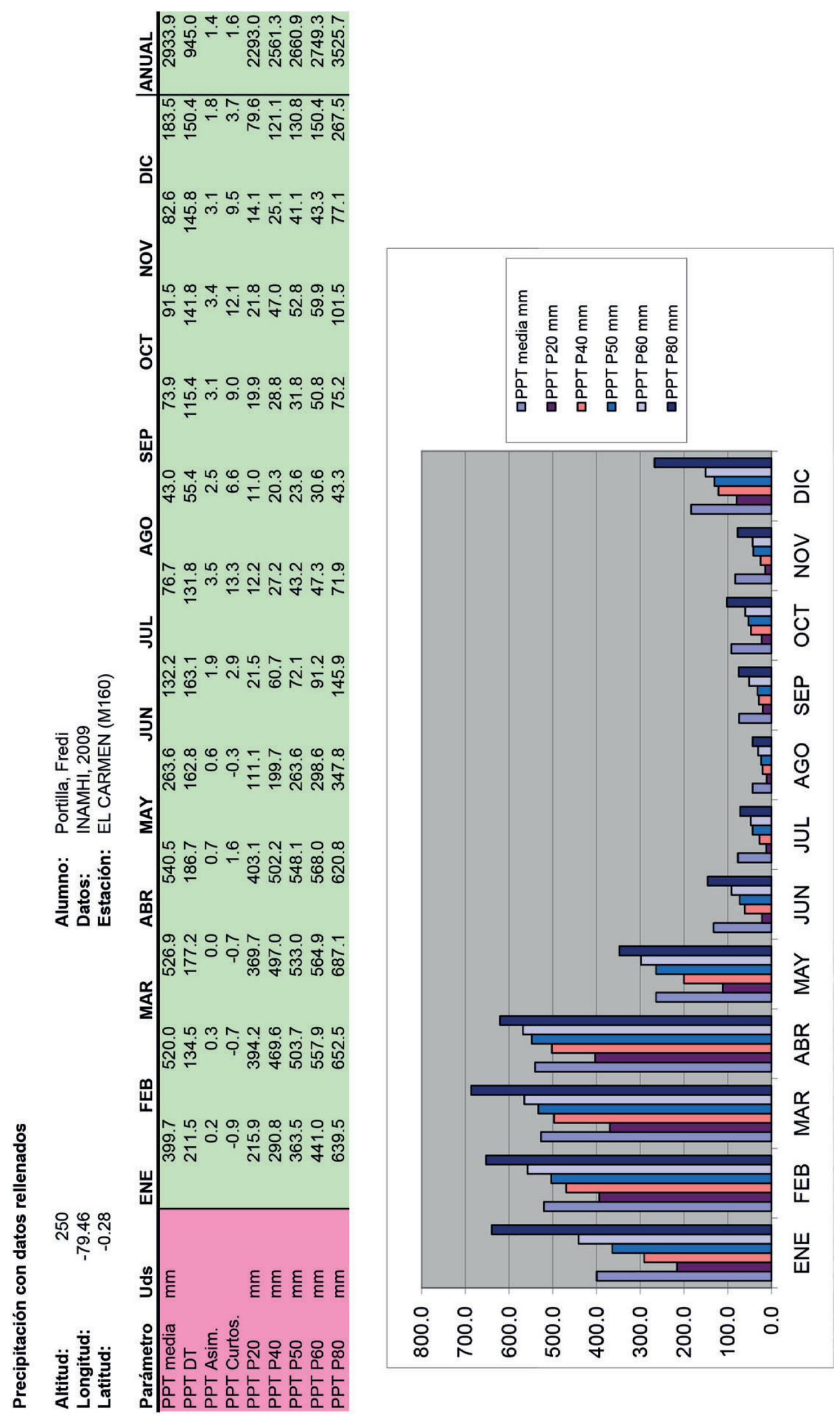

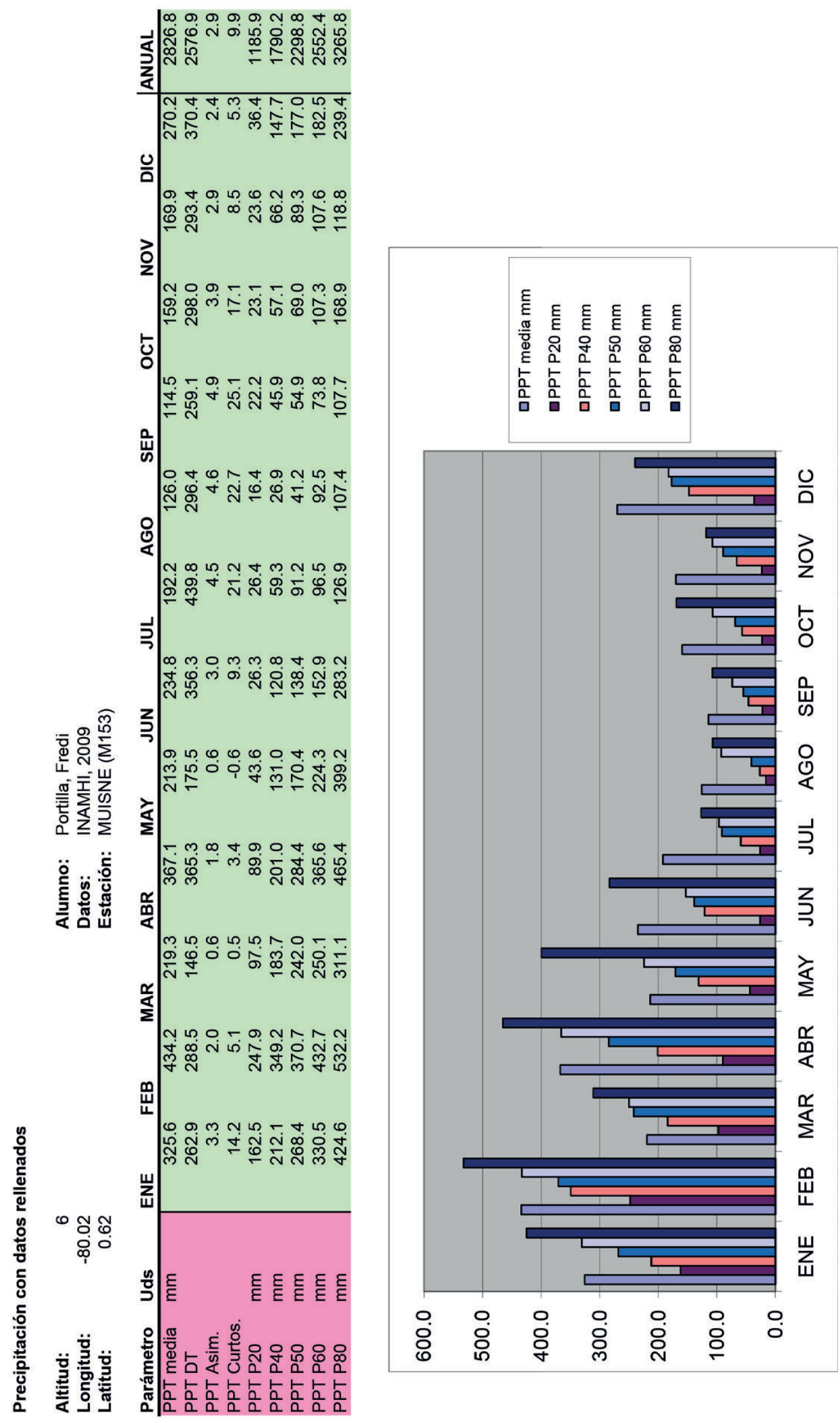


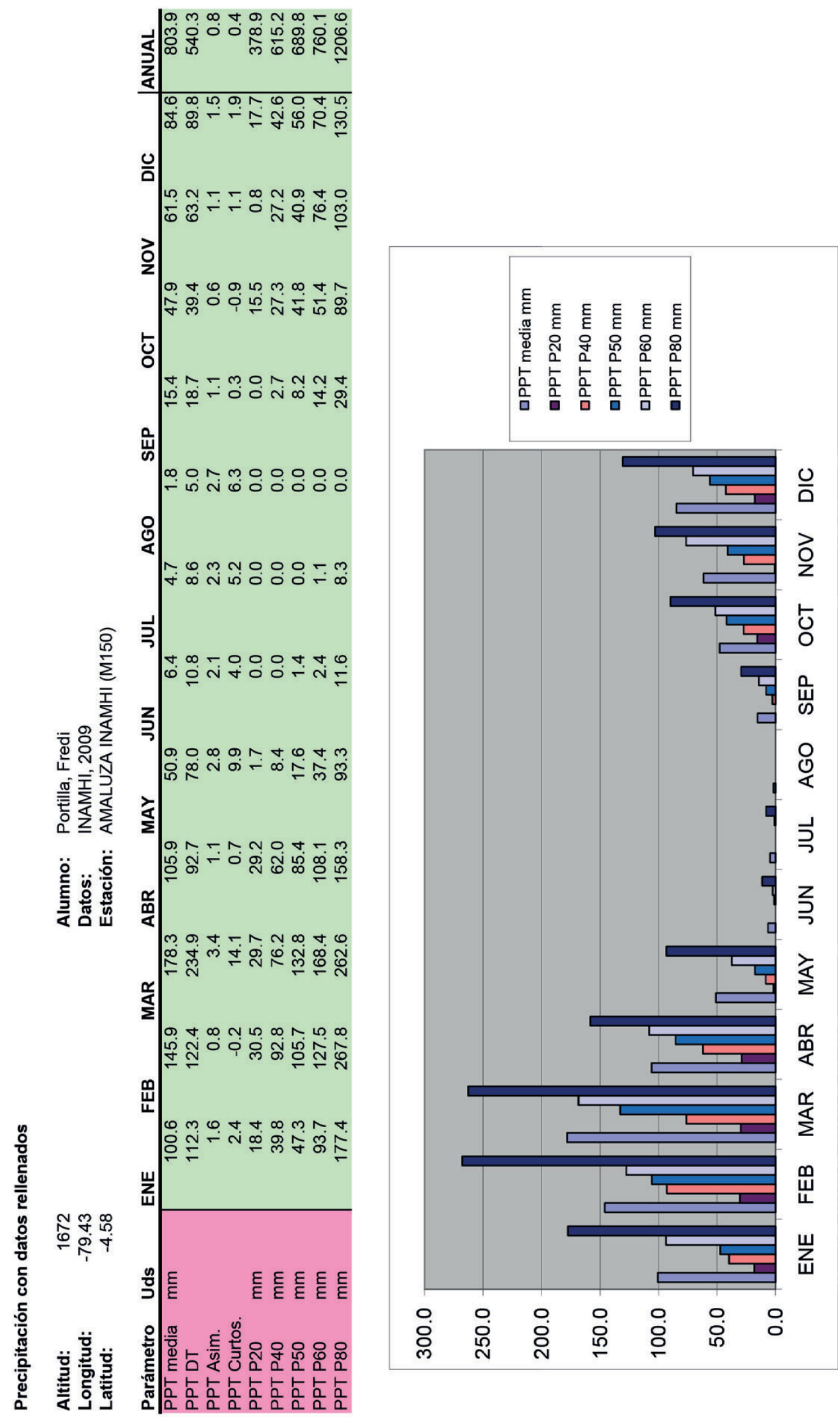



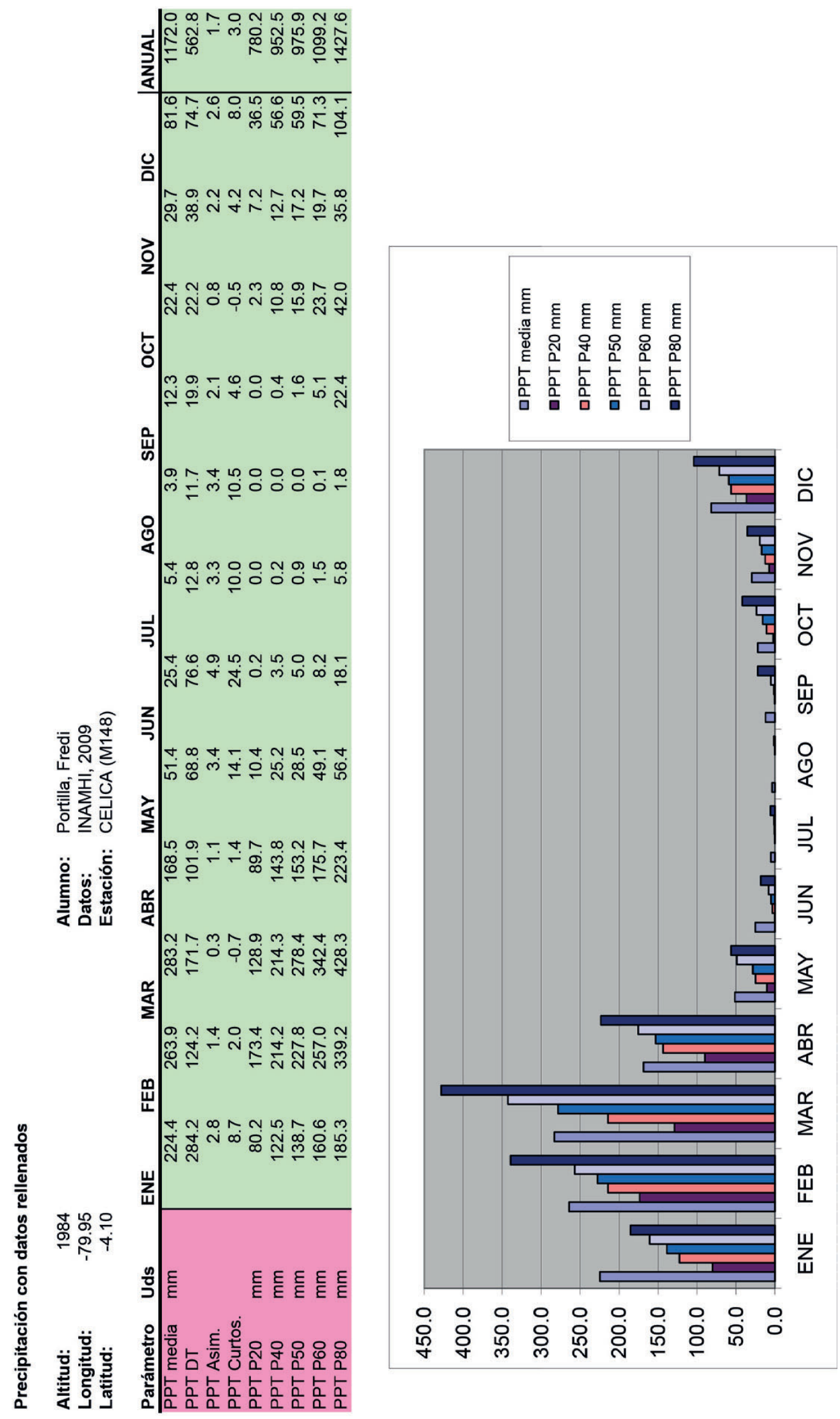

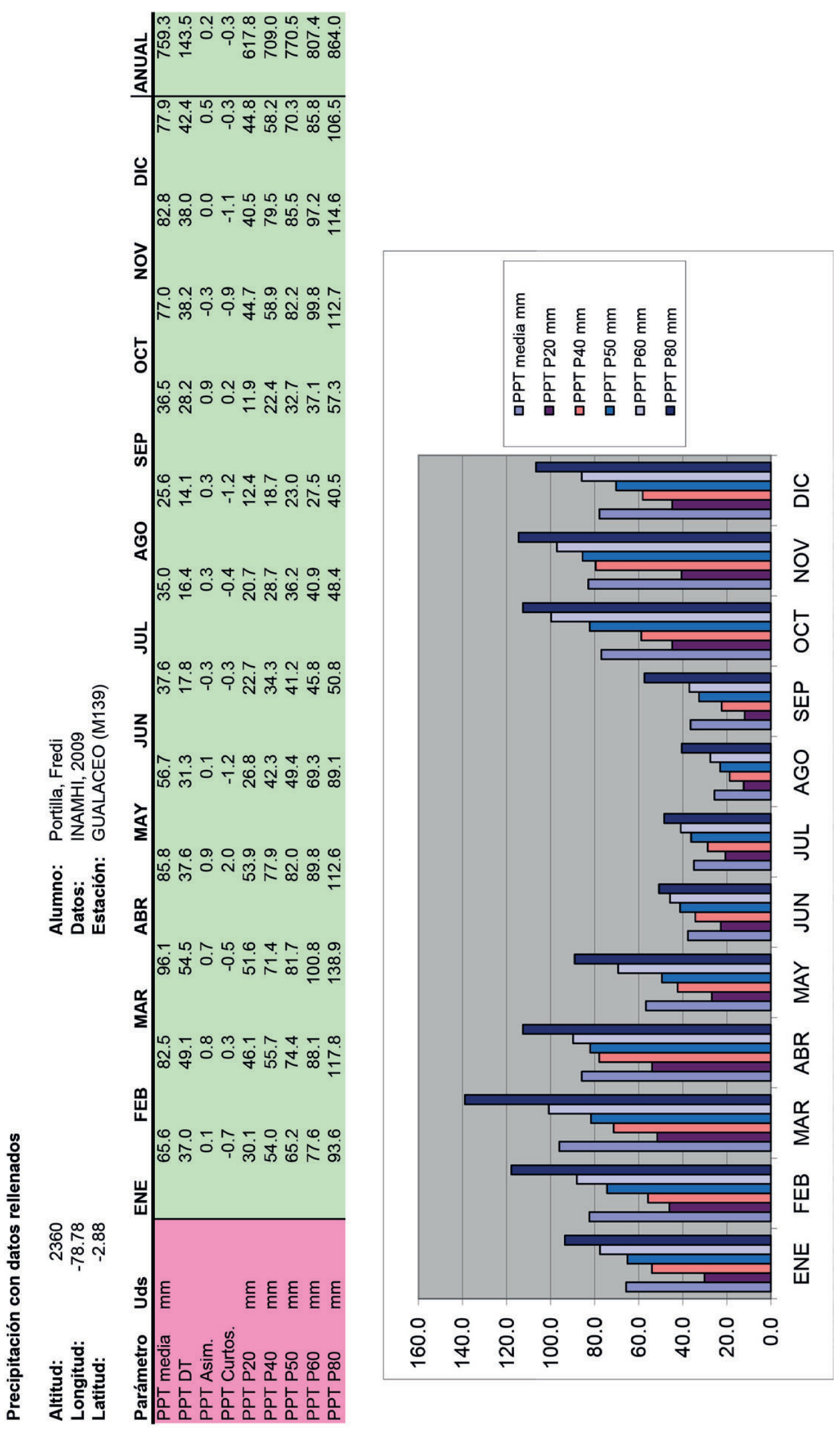

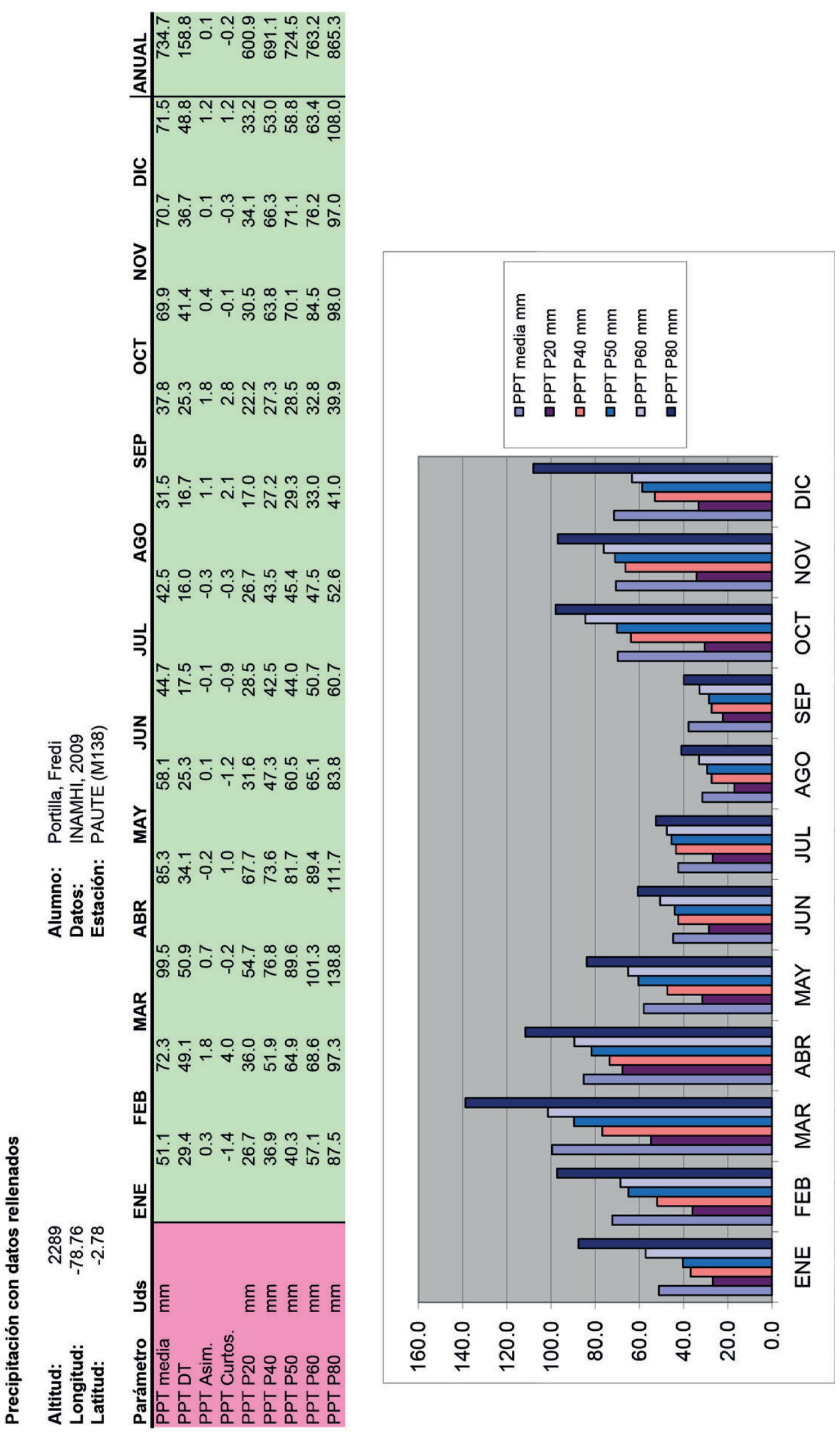


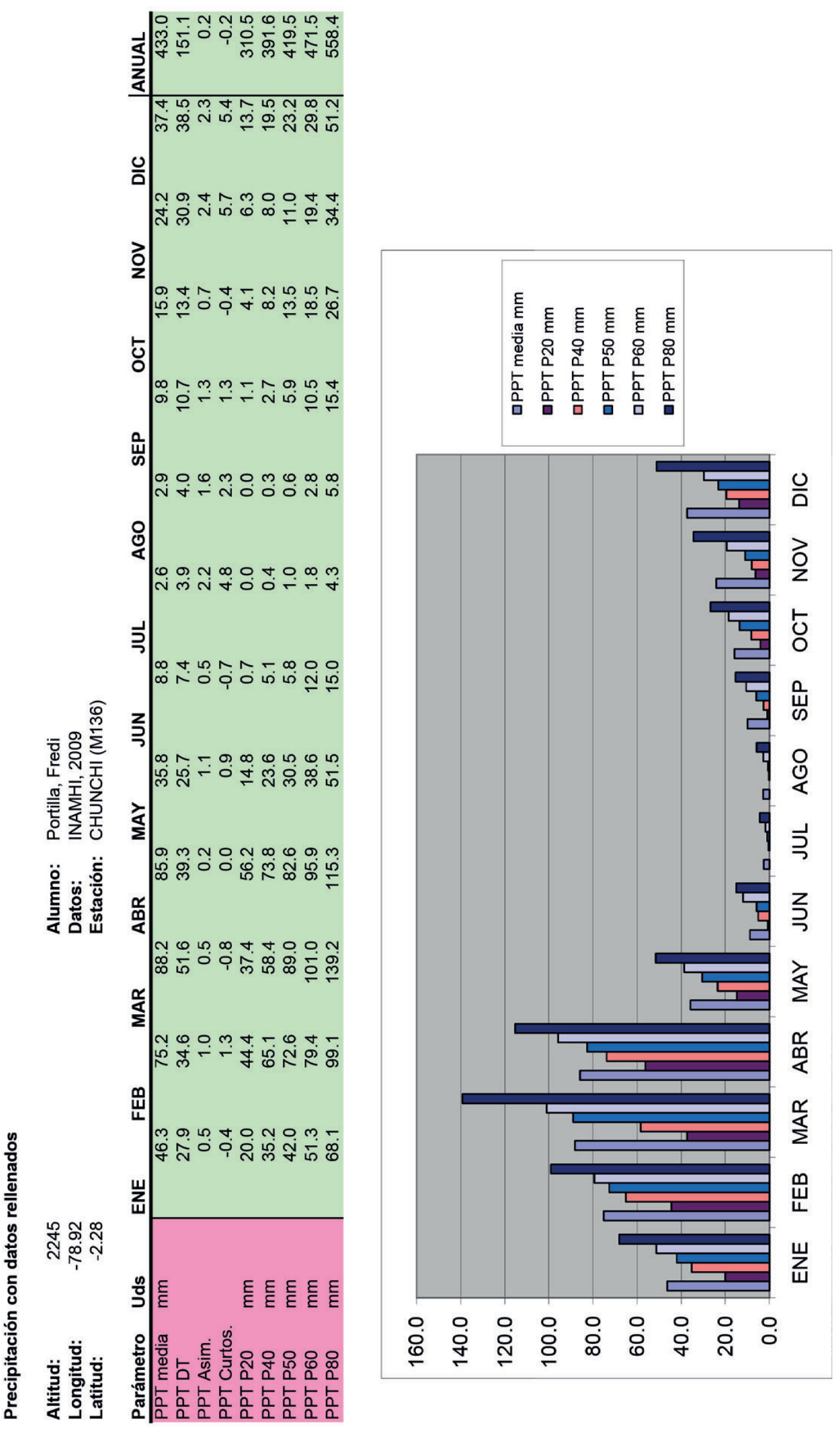




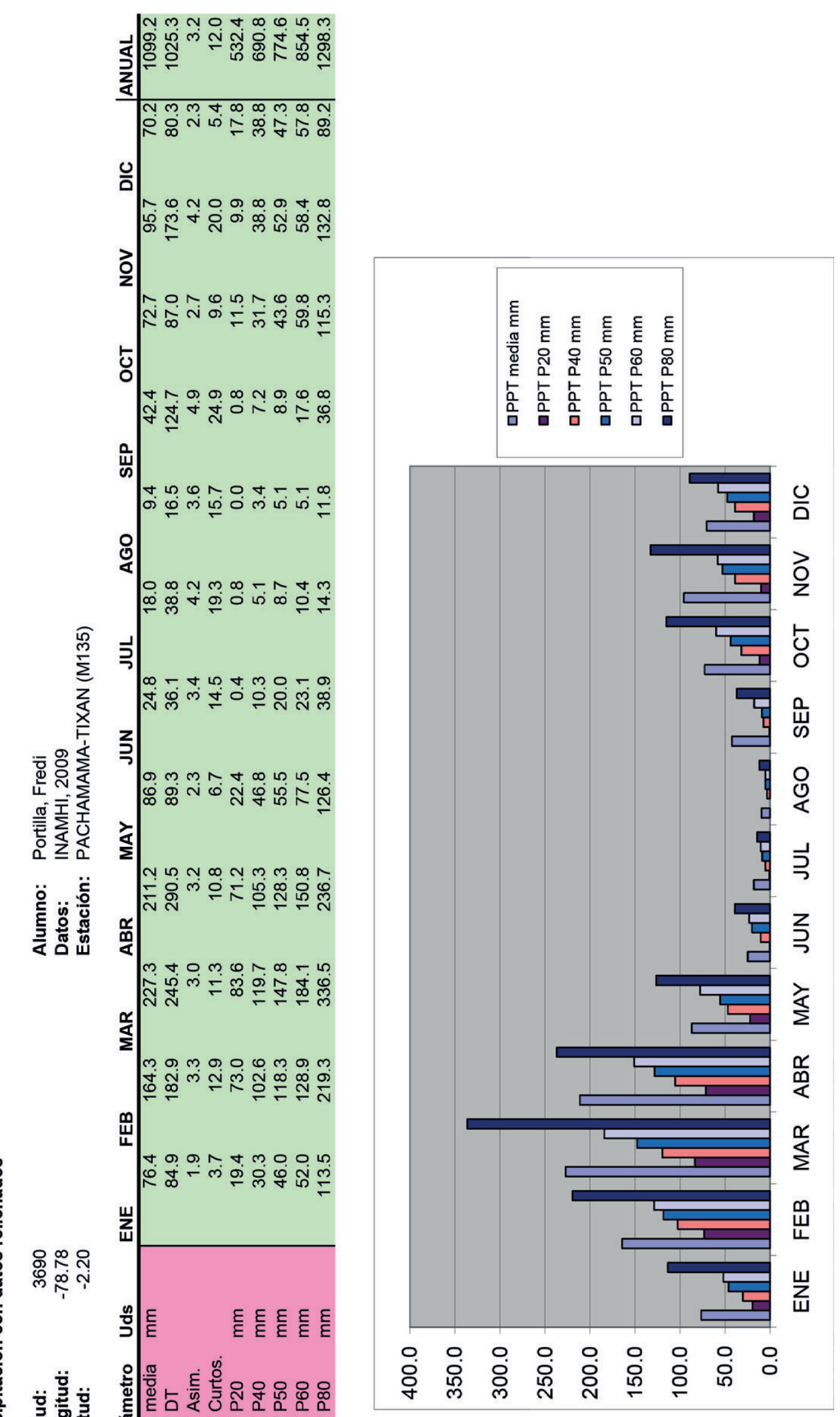



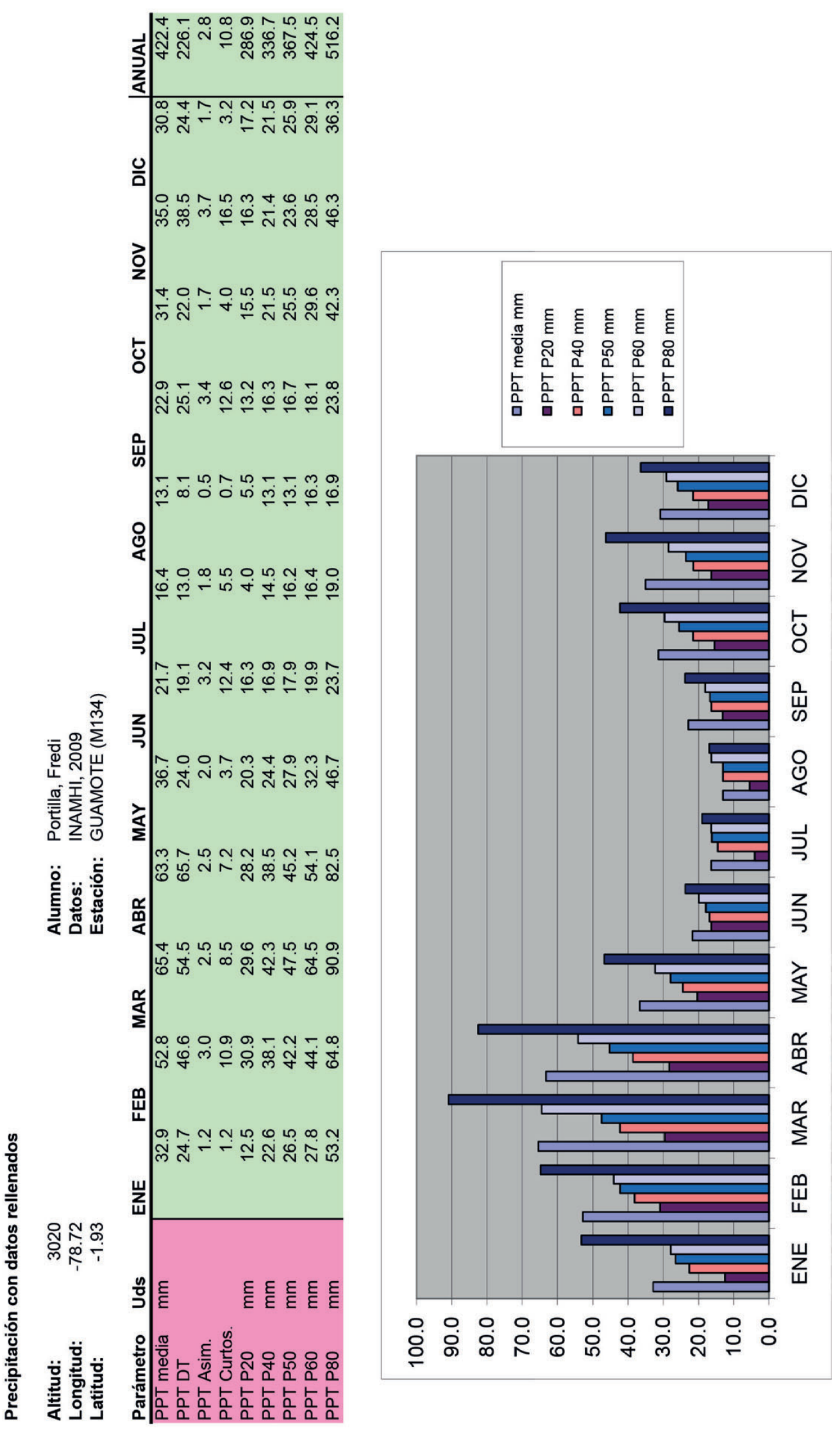

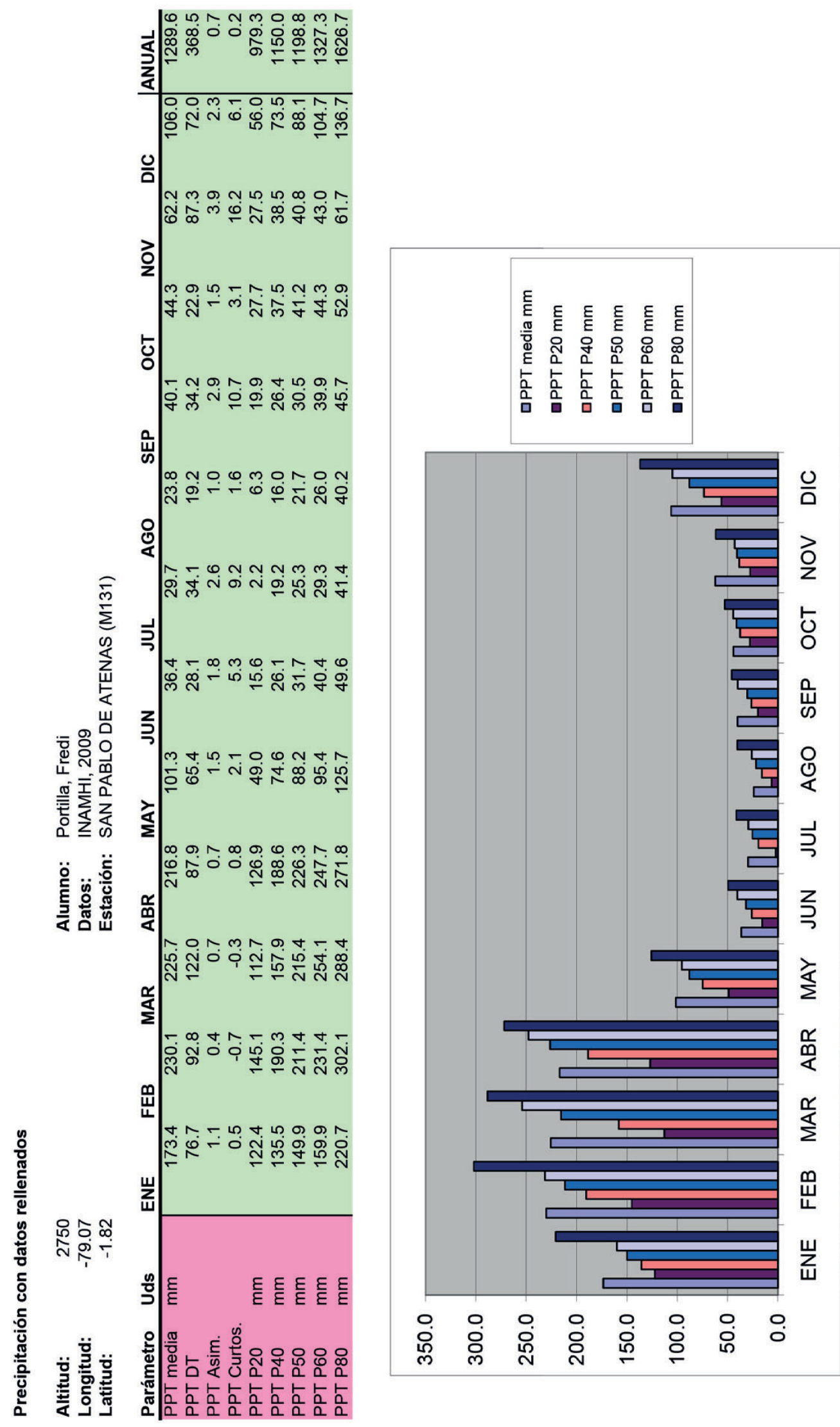


\section{1}
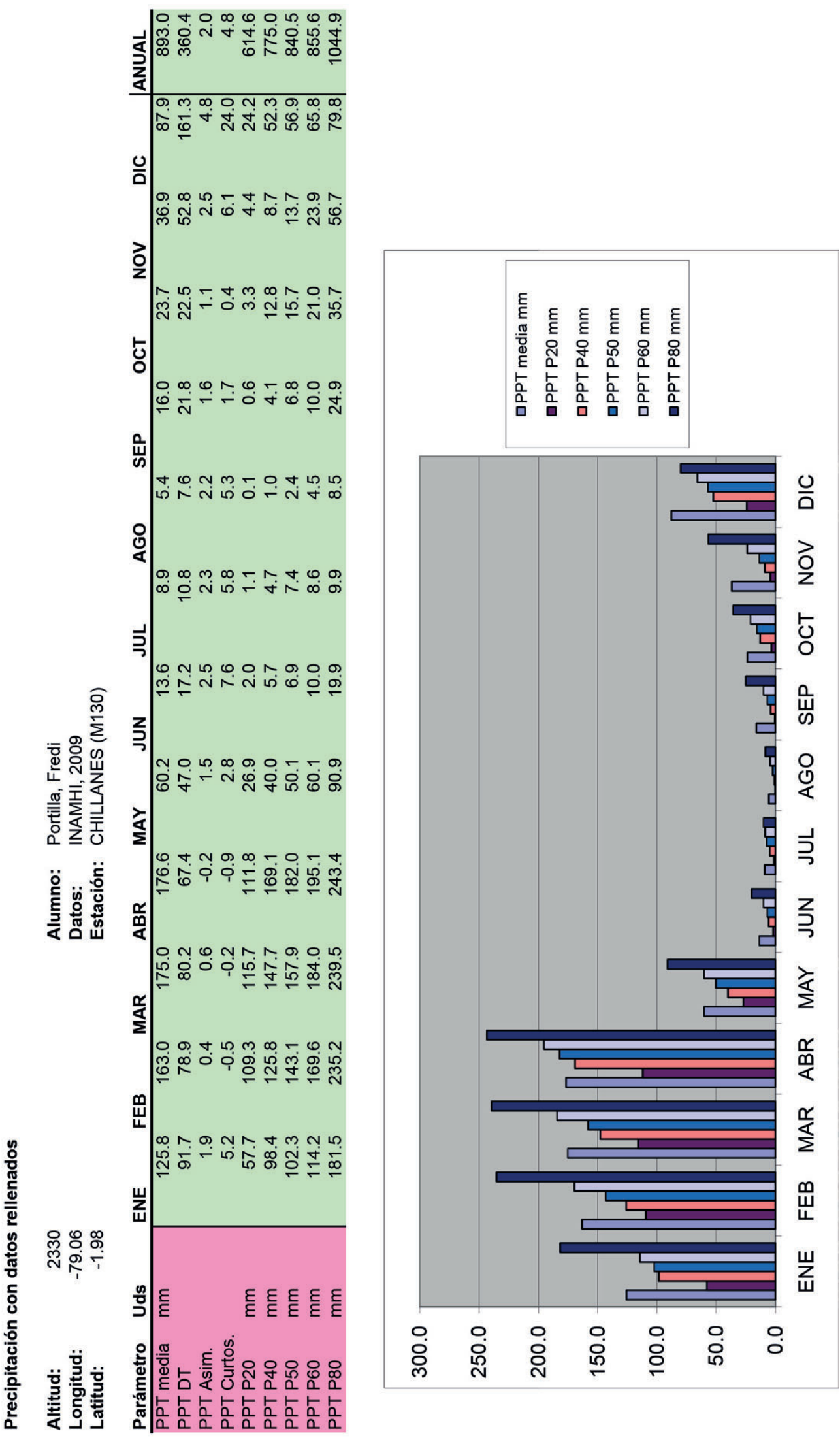


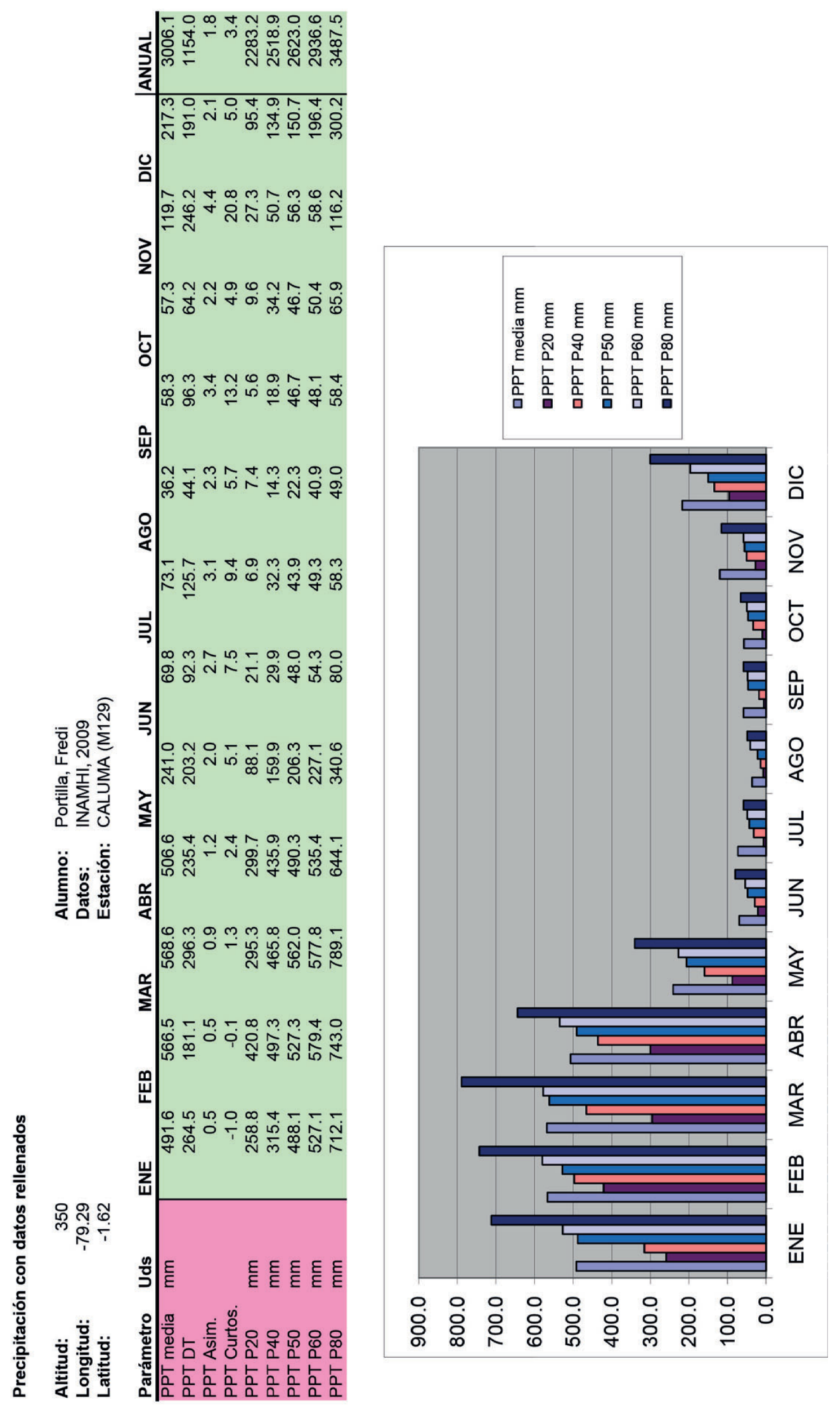



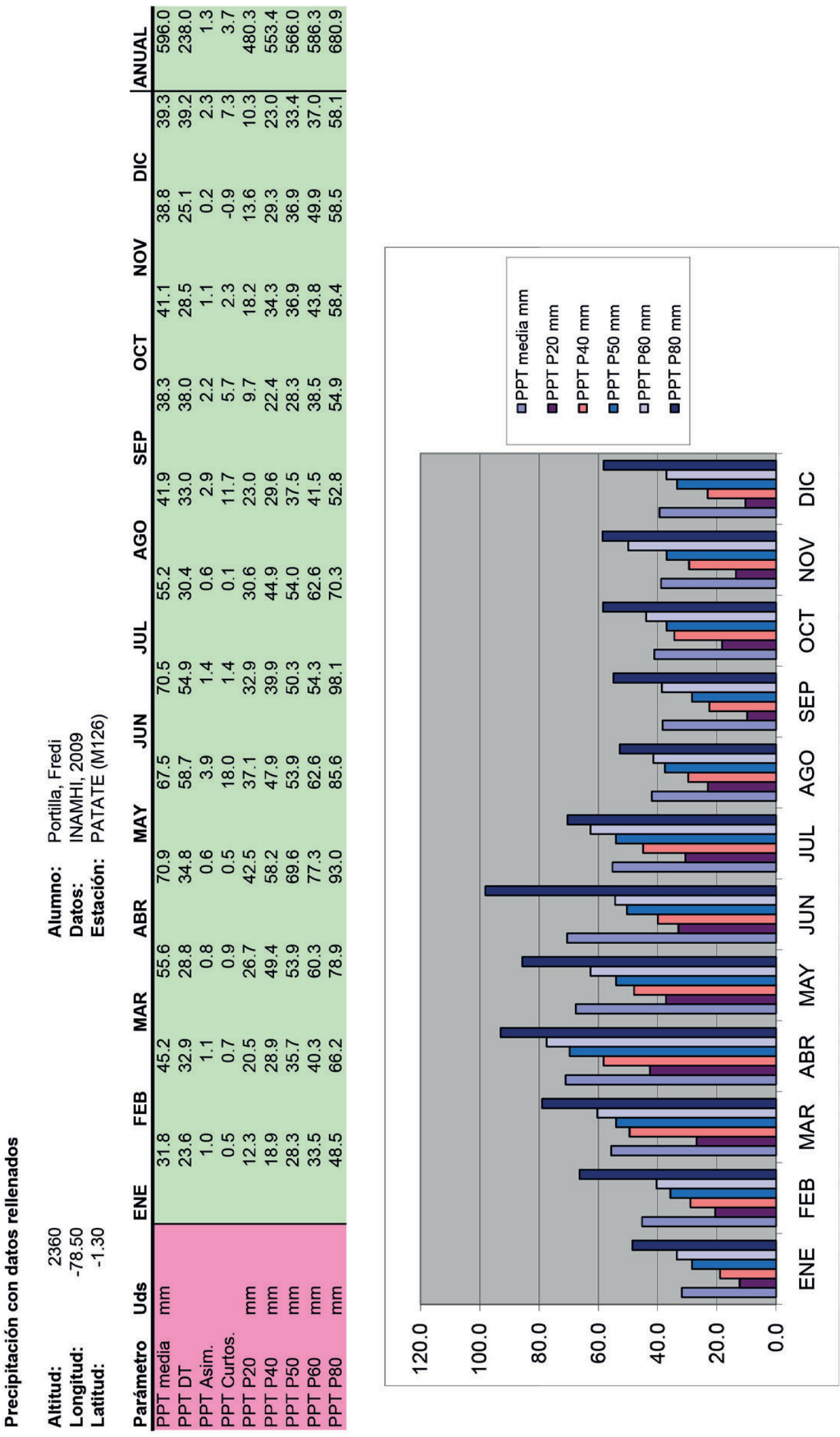

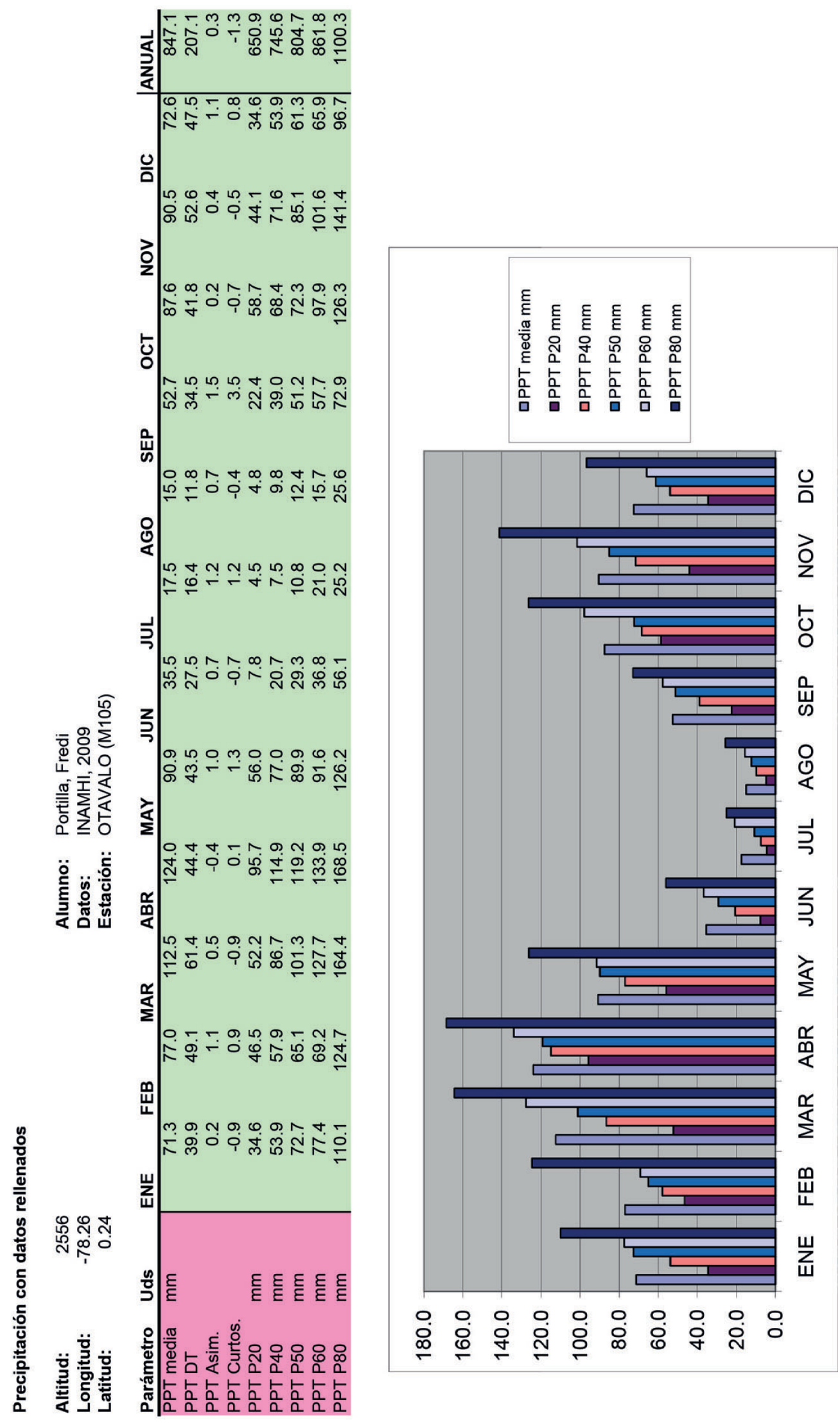

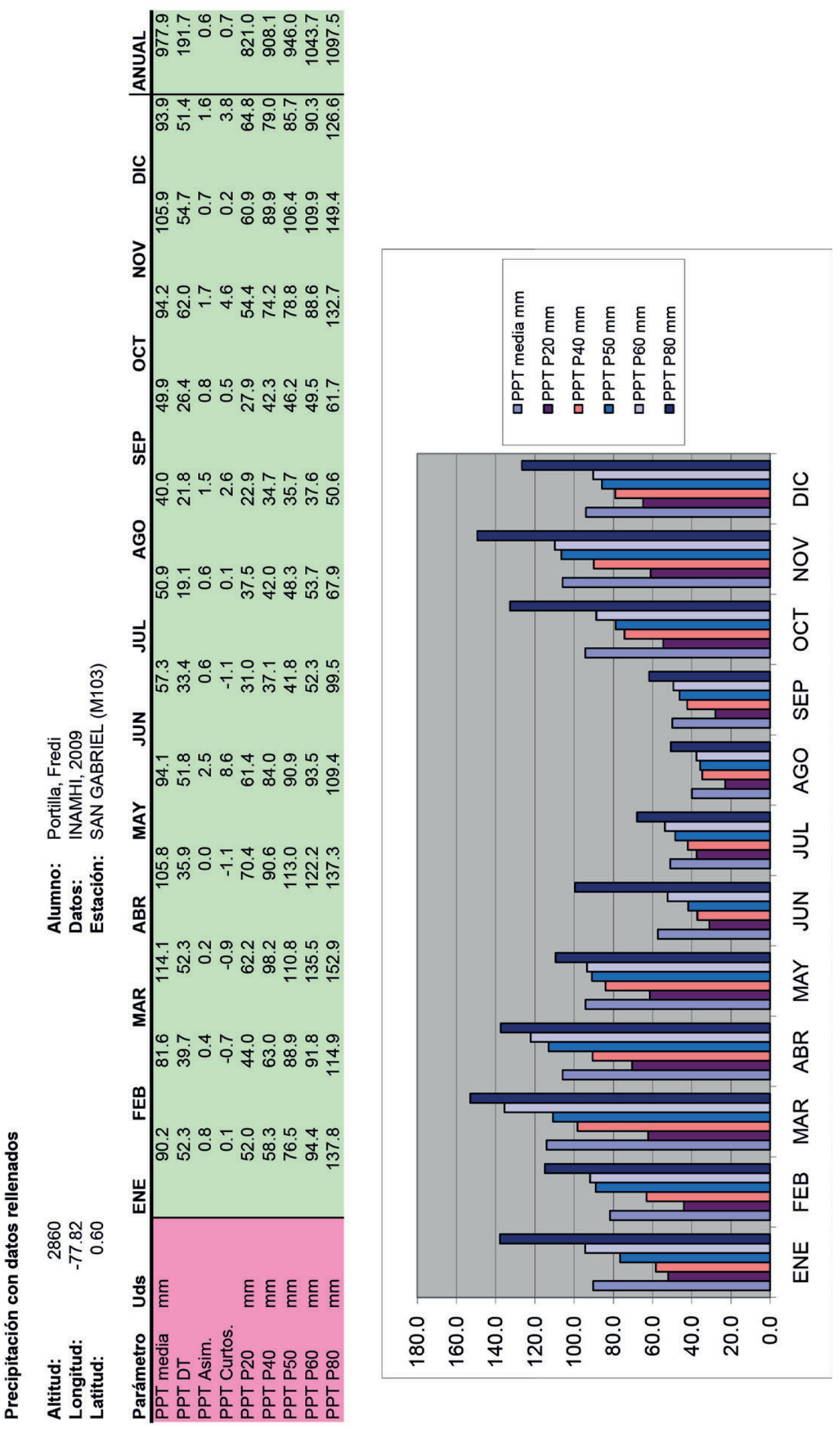


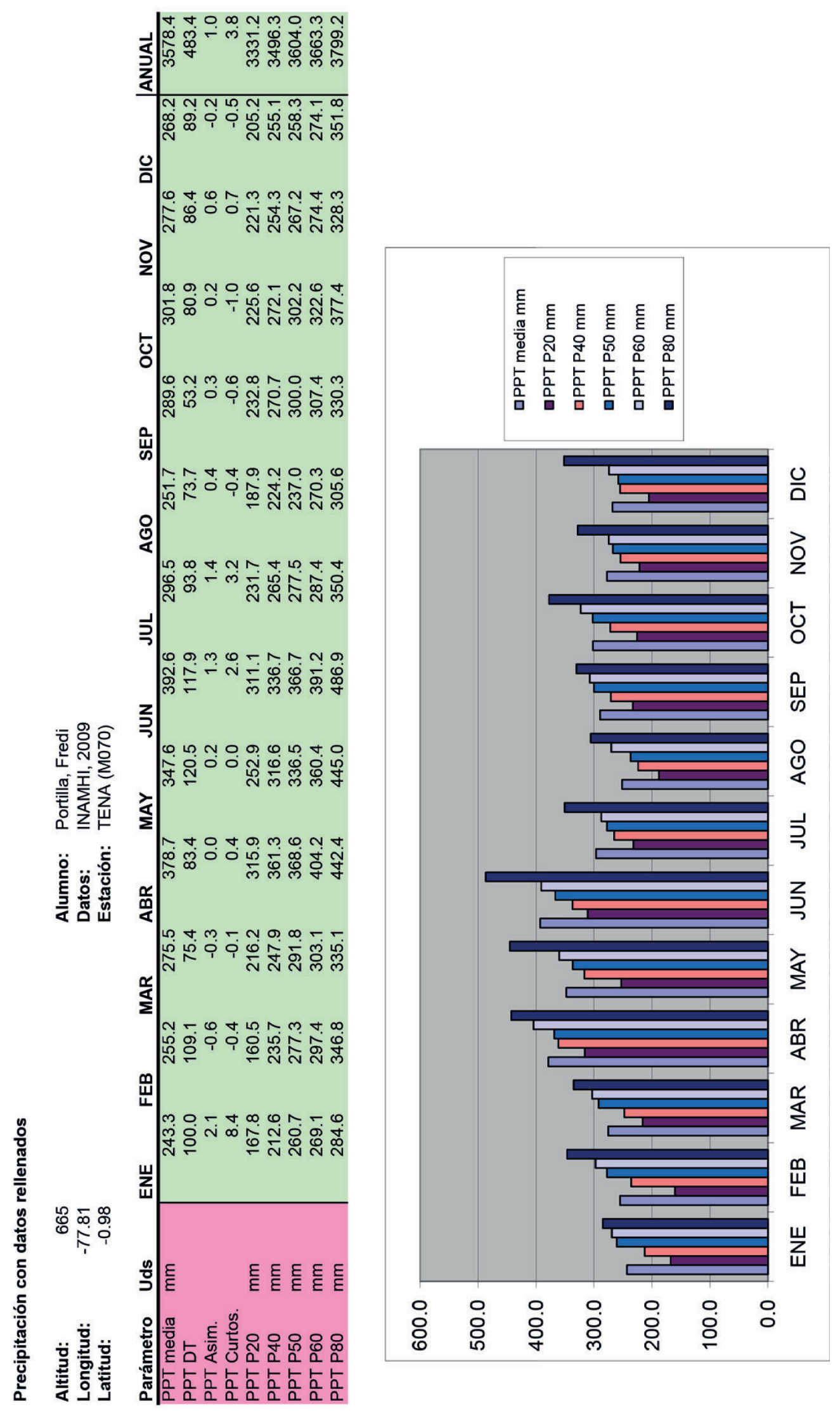



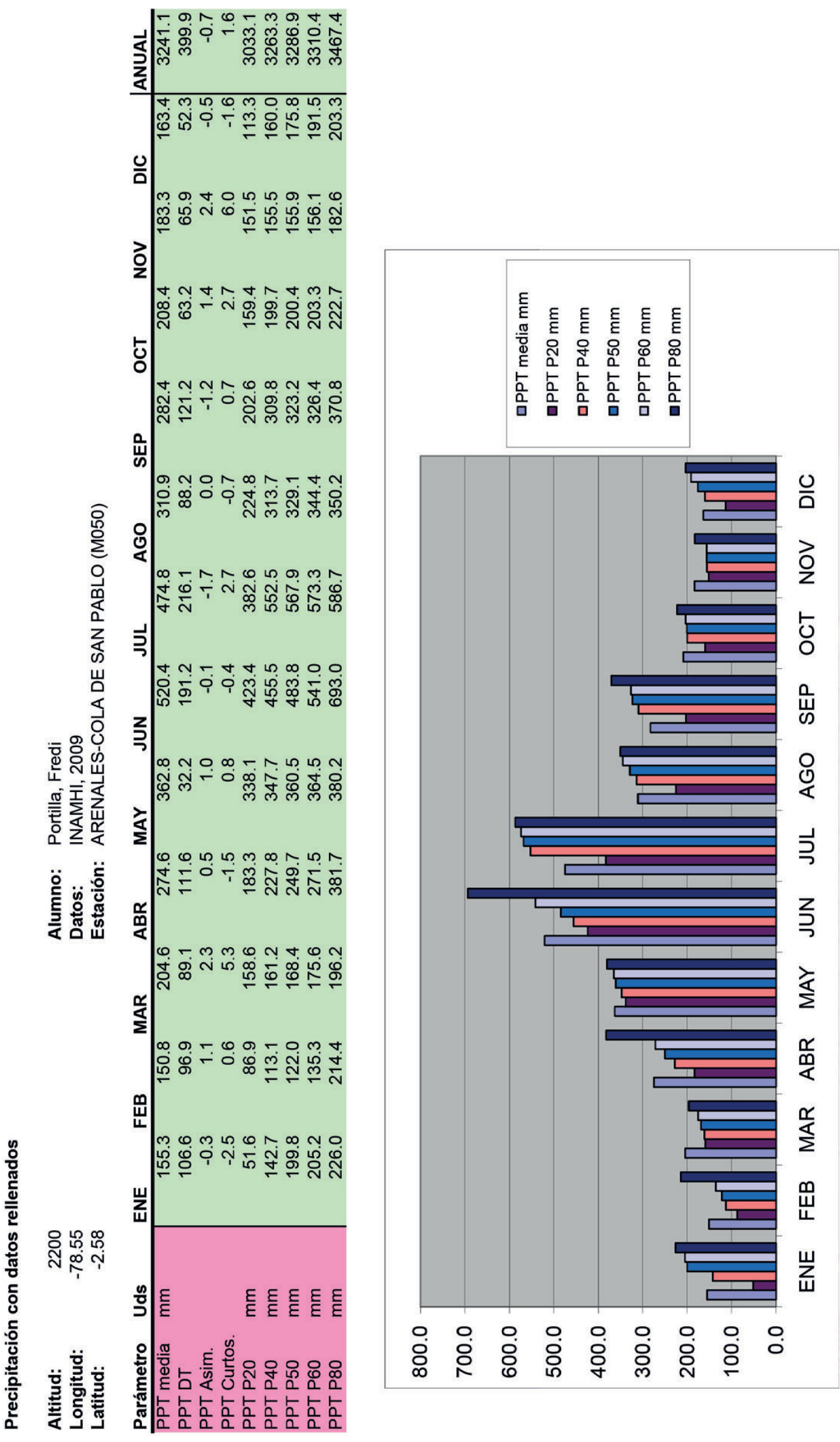


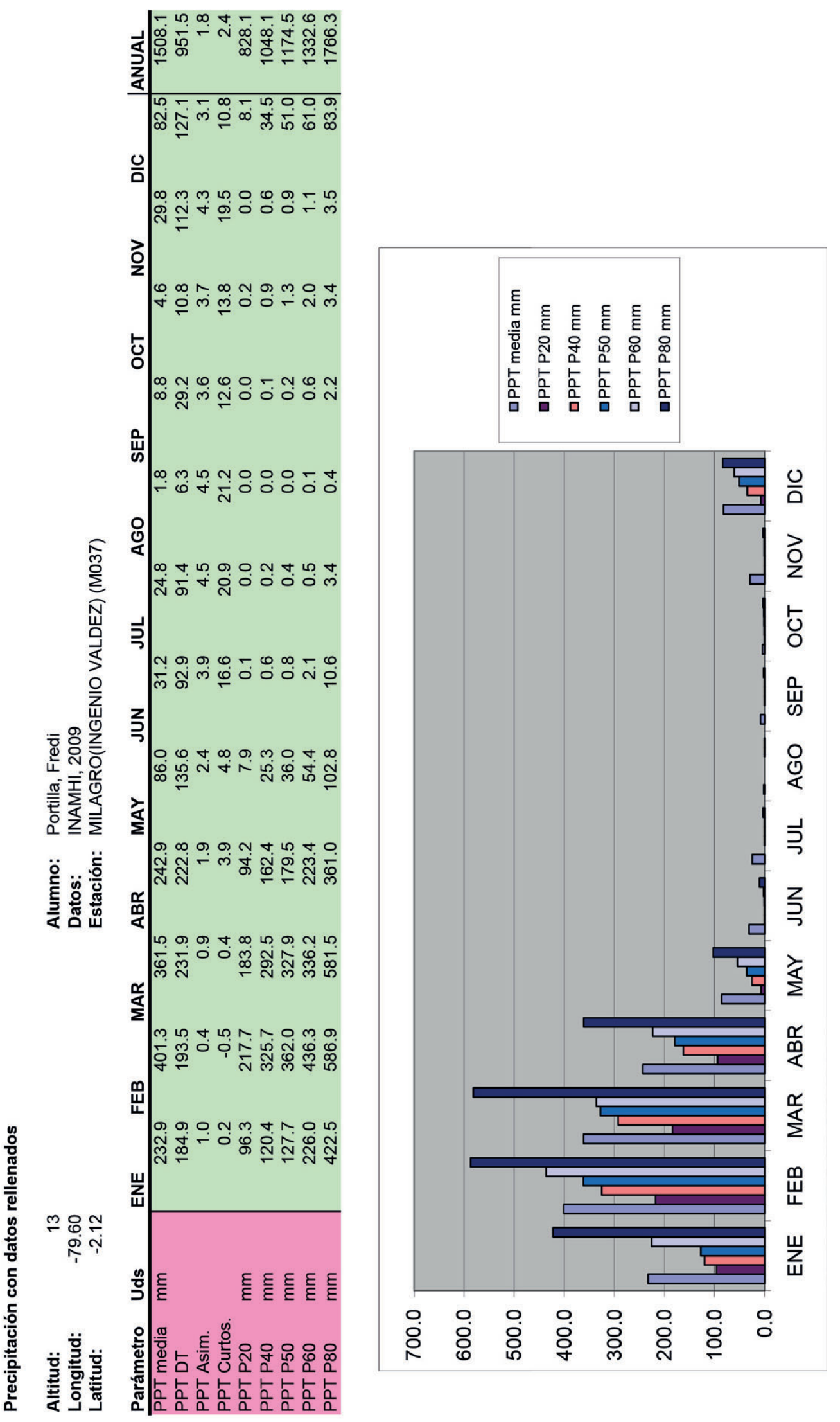



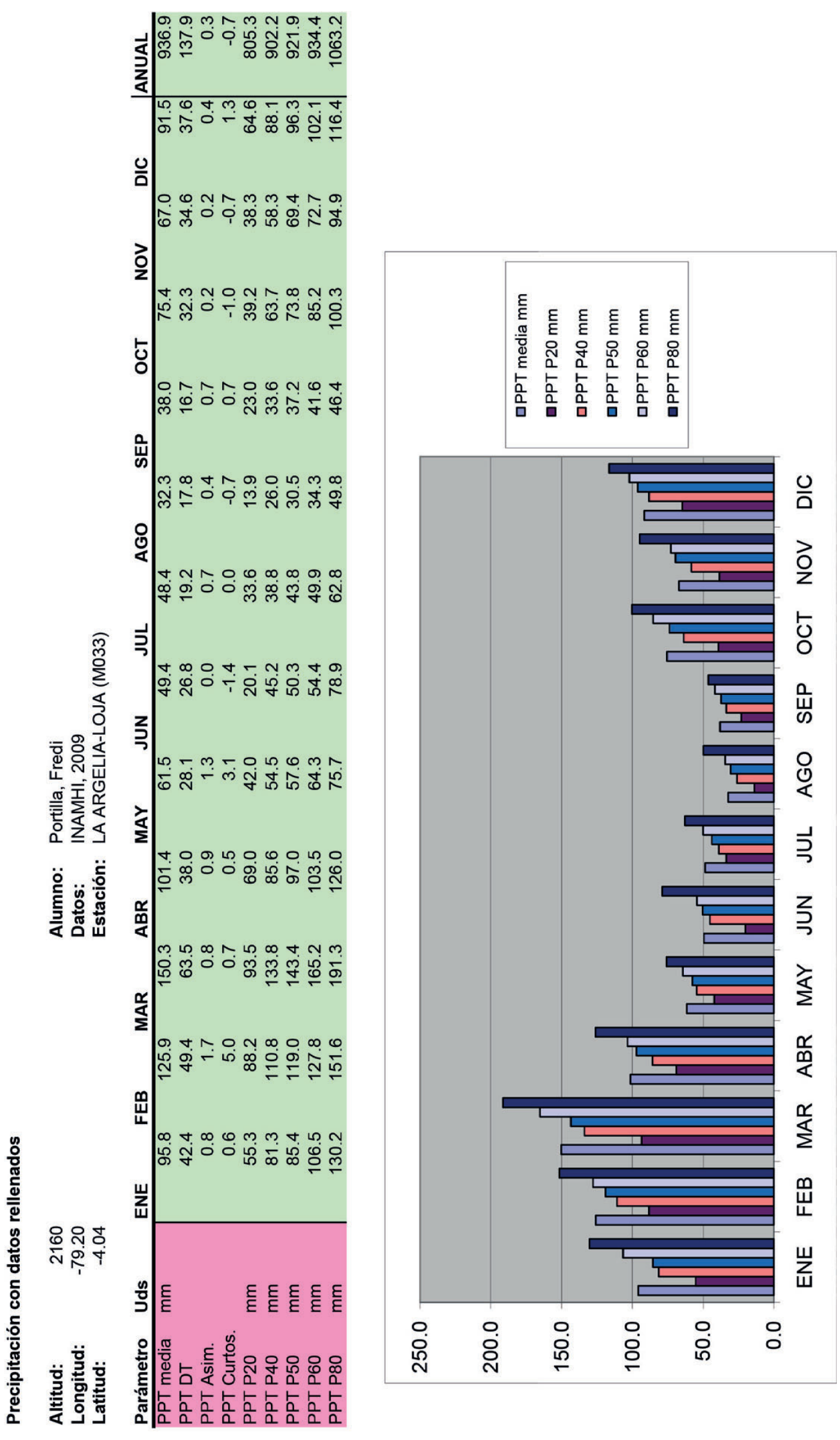

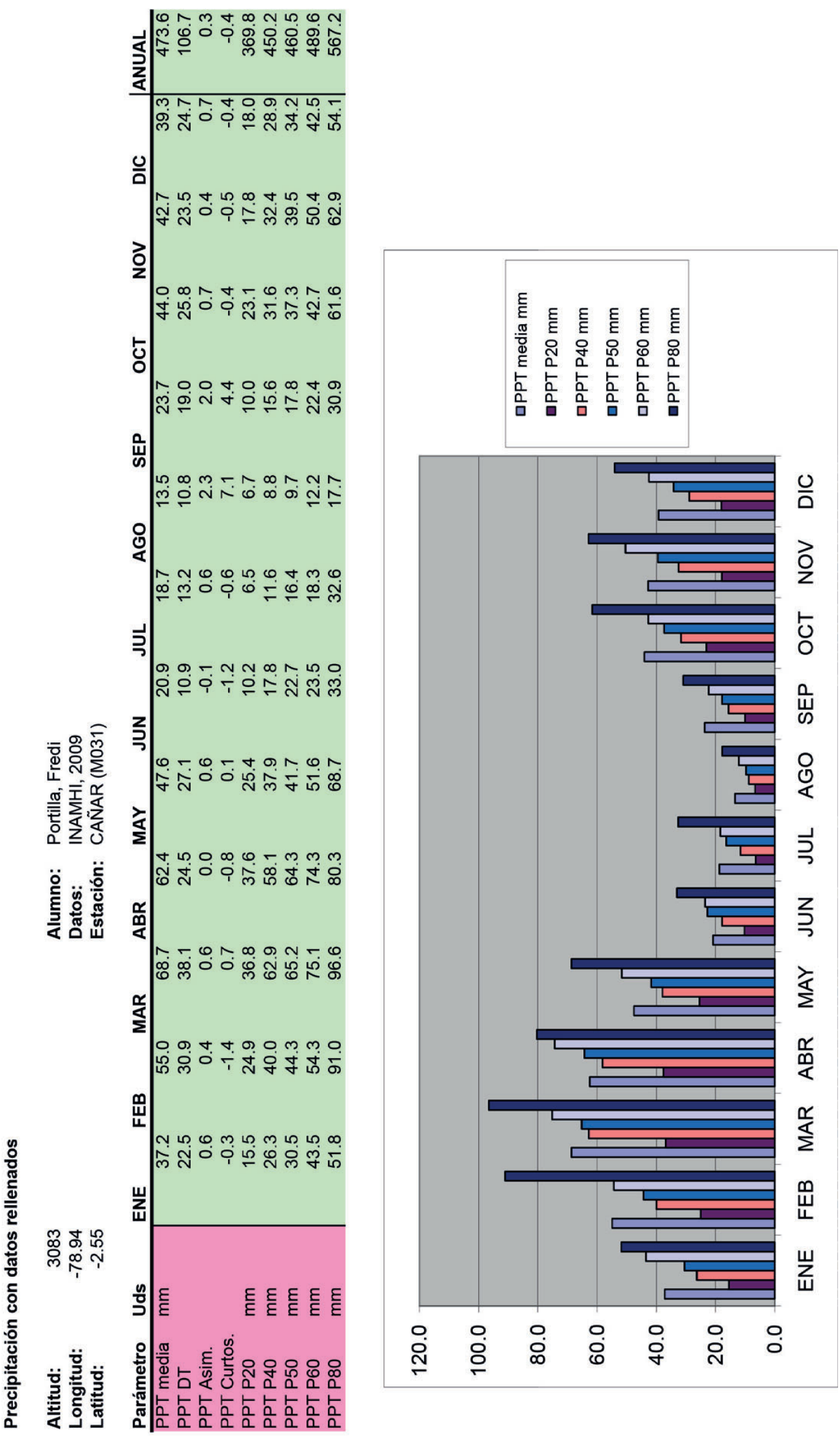


\section{1}
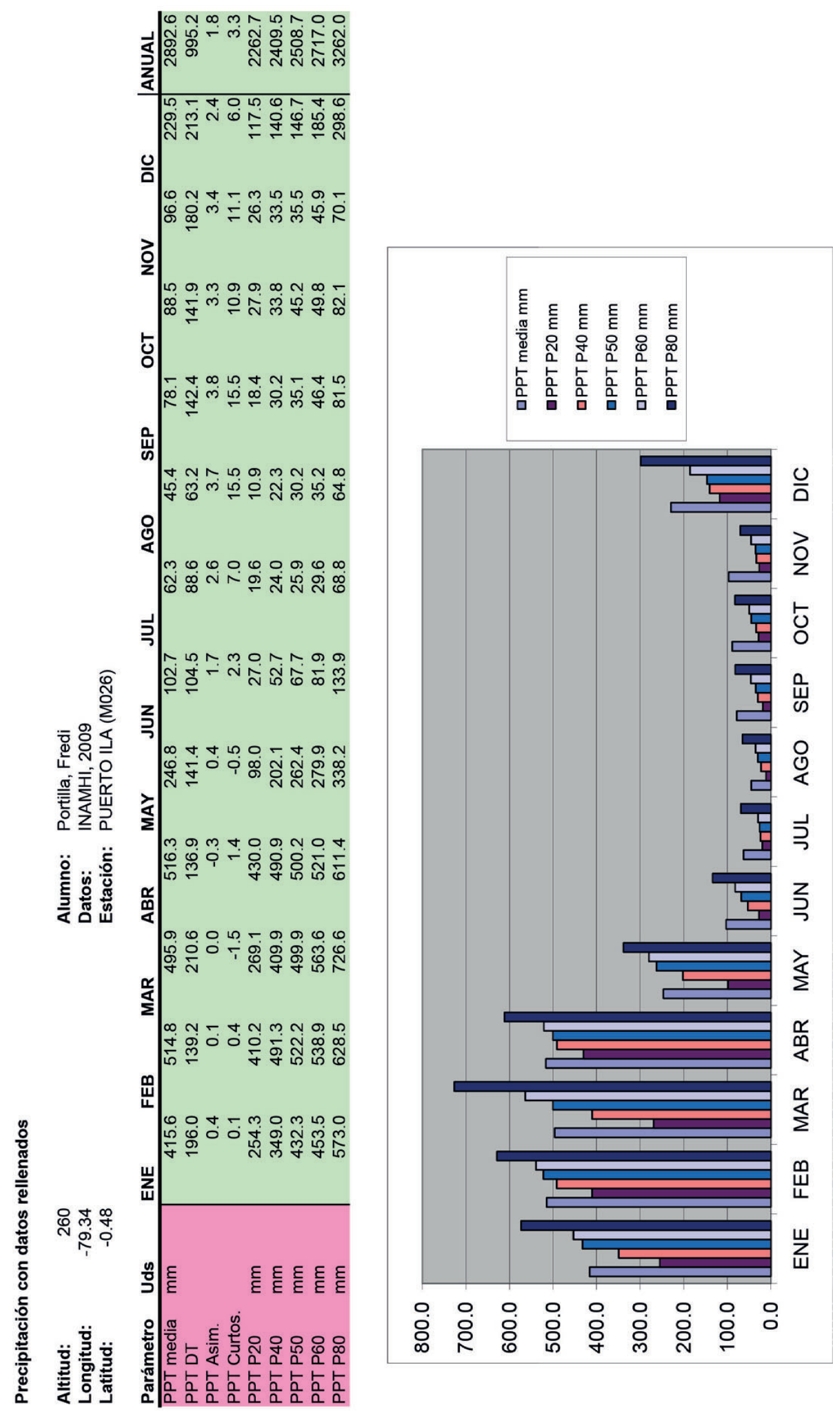
252

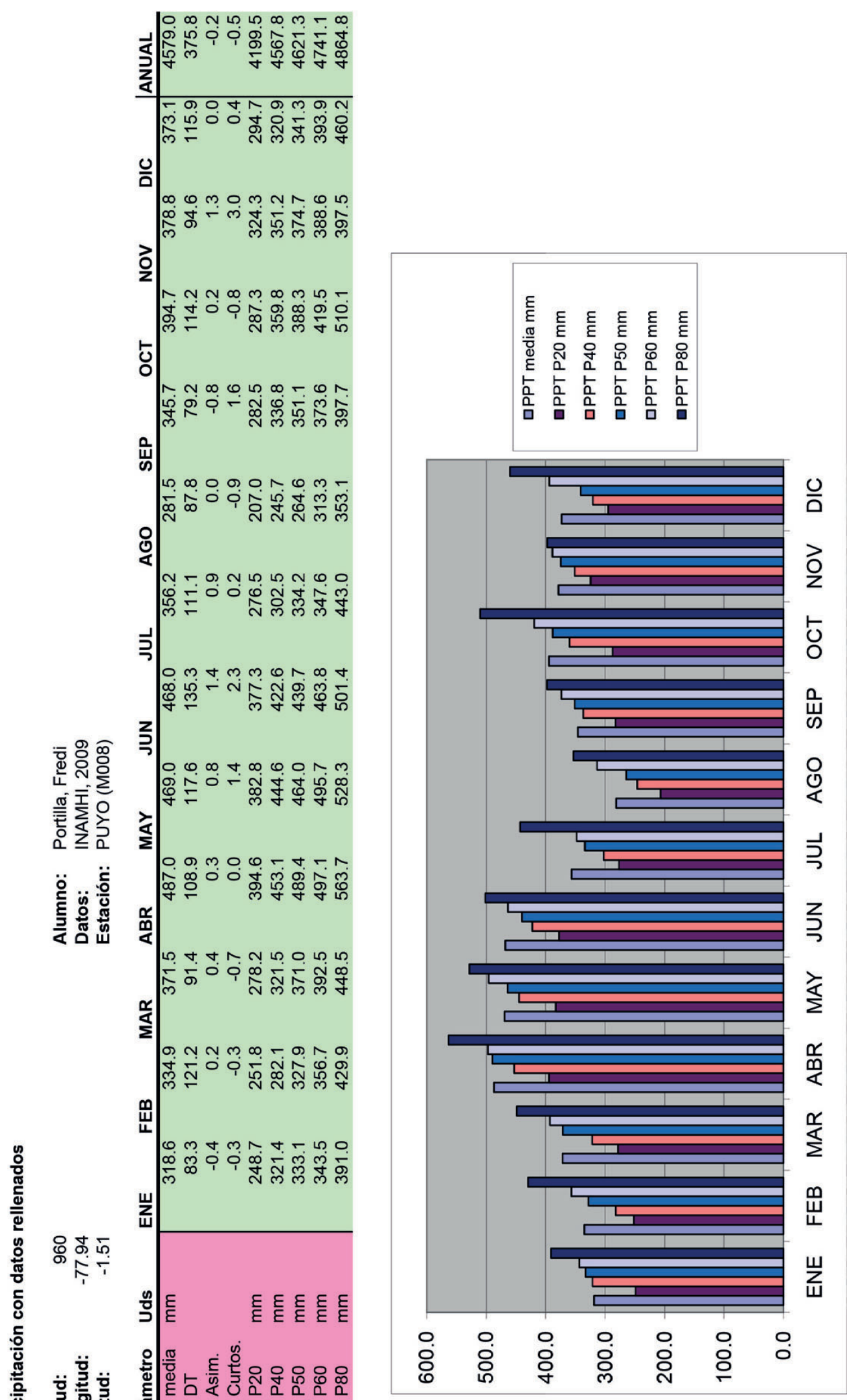



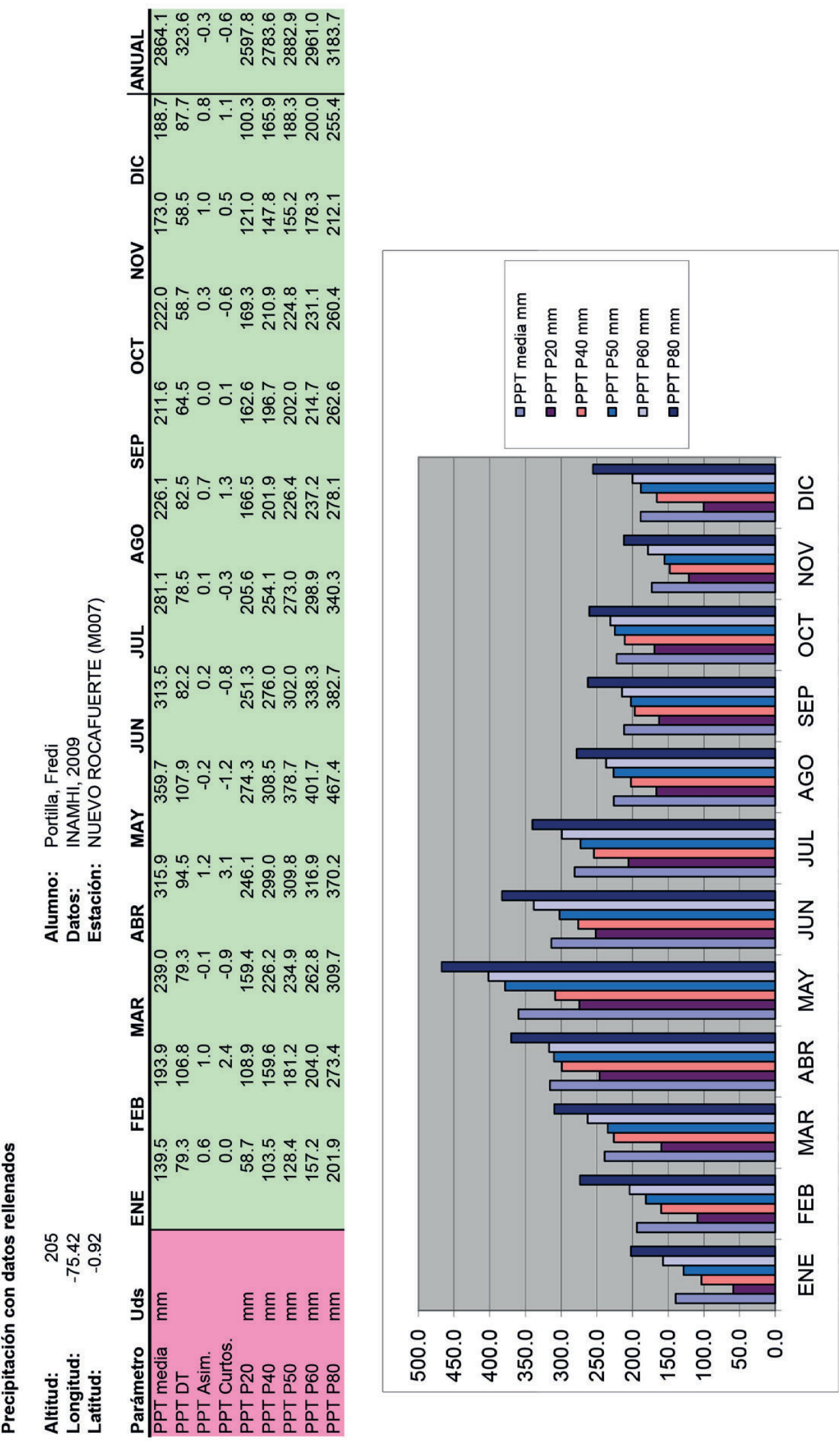

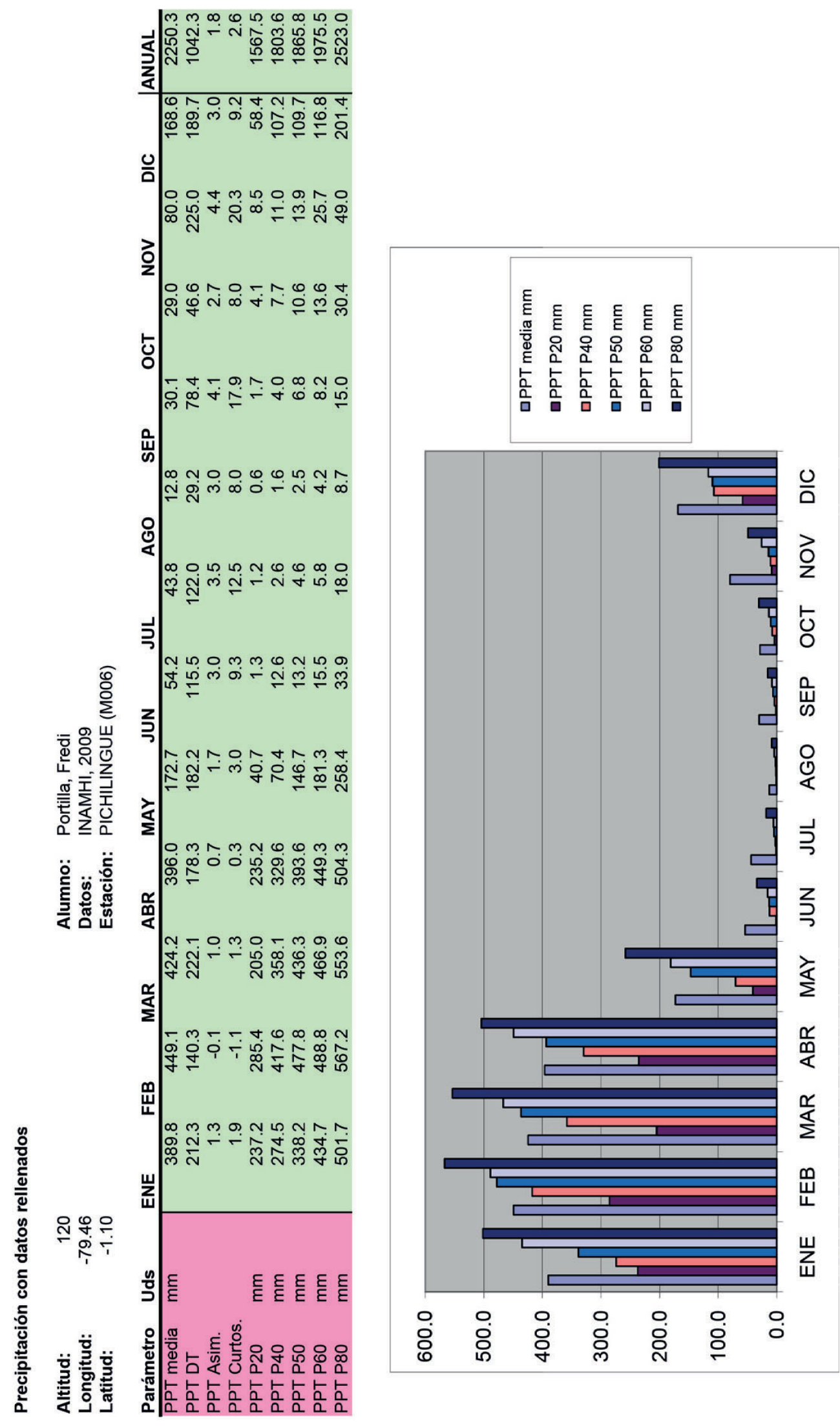

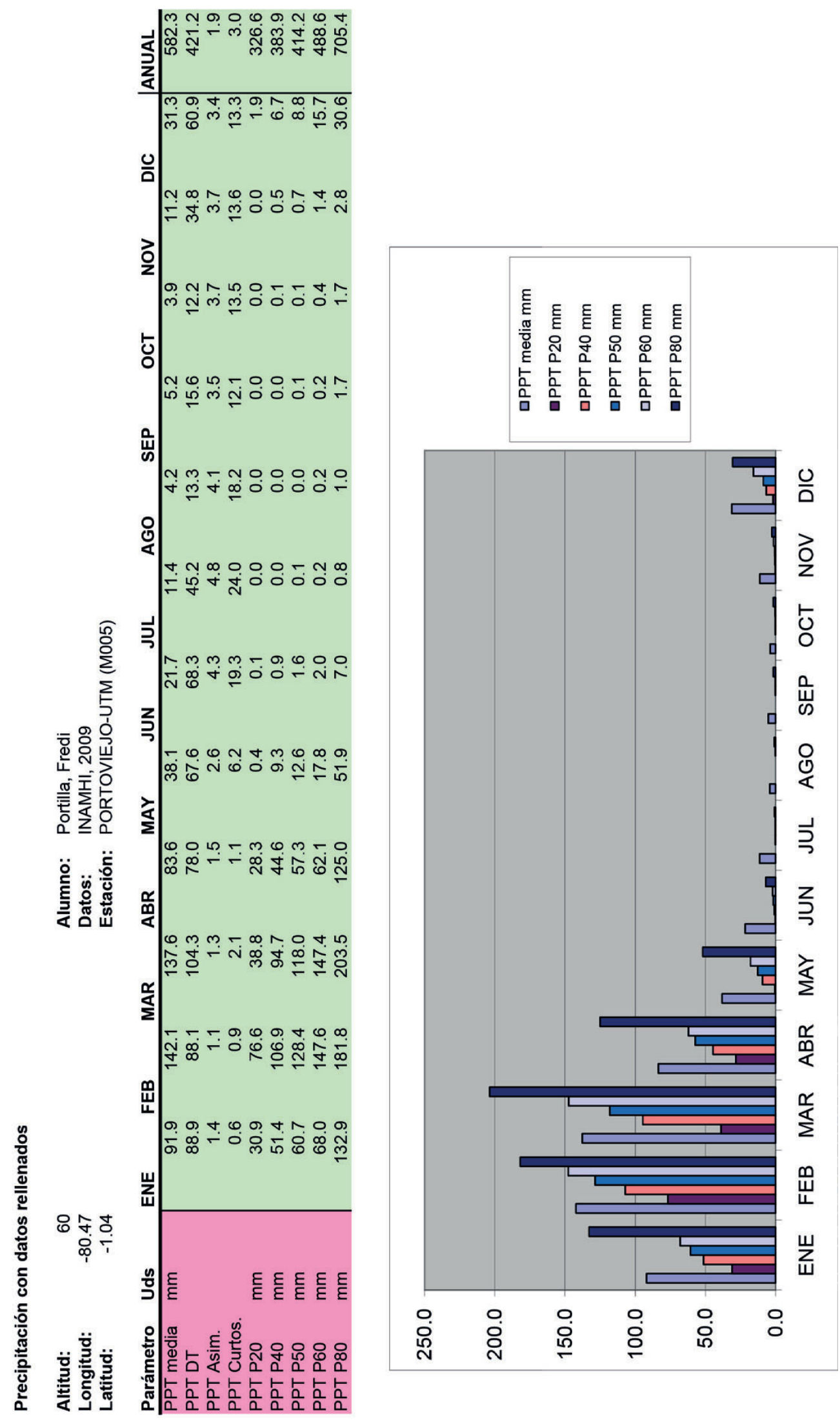

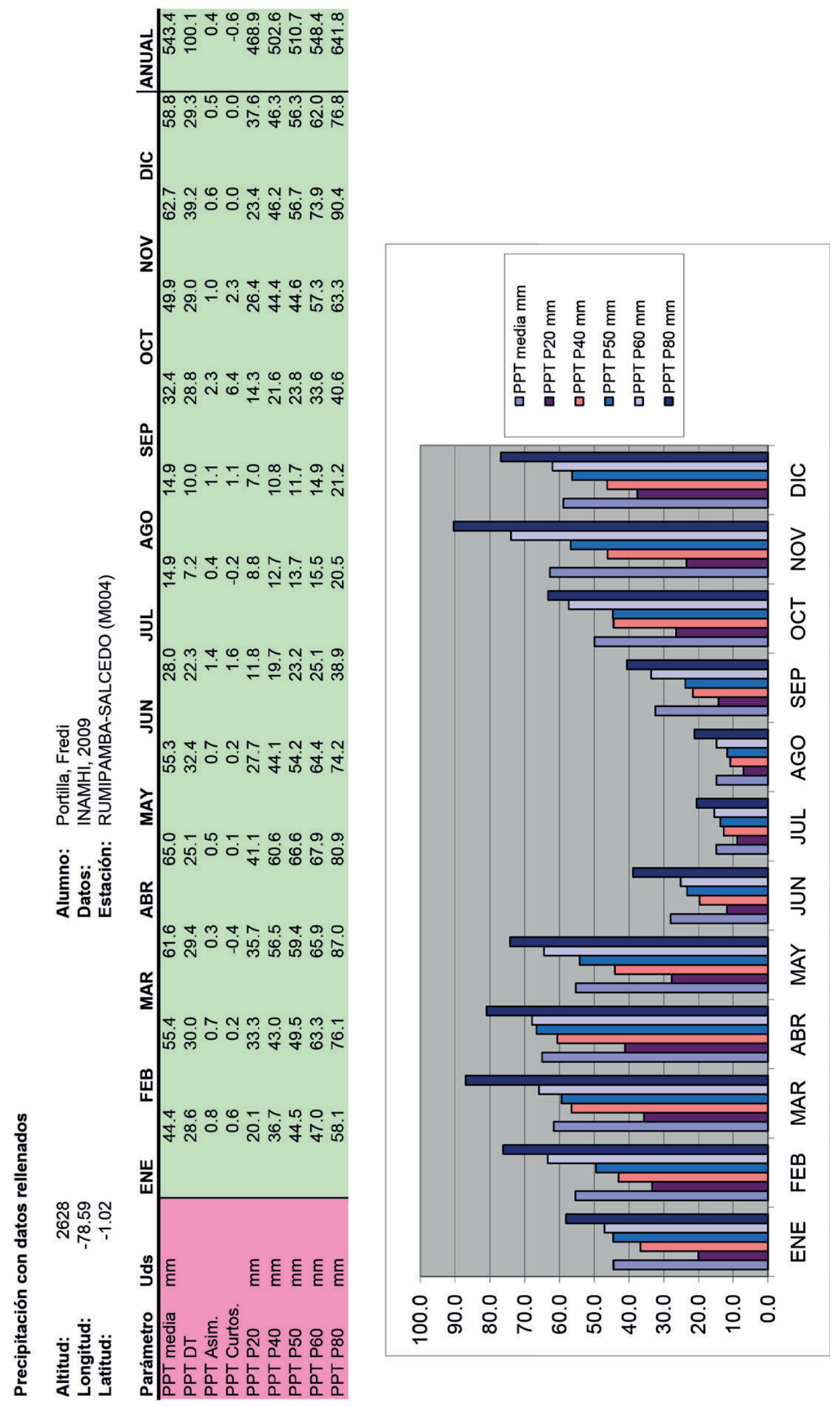

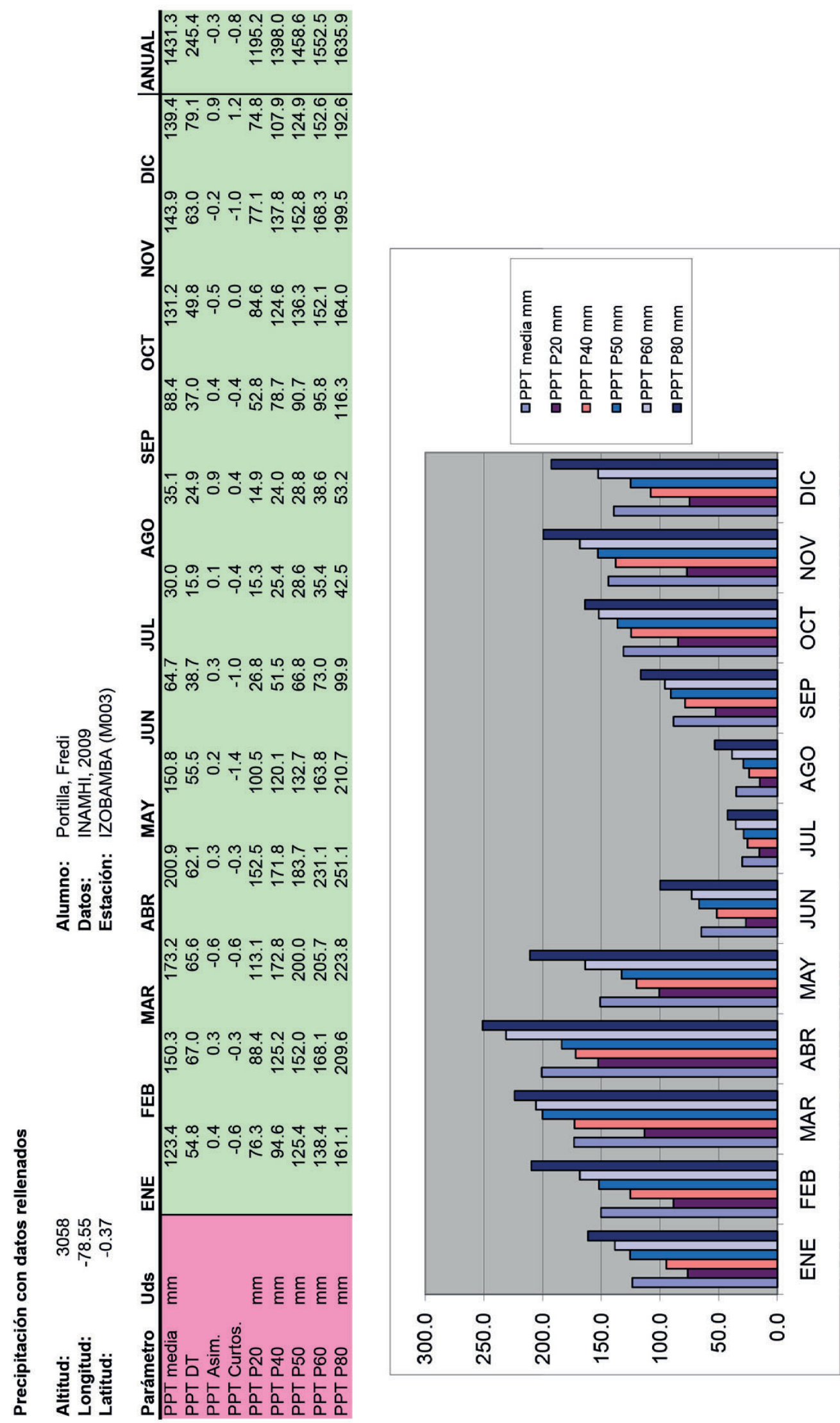

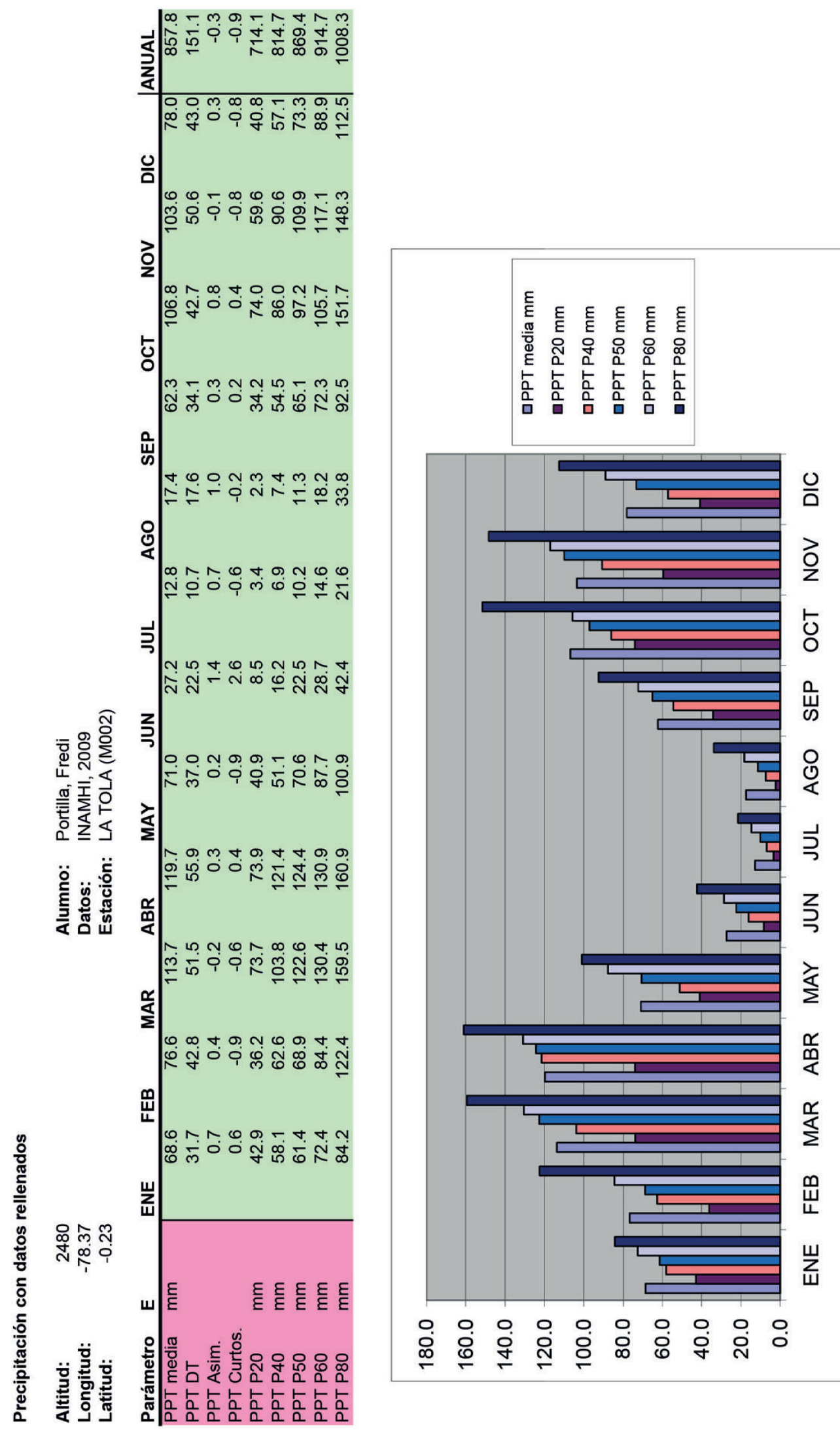


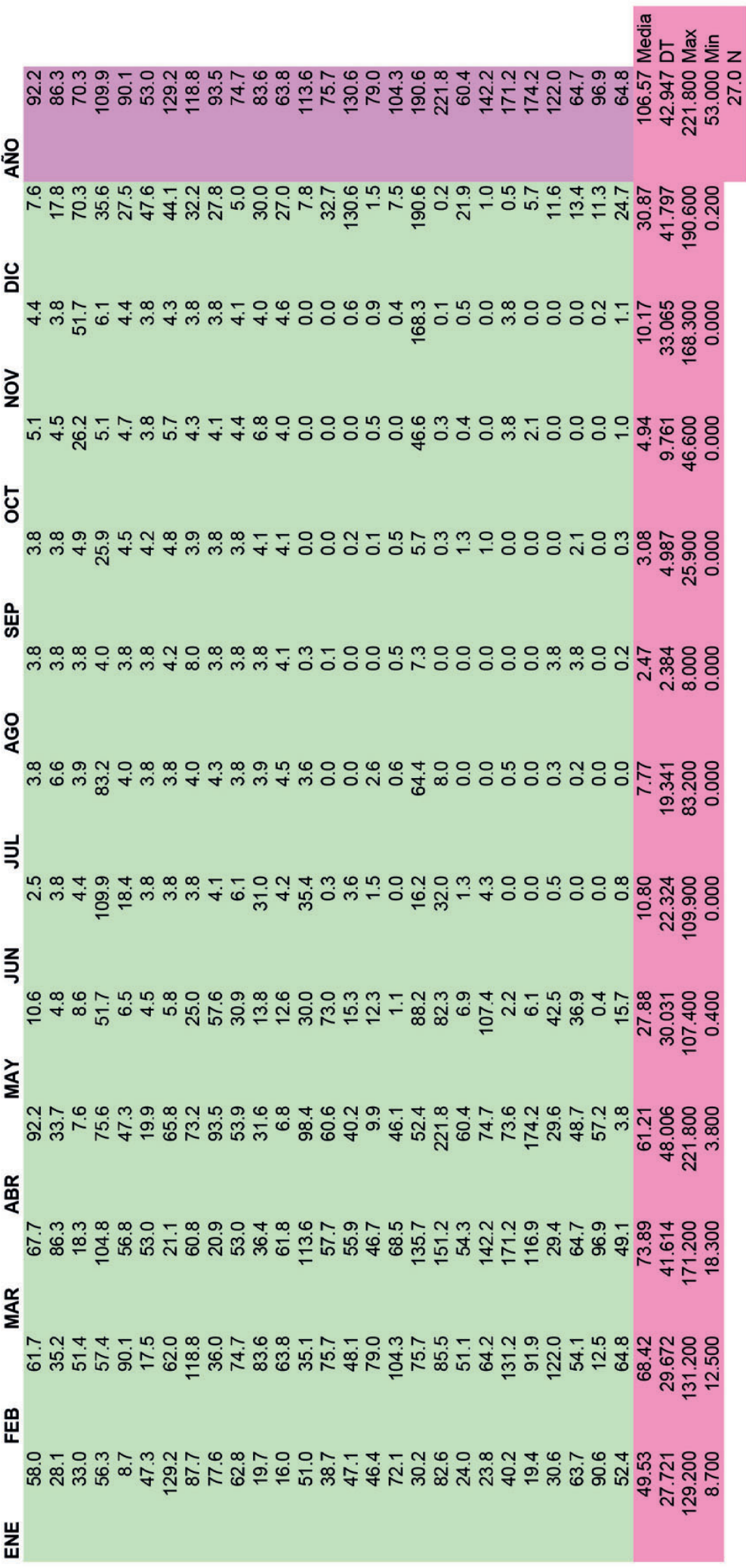




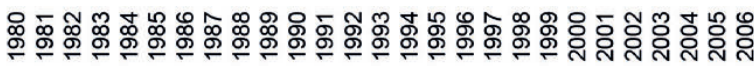

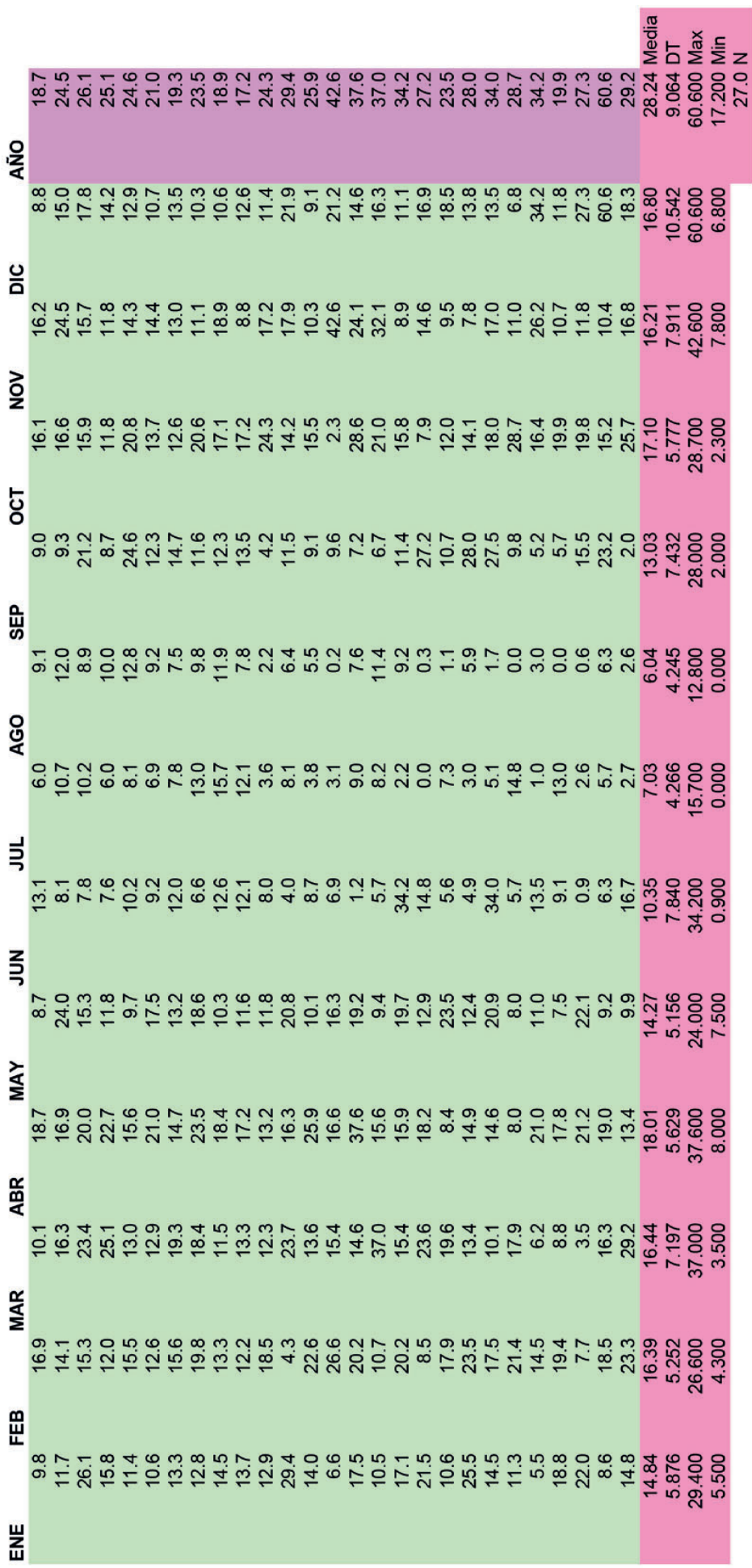




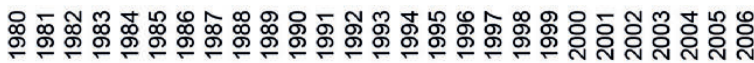

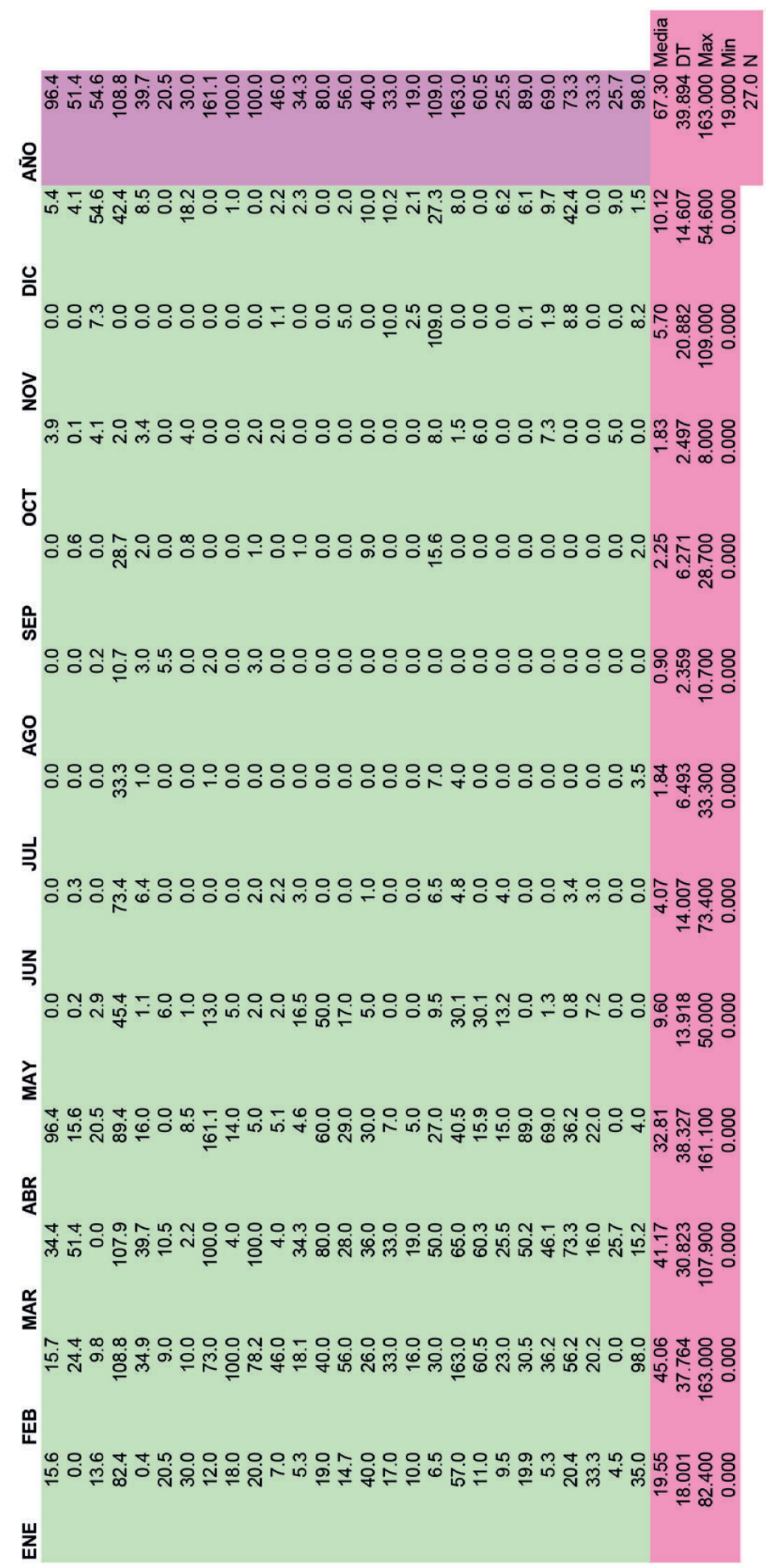




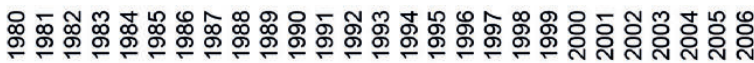

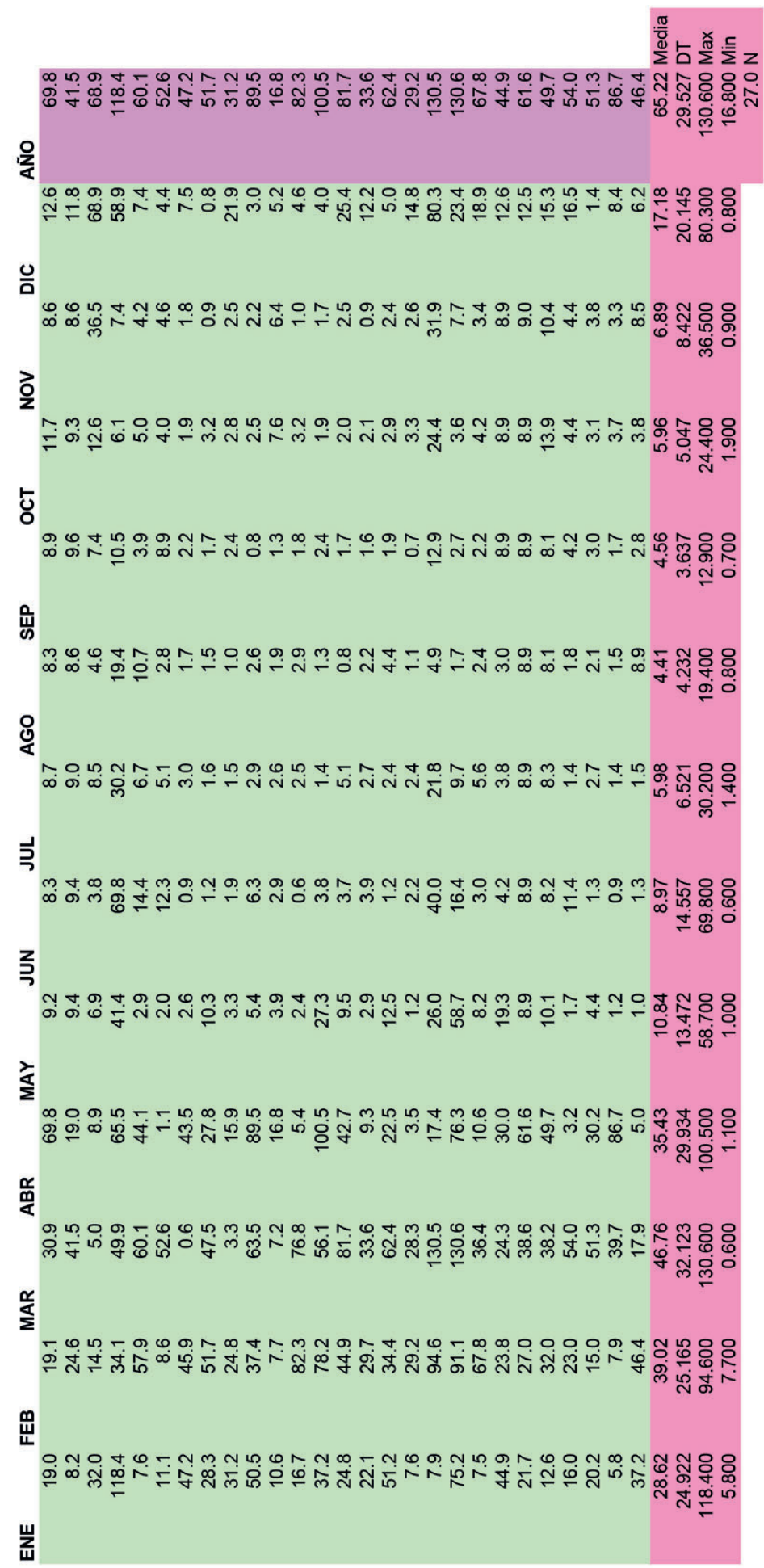




\section{3}

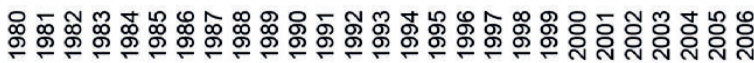

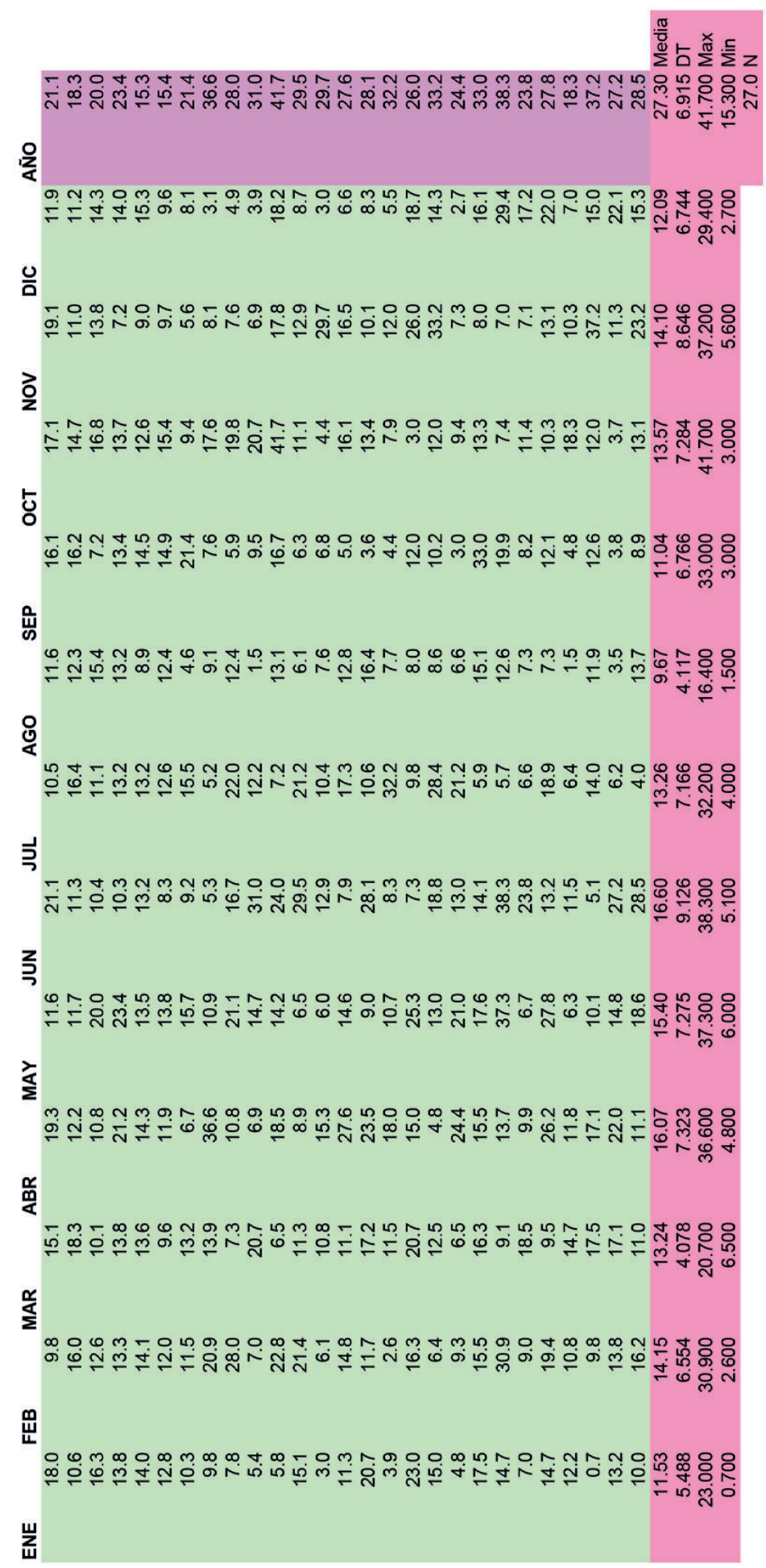




\section{4}

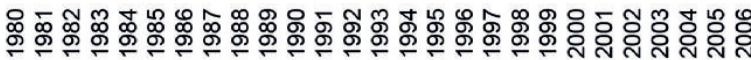

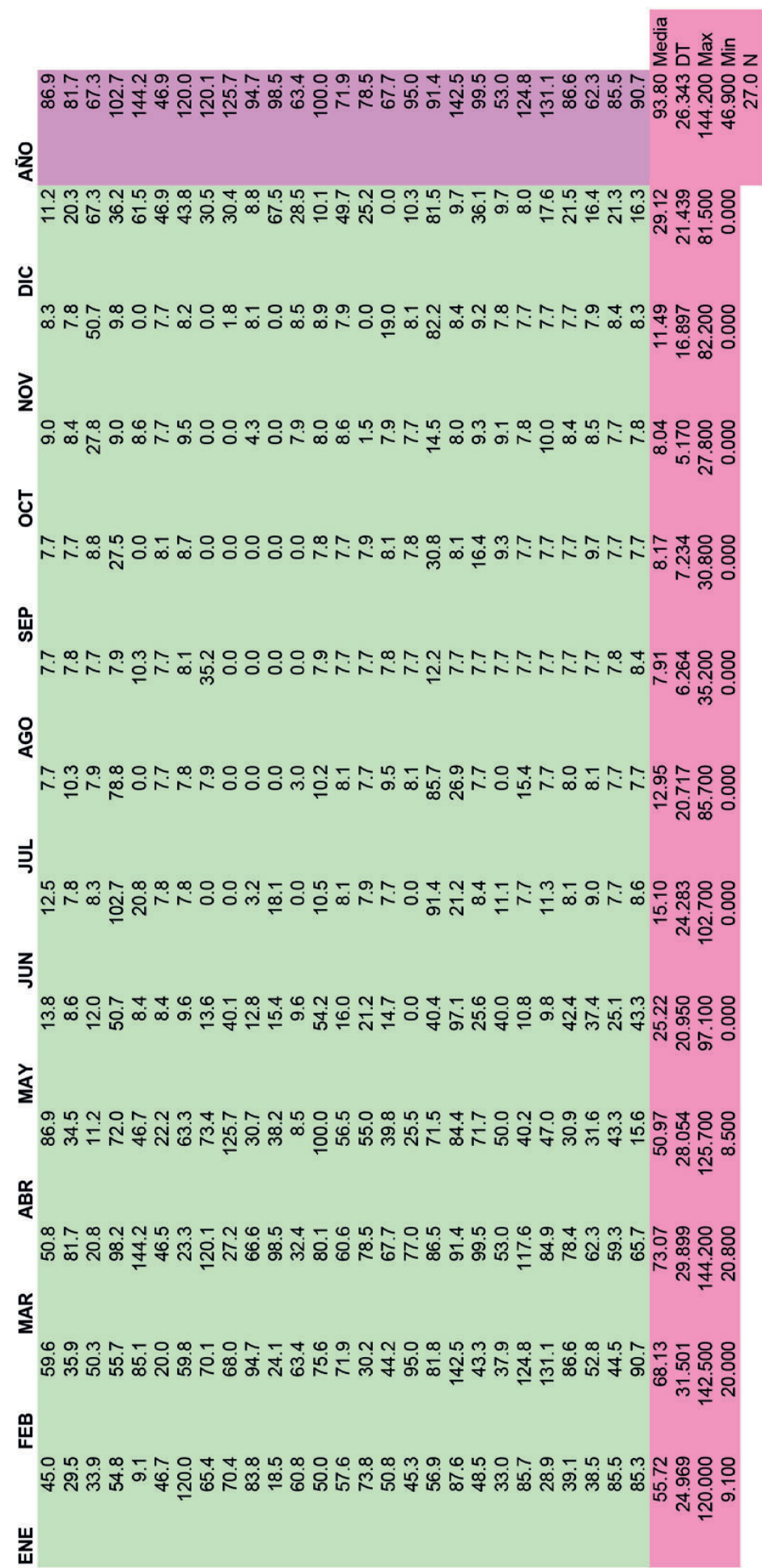




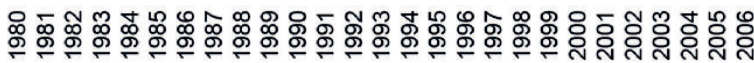

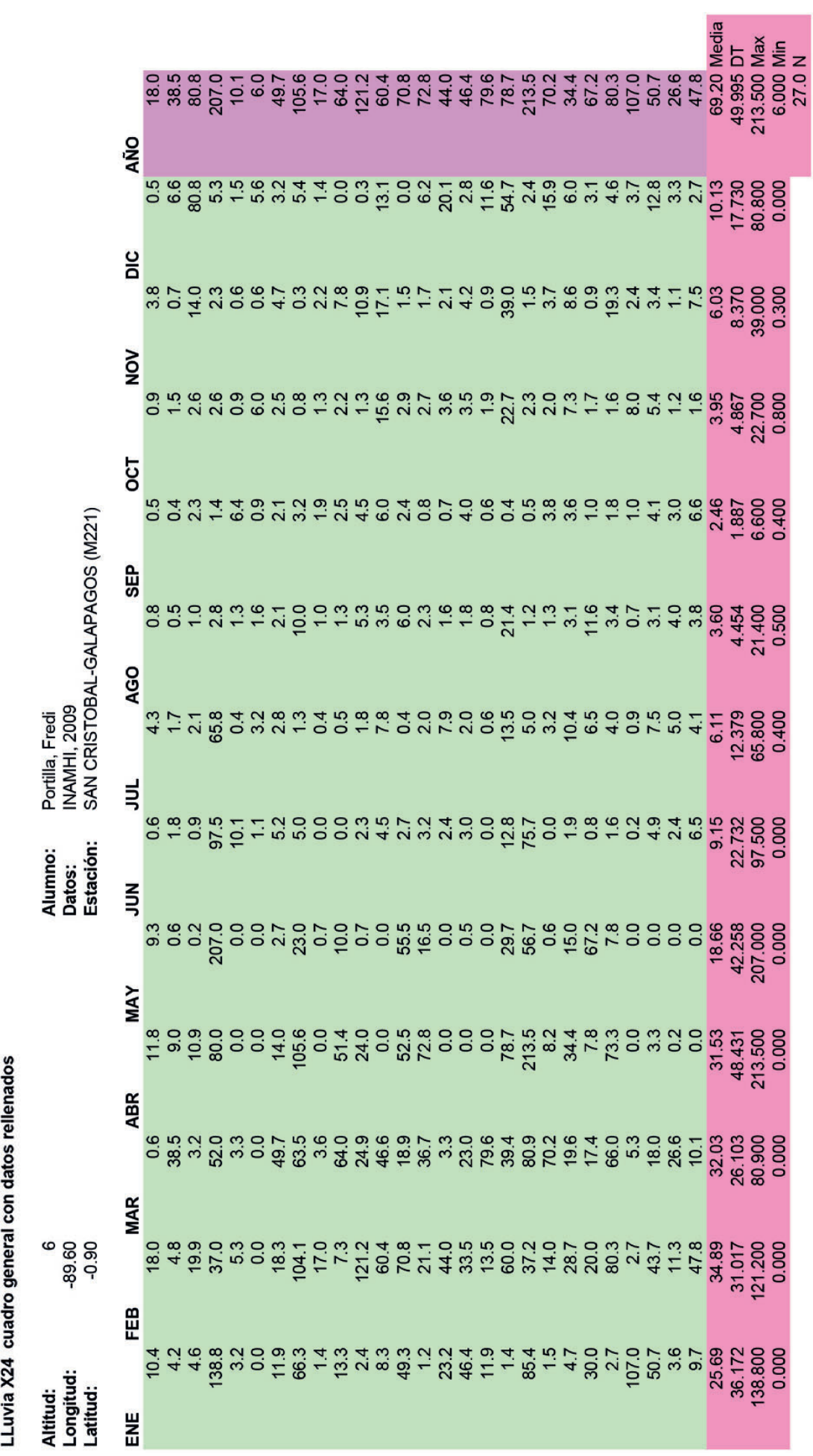




\section{6}

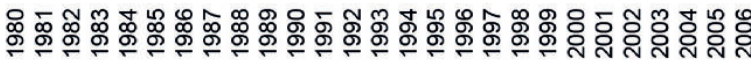

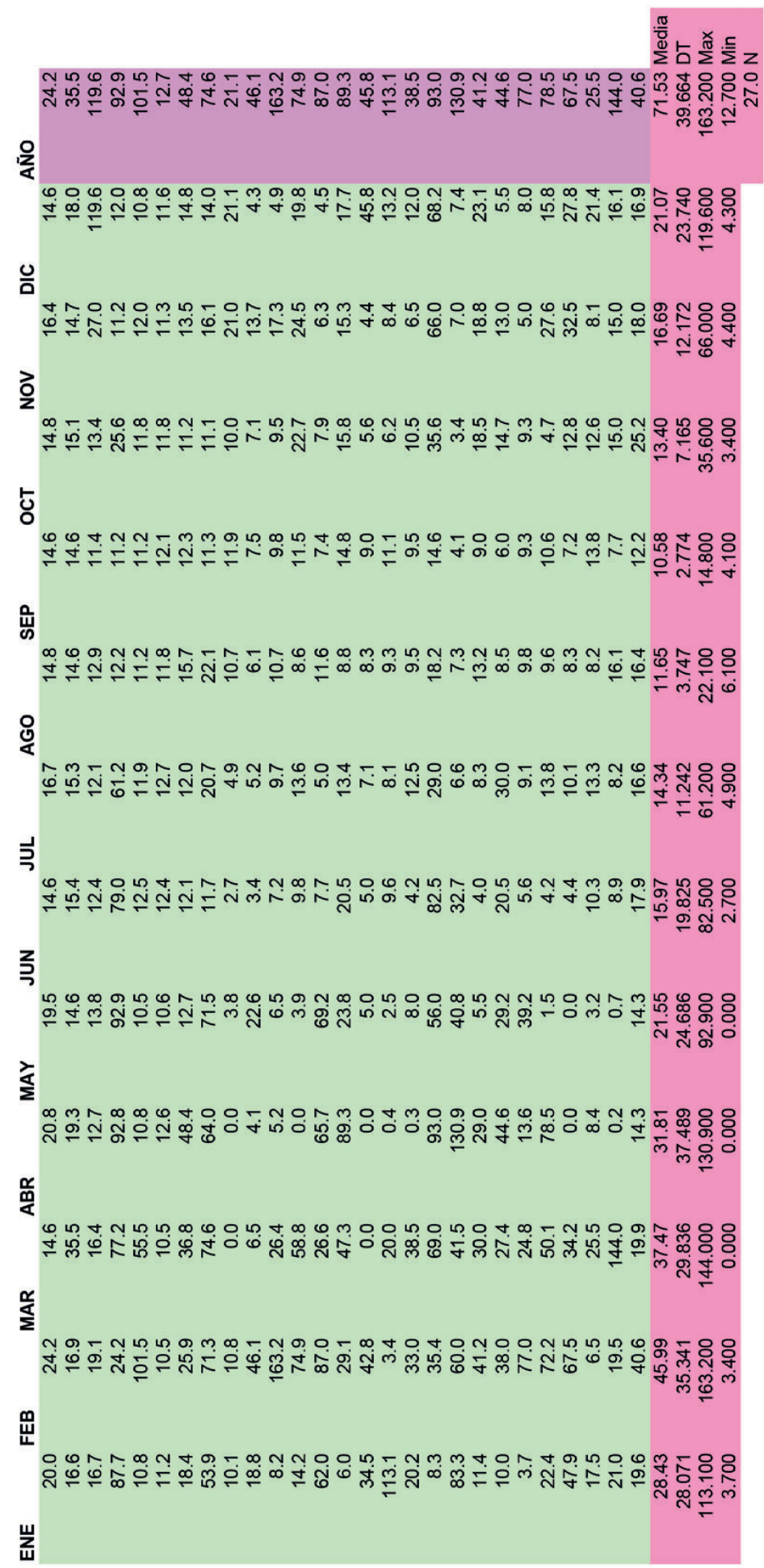




\section{7}

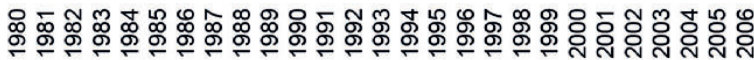

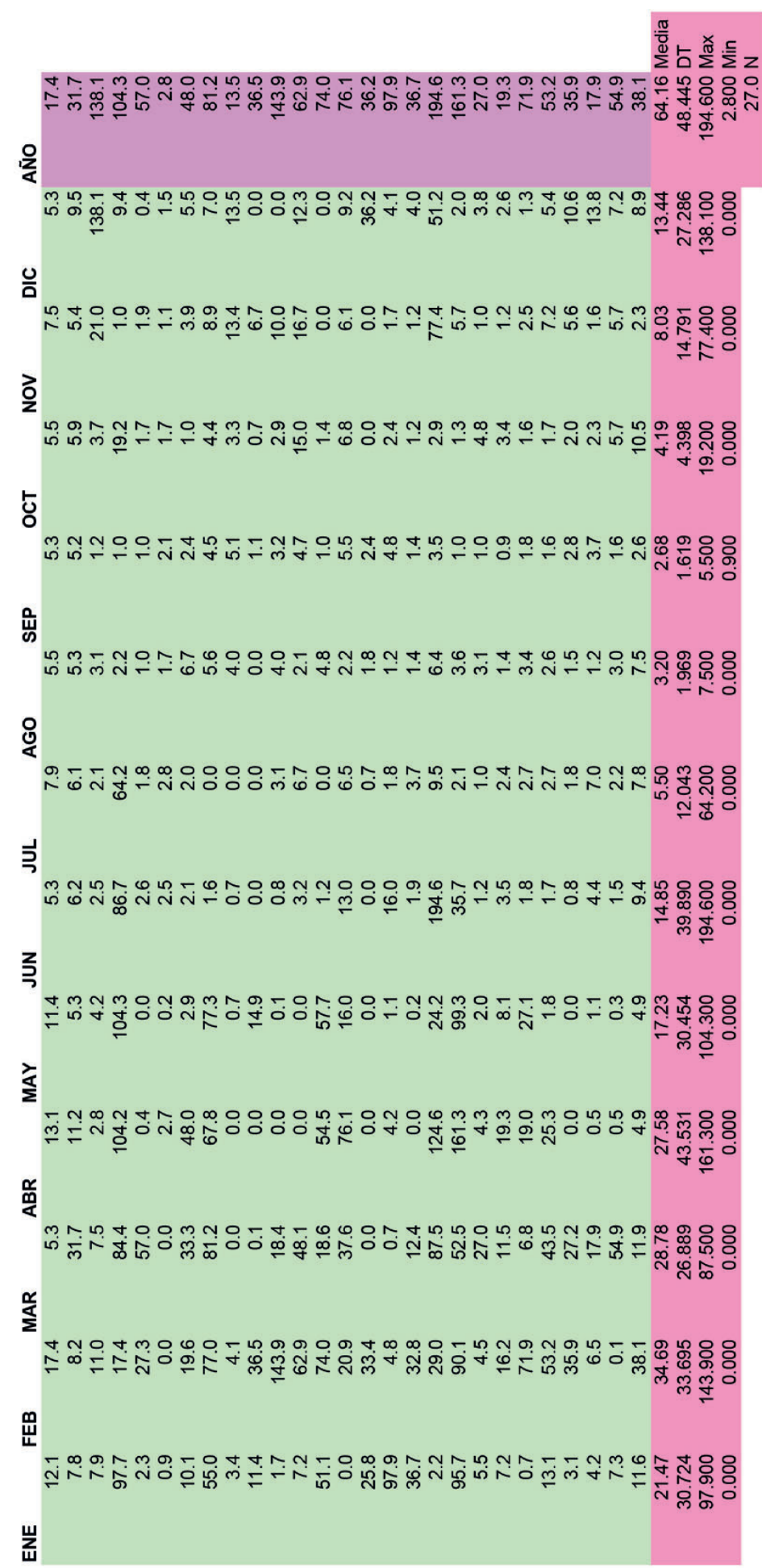




\section{8}

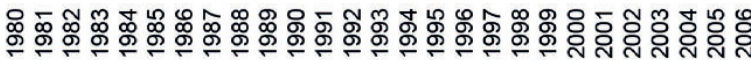

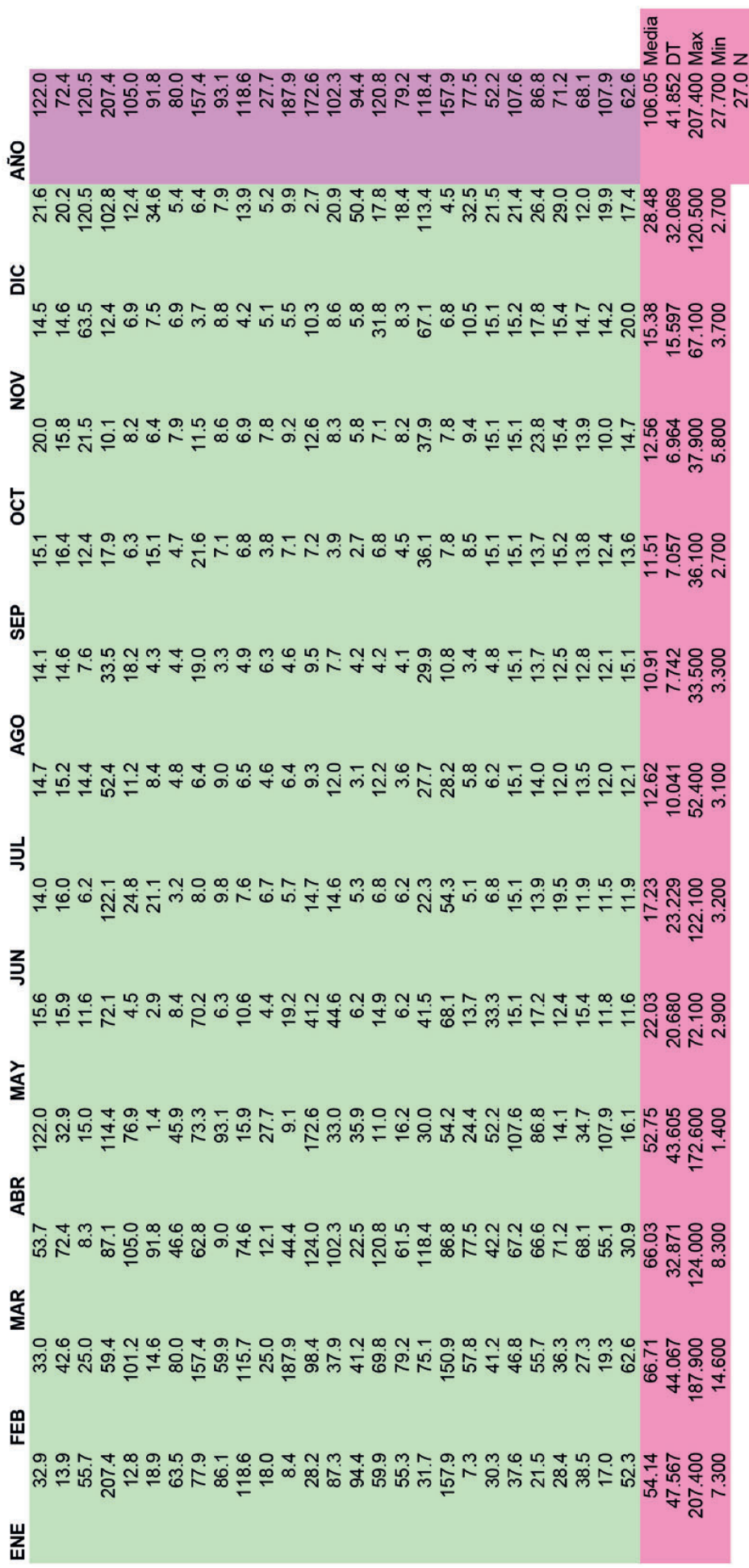




\section{9}

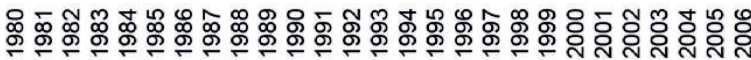

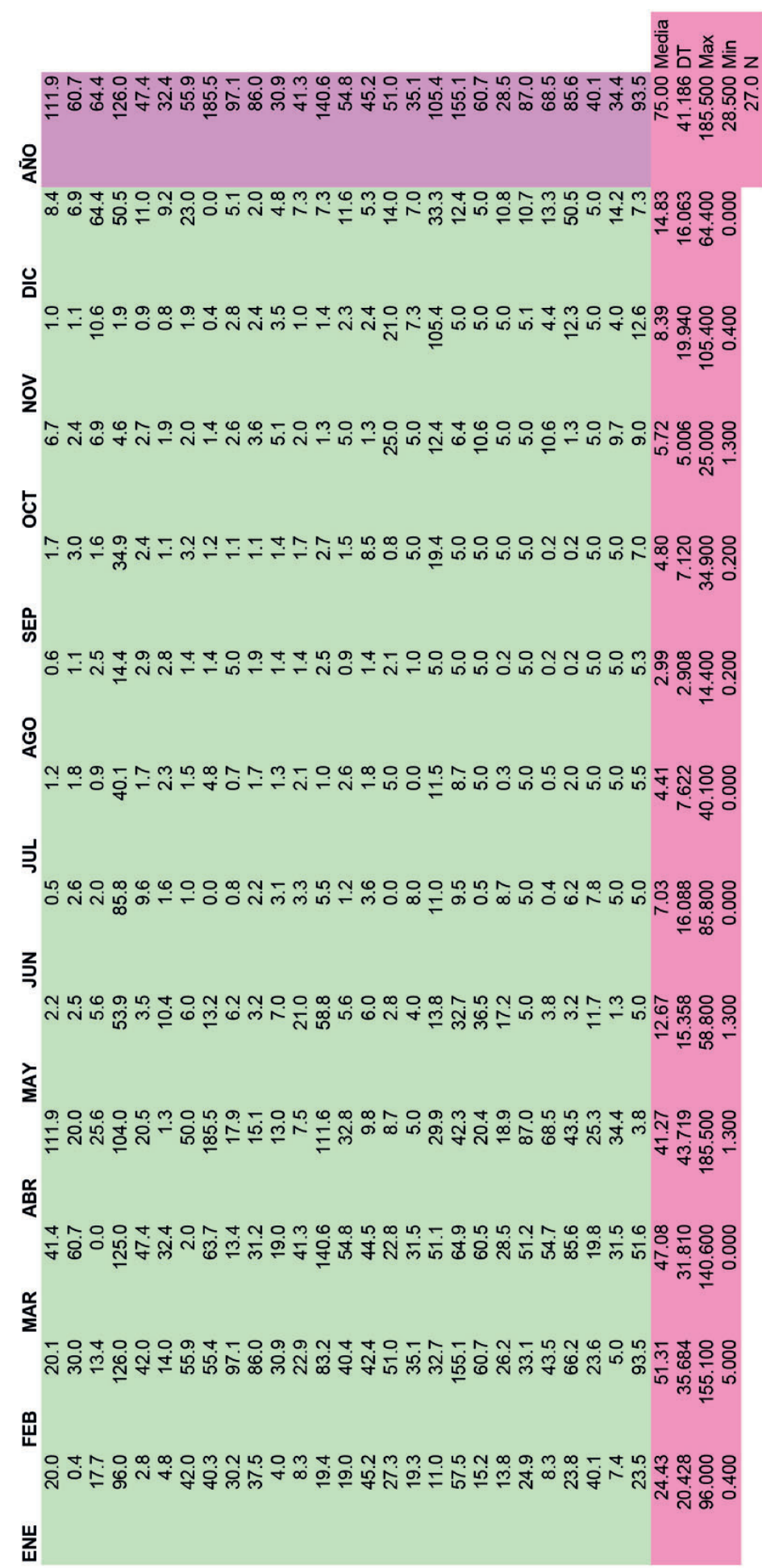




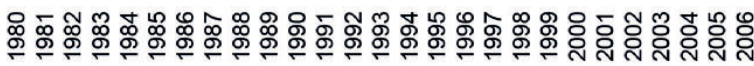

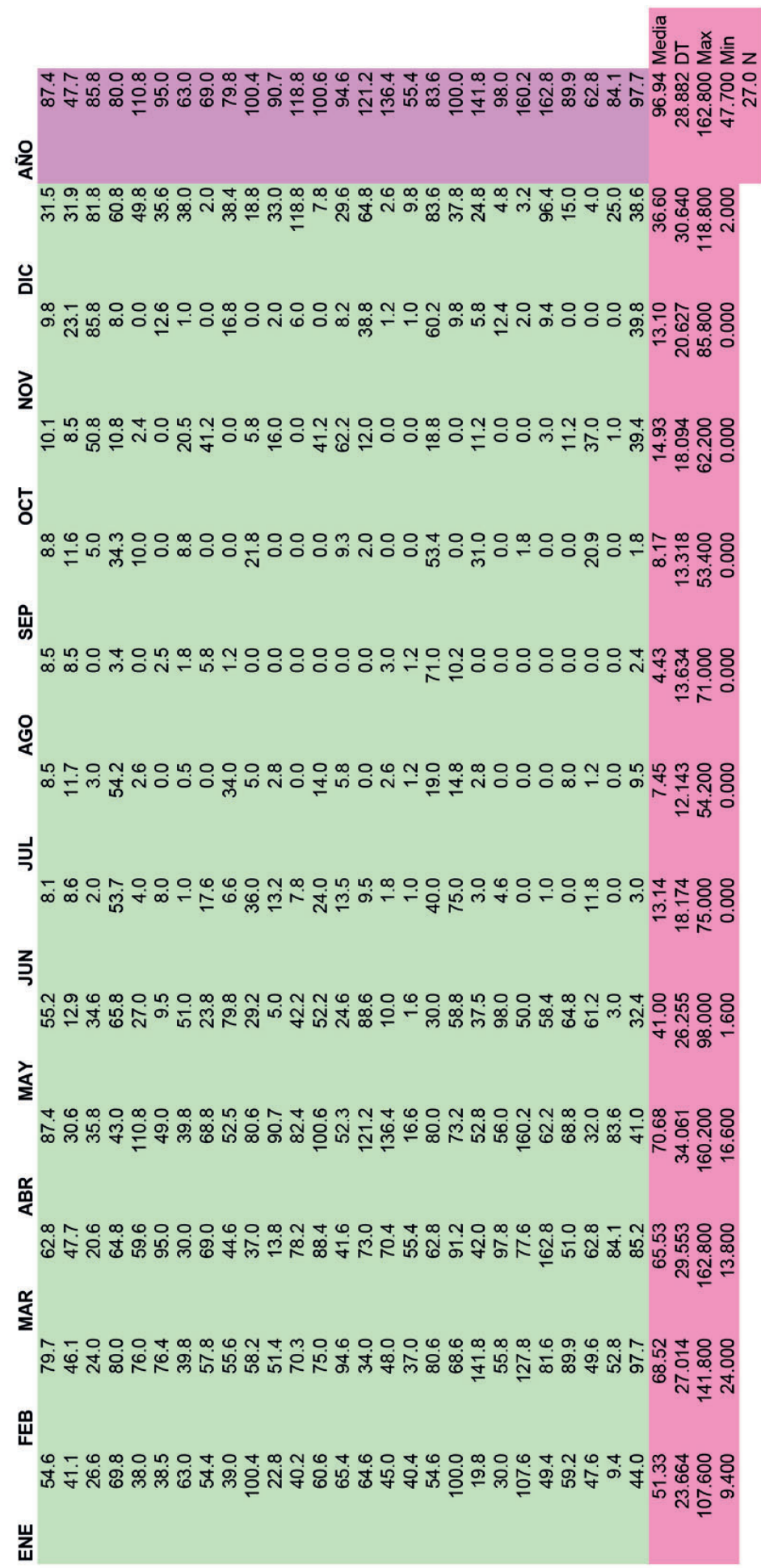




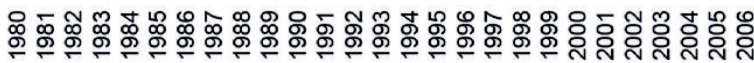

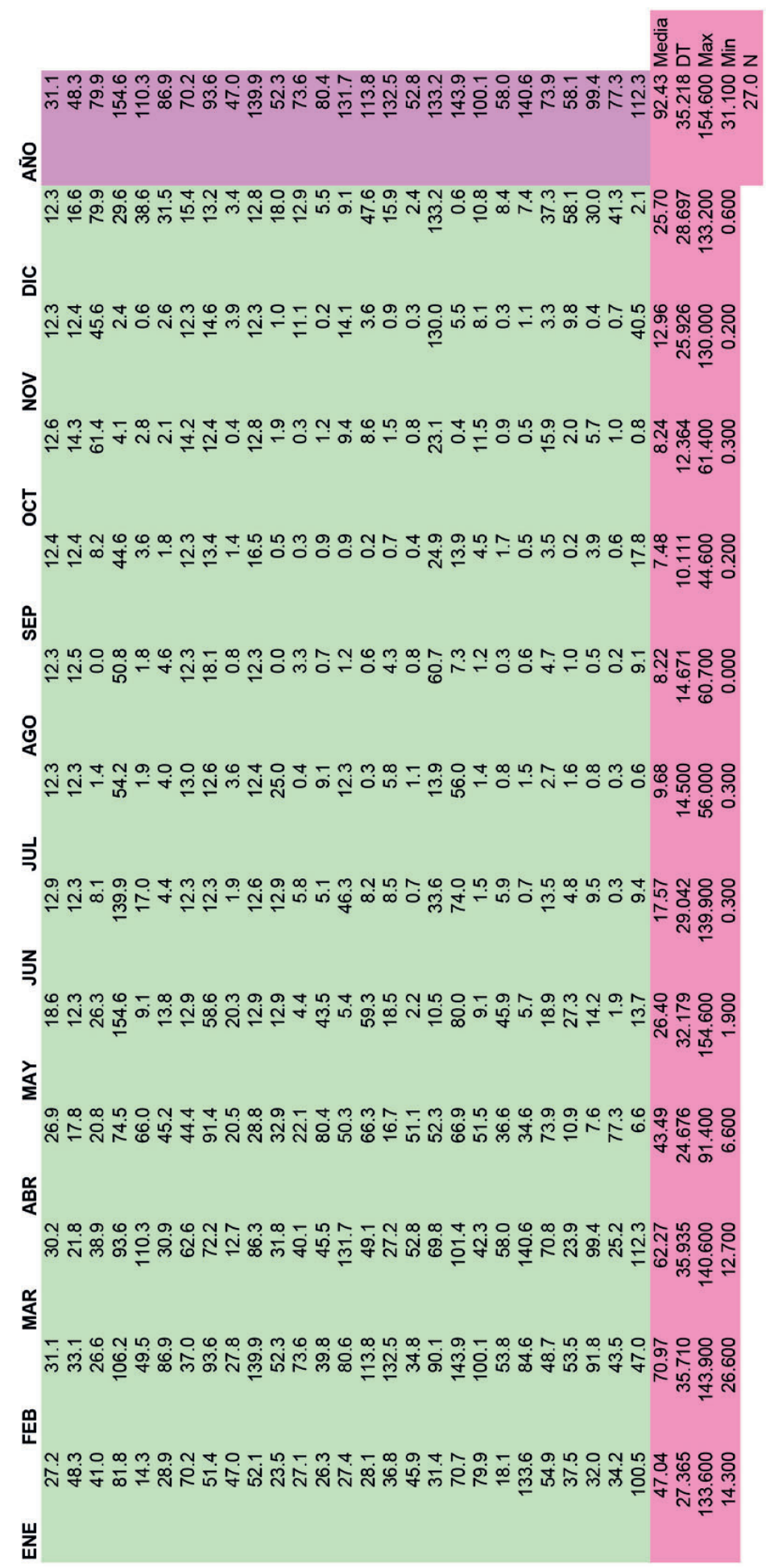




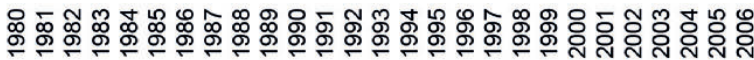

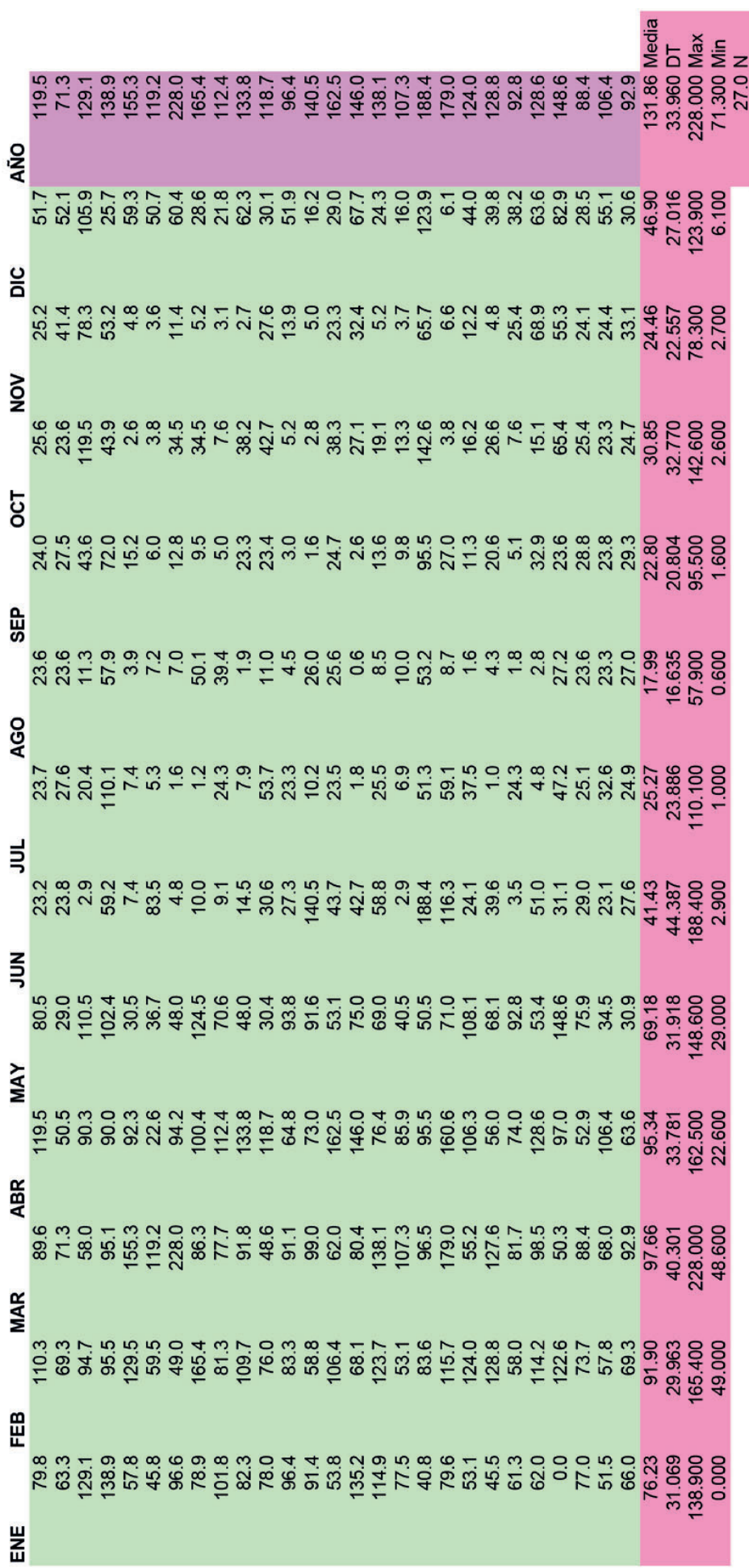




\section{3}

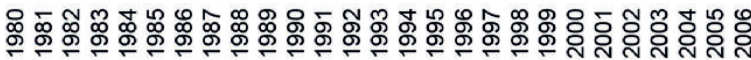

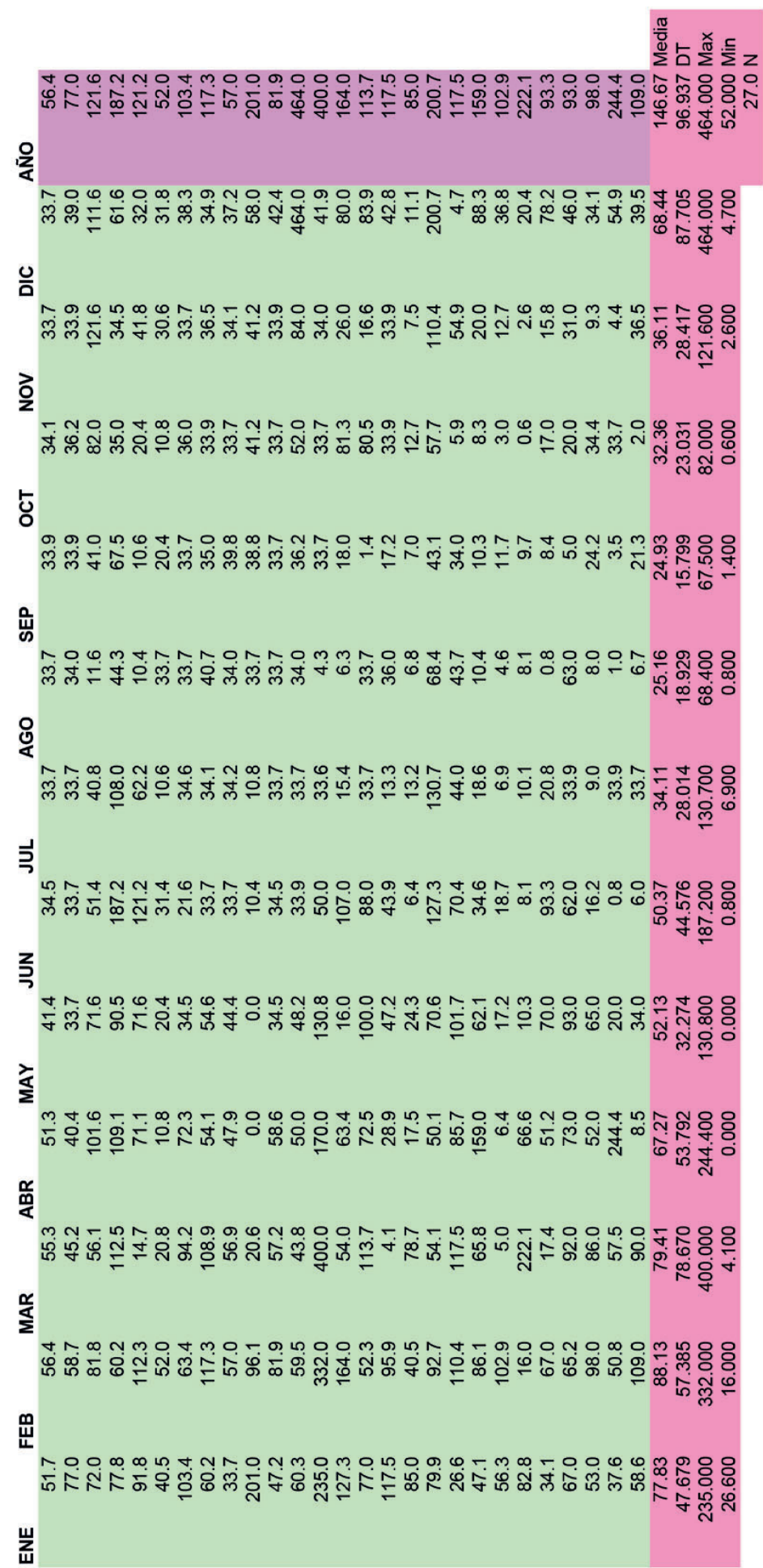




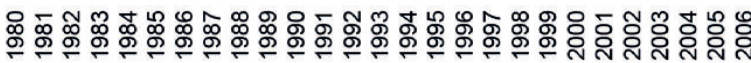

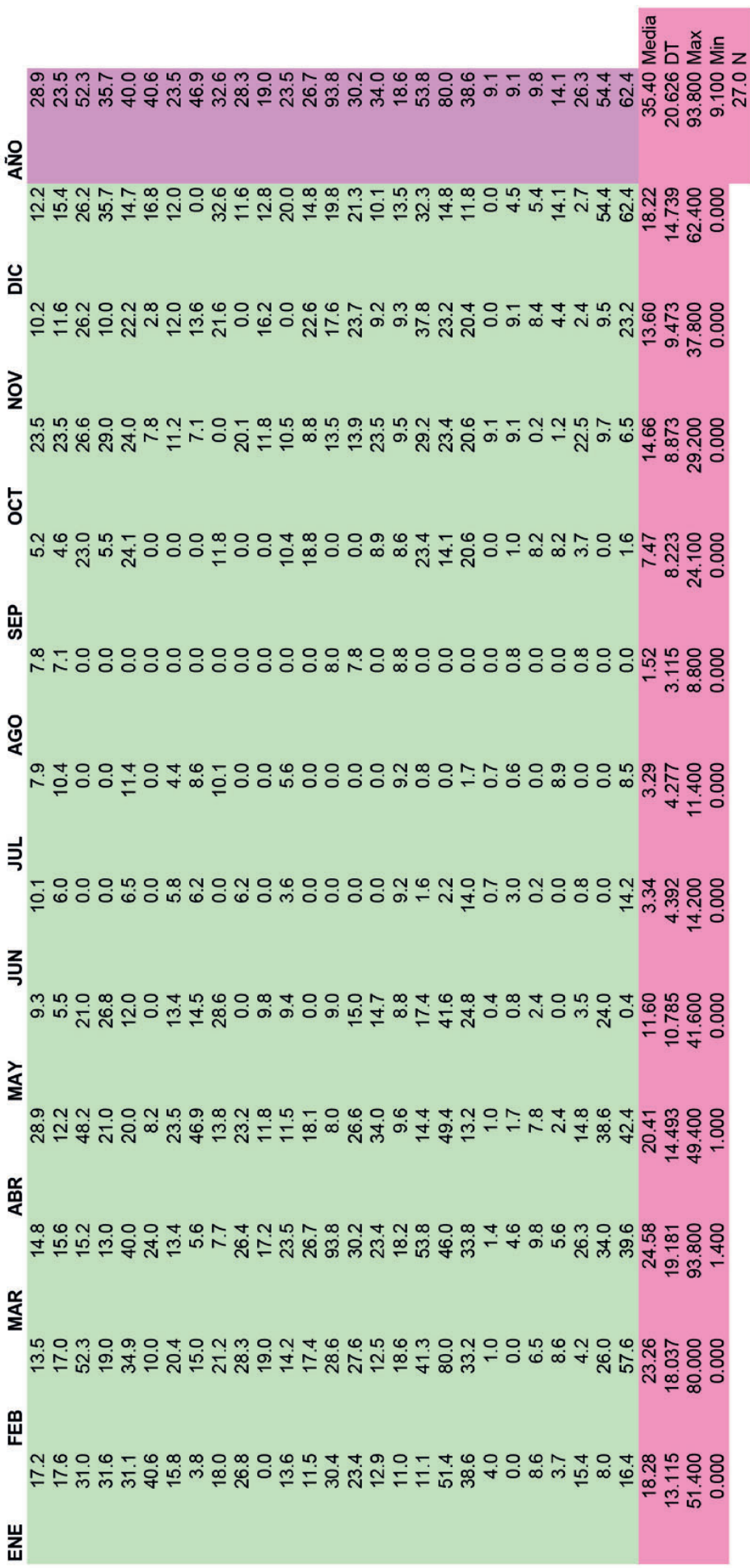




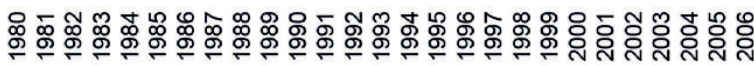

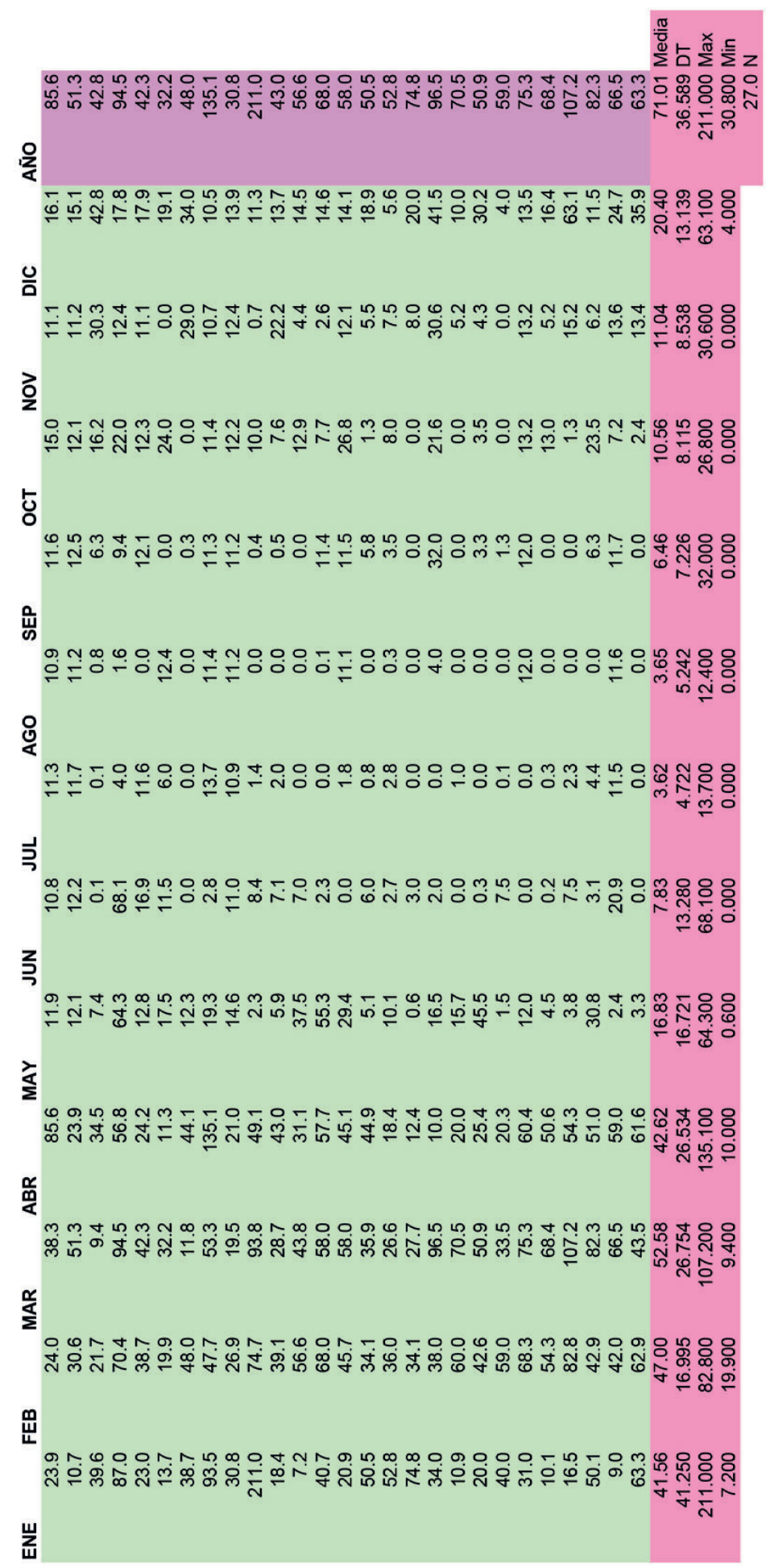




\section{6}

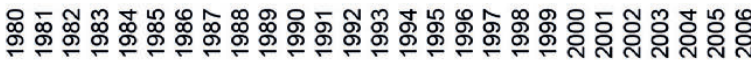

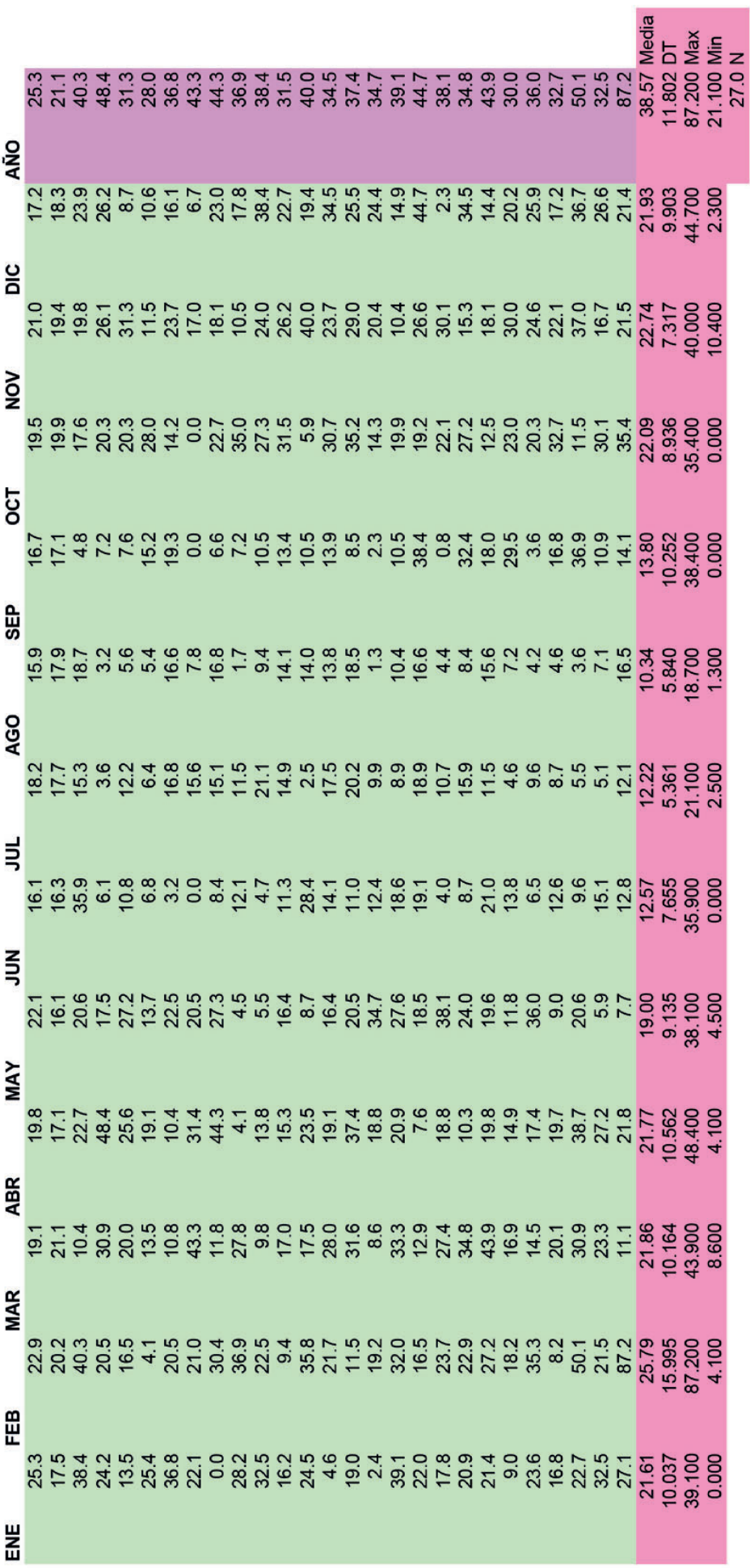




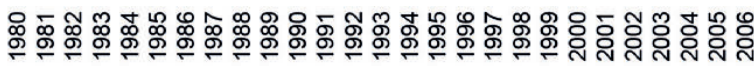

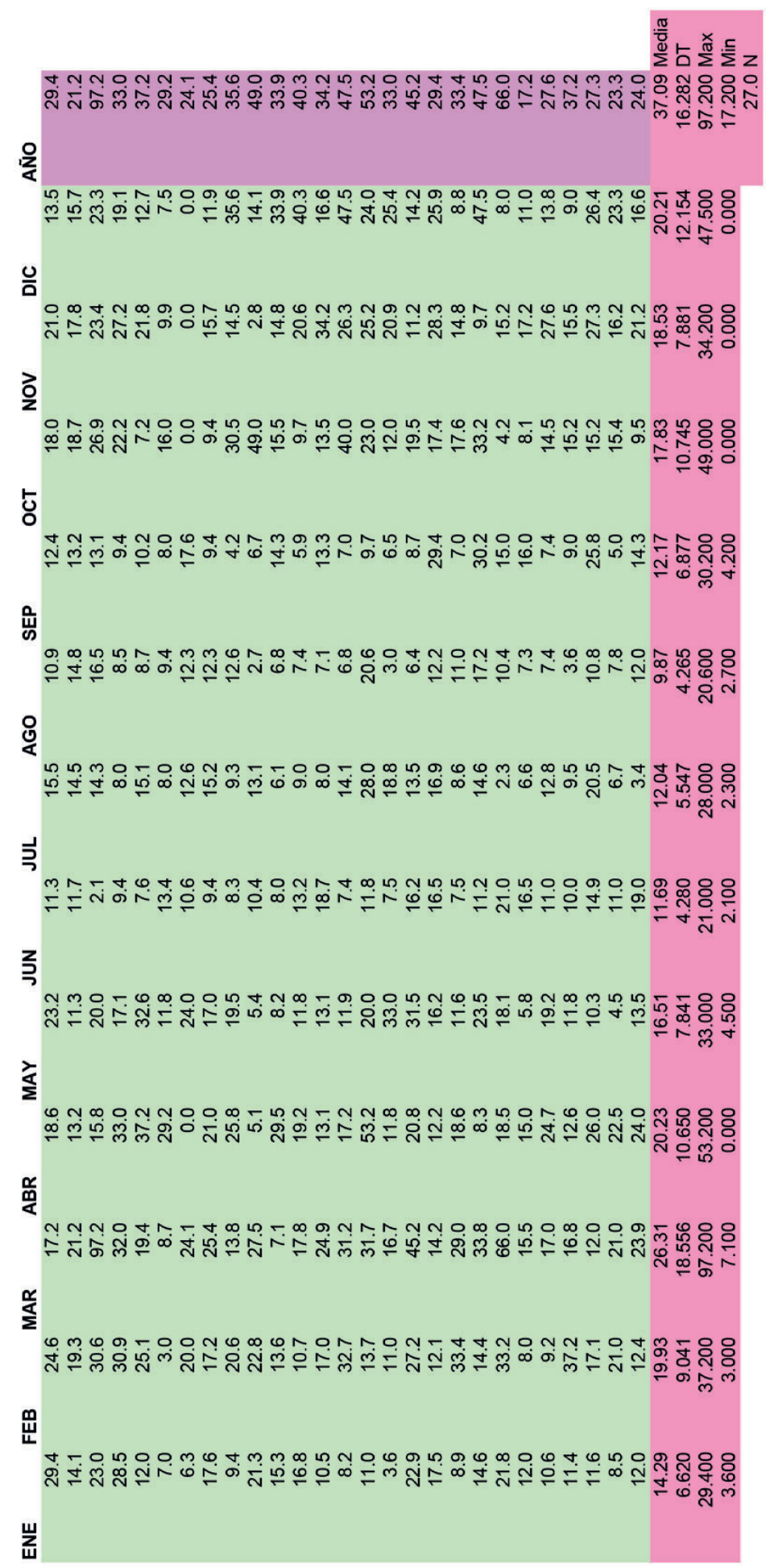




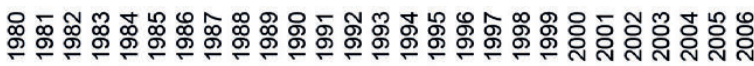

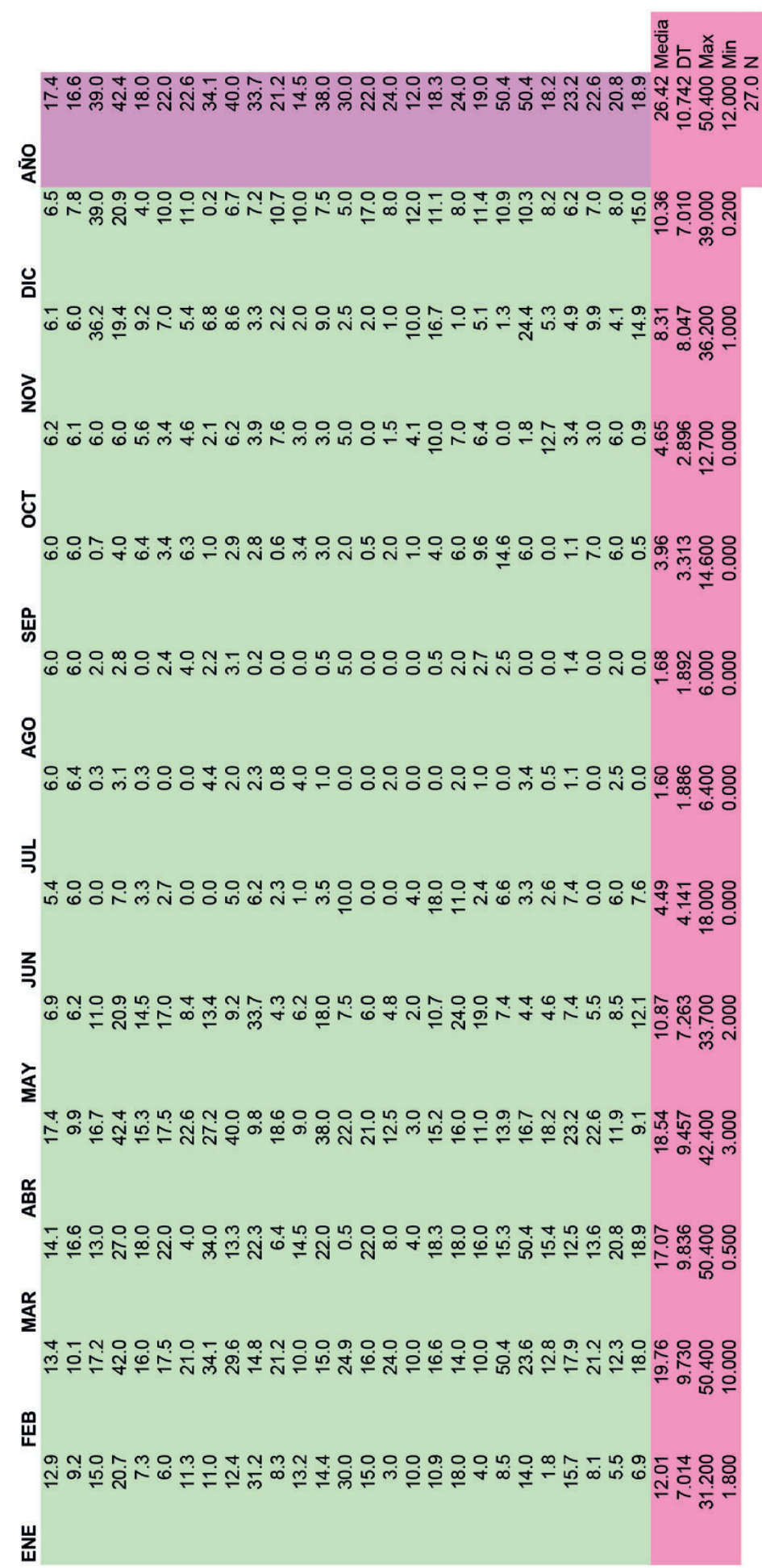




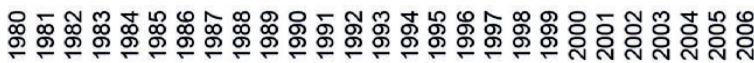

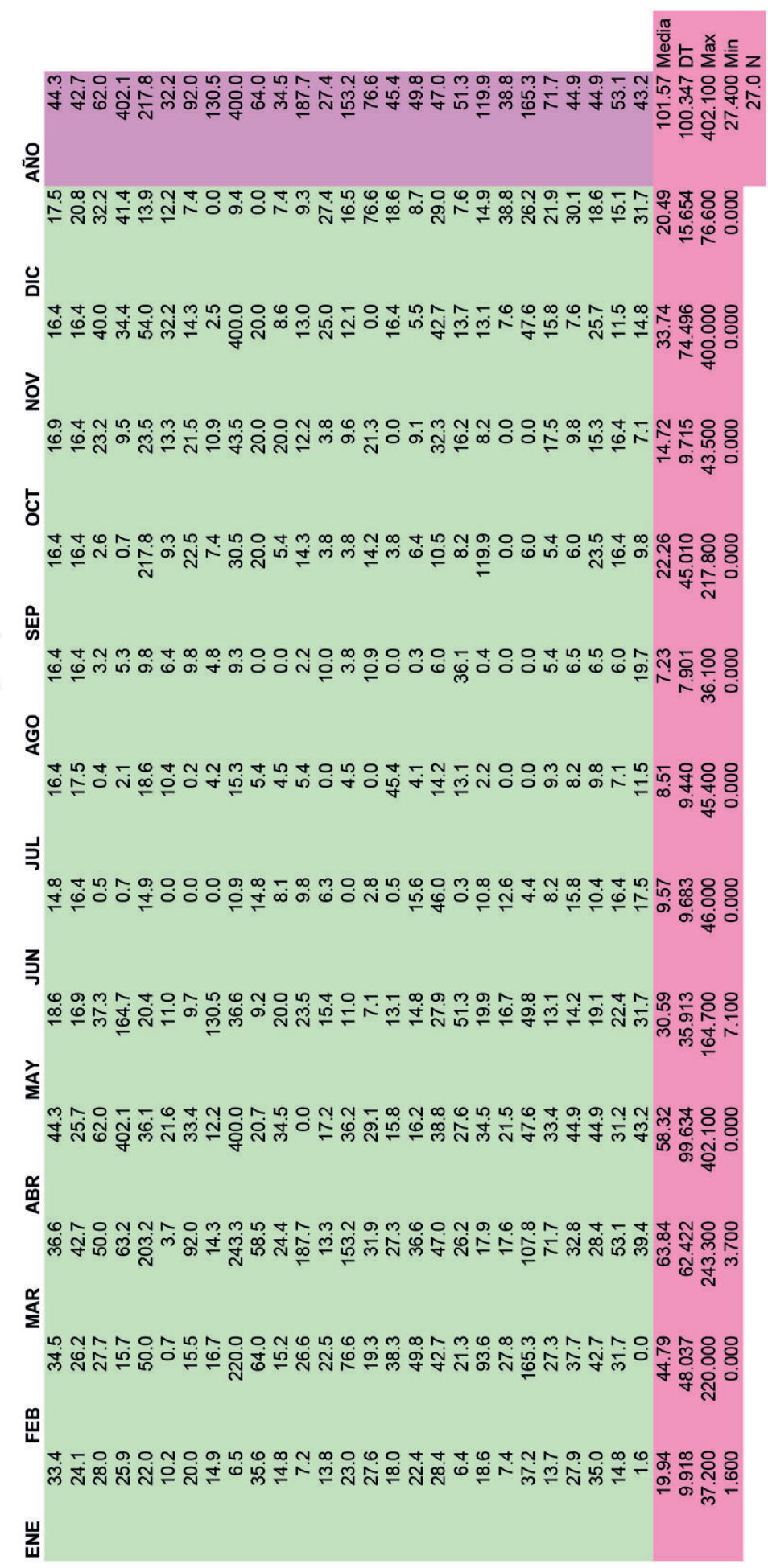




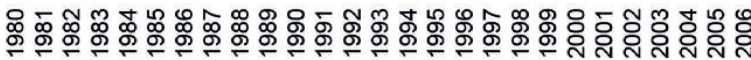

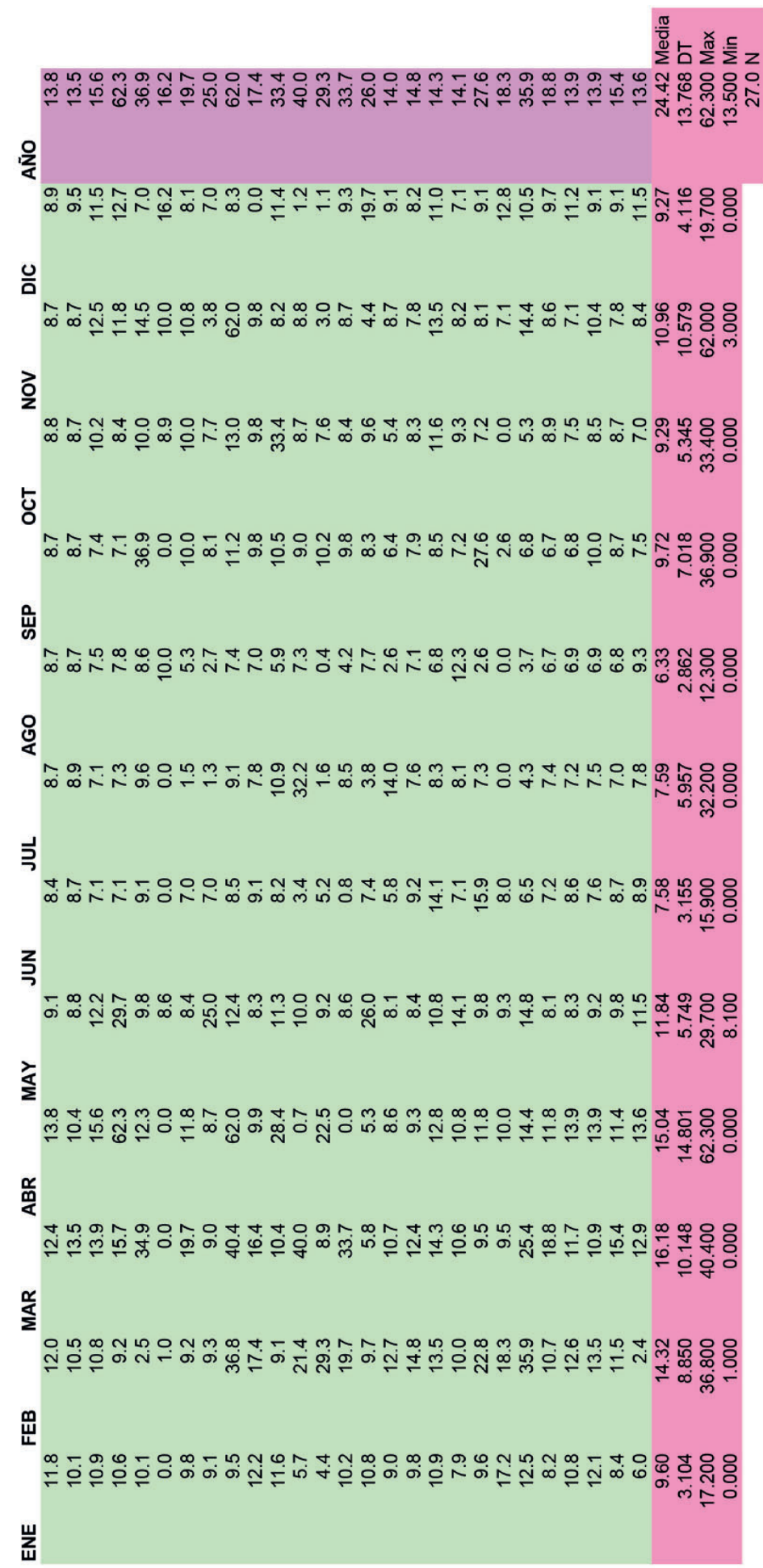




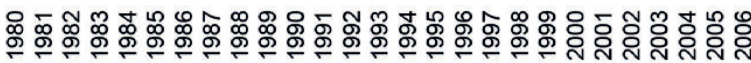

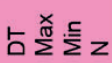

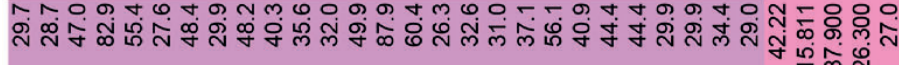

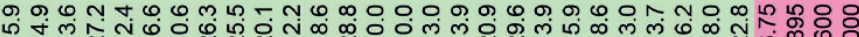
눈

辰

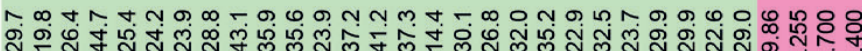

爱

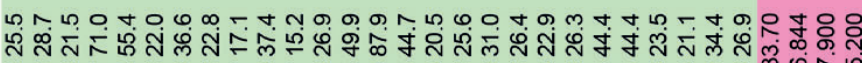

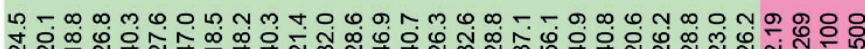

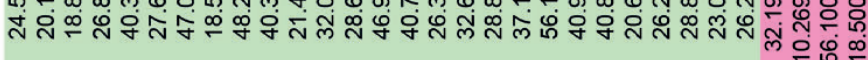
罚

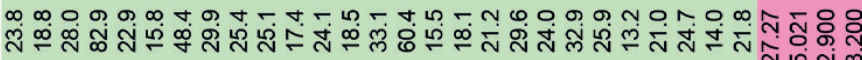
荘 


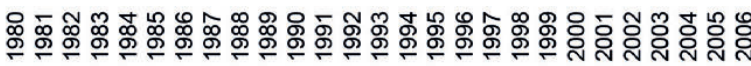

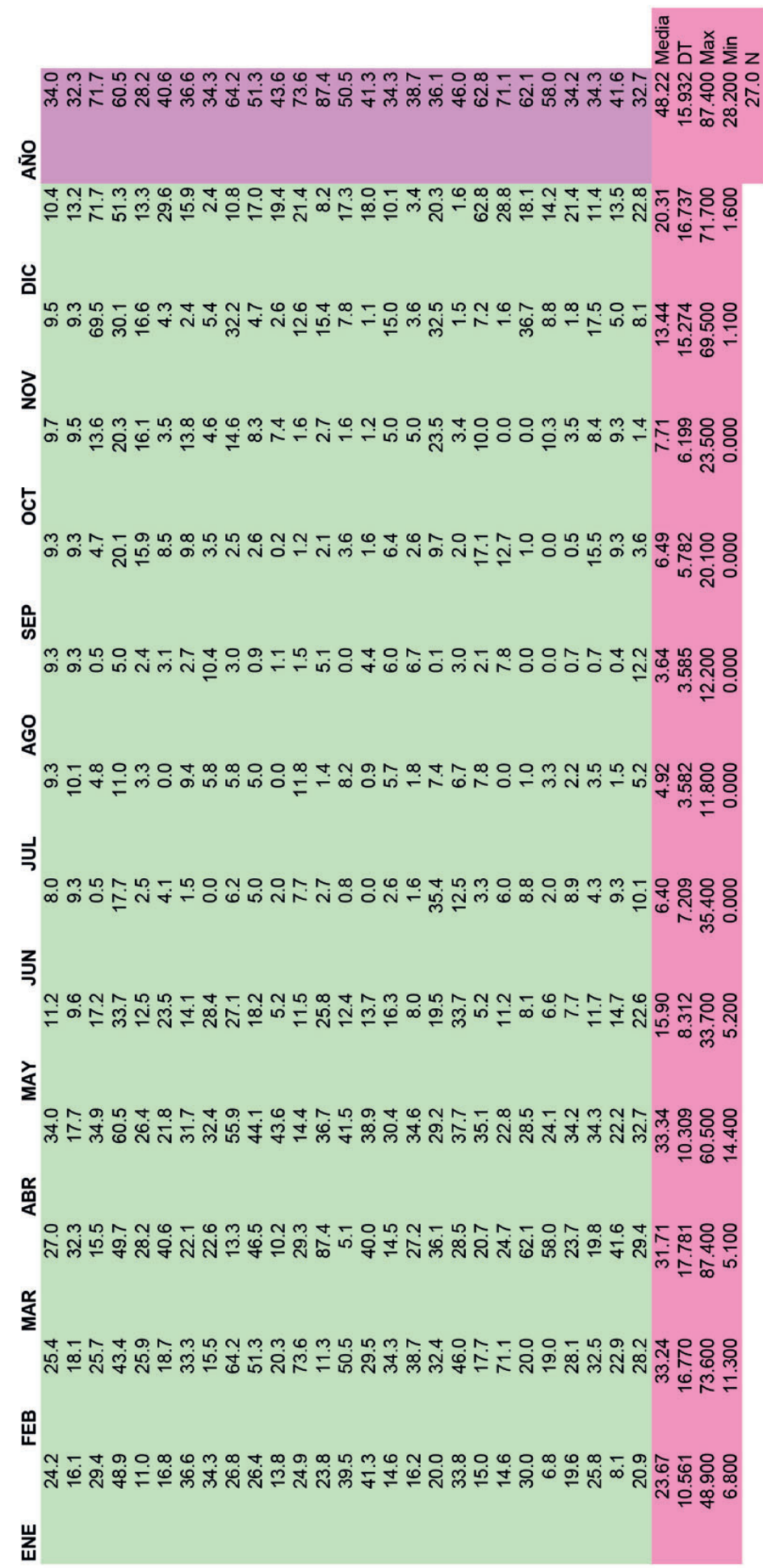




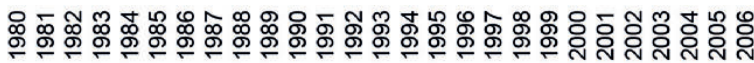

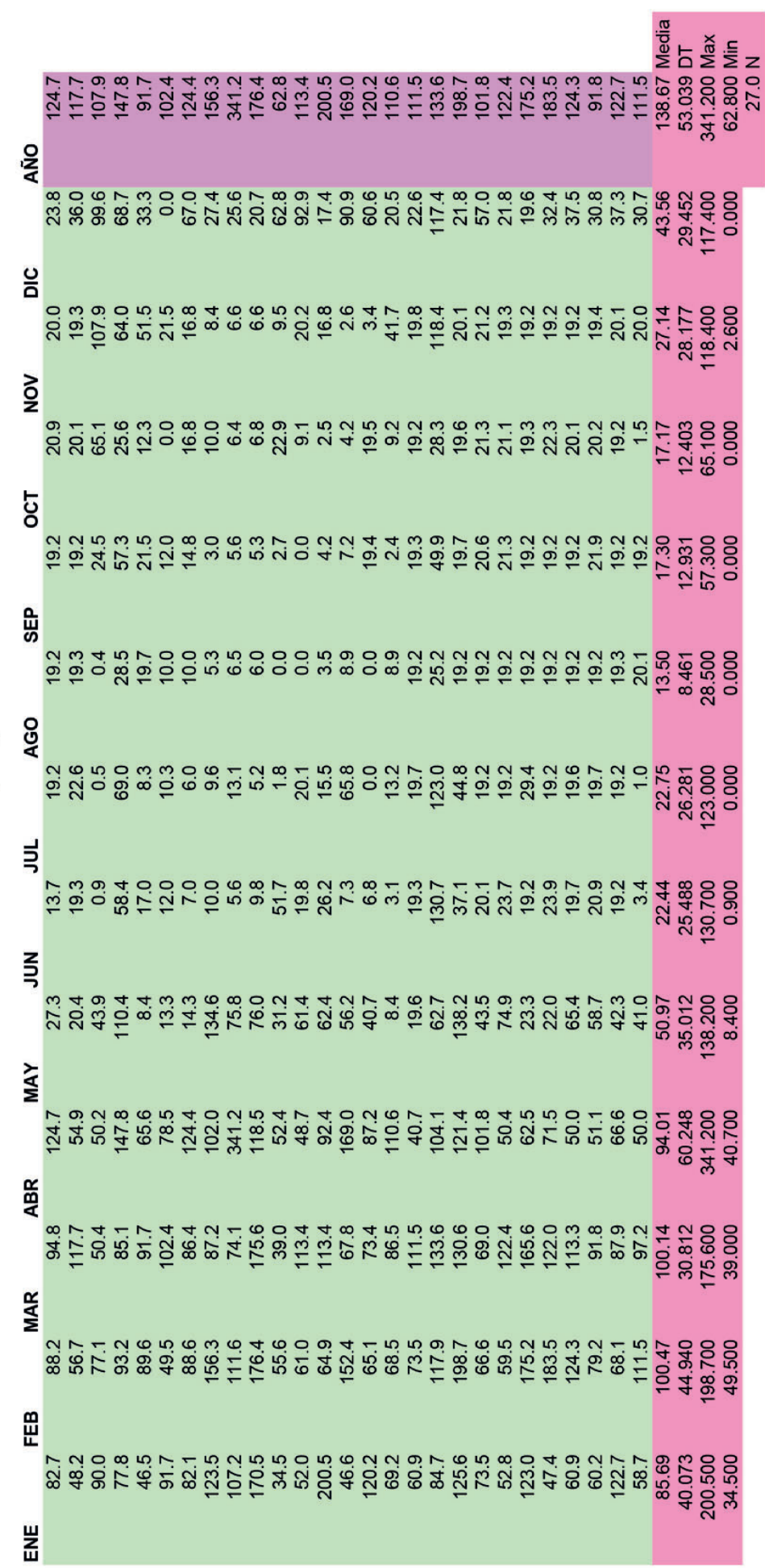




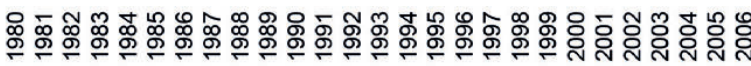

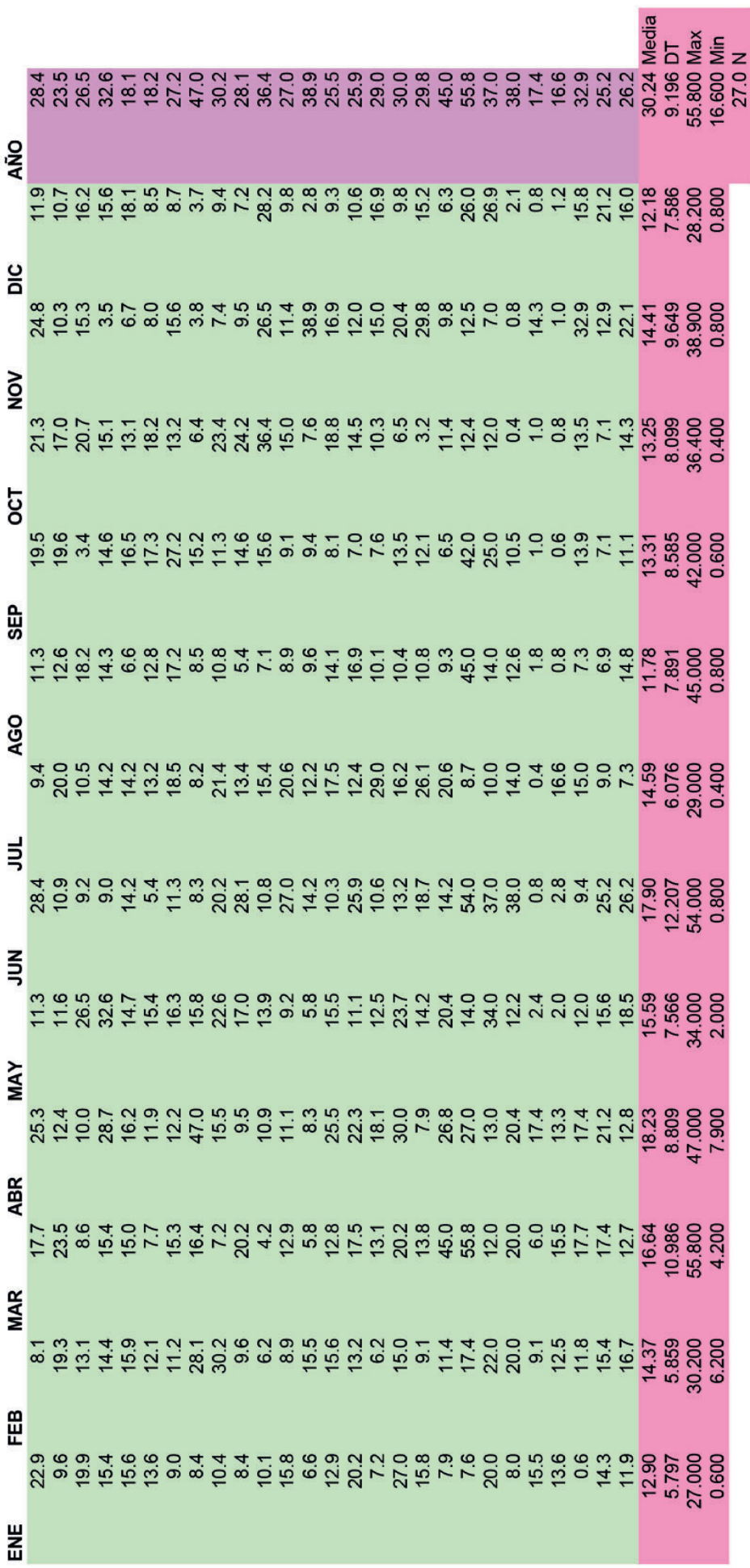




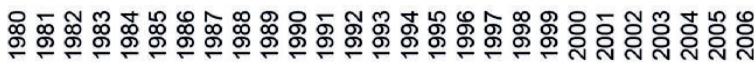

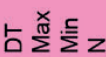

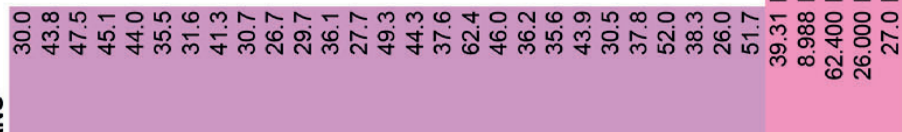

象

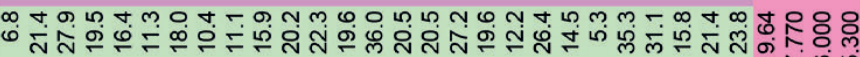

음

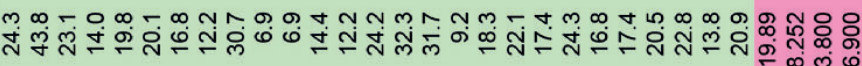

을

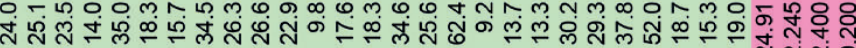

'气

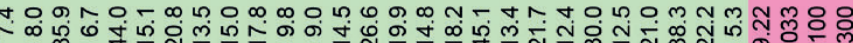

峞

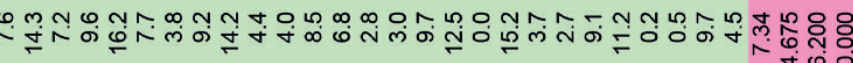

ᄋ

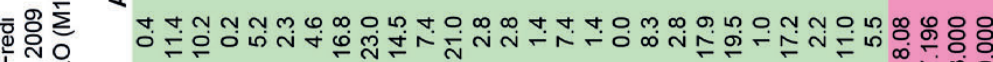

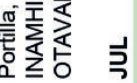

䓂范范

ம்

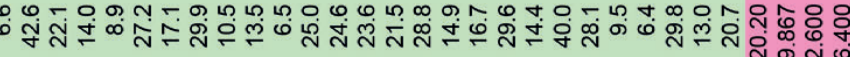

¿

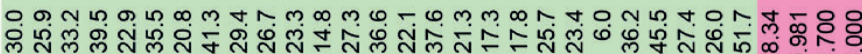

䜱

の

$\frac{\alpha}{\Sigma}$

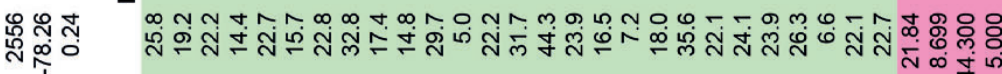

妥

б-

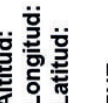

崖 


\section{6}

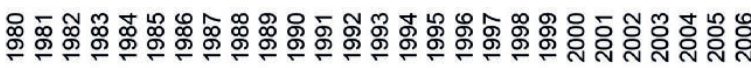

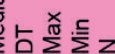

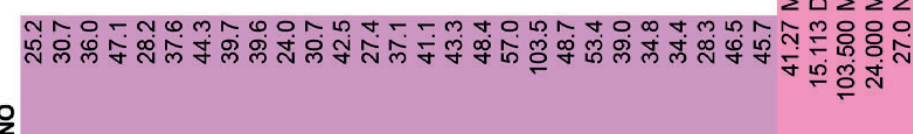

察

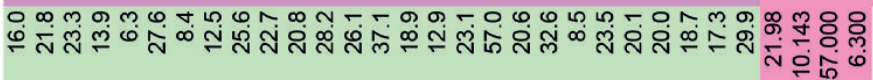

늠

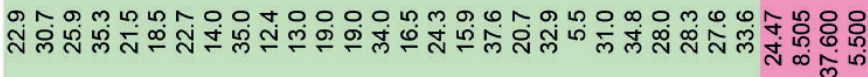

o

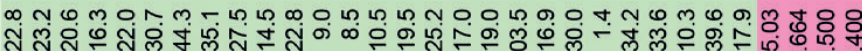

¿

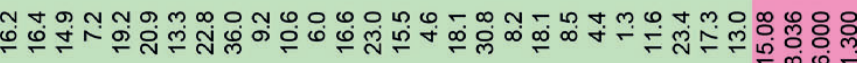

崖

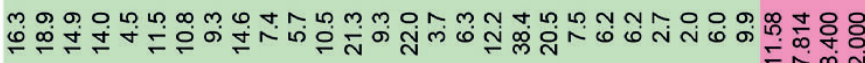

产 인

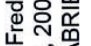

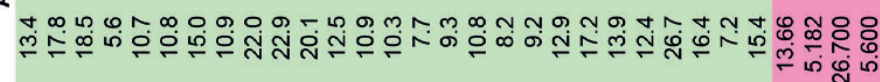

马

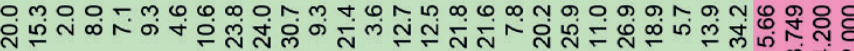

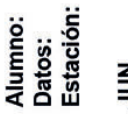

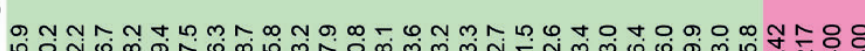

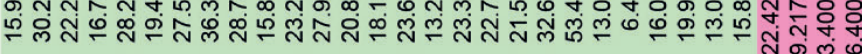

¿

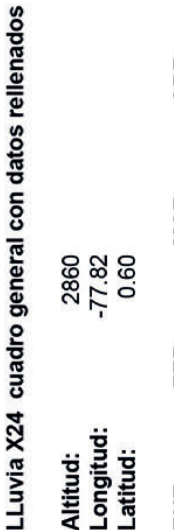

ก แ

岗

彊

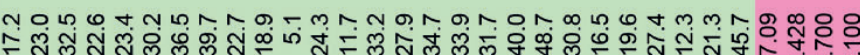

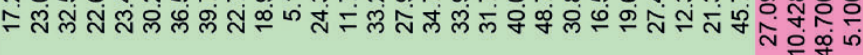

$\frac{\alpha}{\Sigma}$

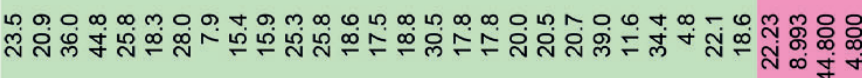

畋

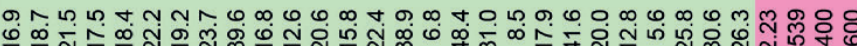

மำ

崫 


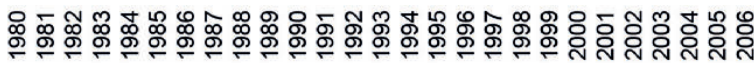

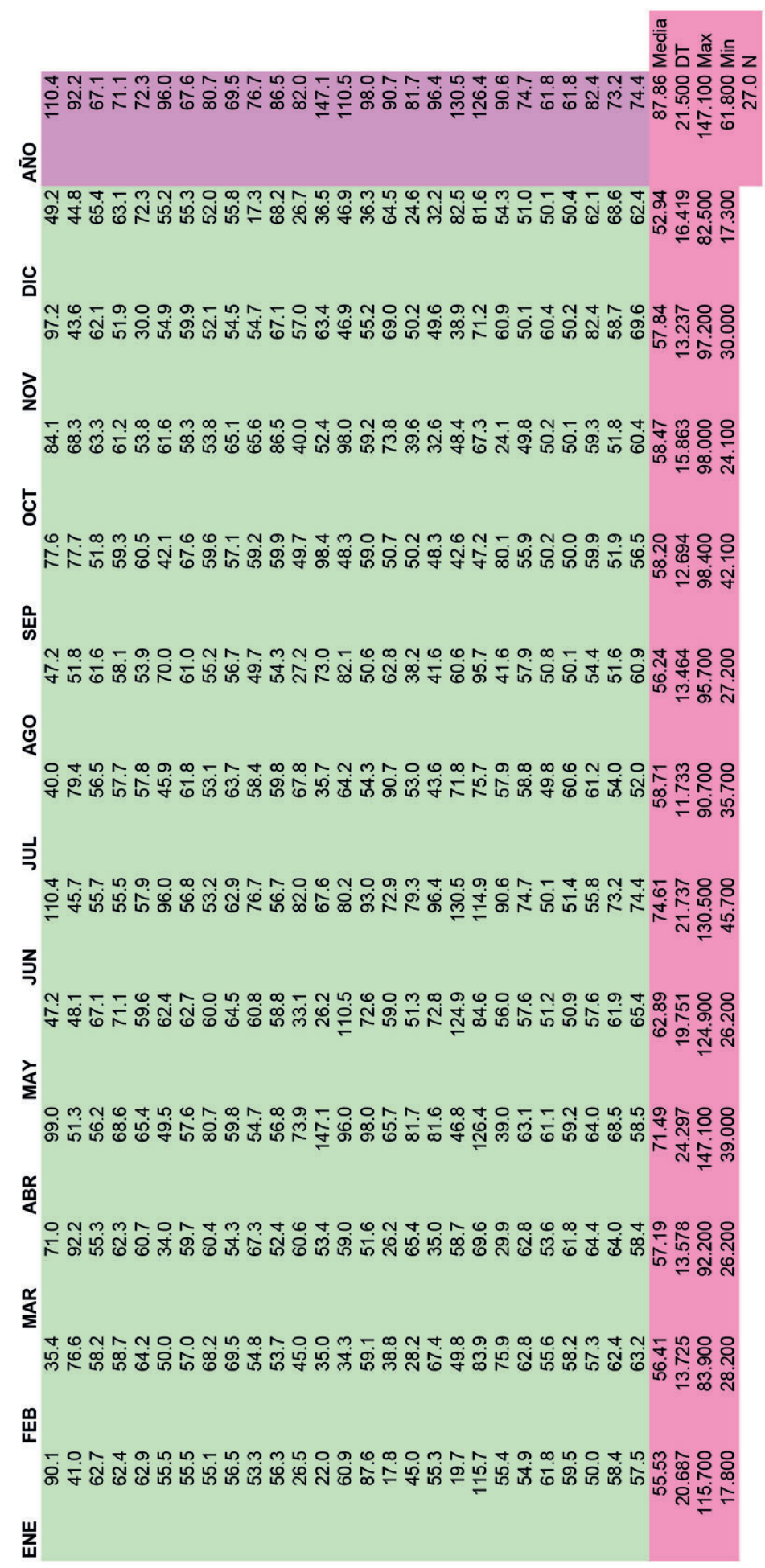




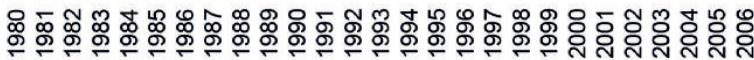

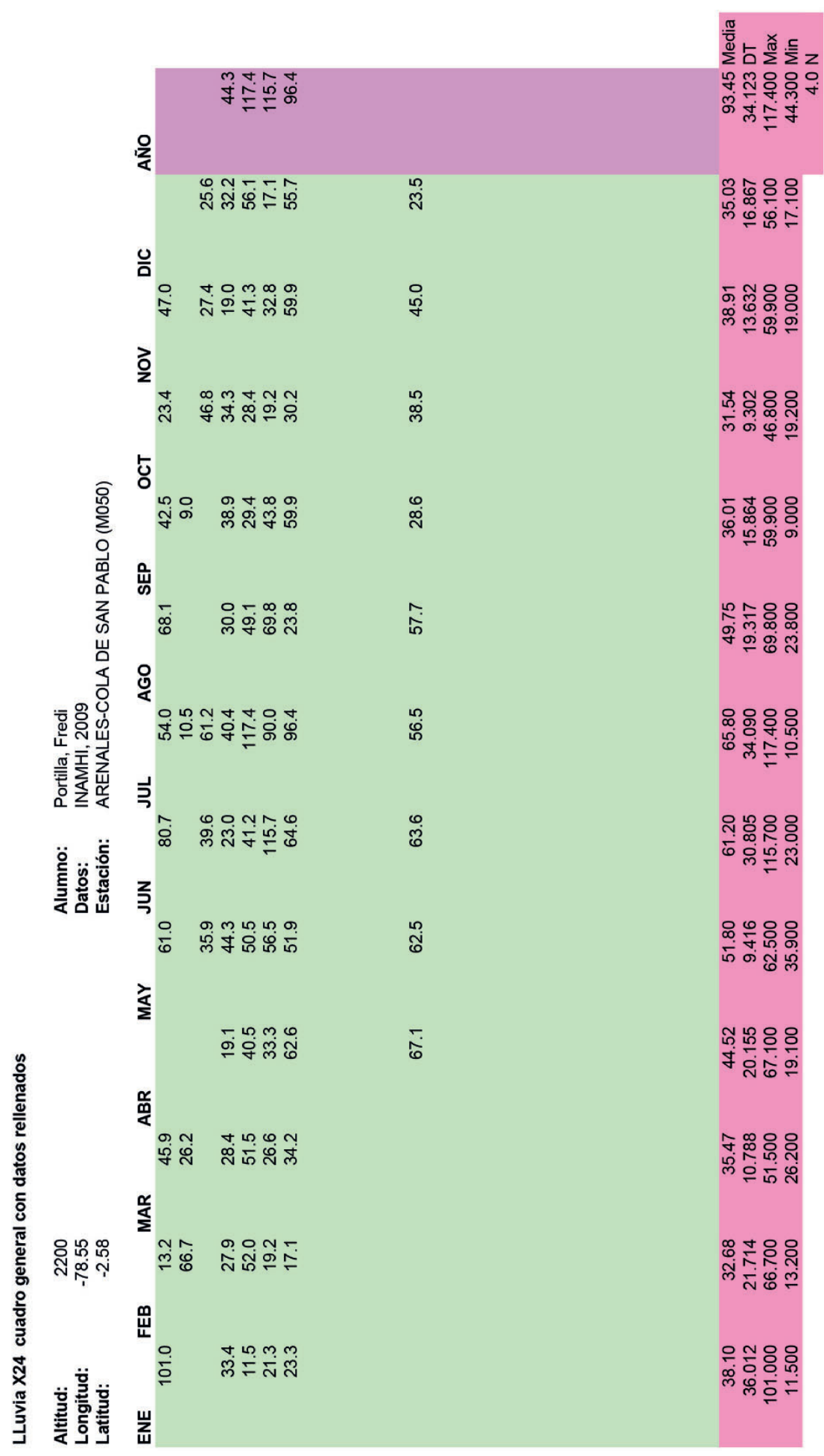




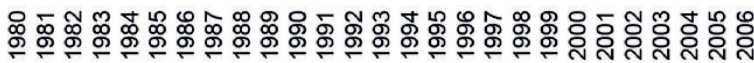

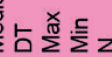

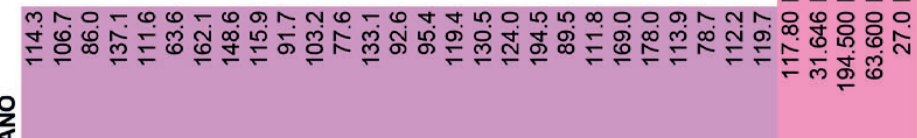

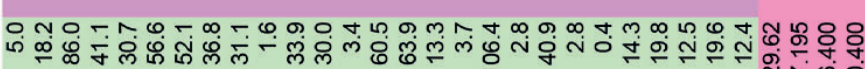

음

๓

วิ

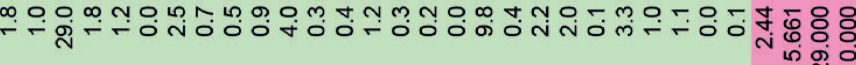

¿

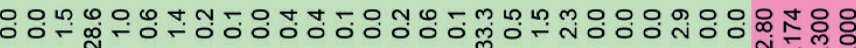

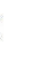

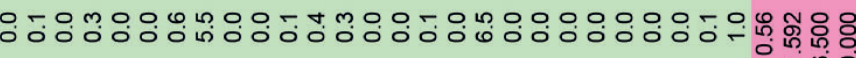

언

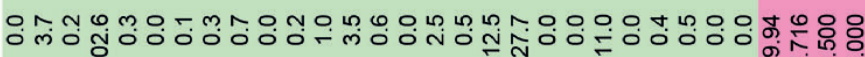

s

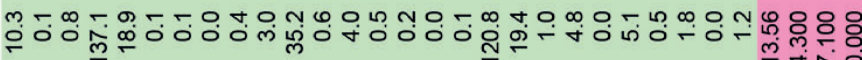

官范范

ב

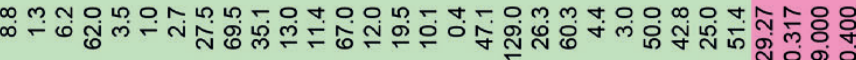

交

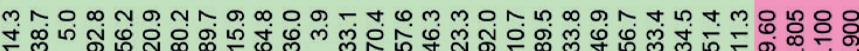

爱

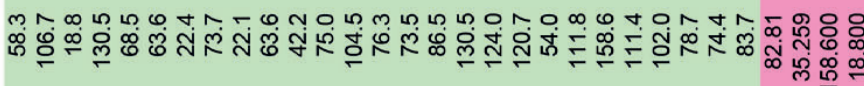

迹

$08 \div$

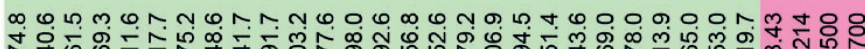

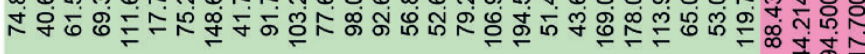

崭

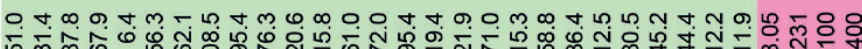

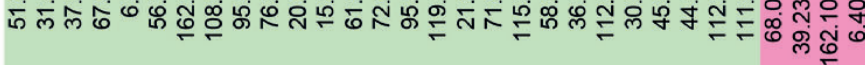

씬 


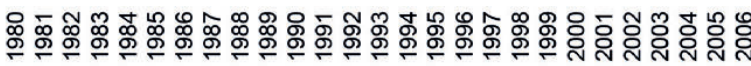

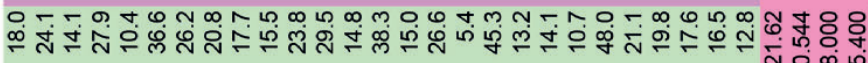

음

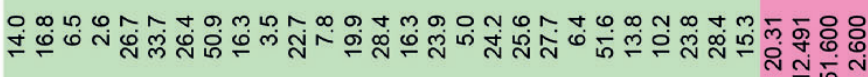

혼

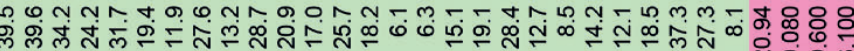

to

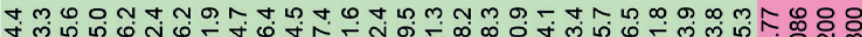

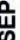

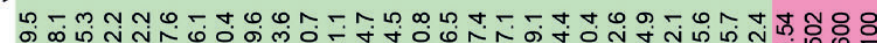

का

$\stackrel{8}{8}$

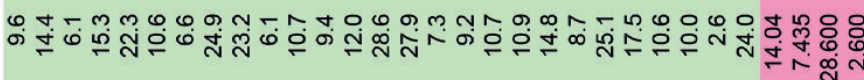

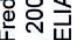

د

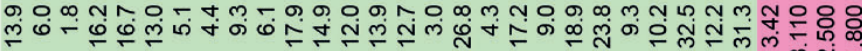

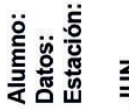

골

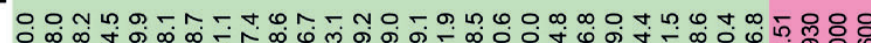

嬡

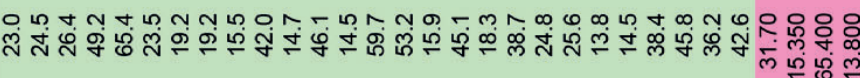

$\frac{\alpha}{2}$

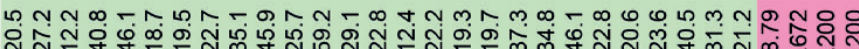

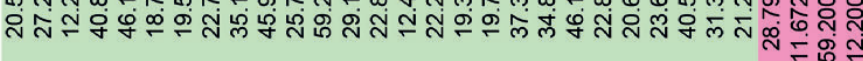

忍

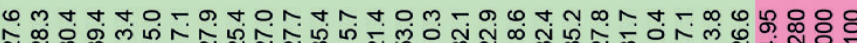

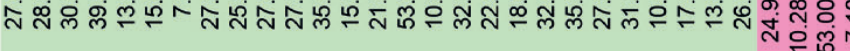

宸 


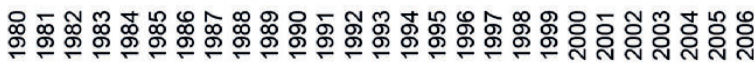

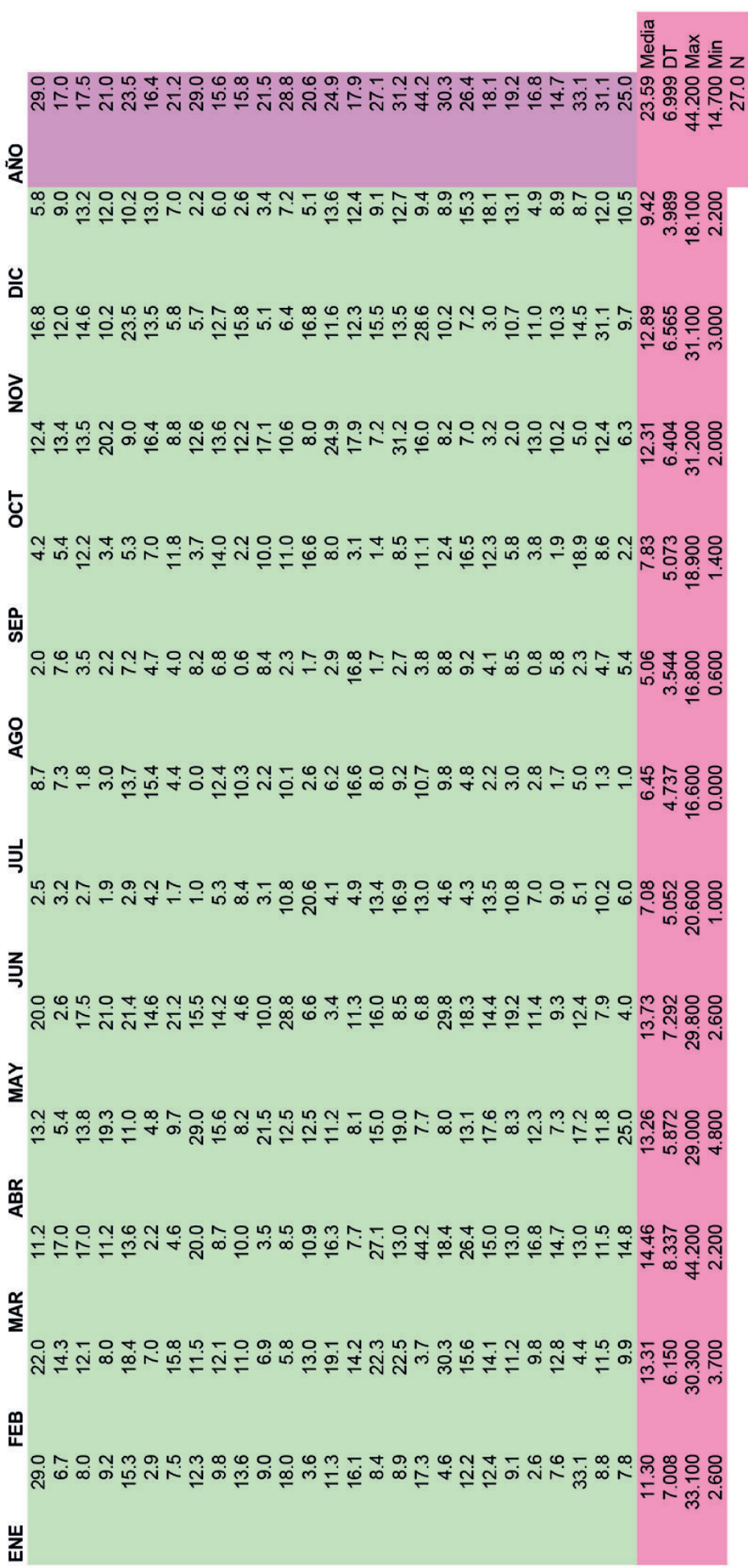




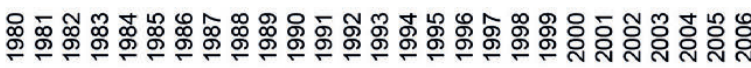

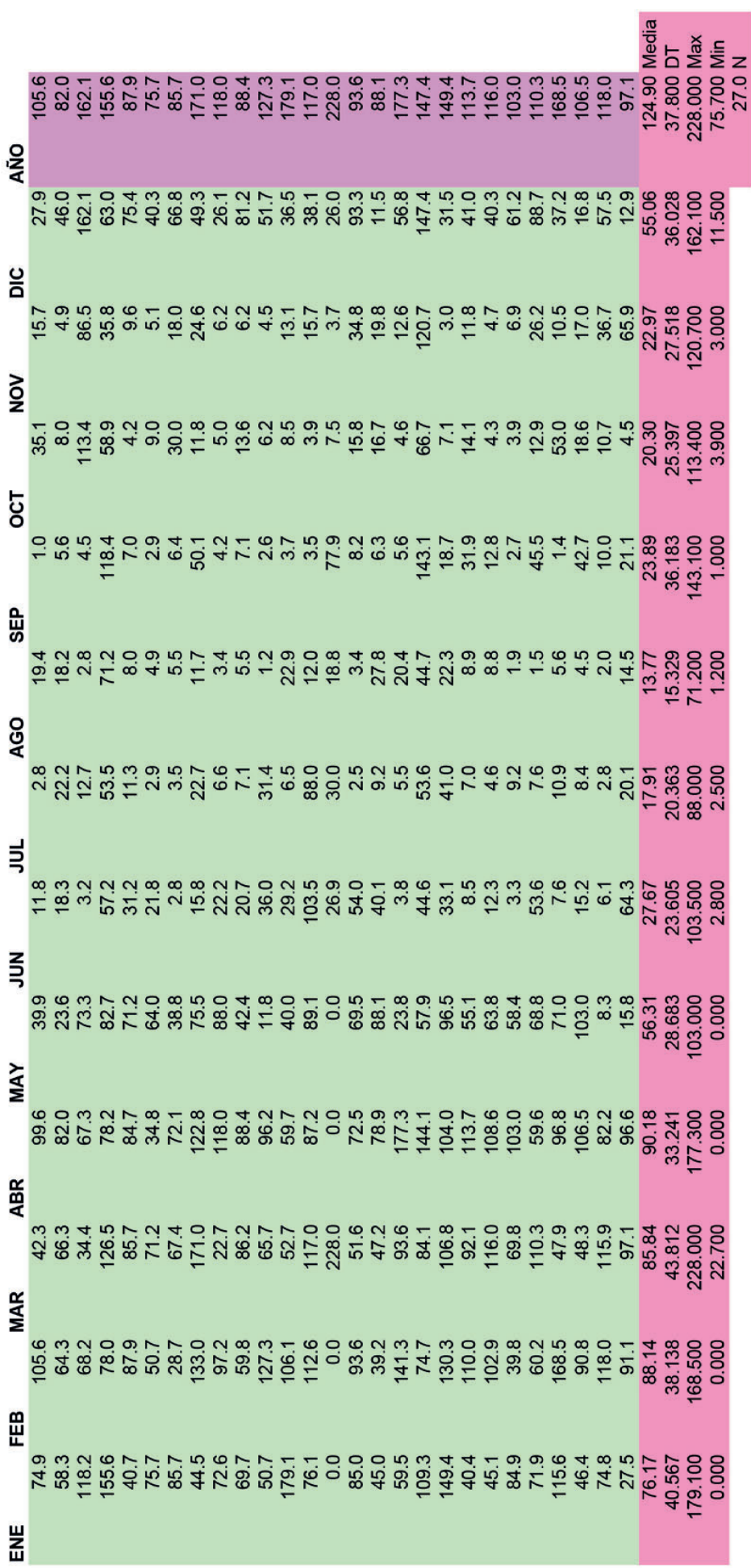




\section{3}

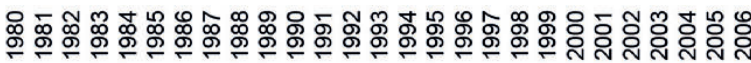

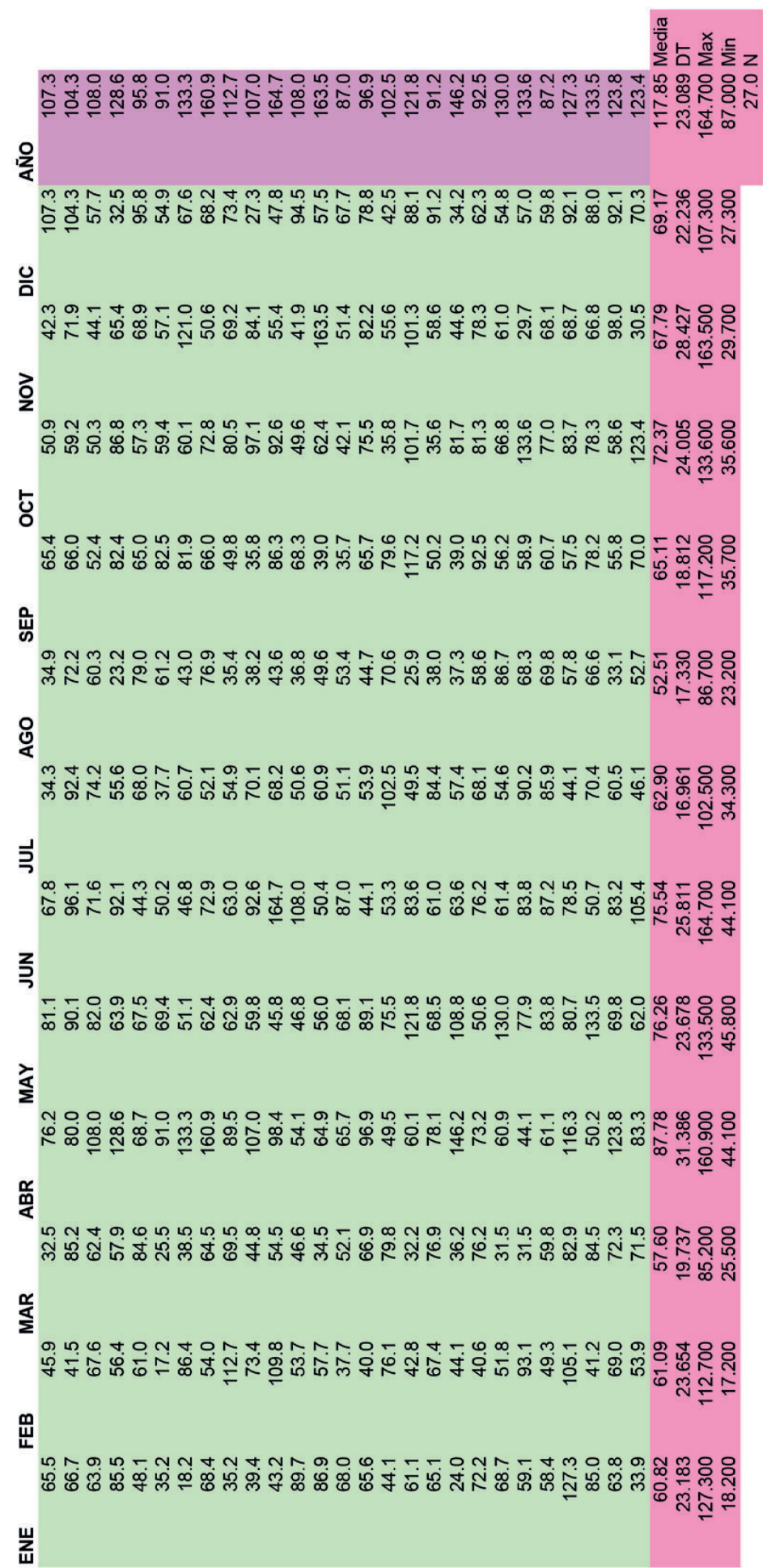




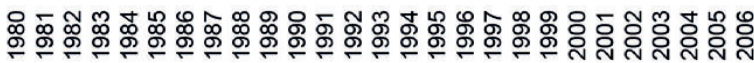

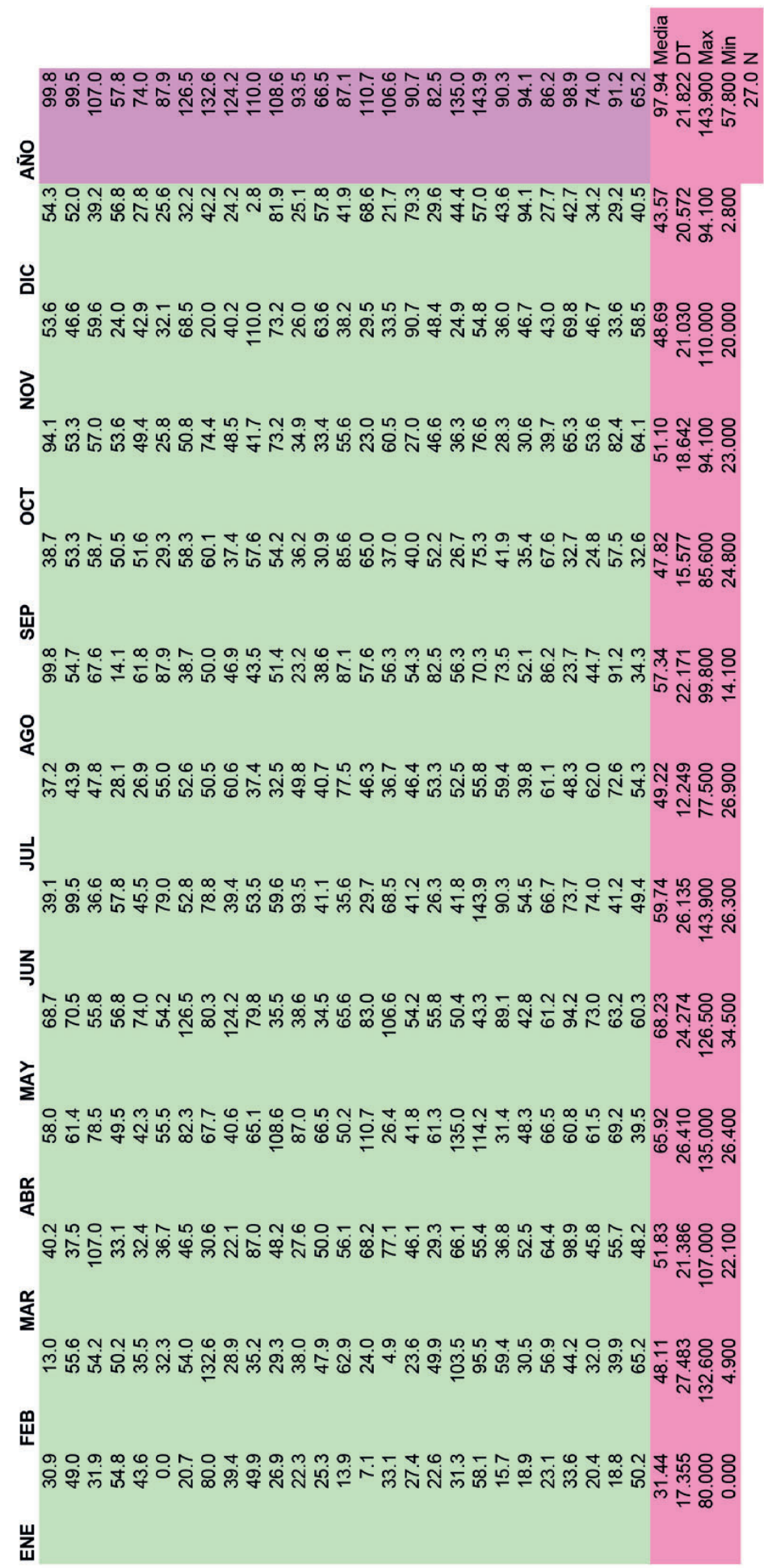




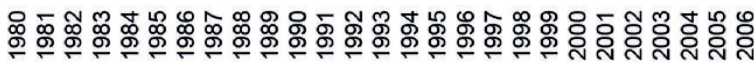




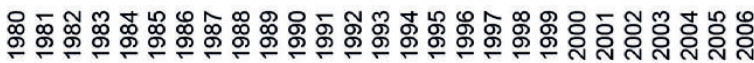

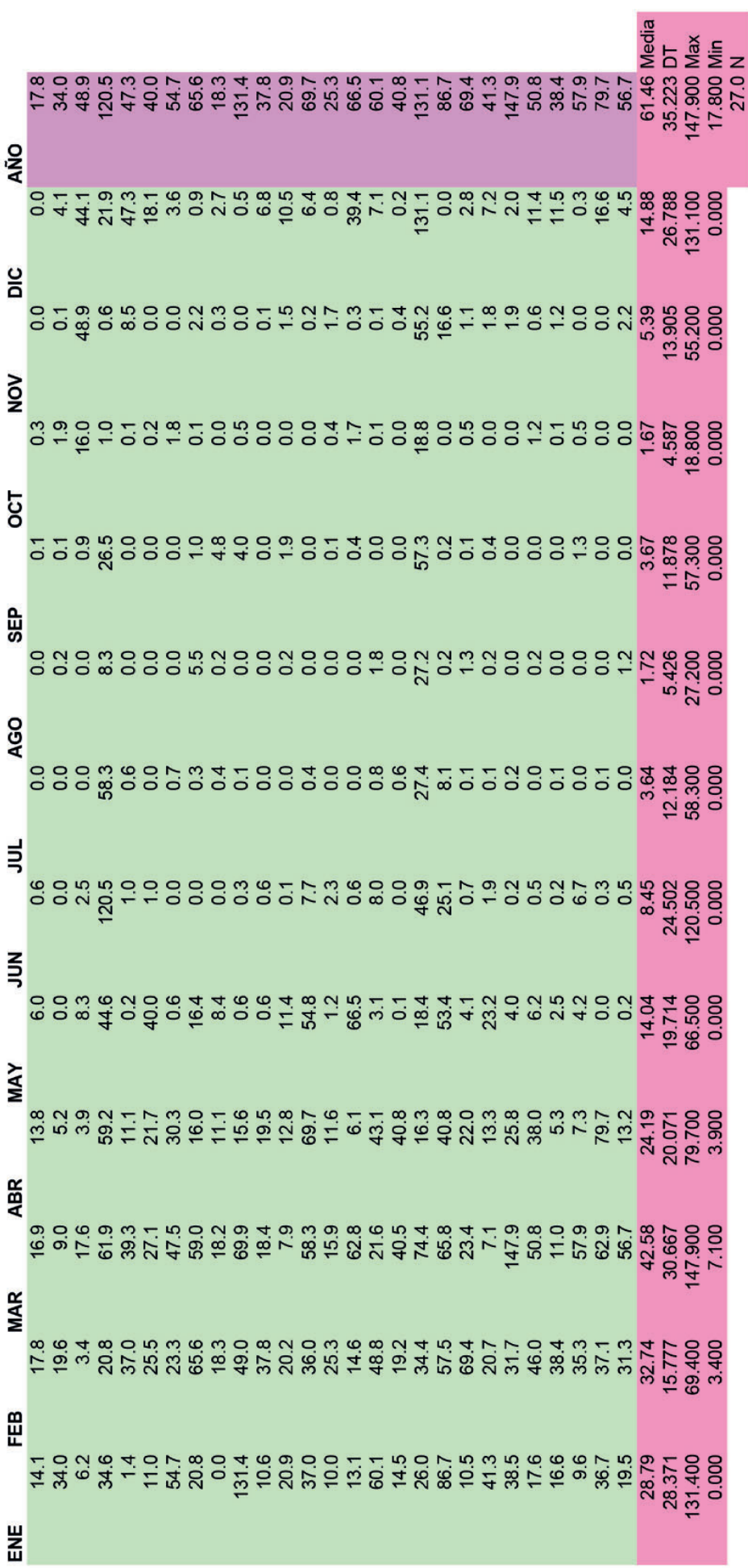




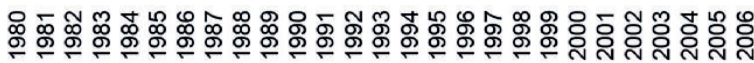

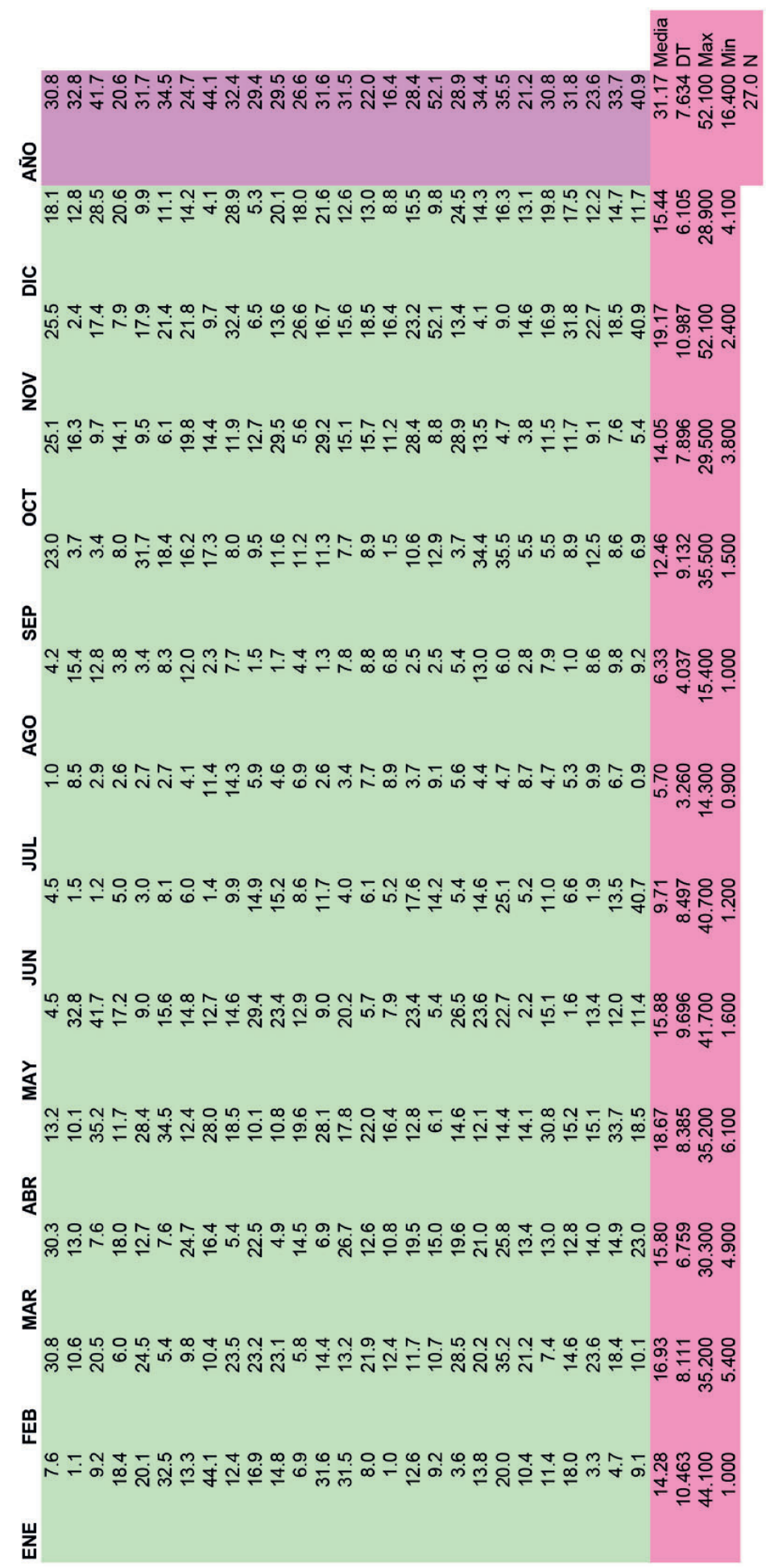




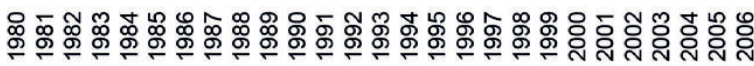

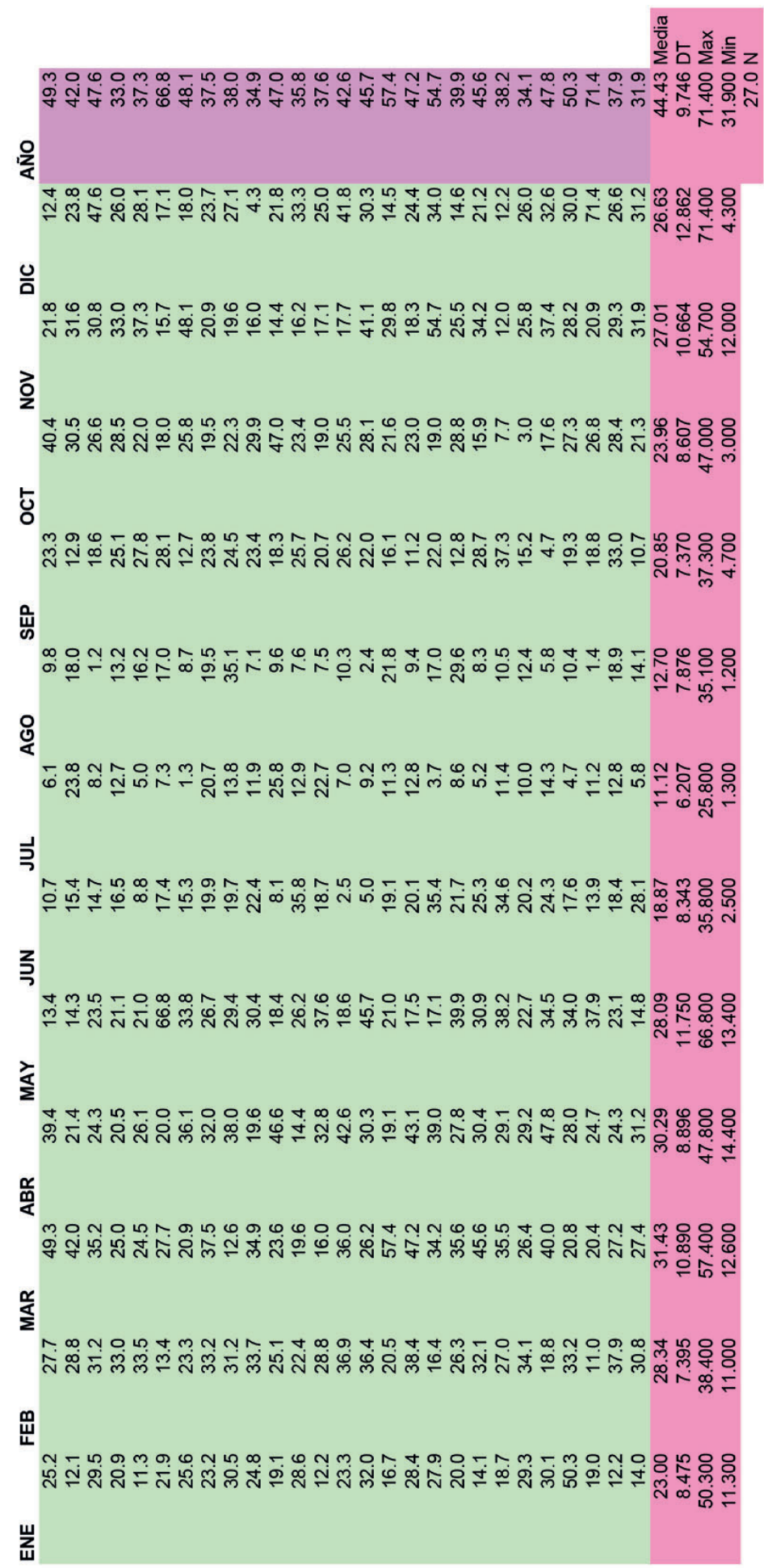




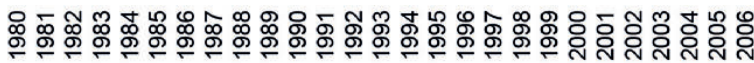

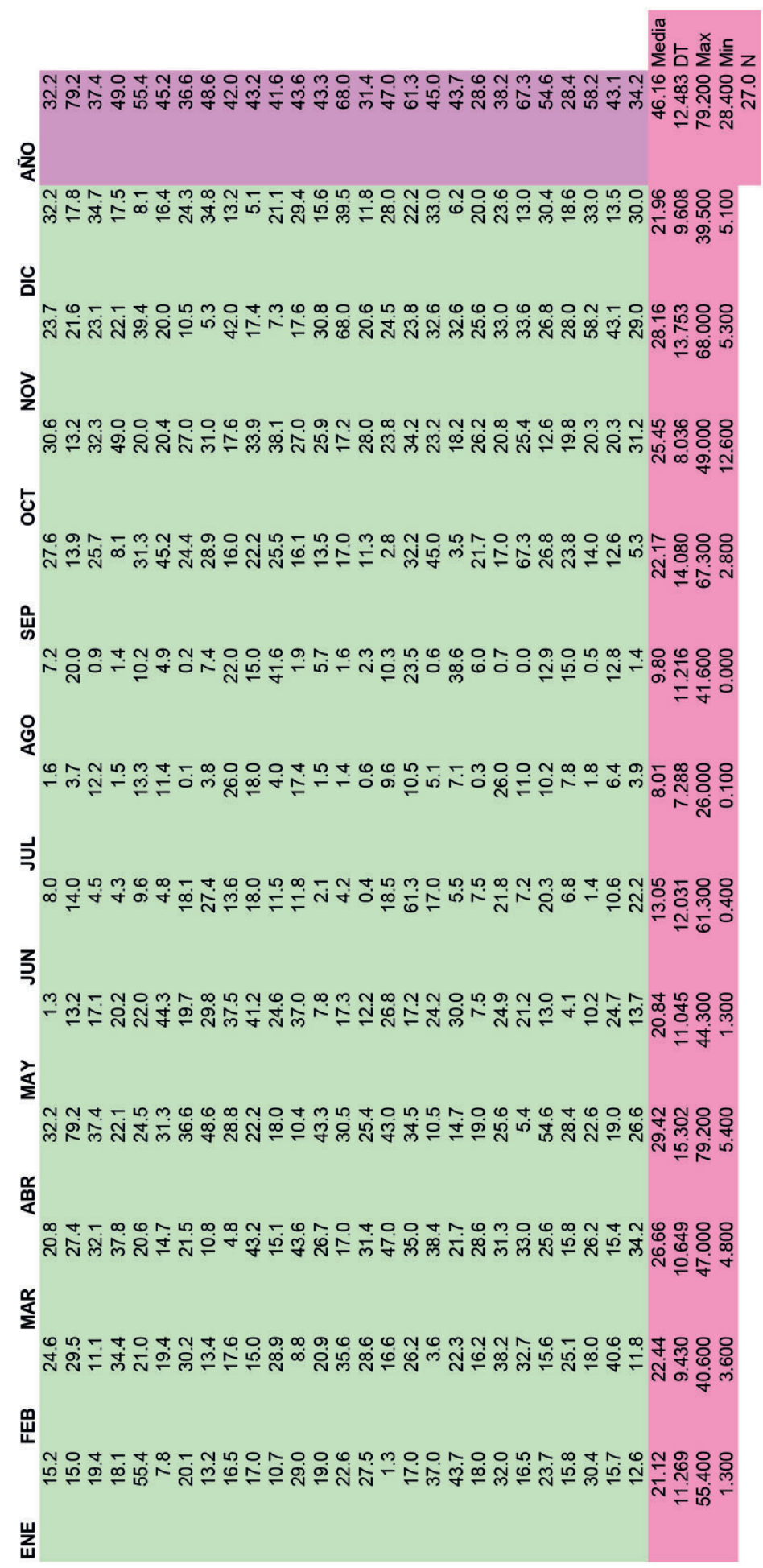


300

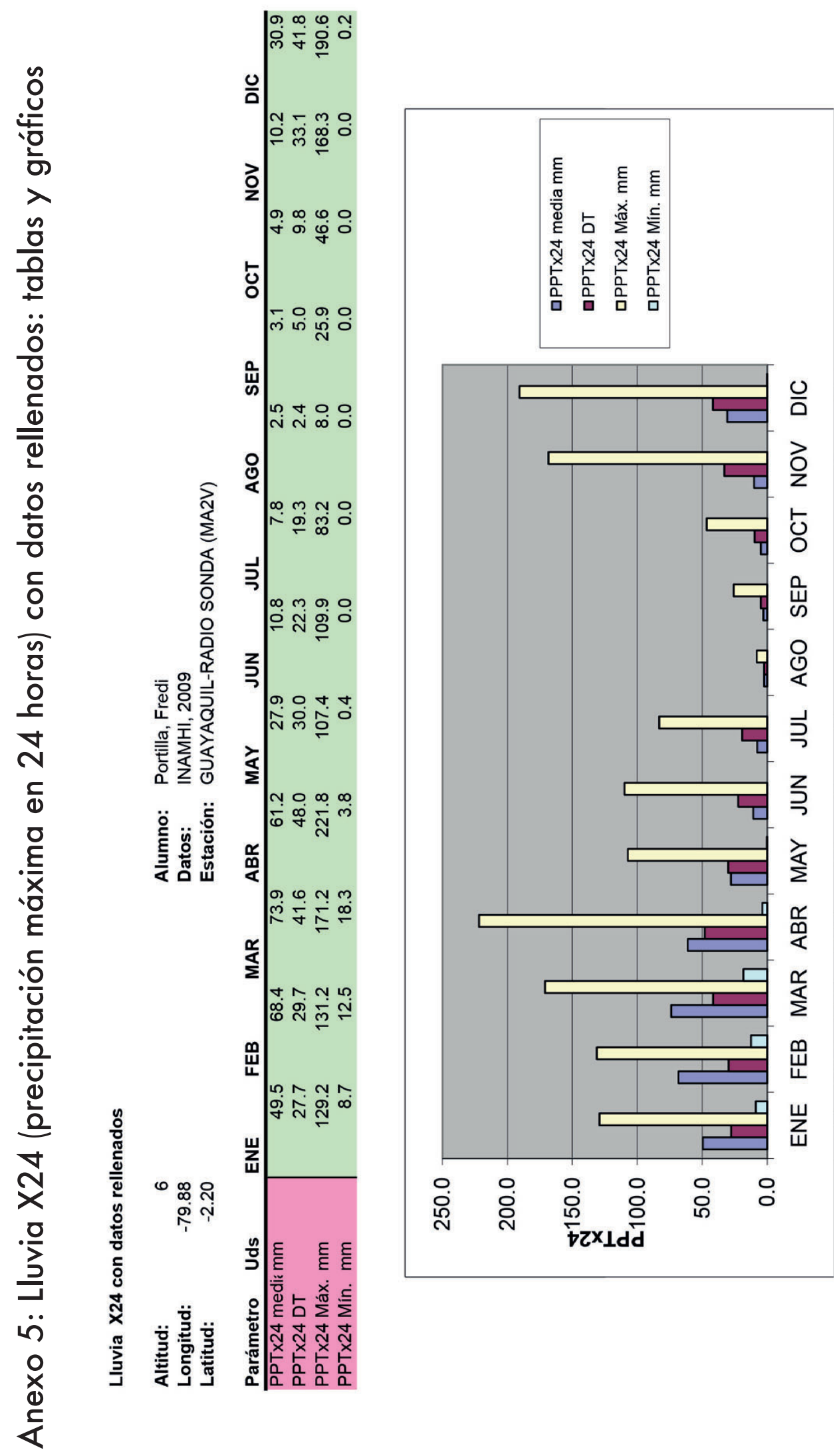


301

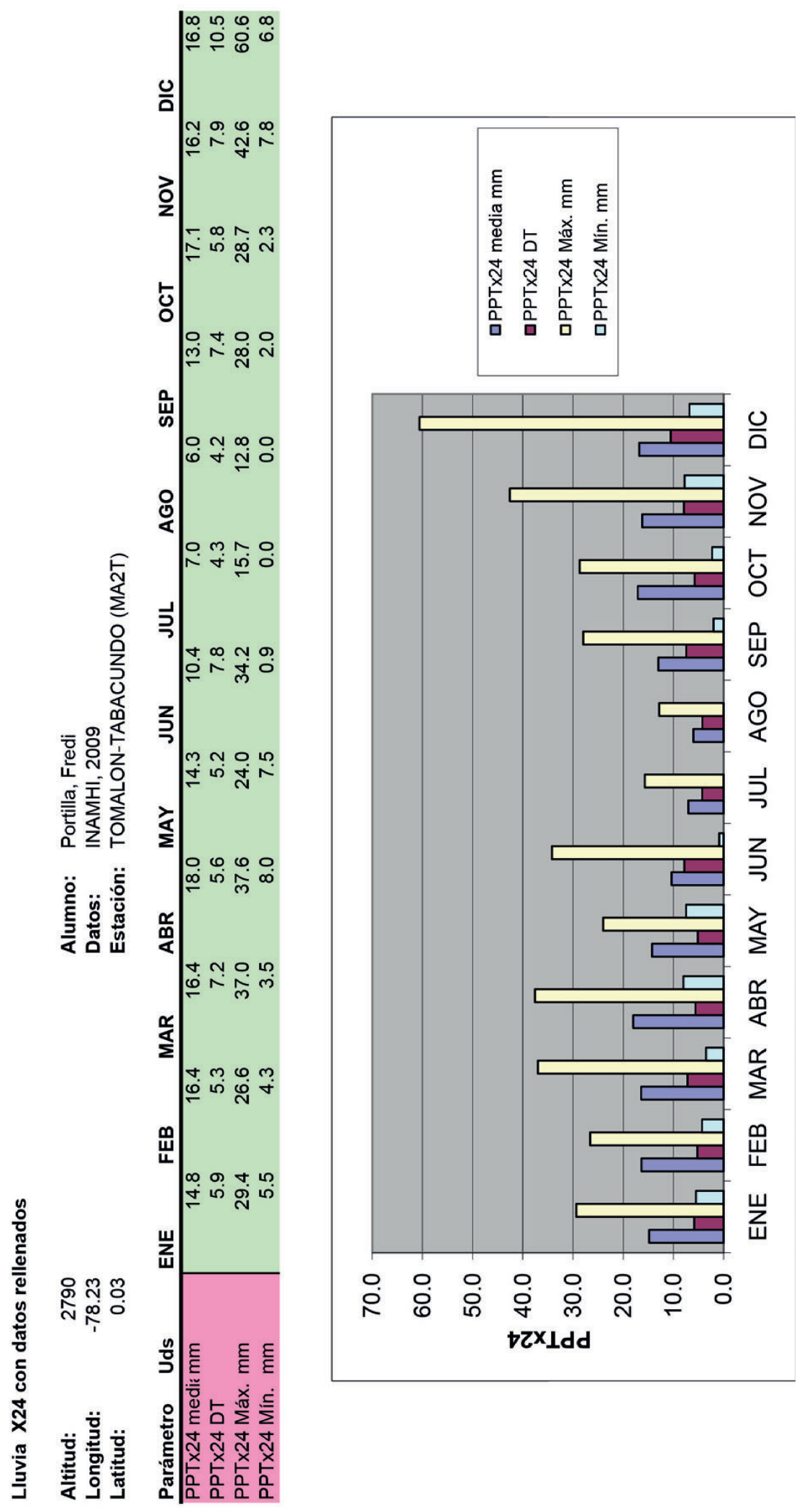



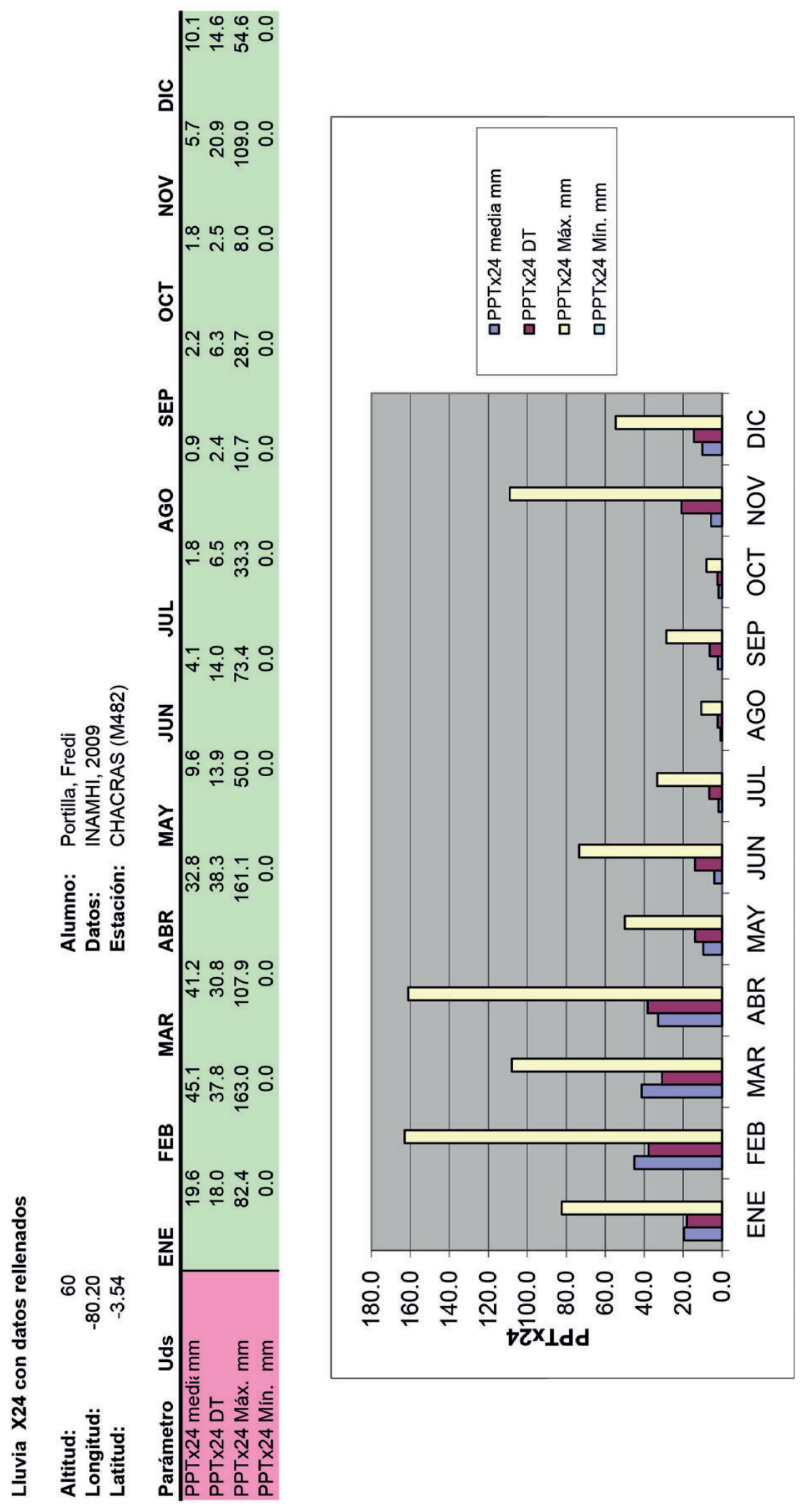


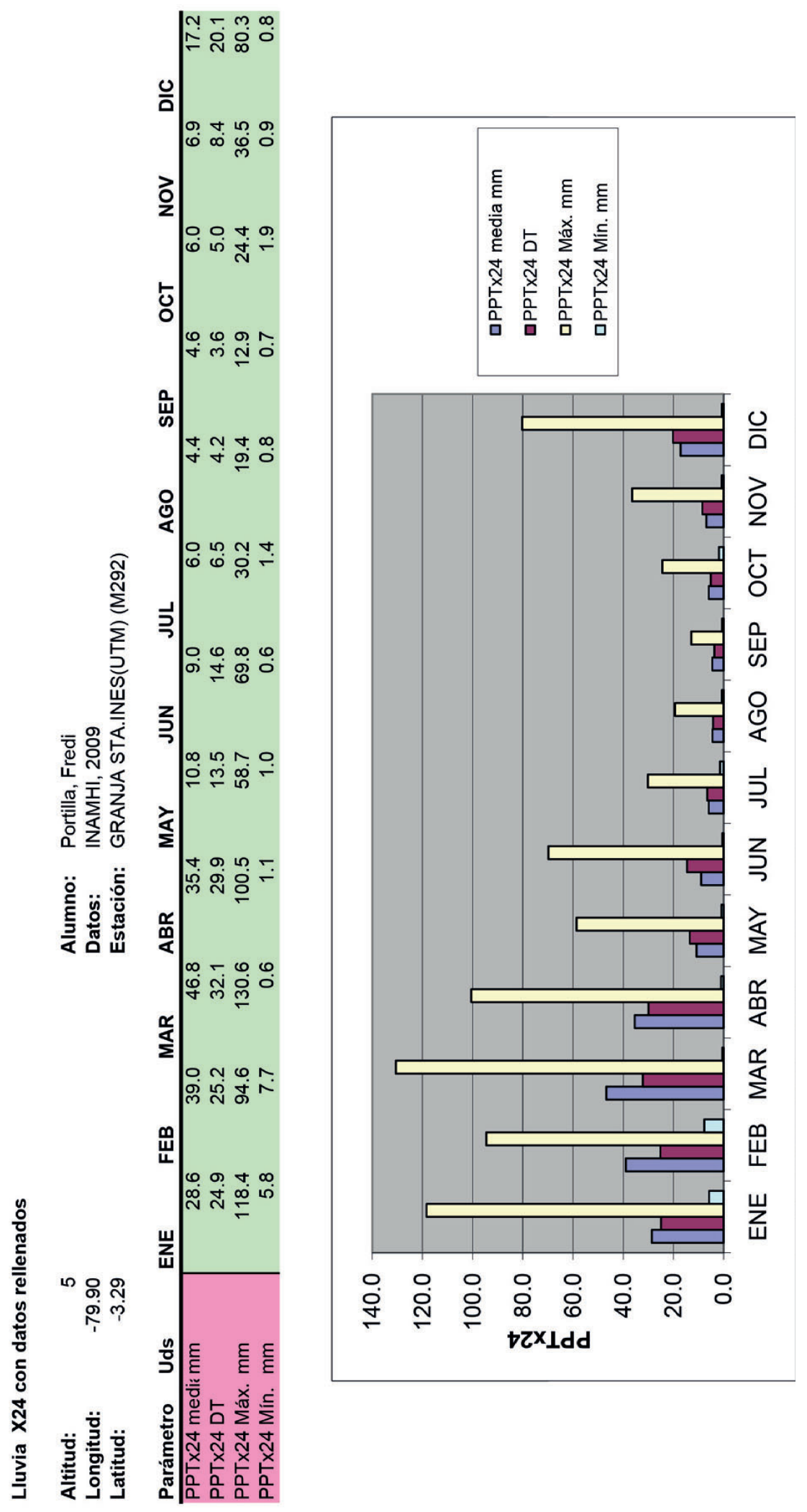




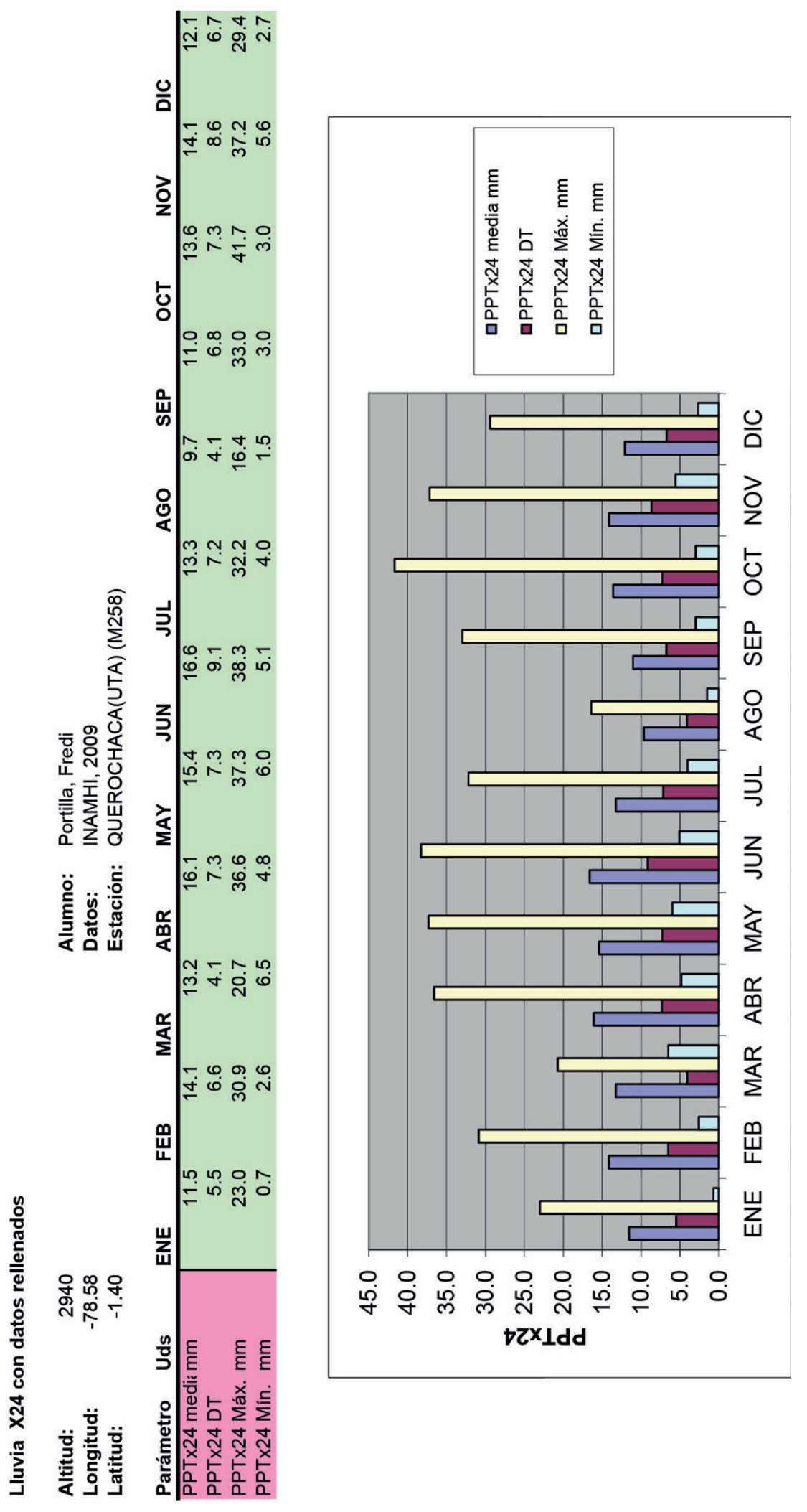




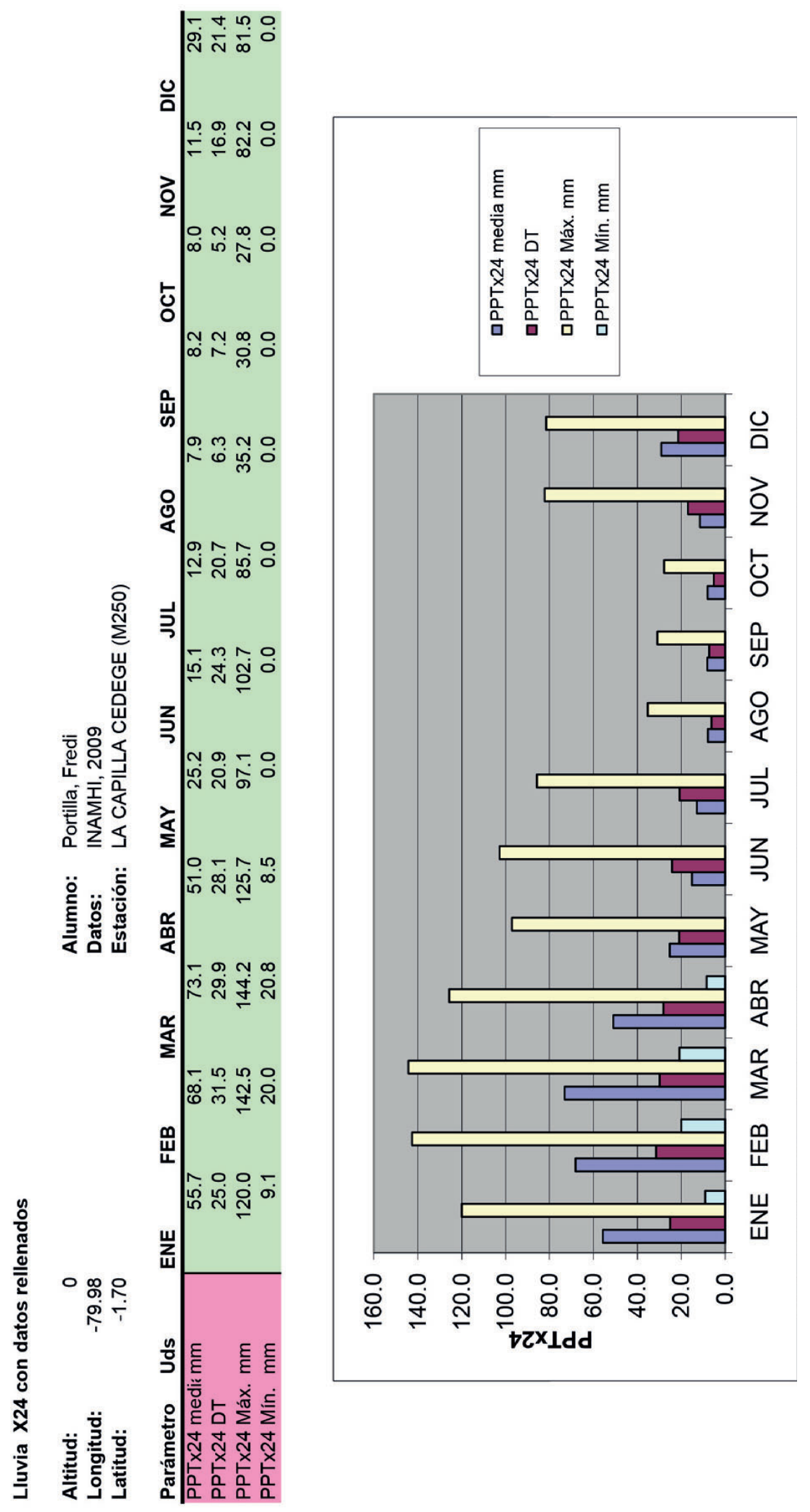




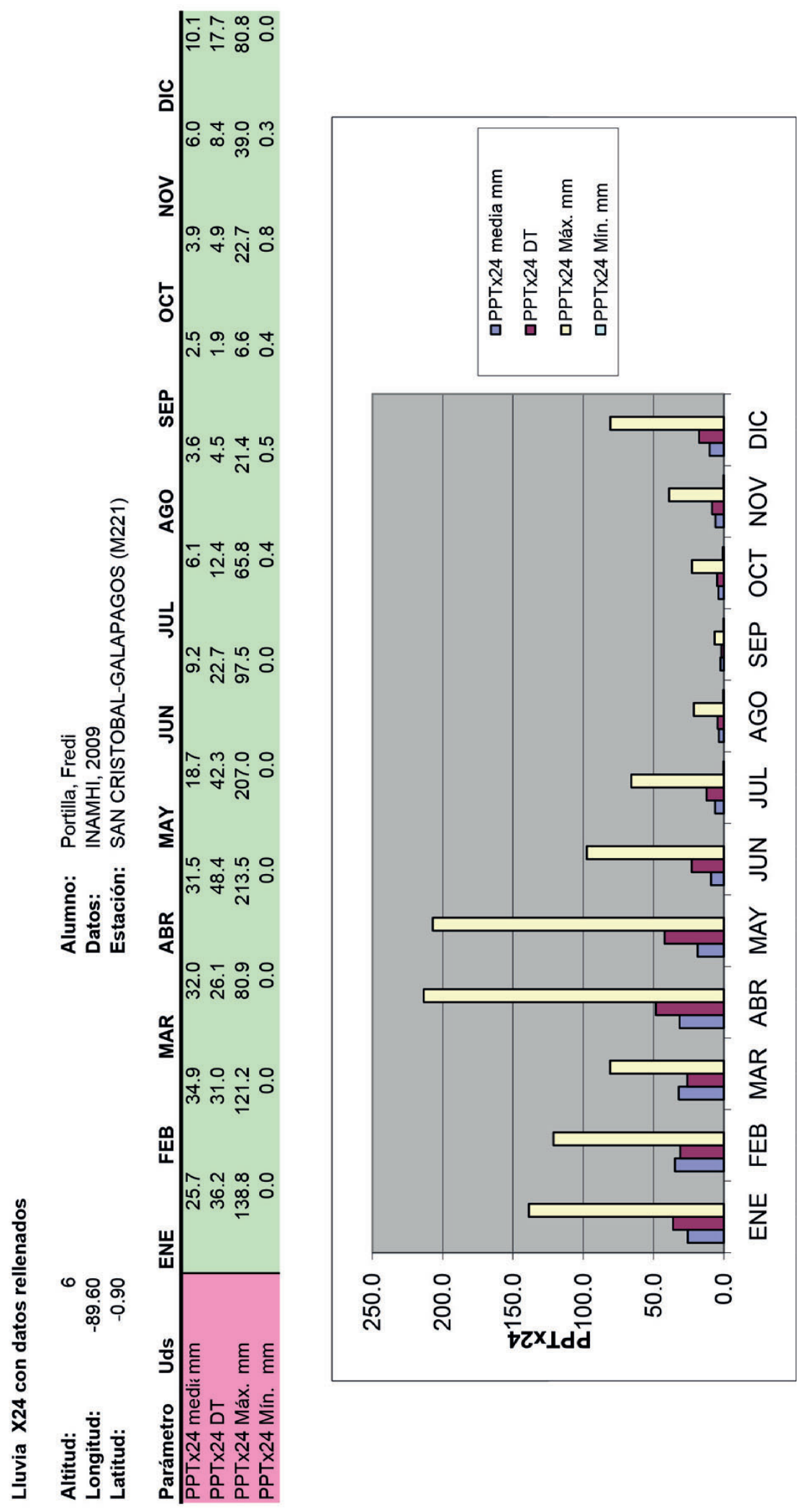




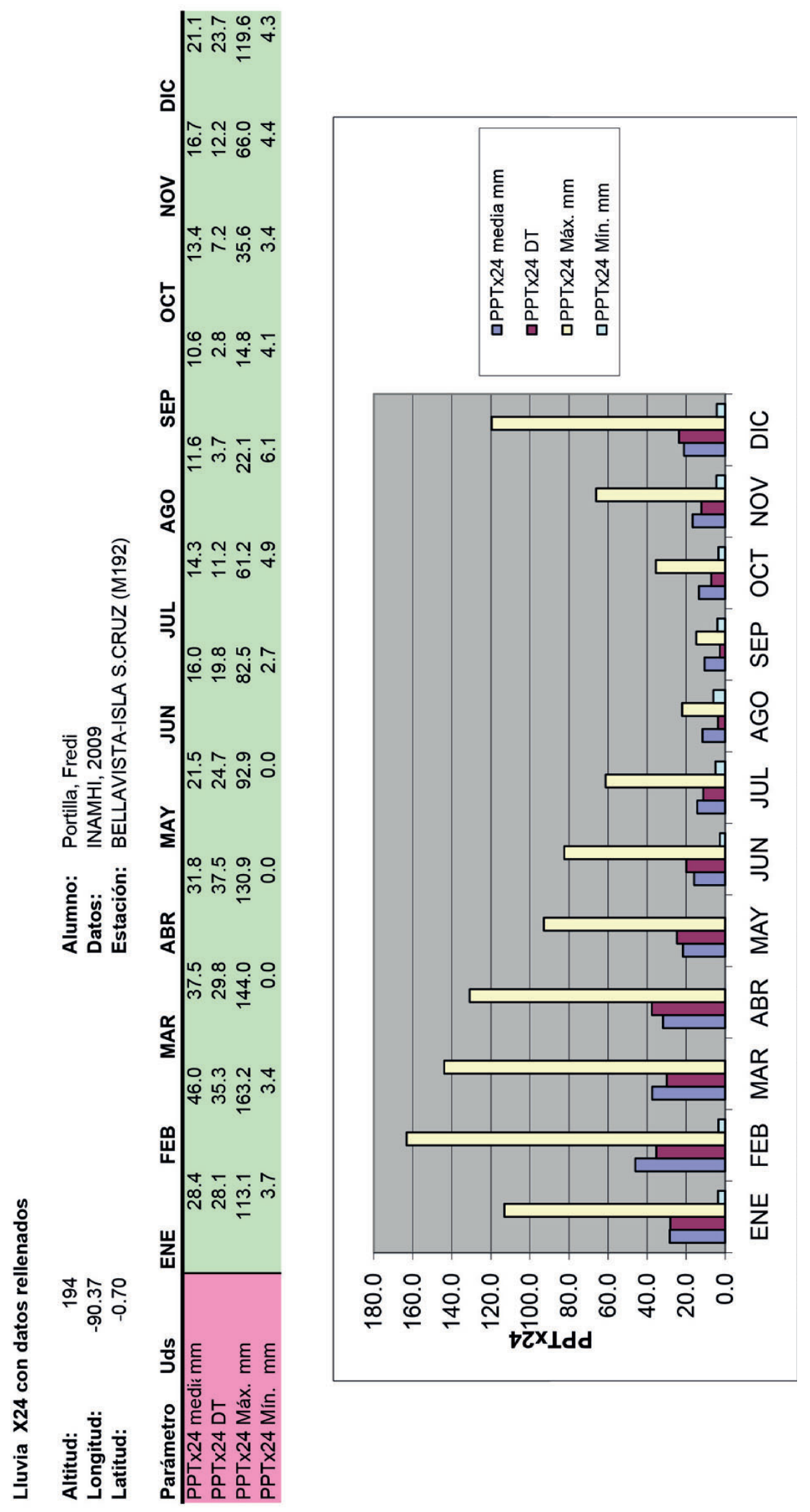




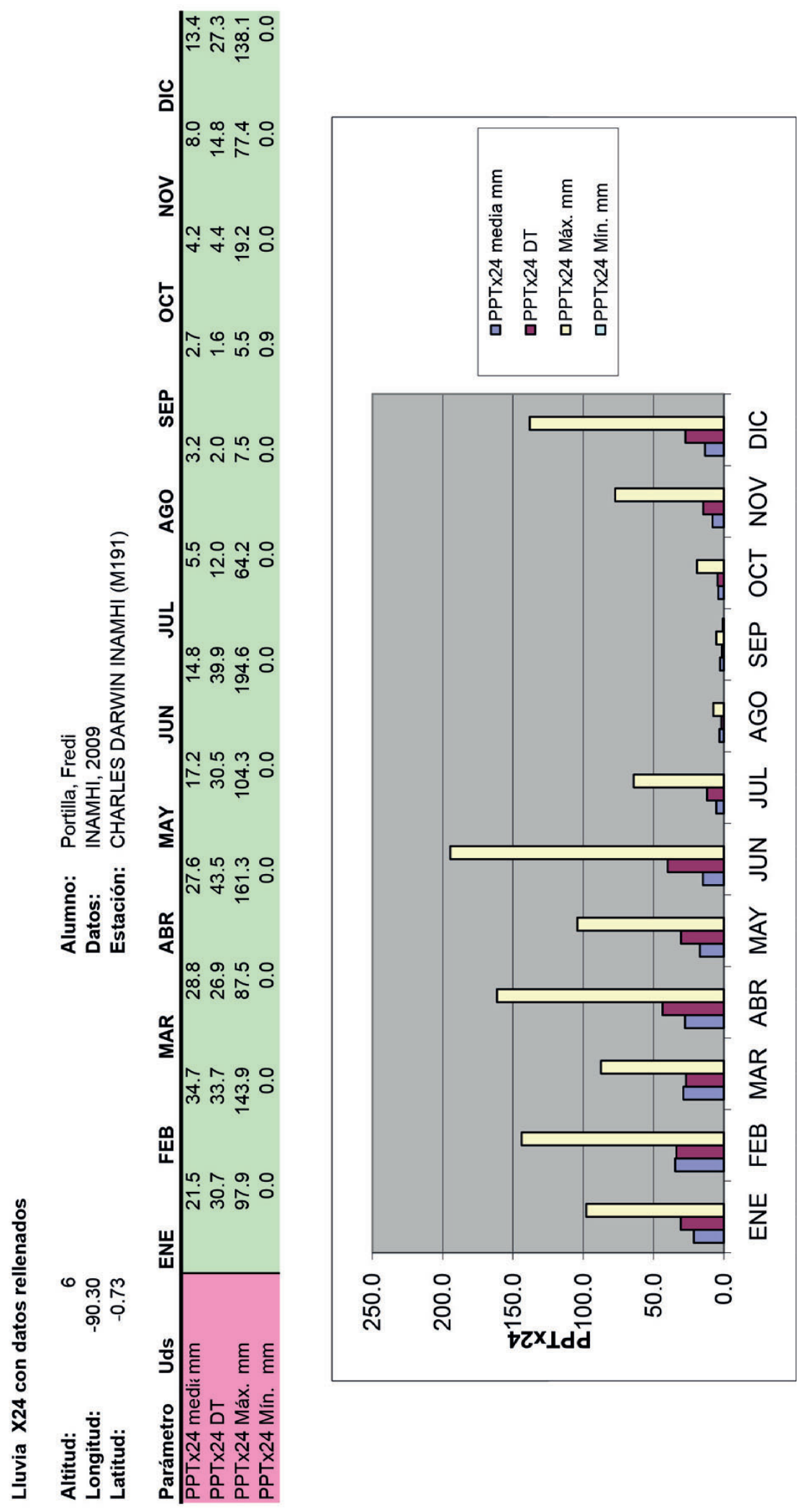




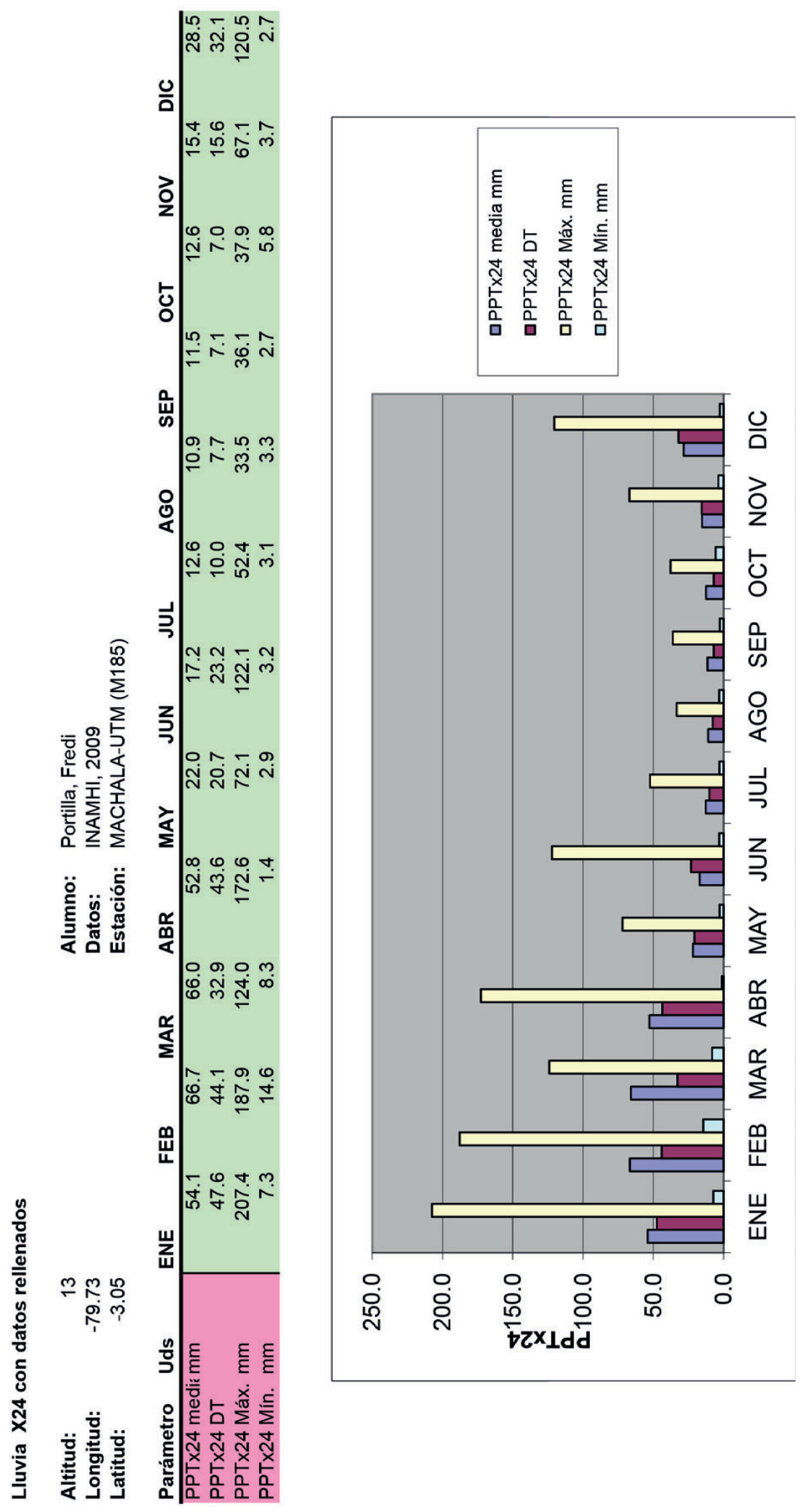


310

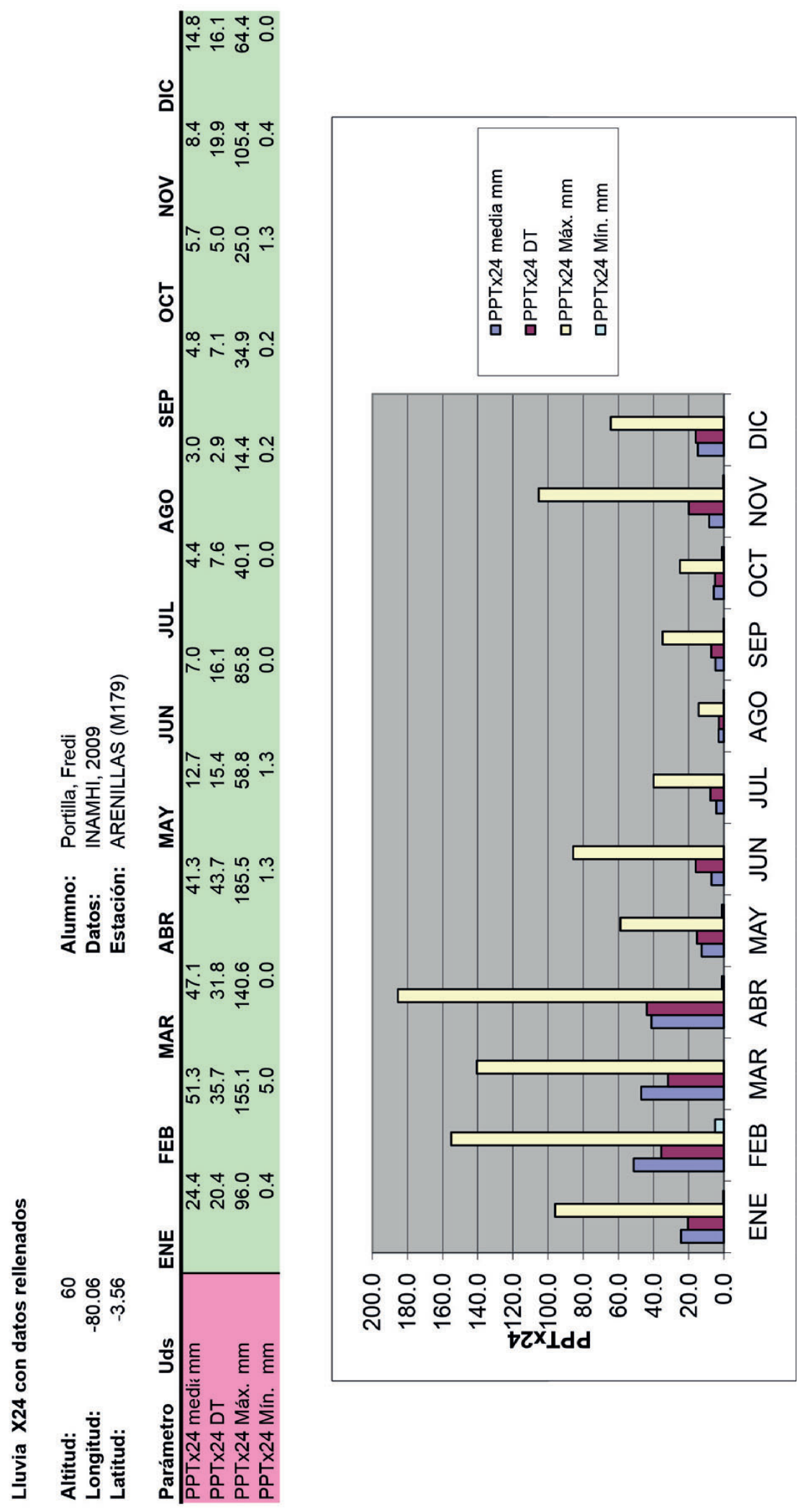




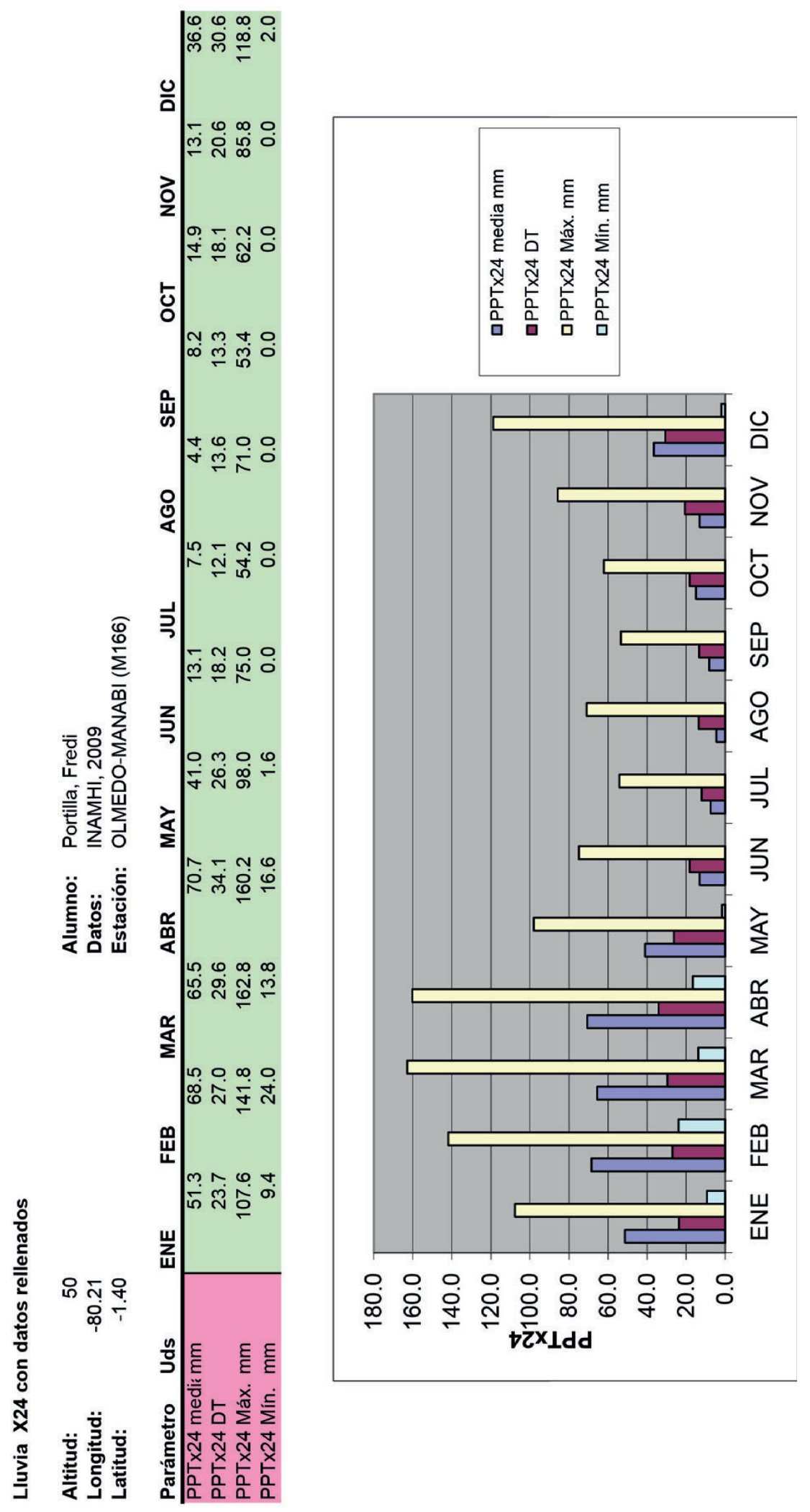



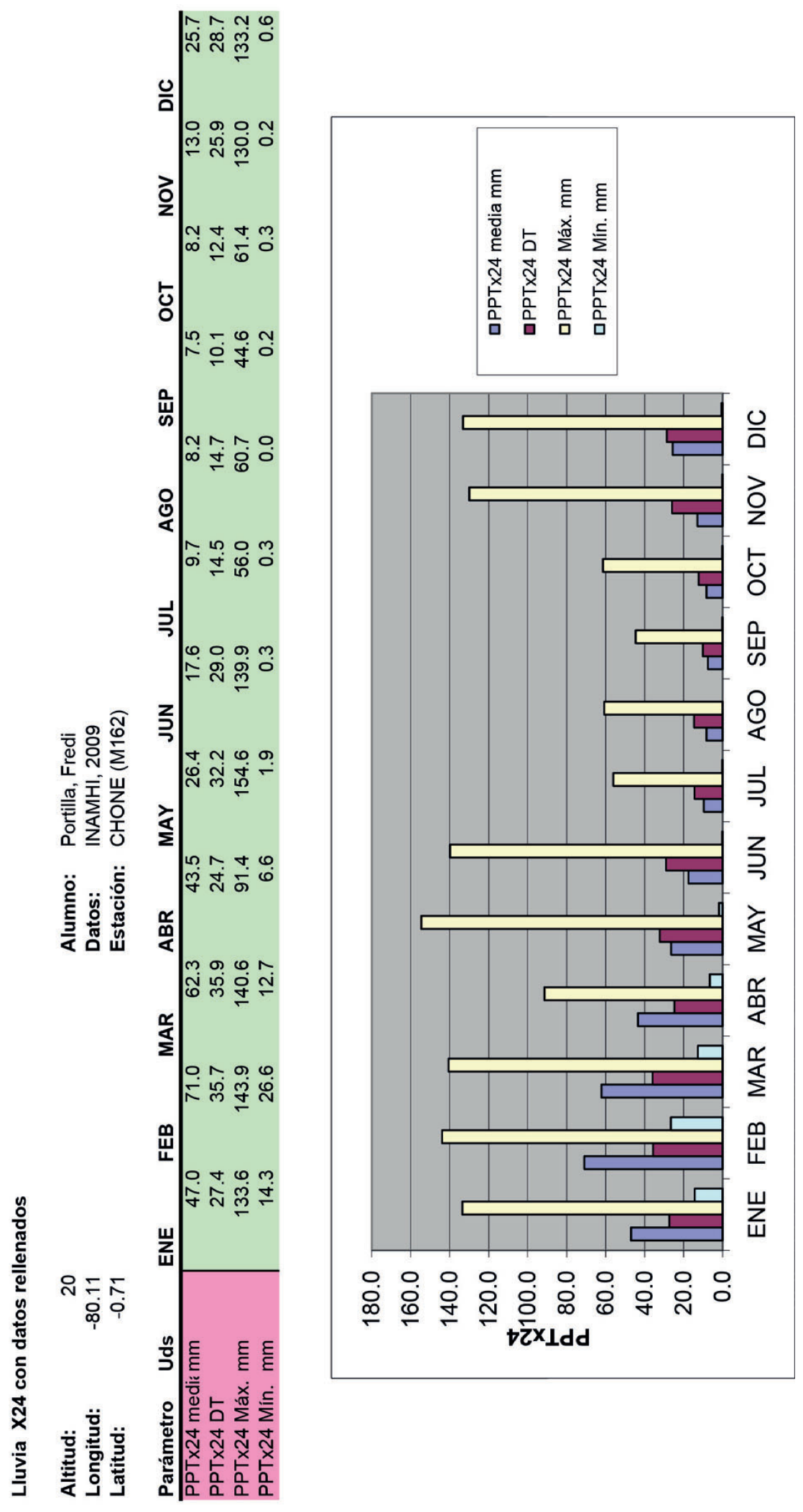


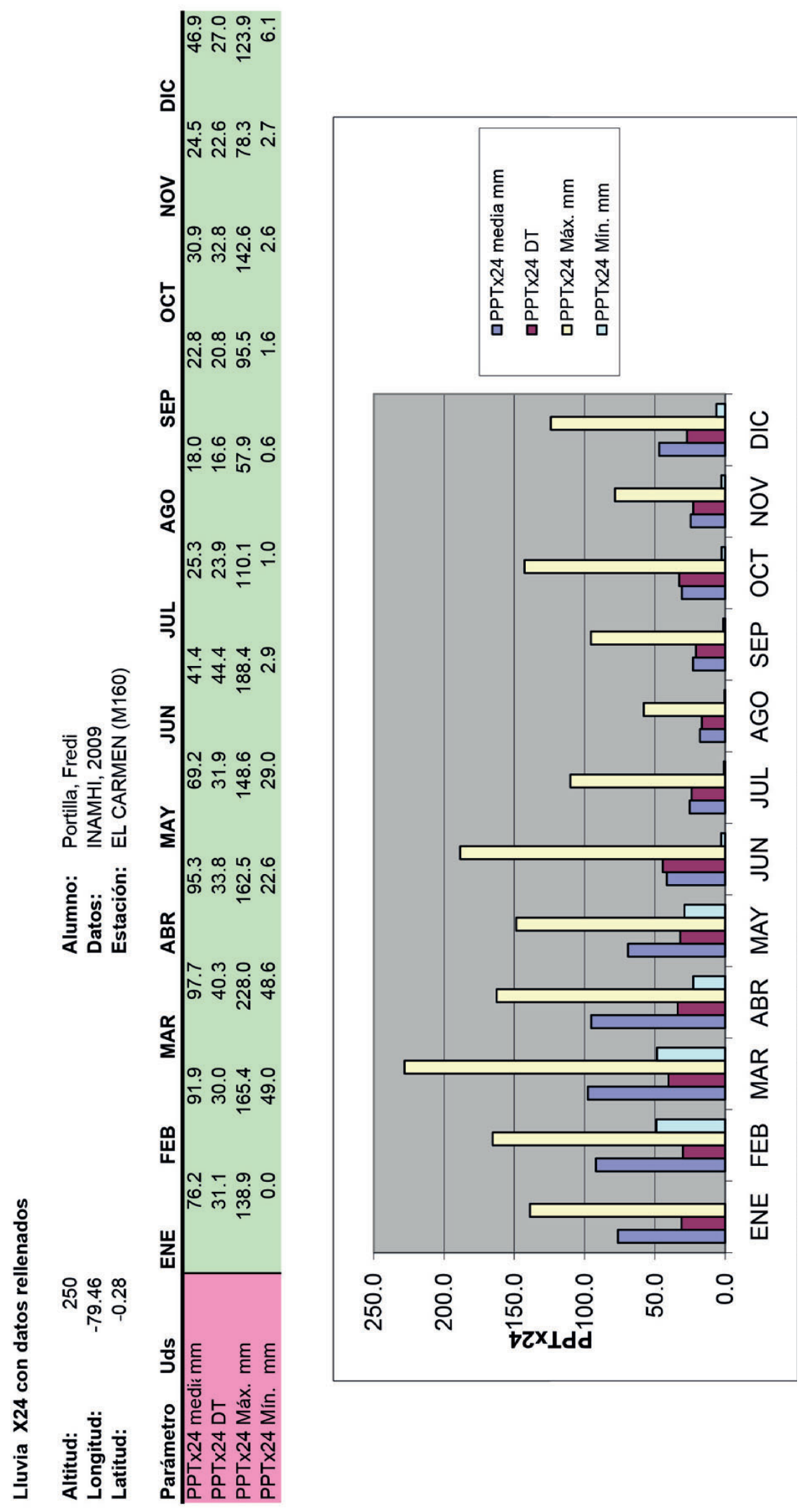




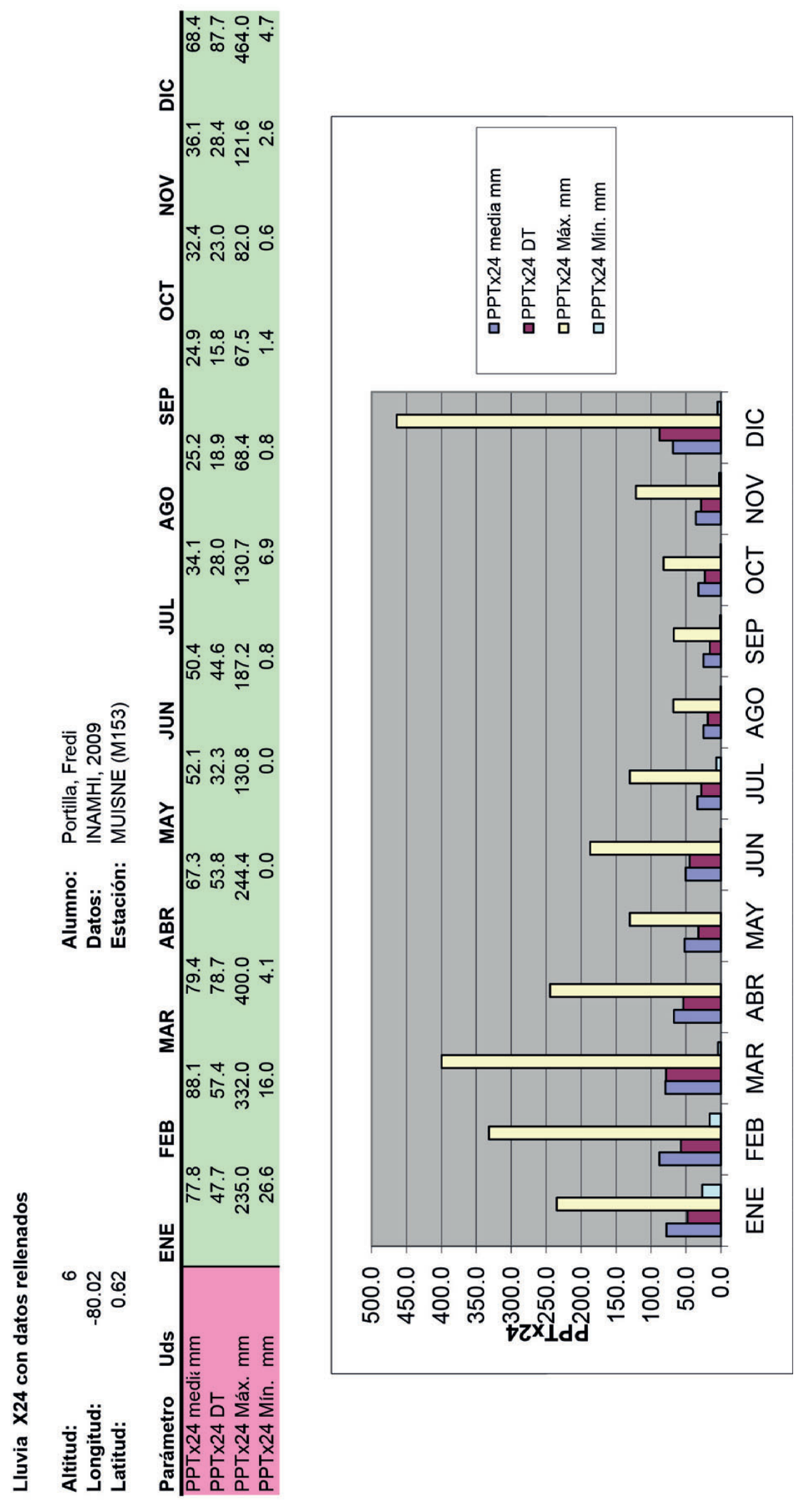




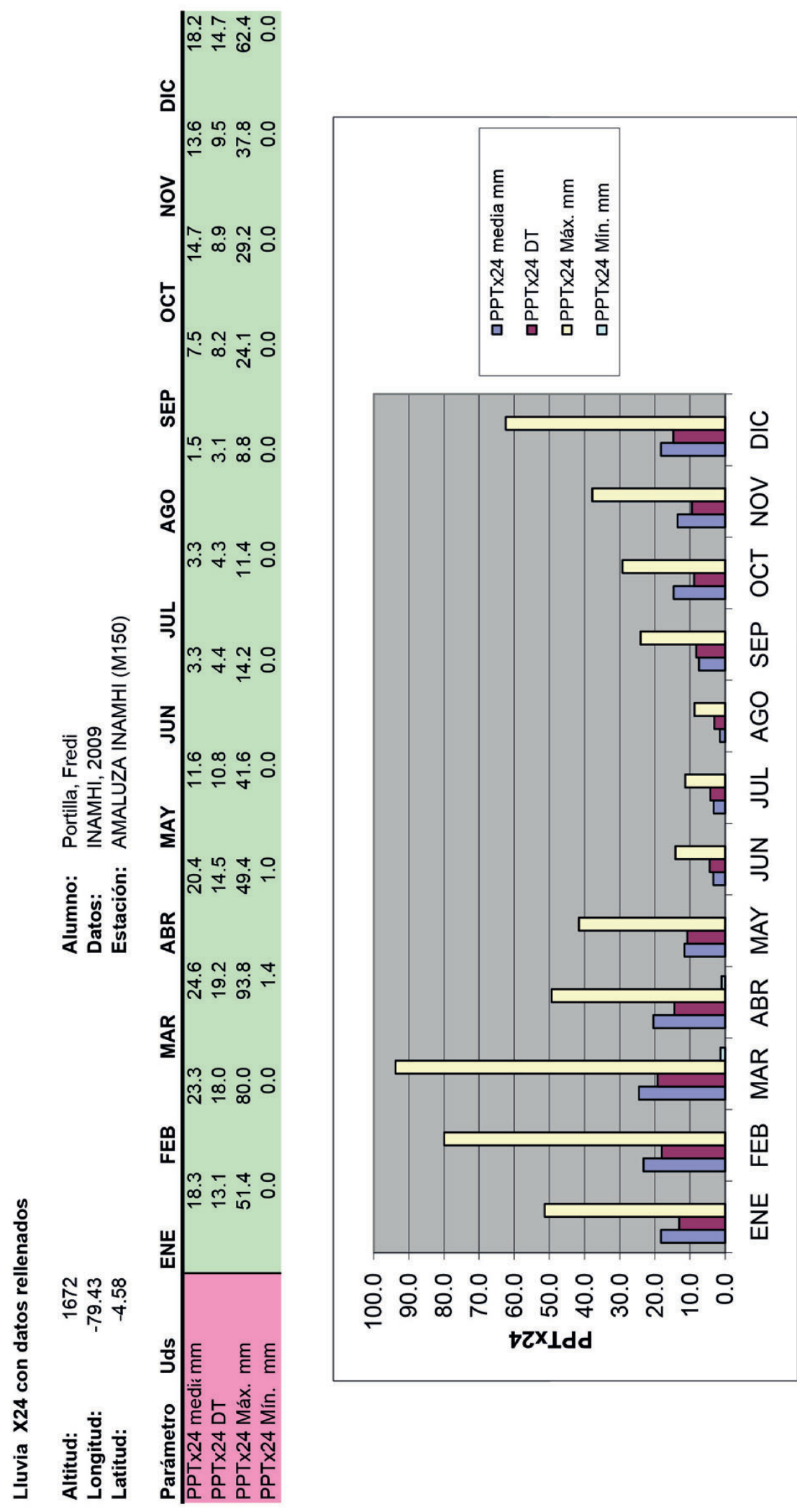




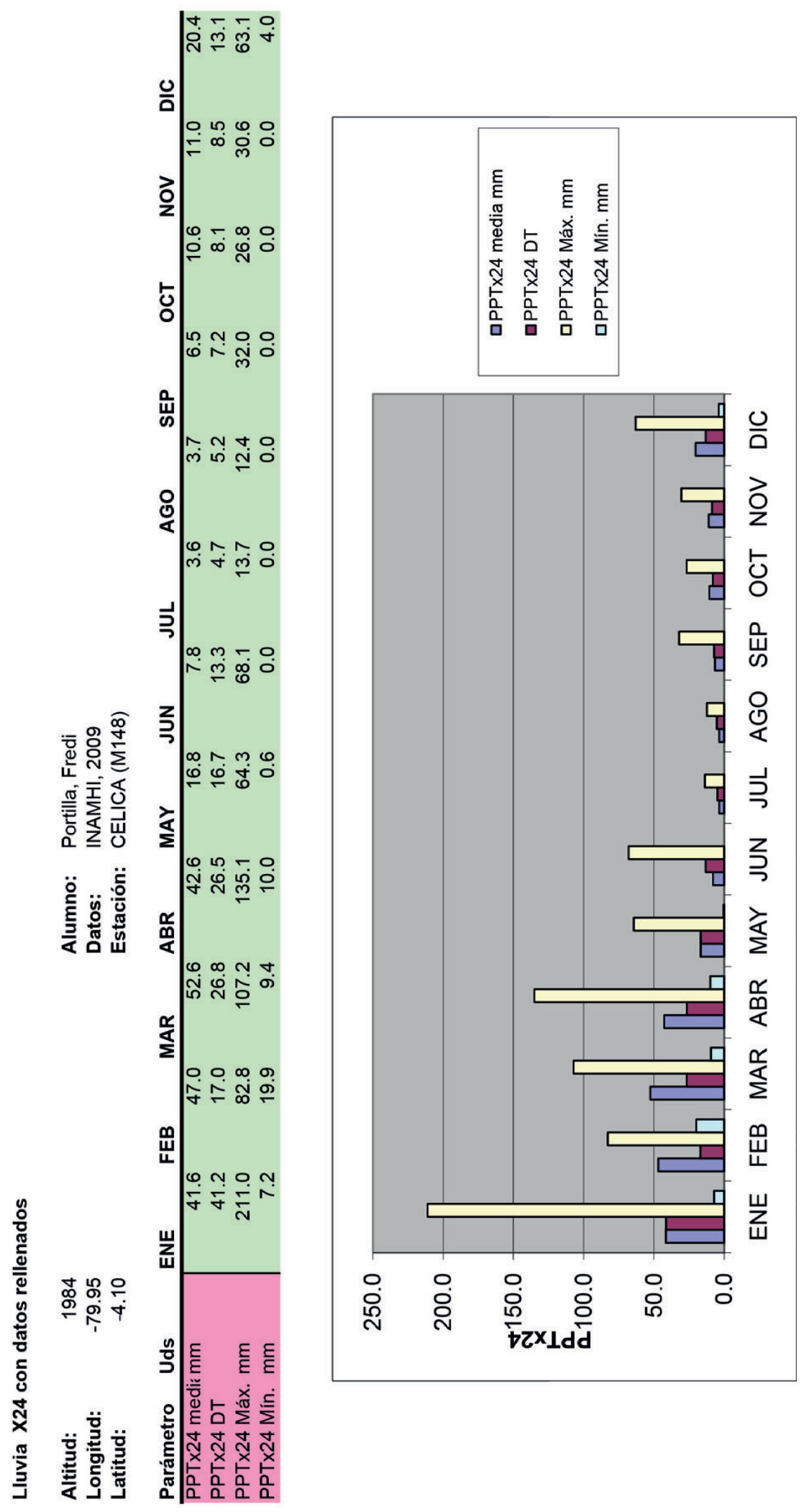




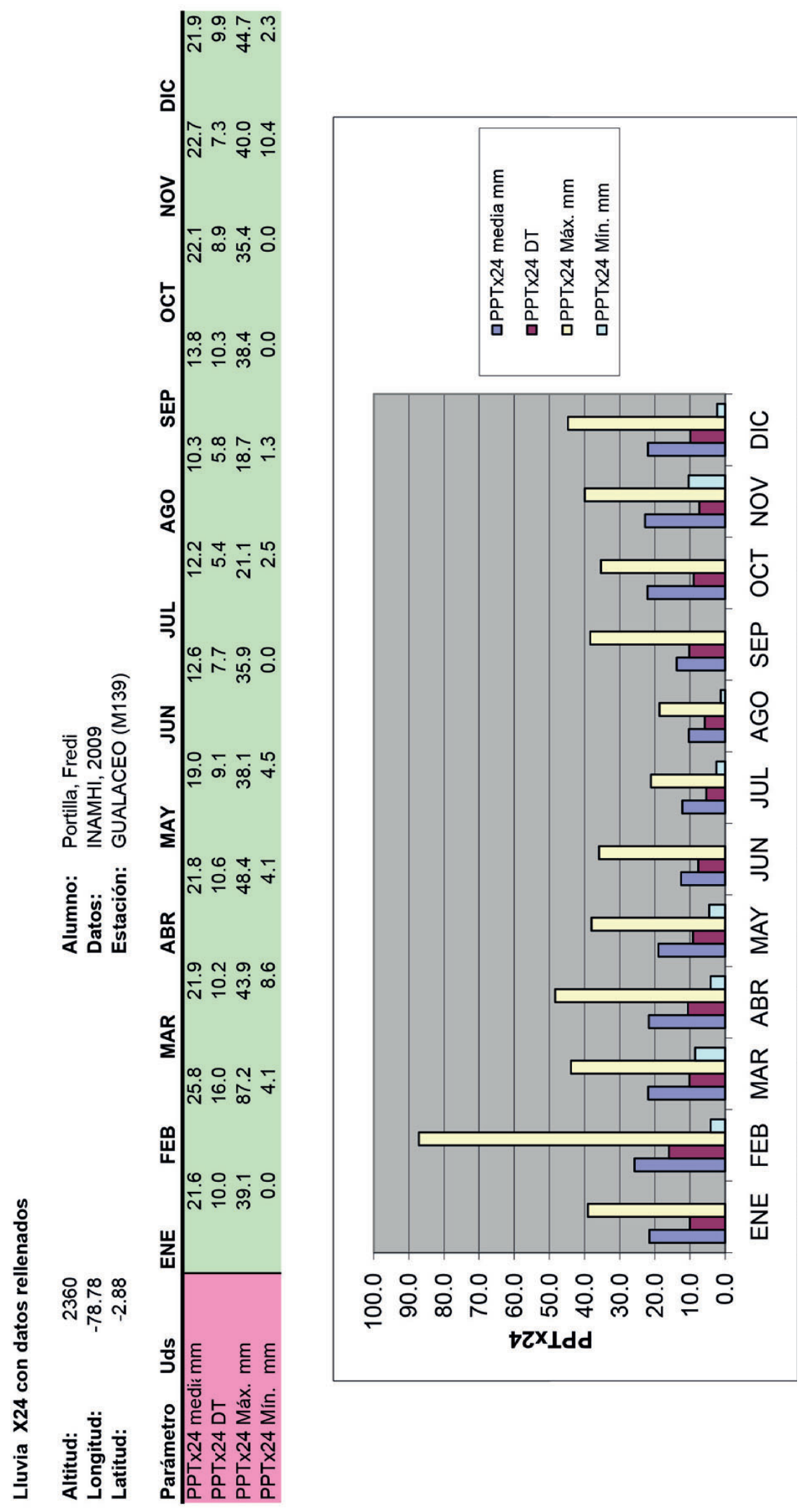




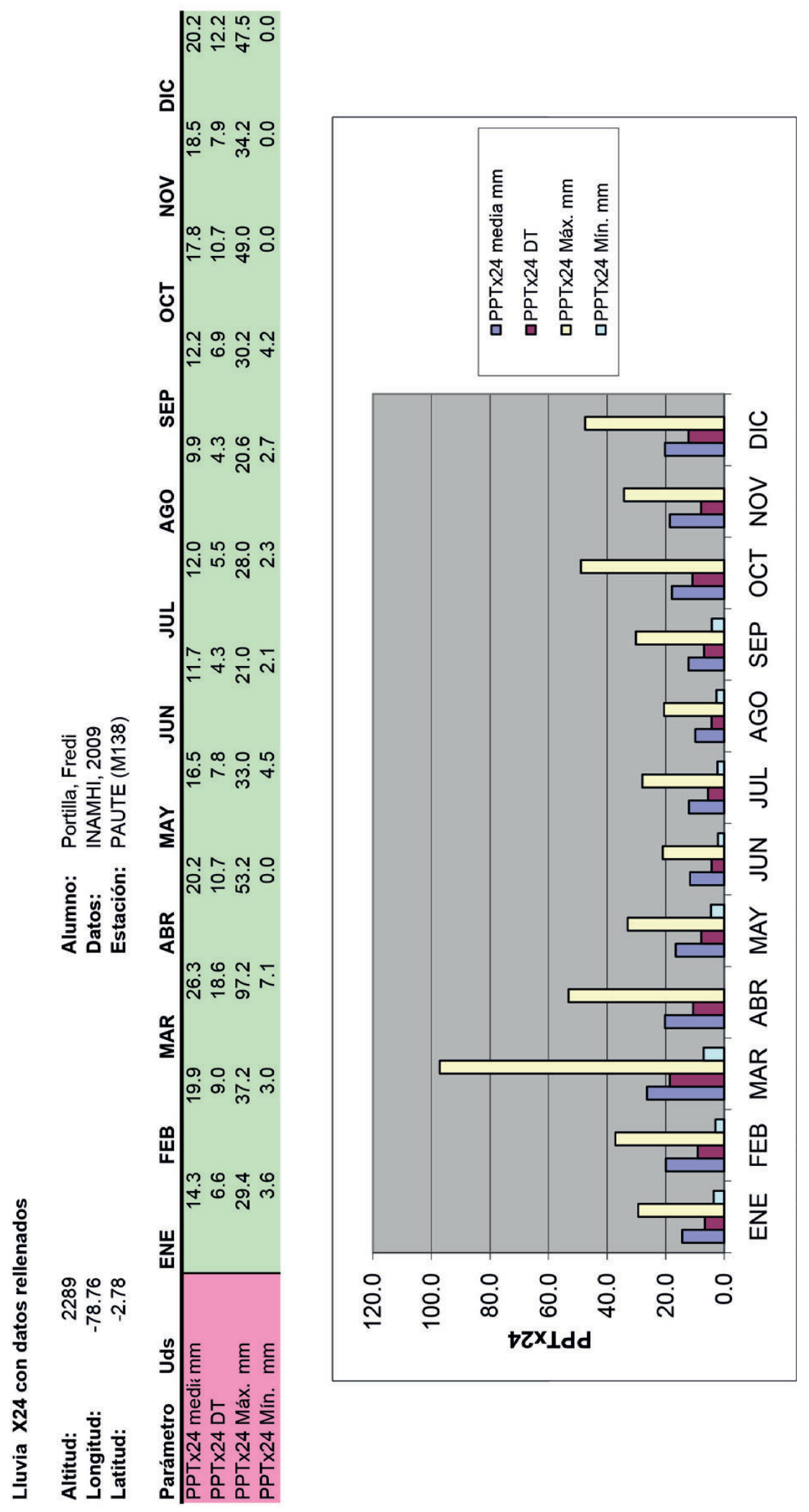




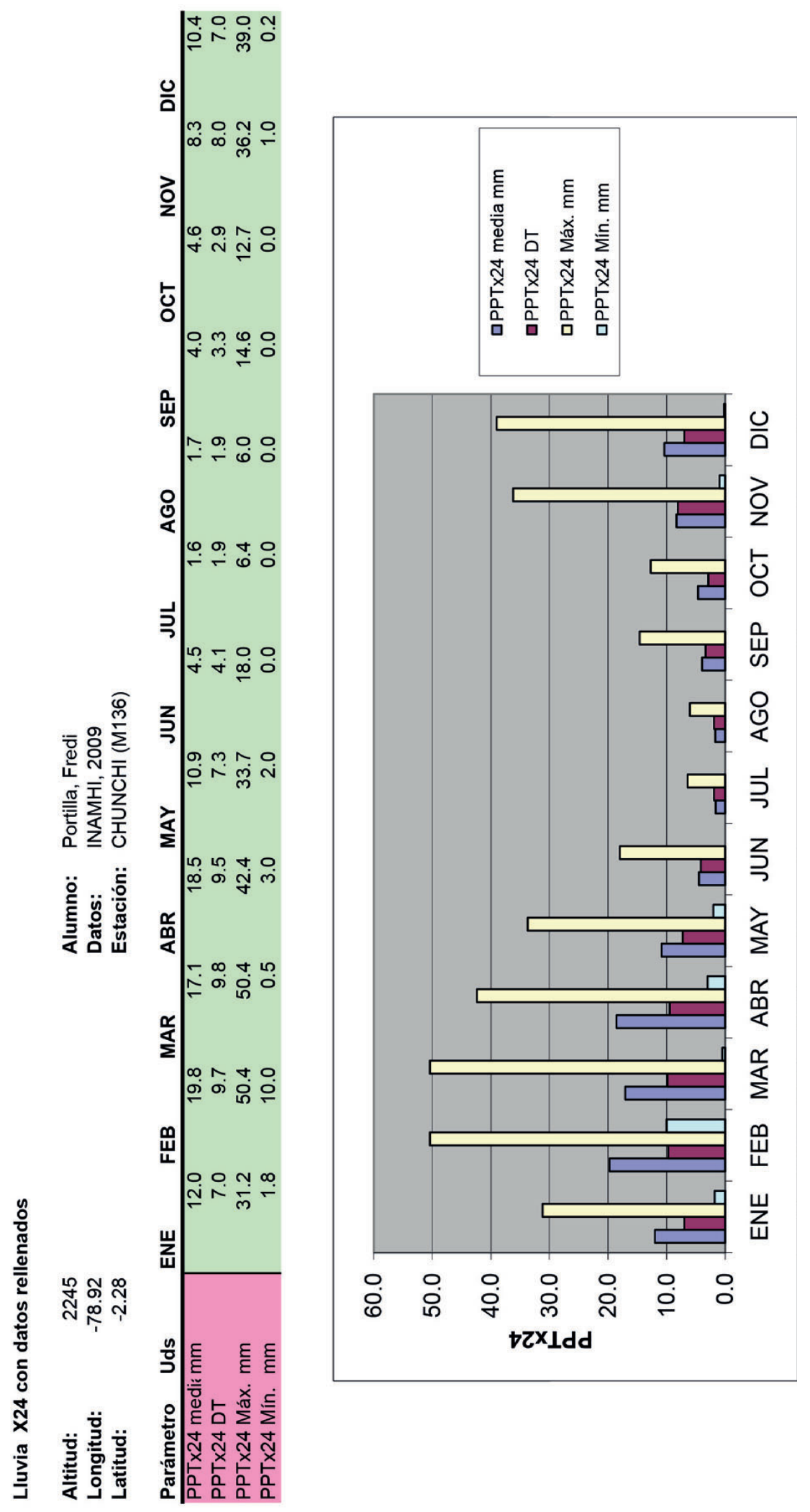




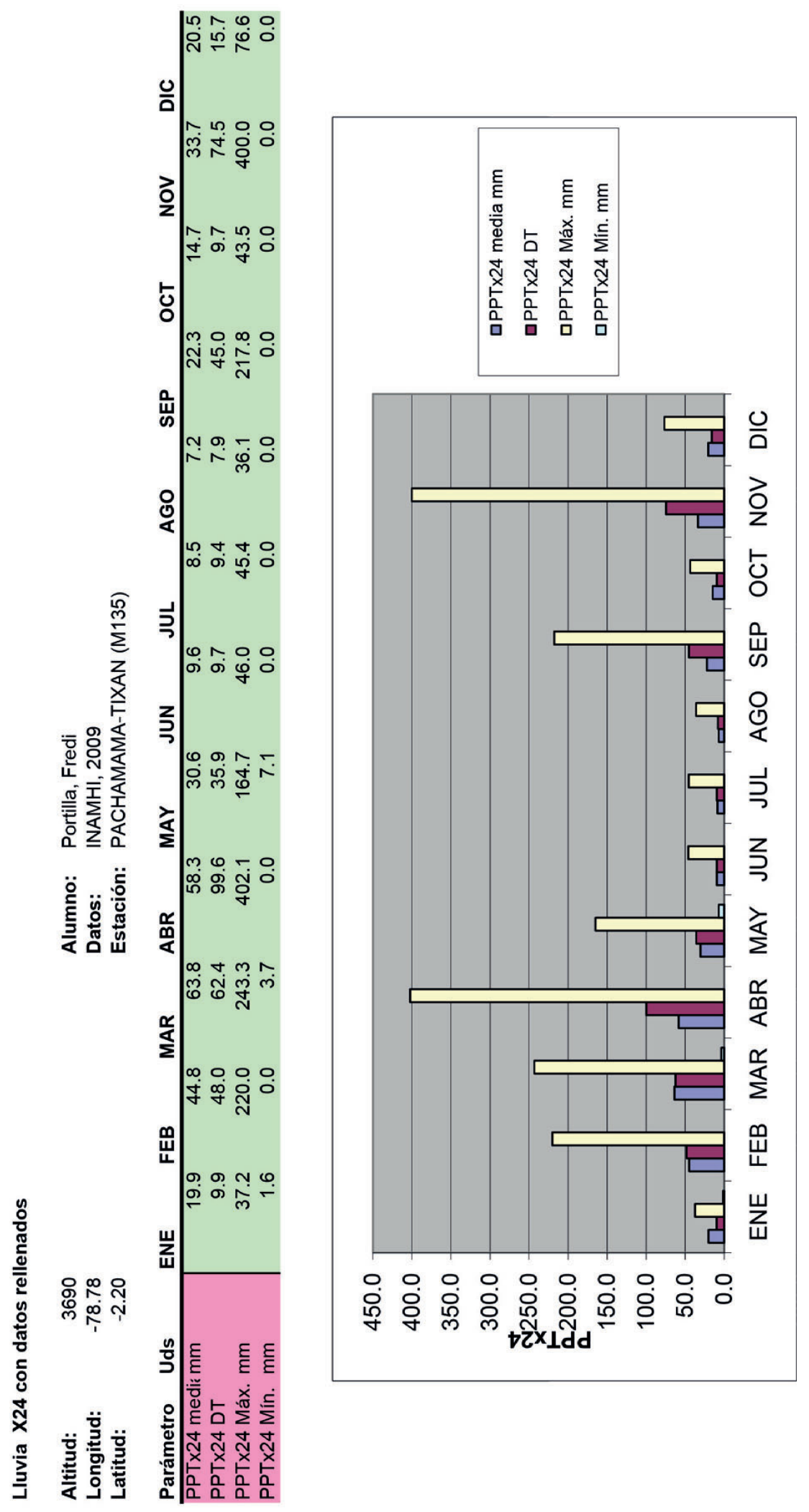




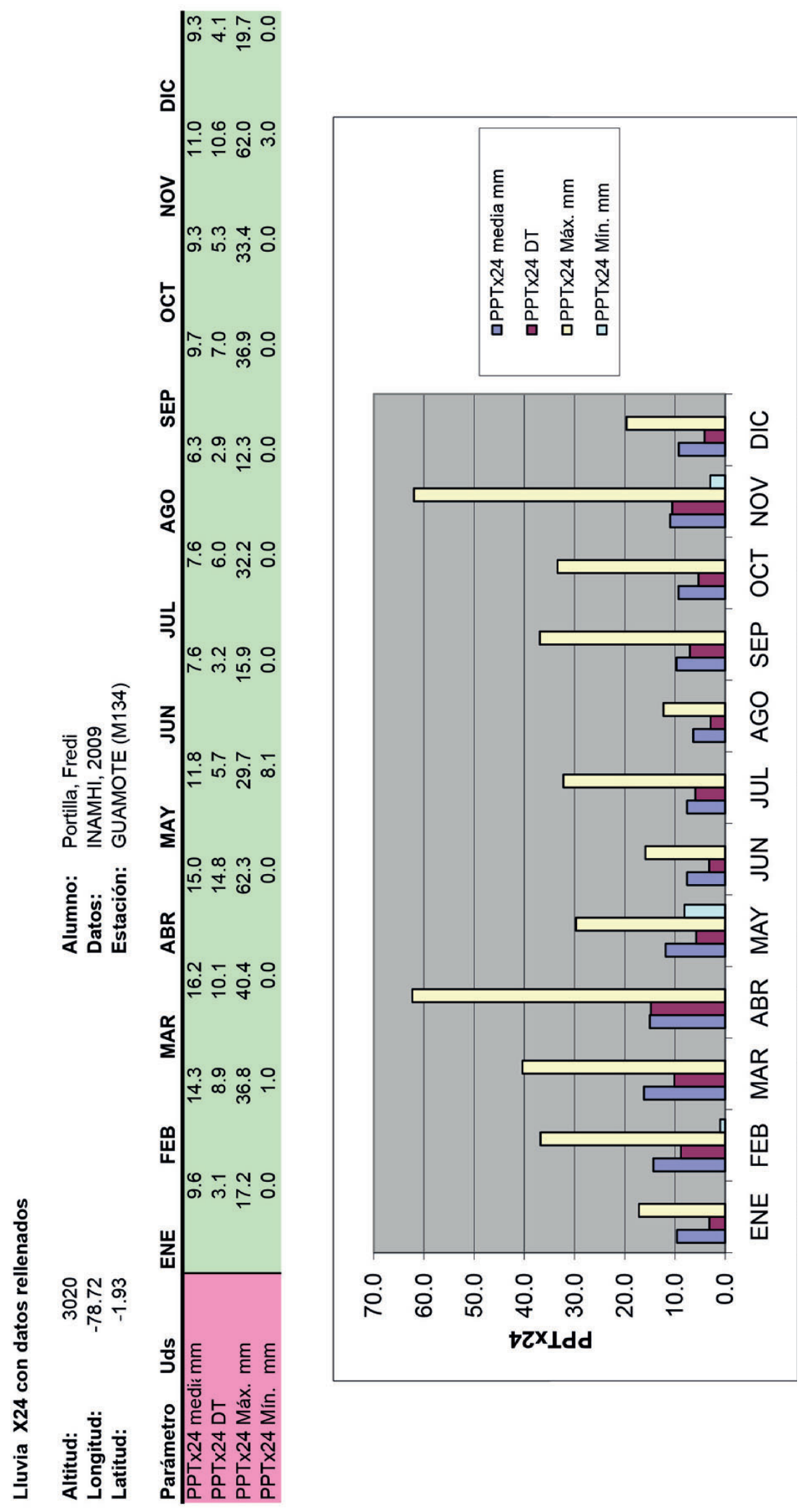




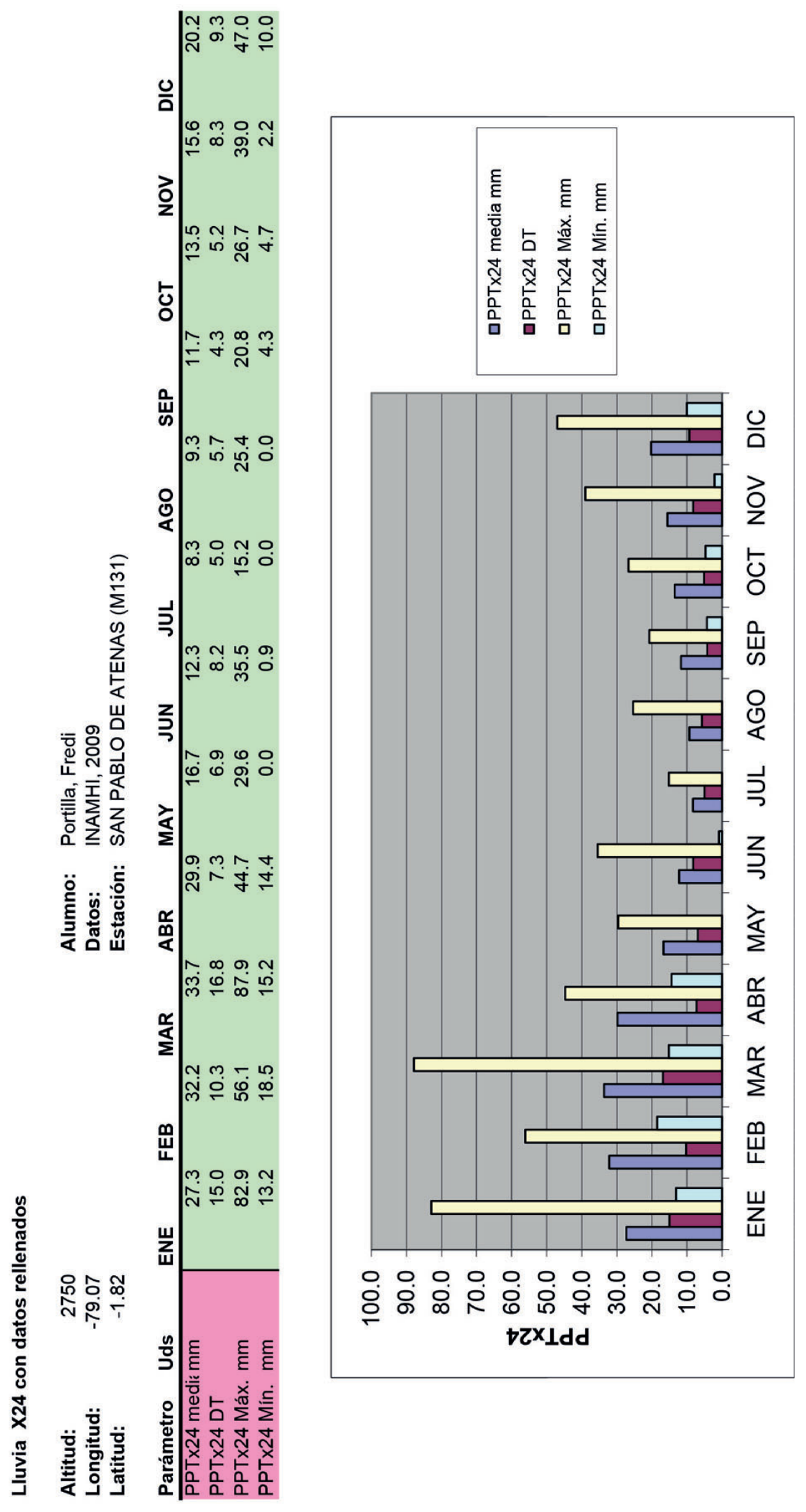




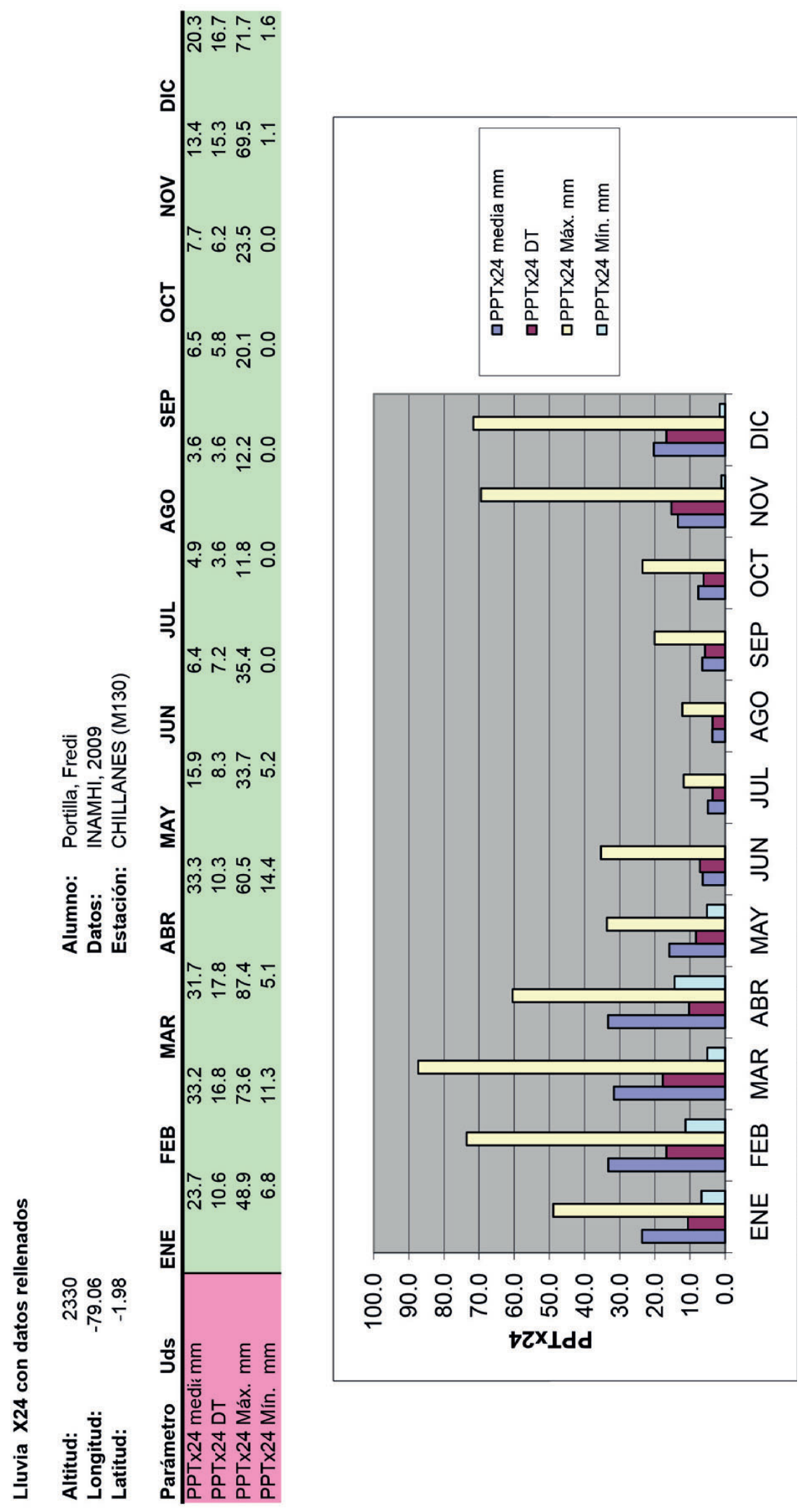




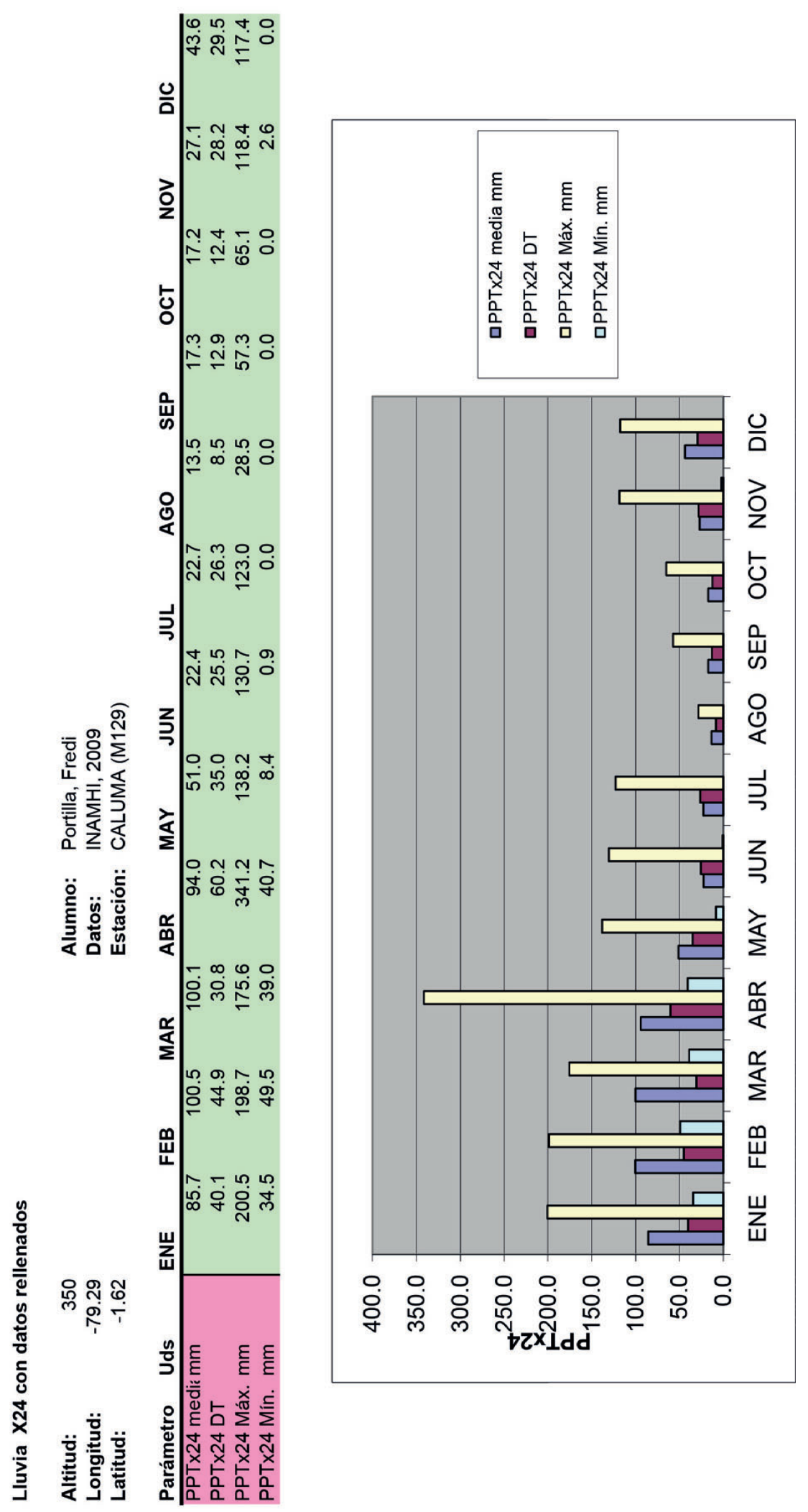




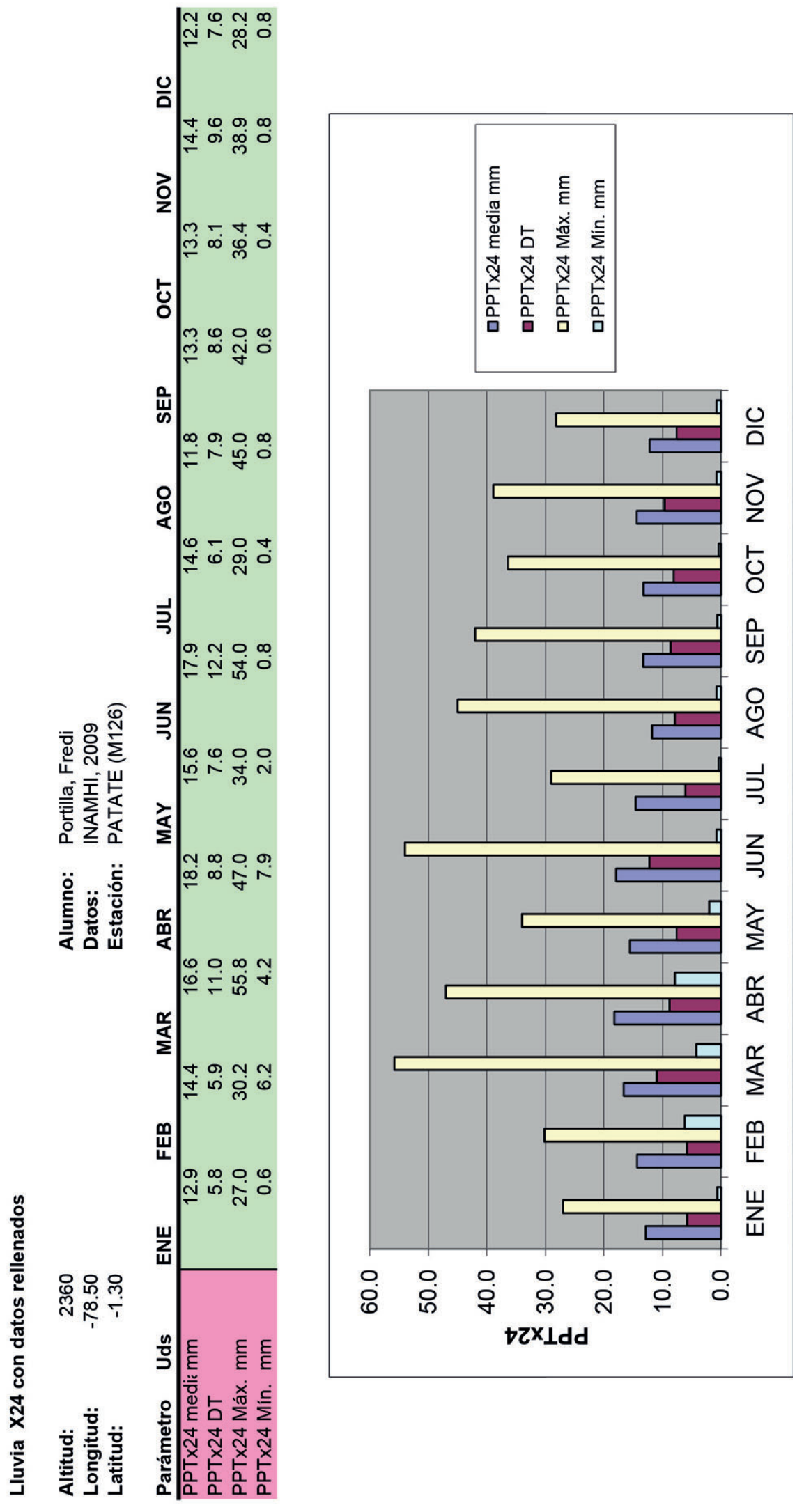



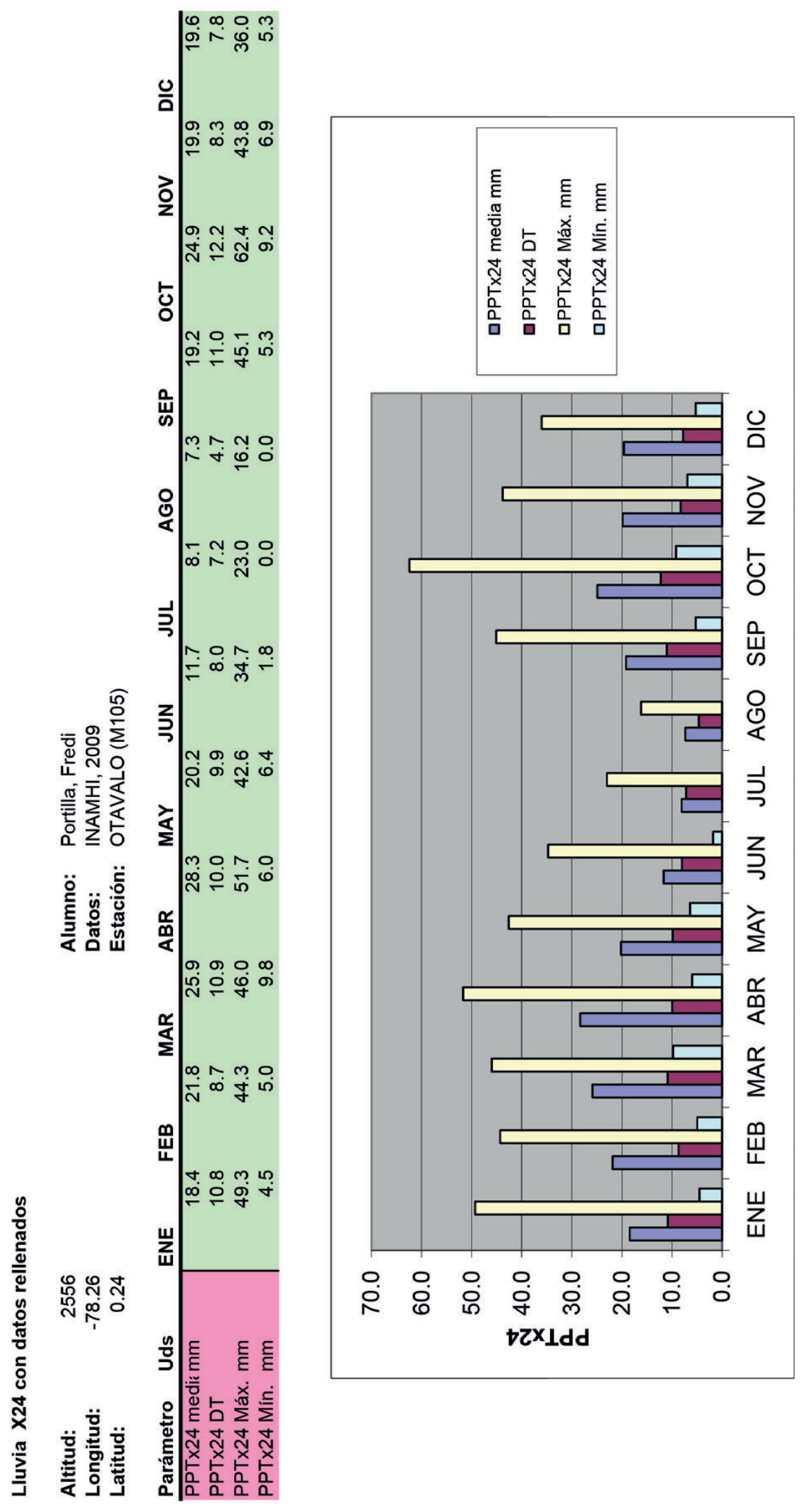


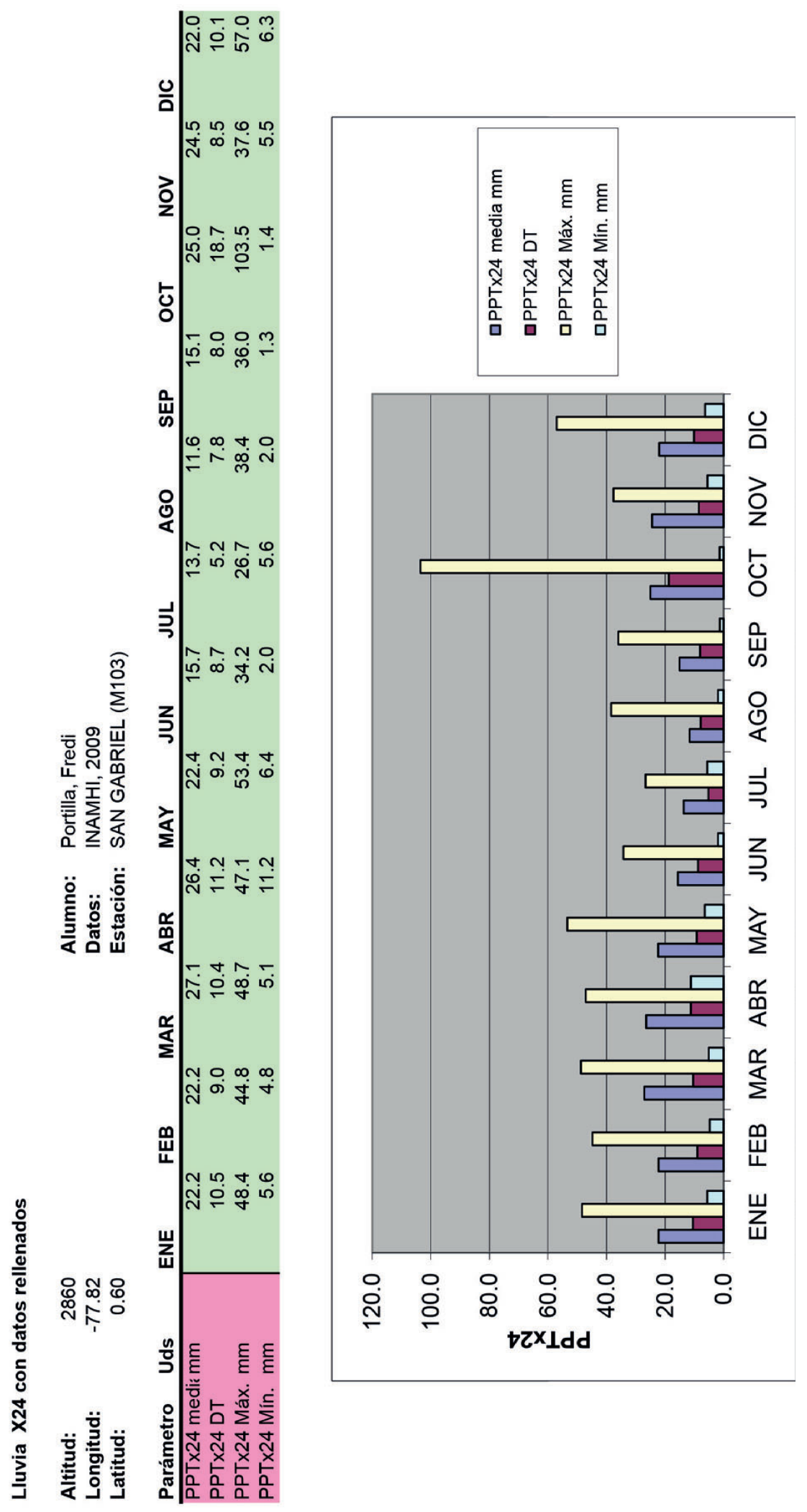




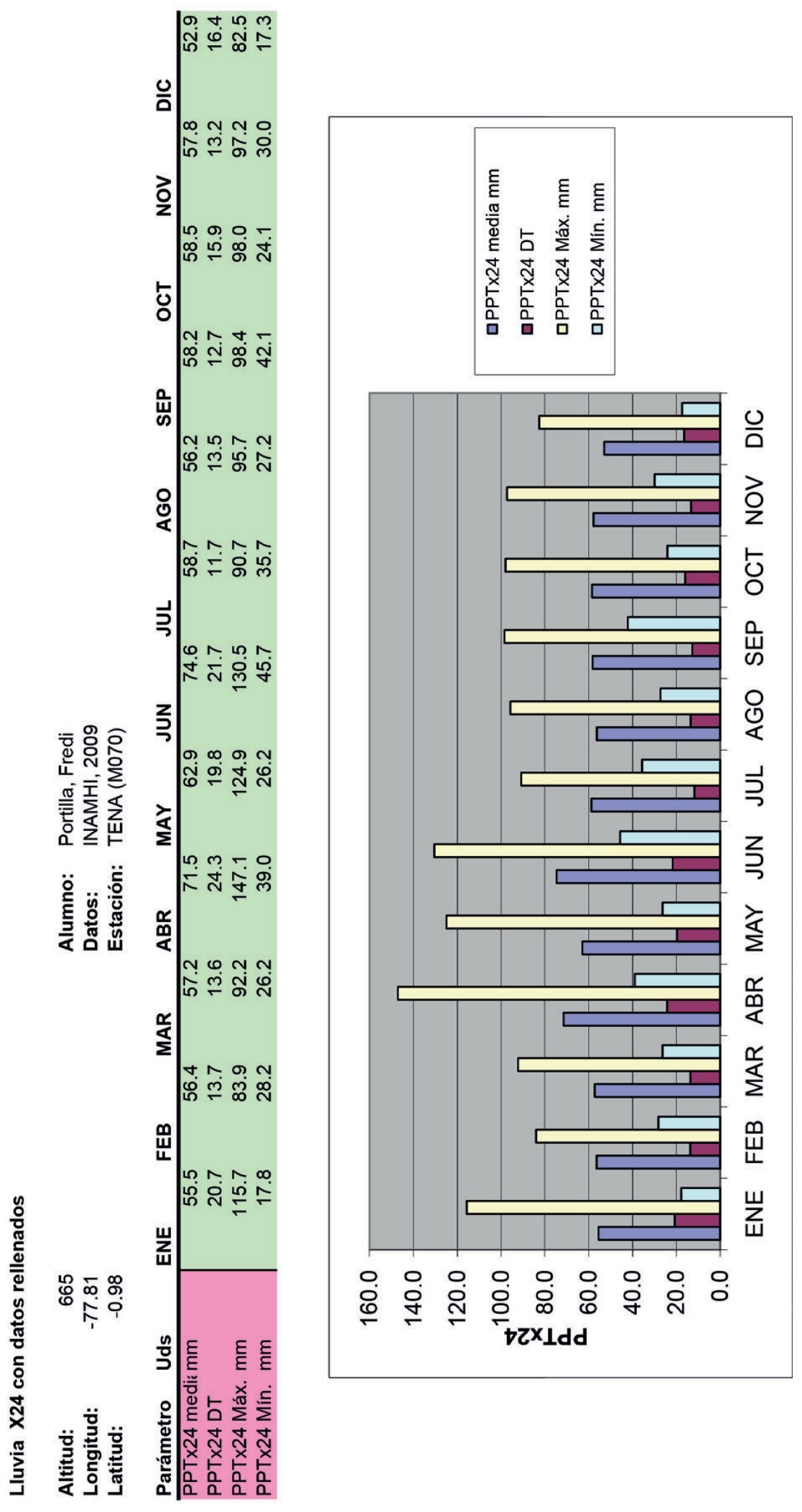




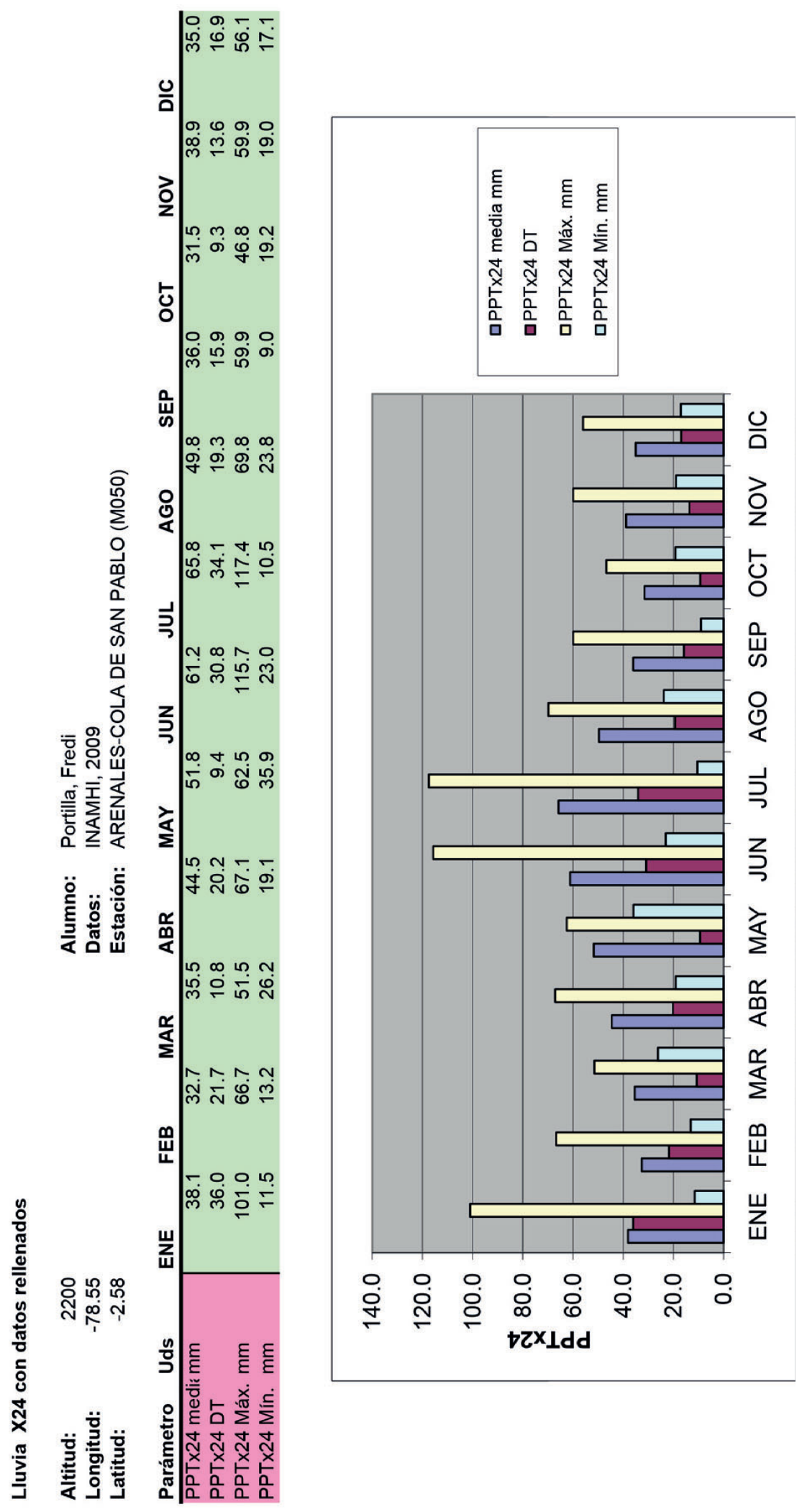




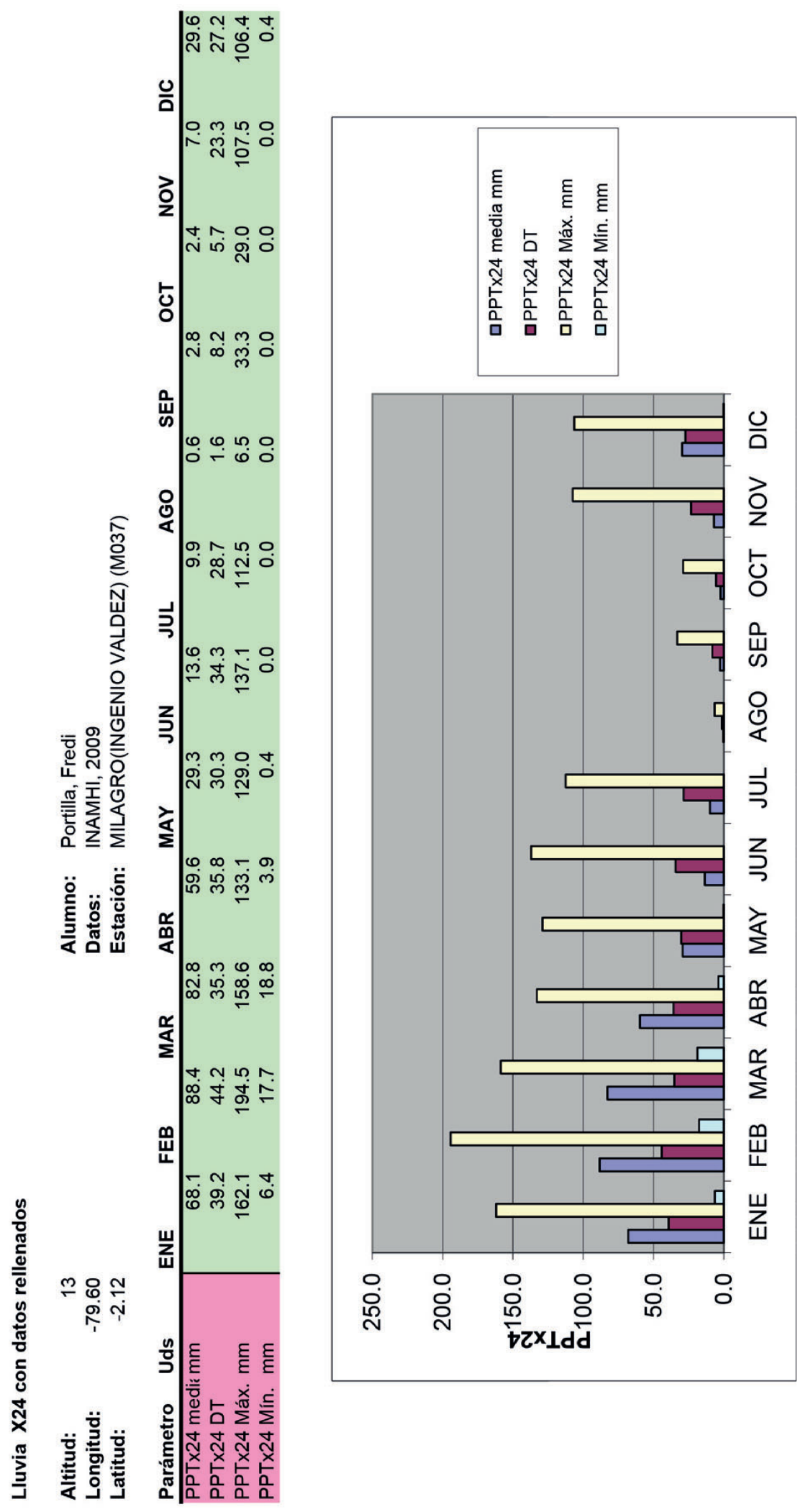




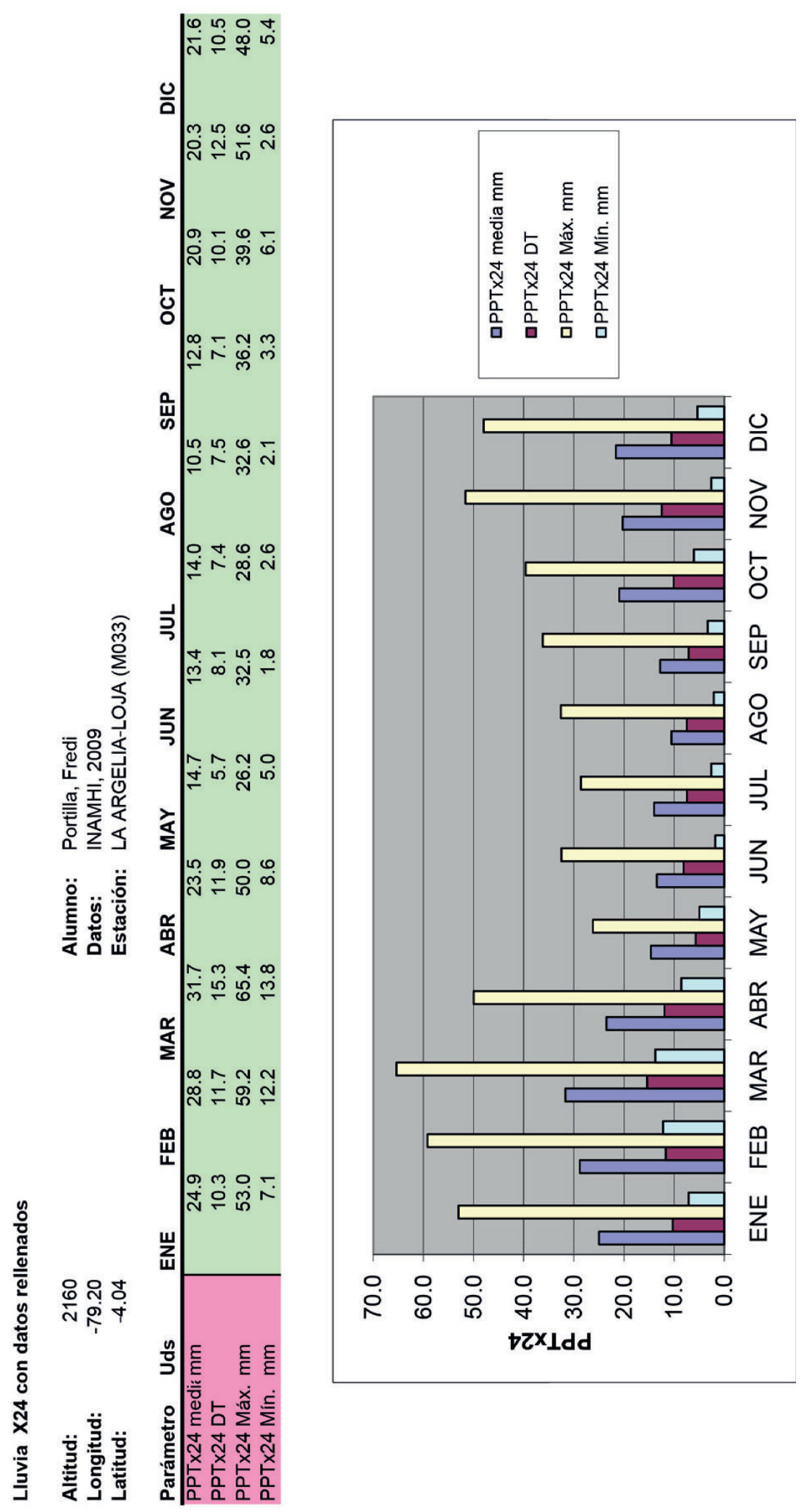




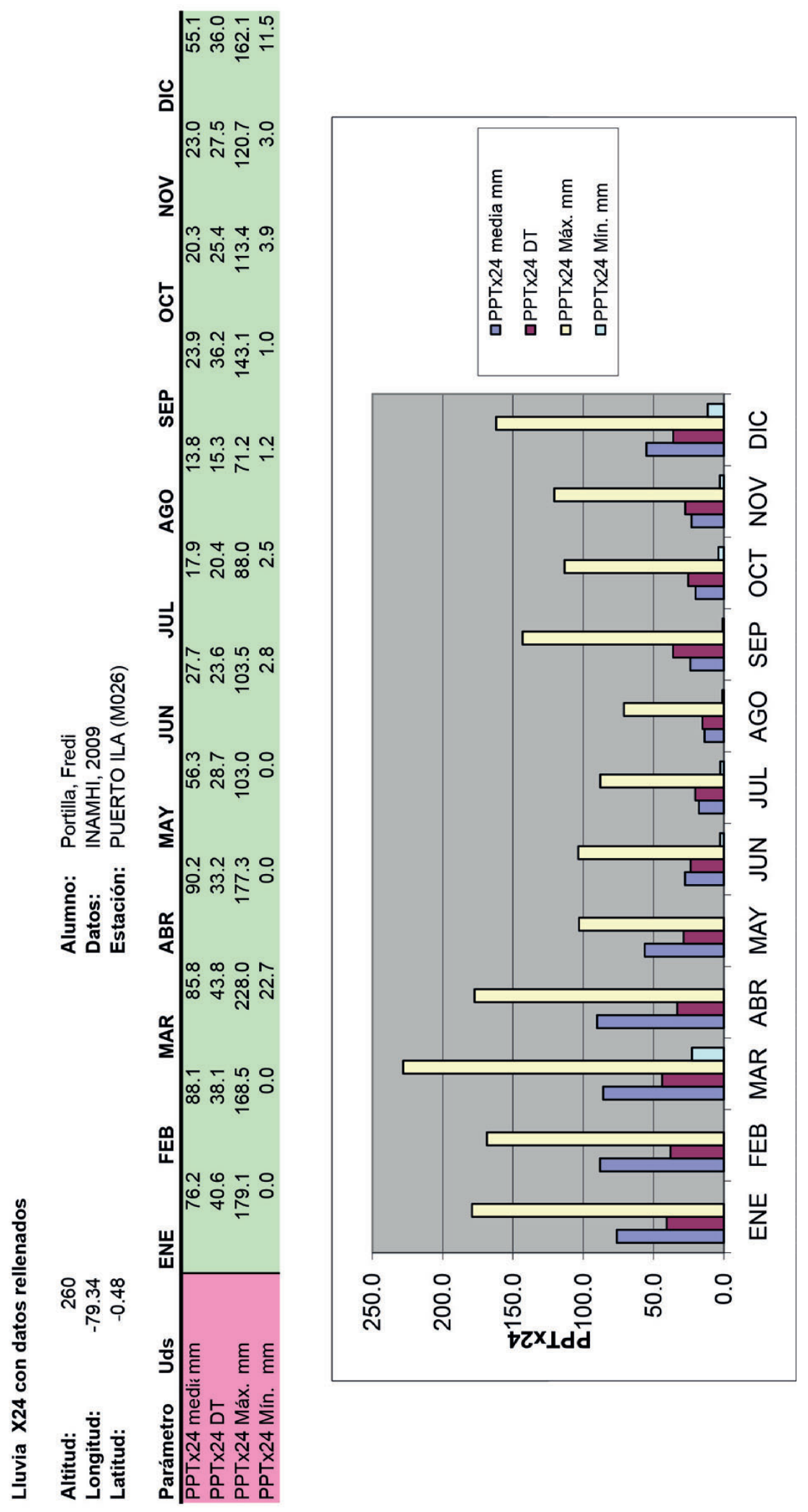




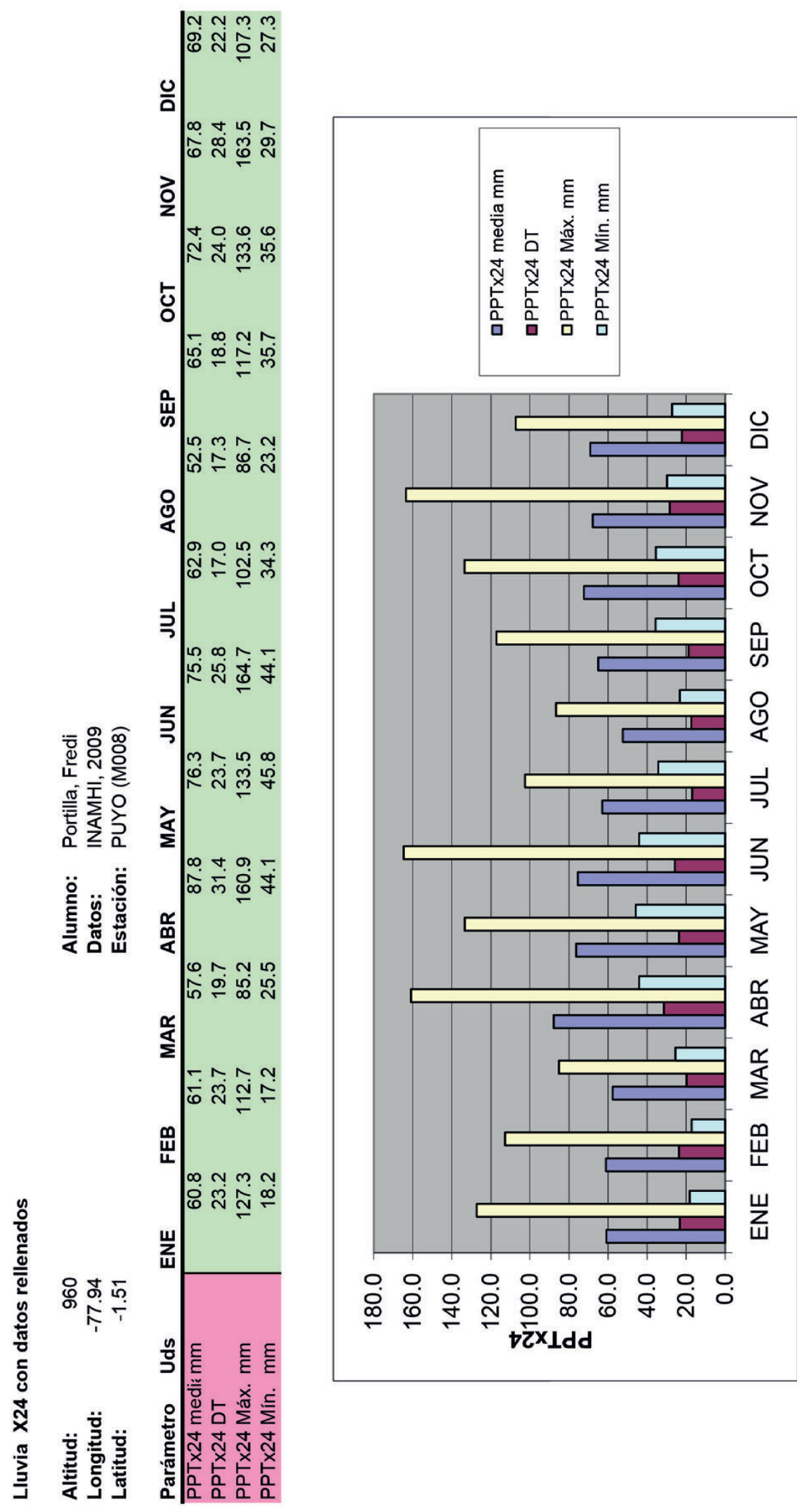




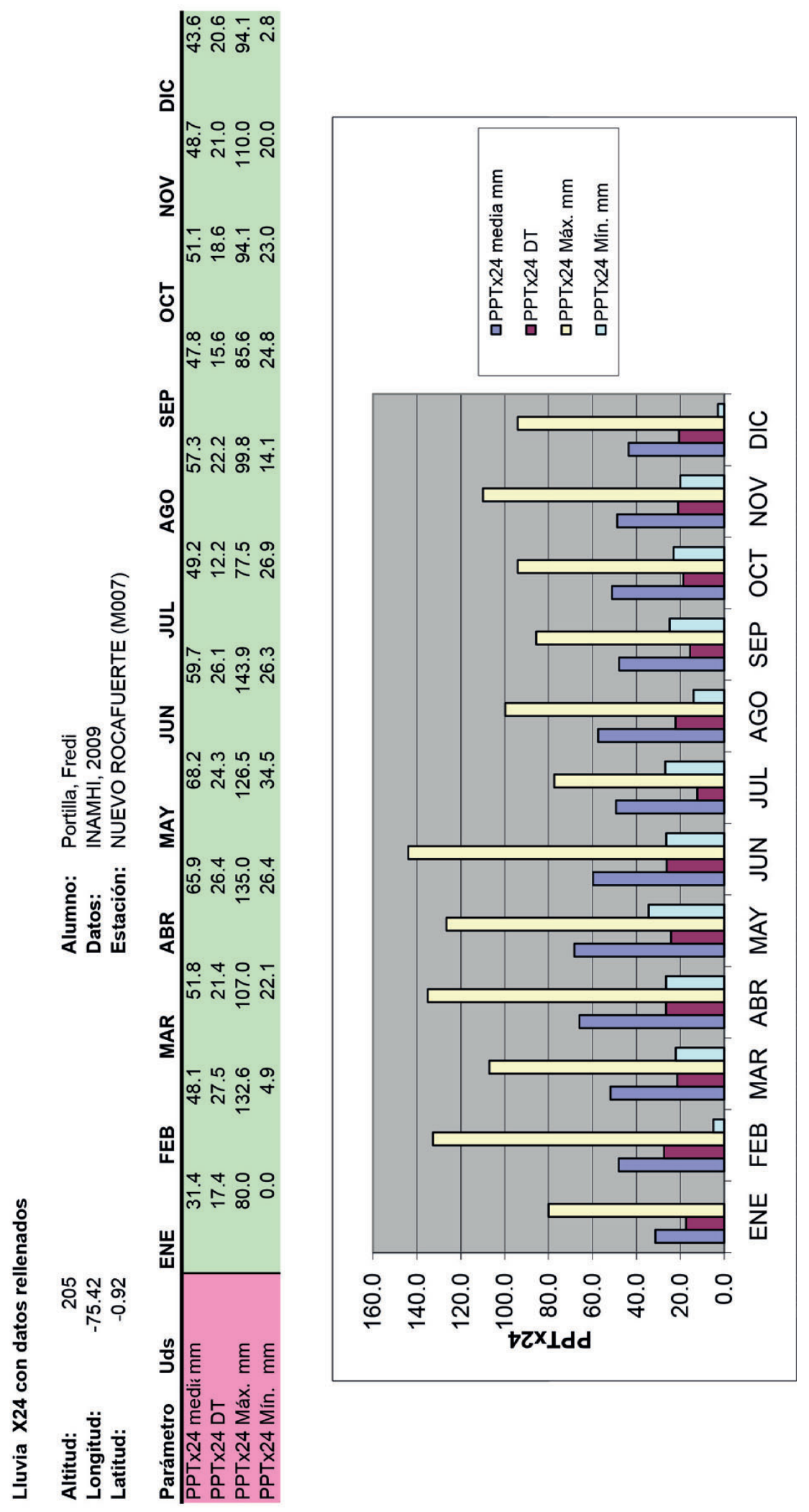




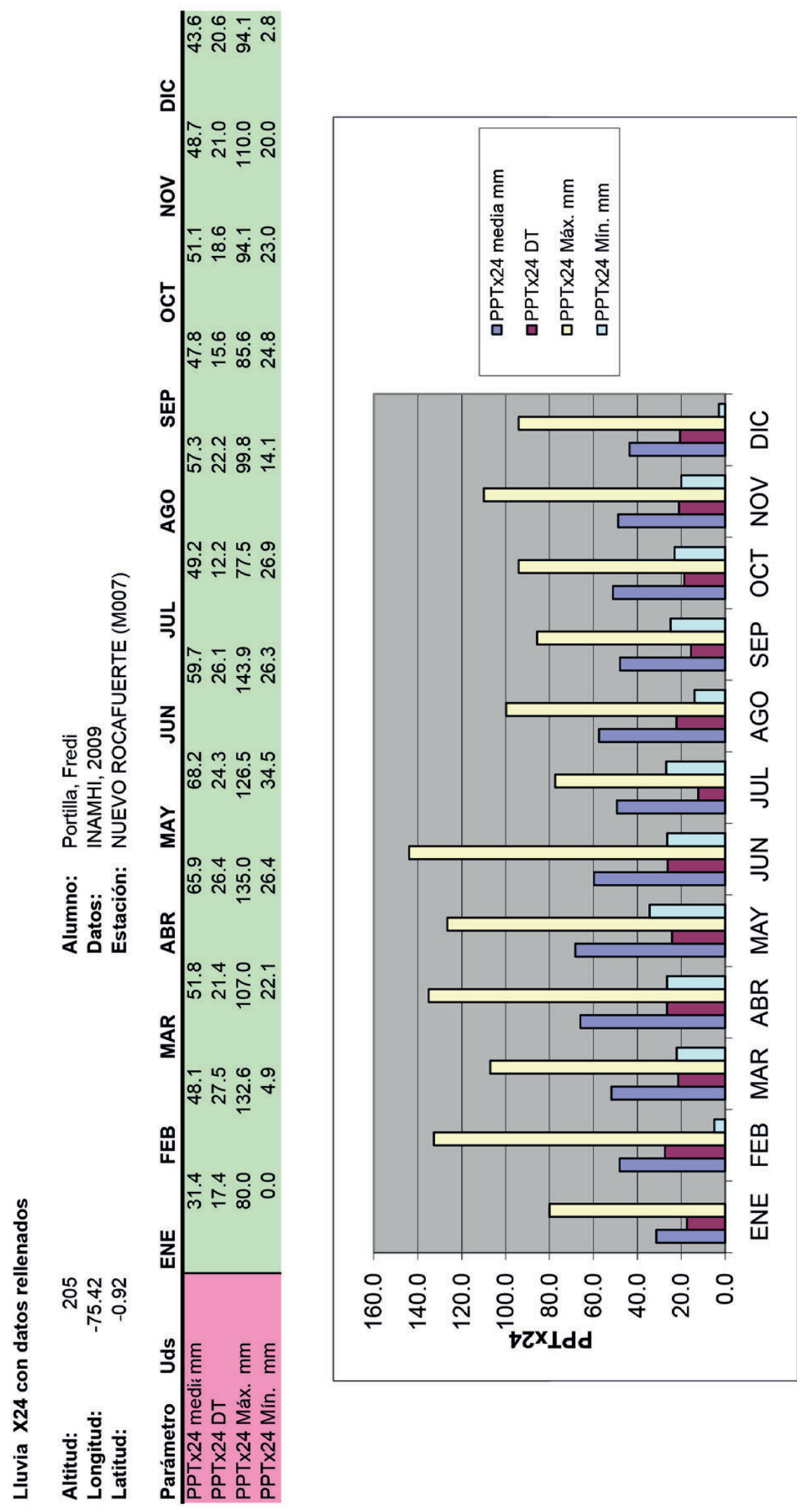



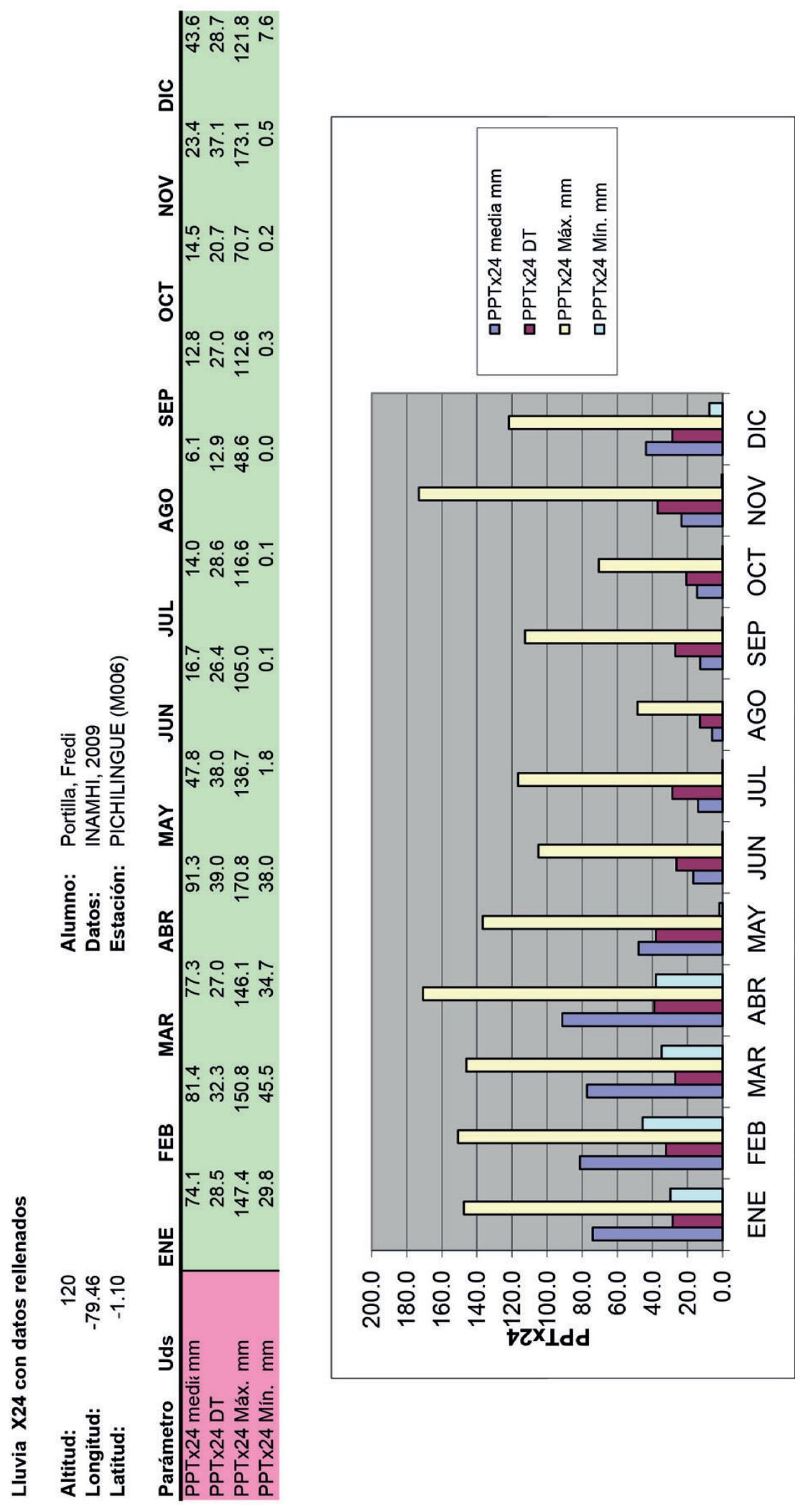


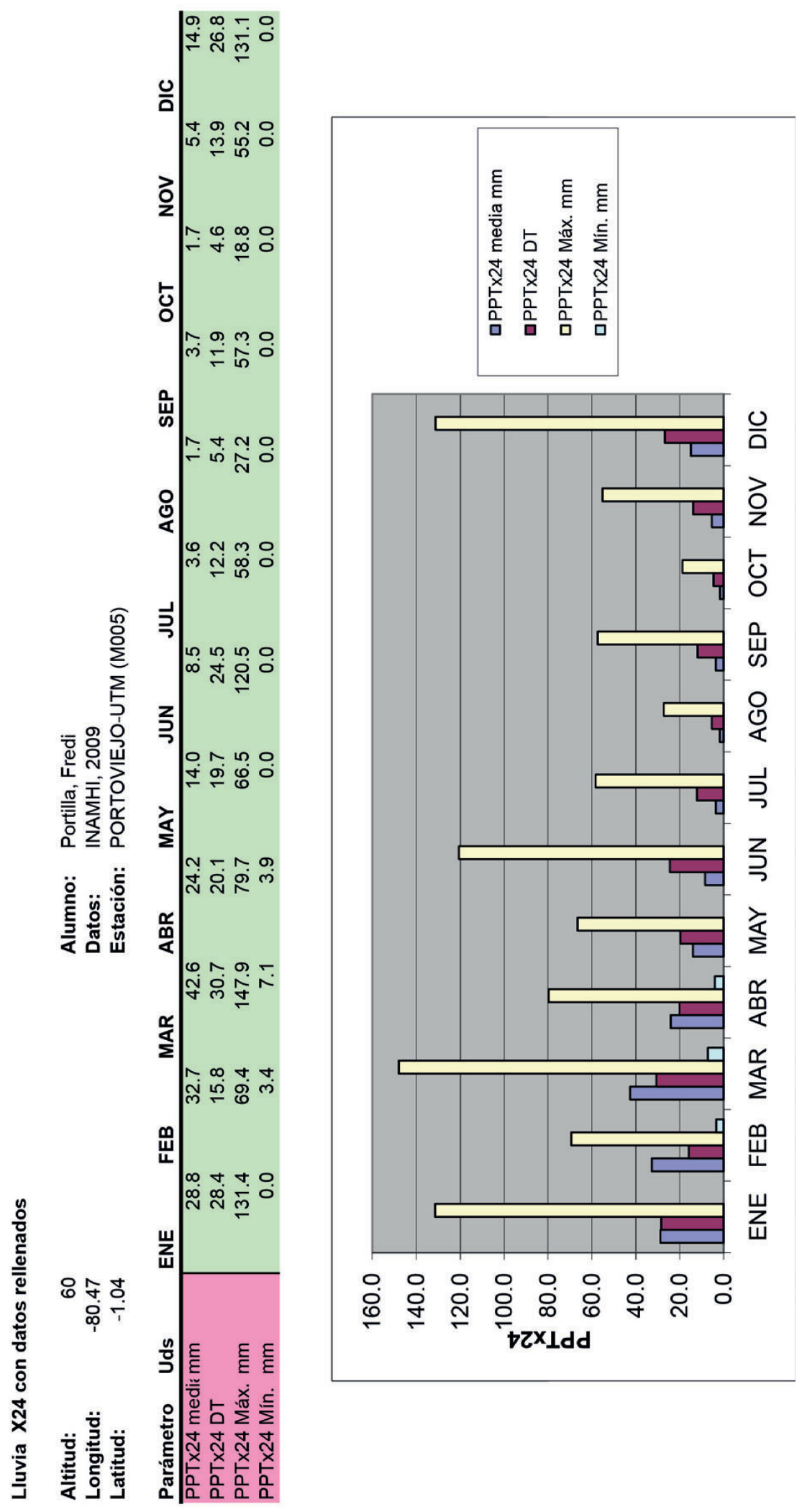




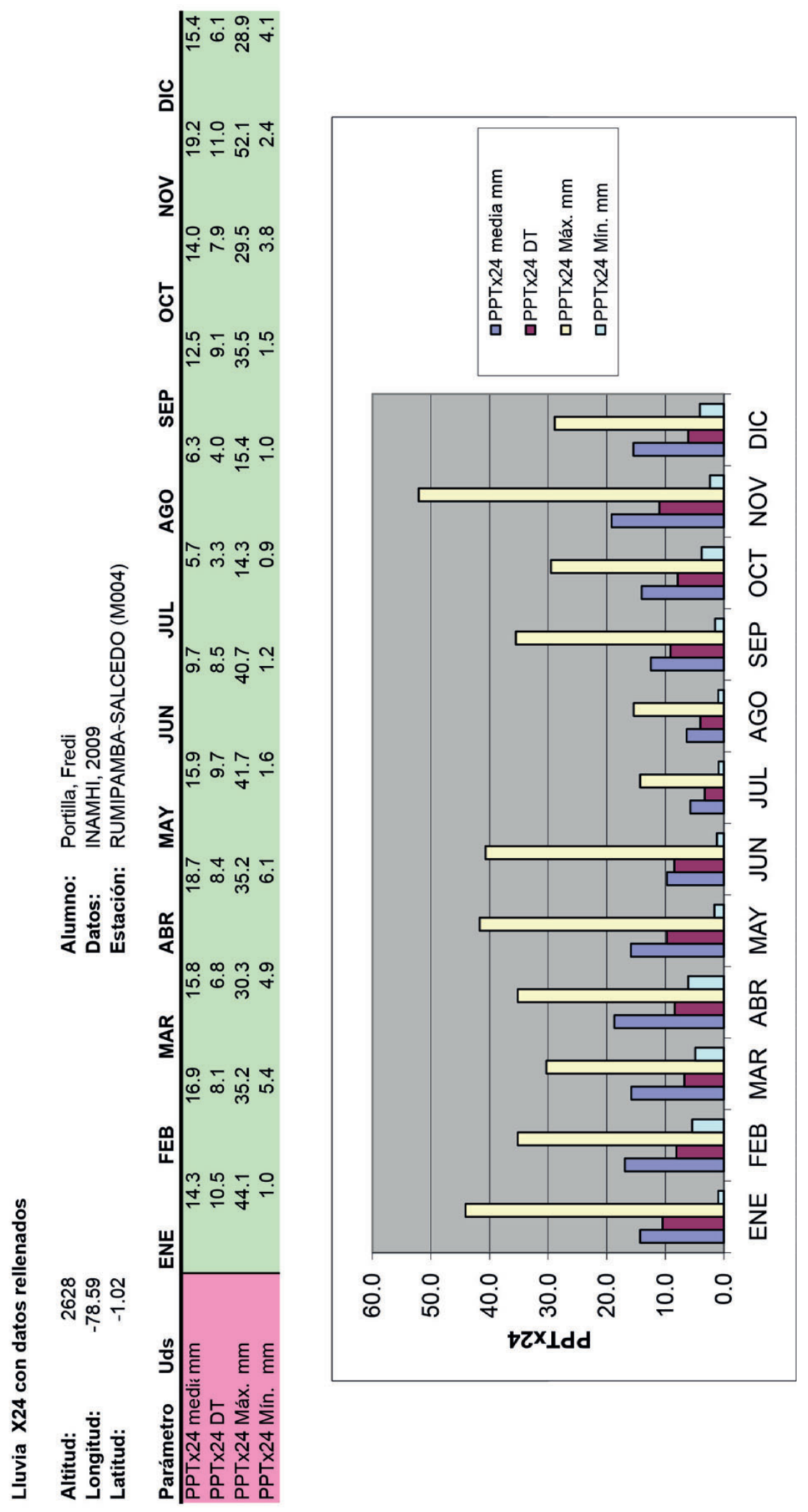




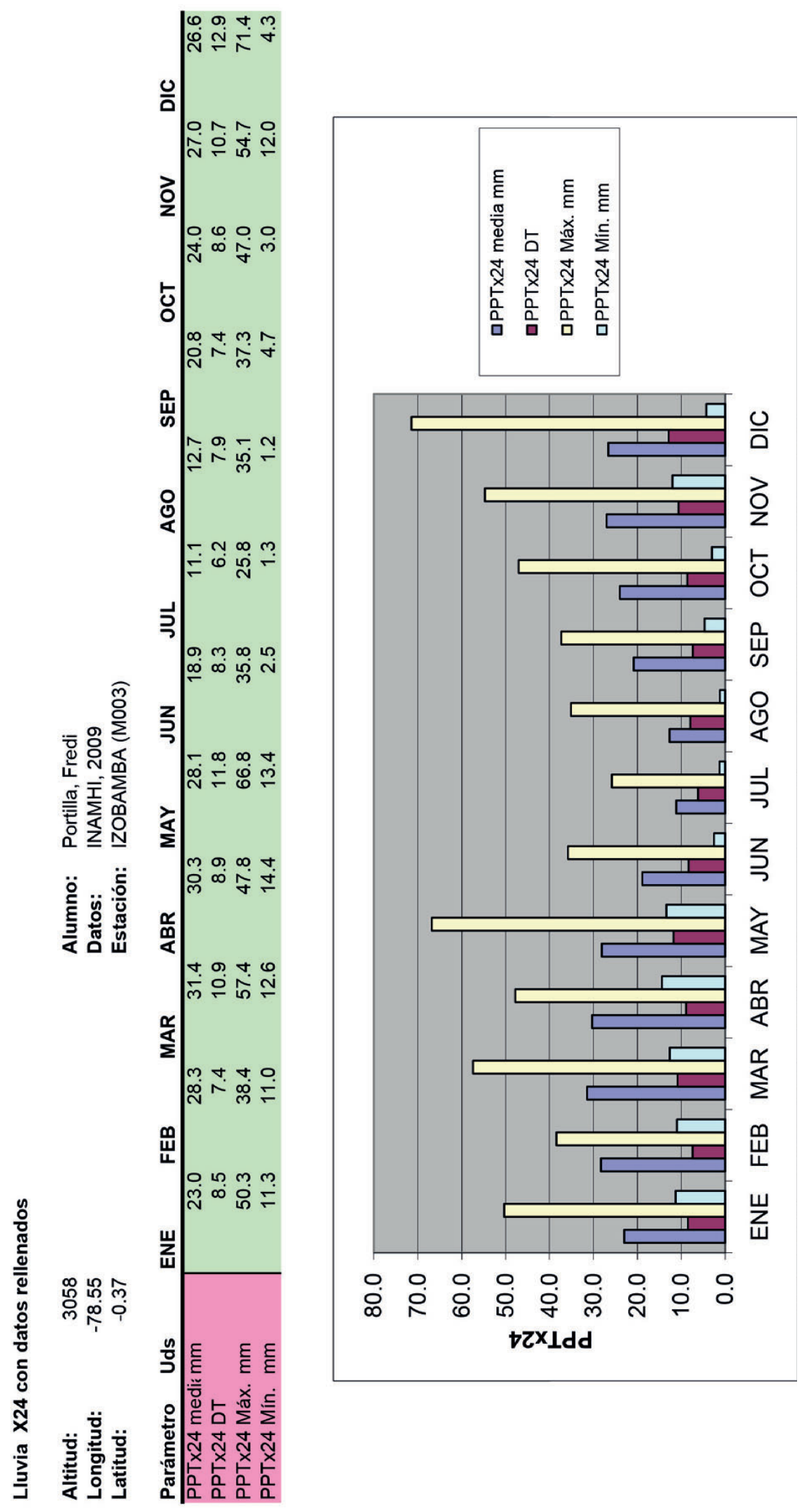




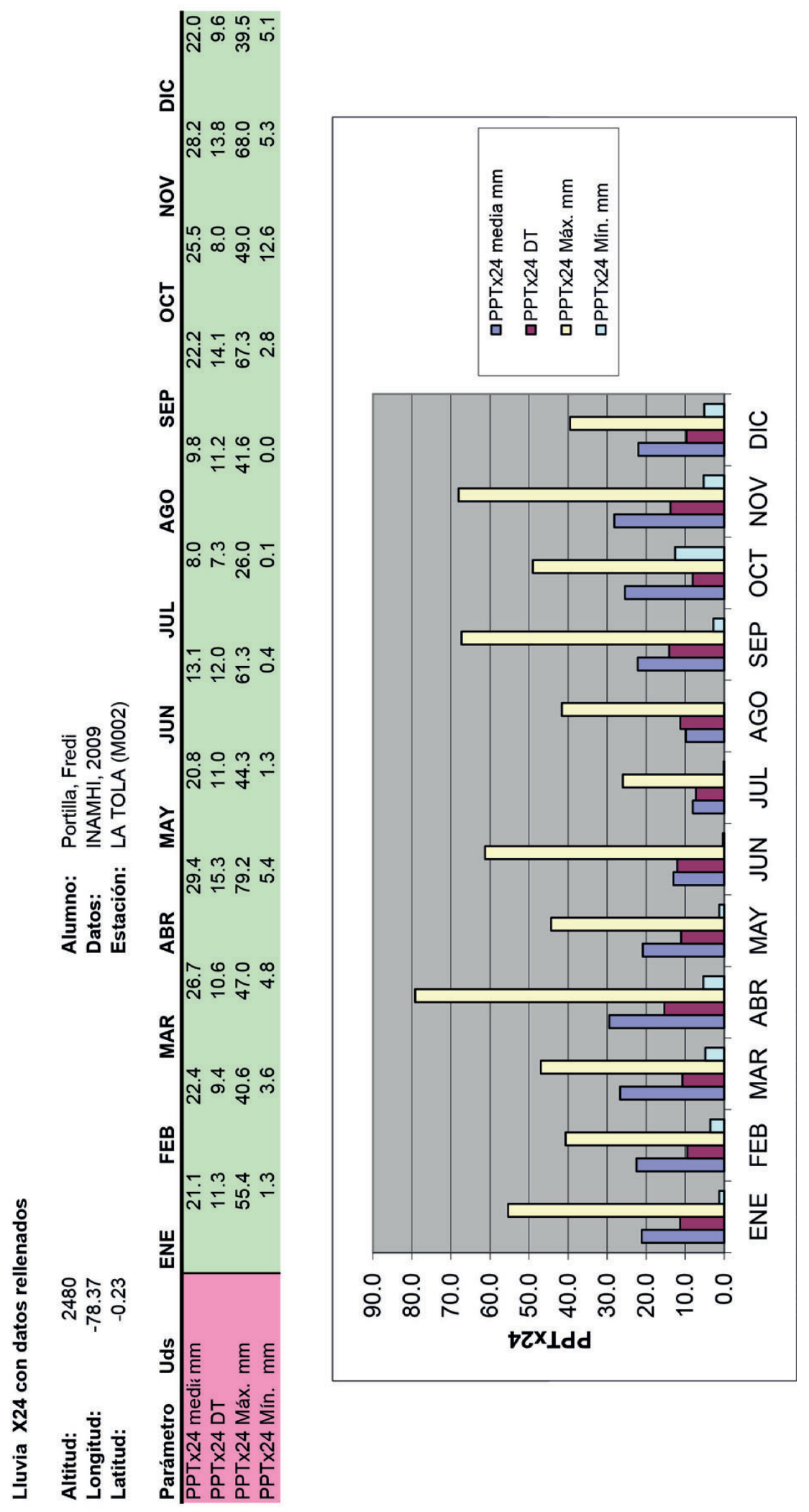


o

ఏ

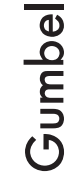

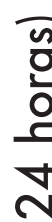

๘

.

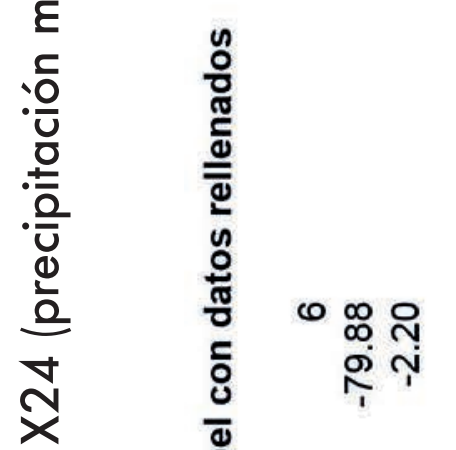

$\stackrel{\frac{0}{3}}{3}$

竞

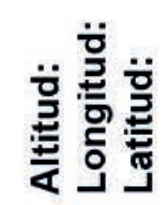

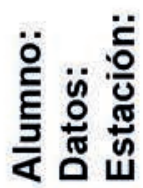

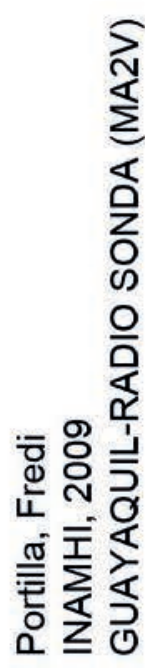



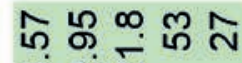
ठำ

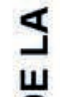

㟧

옹

.

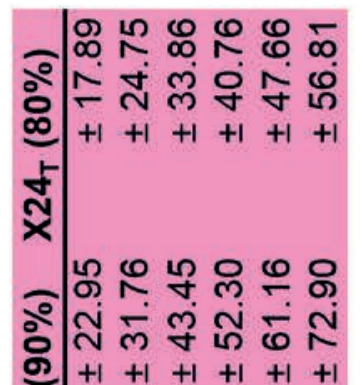

त्ष

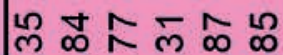

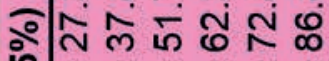

ติ

$+1+1+1+1+1+1$

x

๓ $\bullet \circ \bullet$ ก

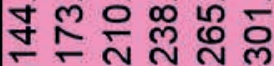

กับ

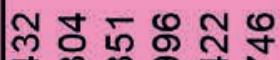

舟

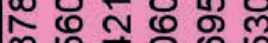

1

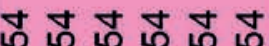

808080

두두둔

के

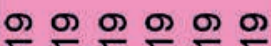

$m$ m $m$ m

กิ กี กี กี

○ 00000

ร

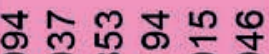

ब

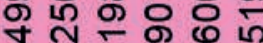

- त लं म

占

n으늉ㅇ으율 


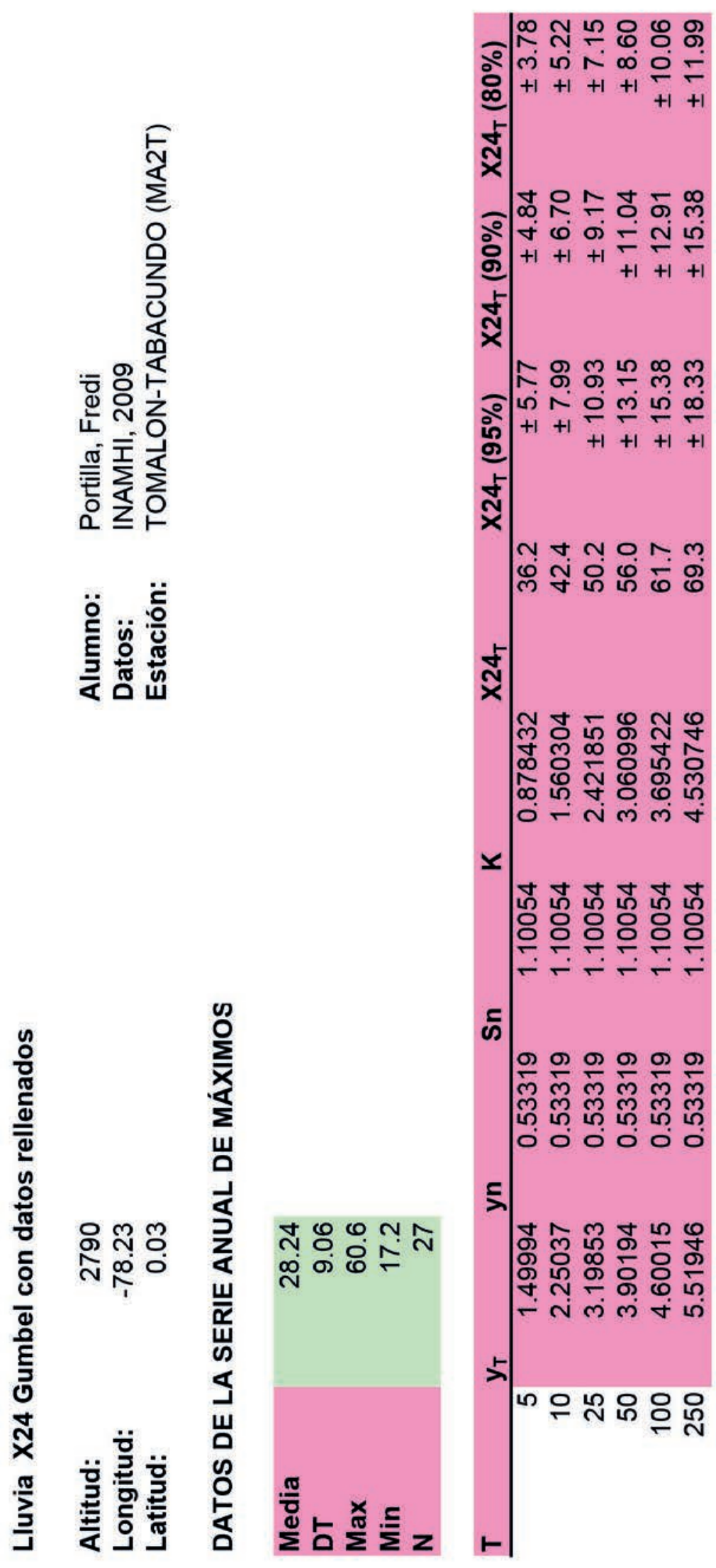



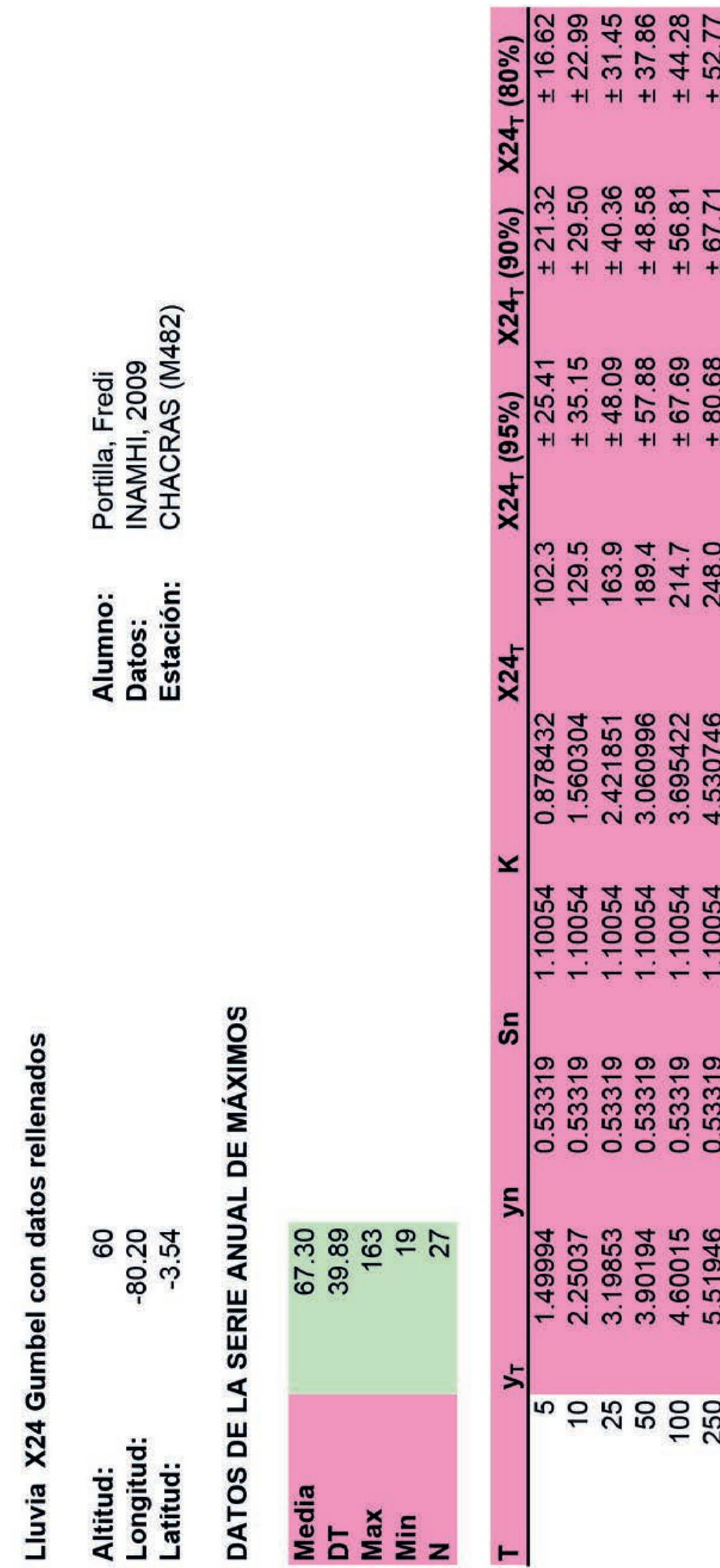

유ㅁㅛㅠㅇㅠ

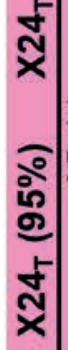

ๆ

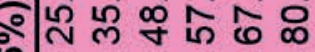

ก $+1+1+1+1+1+1$

$m$ เ

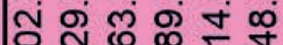

齐

ำ

พำ

ळ $\overline{0}$

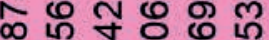

० - लें लं

$x$

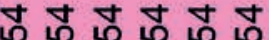

$\circ$ 응ㅇㅇㅇㅛ

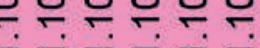

ธุ

으 으음으음음

m m m m

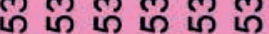

० 0 0 000

s ธิ

0 ल

ปิ⿵人丶 ภ 잉응 ข

त ल

占

n으 늉으율

愛 

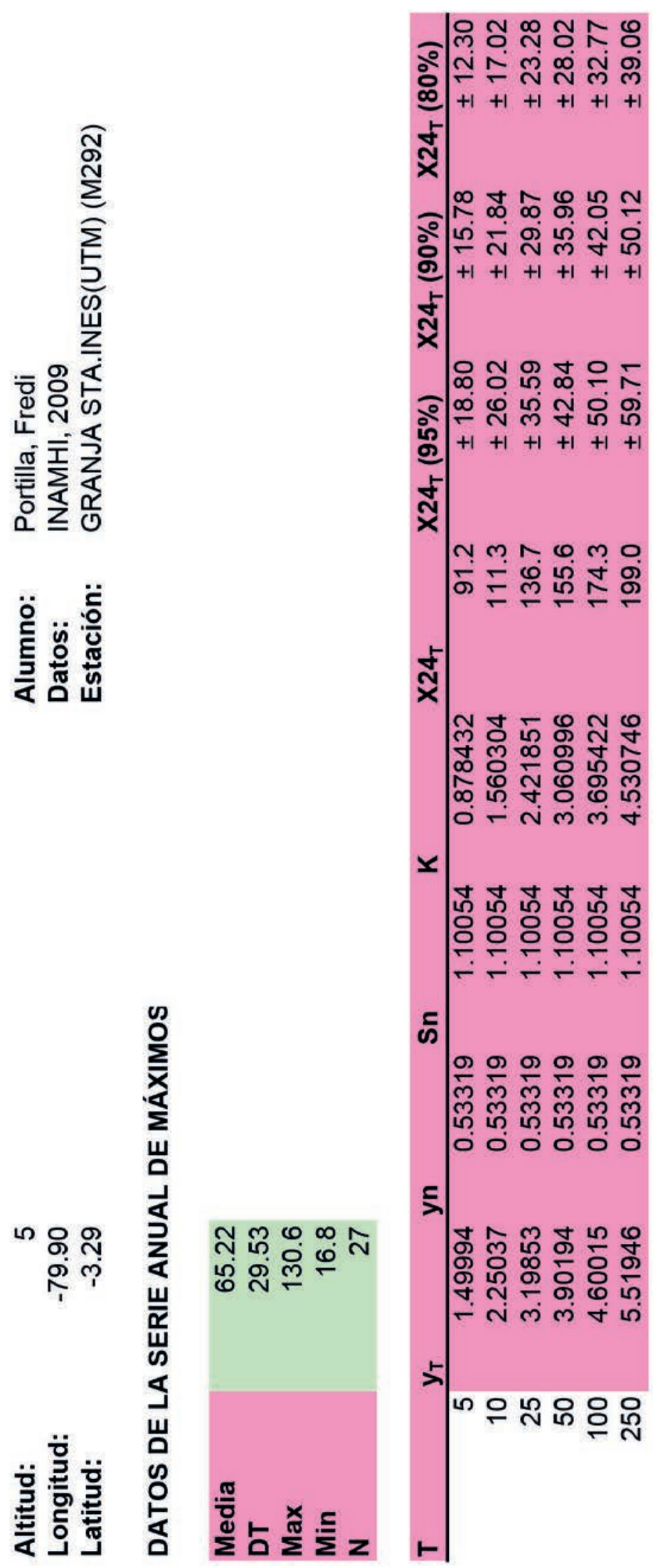

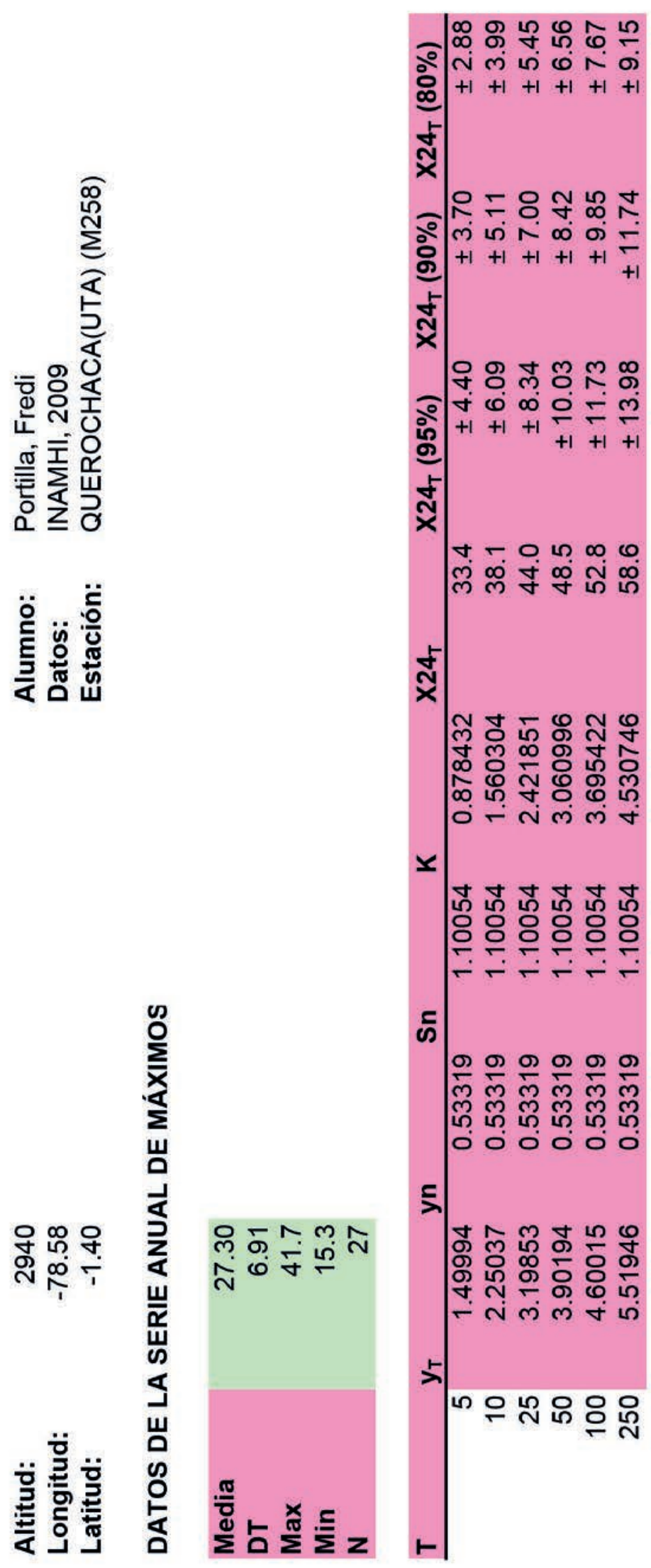

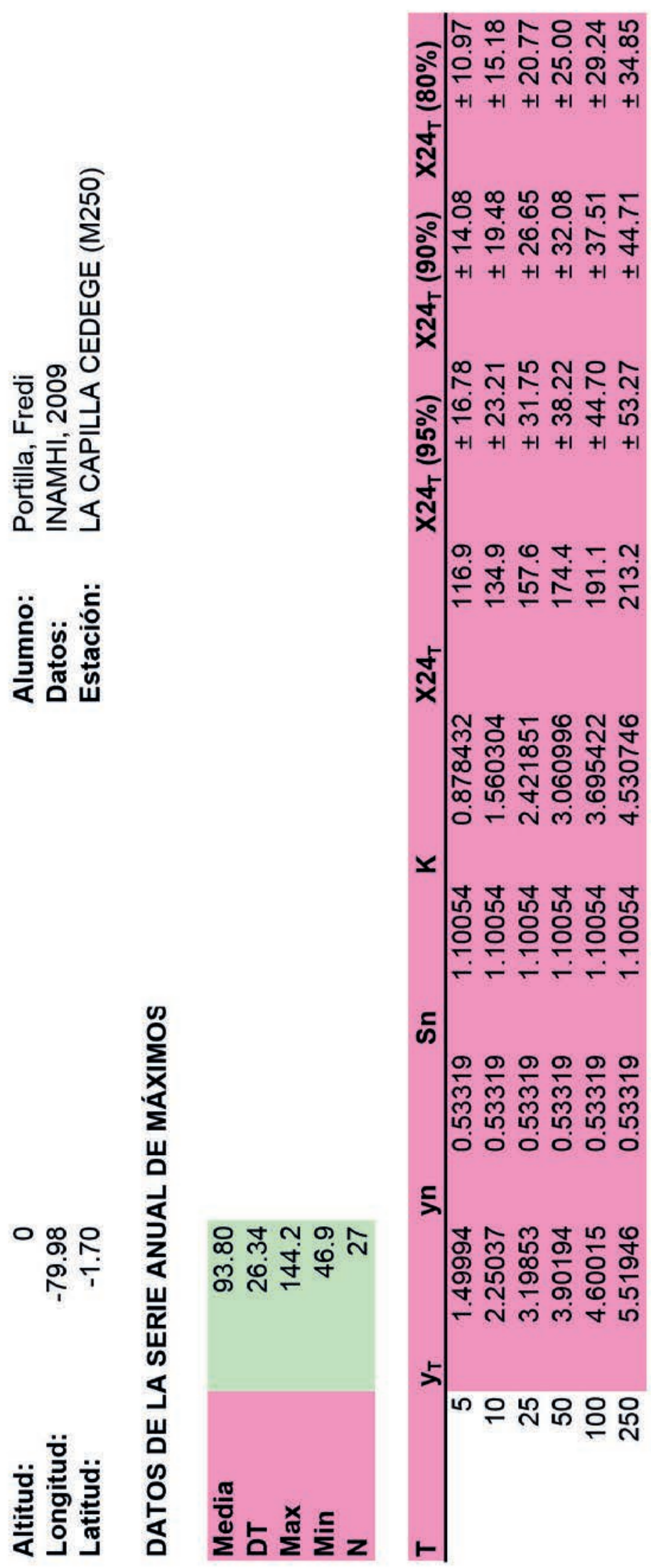

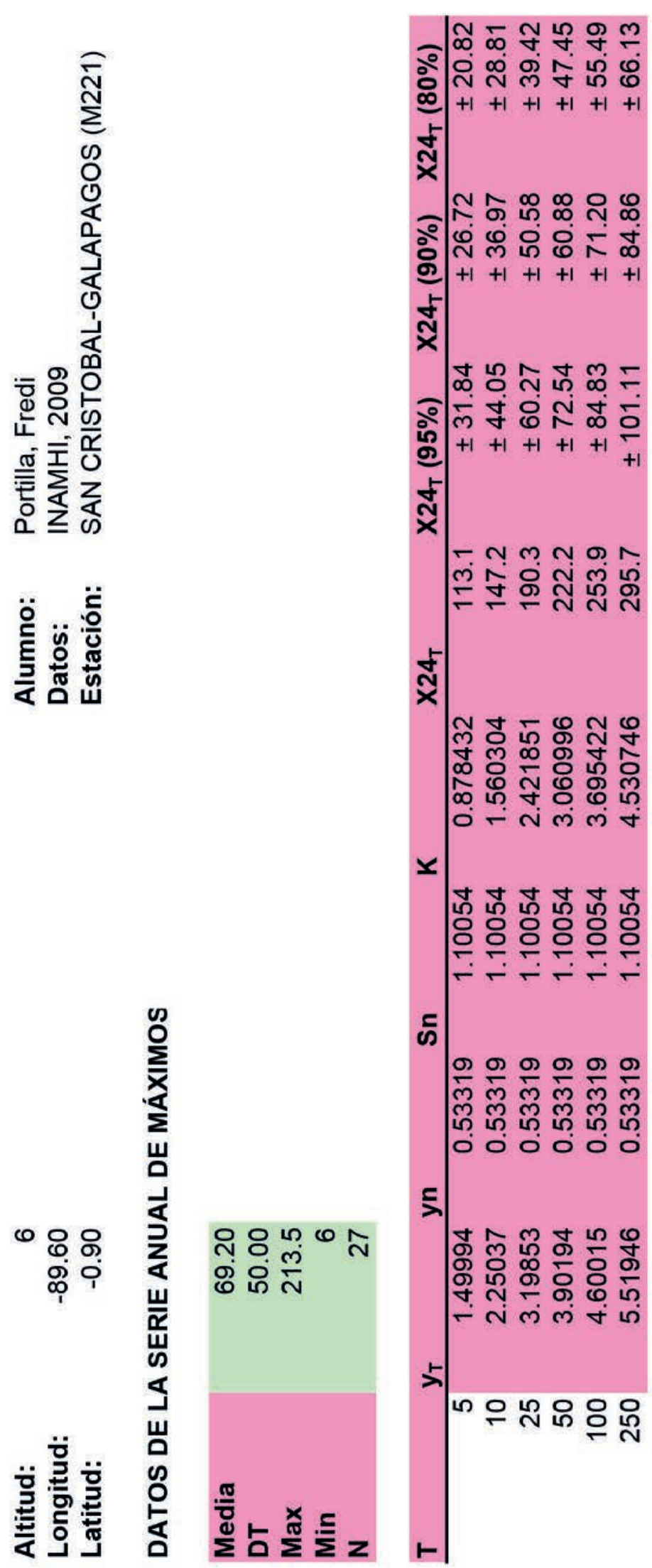

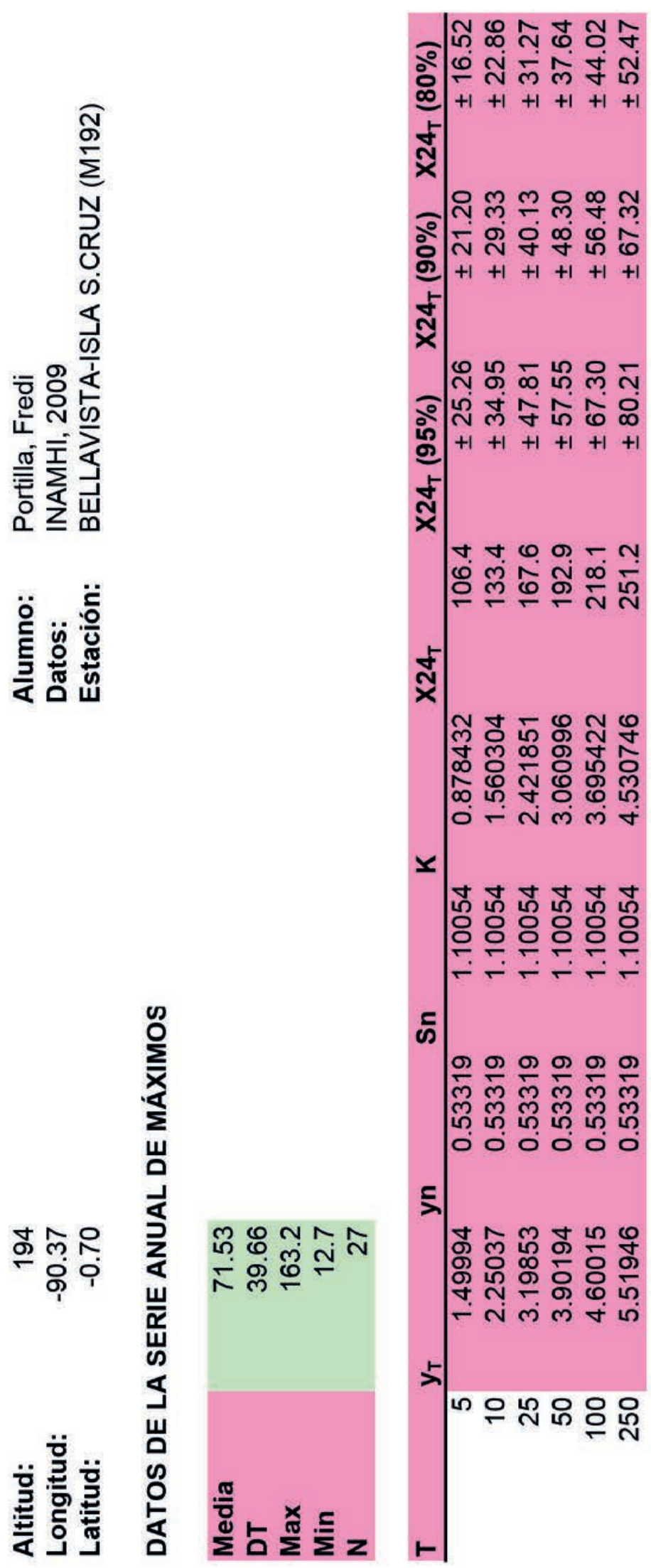


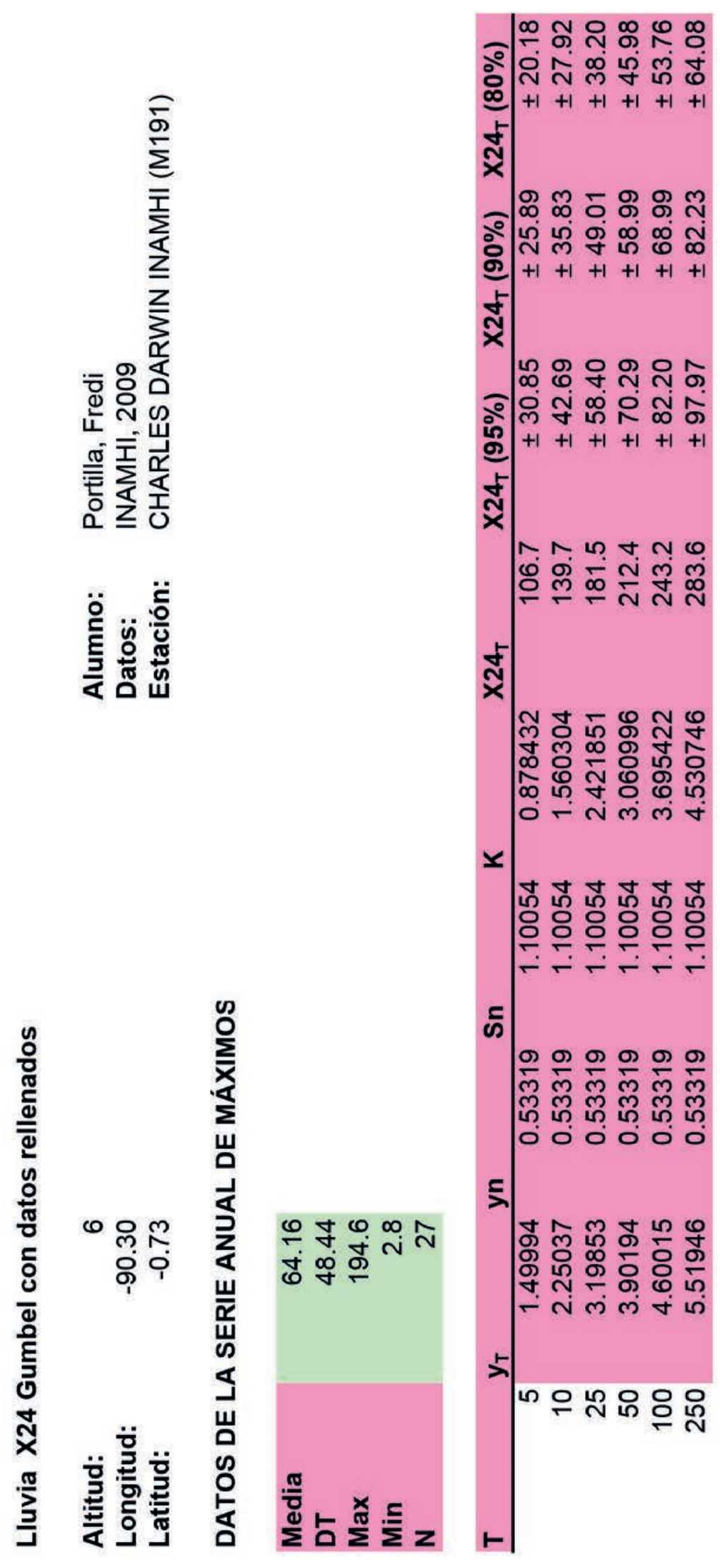



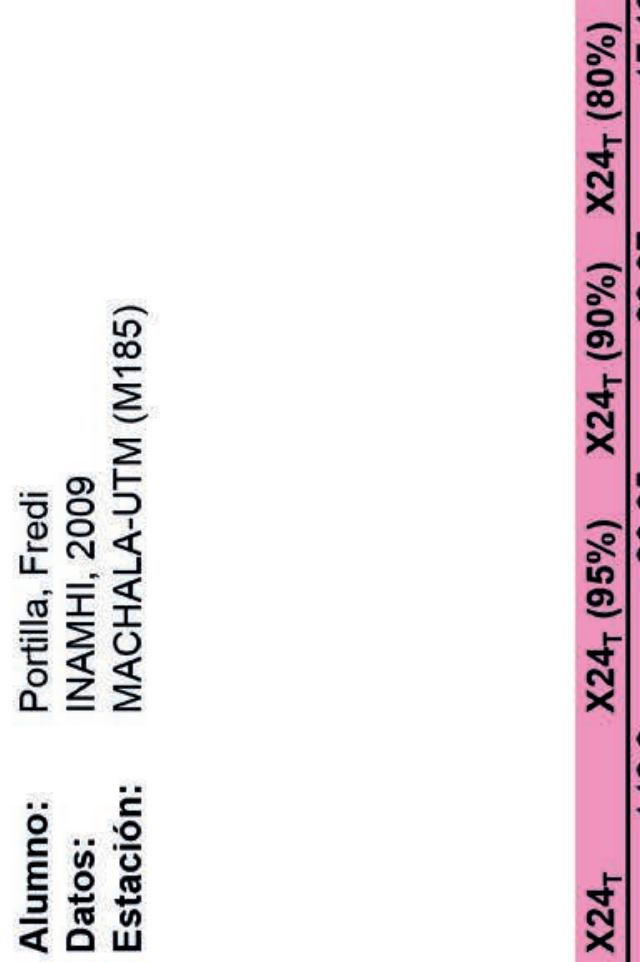

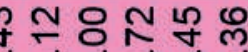

ㅎํ m

$+1+1+1+1+1+1$

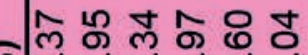

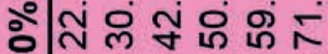

$+1+1+1+1+1+1$

妾

๒

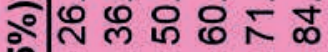

$+1+1+1+1+1+1$

离

$\infty$ t n N

N $\leftarrow$ \&

ষN

䇉

ำ์

भั

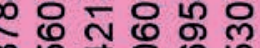

ஸ

$\leq$

प吉吉吉

ㅇㅇㅇㅇㅇㅇ

으으응으으은

능

$\sum_{\substack{x \\ \frac{1}{x}}}^{0}$

ติ

음음ㄷㄷ으음ㅇ

m $m$ m

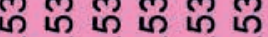

○ 00000

$\stackrel{\text { ก }}{\frac{1}{2}}$

旁

๓

嵓

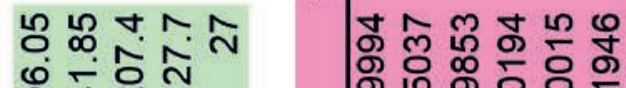

ริ

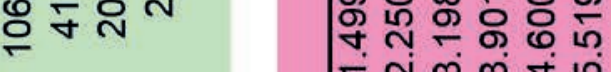

है 㟧

㞺

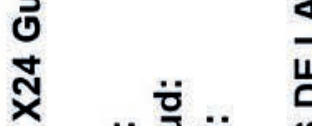

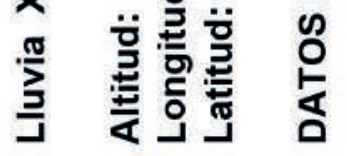

旁

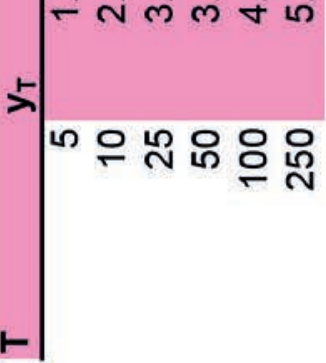




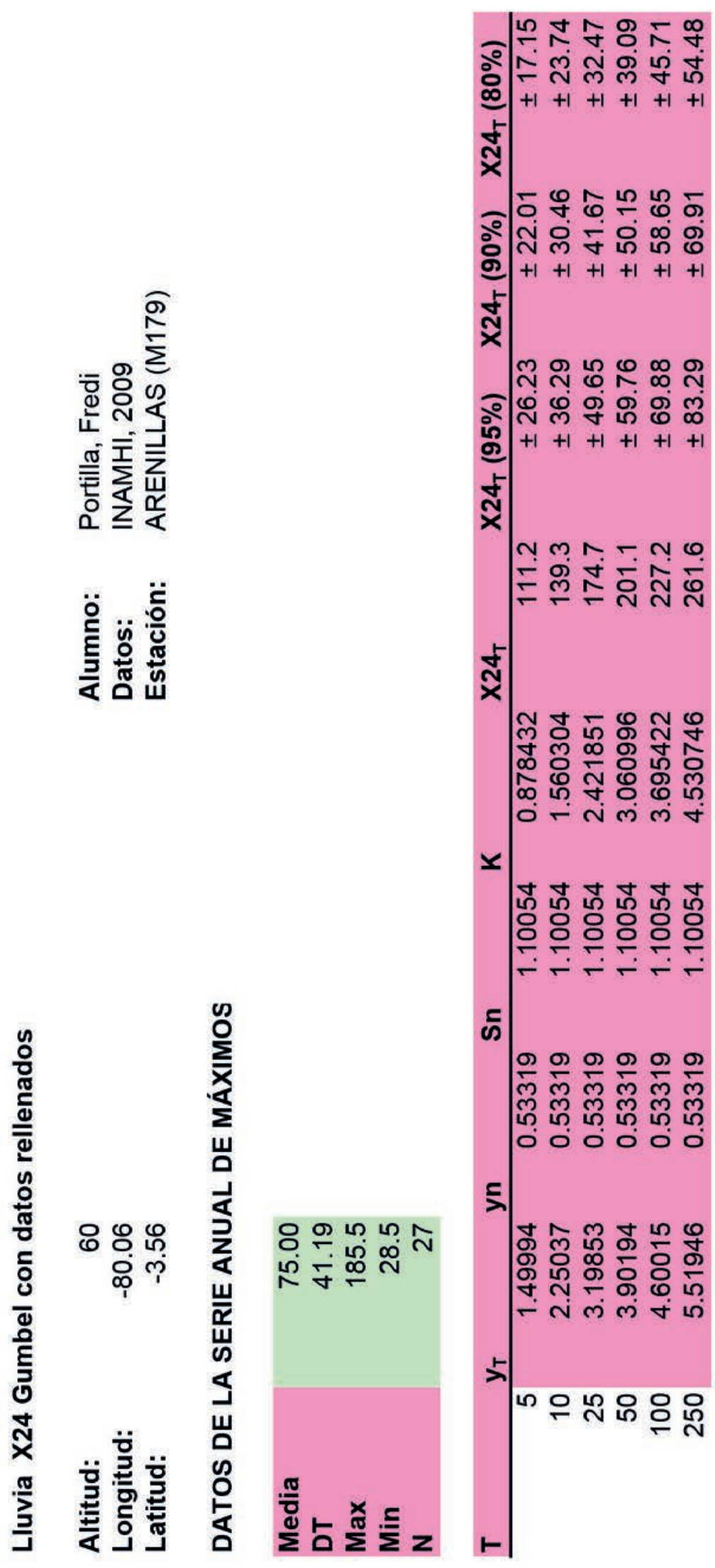



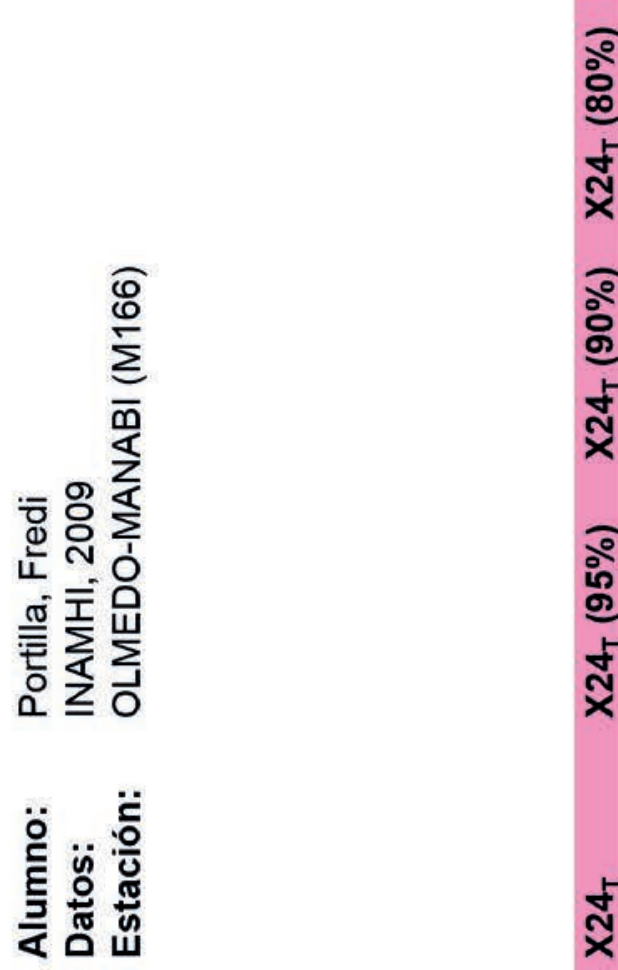

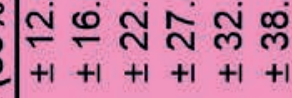

×

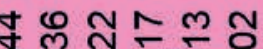

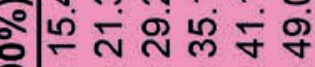

$+1+1+1+1+1+1$

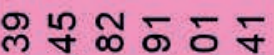
○

$+1+1+1+1+1$

文

m 0 の

กู่

ฟ

ํำ

พ

뜌ํำ

० त लं

$\leq$

オオ甘オオ

응ㅇㅇㅇㅇㅇㅇㅡ

는 으은으는

음

일

क

음음ㄷㄷ으음ㅇ

m $m$ m

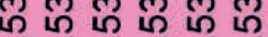

० 00000

은

은도 옹

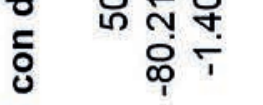

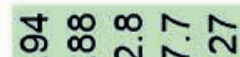

ริ ๑

है 崫

๙ $\div$

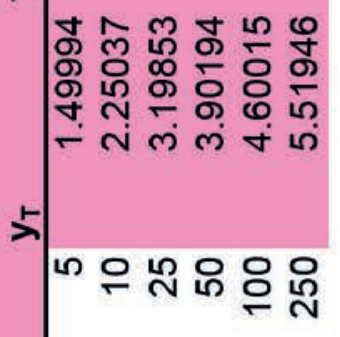

กับ

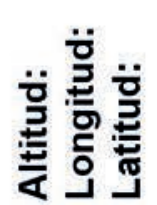

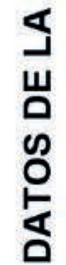

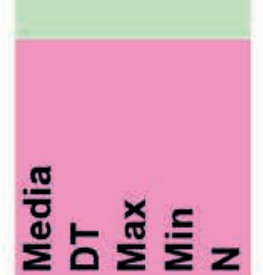

으유요응유 

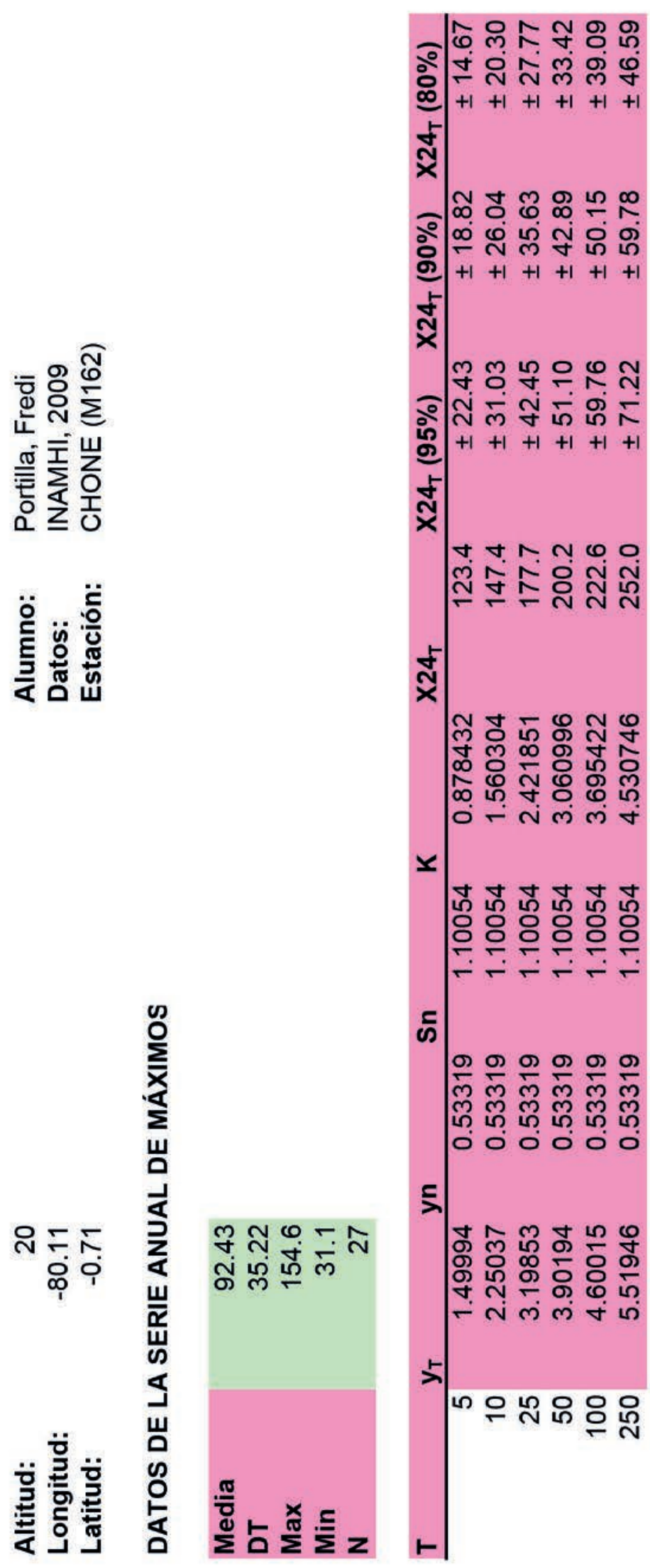

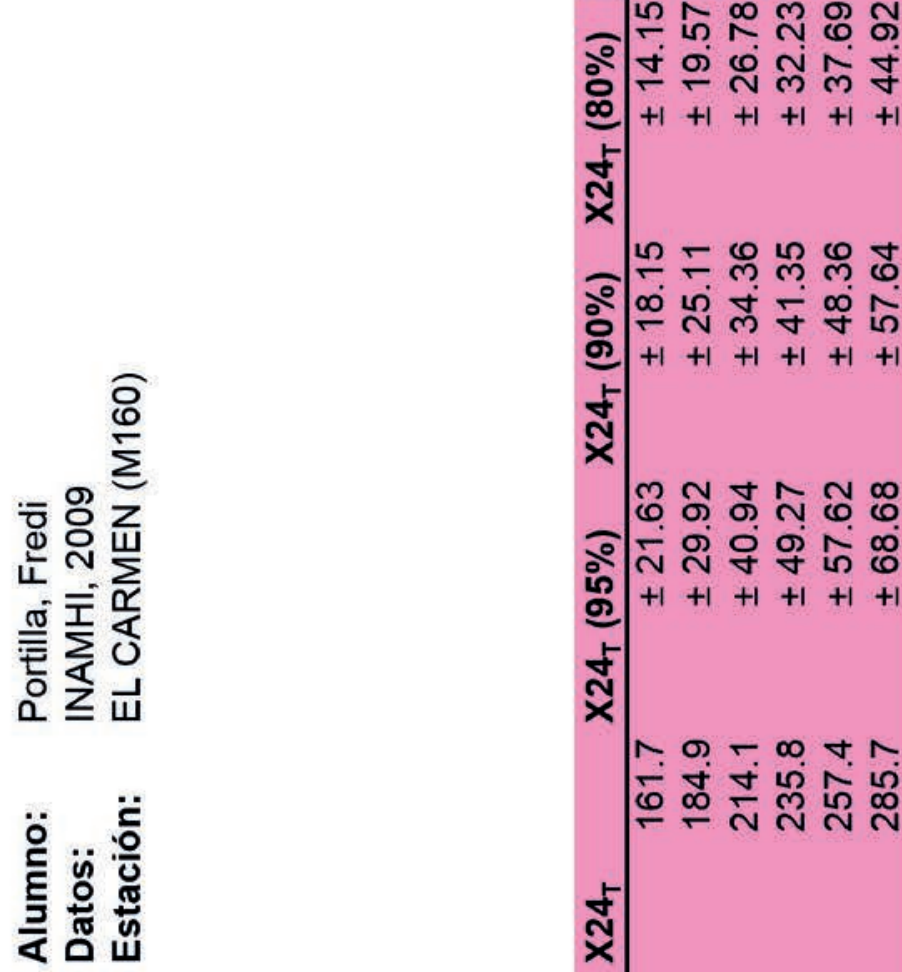

齐

ㄴำ भั 0 듀요

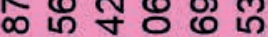
○ - लं mं

$x$

过吉吉吉 용ㅇㅇㅇ 는 으 으 으는

을

ติ

음으묻으음ㅇ लू

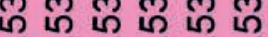
○०000

ำ

웅

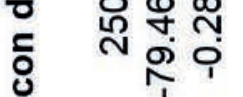
œ

ริ ल m

齐

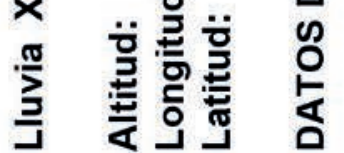




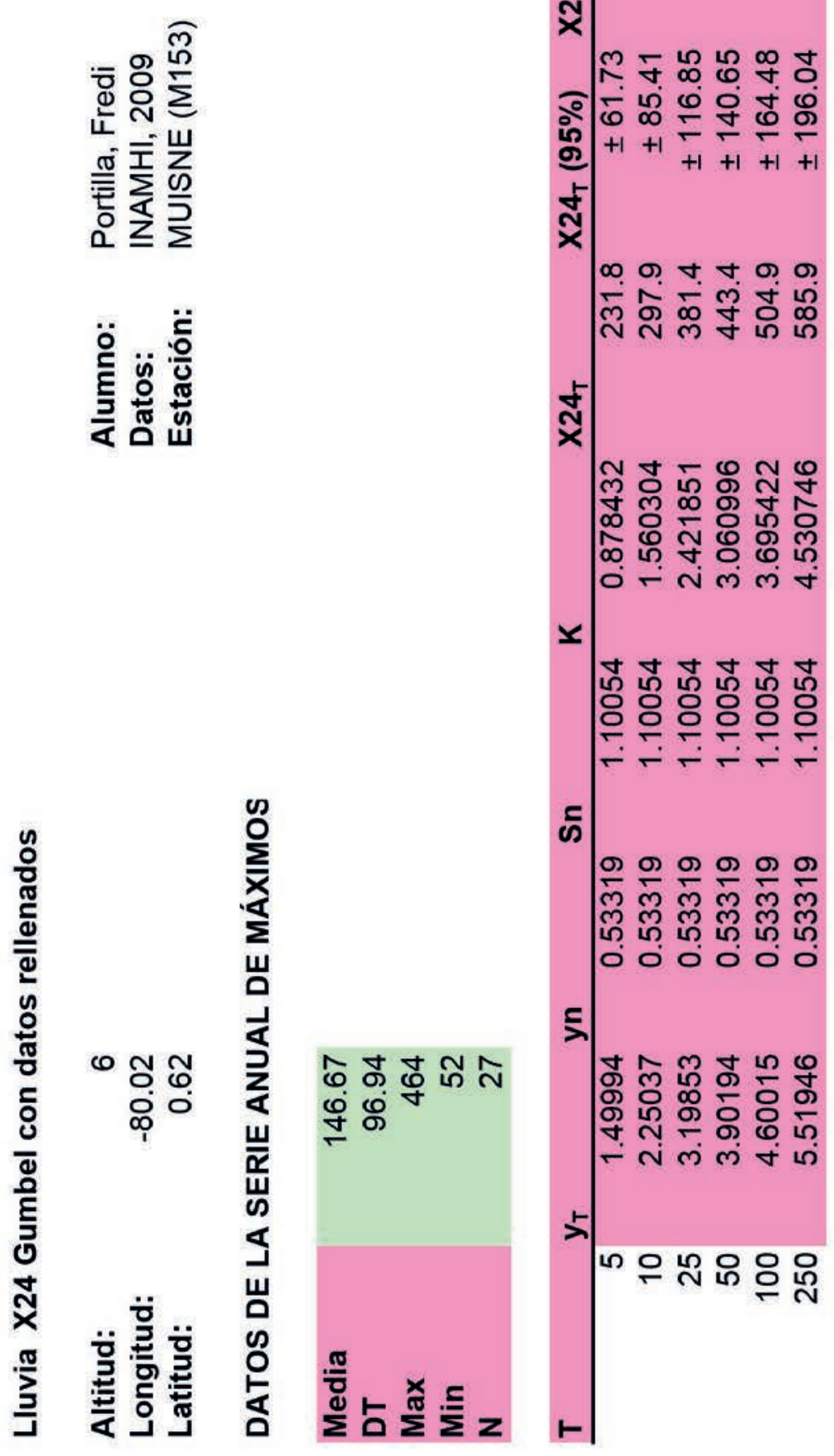



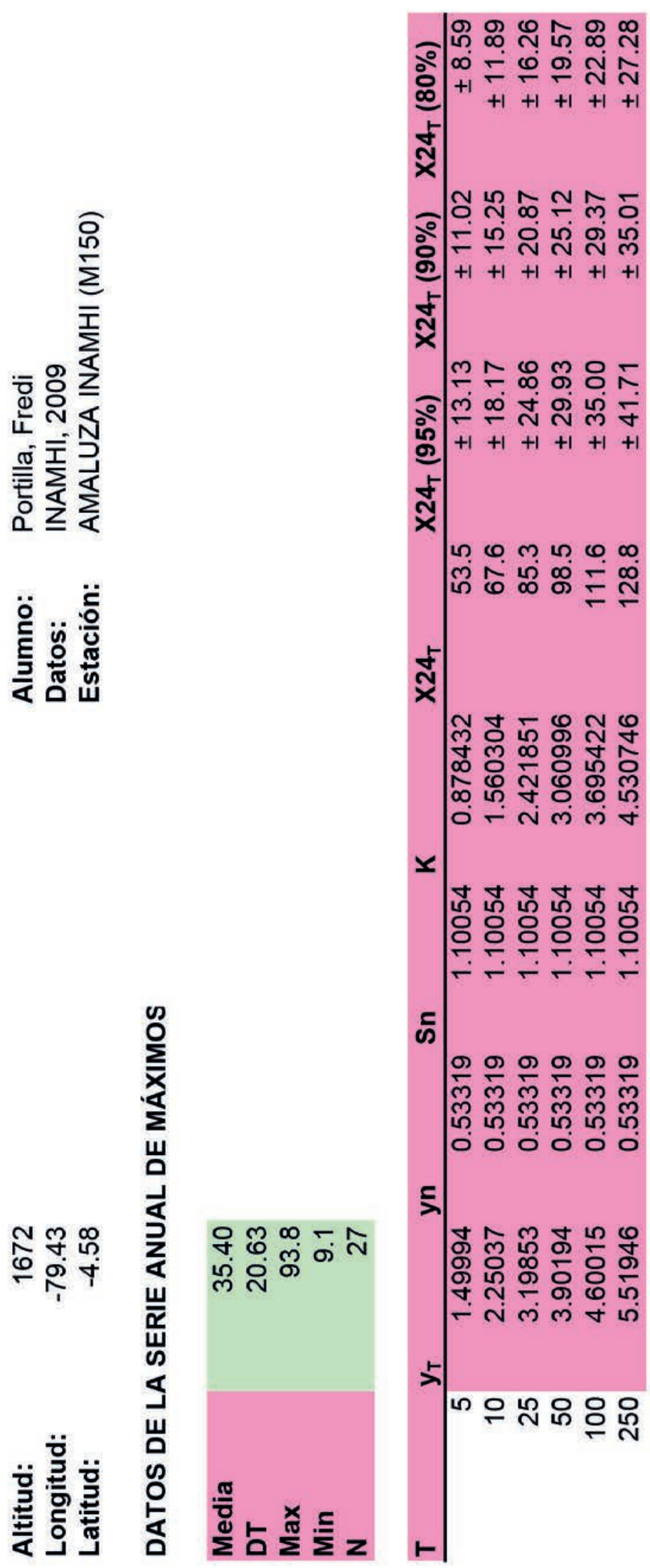

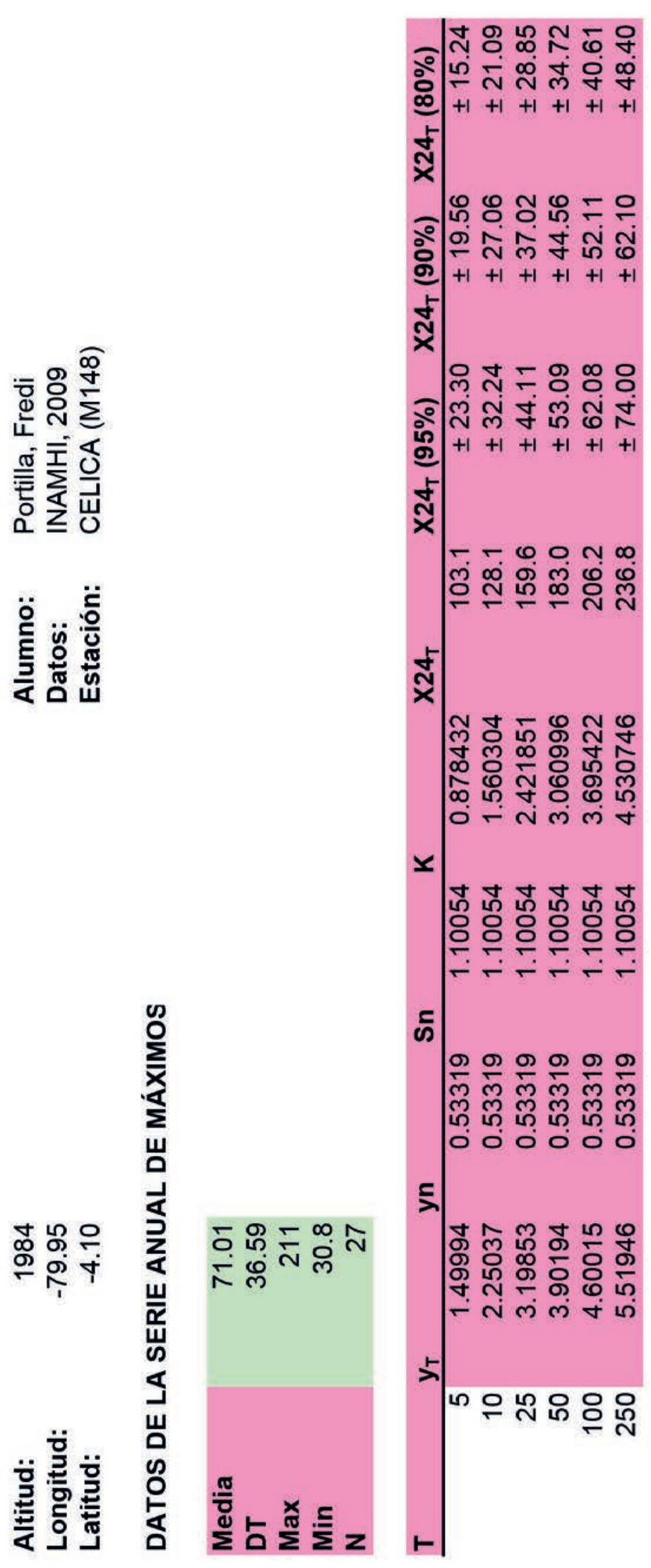


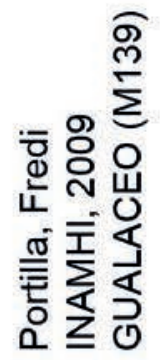

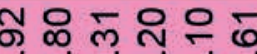

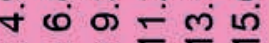

$+1+1+1+1+1$

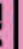

ர

$\omega \infty \div \dot{0}$

$+1+1 \div \div$

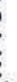

齐

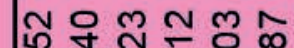

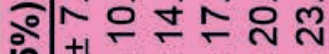

ร)

$+1+1+1+1+1$

齐

兰

mo-nNo

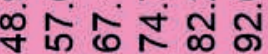

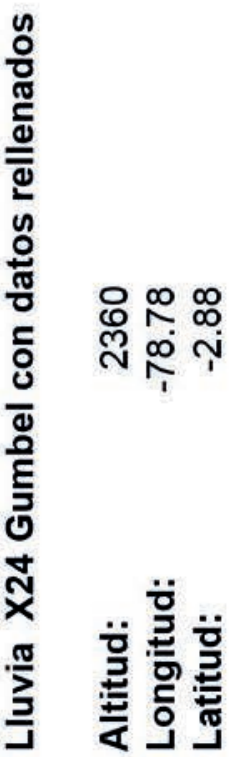

Un

ஸิ옳ำ

$\infty \stackrel{\infty}{=} \dot{\sim}$

ติ

ㄴำ

พำ

듀

$\infty$ น ४

० - लें ले

$x$

过吉吉吉

ㅇㅇㅇㅇㅇㅇㅇㅇ

두둔둔

음음음음음

m m m m

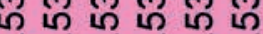

○ 00000

ริ)

オ

ชํำ

- ते लें

5

으 늉으율

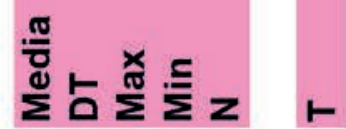



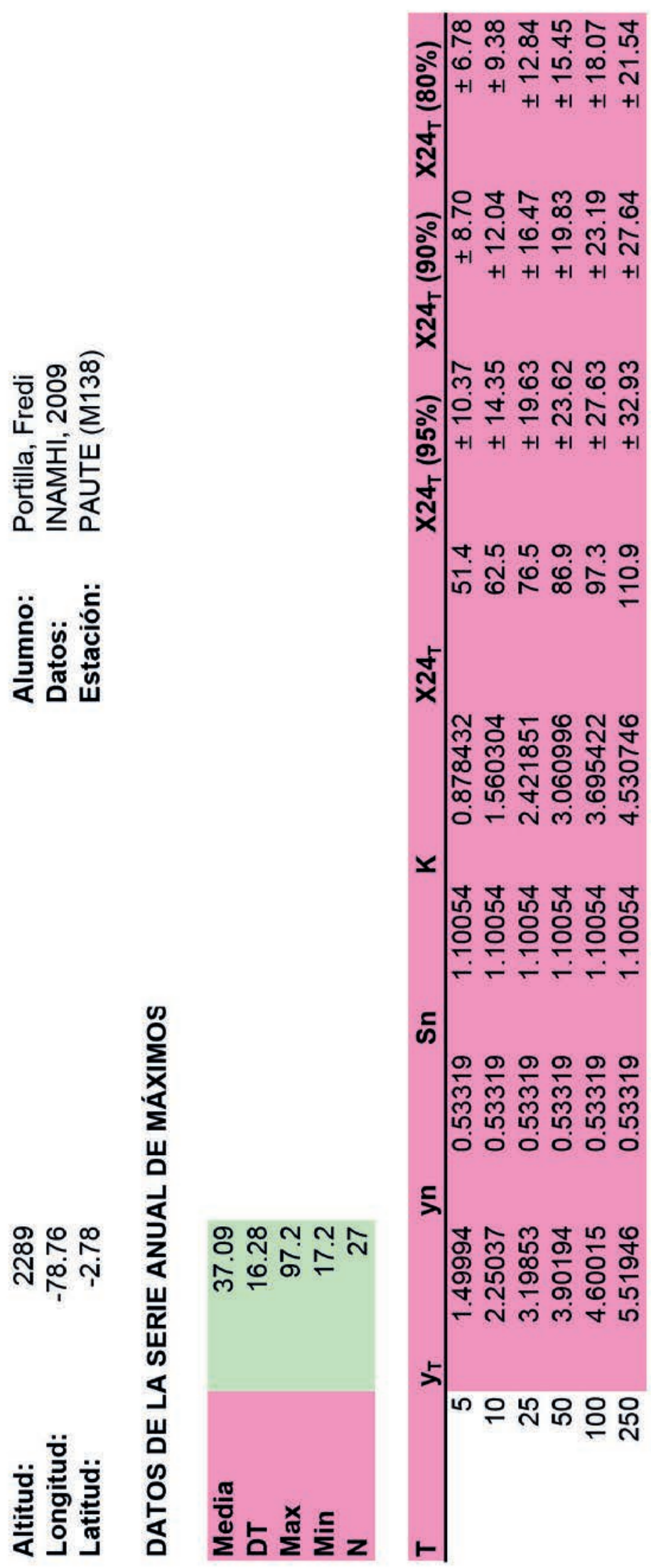

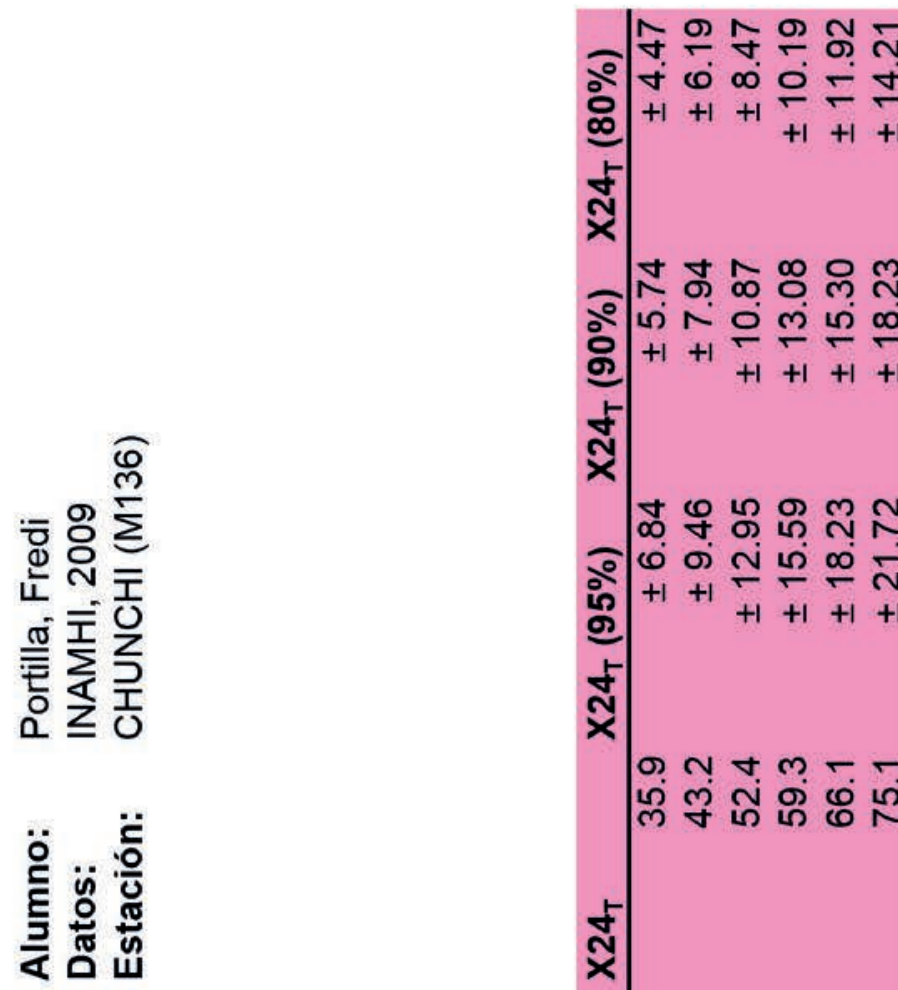

$N \forall m-\leftarrow$

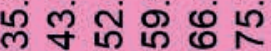

ฌ $\stackrel{0}{0} \div \stackrel{\sim}{\leftarrow}$

ํำ mํํ용 œ ஸ ० - ले ले

$x$

オオ甘オオ 응ㅇㅇㅇㅇㅇㅇㅇㅛ 둔둔다.

ติ

무욤요 $m$ m $m$ m ก ก กิ กี กี - 00000

도 ஸ் 은

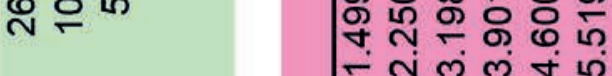

5 으 늉으윤

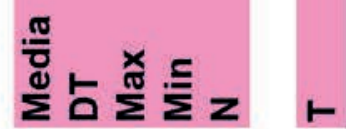



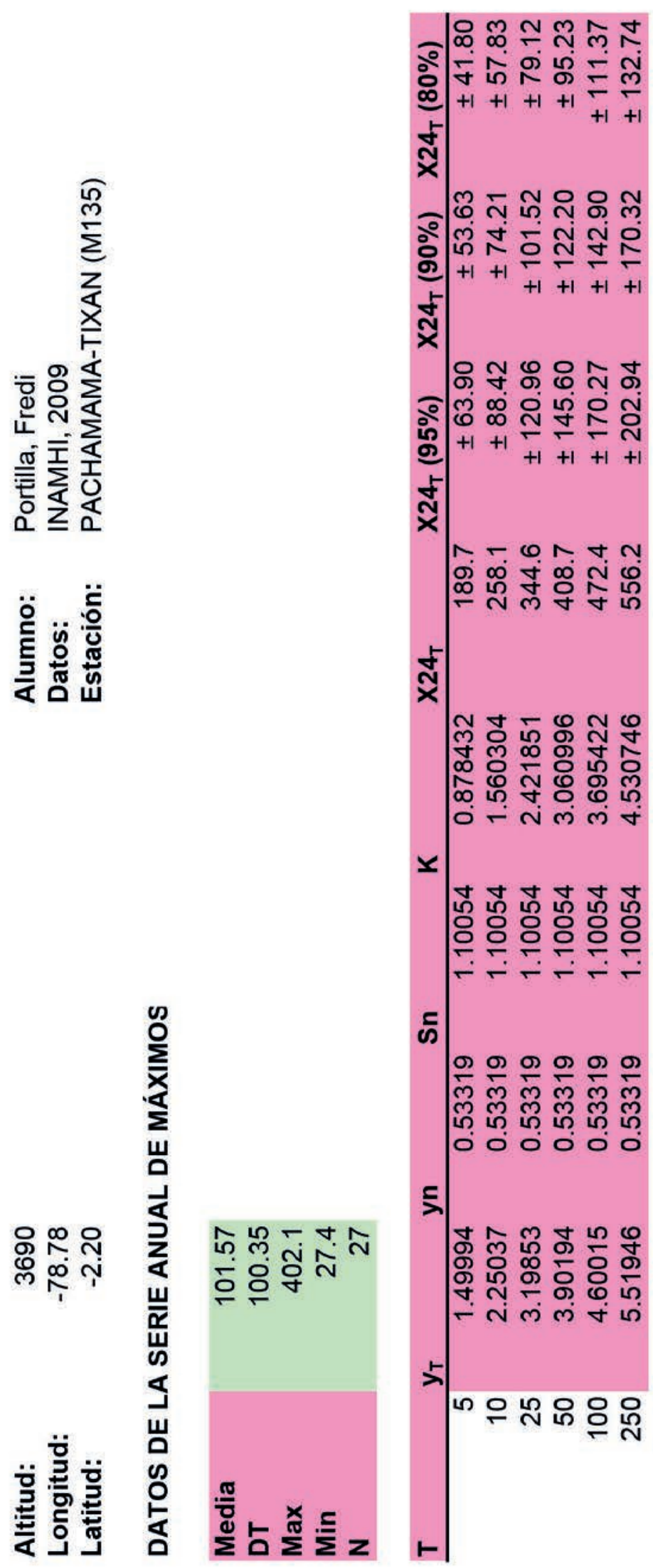

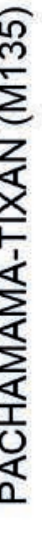



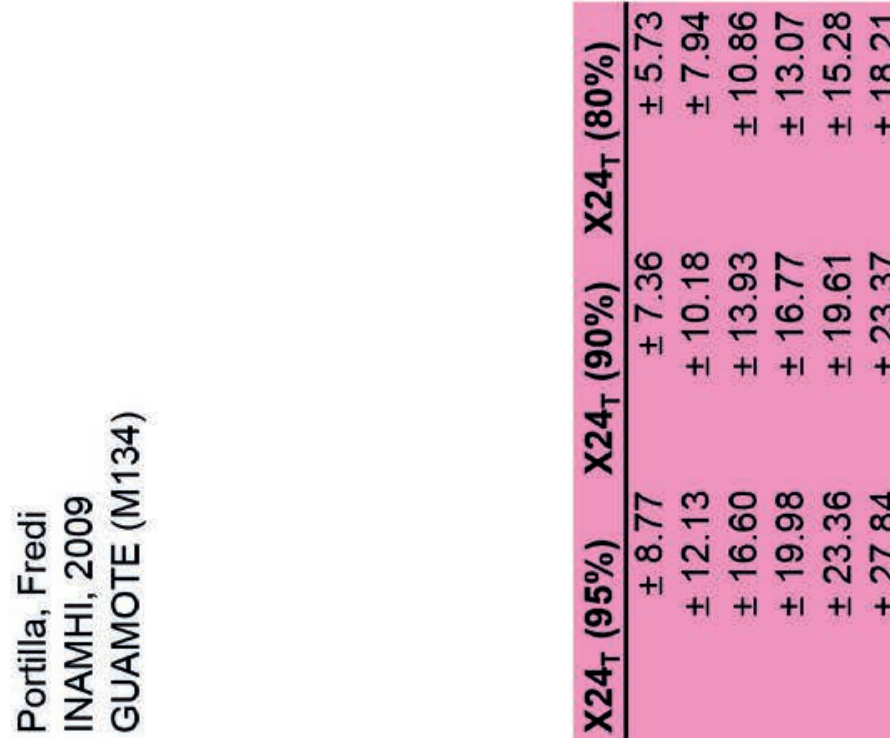

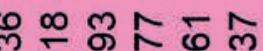
웅

을 응

の $\infty \cdots \infty$

लै 守
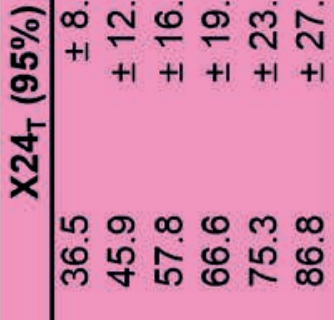

艾

ํำ

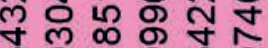

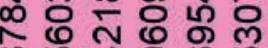

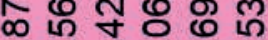
० - लें ले

$x$

过吉吉吉 응ㅇㅇㅇㅇㅇ 둔두두

ต

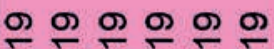
m m m m

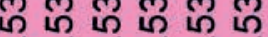
○ 0000

윰

ㅇำ

⿺辶万

พลก แก

ริ

㫕

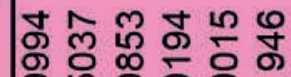
ช

ठํ ग

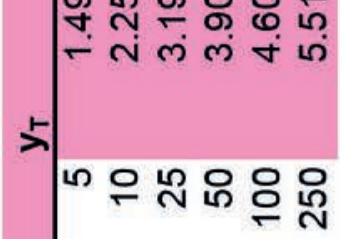

শั

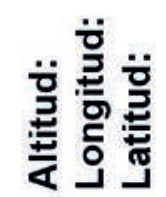

品

旁

으 늉으을 


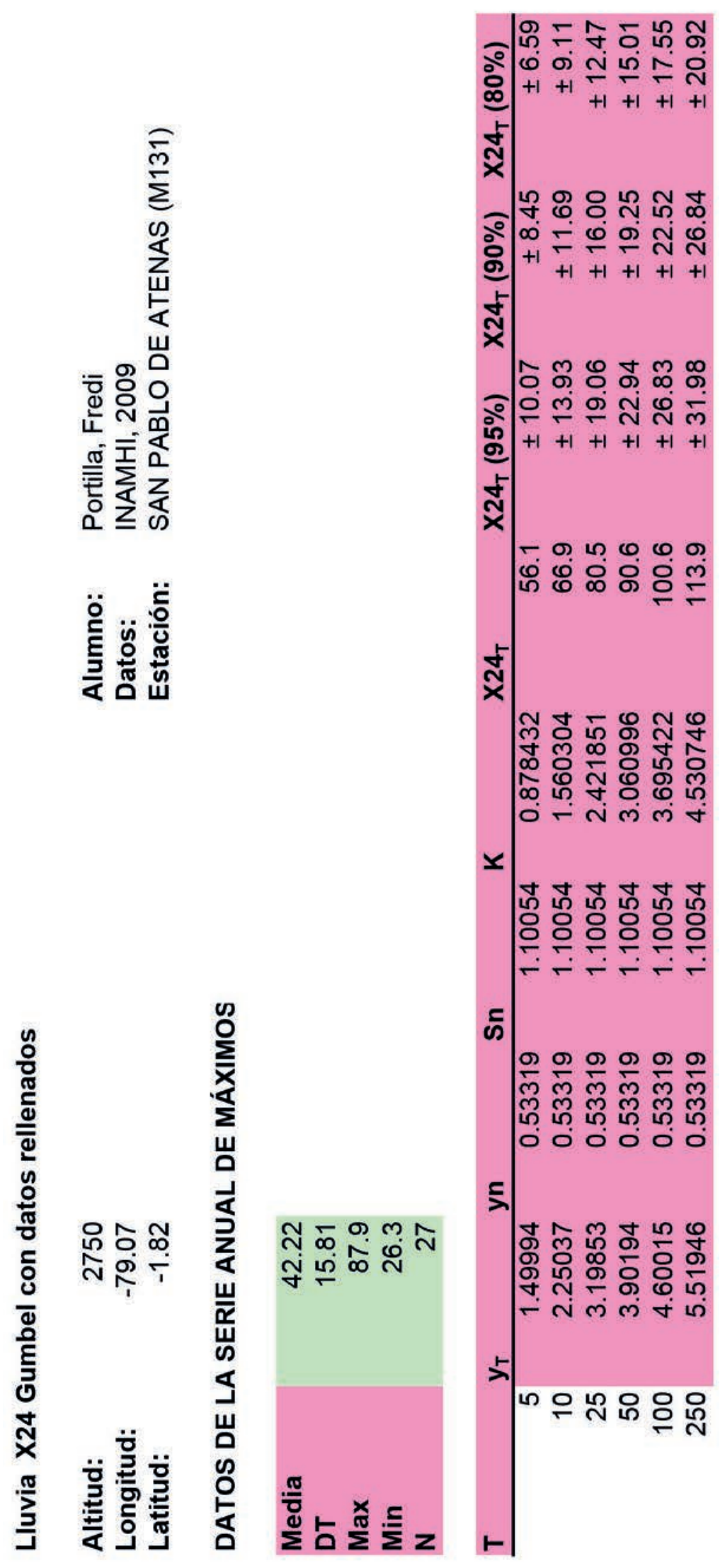



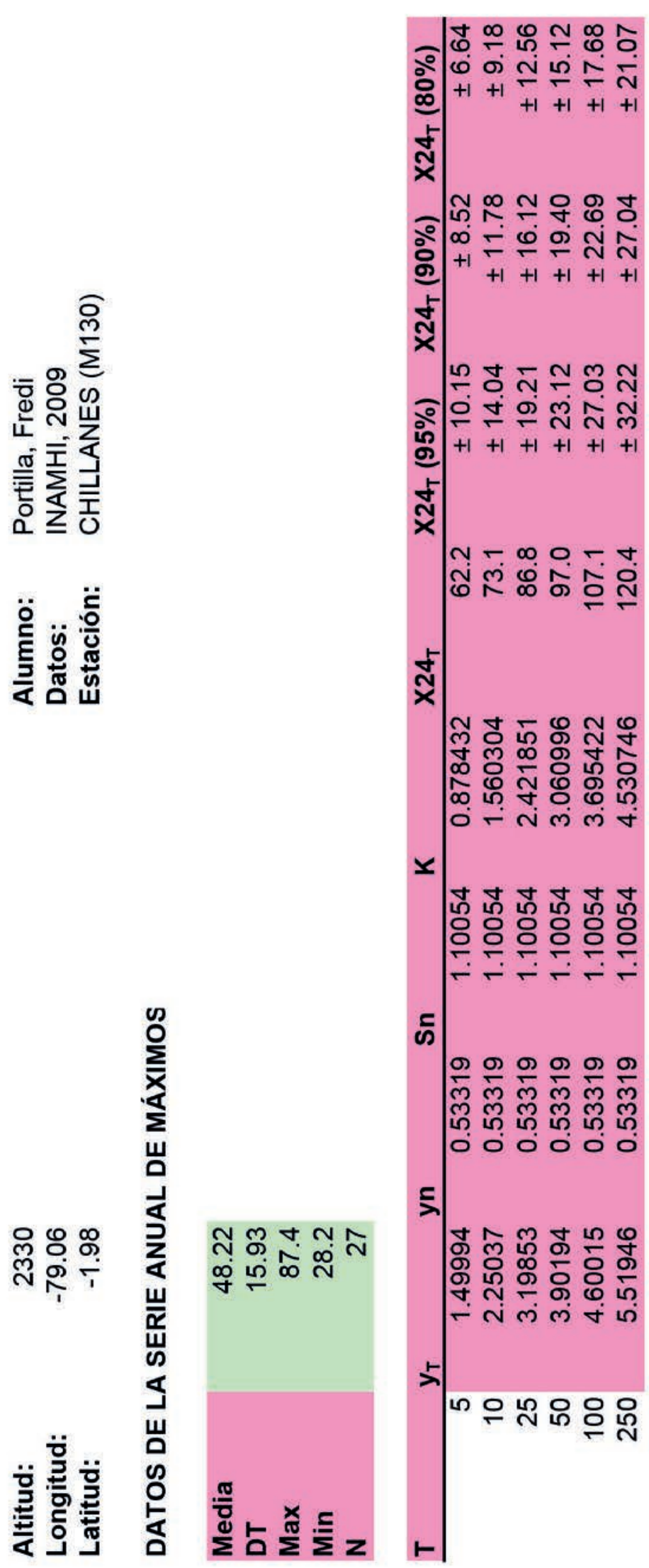

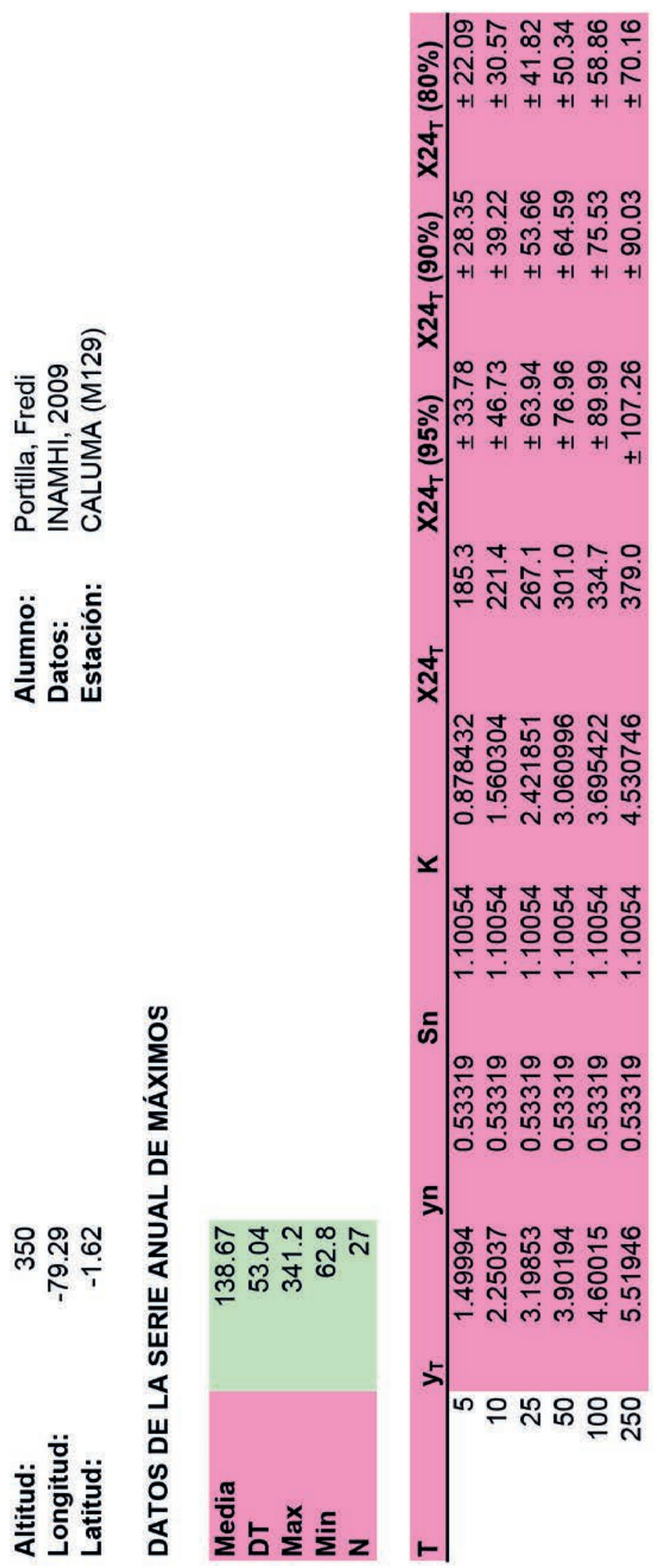

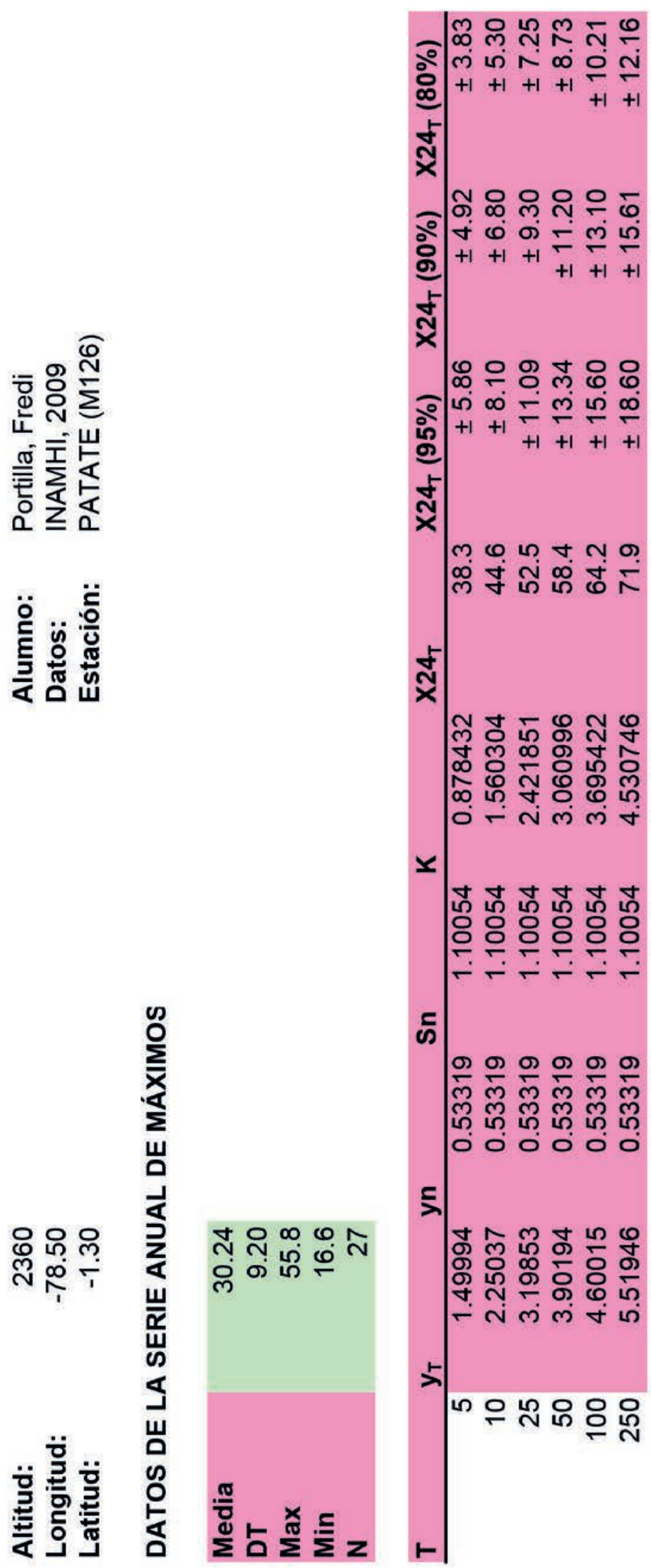

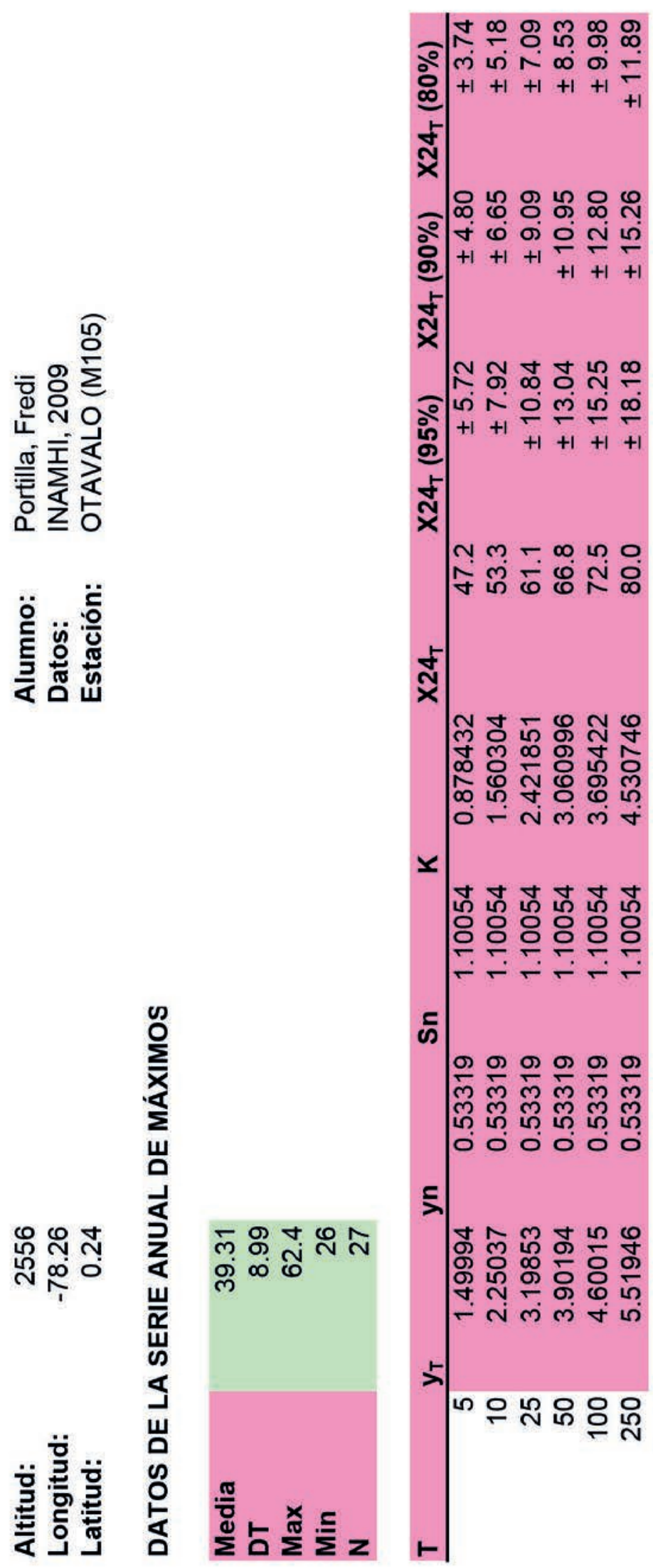


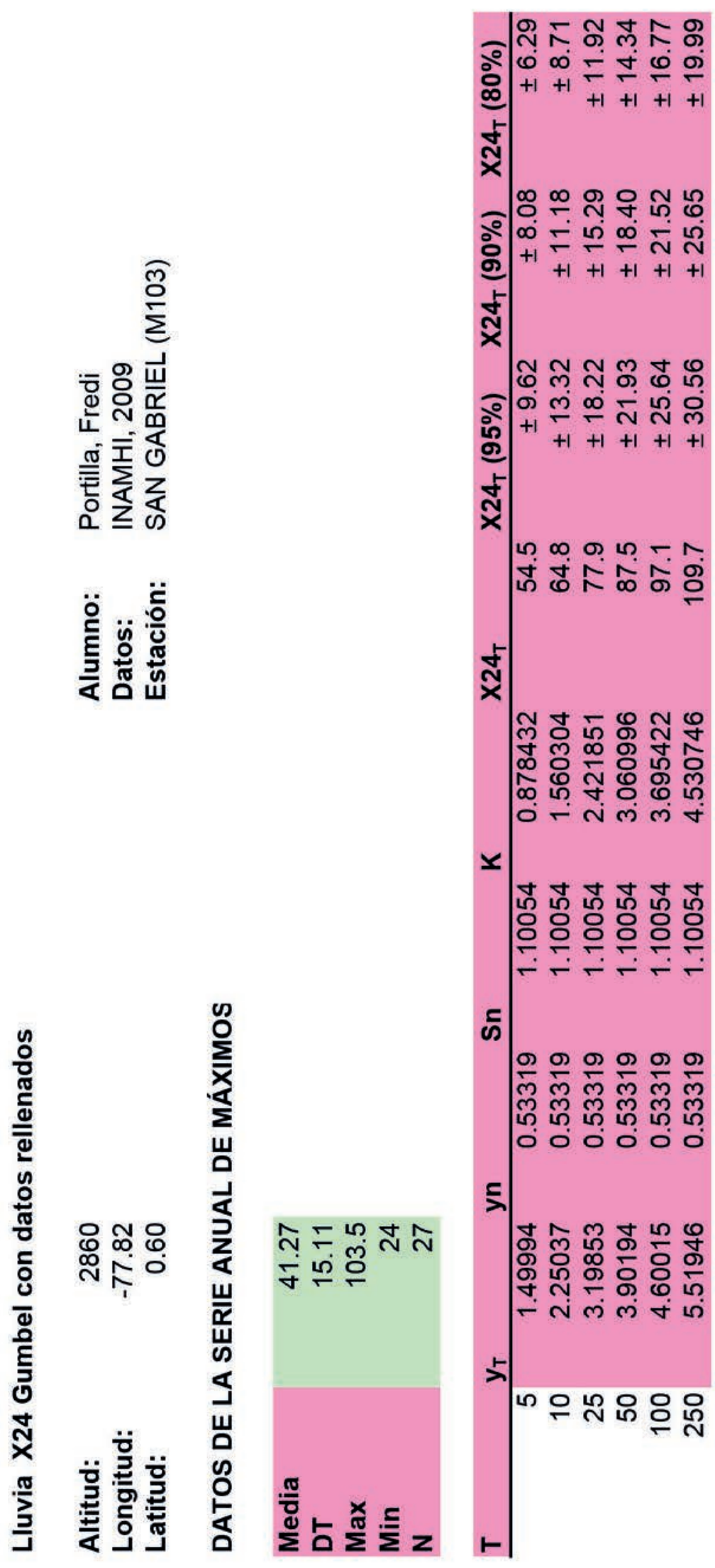



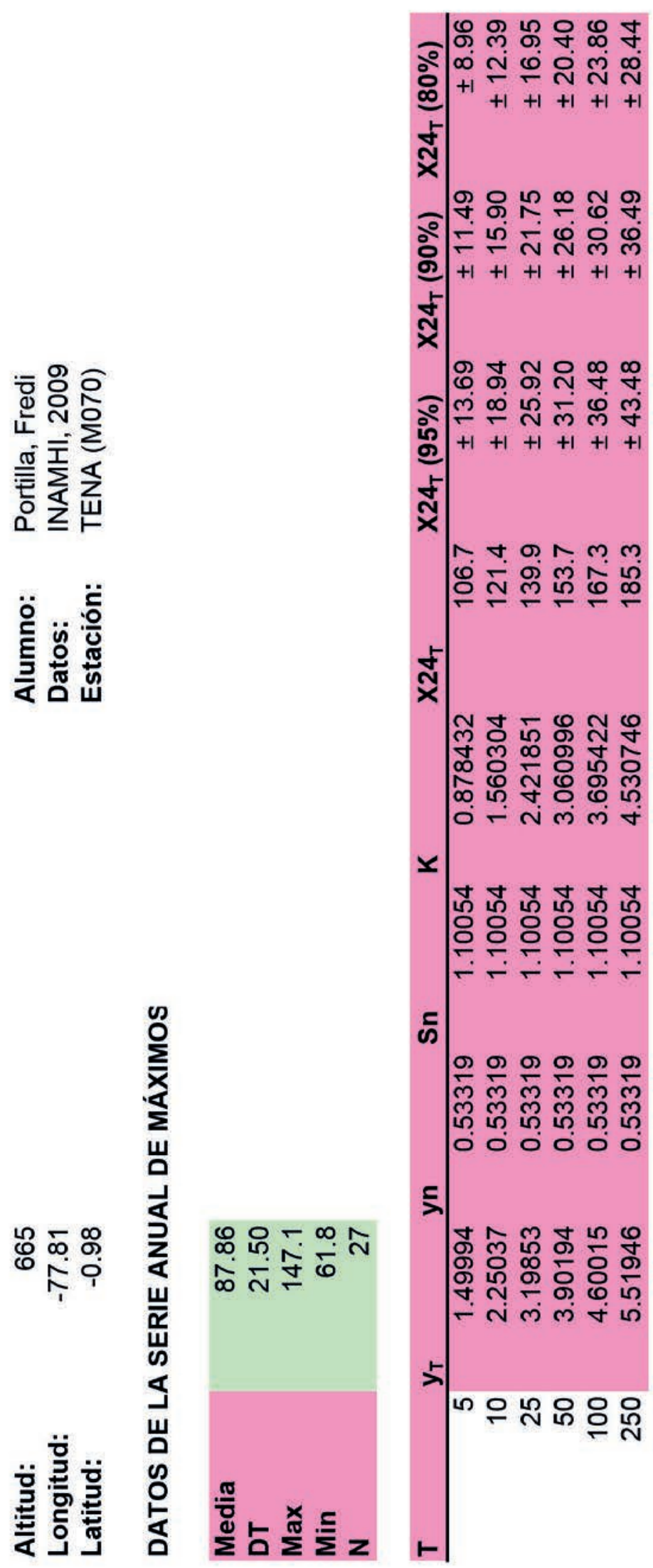

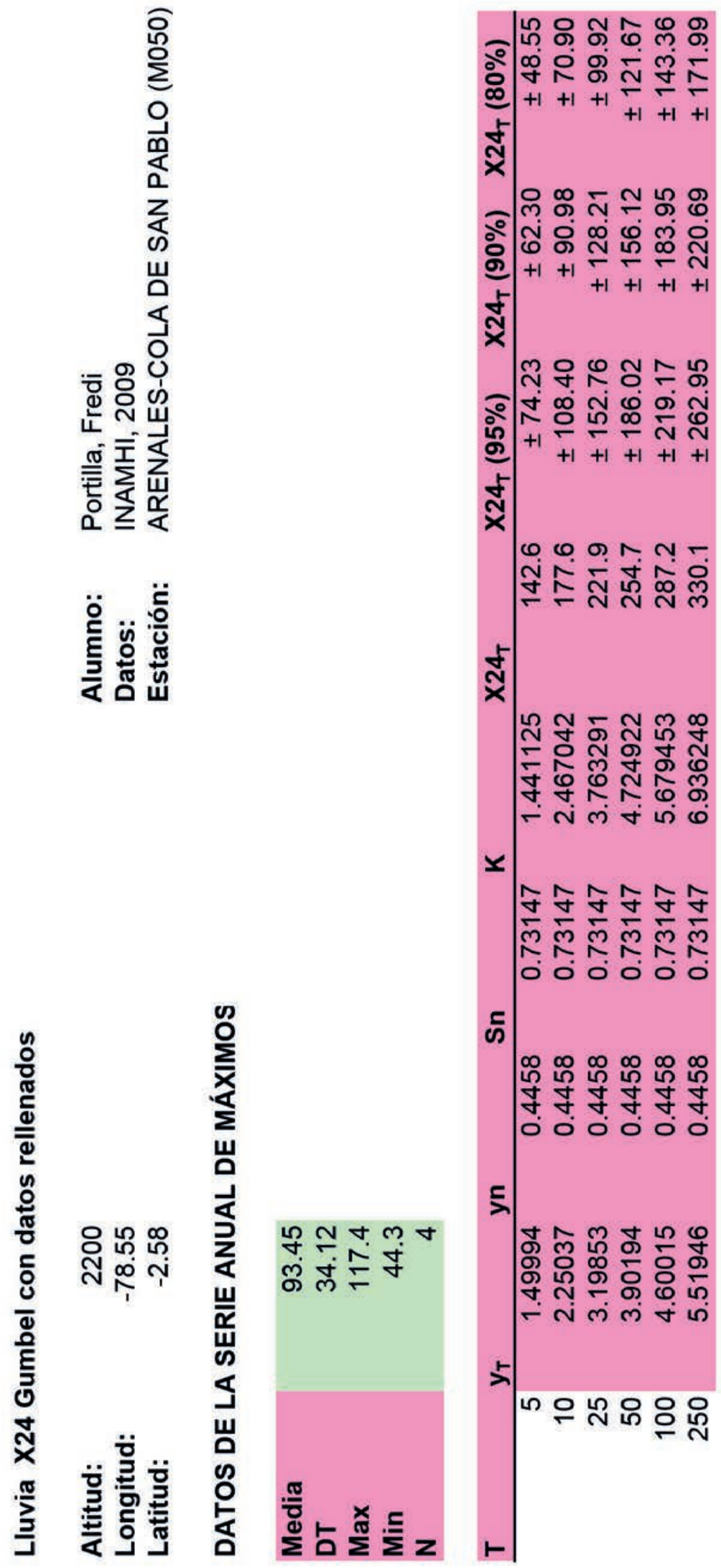

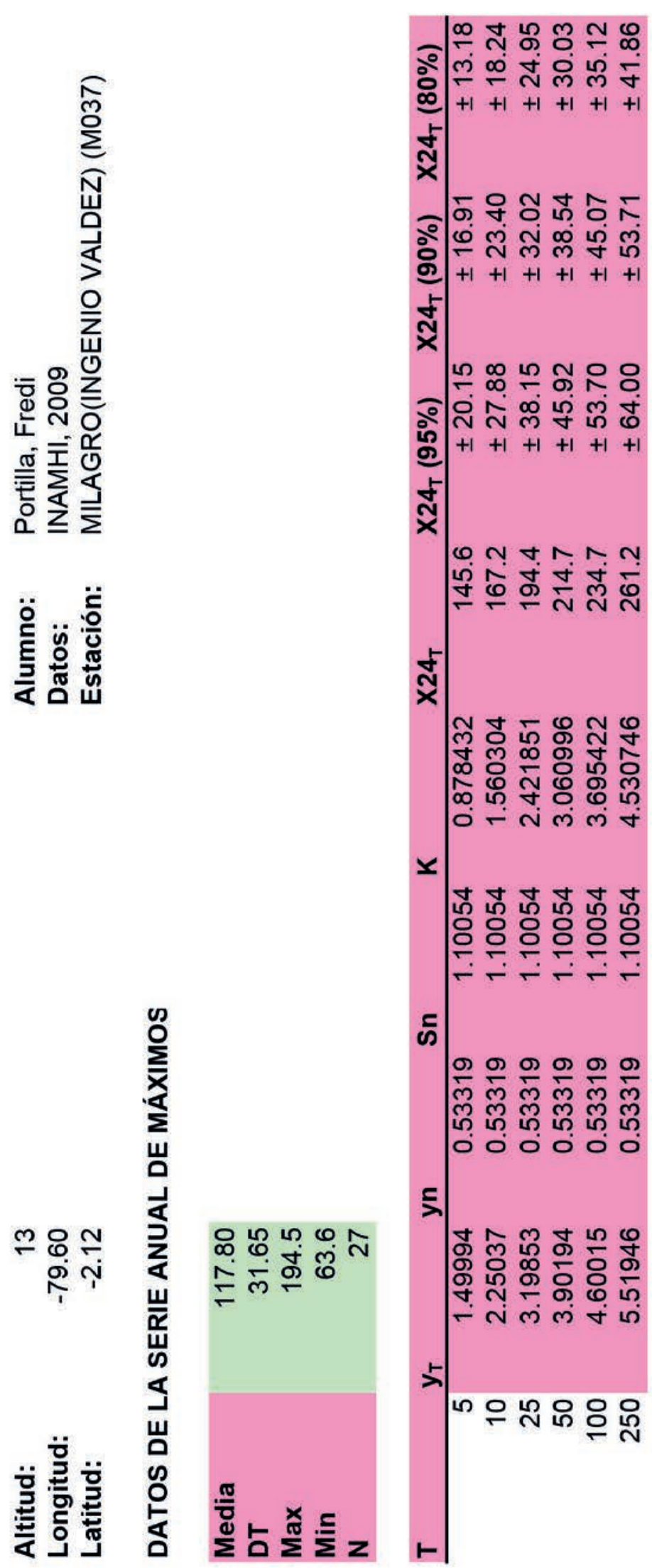

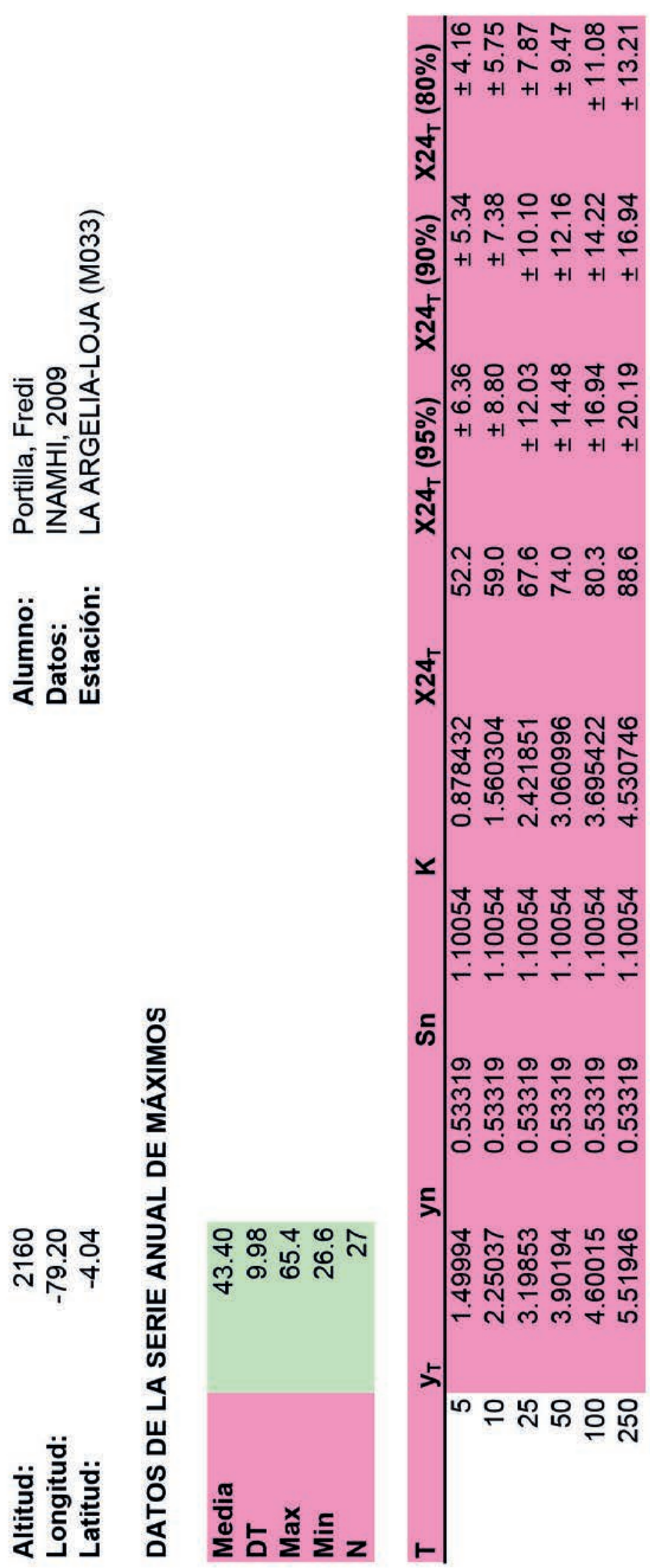

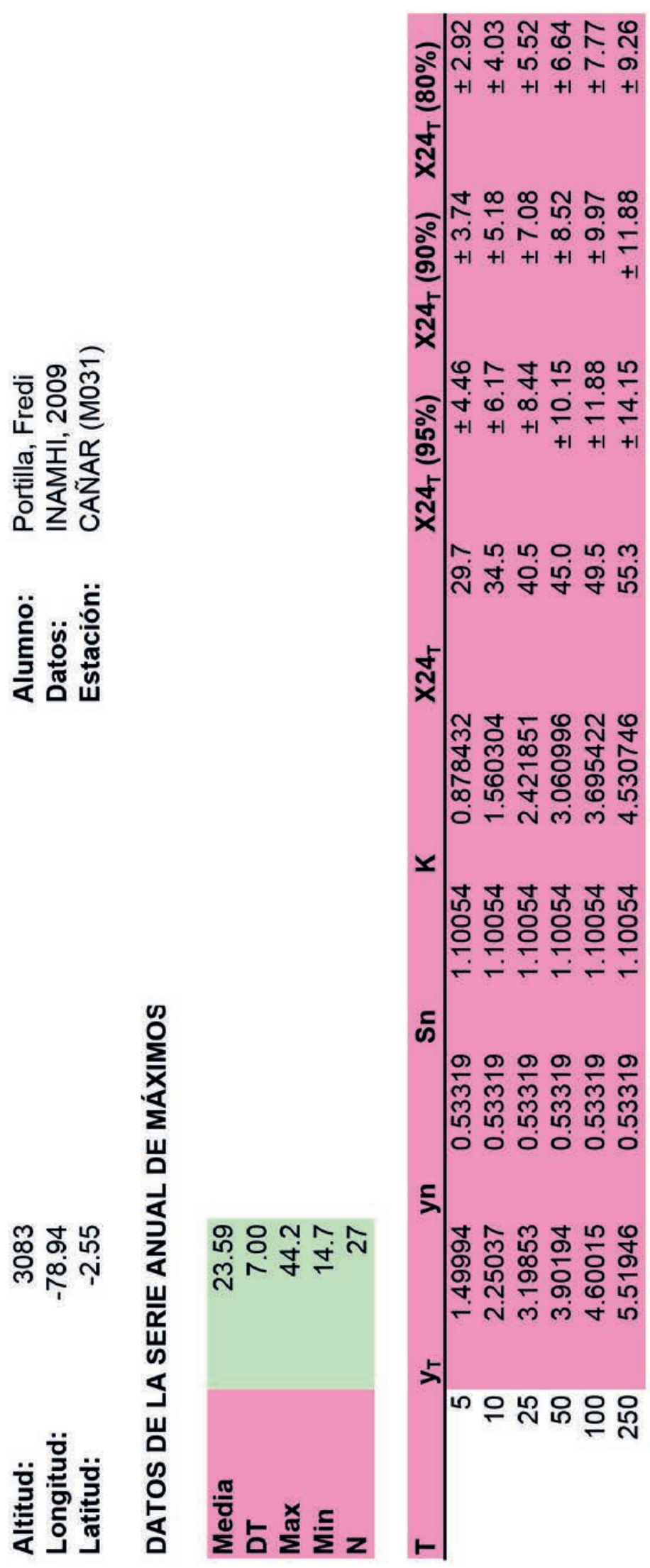

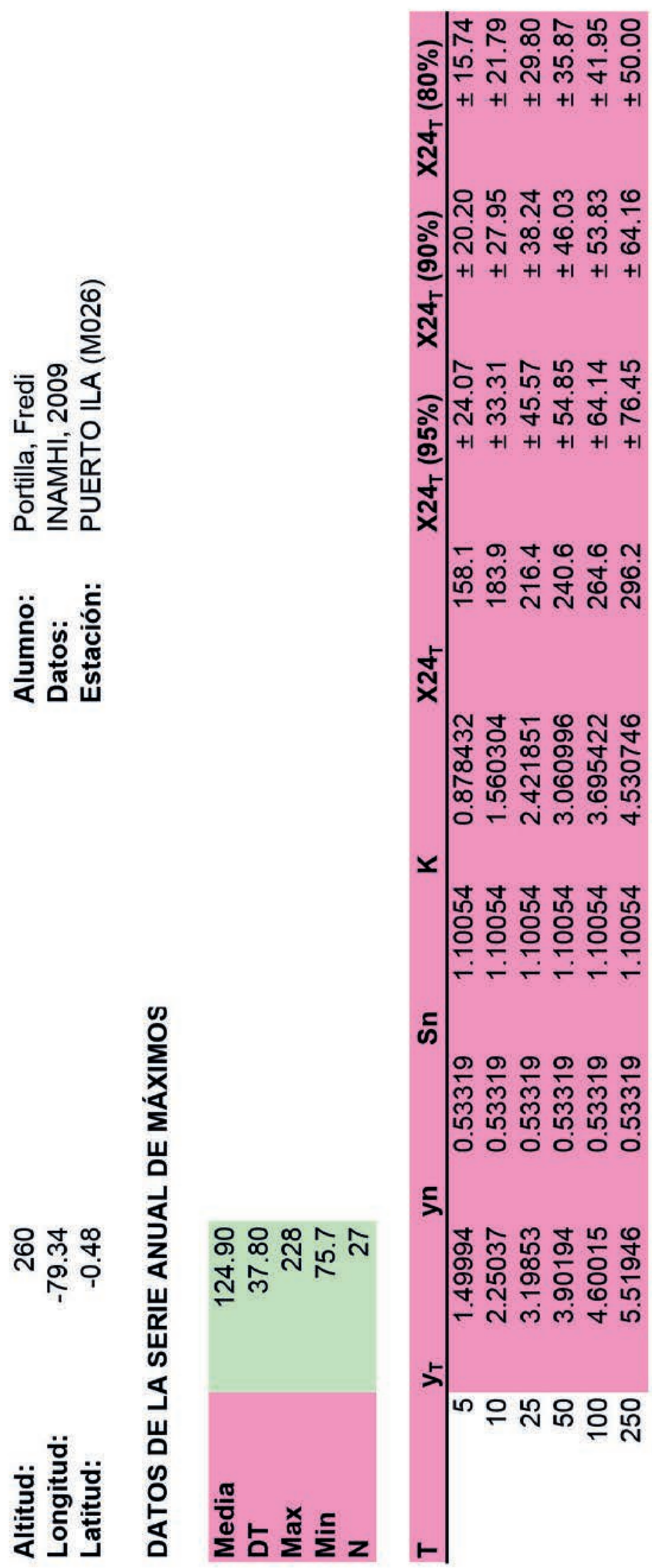

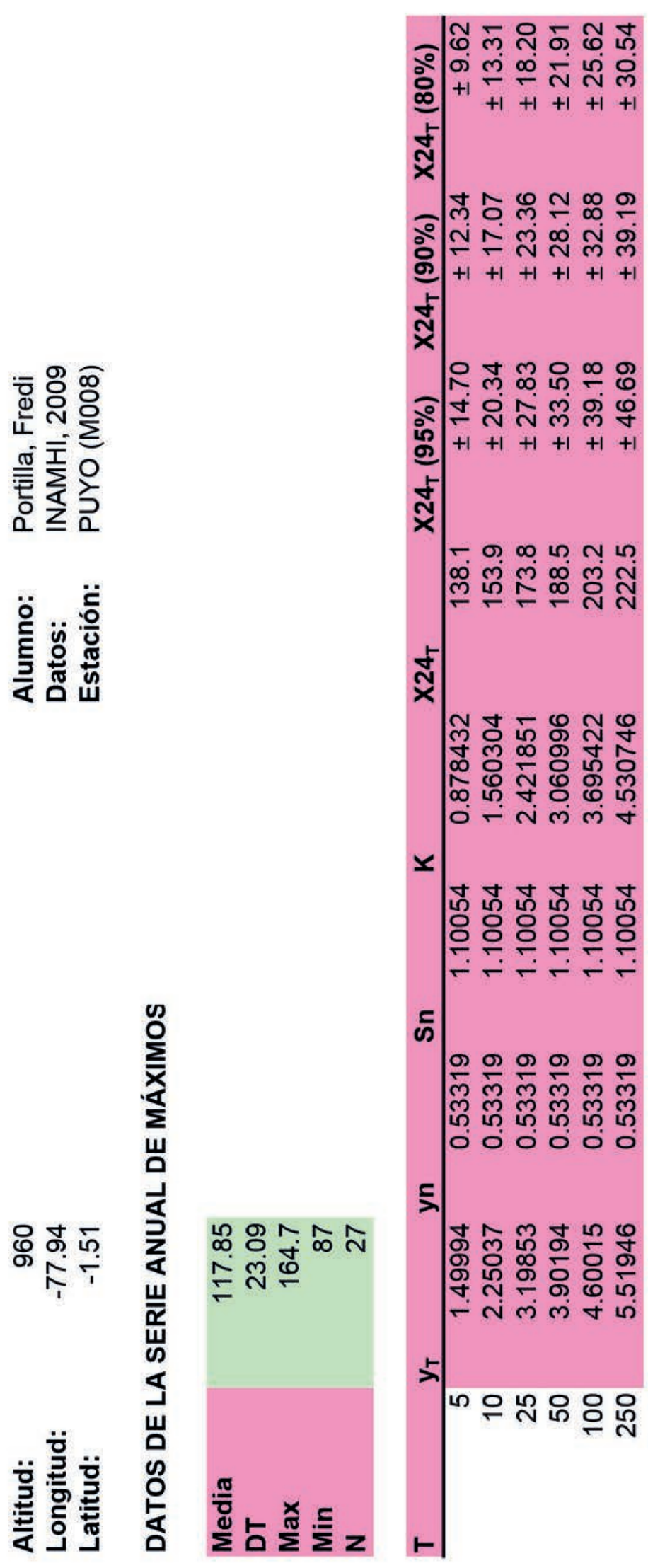

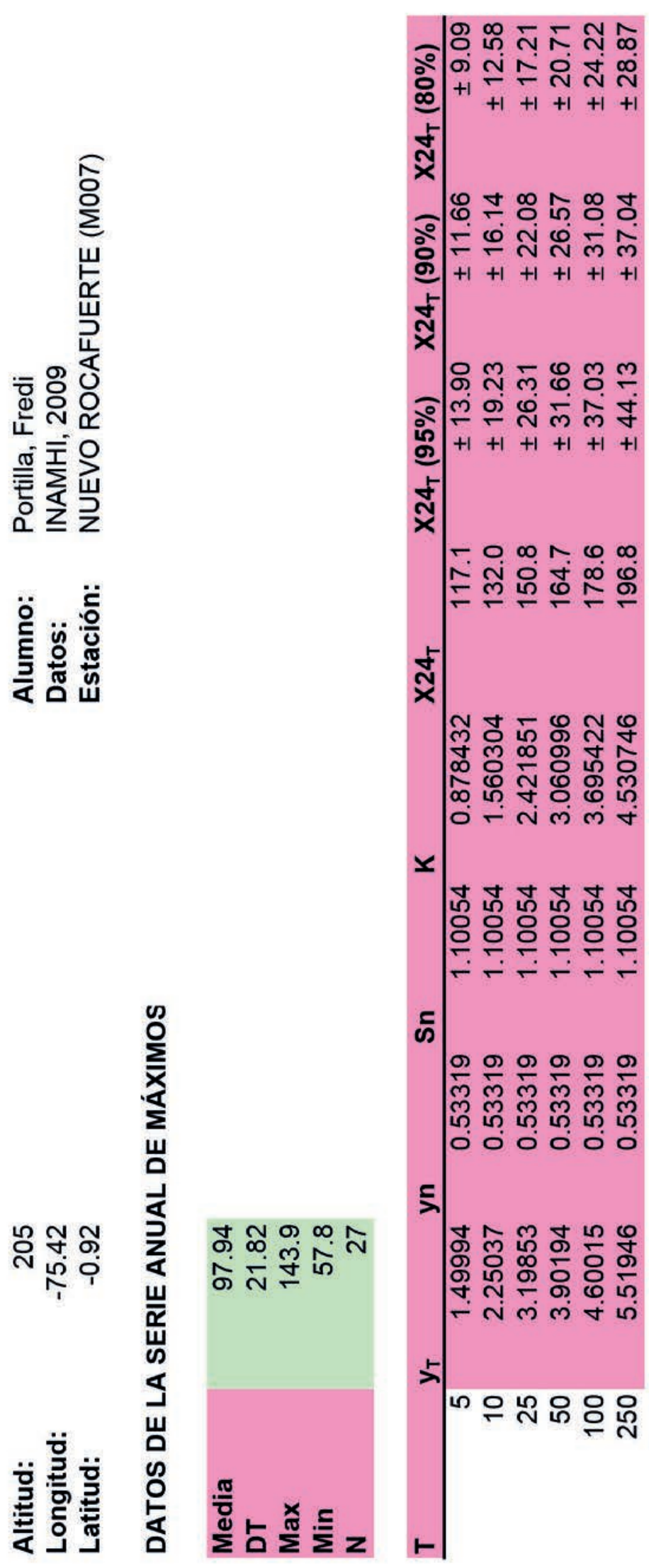


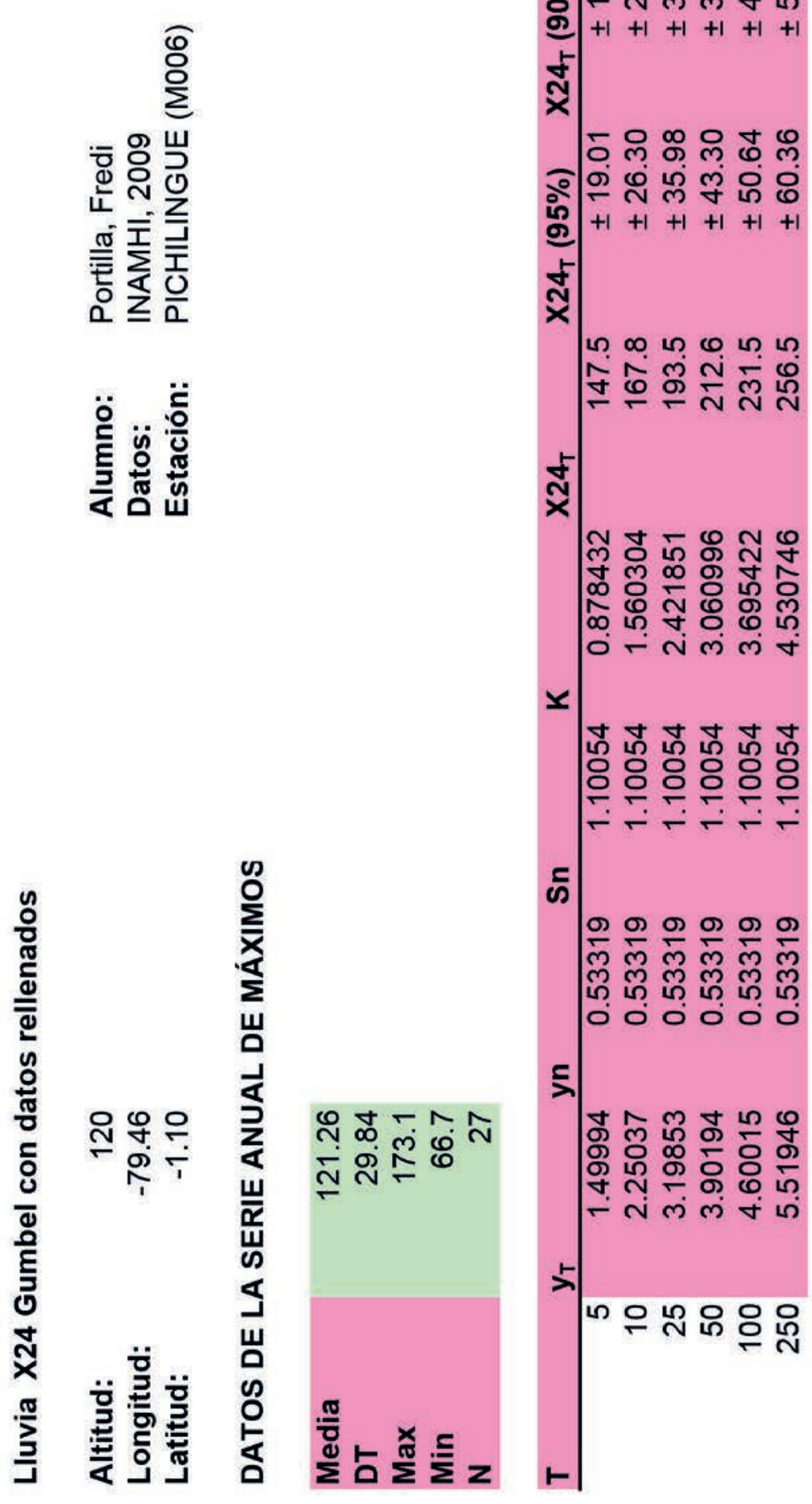



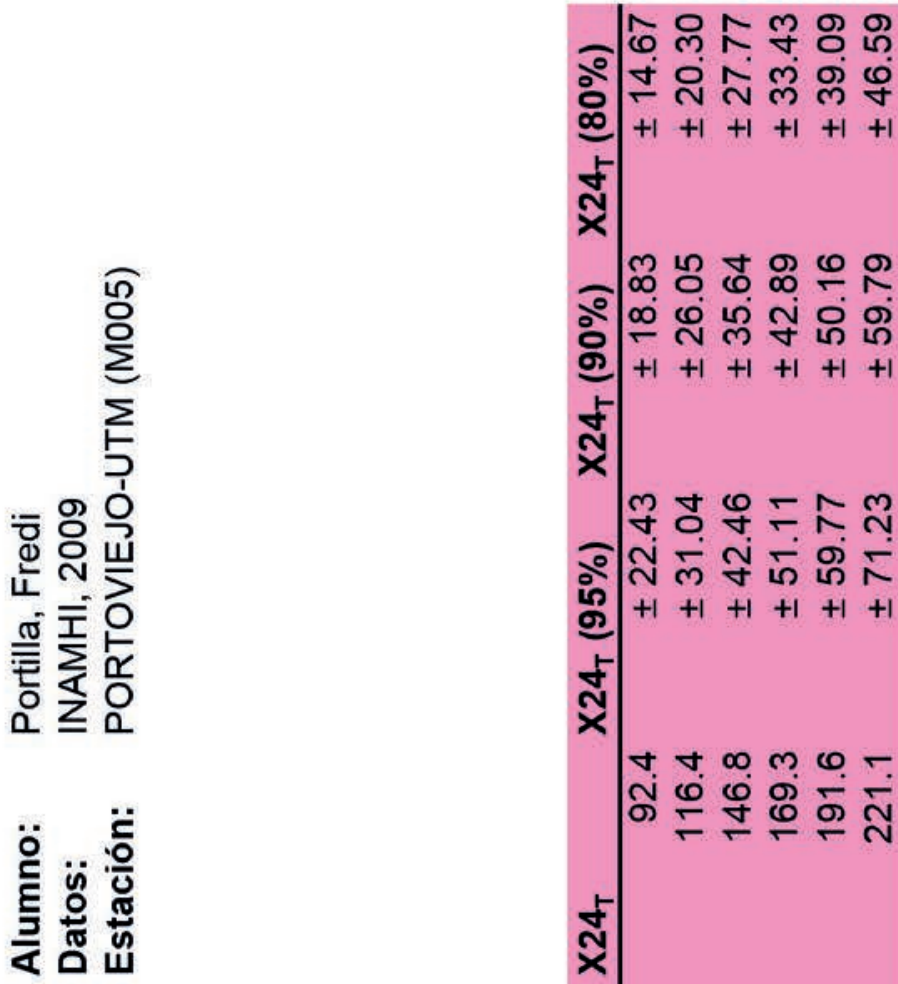

त्र

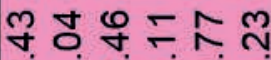

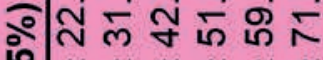
เร $+1+1+1+1+1+1$

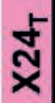

$\forall \forall \infty m \bullet-$

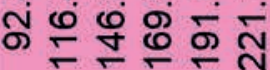
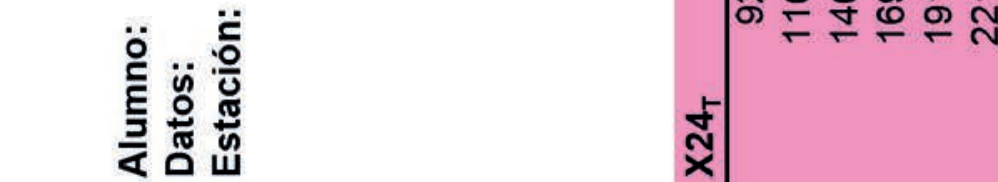

떤ㄷำ 广ै \% 듀용

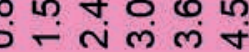

芯莳吉吉 880800 둗ㄷㄴ

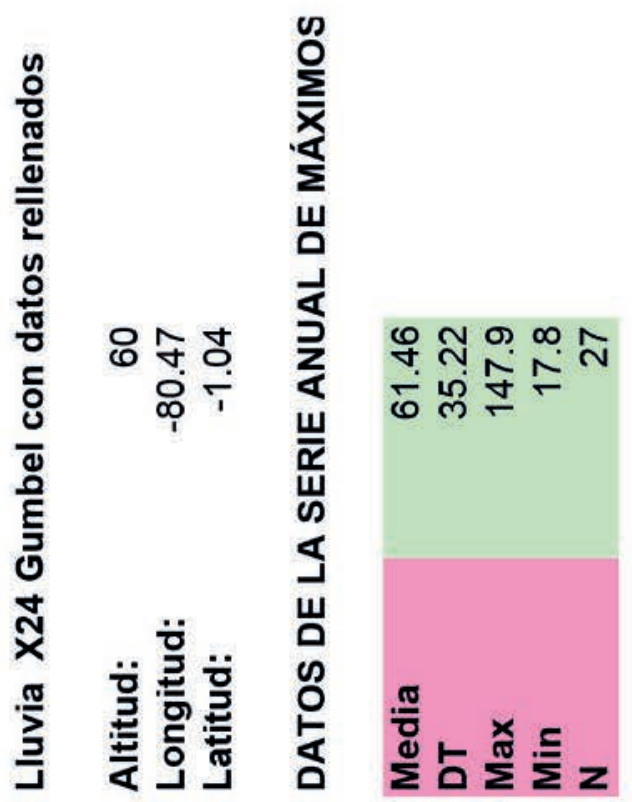

ติ

모 음 므 m $m$ m $m$ กิ กี กี กี - 00000

ร

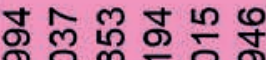
응 응요 으 ช ำ 유 - तल ल

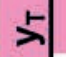

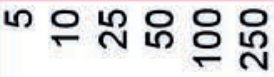




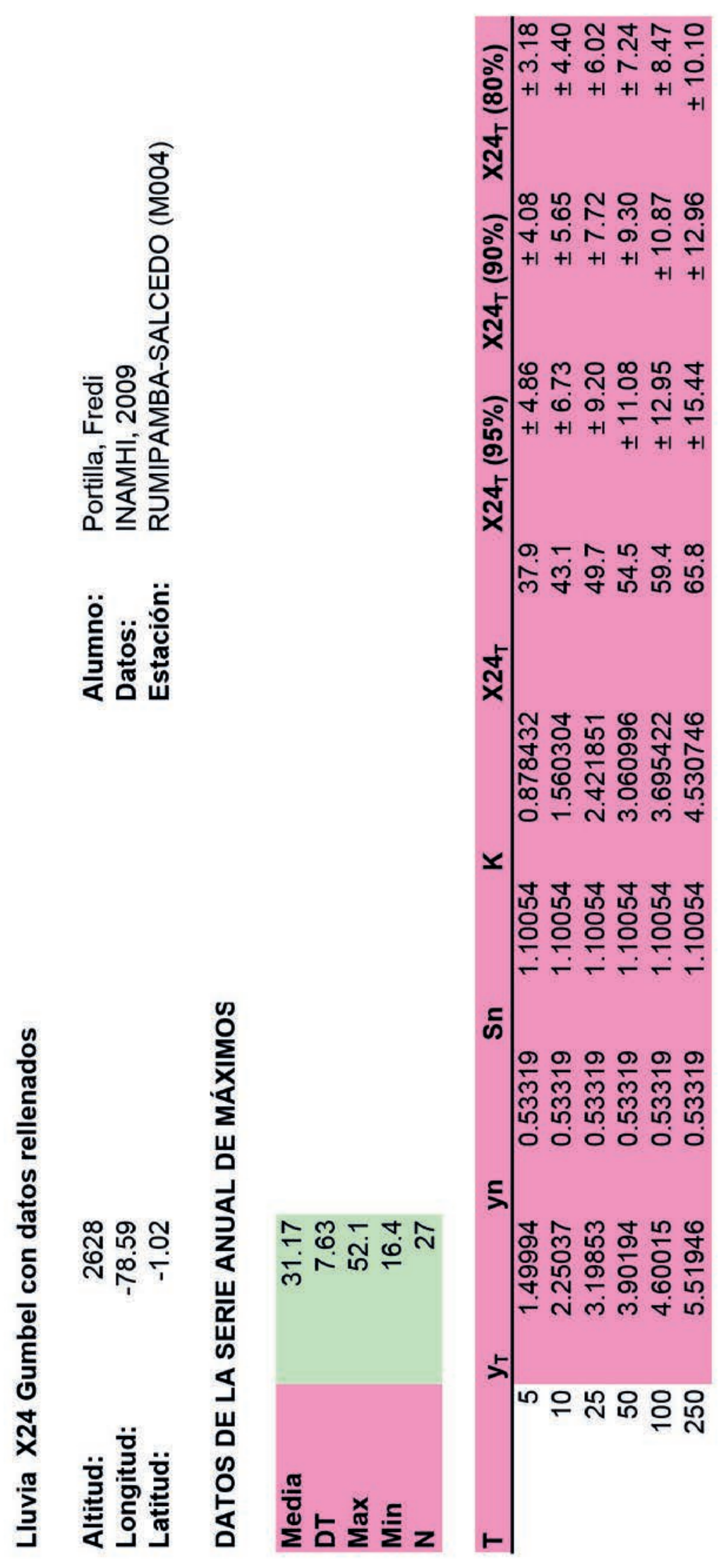




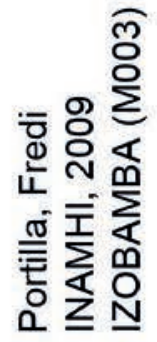

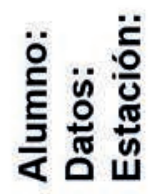

స

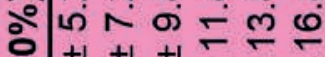

テั

$\omega \infty \div \pm 0$ ஸे

$+1+1+1+1+1$

○ 6 ○ ஸा

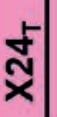

ำธ ช œ 듀융 ๓ ० - ले ले

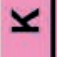

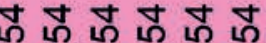
응 응요응 둔두눋

ติ

무욤요 $m$ m $m$ m iी กี กี กี กै ○ 00000

든 ปั่ ชㅇํㅇํㅇ응 न - त ल लं

5

으 뉴음유 윤

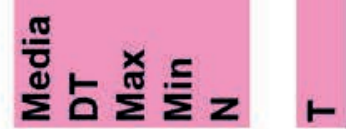



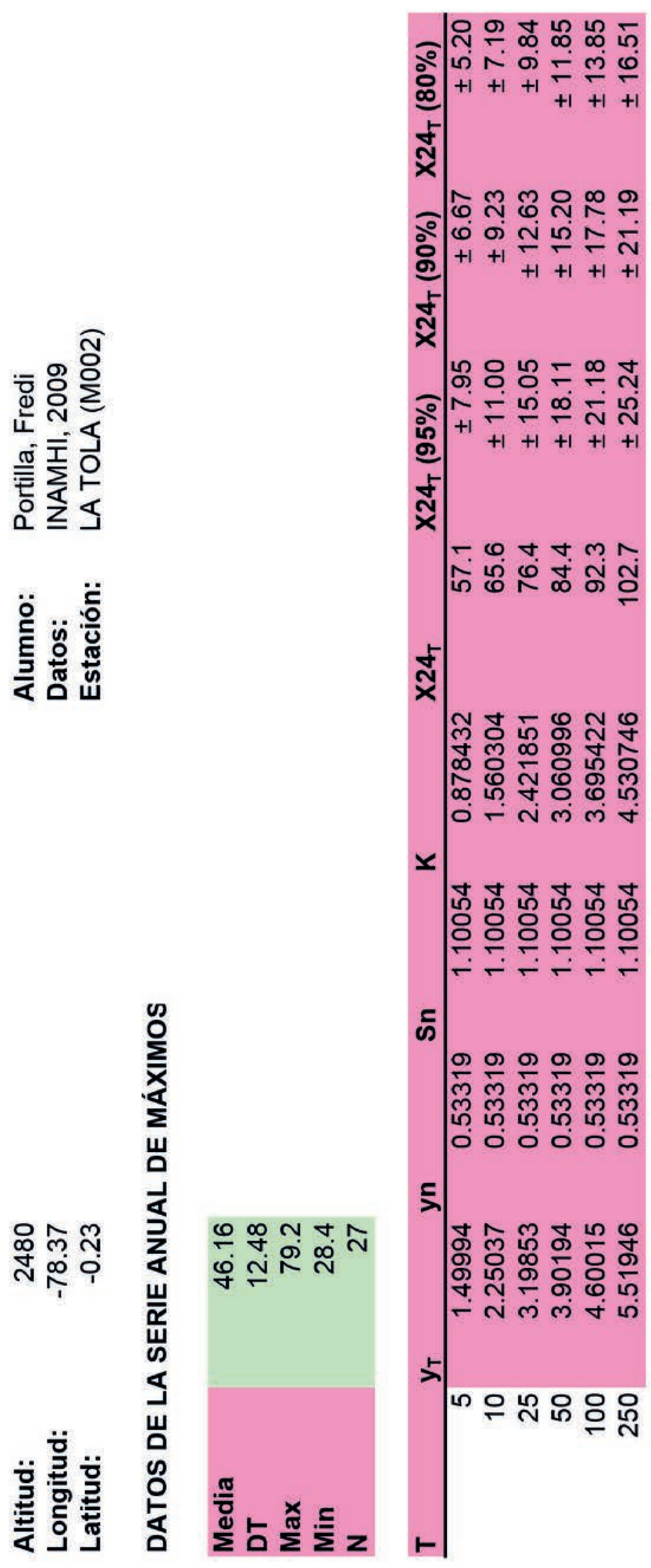


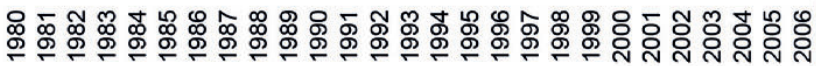

음

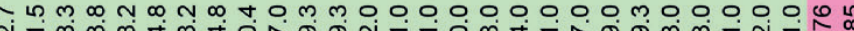

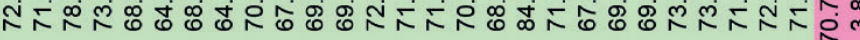

के

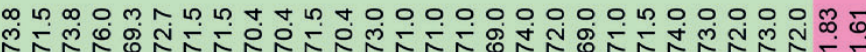

క

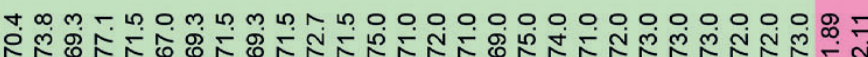
苟

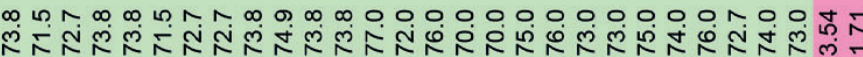

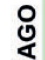

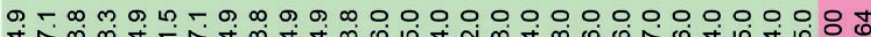

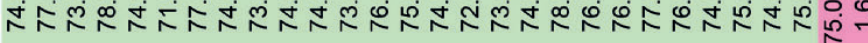

s

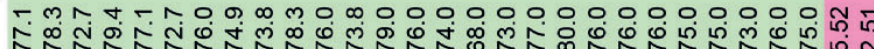

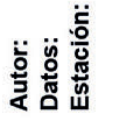

\section{马}

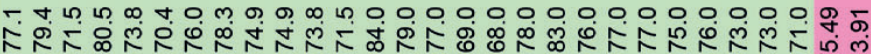

妾

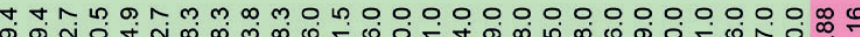

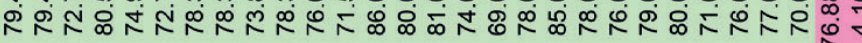

営

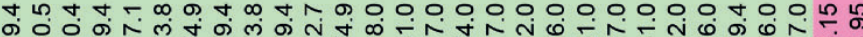

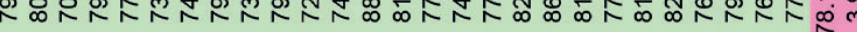

$\frac{2}{2}$

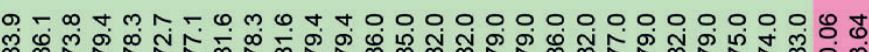

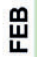
质 


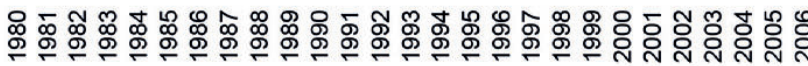




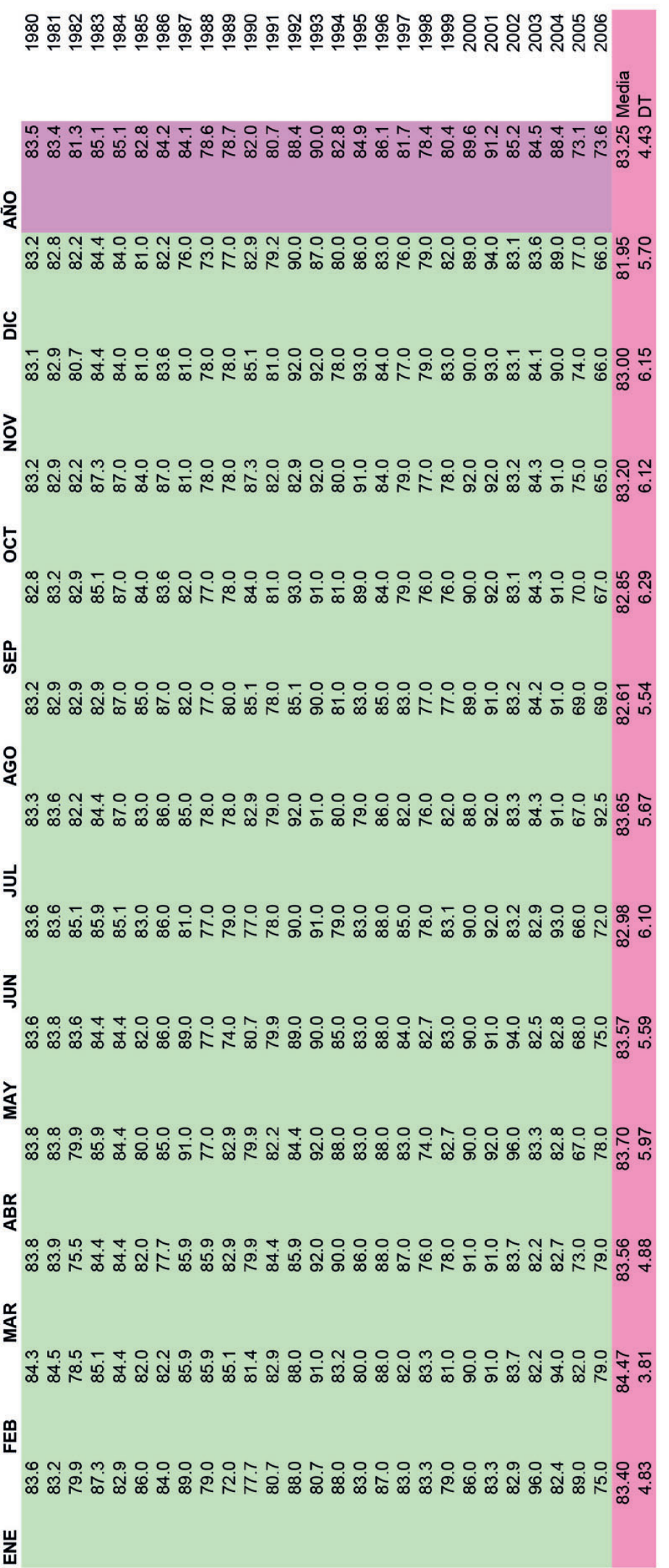




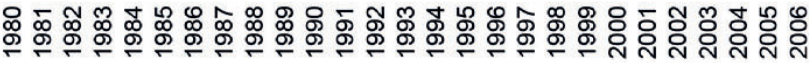
舟

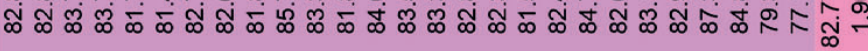

安

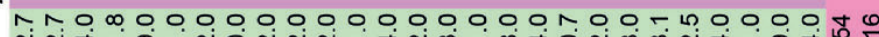
রิ

$\frac{0}{0}$

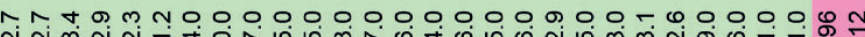

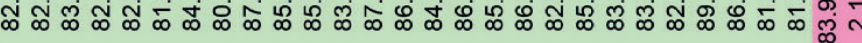

z)

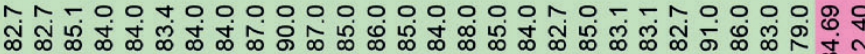
鸟

人 வ் 离

hNort400mo ஸ்

¿

Non n N t $000000000000000-000000$ ก வ

S

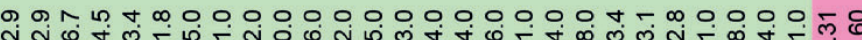
范范范荡

$\infty \infty_{\infty} \infty \infty_{\infty} \sum_{\infty} \infty \infty_{\infty}$

\section{$\mathbf{z}$}

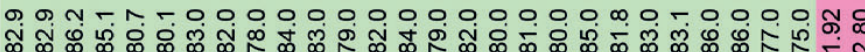

¿

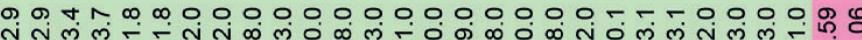

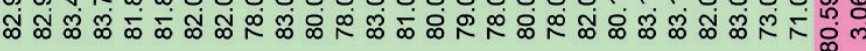

益

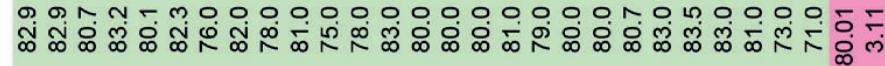

$\frac{\alpha}{2}$

ก

o th n m

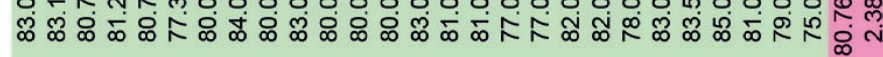

延

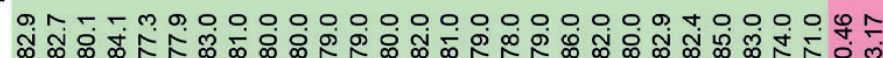




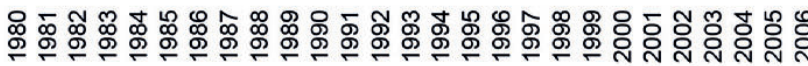

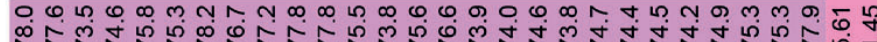

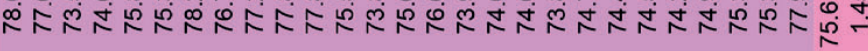

究

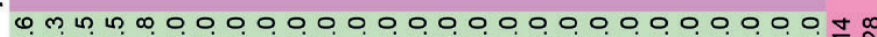

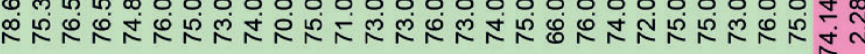

$\underline{0}$

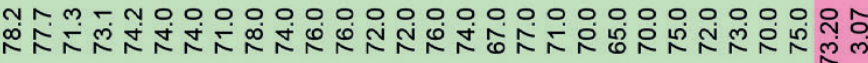

흐

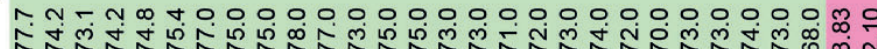
Ł

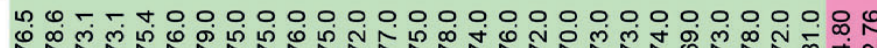

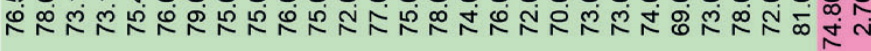

$400--\pi 00000000000000000000000$

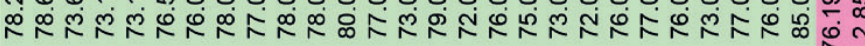

\&

00 n n

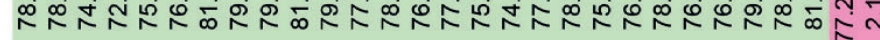

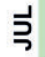

n

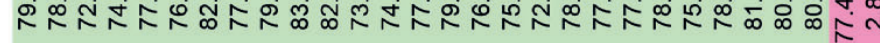
范范范

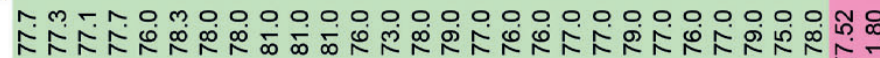

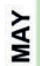

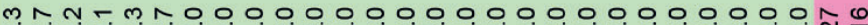

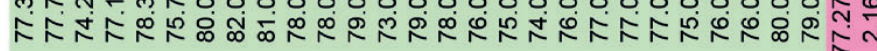

㩊 Nָ

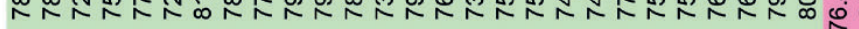

$\stackrel{\alpha}{\Sigma}$

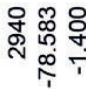

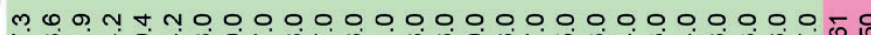

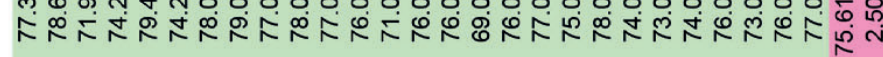

思 ᄂ

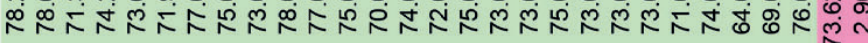
崖 


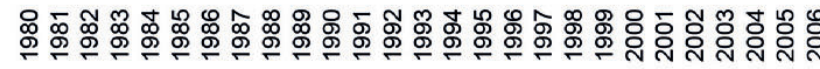

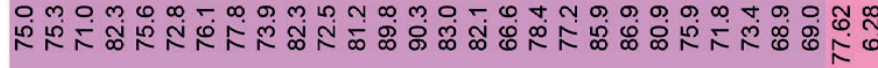

安

mon

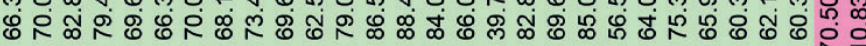

$\frac{0}{0}$

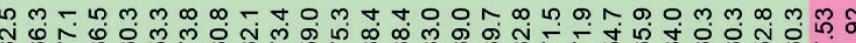

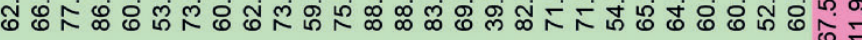

วิ

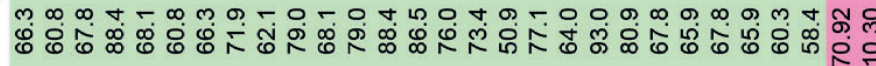

๖

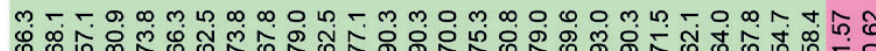

峞

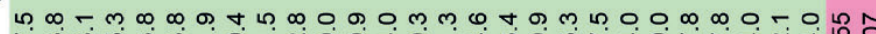

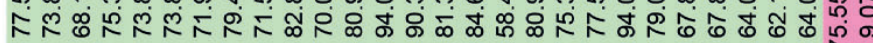

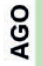
๓ К

s 우의 no ๒ ๓

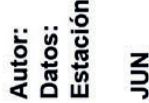

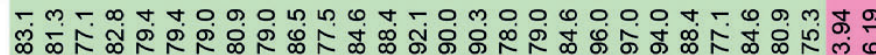

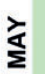

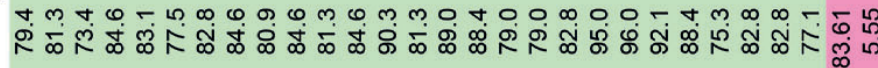

盢

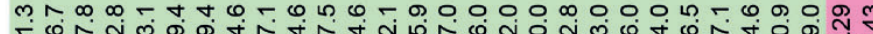

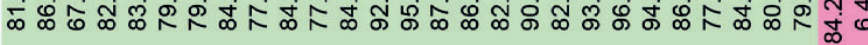

\section{$\frac{\alpha}{\Sigma}$}

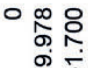
m 0 m m m t t 0 t m

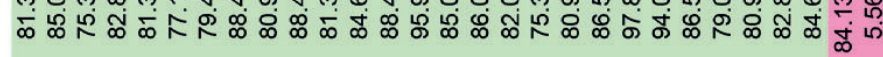
崭

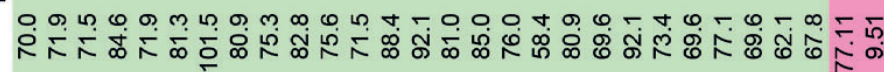
荘 


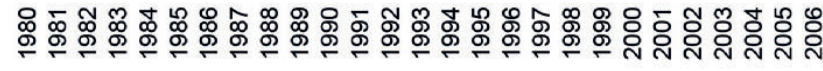

m人 t

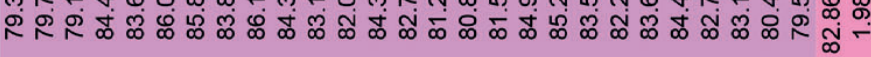

安

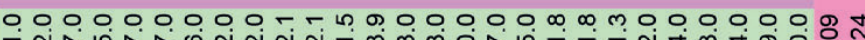

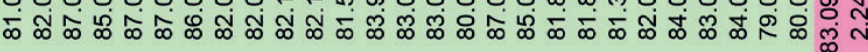

음

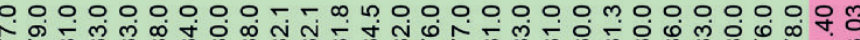

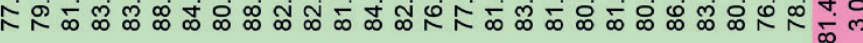

วิ

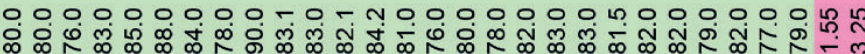

๖

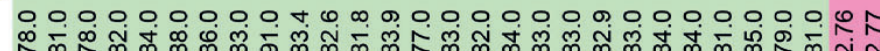

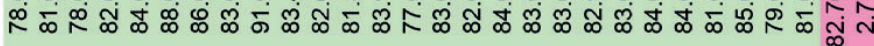
峞

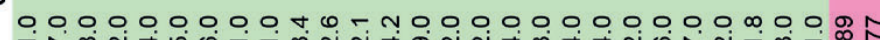

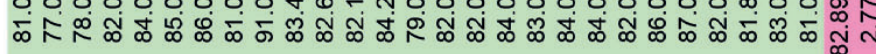

¿ำ

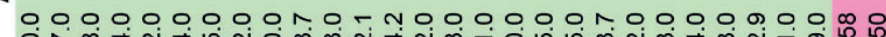

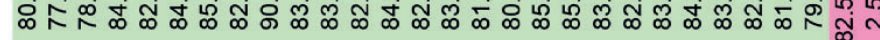

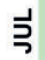

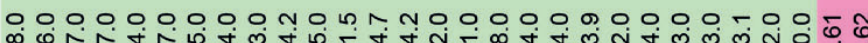

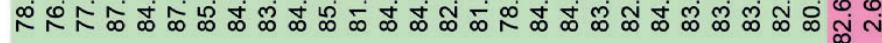

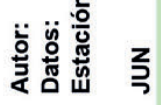

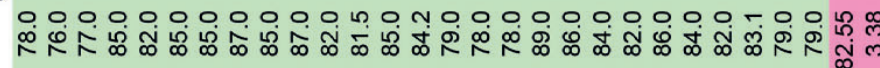

¿

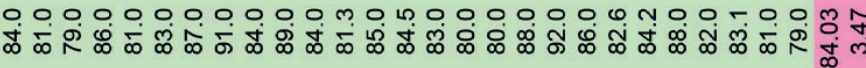

$\stackrel{\frac{\alpha}{m}}{\frac{0}{4}}$

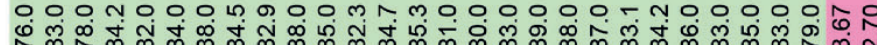
$\sim \prod_{\infty}$

\section{$\stackrel{\alpha}{\Sigma}$}

융요

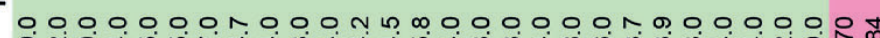
क्ष

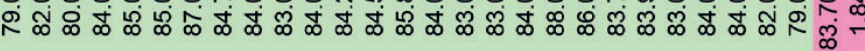

延

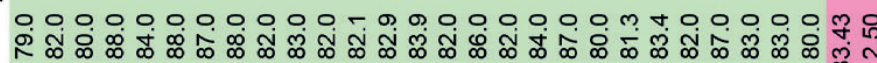
宸 


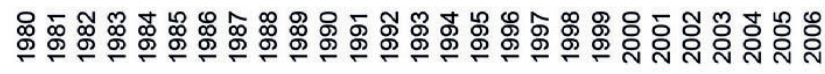

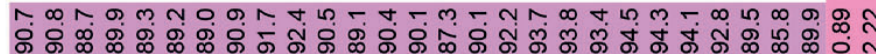

安

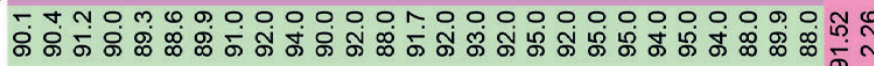

$\stackrel{0}{0}$ 0 - morthmo

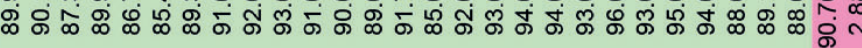

วิ

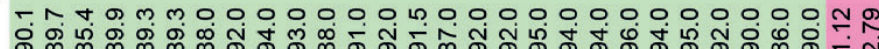
Ł

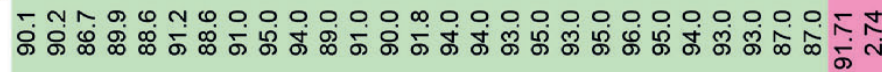
飠

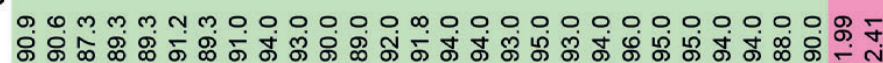

¿

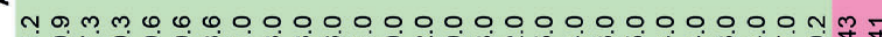

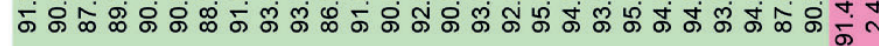

今 눈

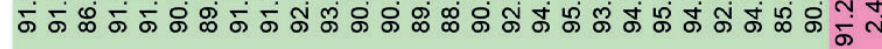

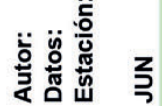

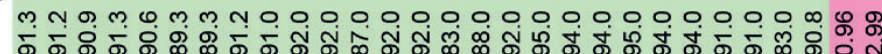
$\grave{\mathrm{s}}$

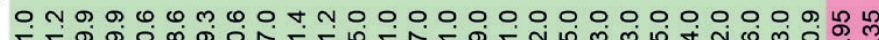

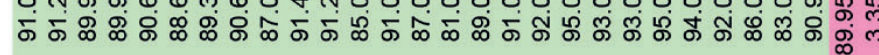

㩊

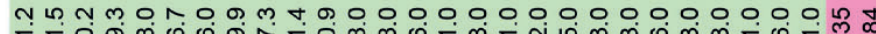

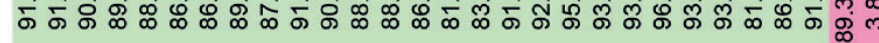

$\frac{\alpha}{\Sigma}$

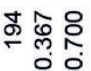
4⿻ Б்

邑

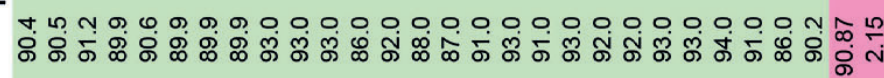
兰蒡 荘 


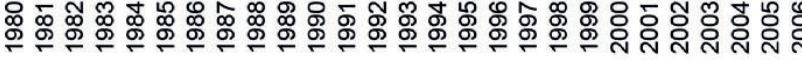

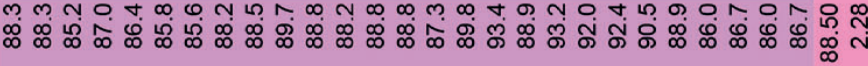

安

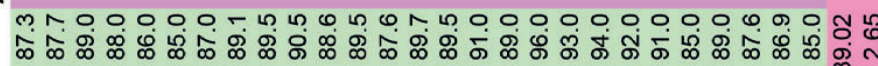

$\underline{0}$ o m o o o o o - n o -

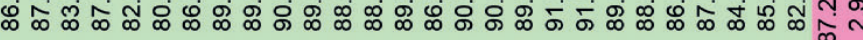

z)

m几

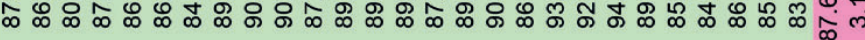

¿ ஸि.

峞

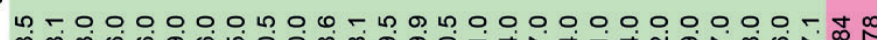
ळ

$\stackrel{8}{4}$

0 n 0000000 O 0 o வ

s

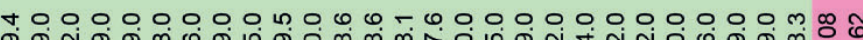
范范范

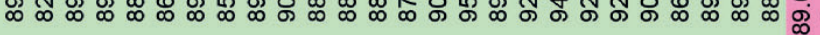

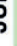

궁요

¿

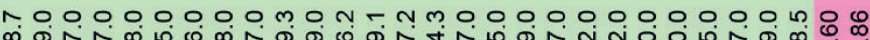
ळ

$\stackrel{\frac{\alpha}{m}}{\frac{0}{4}}$

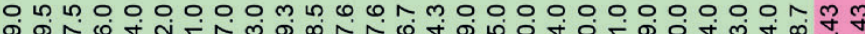

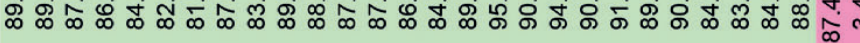

\section{$\frac{\alpha}{2}$}

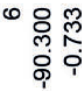

암

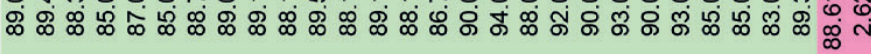

延

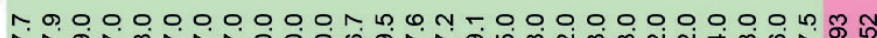

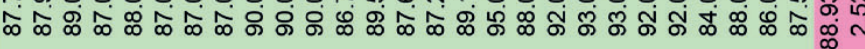




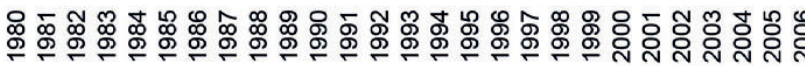

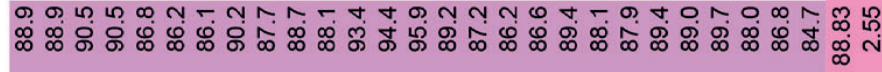

安

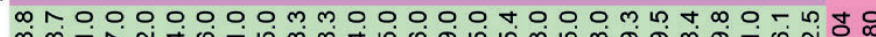
œ

$\stackrel{0}{0}$

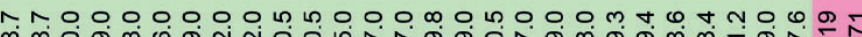

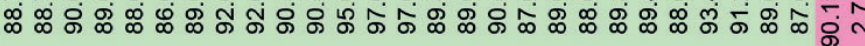

ว

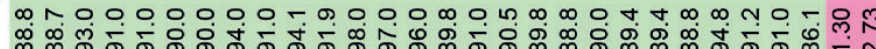

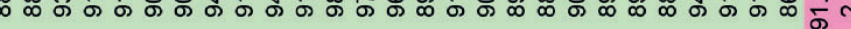

Ł ڤஸ

跑

m NOOOOOOOONOOONLOOOOOMmœ

\& œ ळ

క

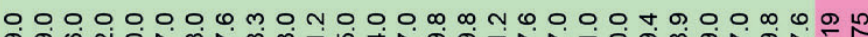

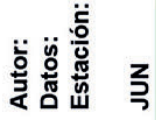

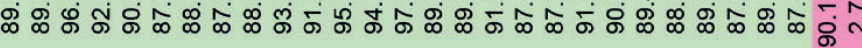

ळ ळ.

¿

ळळ

$\stackrel{\frac{\alpha}{m}}{\frac{\mathrm{m}}{4}}$

- 000000 t $000000000000 m-0,1 m m$

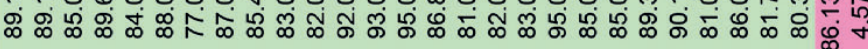

$\frac{\alpha}{\Sigma}$

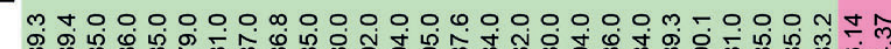

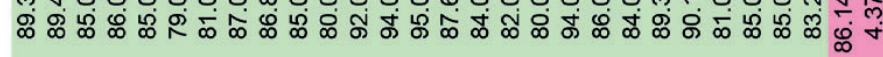

延

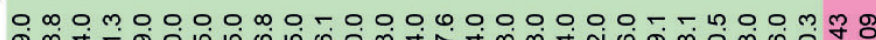

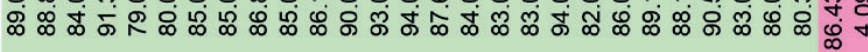
崖 


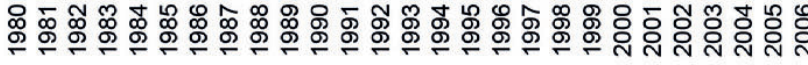
సิ่

安

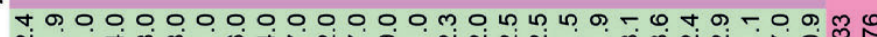

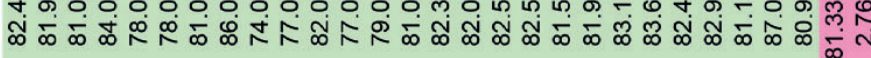

$\underline{0}$

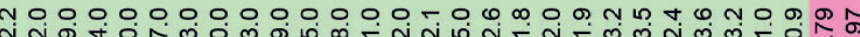
๓

z)

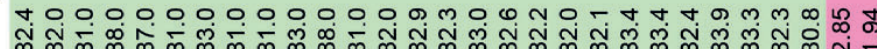

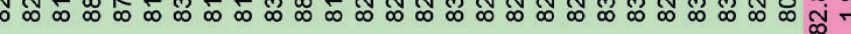

క

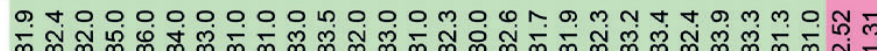
ए广

岃

t $00000000000000 m \omega 0$ n $0-\pi+m m N N \frac{1}{4}$ ๙

운

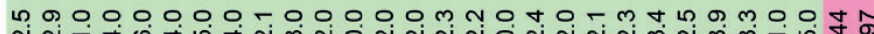

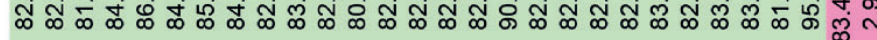

弓

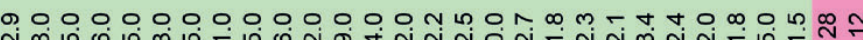

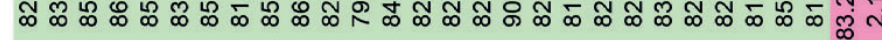

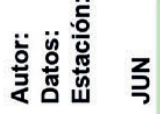

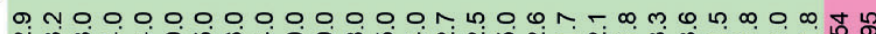

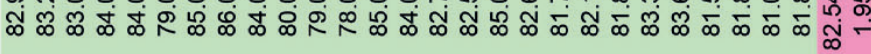

¿

4⿻ ఐ

$\stackrel{\frac{\alpha}{m}}{\frac{m}{4}}$ N ஹळ

$\stackrel{\frac{\alpha}{\overleftarrow{L}}}{\Sigma}$

$8:$

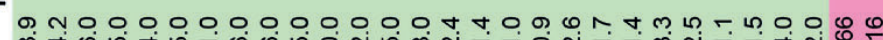

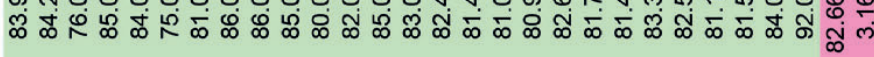

思

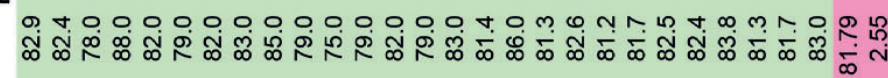

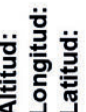
崖 


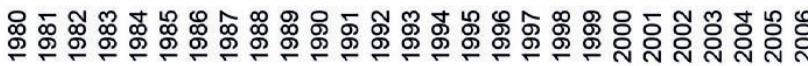

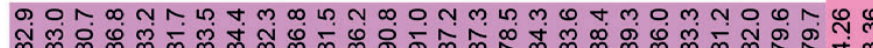

足

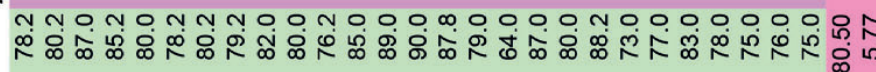

은

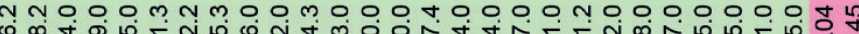

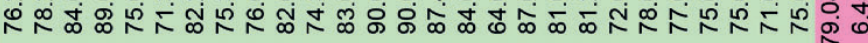

zे

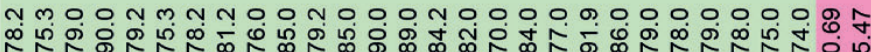

to

nุ n m o n n n n

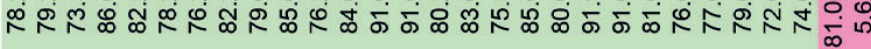

峞

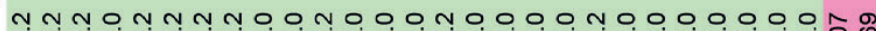

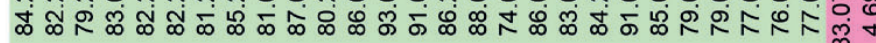

인 n n o on non ஹळ

弓

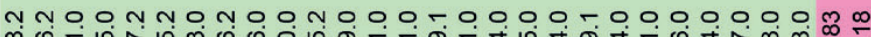

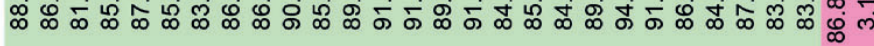
范范范范

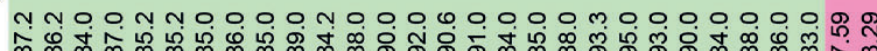

¿

n n

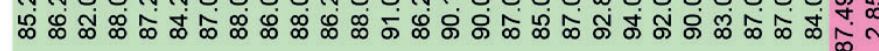

$\stackrel{\frac{0}{m}}{\frac{\operatorname{mos}}{4}}$

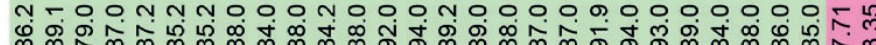
ฌ ฌ

\section{$\stackrel{\frac{\alpha}{\overleftarrow{L}}}{\Sigma}$}

ก ก ळ

思

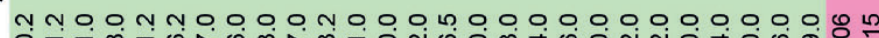

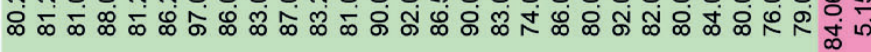
崖 


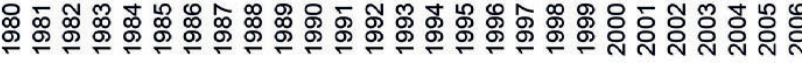

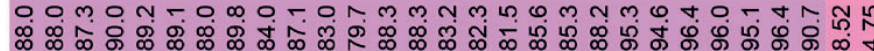

察

ONOOOOOOONOOOOOOOOOOOOOOOOONM

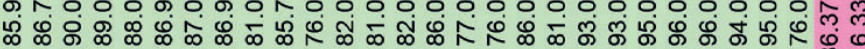

$\frac{0}{\Delta}$ - $20000-n 00000 m 0000000000000 n$

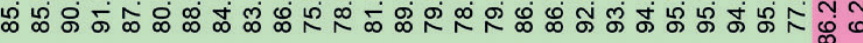

วิ

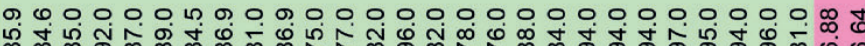

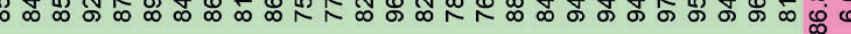

¿ ळ ॠ

峞

صN O O O O N O O N O O O O O O O O O O O O O O O O O O O ळ

-

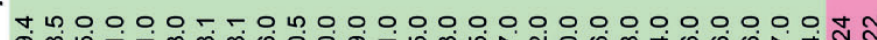

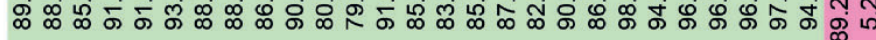

5

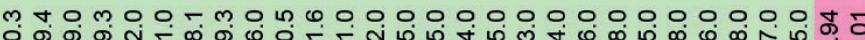

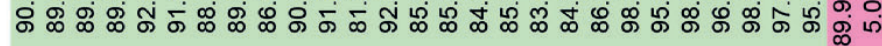

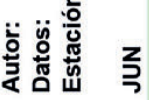

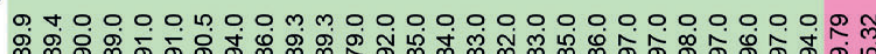
¿

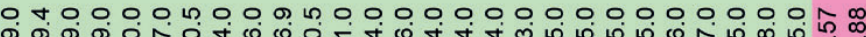

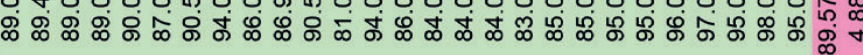

㩊 $\checkmark \infty 0 m 00-000,0000000000000000 m$

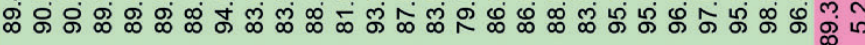

$\stackrel{\frac{\alpha}{\alpha}}{\Sigma}$

ㅇํㅇํํำำ

\% $0000-000 m 000000000000000000$

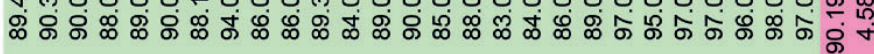

甾

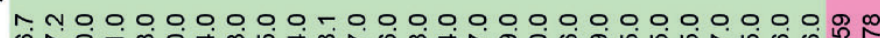
芦薃

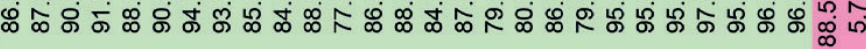

崖 


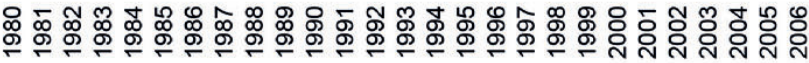

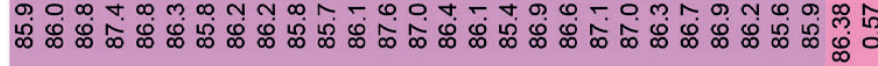

安

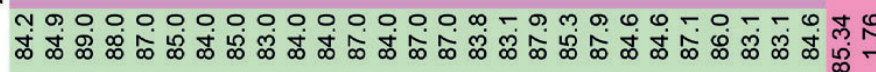

문

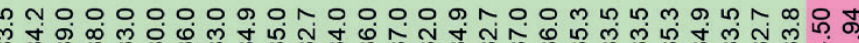

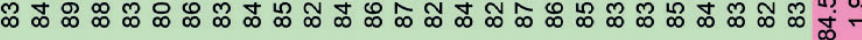

оे

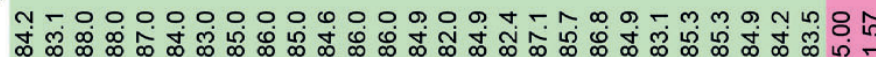
Łั

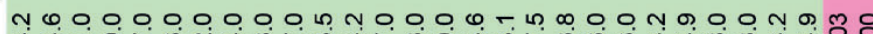

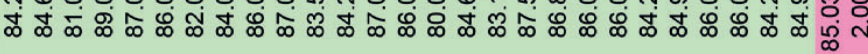

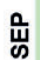

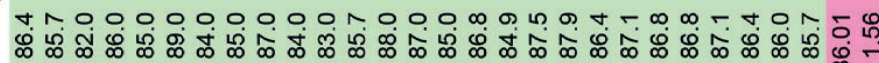
\& -

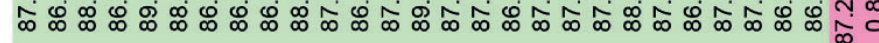

S

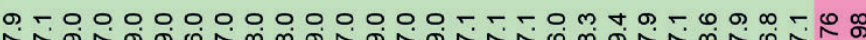
மெ 语范范

م

$\grave{\Sigma}$

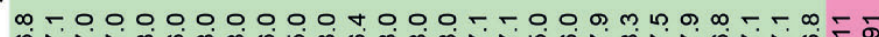

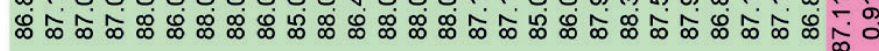

$\stackrel{\frac{0}{m}}{\frac{\mathrm{m}}{4}}$

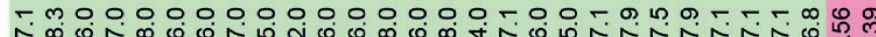

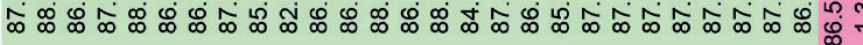

$\stackrel{\alpha}{\Sigma}$

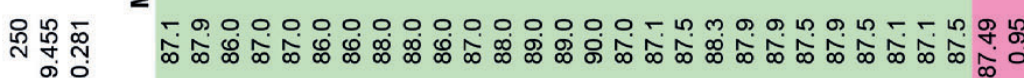
思

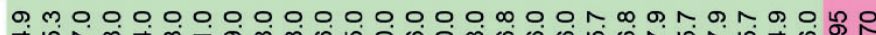
एळ 岩 


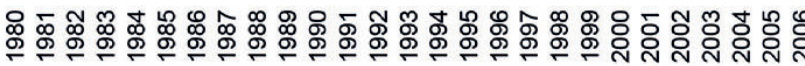
舟

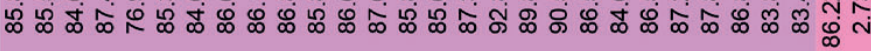

安

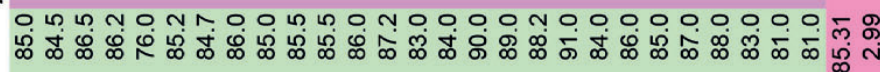

$\frac{0}{\square}$ o o o n o n n n n n

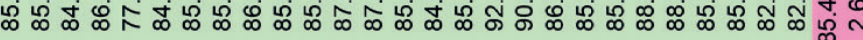

วิ

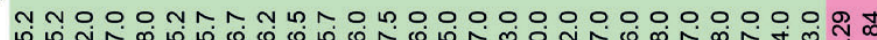

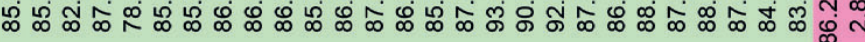

Ł

พุ กุ ๗

莭

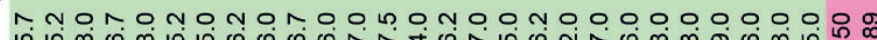

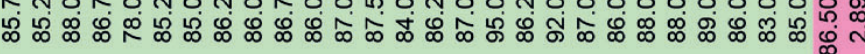

¿

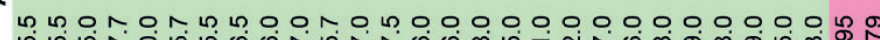
๒め

క

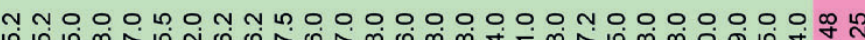

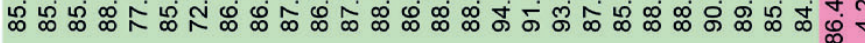

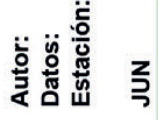

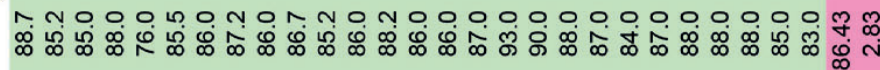

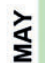

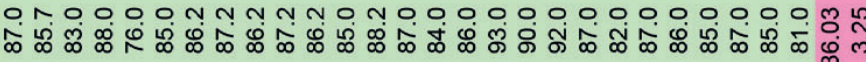

㩊 nho nothonhth

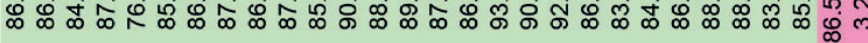

$\stackrel{\frac{\alpha}{4}}{\Sigma}$

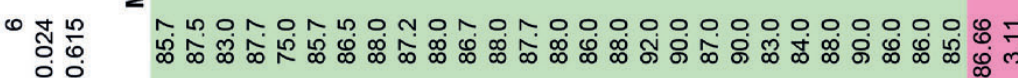

思

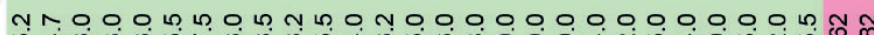

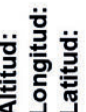

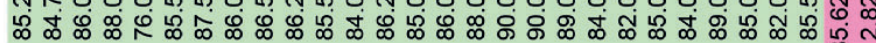
荘 


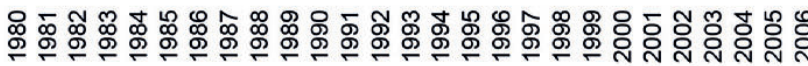

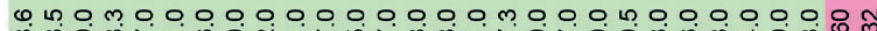

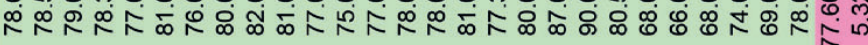

䓀

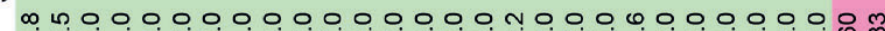

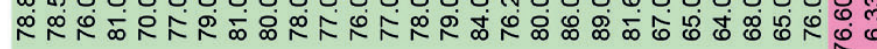

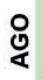

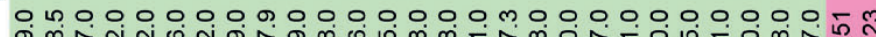

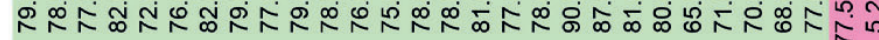

5 舟 范范范

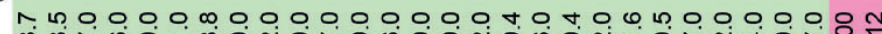

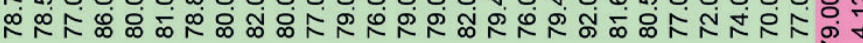
¿̌̀

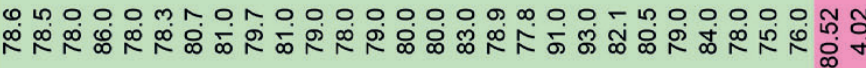

噮

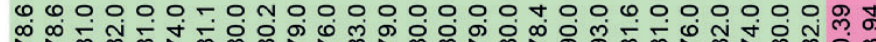

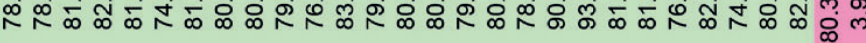

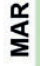
裔旁怘

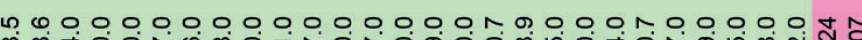

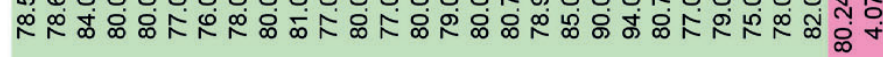

稒

个一

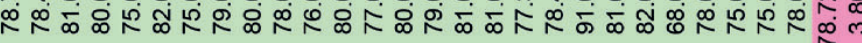




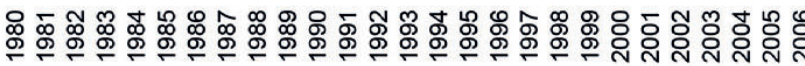

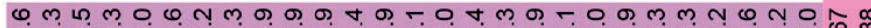

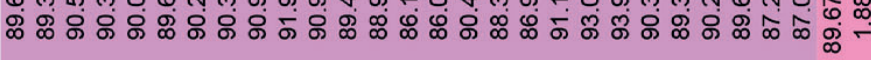

安

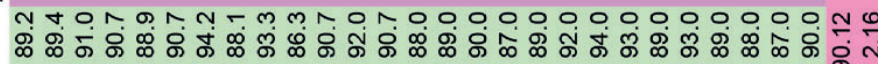

음

m m

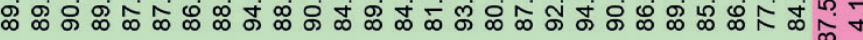

วิ

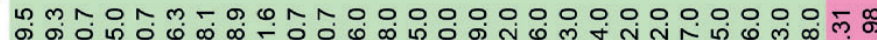

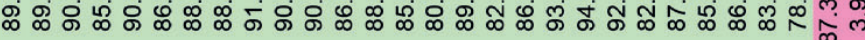

Ł

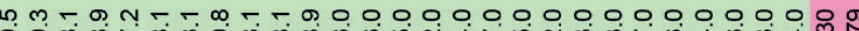

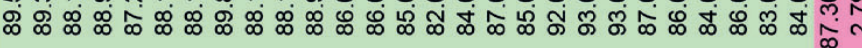

岀

amnLOळ

운

NM⿻ $-\infty \infty N C-0,000000000000-000-\infty$

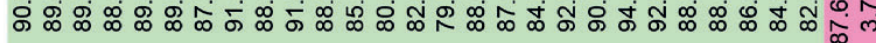

马

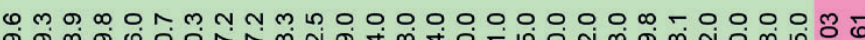

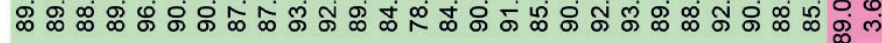

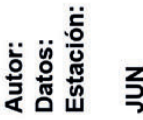

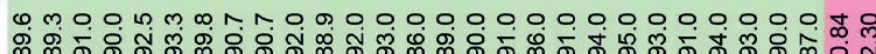

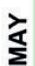

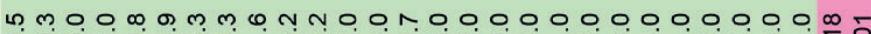

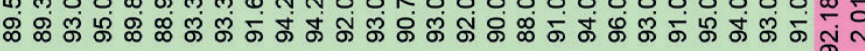

临

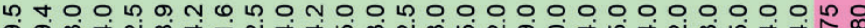

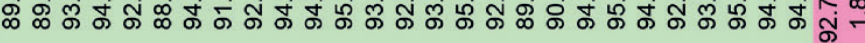

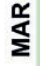
苏 m.tor n m m m o n o o r o o m mo o o mo o o o o o

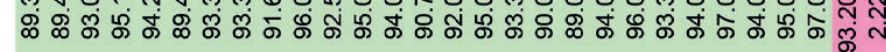
思

6.

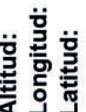

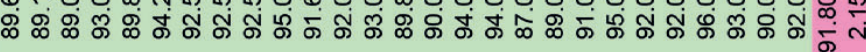
崖 


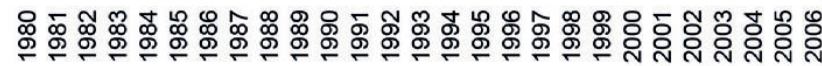

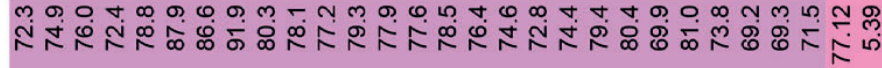

운

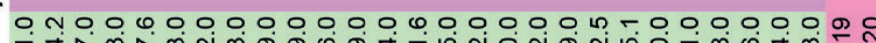

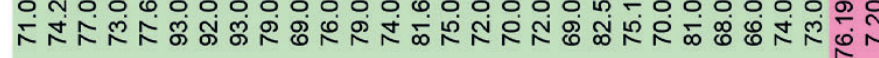

문

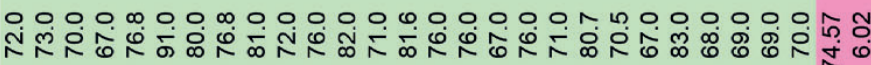

ว

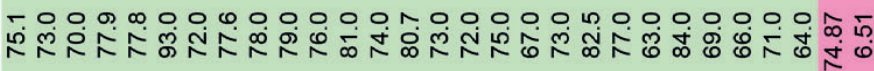
Ł

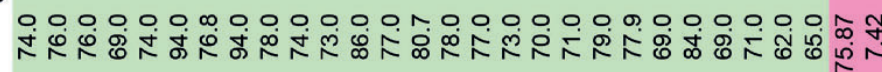
䓀

000000 n $0000000000-000000000-5$

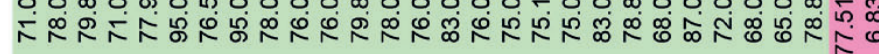

웅

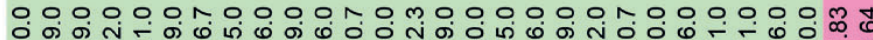
र5

马

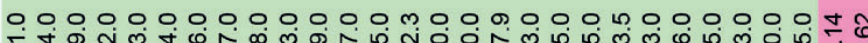
范范范

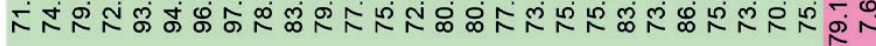

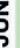

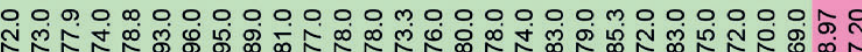

¿े

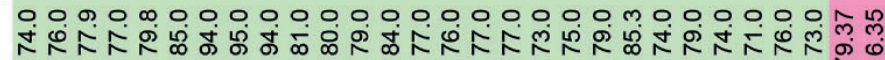

繙

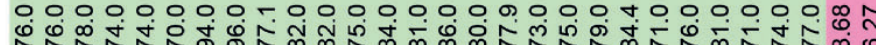

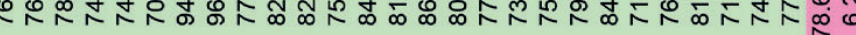

$\stackrel{\alpha}{\Sigma}$

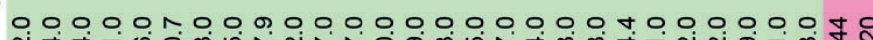

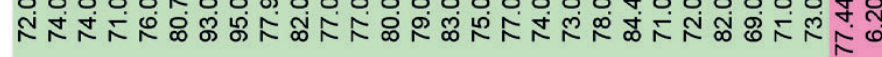

畄

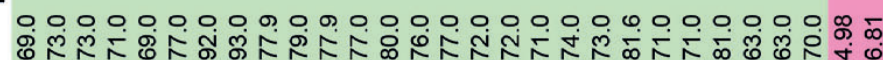
厦 


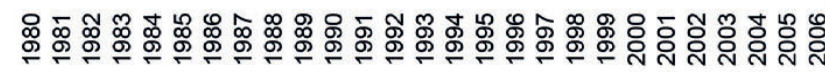

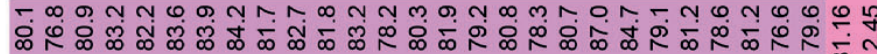

은

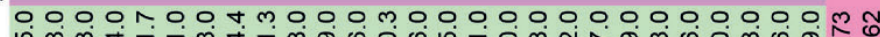

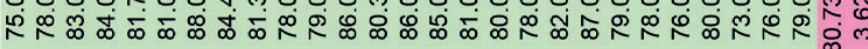

음

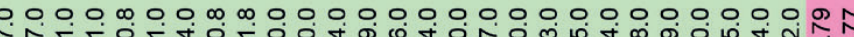

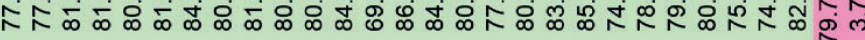

zo

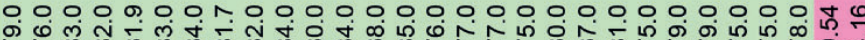

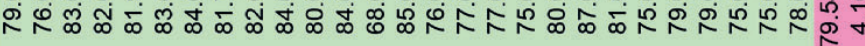

to

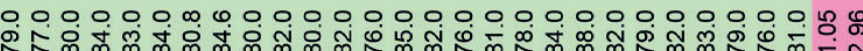
峞 ڤ户்

¿ 00000010000000000000000000

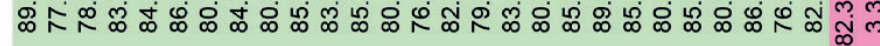

5 $000000-m 0000000000000000000 \bar{m}$

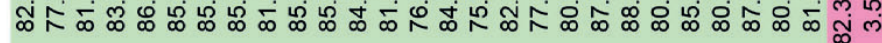

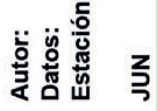

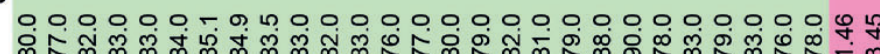
爻

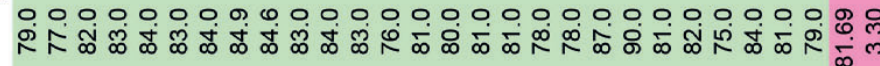

爱

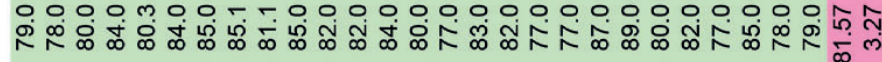

$\frac{\alpha}{\alpha}$

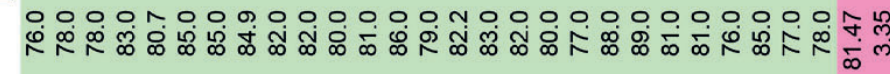
思

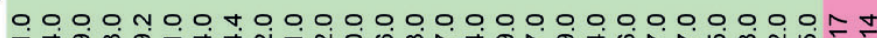

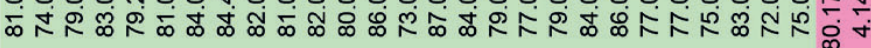
状 
401

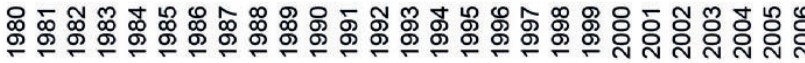

$0 \omega \infty$ ต

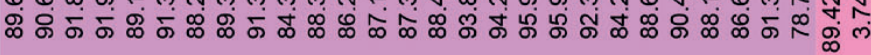

安 ळ

뭉

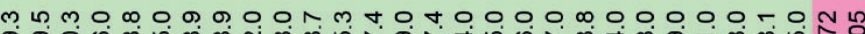

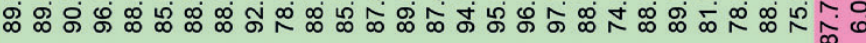

ว

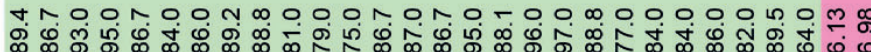
Ł ळ

亗

n $\infty$ n 0 o o n m

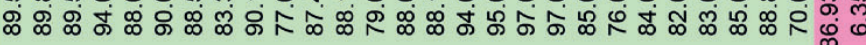

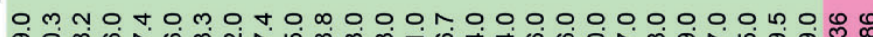

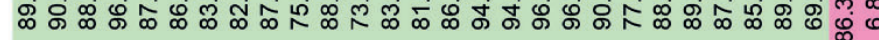

5 n

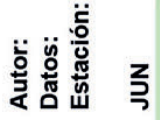

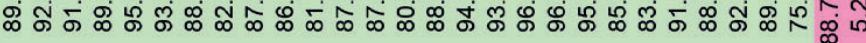

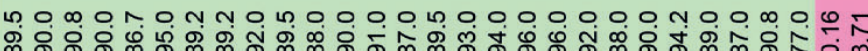

๘্

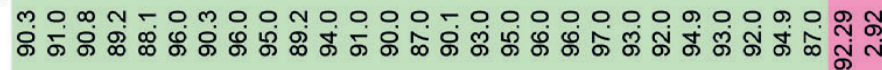

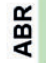

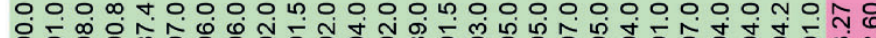

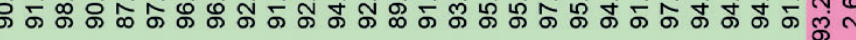

$\stackrel{\alpha}{\overleftarrow{L}}$

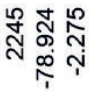

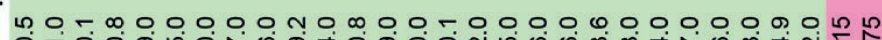

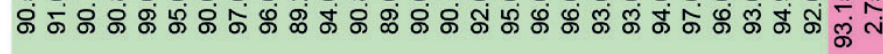
思

ஊ 崖 


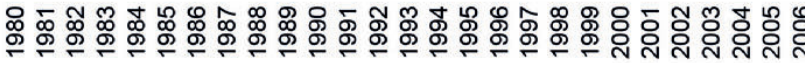

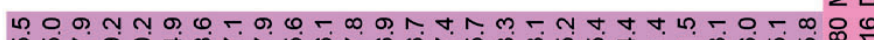 ळ

安

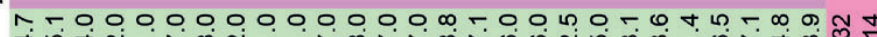

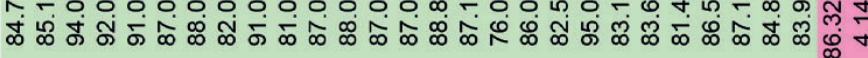

$\frac{0}{\square}$

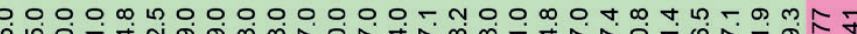
めळ

วे

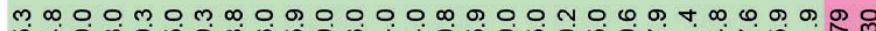

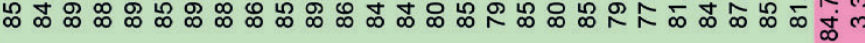

Ł

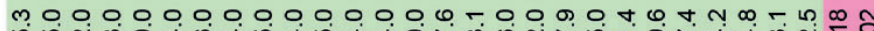

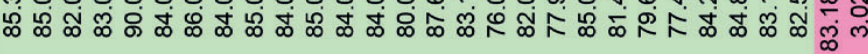
䕇

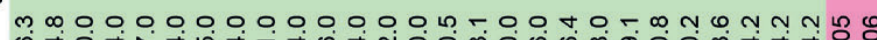

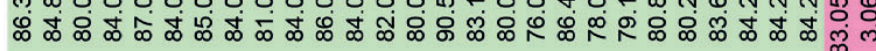

$\stackrel{8}{8}$

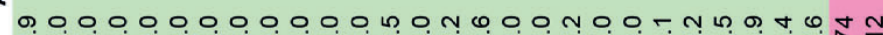

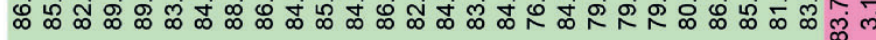

马

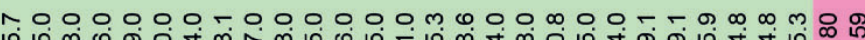

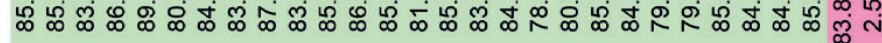

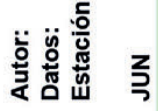

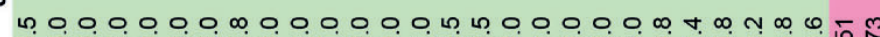

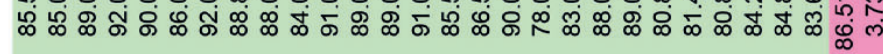

文

$m 00000 m 0000000 m 0000000106-0 h 40$

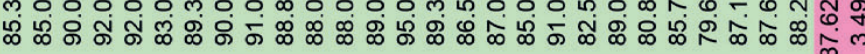

㩊 $m-0$
$m-0$

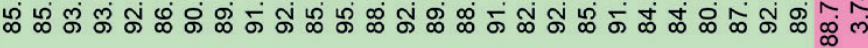

$\frac{\alpha}{2}$

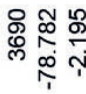

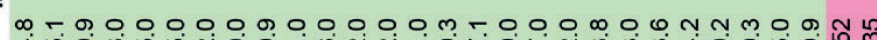
ळ 峉

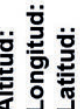

0 n $0000000000000 m 000 m 0000-00$

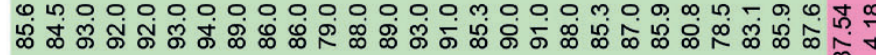
岂 


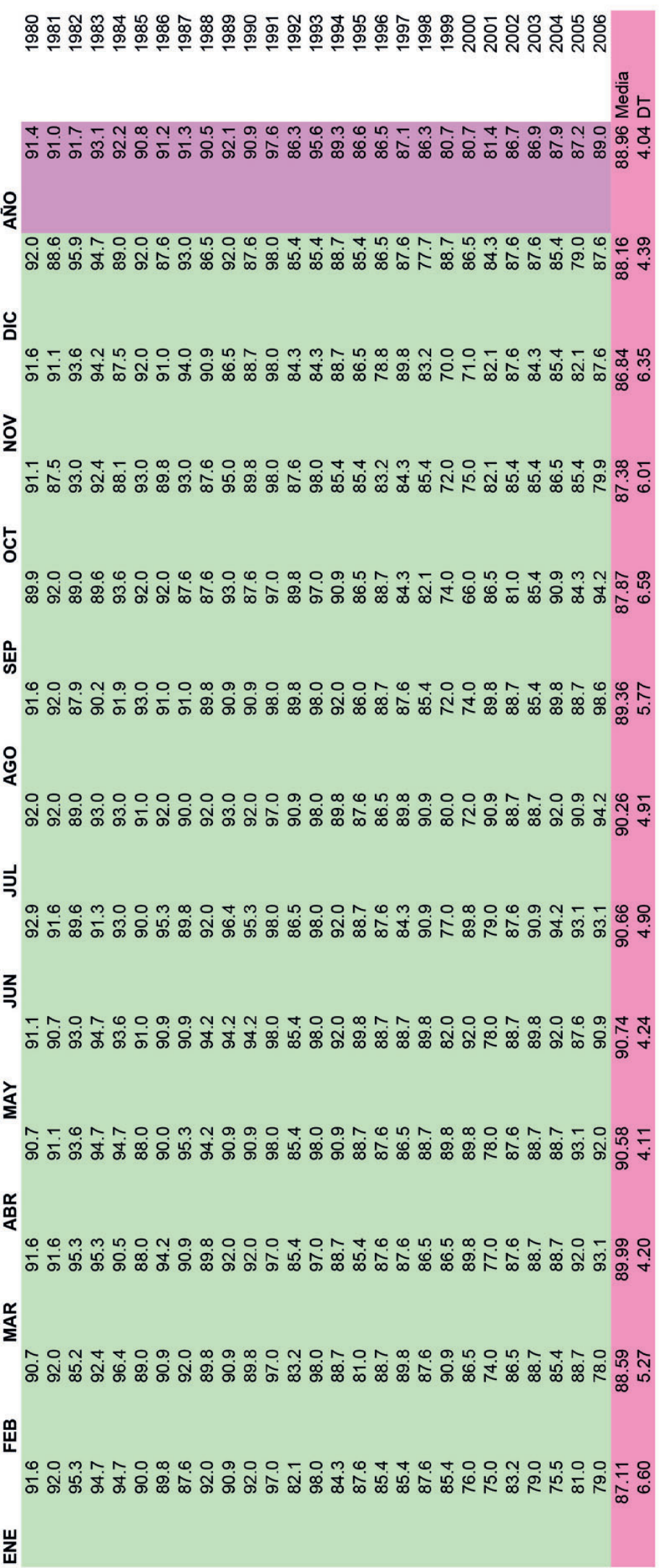


404

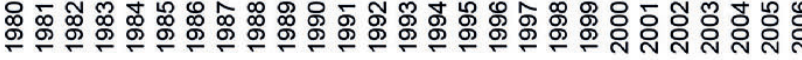

ம

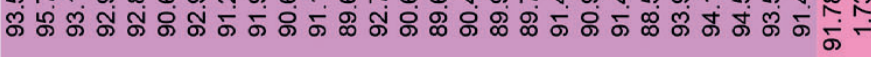

安

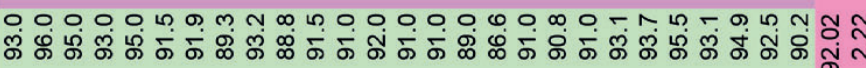

음 m 00 o o n m m T n

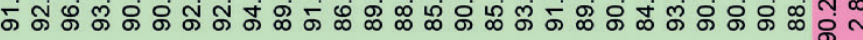

ว

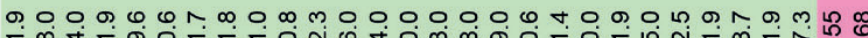

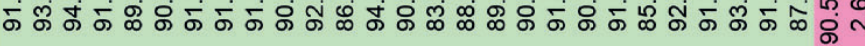

\section{¿}

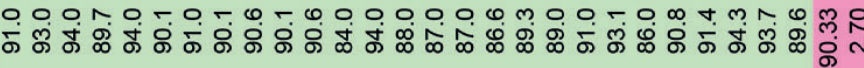

㟧

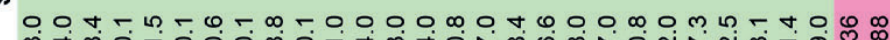
ウं்

\&

o o m o m

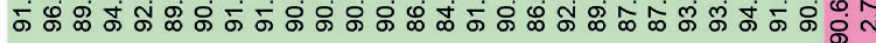

弓

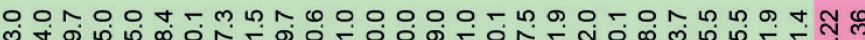

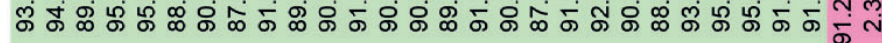

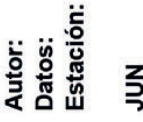

o o mo o o 0 .

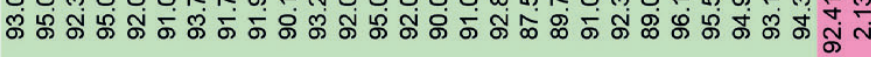

¿

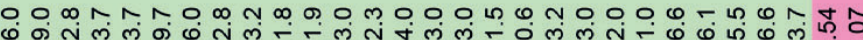

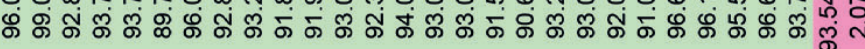

$\stackrel{\frac{\alpha}{m}}{\frac{0}{4}}$

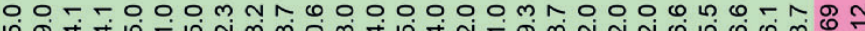

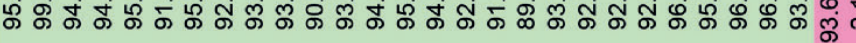

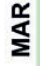
은

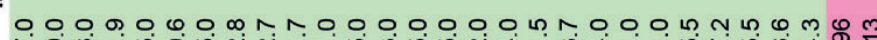

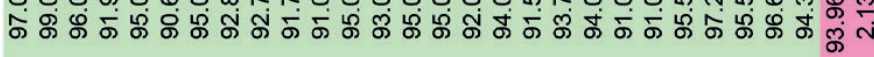

延

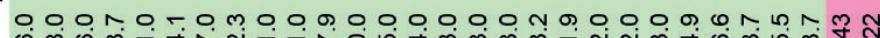
芦总

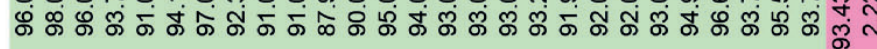

崖 


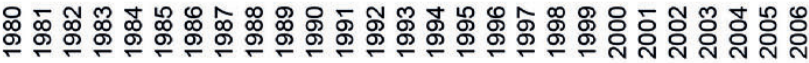

กูก ก

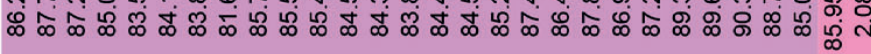

安

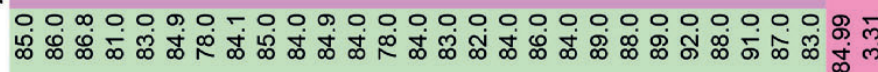

$\dddot{0}$

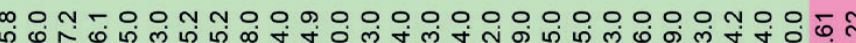

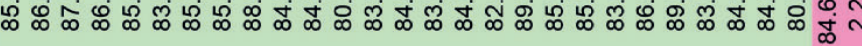

วิ

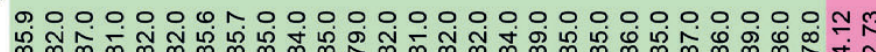

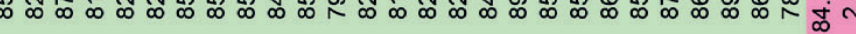

Ł

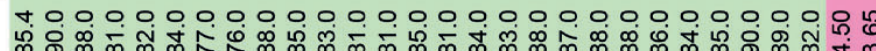
峞

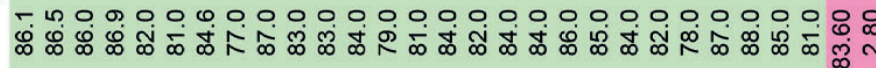

$\sum^{\circ}$

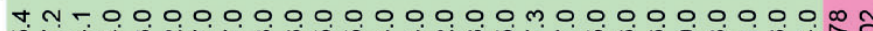

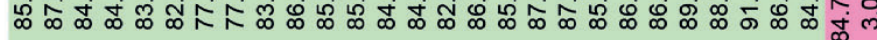

s

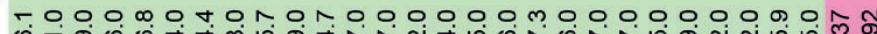

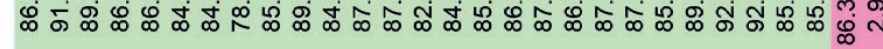

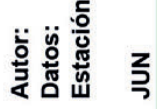

$-\infty 0000100000000000000000000 m$

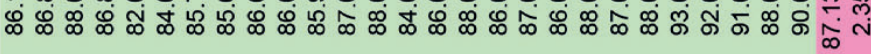

$\grave{\varepsilon}$ 4TON $\widehat{\infty}$

㩊

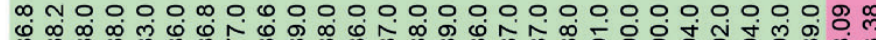

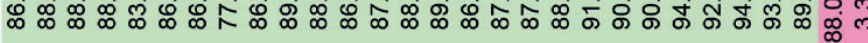

$\frac{\alpha}{\frac{\alpha}{\alpha}}$ 啇

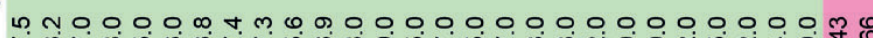

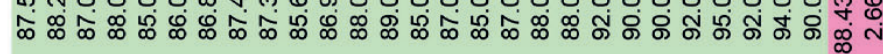

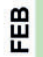

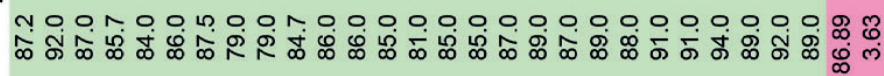
芦蒡总 荘 


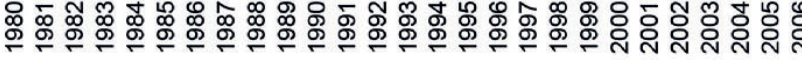

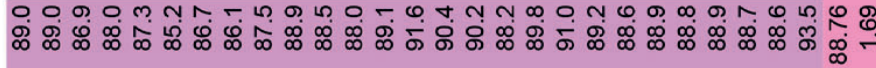

安

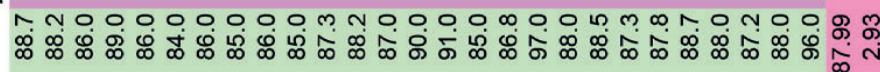

$\frac{0}{\square}$ ம m 0 0 o o o o o o o o o o o o o o h m m œ

ว

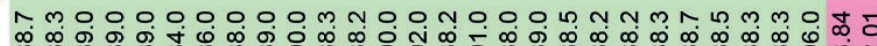

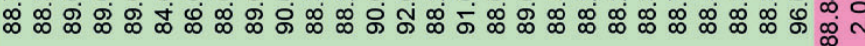

Ł

누

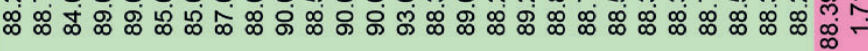

部

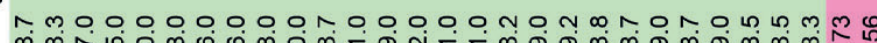

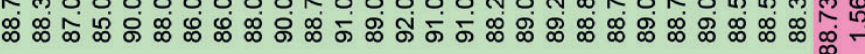

$\stackrel{8}{8}$

mno め。்

క

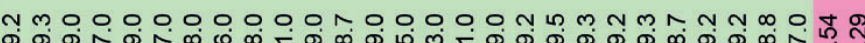

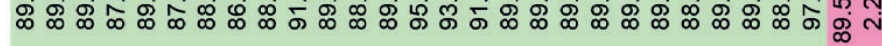

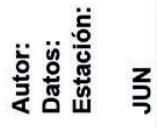

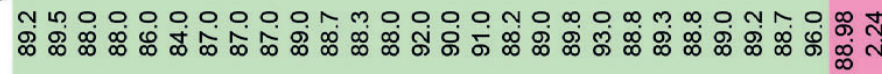

文

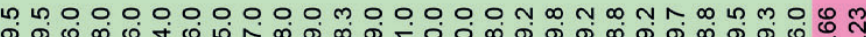

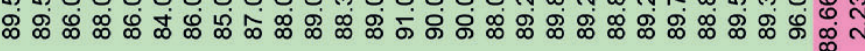

㩊 茴

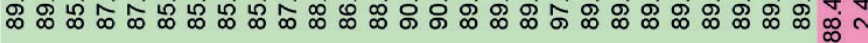

\section{$\frac{\alpha}{\alpha}$}

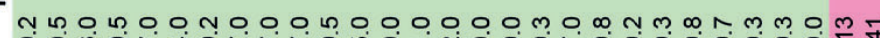

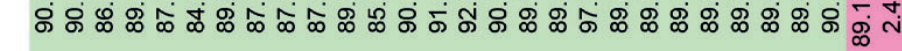

乨

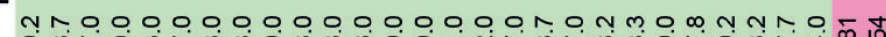

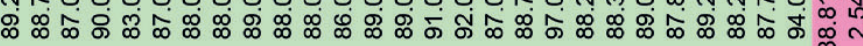

荘 


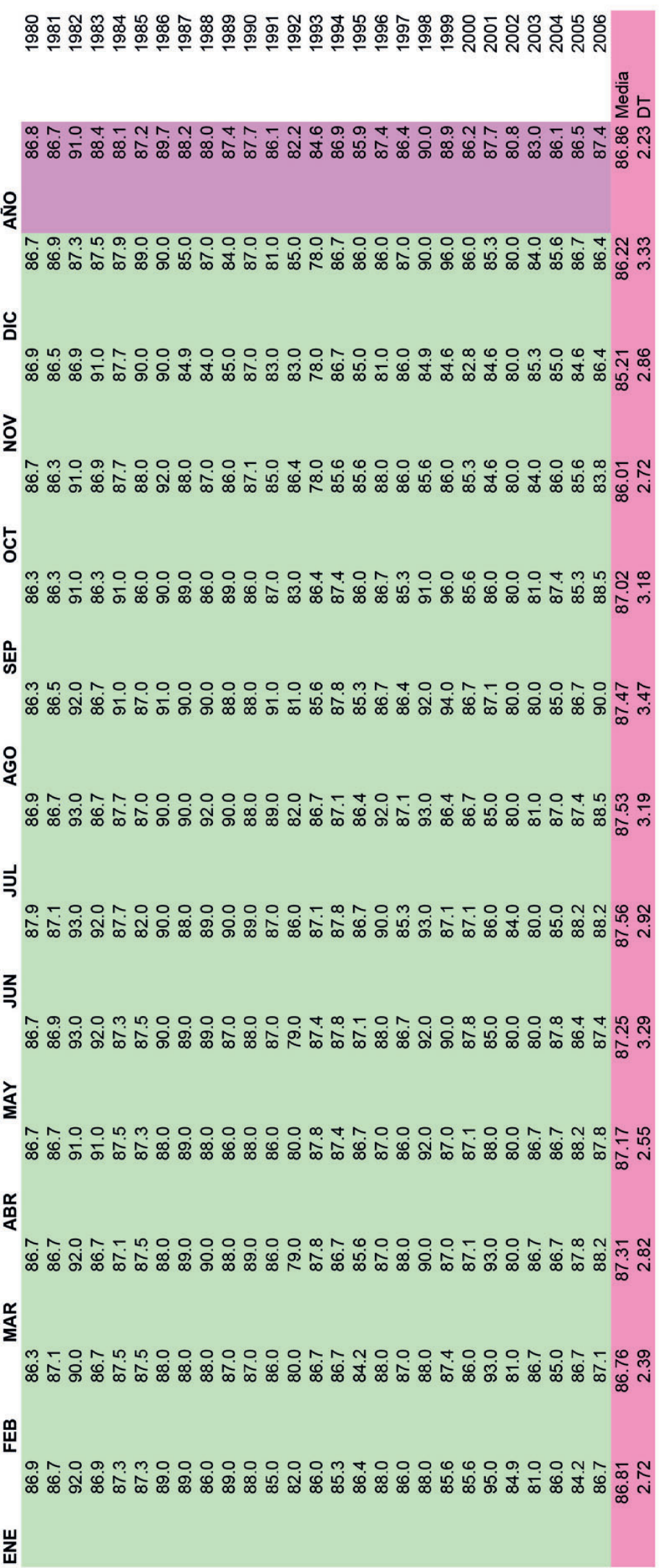




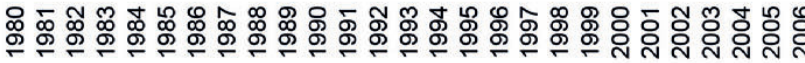

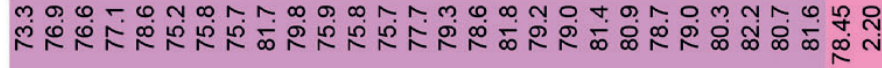

安

00000000000000010000000000000

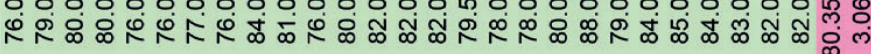

음

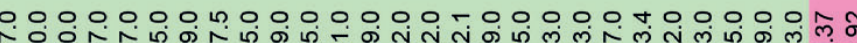

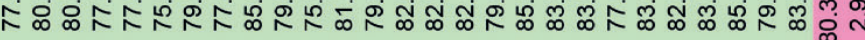

วิ

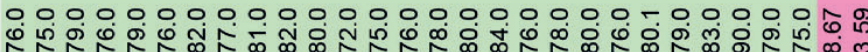

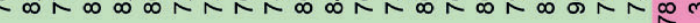

Ł

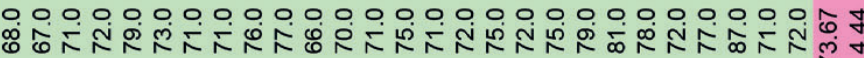

岀

00000000000000000000000000045

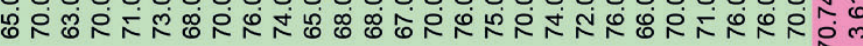

인

000000000000000000000 n 0000000

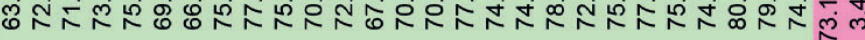

5

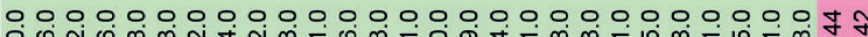

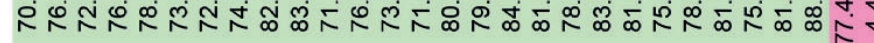

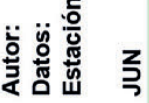

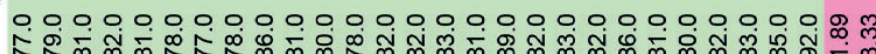

¿

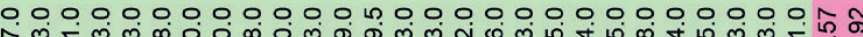

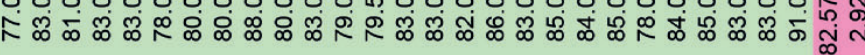

㩊

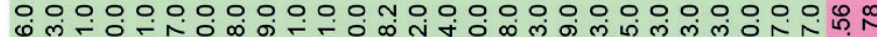

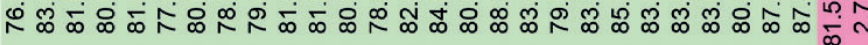

\section{$\stackrel{\frac{\alpha}{\alpha}}{\Sigma}$}

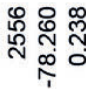

00000000000000000000000000040 ๓

思

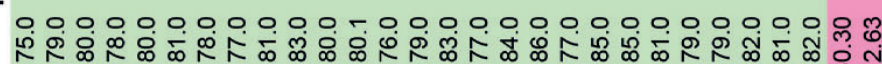
宸 


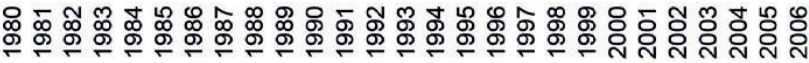

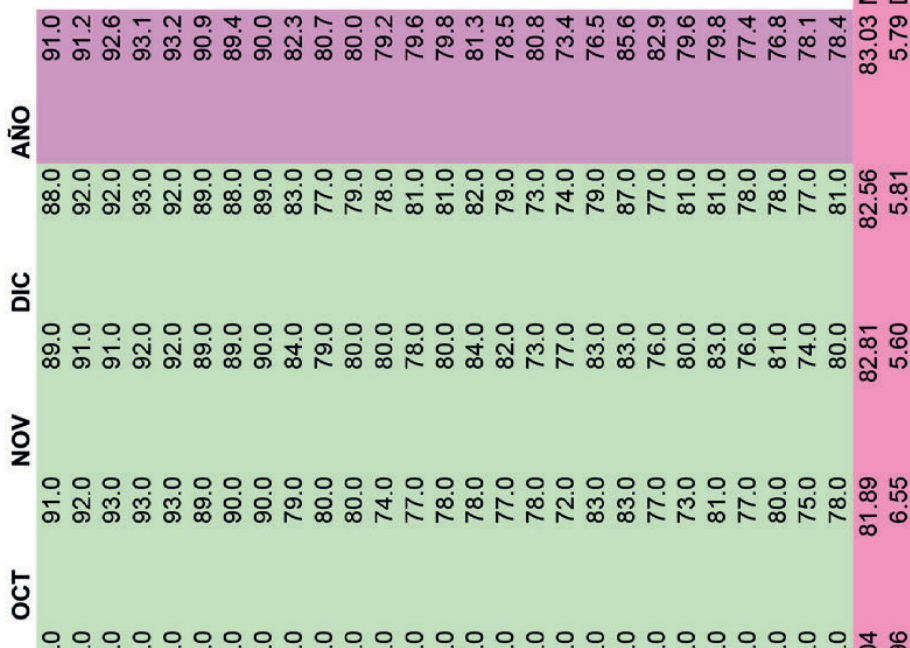

ภำ

飠

0 o o o o o o o o o o o o o o o o o o o o o o o o o o

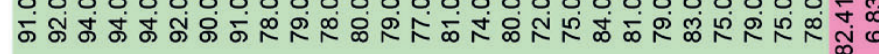

\&

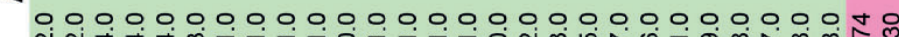

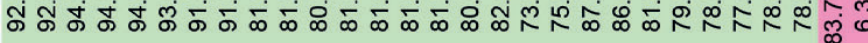

క

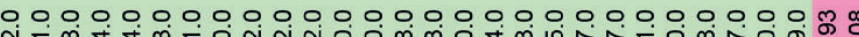

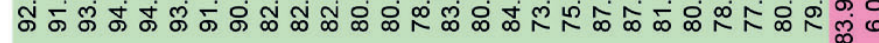

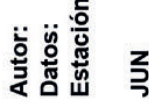

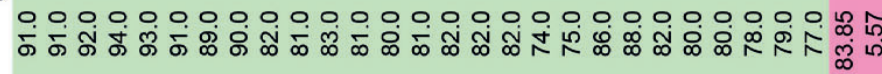

文

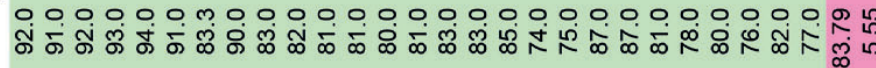

㩊

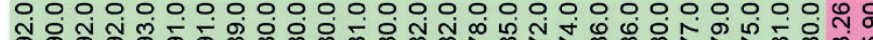

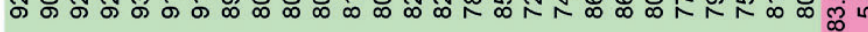

$\frac{\alpha}{\Sigma}$

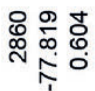

0000000000000000000000000004

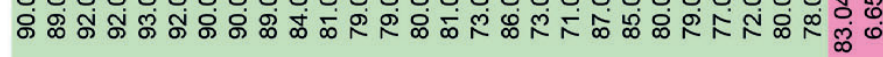

思

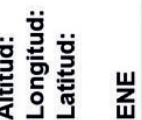

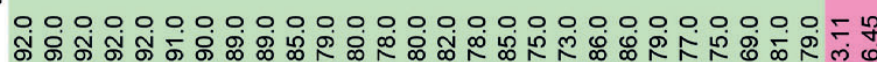




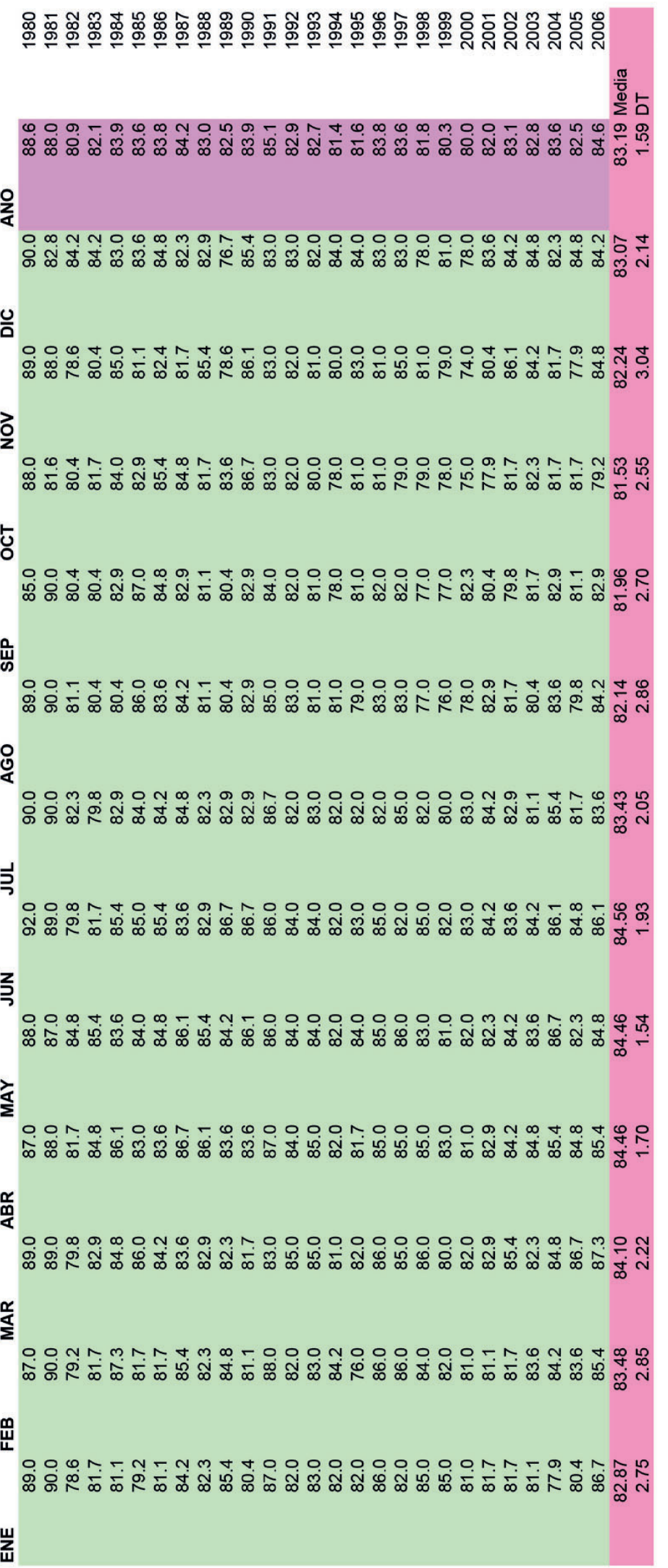




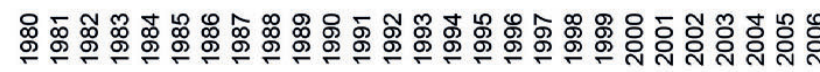

$\stackrel{5}{5}$

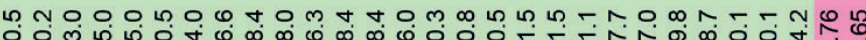

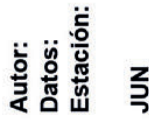

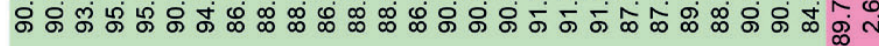

\section{西}

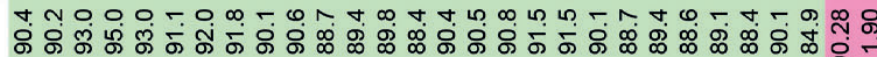

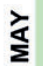

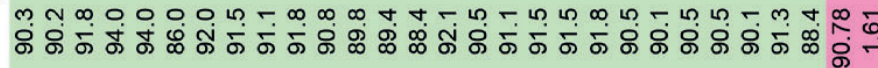

盢

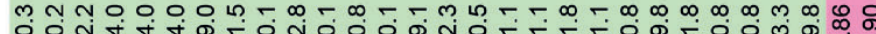

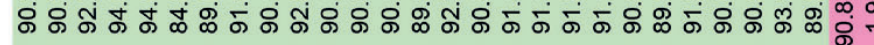

$\stackrel{\alpha}{\Sigma}$ 玄织命

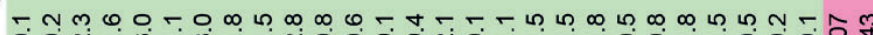

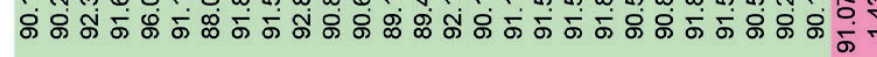

思

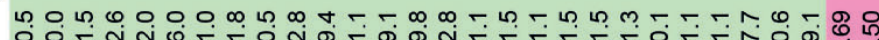
芦蒡

宸 


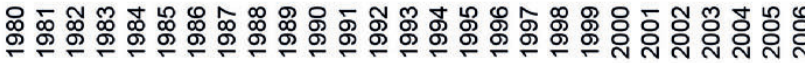

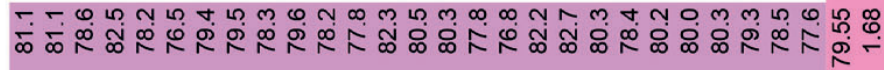

安

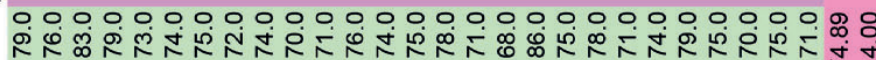

음

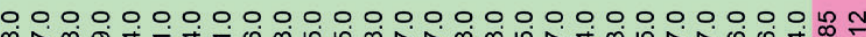

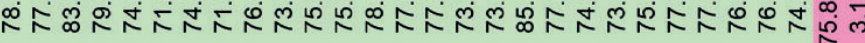

을

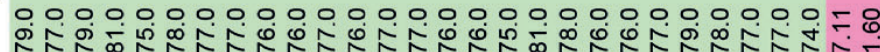

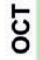

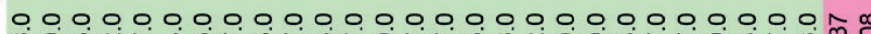

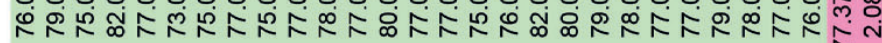
岂

0.00000000000000000000000000 .85

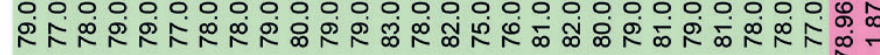

8

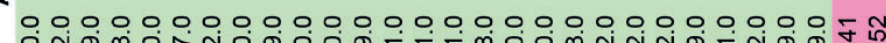

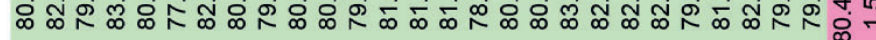

s

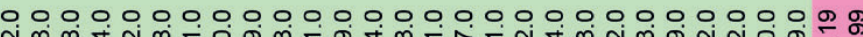

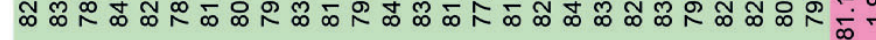

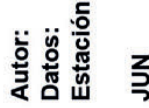

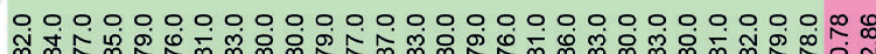
¿ $000000000000000000000000000 \%$

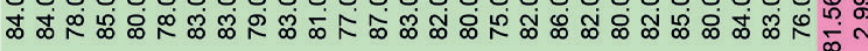

愛

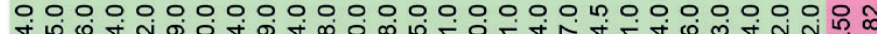

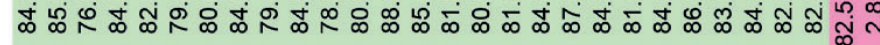

\section{$\frac{\alpha}{2}$}

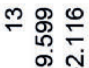

$000000000000000000000000000 m$ ळ

思

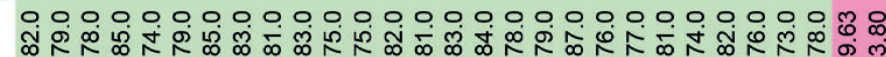




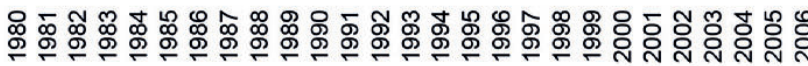

Oㅁ

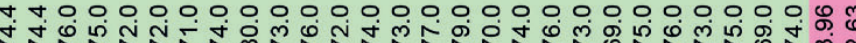
thiskisitis

zo

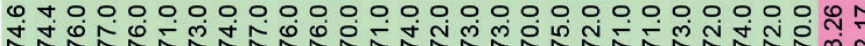
in

¿

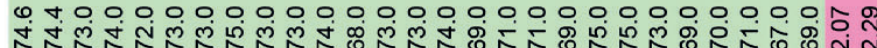
芯

- 400000000000000000000000004.

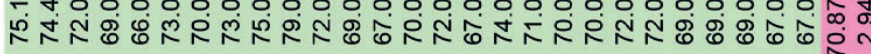

8

440000000000000000000000000.0

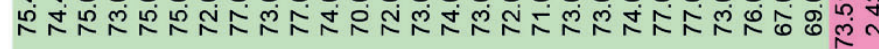

s

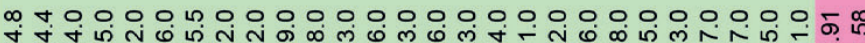

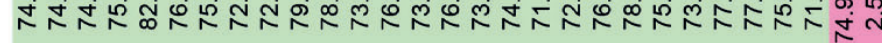

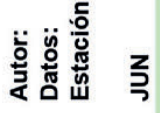

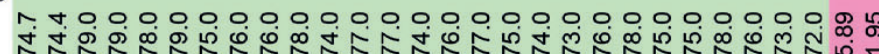

文 $0.40000000000000000000000000, i n \infty$

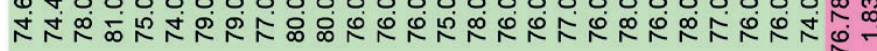

㩊

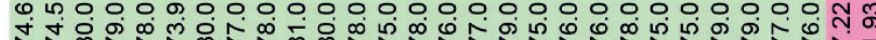
hi

$\frac{\alpha}{\underline{\alpha}}$ ๕

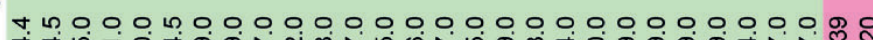

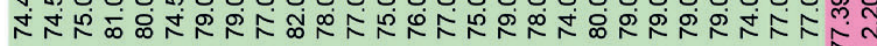
思

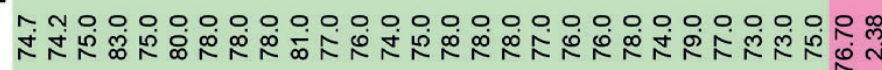
荘 


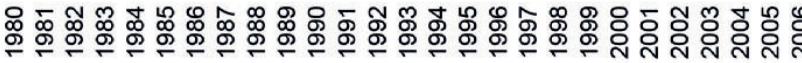

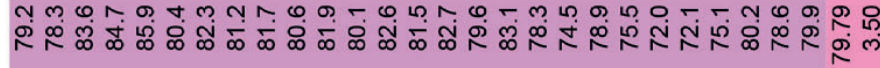

安

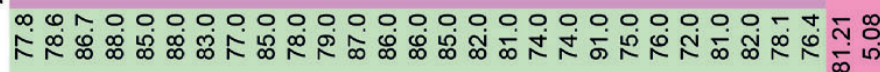

음

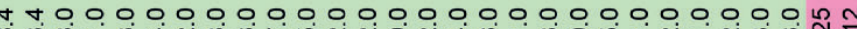

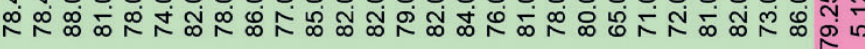

zo の-

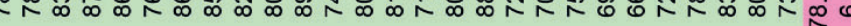

'̌

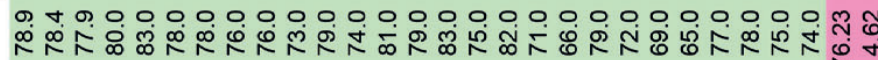

峞

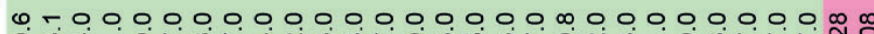

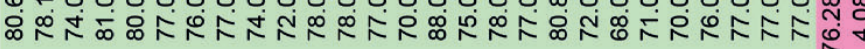

¿

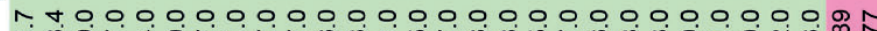

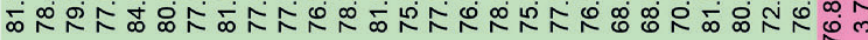

!

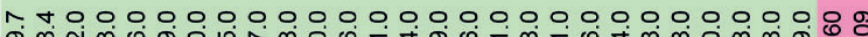

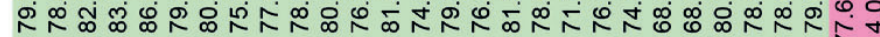

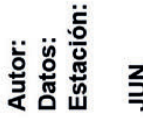

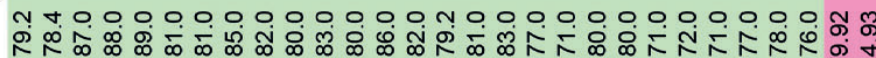

ญั

0.70000000000000000000010000 .700

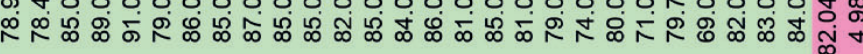

㩊

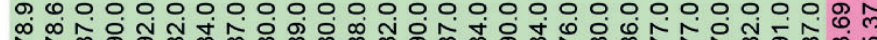

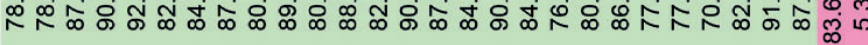

$\frac{\alpha}{\alpha}$

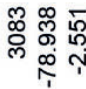

$-00000000000000000000000040 \hat{0}$

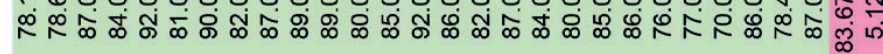

峉 n 0 n $0000000000000000000000000=4$ 芦薃

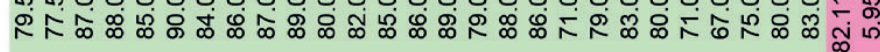




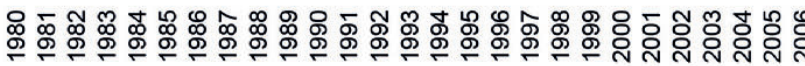

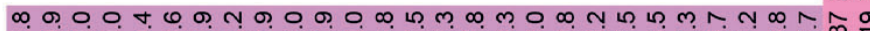

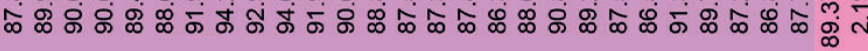

安 ம

$\frac{0}{0}$ 0

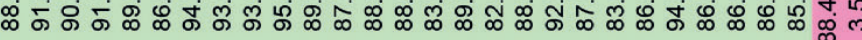

วे

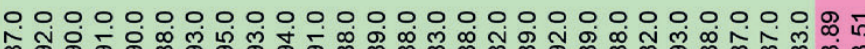

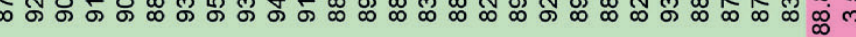

Ł

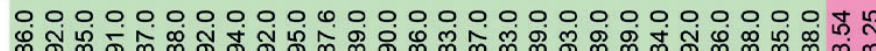

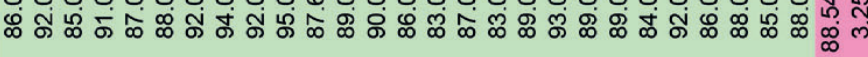

莭

000000000000000000000000000 ก ๓

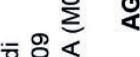

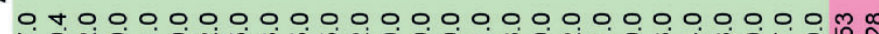

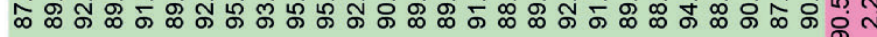

s

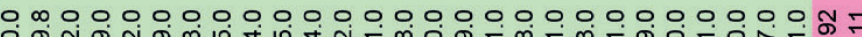

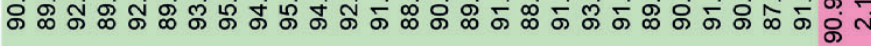
范范范范

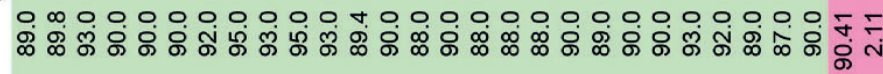
¿ $0,0000000000+0.00000000000000 .0$ ம்

盢

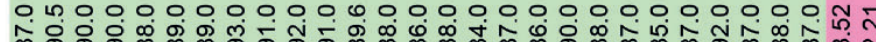

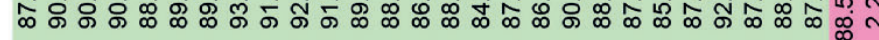

\section{$\frac{\alpha}{\Sigma}$}

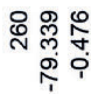

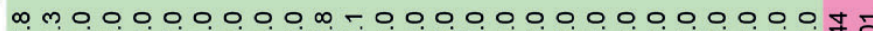

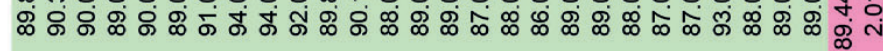
延 ก

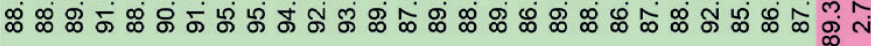
崖 


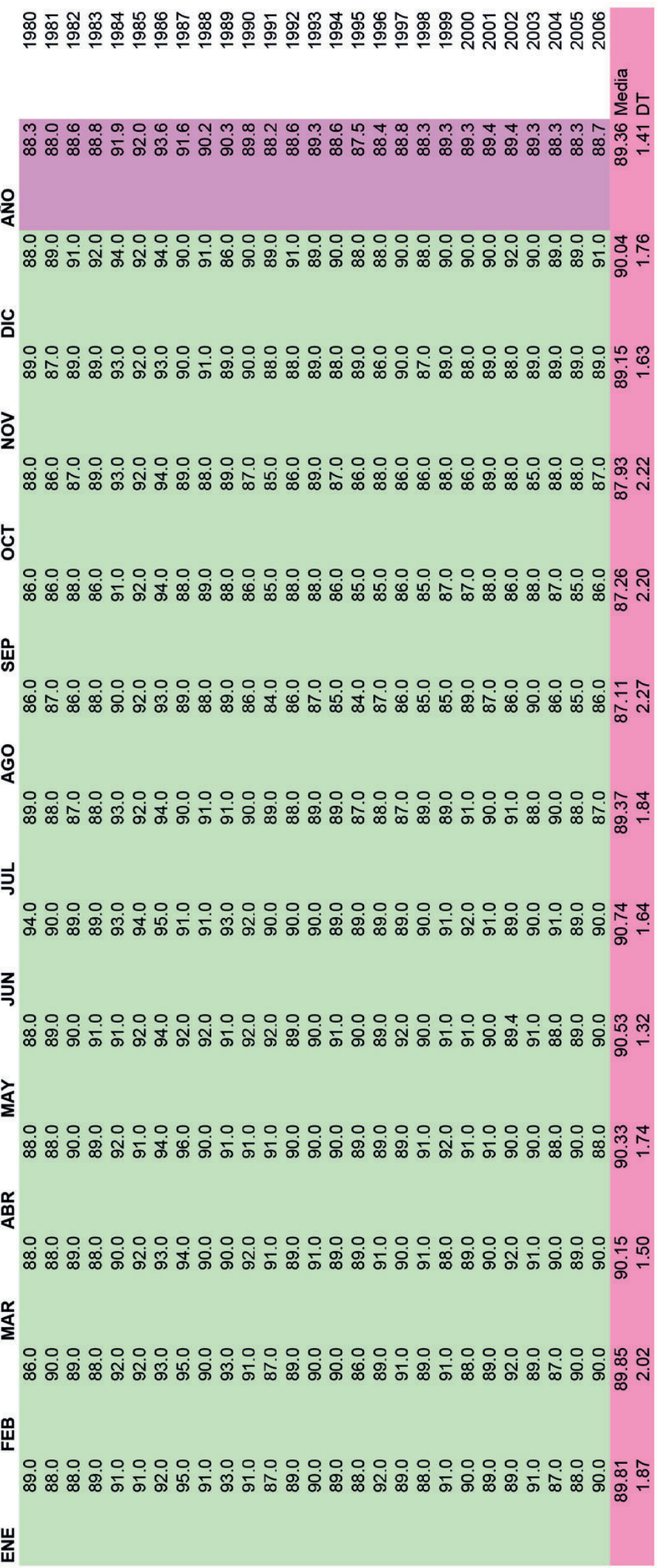




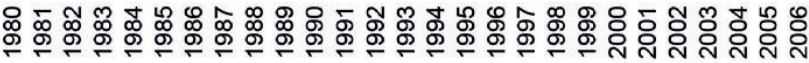

d

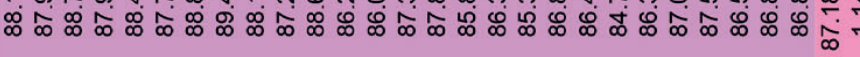

安

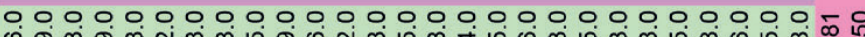
ळ

음

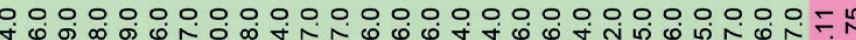
एळ

zे

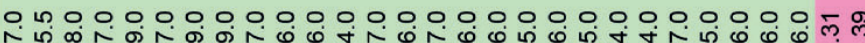

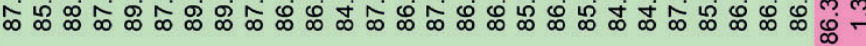

క

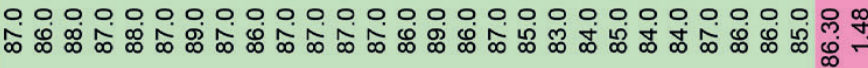

๗ั

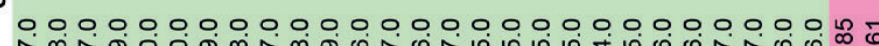
மெ

운

000000000000000000000000000.5

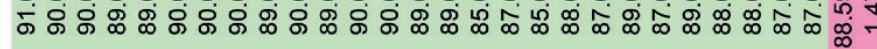

5

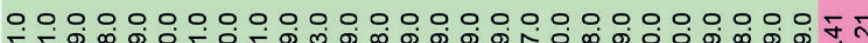

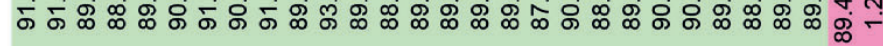

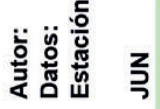

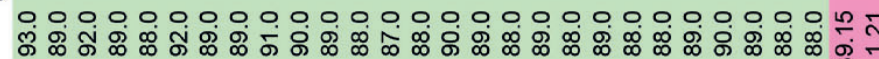

¿ ऊু

盢

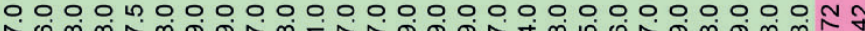

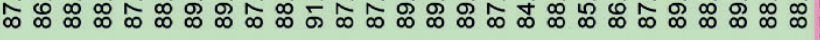

$\stackrel{\alpha}{\Sigma}$

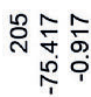

$000000000000000000000000000=0$

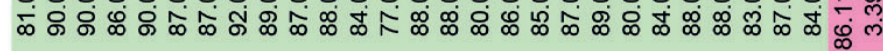

思

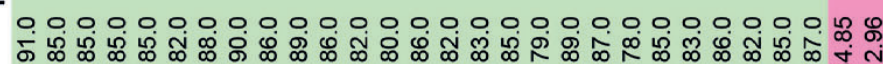

崖 


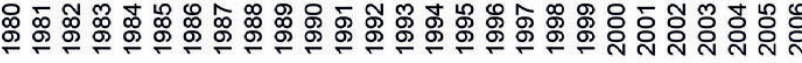

T $\infty$ m

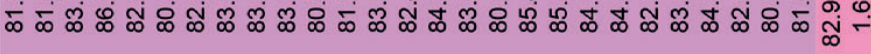

安

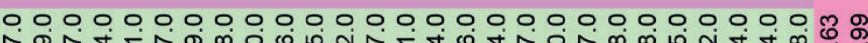

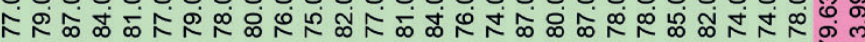

$\underline{0}$

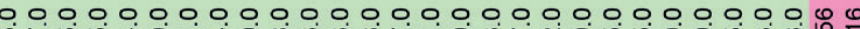

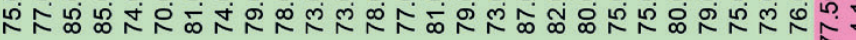

วิ

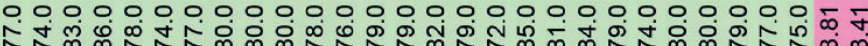

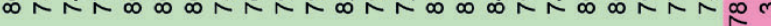

\section{$\overline{8}$}

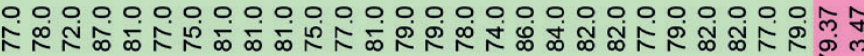

岀

$000000000000000000000000000 N$

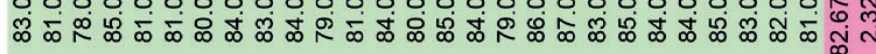

융 00000000000000000000000000000 ゆळ

$\stackrel{5}{5}$

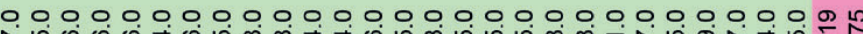
ம் 范皆总

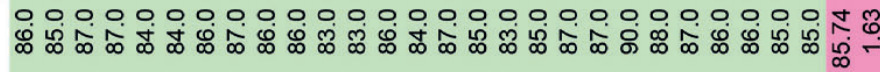

¿ิ

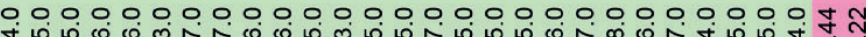

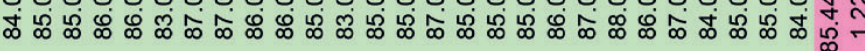

$\stackrel{\frac{\alpha}{m}}{\frac{0}{4}}$ 0000000000000000000000000000,0 ゆ

$\stackrel{\alpha}{\Sigma}$

ำ ํํำ

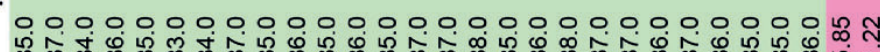
ळळ

思

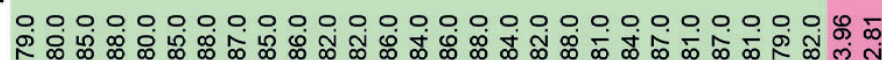
宸 


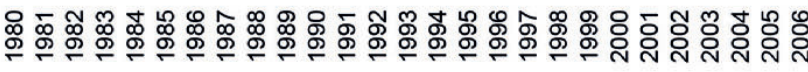

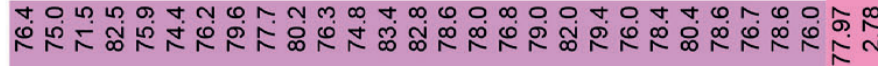

安

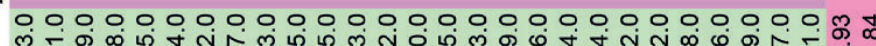

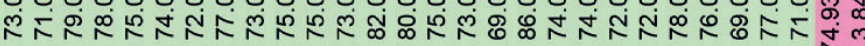

음

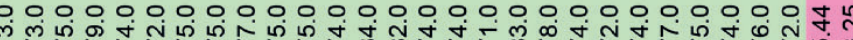

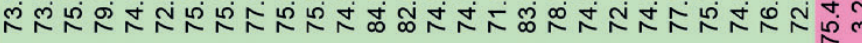

zे

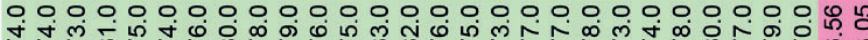

เ

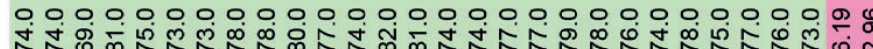

芯

00000000000000000000000000000

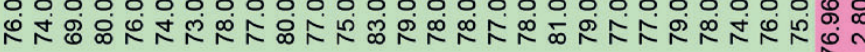

¿

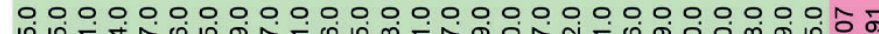

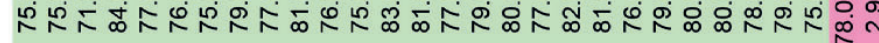

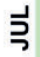

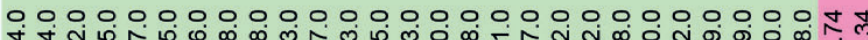

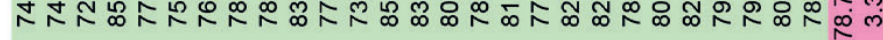

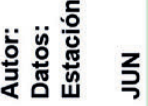

$0.0 .0 .0 .0 .0 .000 .000 .0 .0 .0 .0 .0 .0,0$

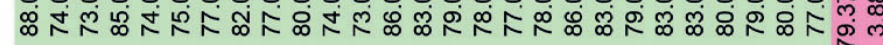

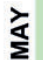

$000000000000000000000000000 \pi=$ ๓

噮 응이있

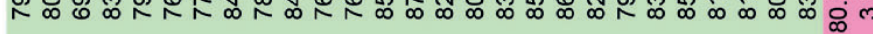

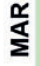

00000000000000000000000000000

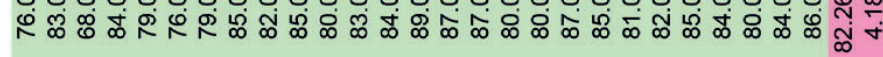

稒

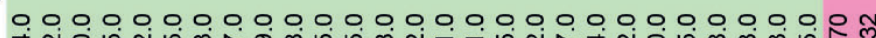
芦蒡弟

宸 


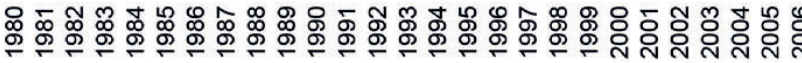

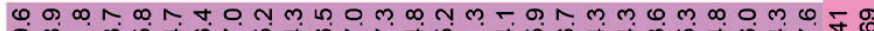

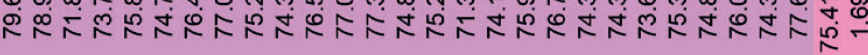

究

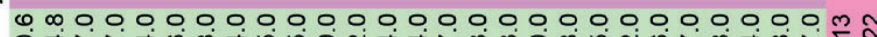

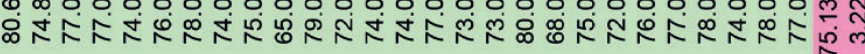

음

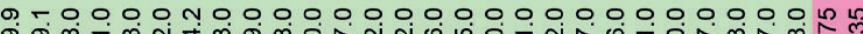

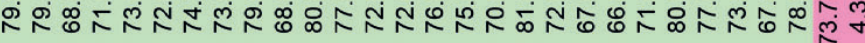

ว -

Ł

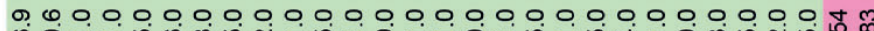

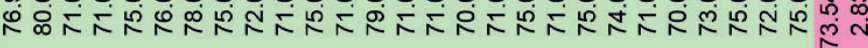

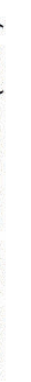

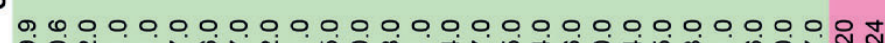

bis.

운

000000000000000000000000000.0 ๓

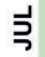

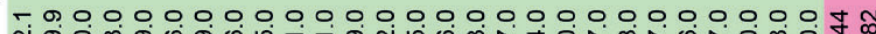

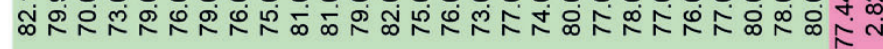
范范蓄

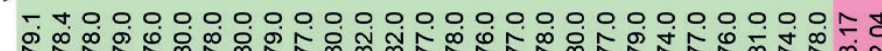
¿ $4=0.0000000000000000000000000$

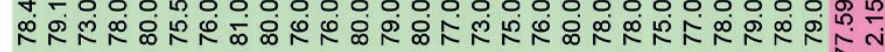

㩊

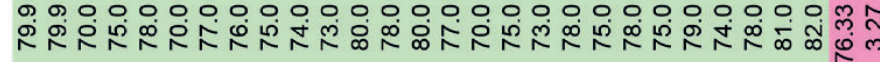

$\stackrel{\alpha}{\Sigma}$ ๙ึ๊

$+00000000000000000000000000 \%$

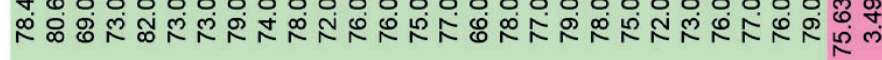

思

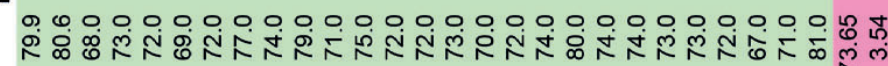
芦葶

崖 


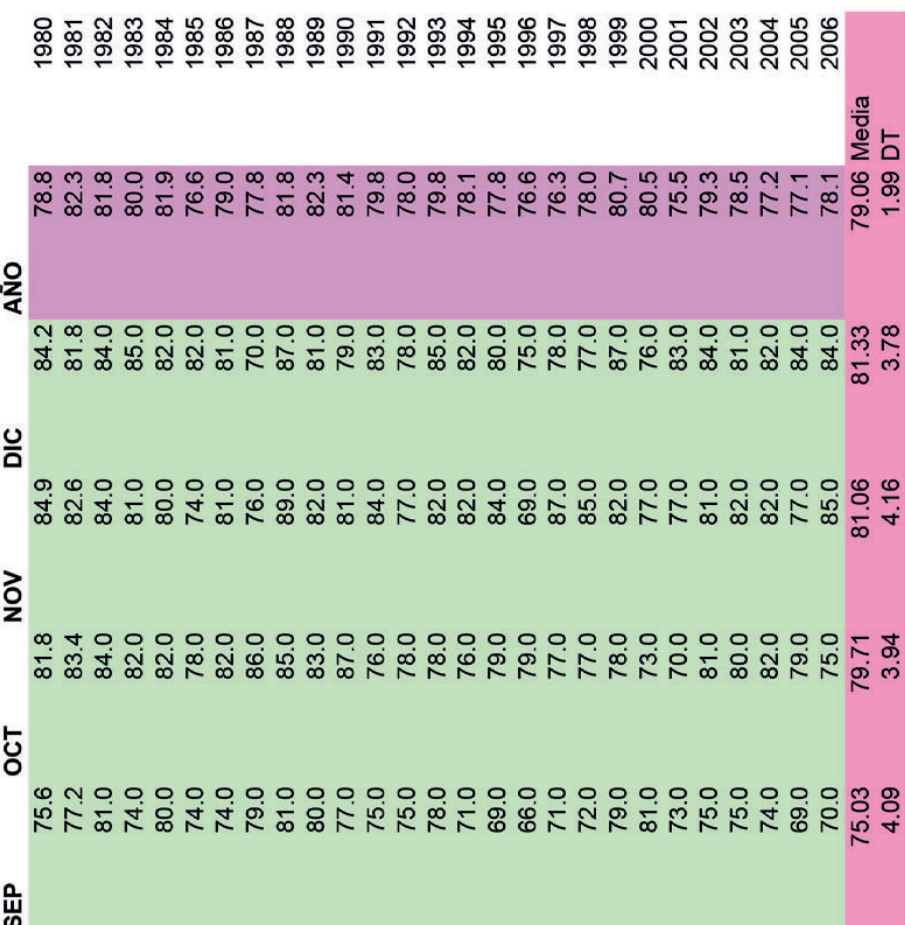

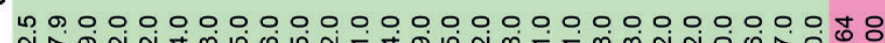
ก5.

¿

m 00000000000000000000000000 m

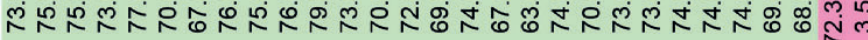

5

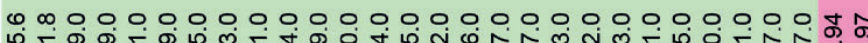

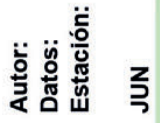

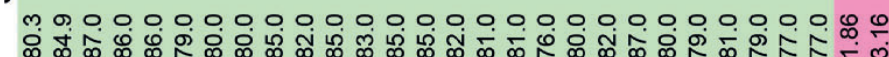

¿

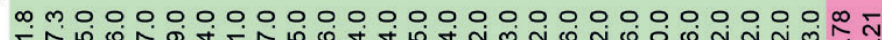
๓

$\stackrel{\frac{\alpha}{m}}{\frac{\mathrm{m}}{4}}$

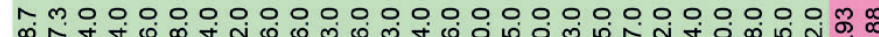

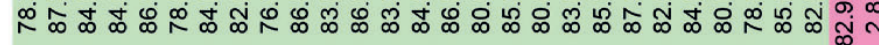

\section{$\stackrel{\frac{\alpha}{\overleftarrow{L}}}{\Sigma}$}

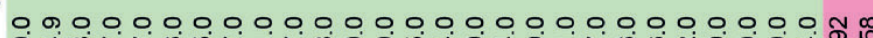

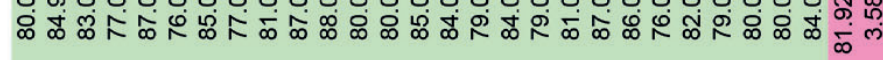

虫

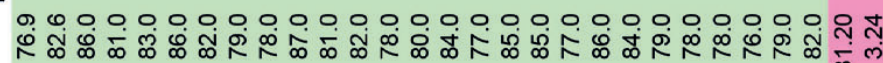

崖 


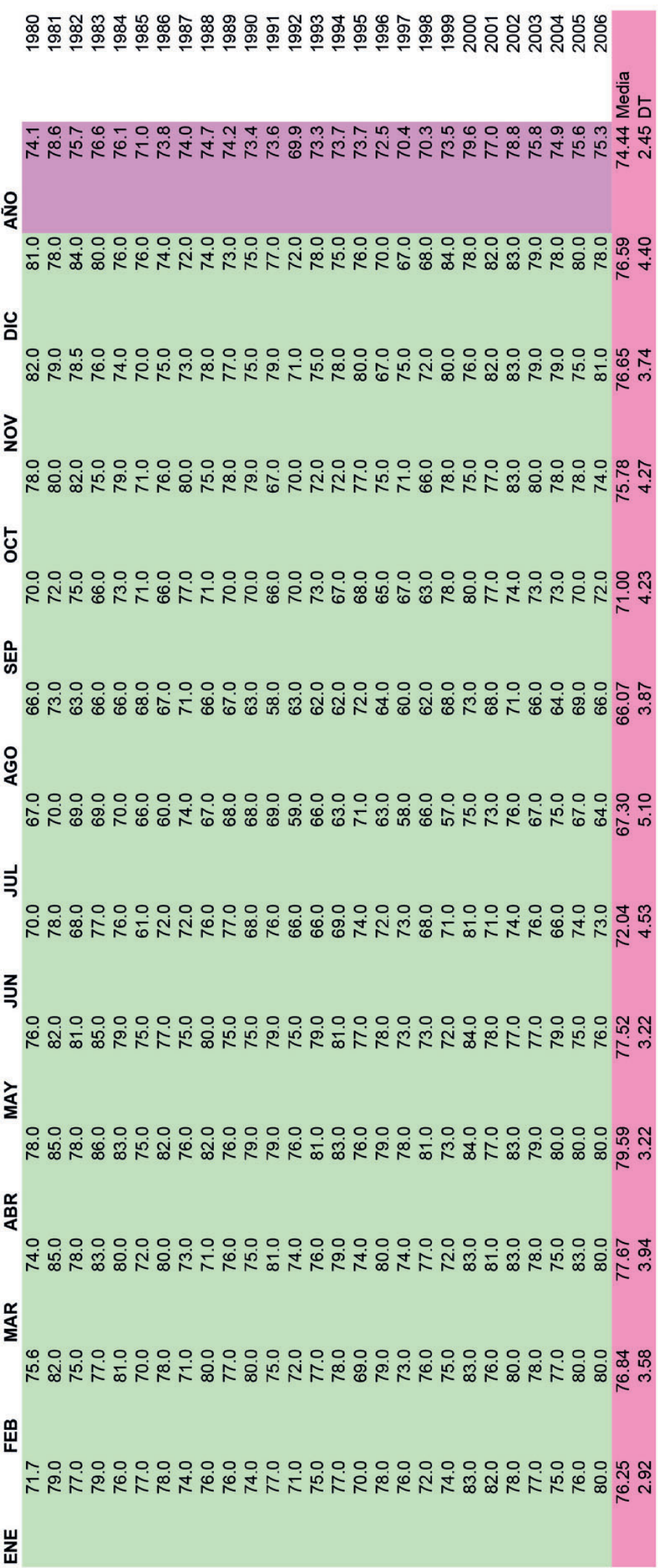



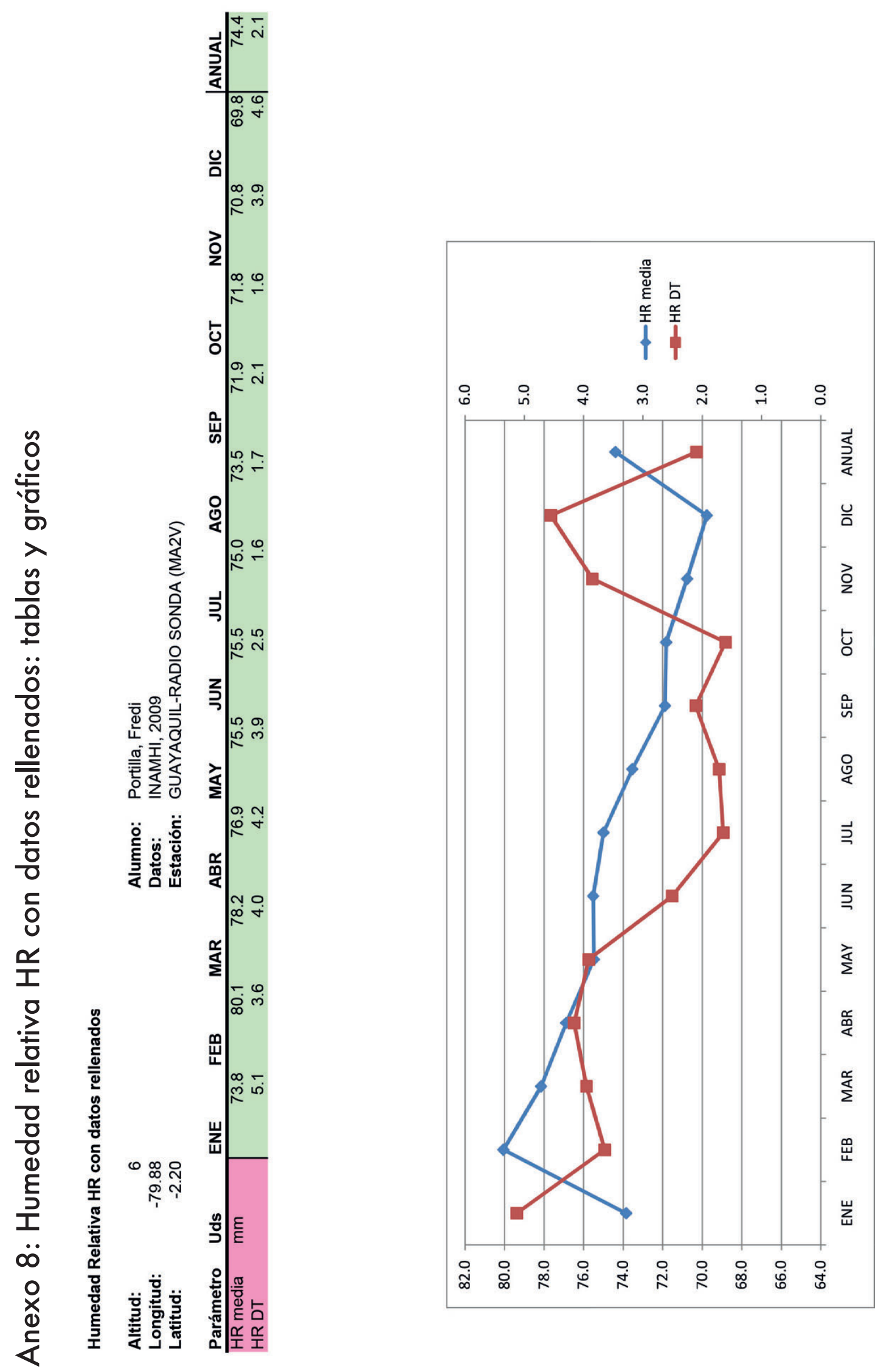

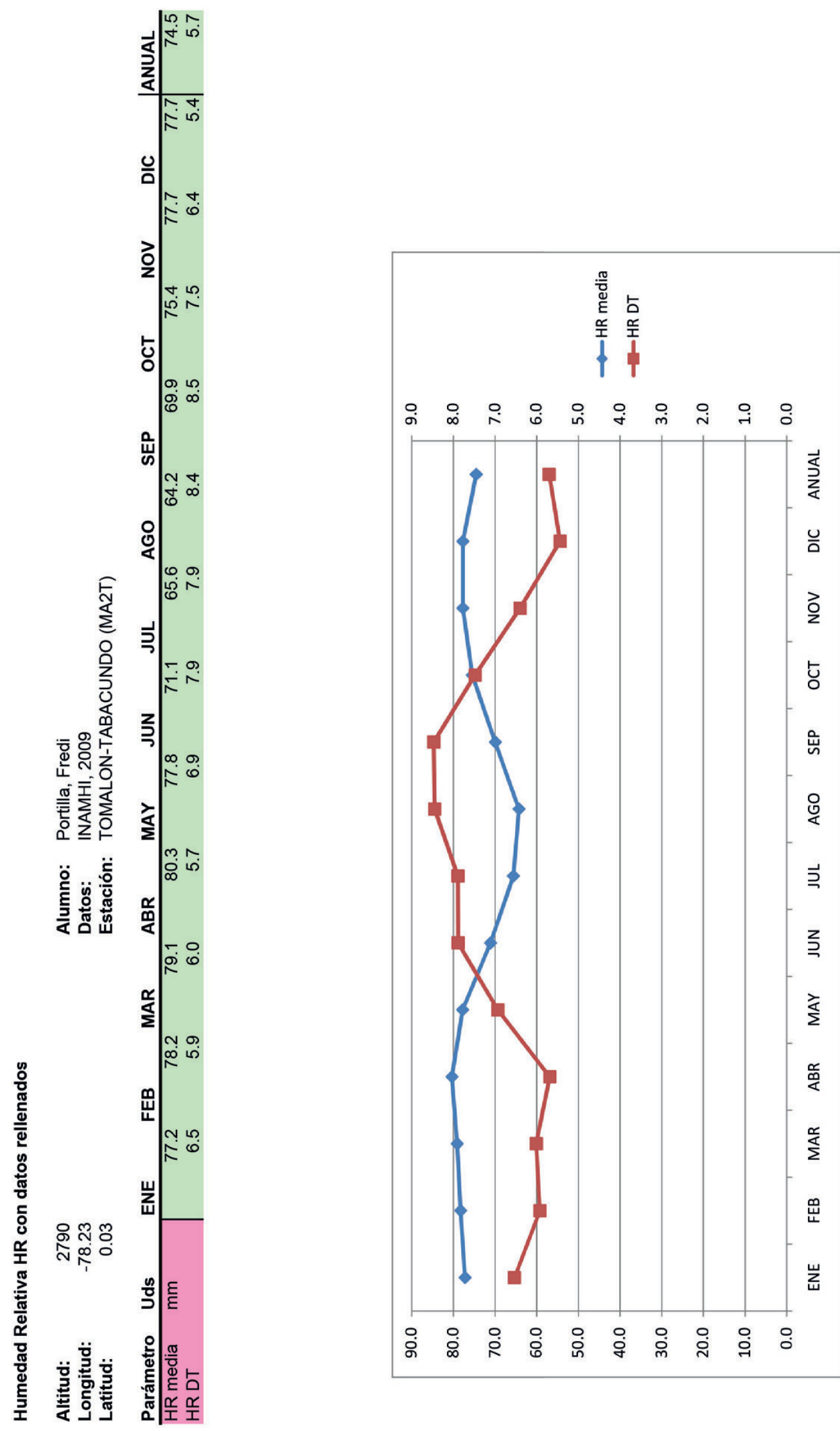

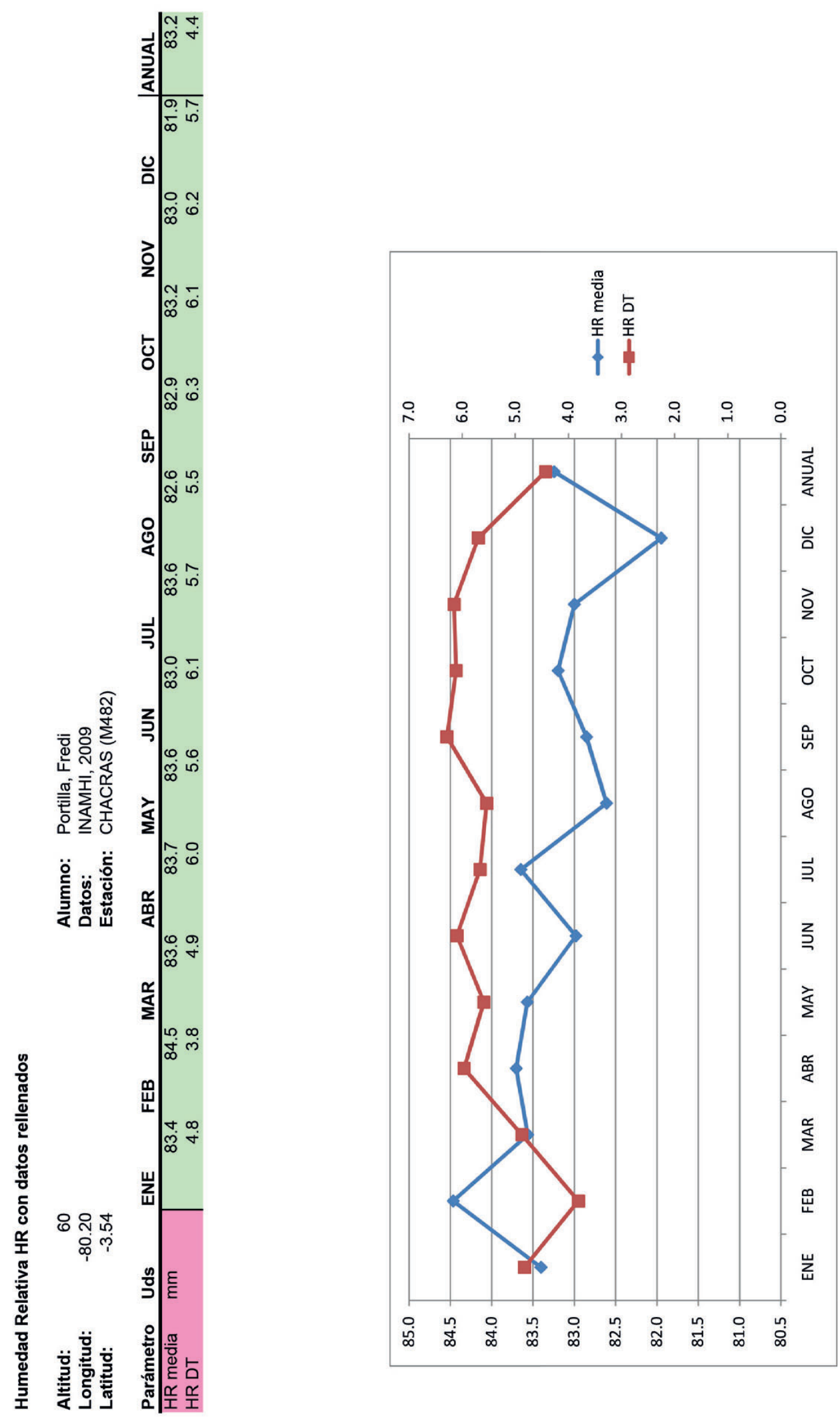

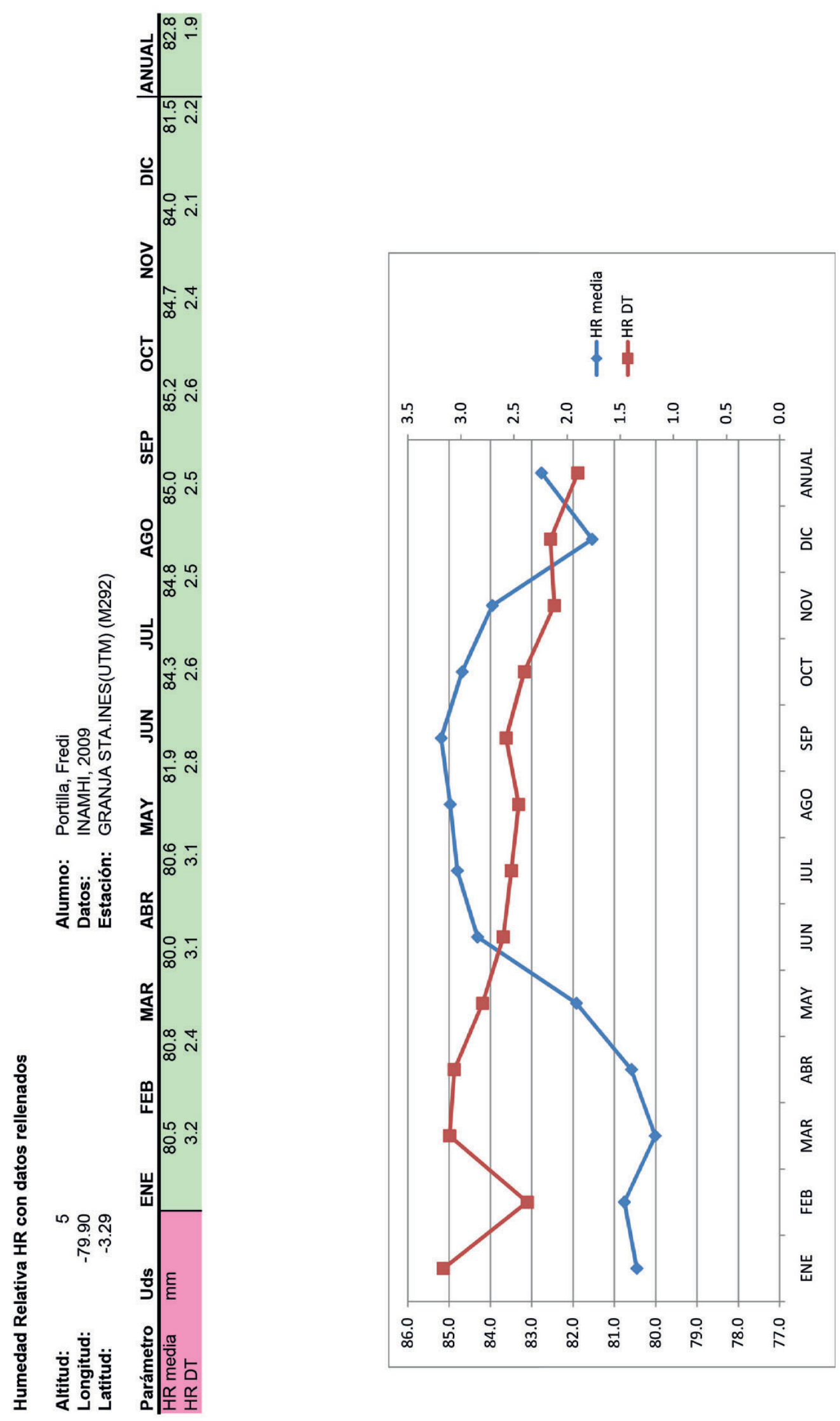

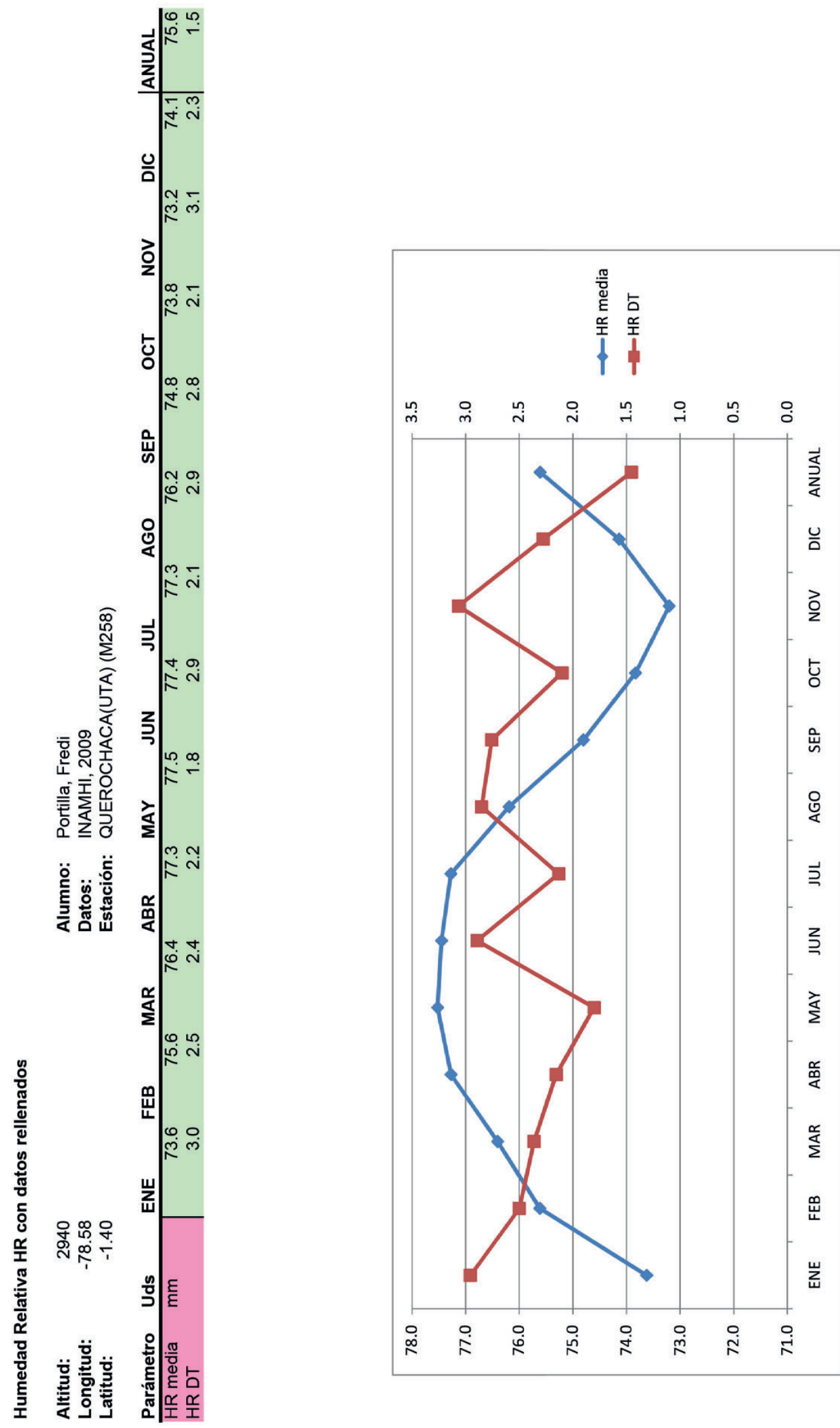

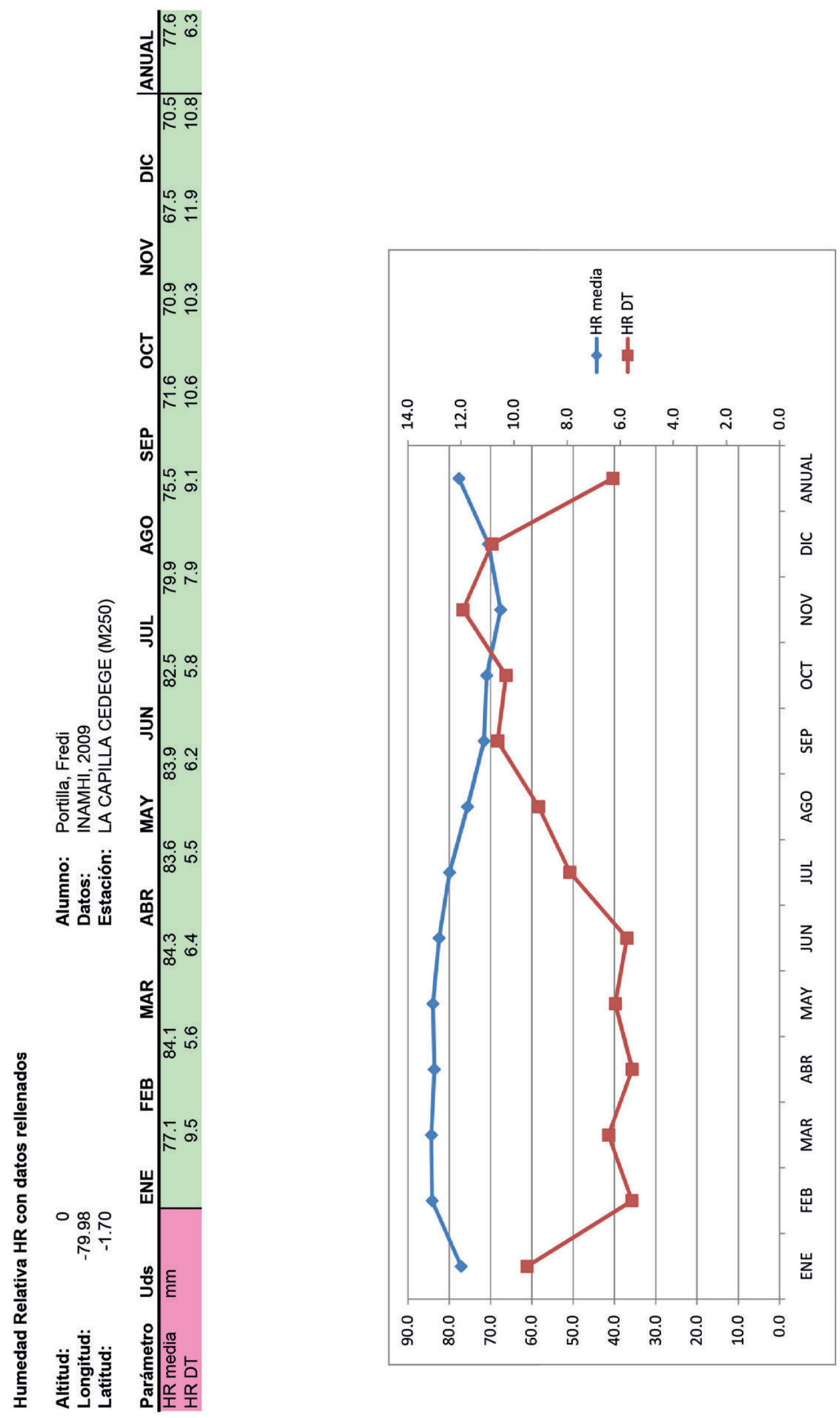

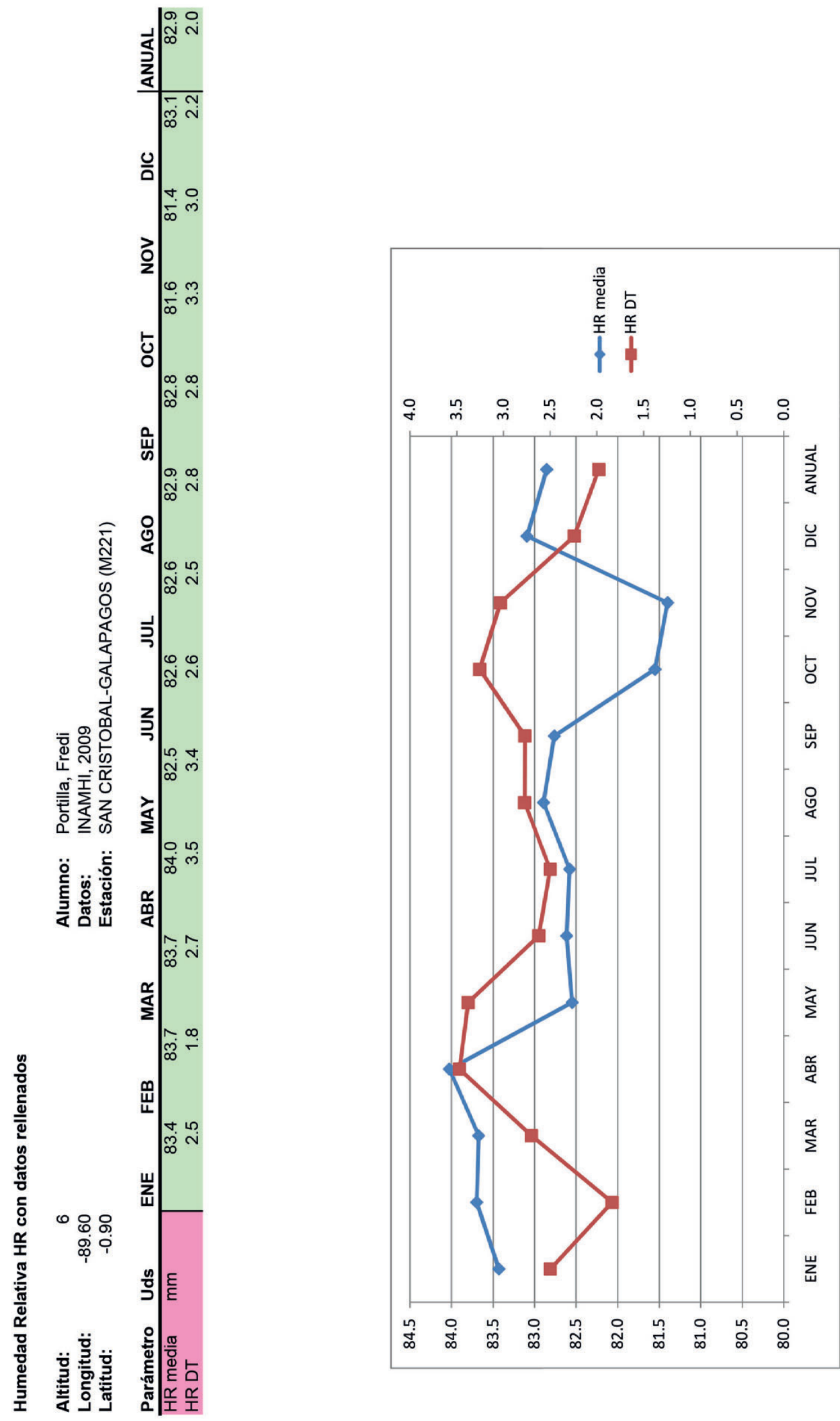

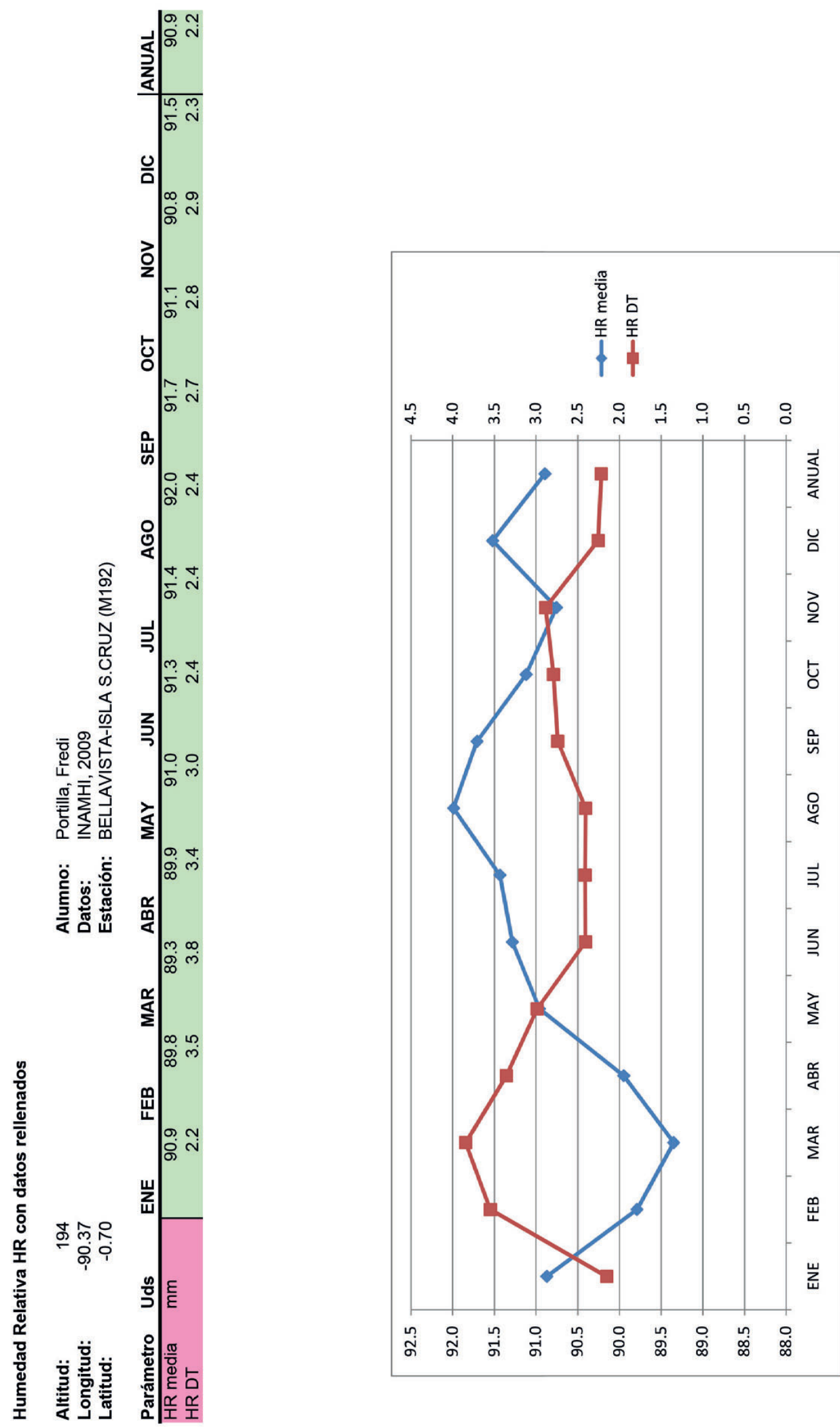

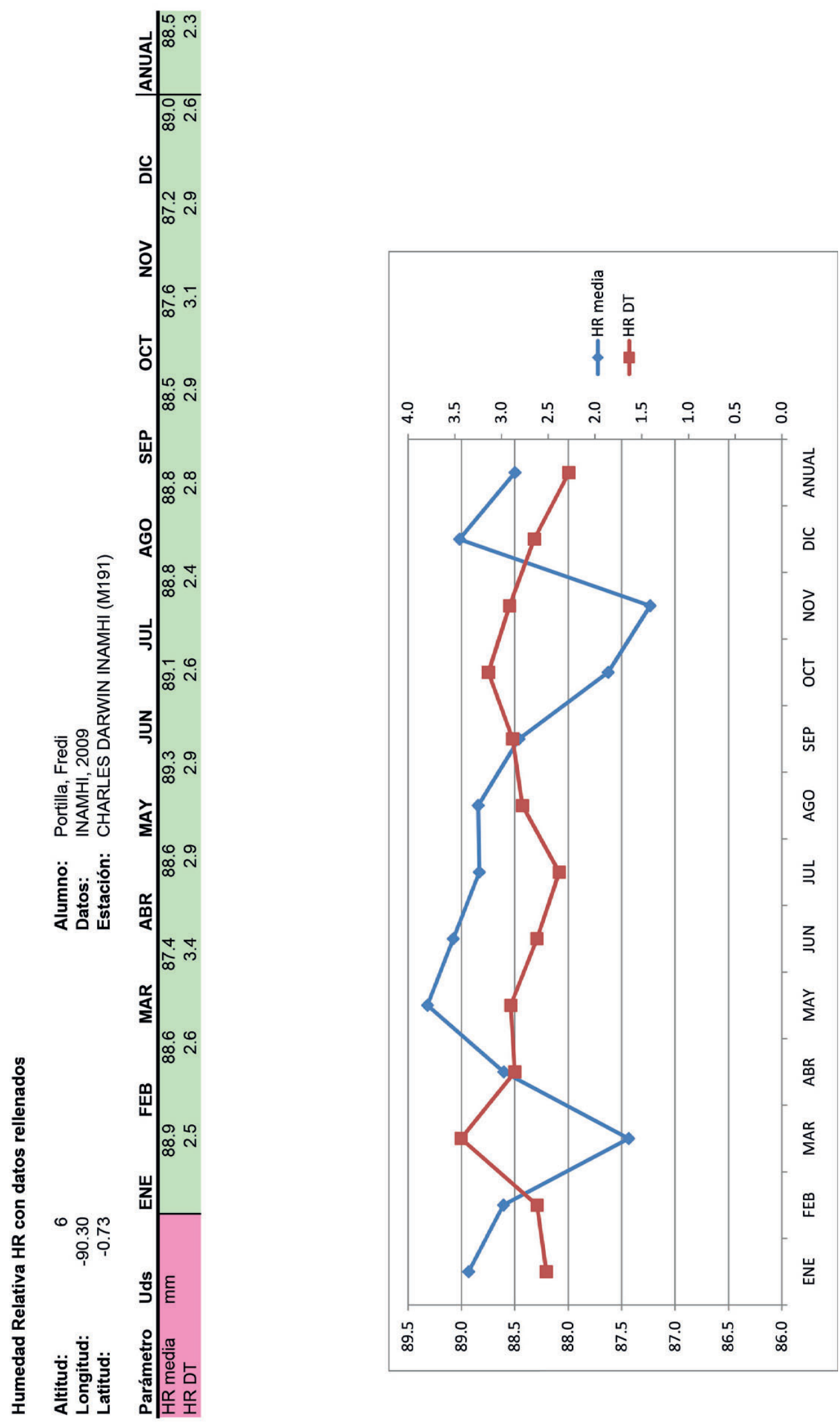

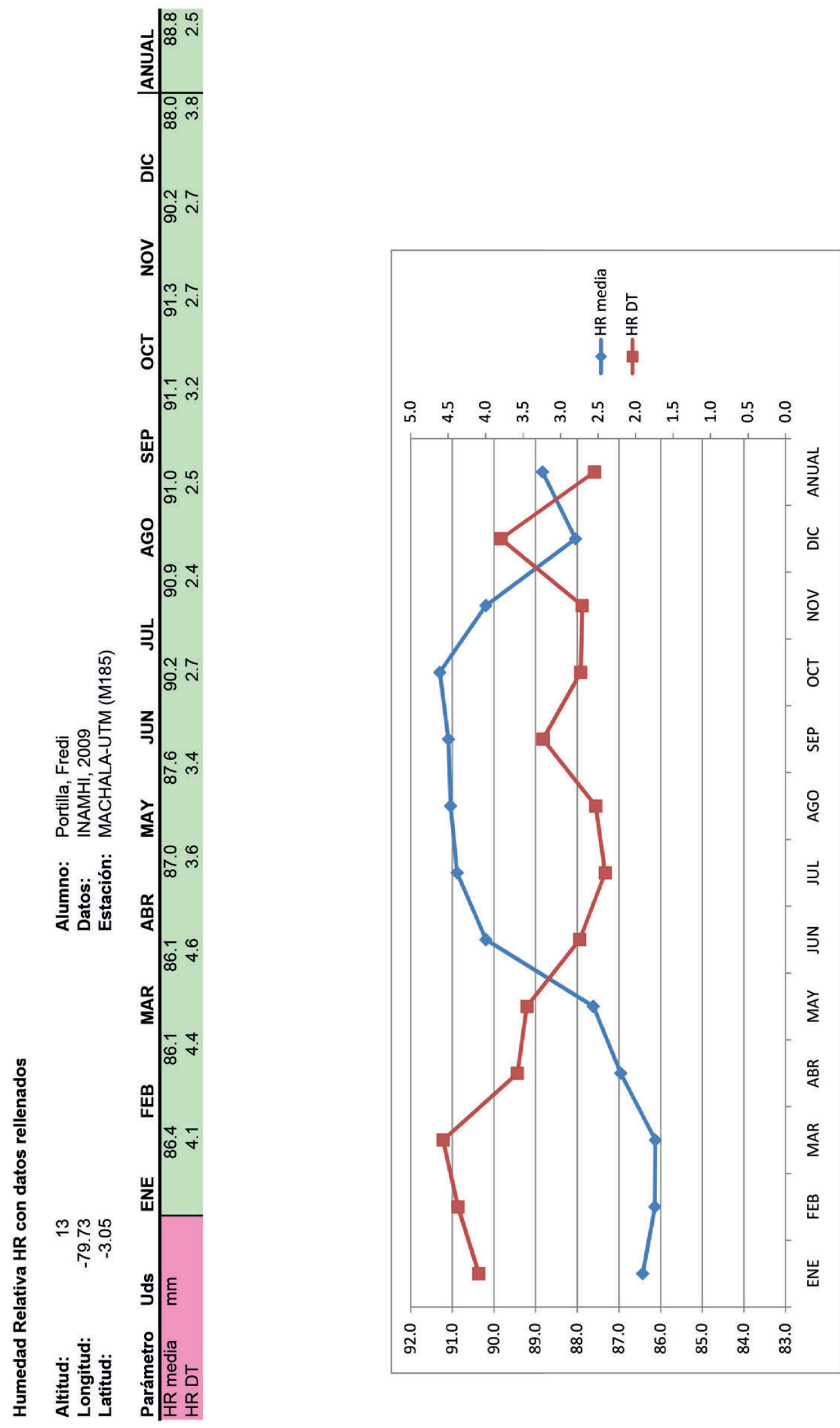

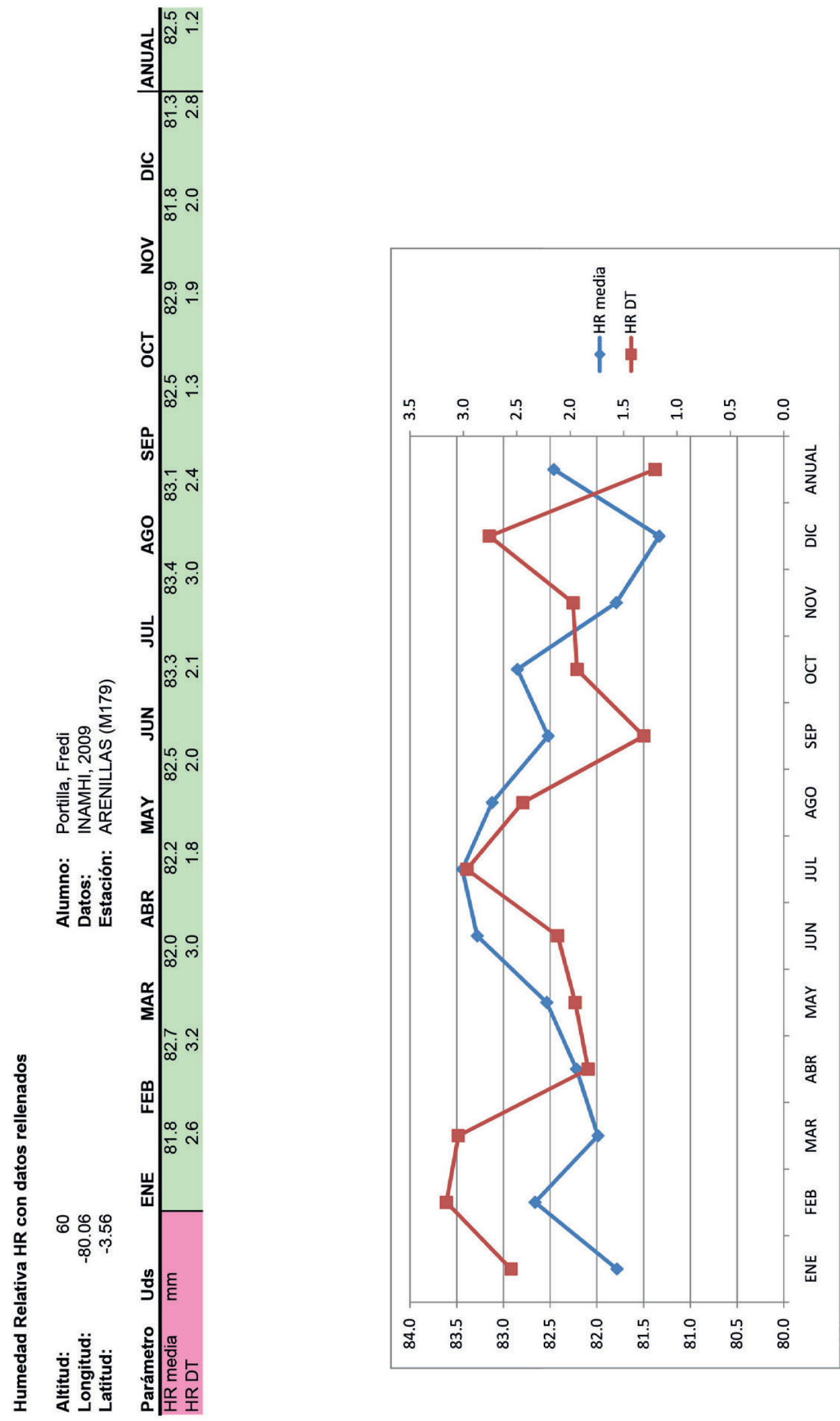

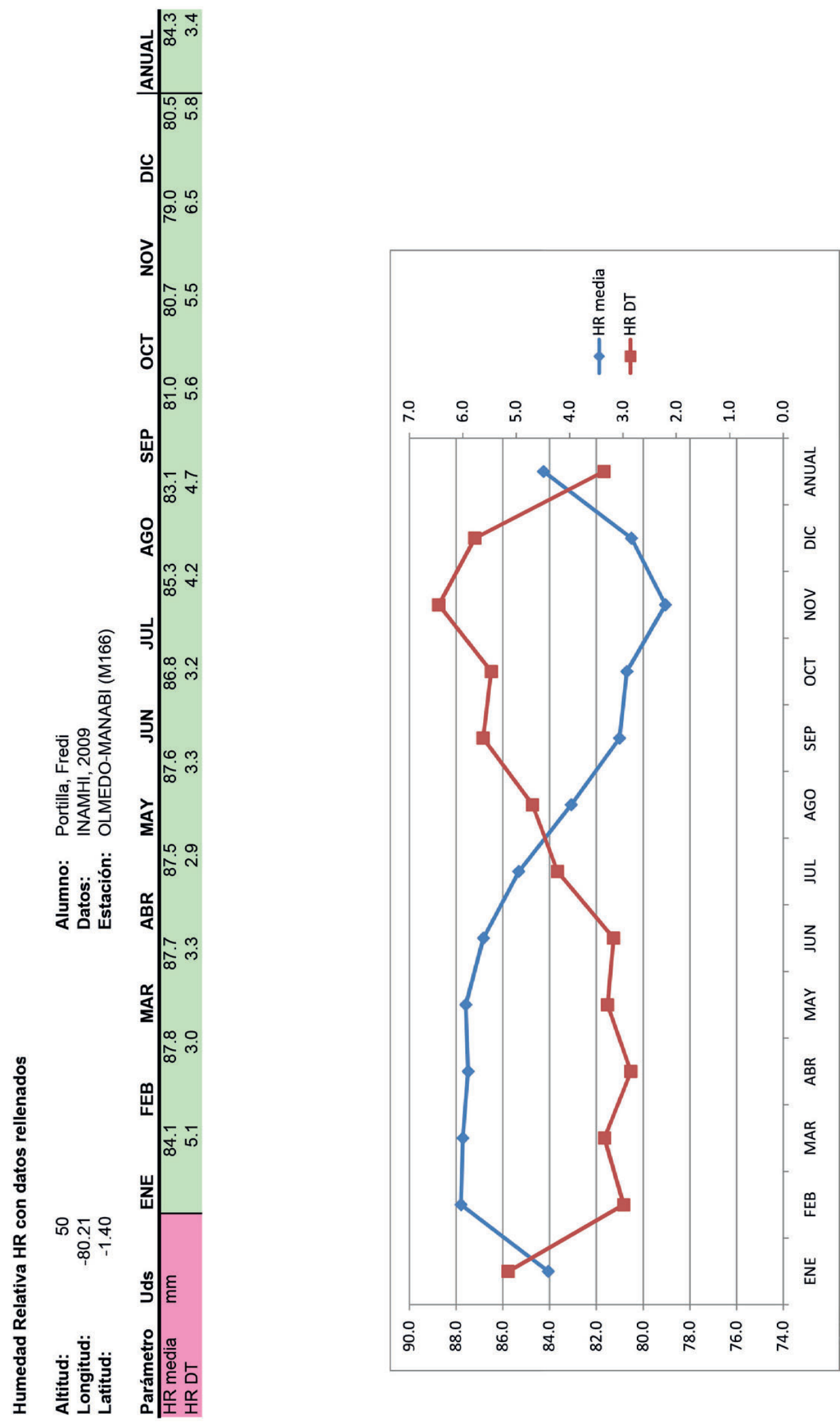

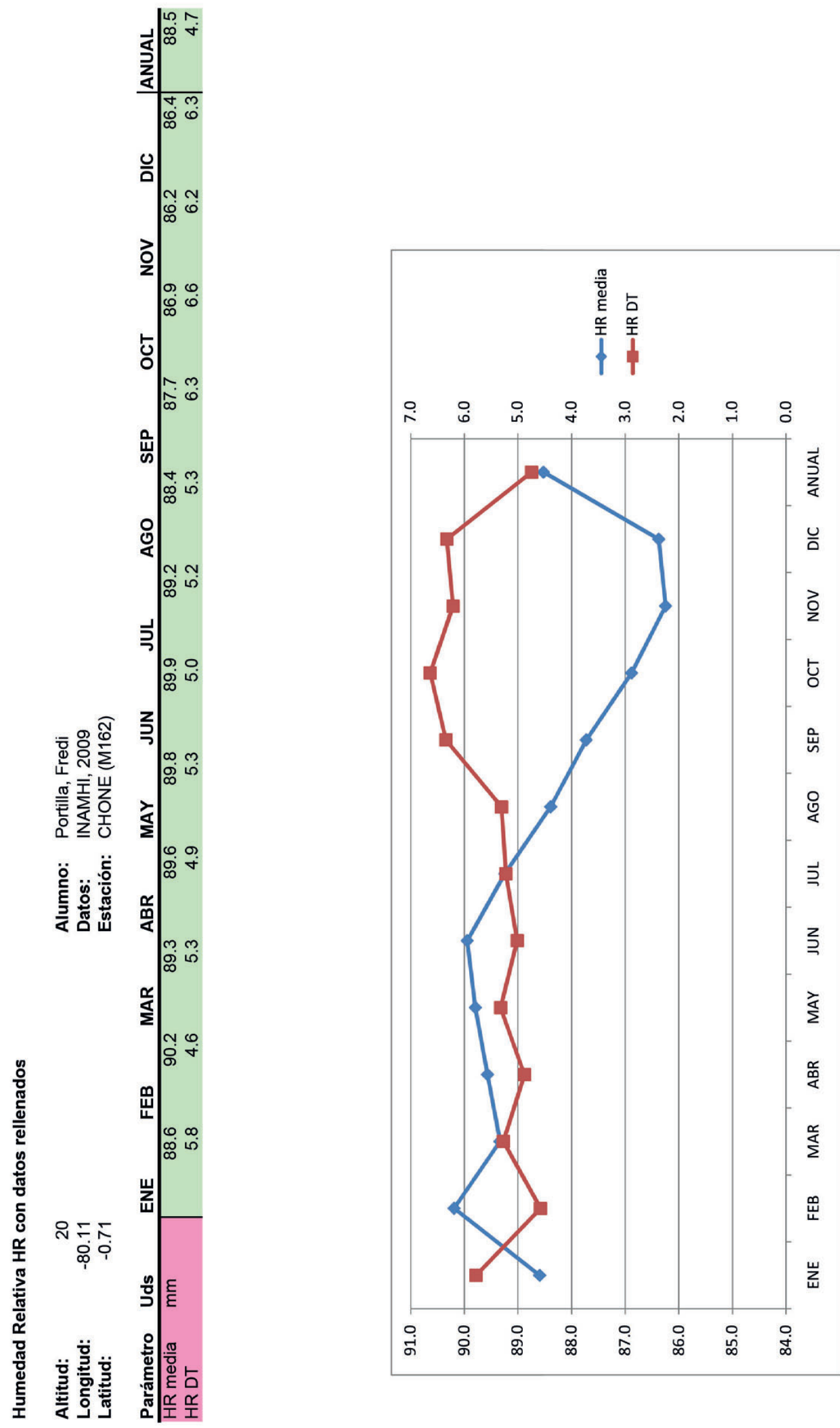

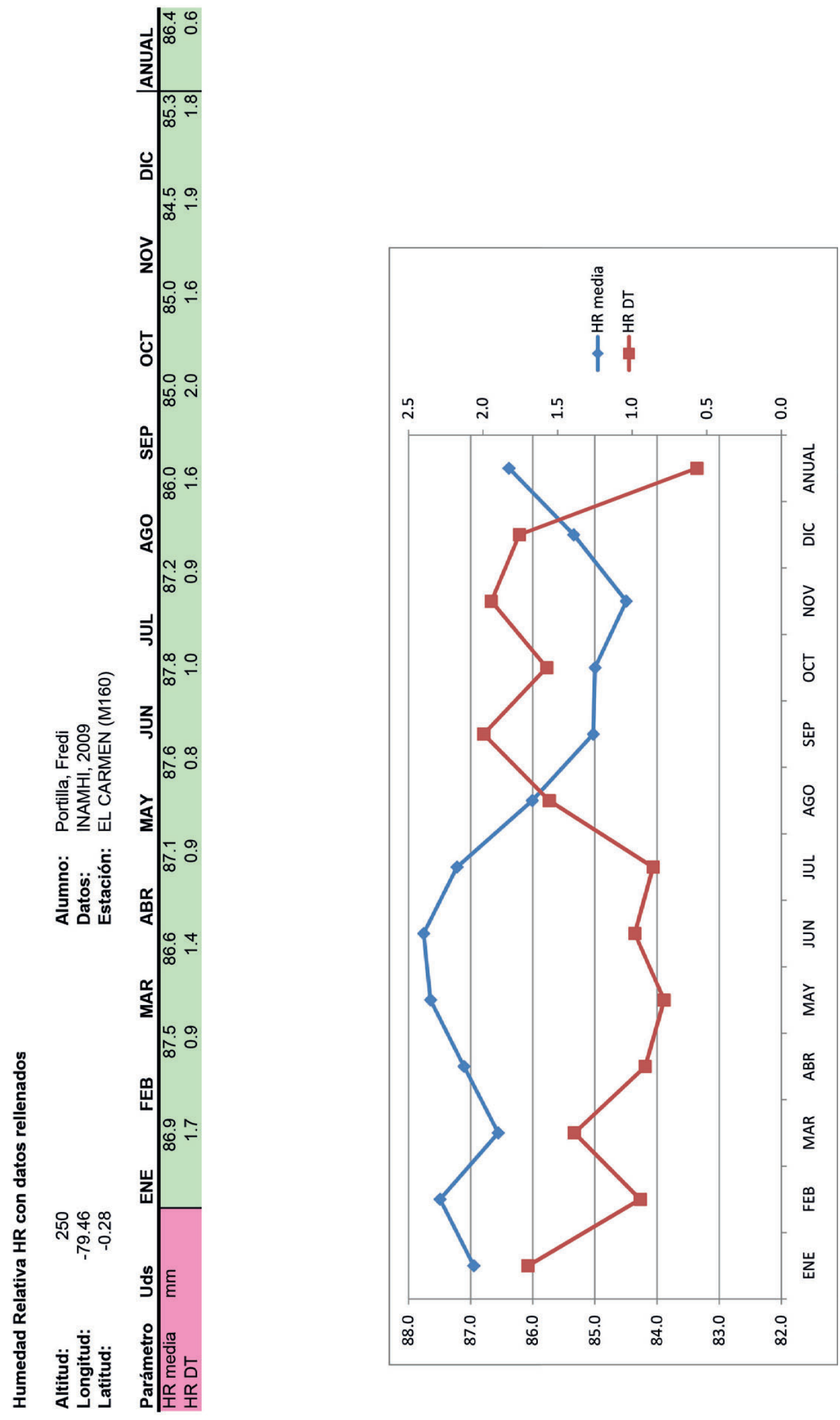

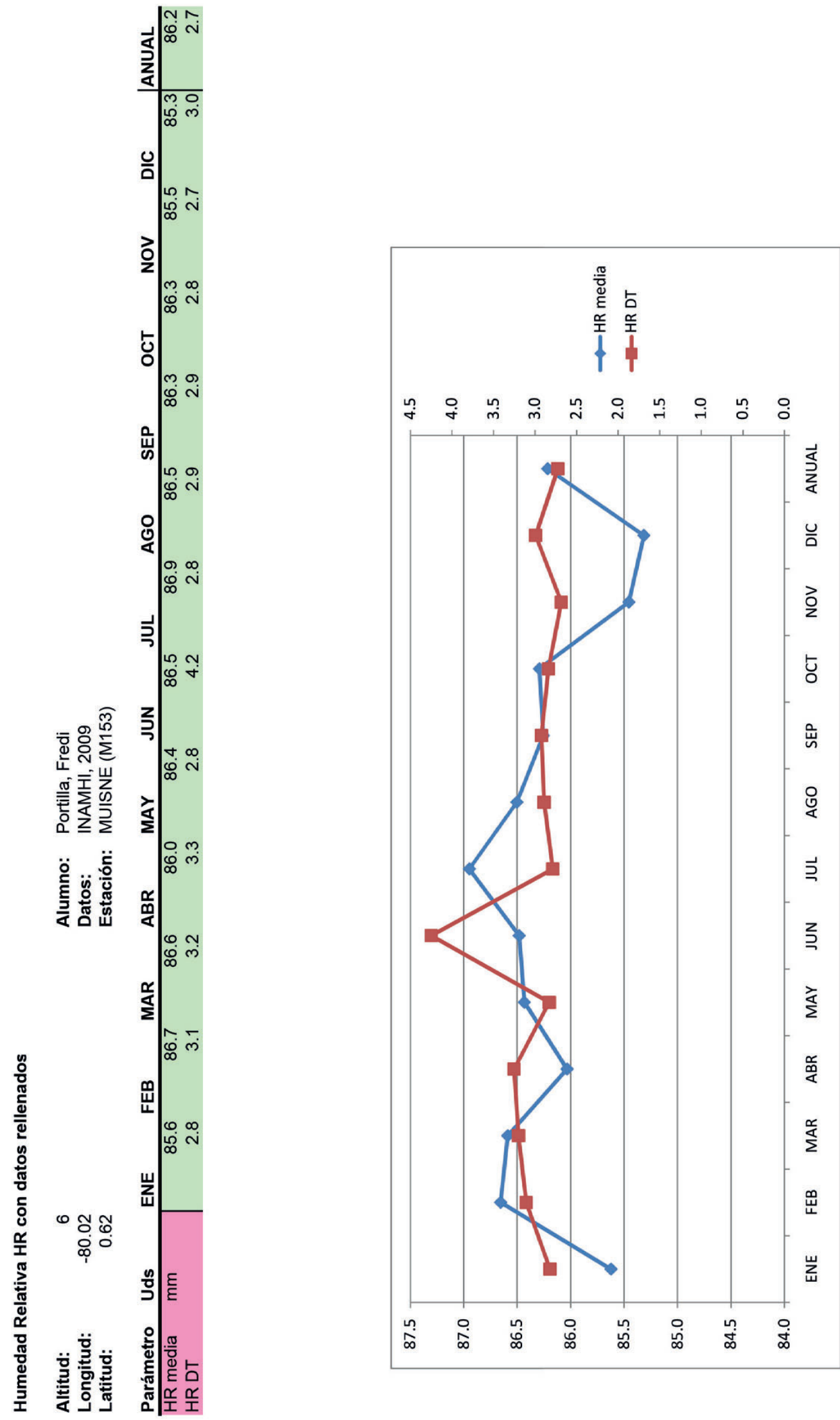

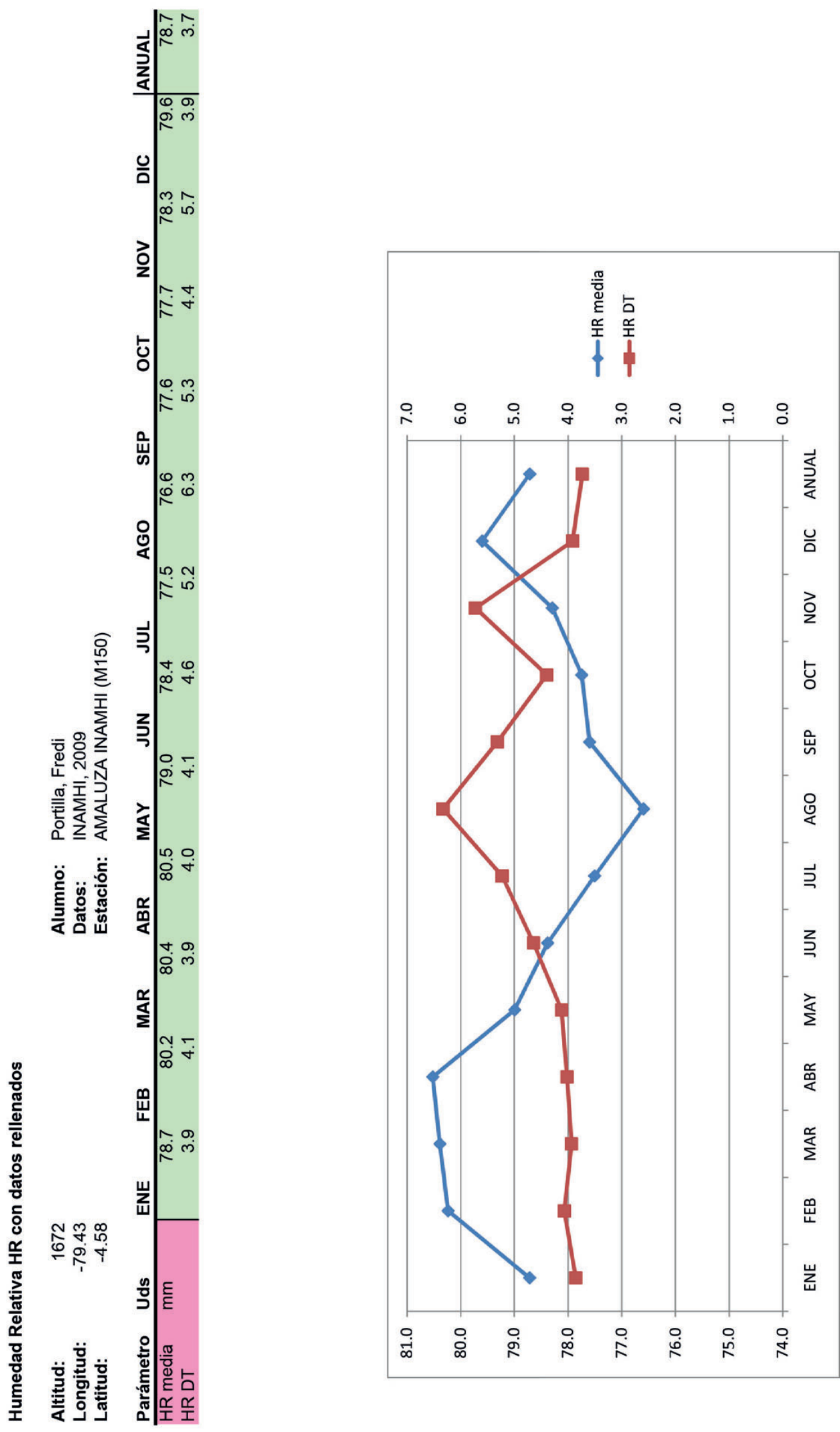

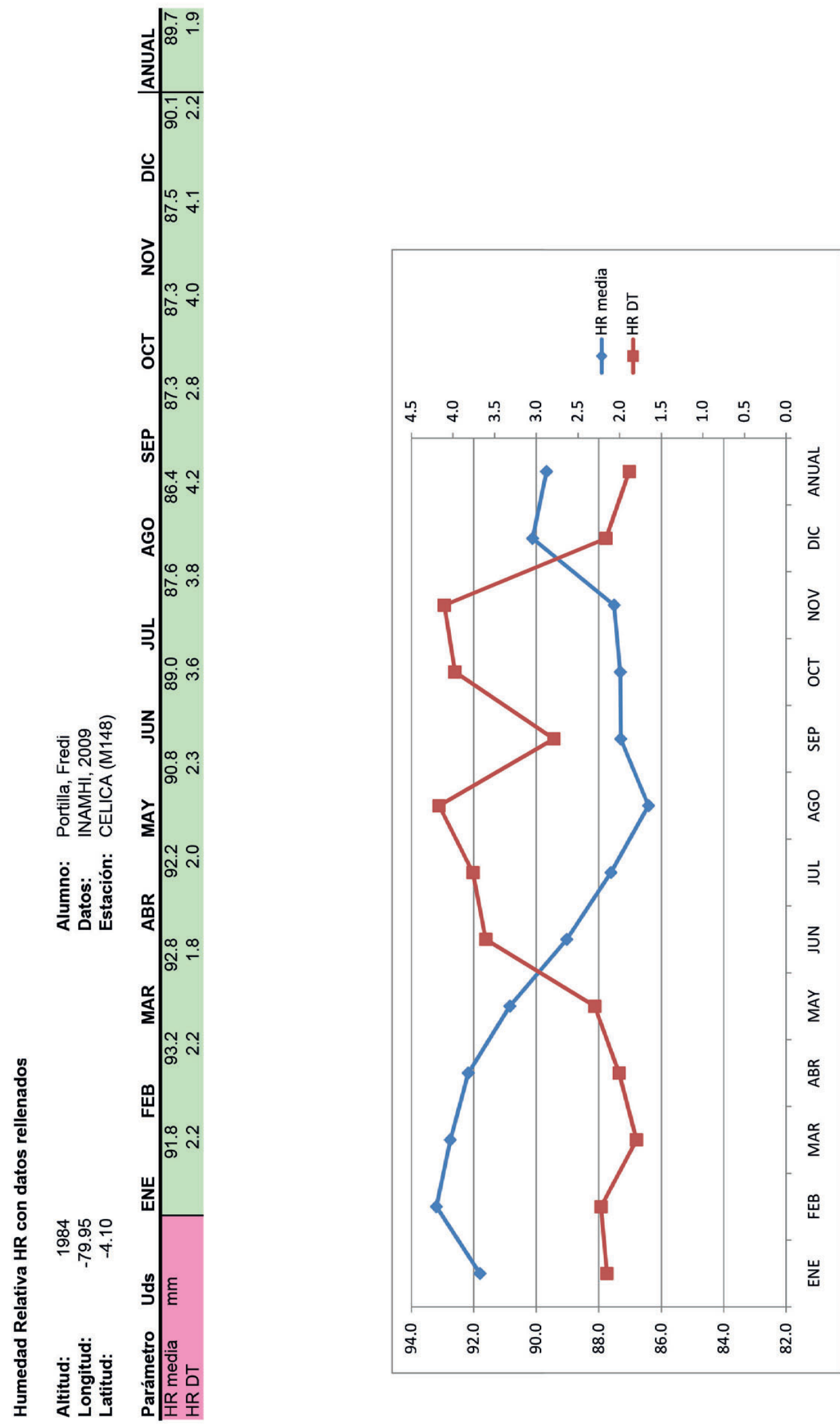

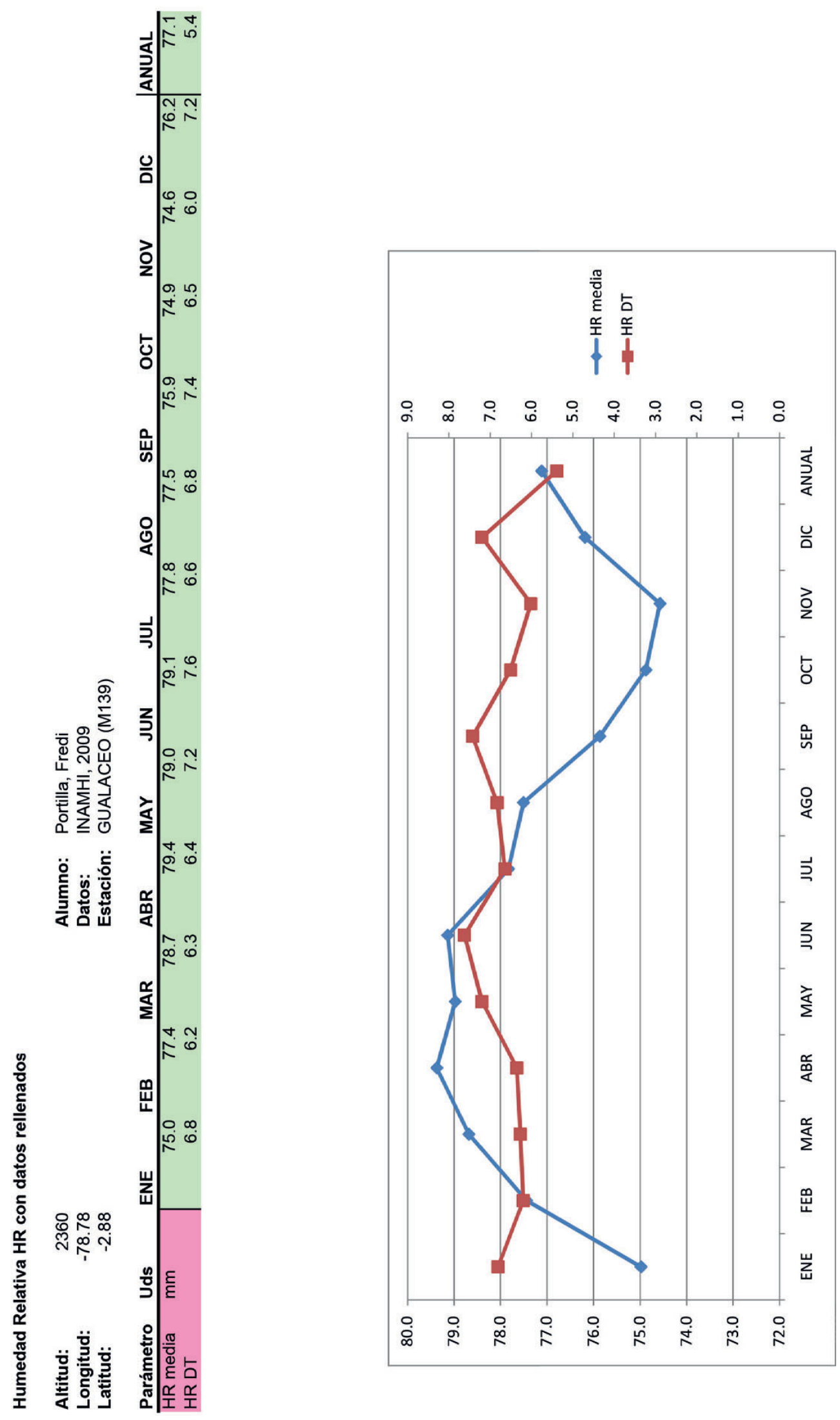

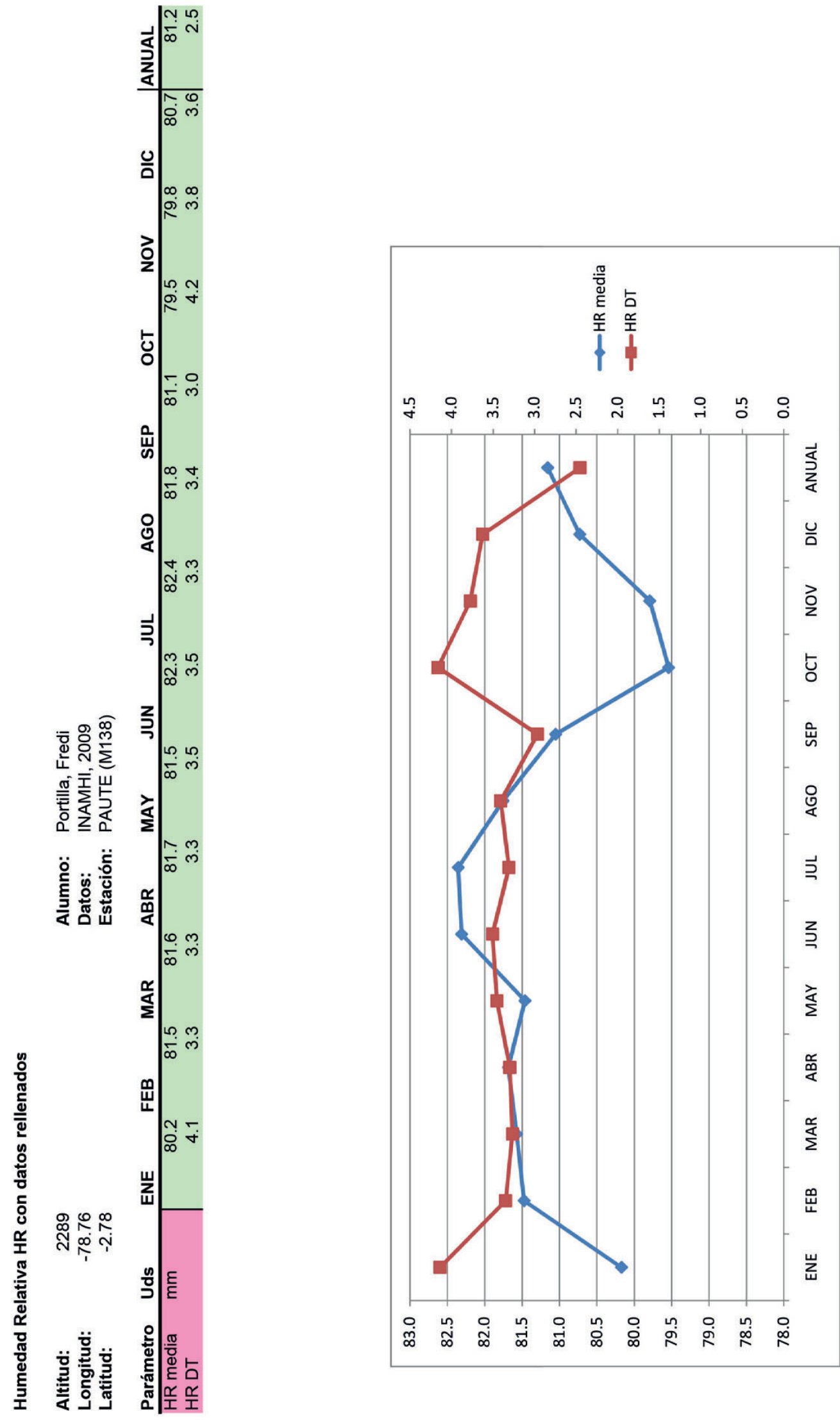

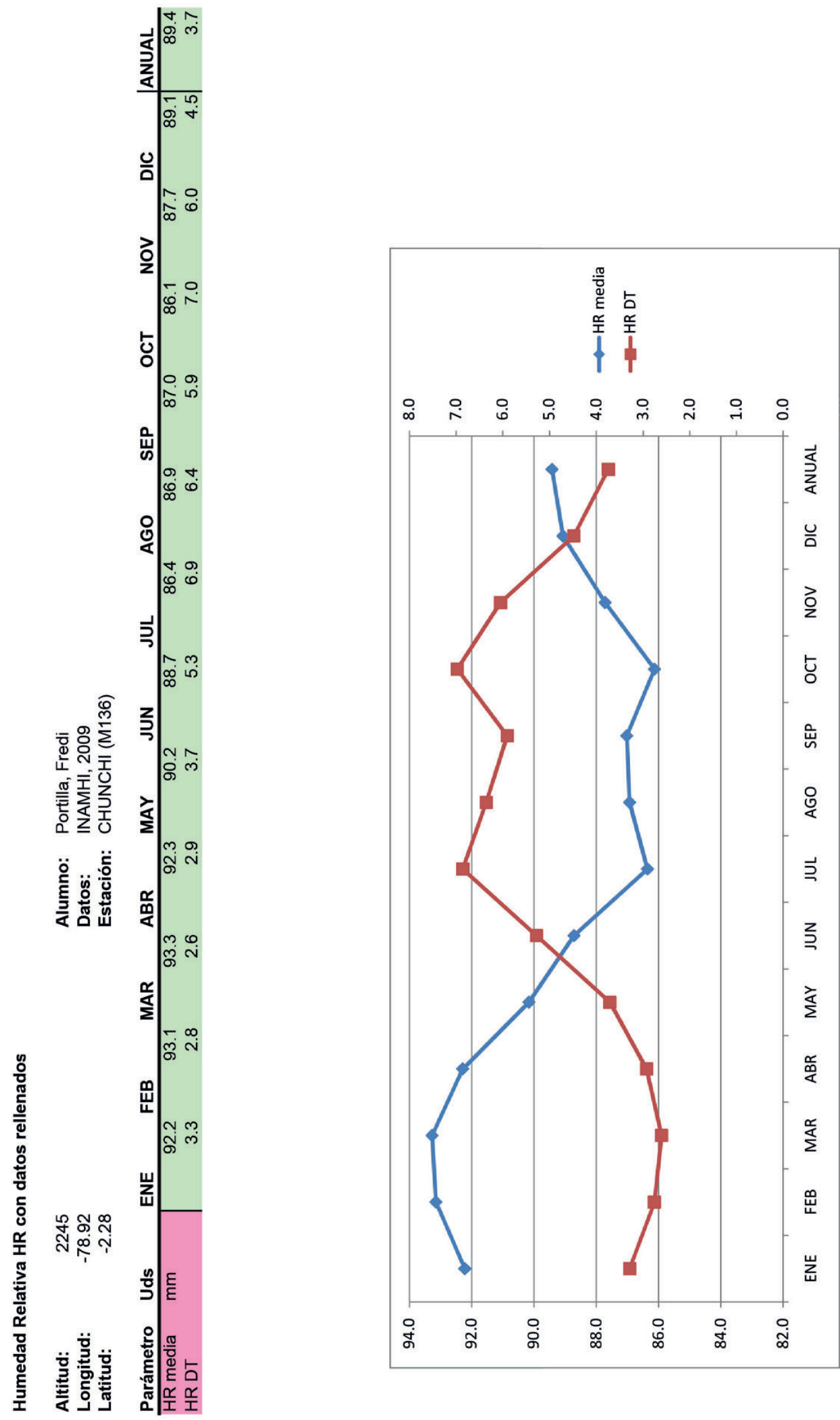

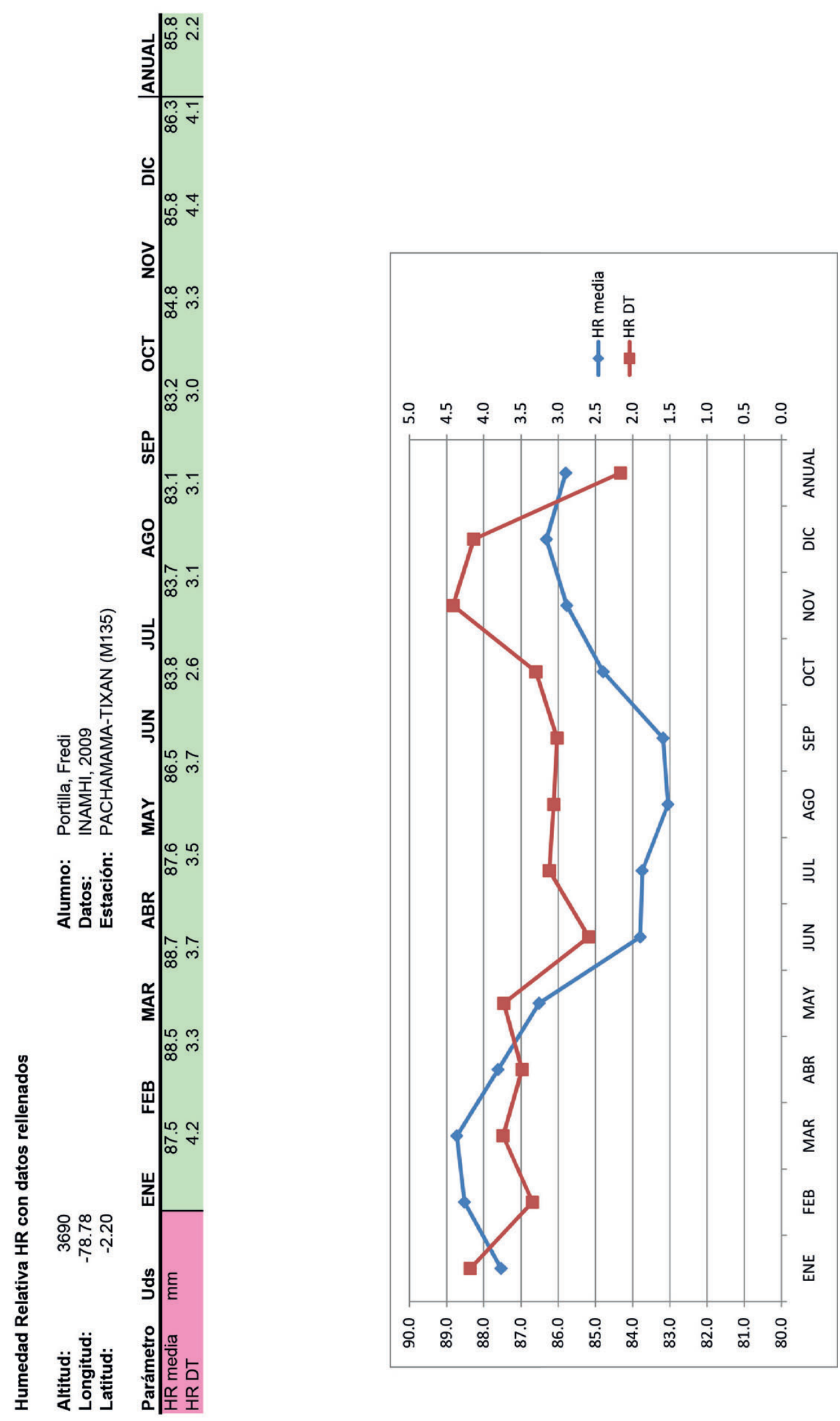

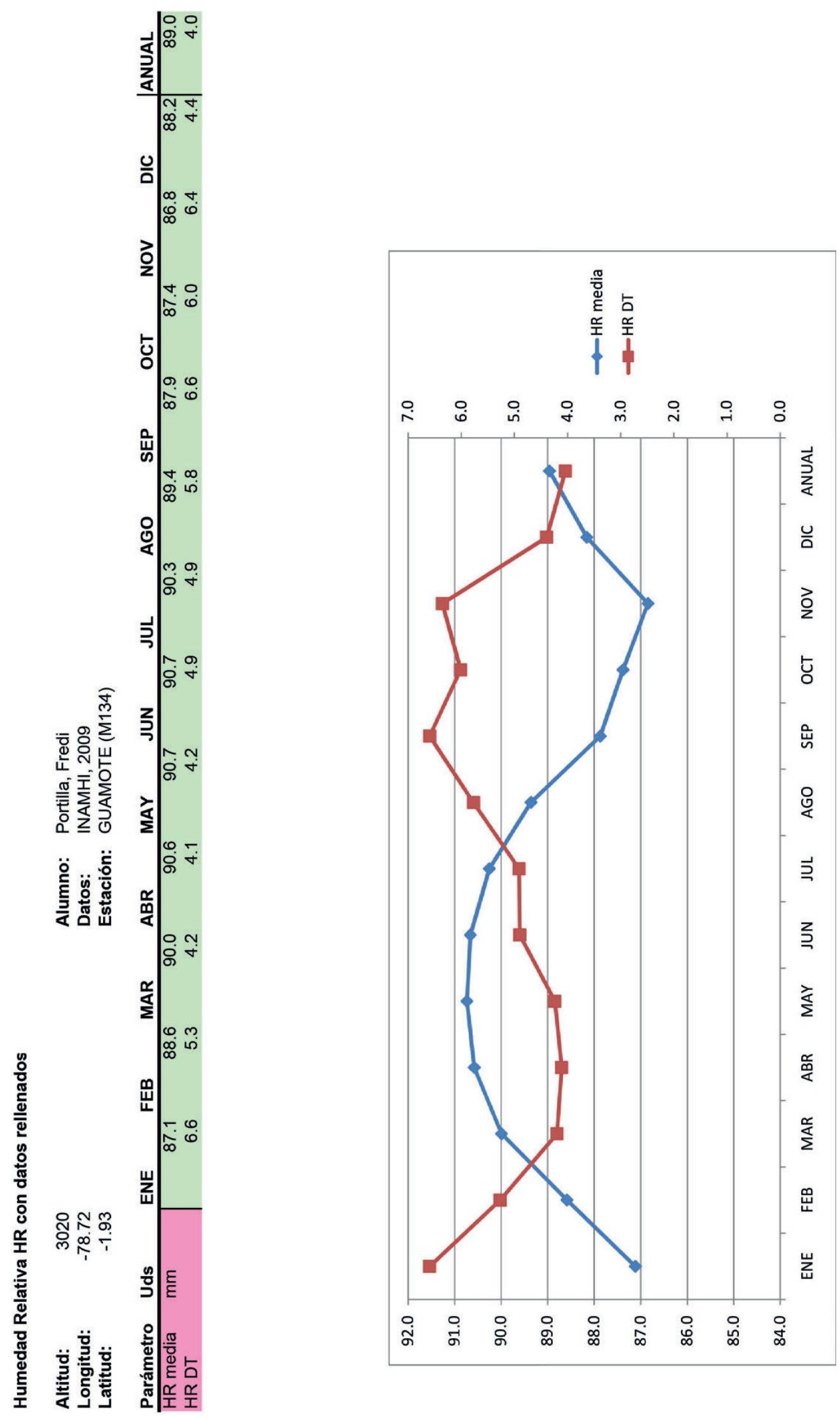

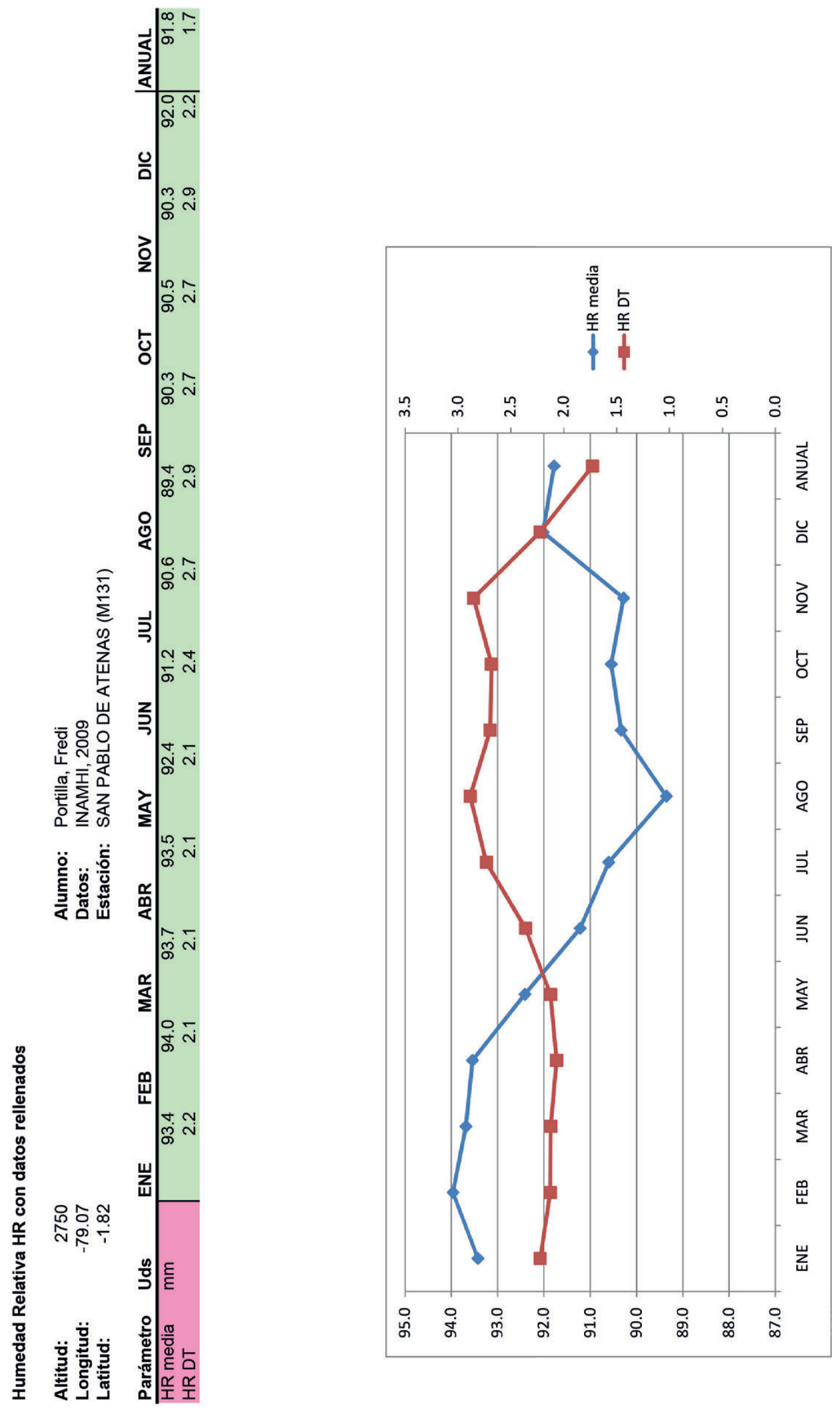

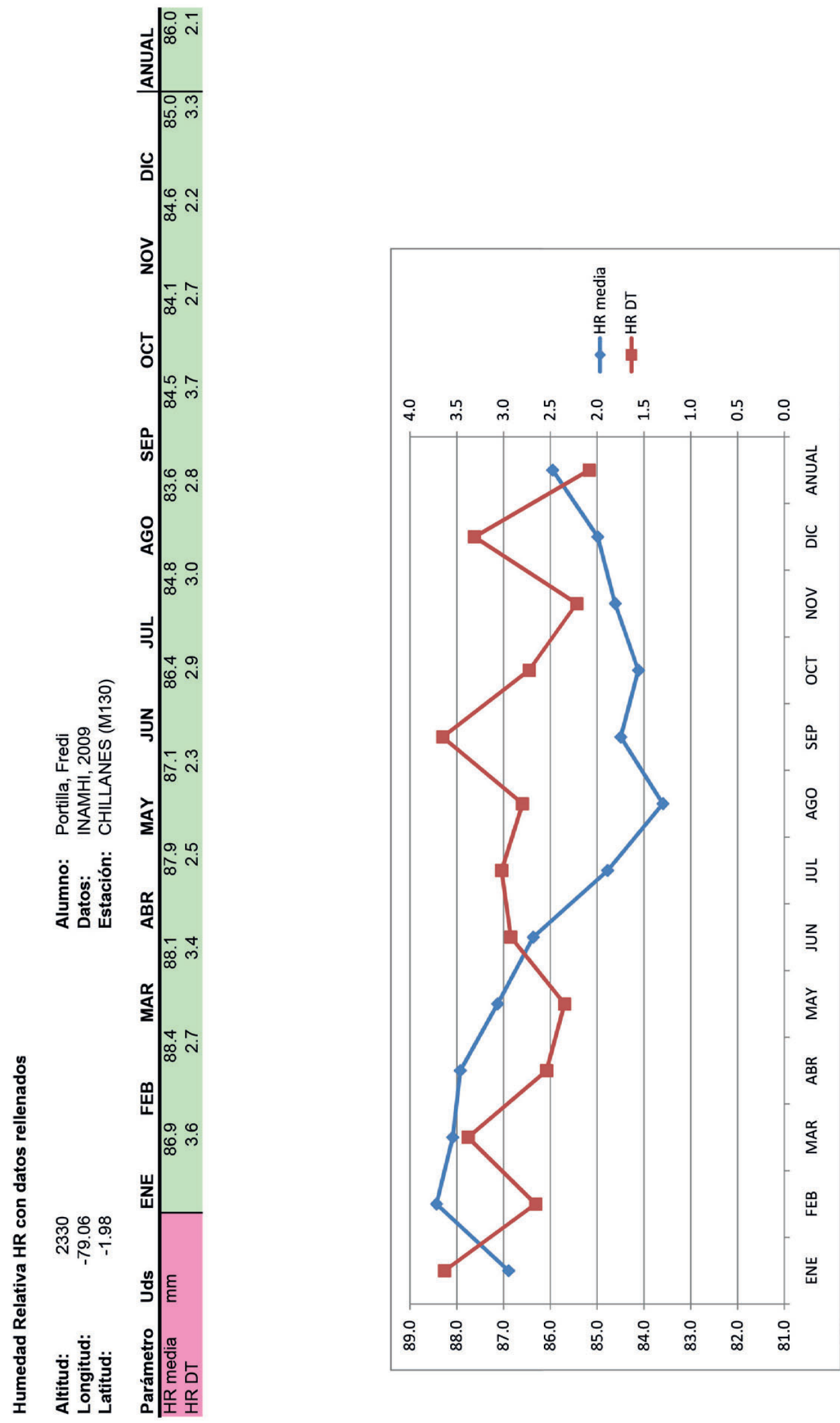

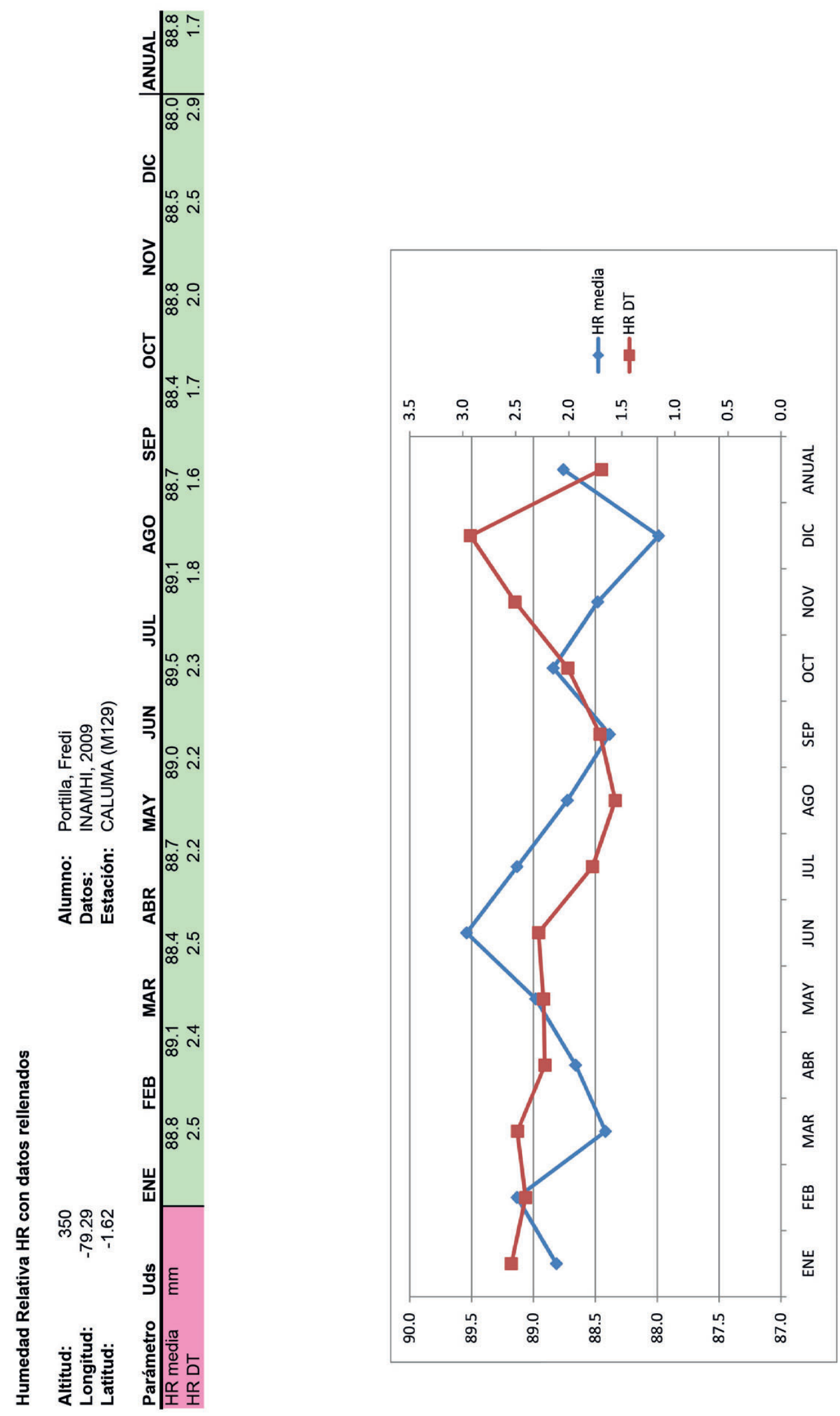

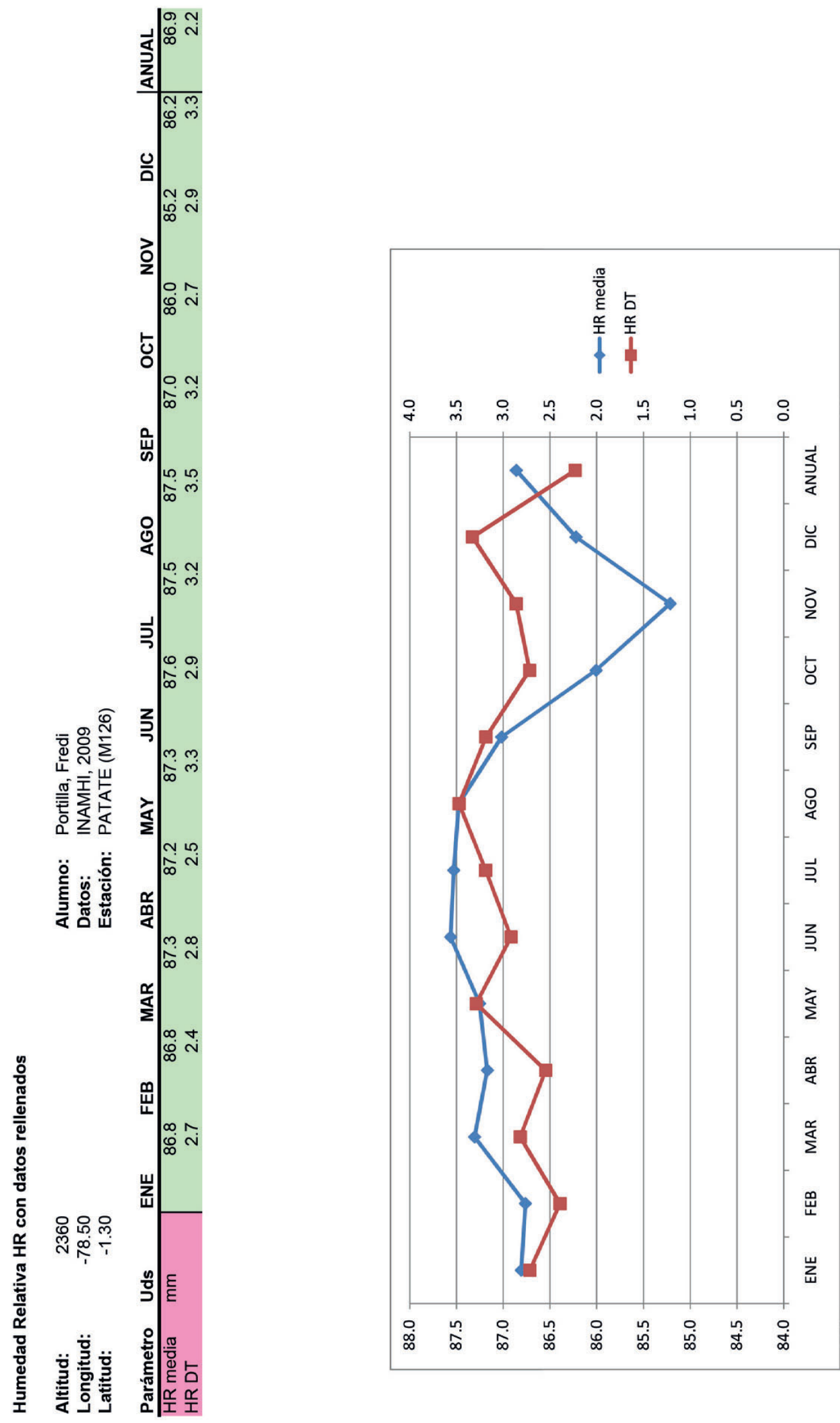

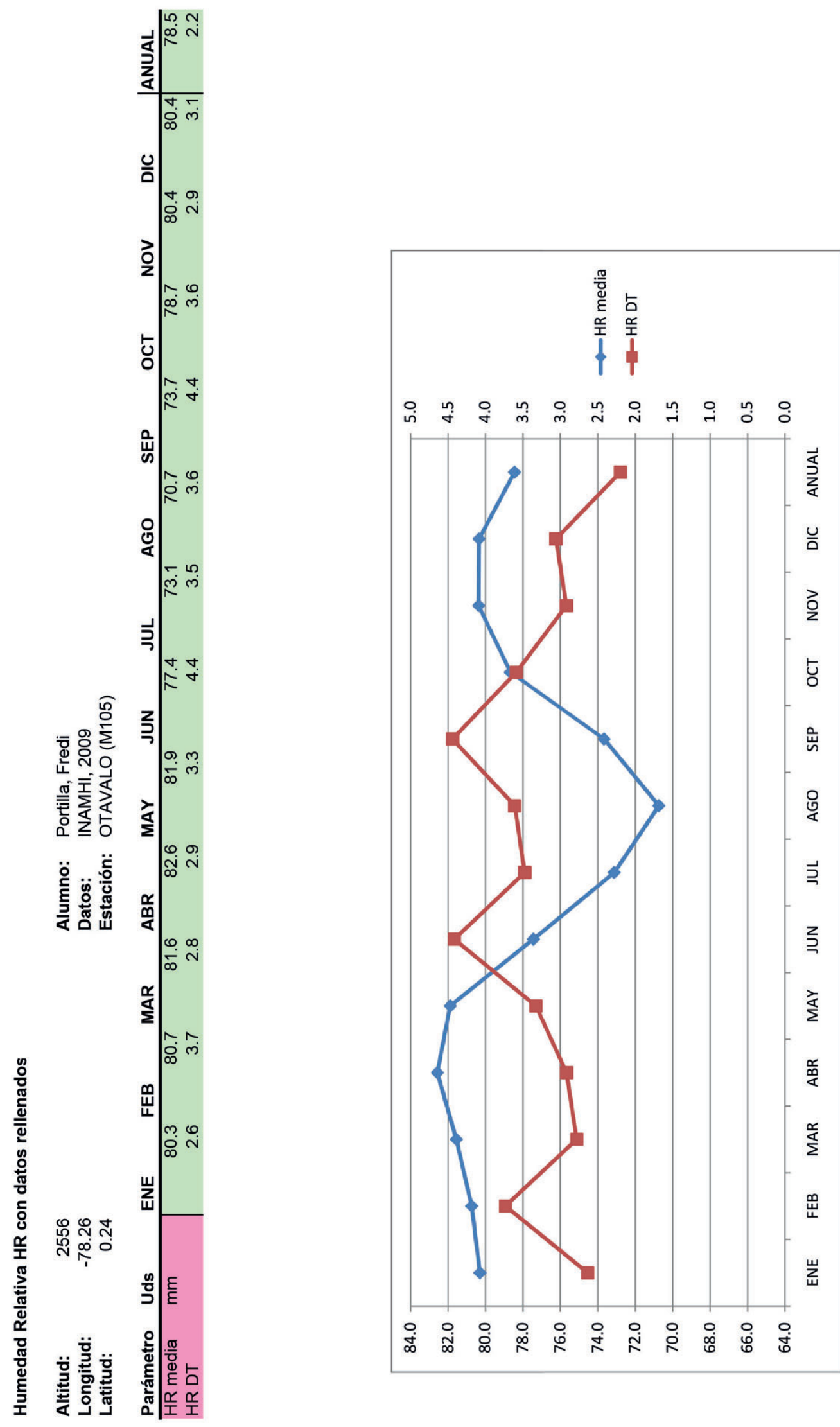

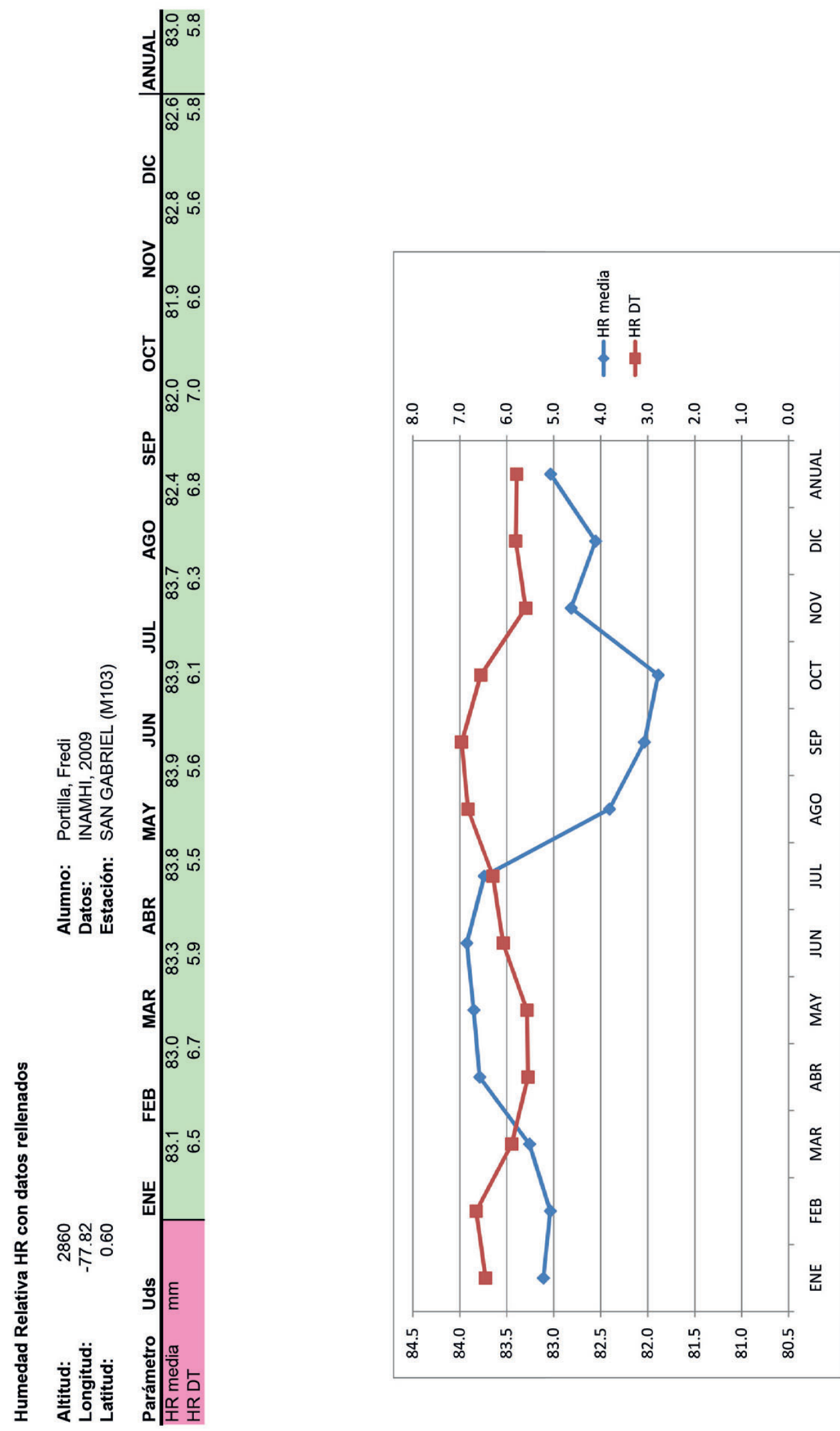

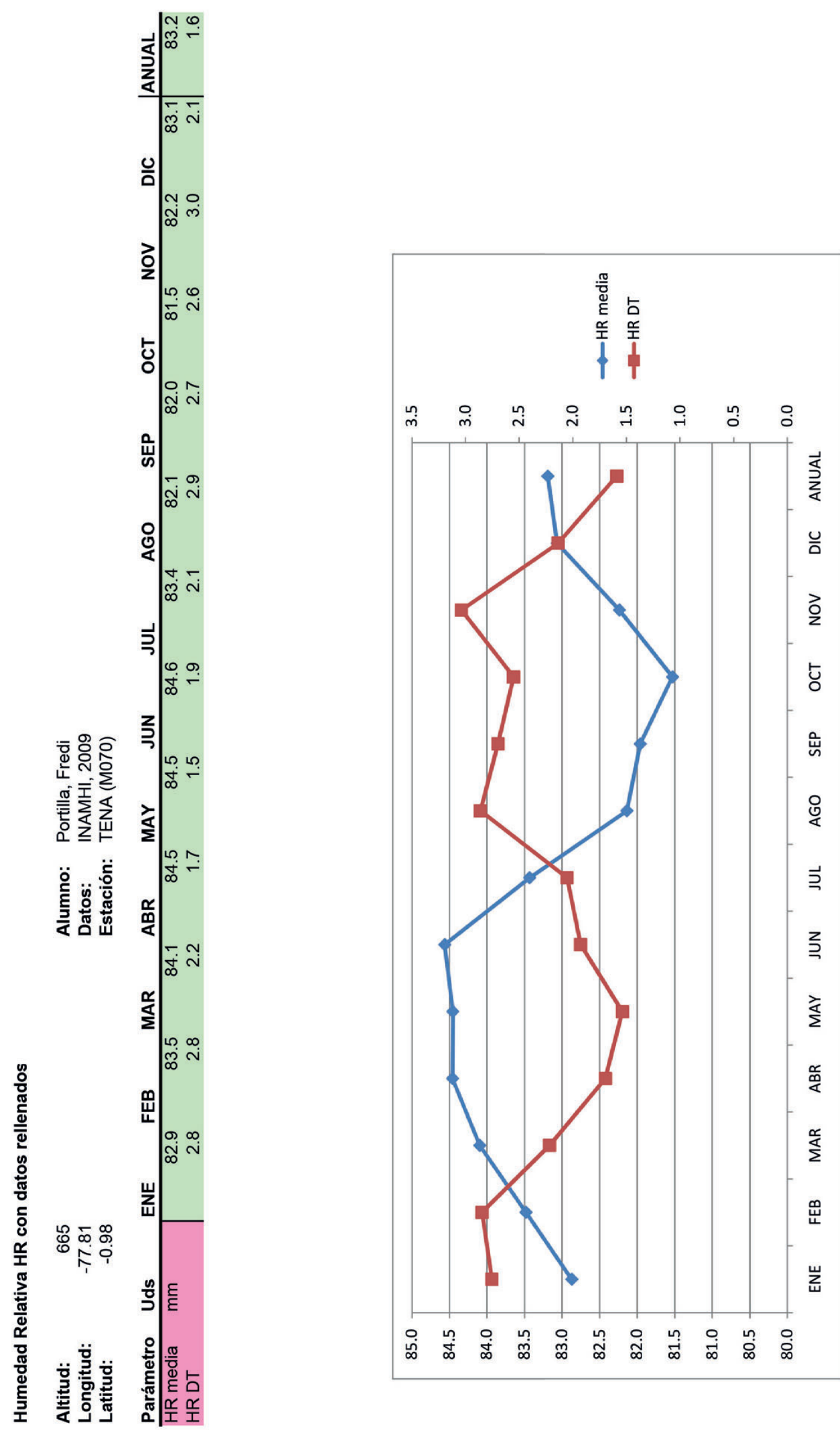

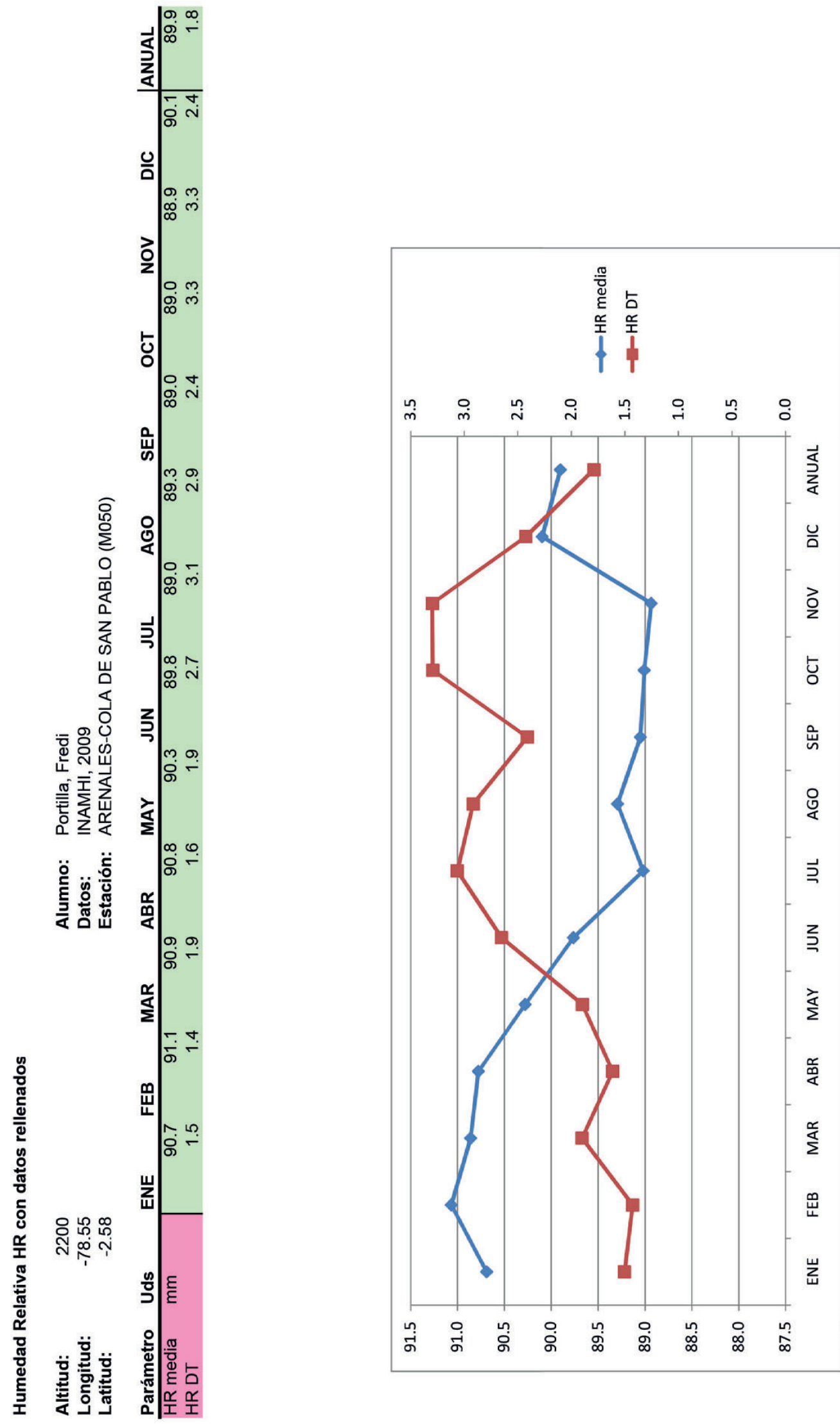

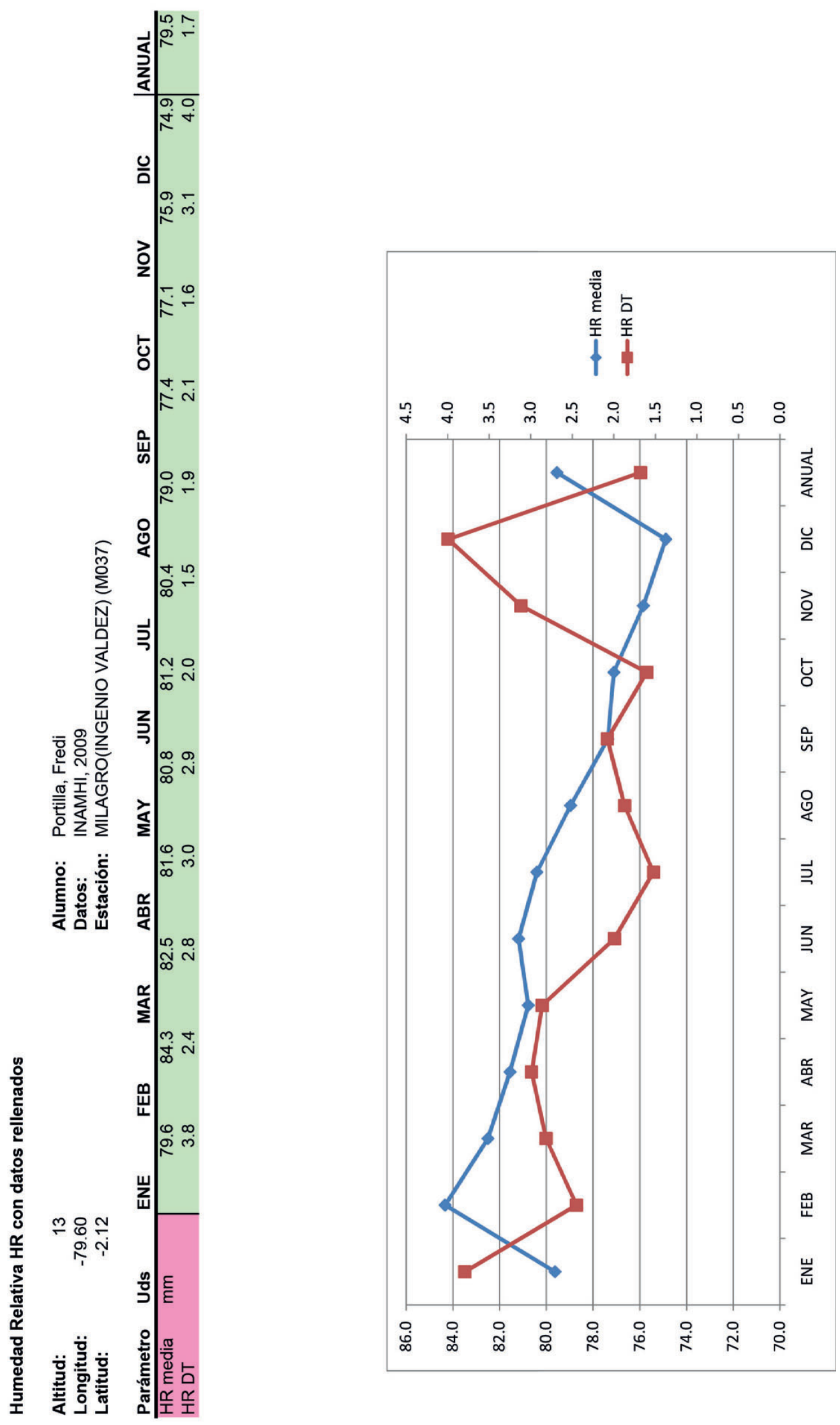

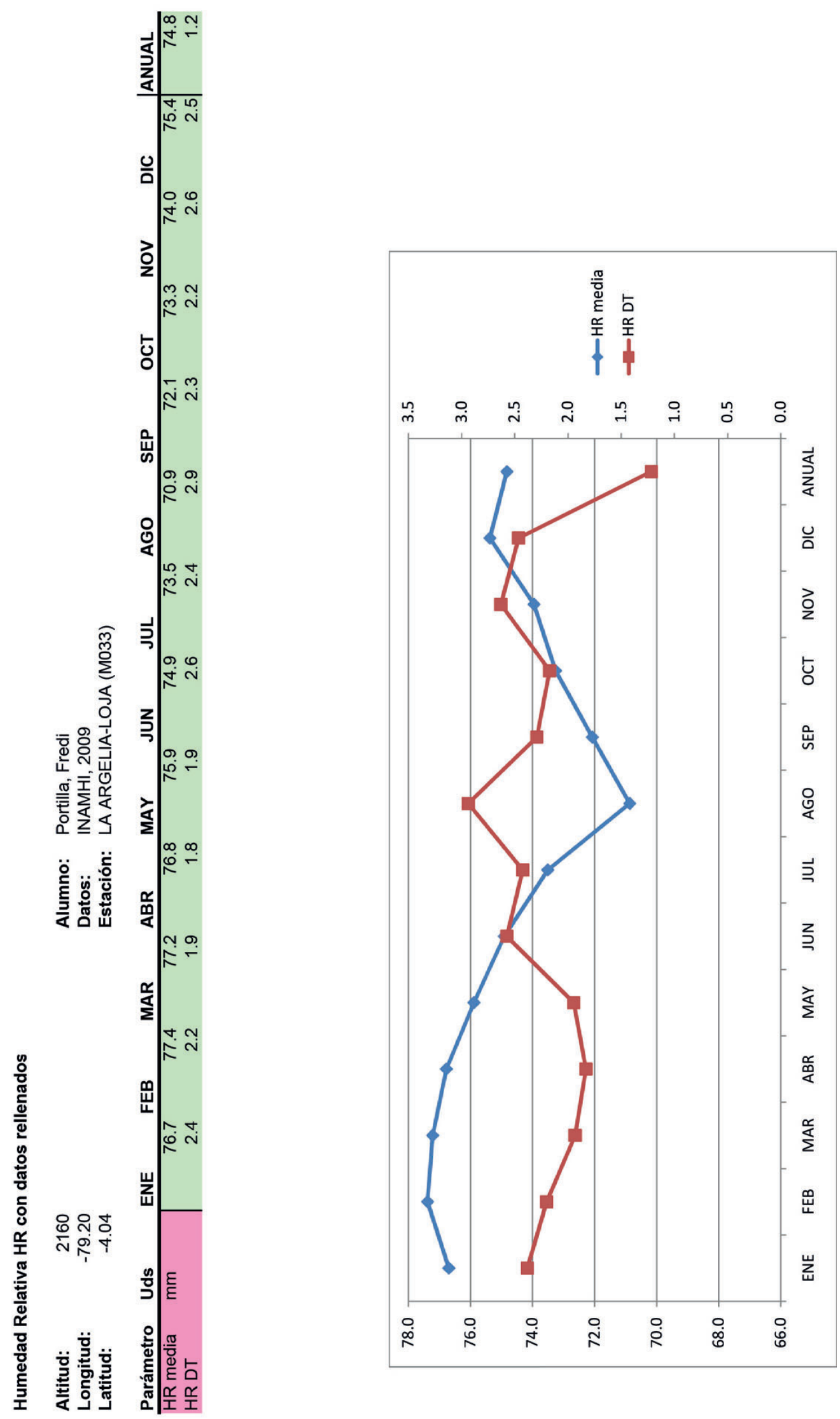

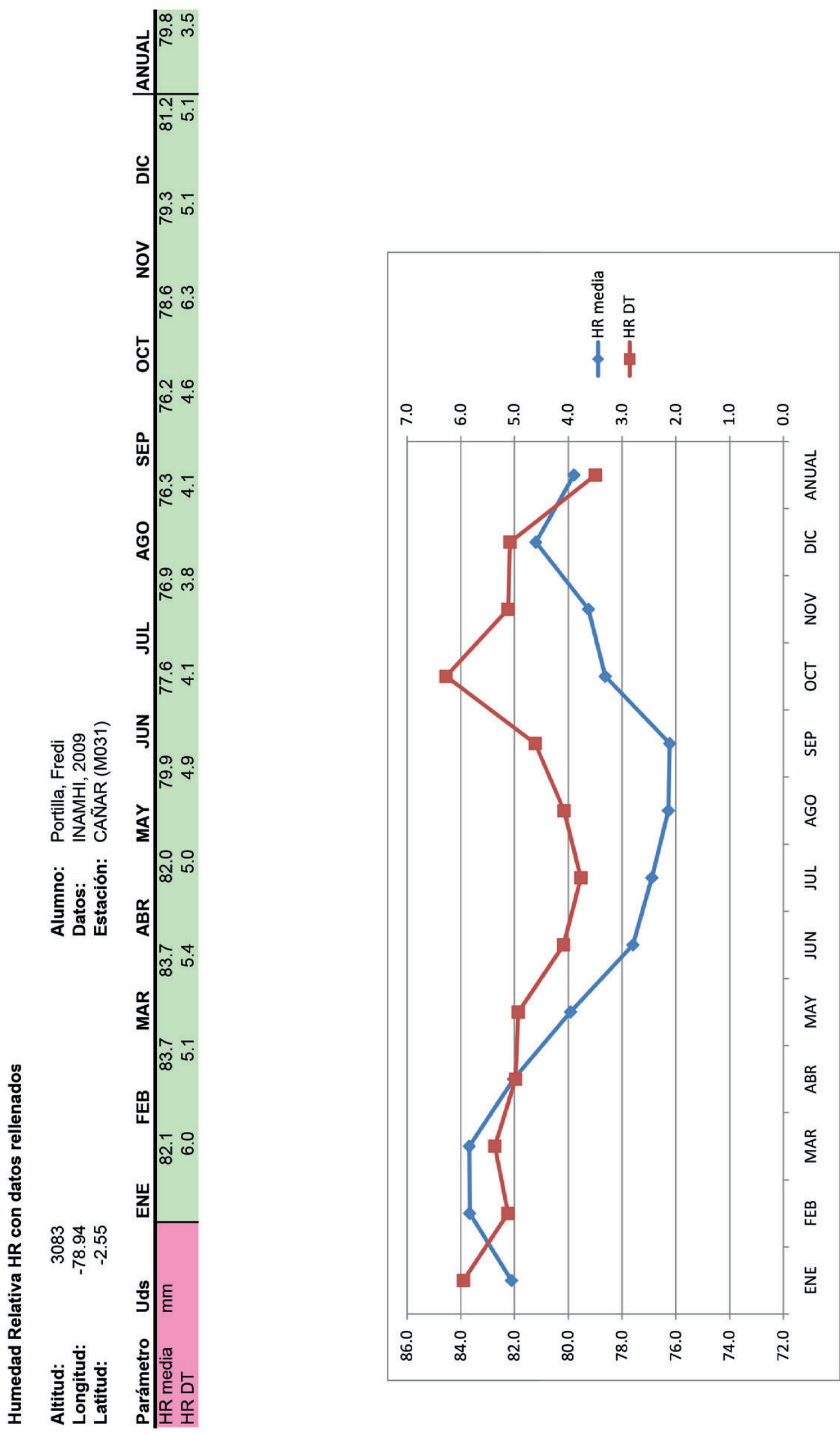

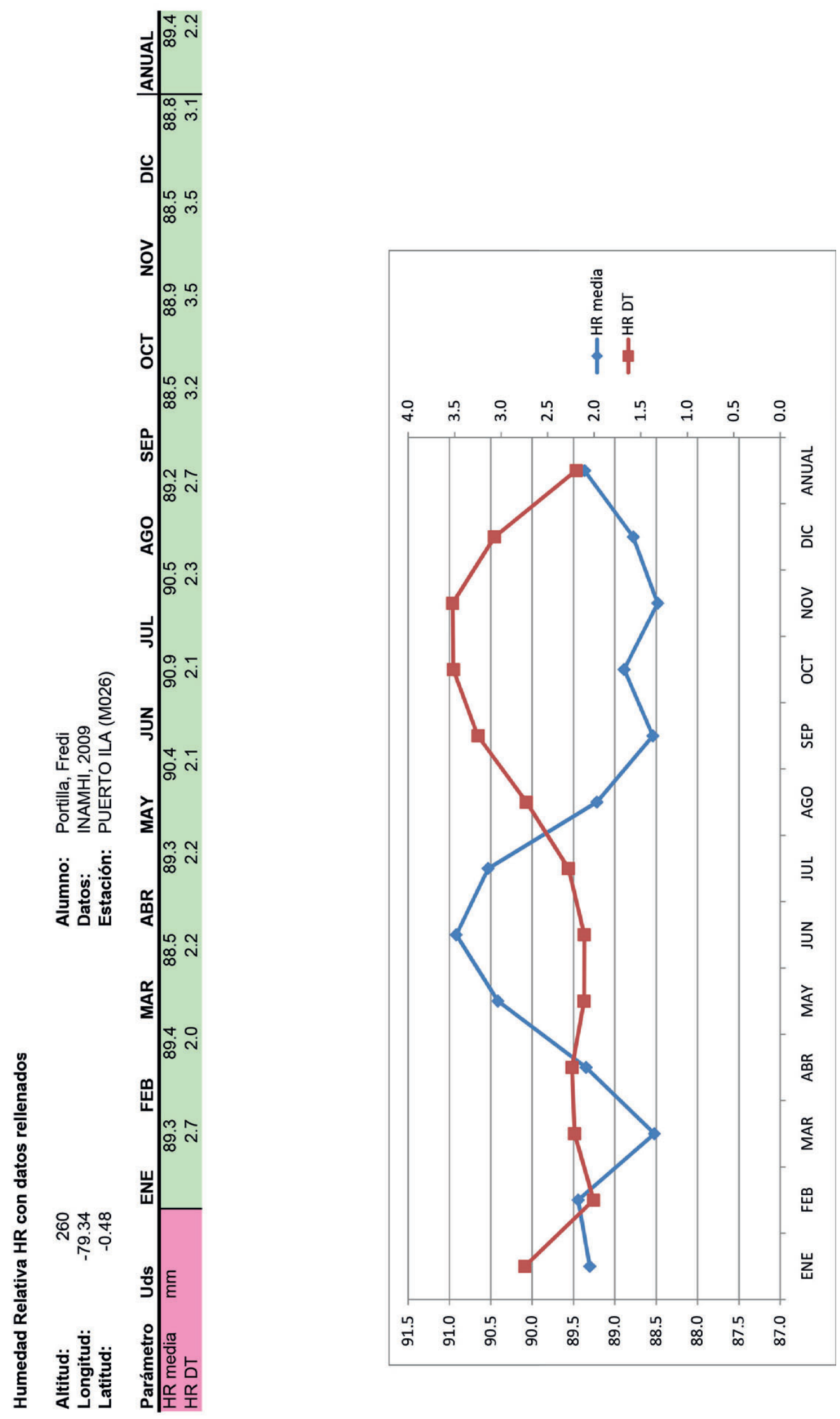

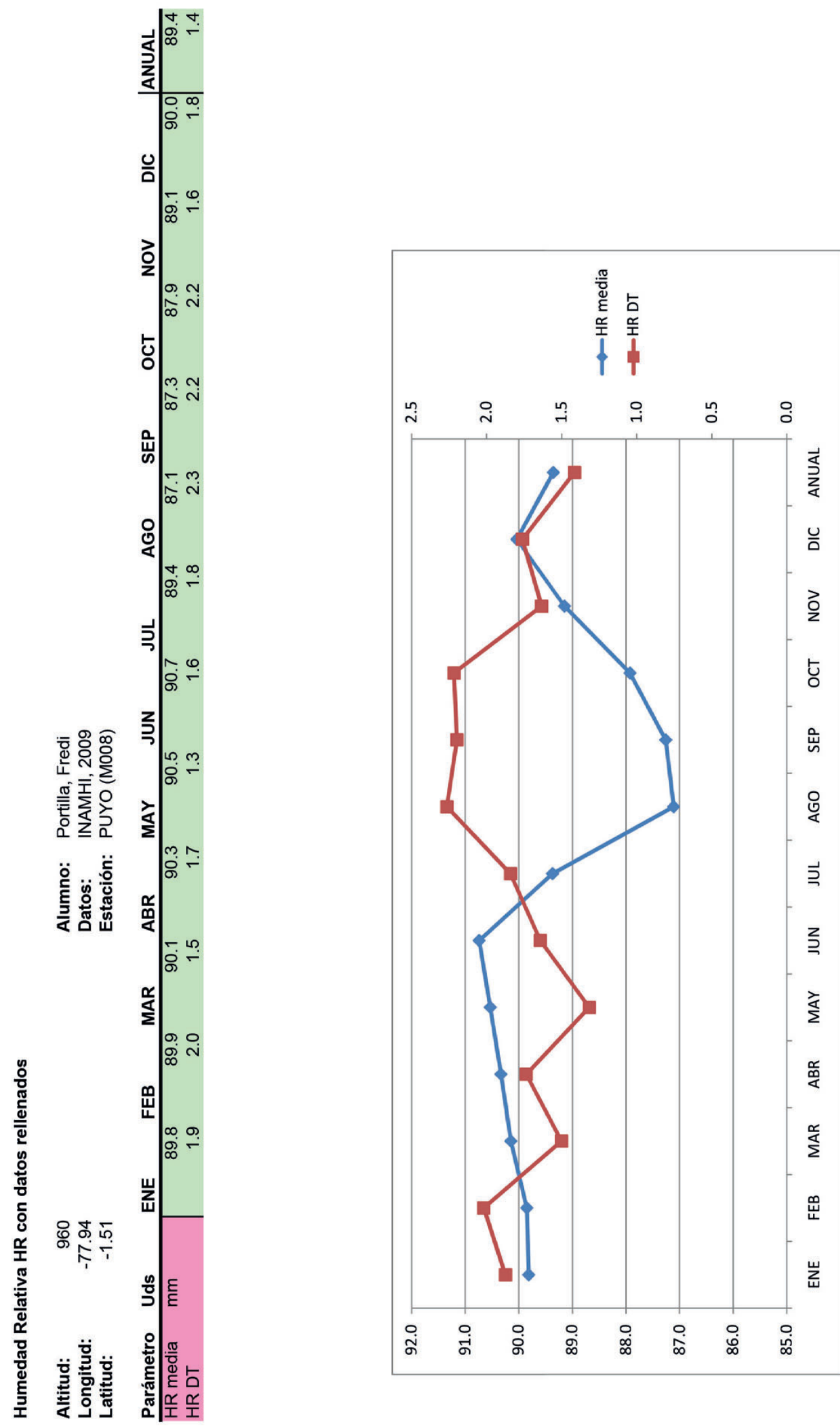

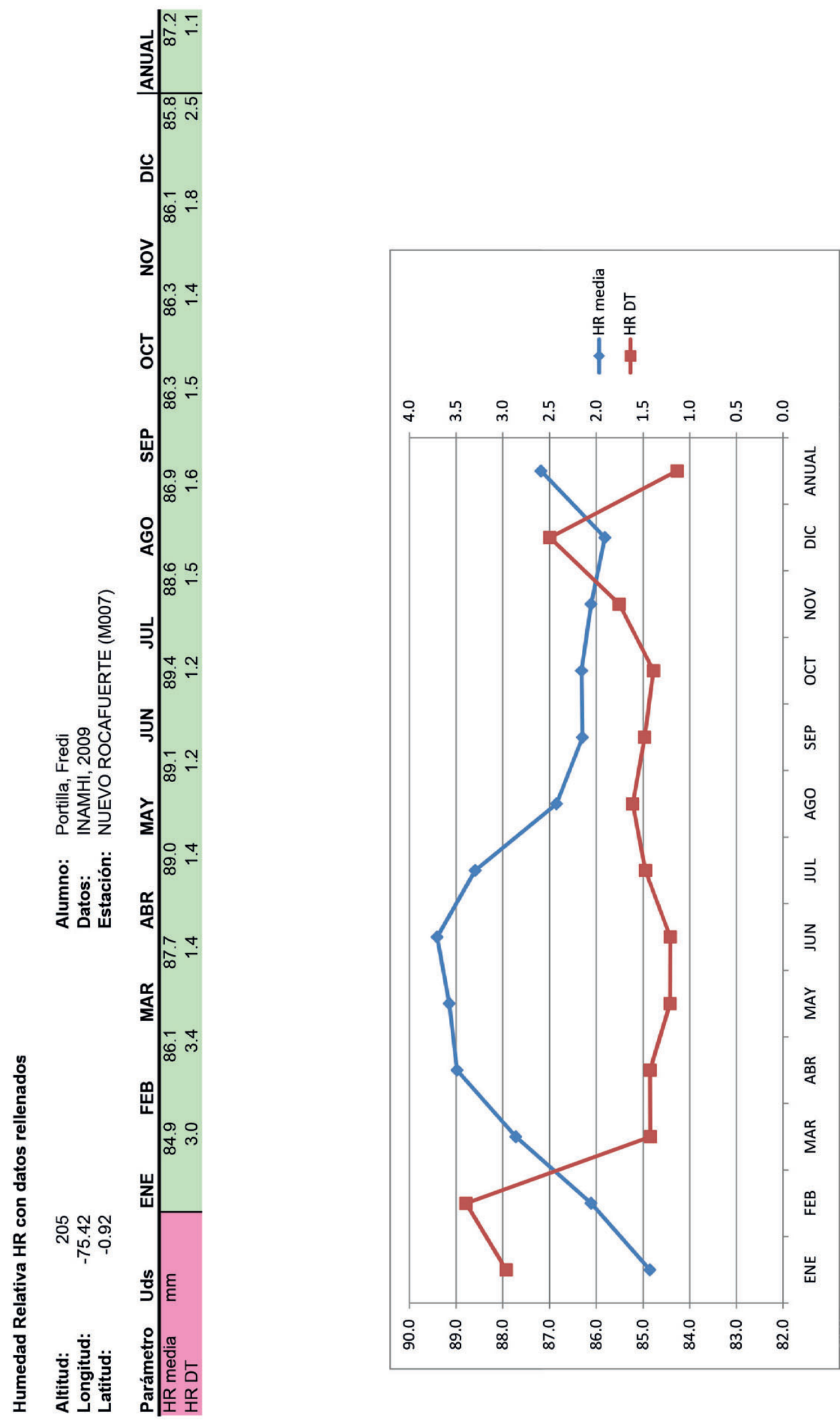

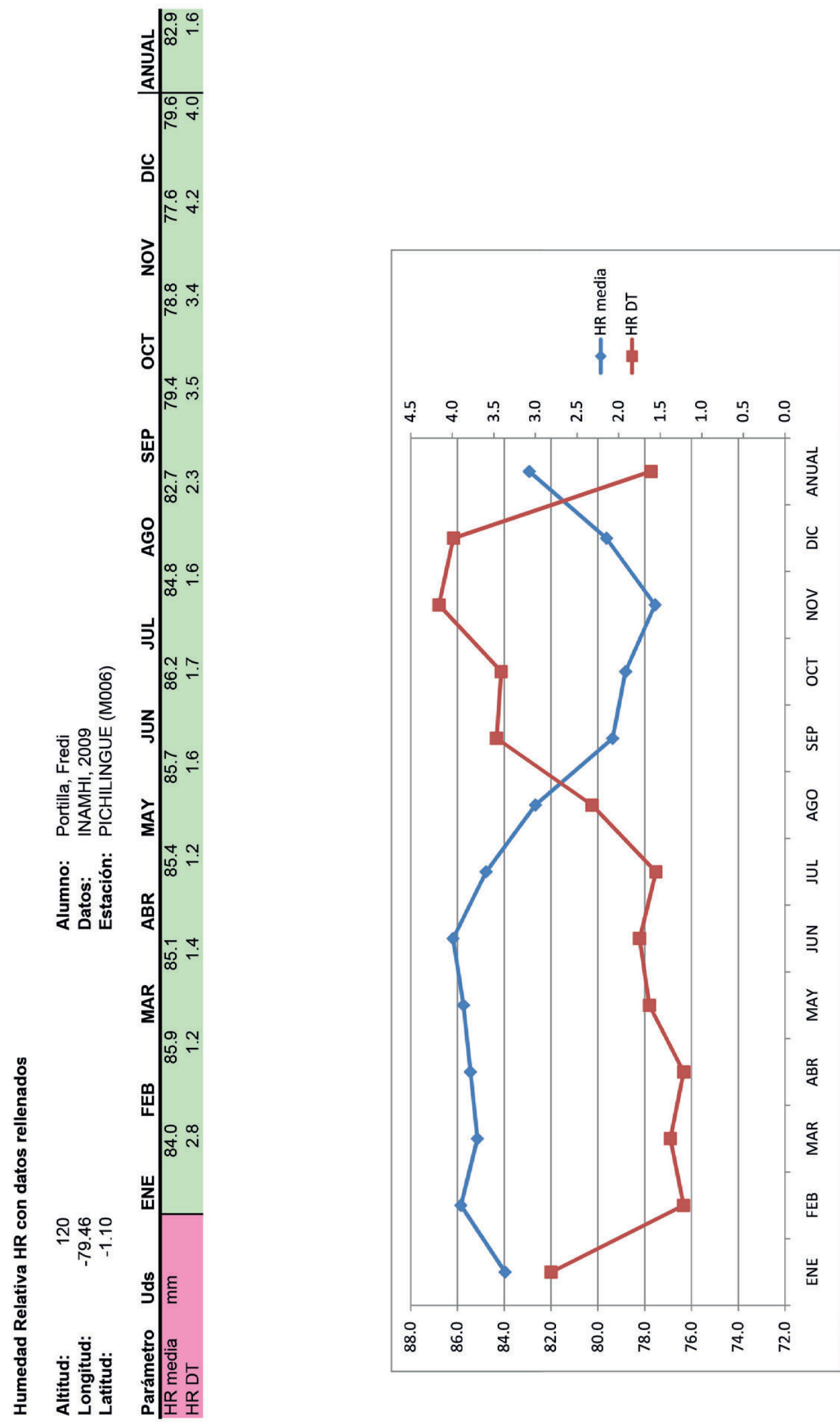

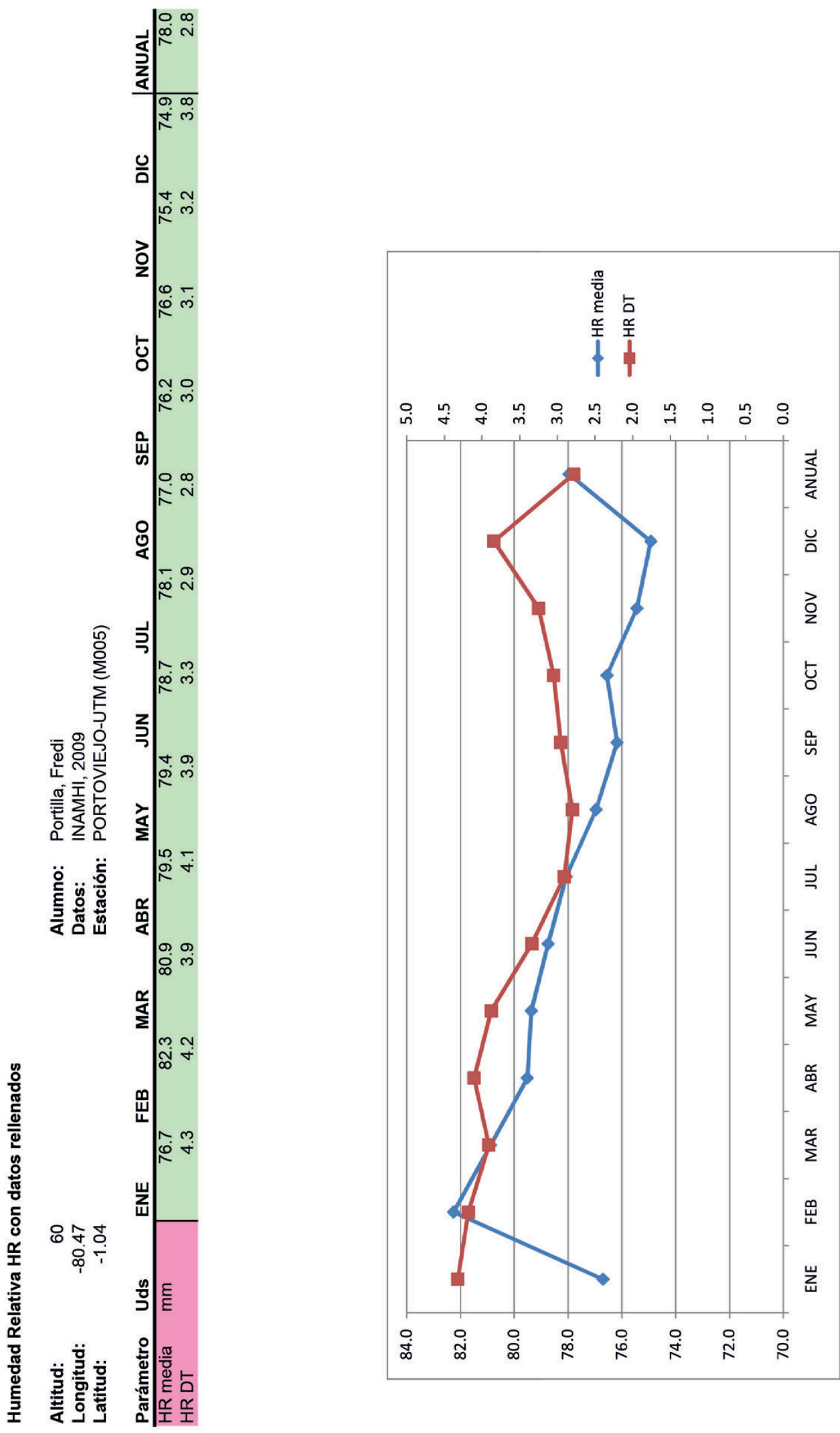

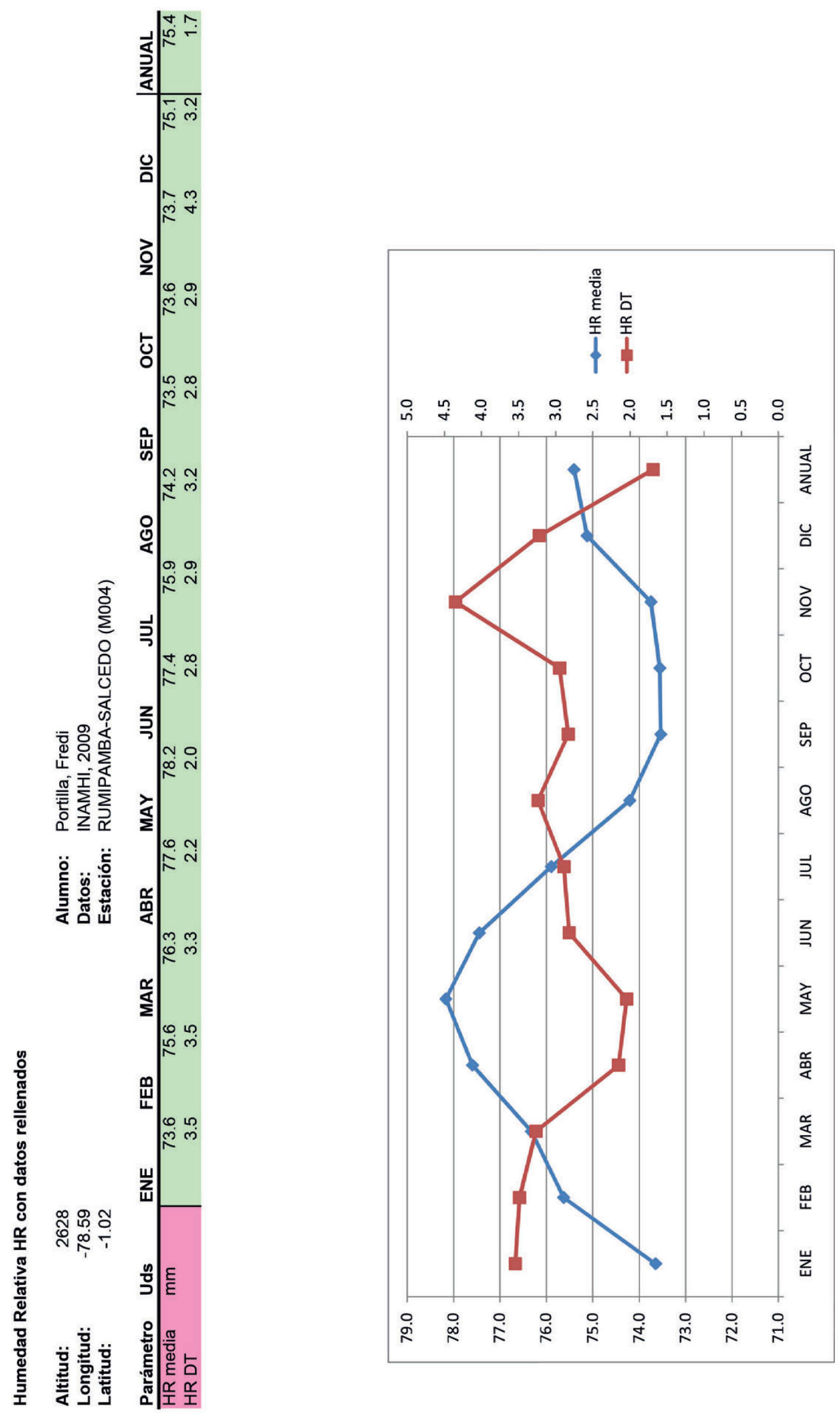

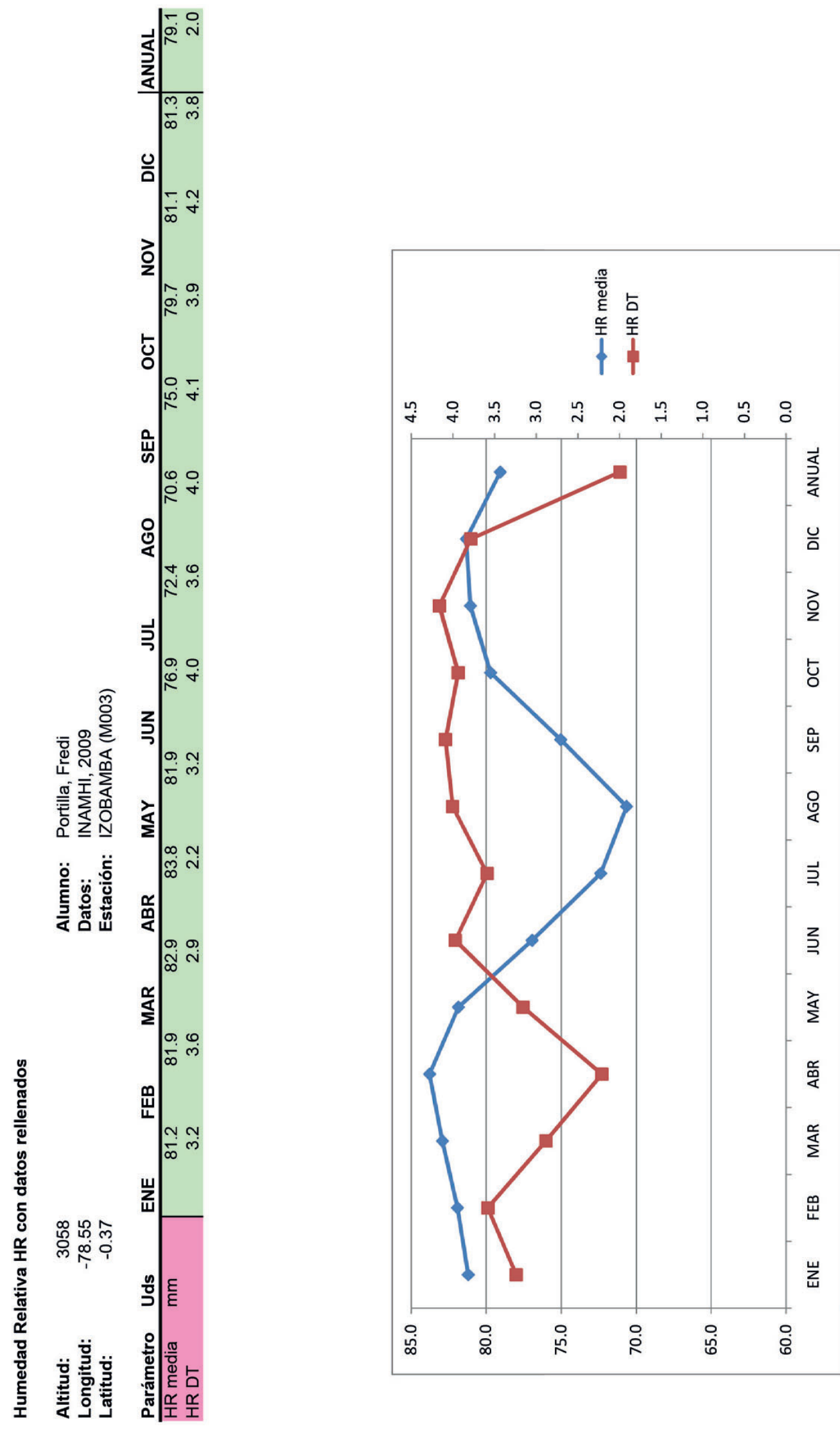

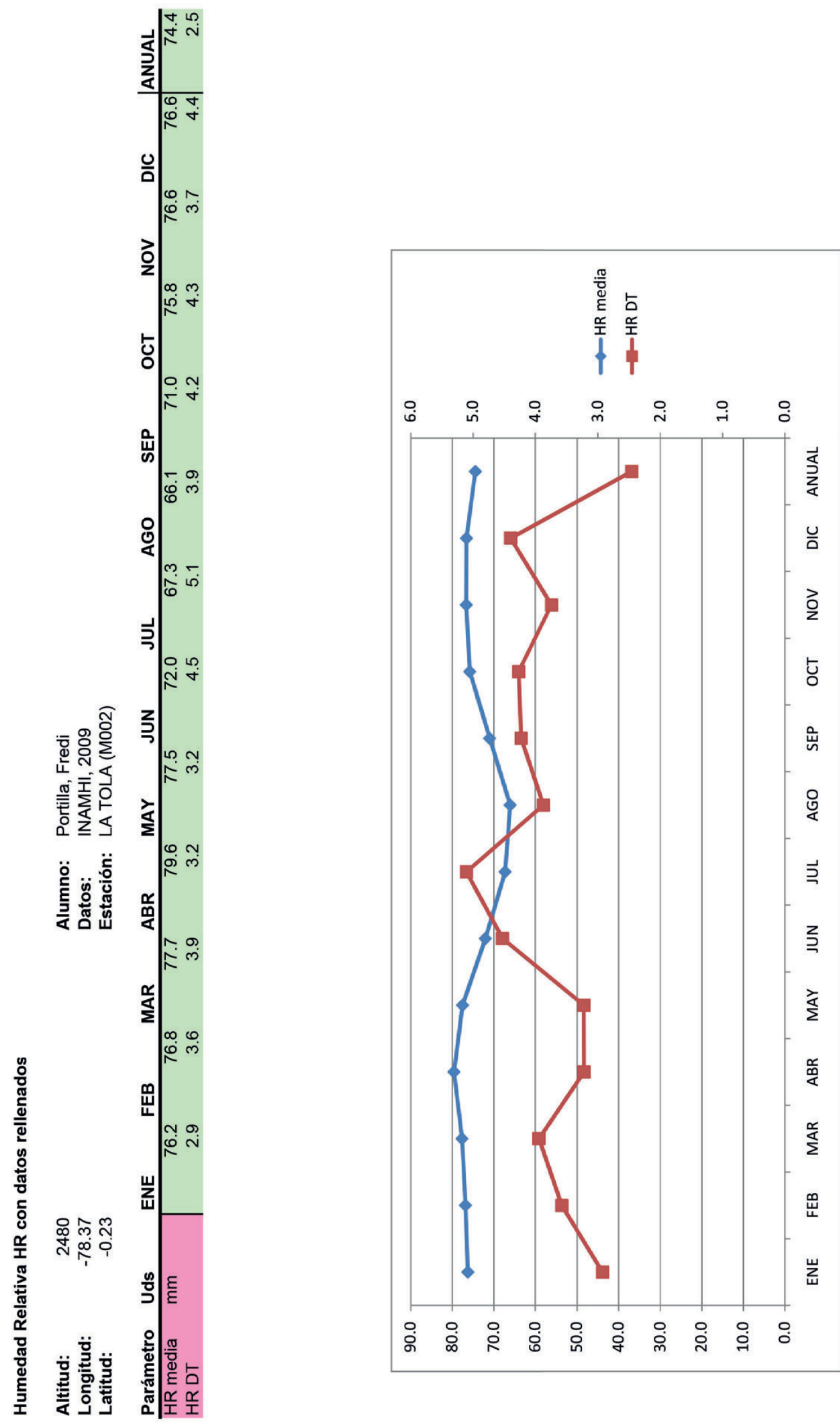


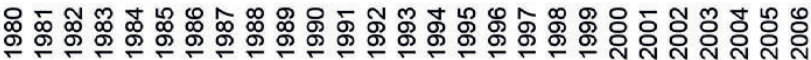

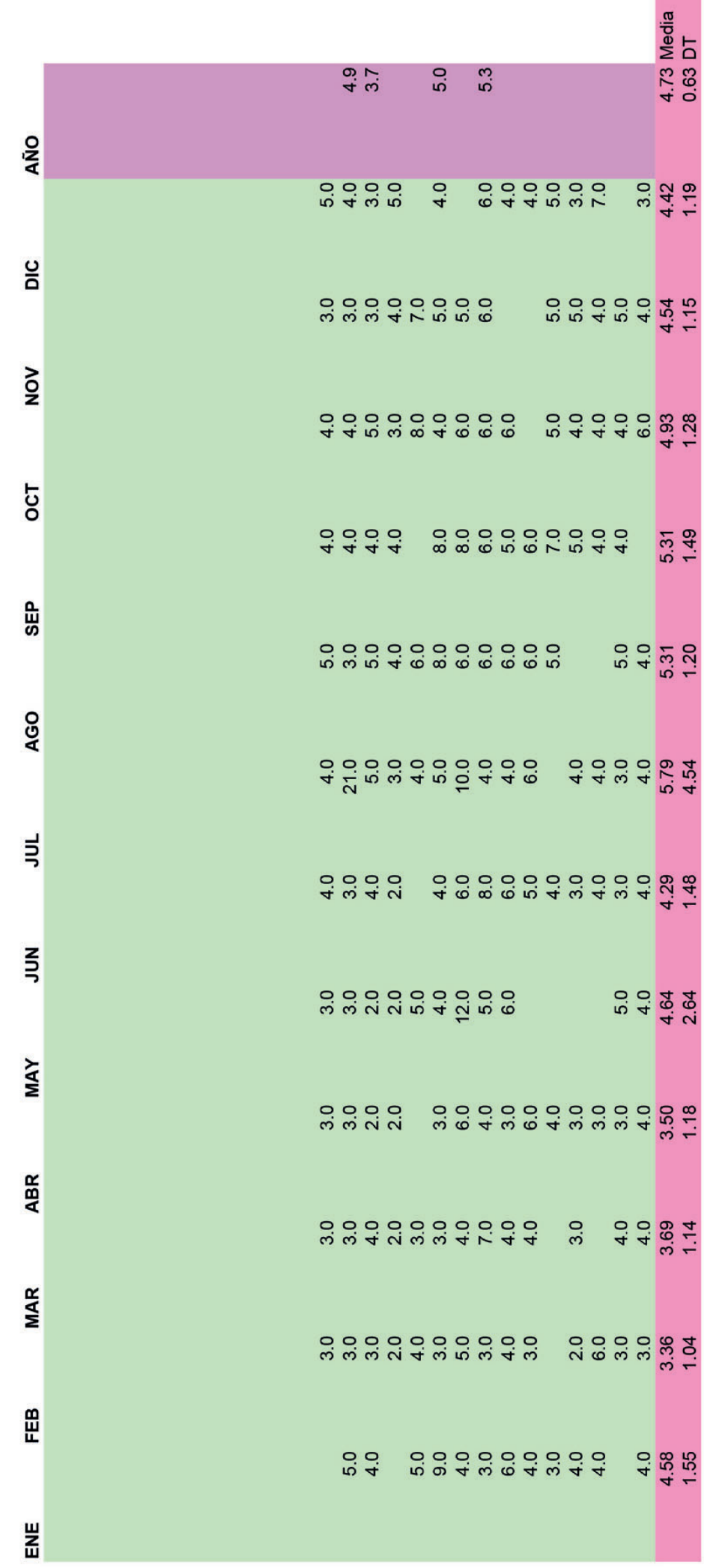


465

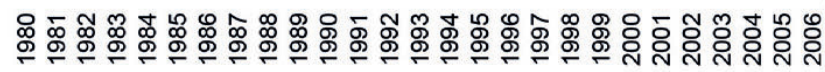

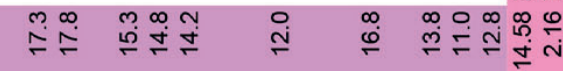

学

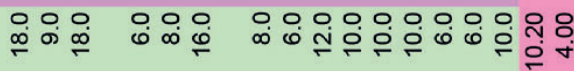

음

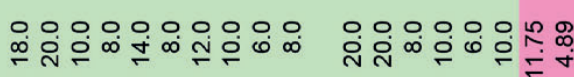

o

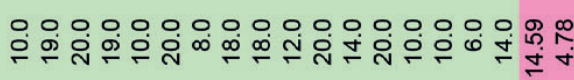

เ

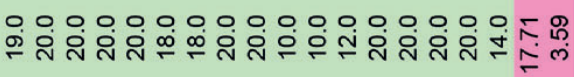

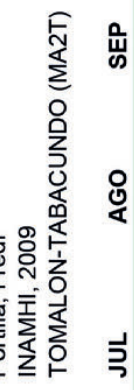

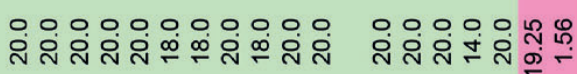

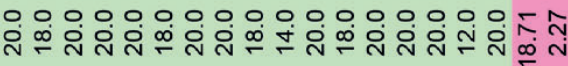

క

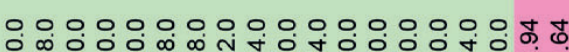

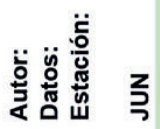

玄

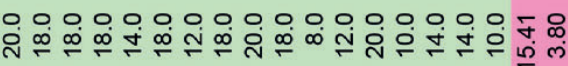

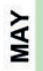

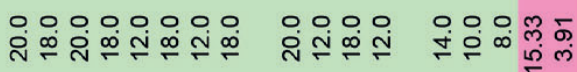

$\frac{\alpha}{\frac{\alpha}{\alpha}}$

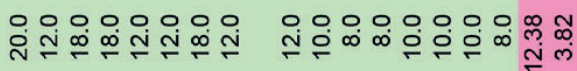

옹ำ

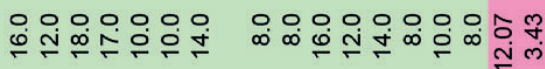

延

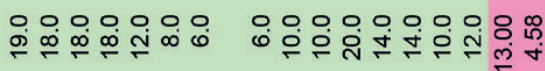

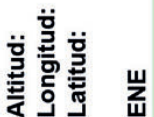




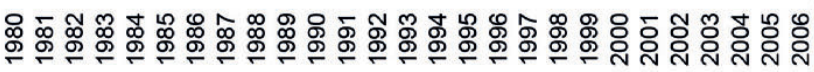

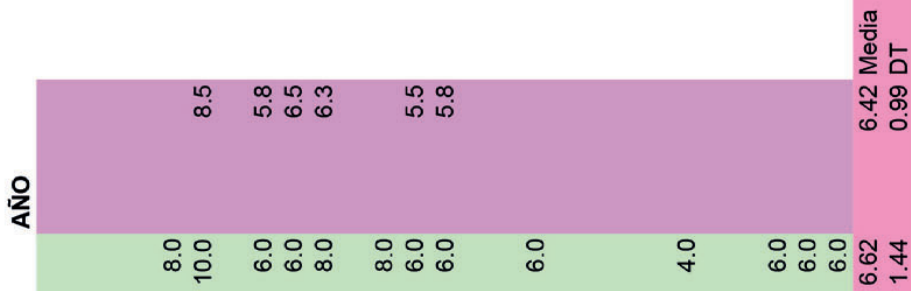

$\frac{0}{\square}$

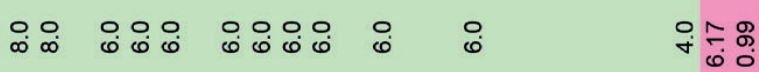

o

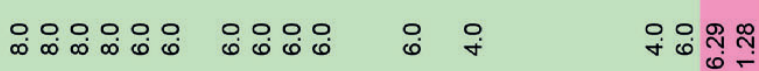

Ł

웅이

峞

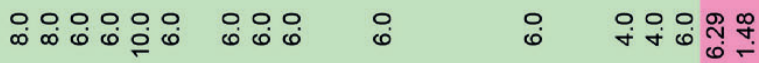

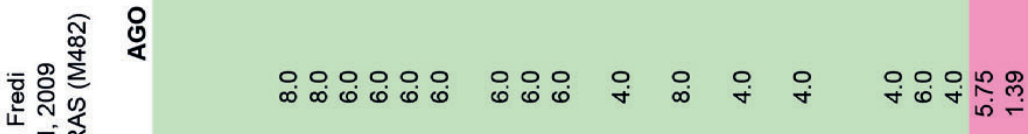

定

๖

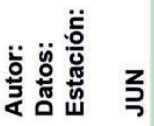

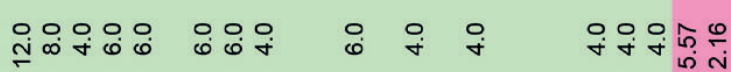

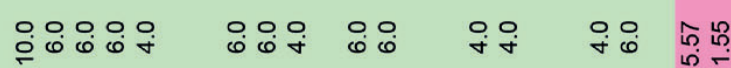

$\overleftrightarrow{a}$

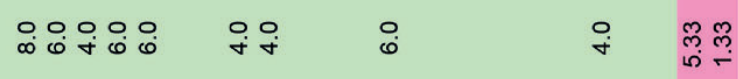

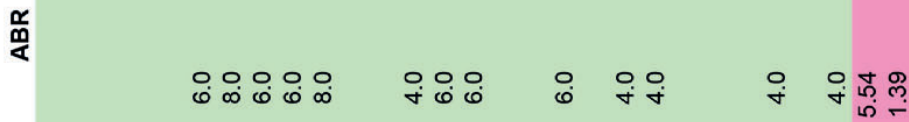

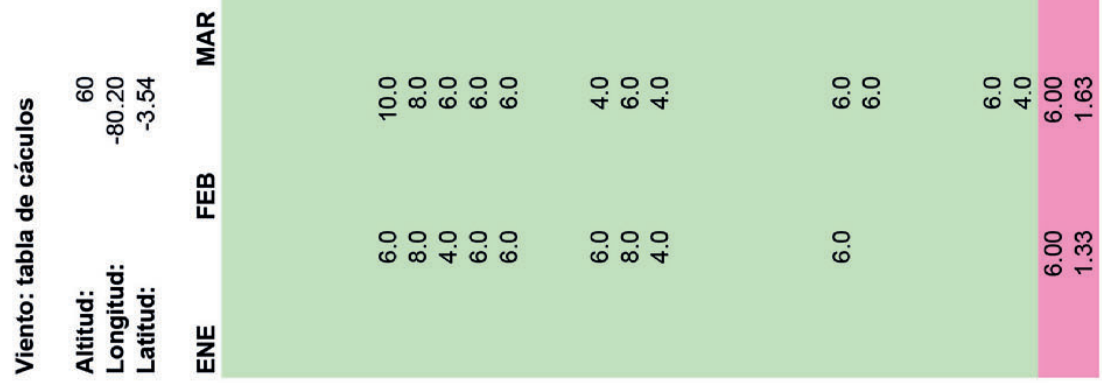




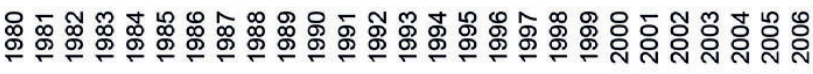

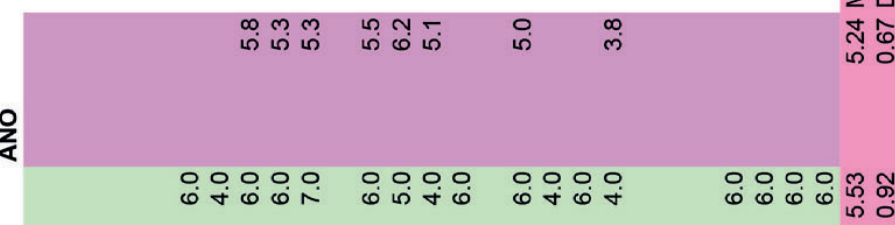

$\frac{0}{0}$

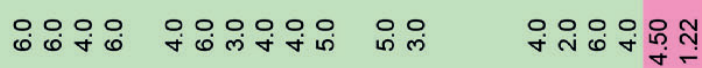

z)

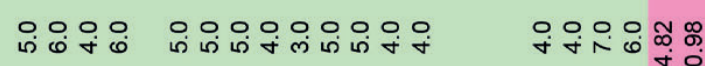

Ł

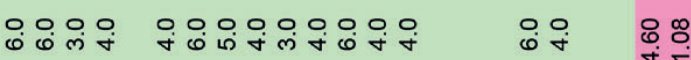

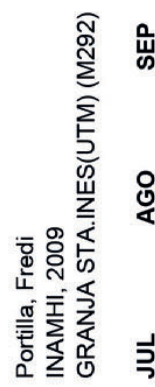

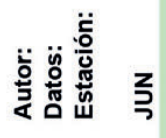

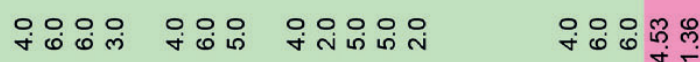

웁입ㅇ

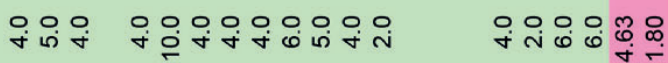

s

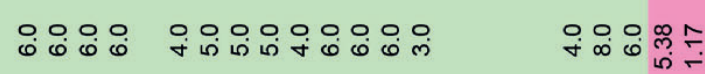

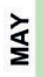

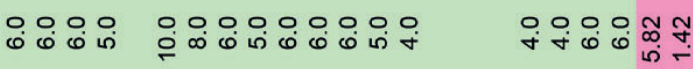

$\stackrel{\frac{\alpha}{0}}{\frac{1}{4}}$

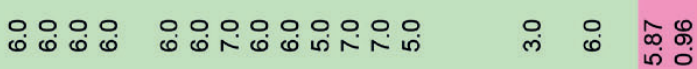

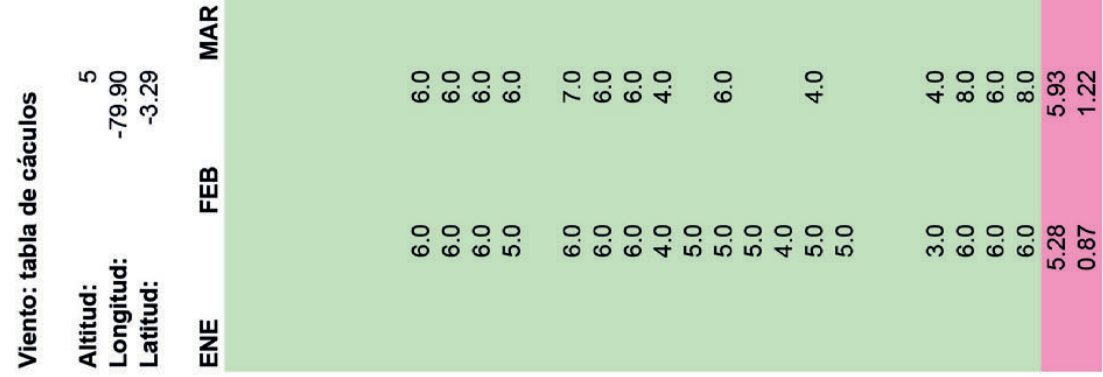




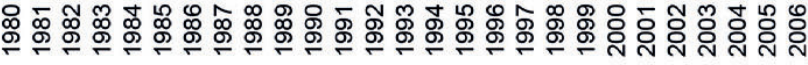

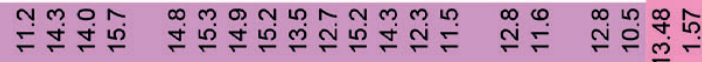

운

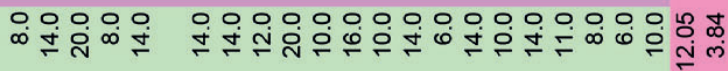

음

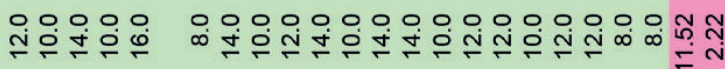

o

心

Ł

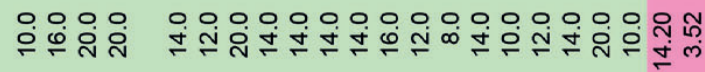

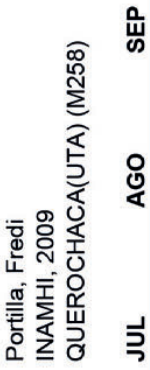

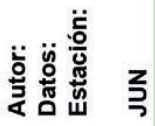

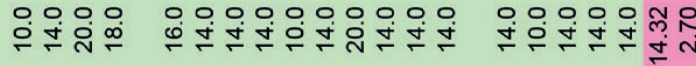

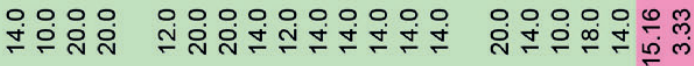

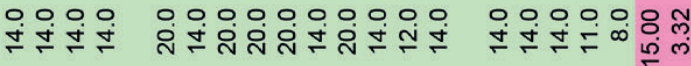

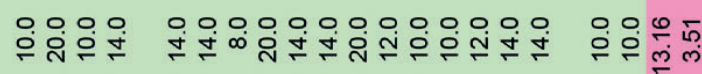

爻

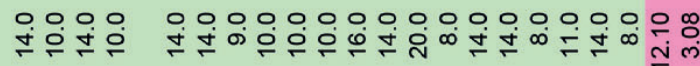

㩊

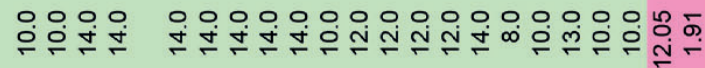

우울

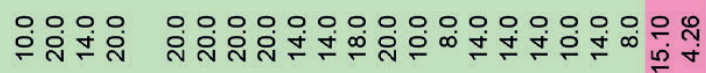

思

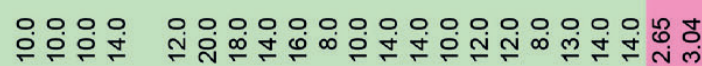


469

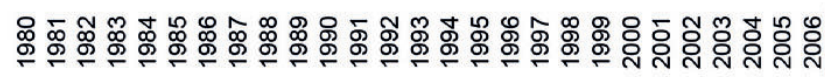

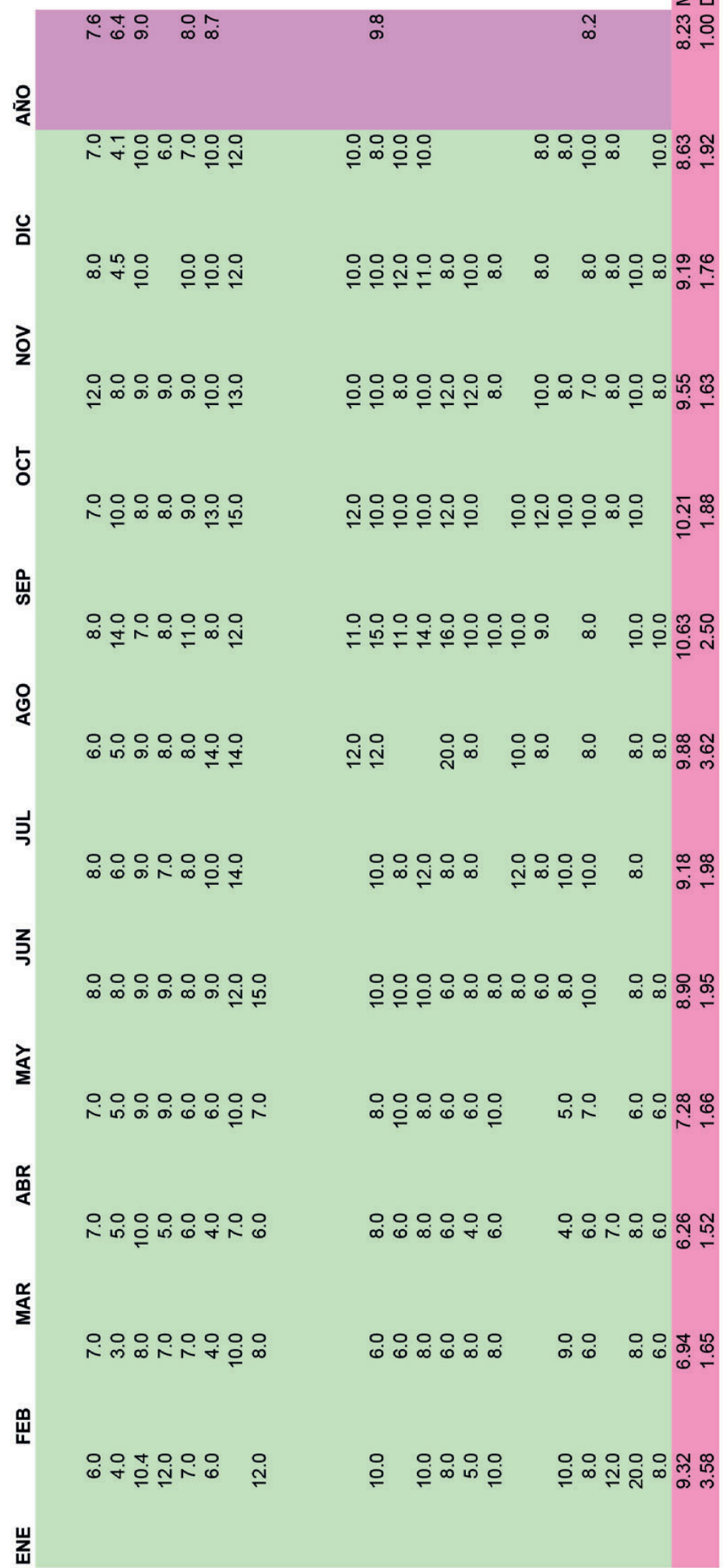




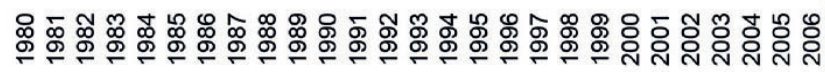

穼

음

을

iे

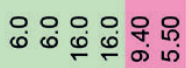

Łั

입 앙

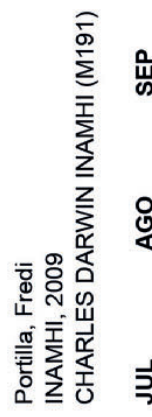

웅 잉

$\stackrel{0}{\circ}$

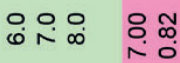

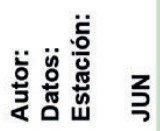

웃잉 앵웅

z

촐

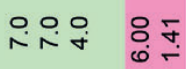

㩊

$\check{\pi}$

ำ융

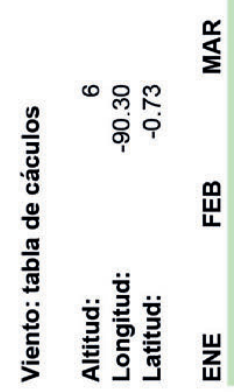

웅으 운

웃잉요 웃 


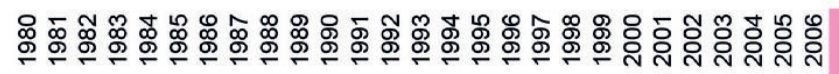

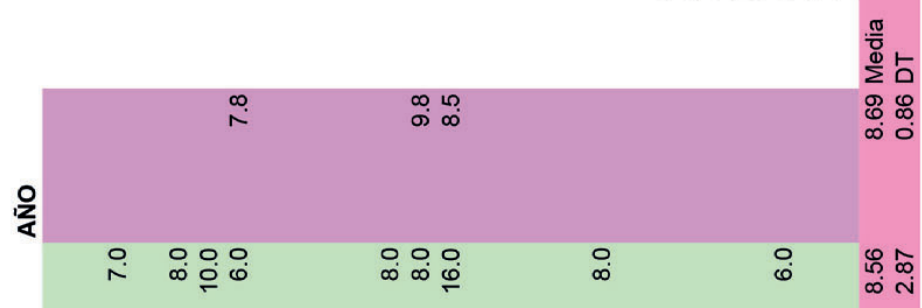

음

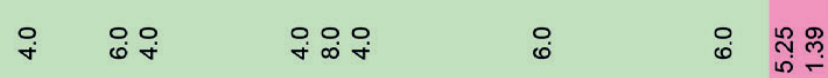

?

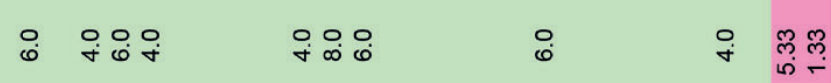

¿

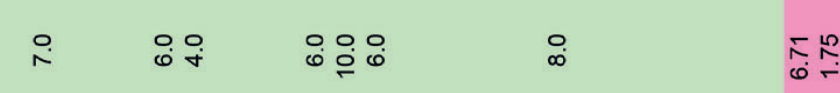

䢞

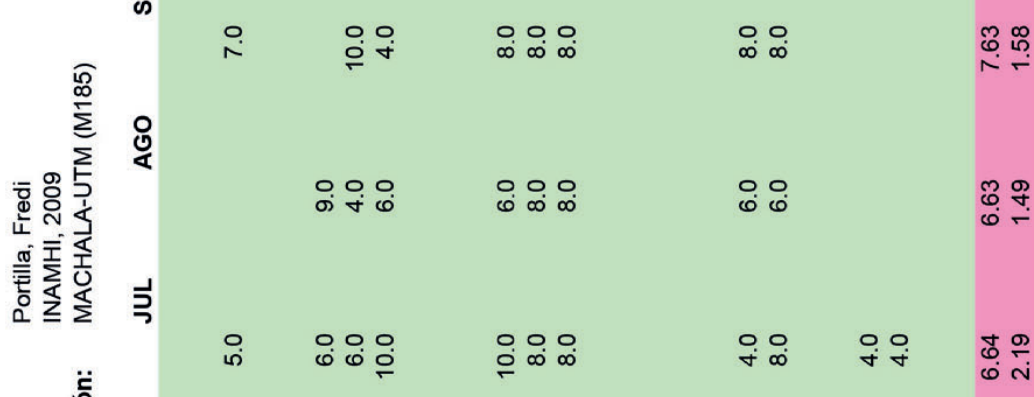

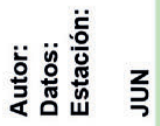

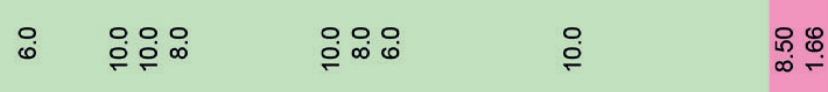

文

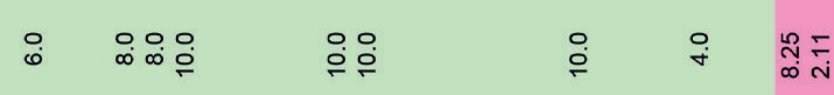

㠃

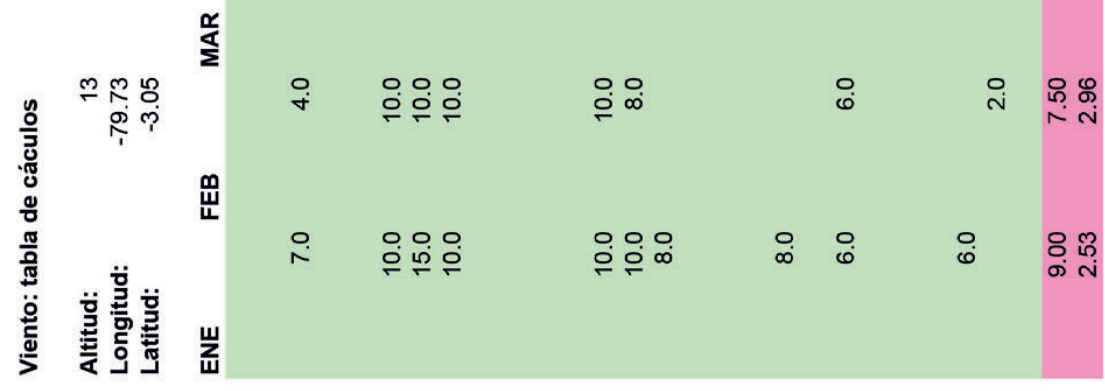




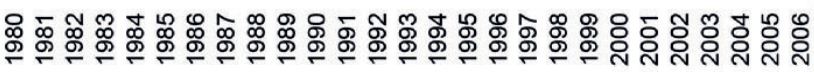

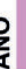

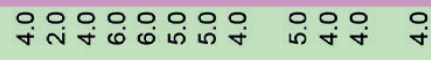

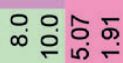

$\frac{0}{0}$

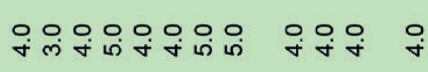

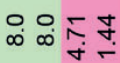

을

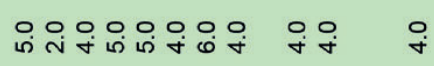

เ

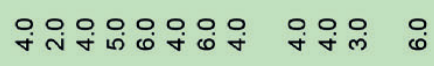

遌

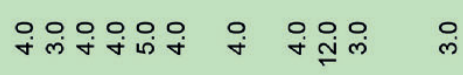

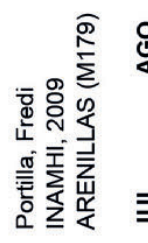

¿

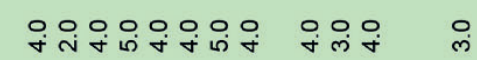

s

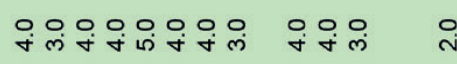

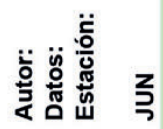

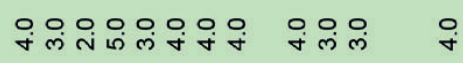

ㅇ.

$\stackrel{\gtrless}{\Sigma}$

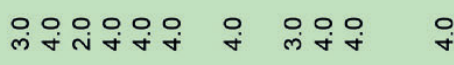

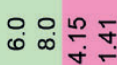

㩊

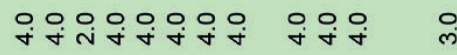

웅웅용요

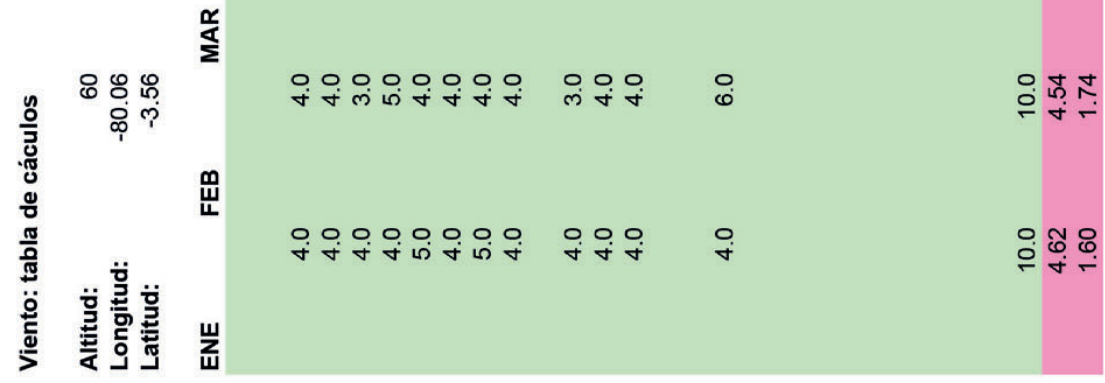




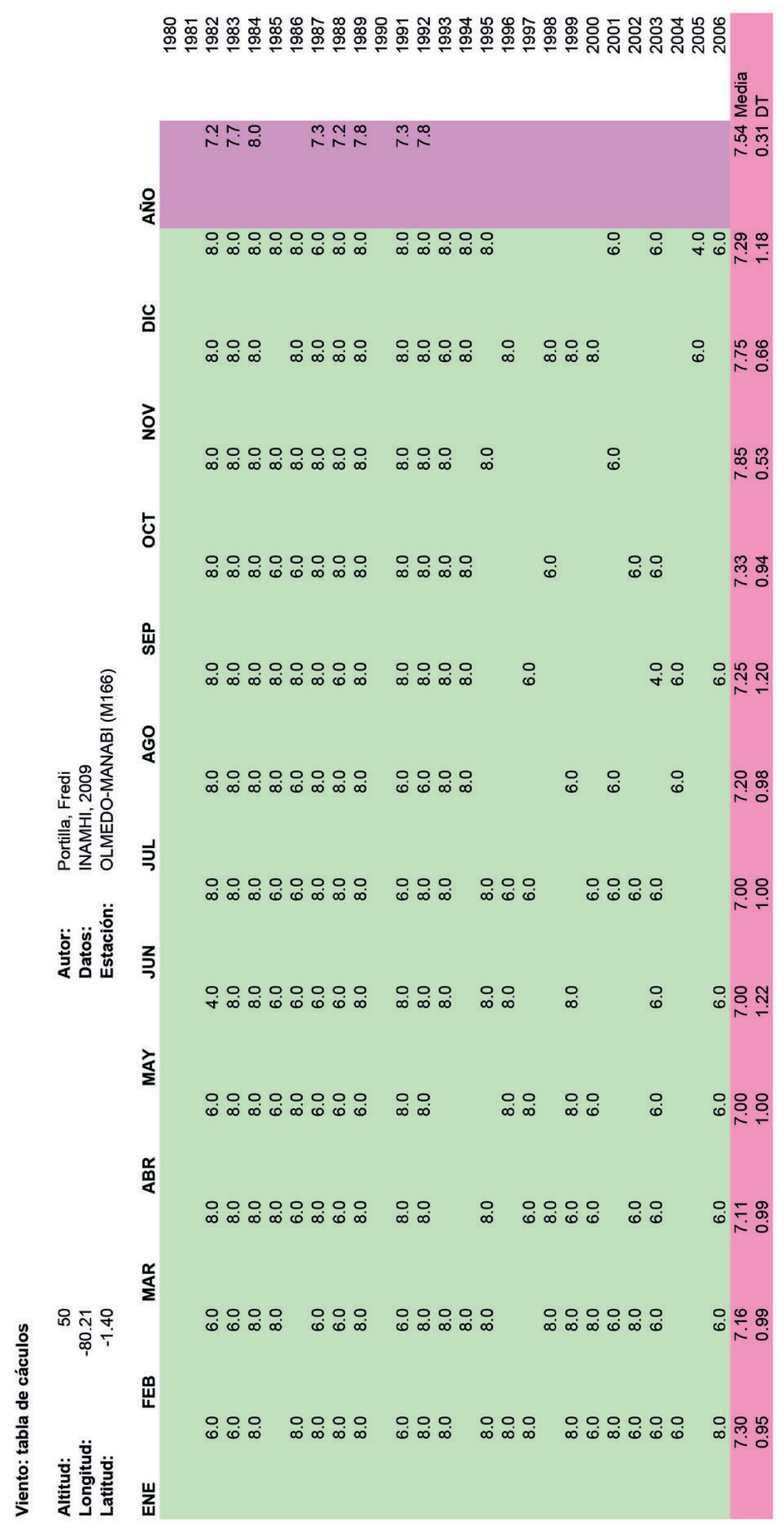




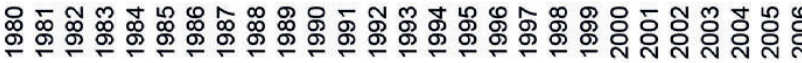

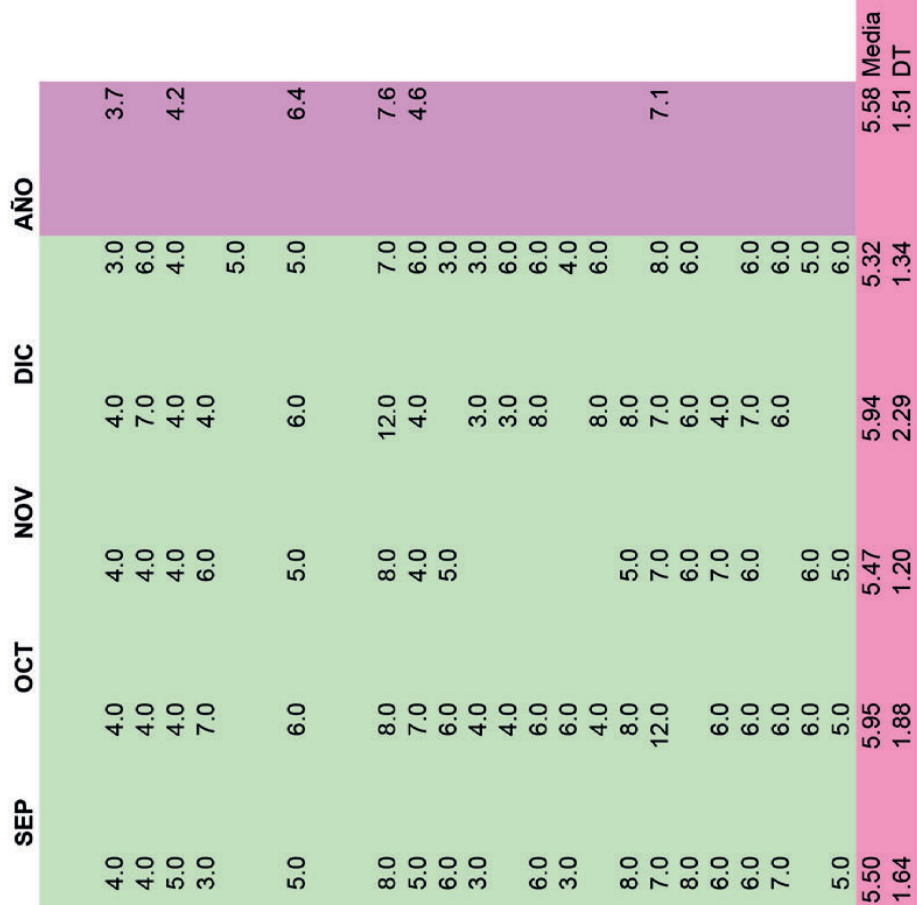

¿

㩊

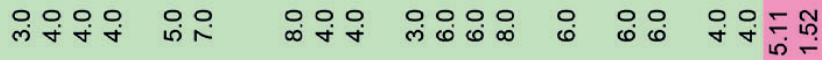

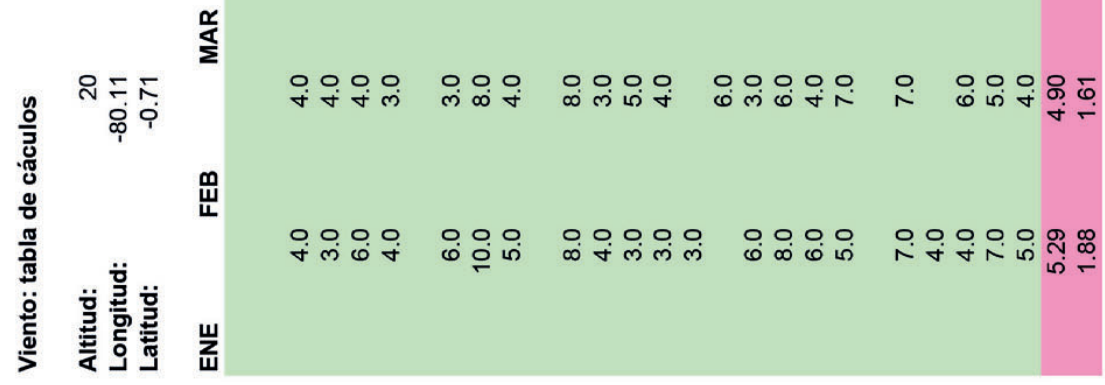




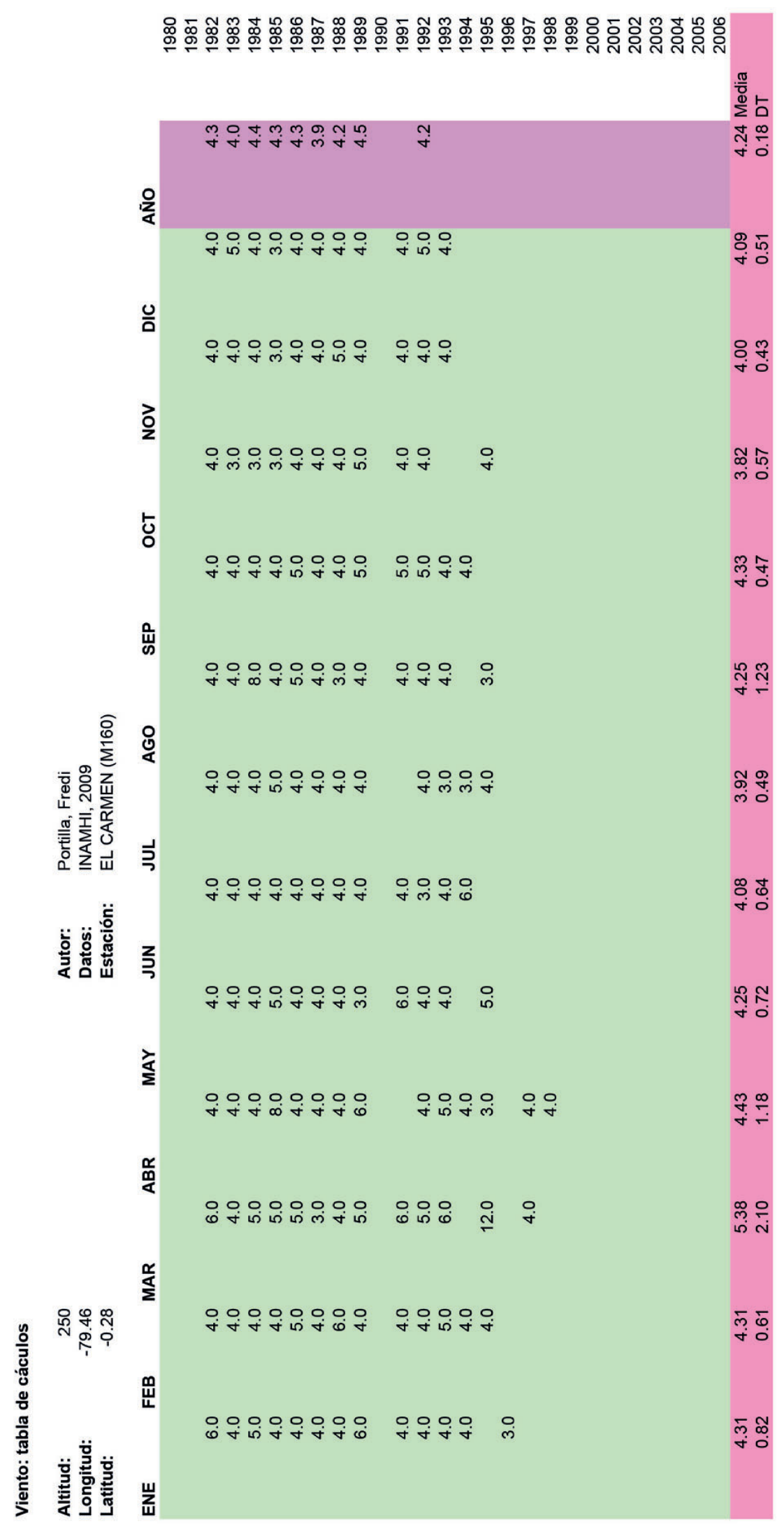




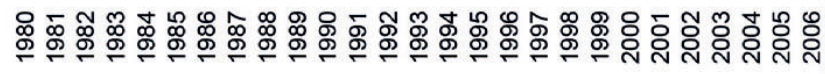

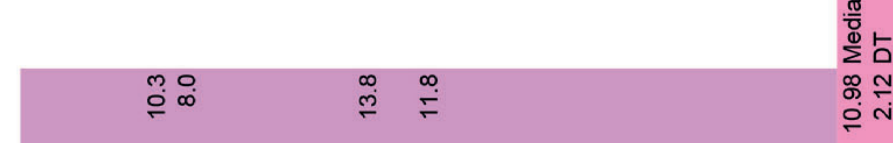

学

엇 웅

$\stackrel{0}{\square}$

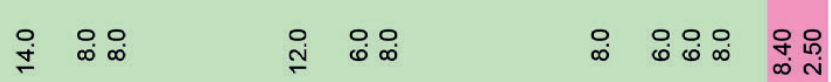

을

序

เ

산

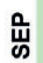
$\stackrel{\circ}{\mathrm{i}} \stackrel{\circ}{\circ}$
$\stackrel{\circ}{\circ} \stackrel{ }{\stackrel{9}{0}}$
œ

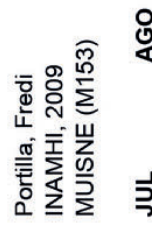

엉

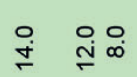

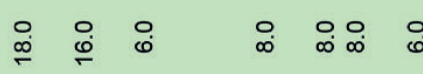

웅

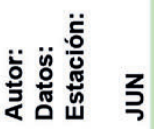

过

过

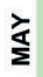

임

$\frac{\alpha}{\frac{0}{\alpha}}$

잉 $\quad$ 잉

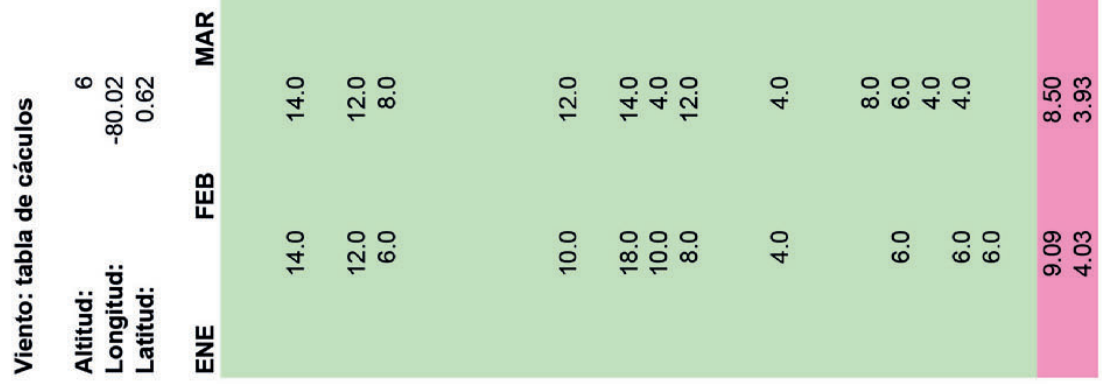




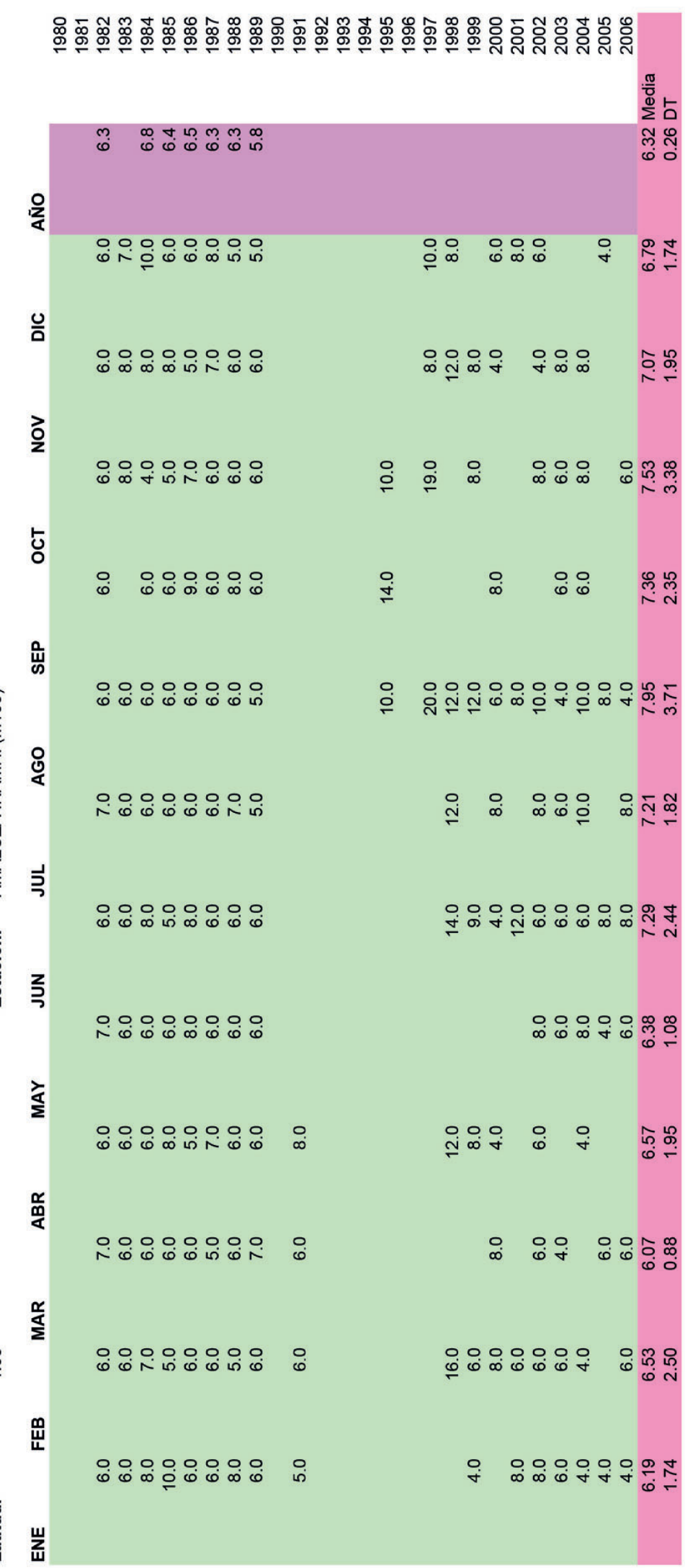




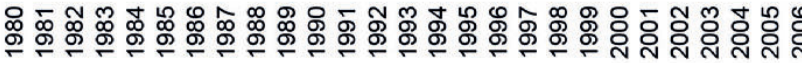

量

这

음

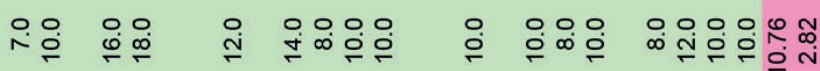

을

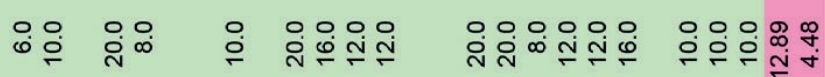

‘

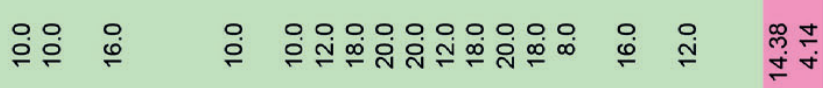

䓵

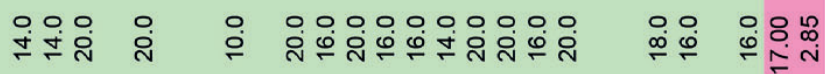

:

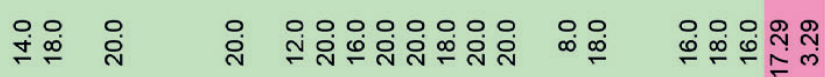

今

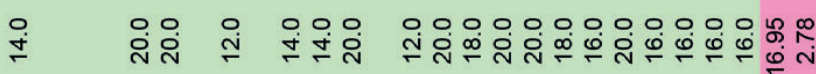

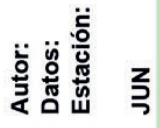

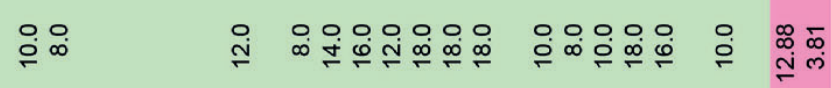

文

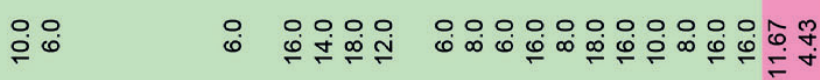

㩊

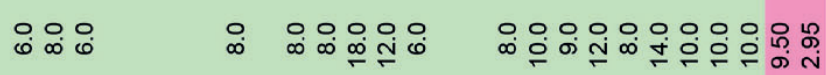

象

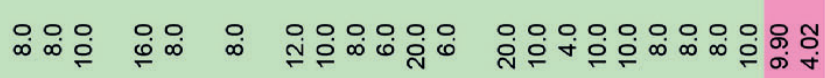




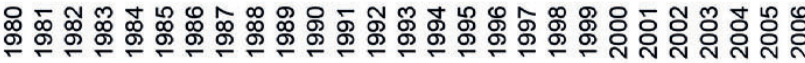

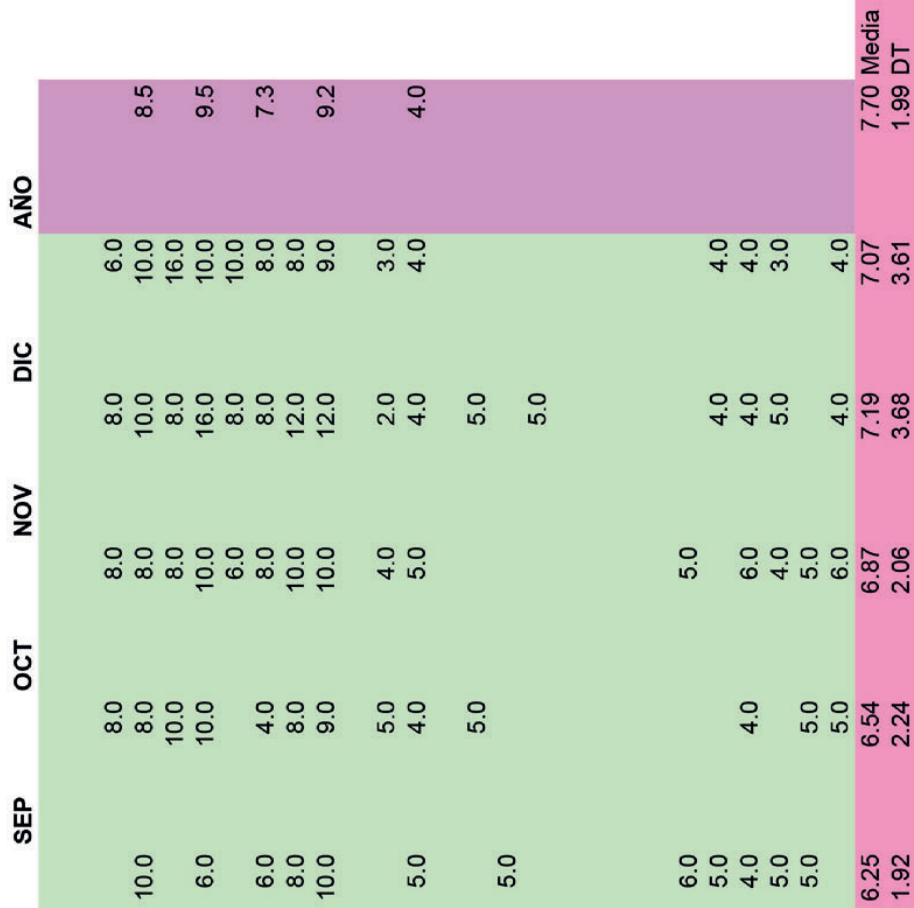

8

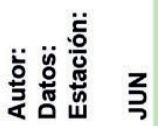

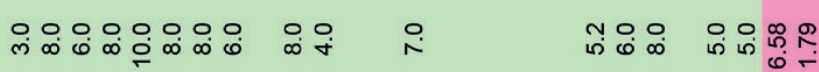

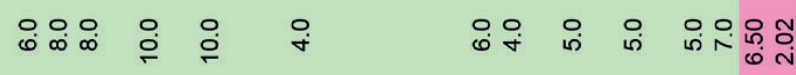

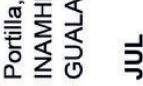

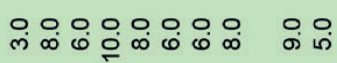

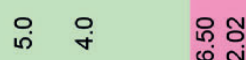

$\stackrel{\grave{c}}{\Sigma}$

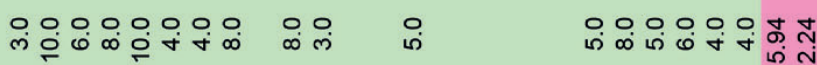

㩊

웃 우음

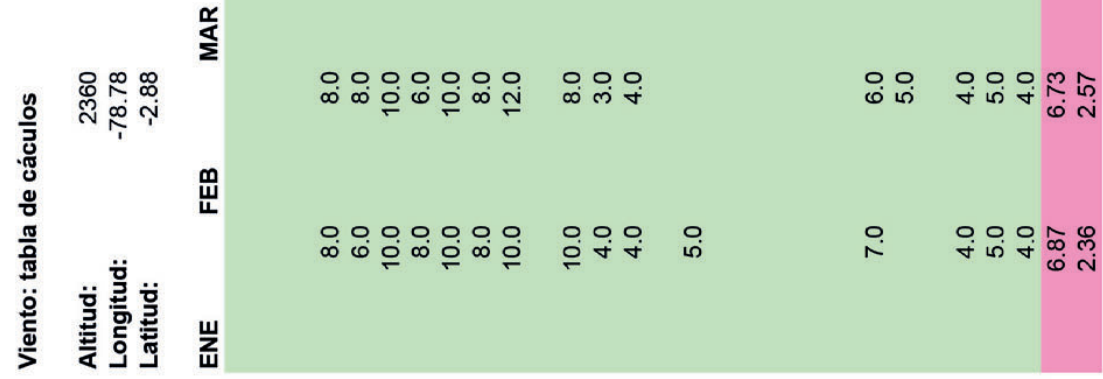




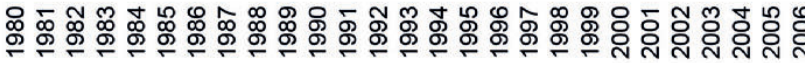

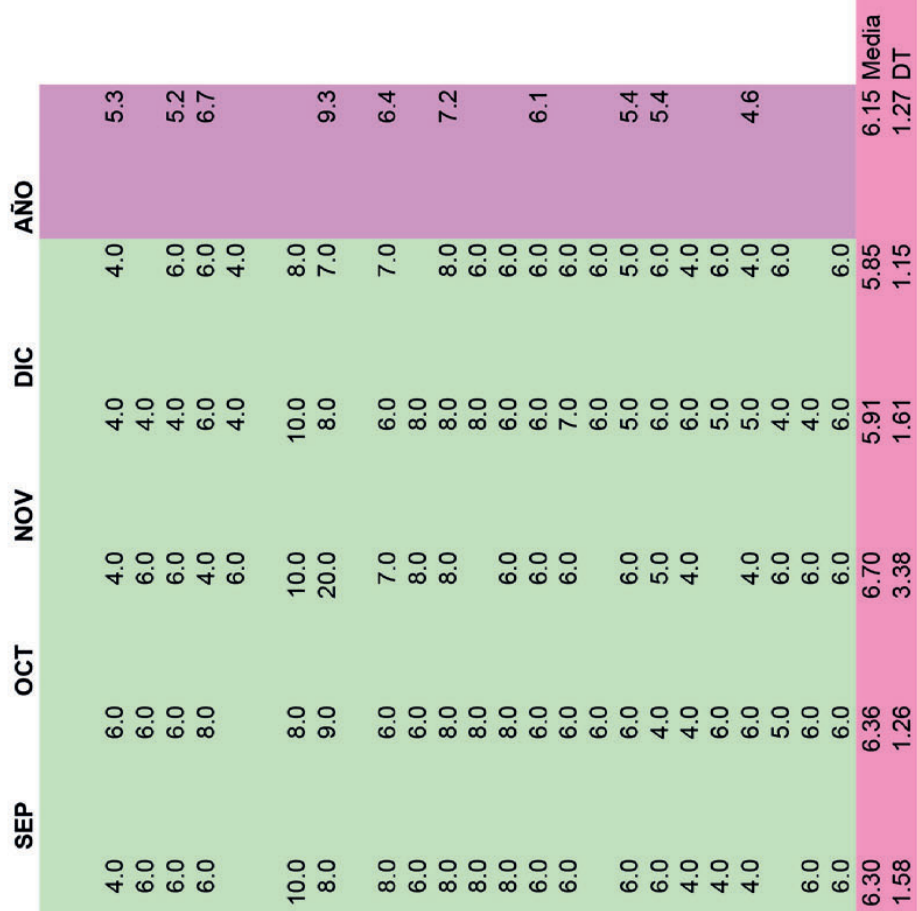

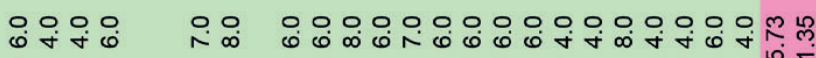

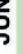

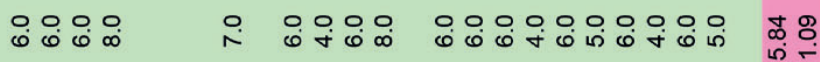

$\frac{2}{2}$

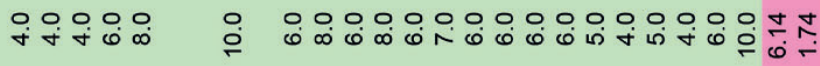

㩊

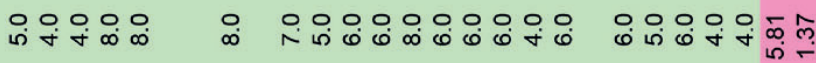

$\frac{\alpha}{2}$

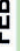

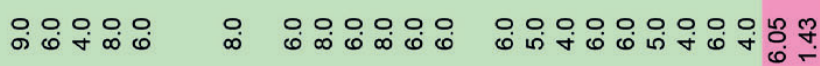


481

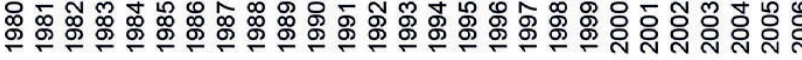

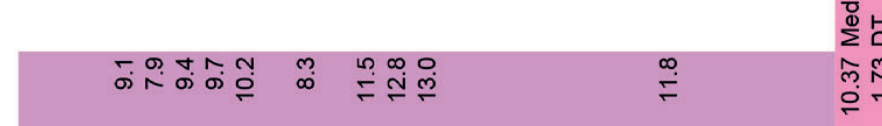

这

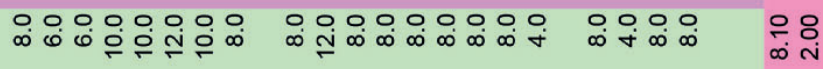

음

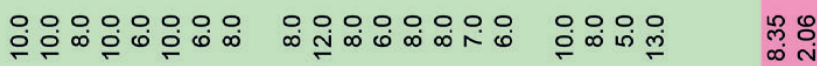

ว

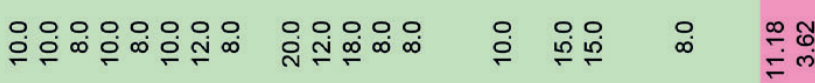

Ł

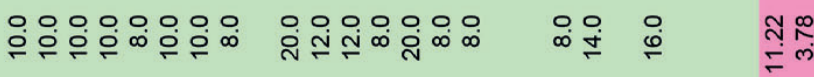

号

ํㅜㅇ융ำ

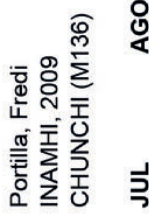

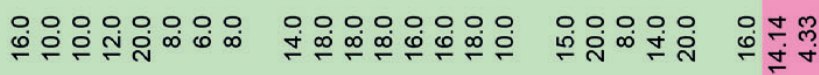

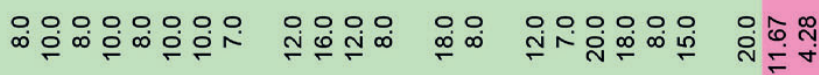

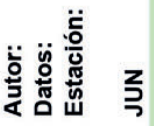

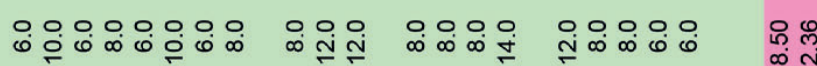

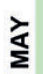

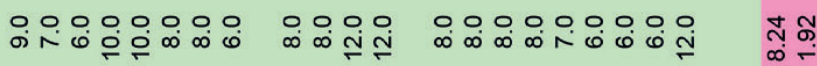

$\stackrel{\frac{\alpha}{0}}{\frac{1}{4}}$

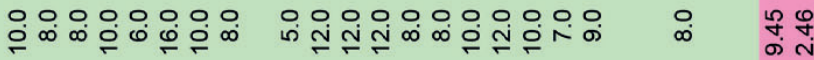

$\stackrel{\alpha}{\overleftarrow{\alpha}}$

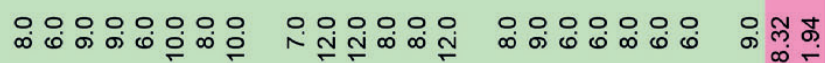

罟

웅응 


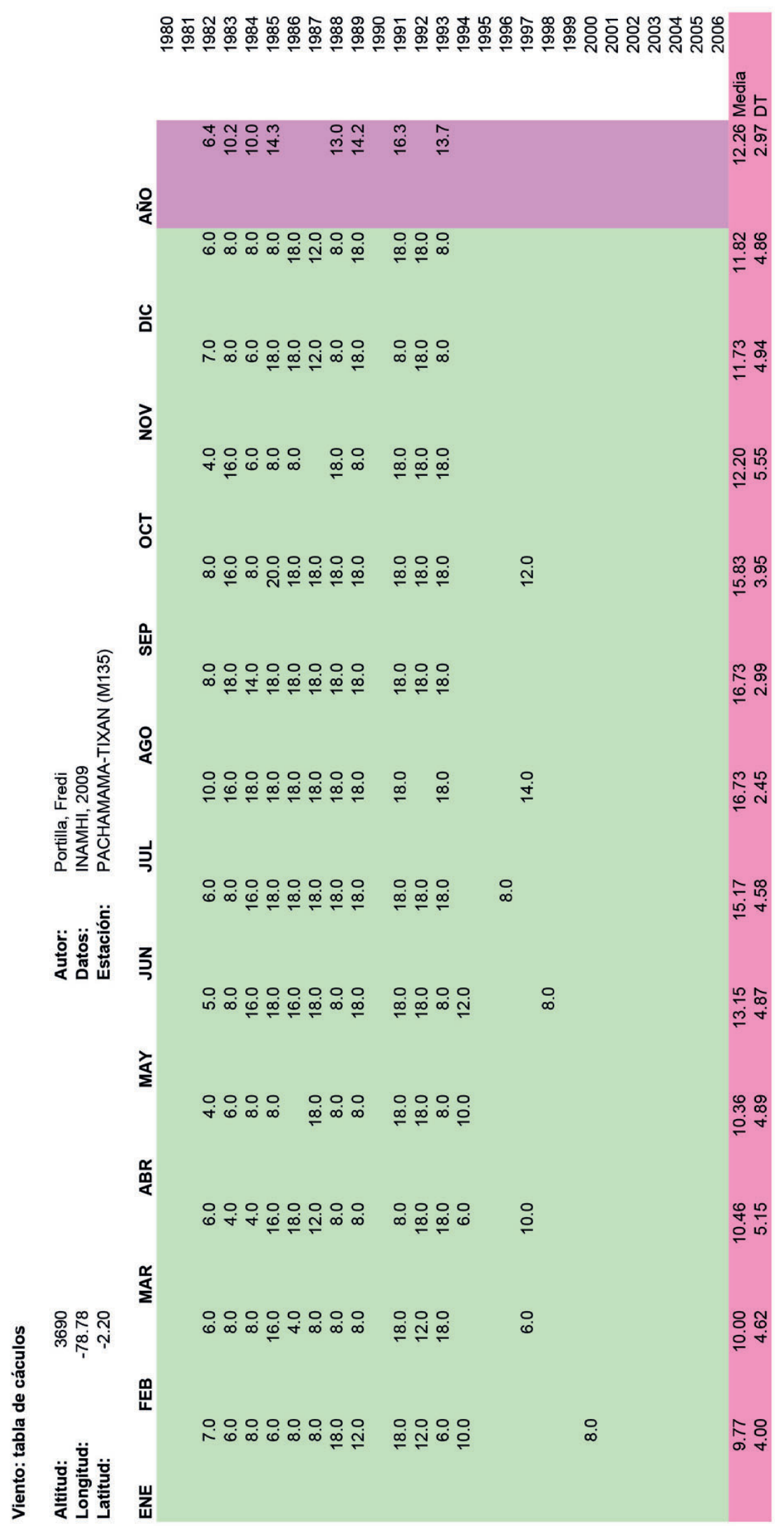




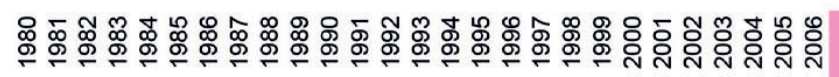

是

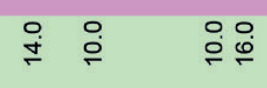

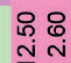

임

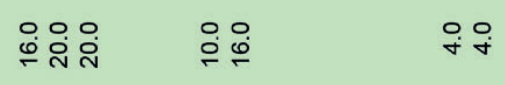

?

$\stackrel{\circ}{\circ} \stackrel{\circ}{\circ} \stackrel{\circ}{\circ}$

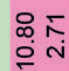

Ł

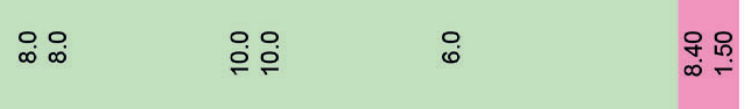

哭

๓ெ

৪:

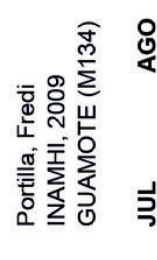

范范范范

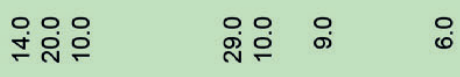

욤

实

요 용

$\stackrel{\circ}{+}$

유ำ

马

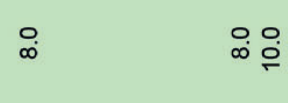

厄़्ठ

文

웅

웅

$\stackrel{\circ}{\circ}$

웅울

璦

웅

웅

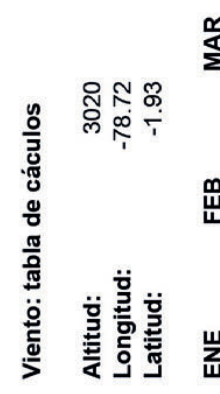




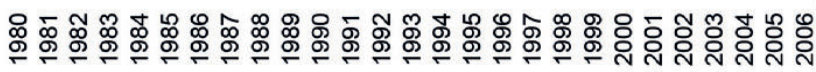

$\frac{2}{4}$

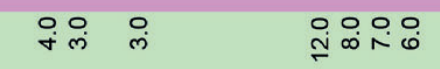

용

음

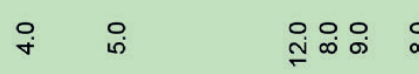

$\stackrel{\circ}{\circ}$

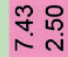

한

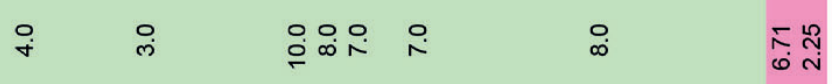

๖

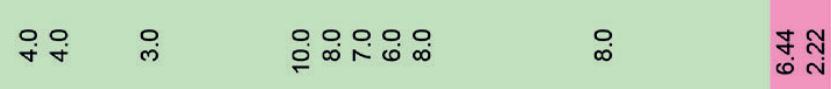

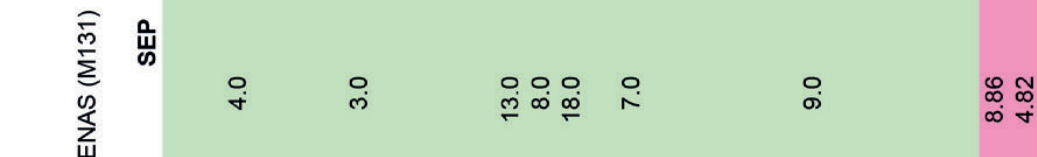

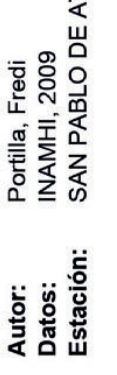

:

is

웅우웅

赵

引

ㅇํㅇ

웅응웅우

$\stackrel{\circ}{\circ}$

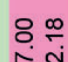

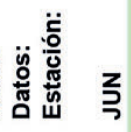

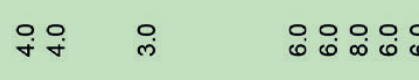

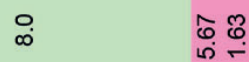

$\frac{2}{2}$

우 앙

$\stackrel{\infty}{\infty}$

두욤

㩊

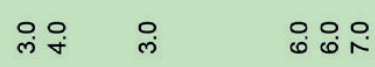

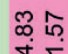

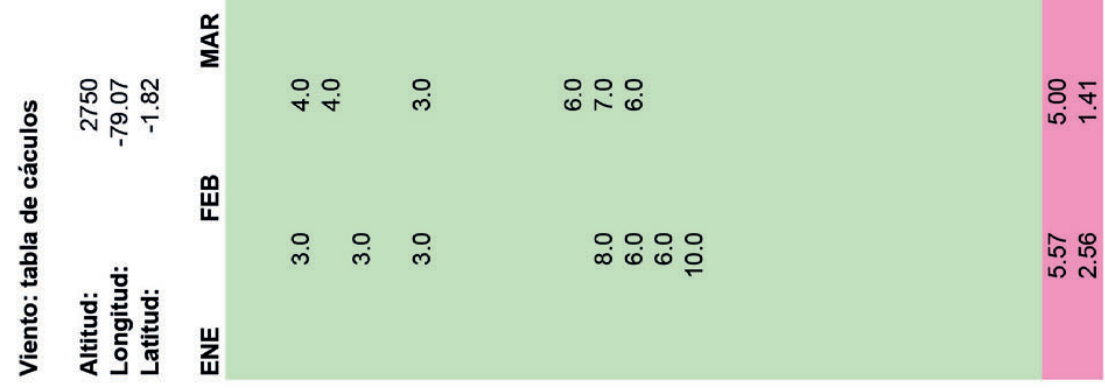


485

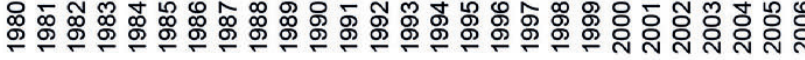

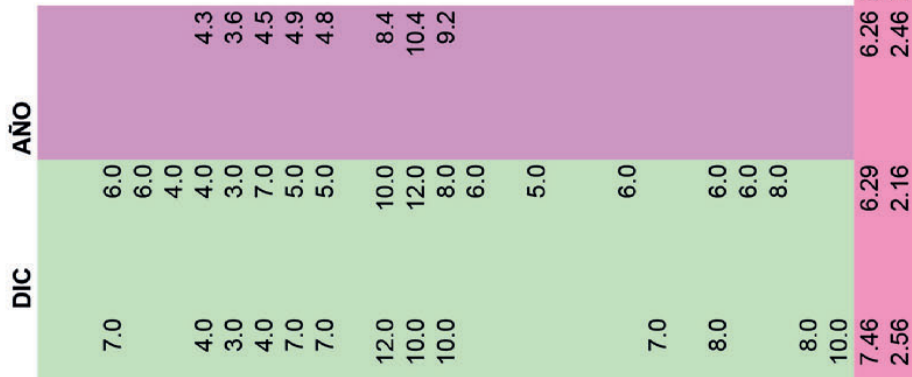

ว

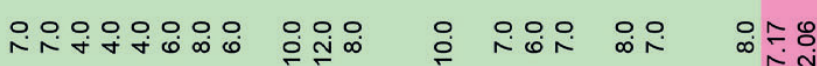

Ł

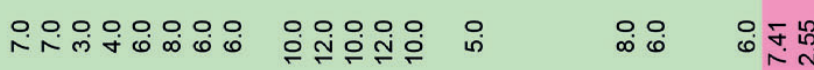

谓

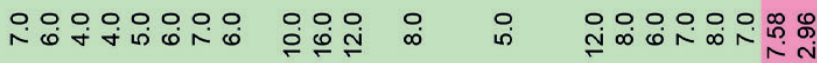

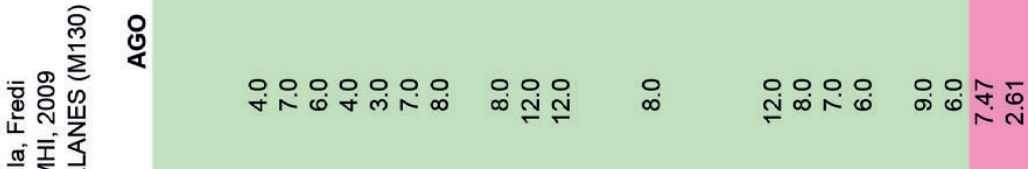

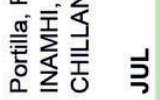

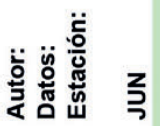

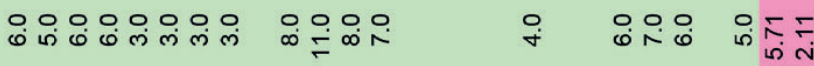

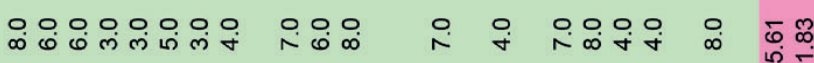

$\grave{\varepsilon}$

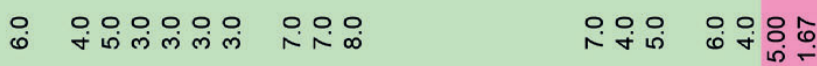

㩊

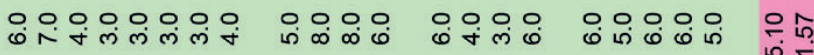

$\frac{\alpha}{\Sigma}$

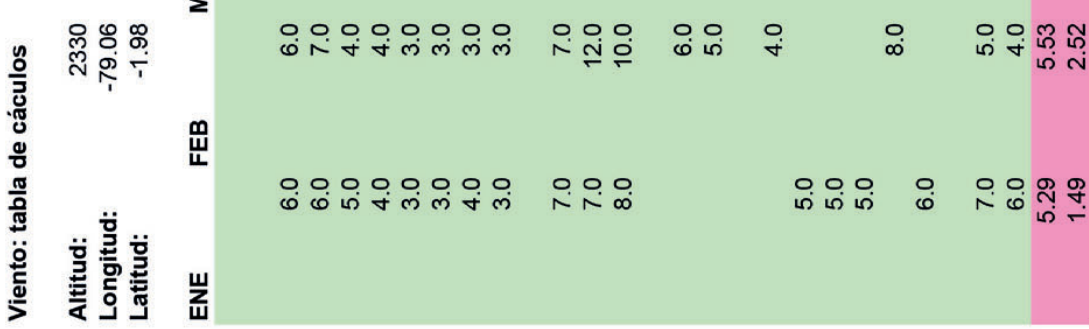




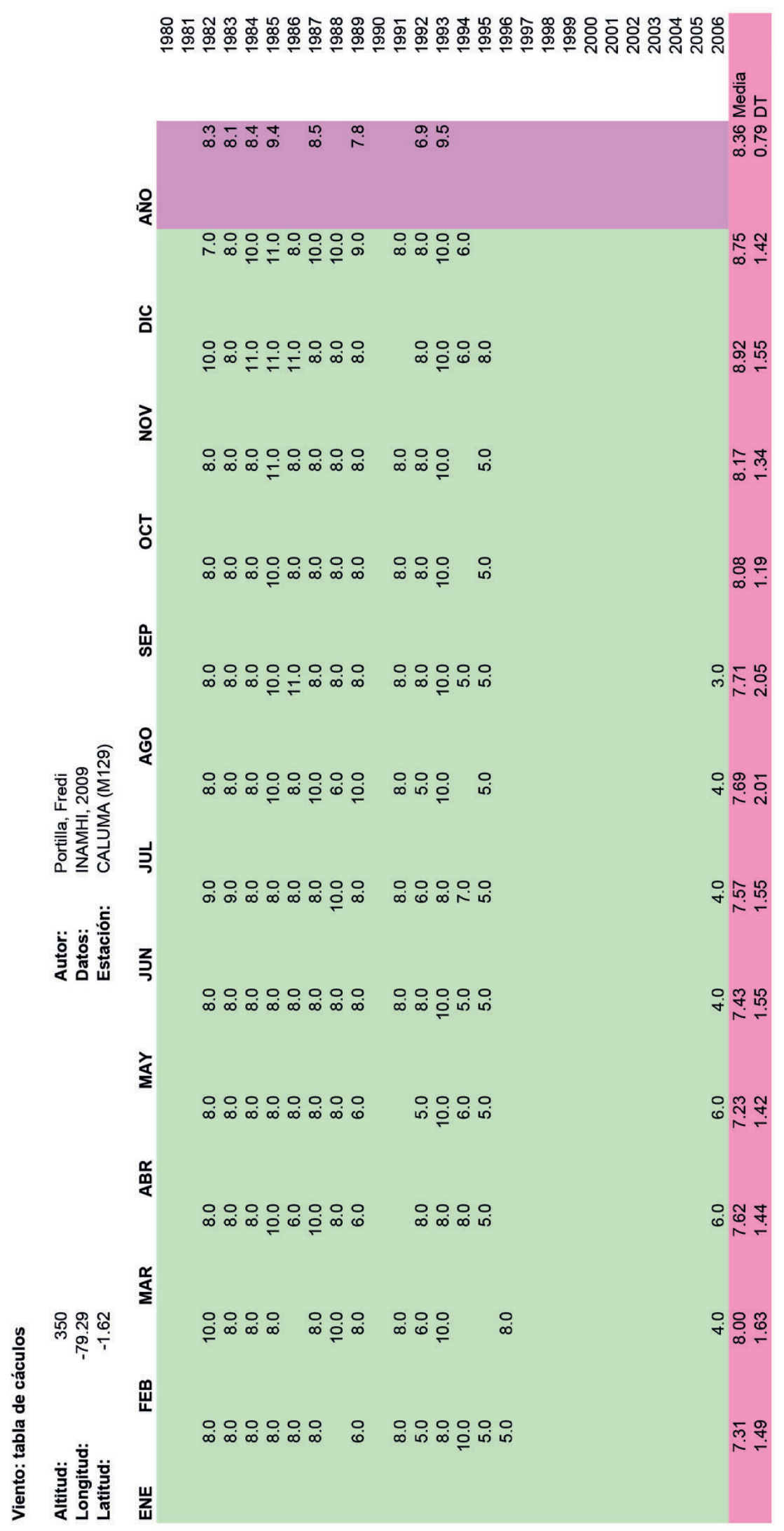




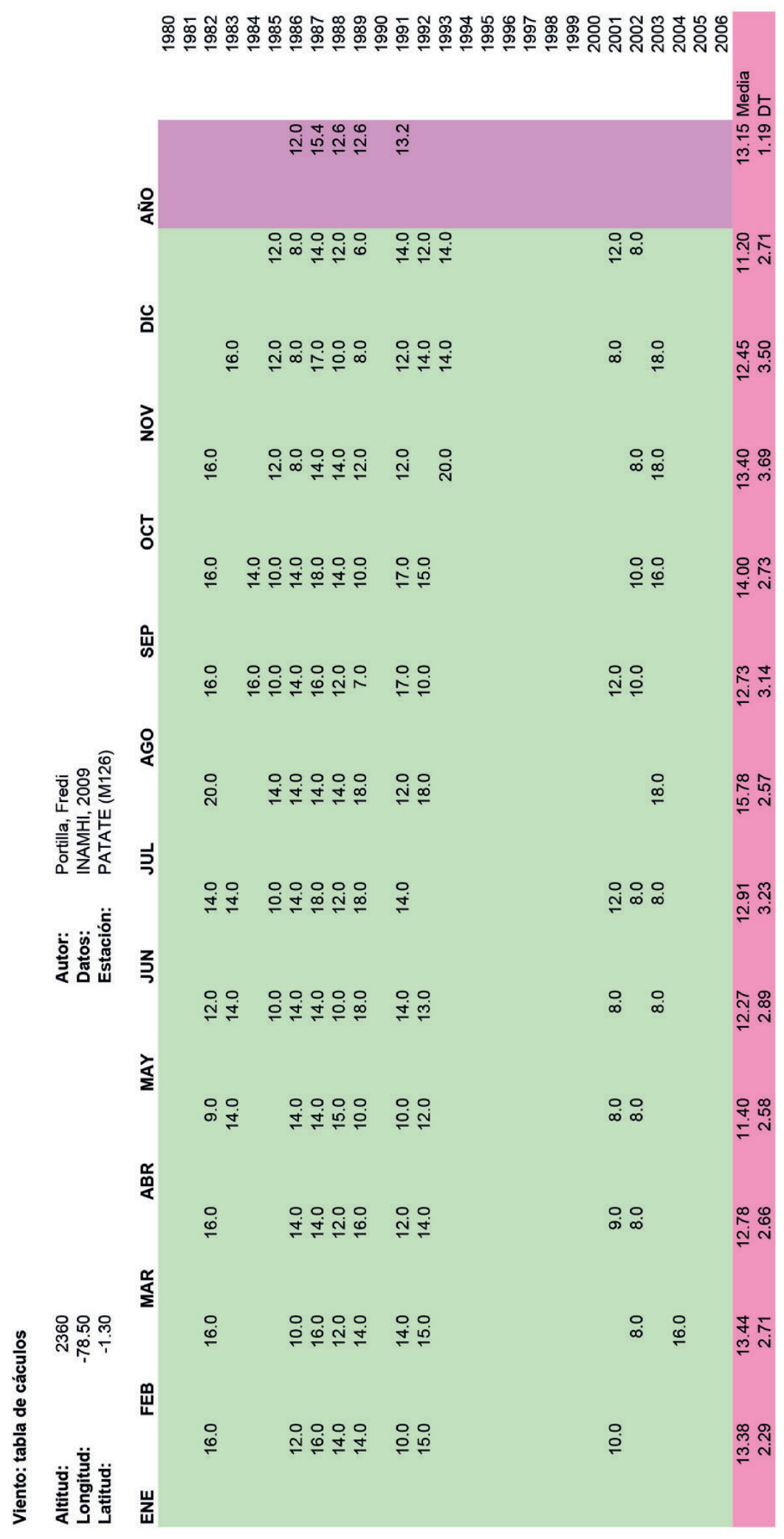


488

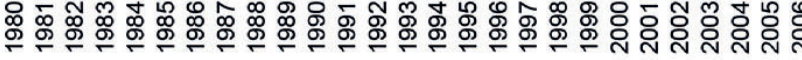

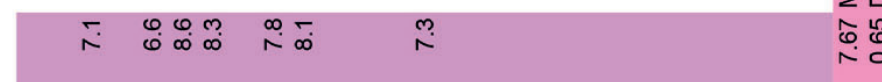

这

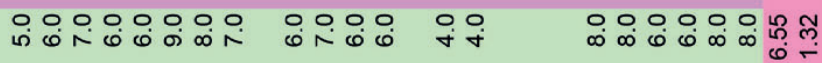

$\frac{0}{0}$

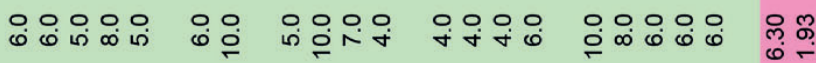

zे

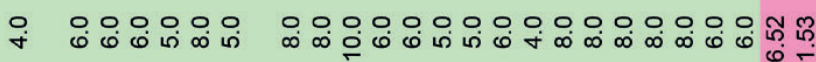

Ł

ఐ

岂

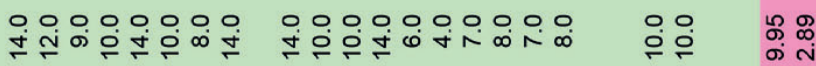

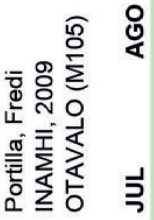

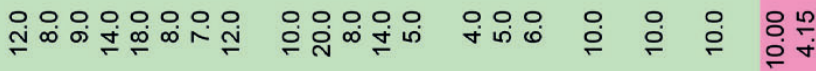

芒记蒿

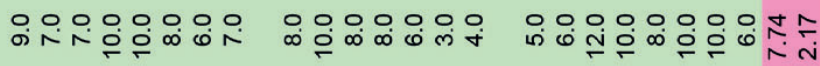

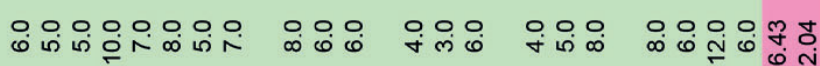

$\gtreqless$

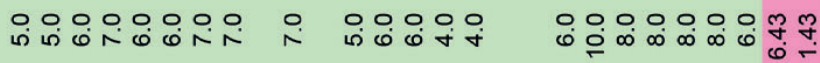

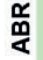

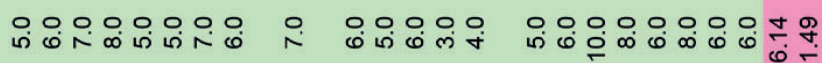

$\frac{\alpha}{\Sigma}$

党㲾范

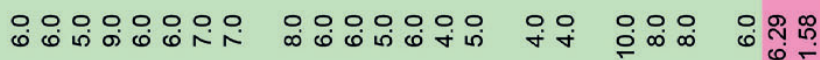

虫

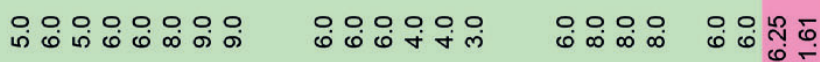

崖 


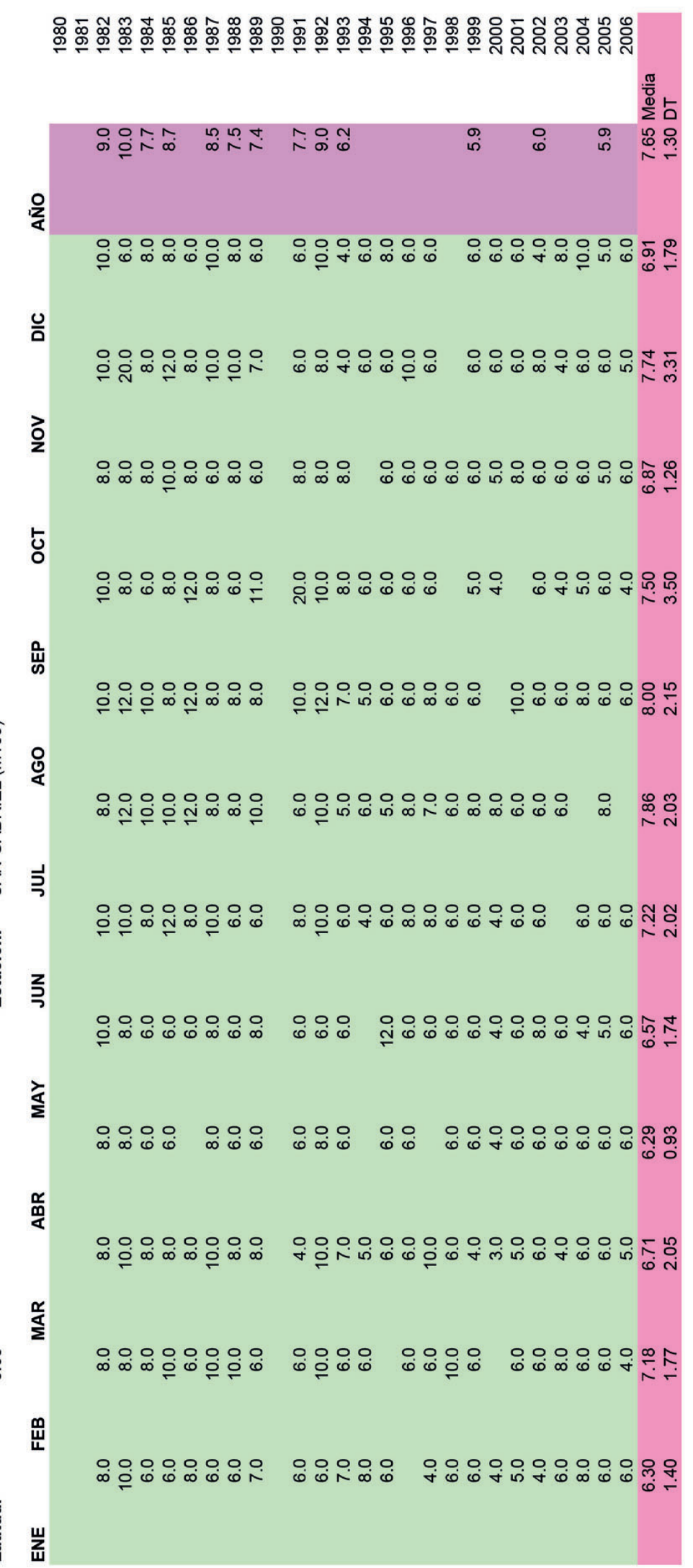




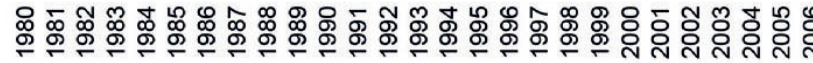

$\stackrel{\infty}{\infty} \infty$

这

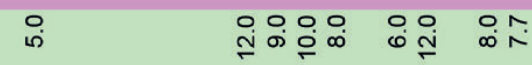

음

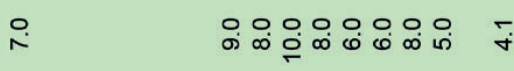

o

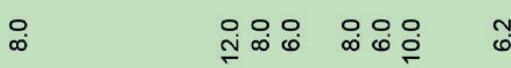

Ł

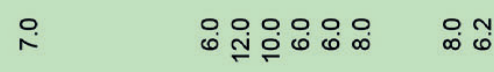

峞

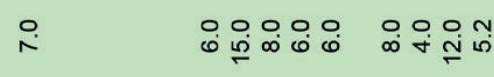

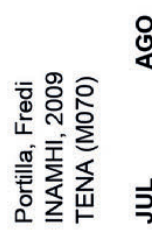

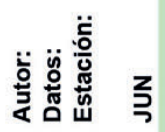

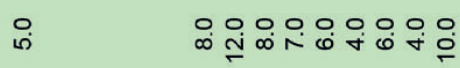

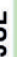

$\neg$

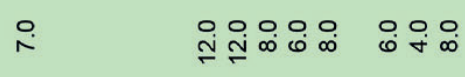

$\overleftrightarrow{\frac{x}{2}}$

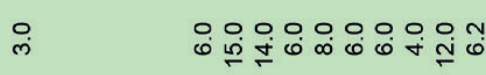

鯄

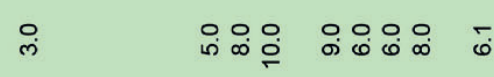

営 


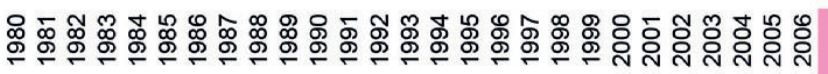

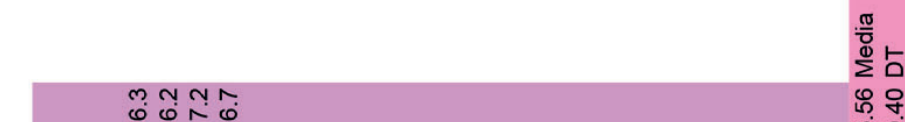

安

웋웅우웅요

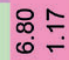

음

엏욹웅영

oे

웅웅웅웅웅

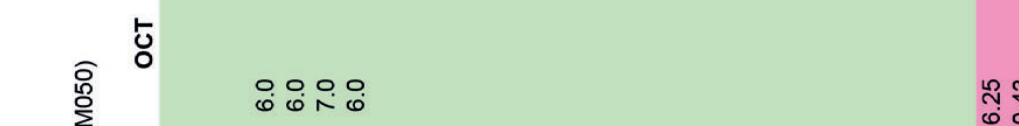

飠

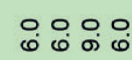

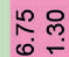

웅

कृ 잉

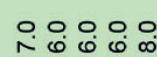

5

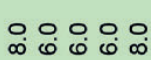

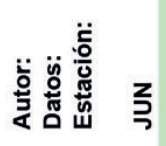

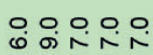

$\frac{\grave{t}}{2}$

웉웅웅웅

$\frac{\alpha}{\frac{0}{\alpha}}$

웋웅요영

乨

웋웅우웅 
492

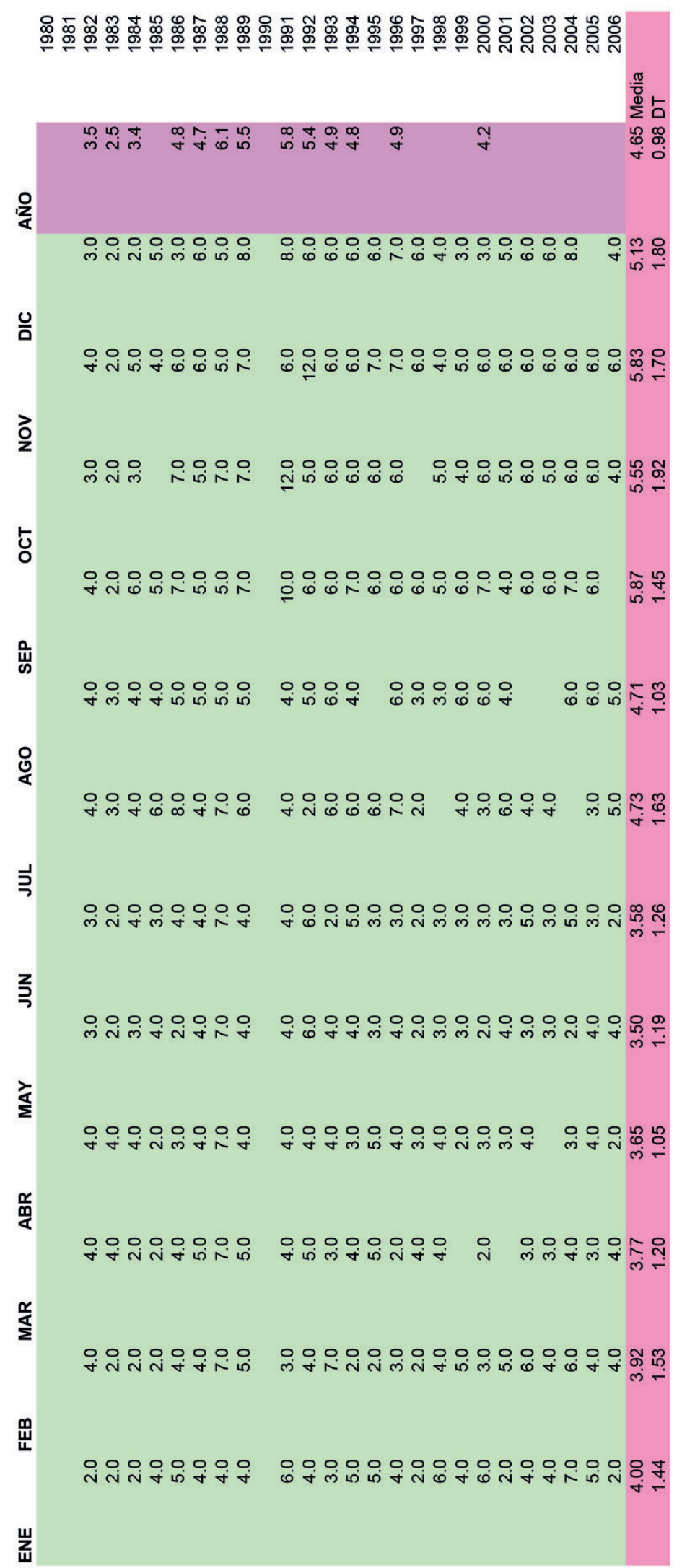




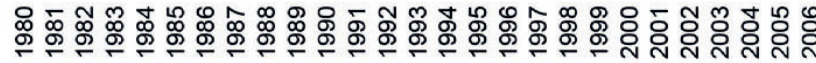

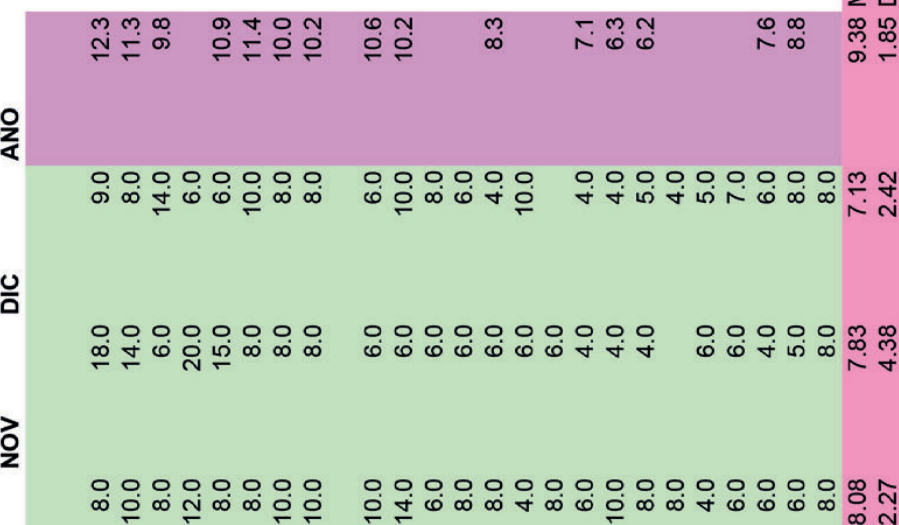

Ł

언운워

论

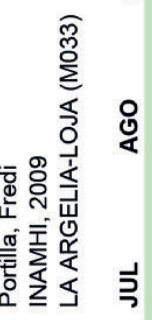

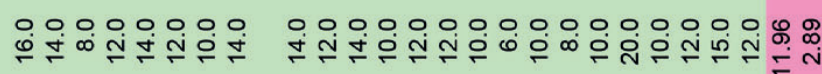

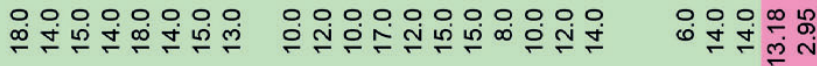

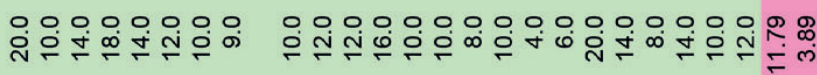

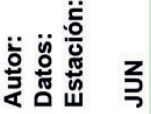

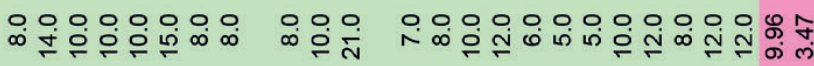

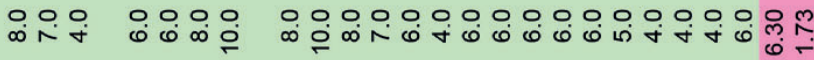

㩊

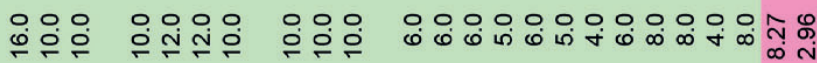

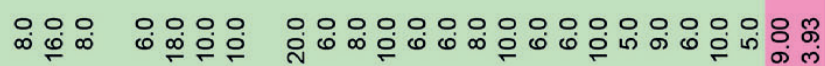

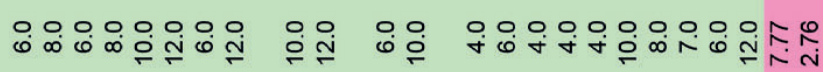

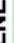




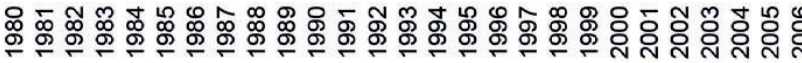

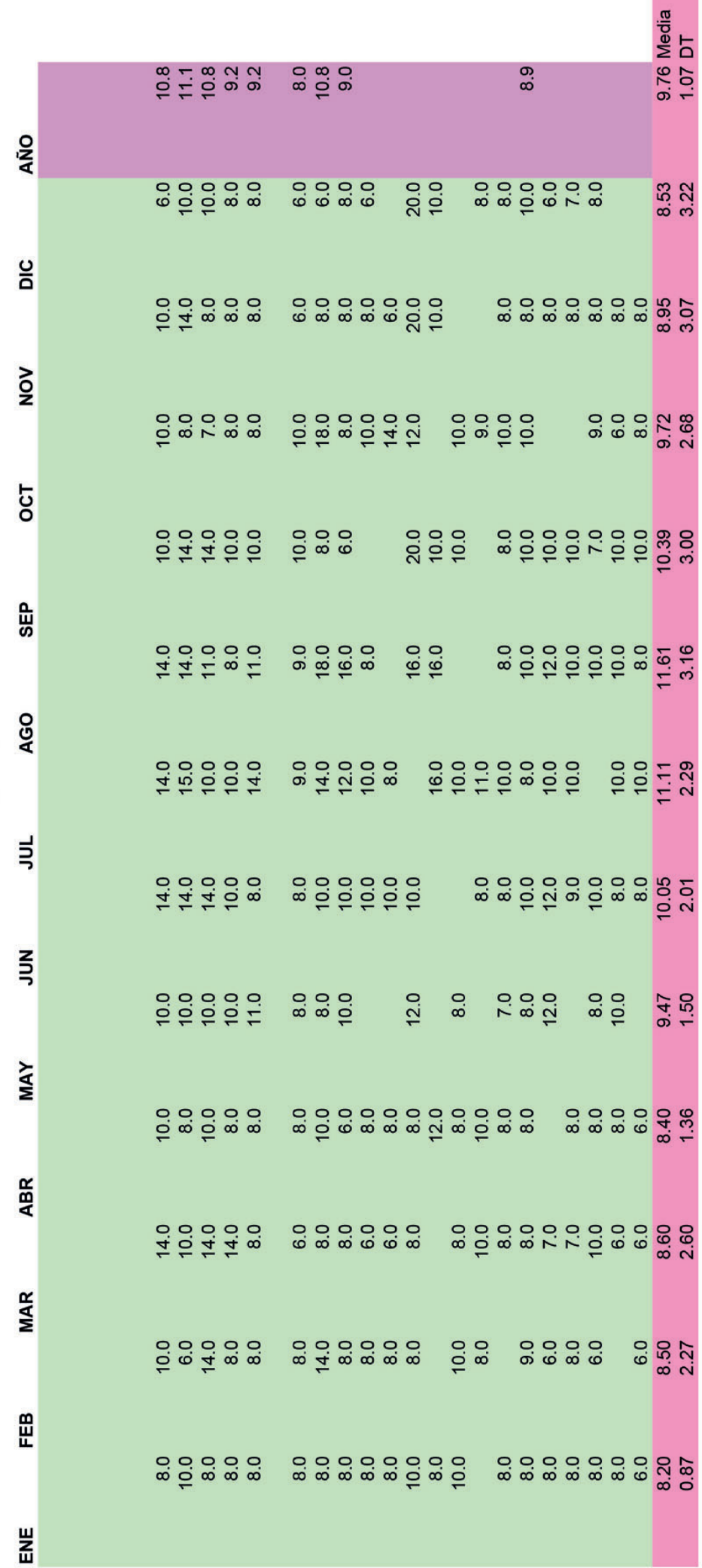


495

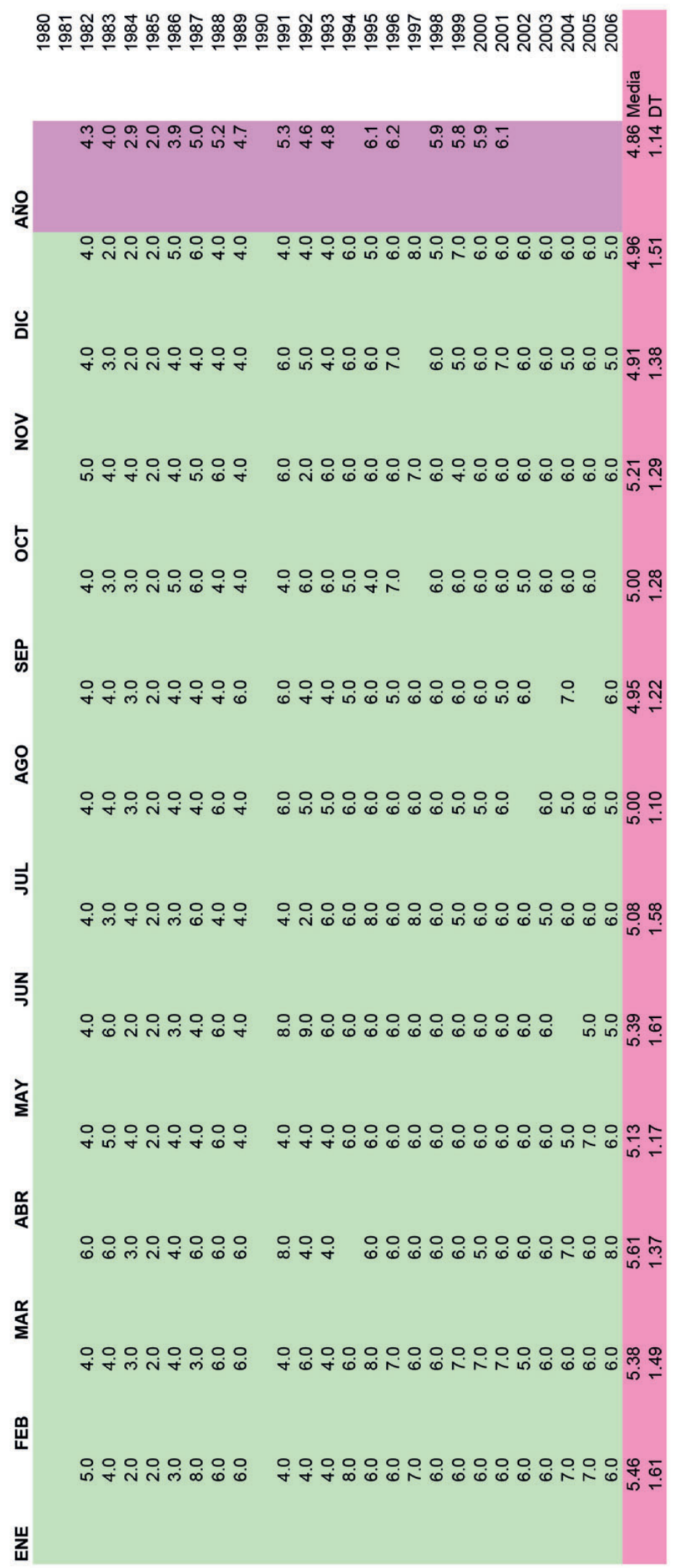




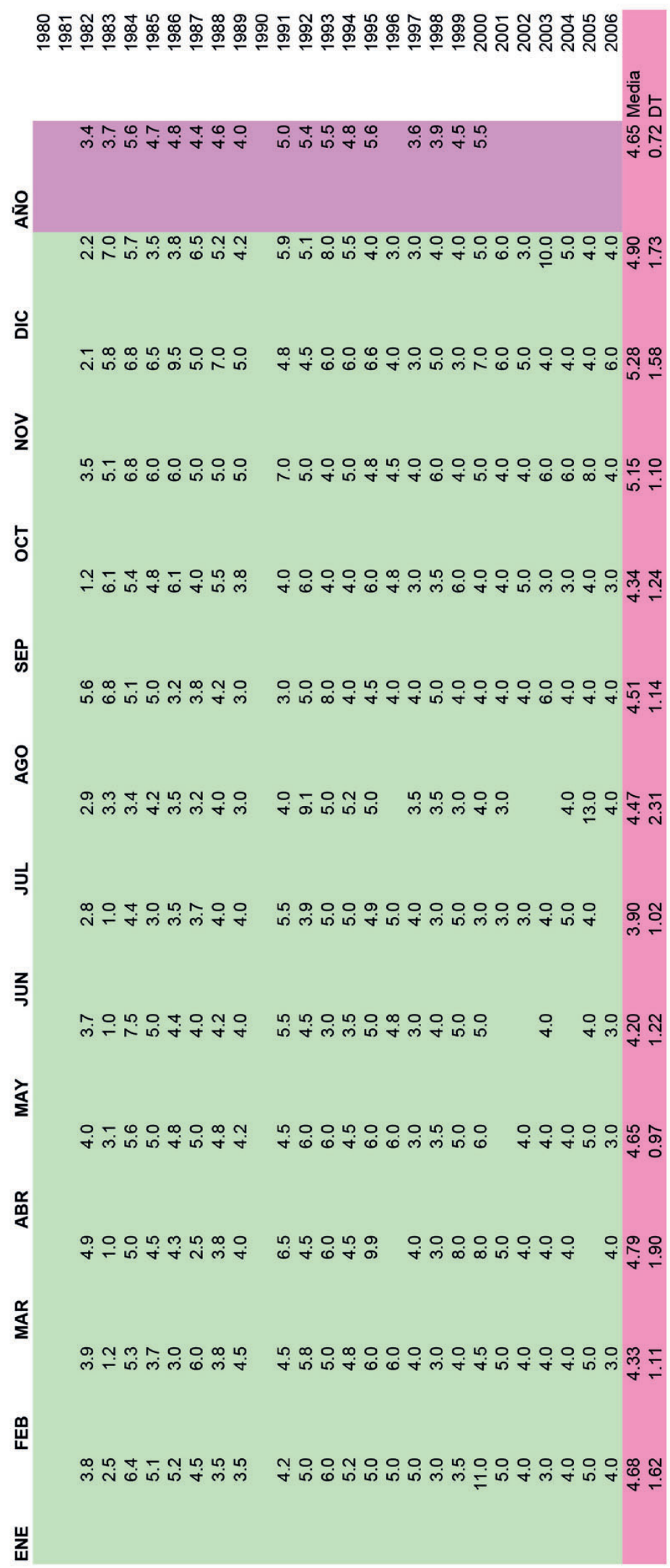




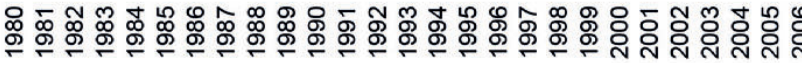

$\frac{10}{4}$

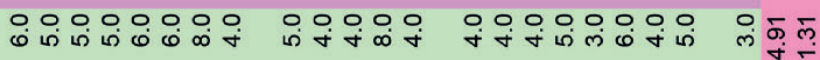

$\frac{0}{0}$

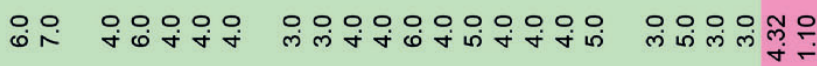

ว

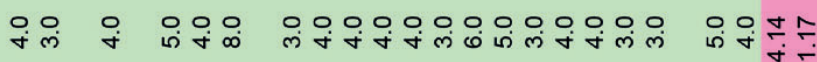

Ł

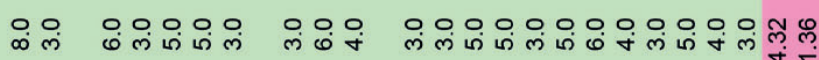

㩊

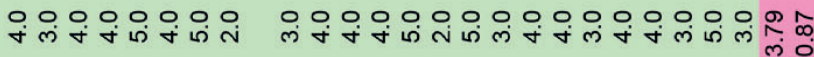

$\frac{\alpha}{\Sigma}$

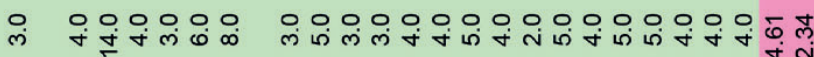

思 


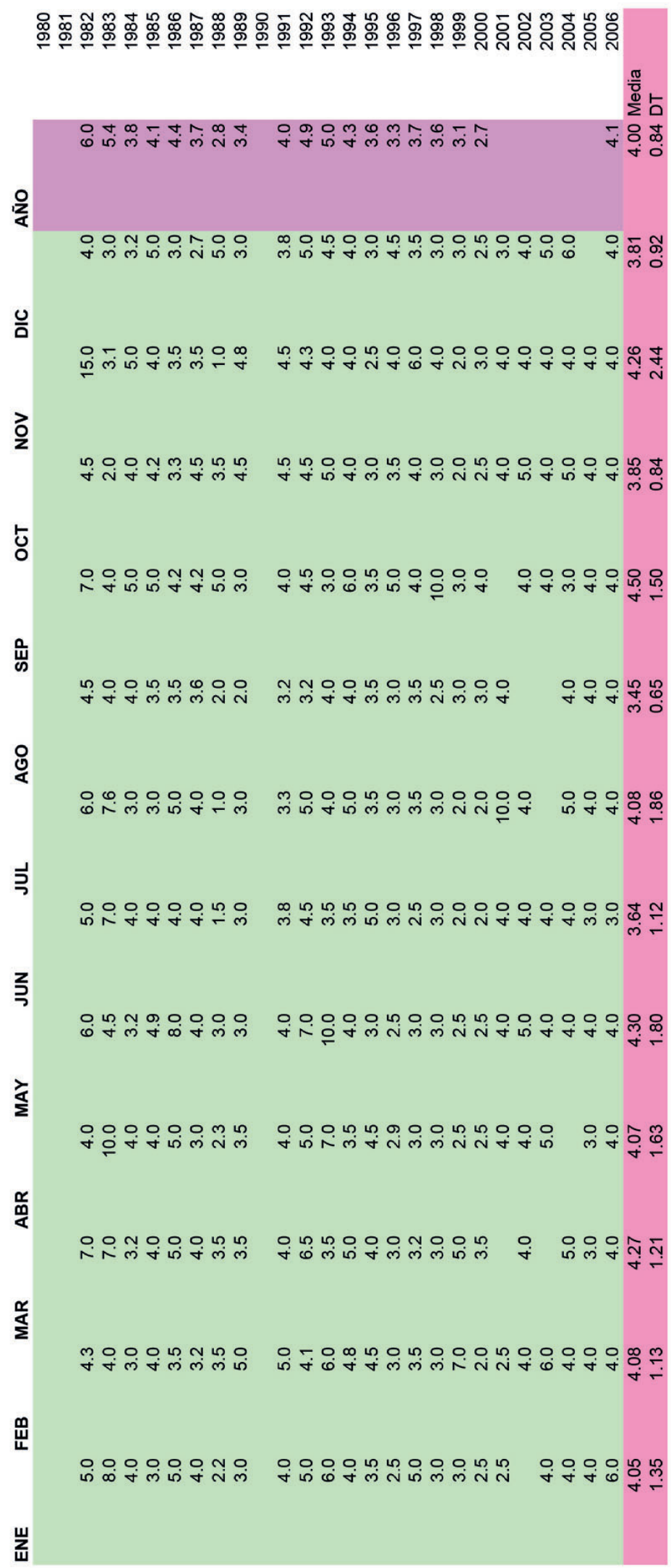




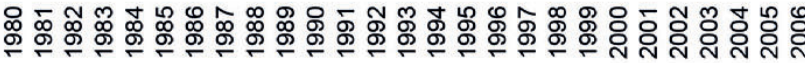

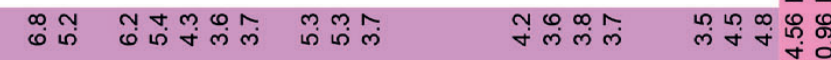

운

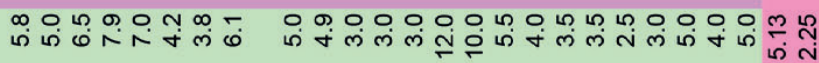

$\frac{0}{0}$

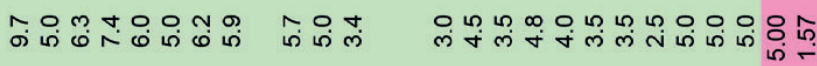

ว

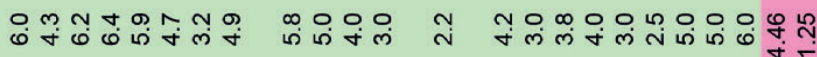

Ł

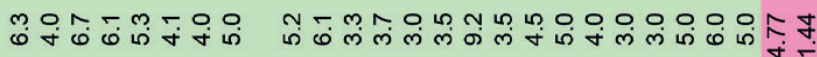

㞻

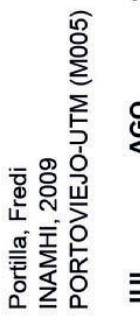

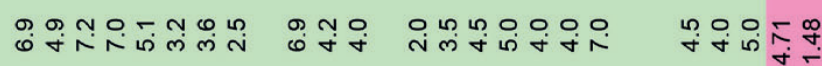

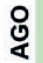

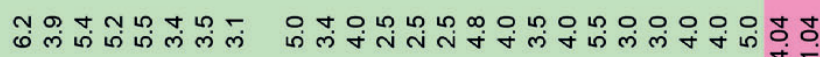

5

우

范范雚

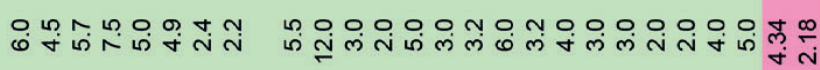

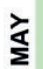

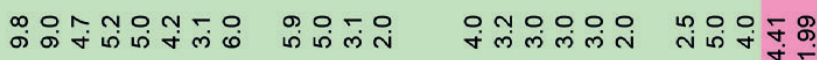

$\stackrel{\frac{\alpha}{m}}{\frac{1}{\alpha}}$

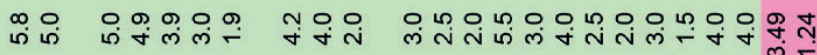

$\stackrel{\frac{\alpha}{\alpha}}{\Sigma}$

8 安草

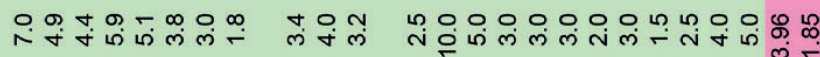

延

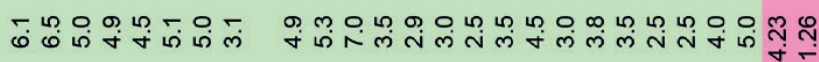

崖 


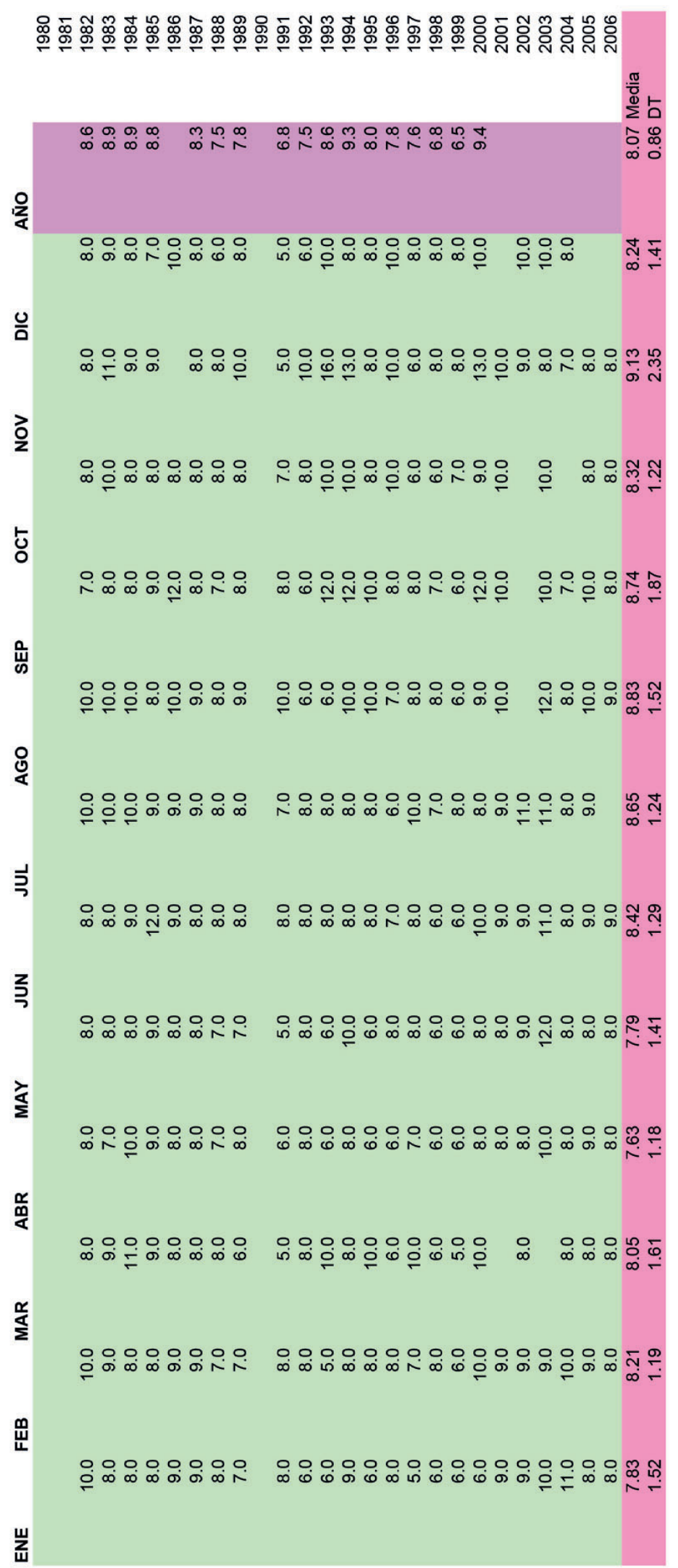


501

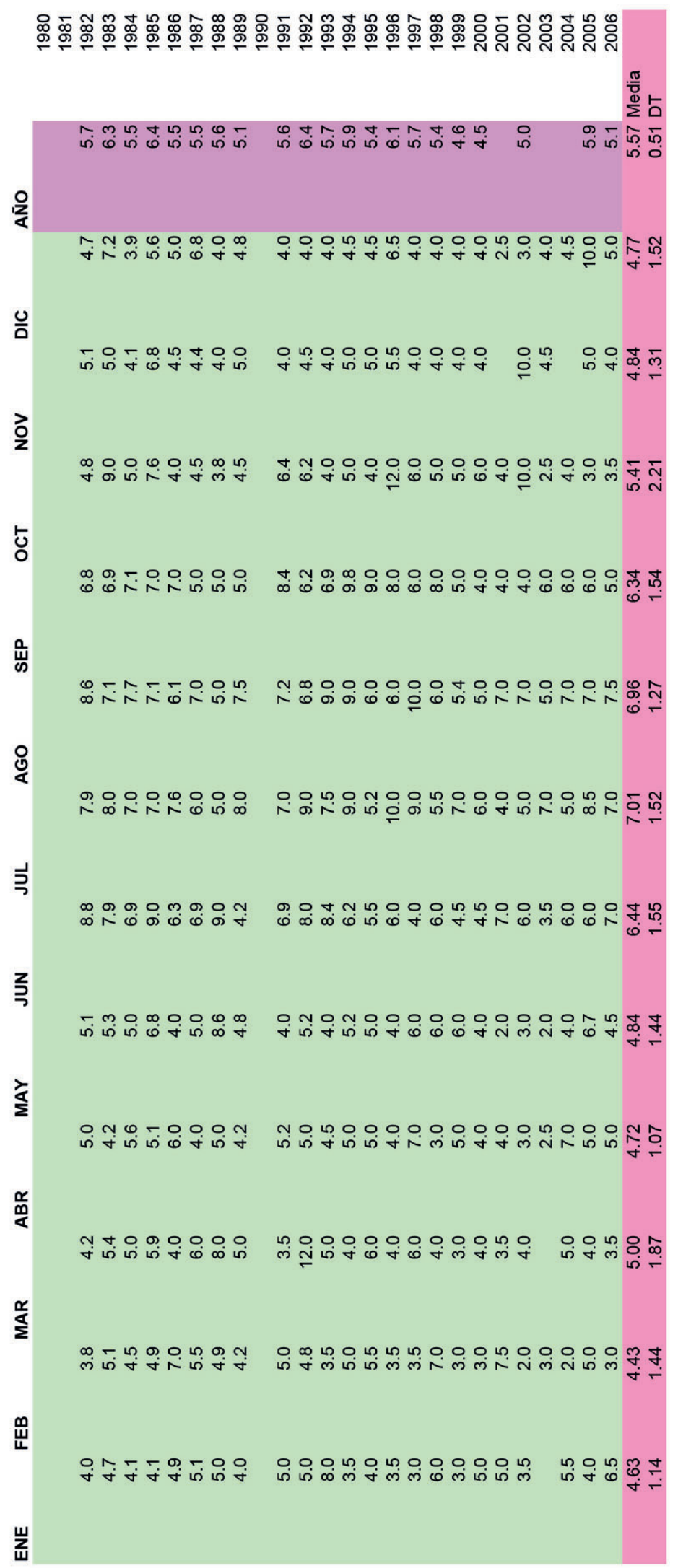


502

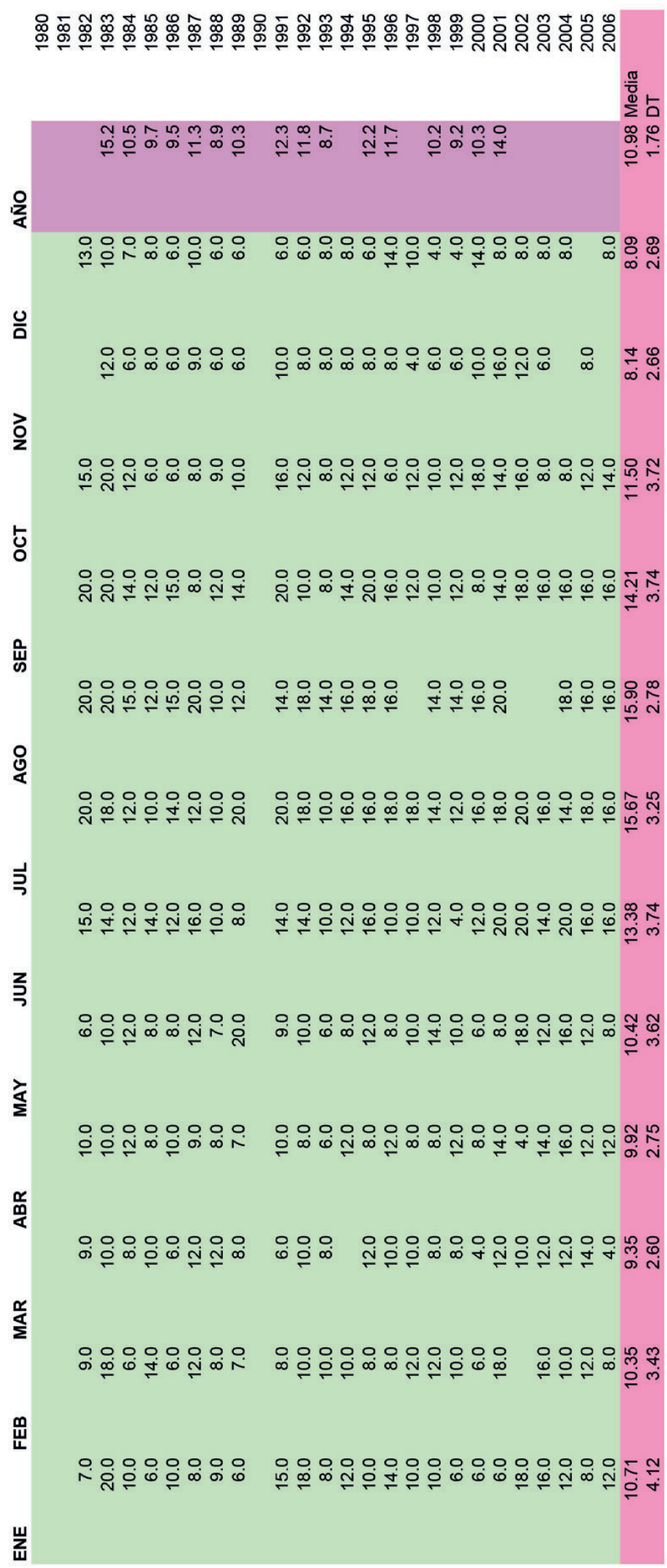




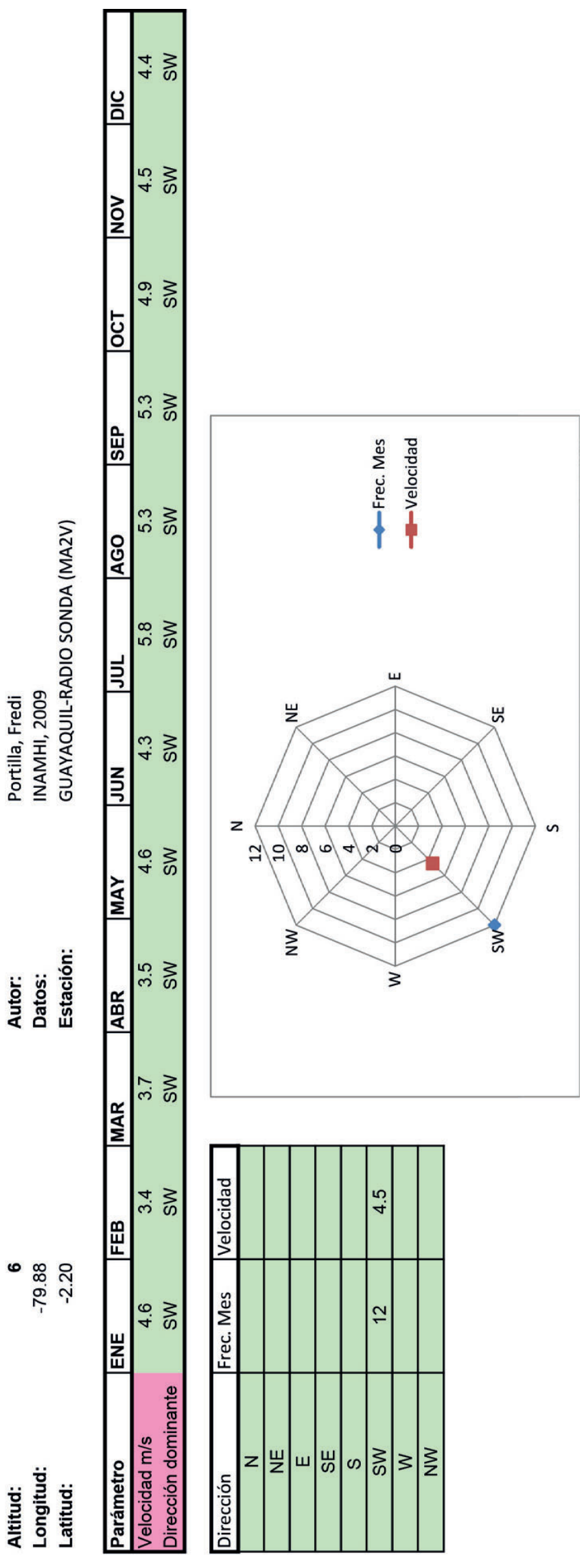




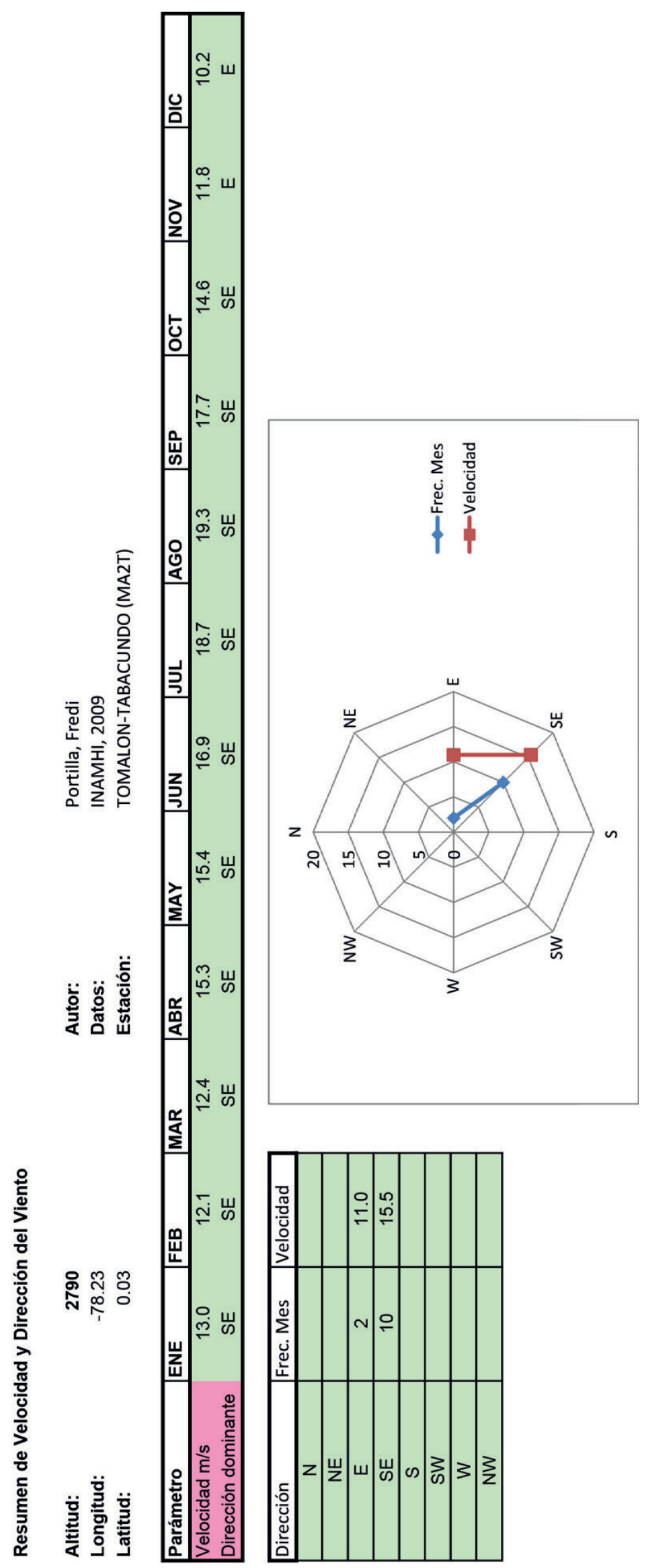




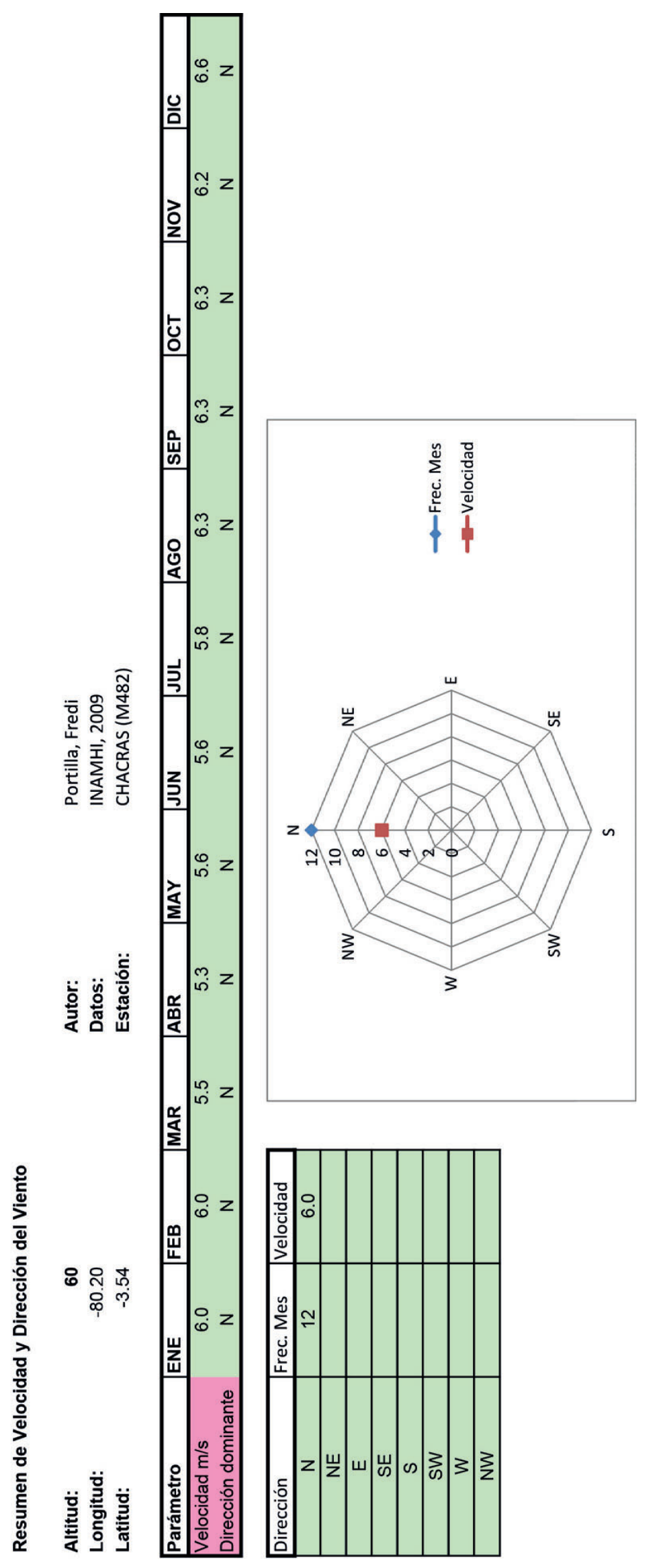




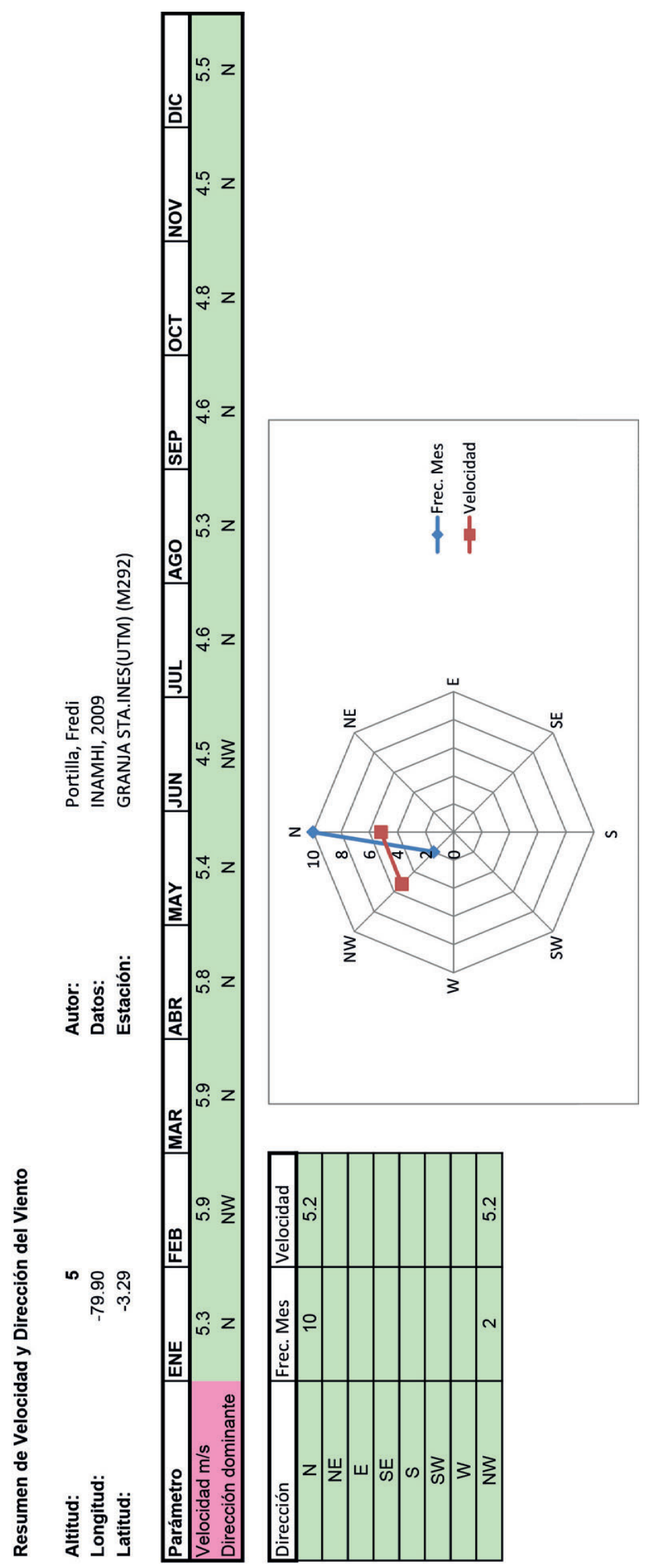




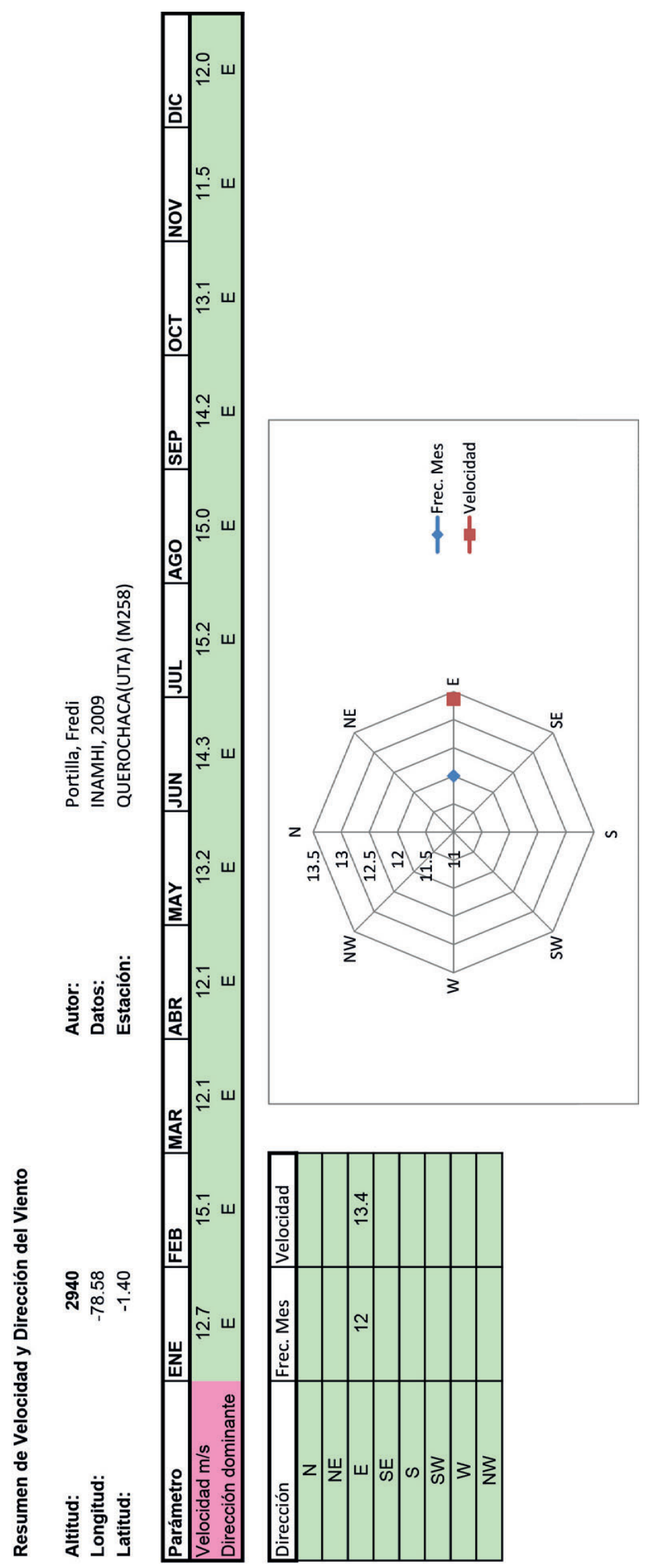




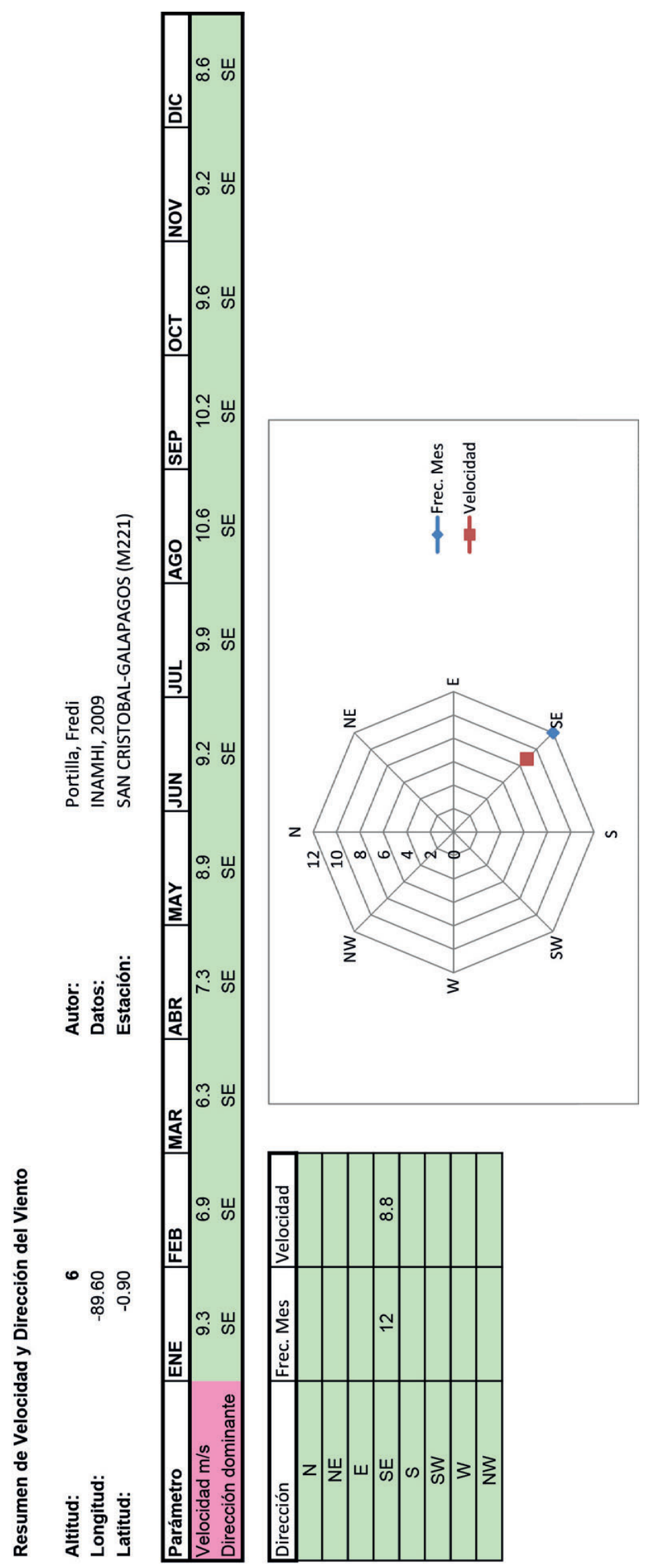




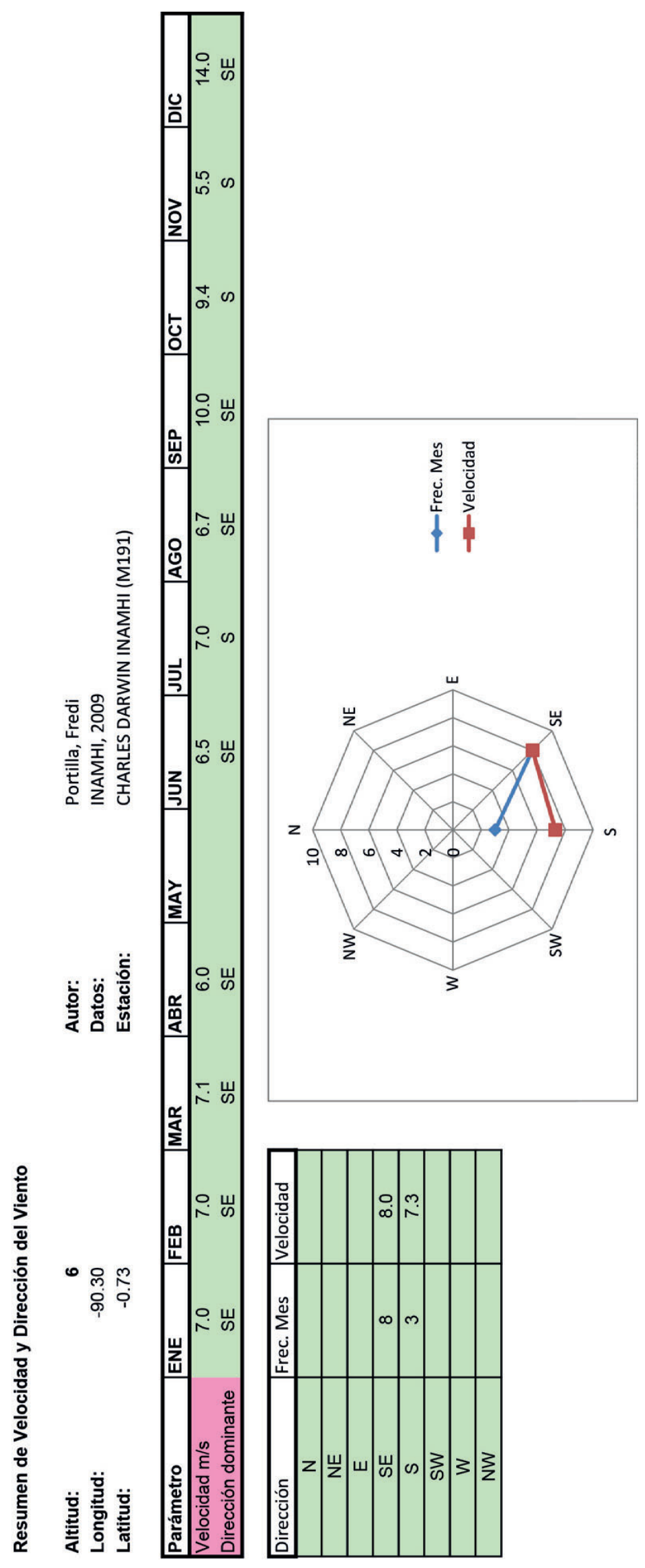




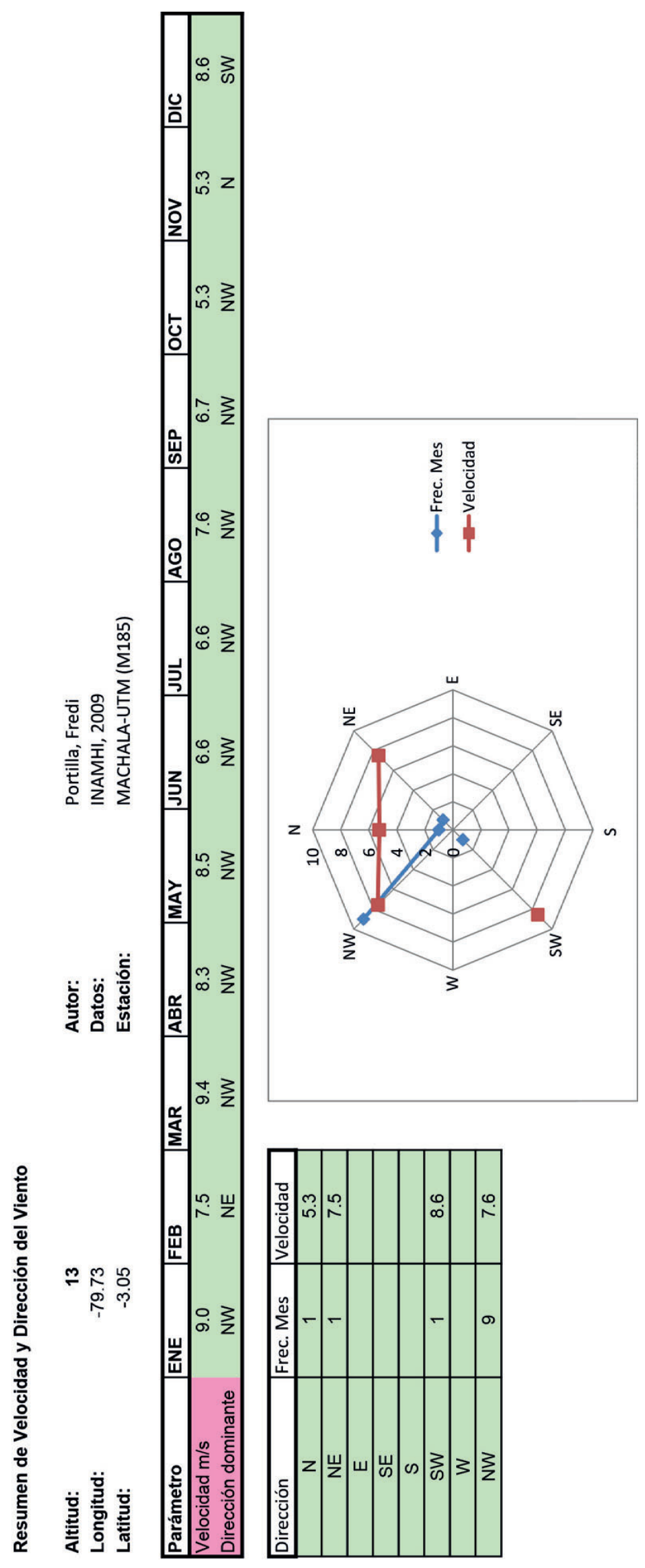




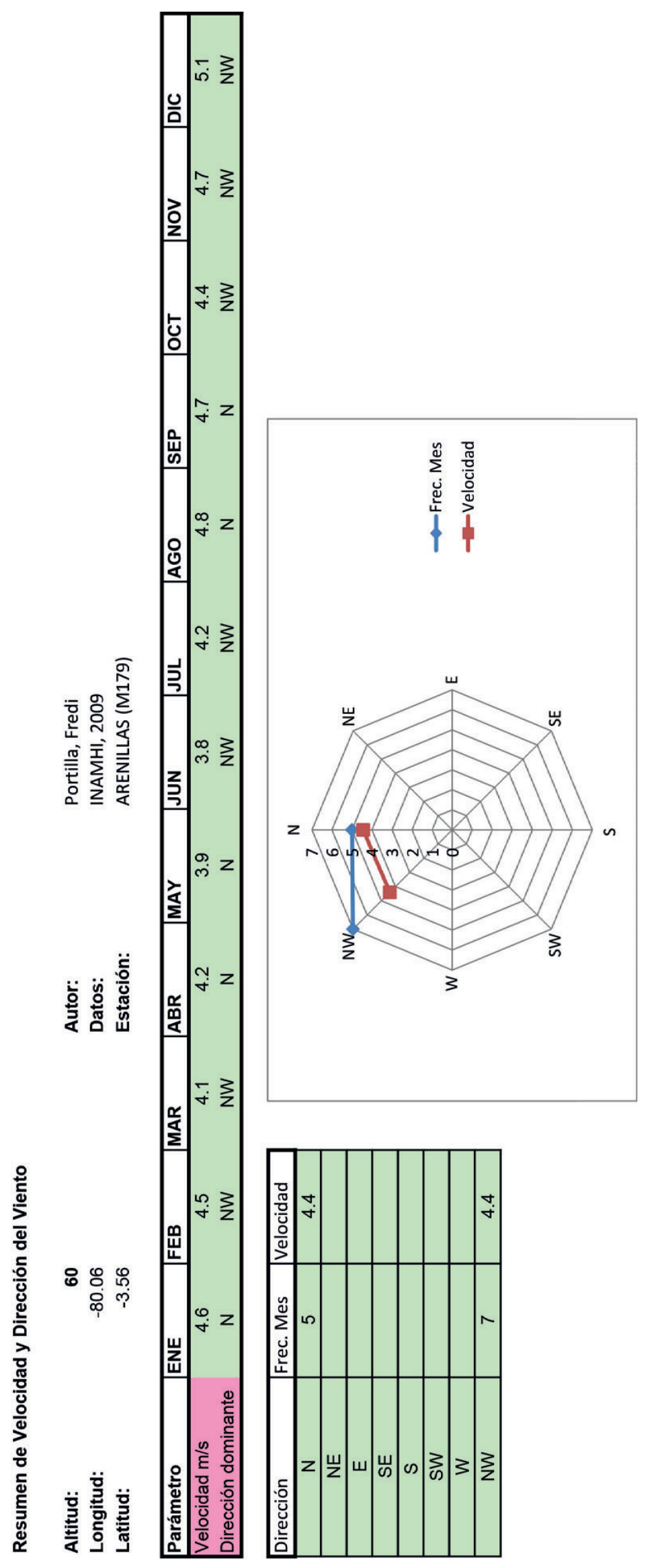




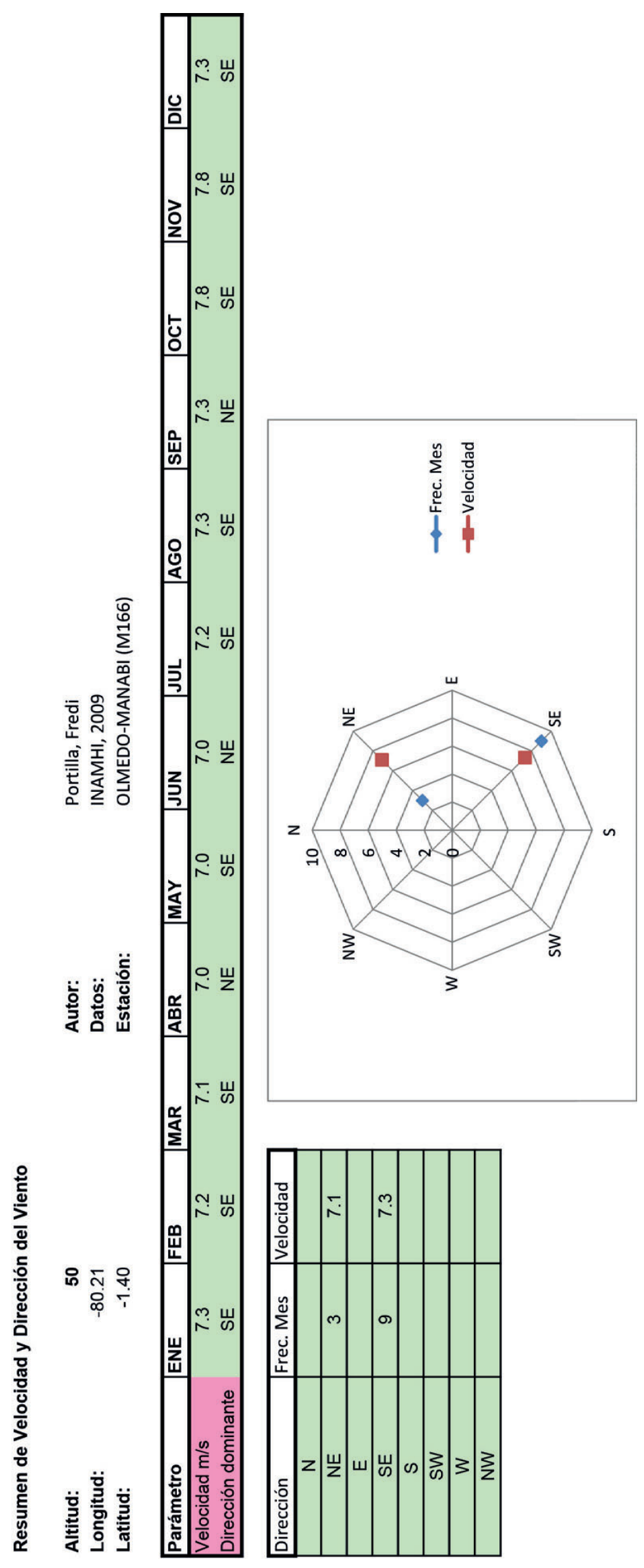




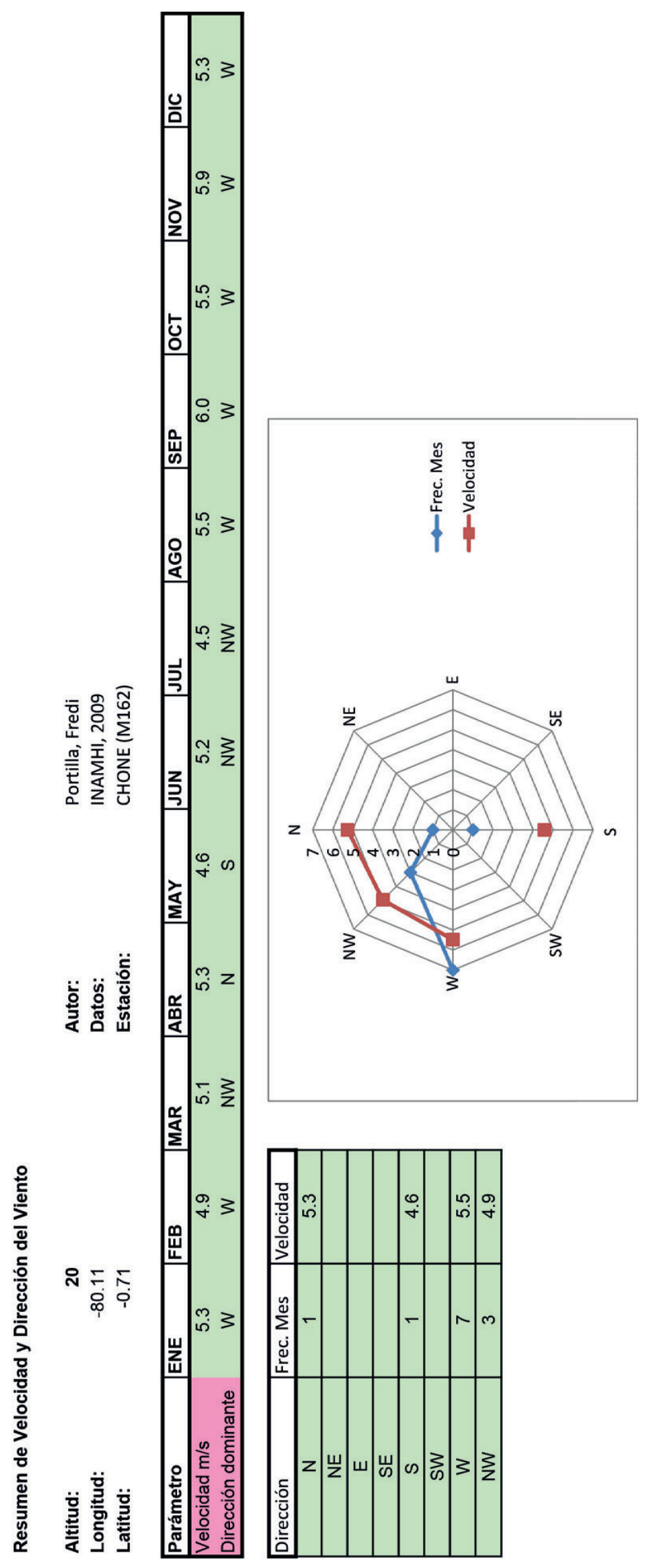




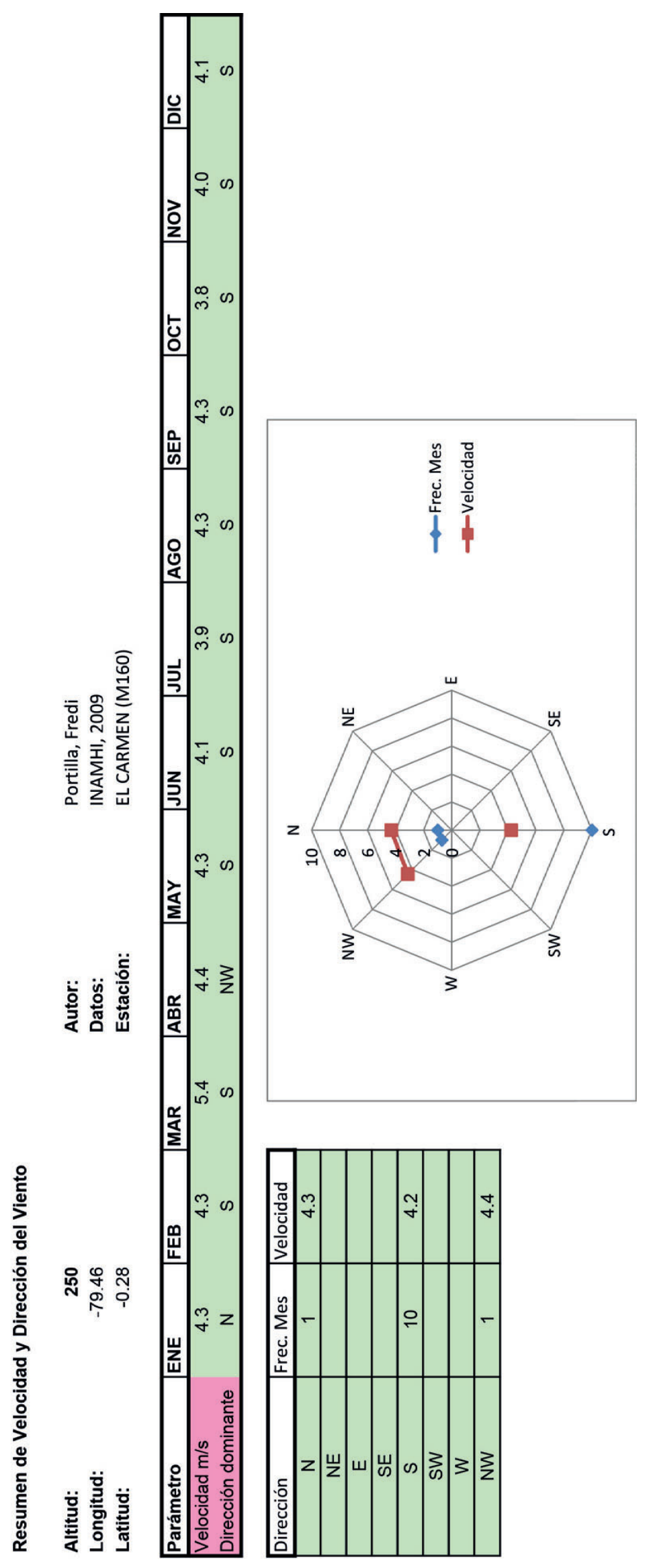




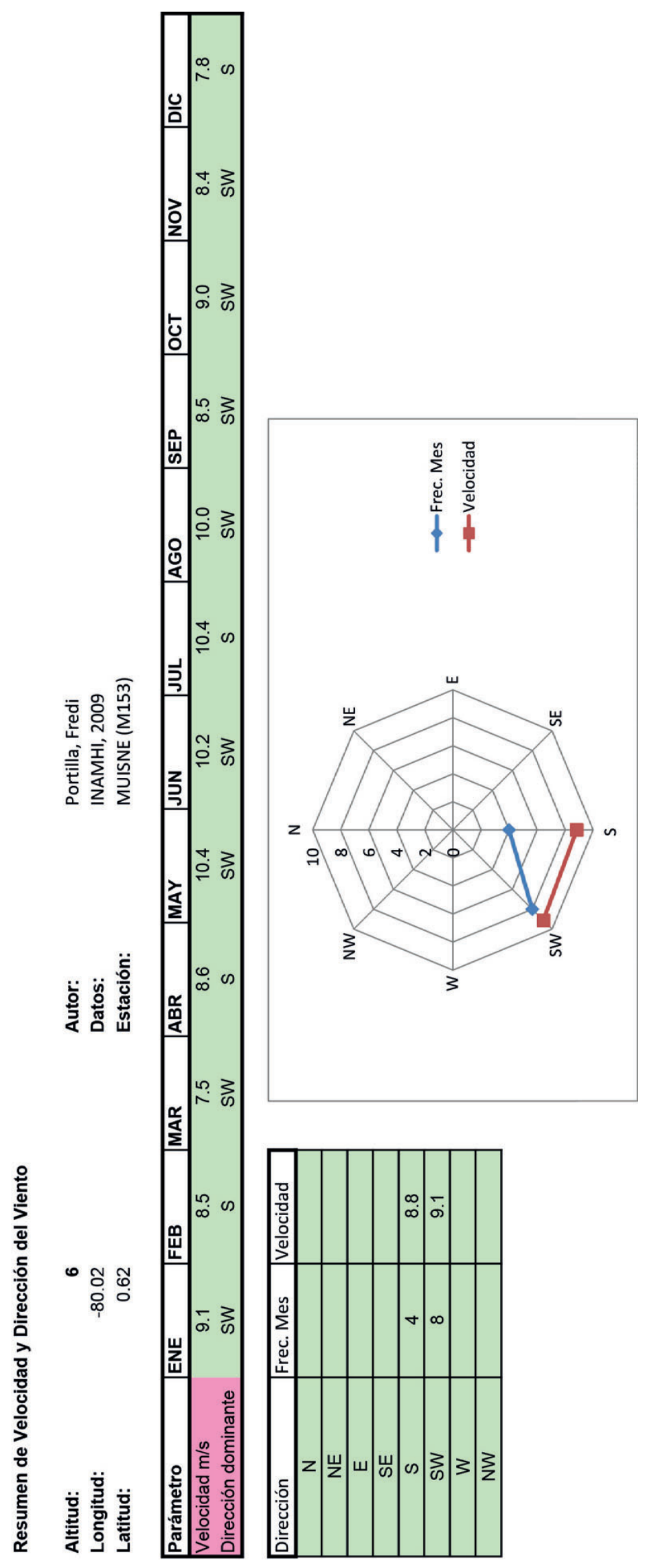




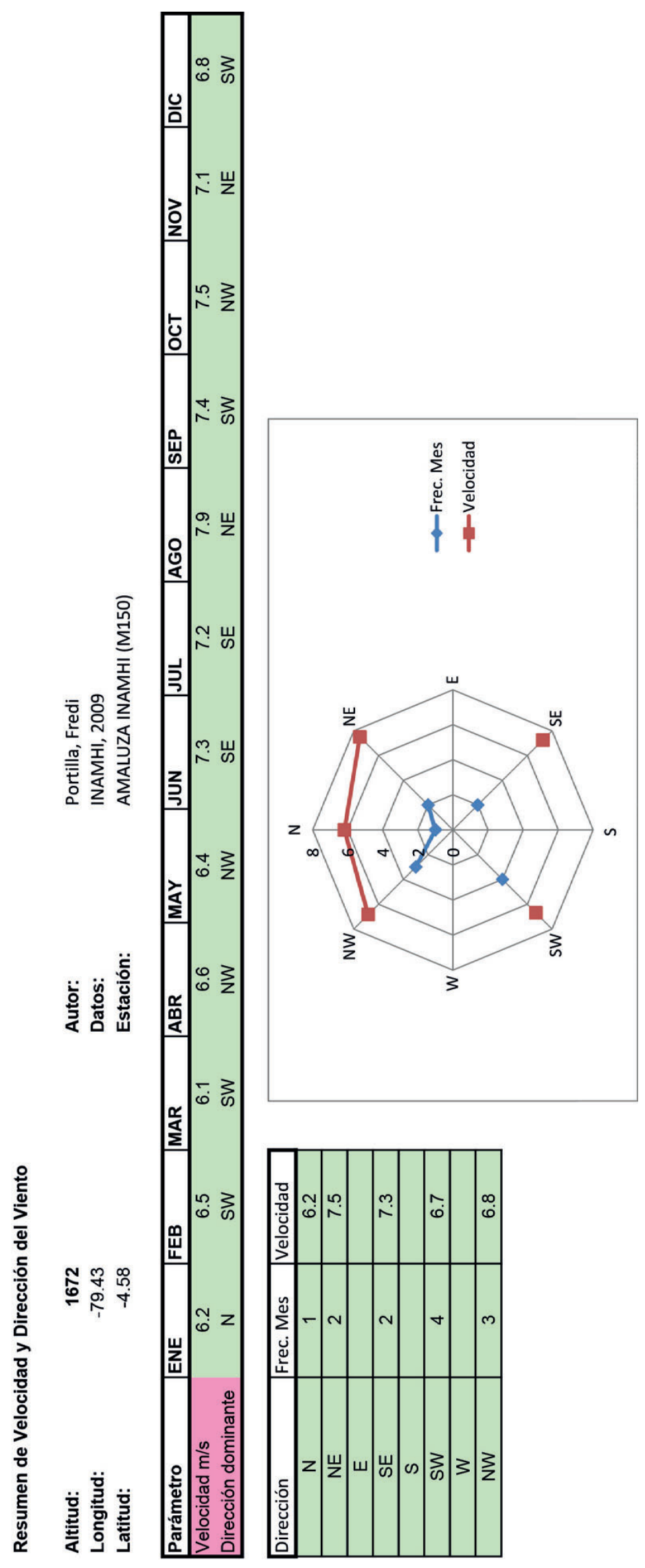




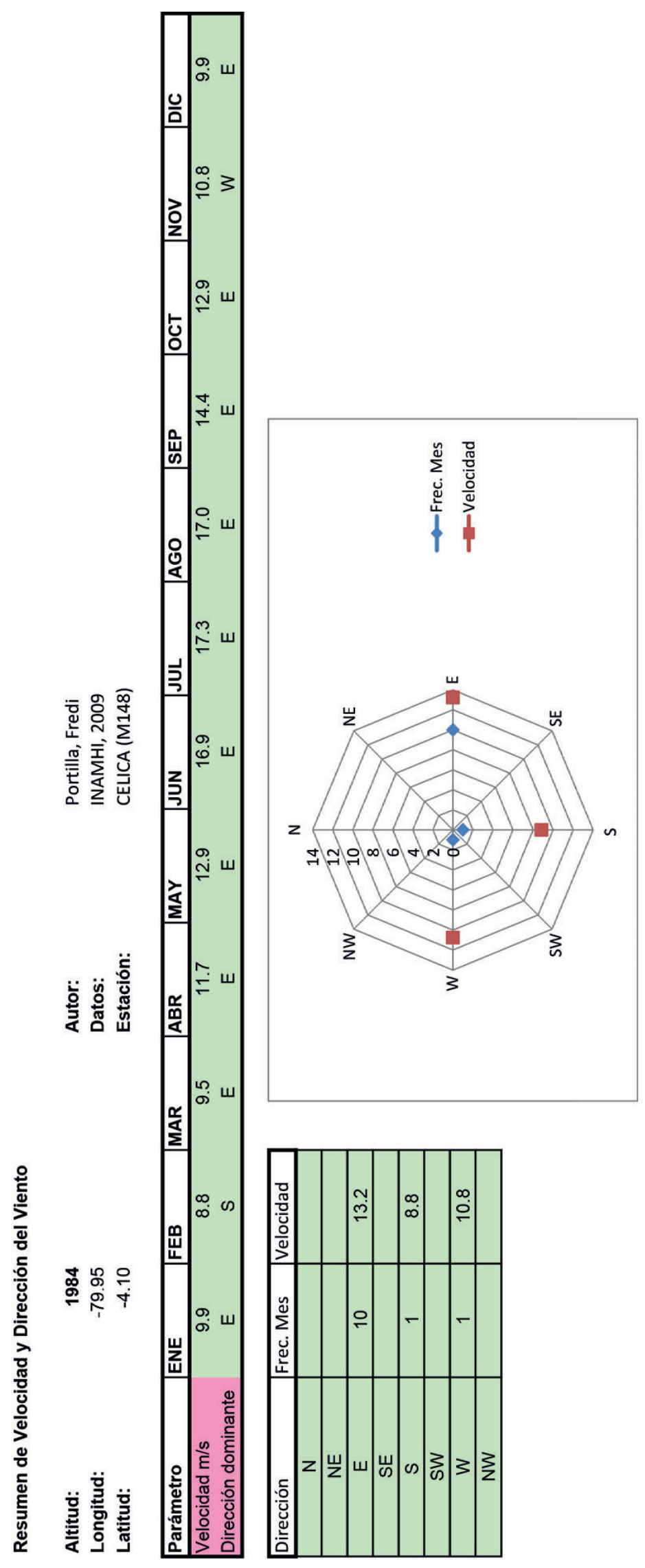




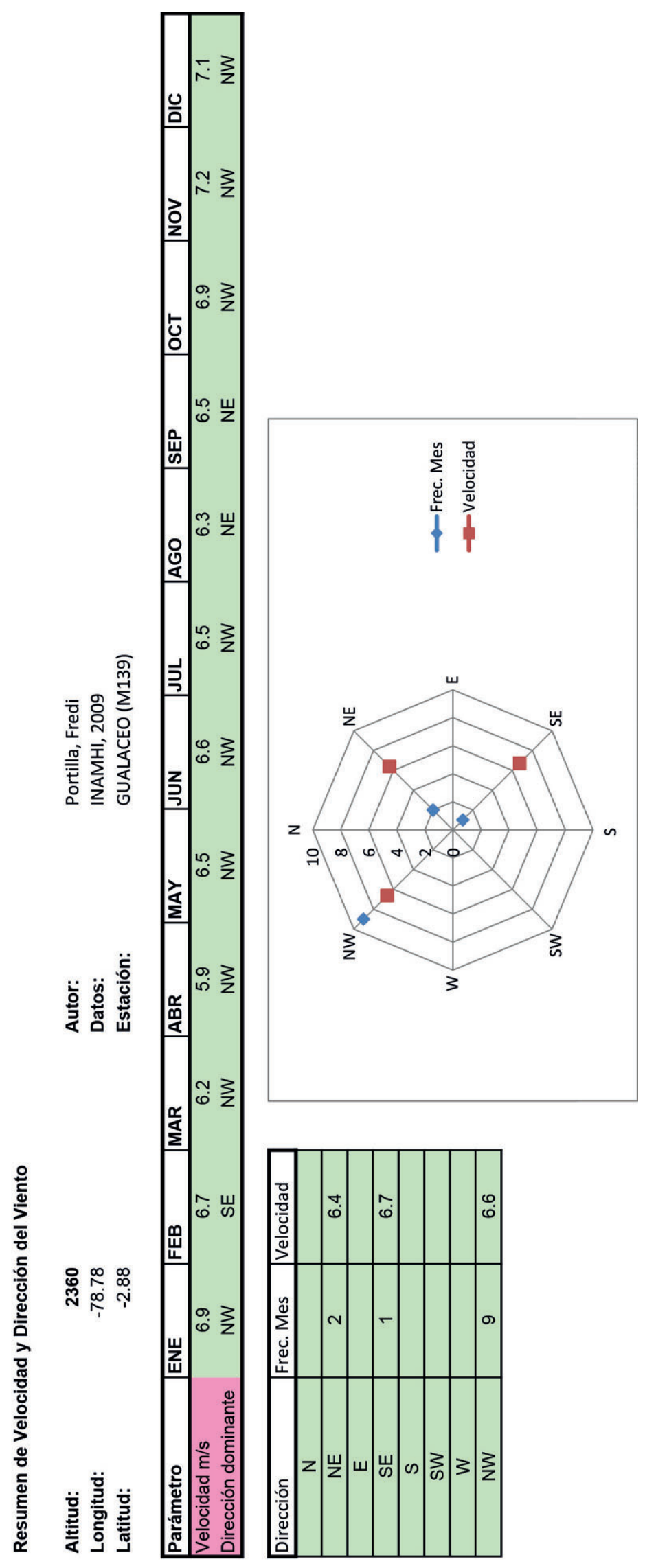




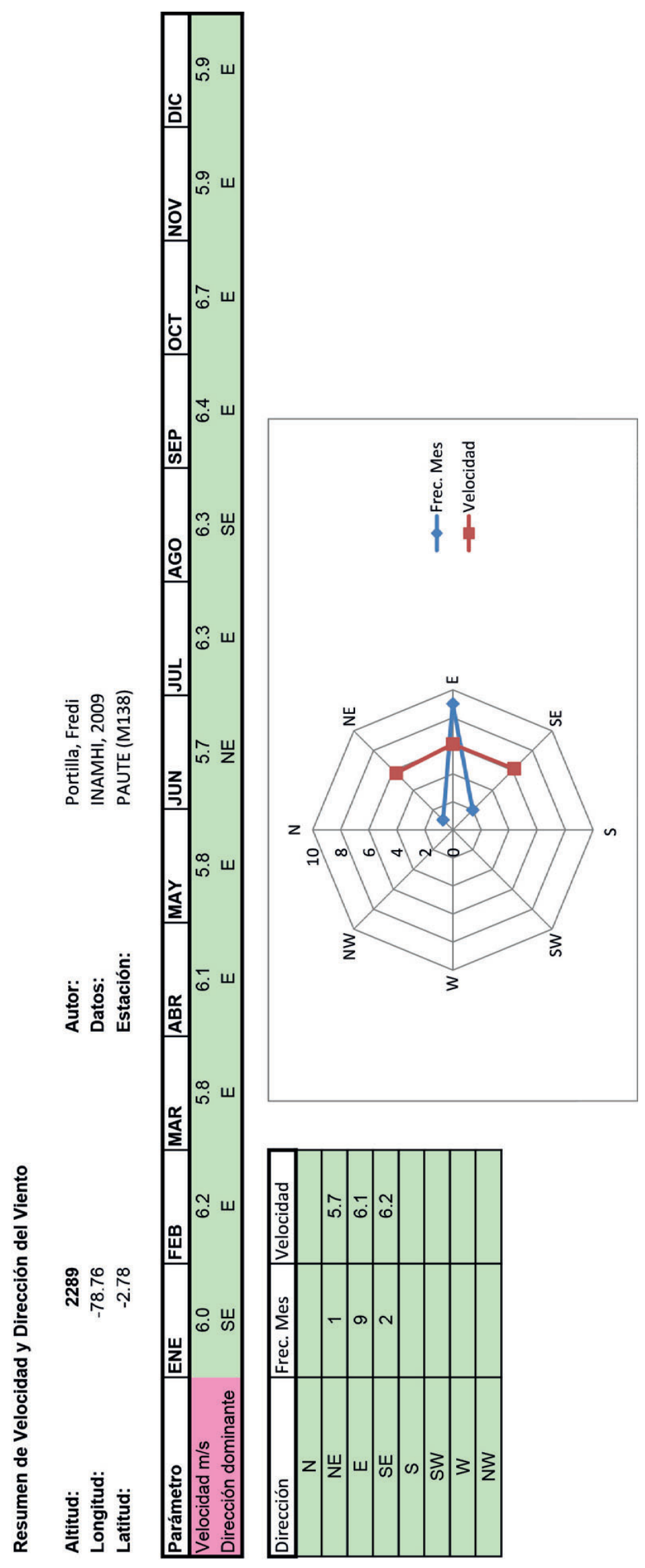




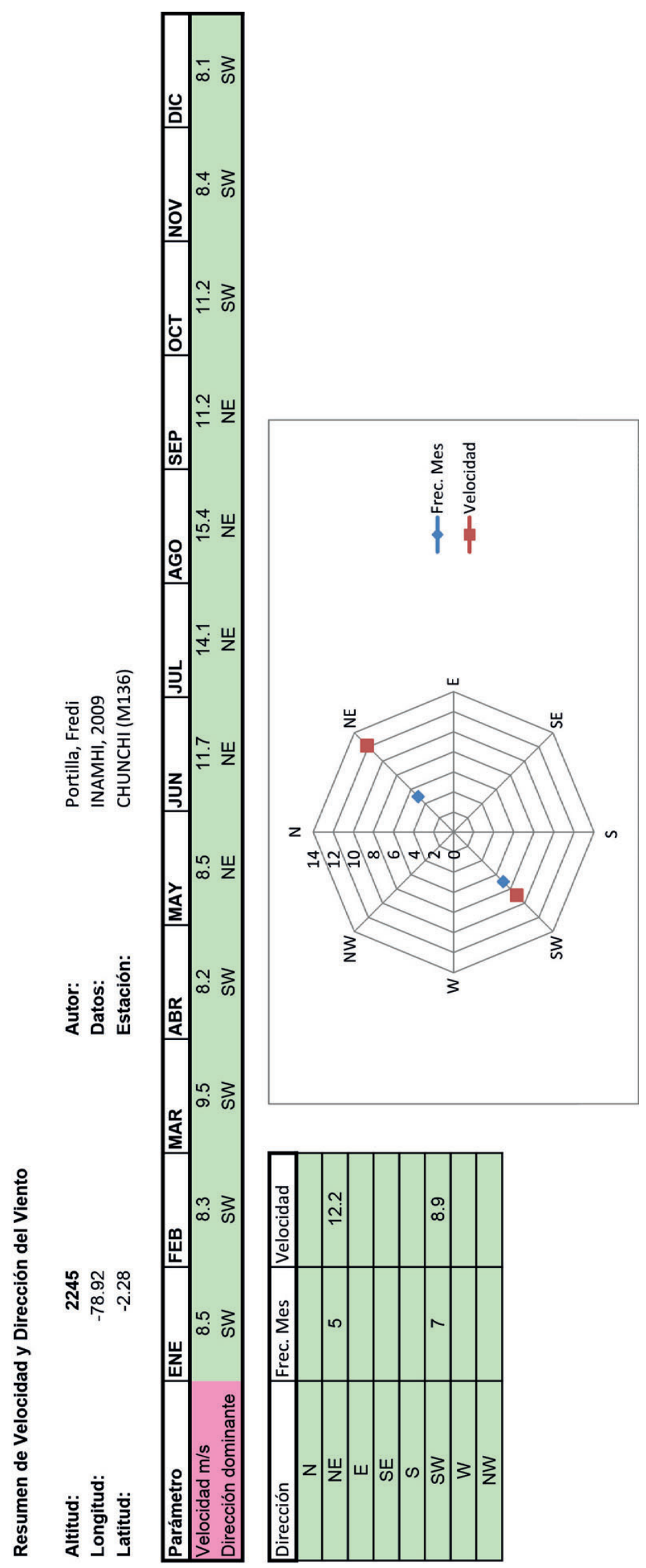




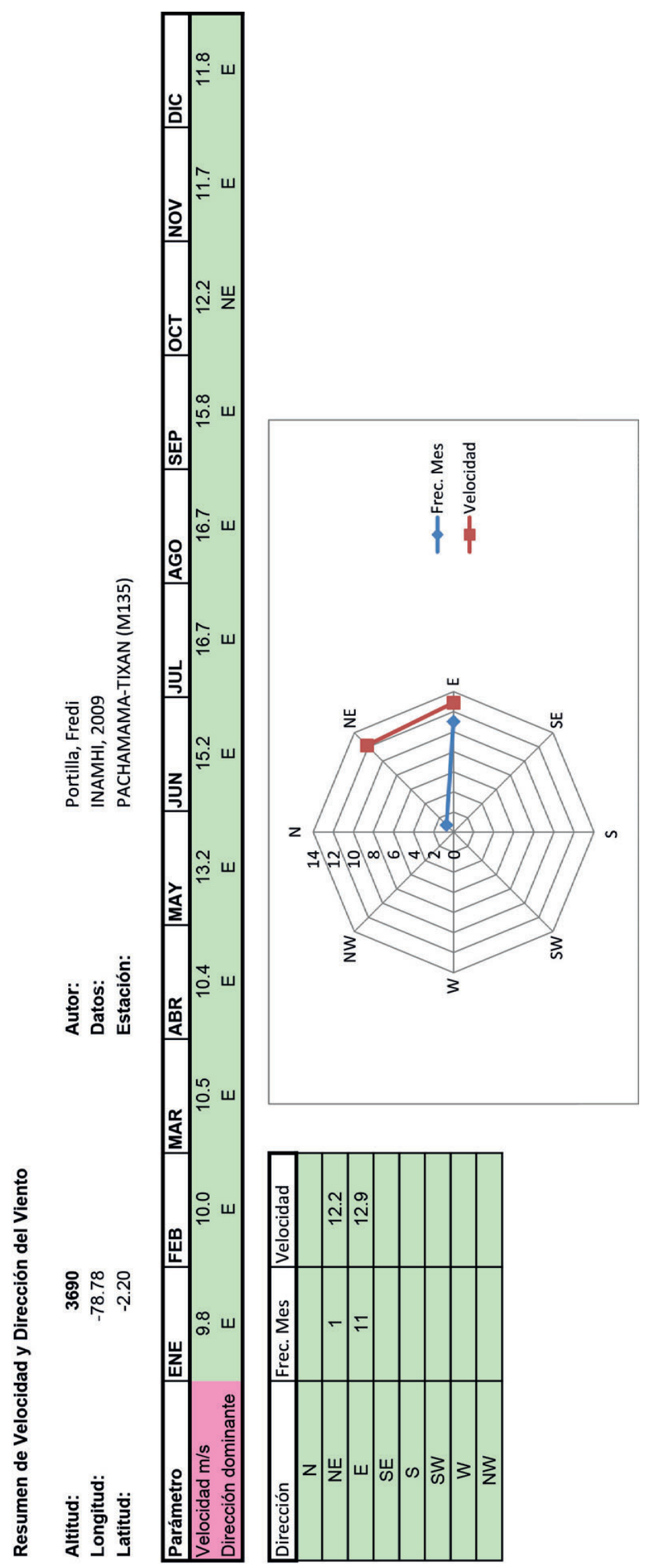




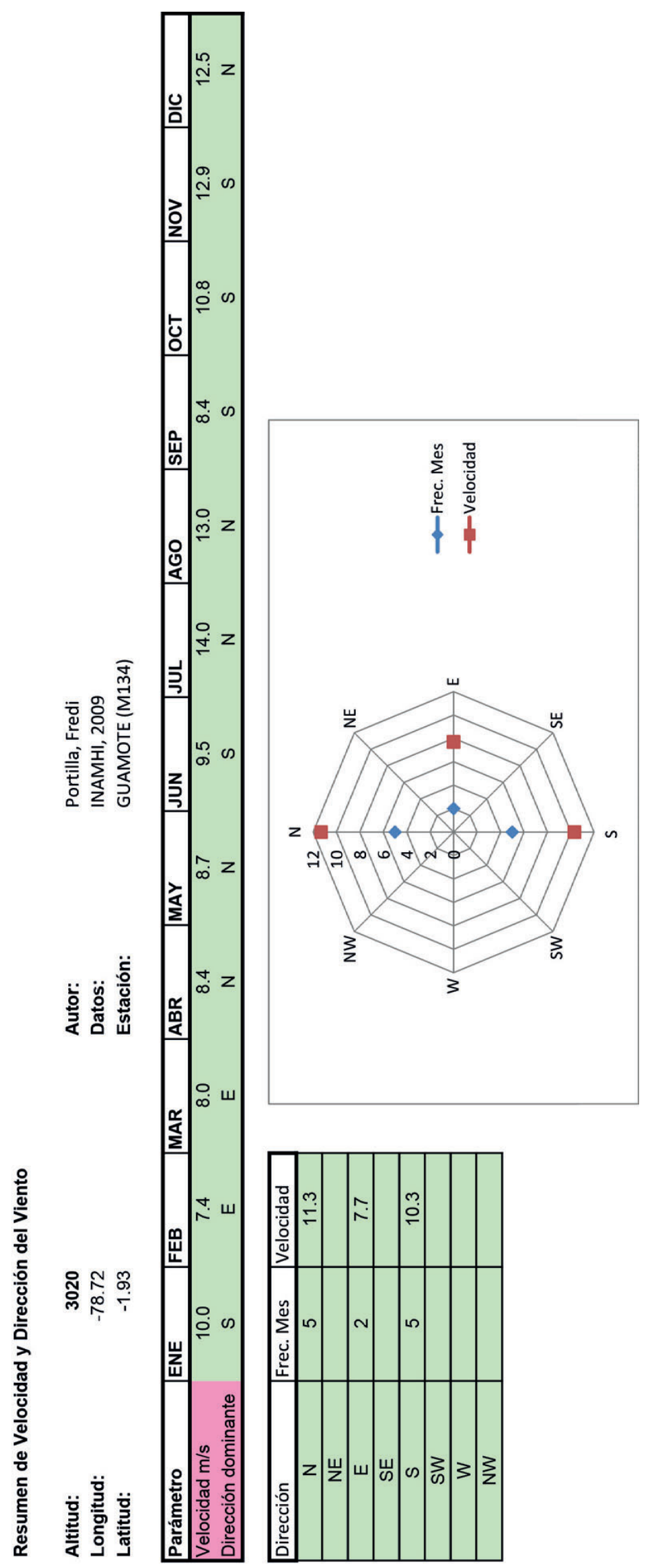




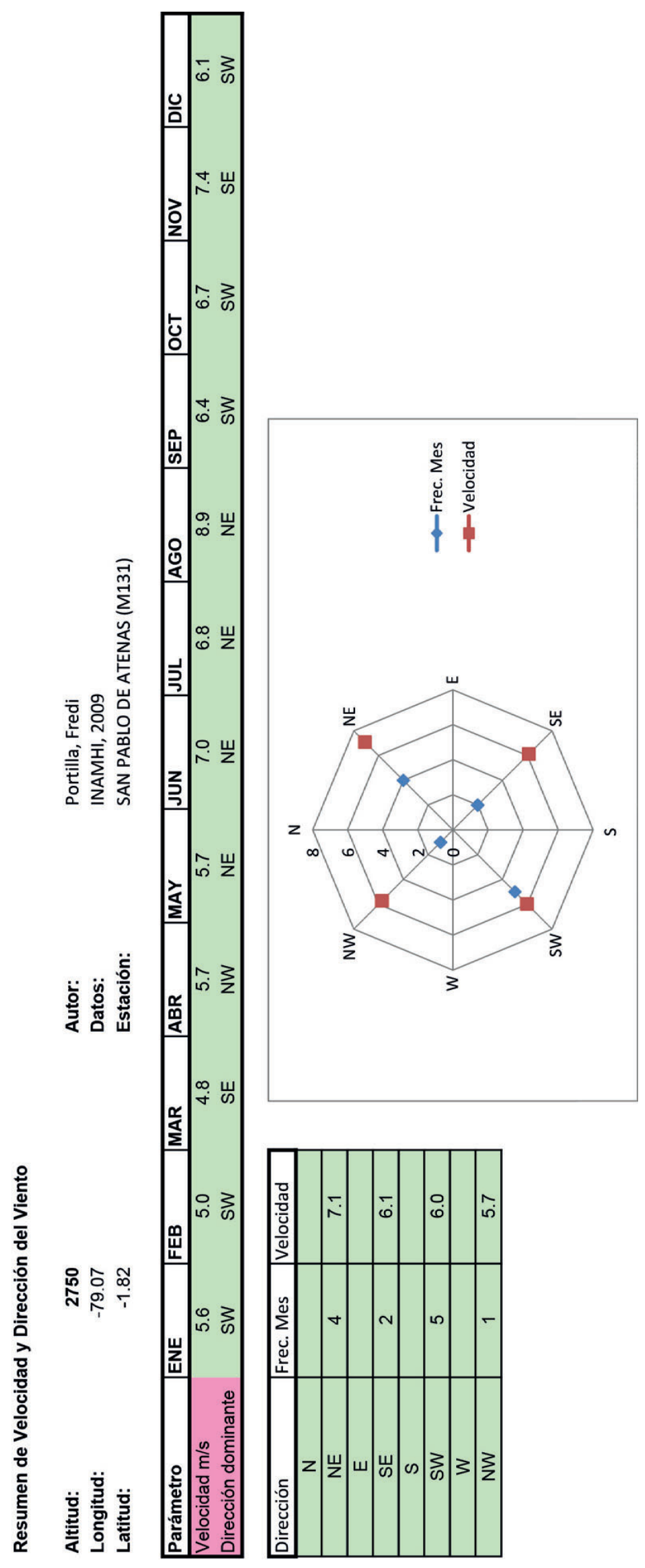




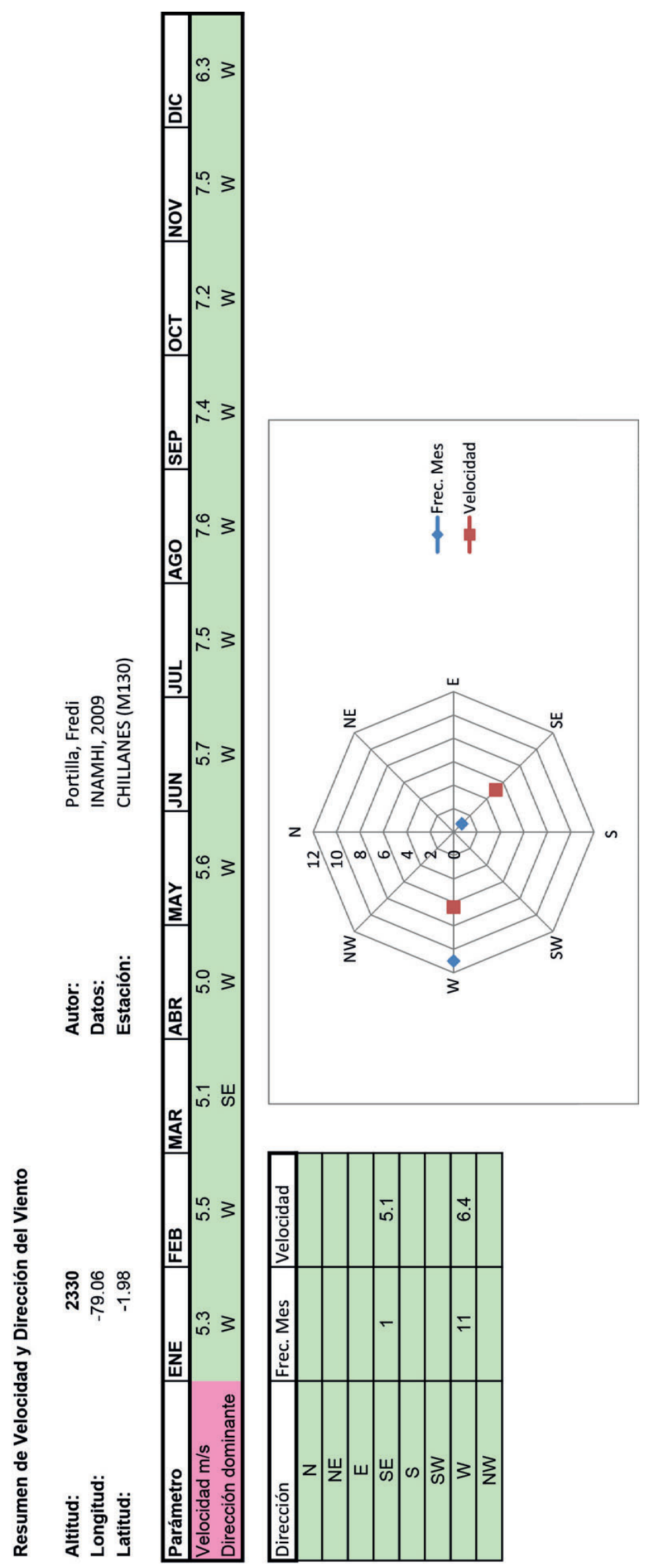




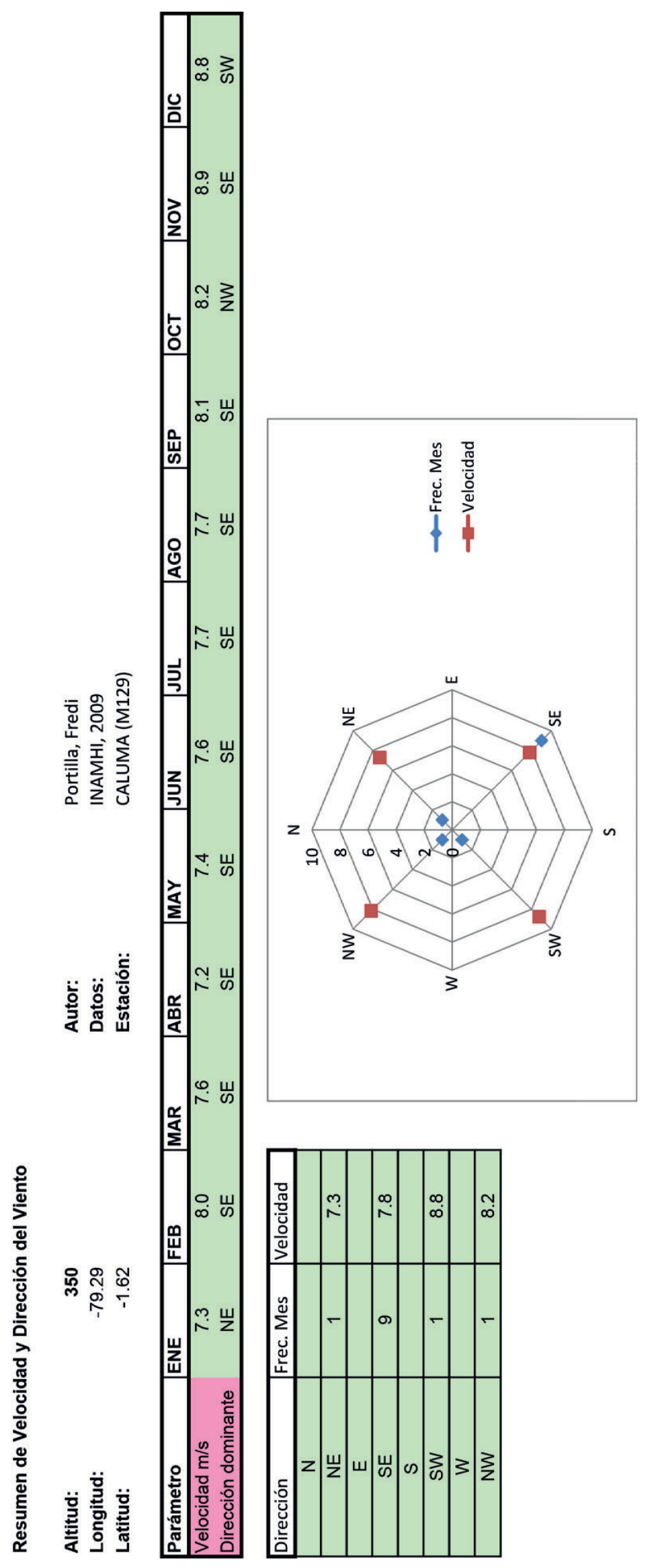




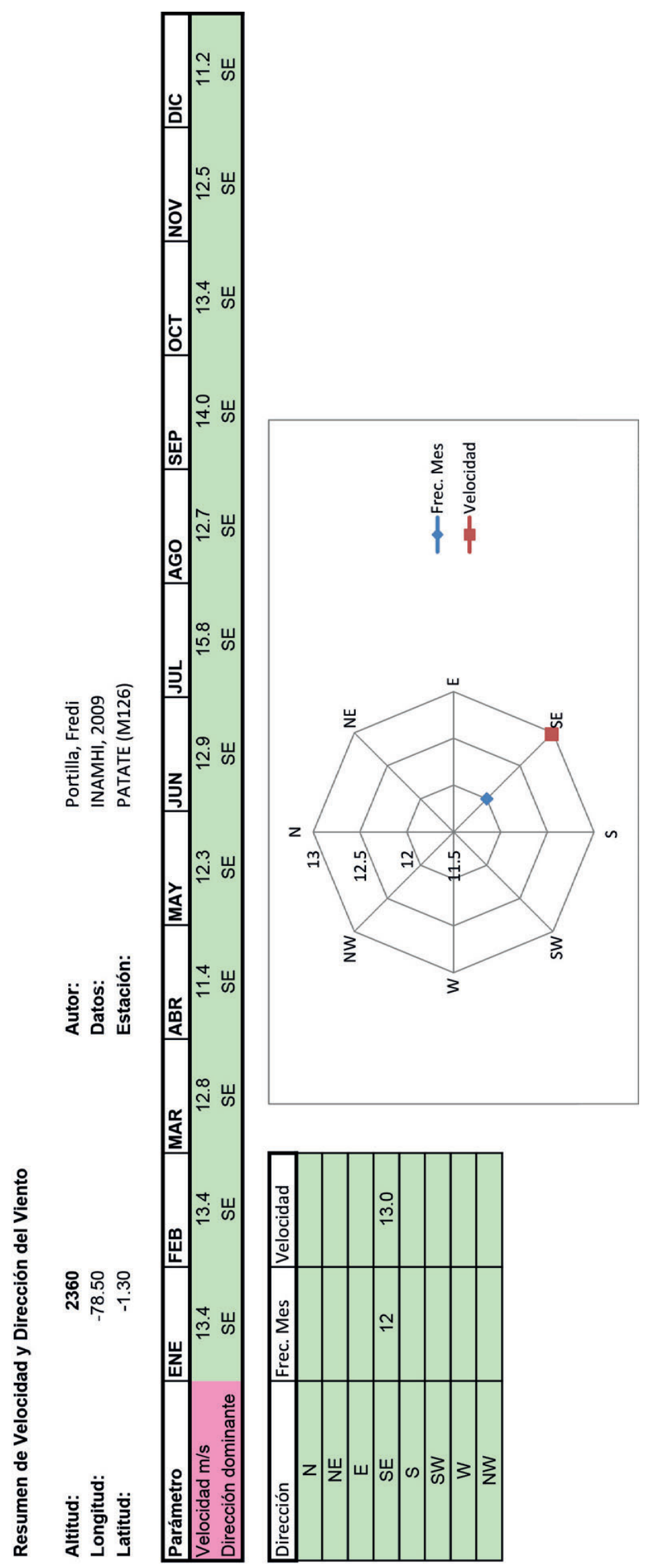




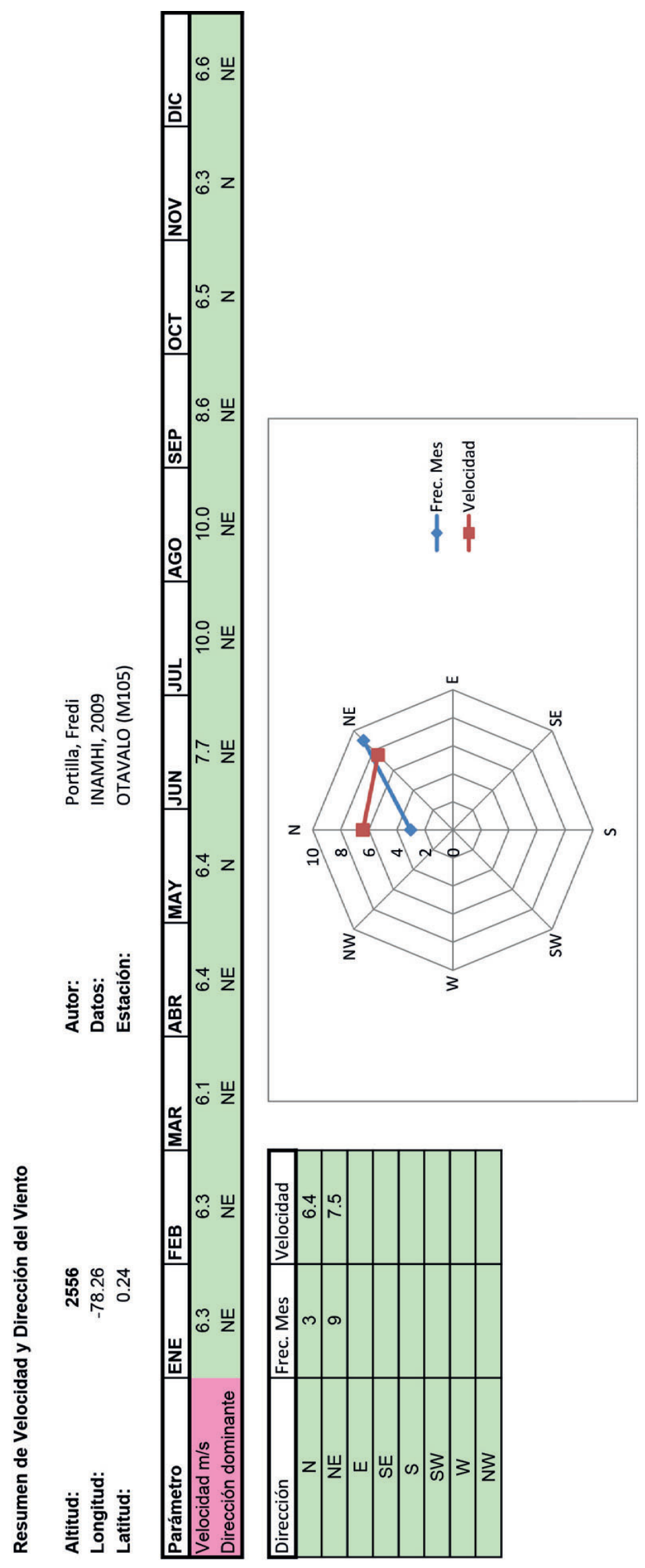




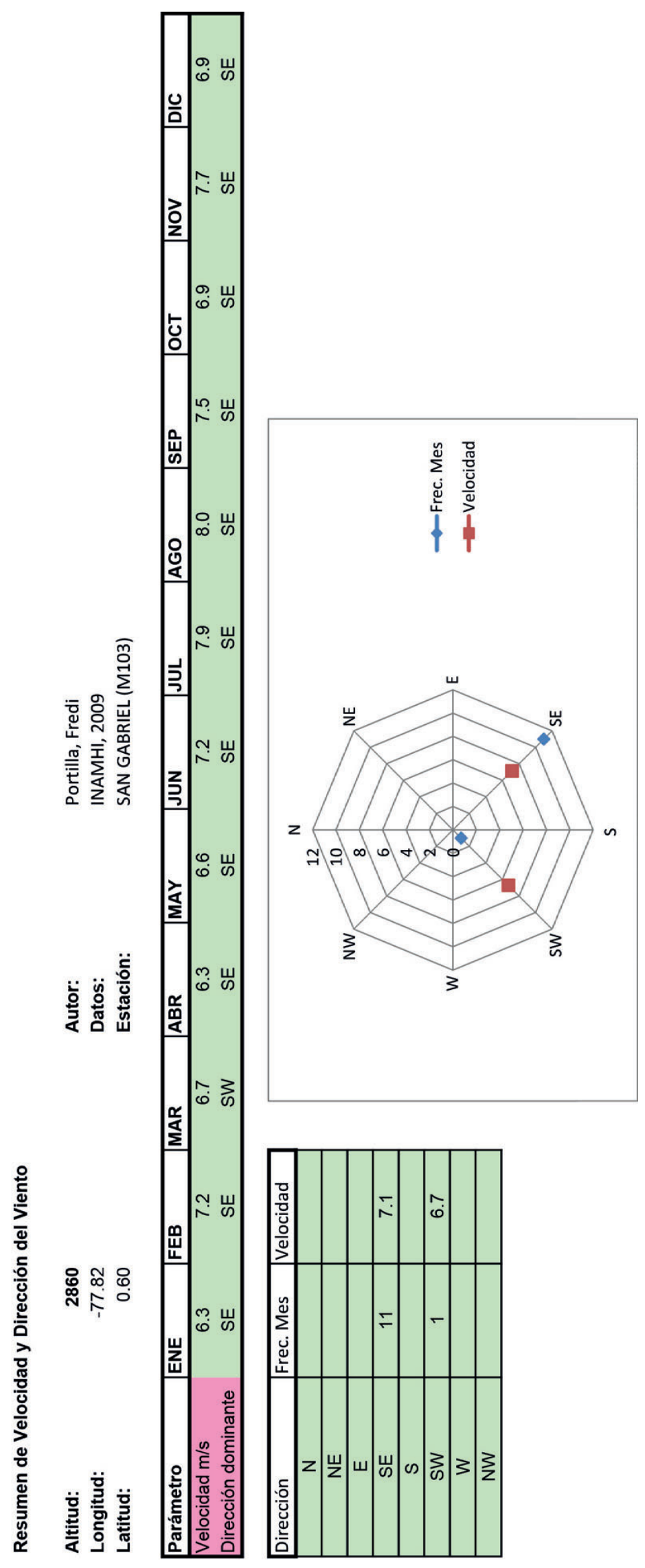




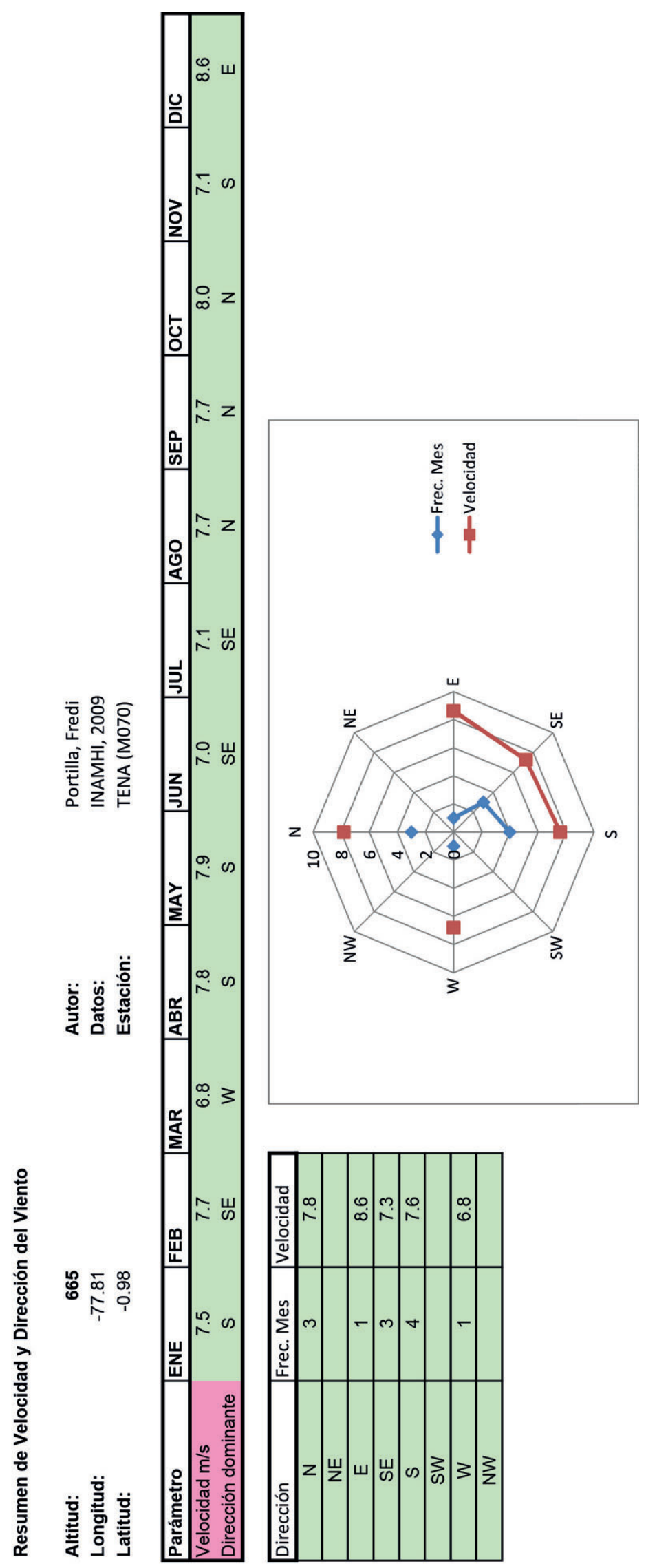




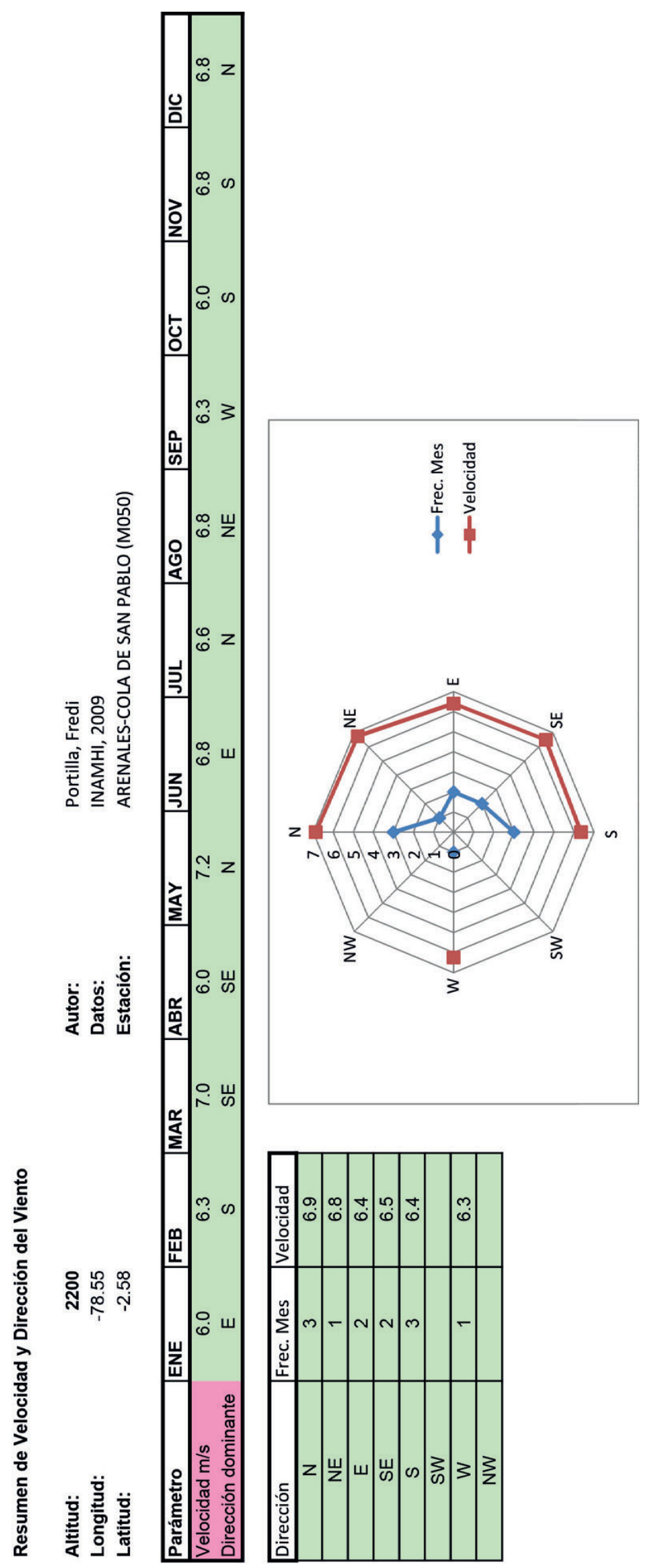




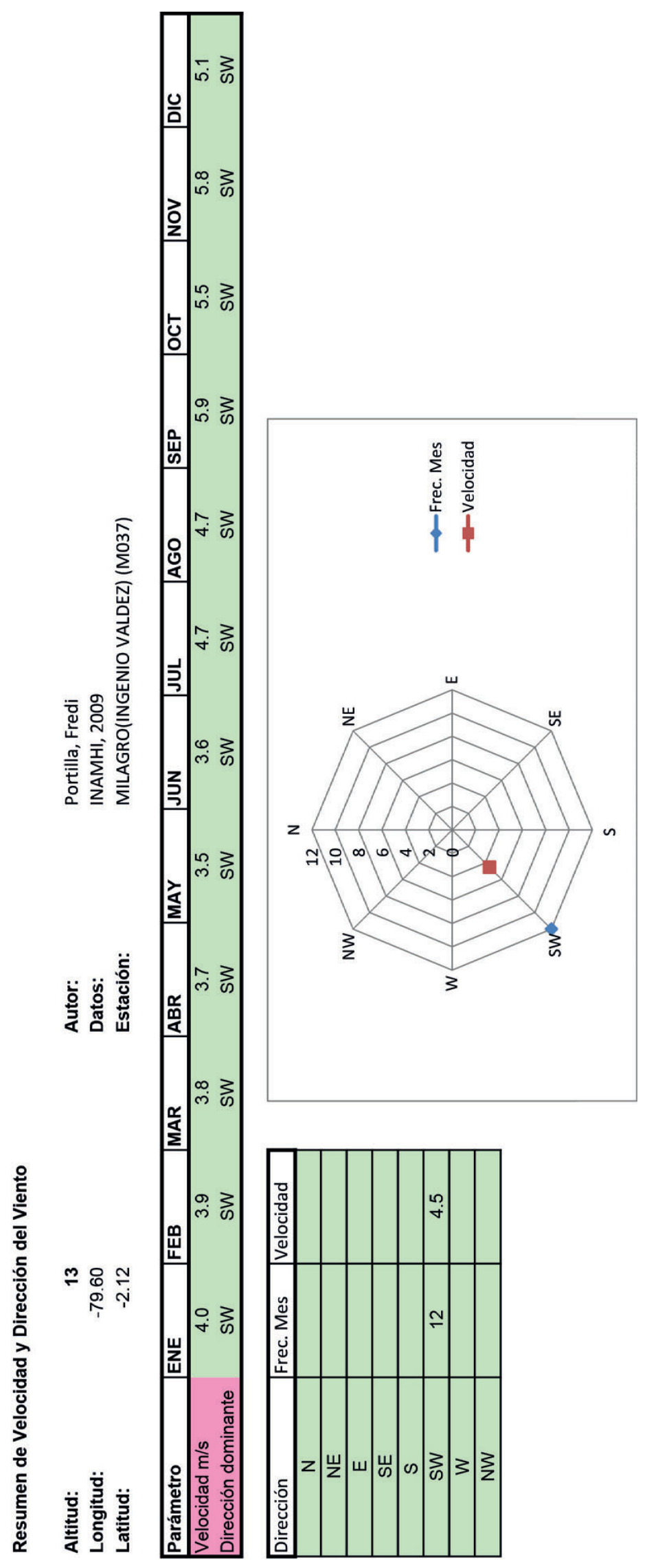




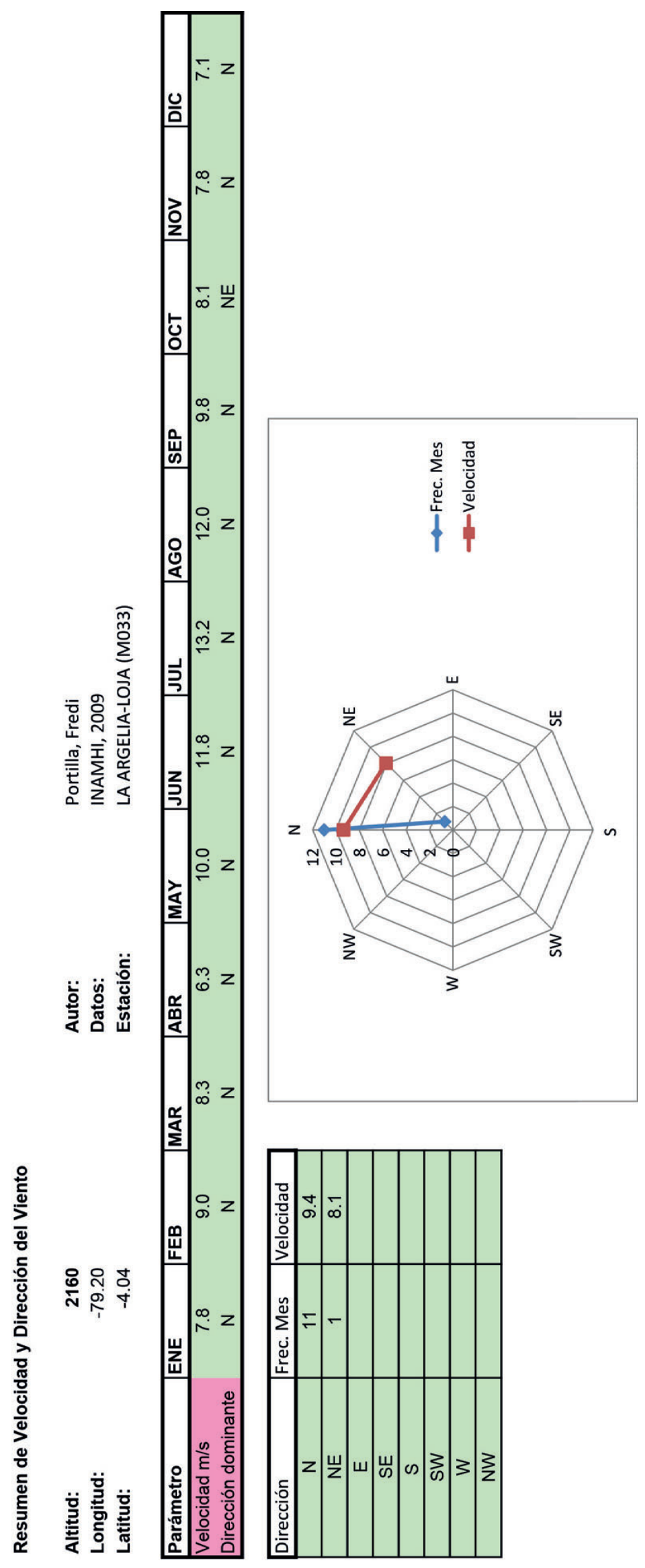




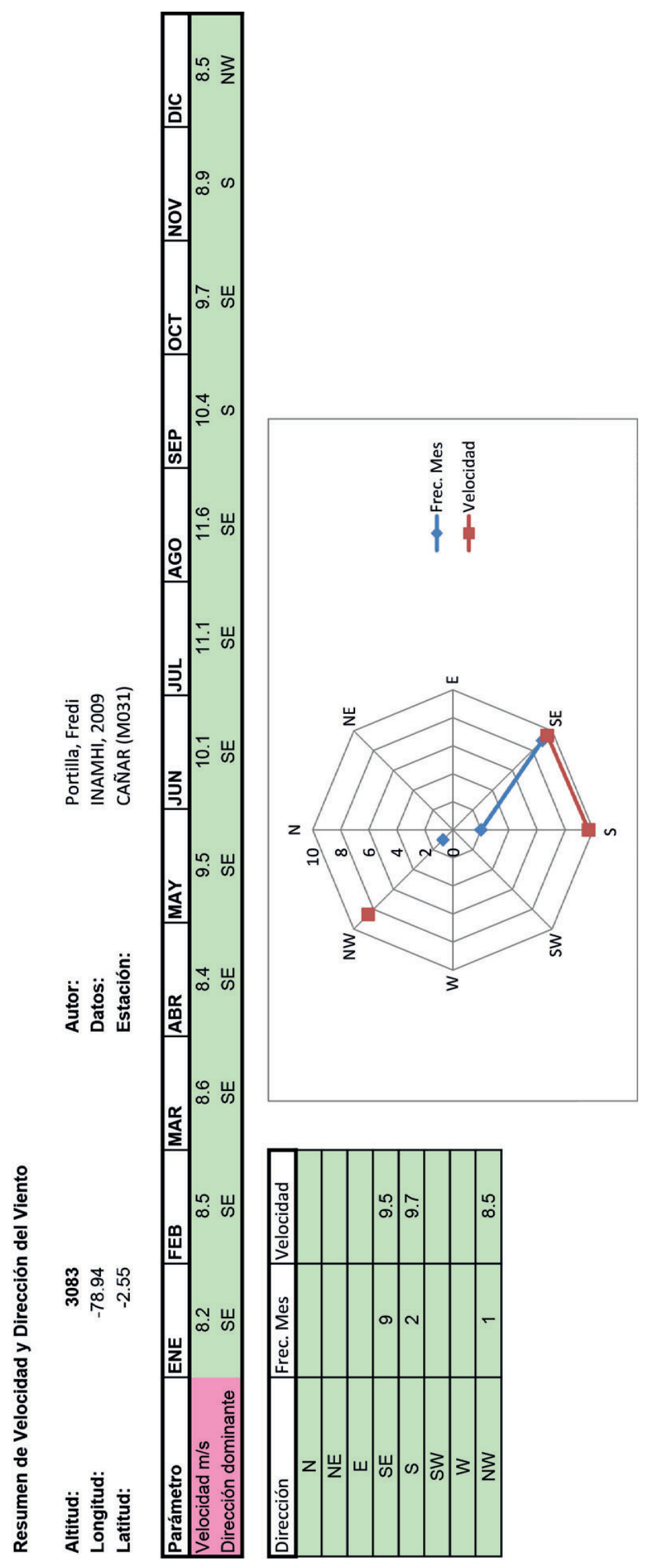




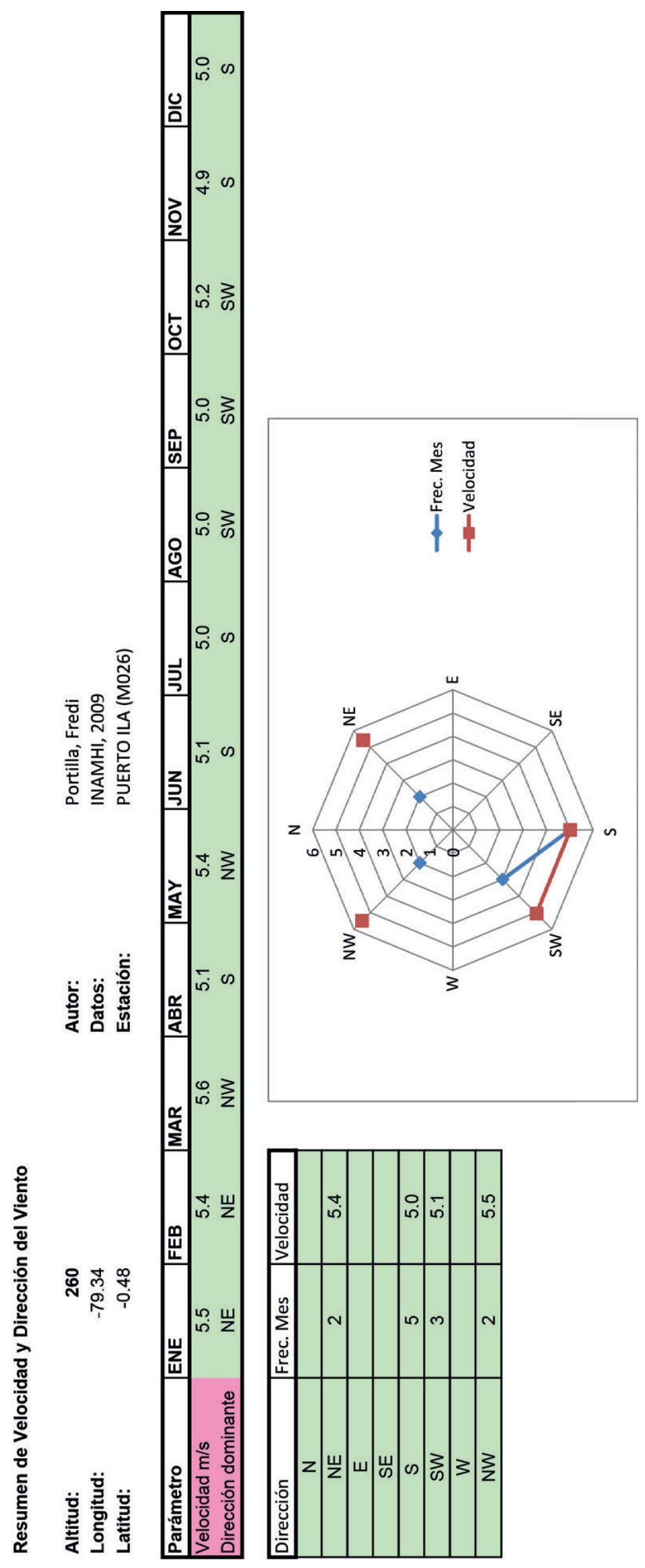




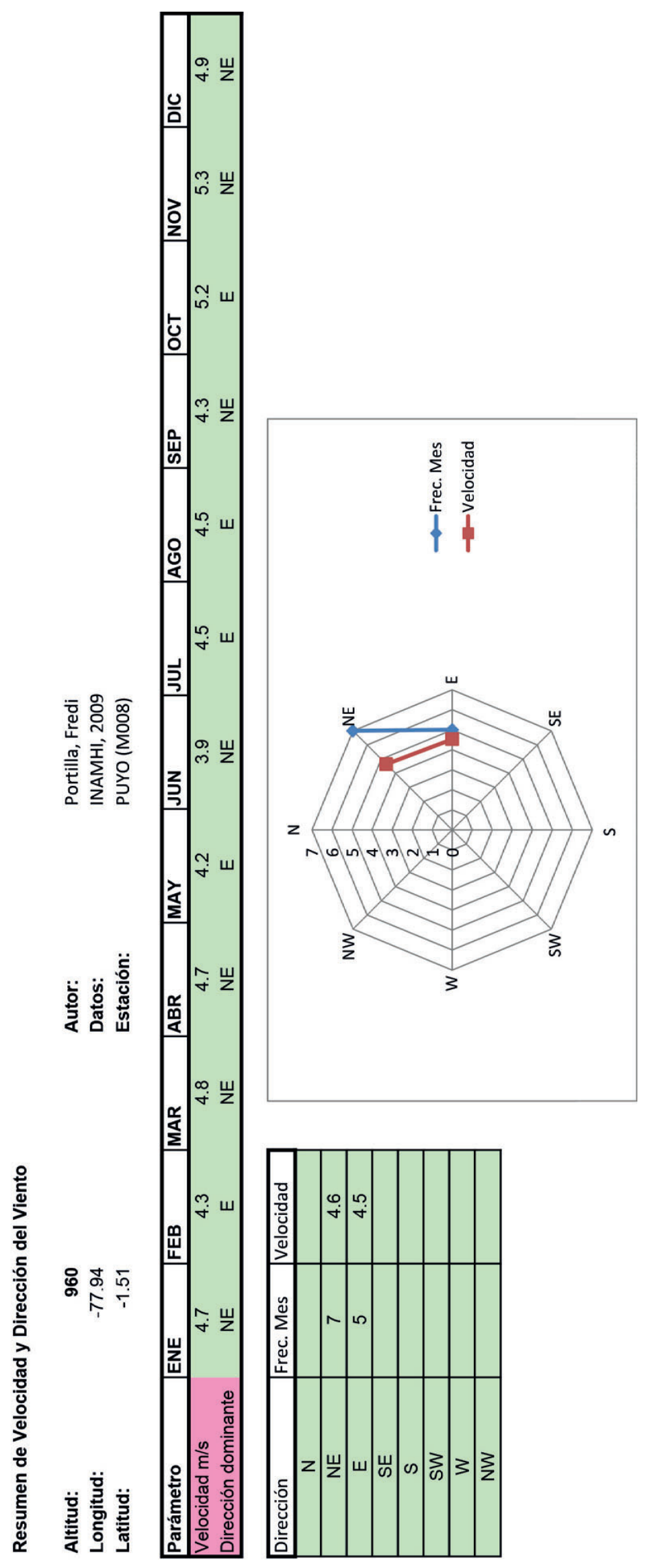




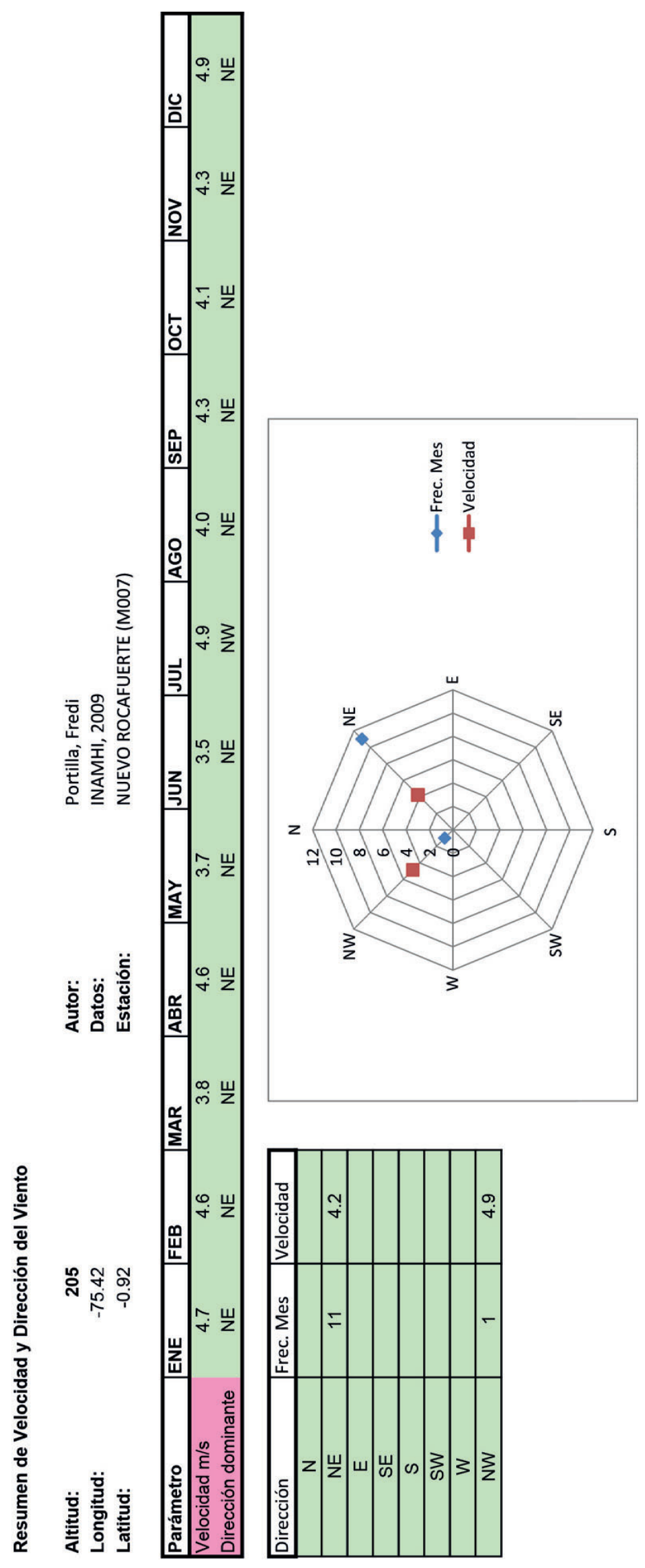




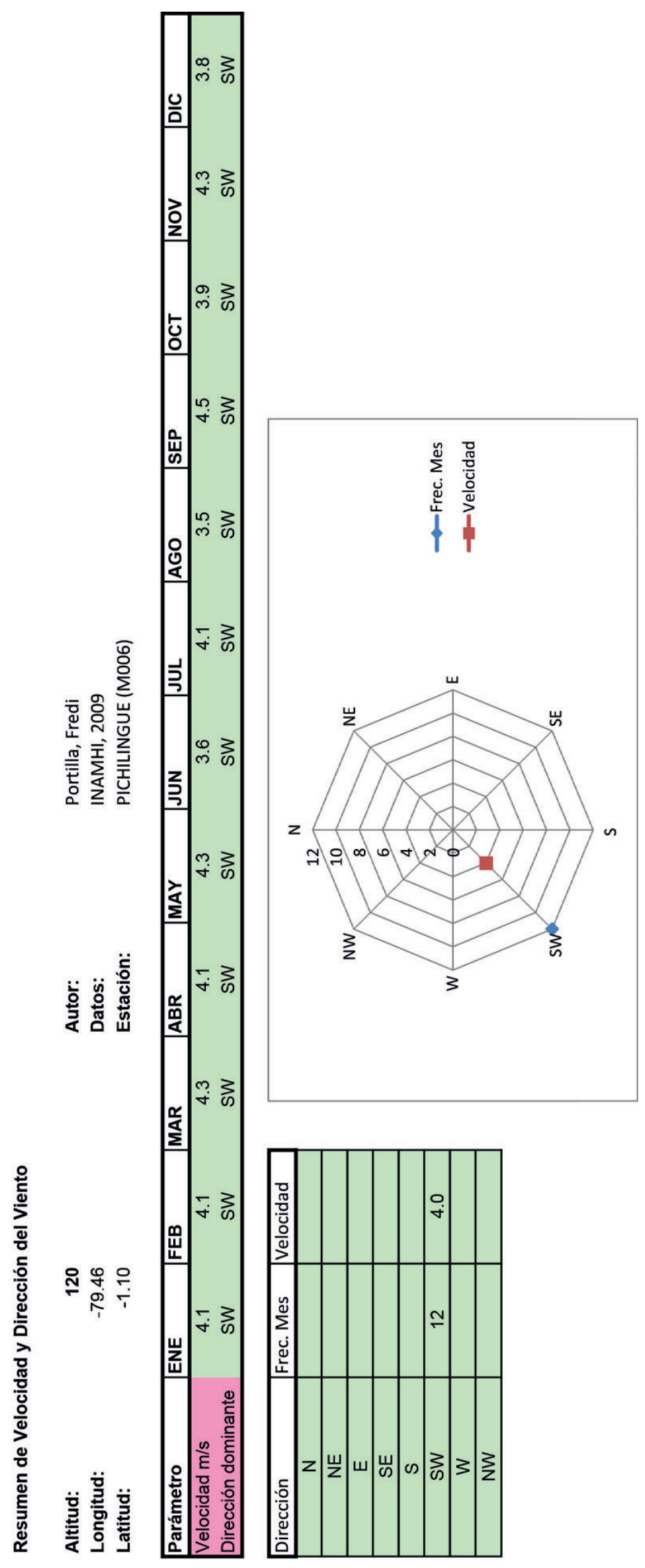




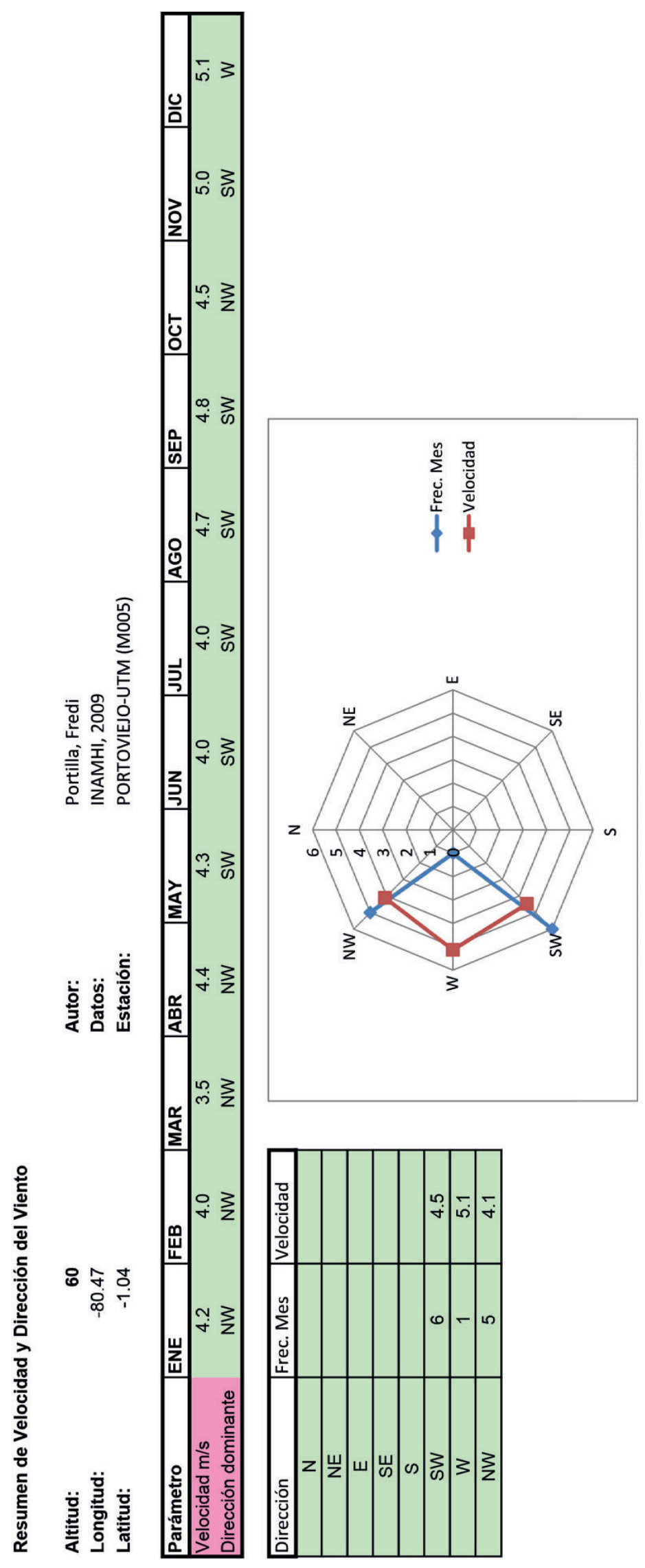




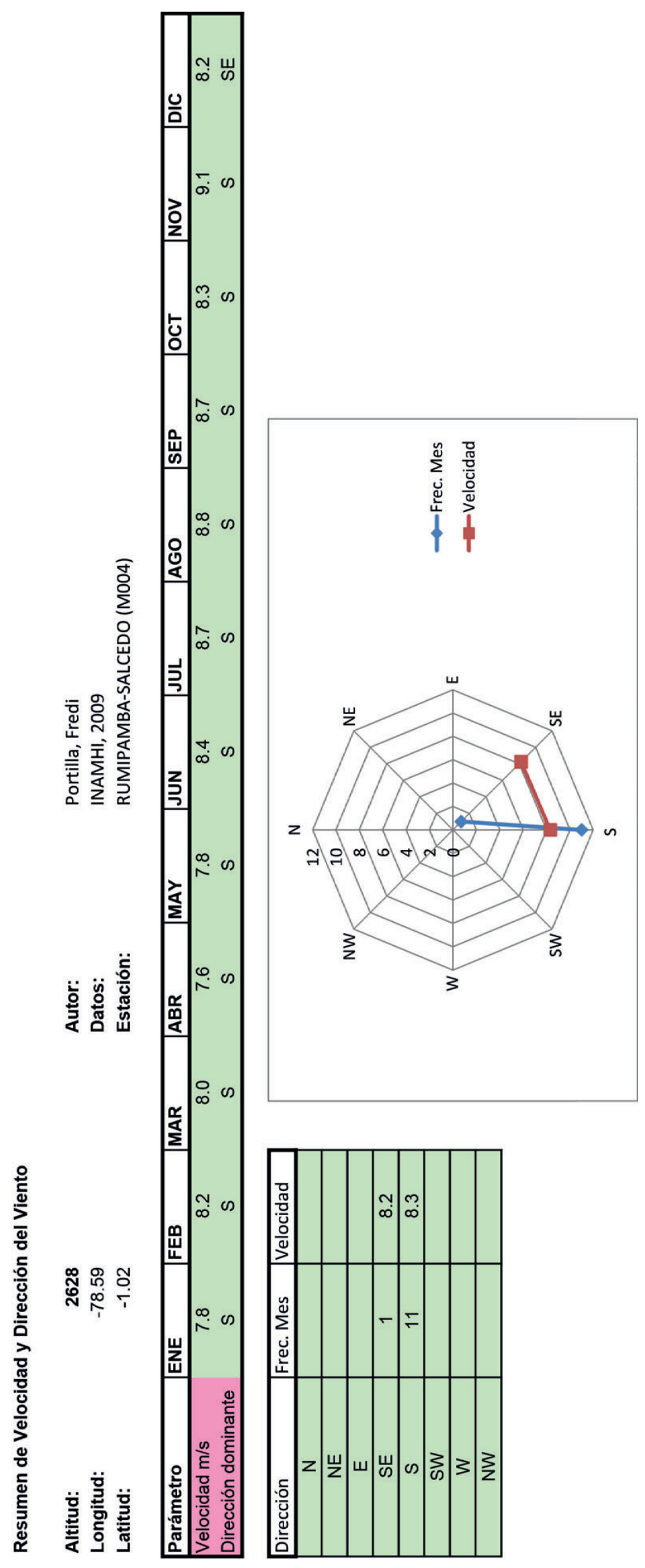


540

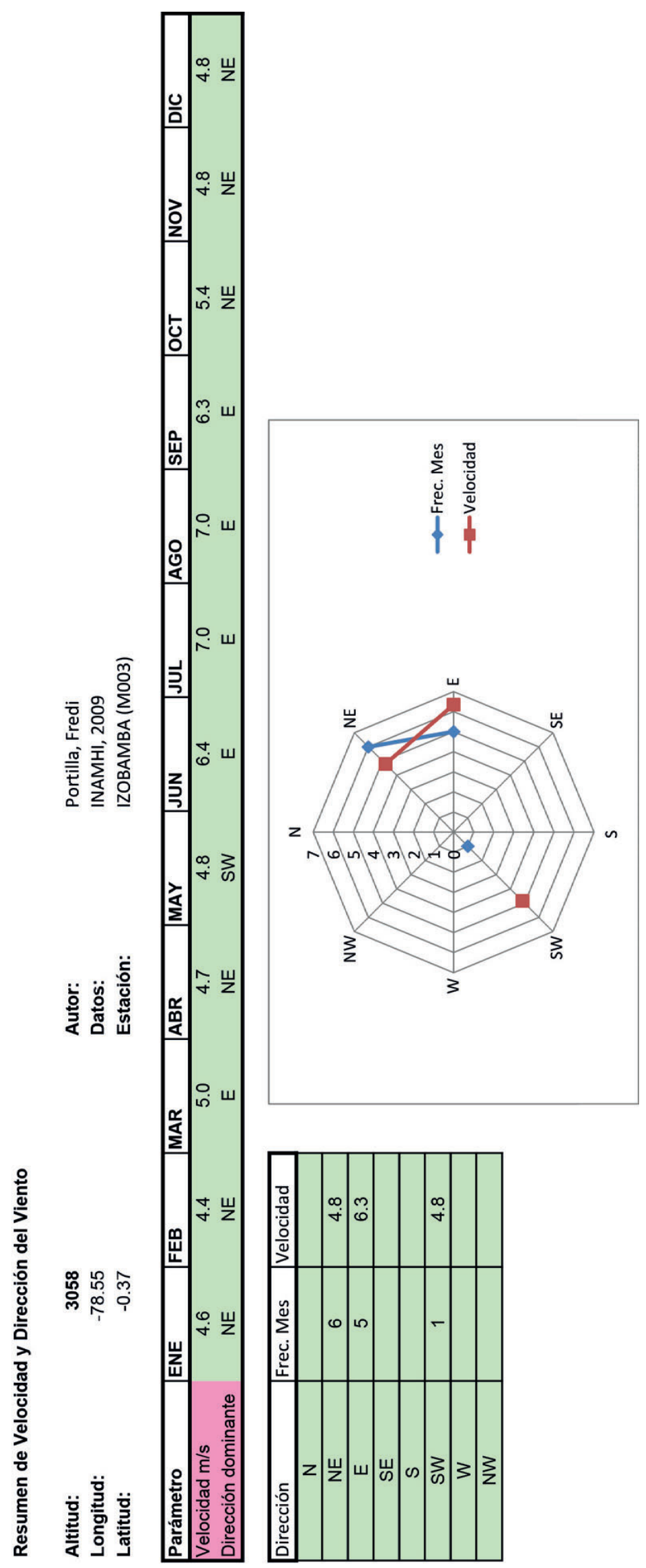




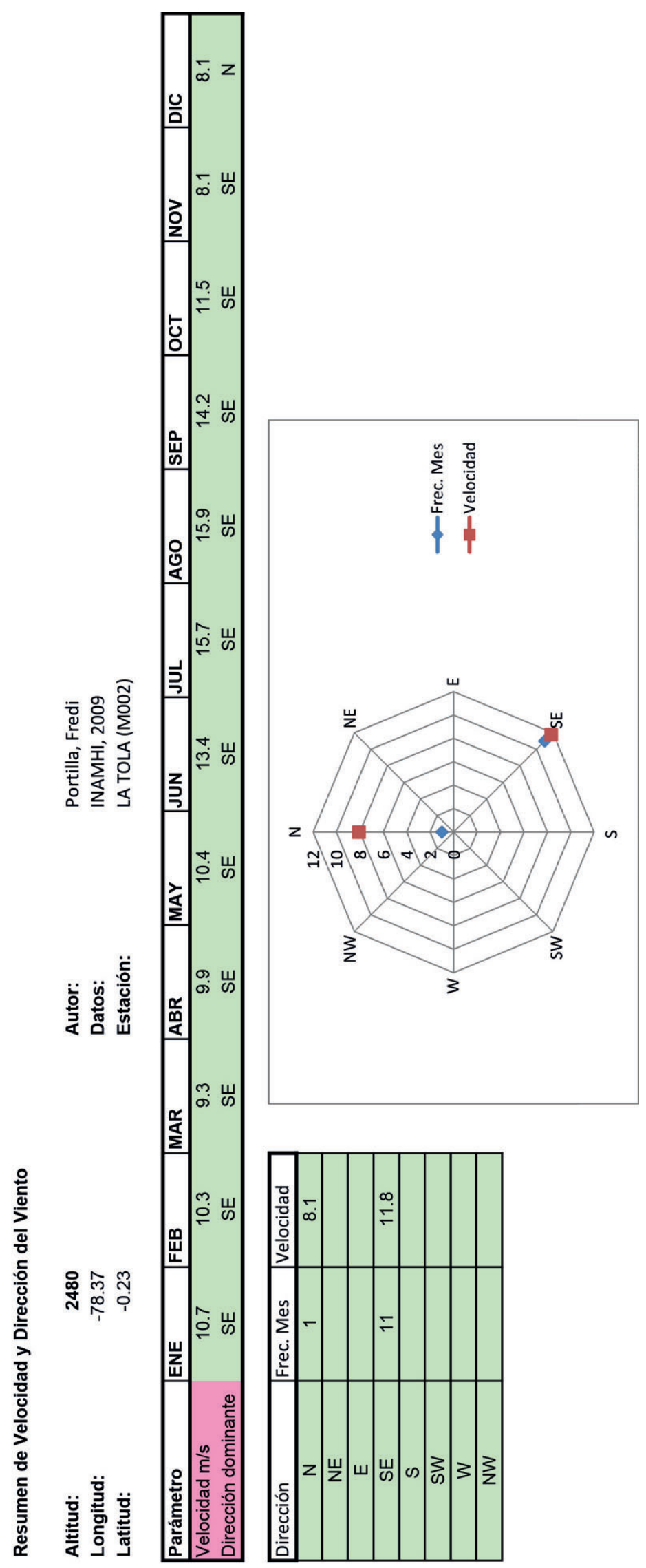




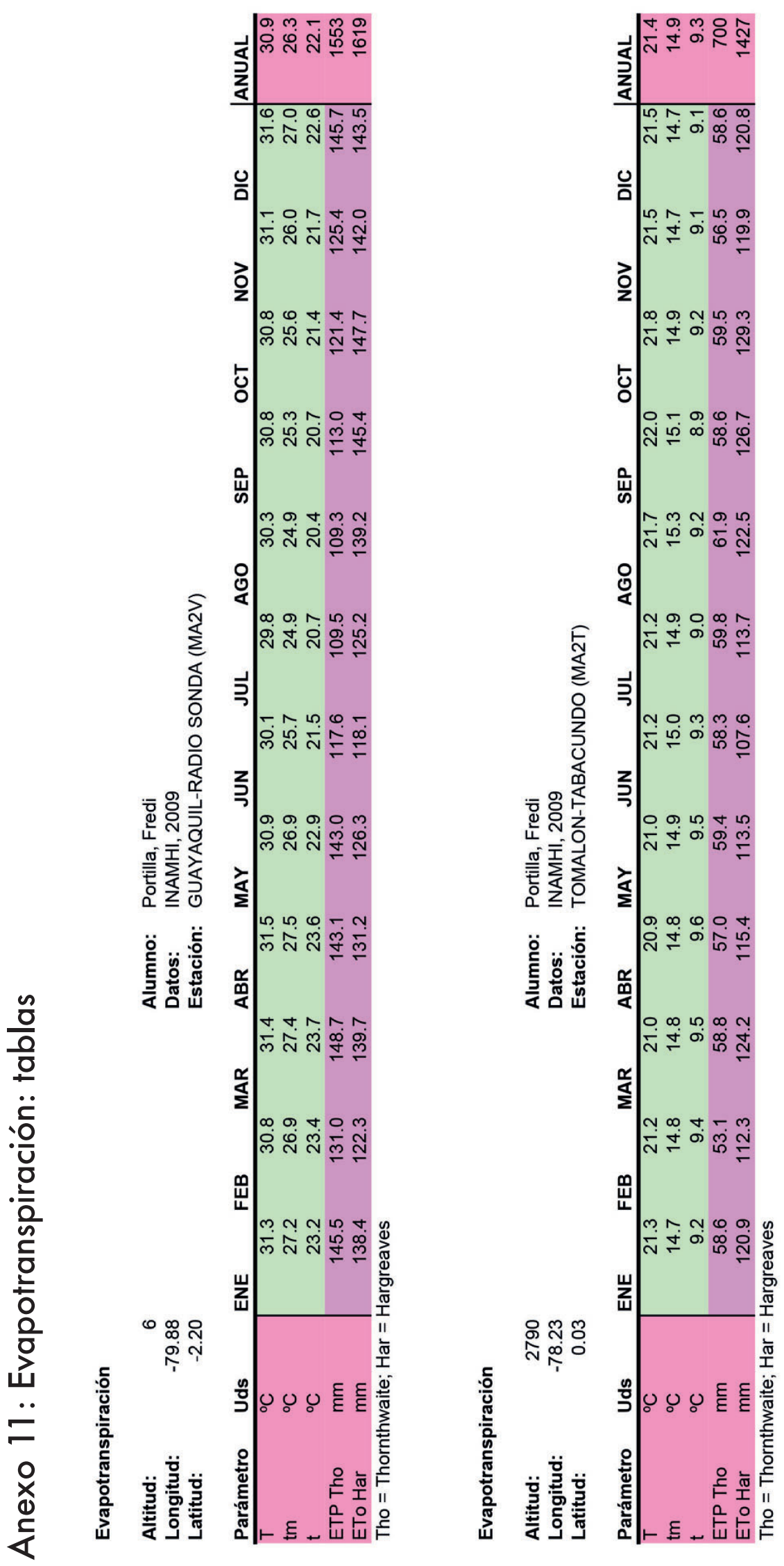



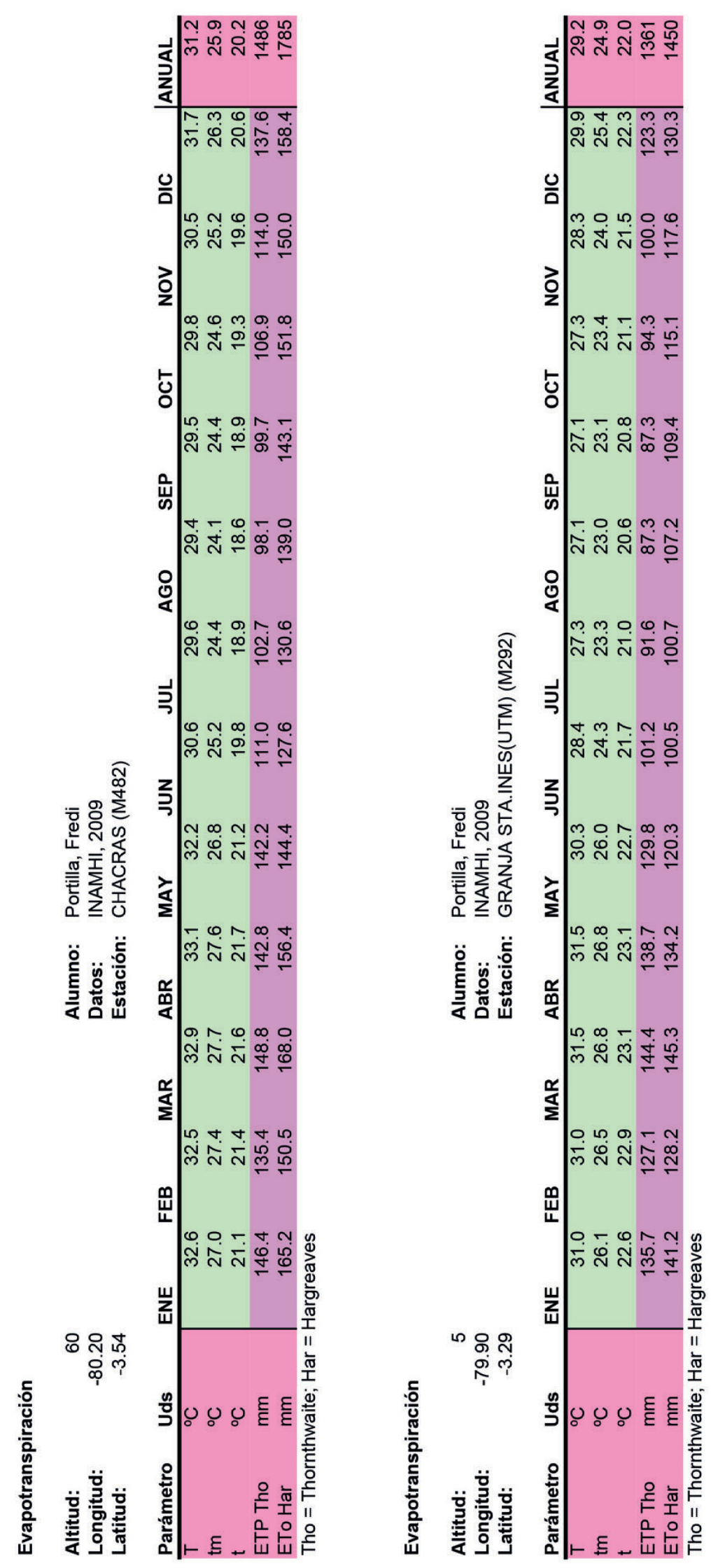

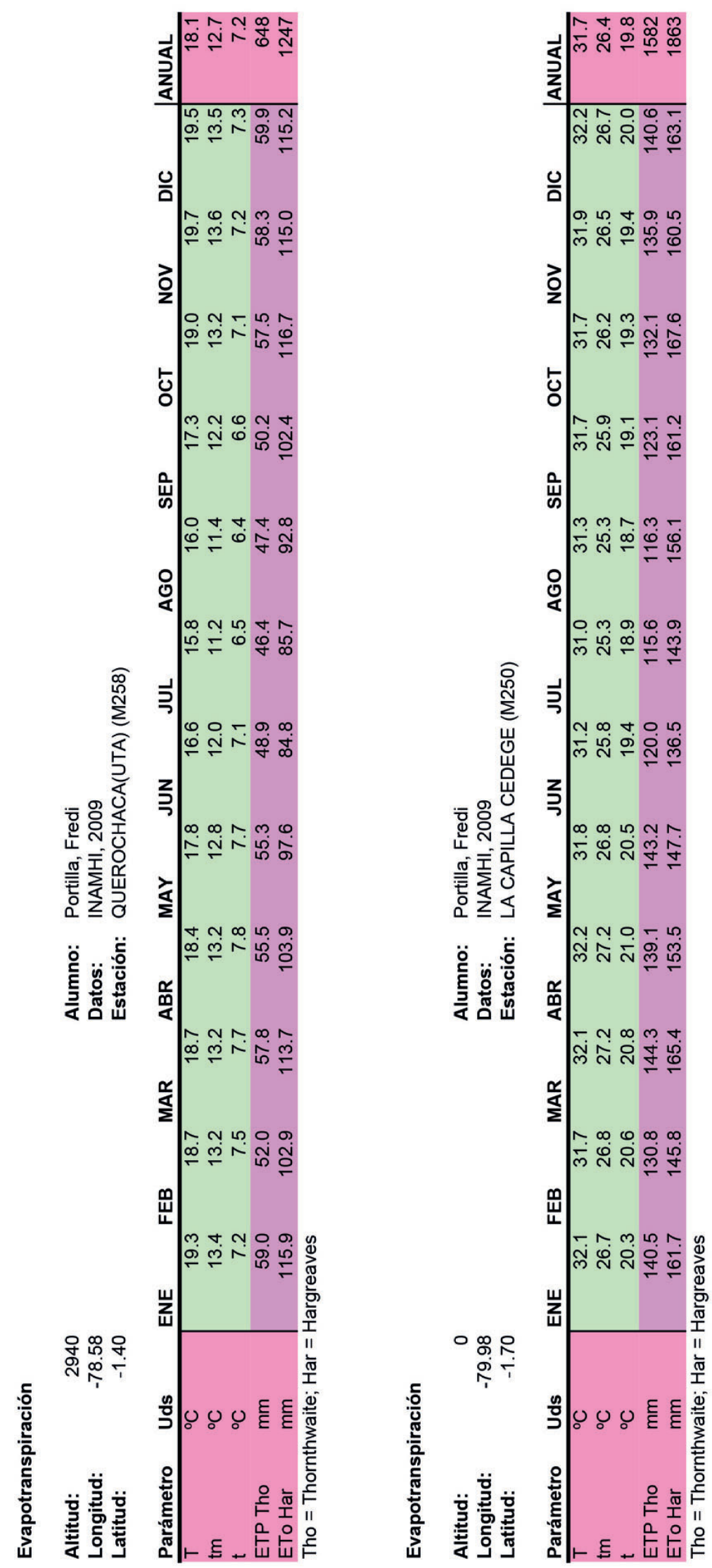

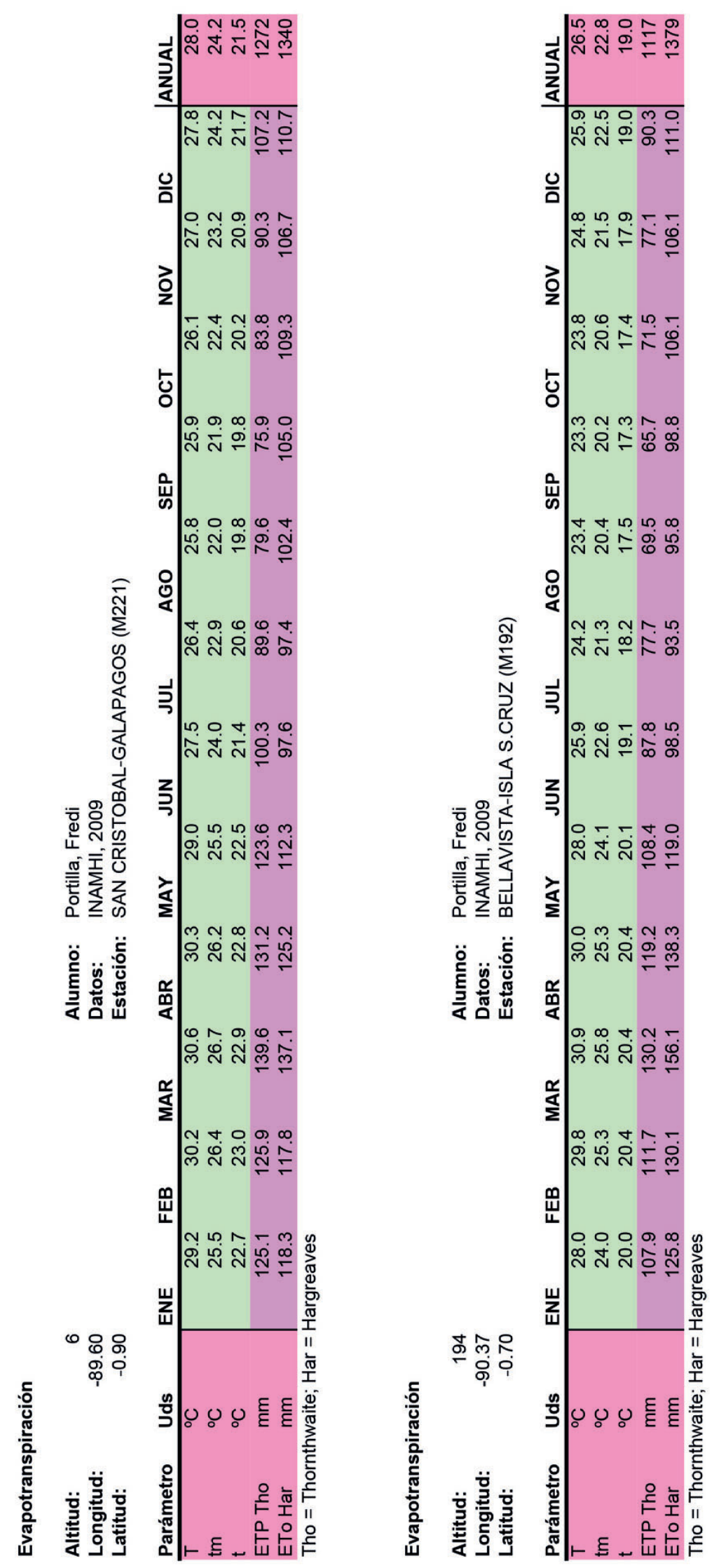


\section{6}
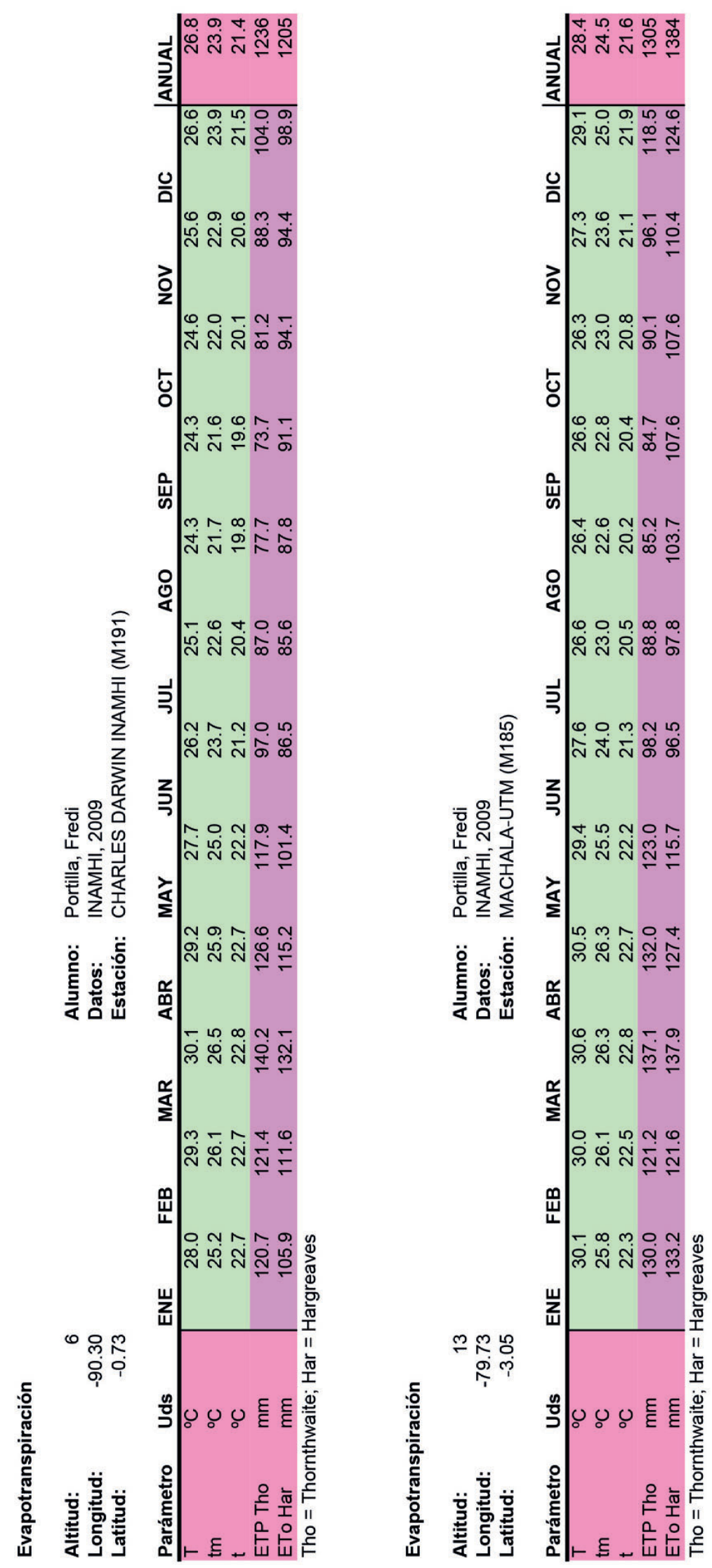

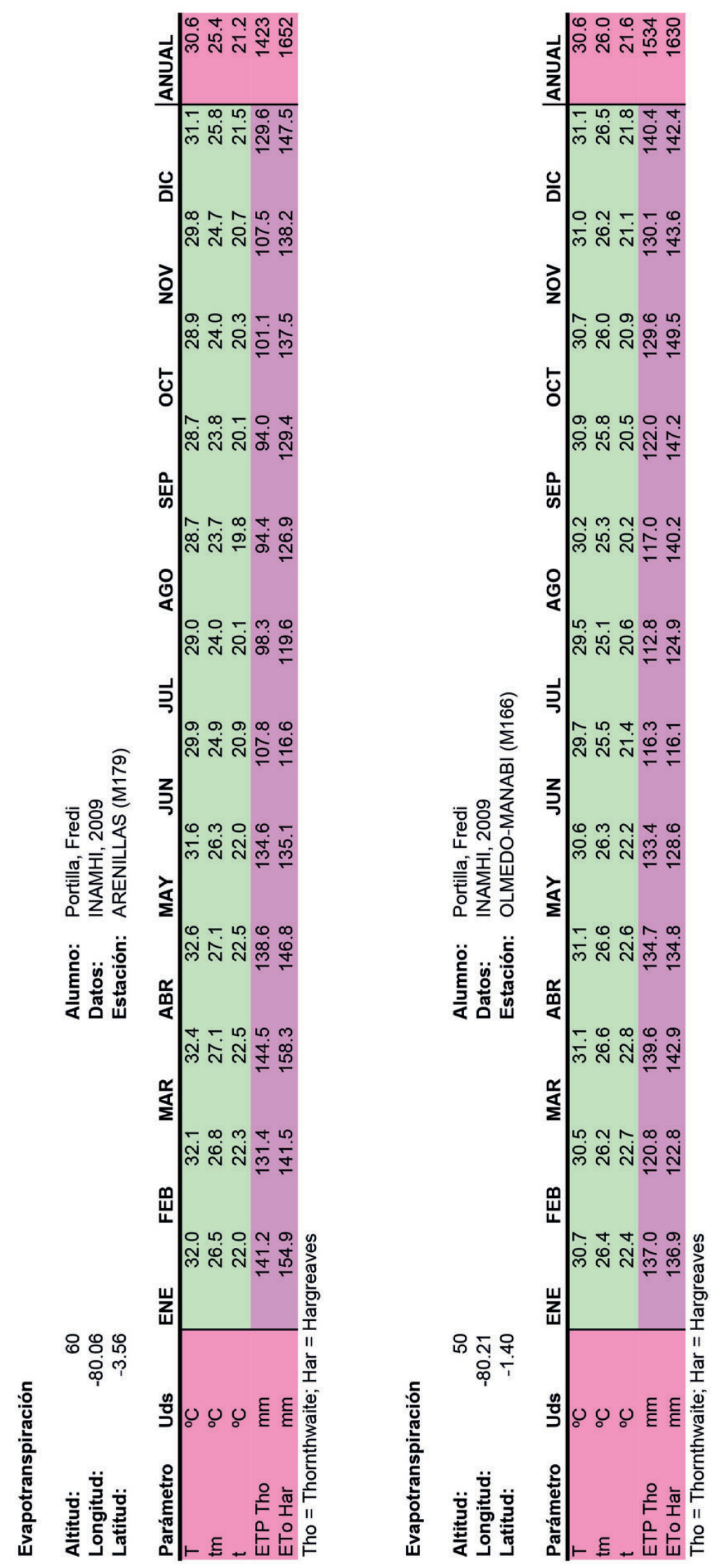


\section{8}
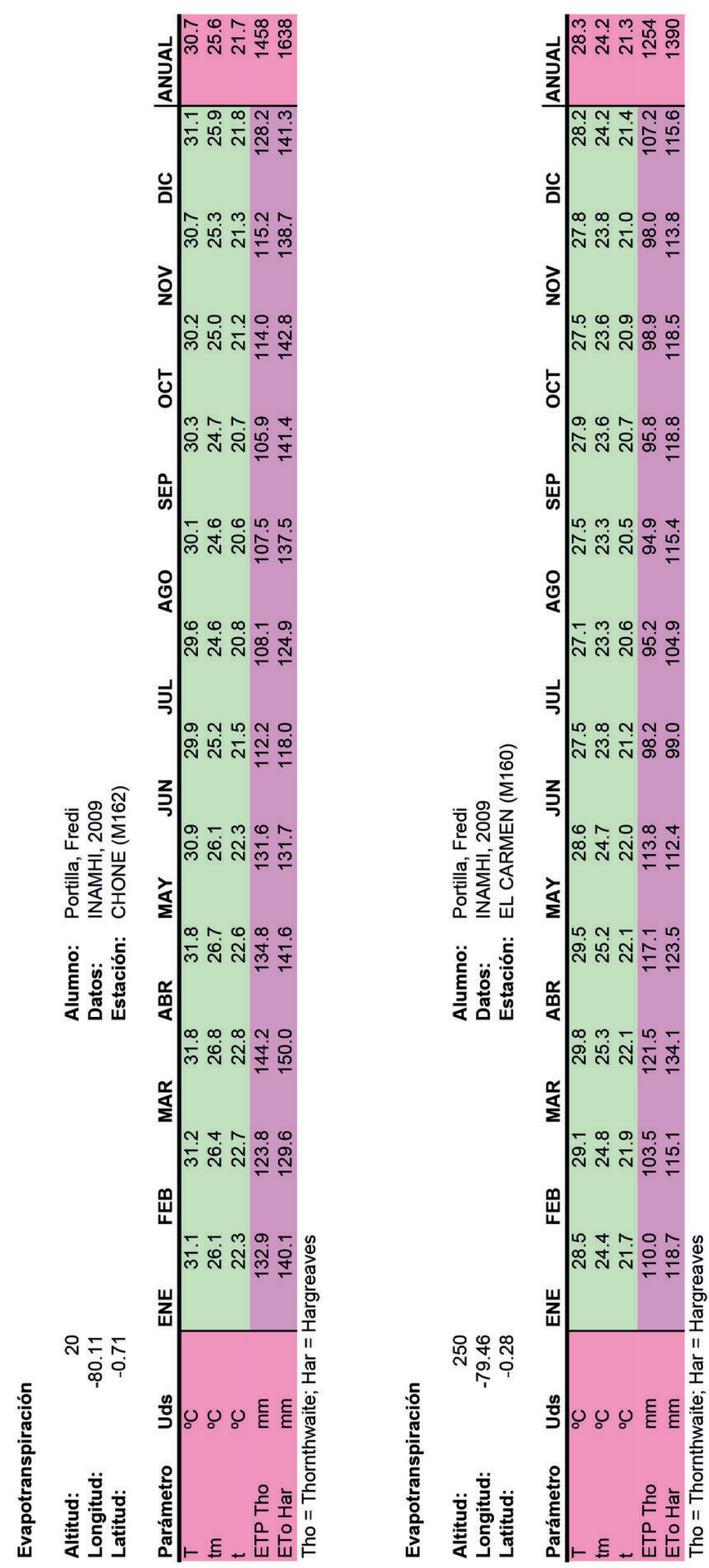

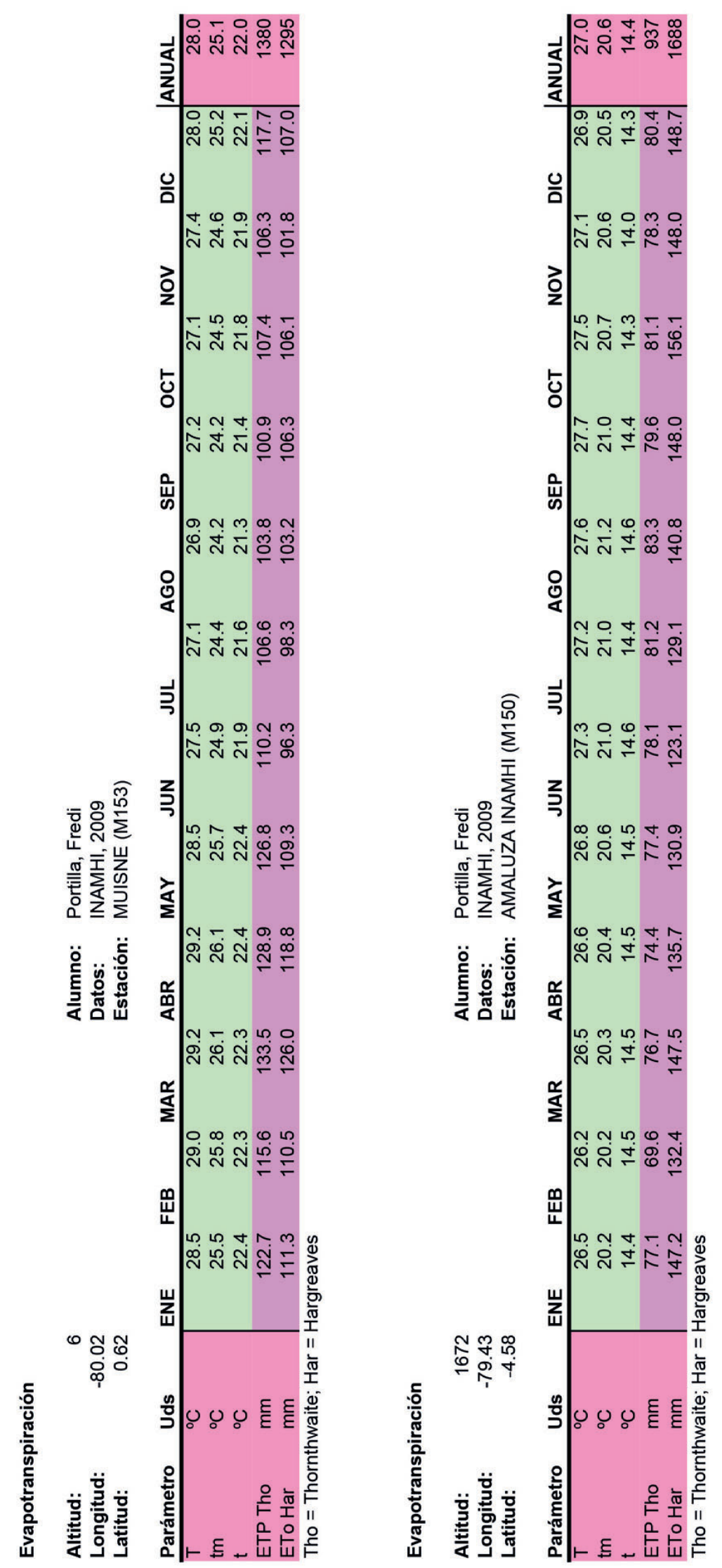

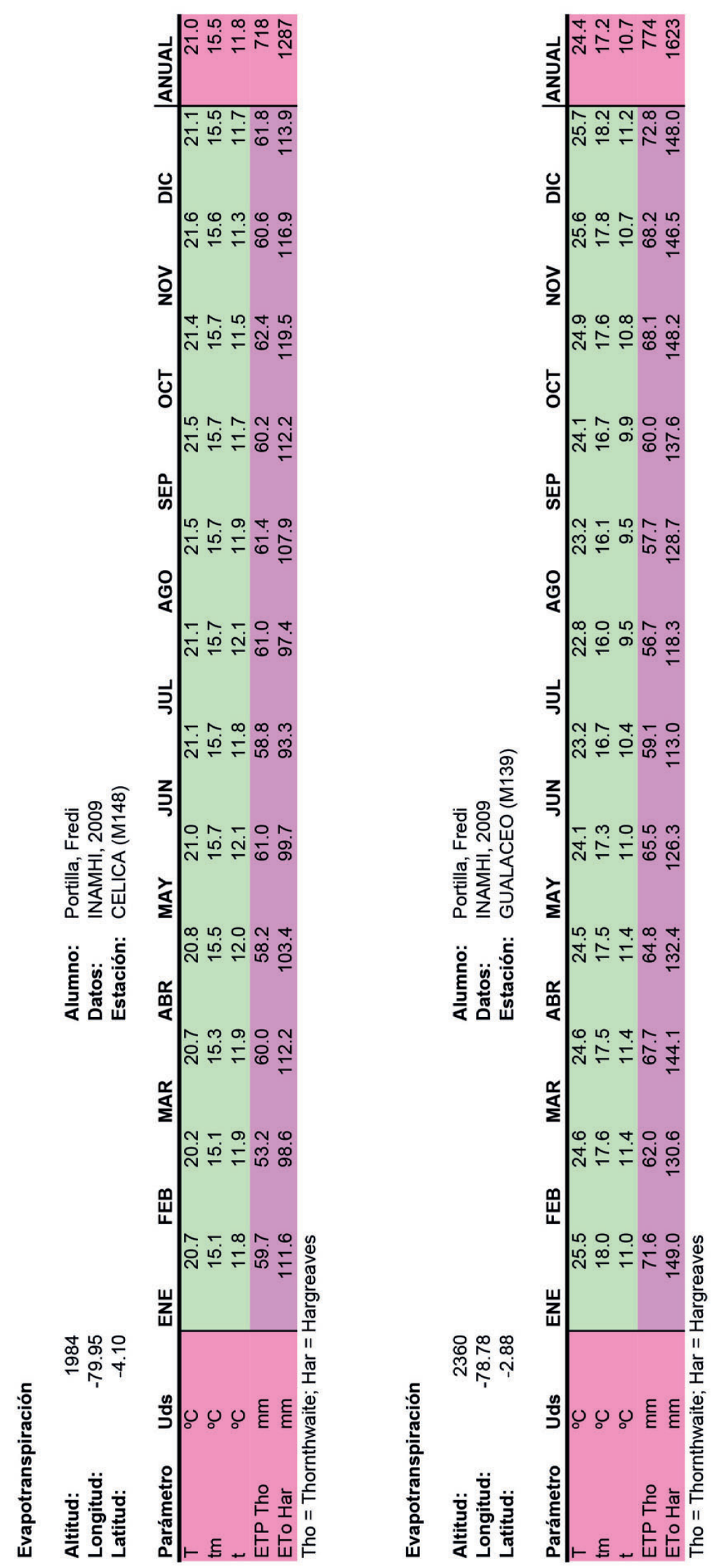

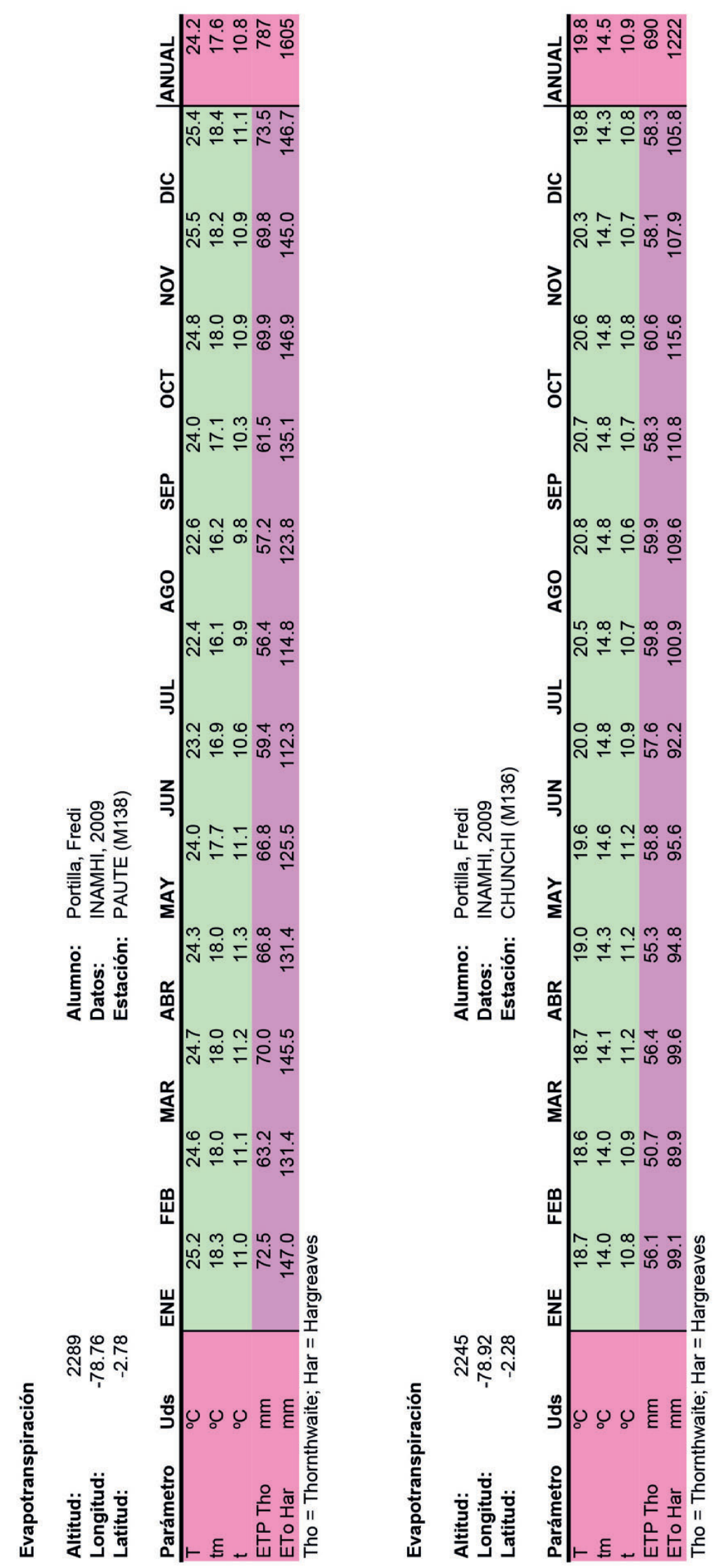

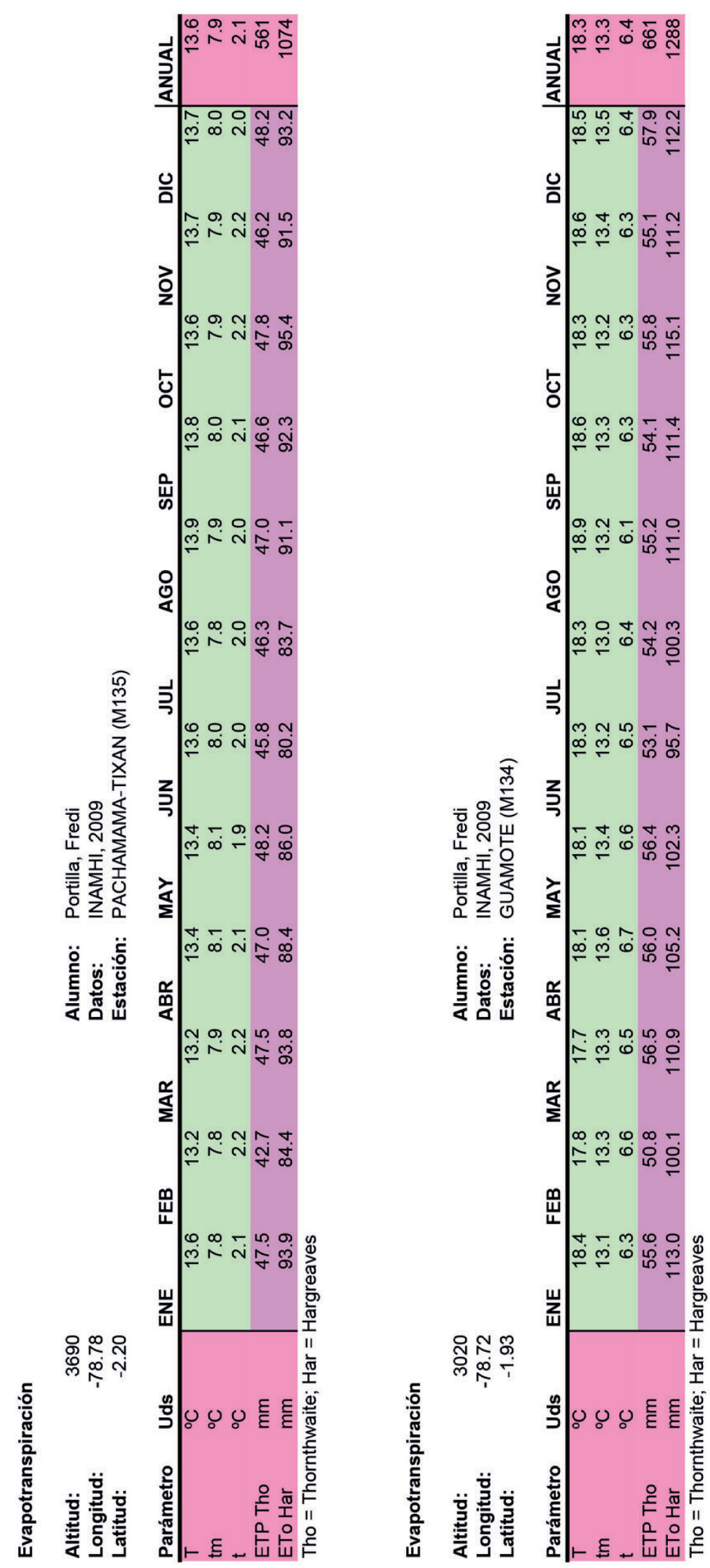

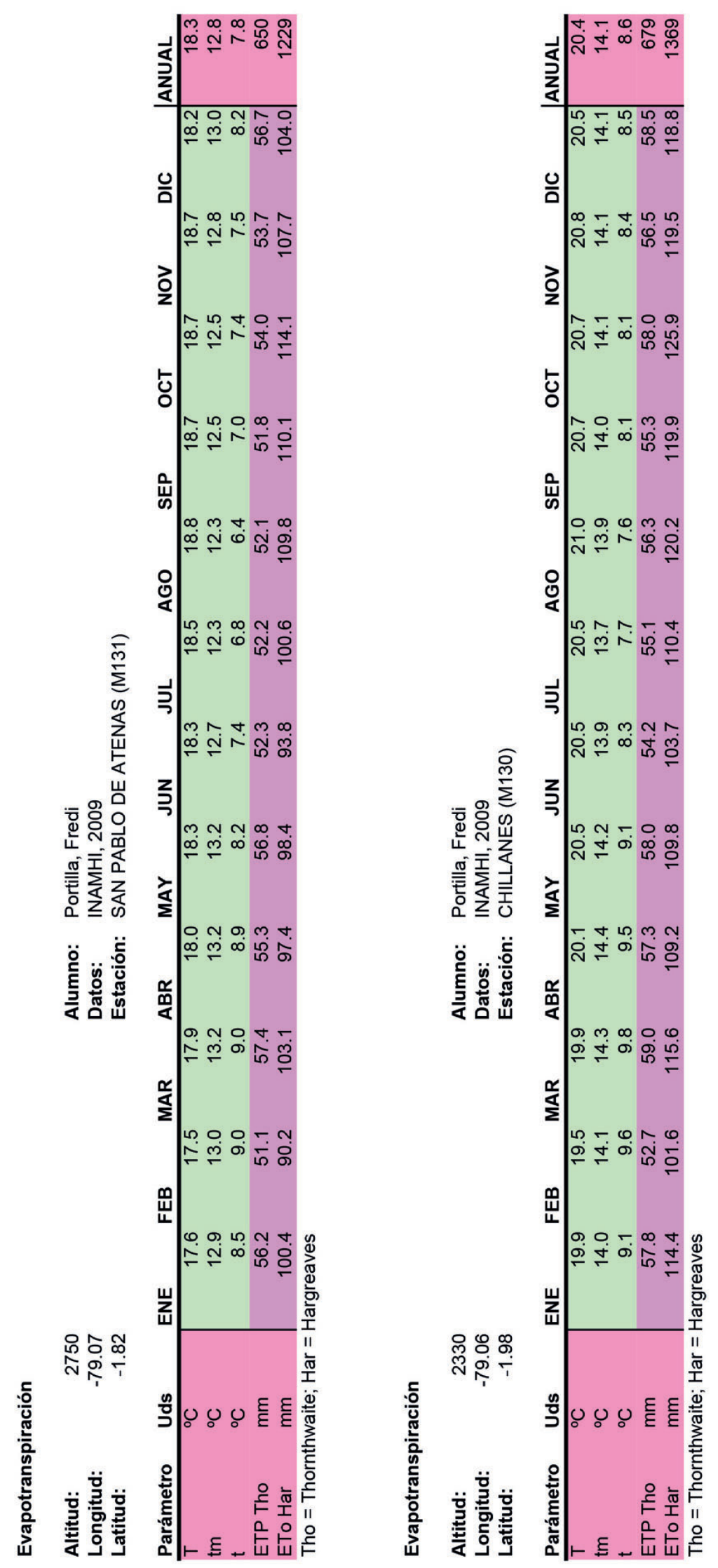

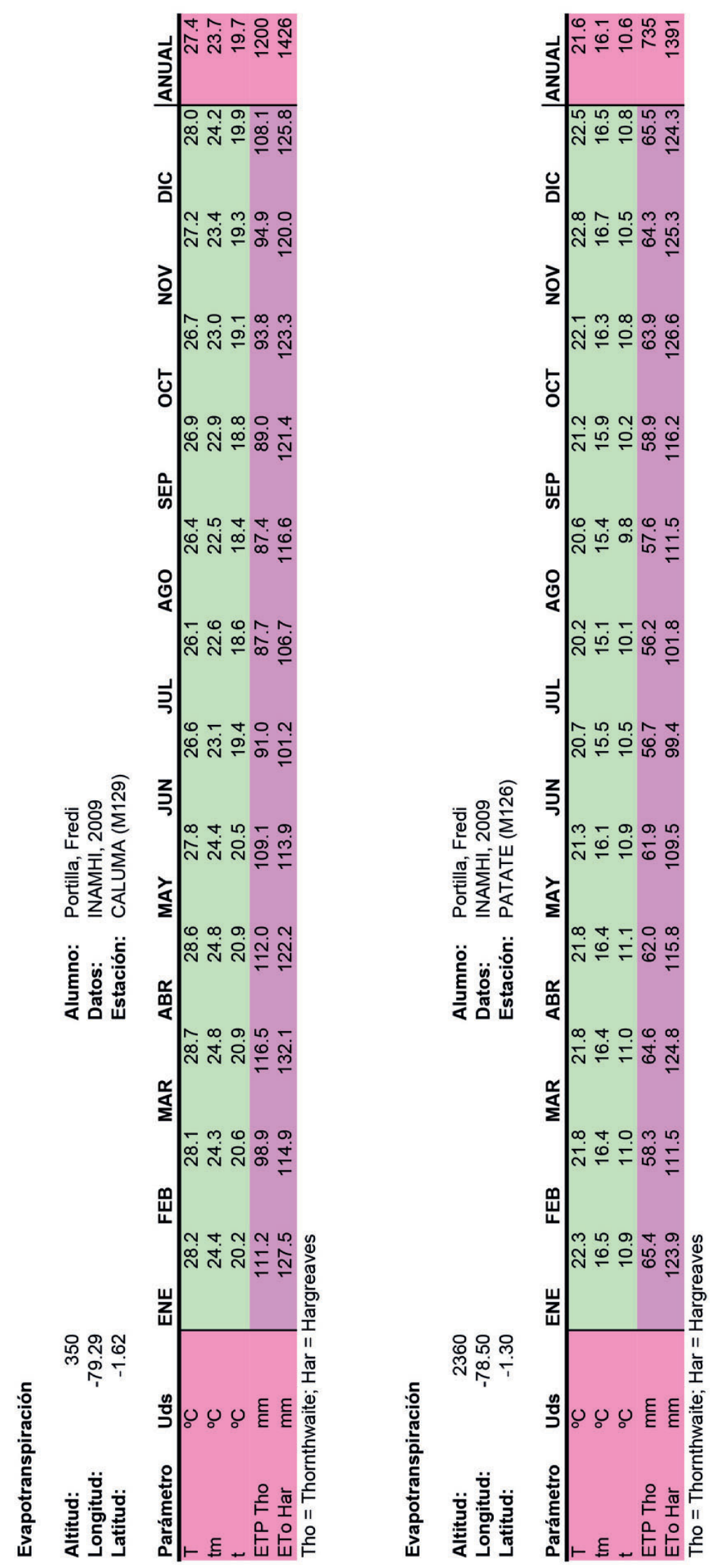

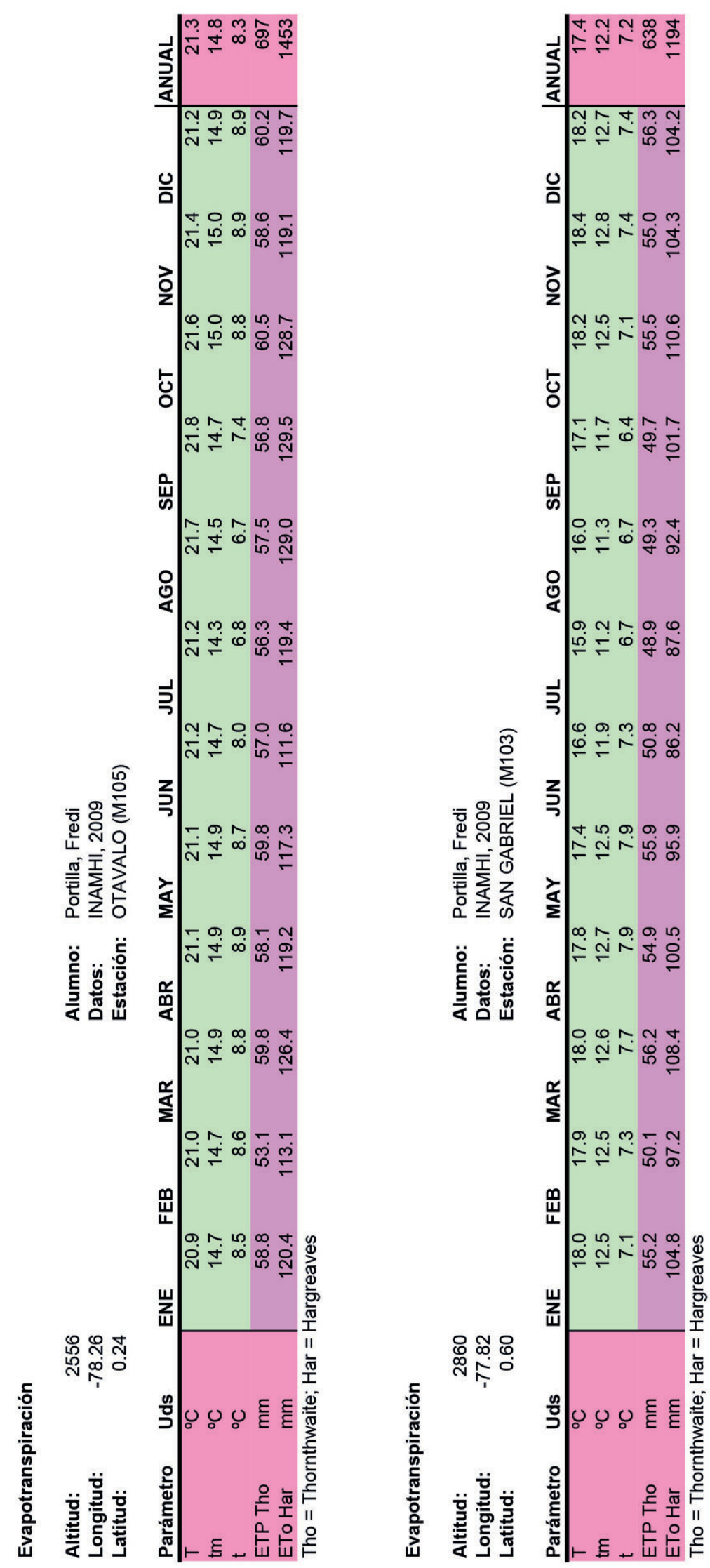


\section{6}
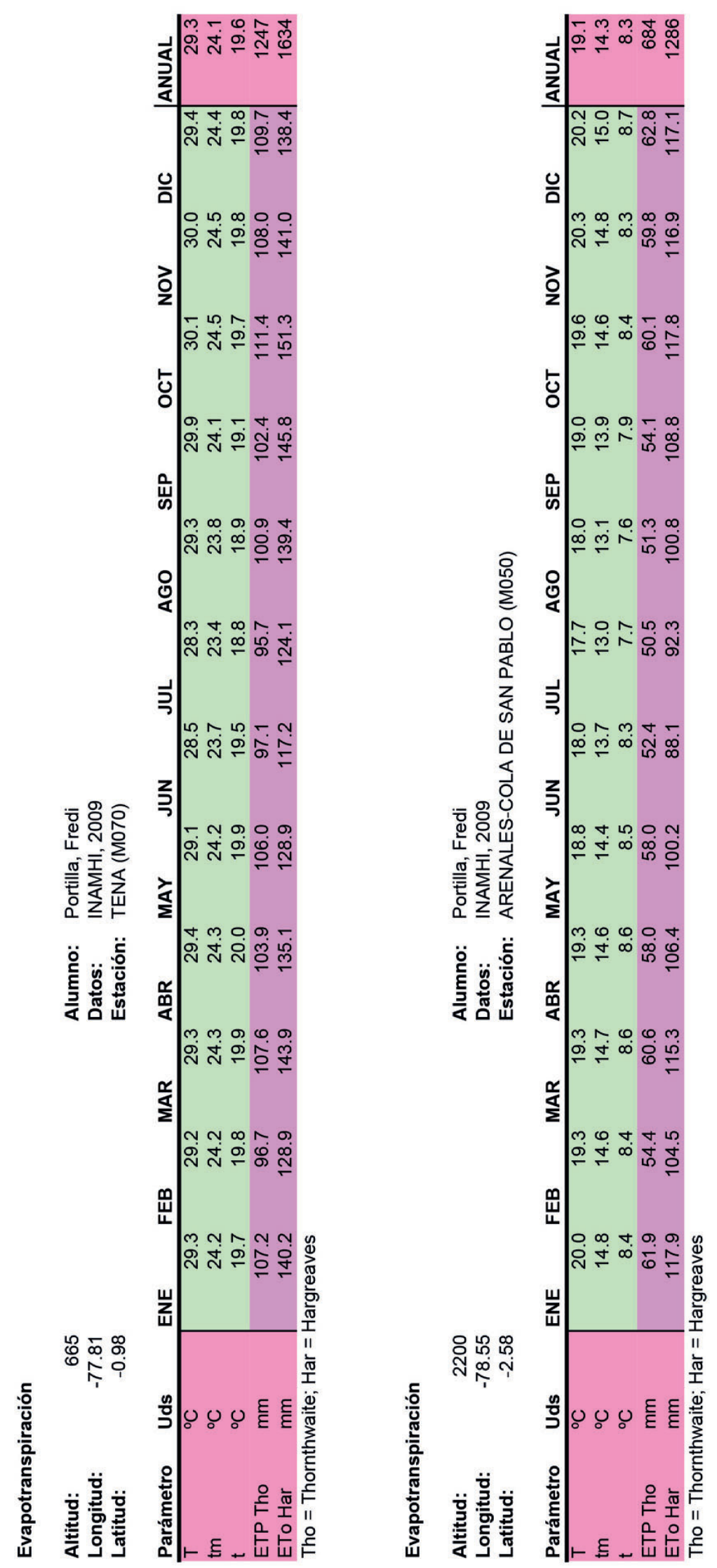

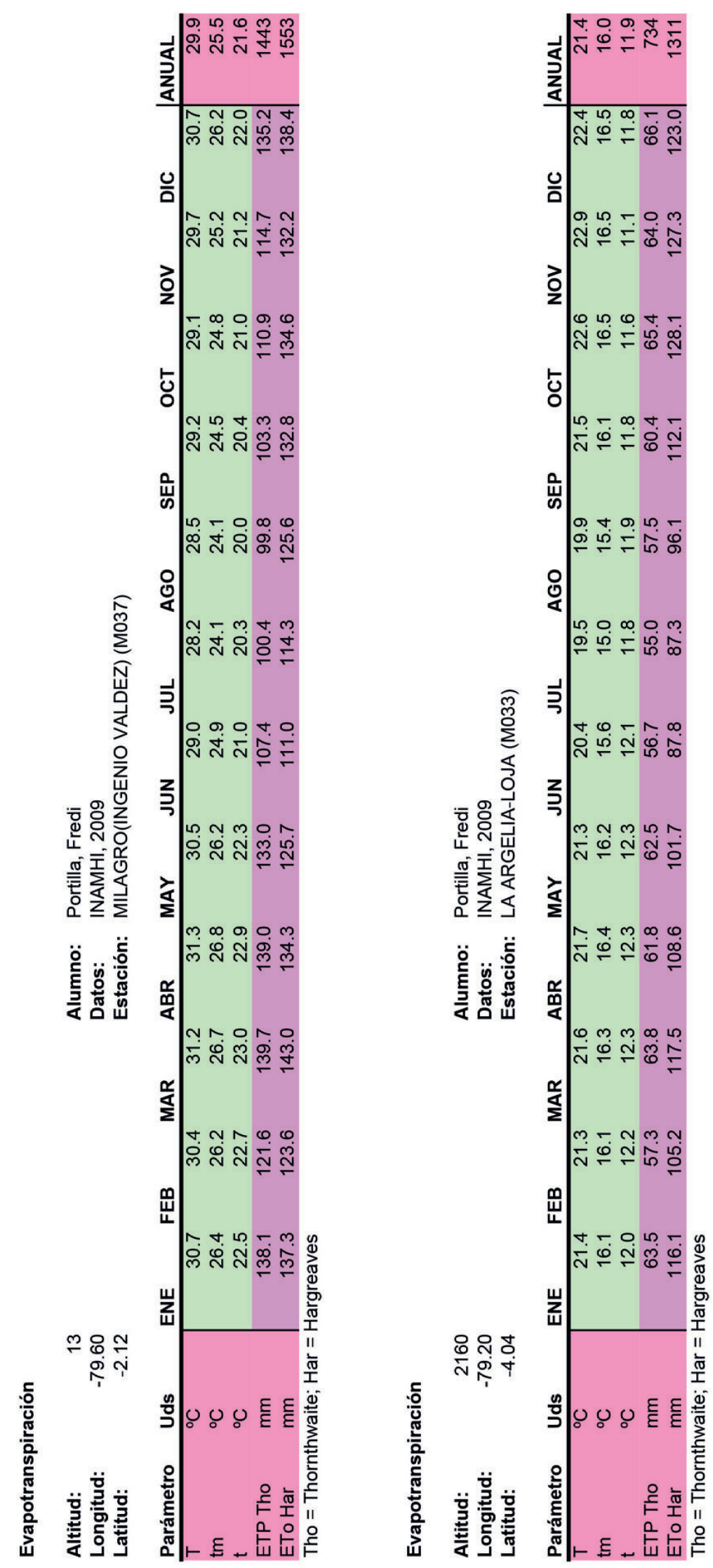

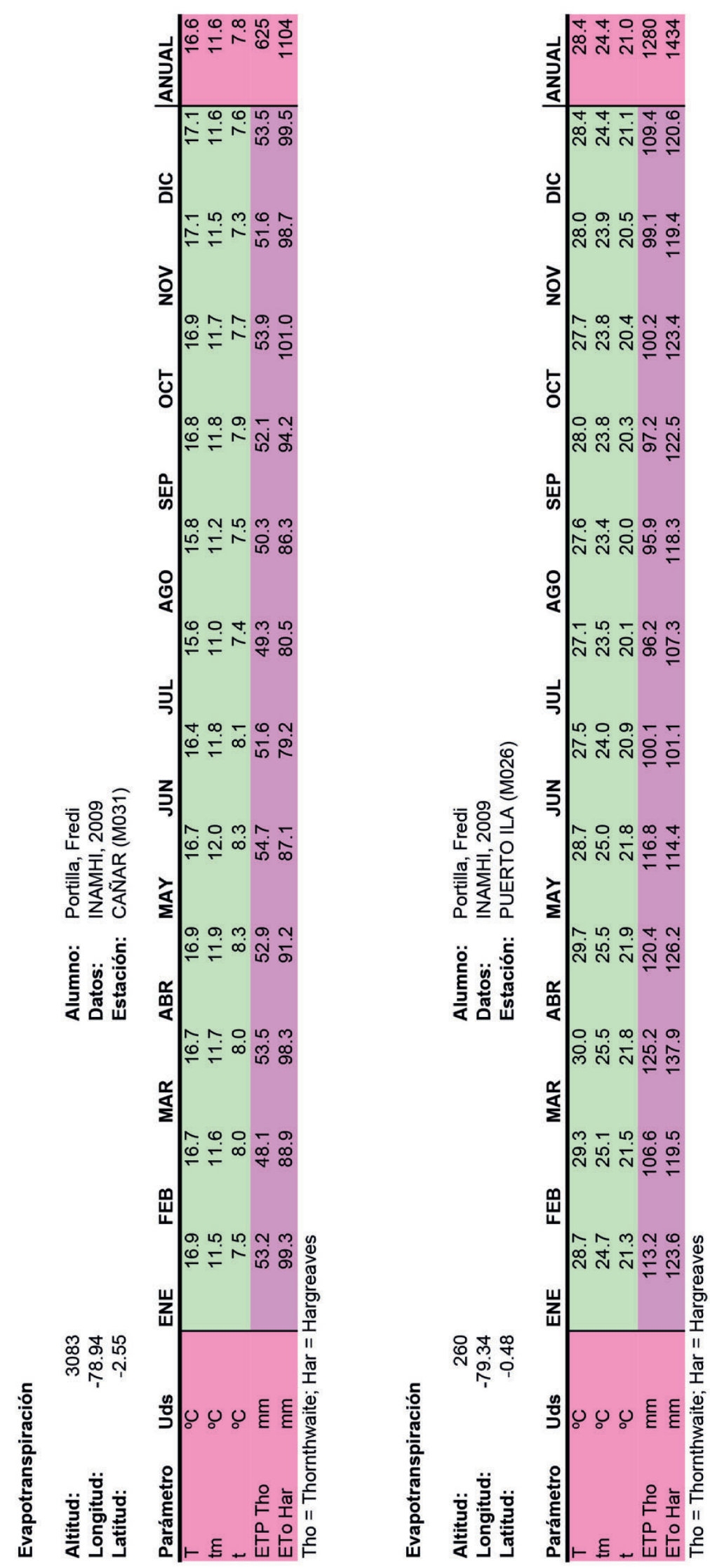

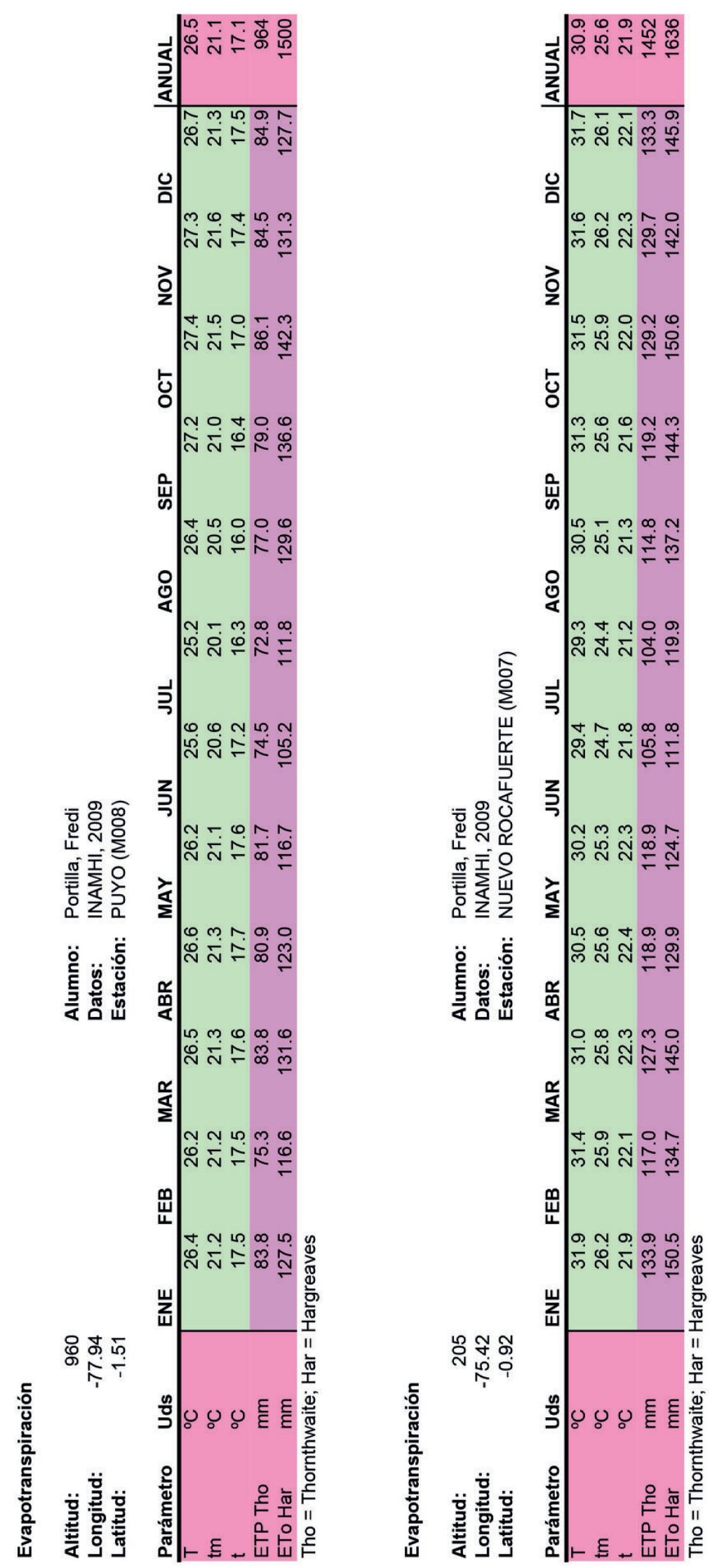

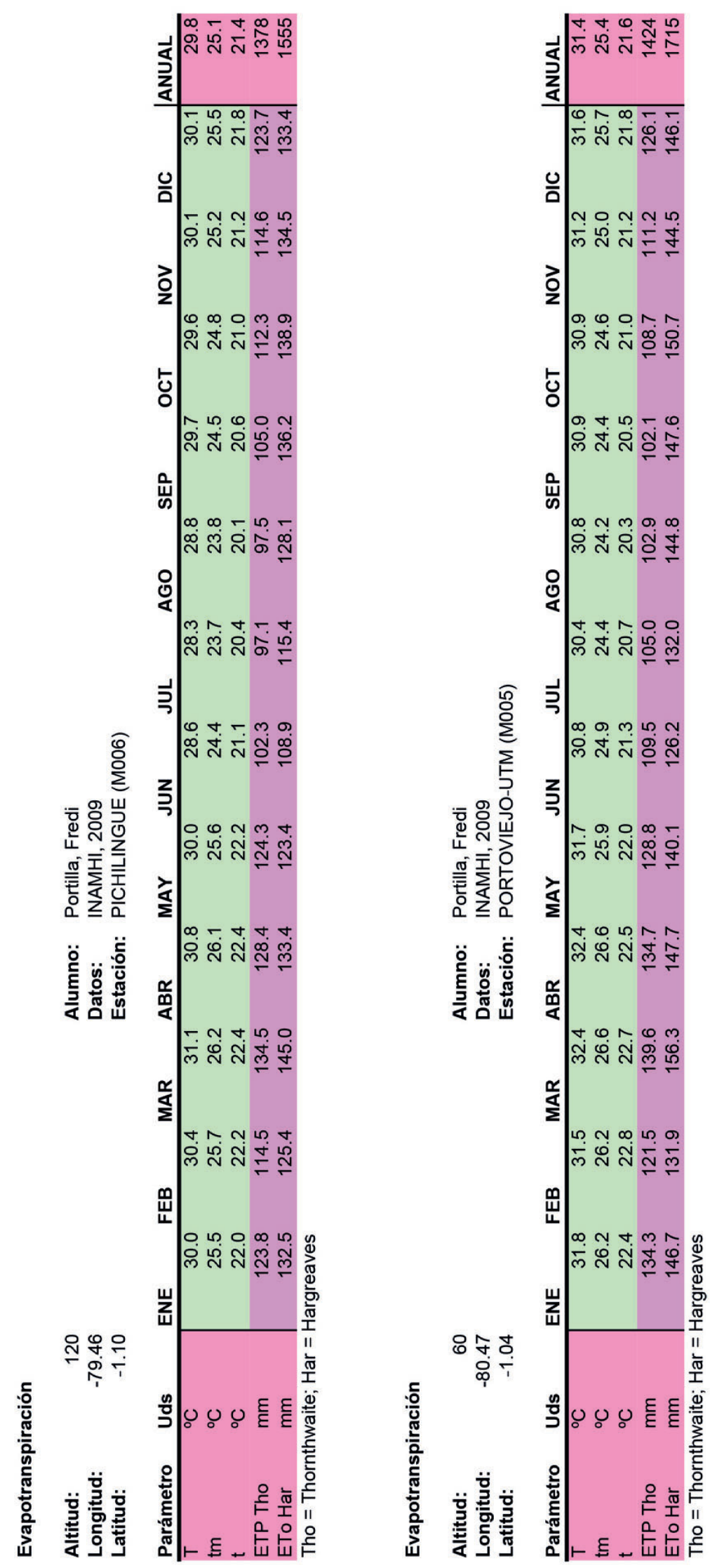


\section{1}
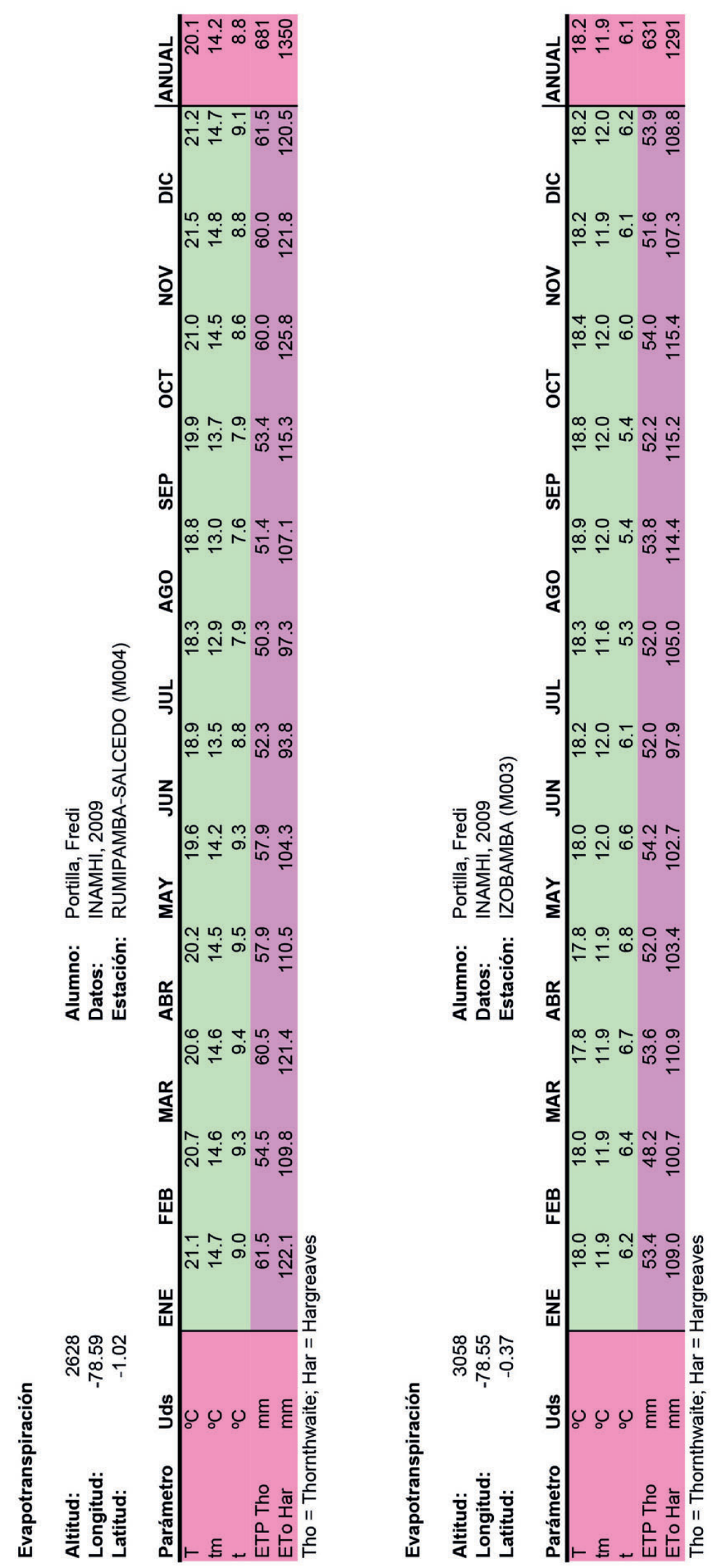


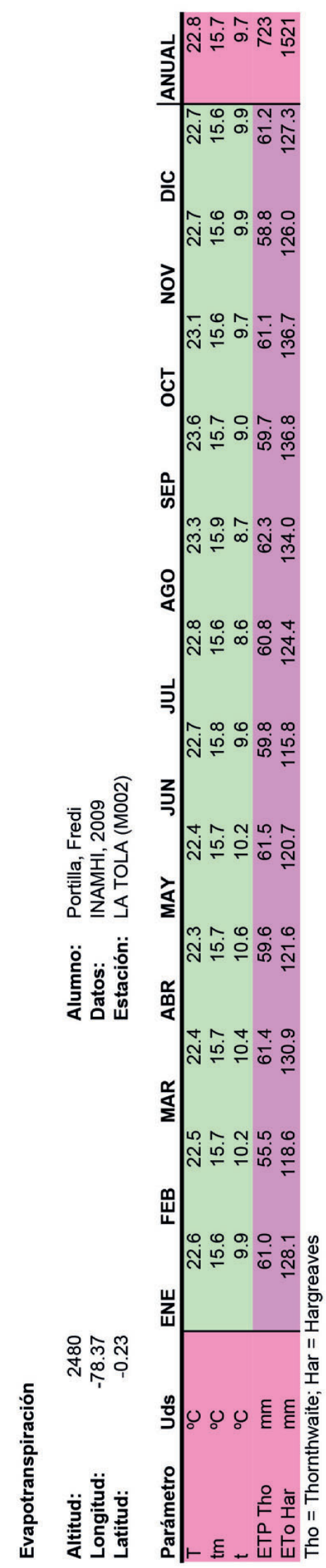



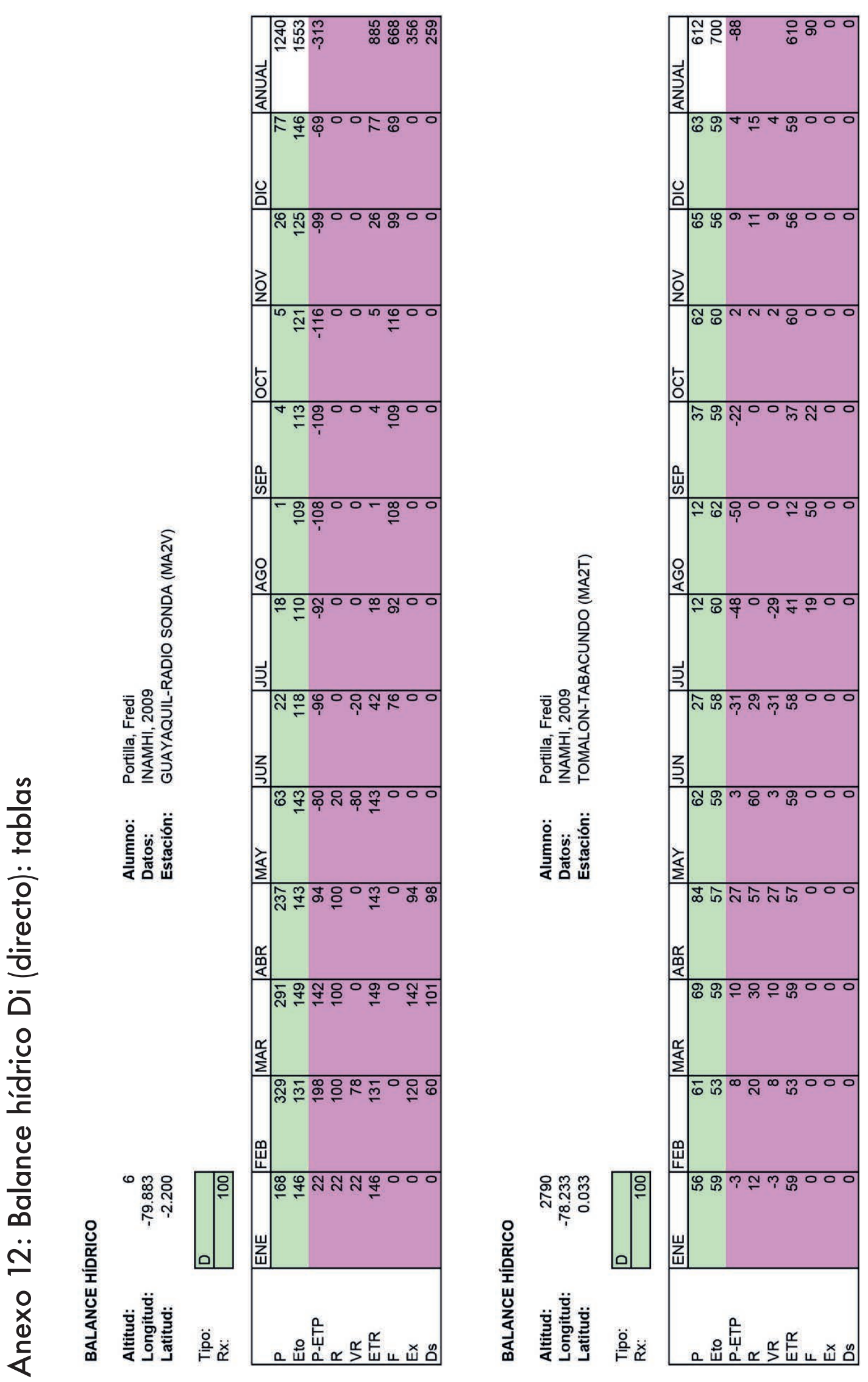


\section{4}

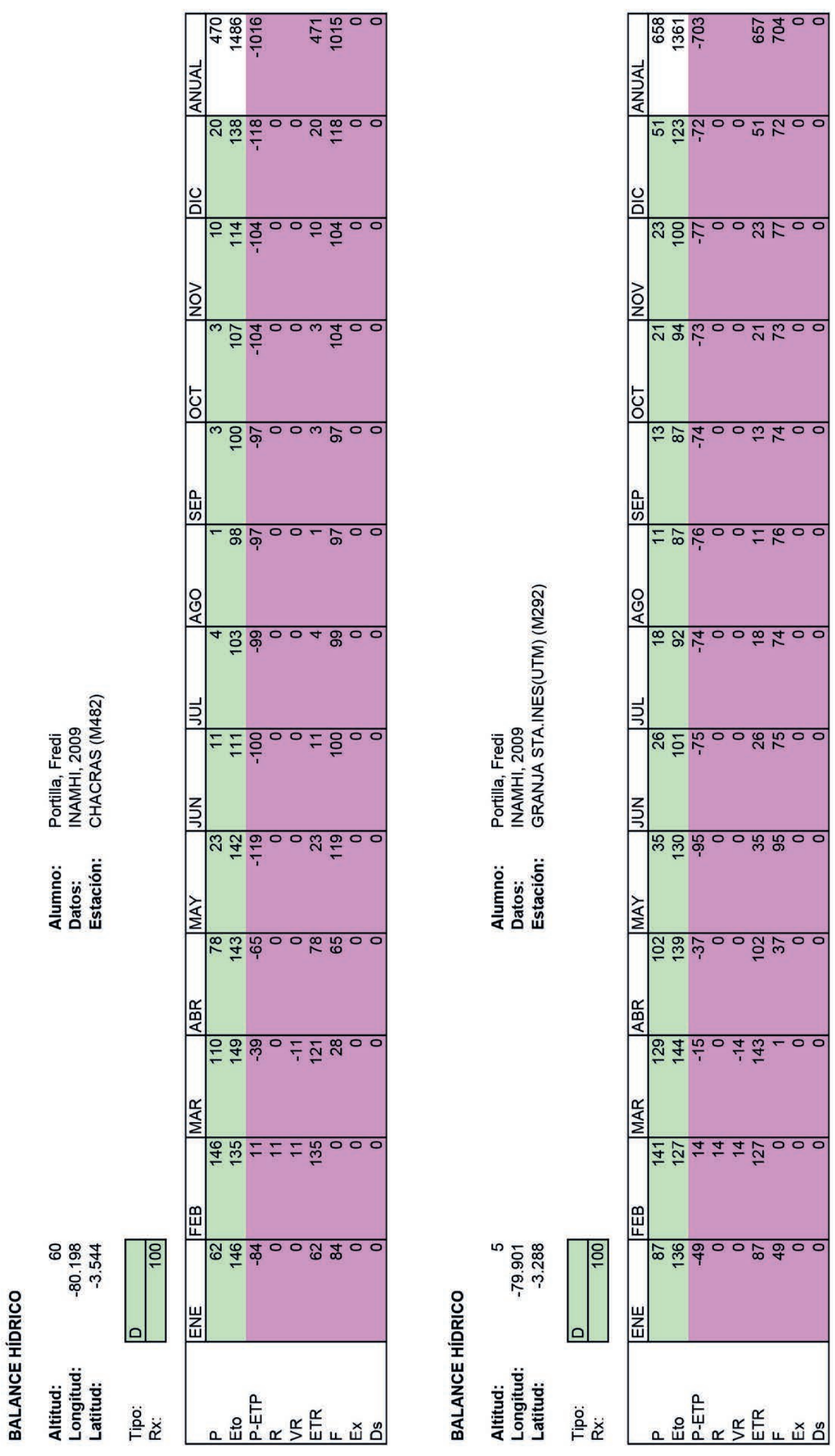




\section{5}
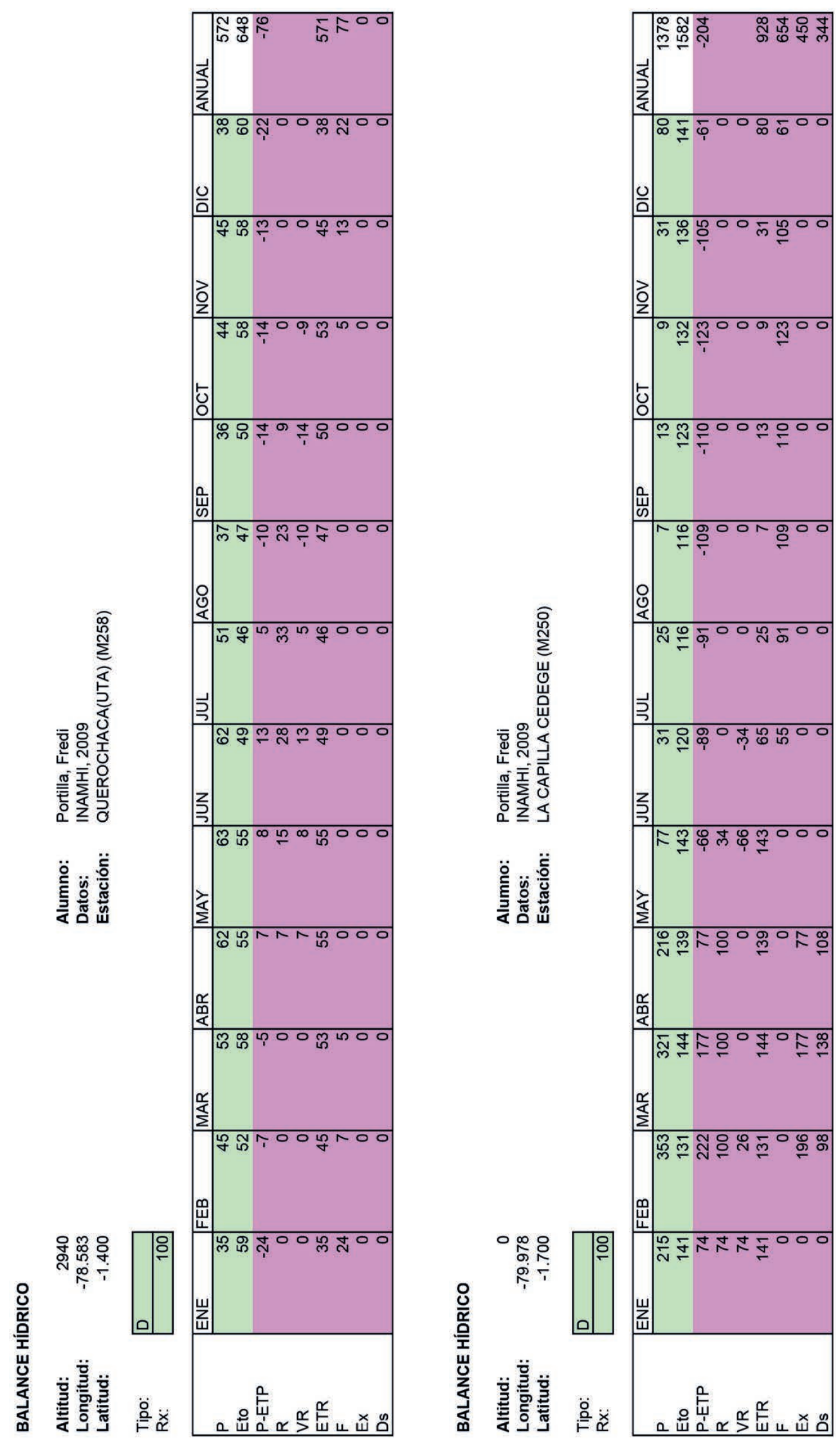


\section{6}

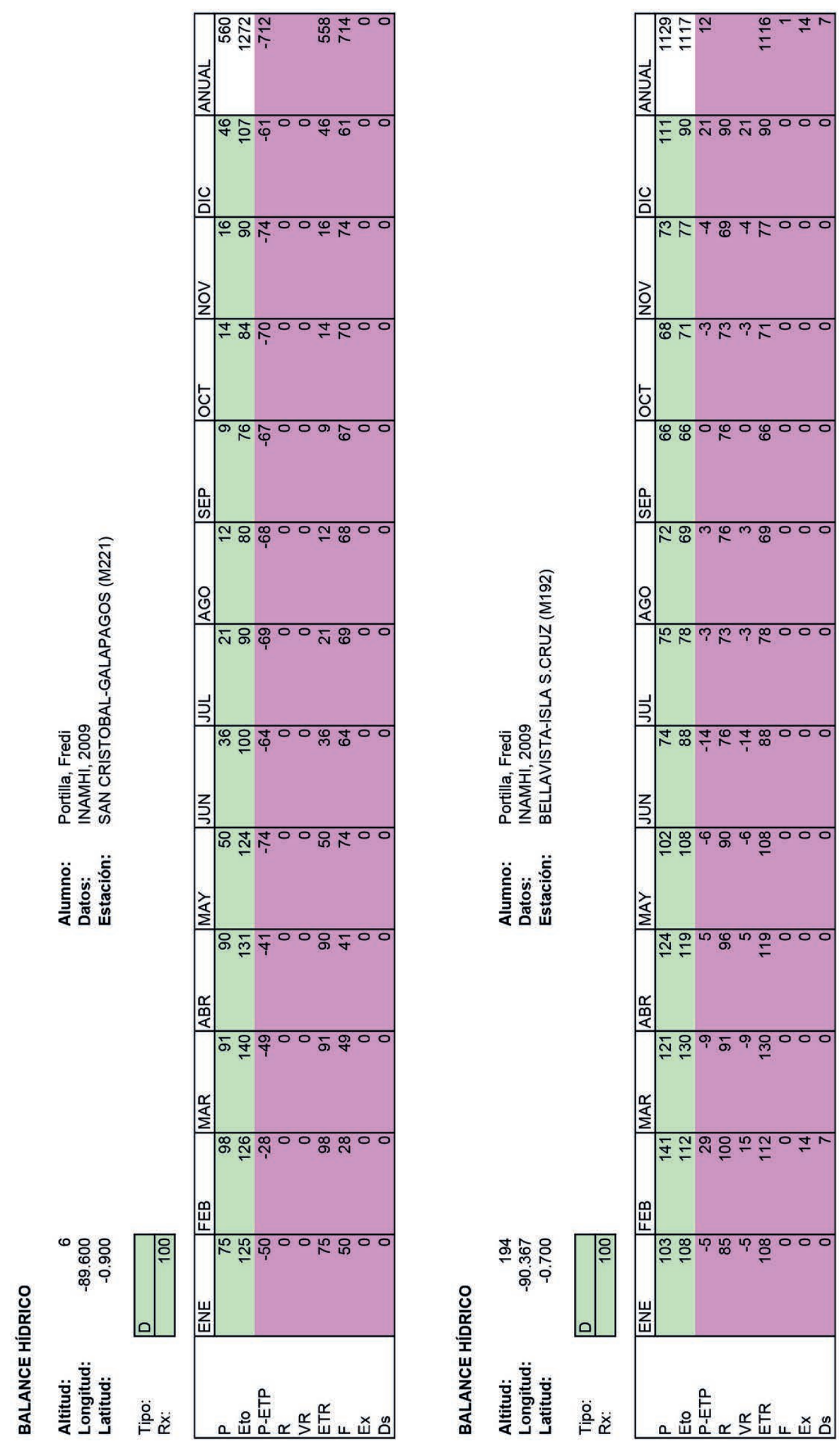



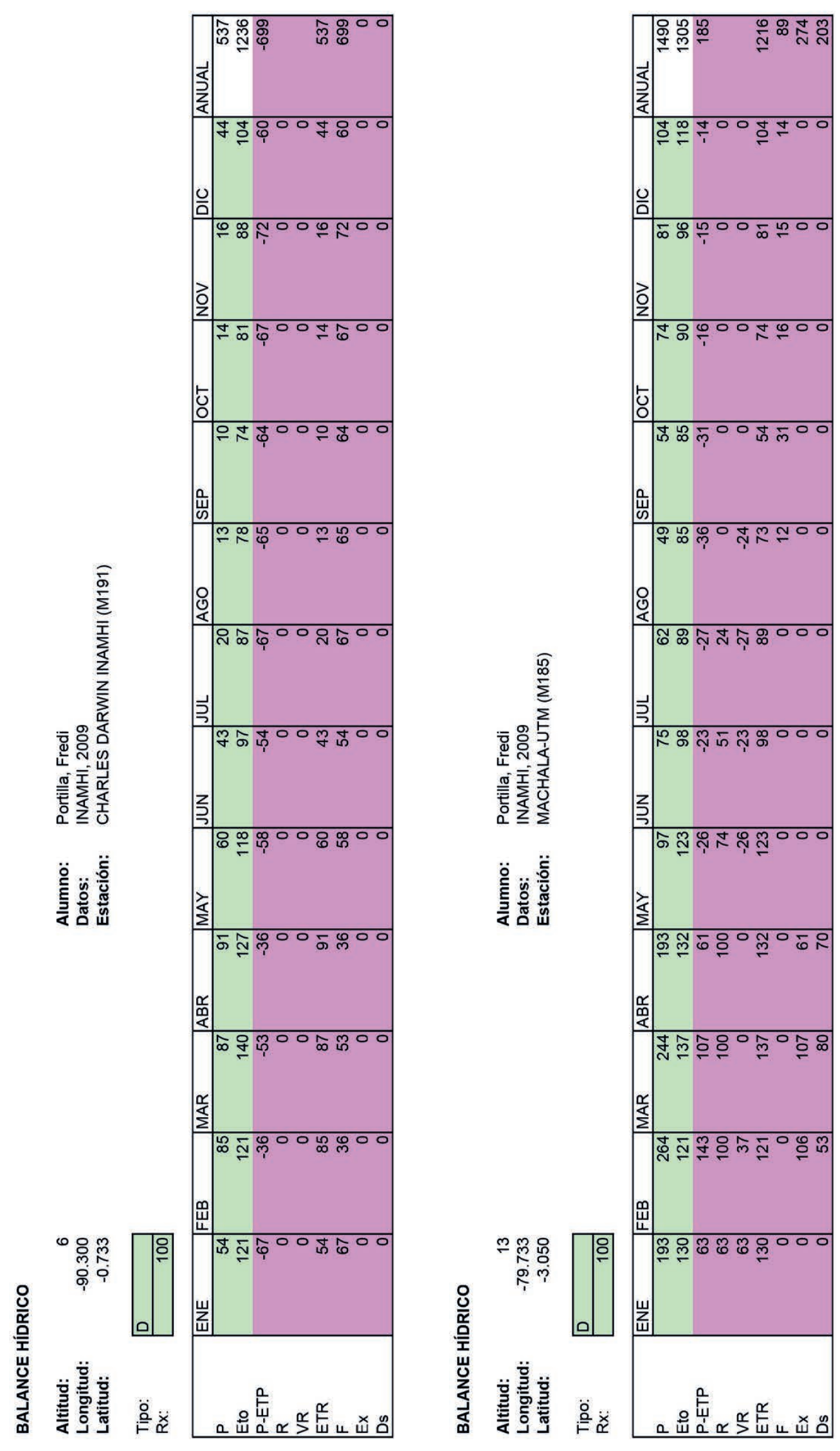


\section{8}

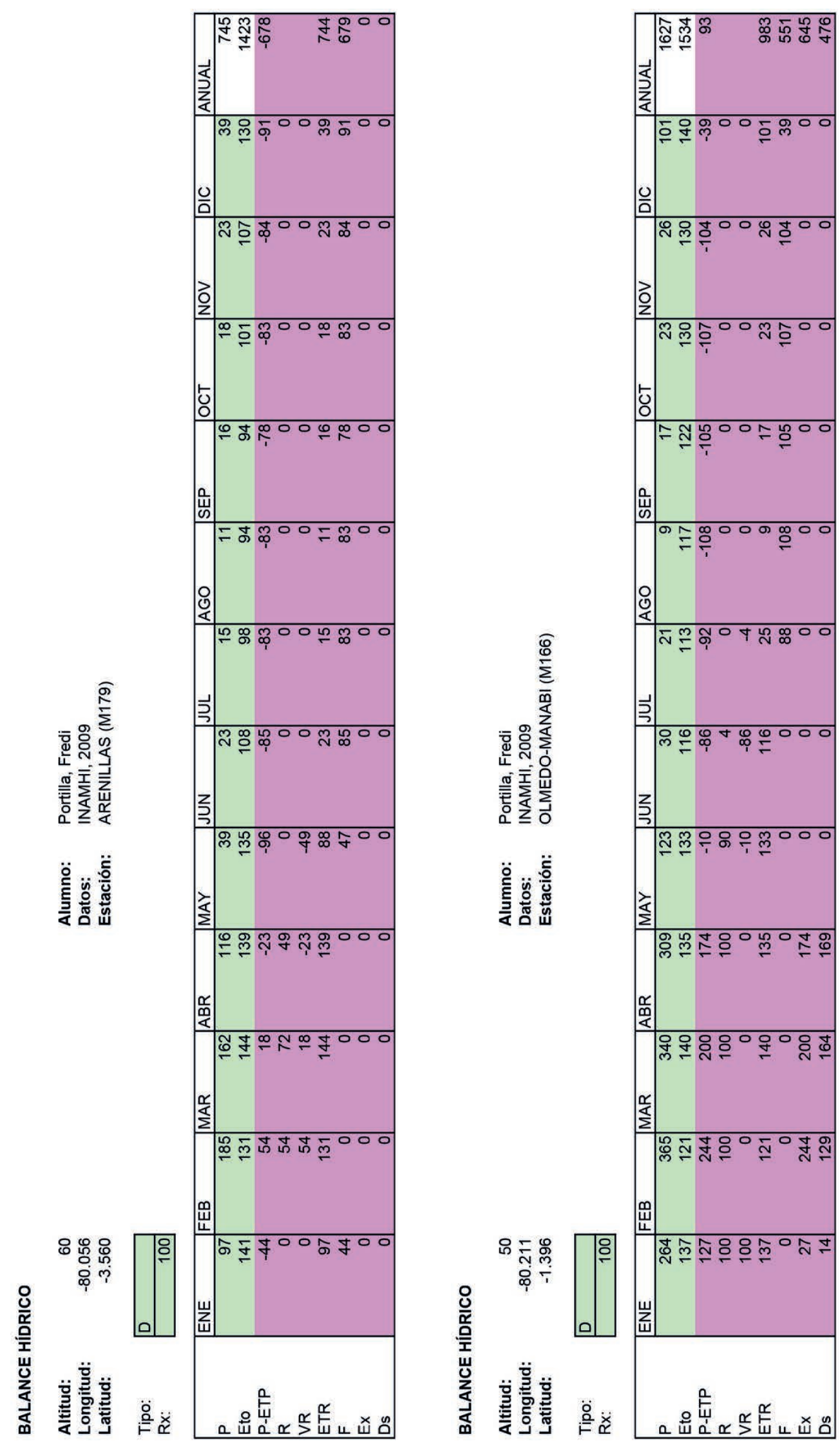




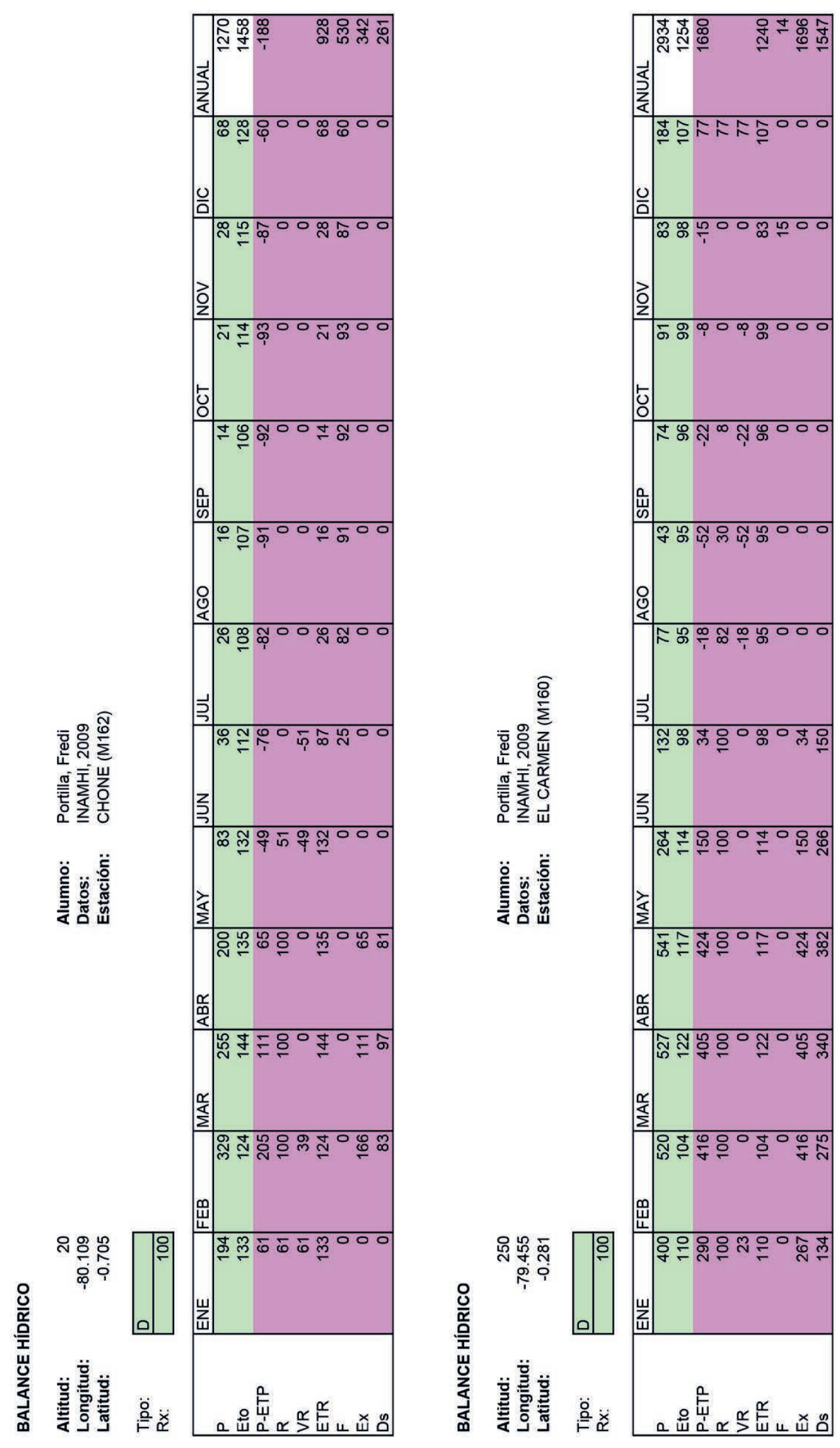




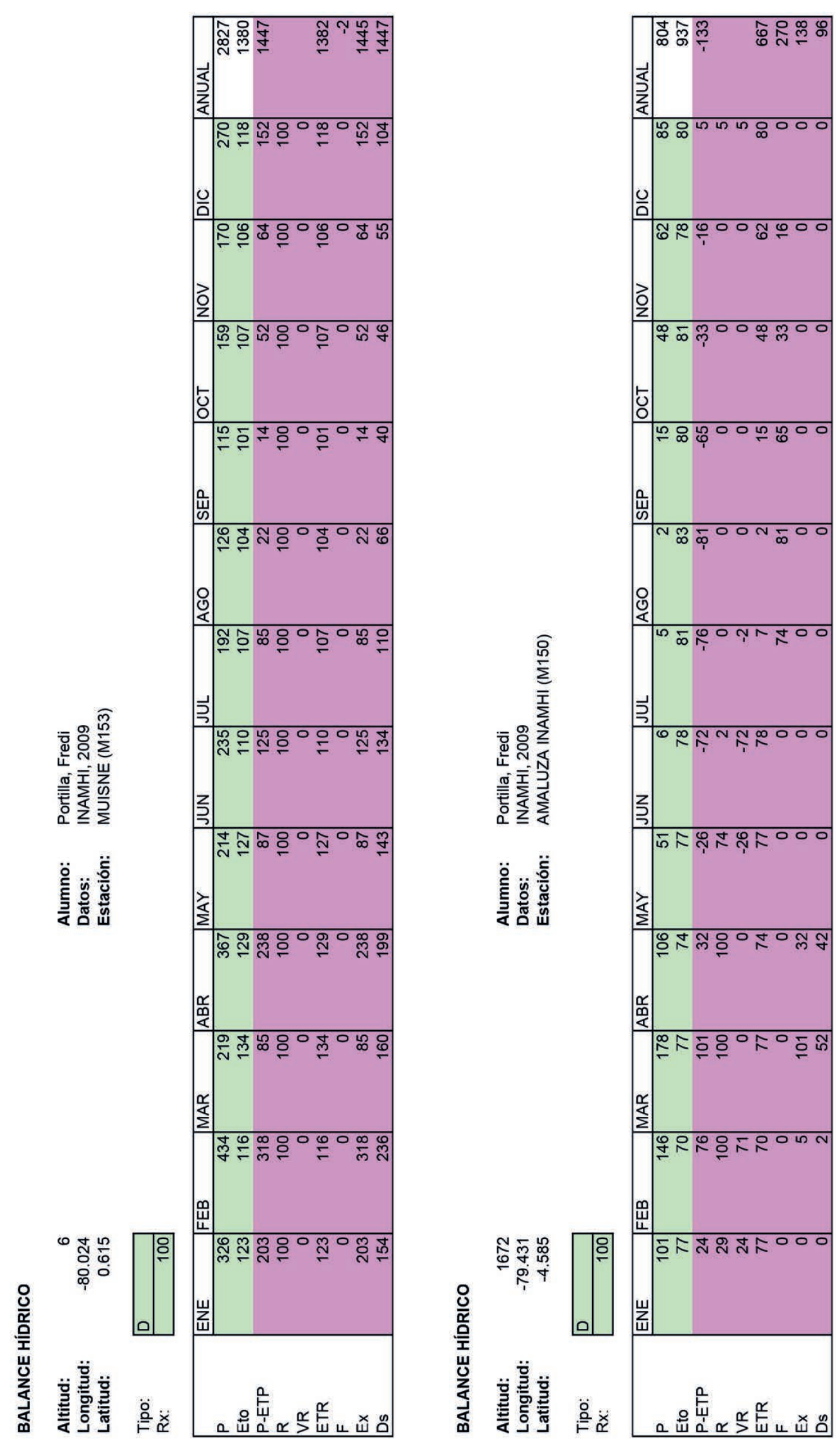




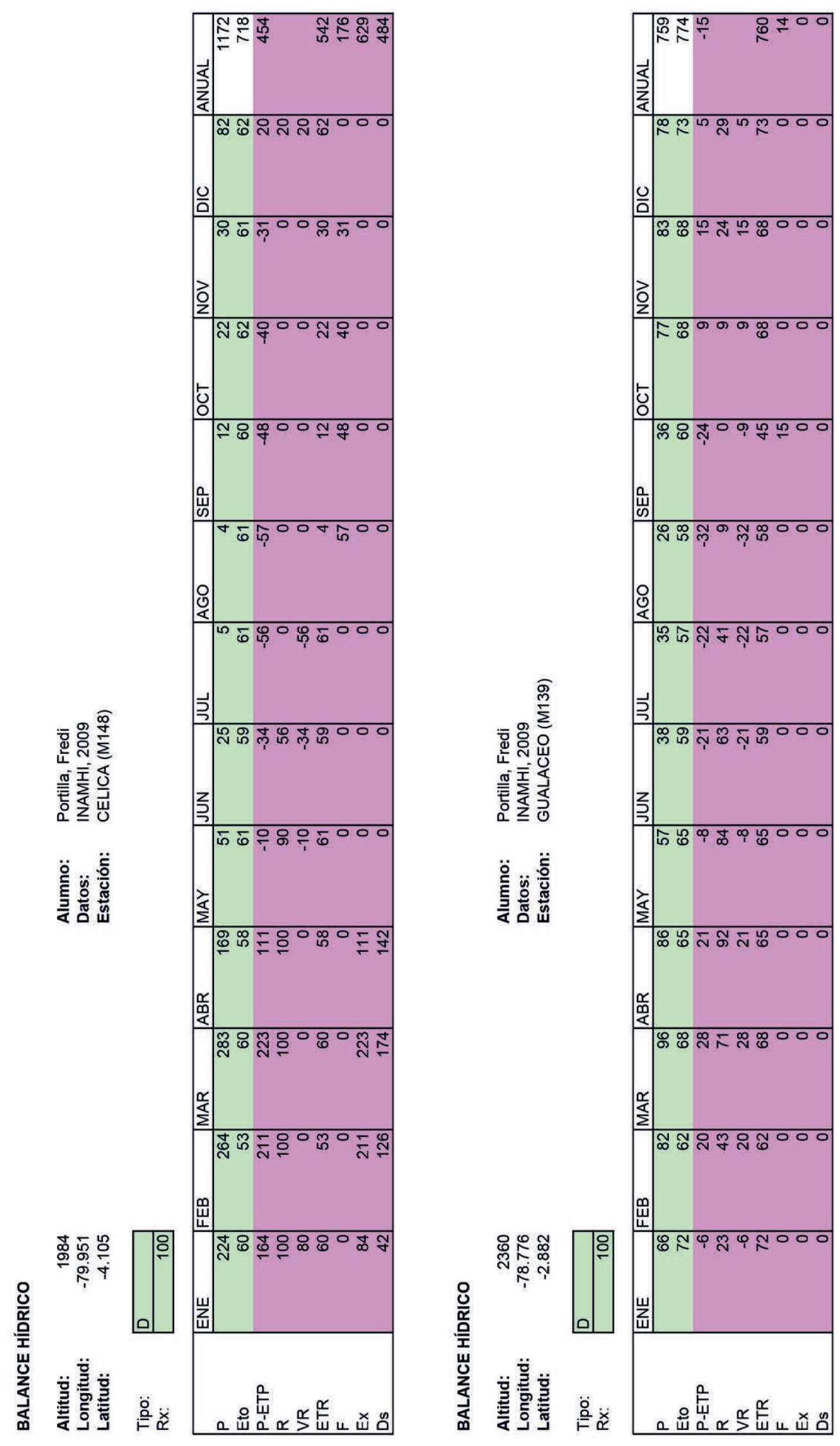




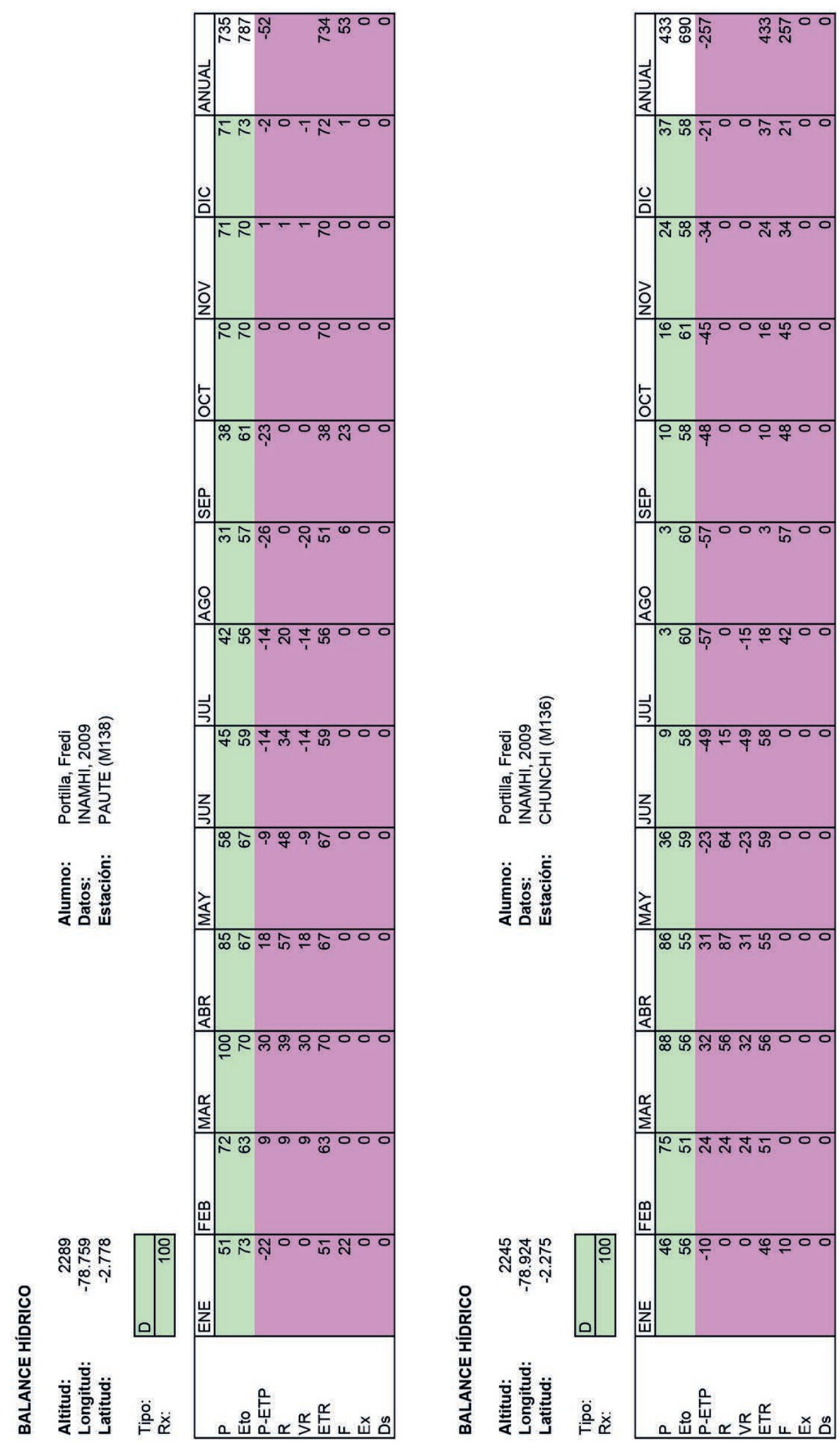




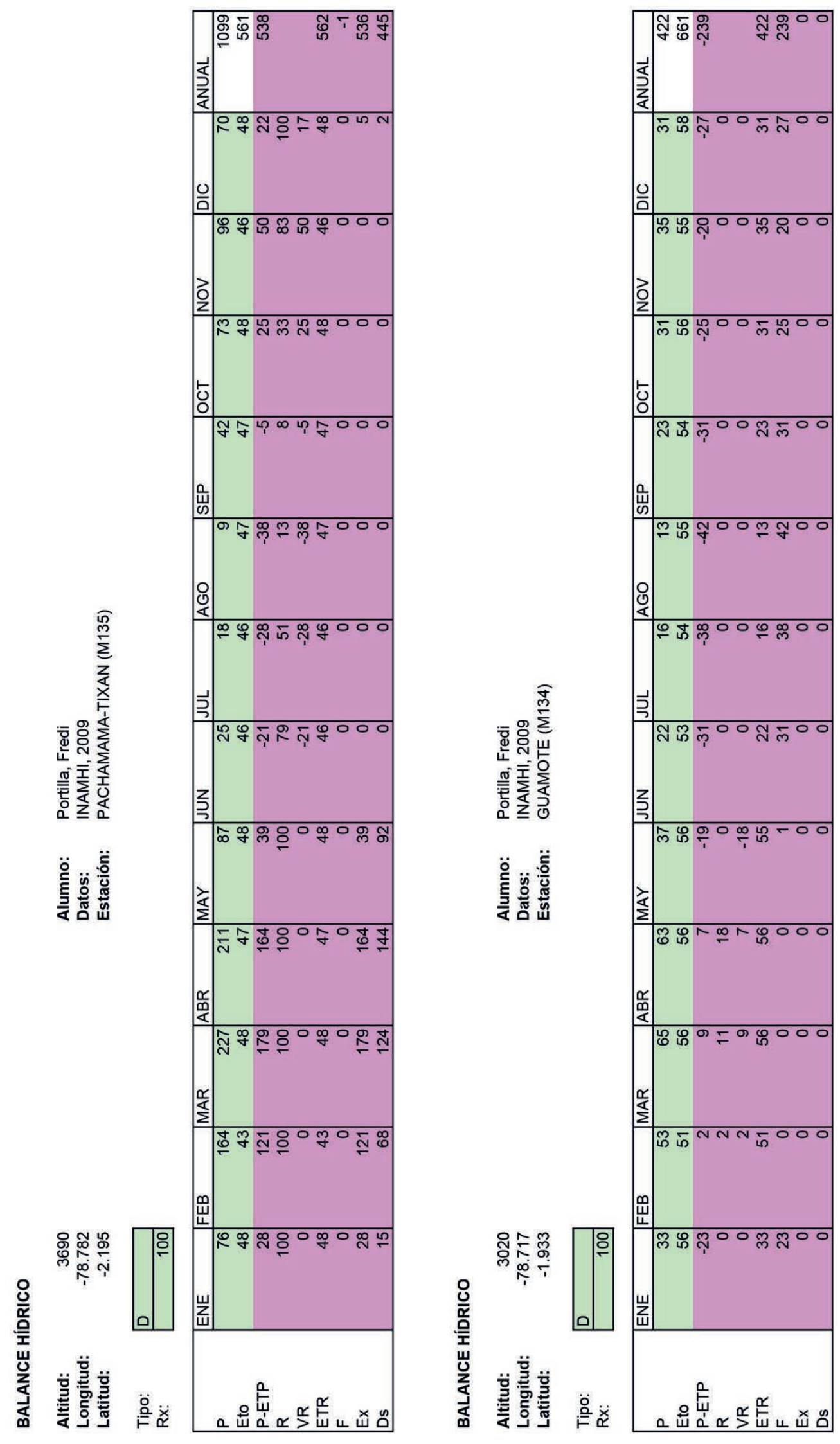




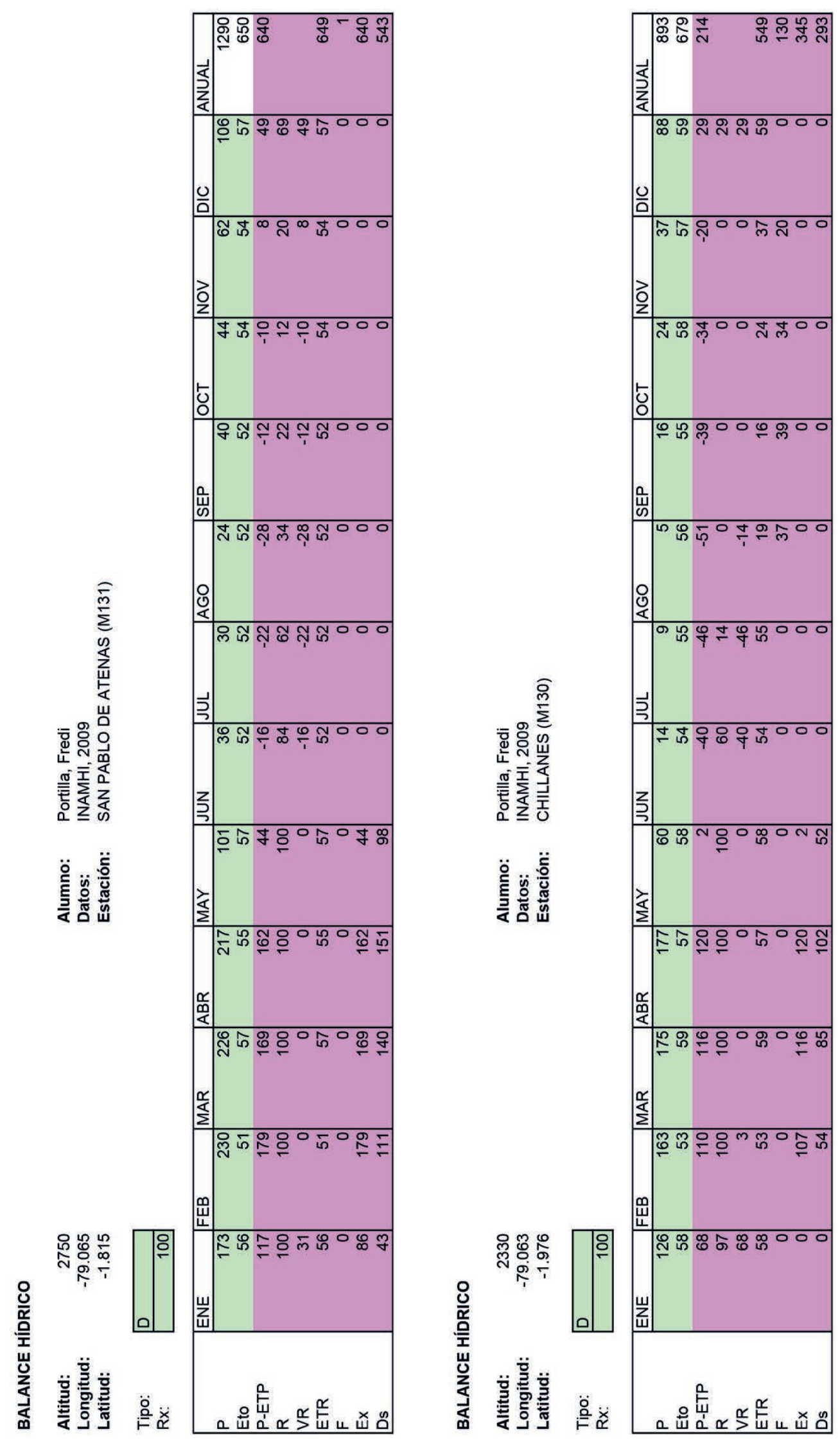




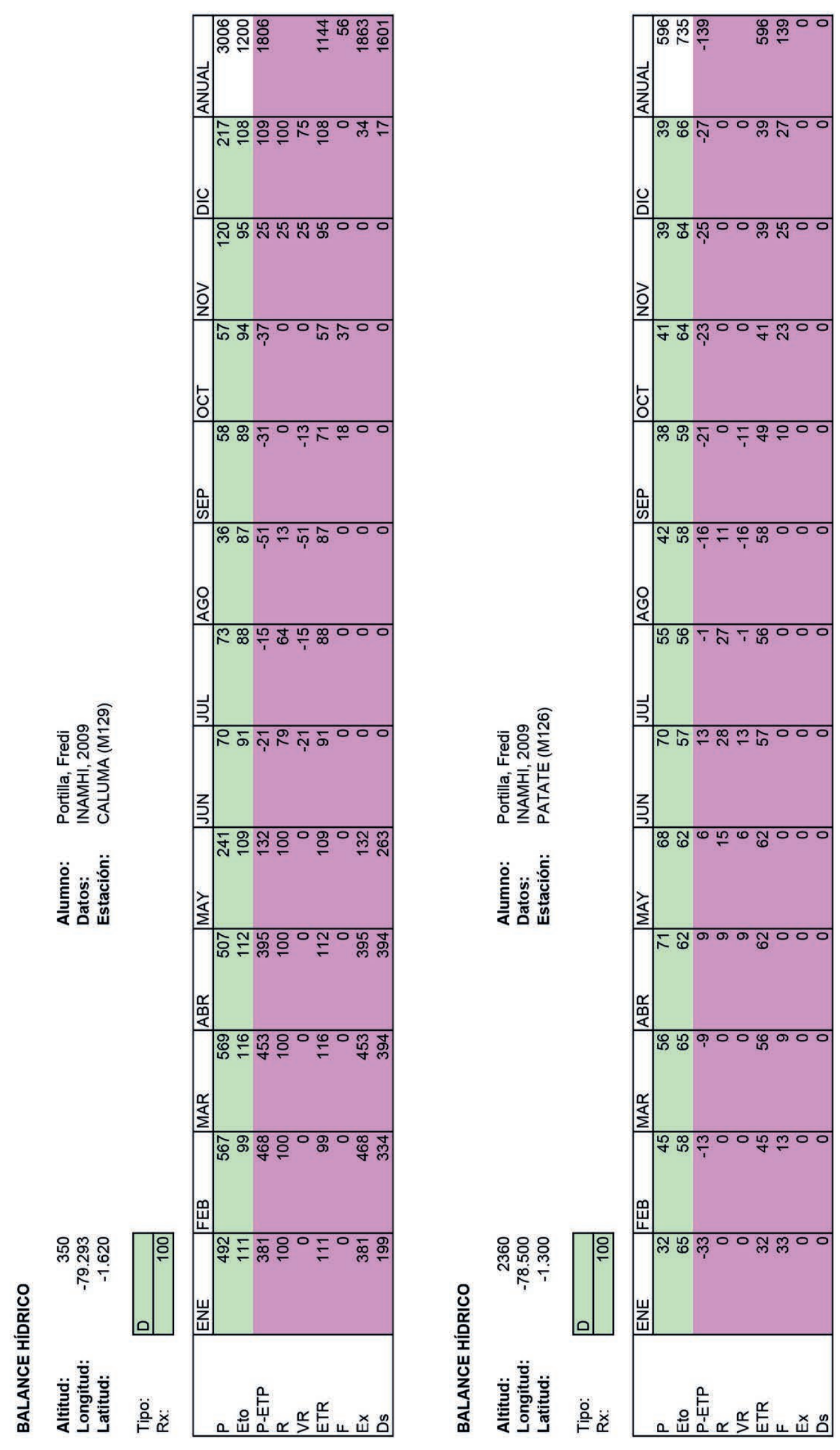




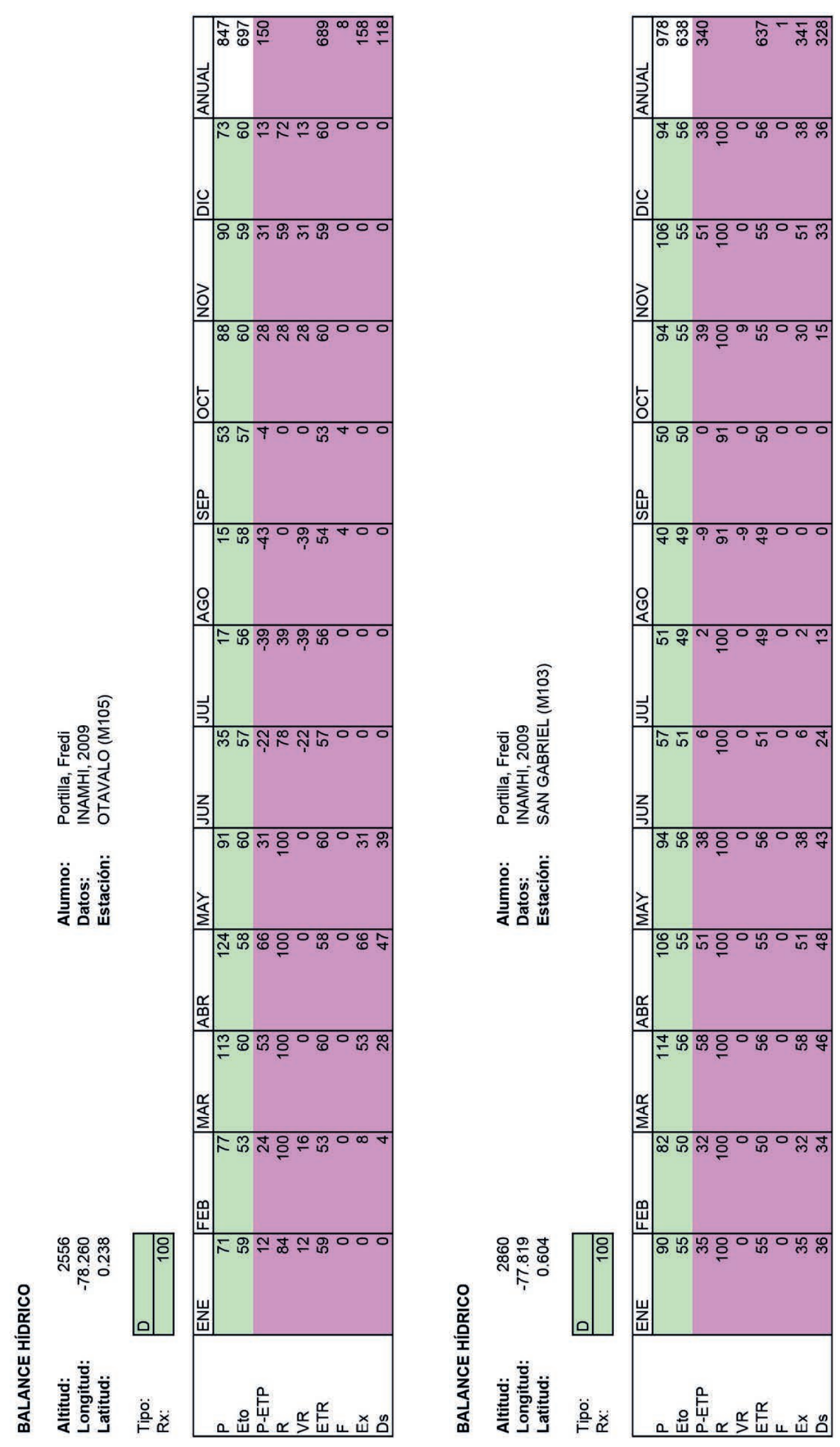




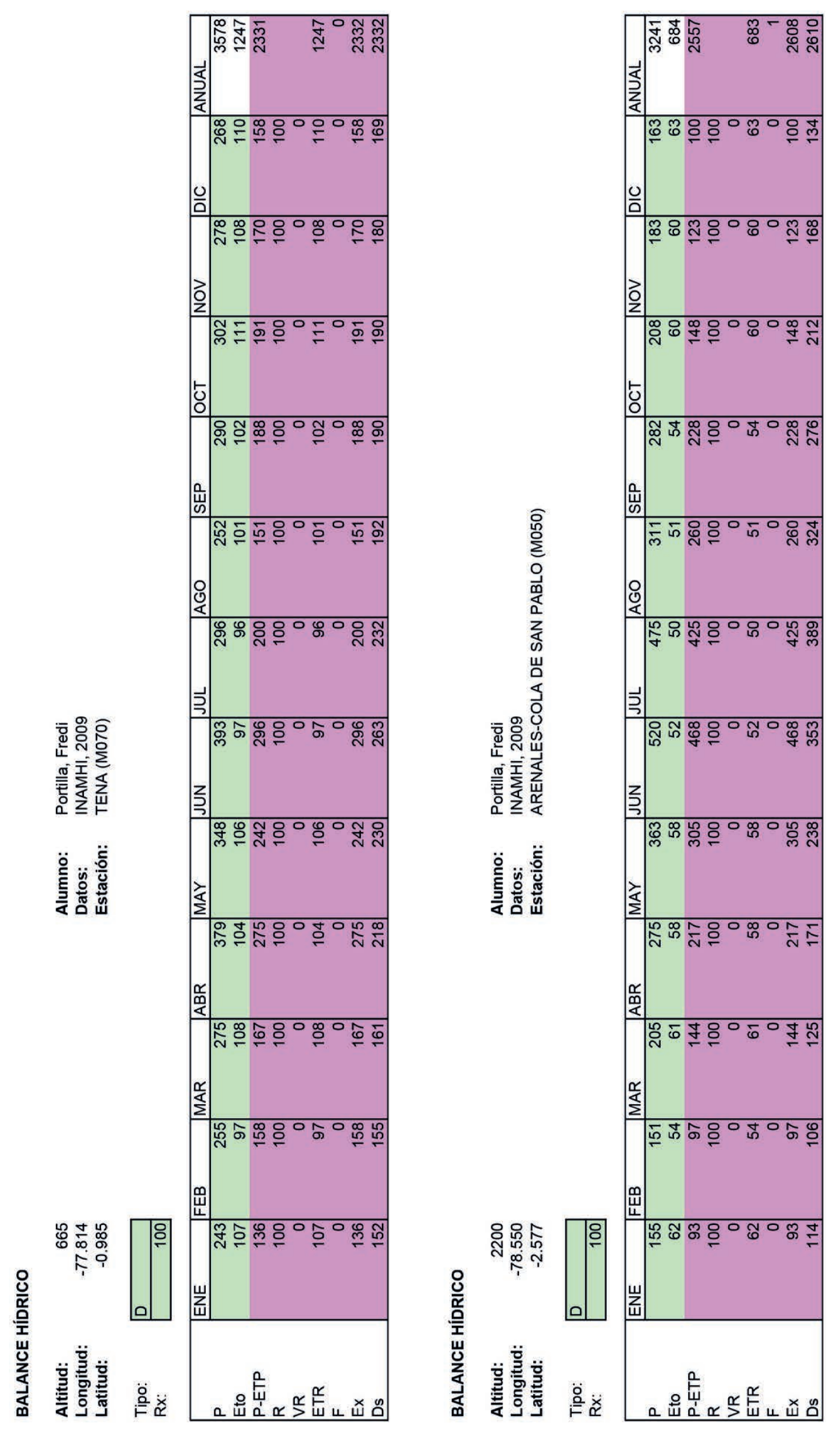




\section{8}

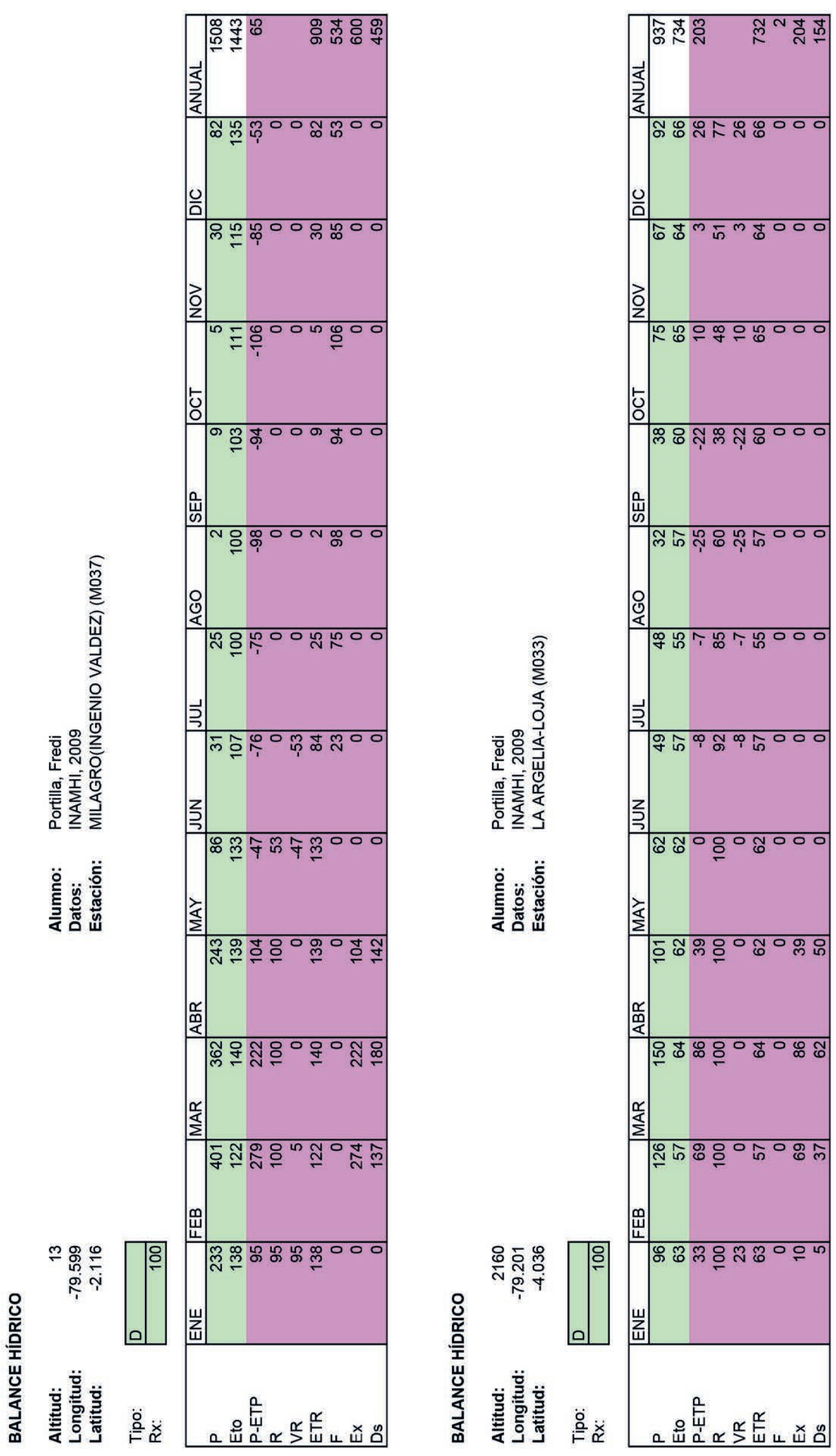




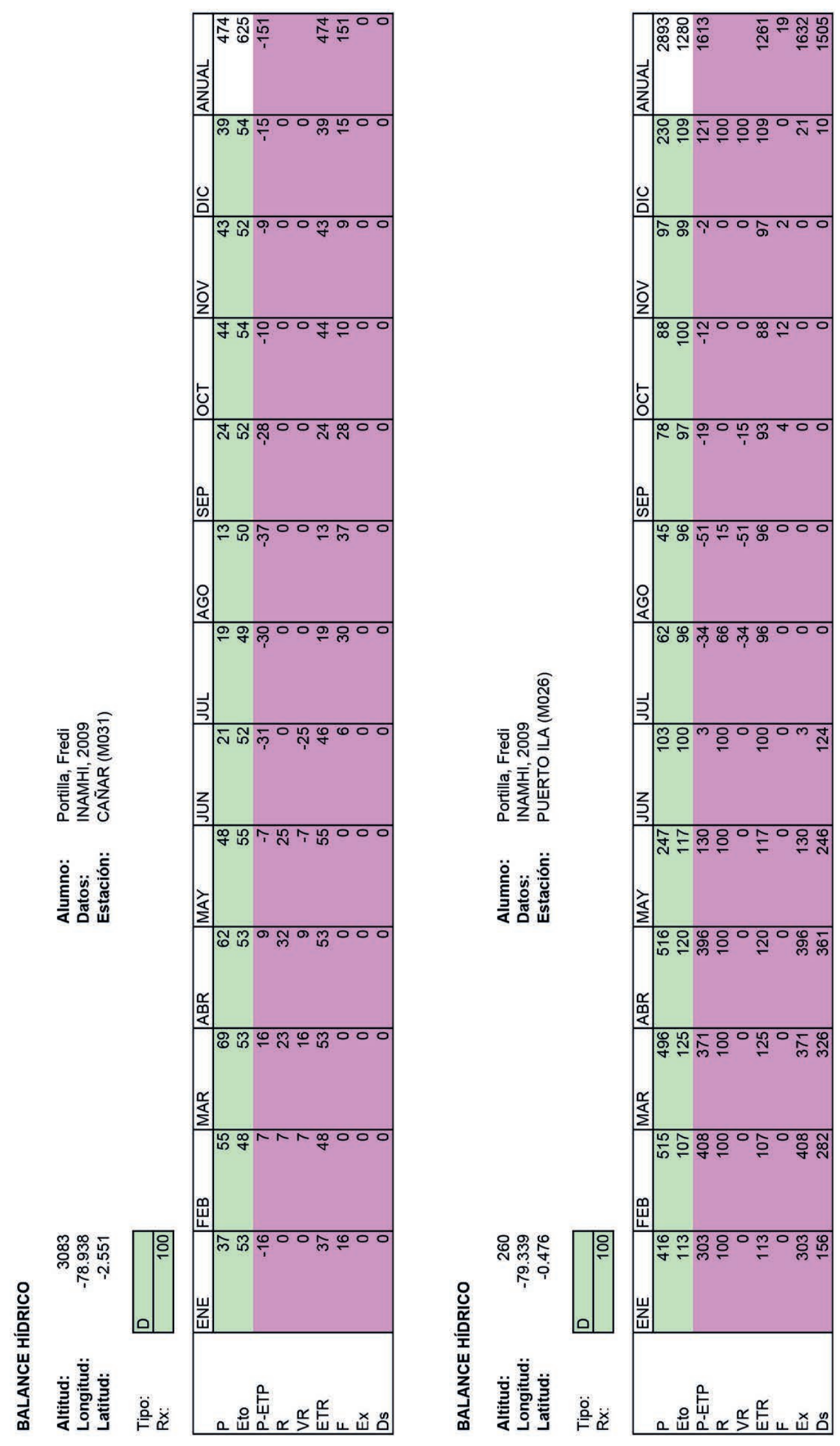




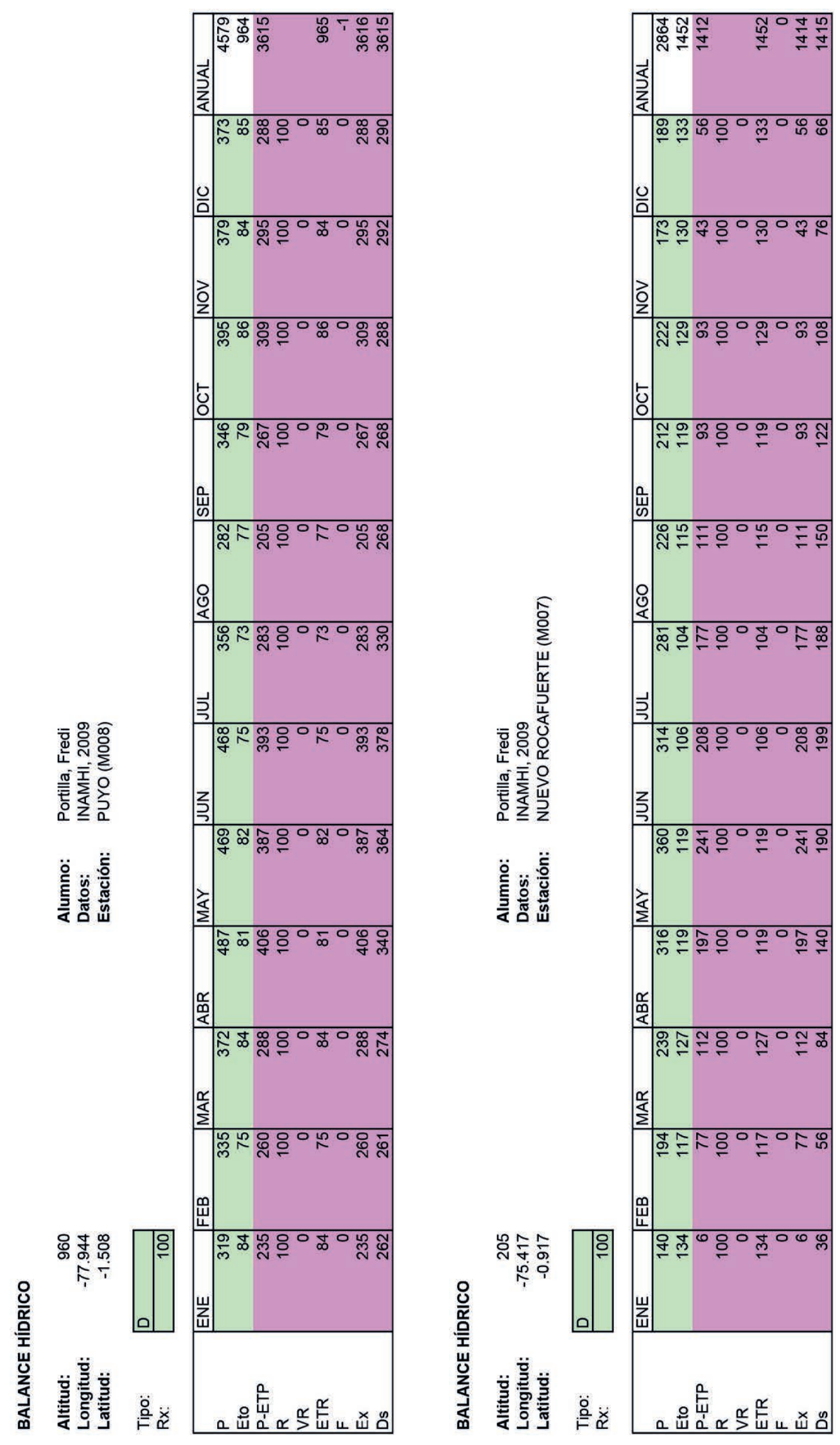




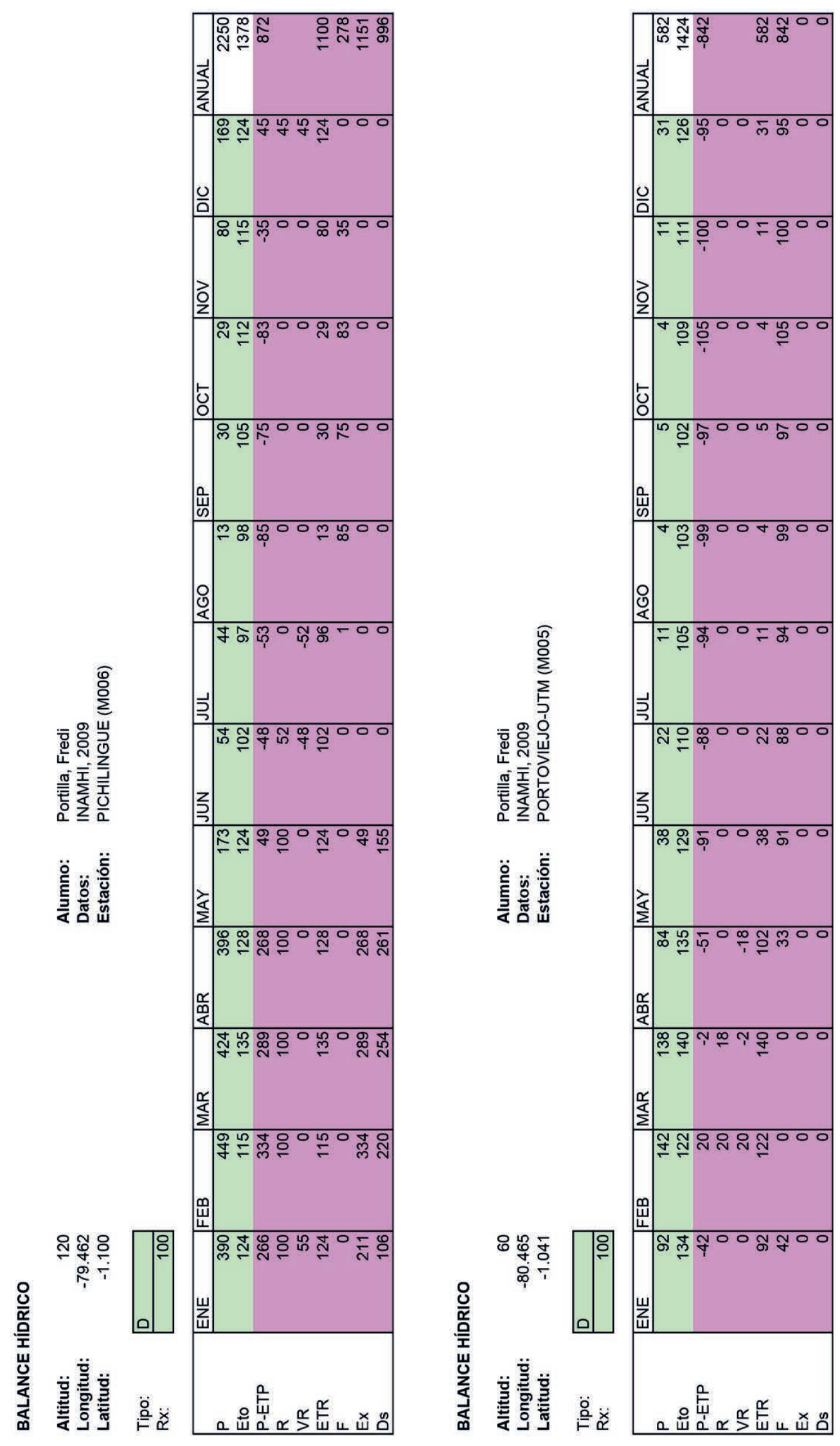



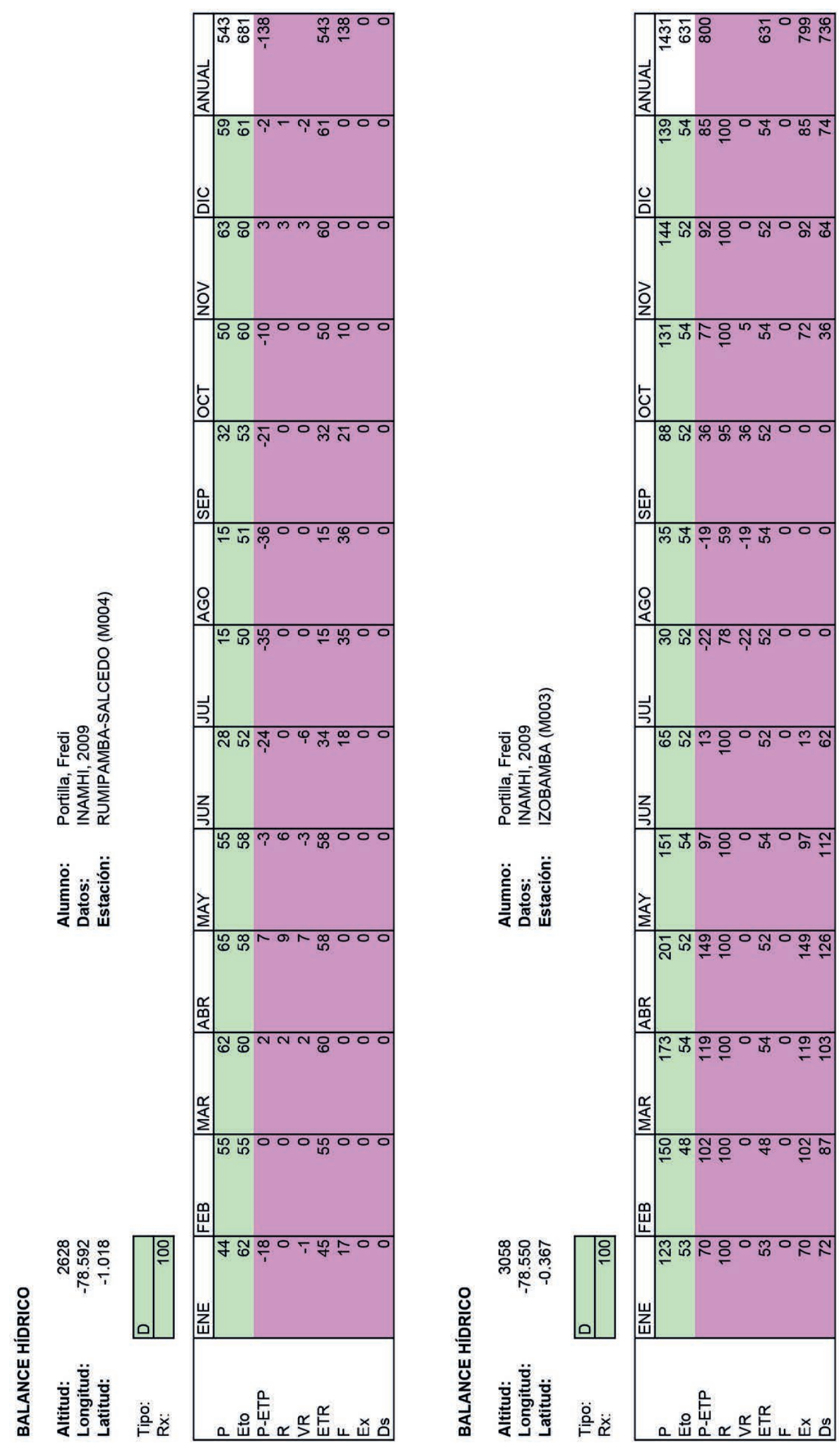


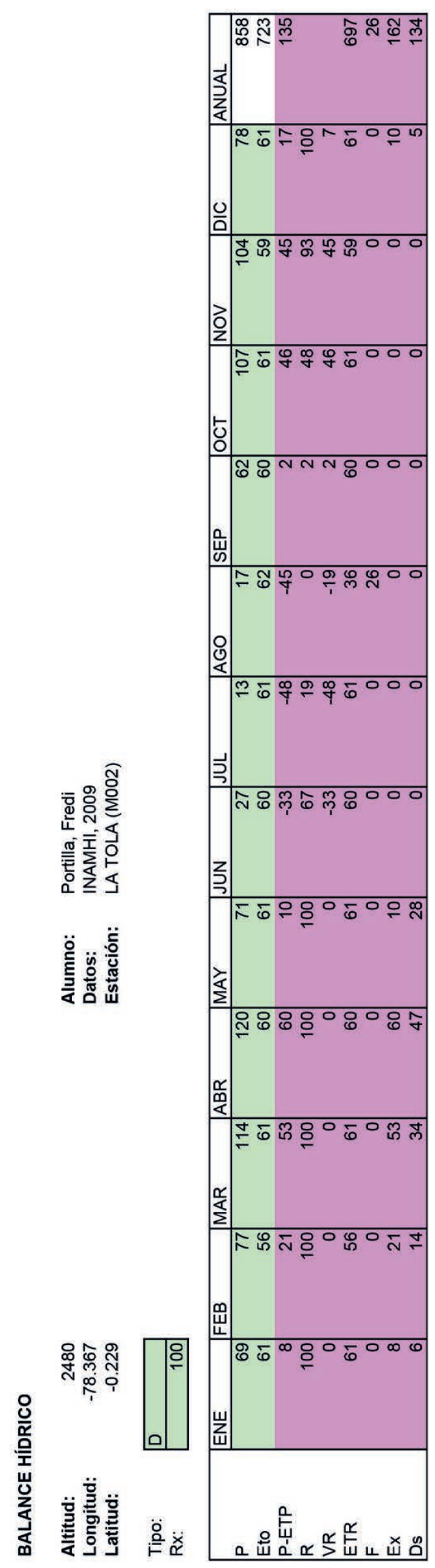



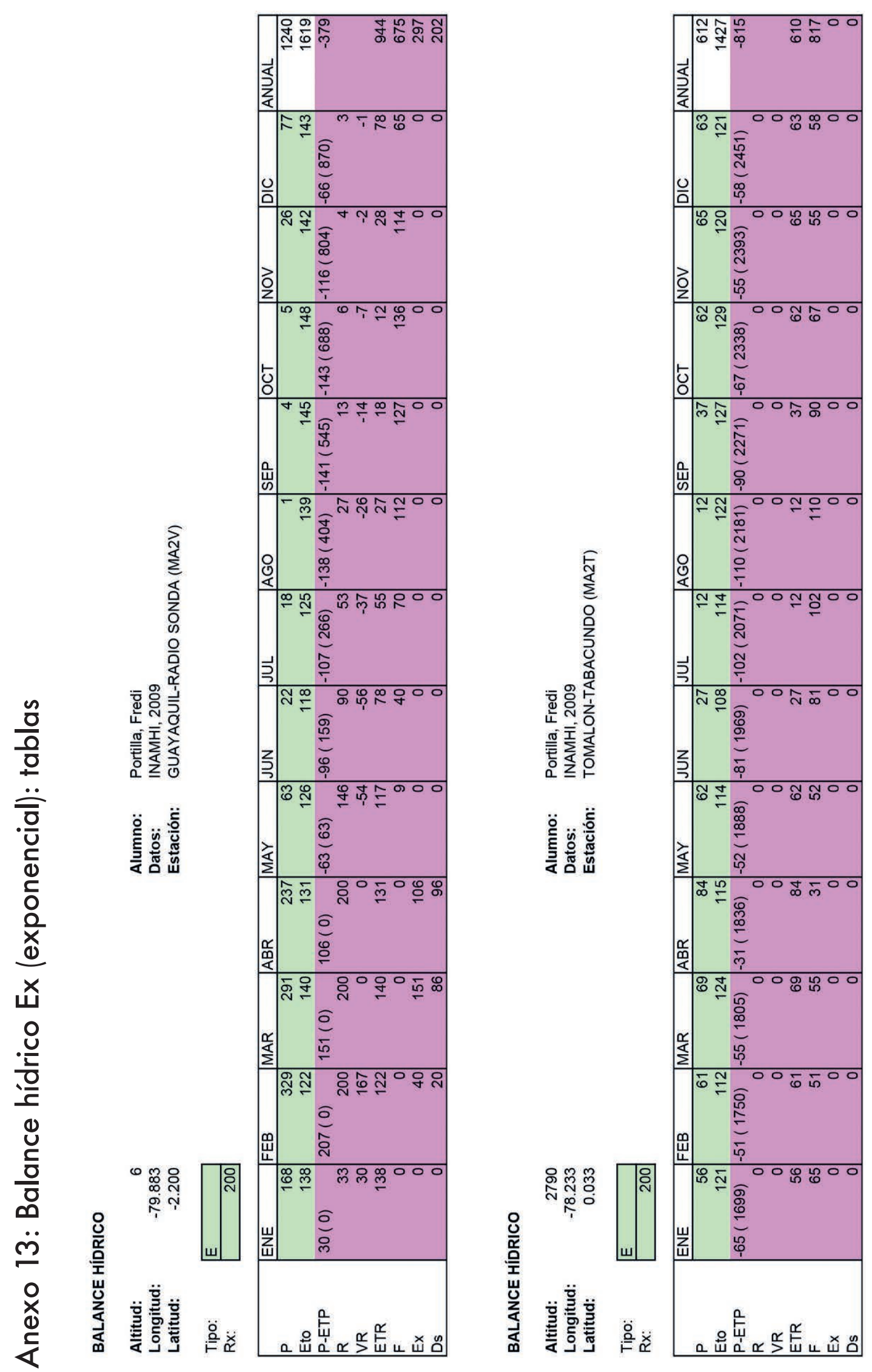


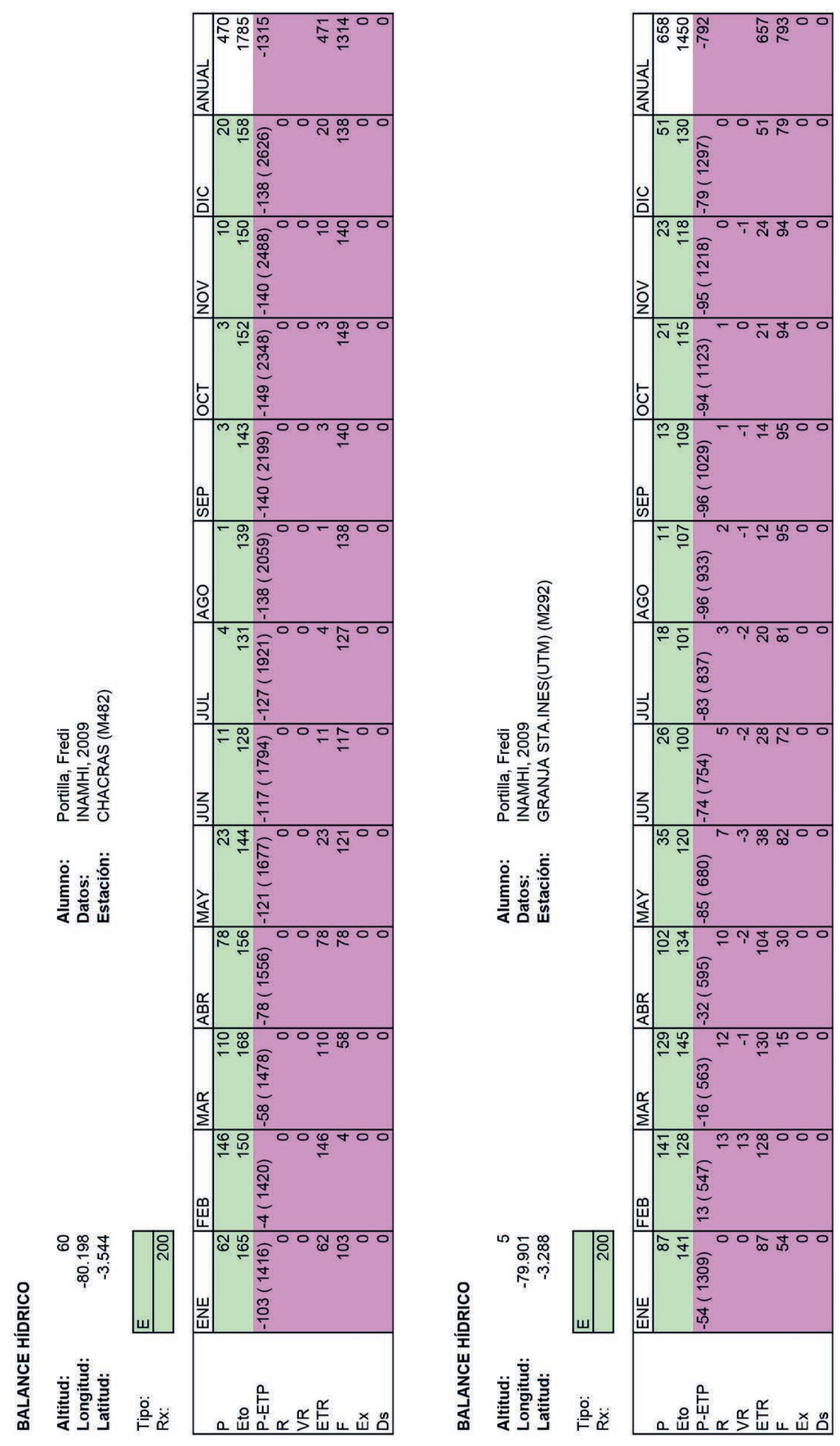



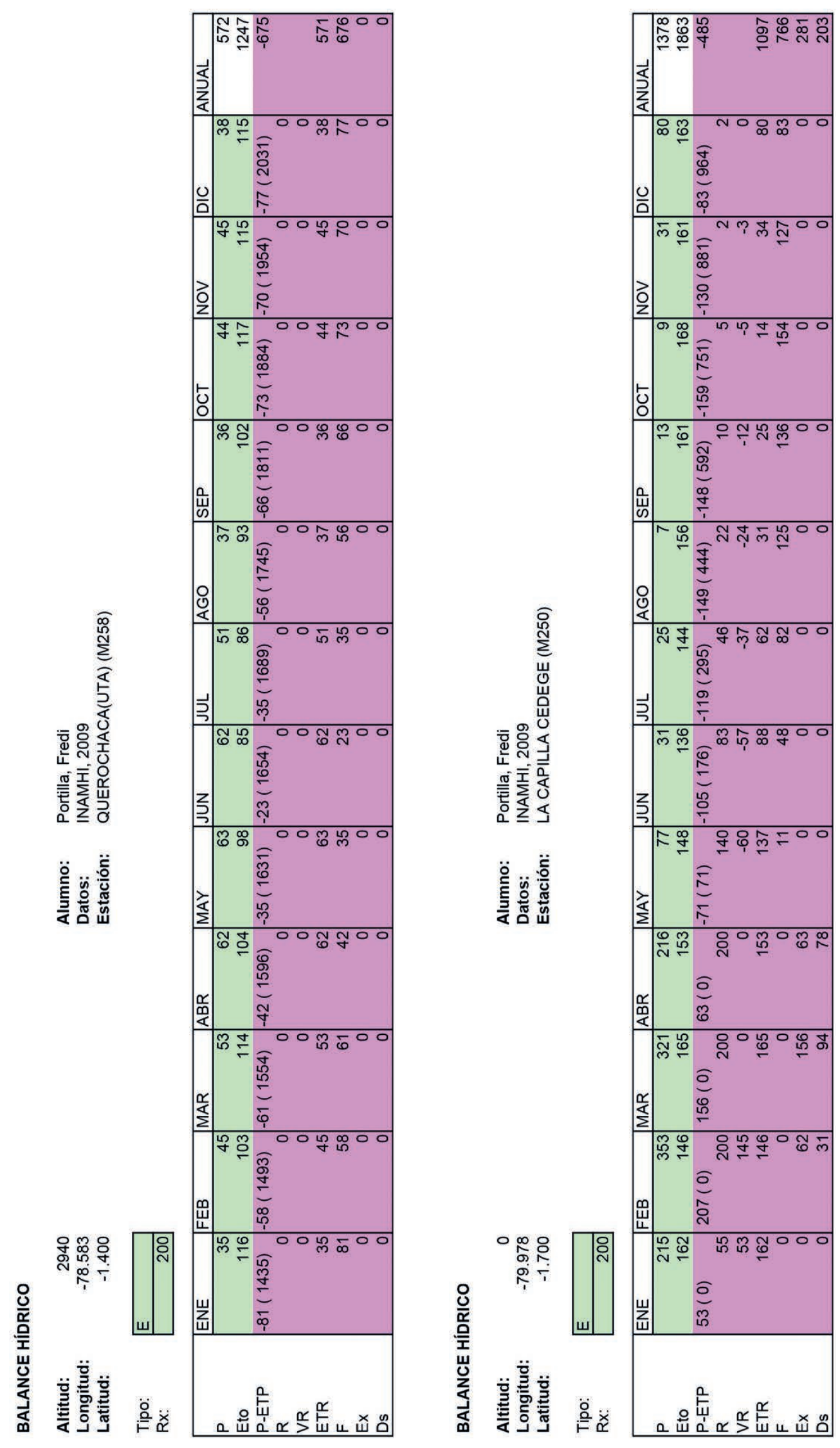

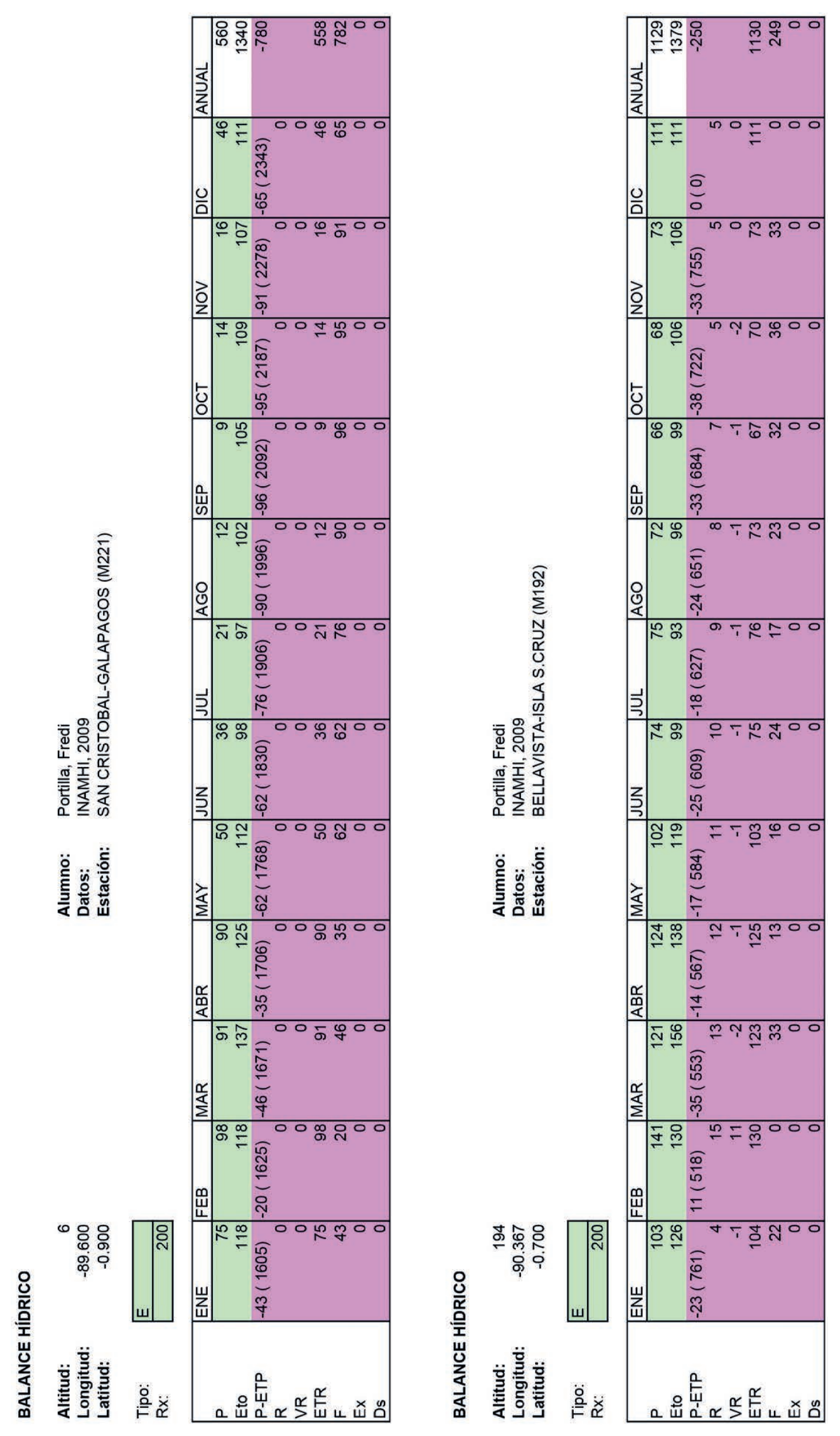

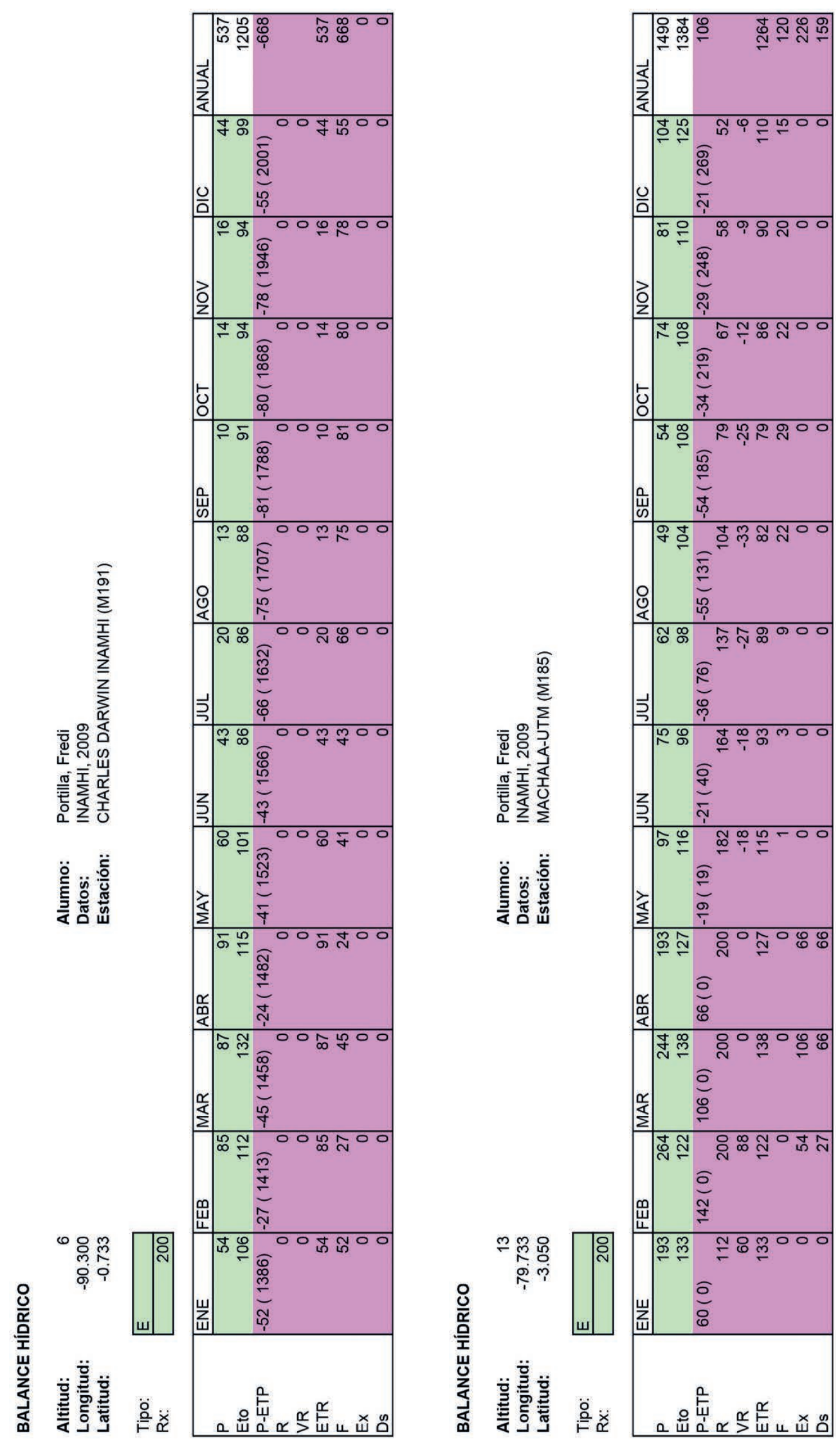


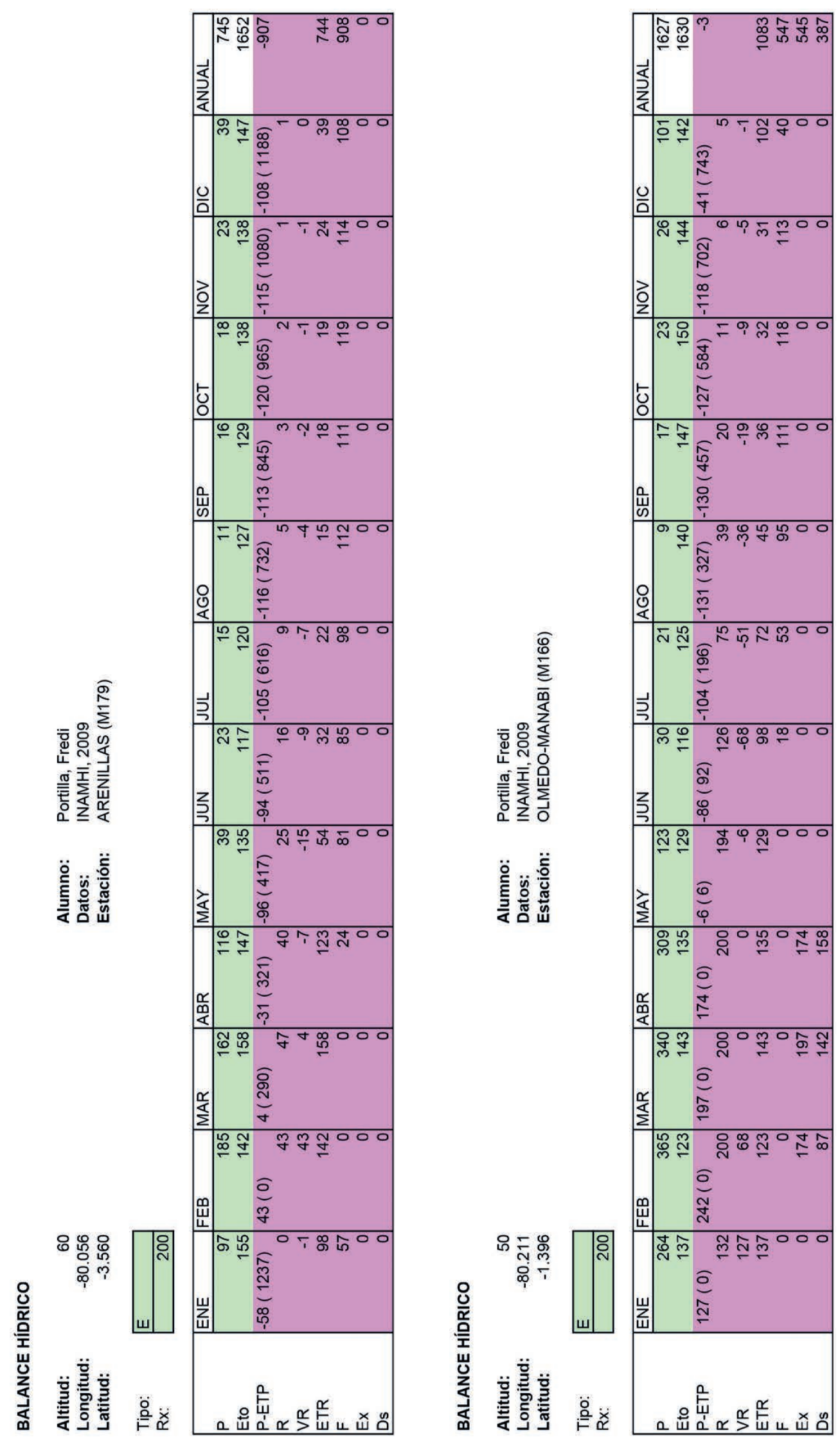




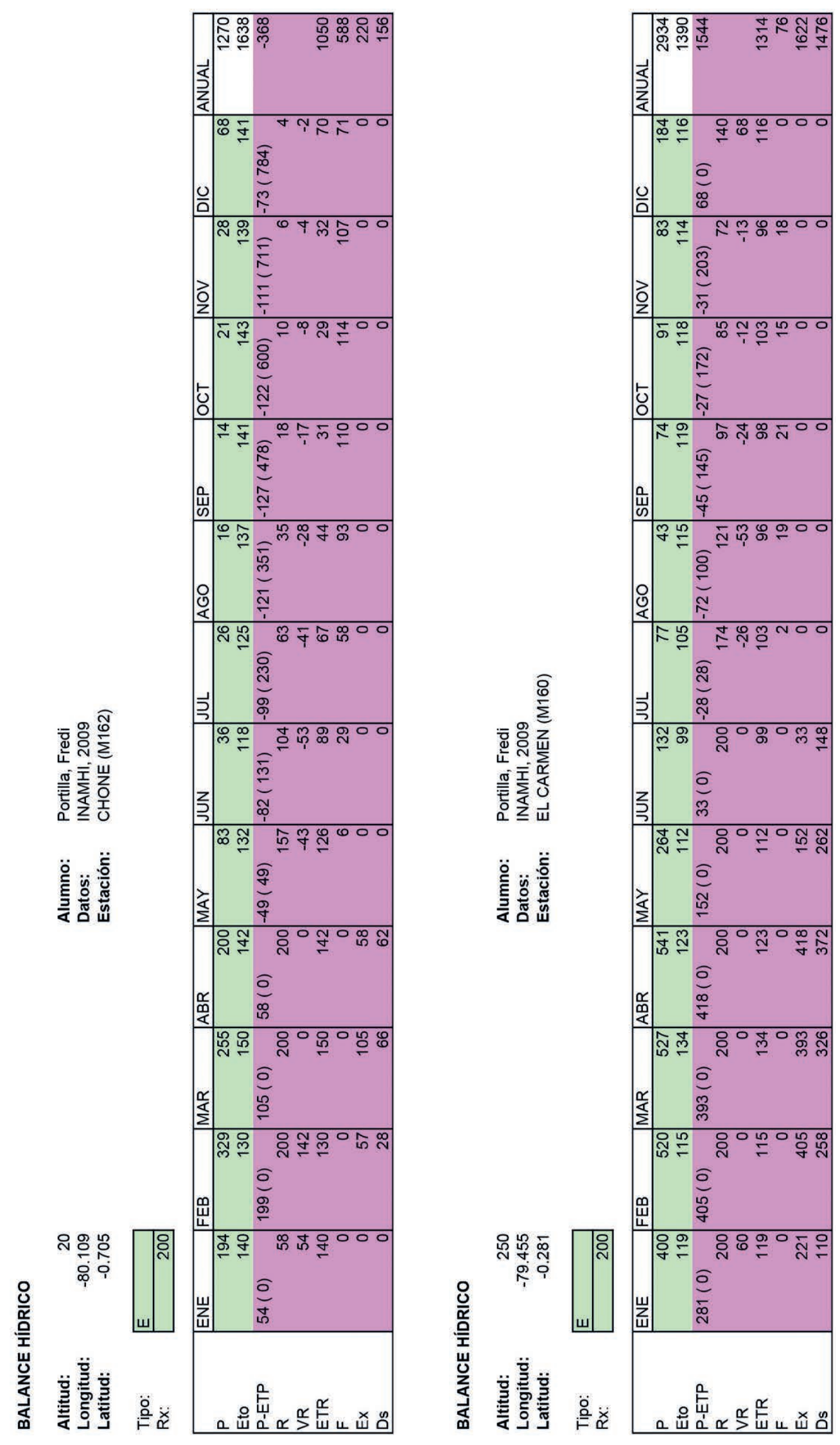




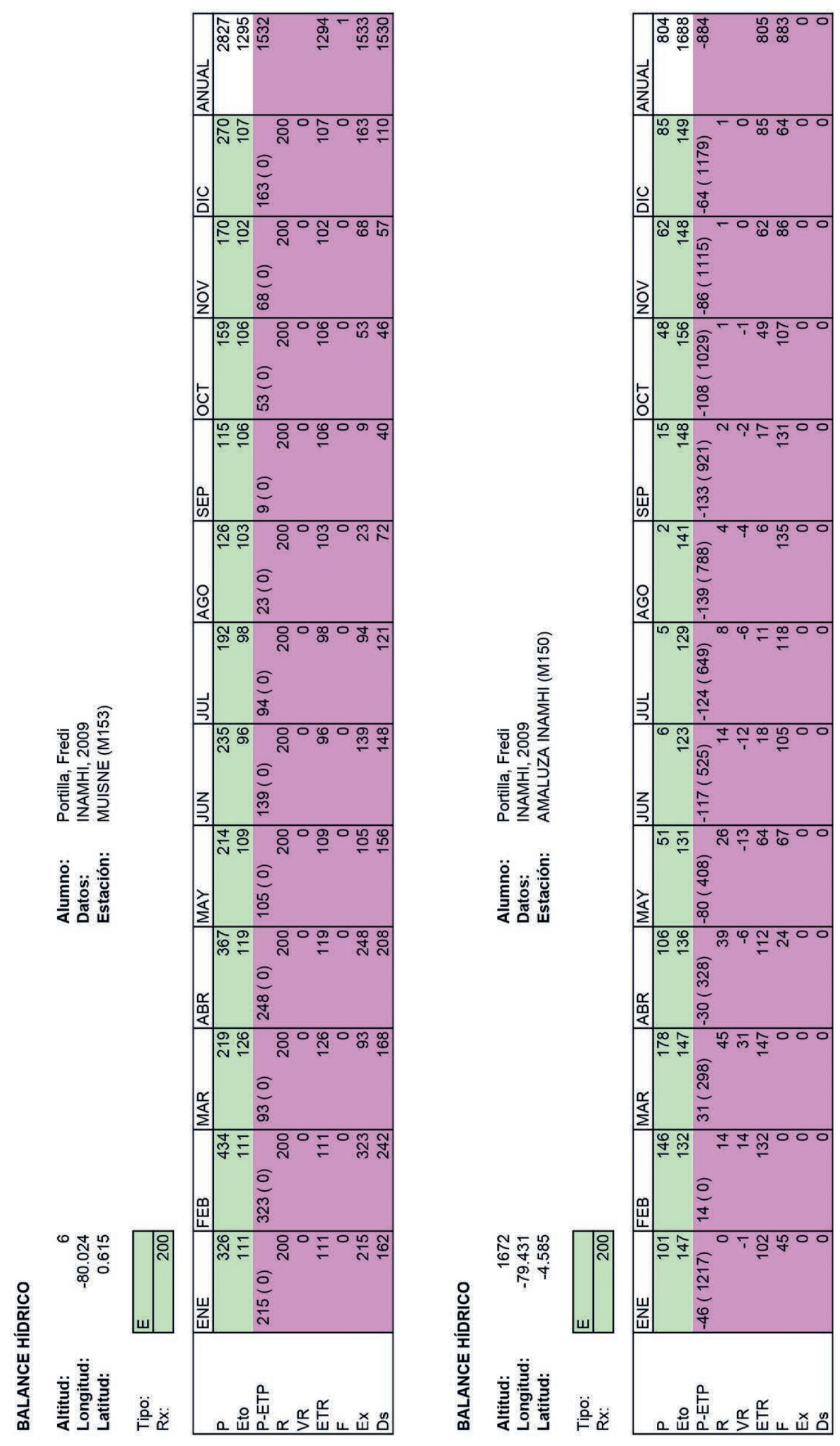




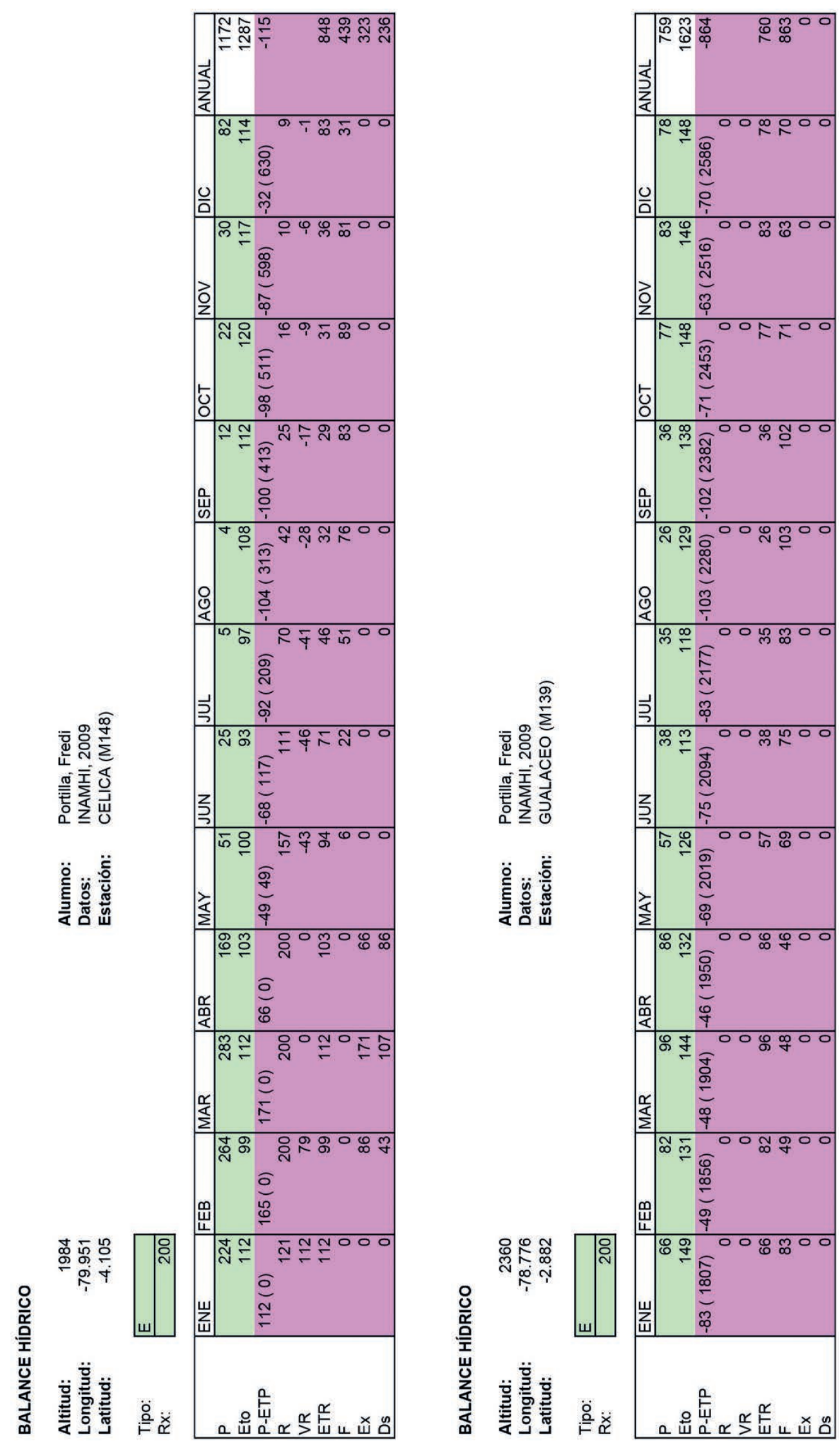




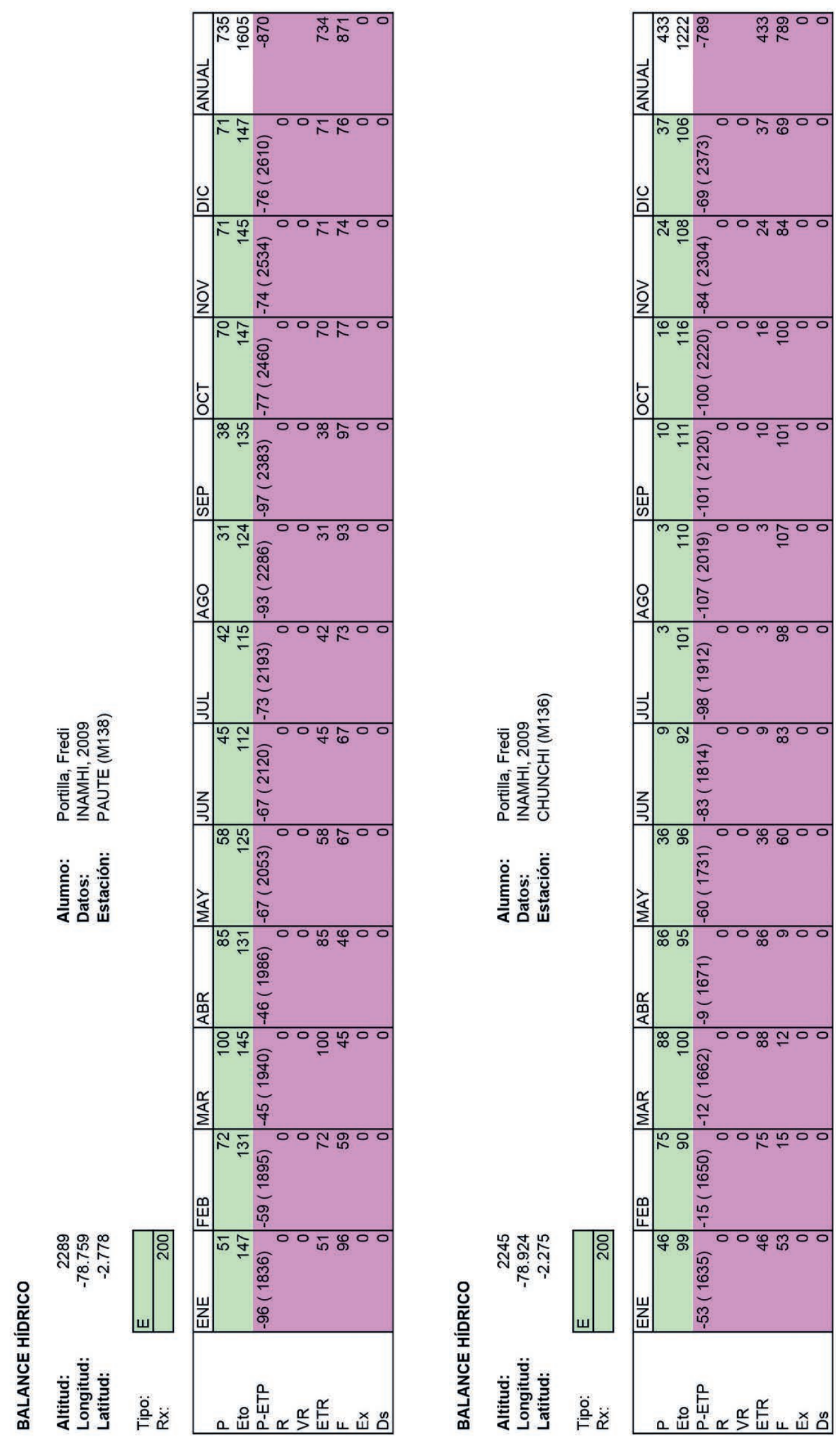



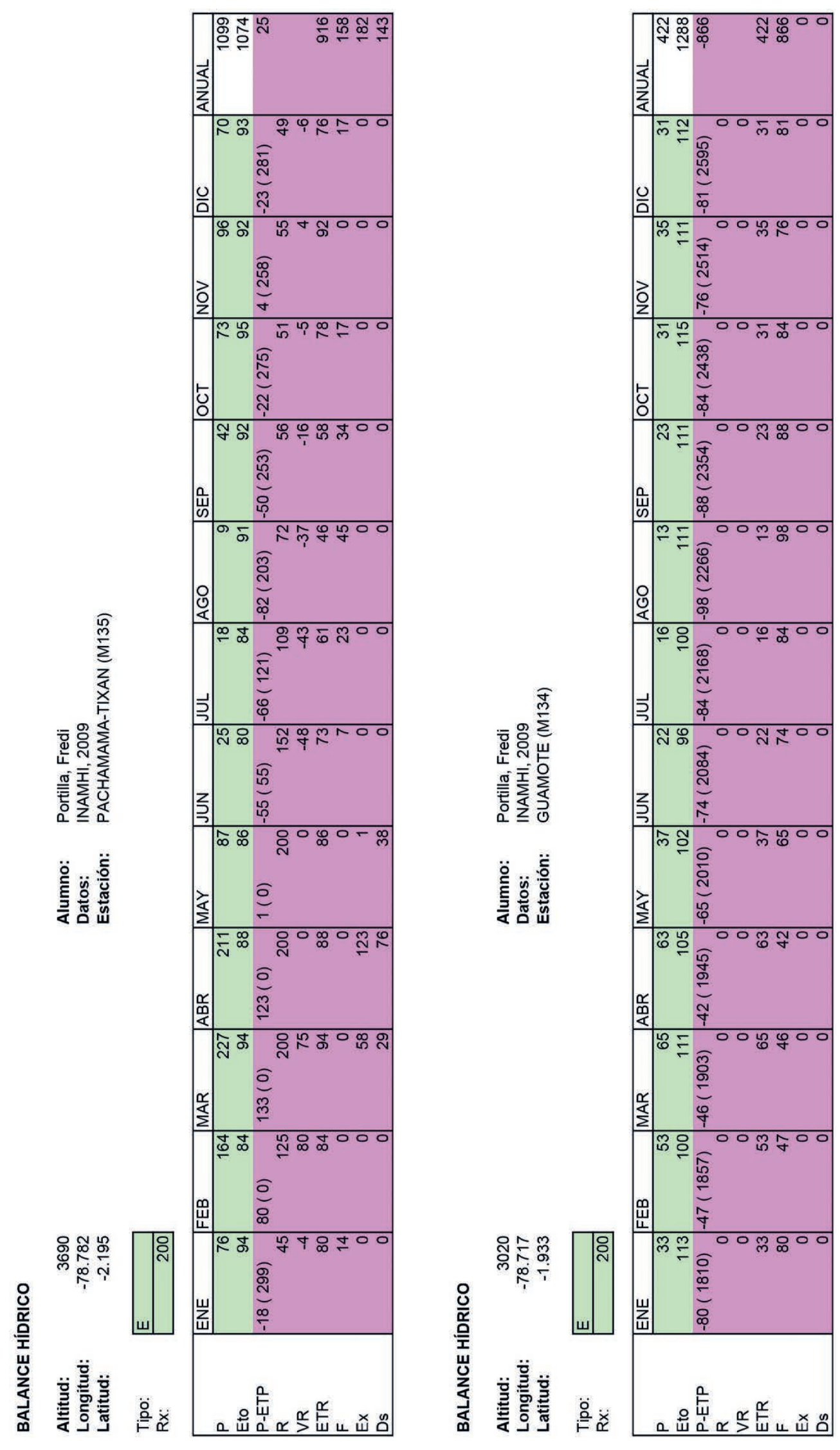


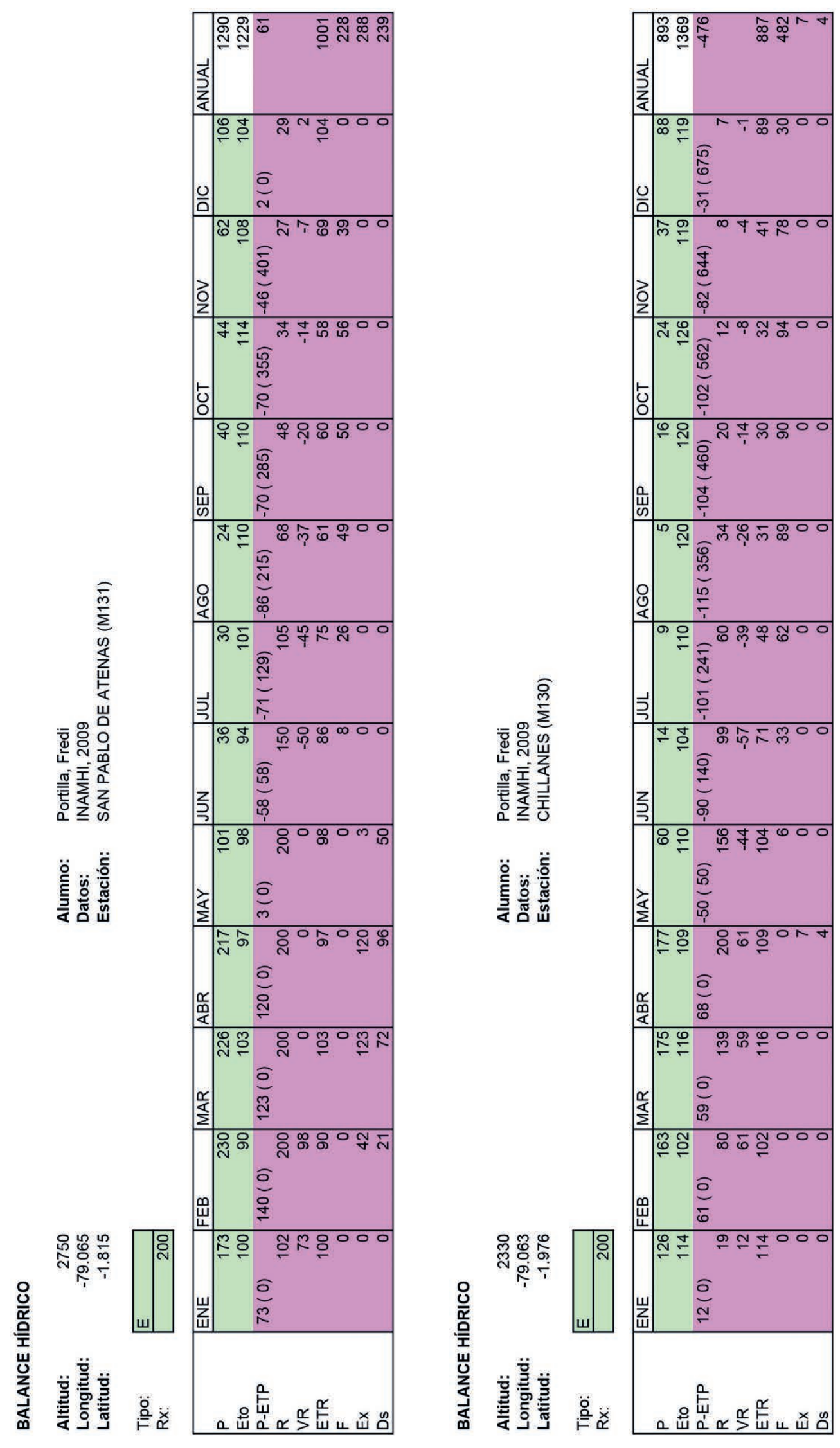




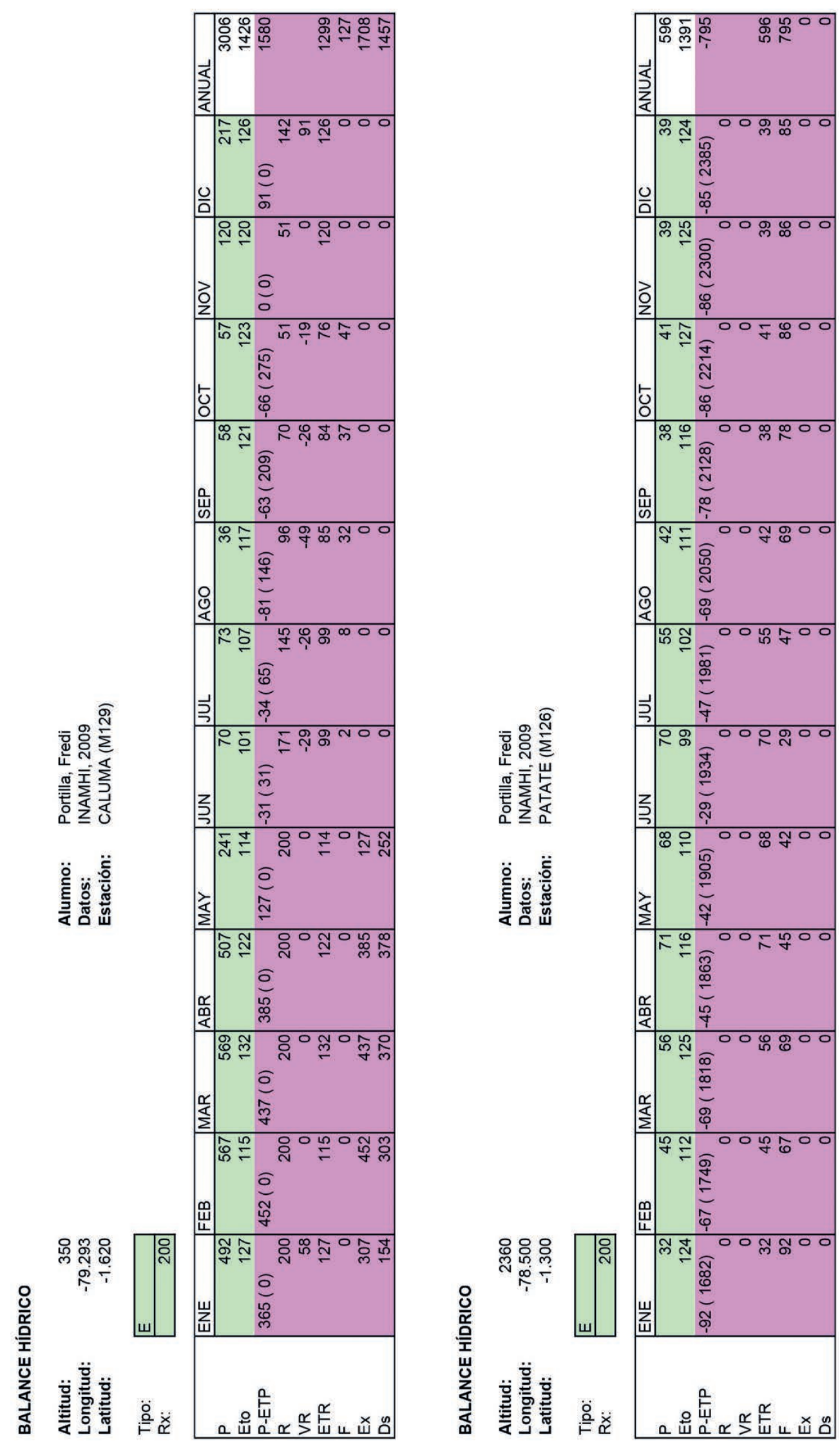




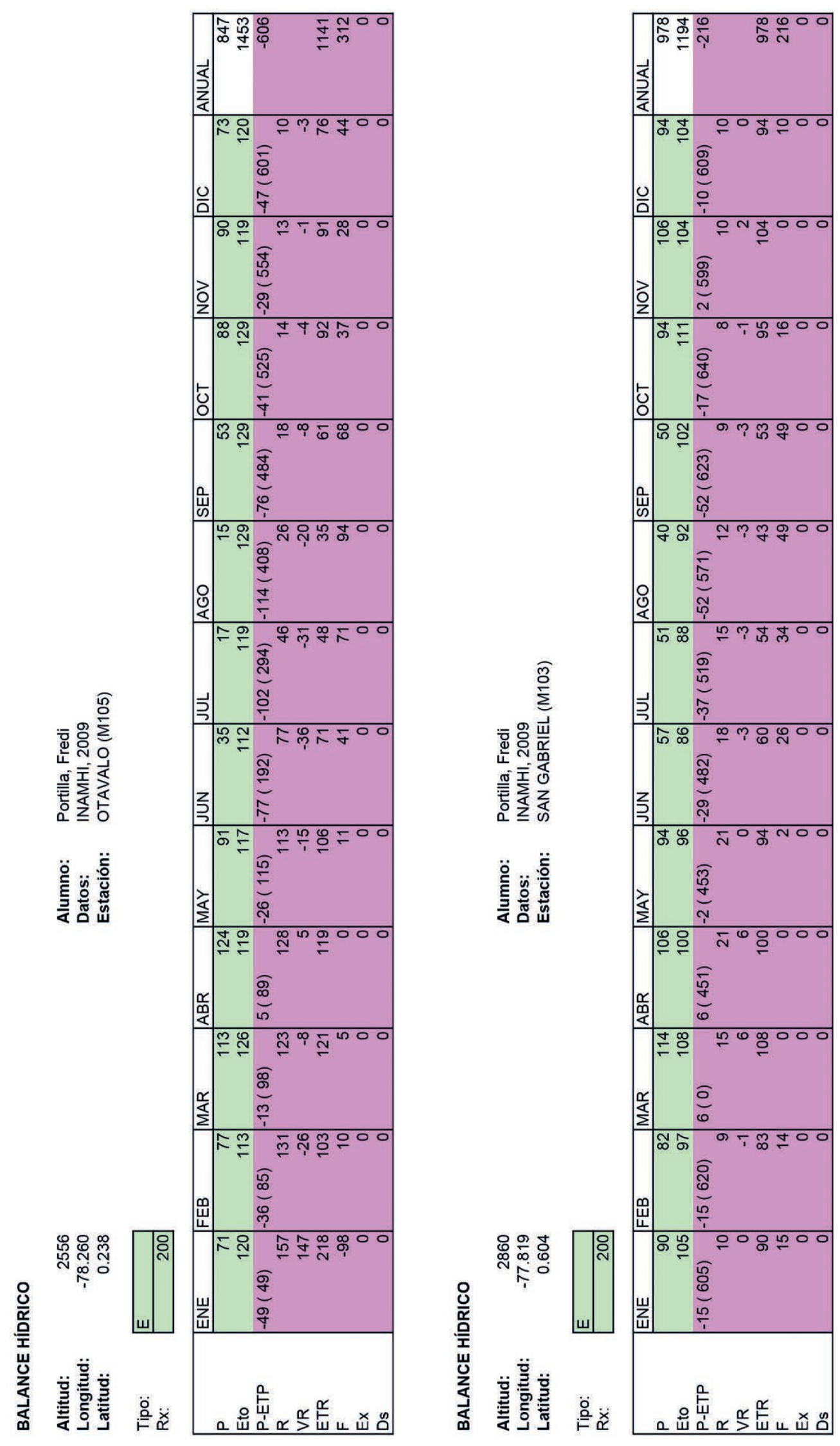




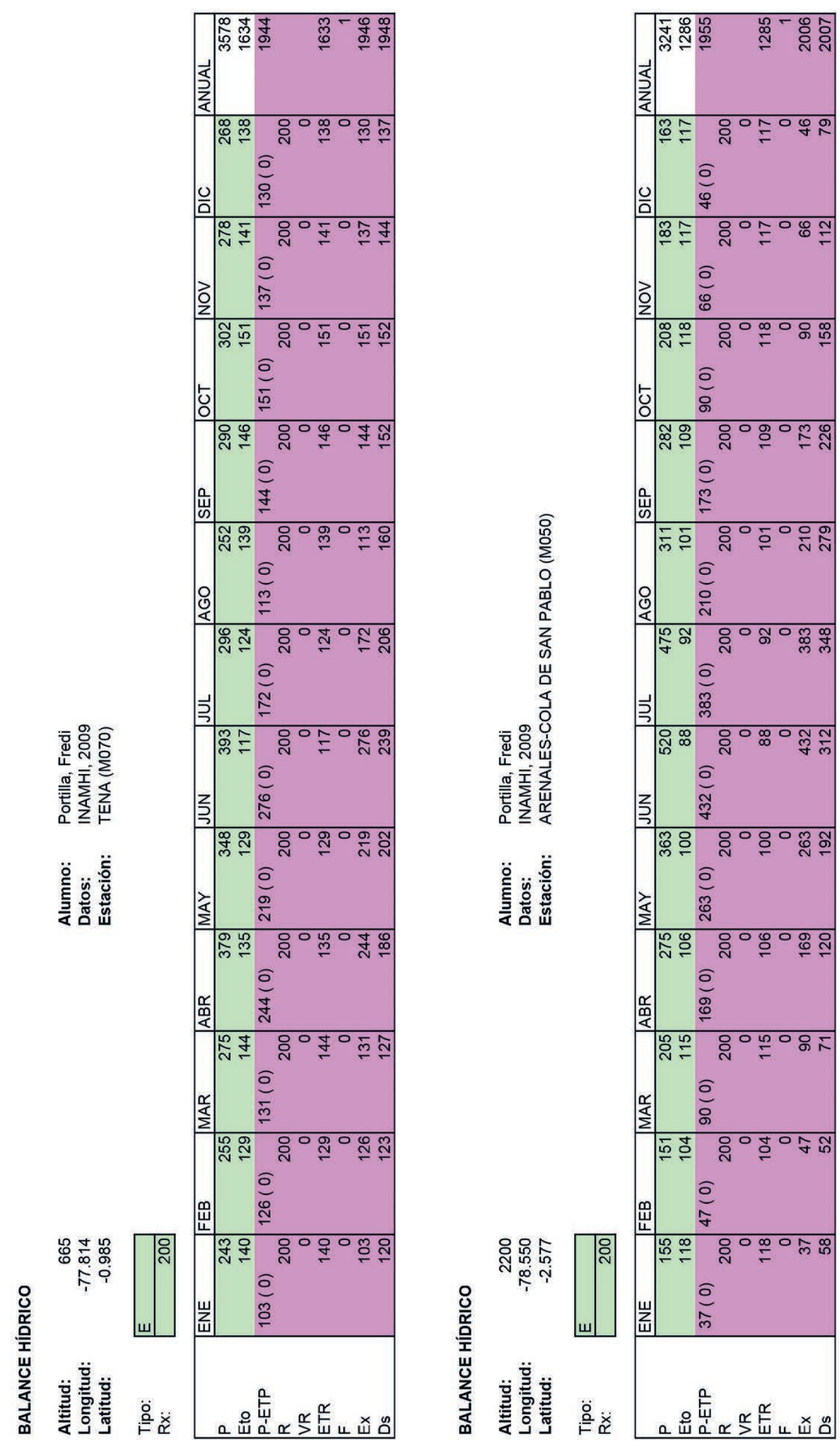




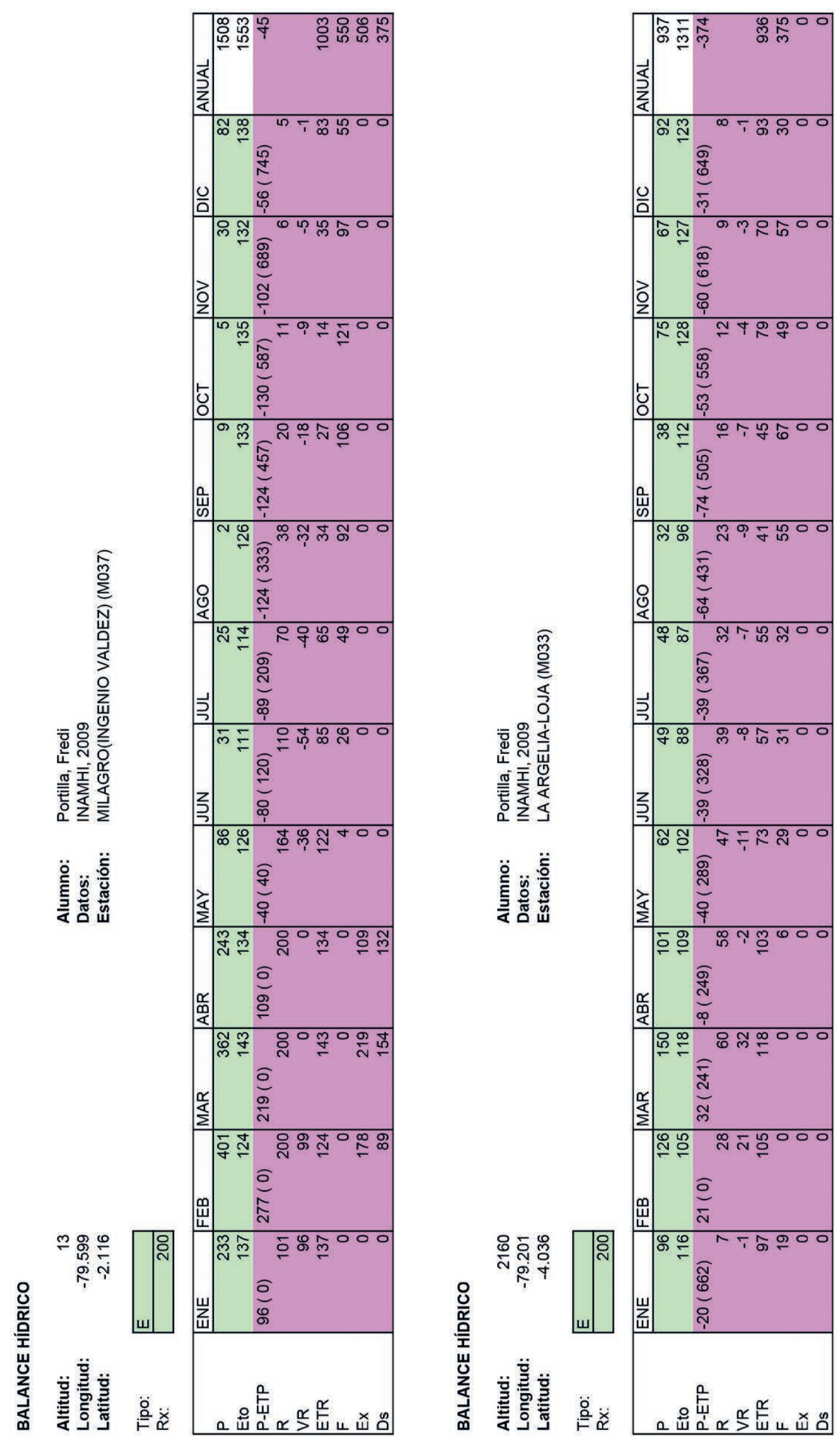



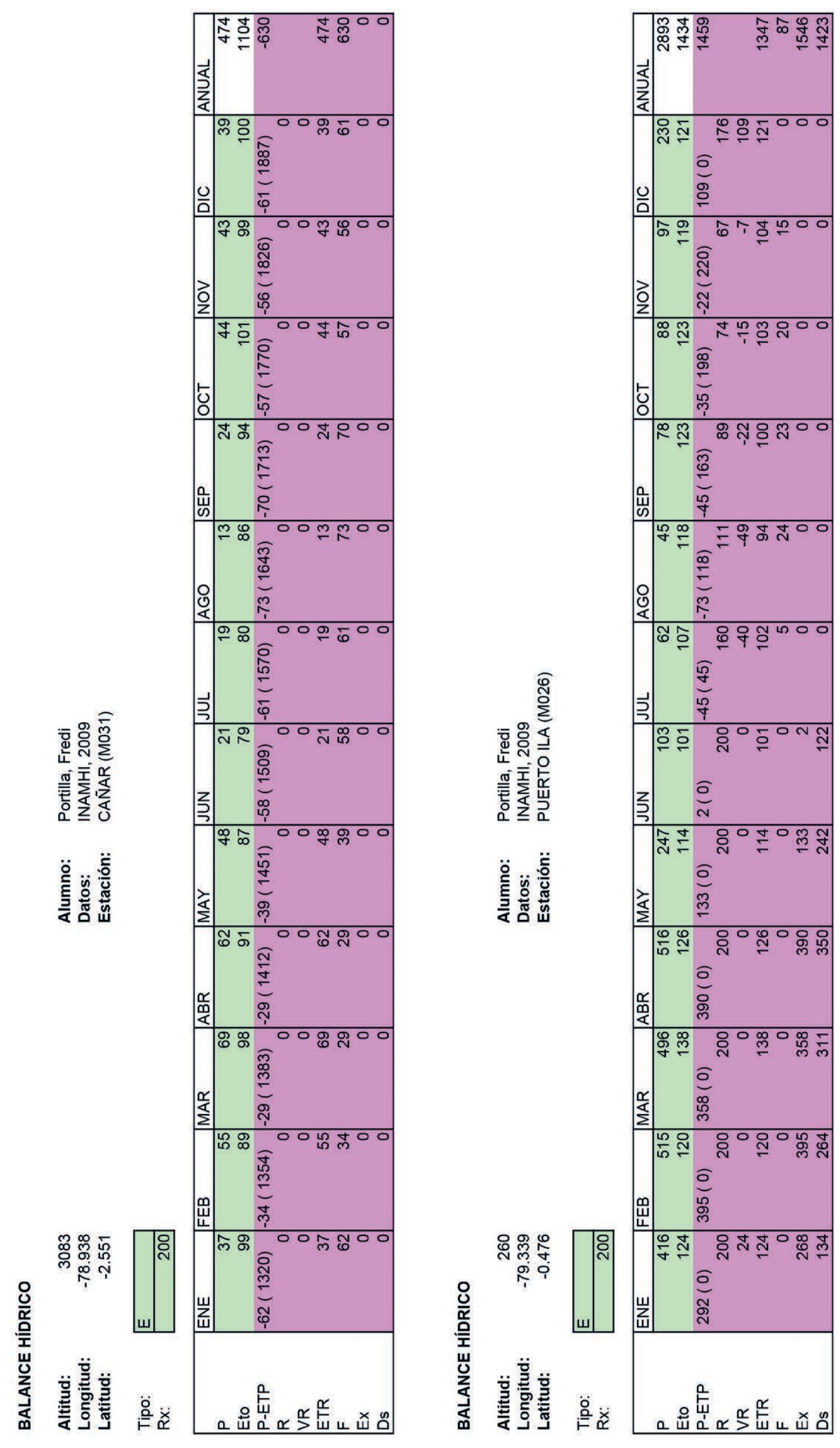


\section{1}

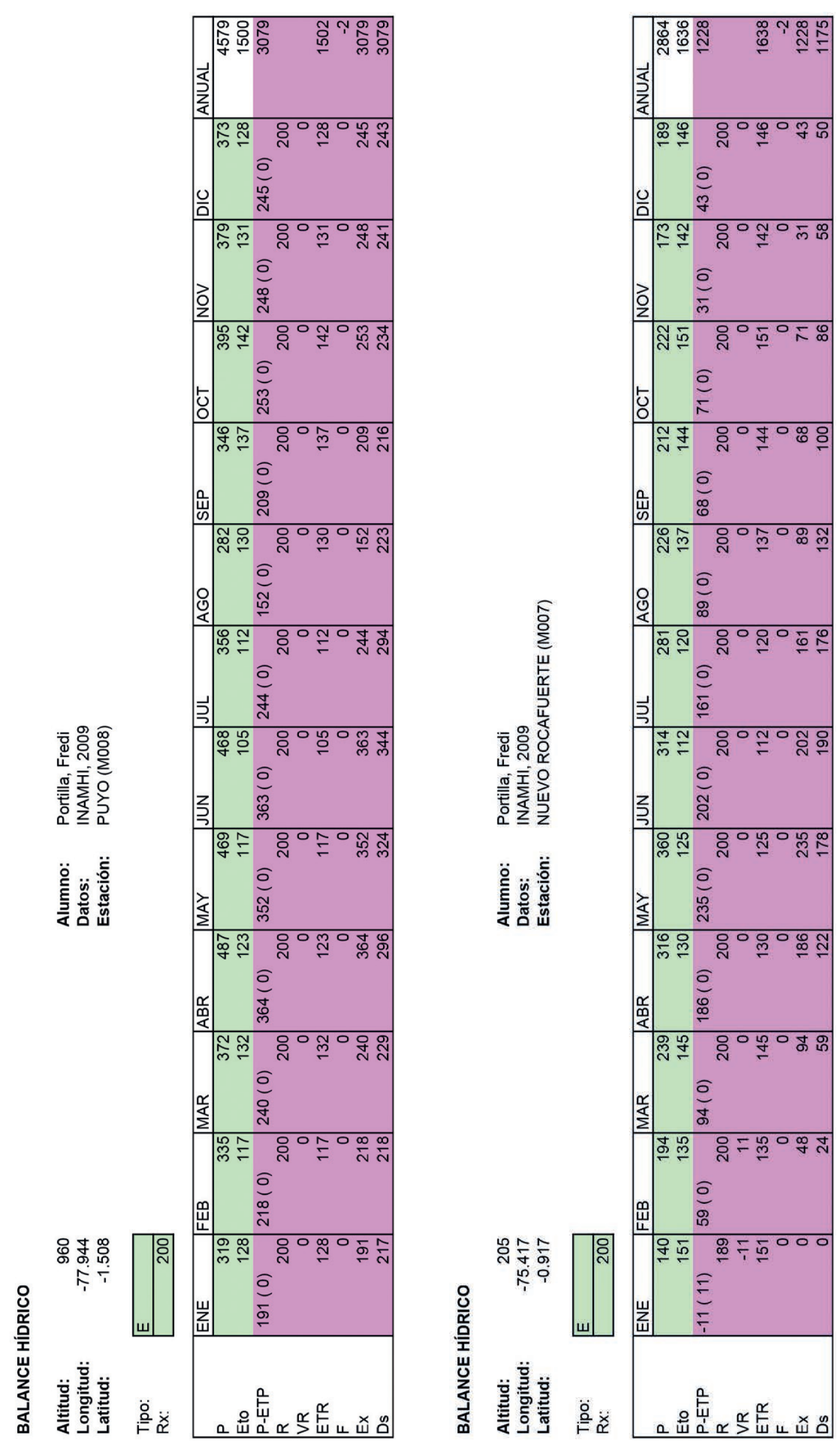




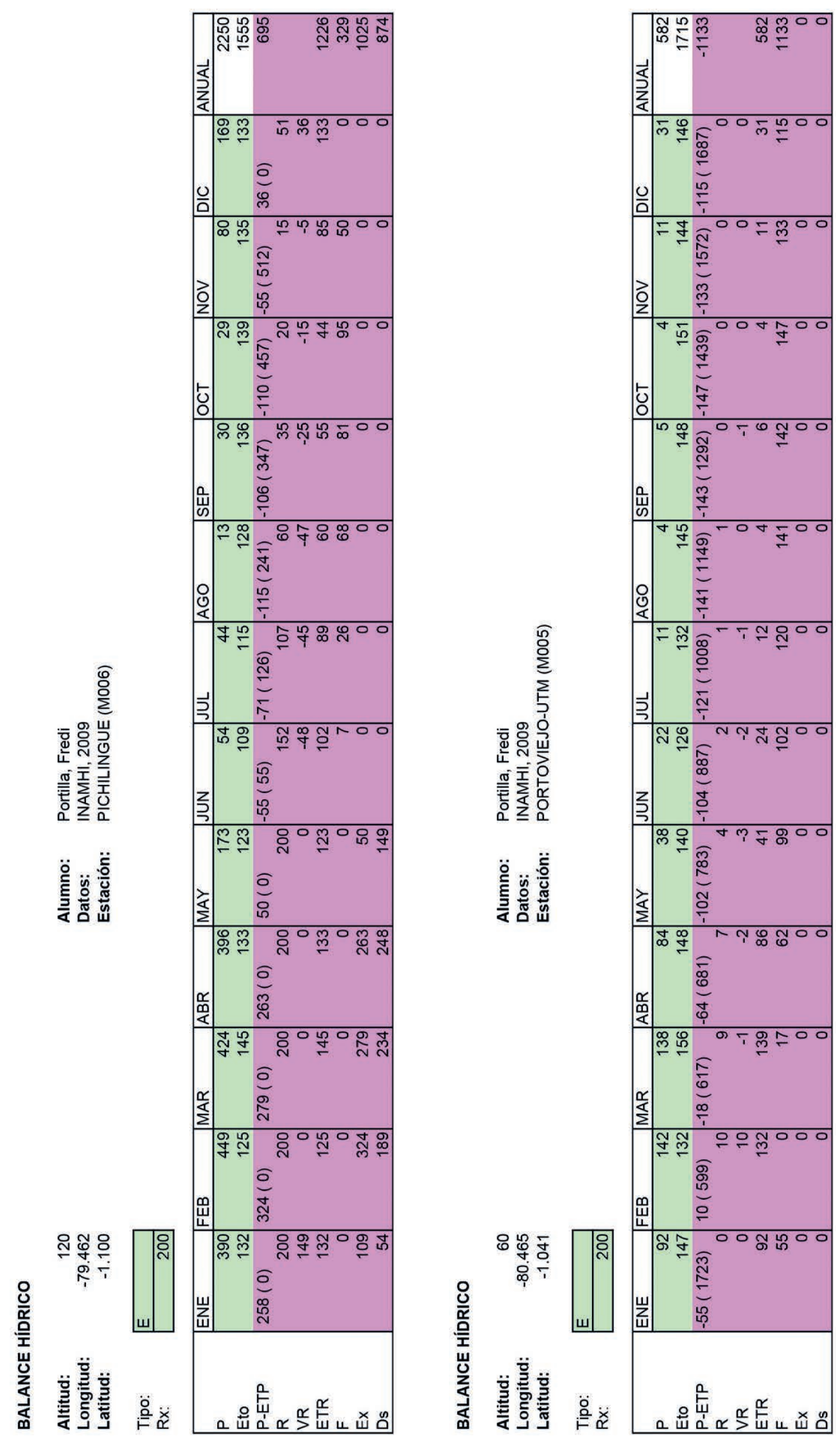



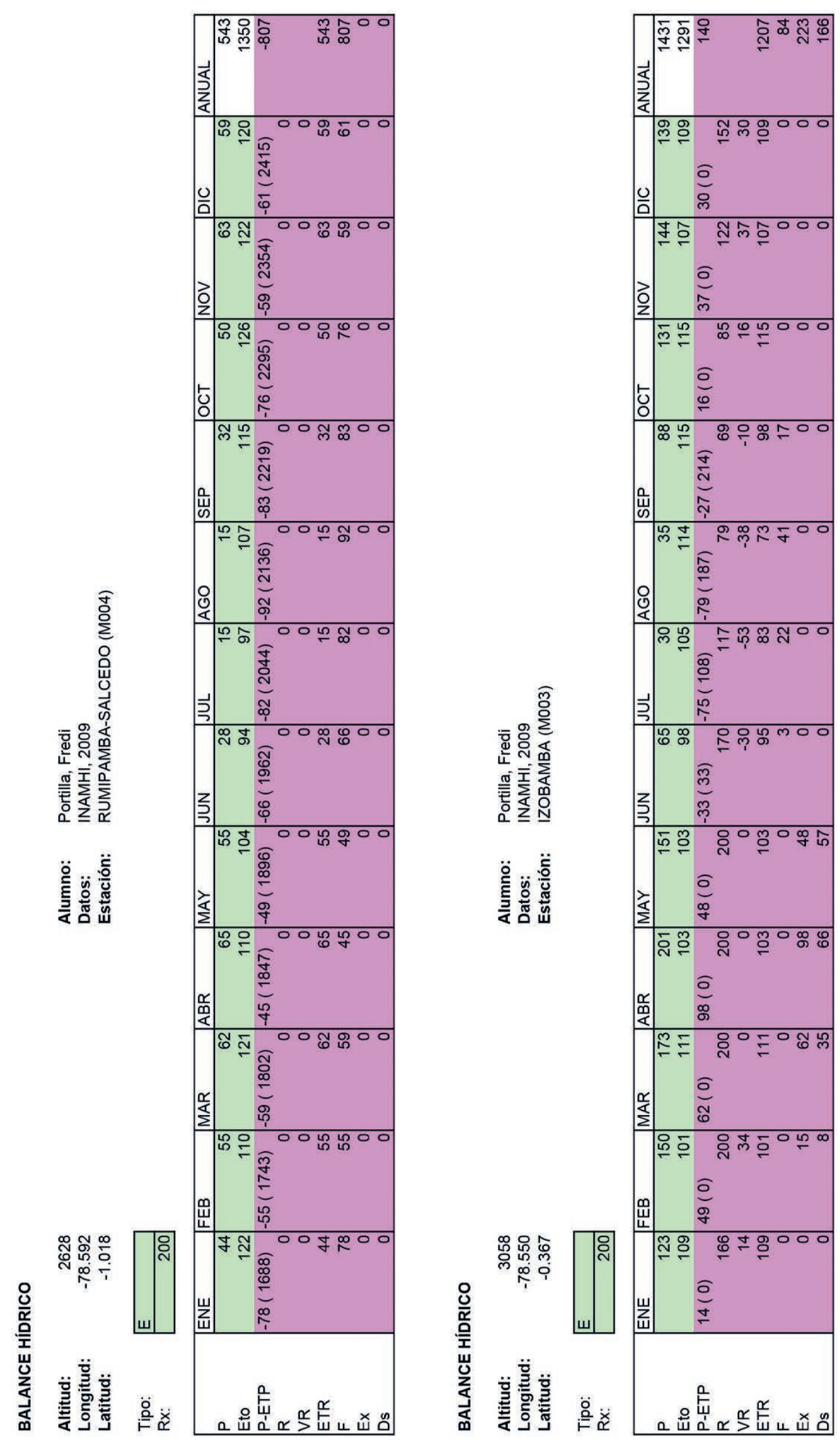


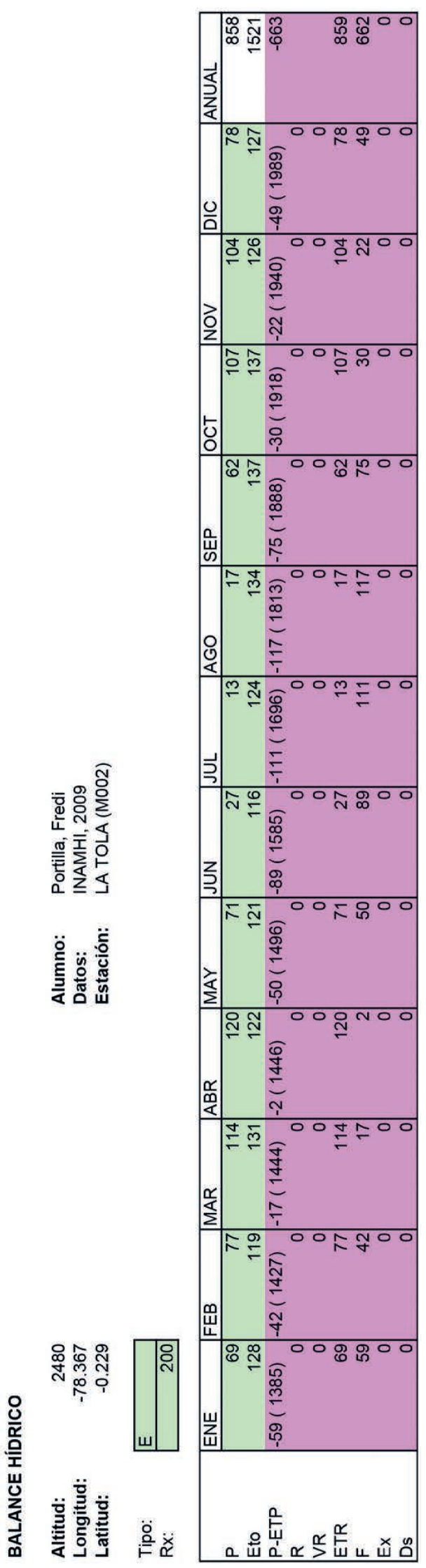




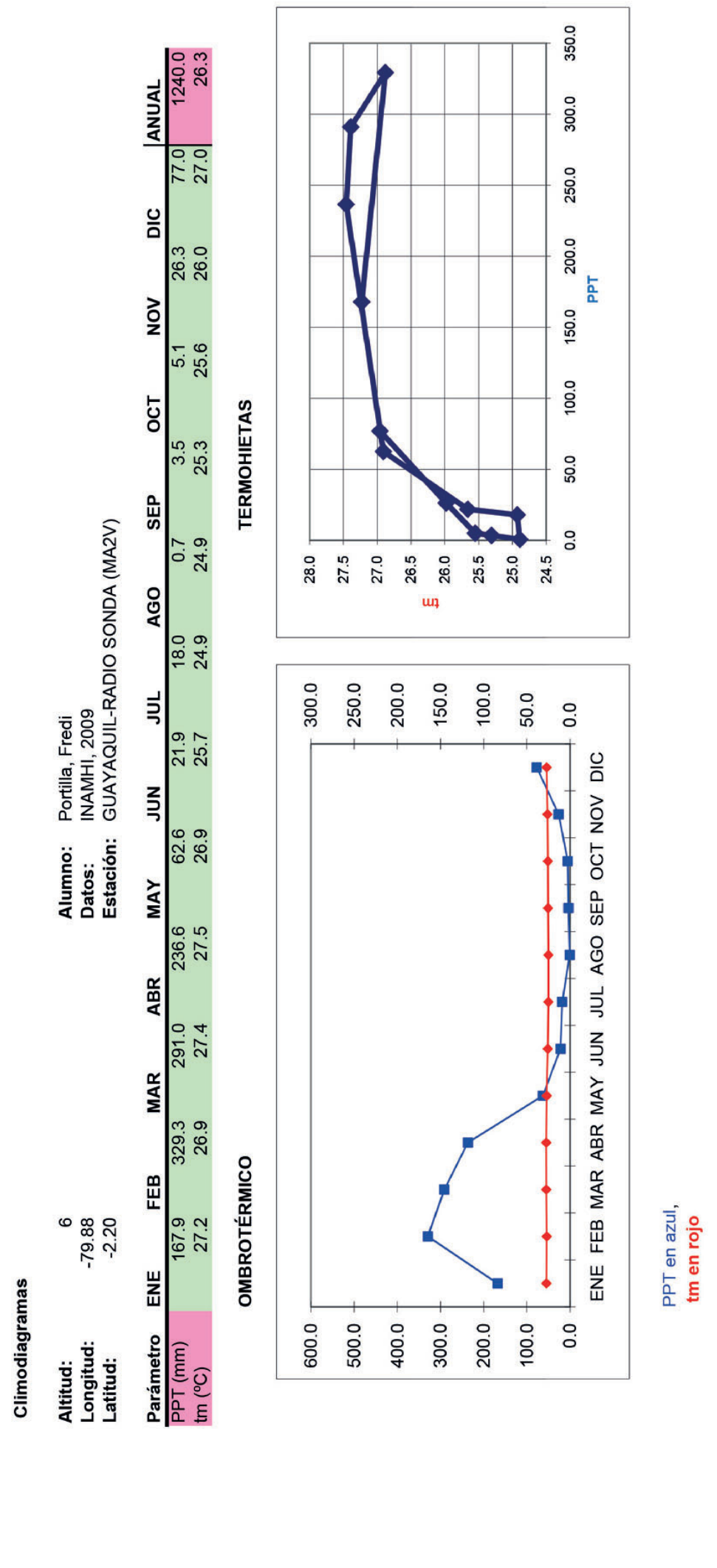




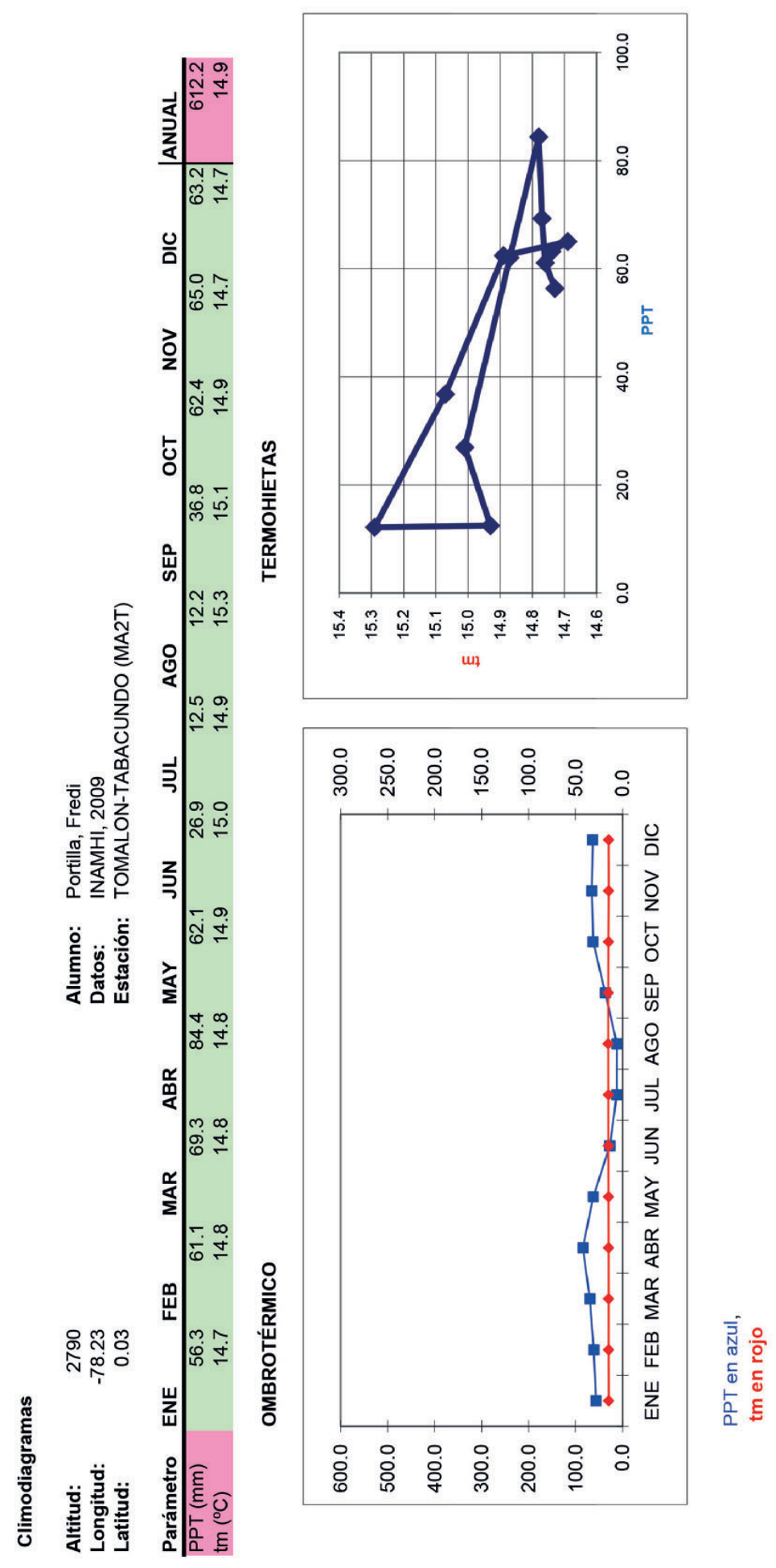




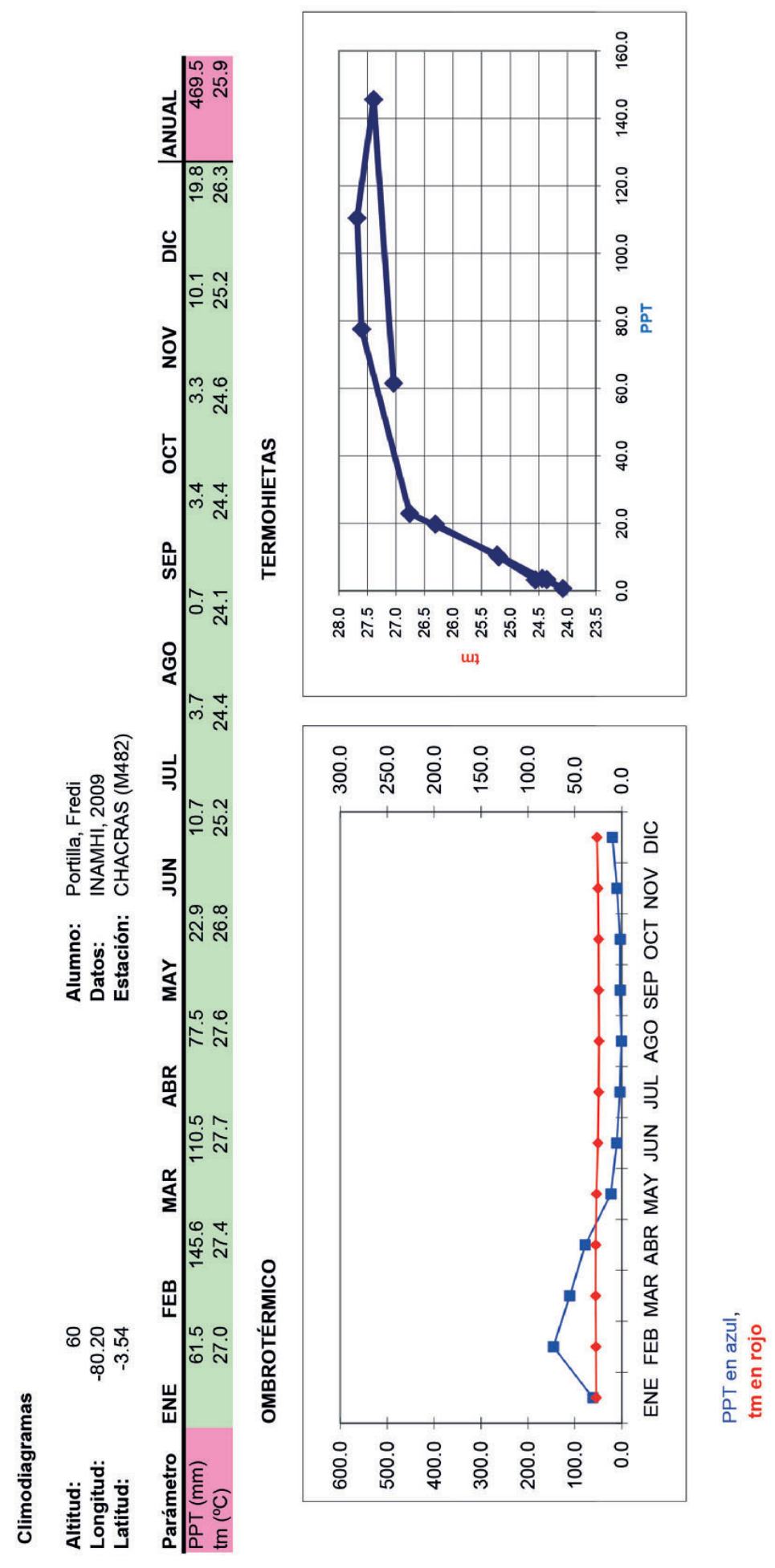




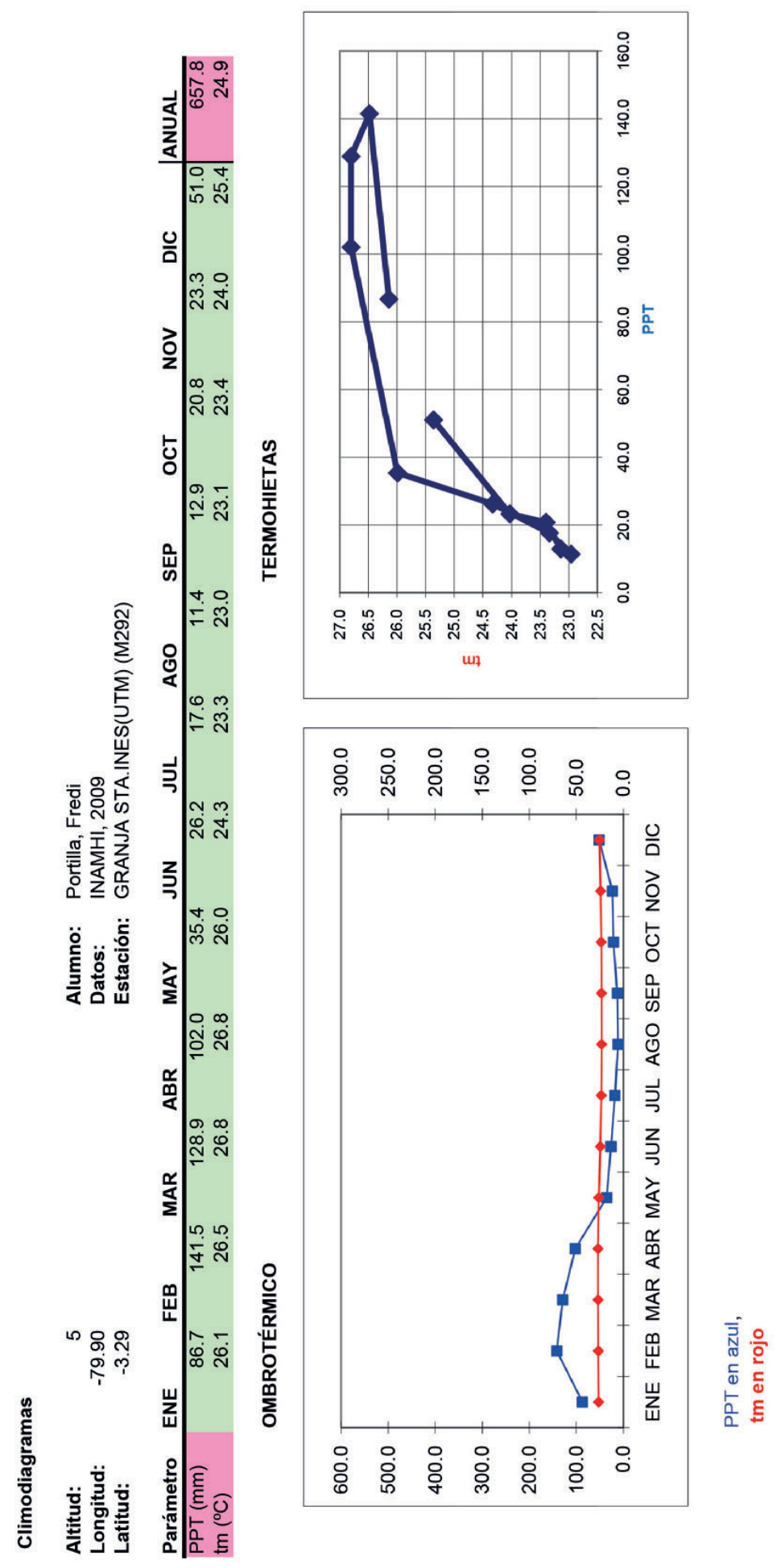




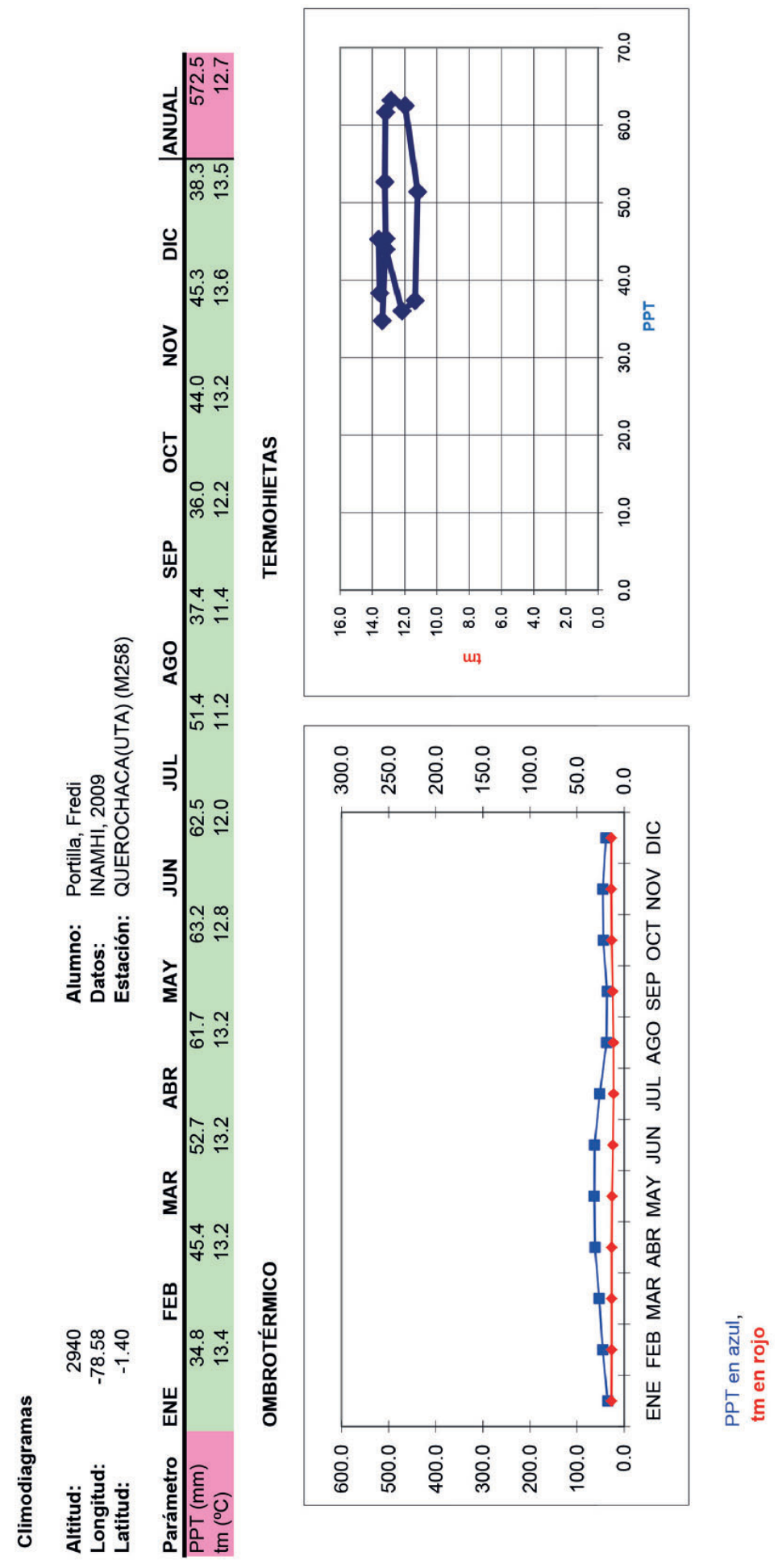




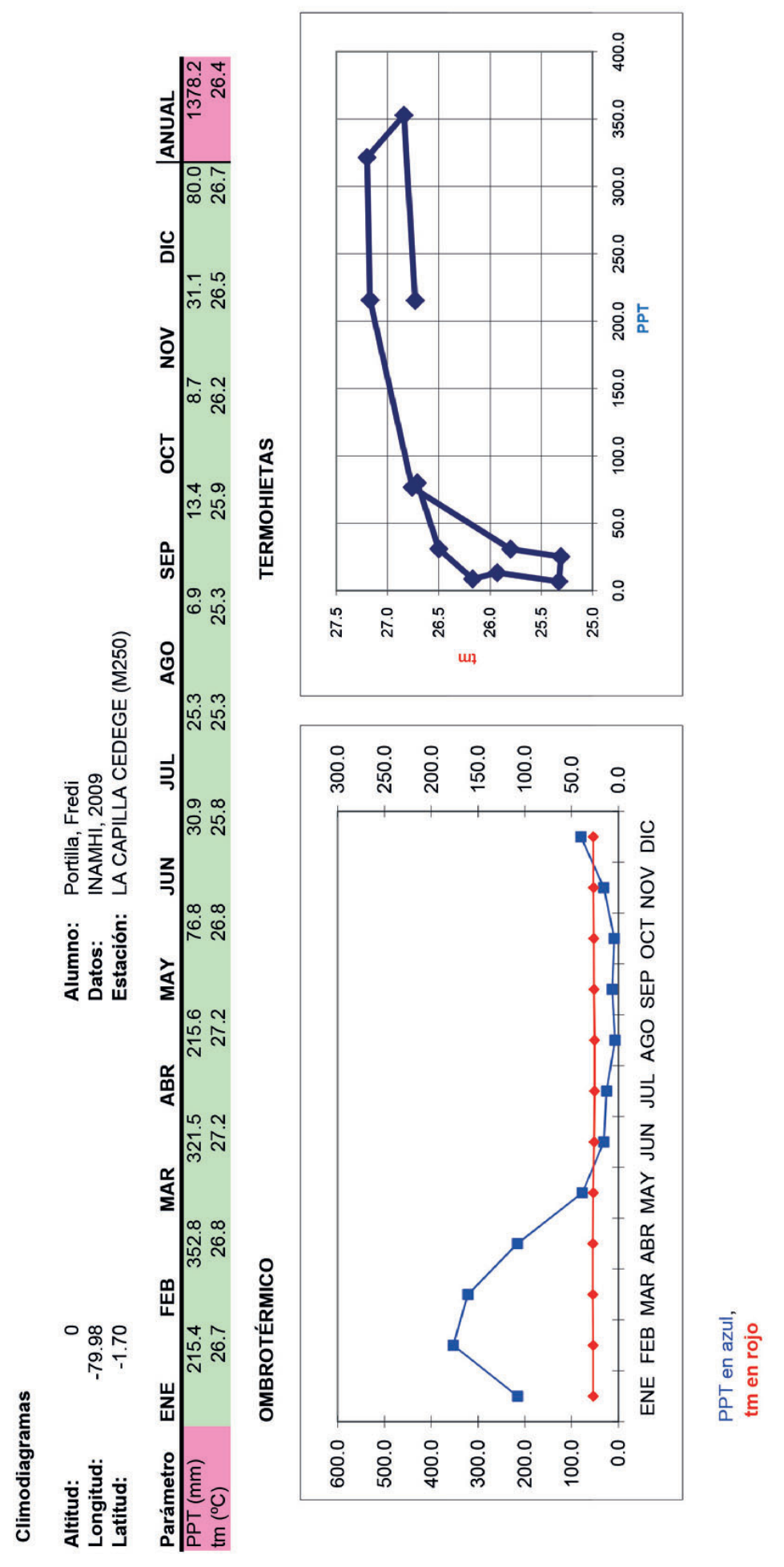




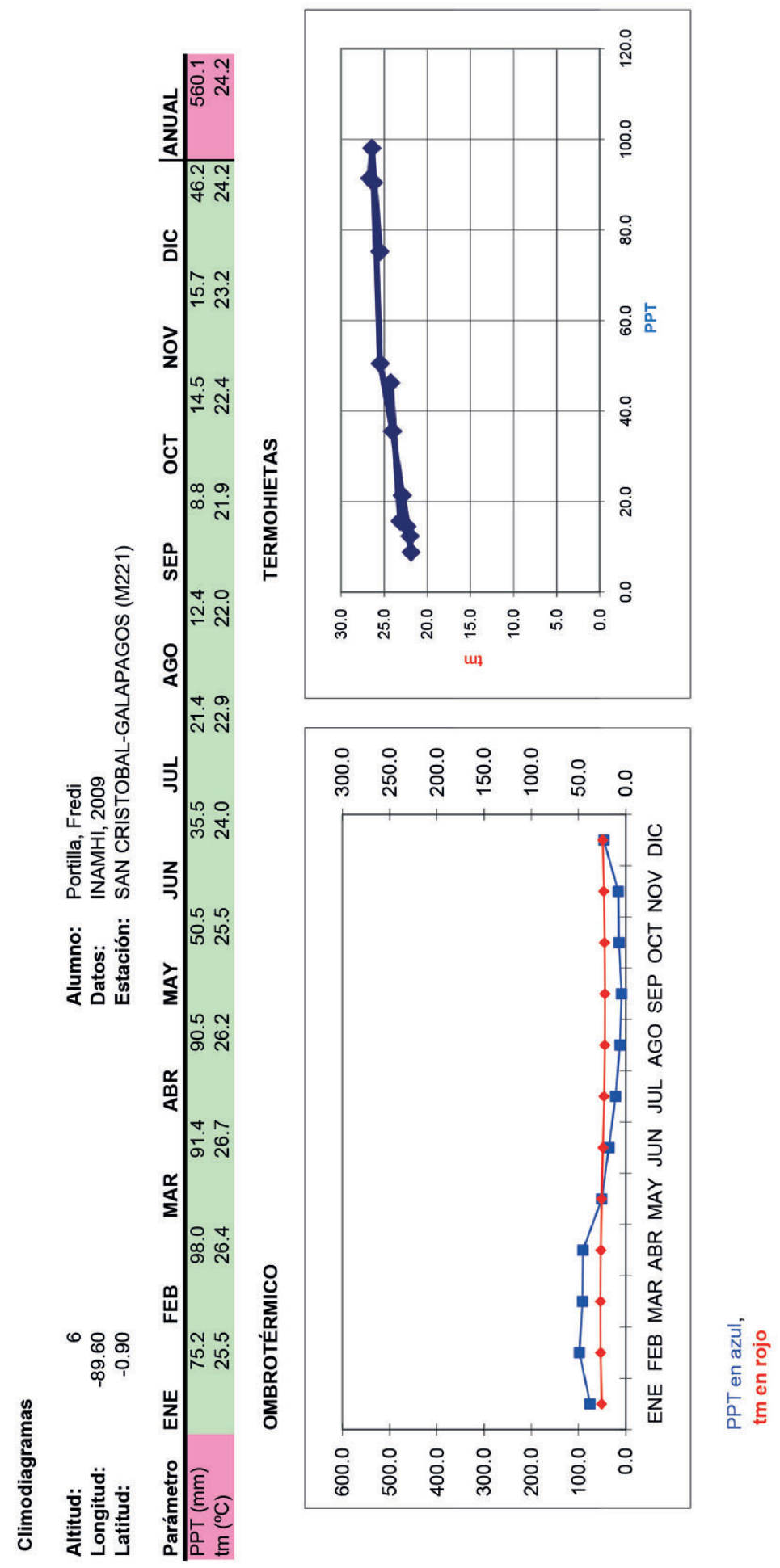




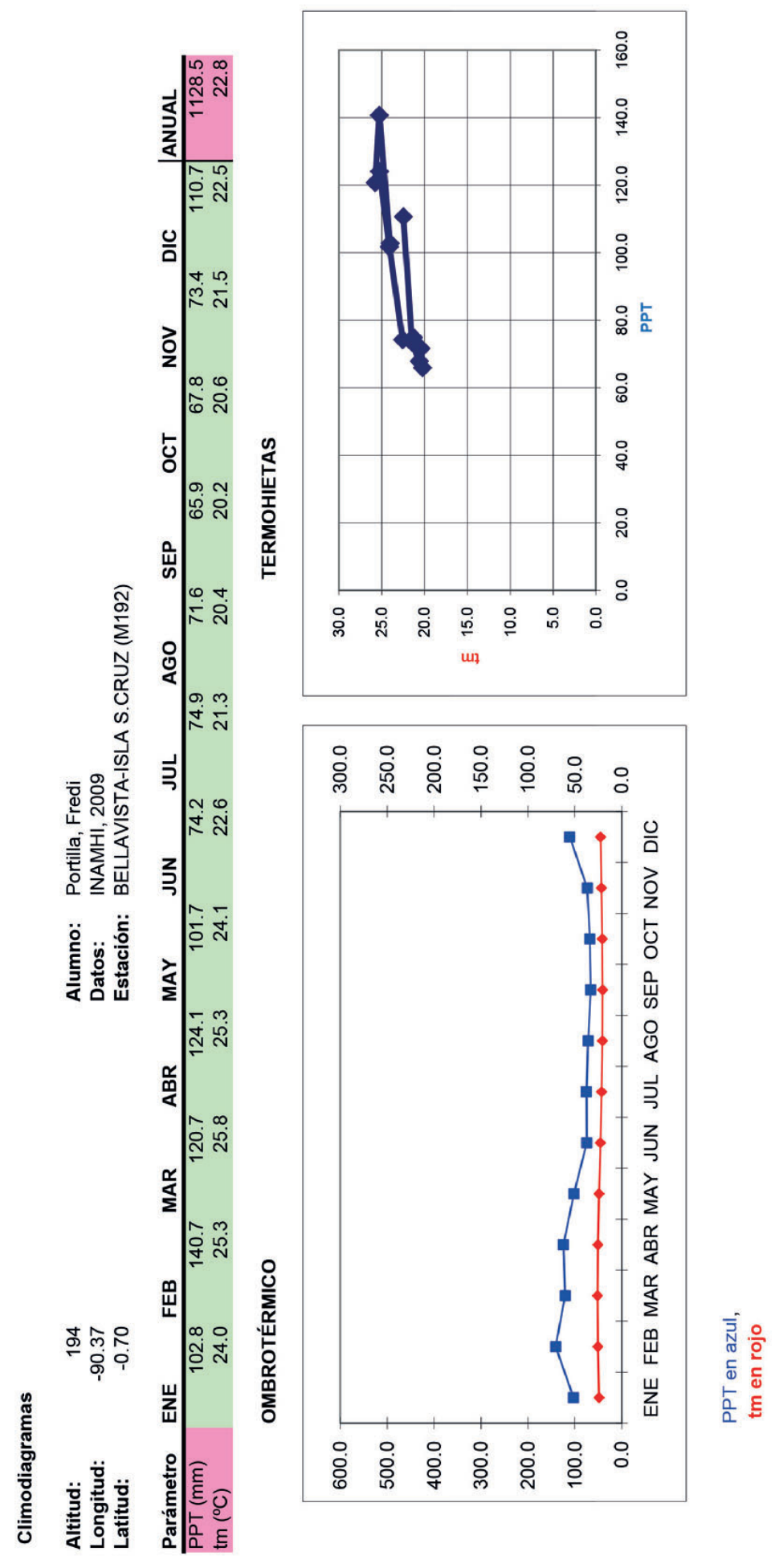




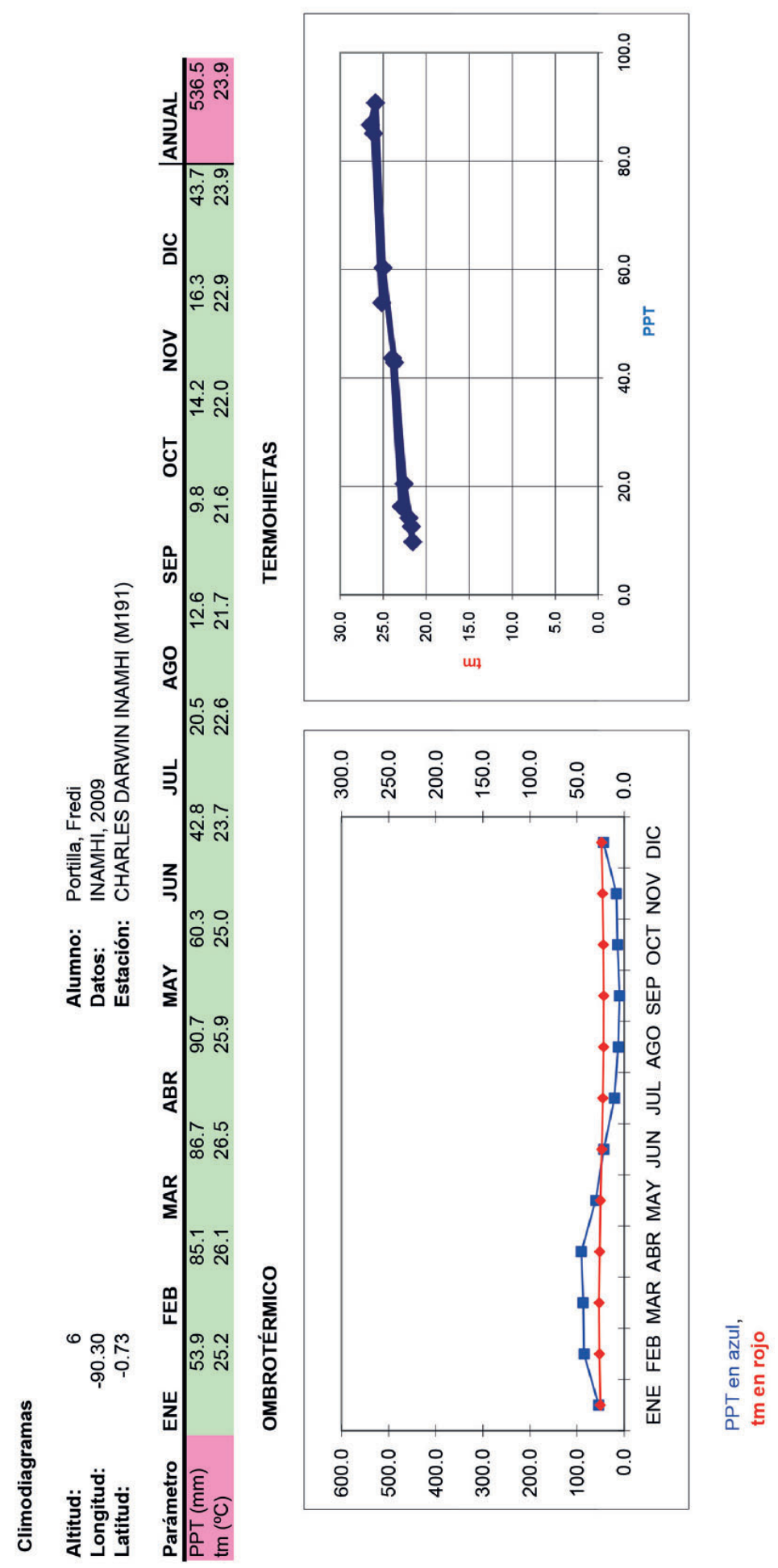




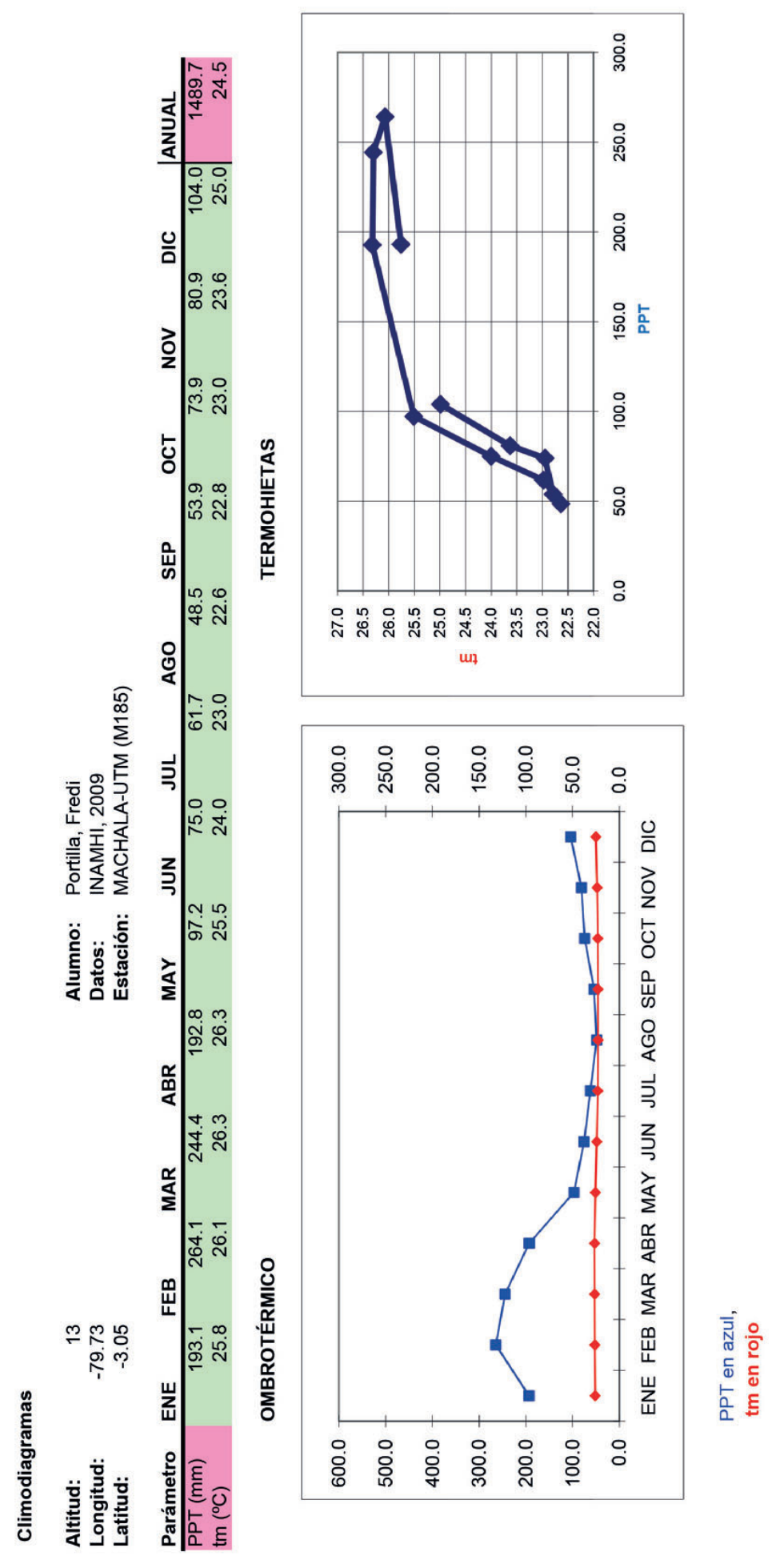




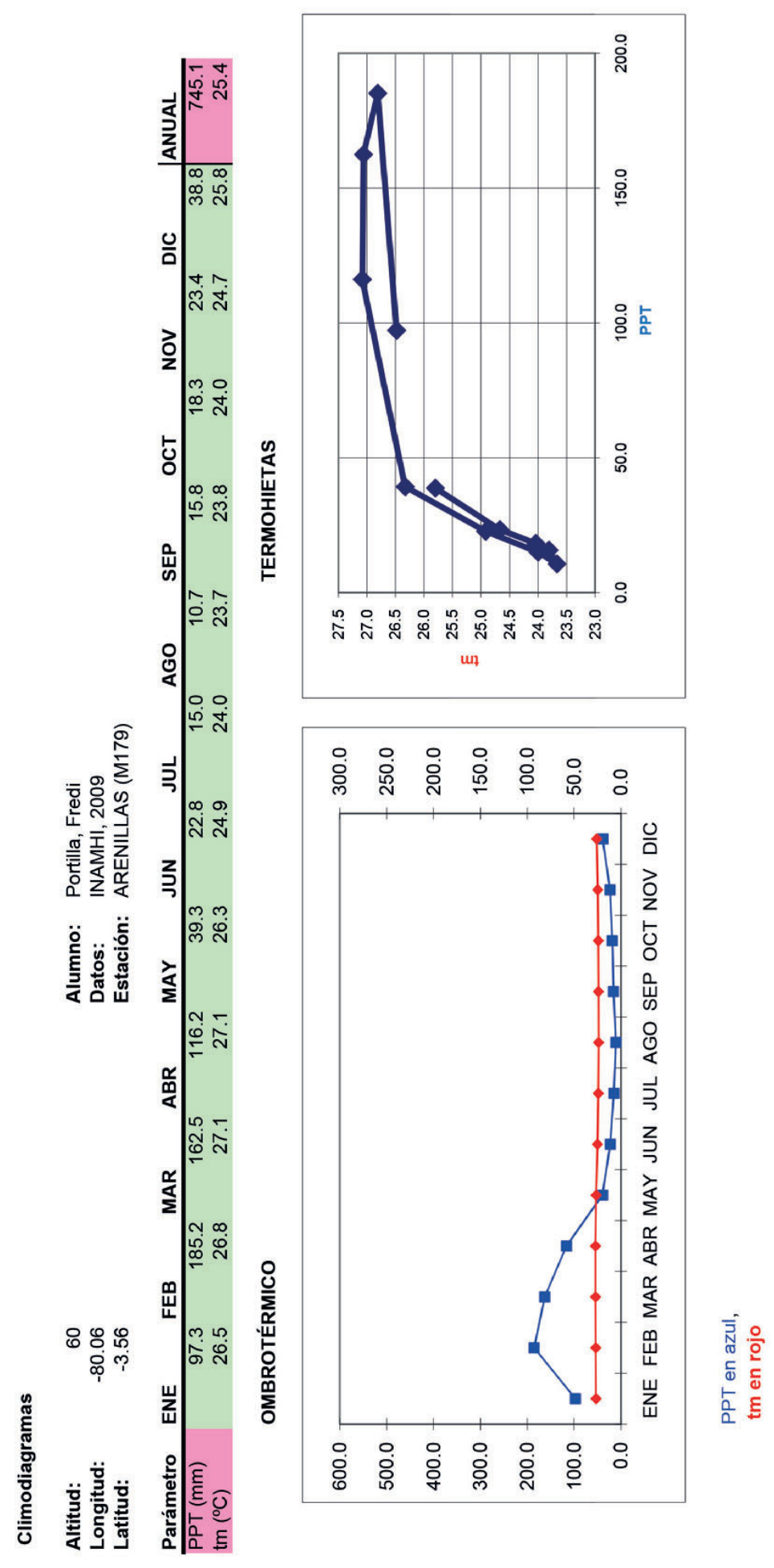




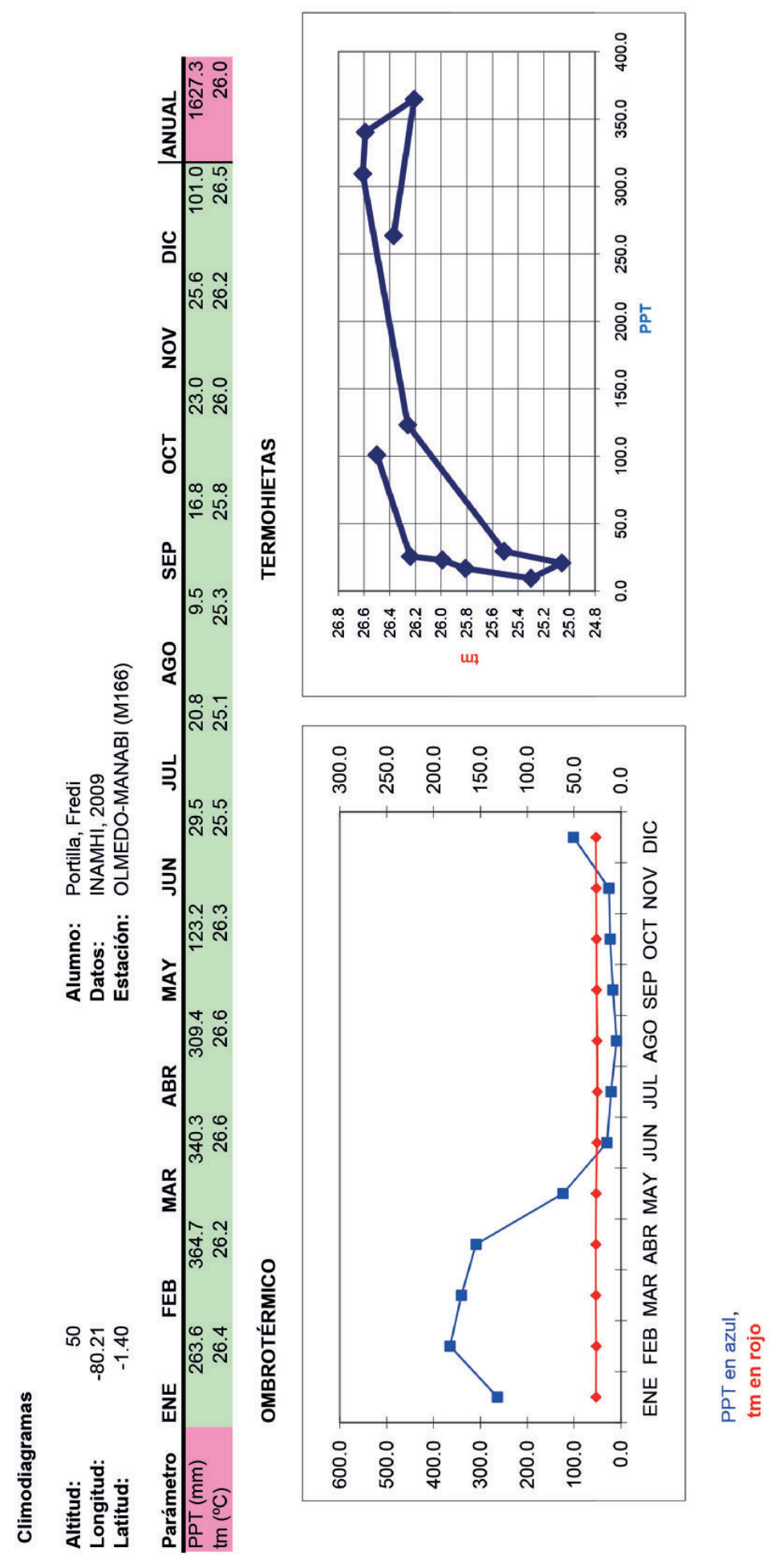




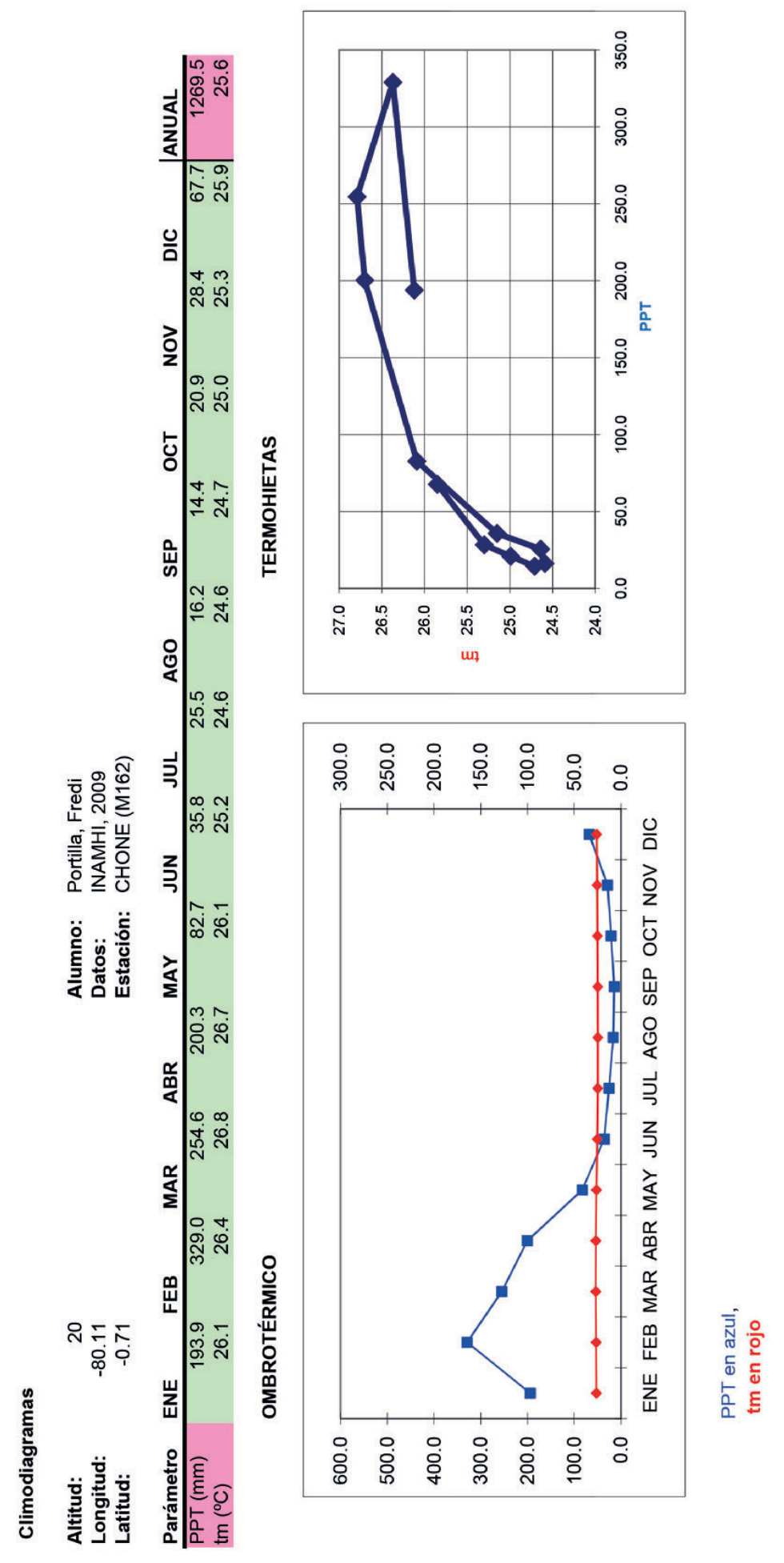




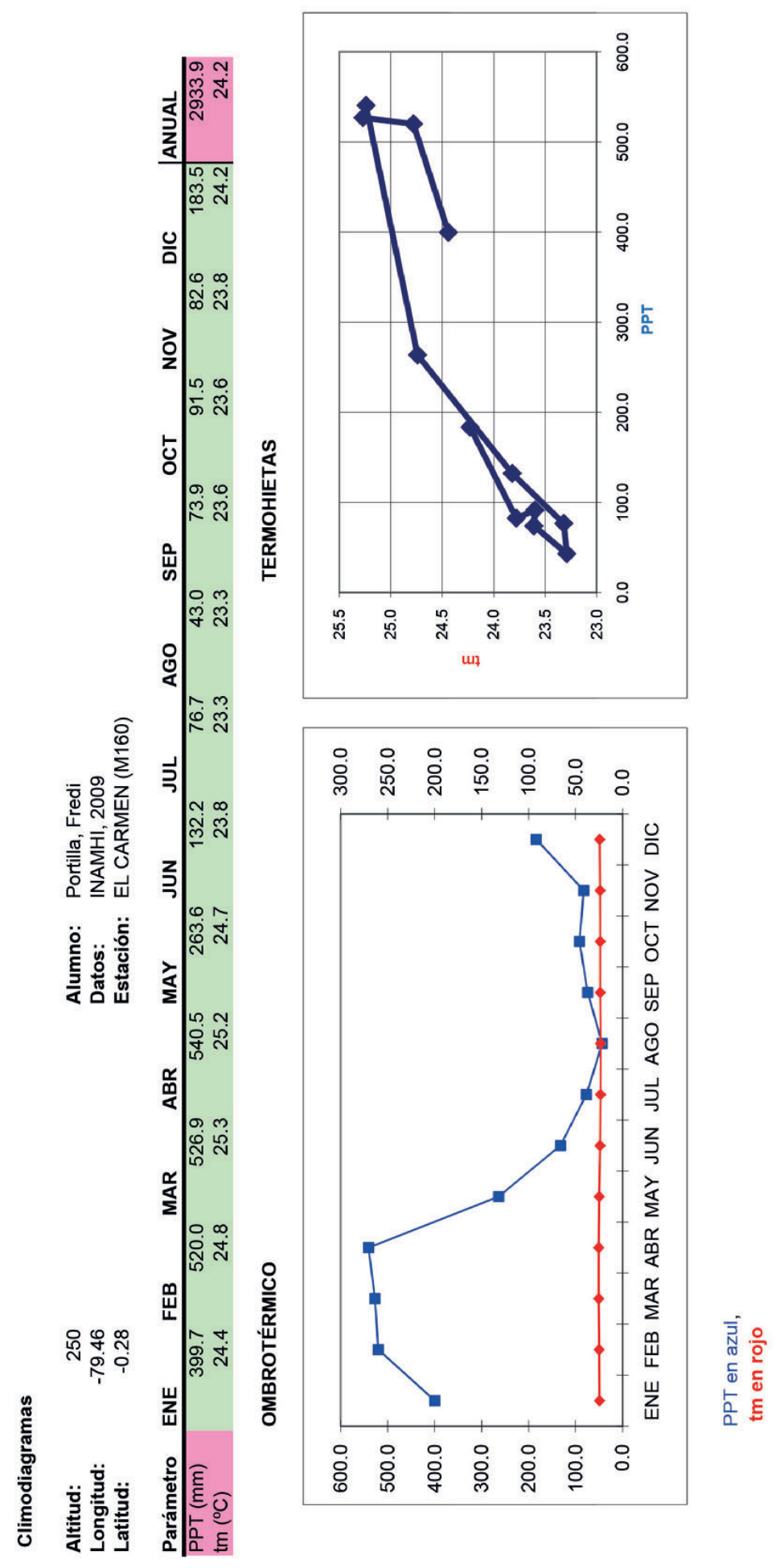




\section{9}

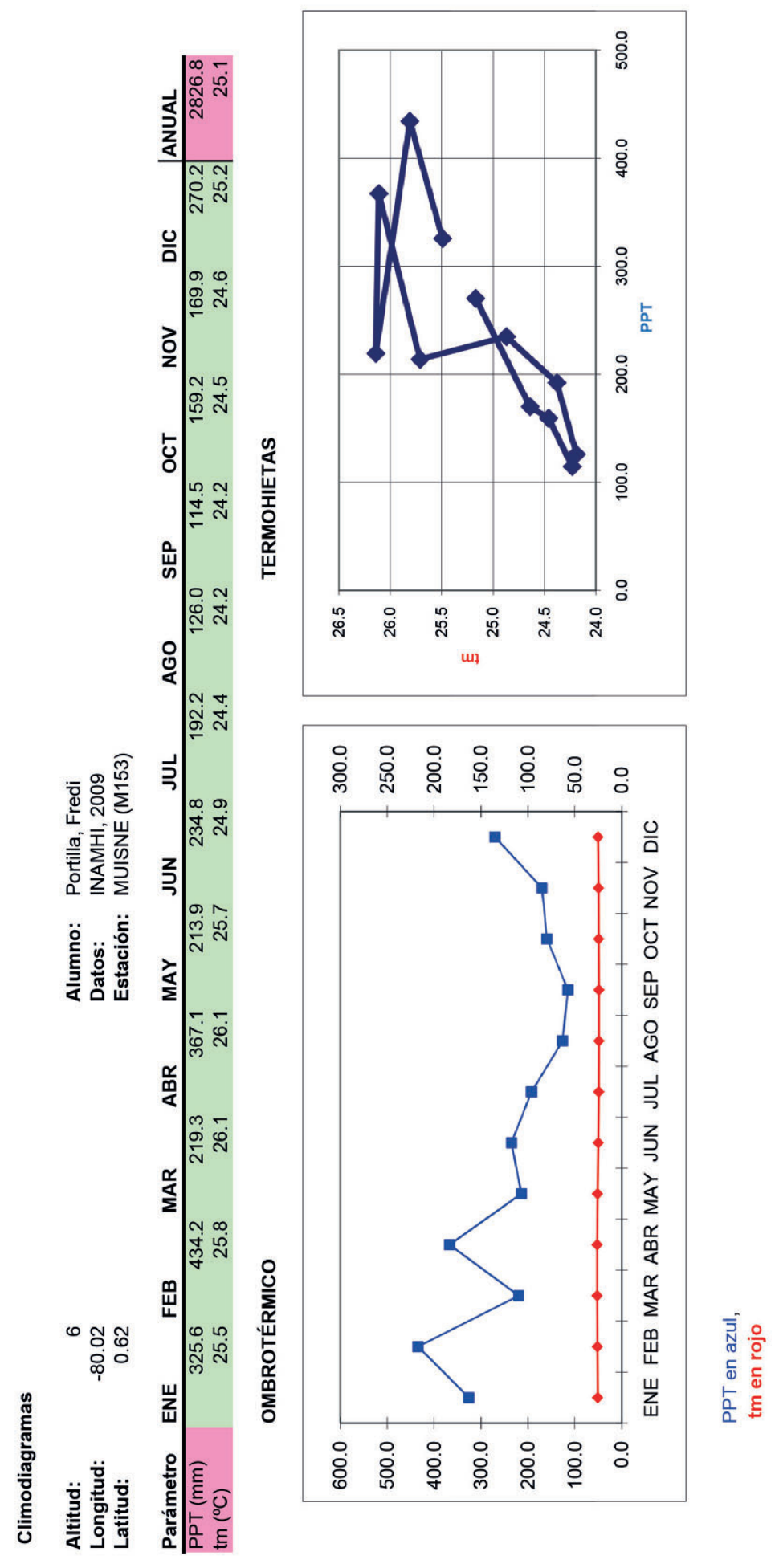




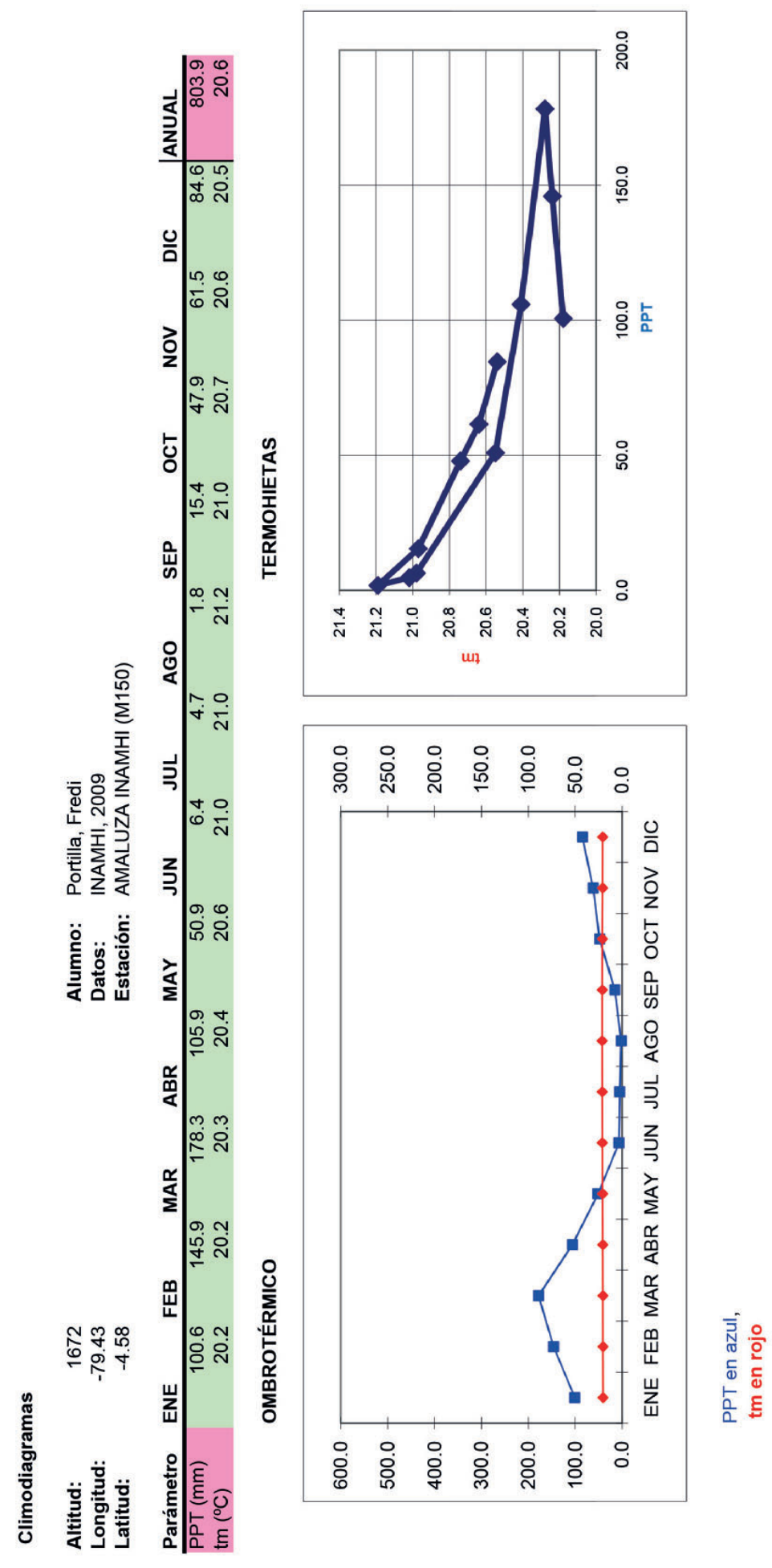




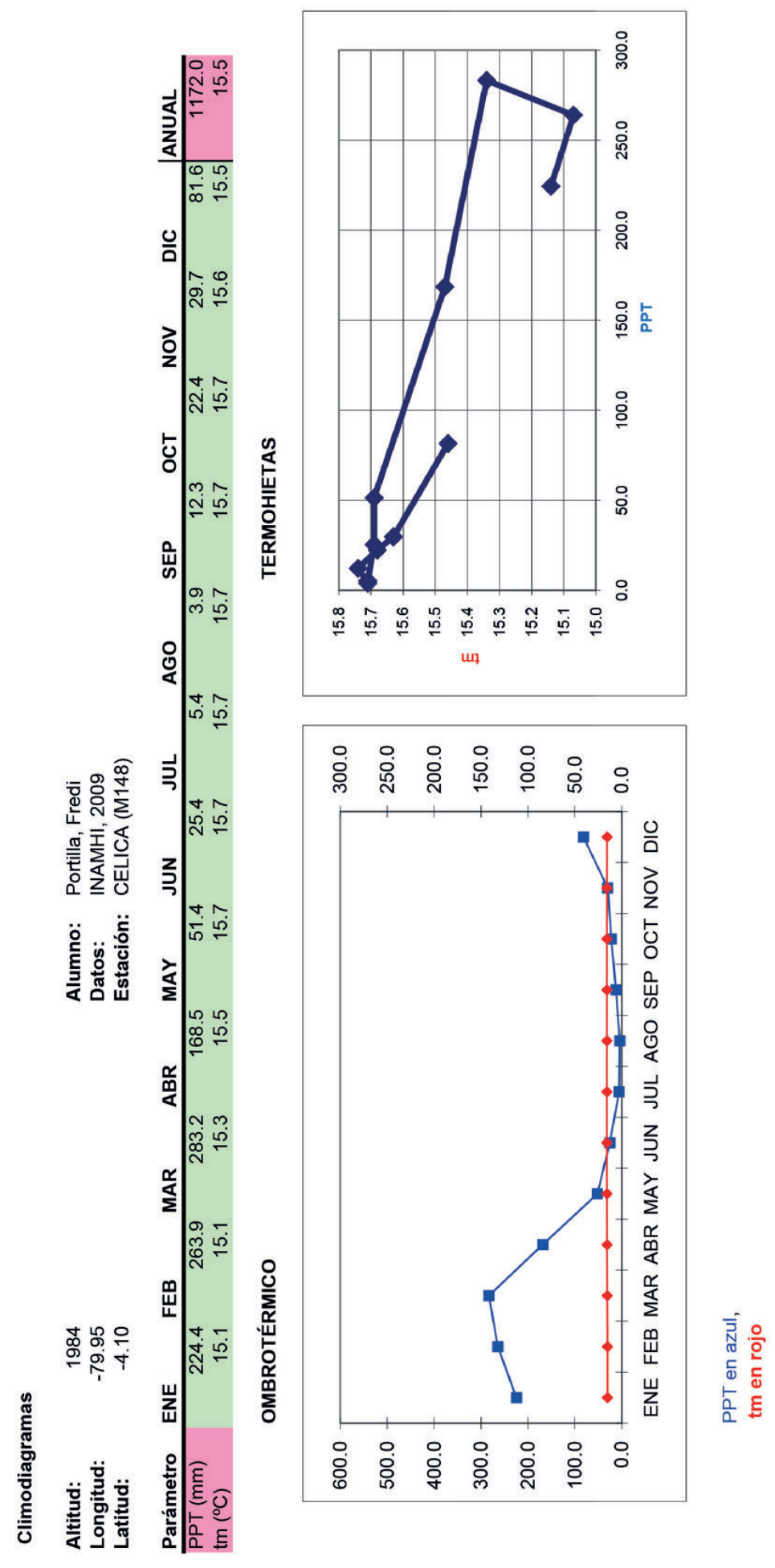




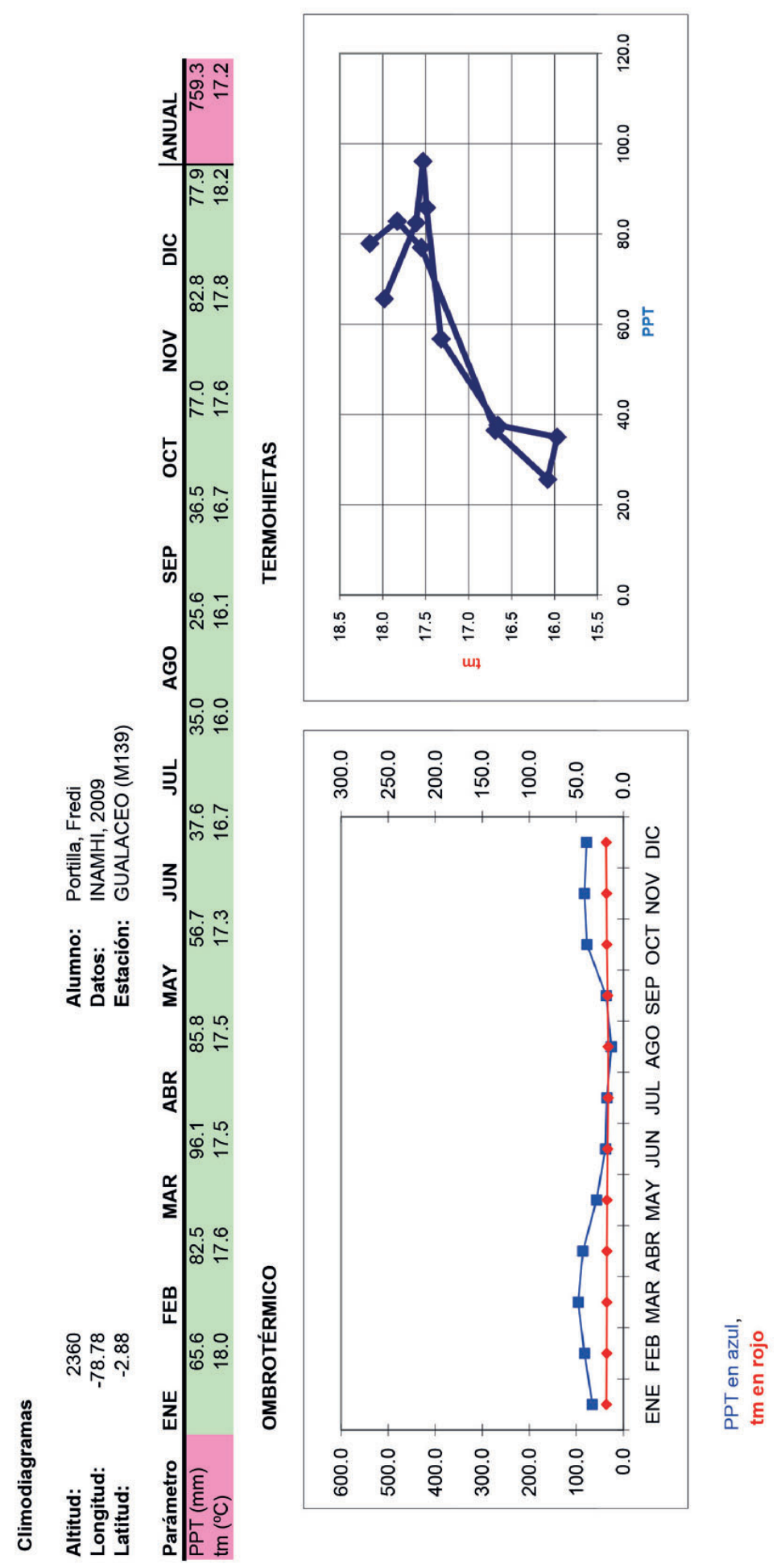




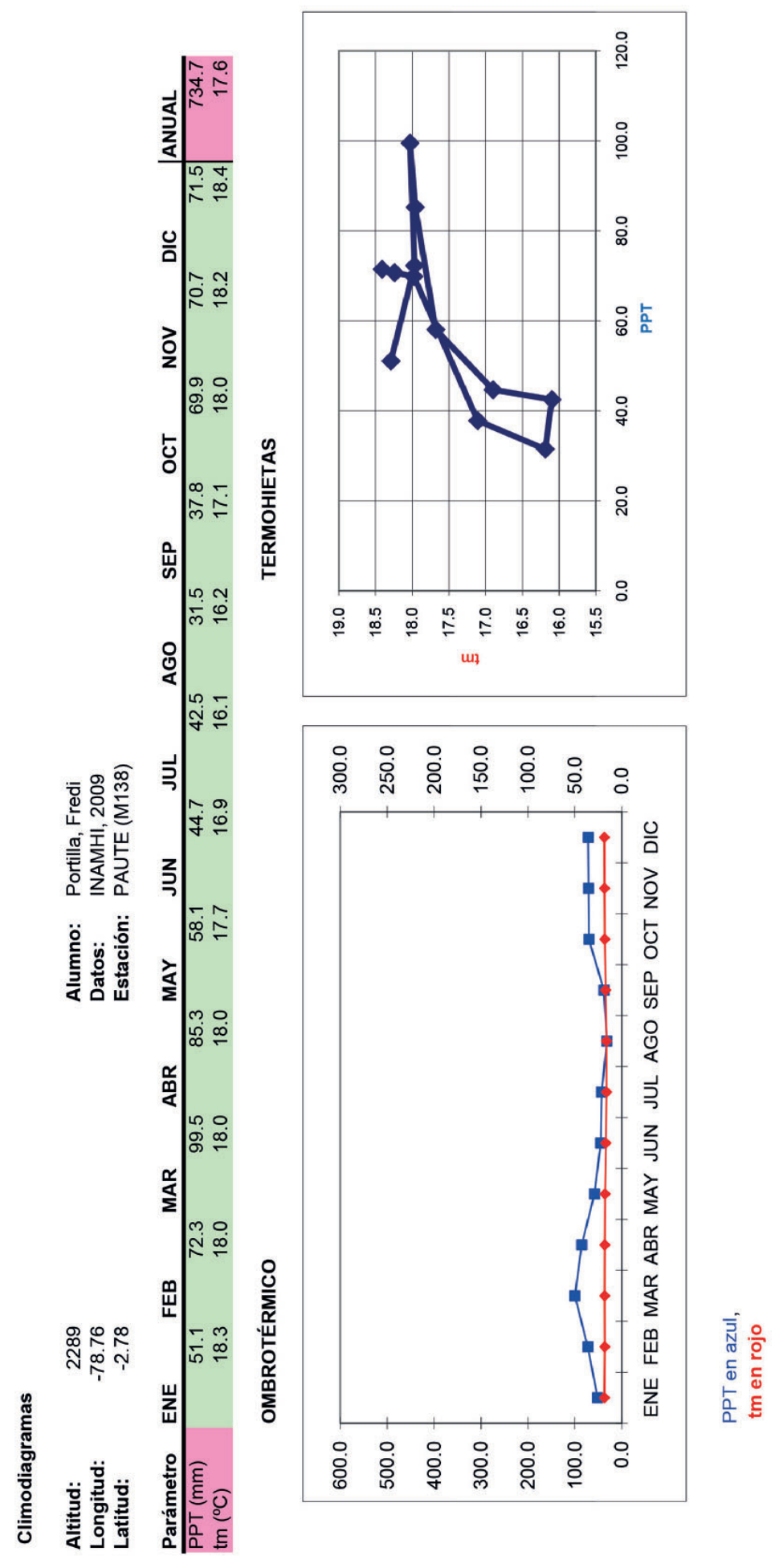




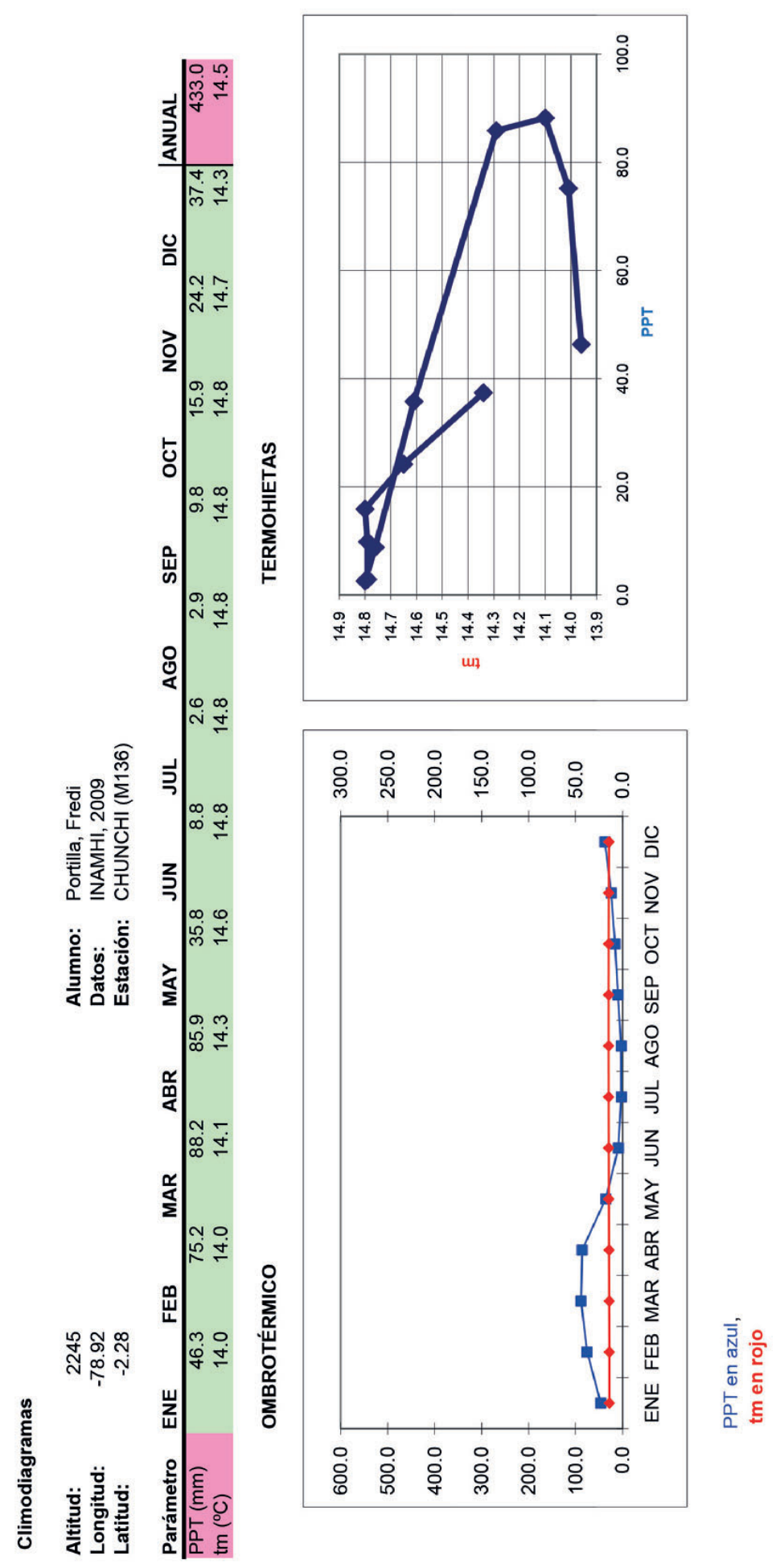




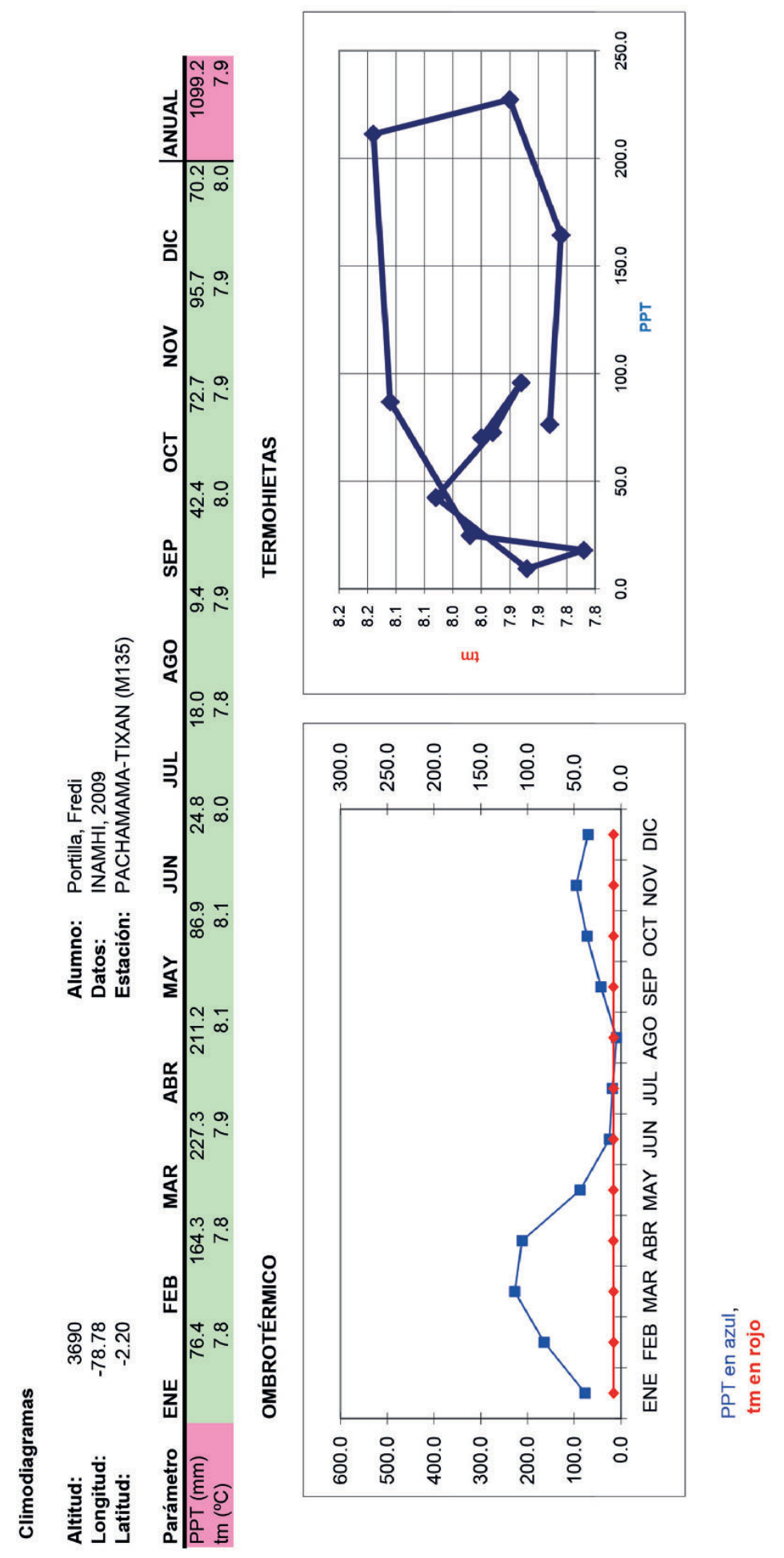




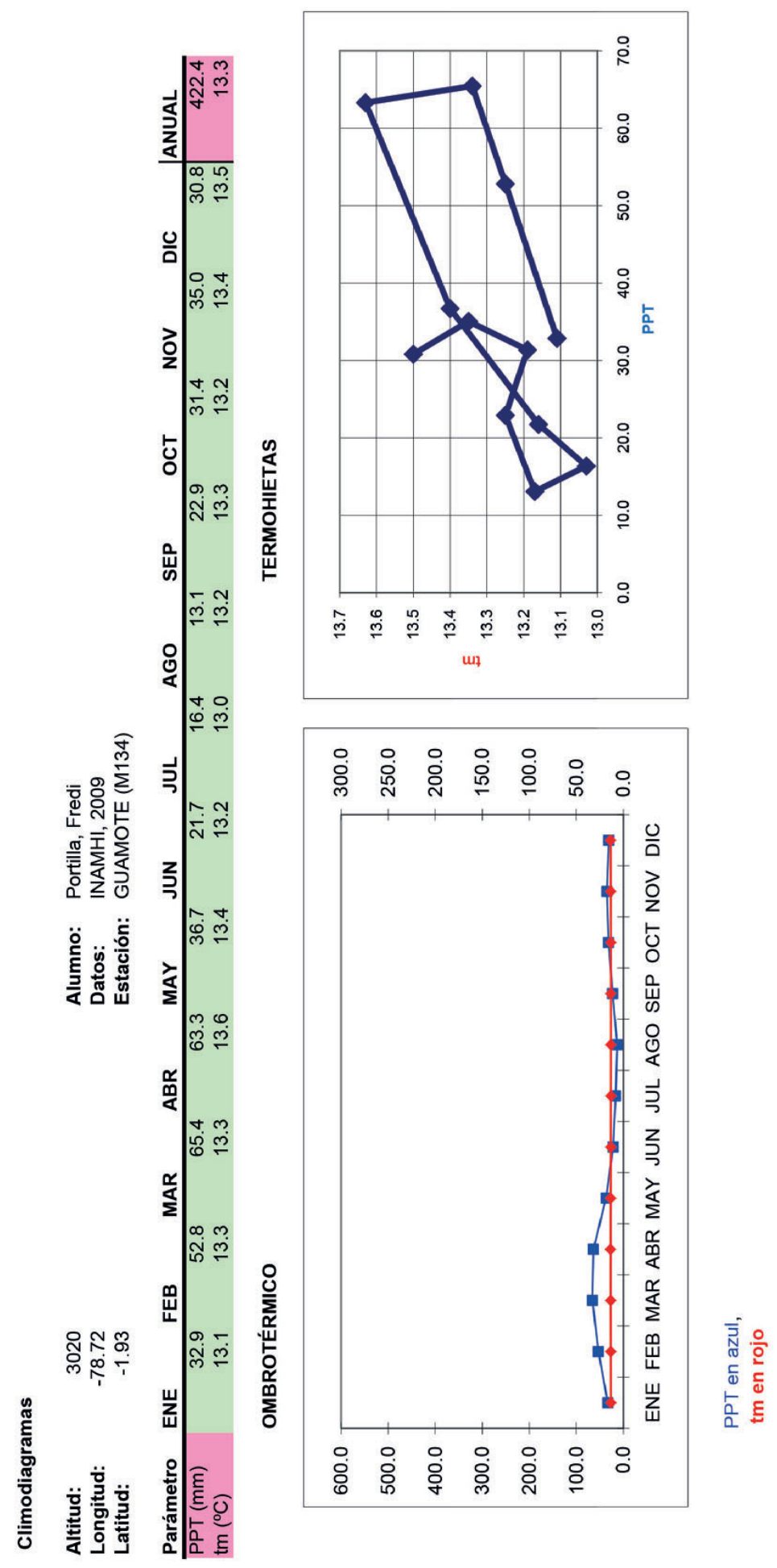




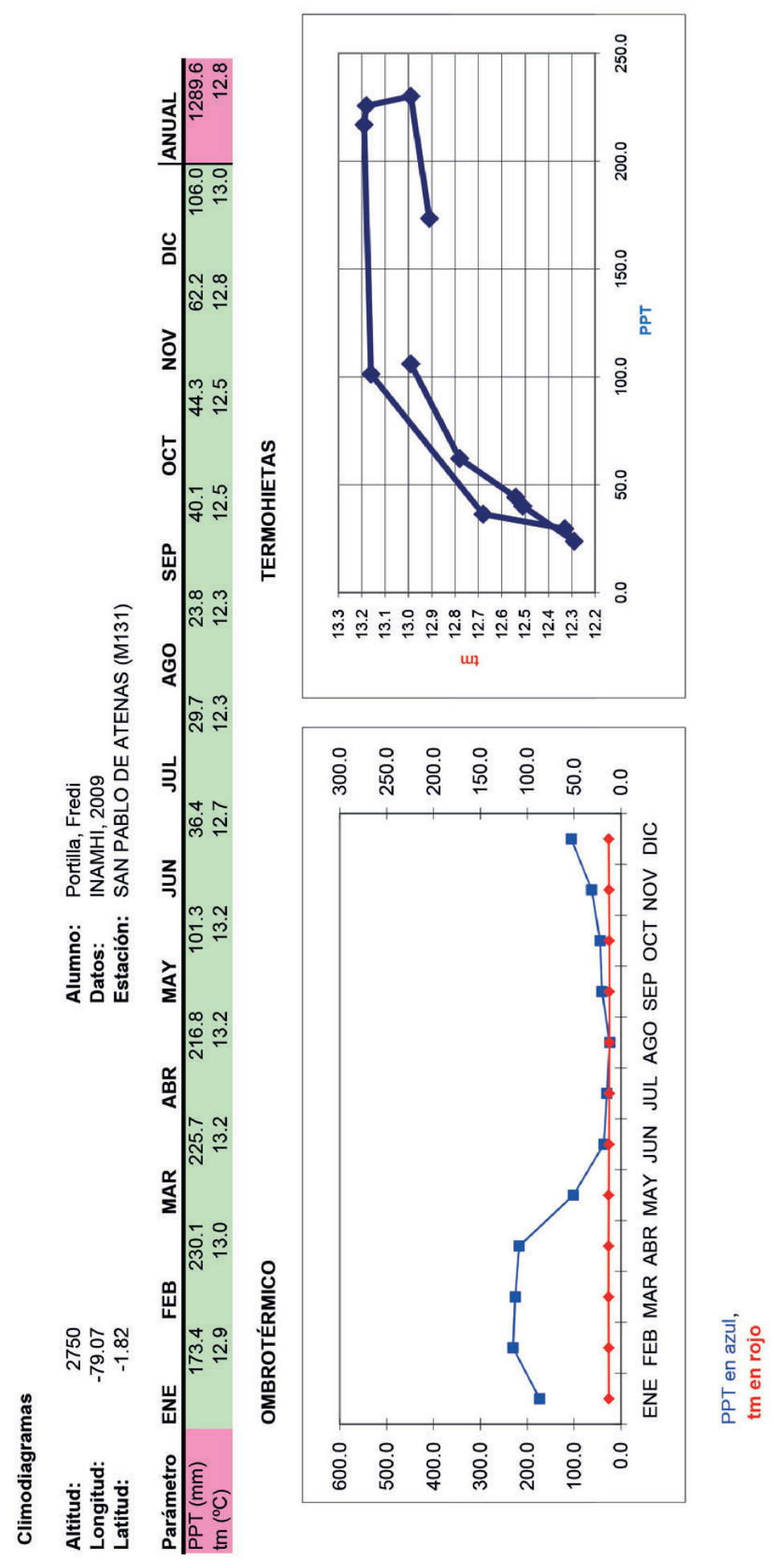




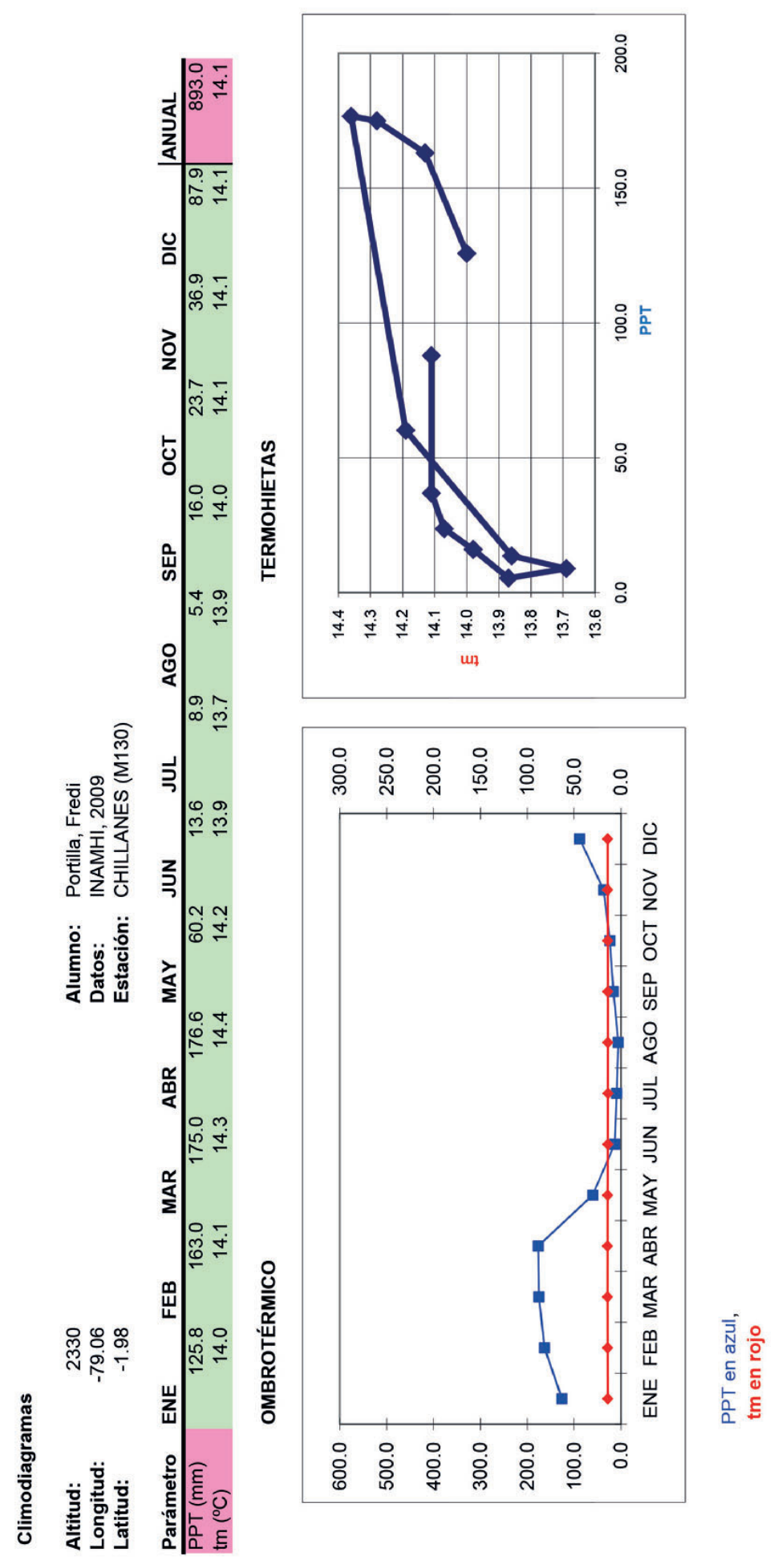




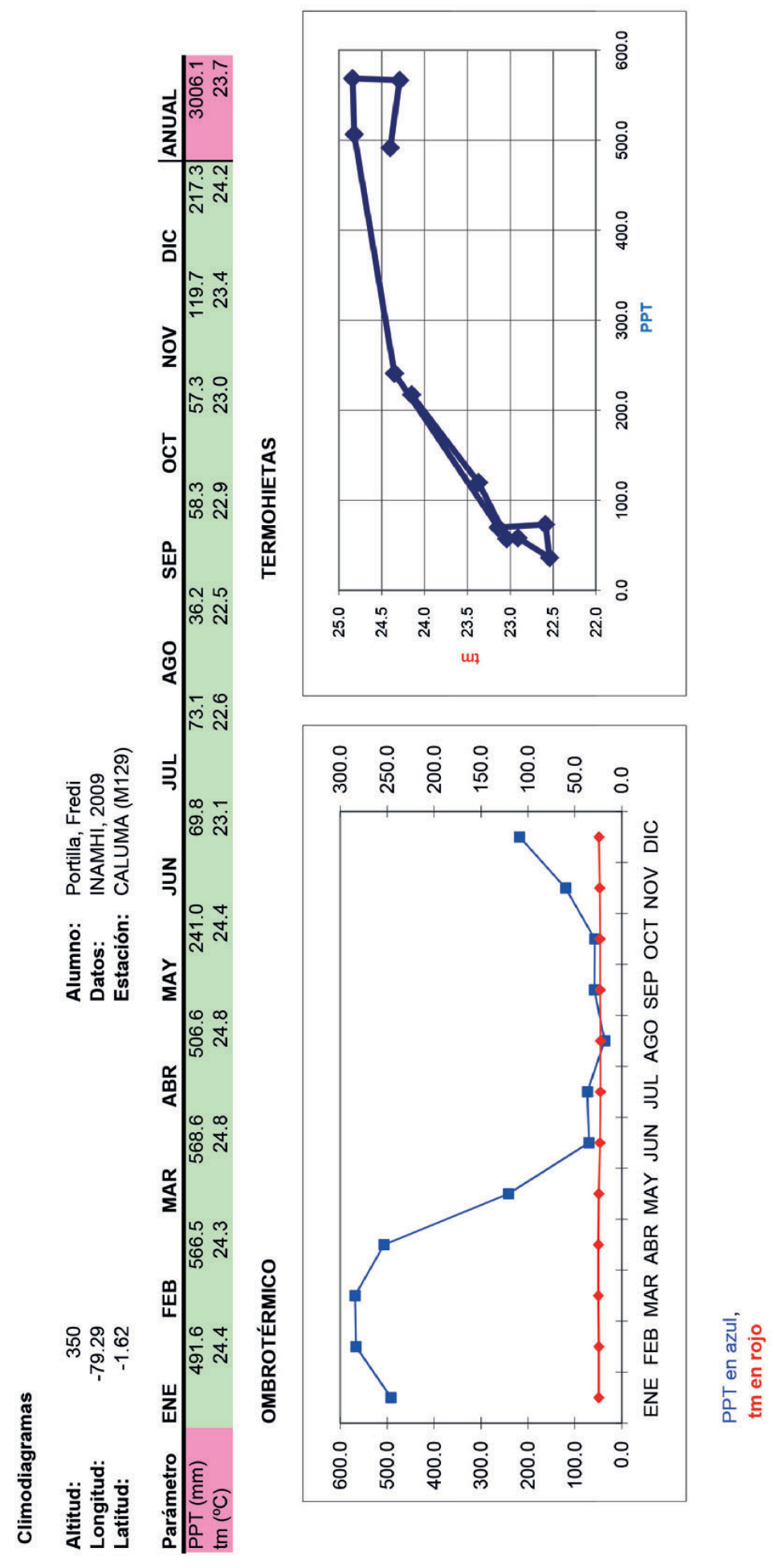




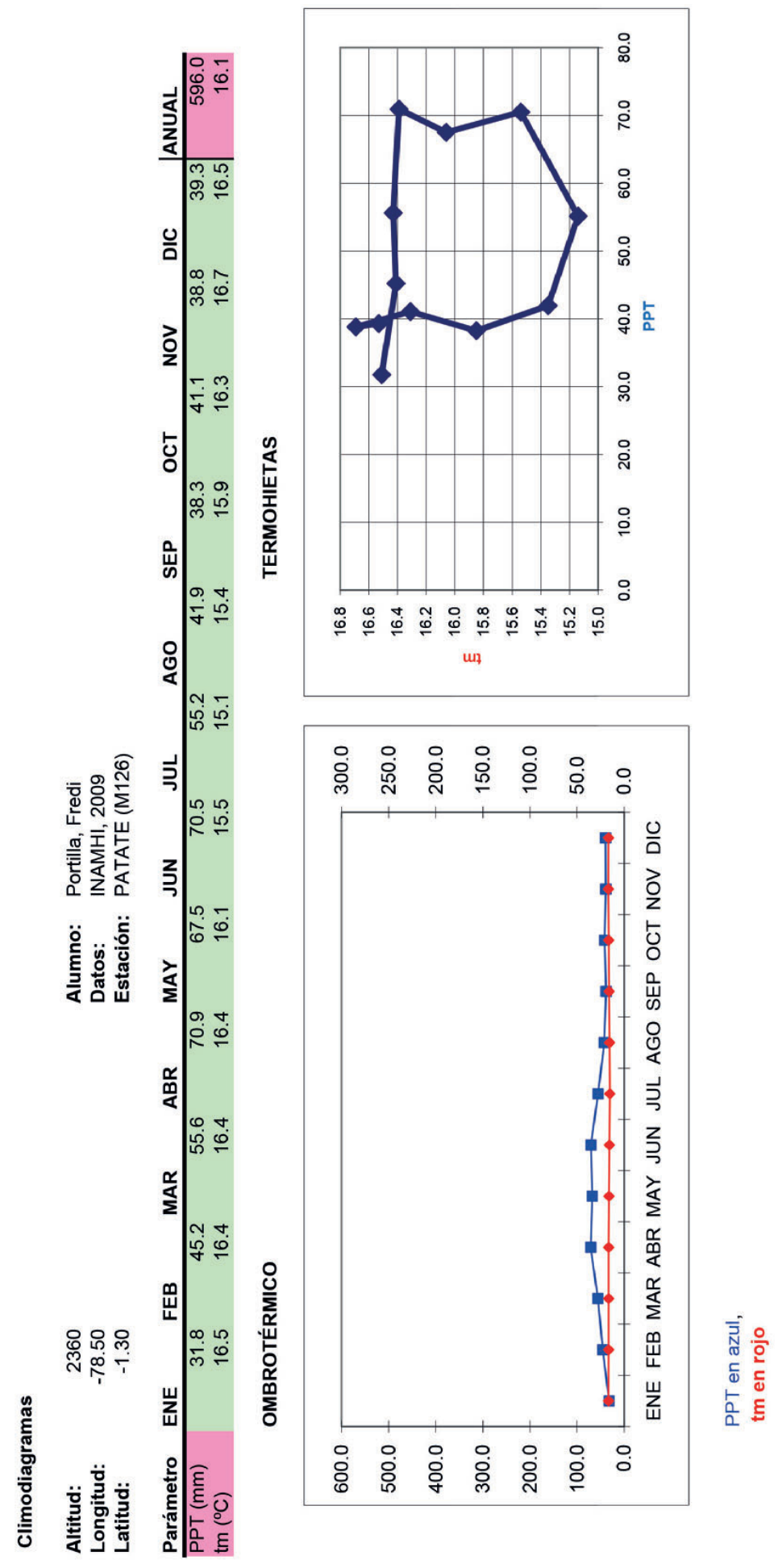




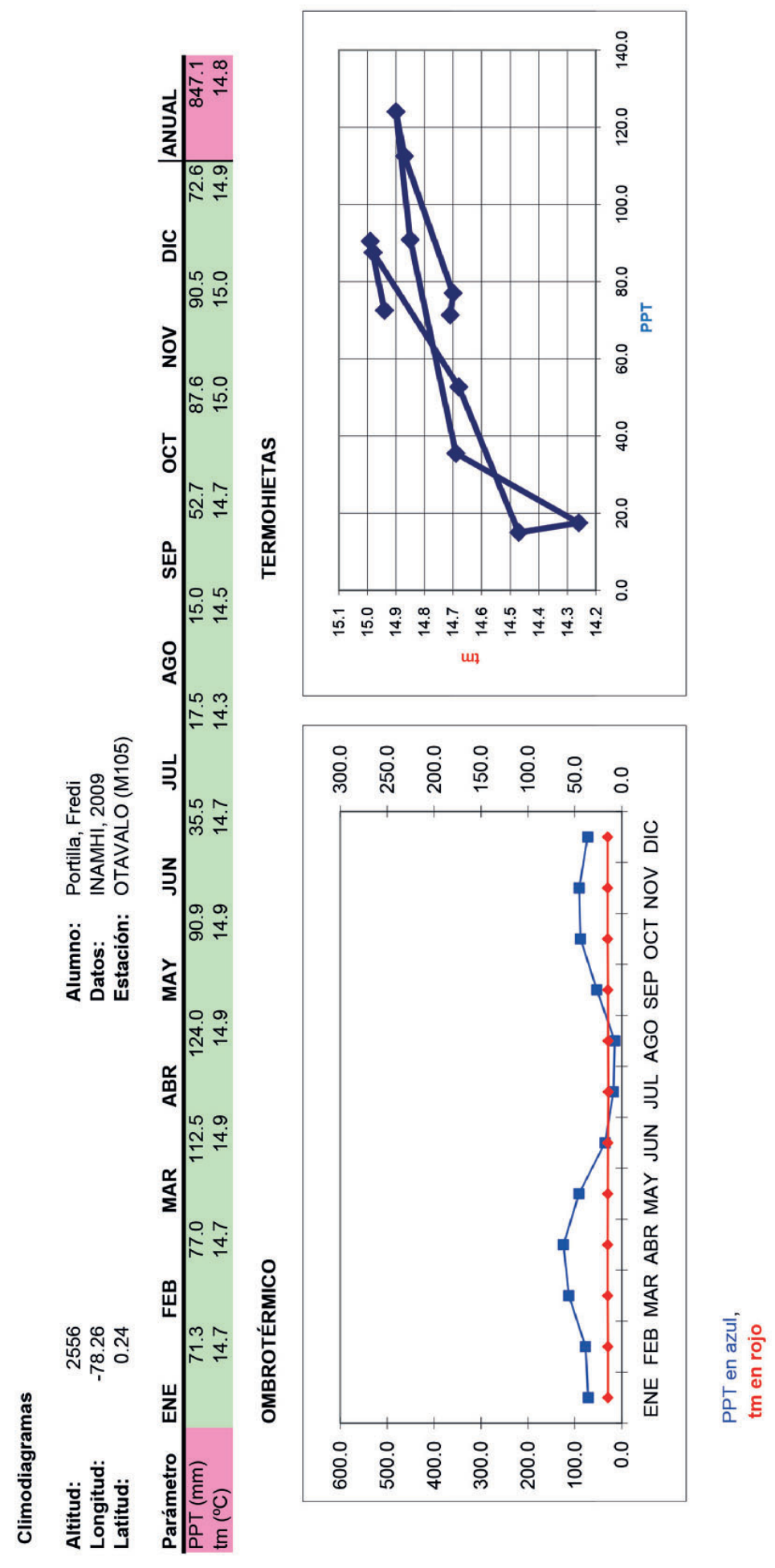




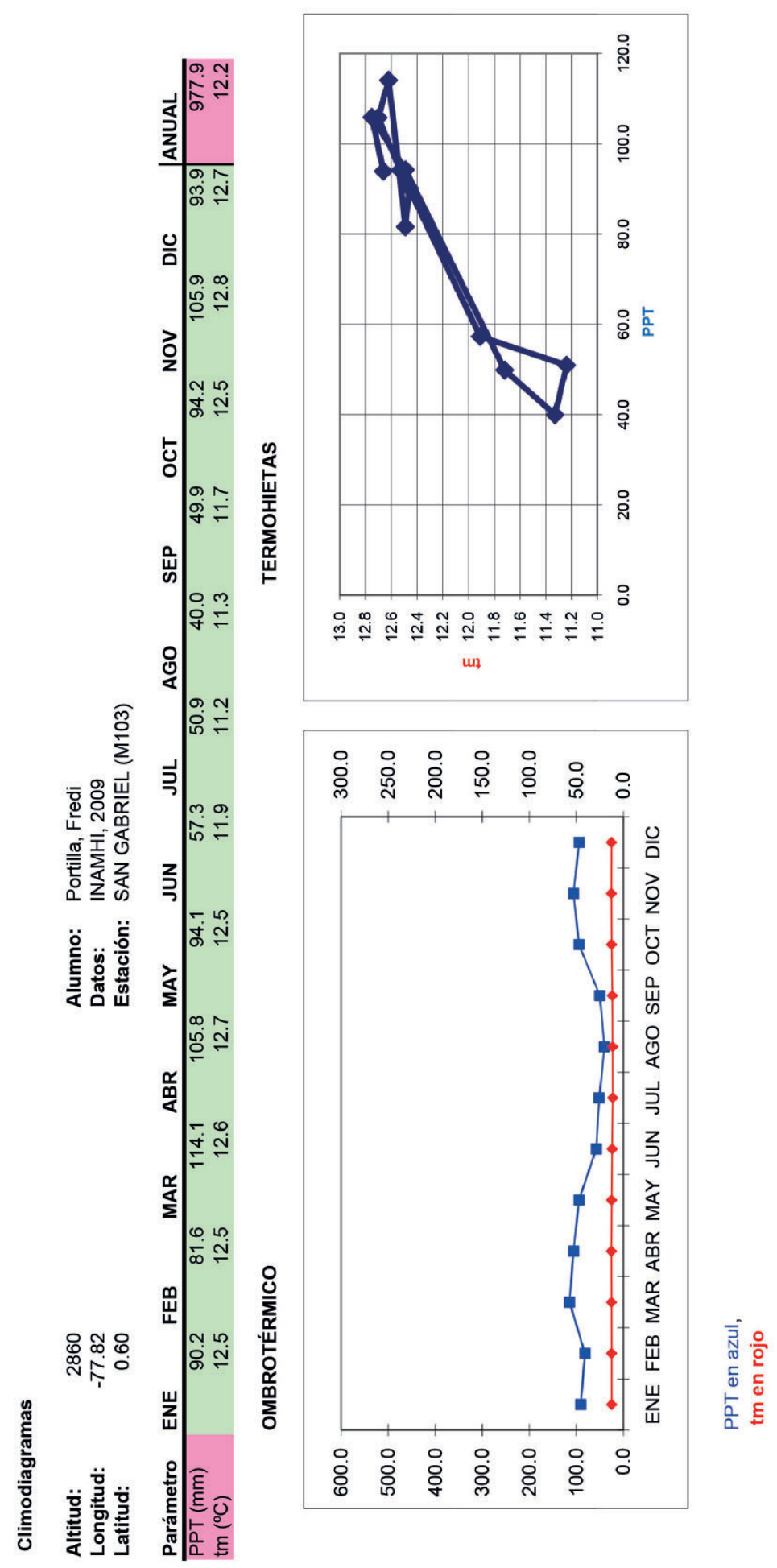




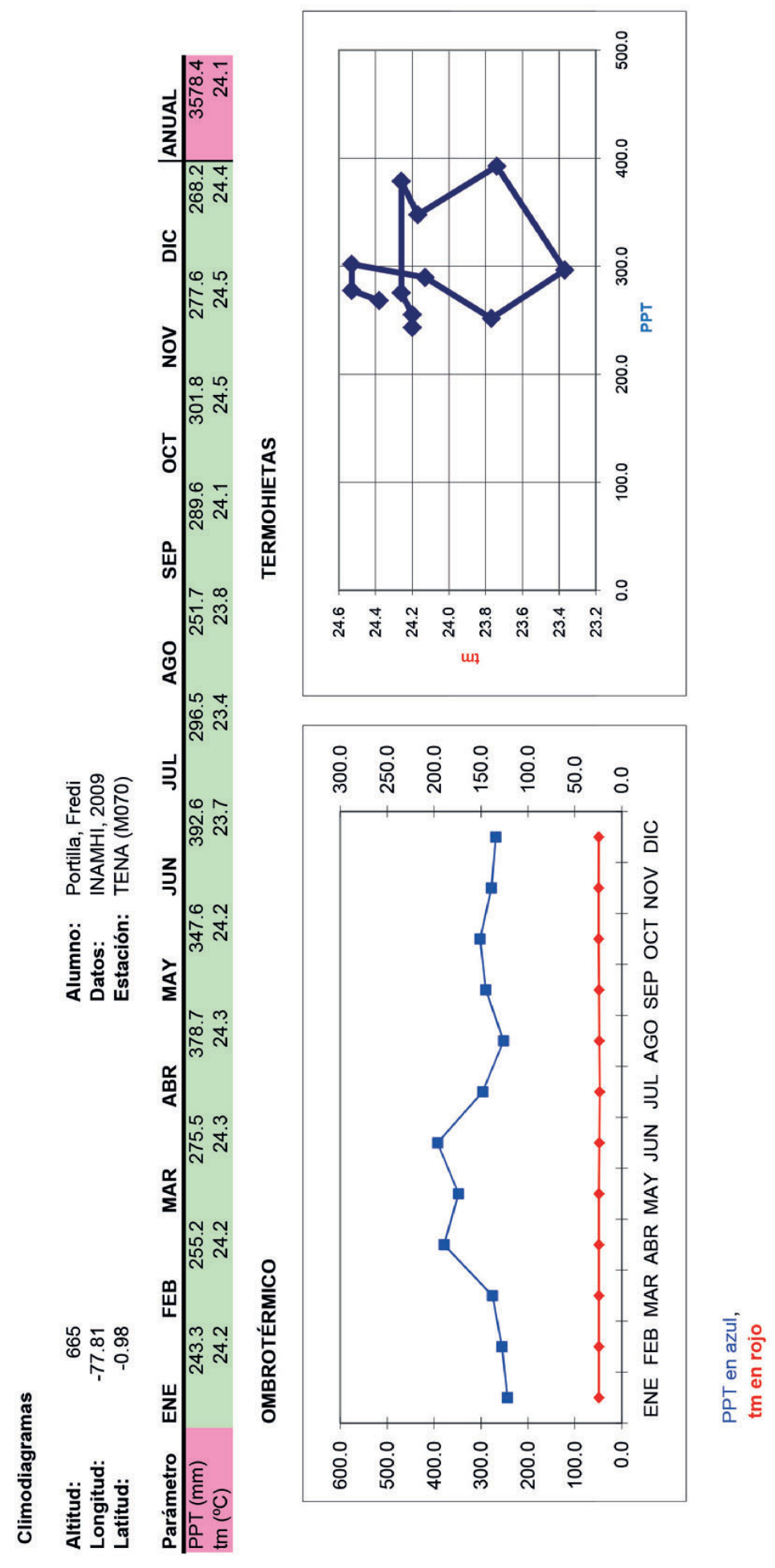




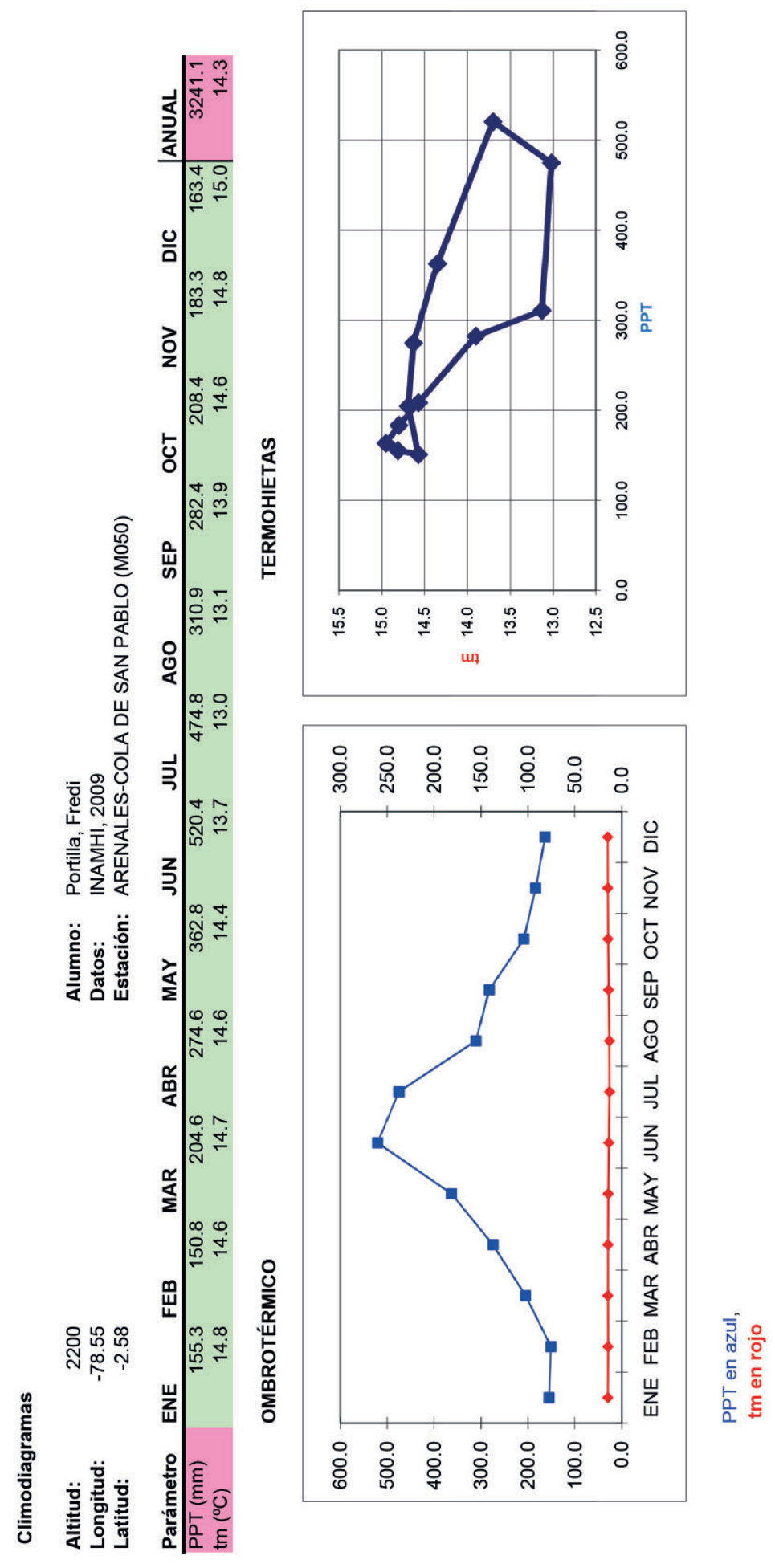




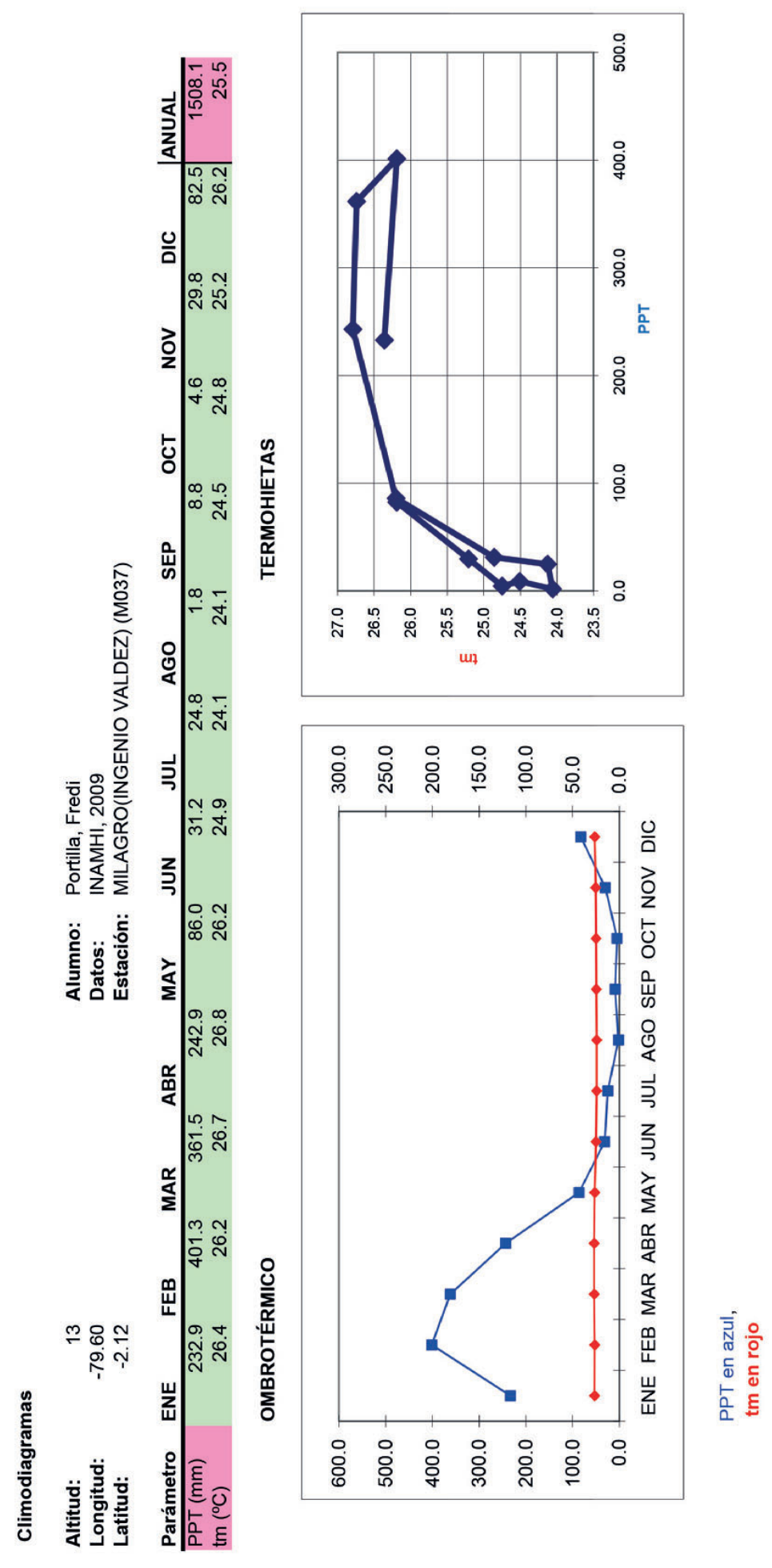




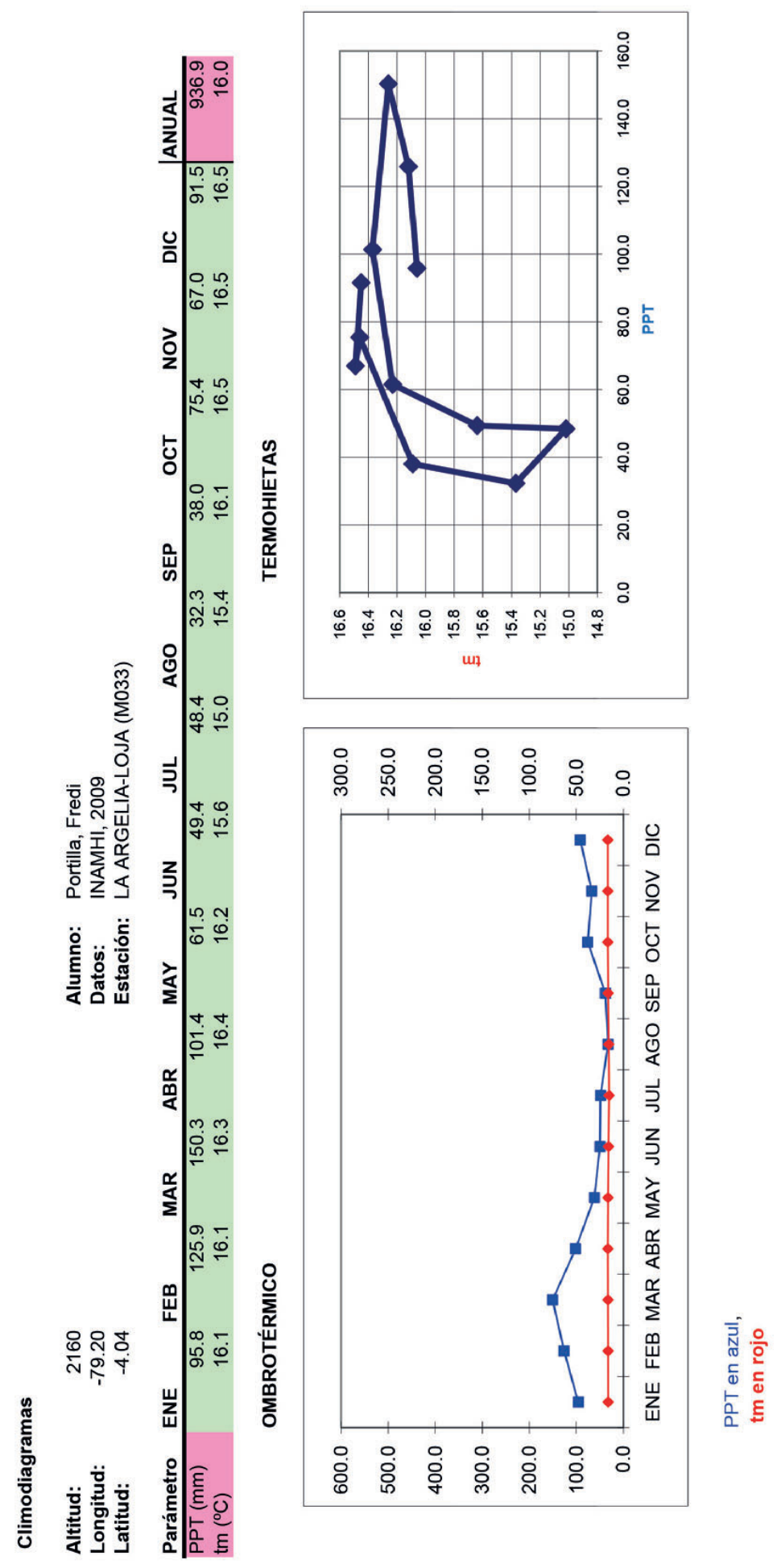




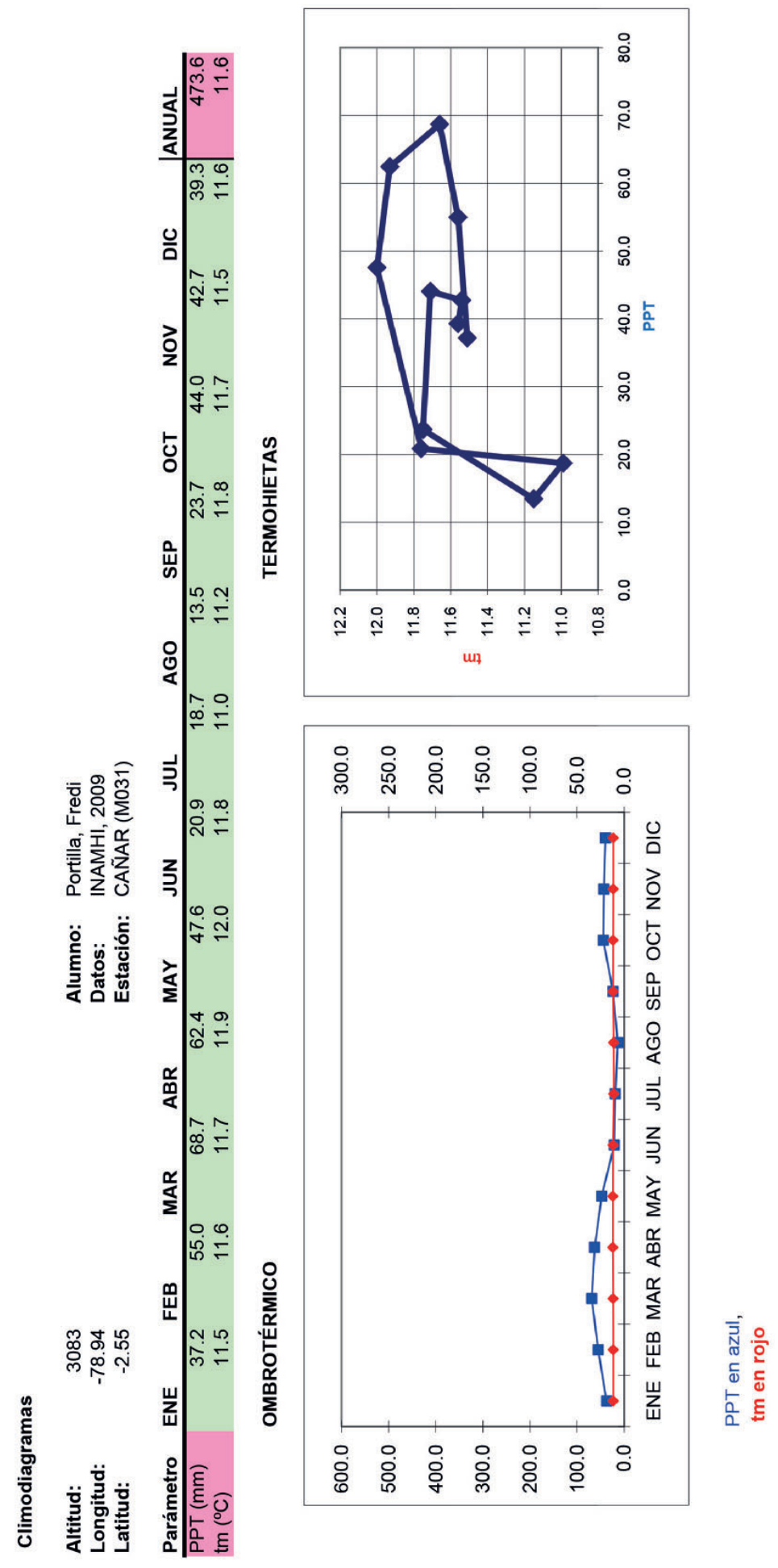




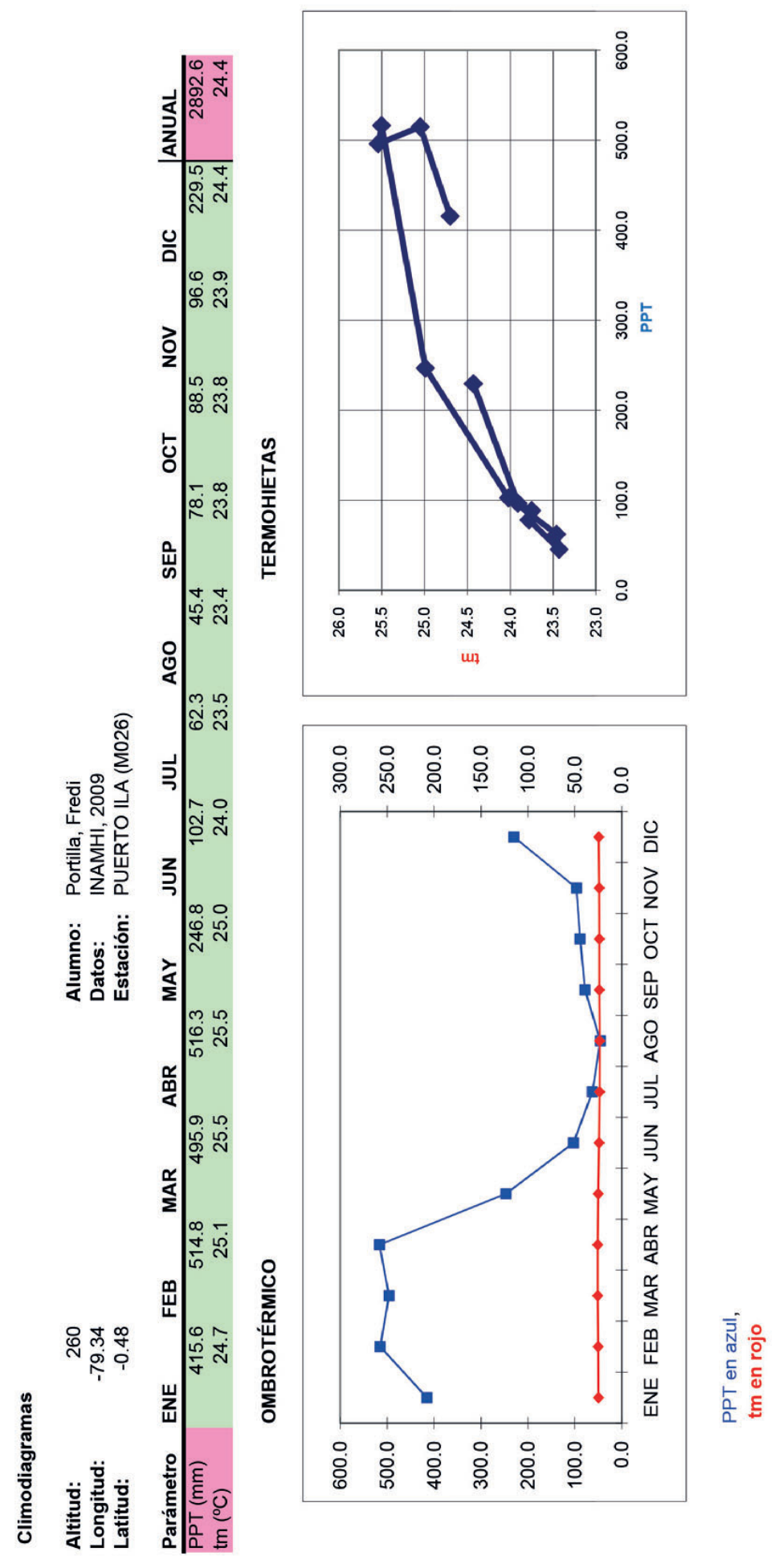




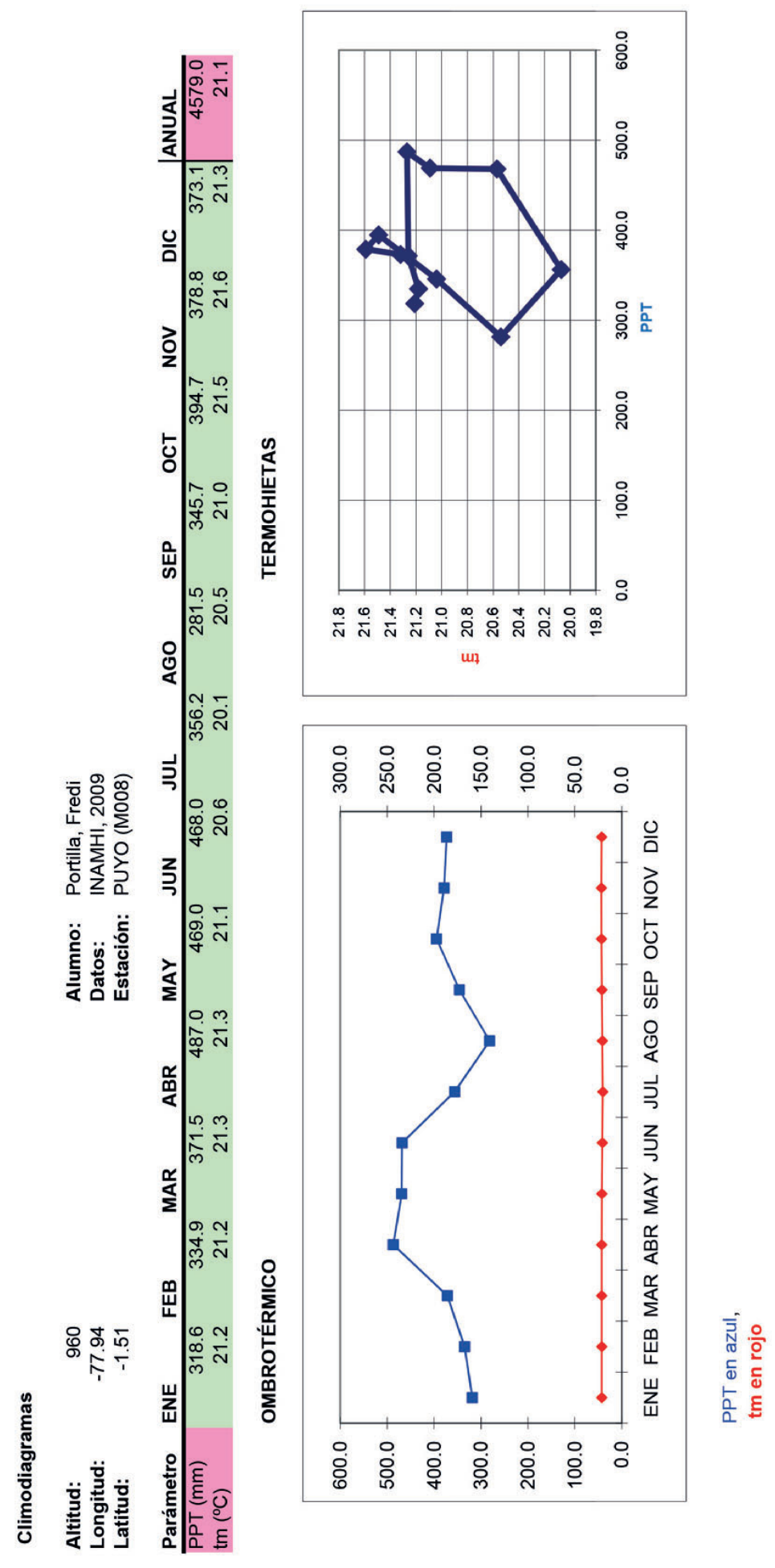




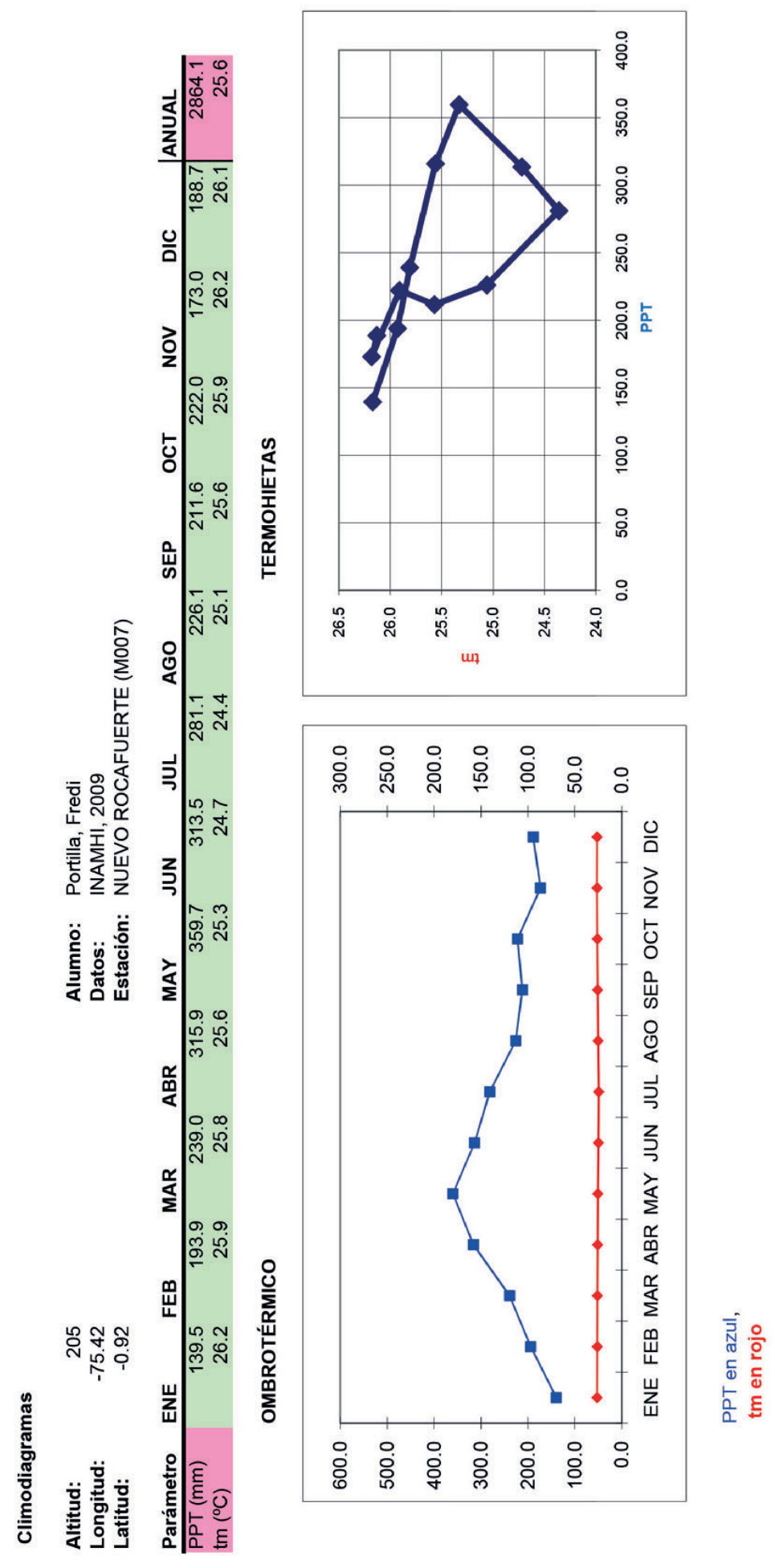




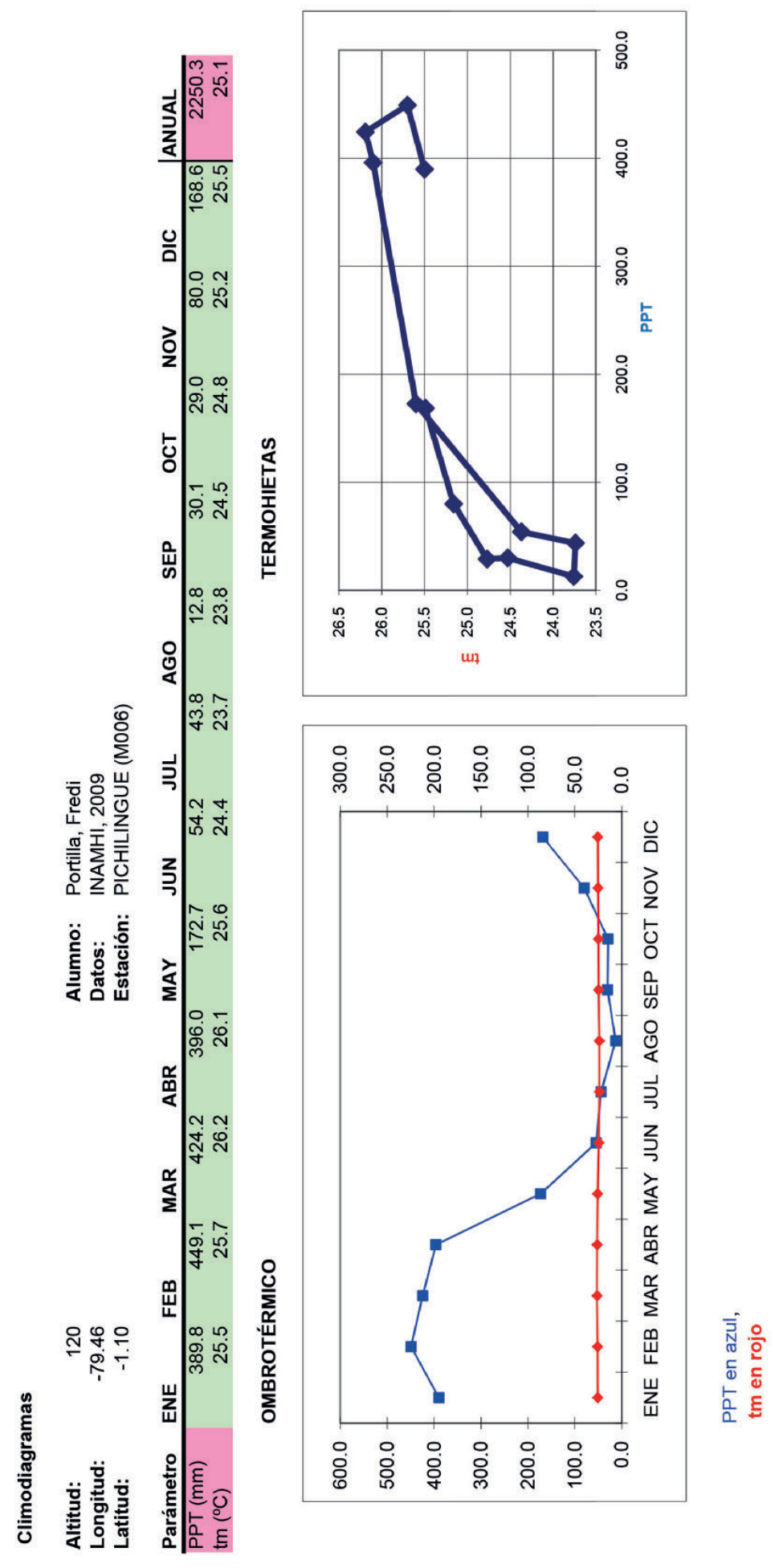




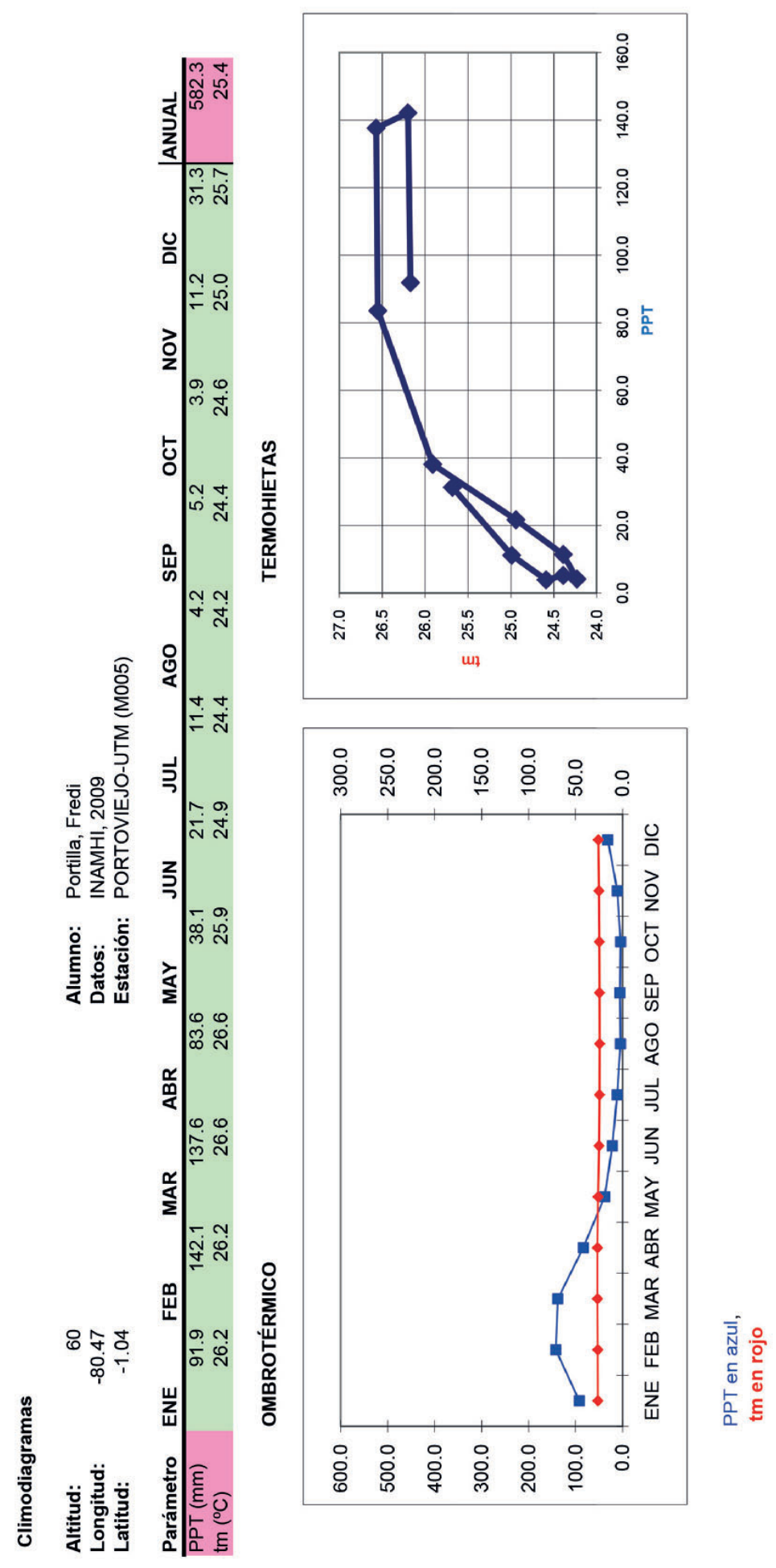




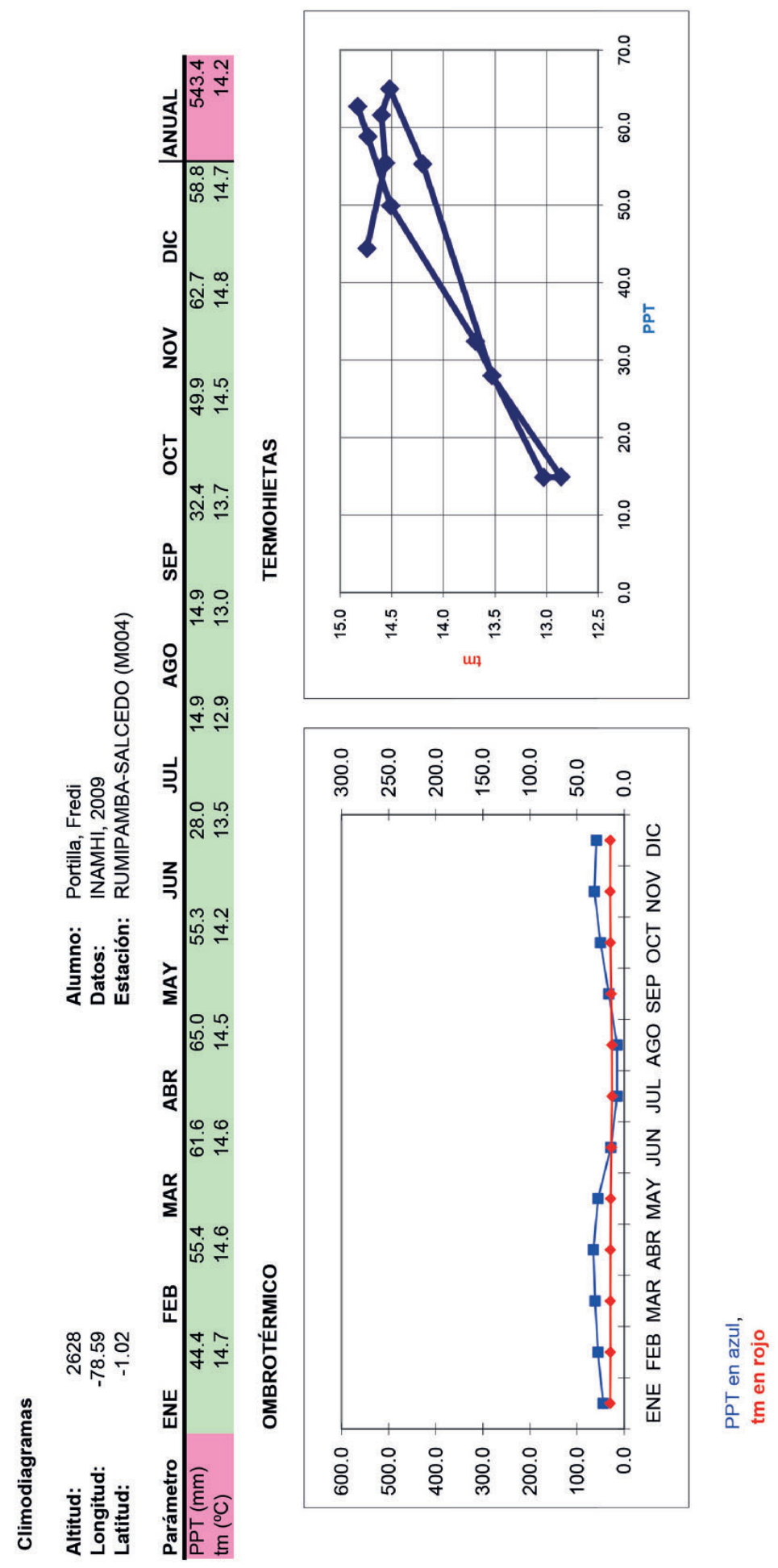




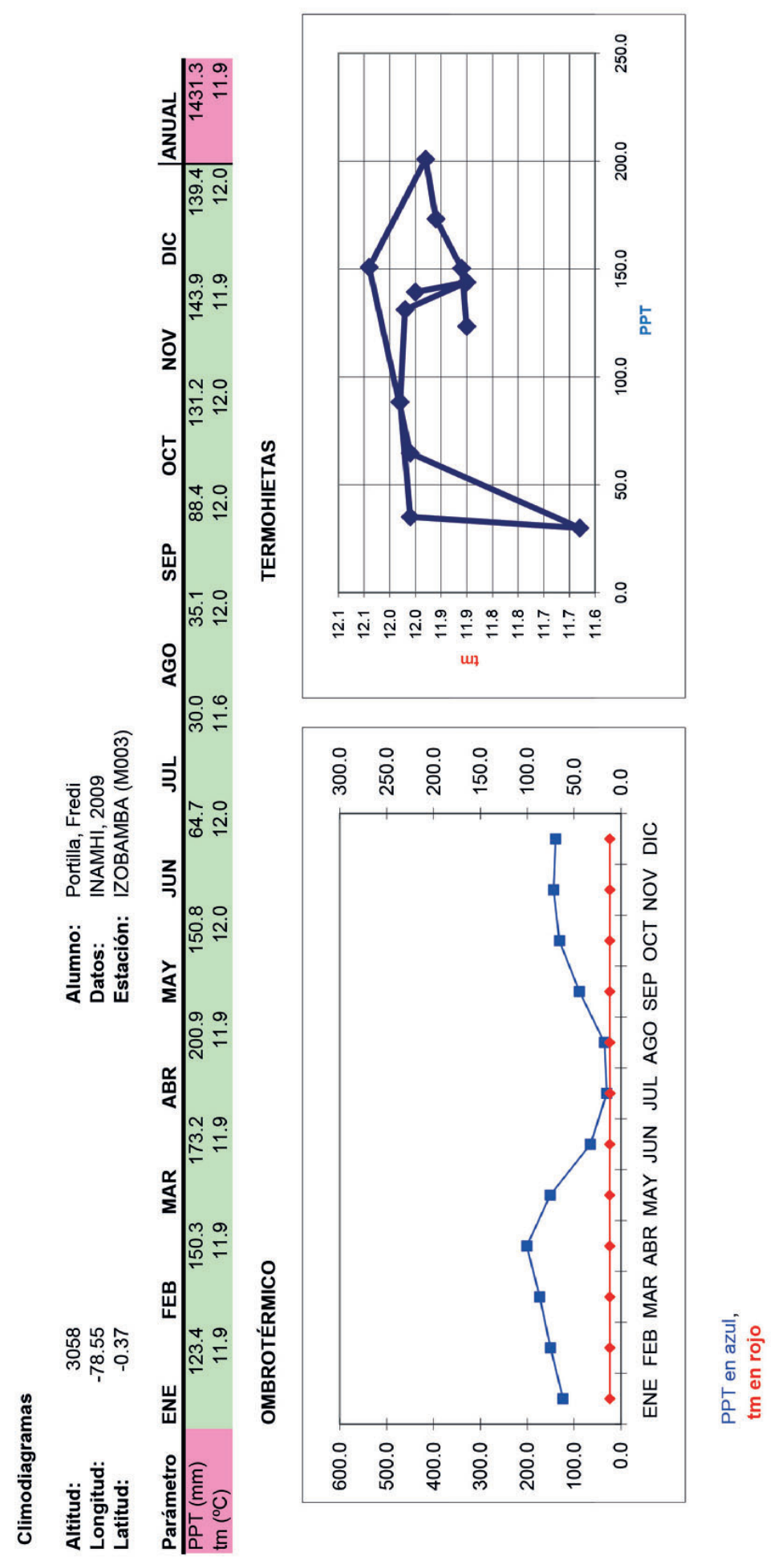




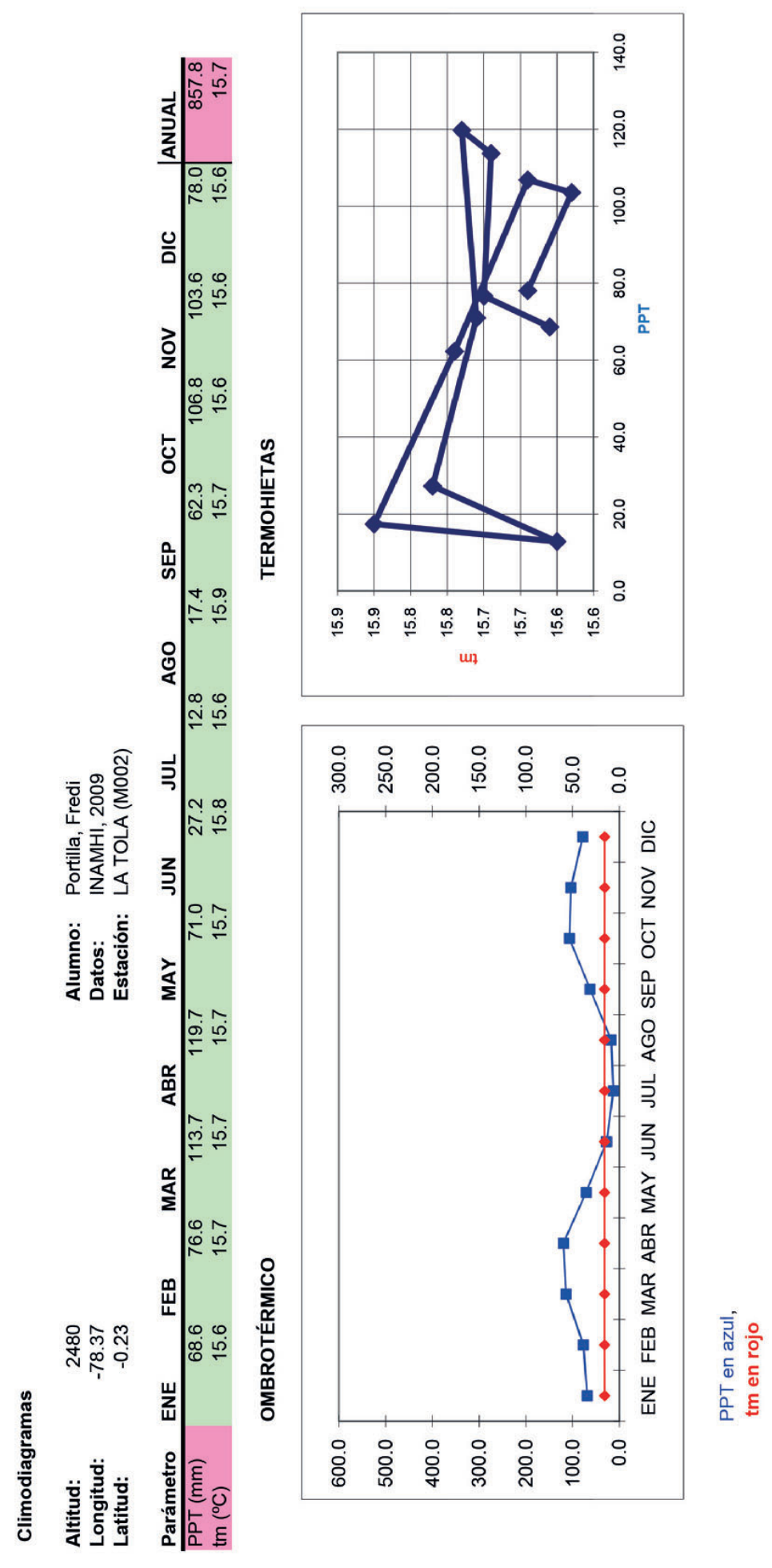





\section{Área de Ciencias de la Vida}

Carrera de Ingeniería Ambiental

a climatología indudablemente es una ciencia aplicable a todas las áreas del conocimiento y en este caso de enorme trascendencia para el área de la Ingeniería Agronómica, Ambiental y afines. El presente trabajo constituye una aproximación a la climatología del Ecuador continental e insular en base de datos oficiales que propende servir a futuro para estudios de aplicación en el área de ciencias de la vida.

Los estudios relativos al clima del Ecuador regularmente han estado enfocados al sector turístico, área importante de desarrollo; sin embargo es menester estructurar una climatología que tenga aplicación en el área agropecuaria y ambiental, fuente de autoconsumo y de generación de divisas.

No se encuentra, sin embargo, una climatología estadística sistemática del Ecuador que permita situarse con una cierta amplitud en el contexto de un estudio climático del conjunto del país.

A partir de datos oficiales proporcionados por el INAMHI (Instituto Nacional de Meteorología e Hidrología del Ecuador), el presente trabajo tiene como objetivo formular una climatología estadística básica que nos permita afrontar trabajos más específicos posteriormente.
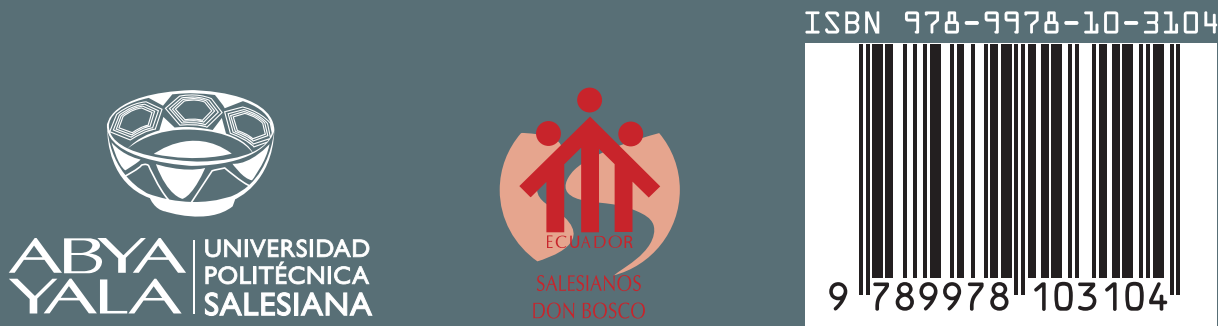